\title{
Top-Down Model Development Using Data Generated from a Complex Numerical Reservoir Simulation with Water Injection
}

\author{
Yvon Andrea Martinez \\ yamartinezgomez@mix.wvu.edu
}

Follow this and additional works at: https://researchrepository.wvu.edu/etd

Part of the Other Engineering Commons

\footnotetext{
Recommended Citation

Martinez, Yvon Andrea, "Top-Down Model Development Using Data Generated from a Complex Numerical Reservoir Simulation with Water Injection" (2020). Graduate Theses, Dissertations, and Problem Reports. 7571.

https://researchrepository.wvu.edu/etd/7571

This Thesis is protected by copyright and/or related rights. It has been brought to you by the The Research Repository @ WVU with permission from the rights-holder(s). You are free to use this Thesis in any way that is permitted by the copyright and related rights legislation that applies to your use. For other uses you must obtain permission from the rights-holder(s) directly, unless additional rights are indicated by a Creative Commons license in the record and/ or on the work itself. This Thesis has been accepted for inclusion in WVU Graduate Theses, Dissertations, and Problem Reports collection by an authorized administrator of The Research Repository @ WVU. For more information, please contact researchrepository@mail.wvu.edu.
} 


\title{
TOP-DOWN MODEL DEVELOPMENT USING DATA GENERATED FROM A COMPLEX NUMERICAL RESERVOIR SIMULATION WITH WATER INJECTION
}

\author{
Yvon Andrea Martinez Gomez
}

\begin{abstract}
Thesis submitted
to the Benjamin M. Statler College of Engineering and Mineral Resources

at West Virginia University

in partial fulfillment of the requirements for the degree of

Master of Science in

Petroleum and Natural Gas Engineering

Shahab Mohaghegh, Ph.D., Chair and Research Advisor

Kashy Aminian, Ph.D.

Sam Ameri, Ph.D.

Mehrdad Zamirian, Ph.D.

Department of Petroleum and Natural Gas Engineering
\end{abstract}

Morgantown, West Virginia

2020

Keywords: Artificial Intelligence, Machine Learning, Artificial Neural Networks, Data-Driven Modeling, Top-Down Modeling

Copyright@ 2020, Martinez 


\title{
ABSTRACT
}

\section{Top-Down Model Development Using Data Generated from a Complex Numerical Reservoir Simulation with Water Injection}

\author{
Yvon Martinez
}

Numerical simulation and data-driven modeling are two current approaches in engineering reservoir modeling. Numerical reservoir simulation attempts to match past production history by modifying reservoir properties of the model. After multiple computationally intensive trial and error efforts, accurate history matches are identified. These history matches are used by project management for production forecasting purposes. Data-driven reservoir modeling utilizes measured data and is, therefore, free of assumptions that are often included in numerical reservoir simulations. Artificial intelligence and machine learning algorithms are technologies implemented in the development of a data-driven reservoir model with efforts to learn fluid flow through porous media from the datasets provided to the system. Training, calibration, and validation datasets ensure the success during the teaching process.

Models, such as oil, gas, and water production, reservoir pressure and water saturation, are trained, calibrated, verified to ensure the success in the teaching process. After appropriate hyperparameter tuning, well-trained models are tested on blind datasets. This leads to the model being deployed on new datasets to again test the model's performance during forecasting. The accuracy is based upon the model achieving a similar result to what numerical simulation found on the same dataset.

The objective of this thesis is to use a 22-year dataset from a reservoir model generated by a numerical simulator that undergoes many complexities to approach the reality that takes place in the industry through the use of operational constraints, workover events requiring shut-in, random bottom hole pressure ("BHP") trend, etc. Should the Top Down Model ("TDM") be able to accurately learn the relationships between input attributes and outputs from the data, a similar procedure can then be applied to real field data in the future. The TDM's capabilities will attempt to be proved when the blind validation's in-time results match the data from the numerical simulation reservoir model. This will be done by excluding the data from the training, calibration, 
and validation datasets used to create the TDM. This thesis's results should demonstrate that datadriven modeling is capable of history matching and forecasting the complexities of a reservoir. 


\section{Contents}

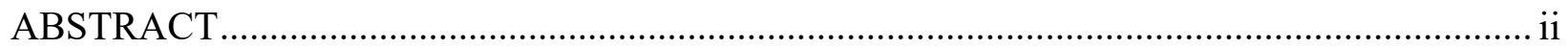

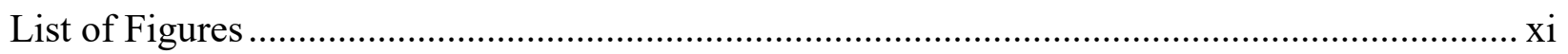

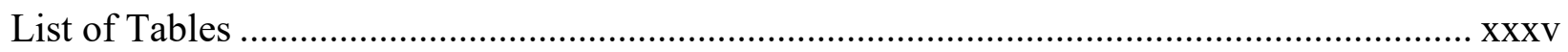

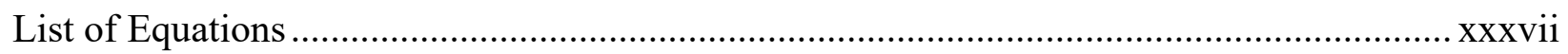

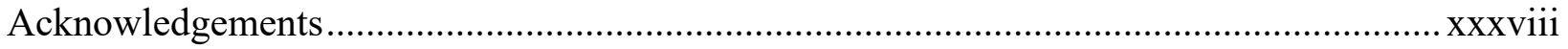

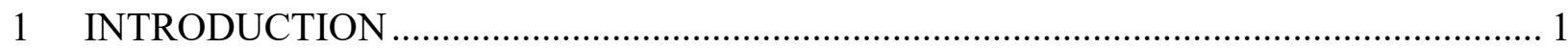

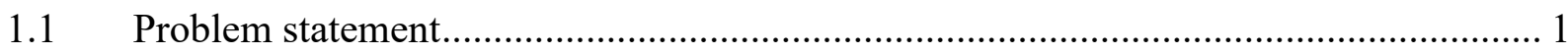

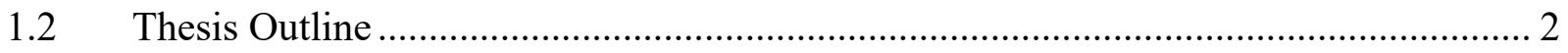

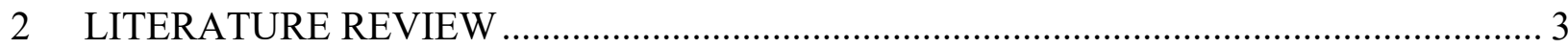

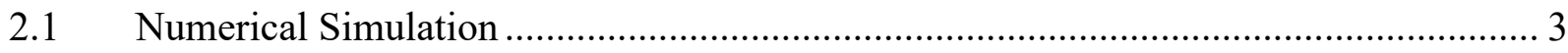

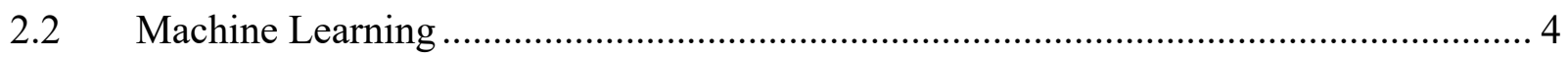

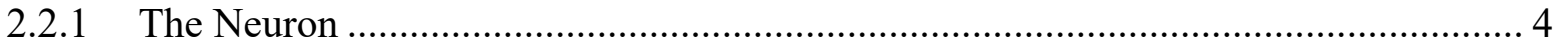

2.2.2 Artificial Neuron - Structure Replication...................................................... 5

2.2.3 Artificial Neural Networks ....................................................................... 6

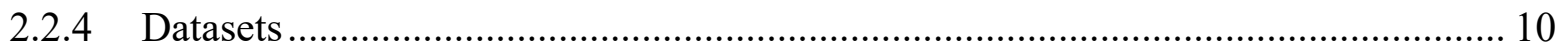

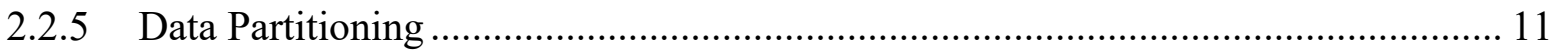

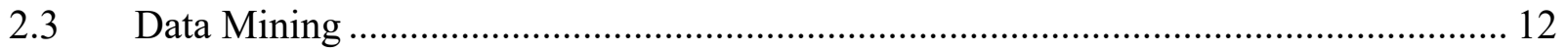

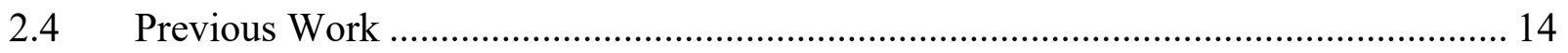




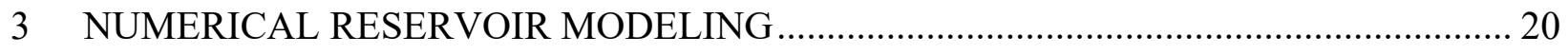

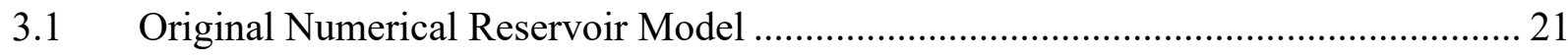

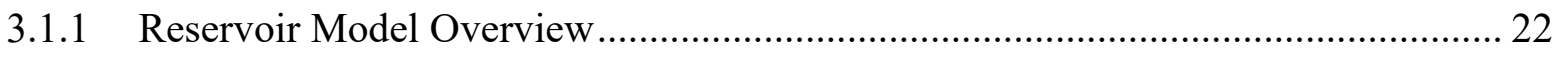

3.1.1.1 General Properties................................................................................. 22

3.1.1.2 Original Map Files ............................................................................. 23

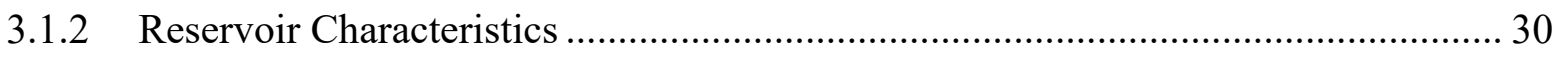

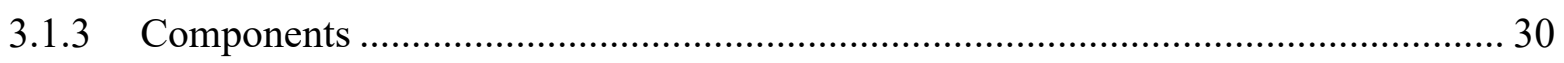

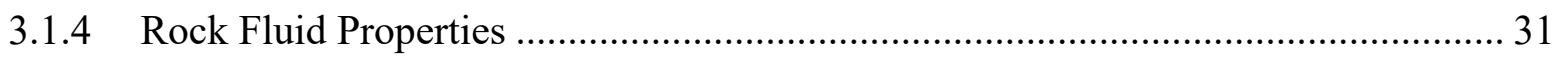

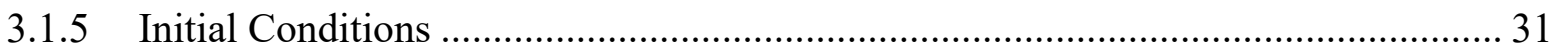

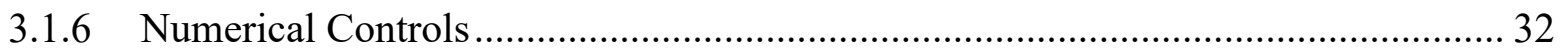

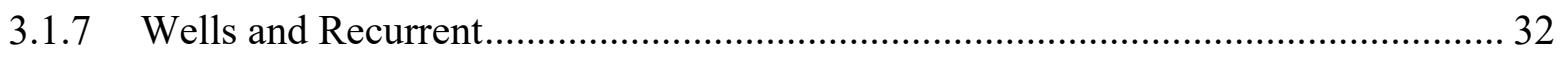

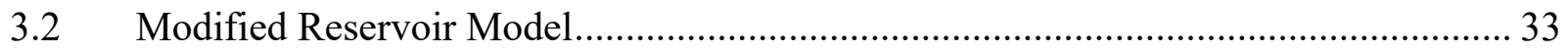

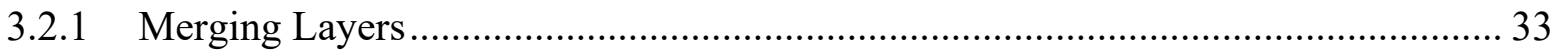

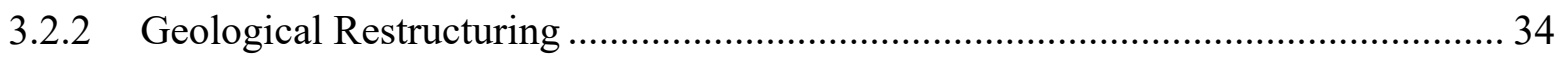

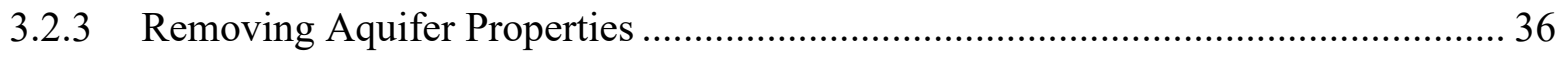

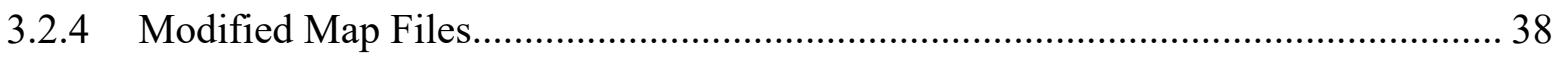

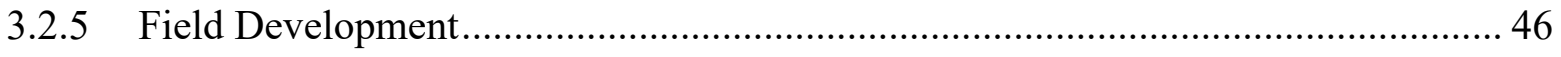

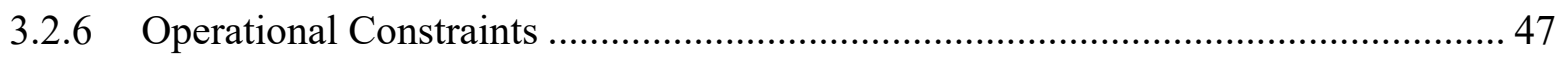

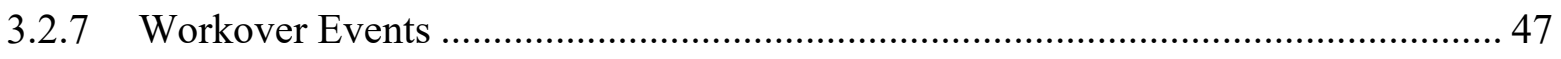

3.2.8 Partial Completion Strategy:........................................................................... 50

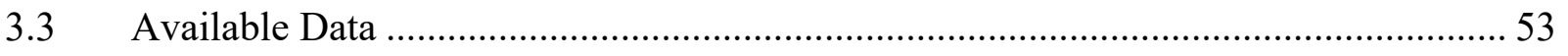

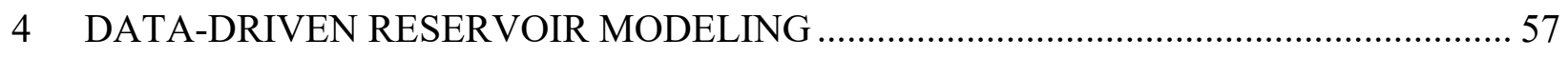

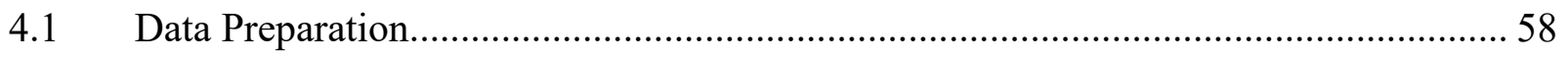

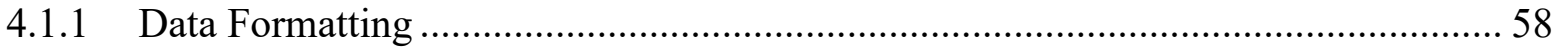




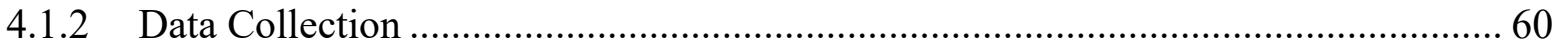

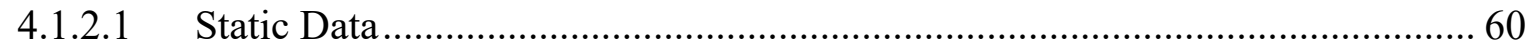

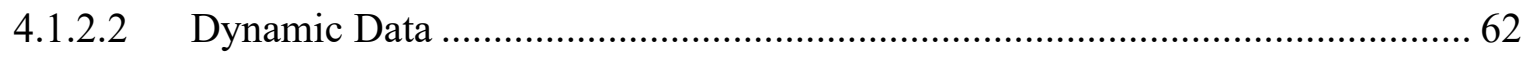

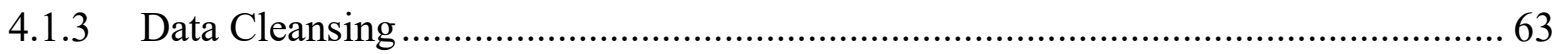

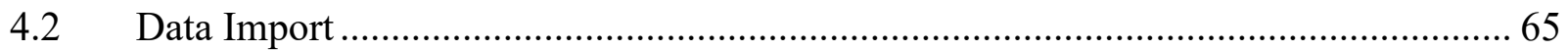

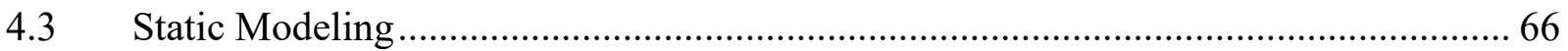

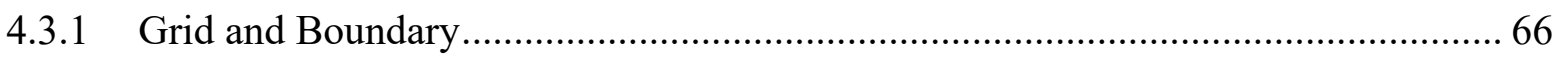

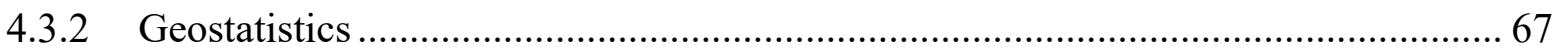

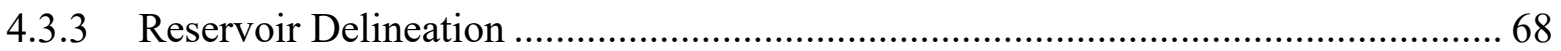

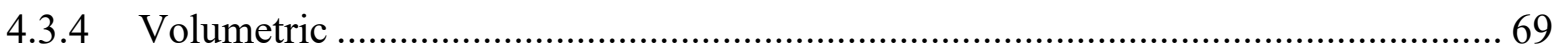

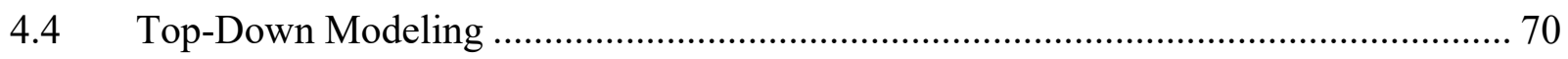

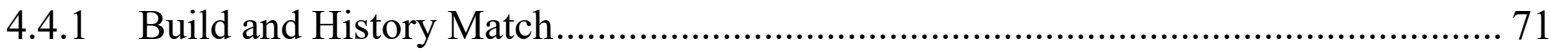

4.4.1.1 Scenario 1 - Random Partitioning TDM ………………………………....... 72

4.4.1.2 Scenario 2 - Mixed Partitioning (1 Year Validation) ........................................ 78

4.4.1.3 Scenario 3 - Mixed Partitioning (2 Year Validation) ……………………....... 82

4.4.1.4 Scenario 4 - Mixed Partitioning (1 Year Forecast) .......................................... 87

4.4.1.5 Scenario 5 - Mixed Partitioning (2 Year Forecast) ……………...................... 92

4.4.2 Summary of Conducted Scenarios ............................................................................. 97

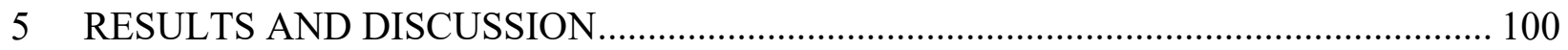

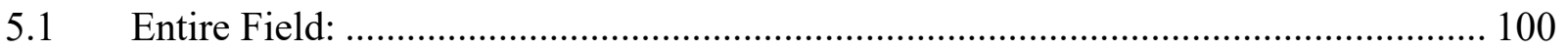

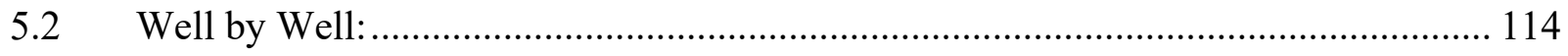

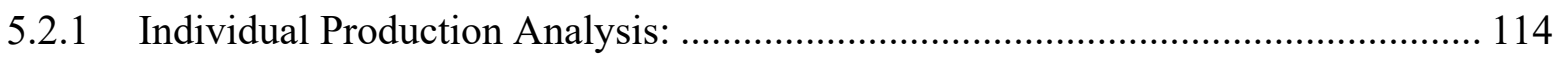

5.2.2 Collective Production Analysis: ............................................................................ 119 


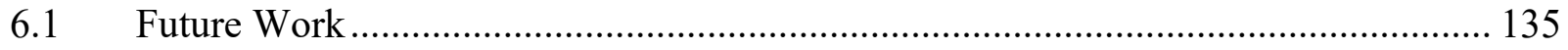

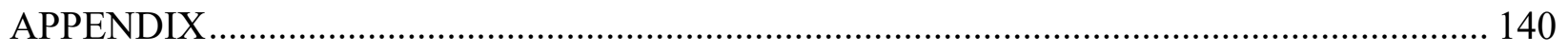

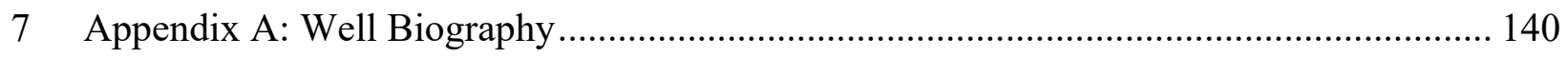

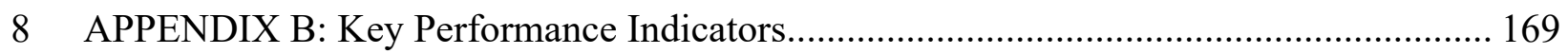

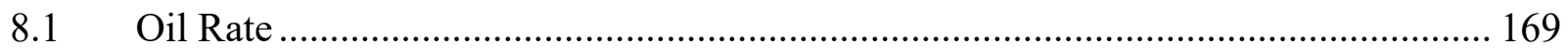

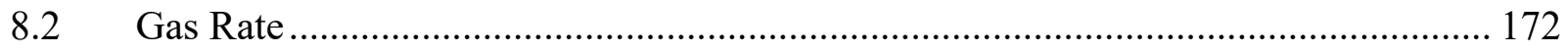

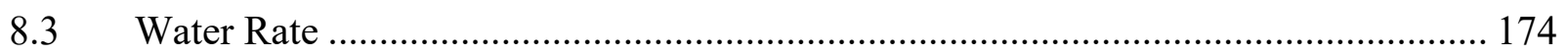

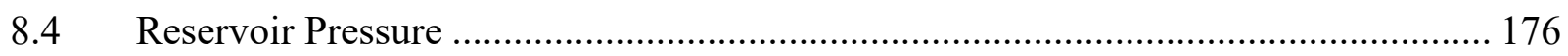

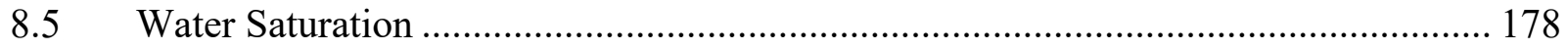

9 APPENDIX C: Scenario 1 - Random Partitioning TDM ……………………................ 180

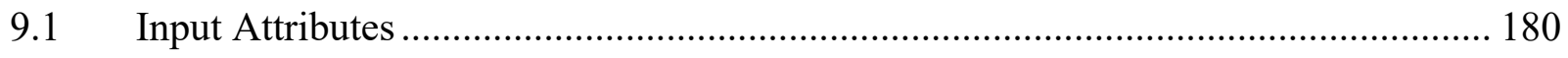

9.1.1 Oil Predictive Model...................................................................................... 180

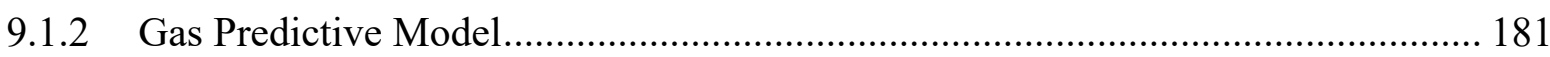

9.1.3 Water Predictive Model .................................................................................... 182

9.1.4 Reservoir Pressure Predictive Model..................................................................... 183

9.1.5 Water Saturation Predictive Model................................................................ 184

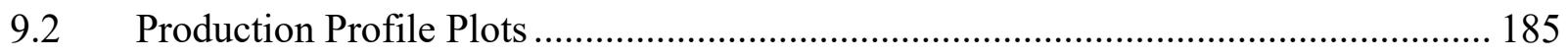

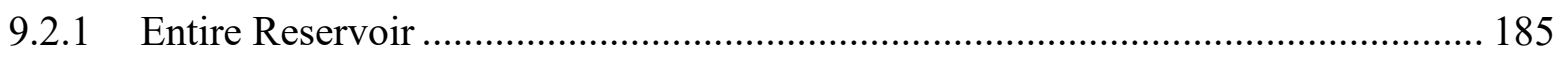

9.2.2 Good History Match of Production..................................................................... 186

9.2.3 Average History Match of Production..................................................................... 200

9.2.4 Poor History Match of Production ........................................................................ 215 
10 Appendix D: Scenario 2 - Mixed Partitioning TDM (1 Year Validation) ........................ 220

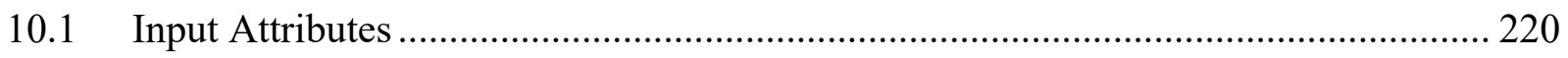

10.1.1 Oil Predictive Model............................................................................... 220

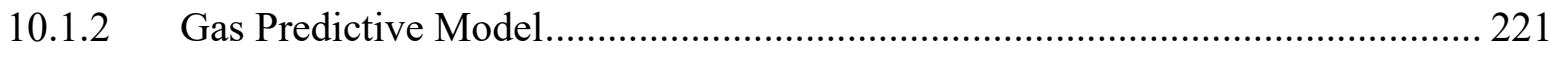

10.1.3 Water Predictive Model ............................................................................ 222

10.1.4 Reservoir Pressure Predictive Model ......................................................... 223

10.1.5 Water Saturation Predictive Model............................................................. 224

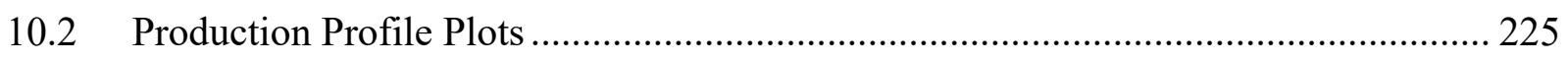

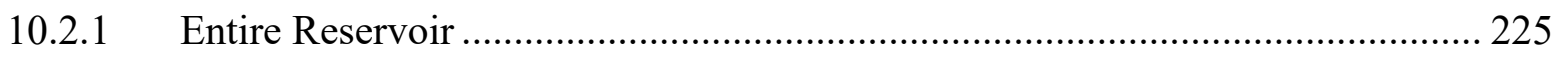

10.2.2 Good History Match of Production................................................................ 226

10.2.3 Average History Match of Production ........................................................ 240

10.2.4 Poor History Match of Production.................................................................. 254

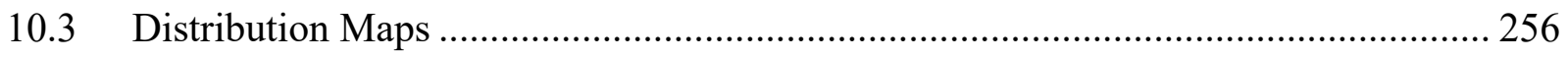

11 Appendix E: Scenario 3: Mixed Partitioning TDM (2 Year Validation) ......................... 260

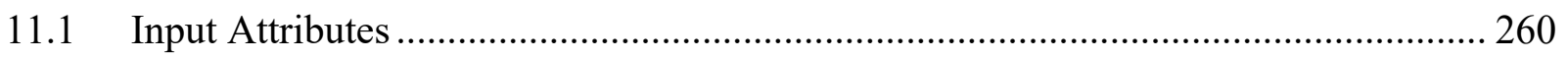

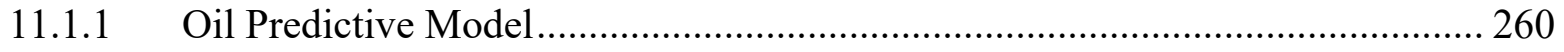

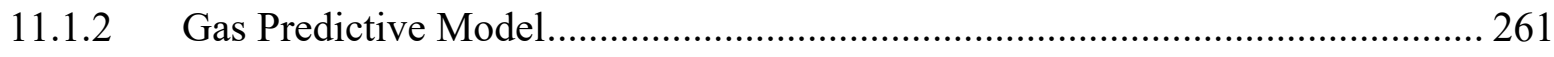

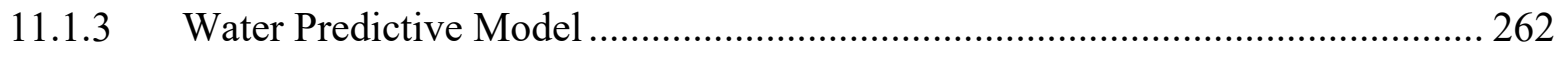

11.1.4 Reservoir Pressure Predictive Model ......................................................... 263

11.1.5 Water Saturation Predictive Model............................................................ 264

11.2 Production Profile Plots ................................................................................. 265

11.2.1 Entire Reservoir ...................................................................................... 265 
11.2.2 Good History Match of Production...................................................................... 266

11.2.3 Average History Match of Production ............................................................... 277

11.2.4 Poor History Match of Production..................................................................... 293

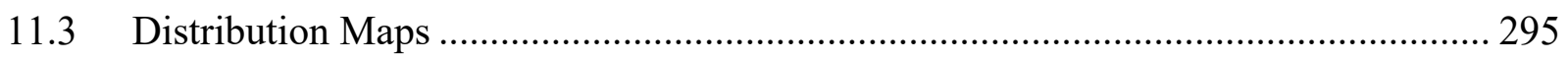

12 Appendix F: Scenario 4 - Mixed Partitioning TDM (1 Year Forecast) .............................. 299

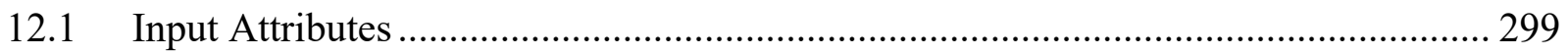

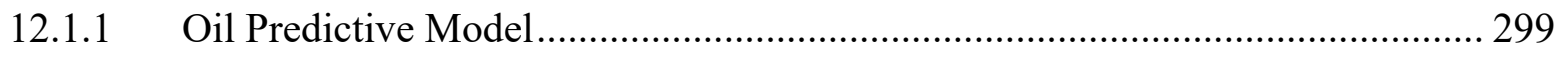

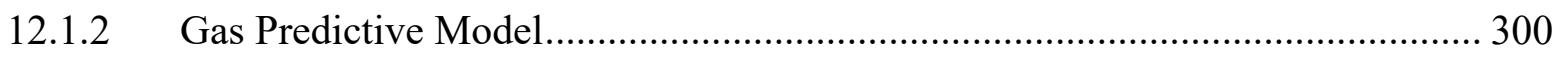

12.1.3 Water Predictive Model ...................................................................................... 301

12.1.4 Reservoir Pressure Predictive Model.............................................................. 302

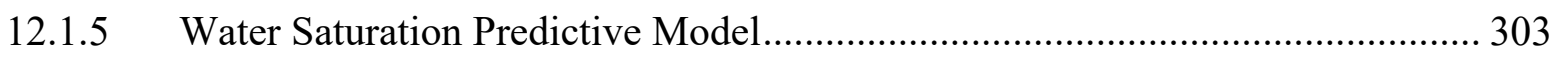

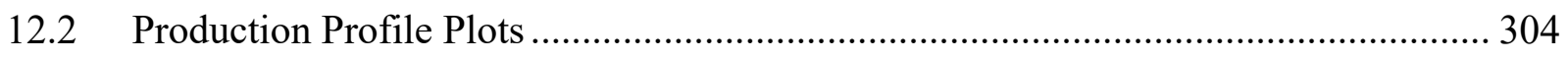

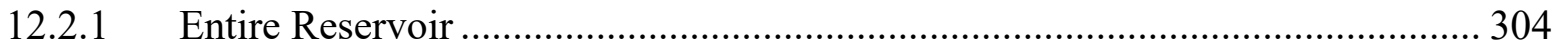

12.2.2 Good History Match of Production....................................................................... 305

12.2.3 Average History Match of Production ............................................................ 325

12.2.4 Poor History Match of Production ..................................................................... 334

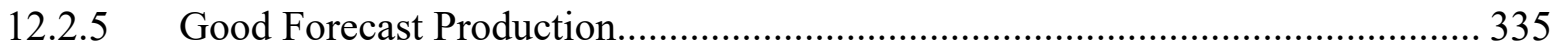

12.2.6 Average Forecast Production........................................................................ 340

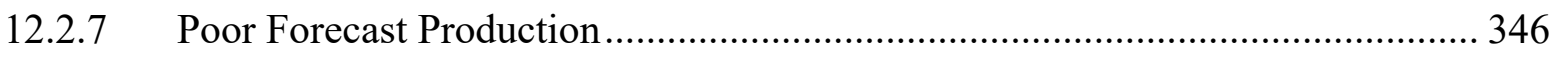

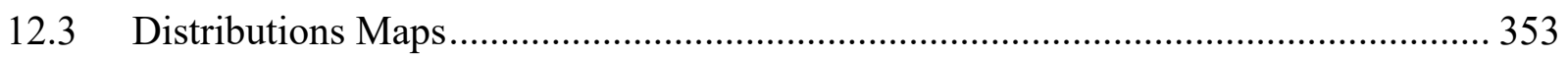

13 Appendix G: Scenario 5 - Mixed Partitioning (2 Year Forecast) ......................................... 357

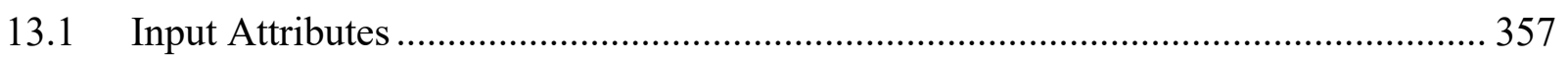

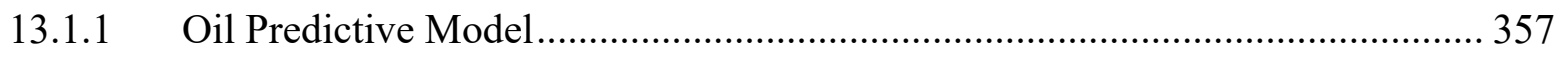




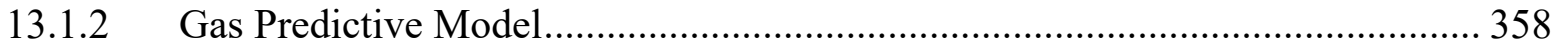

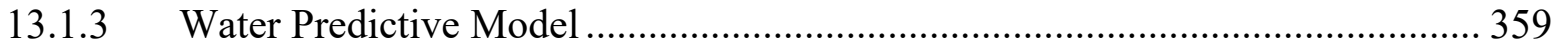

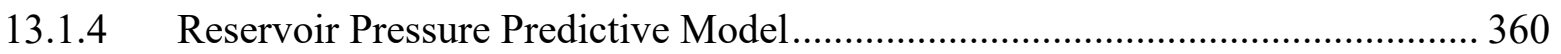

13.1.5 Water Saturation Predictive Model.................................................................. 361

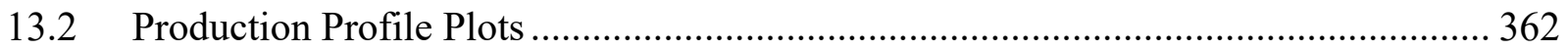

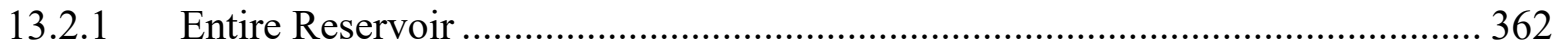

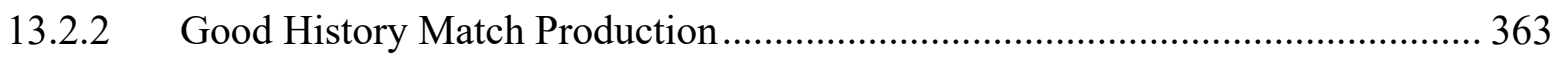

13.2.3 Average History Match of Production ............................................................... 378

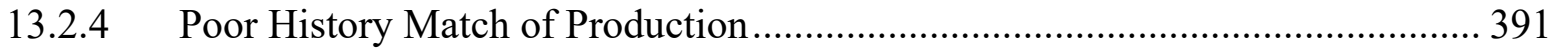

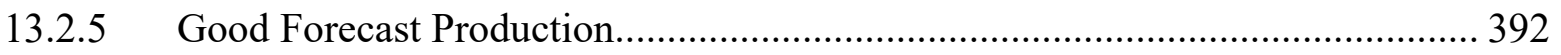

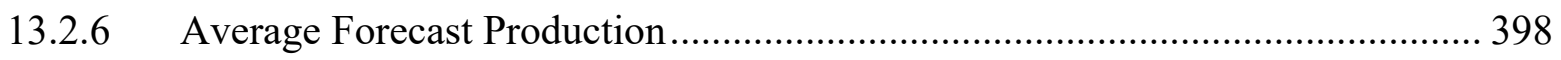

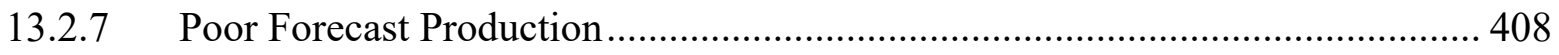

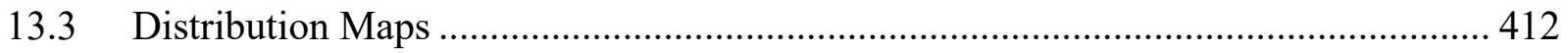




\section{List of Figures}

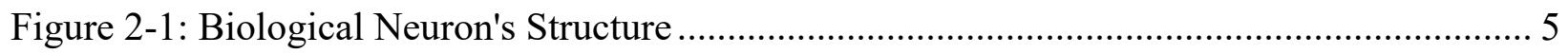

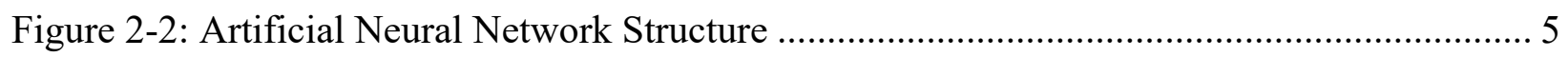

Figure 2-3: Mathematical Representation of a Neural Network.................................................. 7

Figure 2-4: Logistic Sigmoid Activation Function .................................................................. 9

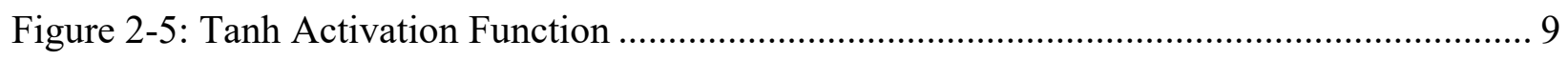

Figure 2-6: Leaky Relu Activation Function ......................................................................... 9

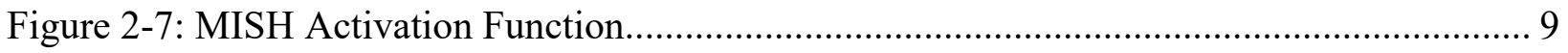

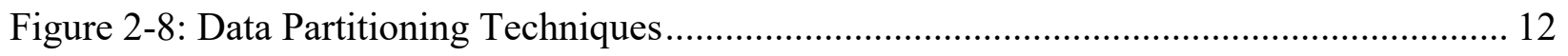

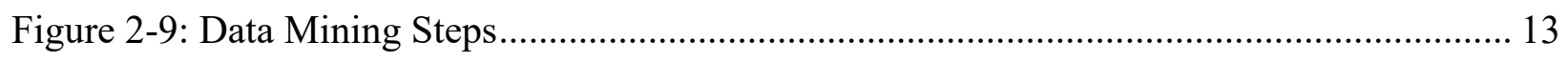

Figure 2-10: TDM prediction against historical Production of Well A [20] ................................ 15

Figure 2-11: History Match and Forecasting Results for Oil (A), Gas (B) and Water (C) the Entire

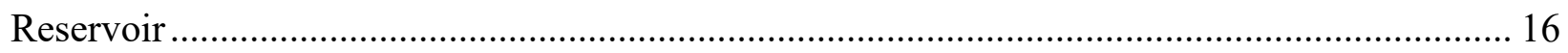

Figure 2-12: Comparison between the predicted and the target flow rate ratio $(\mathrm{Q} / \mathrm{Q} \max )$ using the ANN model for the (A) training and (B) testing datasets [21] .................................................. 17

Figure 2-13: Neural Network Development Results for Training (A), Calibration (B), Verification

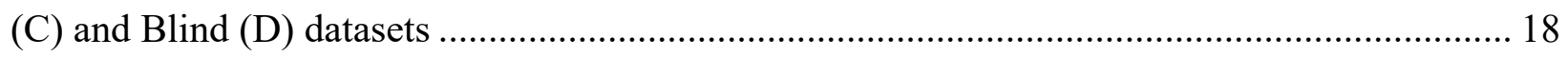

Figure 2-14: Generated output "NN-PHIE" and actual value "PHIE" ......................................... 19

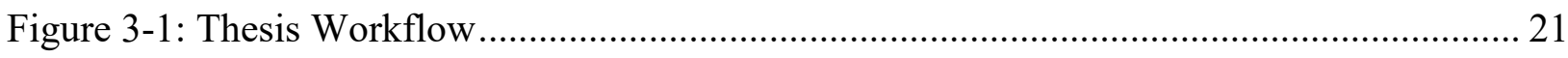

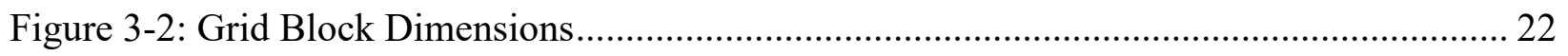

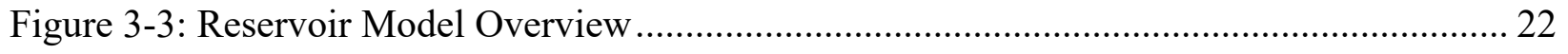

Figure 3-4: Porosity Map Files for All 6 Layers........................................................................ 24

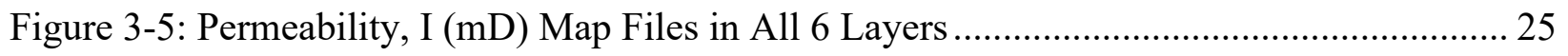

Figure 3-6: Permeability, K (mD) Map Files in All 6 Layers ..................................................... 27 
Figure 3-7: Initial Water Saturation Map Files for All 6 Layers .......................................... 28

Figure 3-8: Grid Thickness (ft) Map Files for all 6 Layers .................................................. 29

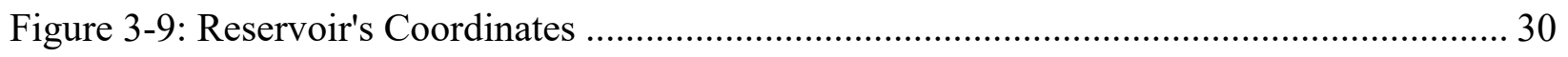

Figure 3-10: Relative Permeability Curves...................................................................... 31

Figure 3-11: Well Locations on Initial Water Saturation Map ............................................ 32

Figure 3-12: Original Model - 6 Geological Layers .............................................................. 33

Figure 3-13: Thesis Model - 3 Merged Geological Layers................................................... 33

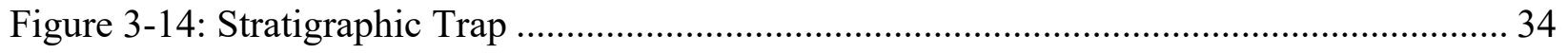

Figure 3-15: Original Model - Anticline/Syncline Pair ...................................................... 35

Figure 3-16: Thesis Model - Stratigraphic Trap.............................................................. 35

Figure 3-17: Thesis Grid Top Map File ........................................................................ 36

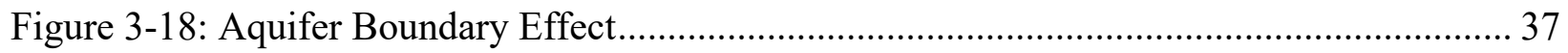

Figure 3-19: Thesis - Porosity Map Files ............................................................................ 39

Figure 3-20: Porosity Distribution -3 Layers ............................................................ 40

Figure 3-21: Thesis - Permeability, I Map Files ................................................................. 41

Figure 3-22: Permeability (I, J direction) - 3 Layers......................................................... 42

Figure 3-23: Thesis - Permeability, K Map Files ........................................................... 43

Figure 3-24: Permeability (K-direction) - 3 Layers ....................................................... 44

Figure 3-25: Thesis - Initial Water Saturation Map Files ................................................. 45

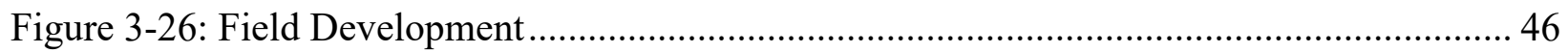

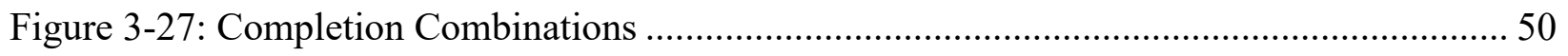

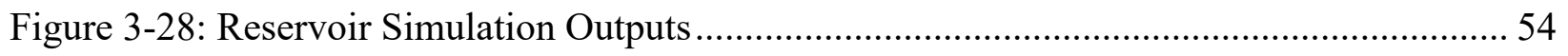

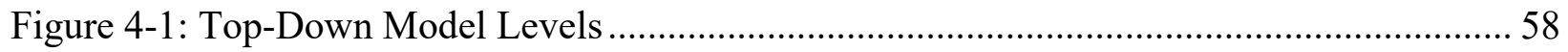

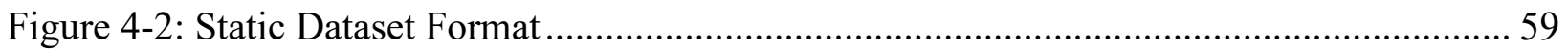




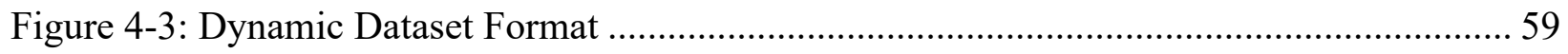

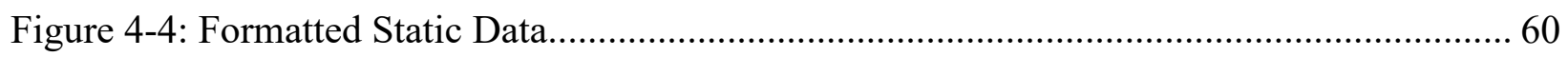

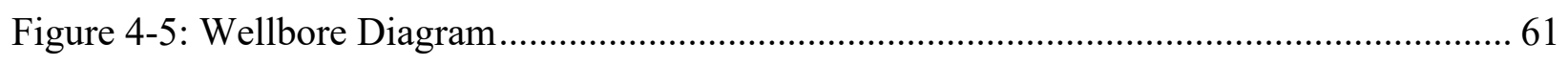

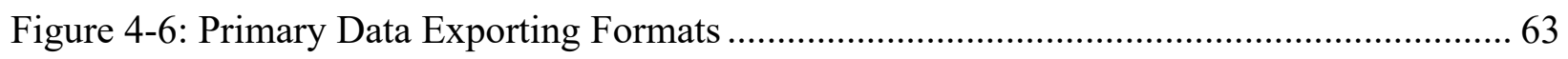

Figure 4-7: Simple Average Methods vs Weight Average Method Example ................................ 64

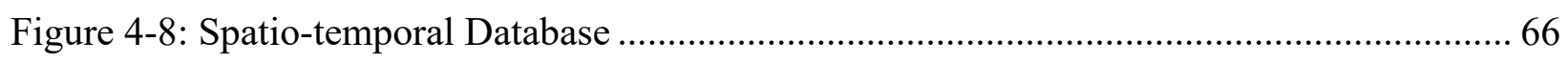

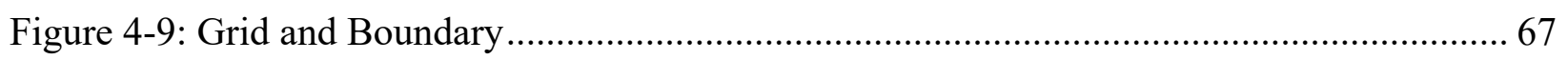

Figure 4-10: Static and Dynamic Spatial-Interpolation Using Inverse Distance Weighting Method 68

Figure 4-11: Reservoir Delineation using Voronoi Technique..................................................... 69

Figure 4-12: Top-Down Modeling - History Match and Forecast ................................................ 70

Figure 4-13: Scenario 1 - Development Dataset........................................................................ 72

Figure 4-14: Neural Network Data Preparation - Oil Model ........................................................ 73

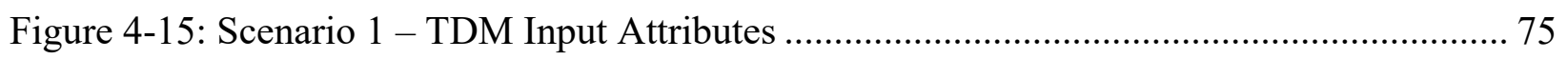

Figure 4-16: Scenario 1 - Neural Network Data Partitioning .......................................................... 76

Figure 4-17: Scenario 1 - Partitioning Cross Plot Results .............................................................. 77

Figure 4-18: Scenario 2 - Development Dataset.......................................................................... 78

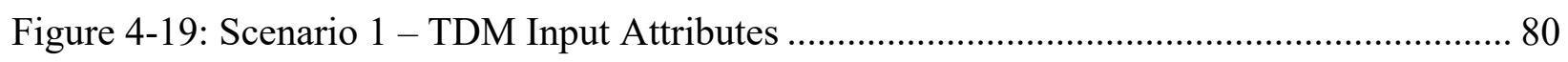

Figure 4-20: Scenario 2 - Neural Network Data Partitioning ……………………………............ 80

Figure 4-21: Scenario 2 - Partitioning Cross Plot Results ........................................................ 81

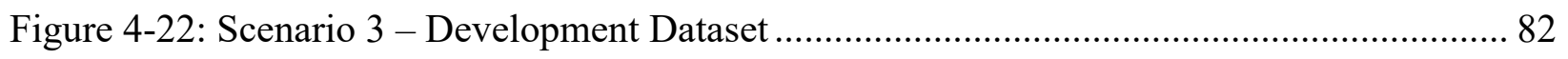

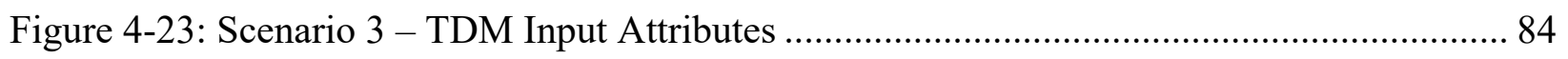

Figure 4-24: Scenario 3 - Neural Network Data Partitioning ……………………………….... 85

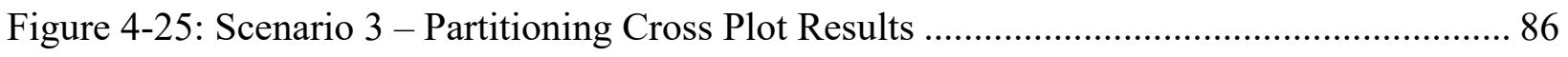


Figure 4-26: Scenario 4: Development and Deployment Datasets ........................................ 87

Figure 4-27: Scenario 4 - TDM Input Attributes .......................................................... 90

Figure 4-28: Scenario 4 - Neural Network Data Partitioning ............................................. 90

Figure 4-29: Scenario 4 - Partitioning Cross Plot Results .................................................... 91

Figure 4-30: Scenario 5 - Development and Deployment Datasets ....................................... 92

Figure 4-31: Scenario 5 - TDM Input Attributes ............................................................ 94

Figure 4-32: Scenario 5 - Neural Network Data Partitioning ............................................... 95

Figure 4-33: Scenario 5 - Partitioning Cross Plot Results .................................................. 96

Figure 5-1: Scenario 1 - Entire Field Production Profiles.................................................. 102

Figure 5-2: Scenario 2 - Entire Field Production Profiles................................................ 103

Figure 5-3: Scenario 3 - Entire Field Production Profiles................................................. 104

Figure 5-4: Scenario 4 - Entire Field Production Profiles................................................. 105

Figure 5-5: Scenario 5 - Entire Field Production Profiles................................................ 106

Figure 5-6: Selected Dates for Distribution Maps During Validation and Forecast.................. 107

Figure 5-7: Distribution Maps During Validation ............................................................... 111

Figure 5-8: Distribution Maps During Forecast........................................................... 112

Figure 5-9: Good History Match of Individual Production Profiles ...................................... 115

Figure 5-10: Average History Match of Individual Production Profiles ............................... 116

Figure 5-11: Poor History Match of Individual Production Profiles .................................... 117

Figure 5-12: Acceptable History Match of Production........................................................ 122

Figure 5-13: Average History Match of Production ...................................................... 125

Figure 5-14: Poor Production History Match ................................................................. 127

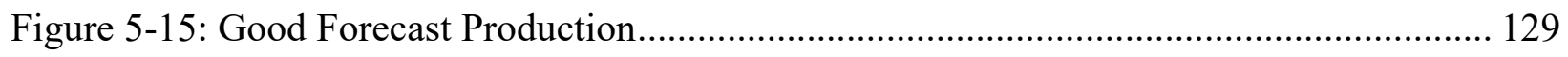

Figure 5-16: Average Forecast Production ..................................................................... 131 


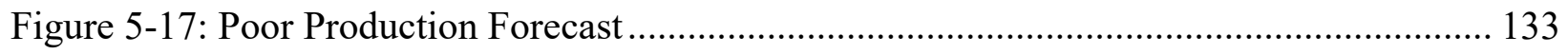

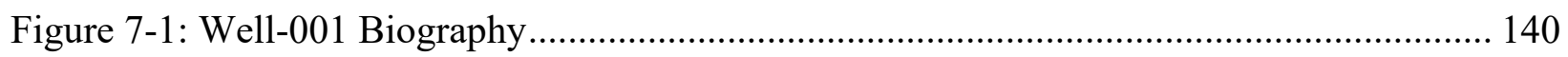

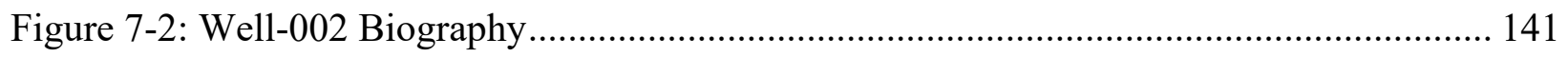

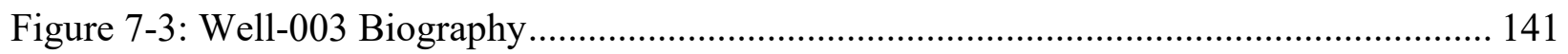

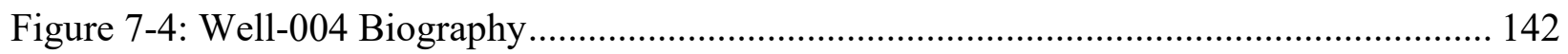

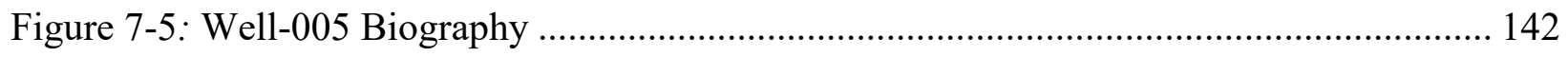

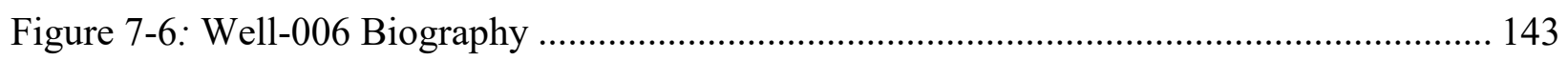

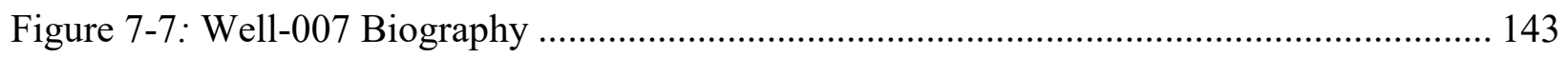

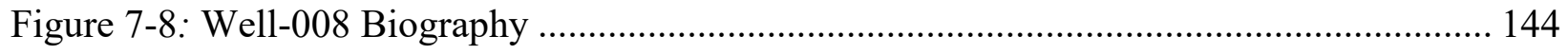

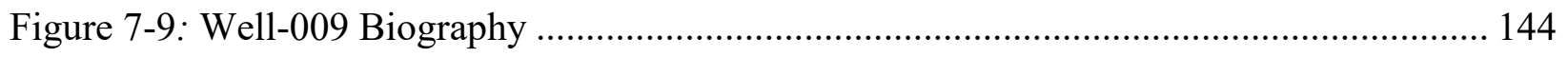

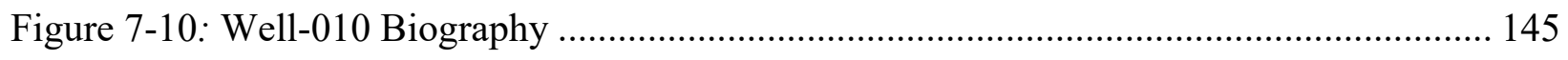

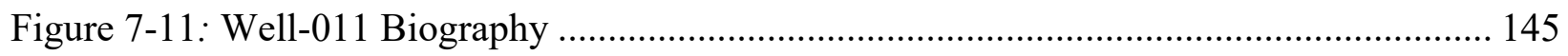

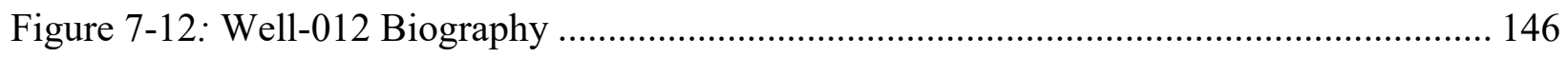

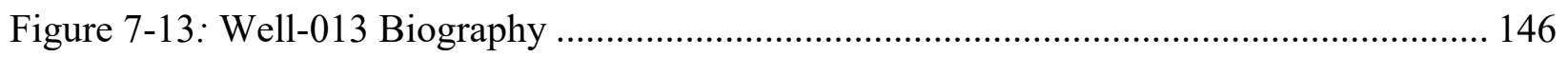

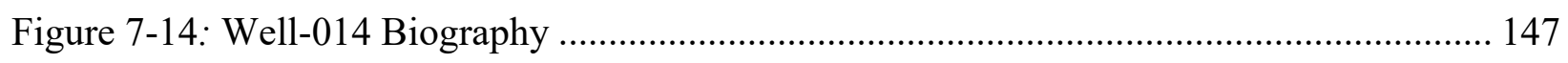

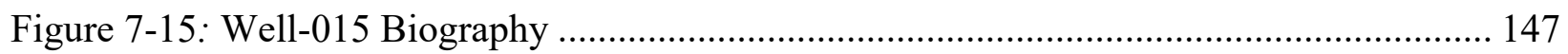

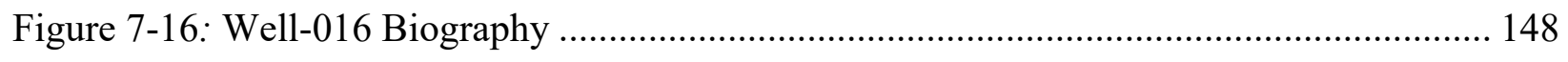

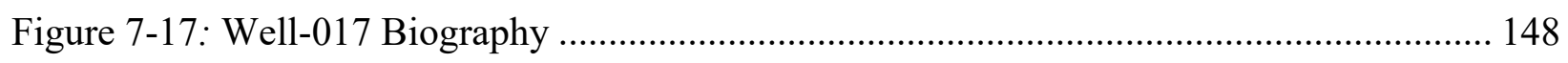

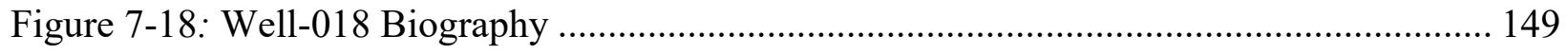

Figure 7-19: Well-019 Biography .................................................................................. 149

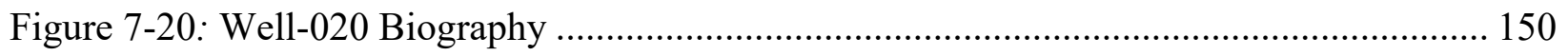

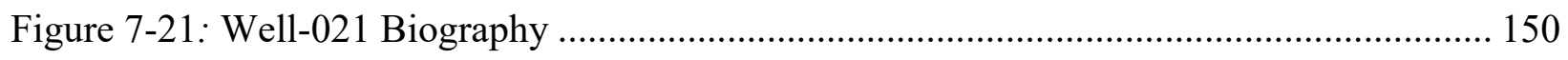

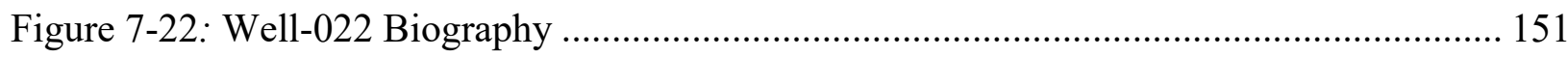

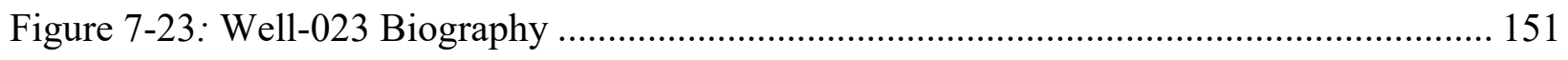




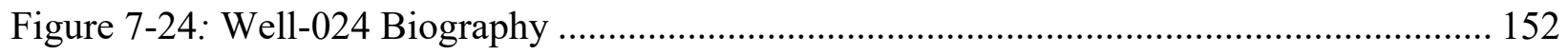

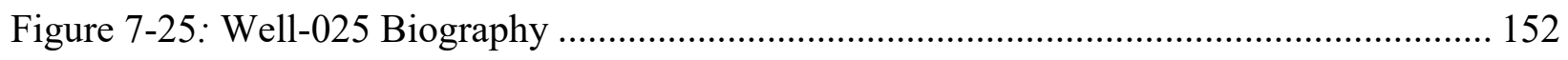

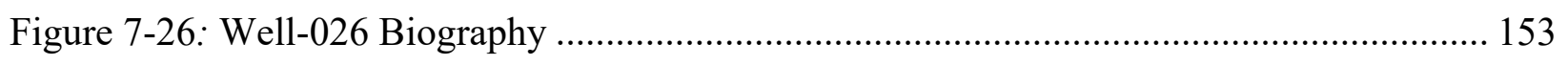

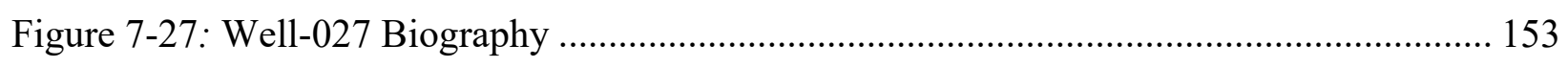

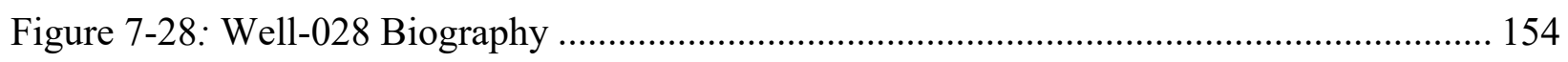

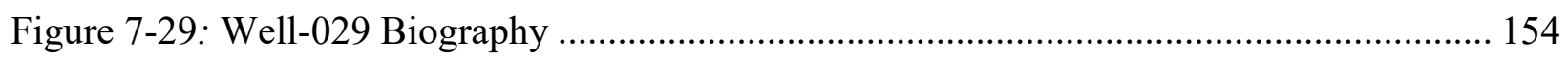

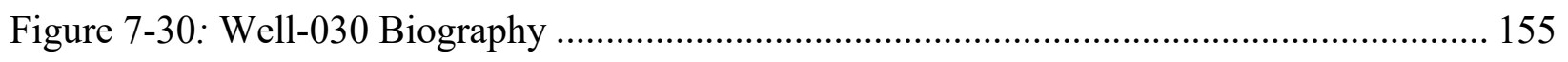

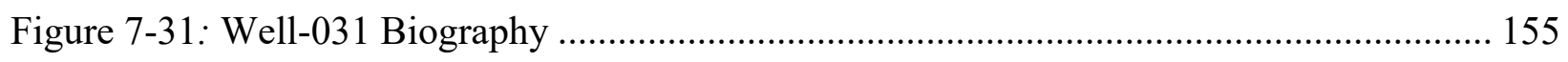

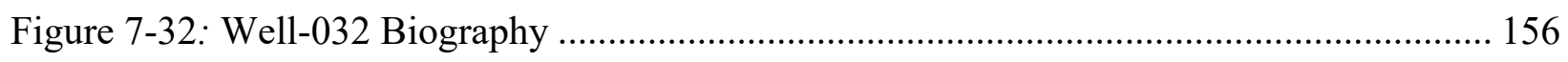

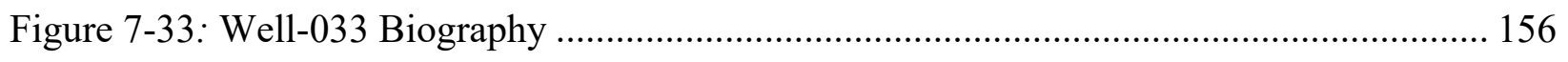

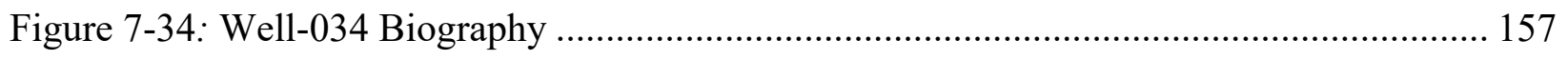

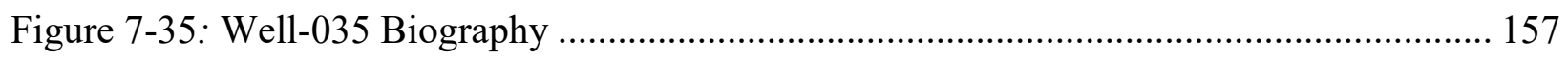

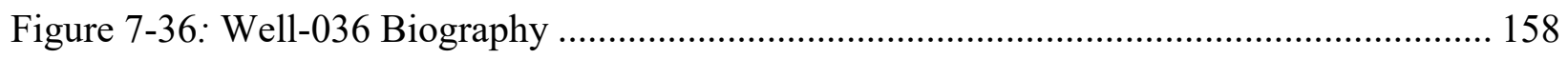

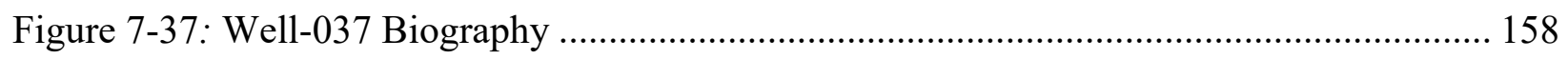

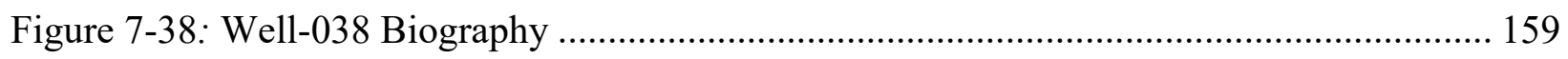

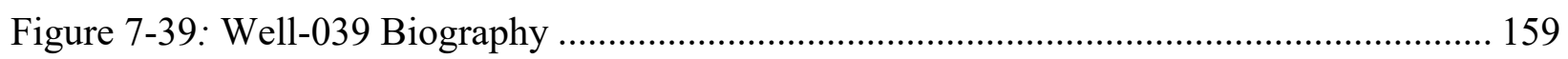

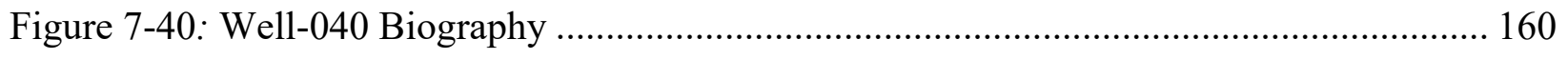

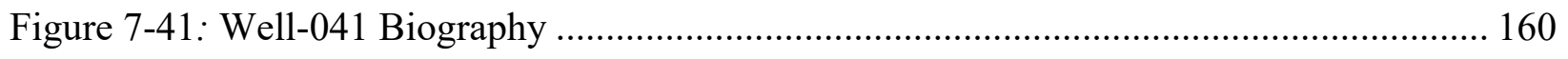

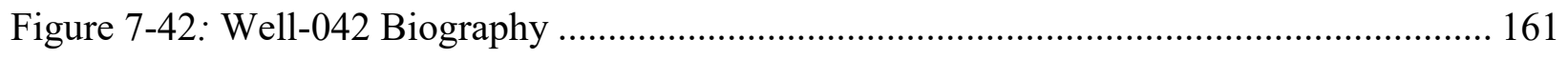

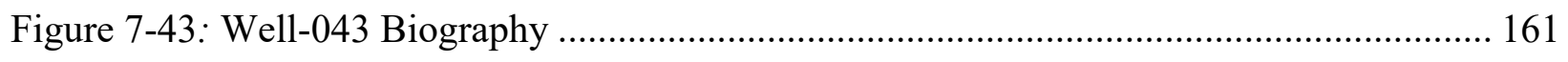

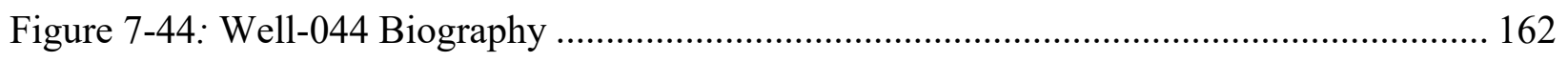

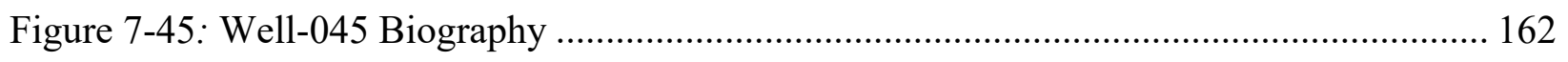

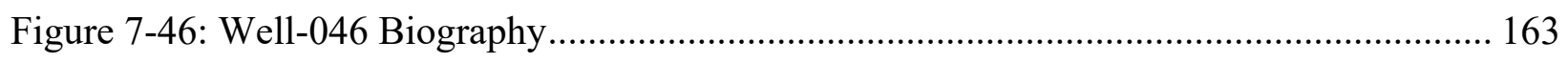

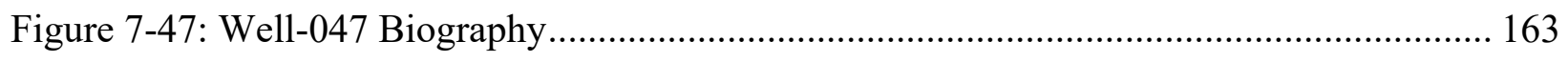




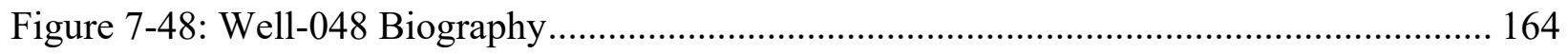

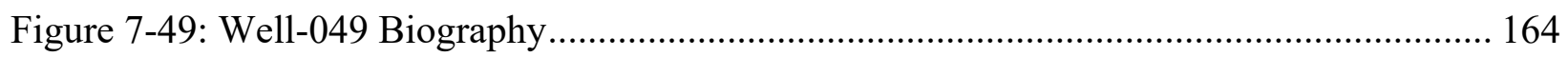

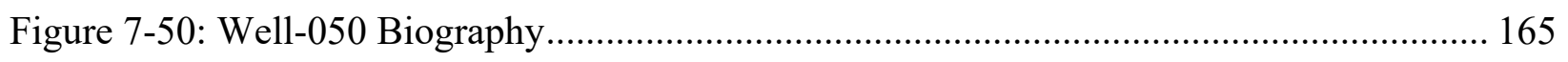

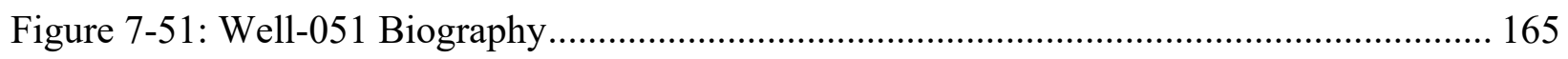

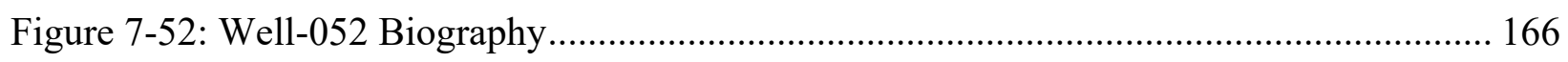

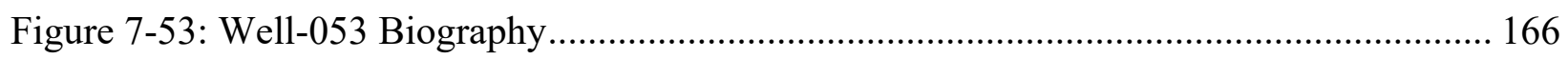

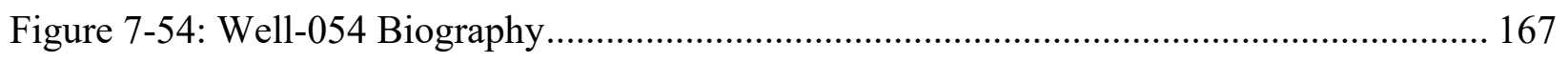

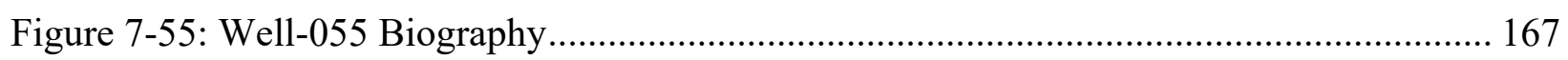

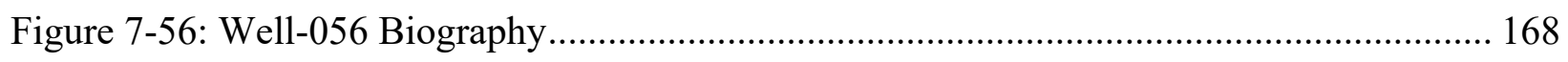

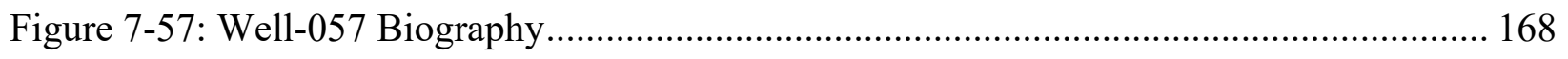

Figure 8-1: Oil Rate - Focal Static Attributes KPI................................................................. 169

Figure 8-2: Oil Rate - Focal Dynamic Attributes KPI ………................................................ 170

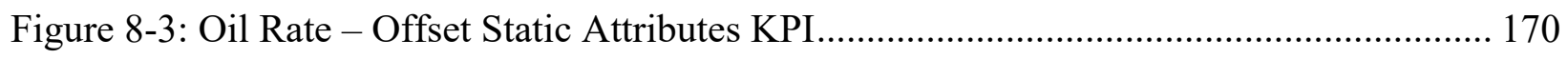

Figure 8-4: Oil Rate - Offset Dynamic Attributes KPI ........................................................... 171

Figure 8-5: Gas Rate - Focal Static Attributes KPI............................................................... 172

Figure 8-6: Gas Rate - Focal Dynamic Attributes KPI ......................................................... 172

Figure 8-7: Gas Rate - Offset Static Attributes KPI................................................................ 173

Figure 8-8: Gas Rate - Offset Dynamic Attributes KPI ......................................................... 173

Figure 8-9: Water Rate - Focal Static Attributes KPI ........................................................... 174

Figure 8-10: Water Rate - Focal Dynamic Attributes KPI....................................................... 174

Figure 8-11: Water Rate - Offset Static Attributes KPI ...................................................... 175

Figure 8-12: Water Rate - Offset Dynamic Attributes KPI ……………………...................... 175

Figure 8-13: Reservoir Pressure - Focal Static Attributes KPI ……………………………..... 176

Figure 8-14: Reservoir Pressure - Focal Dynamic Attributes KPI.............................................. 176 
Figure 8-15: Reservoir Pressure - Offset Static Attributes KPI ............................................... 177

Figure 8-16: Reservoir Pressure - Offset Dynamic Attributes KPI ......................................... 177

Figure 8-17: Water Saturation - Focal Static Attributes KPI .................................................. 178

Figure 8-18: Water Saturation - Focal Dynamic Attributes KPI ........................................... 178

Figure 8-19: Water Saturation - Offset Static Attributes KPI................................................. 179

Figure 8-20: Water Saturation - Focal Dynamic Attributes KPI ............................................... 179

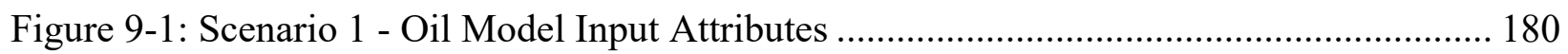

Figure 9-2: Scenario 1 - Gas Model Input Attributes ................................................................. 181

Figure 9-3: Scenario 1 - Water Model Input Attributes........................................................... 182

Figure 9-4: Scenario 1 - Reservoir Pressure Model Input Attributes............................................ 183

Figure 9-5: Scenario 1 - Water Saturation Model Input Attributes............................................. 184

Figure 9-6: Scenario 1 - Entire Field Production ......................................................................... 185

Figure 9-7: Scenario 1 - Well-003 Production History Match................................................... 186

Figure 9-8: Scenario 1 - Well-007 Production History Match..................................................... 186

Figure 9-9: Scenario 1 - Well-009 Production History Match..................................................... 187

Figure 9-10: Scenario 1 - Well-010 Production History Match.................................................. 187

Figure 9-11: Scenario 1 - Well-015 Production History Match.................................................. 188

Figure 9-12: Scenario 1 - Well-017 Production History Match.................................................... 188

Figure 9-13: Scenario 1 - Well-018 Production History Match.................................................. 189

Figure 9-14: Scenario 1 - Well-020 Production History Match.................................................. 189

Figure 9-15: Scenario 1 - Well-021 Production History Match................................................. 190

Figure 9-16: Scenario 1 - Well-024 Production History Match.................................................. 190

Figure 9-17: Scenario 1 - Well-025 Production History Match................................................... 191

Figure 9-18: Scenario 1 - Well-030 Production History Match.................................................... 191 
Figure 9-19: Scenario 1 - Well-031 Production History Match.................................................. 192

Figure 9-20: Scenario 1 - Well-035 Production History Match.................................................. 192

Figure 9-21: Scenario 1 - Well-036 Production History Match.................................................. 193

Figure 9-22: Scenario 1 - Well-038 Production History Match.................................................... 193

Figure 9-23: Scenario 1 - Well-040 Production History Match................................................. 194

Figure 9-24: Scenario 1 - Well-041 Production History Match.................................................. 194

Figure 9-25: Scenario 1 - Well-045 Production History Match.................................................. 195

Figure 9-26: Scenario 1 - Well-046 Production History Match................................................... 195

Figure 9-27: Scenario 1 - Well-047 Production History Match.................................................... 196

Figure 9-28: Scenario 1 - Well-049 Production History Match................................................... 196

Figure 9-29: Scenario 1 - Well-050 Production History Match.................................................... 197

Figure 9-30: Scenario 1 - Well-051 Production History Match..................................................... 197

Figure 9-31: Scenario 1 - Well-052 Production History Match.................................................. 198

Figure 9-32: Scenario 1 - Well-053 Production History Match.................................................... 198

Figure 9-33: Scenario 1 - Well-056 Production History Match................................................. 199

Figure 9-34: Scenario 1 - Well-057 Production History Match................................................. 199

Figure 9-35: Scenario 1 - Well-001 Production History Match..................................................... 200

Figure 9-36: Scenario 1 - Well-002 Production History Match.................................................. 201

Figure 9-37: Scenario 1 - Well-004 Production History Match.................................................. 201

Figure 9-38: Scenario 1 - Well-005 Production History Match................................................... 202

Figure 9-39: Scenario 1 - Well-006 Production History Match................................................. 202

Figure 9-40: Scenario 1 - Well-008 Production History Match................................................. 203

Figure 9-41: Scenario 1 - Well-011 Production History Match.................................................. 203

Figure 9-42: Scenario 1 - Well-012 Production History Match.................................................... 204 
Figure 9-43: Scenario 1 - Well-013 Production History Match.................................................. 204

Figure 9-44: Scenario 1 - Well-014 Production History Match.................................................. 205

Figure 9-45: Scenario 1 - Well-016 Production History Match.................................................. 205

Figure 9-46: Scenario 1 - Well-019 Production History Match.................................................. 206

Figure 9-47: Scenario 1 - Well-022 Production History Match.................................................. 206

Figure 9-48: Scenario 1 - Well-023 Production History Match.................................................. 207

Figure 9-49: Scenario 1 - Well-026 Production History Match................................................ 207

Figure 9-50: Scenario 1 - Well-027 Production History Match................................................... 208

Figure 9-51: Scenario 1 - Well-028 Production History Match................................................. 208

Figure 9-52: Scenario 1 - Well-029 Production History Match.................................................. 209

Figure 9-53: Scenario 1 - Well-032 Production History Match.................................................. 209

Figure 9-54: Scenario 1 - Well-033 Production History Match................................................... 210

Figure 9-55: Scenario 1 - Well-034 Production History Match................................................. 210

Figure 9-56: Scenario 1 - Well-037 Production History Match.................................................... 211

Figure 9-57: Scenario 1 - Well-039 Production History Match.................................................... 211

Figure 9-58: Scenario 1 - Well-042 Production History Match................................................. 212

Figure 9-59: Scenario 1 - Well-043 Production History Match................................................. 212

Figure 9-60: Scenario 1 - Well-044 Production History Match.................................................... 213

Figure 9-61: Scenario 1 - Well-054 Production History Match................................................... 213

Figure 9-62: Scenario 1 - Well-055 Production History Match.................................................. 214

Figure 9-63: Scenario 1 - Well-048 Production History Match................................................. 215

Figure 9-64: Scenario 1 - Distribution Maps at Different Timesteps ……………………….... 219

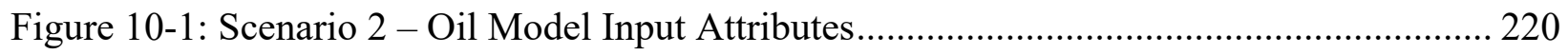

Figure 10-2: Scenario 2 - Gas Model Input Attributes.............................................................. 221 
Figure 10-3: Scenario 2 - Water Model Input Attributes .......................................................... 222

Figure 10-4: Scenario 2 - Reservoir Pressure Model Input Attributes........................................ 223

Figure 10-5: Scenario 2 - Water Saturation Model Input Attributes.......................................... 224

Figure 10-6: Scenario 2 - Entire Field Production ................................................................. 225

Figure 10-7: Scenario 2 - Well-002 Production History Match................................................ 226

Figure 10-8: Scenario 2 - Well-004 Production History Match................................................. 227

Figure 10-9: Scenario 2 - Well-006 Production History Match................................................ 227

Figure 10-10: Scenario 2 - Well-007 Production History Match................................................ 228

Figure 10-11: Scenario 2 - Well-009 Production History Match............................................... 228

Figure 10-12: Scenario 2 - Well-010 Production History Match................................................. 229

Figure 10-13: Scenario 2 - Well-012 Production History Match................................................ 229

Figure 10-14: Scenario 2 - Well-013 Production History Match................................................ 230

Figure 10-15: Scenario 2 - Well-015 Production History Match............................................... 230

Figure 10-16: Scenario 2 - Well-017 Production History Match................................................ 231

Figure 10-17: Scenario 2 - Well-022 Production History Match.............................................. 231

Figure 10-18: Scenario 2 - Well-024 Production History Match.............................................. 232

Figure 10-19: Scenario 2 - Well-025 Production History Match................................................ 232

Figure 10-20: Scenario 2 - Well-027 Production History Match................................................ 233

Figure 10-21: Scenario 2 - Well-030 Production History Match.............................................. 233

Figure 10-22: Scenario 2 - Well-031 Production History Match................................................ 234

Figure 10-23: Scenario 2 - Well-033 Production History Match.............................................. 234

Figure 10-24: Scenario 2 - Well-035 Production History Match............................................... 235

Figure 10-25: Scenario 2 - Well-041 Production History Match............................................... 235

Figure 10-26: Scenario 2 - Well-045 Production History Match................................................. 236 
Figure 10-27: Scenario 2 - Well-046 Production History Match............................................... 236

Figure 10-28: Scenario 2 - Well-047 Production History Match............................................. 237

Figure 10-29: Scenario 2 - Well-050 Production History Match................................................ 237

Figure 10-30: Scenario 2 - Well-051 Production History Match.............................................. 238

Figure 10-31: Scenario 2 - Well-052 Production History Match............................................. 238

Figure 10-32: Scenario 2 - Well-053 Production History Match................................................ 239

Figure 10-33: Scenario 2 - Well-055 Production History Match............................................... 239

Figure 10-34: Scenario 2 - Well-057 Production History Match................................................ 240

Figure 10-35: Scenario 2 - Well-001 Production History Match................................................ 240

Figure 10-36: Scenario 2 - Well-003 Production History Match................................................... 241

Figure 10-37: Scenario 2 - Well-005 Production History Match................................................. 241

Figure 10-38: Scenario 2 - Well-008 Production History Match................................................ 242

Figure 10-39: Scenario 2 - Well-011 Production History Match............................................... 242

Figure 10-40: Scenario 2 - Well-014 Production History Match................................................ 243

Figure 10-41: Scenario 2 - Well-018 Production History Match................................................ 243

Figure 10-42: Scenario 2 - Well-019 Production History Match................................................ 244

Figure 10-43: Scenario 2 - Well-020 Production History Match.................................................. 244

Figure 10-44: Scenario 2 - Well-021 Production History Match................................................. 245

Figure 10-45: Scenario 2 - Well-023 Production History Match............................................... 245

Figure 10-46: Scenario 2 - Well-026 Production History Match................................................ 246

Figure 10-47: Scenario 2 - Well-028 Production History Match................................................. 246

Figure 10-48: Scenario 2 - Well-029 Production History Match............................................... 247

Figure 10-49: Scenario 2 - Well-032 Production History Match................................................ 247

Figure 10-50: Scenario 2 - Well-034 Production History Match............................................... 248 
Figure 10-51: Scenario 2 - Well-036 Production History Match............................................... 248

Figure 10-52: Scenario 2 - Well-037 Production History Match............................................. 249

Figure 10-53: Scenario 2 - Well-038 Production History Match................................................ 249

Figure 10-54: Scenario 2 - Well-039 Production History Match............................................. 250

Figure 10-55: Scenario 2 - Well-040 Production History Match............................................. 250

Figure 10-56: Scenario 2 - Well-042 Production History Match............................................... 251

Figure 10-57: Scenario 2 - Well-043 Production History Match.............................................. 251

Figure 10-58: Scenario 2 - Well-044 Production History Match............................................... 252

Figure 10-59: Scenario 2 - Well-049 Production History Match............................................... 252

Figure 10-60: Scenario 2 - Well-054 Production History Match................................................ 253

Figure 10-61: Scenario 2 - Well-056 Production History Match................................................ 253

Figure 10-62: Scenario 2 - Well-016 Production History Match................................................ 254

Figure 10-63: Scenario 2 - Well-048 Production History Match................................................ 255

Figure 10-64: Scenario 2 - Distribution Maps at Different Timesteps ....................................... 259

Figure 11-1: Scenario 3 - Oil Model Input Attributes............................................................. 260

Figure 11-2: Scenario 3 - Gas Model Input Attributes................................................................ 261

Figure 11-3: Scenario 3 - Water Model Input Attributes .............................................................. 262

Figure 11-4: Scenario 3 - Reservoir Pressure Model Input Attributes......................................... 263

Figure 11-5: Scenario 3 - Water Saturation Model Input Attributes........................................... 264

Figure 11-6: Scenario 3 - Entire Field Production .................................................................. 265

Figure 11-7: Scenario 3 - Well-002 Production History Match.................................................. 266

Figure 11-8: Scenario 3 - Well-004 Production History Match................................................. 266

Figure 11-9: Scenario 3 - Well-006 Production History Match.................................................. 267

Figure 11-10: Scenario 3 - Well-007 Production History Match................................................. 267 
Figure 11-11: Scenario 3 - Well-009 Production History Match................................................ 268

Figure 11-12: Scenario 3 - Well-010 Production History Match................................................ 268

Figure 11-13: Scenario 3 - Well-015 Production History Match.................................................. 269

Figure 11-14: Scenario 3 - Well-017 Production History Match................................................. 269

Figure 11-15: Scenario 3 - Well-019 Production History Match............................................. 270

Figure 11-16: Scenario 3 - Well-025 Production History Match................................................ 270

Figure 11-17: Scenario 3 - Well-030 Production History Match............................................... 271

Figure 11-18: Scenario 3 - Well-031 Production History Match.................................................. 271

Figure 11-19: Scenario 3 - Well-035 Production History Match................................................. 272

Figure 11-20: Scenario 3 - Well-039 Production History Match............................................... 272

Figure 11-21: Scenario 3 - Well-041 Production History Match............................................... 273

Figure 11-22: Scenario 3 - Well-045 Production History Match............................................... 273

Figure 11-23: Scenario 3 - Well-046 Production History Match................................................ 274

Figure 11-24: Scenario 3 - Well-047 Production History Match................................................ 274

Figure 11-25: Scenario 3 - Well-050 Production History Match................................................ 275

Figure 11-26: Scenario 3 - Well-051 Production History Match............................................... 275

Figure 11-27: Scenario 3 - Well-055 Production History Match................................................... 276

Figure 11-28: Scenario 3 - Well-057 Production History Match................................................. 276

Figure 11-29: Scenario 3 - Well-001 Production History Match................................................. 277

Figure 11-30: Scenario 3 - Well-003 Production History Match................................................ 277

Figure 11-31: Scenario 3 - Well-005 Production History Match............................................... 278

Figure 11-32: Scenario 3 - Well-008 Production History Match............................................... 278

Figure 11-33: Scenario 3 - Well-011 Production History Match............................................... 279

Figure 11-34: Scenario 3 - Well-012 Production History Match............................................... 279 
Figure 11-35: Scenario 3 - Well-013 Production History Match................................................ 280

Figure 11-36: Scenario 3 - Well-014 Production History Match............................................... 280

Figure 11-37: Scenario 3 - Well-016 Production History Match.............................................. 281

Figure 11-38: Scenario 3 - Well-018 Production History Match................................................. 281

Figure 11-39: Scenario 3 - Well-020 Production History Match............................................. 282

Figure 11-40: Scenario 3 - Well-021 Production History Match.................................................. 282

Figure 11-41: Scenario 3 - Well-022 Production History Match............................................. 283

Figure 11-42: Scenario 3 - Well-023 Production History Match................................................ 283

Figure 11-43: Scenario 3 - Well-024 Production History Match................................................. 284

Figure 11-44: Scenario 3 - Well-026 Production History Match................................................... 284

Figure 11-45: Scenario 3 - Well-027 Production History Match.............................................. 285

Figure 11-46: Scenario 3 - Well-028 Production History Match................................................. 285

Figure 11-47: Scenario 3 - Well-029 Production History Match............................................... 286

Figure 11-48: Scenario 3 - Well-032 Production History Match................................................ 286

Figure 11-49: Scenario 3 - Well-033 Production History Match................................................. 287

Figure 11-50: Scenario 3 - Well-034 Production History Match................................................. 287

Figure 11-51: Scenario 3 - Well-037 Production History Match................................................... 288

Figure 11-52: Scenario 3 - Well-038 Production History Match................................................. 288

Figure 11-53: Scenario 3 - Well-040 Production History Match.................................................. 289

Figure 11-54: Scenario 3 - Well-042 Production History Match................................................ 289

Figure 11-55: Scenario 3 - Well-043 Production History Match.............................................. 290

Figure 11-56: Scenario 3 - Well-044 Production History Match............................................... 290

Figure 11-57: Scenario 3 - Well-049 Production History Match................................................ 291

Figure 11-58: Scenario 3 - Well-052 Production History Match................................................. 291 
Figure 11-59: Scenario 3 - Well-053 Production History Match................................................ 292

Figure 11-60: Scenario 3 - Well-056 Production History Match............................................... 292

Figure 11-61: Scenario 3 - Well-036 Production History Match................................................. 293

Figure 11-62: Scenario 3 - Well-048 Production History Match............................................... 293

Figure 11-63: Scenario 3 - Well-054 Production History Match.............................................. 294

Figure 11-64: Scenario 3 - Distribution Maps at Different Timesteps ....................................... 298

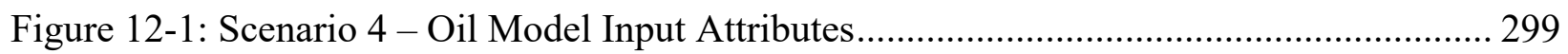

Figure 12-2: Scenario 4 - Gas Model Input Attributes............................................................. 300

Figure 12-3: Scenario 4 - Water Model Input Attributes ............................................................. 301

Figure 12-4: Scenario 4 - Reservoir Pressure Model Input Attributes.......................................... 302

Figure 12-5: Scenario 4 - Water Saturation Model Input Attributes............................................ 303

Figure 12-6: Scenario 4 - Entire Field Production ....................................................................... 304

Figure 12-7: Scenario 4 - Well-001 Production History Match.................................................. 305

Figure 12-8: Scenario 4 - Well-003 Production History Match.................................................. 305

Figure 12-9: Scenario 4 - Well-006 Production History Match...................................................... 306

Figure 12-10: Scenario 4 - Well-009 Production History Match................................................ 306

Figure 12-11: Scenario 4 - Well-010 Production History Match..................................................... 307

Figure 12-12: Scenario 4 - Well-013 Production History Match................................................... 307

Figure 12-13: Scenario 4 - Well-014 Production History Match.................................................. 308

Figure 12-14: Scenario 4 - Well-015 Production History Match................................................. 308

Figure 12-15: Scenario 4 - Well-018 Production History Match.................................................. 309

Figure 12-16: Scenario 4 - Well-019 Production History Match................................................. 309

Figure 12-17: Scenario 4 - Well-020 Production History Match............................................... 310

Figure 12-18: Scenario 4 - Well-022 Production History Match................................................ 310 
Figure 12-19: Scenario 4 - Well-023 Production History Match................................................ 311

Figure 12-20: Scenario 4 - Well-024 Production History Match............................................... 311

Figure 12-21: Scenario 4 - Well-025 Production History Match................................................. 312

Figure 12-22: Scenario 4 - Well-027 Production History Match................................................... 312

Figure 12-23: Scenario 4 - Well-029 Production History Match.................................................. 313

Figure 12-24: Scenario 4 - Well-030 Production History Match.............................................. 313

Figure 12-25: Scenario 4 - Well-031 Production History Match.............................................. 314

Figure 12-26: Scenario 4 - Well-033 Production History Match.................................................. 314

Figure 12-27: Scenario 4 - Well-034 Production History Match................................................ 315

Figure 12-28: Scenario 4 - Well-035 Production History Match................................................ 315

Figure 12-29: Scenario 4 - Well-036 Production History Match................................................. 316

Figure 12-30: Scenario 4 - Well-038 Production History Match................................................. 316

Figure 12-31: Scenario 4 - Well-040 Production History Match................................................. 317

Figure 12-32: Scenario 4 - Well-041 Production History Match................................................. 317

Figure 12-33: Scenario 4 - Well-042 Production History Match................................................. 318

Figure 12-34: Scenario 4 - Well-043 Production History Match................................................ 318

Figure 12-35: Scenario 4 - Well-045 Production History Match................................................. 319

Figure 12-36: Scenario 4 - Well-047 Production History Match.................................................. 319

Figure 12-37: Scenario 4 - Well-048 Production History Match................................................ 320

Figure 12-38: Scenario 4 - Well-049 Production History Match.................................................. 320

Figure 12-39: Scenario 4 - Well-050 Production History Match................................................ 321

Figure 12-40: Scenario 4 - Well-051 Production History Match................................................ 321

Figure 12-41: Scenario 4 - Well-052 Production History Match................................................ 322

Figure 12-42: Scenario 4 - Well-053 Production History Match............................................... 322 
Figure 12-43: Scenario 4 - Well-054 Production History Match.......................................... 323

Figure 12-44: Scenario 4 - Well-055 Production History Match.......................................... 323

Figure 12-45: Scenario 4 - Well-056 Production History Match......................................... 324

Figure 12-46: Scenario 4 - Well-057 Production History Match.......................................... 324

Figure 12-47: Scenario 4 - Well-002 Production History Match........................................... 325

Figure 12-48: Scenario 4 - Well-004 Production History Match........................................... 325

Figure 12-49: Scenario 4 - Well-005 Production History Match........................................... 326

Figure 12-50: Scenario 4 - Well-007 Production History Match............................................. 326

Figure 12-51: Scenario 4 - Well-008 Production History Match......................................... 327

Figure 12-52: Scenario 4 - Well-012 Production History Match......................................... 327

Figure 12-53: Scenario 4 - Well-016 Production History Match........................................... 328

Figure 12-54: Scenario 4 - Well-017 Production History Match.......................................... 328

Figure 12-55: Scenario 4 - Well-021 Production History Match.......................................... 329

Figure 12-56: Scenario 4 - Well-026 Production History Match.......................................... 329

Figure 12-57: Scenario 4 - Well-028 Production History Match.......................................... 330

Figure 12-58: Scenario 4 - Well-032 Production History Match............................................ 330

Figure 12-59: Scenario 4 - Well-037 Production History Match.......................................... 331

Figure 12-60: Scenario 4 - Well-039 Production History Match........................................... 331

Figure 12-61: Scenario 4 - Well-044 Production History Match.......................................... 332

Figure 12-62: Scenario 4 - Well-046 Production History Match.......................................... 332

Figure 12-63: Scenario 4 - Well-002 Forecast Production ................................................ 335

Figure 12-64: Scenario 4 - Well-010 Forecast Production ................................................. 335

Figure 12-65: Scenario 4 - Well-013 Forecast Production ................................................ 336

Figure 12-66: Scenario 4 - Well-019 Forecast Production ............................................... 336 
Figure 12-67: Scenario 4 - Well-022 Forecast Production

Figure 12-68: Scenario 4 - Well-023 Forecast Production 337

Figure 12-69: Scenario 4 - Well-024 Forecast Production 338

Figure 12-70: Scenario 4 - Well-048 Forecast Production 338

Figure 12-71: Scenario 4 - Well-053 Forecast Production 339

Figure 12-72: Scenario 4 - Well-057 Forecast Production 339

Figure 12-73: Scenario 4 - Well-017 Forecast Production 340

Figure 12-74: Scenario 4 - Well-025 Forecast Production 340

Figure 12-75: Scenario 4 - Well-027 Forecast Production 341

Figure 12-76: Scenario 4 - Well-031 Forecast Production 341

Figure 12-77: Scenario 4 - Well-034 Forecast Production 342

Figure 12-78: Scenario 4 - Well-041 Forecast Production 342

Figure 12-79: Scenario 4 - Well-042 Forecast Production 343

Figure 12-80: Scenario 4 - Well-043 Forecast Production 343

Figure 12-81: Scenario 4 - Well-047 Forecast Production 344

Figure 12-82: Scenario 4 - Well-049 Forecast Production 344

Figure 12-83: Scenario 4 - Well-051 Forecast Production 345

Figure 12-84: Scenario 4 - Well-003 Forecast Production 346

Figure 12-85: Scenario 4 - Well-015 Forecast Production 346

Figure 12-86: Scenario 4 - Well-032 Forecast Production 347

Figure 12-87: Scenario 4 - Well-036 Forecast Production 347

Figure 12-88: Scenario 4 - Well-038 Forecast Production 348

Figure 12-89: Scenario 4 - Well-039 Forecast Production 348

Figure 12-90: Scenario 4 - Well-040 Forecast Production 349 
Figure 12-91: Scenario 4 - Well-044 Forecast Production 349

Figure 12-92: Scenario 4 - Well-050 Forecast Production 350

Figure 12-93: Scenario 4 - Well-052 Forecast Production 350

Figure 12-94: Scenario 4 - Well-054 Forecast Production 351

Figure 12-95: Scenario 4 - Well-055 Forecast Production 351

Figure 12-96: Scenario 4 - Well-056 Forecast Production 352

Figure 12-97: Scenario 4 - Distribution Maps at Different Timesteps 356

Figure 13-1: Scenario 5 - Oil Model Input Attributes. 357

Figure 13-2: Scenario 5 - Gas Model Input Attributes. 358

Figure 13-3: Scenario 5 - Water Model Input Attributes 359

Figure 13-4: Scenario 5 - Reservoir Pressure Model Input Attributes. 360

Figure 13-5: Scenario 5 - Water Saturation Model Input Attributes. 361

Figure 13-6: Scenario 5 - Entire Field Production 362

Figure 13-7: Scenario 5 - Well-002 Production History Match. 363

Figure 13-8: Scenario 5 - Well-007 Production History Match. 363

Figure 13-9: Scenario 5 - Well-009 Production History Match. 364

Figure 13-10: Scenario 5 - Well-010 Production History Match 364

Figure 13-11: Scenario 5 - Well-013 Production History Match. 365

Figure 13-12: Scenario 5 - Well-015 Production History Match. 365

Figure 13-13: Scenario 5 - Well-018 Production History Match 366

Figure 13-14: Scenario 5 - Well-019 Production History Match 366

Figure 13-15: Scenario 5 - Well-020 Production History Match 367

Figure 13-16: Scenario 5 - Well-021 Production History Match. 367

Figure 13-17: Scenario 5 - Well-022 Production History Match 368 
Figure 13-18: Scenario 5 - Well-023 Production History Match................................................ 368

Figure 13-19: Scenario 5 - Well-024 Production History Match................................................ 369

Figure 13-20: Scenario 5 - Well-025 Production History Match................................................... 369

Figure 13-21: Scenario 5 - Well-027 Production History Match............................................... 370

Figure 13-22: Scenario 5 - Well-030 Production History Match............................................... 370

Figure 13-23: Scenario 5 - Well-031 Production History Match................................................... 371

Figure 13-24: Scenario 5 - Well-035 Production History Match............................................... 371

Figure 13-25: Scenario 5 - Well-038 Production History Match................................................. 372

Figure 13-26: Scenario 5 - Well-040 Production History Match............................................... 372

Figure 13-27: Scenario 5 - Well-041 Production History Match................................................. 373

Figure 13-28: Scenario 5 - Well-042 Production History Match................................................ 373

Figure 13-29: Scenario 5 - Well-043 Production History Match................................................. 374

Figure 13-30: Scenario 5 - Well-047 Production History Match............................................... 374

Figure 13-31: Scenario 5 - Well-049 Production History Match................................................ 375

Figure 13-32: Scenario 5 - Well-051 Production History Match.................................................. 375

Figure 13-33: Scenario 5 - Well-053 Production History Match................................................ 376

Figure 13-34: Scenario 5 - Well-055 Production History Match.................................................... 376

Figure 13-35: Scenario 5 - Well-057 Production History Match................................................... 377

Figure 13-36: Scenario 5 - Well-001 Production History Match.................................................. 378

Figure 13-37: Scenario 5 - Well-003 Production History Match................................................ 378

Figure 13-38: Scenario 5 - Well-004 Production History Match................................................. 379

Figure 13-39: Scenario 5 - Well-005 Production History Match................................................ 379

Figure 13-40: Scenario 5 - Well-006 Production History Match............................................... 380

Figure 13-41: Scenario 5 - Well-008 Production History Match................................................ 380 
Figure 13-42: Scenario 5 - Well-011 Production History Match................................................ 381

Figure 13-43: Scenario 5 - Well-012 Production History Match............................................... 381

Figure 13-44: Scenario 5 - Well-014 Production History Match.................................................. 382

Figure 13-45: Scenario 5 - Well-017 Production History Match............................................... 382

Figure 13-46: Scenario 5 - Well-026 Production History Match............................................... 383

Figure 13-47: Scenario 5 - Well-028 Production History Match............................................... 383

Figure 13-48: Scenario 5 - Well-029 Production History Match.............................................. 384

Figure 13-49: Scenario 5 - Well-032 Production History Match.................................................. 384

Figure 13-50: Scenario 5 - Well-033 Production History Match............................................... 385

Figure 13-51: Scenario 5 - Well-034 Production History Match................................................ 385

Figure 13-52: Scenario 5 - Well-036 Production History Match................................................. 386

Figure 13-53: Scenario 5 - Well-037 Production History Match................................................. 386

Figure 13-54: Scenario 5 - Well-039 Production History Match................................................. 387

Figure 13-55: Scenario 5 - Well-044 Production History Match................................................. 387

Figure 13-56: Scenario 5 - Well-045 Production History Match.................................................. 388

Figure 13-57: Scenario 5 - Well-048 Production History Match............................................... 388

Figure 13-58: Scenario 5 - Well-050 Production History Match.................................................. 389

Figure 13-59: Scenario 5 - Well-052 Production History Match................................................... 389

Figure 13-60: Scenario 5 - Well-054 Production History Match.................................................. 390

Figure 13-61: Scenario 5 - Well-056 Production History Match................................................ 390

Figure 13-62: Scenario 5 - Well-016 Production History Match................................................. 391

Figure 13-63: Scenario 5 - Well-002 Forecast Production ..................................................... 392

Figure 13-64: Scenario 5 - Well-010 Forecast Production ..................................................... 392

Figure 13-65: Scenario 5 - Well-015 Forecast Production ......................................................... 393 
Figure 13-66: Scenario 5 - Well-029 Forecast Production 393

Figure 13-67: Scenario 5 - Well-031 Forecast Production 394

Figure 13-68: Scenario 5 - Well-035 Forecast Production 394

Figure 13-69: Scenario 5 - Well-042 Forecast Production 395

Figure 13-70: Scenario 5 - Well-044 Forecast Production 395

Figure 13-71: Scenario 5 - Well-047 Forecast Production 396

Figure 13-72: Scenario 5 - Well-049 Forecast Production 396

Figure 13-73: Scenario 5 - Well-051 Forecast Production 397

Figure 13-74: Scenario 5 - Well-013 Forecast Production 398

Figure 13-75: Scenario 5 - Well-017 Forecast Production 398

Figure 13-76: Scenario 5 - Well-019 Forecast Production 399

Figure 13-77: Scenario 5 - Well-022 Forecast Production 399

Figure 13-78: Scenario 5 - Well-023 Forecast Production 400

Figure 13-79: Scenario 5 - Well-024 Forecast Production 400

Figure 13-80: Scenario 5 - Well-027 Forecast Production 401

Figure 13-81: Scenario 5 - Well-032 Forecast Production 401

Figure 13-82: Scenario 5 - Well-034 Forecast Production 402

Figure 13-83: Scenario 5 - Well-036 Forecast Production 402

Figure 13-84: Scenario 5 - Well-038 Forecast Production 403

Figure 13-85: Scenario 5 - Well-039 Forecast Production 403

Figure 13-86: Scenario 5 - Well-040 Forecast Production 404

Figure 13-87: Scenario 5 - Well-041 Forecast Production 404

Figure 13-88: Scenario 5 - Well-043 Forecast Production 405

Figure 13-89: Scenario 5 - Well-045 Forecast Production 405 
Figure 13-90: Scenario 5 - Well-050 Forecast Production ....................................................... 406

Figure 13-91: Scenario 5 - Well-052 Forecast Production ........................................................ 406

Figure 13-92: Scenario 5 - Well-055 Forecast Production ............................................................ 407

Figure 13-93: Scenario 5 - Well-003 Forecast Production ........................................................ 408

Figure 13-94: Scenario 5 - Well-025 Forecast Production ....................................................... 408

Figure 13-95: Scenario 5 - Well-048 Forecast Production ......................................................... 409

Figure 13-96: Scenario 5 - Well-053 Forecast Production ...................................................... 409

Figure 13-97: Scenario 5 - Well-054 Forecast Production ........................................................ 410

Figure 13-98: Scenario 5 - Well-056 Forecast Production .................................................... 410

Figure 13-99: Scenario 5 - Well-057 Production History Match................................................. 411

Figure 13-100: Scenario 5 - Distribution Maps at Different Timesteps .................................... 415 


\section{List of Tables}

Table 3-1: Original Model - Properties Overview .............................................................. 22

Table 3-2: Fluid Component Characteristics ....................................................................... 30

Table 3-3: Combining Layers Into Single Layer ............................................................... 34

Table 3-4: Grid Modification Process................................................................................. 38

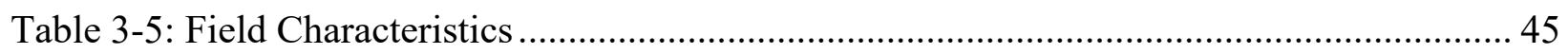

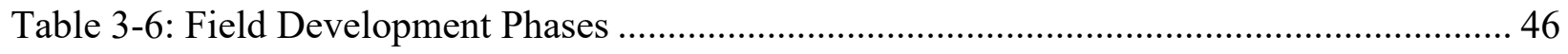

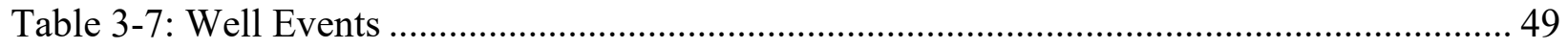

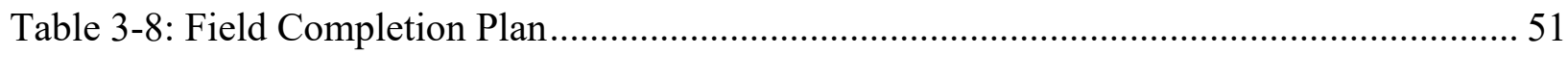

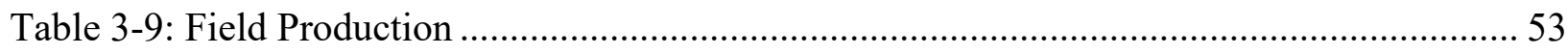

Table 3-10: Cumulative Production Statistics on a Well Basis ................................................ 53

Table 3-11: Well Based Reported Data .............................................................................. 54

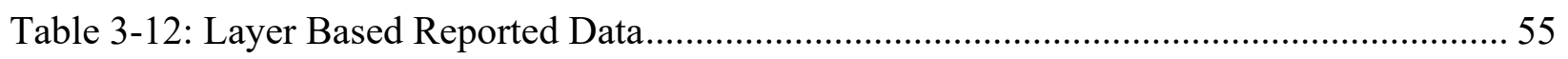

Table 3-13: Special History Reported Data ........................................................................ 55

Table 3-14: Block Properties Reported Data ............................................................... 55

Table 4-1: History Match and Forecast Scenarios - Description ........................................ 71

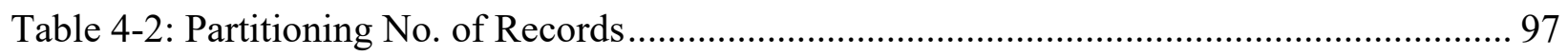

Table 4-3: Predictive Model Input Attributes and No. of Epochs Summary............................ 97

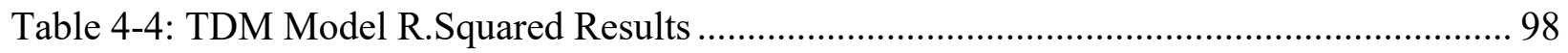

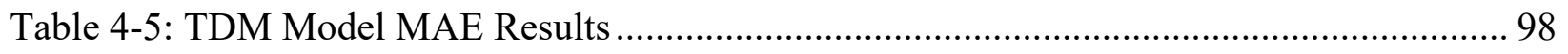

Table 5-1: History Match - Cumulative Field Production Comparison................................. 100

Table 5-2: History Match and Forecast - Cumulative Field Production ................................. 101

Table 5-3: History Match Accuracy of Individual Production Rates .................................. 118 
Table 5-4: Forecast of Individual Production Rates ........................................................ 119

Table 5-5: History Match Production Accuracy …........................................................... 133

Table 5-6: Production Forecast......................................................................................... 133 


\section{List of Equations}

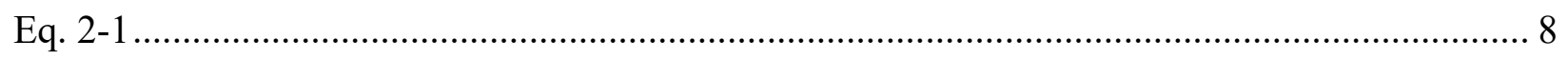

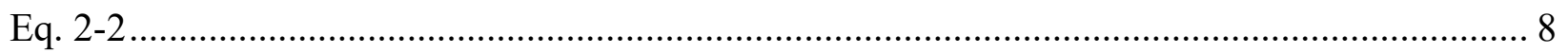

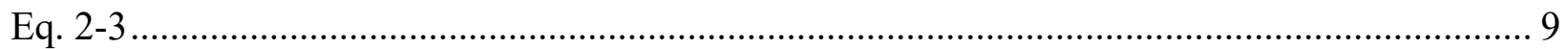

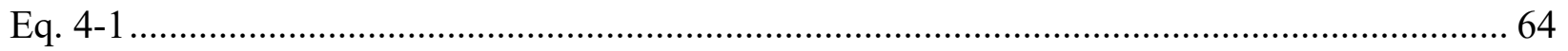

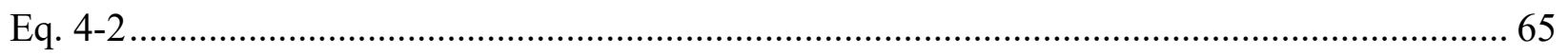

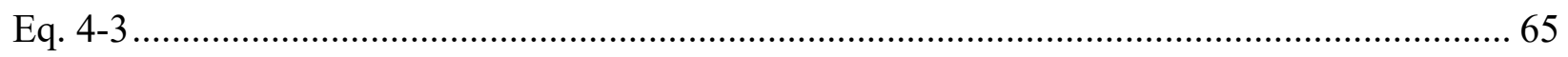




\section{Acknowledgements}

I would like thank Dr. Shahab for being a good mentor during my master's program and for giving the opportunity to be part of the WVU-LEADS research team. His team has inspired and motivated me to strive for excellence. I would like to express my sincerest gratitude to Dr. Ameri and Dr. Aminian for their continuous support and guidance throughout my college career. They have kindly welcomed me into the master's program. I would also like to thank Dr. Zamirian who has devoted time to provide me with suggestions towards my thesis. Lastly, I want to thank my parents for their constant love and support. 


\section{Symbols and Abbreviations}

\begin{tabular}{|l|l|}
\hline \multicolumn{1}{|c|}{ Term } & \multicolumn{1}{c|}{ Description } \\
\hline AI & Artificial Intelligence \\
\hline ANN & Artificial Neural Networks \\
\hline DDM & Data-Driven Modeling \\
\hline KPI & Key Performance Indicators \\
MAE & Mean Absolute Error \\
ML & Machine Learning \\
TDM & Top-Down Modeling \\
\hline
\end{tabular}




\section{CHAPTER 1}

\section{INTRODUCTION}

The oil and natural gas industry provide a reliable source of energy to the world that is sufficient to power industries, heat homes, allow efficient transportation and more. Extracting oil and natural gas from thousands of feet below the Earth's surface encompasses a series of steps; from the exploration stage to the production stage, petroleum engineers continue to innovate and enhance technologies to produce in a safe and profitable manner as expenditures, time, and operational risks are associated in the process [1].

Reservoir modeling allows experts to model the behavior of fluid flow in porous media when access to these reservoirs is not physically possible. Additionally, reservoir modeling allows experts to analyze and interpret data that enables improvements in the production planning, which is a crucial step in the decision-making process of drilling successful new wells.

Some of the traditional approaches used in modeling complex data structures, analyzing and optimizing field production require sophisticated equipment that can be often computationally expensive and time consuming. RTA (Rate Transient Analysis) and DCA (Decline Curve Analysis) have been reliable tools for reservoir modeling. Nevertheless, these are old fashioned approaches that have been around for decades and that add little insight to operations [2].

Currently, the amount of available data, measured or generated, can be used by Artificial Intelligence and Machine Learning algorithms that are capable of learning from past behaviors to provide accurate predictions - history matching and forecasting in the context of oil and gas [2].

\subsection{Problem statement}

This thesis focuses on the applications of reservoir modeling through two different approaches:

1. Traditional Numerical Reservoir Simulation and Modeling

2. Data-Driven Reservoir Simulation and Modeling 
The first is a conventional approach that uses numerical simulations to solve an engineering problem. The second acknowledges the capabilities of artificial intelligence and machine learning to look at reservoir modeling through a different point of view; more specifically through the applications of artificial neural networks [3].

The objective of this thesis is to test and validate the capabilities of Artificial Intelligence (AI) and Machine Learning (ML) by using synthetic data generated from a numerical reservoir model with efforts to create a data-driven reservoir model. The success of the application of these technologies will be determined by the proximity of the data-driven model's predicted data against the numerical simulation actual data.

\subsection{Thesis Outline}

This thesis is divided into the following chapters:

Chapter 1: discusses two current approaches to reservoir modeling and states the objective of the thesis.

Chapter 2: provides a background on numerical simulation, artificial intelligence and machine learning, and the application of artificial neural networks and literature review of previous studies performed on data-driven modeling.

Chapter 3: describes the details of a numerical reservoir model, the modifications performed on the original model and the data exported from the finalized working model (thesis model).

Chapter 4: elaborates on the development of 5 different top-down models using data generated from a numerical reservoir model.

Chapter 5: discusses the results (history match and forecast) obtained from the data-driven reservoir model and compares it to the actual data (numerical reservoir model).

Chapter 6: concludes the thesis and potential future work. 


\section{CHAPTER 2}

\section{LITERATURE REVIEW}

The following chapter provides some background information on (1) numerical simulation, a conventional reservoir modeling approach, (2) the theory and application of machine learning through algorithmic methods such as artificial neural networks and (3) previous work performed on the application of machine learning in the oil and gas industry.

\subsection{Numerical Simulation}

Numerical simulation is a mathematical representation of a physical behavior based on relevant hypothesis and simplified assumptions [4]. Darcy's law is one of the most commonly used models in the oil industry that describes how fluids flow in porous media. The equations associated with solving Darcy flow problems are fairly complex and difficult to solve analytically. As a result, oversimplified linear systems of equations are solved by utilizing memory efficient and parallelizable algorithms [5].

A few steps must be taken in preparation to build a numerical reservoir model. First, the representation of the physical domain is defined by a grid system. A set of pre-defined specifications must be provided; otherwise, default values are used in place. Once the model is physically established, a numerous set of calculations are computed at each grid block with efforts to find a numerical solution that provides some insight about the model's behavior. For example, pressures, saturations, and production rates are obtained after several hours of running a single simulation. The time and computational work from the numerical simulation process often depend on the quality and size of the grids as well as the complexity level of the reservoir model. Mesh refinement is a very important factor for determining an accurate solution. [6].

The second step is to validate the numerical reservoir model by comparing its results against actual measured data. This process is known as history matching. As the name implies, multiple attempts are made to match real measurements (often oil rate history) by modifying the reservoir properties 
of the numerical model. This process may take weeks, months, or years until the model successfully matches history. Once a reservoir model is finalized, calibrated and history matched, it will be used for reservoir planning, forecasting, and investment decisions [7].

Besides numeric modeling possibly taking a significant length of time to generate an accurate reservoir model, it can be incredibly costly. As a result, engineers have long searched for a more efficient and effective method of creating a reservoir model.

\subsection{Machine Learning}

Artificial intelligence is a term that dates back to the 1950's when mathematicians were interested in making intelligent machines capable of learning and problem solving [8].

Machine Learning is a subset of AI and was first defined by Arthur Samuel as "the field of study that gives computers the ability to learn without being explicitly programmed." This definition was reiterated by Tom Mitchell when he proposed that computer programs are said to learn from experience and these improve their performance with respect to some class of tasks [9].

One of the common techniques in machine learning is the application of Artificial Neural Networks (ANN). Artificial Neural Networks are simple mathematical computational algorithms capable of learning from input data and discovering patterns in data (pattern recognition). In the context of reservoir modeling, "machine learning algorithms are trained to model the physics of the phenomena that are of interest". [10]. The application of these technologies does not rely on complex systems of equations or assumptions that are often made in numerical reservoir simulations. Instead, it relies on the quantity and quality of data that the system can learn from to achieve specific goals through flexible adaptation [8].

\subsubsection{The Neuron}

Artificial Neural Networks (ANN) are inspired by the physical, biological, and chemical processes that take place in the human brain and have been developed in efforts to understand and replicated how humans learn. 


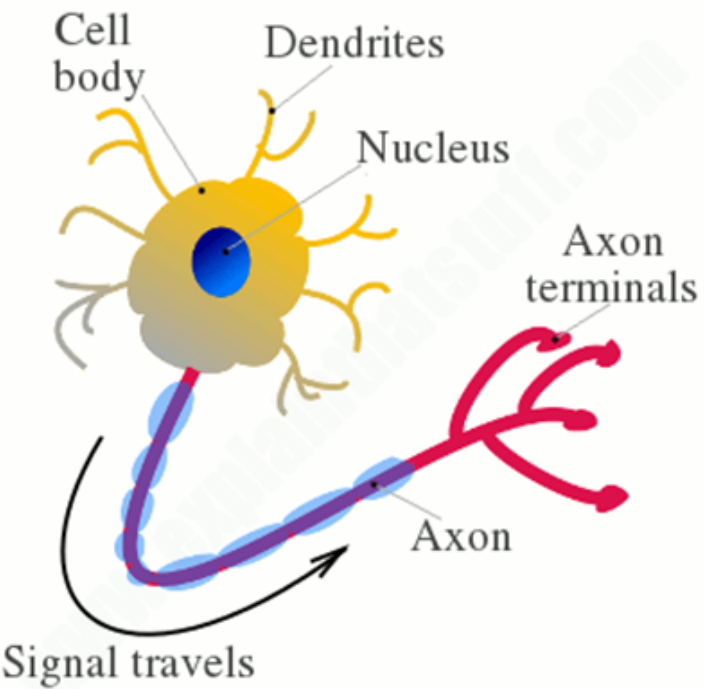

Figure 2-1: Biological Neuron's Structure
In a human brain, millions of neurons exist to receive and carry information. This information is also known as nerve impulses. The main parts of a neuron are the cell body that contains the nucleus and other organelles, dendrites that receive the electrical signal from other neurons, and the axon that passes the information to other neurons. Notice that the cell body is in between the two extremes of the neuron (dendrites and axon). The electrical impulses travel from one neuron to another via synapse, where thousands of dendrites from a neuron meet the axon of another neuron [11].

\subsubsection{Artificial Neuron - Structure Replication}

In a similar fashion, artificial neural networks mainly consist of an input layer, an output layer, and hidden layers. The input layers are similar to a neuron's dendrites, which are made of a set of artificial neurons that receive information from a dataset. As a matter of fact, this information helps the neural network learn.

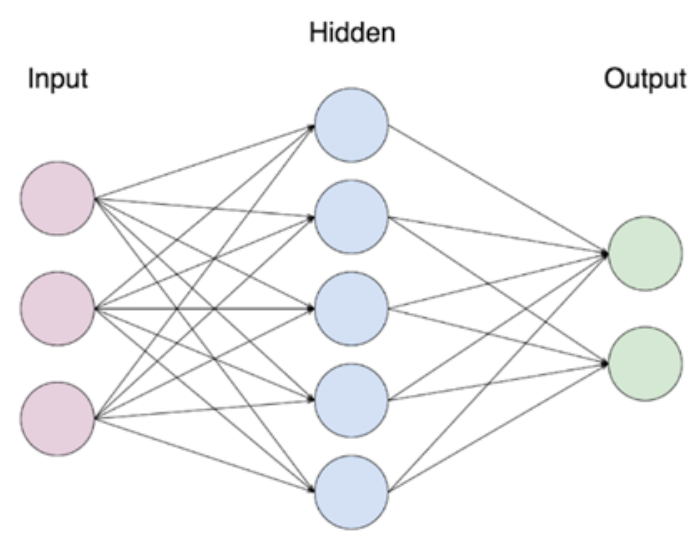
The output layer is similar to the neuron's Figure 2-2: Artificial Neural Network Structure axon; it responds to the information passed to the neural network and determines whether the system has learned the information. Finally, the hidden layers exist to communicate the information between the input and output layers [12]. Figure 2-2 illustrates a neuron's structure replication from a biological neuron's structure that receives, carries, and processes information. 


\subsubsection{Artificial Neural Networks}

As mentioned previously, the architecture of an artificial neural network is often composed of an input layer, a hidden layer, and an output layer. Biologically, the information carried from one neuron to another travels via synapse. Similarly, the strength of the connection between two artificial neurons is represented by weights. The value of each weight determines the strength of the information being fed forward through the neural network. In the context of reservoir modeling, permeability, flowing bottom-hole pressure, and well location have unique contributions to the reservoir's oil production. Therefore, the strength of weight values assigned to each attribute varies, depending on the relationship an attribute has with respect to the output value.

Artificial neural networks seek to strengthen their connections by a process called backpropagation. This process aims to optimize the set of weights assigned to the input neurons with efforts to develop a well-trained predictive model and minimize the total error between the actual output value and the predicted output value.

\section{$\underline{\text { Behavior replication }}$}

The mathematical representation of an artificial neural network is depicted in Figure 2-3. 


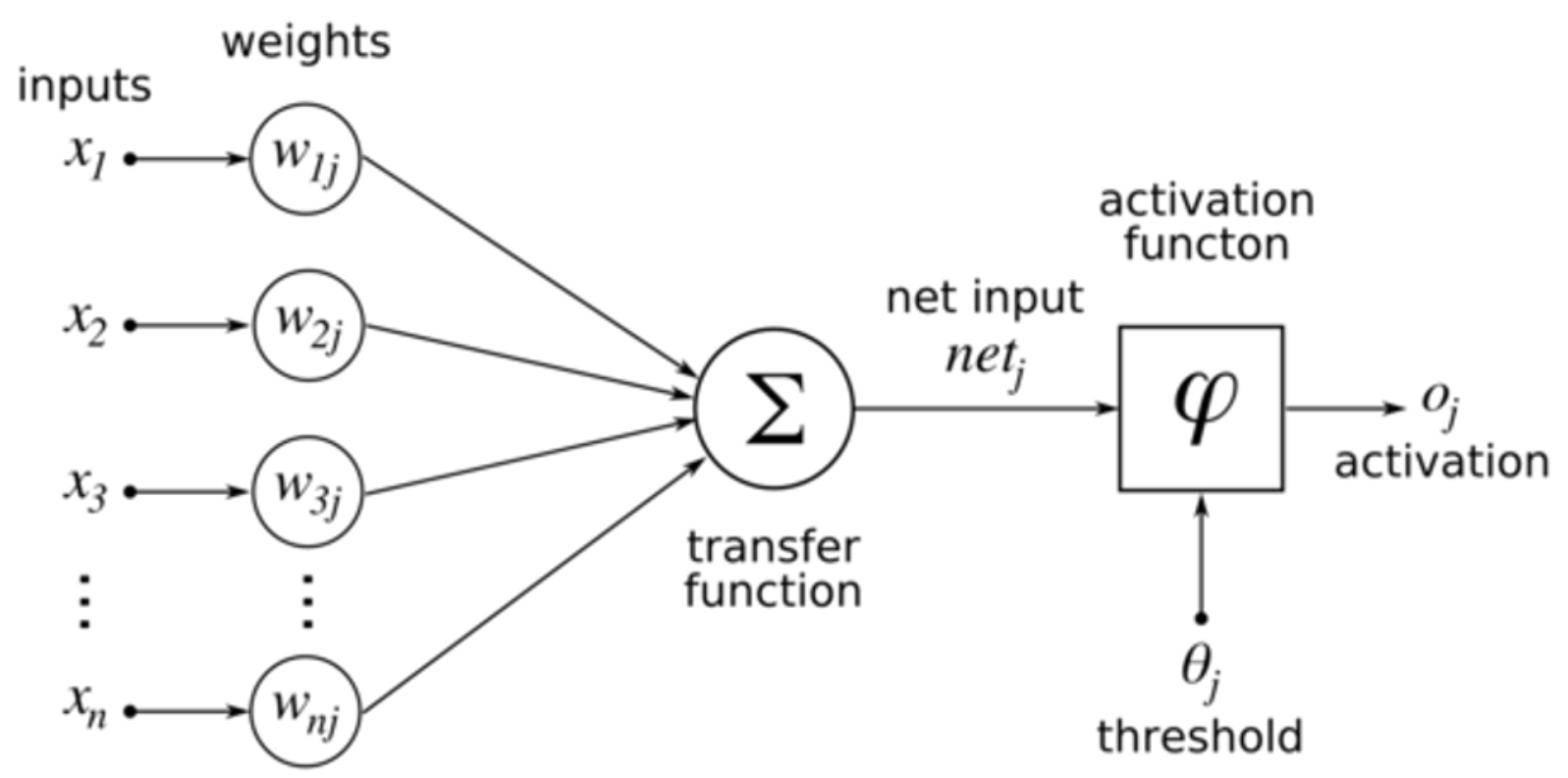

Figure 2-3: Mathematical Representation of a Neural Network

The flow of information starts at the input layers, where a pre-processed target dataset, referred to as the spatio-temporal database in the context of data-driven reservoir modeling, is fed to the system. A transfer function (or transfer potential) is performed on the inputs and their respective weights. The result from the transfer function is passed into a non-linear activation function, $\mathrm{f}(\mathrm{x})$, that determines an output value within a determined range. The output value is then passed to the next neuron layer where the same procedure is repeated [13].

The mathematical procedure is summarized into the following steps:

1. Transfer function

2. Activation function

3. Error function

4. Backpropagation

5. Weight optimization

The transfer function is the dot product, or the sum of products of the inputs and the weights. It is important to note that even if the value used from the input neurons is the same, the output values will change based on the weight values assigned. The values of these weights determine the strength of the pathways between neuron layers [14]. 


$$
\theta=\sum x_{1} w_{1 j}+x_{2} w_{2 j}+x_{3} w_{3 j}+\cdots+x_{n} w_{n j}
$$

A non-linear and differentiable activation function is applied to the result of the transfer function or the sum of the products. The activation function yields an output that is then passed on to the next layer.

Activation functions bring non-linearity to the system which translates to the neural network being able to learn complex systems. Based on the type of data used in training, negative values in the dataset can be handled with proper implementation of activation functions. Tanh outputs values between -1 and 1. Leaky relu keeps some of the negative values in a dataset. Logistic sigmoid displays values from 0 to 1 based on the value obtained from the transfer function [14]. Notice the non-linearity of the activation function in Figure 2-4.

$$
f(\theta)=\frac{1}{1+e^{-\theta}}
$$

Eq. 


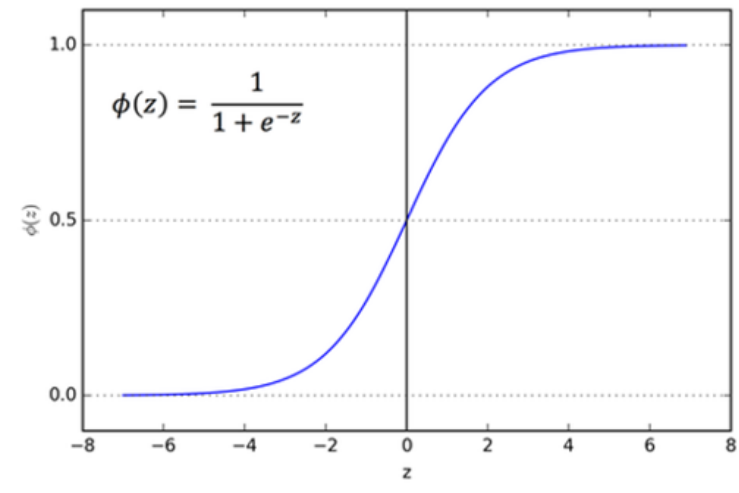

Figure 2-4: Logistic Sigmoid Activation Function

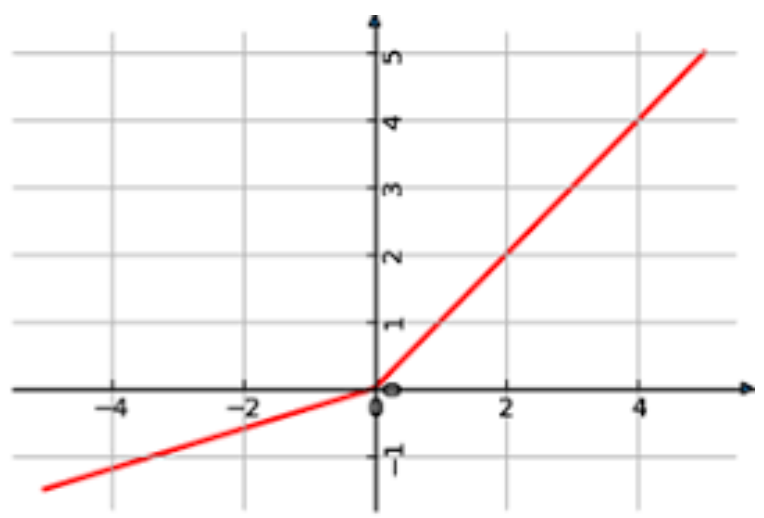

Figure 2-6: Leaky Relu Activation Function

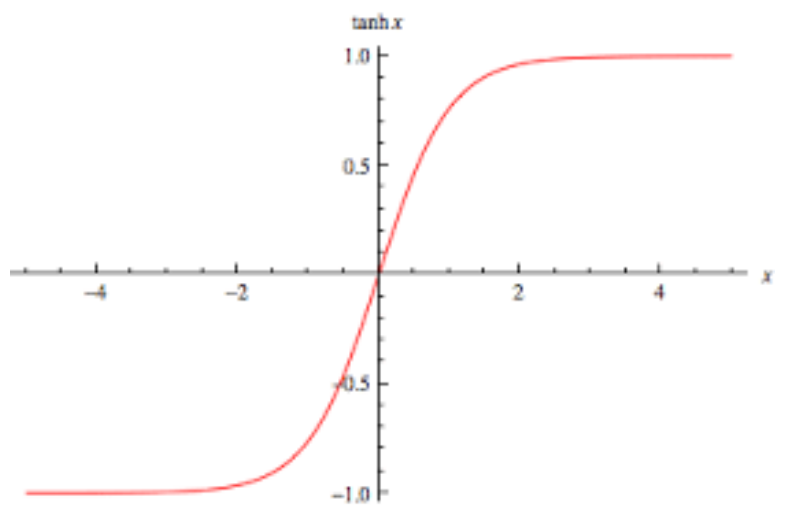

Figure 2-5: Tanh Activation Function

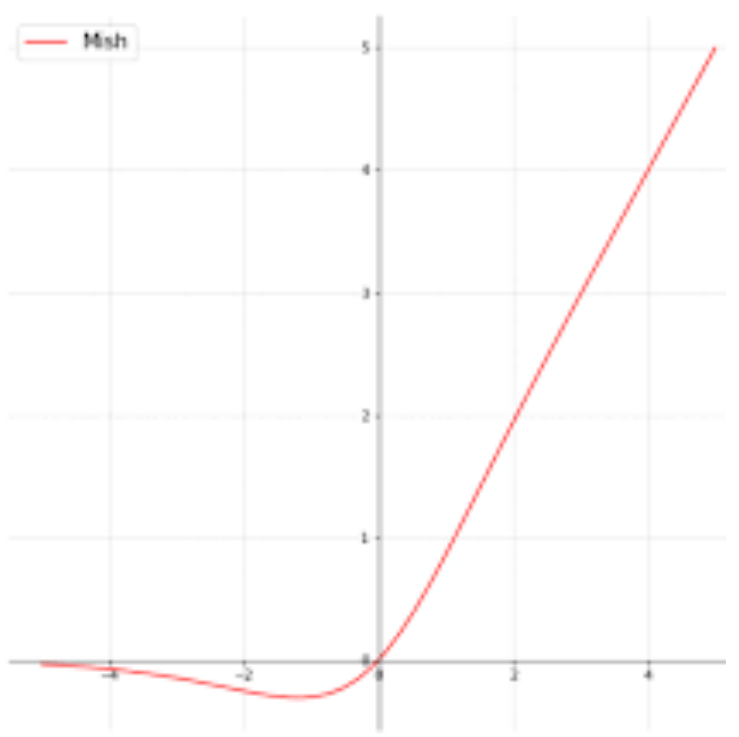

Figure 2-7: MISH Activation Function

The output value calculated at the last hidden layer is compared to the actual output value from the target dataset. The total error is calculated using an error function such as Error Sum of Squared (ESS) shown in Eq. 2-3 [14].

$$
E S S=\sum_{i=1}^{n} \frac{1}{2}\left(Y_{\text {Target }}-Y_{\text {output }}\right)^{2}
$$

Eq. 
The final goal is to minimize the error by updating and correcting all of the weights in the neural network. This process is known as backpropagation. Backpropagation is a training algorithm used in supervised learning using the gradient descent method that modifies the weights of a neural network with efforts to reduce the total error between the calculated output of the neural network and the actual output from the target dataset [15].

\subsubsection{Datasets}

The data used in machine learning and the development of predictive models is often separated into different datasets:

- Training dataset

- Calibration dataset

- Verification or validation dataset

The input layer represents the values of attributes that come from external data. For example, reservoir characteristics, operational constraints, and production measurements can be used as input attributes for a neural network to learn from. If the neural network sees and learns from the data, it means that the data is part of the training dataset.

During training, the neural network continues to learn from the same data as the weights continue to be optimized in efforts minimize the loss function (total error). The calibration dataset is separate from the training dataset and ensures that the model is not overfitting (memorizing the training dataset) or under fitting (not learning).

Lastly, the verification or validation dataset is completely separate from both the training and calibration datasets and it is used to evaluate the performance of the trained and calibrated model [16]. 


\subsubsection{Data Partitioning}

In the context of reservoir modeling, the sequential structure in which each dataset is presented to the neural network impacts the quality of the results and the degree of confidence on the final predictive model. Three types of partitioning (history matching techniques) are discussed:

1. Sequential partitioning

2. Random partitioning

3. Mixed partitioning

The sequential partitioning presents records in the exact order in which these have been arranged in the target dataset. If the data has been arranged based on a timeline, the training, calibration and verification datasets are arranged in the same manner, honoring the sequence of the data. This is the most robust technique used in the development of a data-driven reservoir model [17].

The random partitioning assigns data to the training, calibration and verification datasets in a completely random manner. Due to the nature of this data partitioning type, the sequence of a timeline is not honored and therefore it is not treated as a blind history match. Note that reservoir engineers attempt to history match and forecast a sequential period of time. Therefore, random partitioning is the least robust technique [17].

Lastly, the mixed partitioning, also referred to as multi-random partitioning, is a combination between the sequential and the random partitioning types. While the training and calibration datasets contain randomized data, the verification dataset contains data located at the end of the target dataset [17].

Figure 2-8 depicts the three types of partitioning techniques previously discussed. 


\section{Data Partitioning \\ Training Calibration Validation}

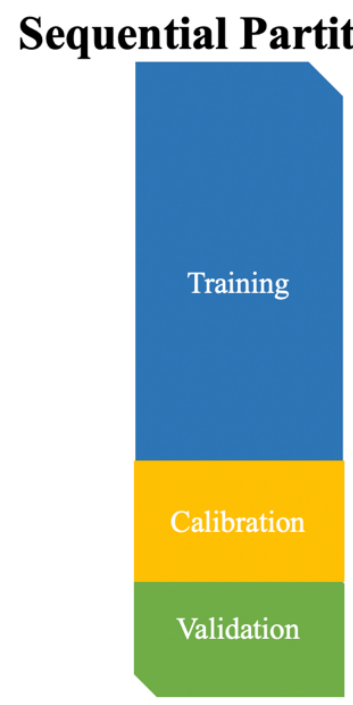

Random Partitioning

Mixed Partitioning
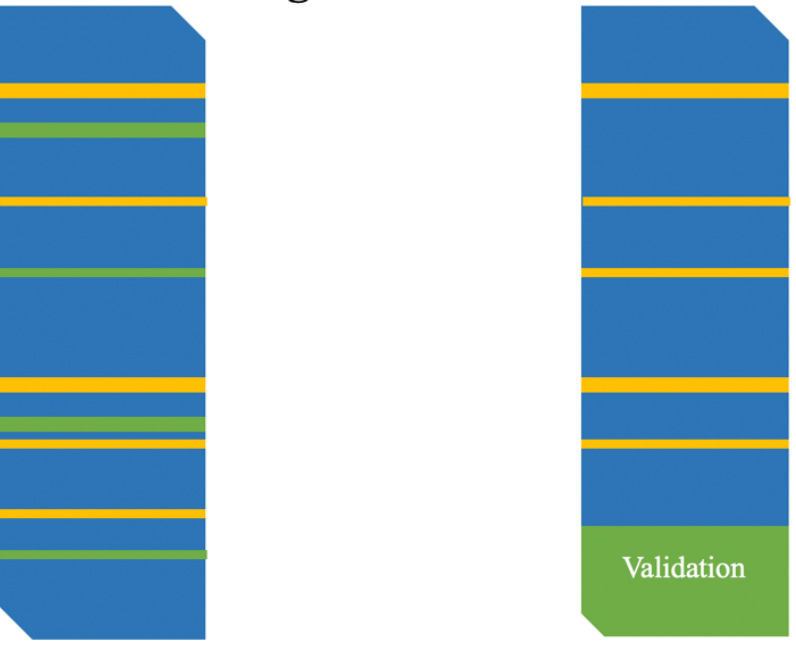

Figure 2-8: Data Partitioning Techniques

\subsection{Data Mining}

Data mining is focused on the process of discovering patterns in large sets of data. However, in order for machine learning algorithms to properly discover such patterns, data pre-processing, a data mining technique, is used to cleanse and prepare the collected data into a useful and standardized format. A brief schematic of important data mining steps is depicted in Figure 2-9 [18]. 


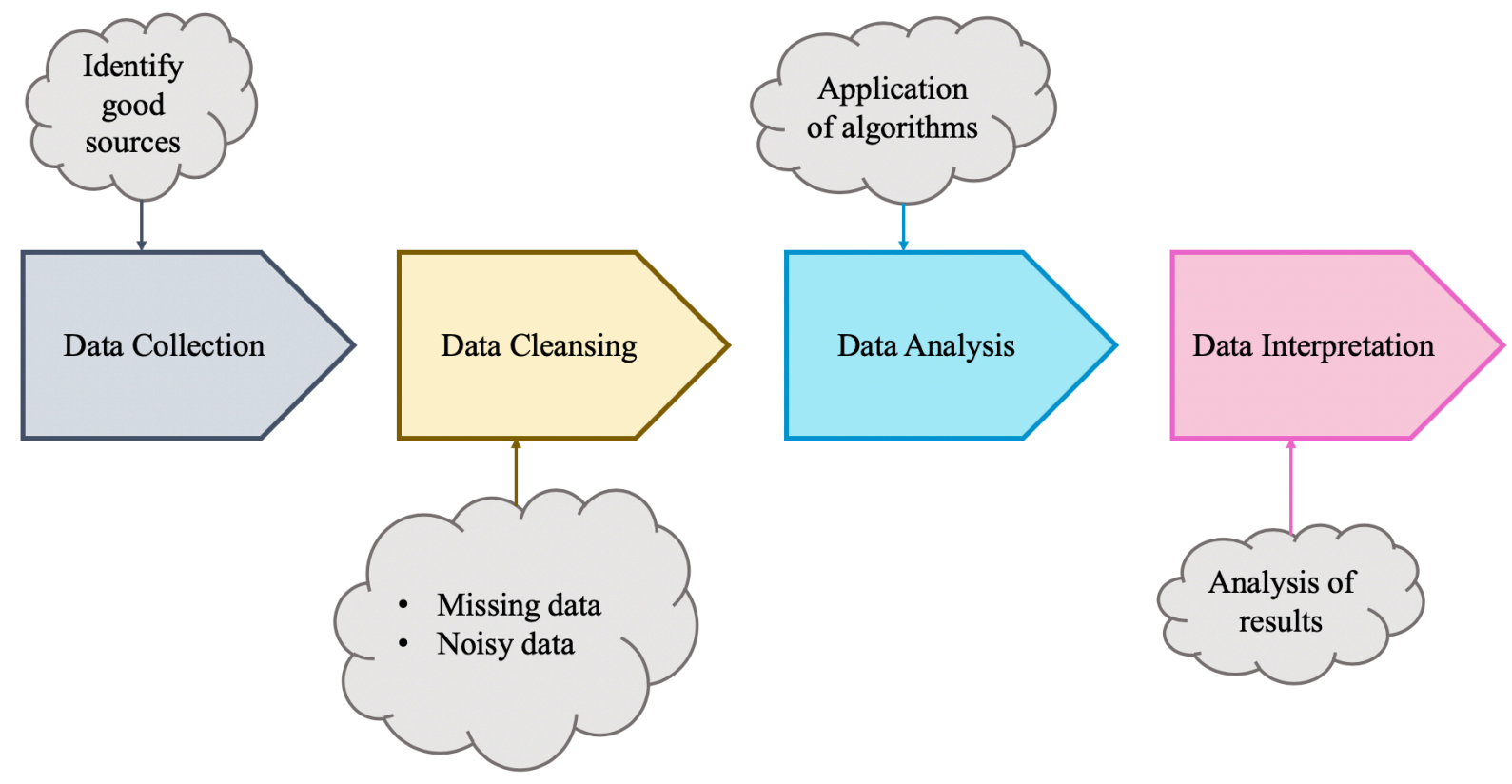

Figure 2-9: Data Mining Steps 


\subsection{Previous Work}

Previous studies acknowledge the capabilities of $\mathrm{AI}$ and $\mathrm{ML}$ techniques as these continue to demonstrate that machines have the ability to interpret and learn from external data with efforts to accurately history match and project future possibilities (forecasting) [19].

Yara Alatrach conducted a study on a low permeability carbonate reservoir located in Abu Dhabi. His study implemented Artificial Neural Networks in the development of a data-driven reservoir model that could learn from past historical data to optimize production and injection to maximize production of the entire field. The main objective of this study was to compare traditional numerical modeling approaches against alternative methods and techniques that honor the physics of a reservoir by using actual field measurements such as seismic surveys, well logs, core analysis, well tests, well production and injection behavior among others. Oil, gas, and water productions, reservoir pressure and water saturation results from the predictive model are compared against the actual data collected from the field are shown in Figure 2-10 [20]. 


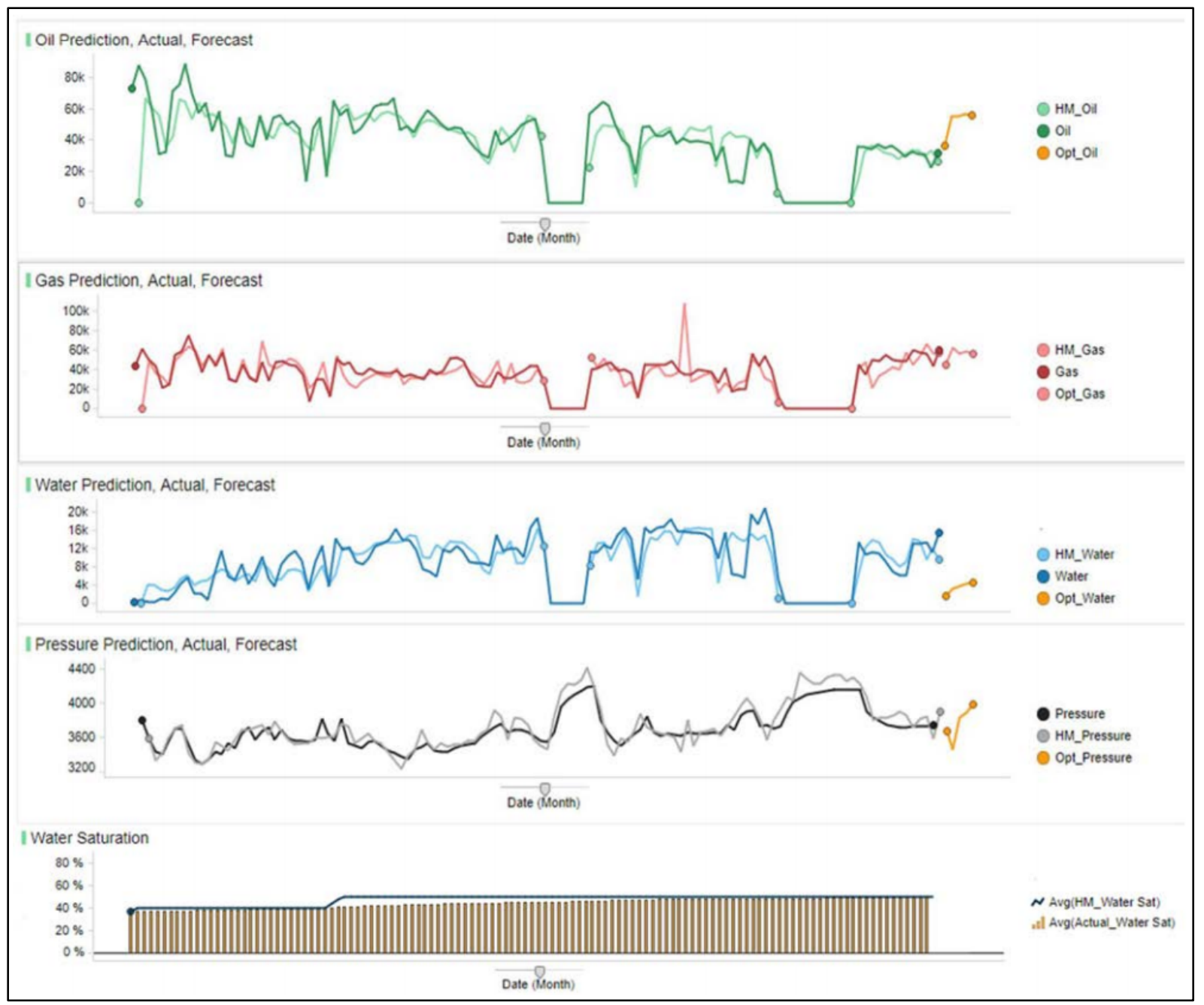

Figure 2-10: TDM prediction against historical Production of Well A [20]

In the same context of reservoir modeling, Hassan Al Haifi demonstrated that data-driven reservoir modeling is a complete alternative to numerical reservoir modeling and that can serve as an appropriate tool for reservoir management. He also emphasized some of the challenges using artificial intelligence and machine learning as these technologies require large amount of quality data to be able to obtaine an accurate predictive model. The history match and forecasting results from the predictive model are compared to the original data generated from a numerical simulation in Figure 2-11. 


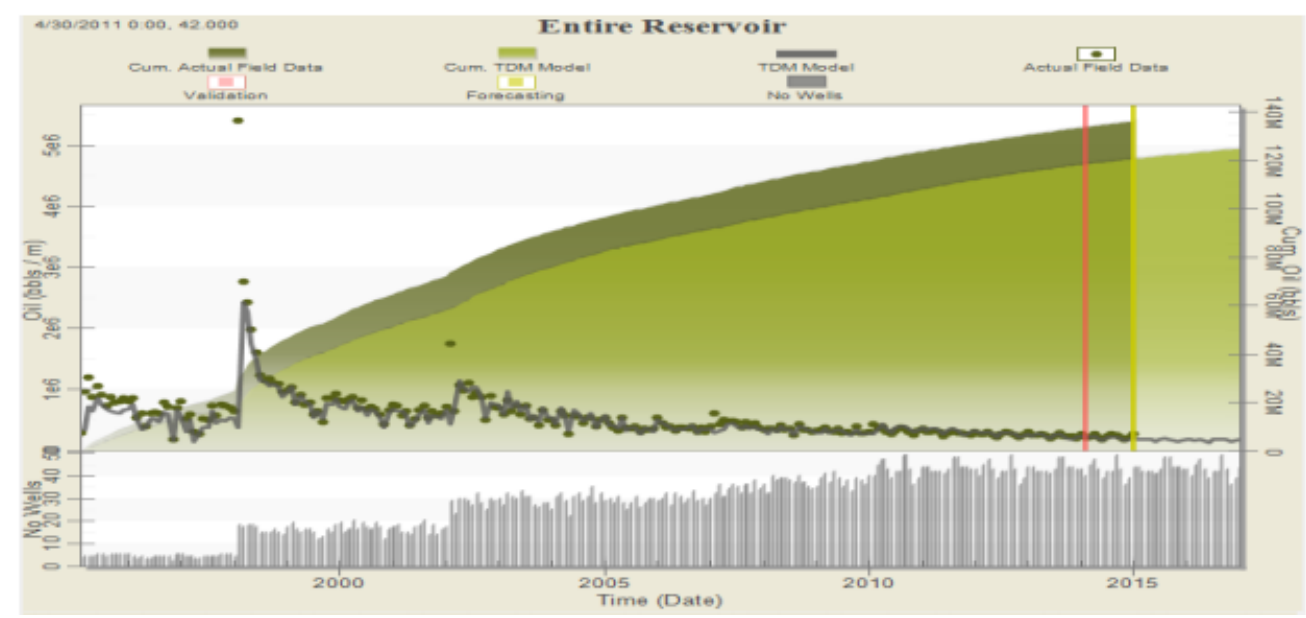

(A)

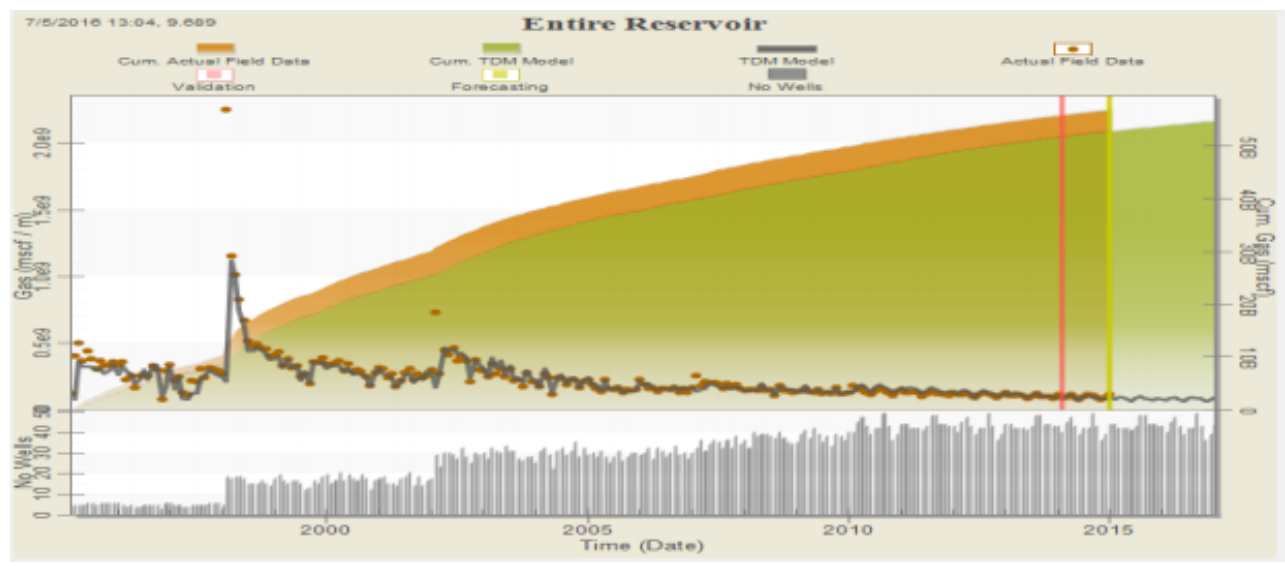

(B)

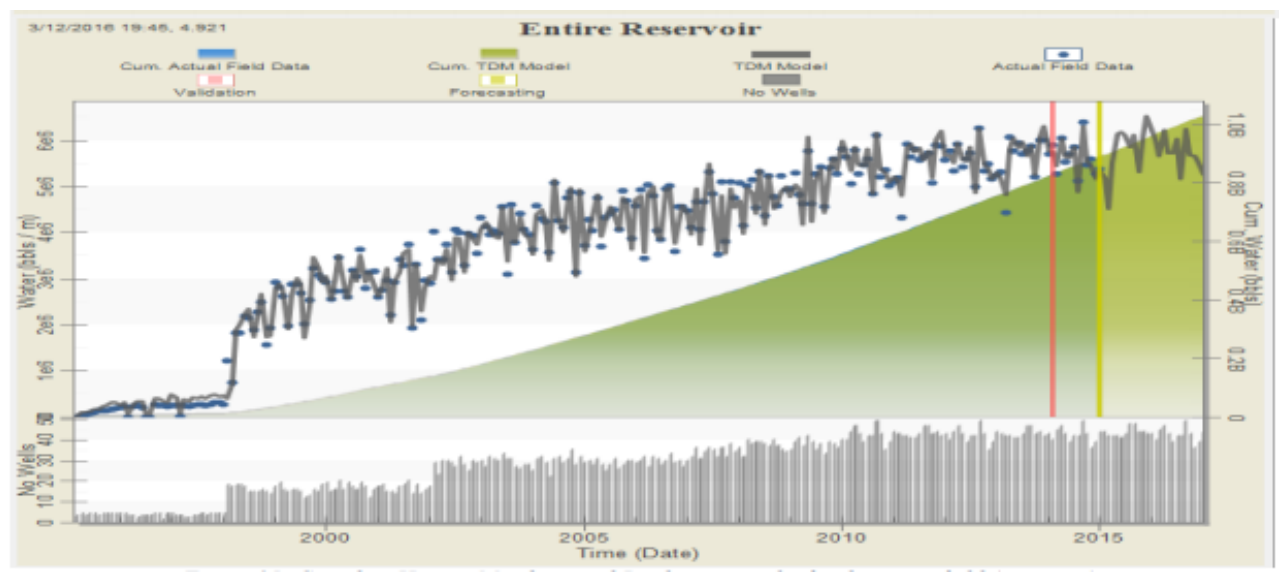

Figure 2-11: History Match and Forecasting Results for Oil (A), Gas (B) and Water (C) the Entire Reservoir

Determining well productivity influences the design and completion of a well. Significant estimations of well productivity have been conducted through the implementation of equations 
and correlations in numerical simulations. Amjed Hassan et al. presented a study to determine well productivity of fishbone wells by implementing 3 different artificial intelligence techniques that aim to reduce the uncertainty associated with numerical simulations. The implementation of Artificial Neural Networks in his study resulted in acceptable matches between the predicted and actual flowrates for fishbone wells. After investigating different case scenarios, a 7.23\% average absolute error and a correlation coefficient of 0.979 was obtained. The training and testing results using Artificial Neural Networks is shown in Figure 2-12 [21].

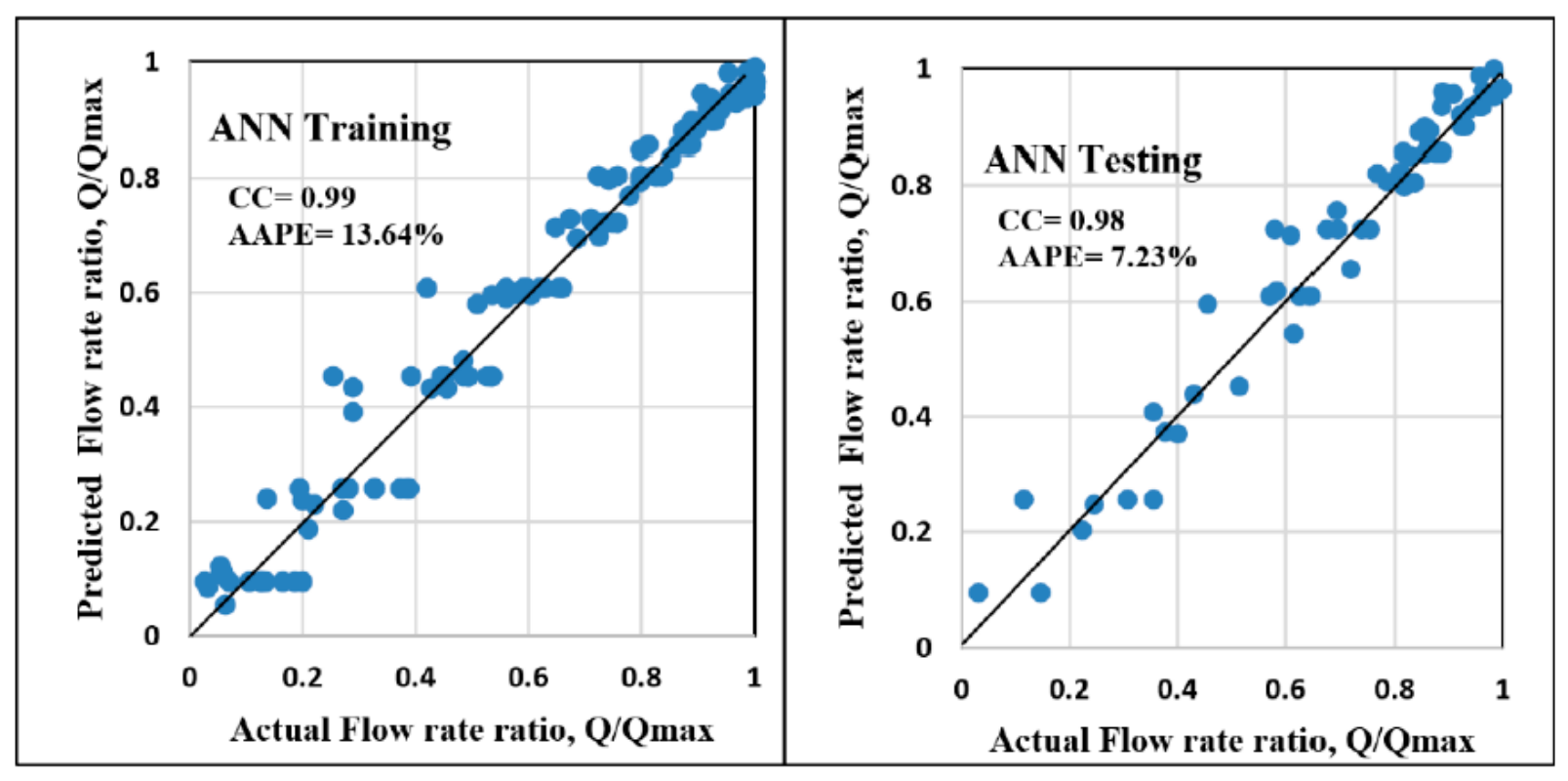

(A)

(B)

Figure 2-12: Comparison between the predicted and the target flow rate ratio $(\mathrm{Q} / \mathrm{Qmax})$ using the ANN model for the (A) training and (B) testing datasets [21]

Well logs are used in the industry to assist petroleum engineers evaluate and allocate the presence of hydrocarbons in a potential reservoir (formation evaluation). It is often the case that well log data is may not be available or it is incomplete. Marwan Alnuaimi successfully used RNN (Regression Neural Networks) to generate synthetic well logs when the information was missing from a particular well log. The application of RNN assisted enhanced the learning process from a variety of well logs representing the physics of the reservoir. Figure 2-13 illustrates the neural network development results. 


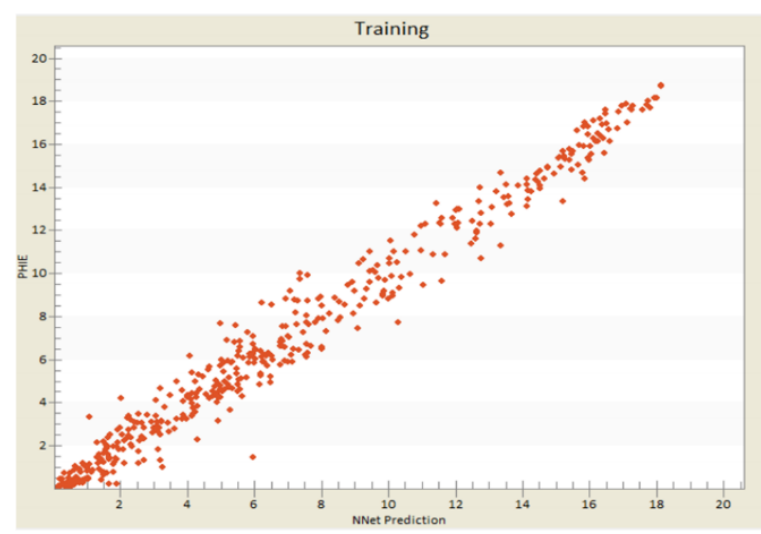

(A)

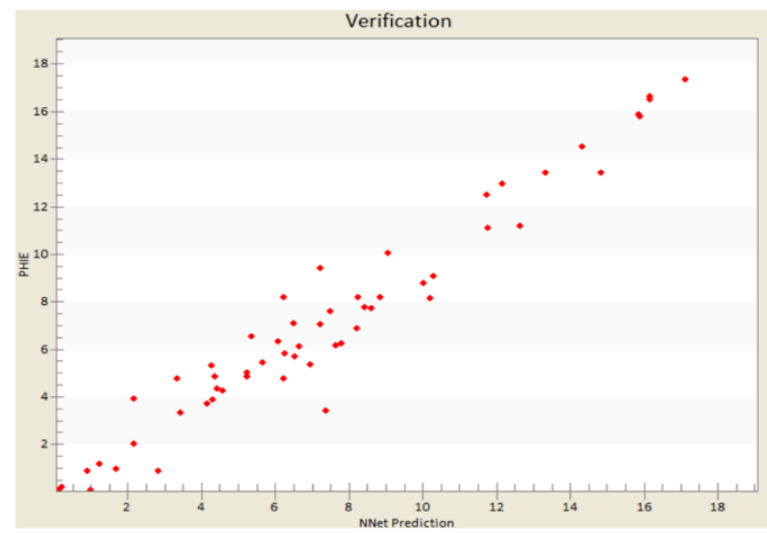

(C)

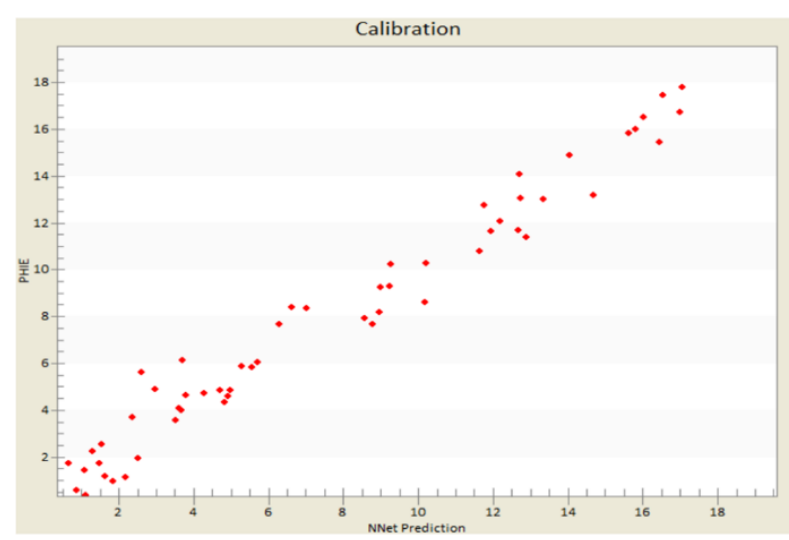

(B)

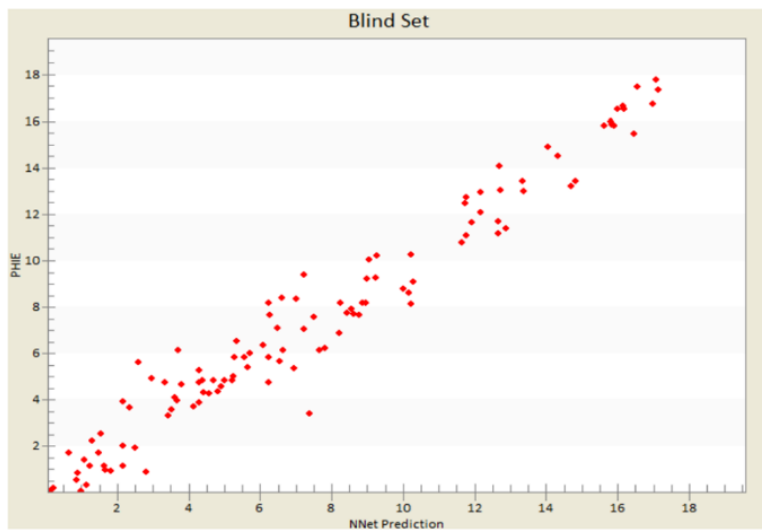

(D)

Figure 2-13: Neural Network Development Results for Training (A), Calibration (B), Verification (C) and Blind (D) datasets

The generated synthetic well logs for effective porosity are illustrated below and compared to the actual effective porosity values in Figure 2-14. 


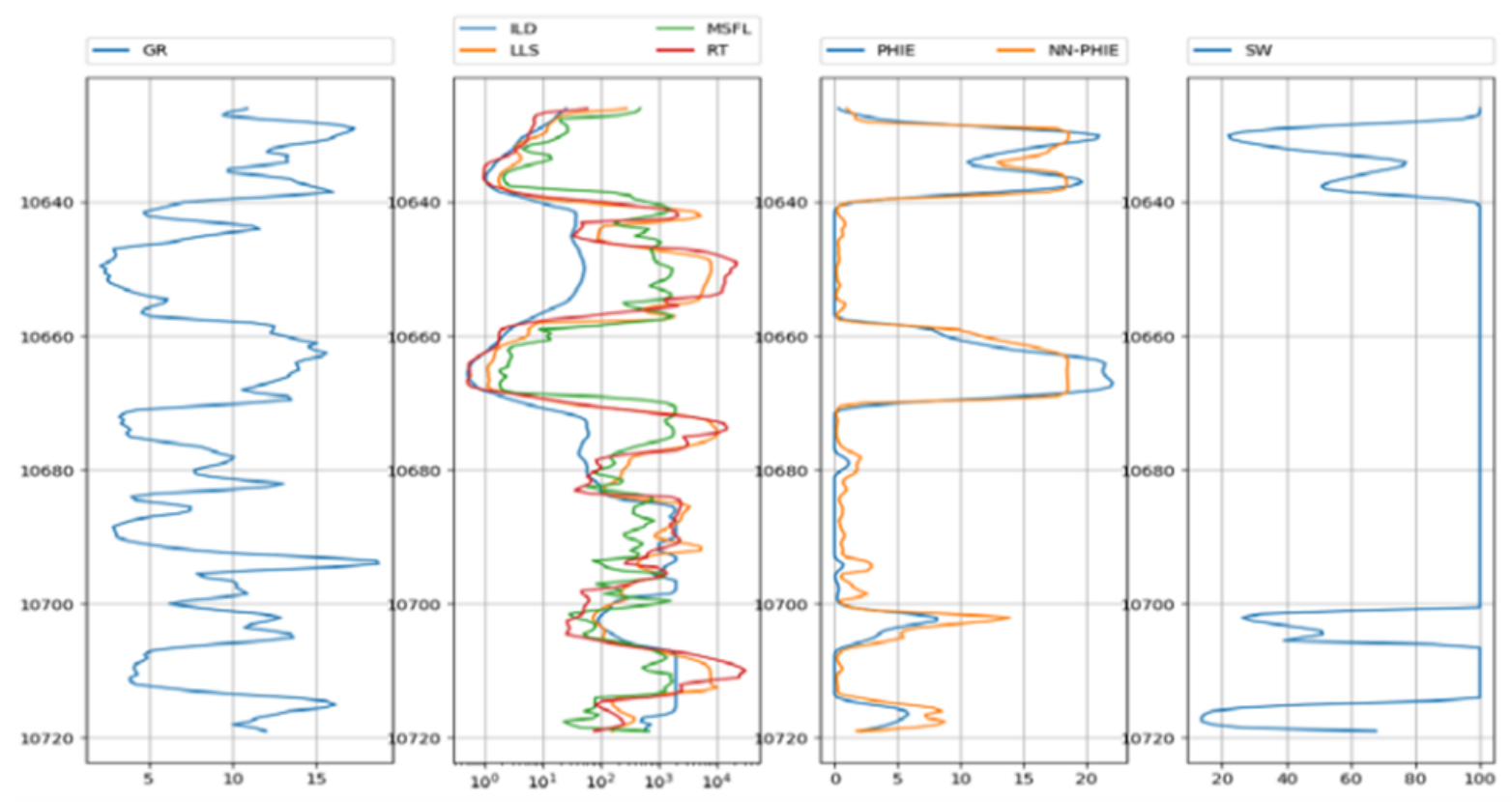

Figure 2-14: Generated output "NN-PHIE" and actual value "PHIE"

Other applications to study fluid behavior in oil and gas reservoirs is the development of smart proxy models. Due to the complexity of the reservoirs, expensive and sophisticated equipment is required to run these types of simulations and therefore, become time-consuming. Smart proxy models are an alternative to numerical simulations that assists reservoir engineers in reservoir development and production management [22]. 


\section{CHAPTER 3}

\section{NUMERICAL RESERVOIR MODELING}

This chapter is divided into three sections. The first section elaborates on the specifications of a numerical reservoir model created by a group of students at West Virginia University using CMG, a commercial numerical simulator. The model was further modified and provided by Joshua Dietz in order to accomplish the objectives of thesis. The second section describes the modifications performed on the original model with efforts to approach real-field events. The last section provides information of the data exported from the conducted numerical simulation of the finalized numerical reservoir model version.

Figure 3-1 provides a visual workflow for the development of the thesis, where an original numerical reservoir model, "Model A" in Figure 3-1, was provided as the foundation of a further developed and far more complex reservoir model, "Model B" in Figure 3-1. The data obtained from the more complex reservoir model was used for the development of a data-driven reservoir model.

The numerical reservoir simulation results are to be compared to the results obtained from the data-driven reservoir model. 


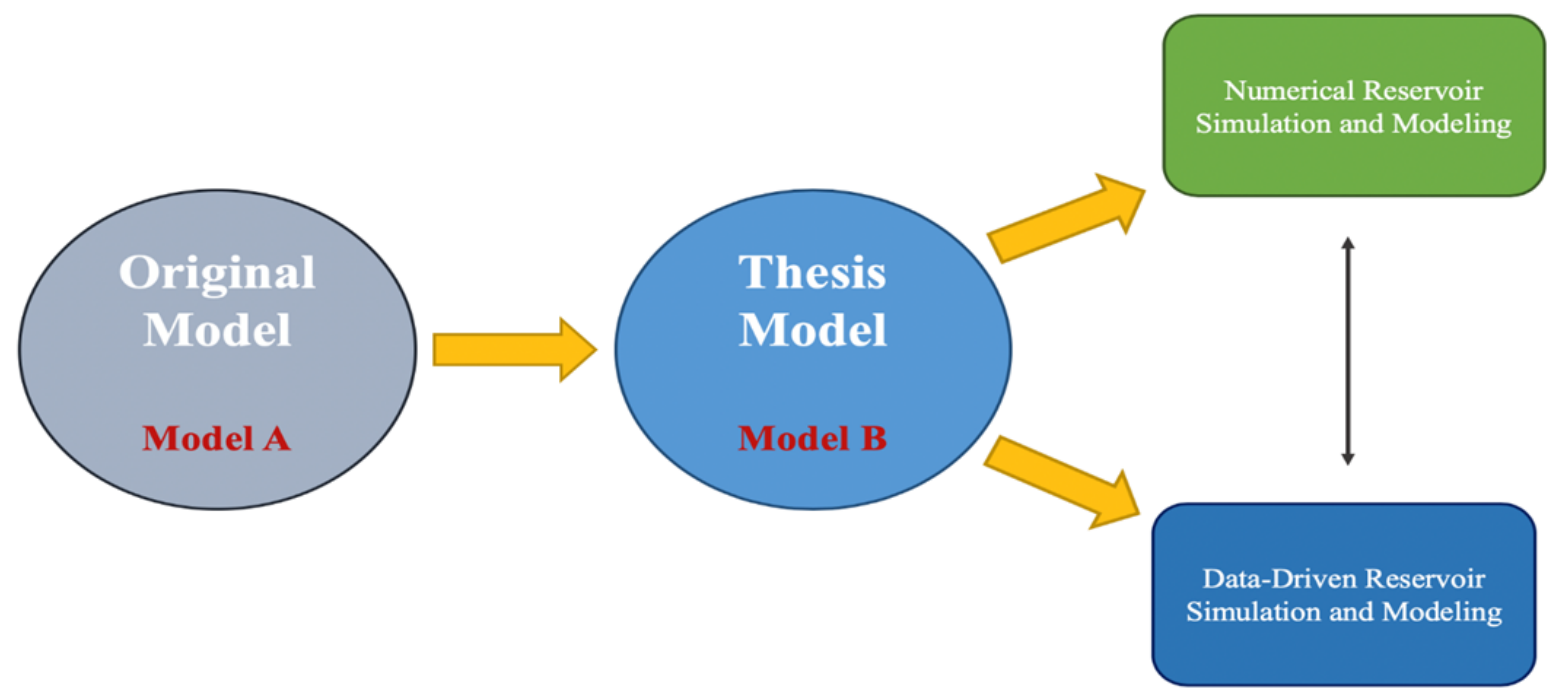

Figure 3-1: Thesis Workflow

\subsection{Original Numerical Reservoir Model}

A 6 layered under saturated reservoir was originally created using Builder (a module supported by CMG simulators) by a group of students at West Virginia University. The general properties of the field are listed below and discussed into more detail in the following sections:
a. Reservoir Model Overview
b. Grid construction and structure
c. Reservoir characteristics
d. Description of flowing components
e. Rock fluid properties
f. Initial conditions
g. Numerical controls
h. Allocation of wells with their respective production/injection constrains and completion plan as a function of time.




\subsubsection{Reservoir Model Overview}

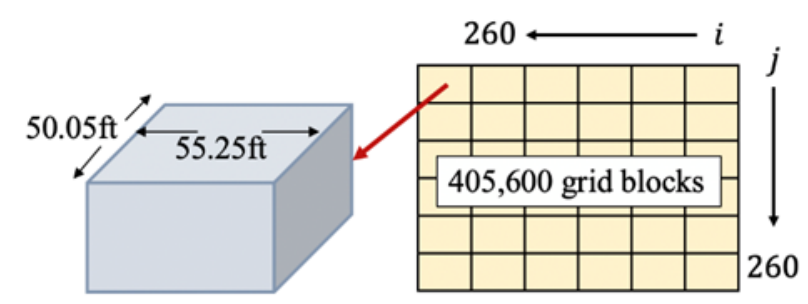

Figure 3-2: Grid Block Dimensions

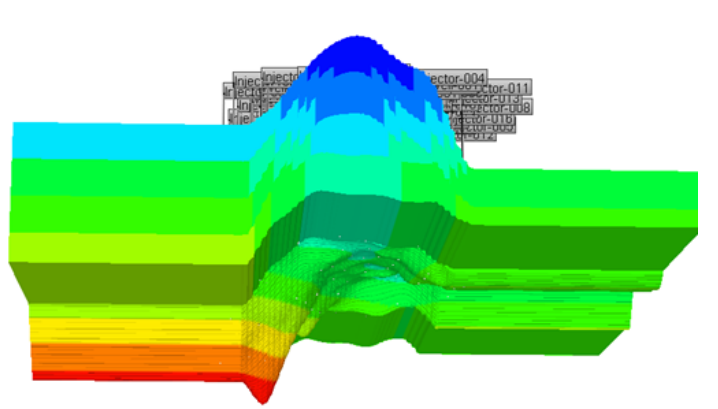

Figure 3-3: Reservoir Model Overview

The field consists of a total of 77 wells placed on a $260 \mathrm{i} \times 260 \mathrm{j} \times 6 \mathrm{k}$ corner point grid. The anticline/syncline pair structure is surrounded by an aquifer that provides pressure support to the field. The field started production on January $1^{\text {st }}$ of 1995 and ended production 22 years after on January $1^{\text {st }}$ of 2017.

\subsubsection{General Properties}

The properties of the original model are summarized in Table 3-1:

Table 3-1: Original Model - Properties Overview 

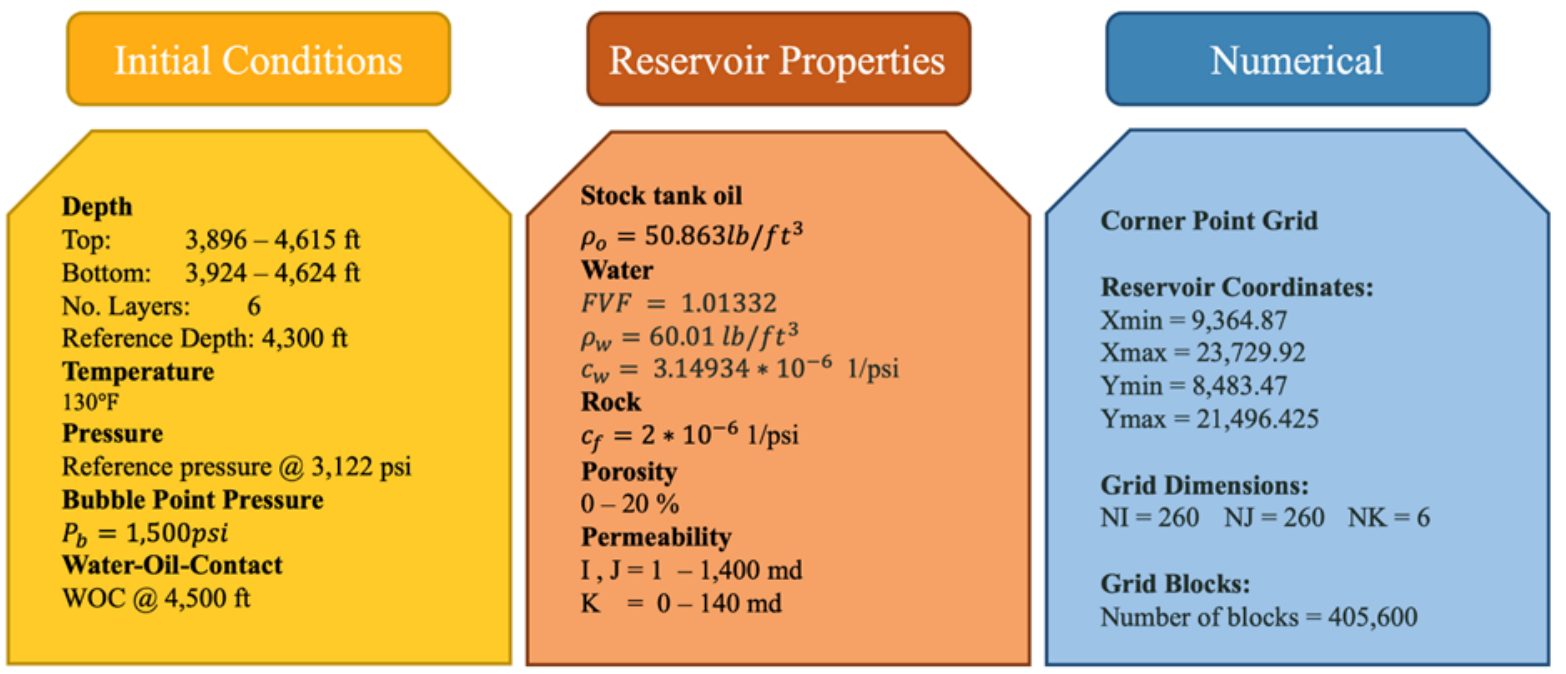

\subsubsection{Original Map Files}

The reservoir properties of the field, such as porosity, permeability, initial water saturation, and grid thickness distributions in each layer are presented below:
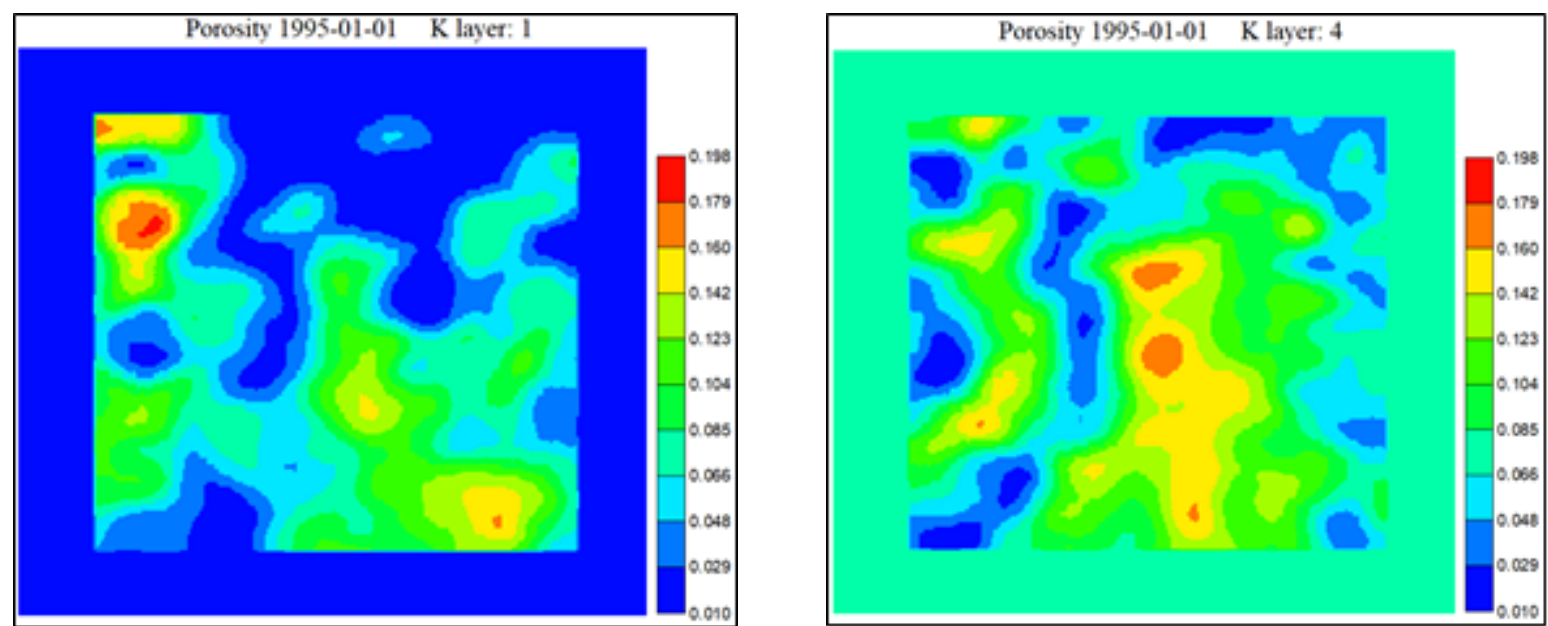

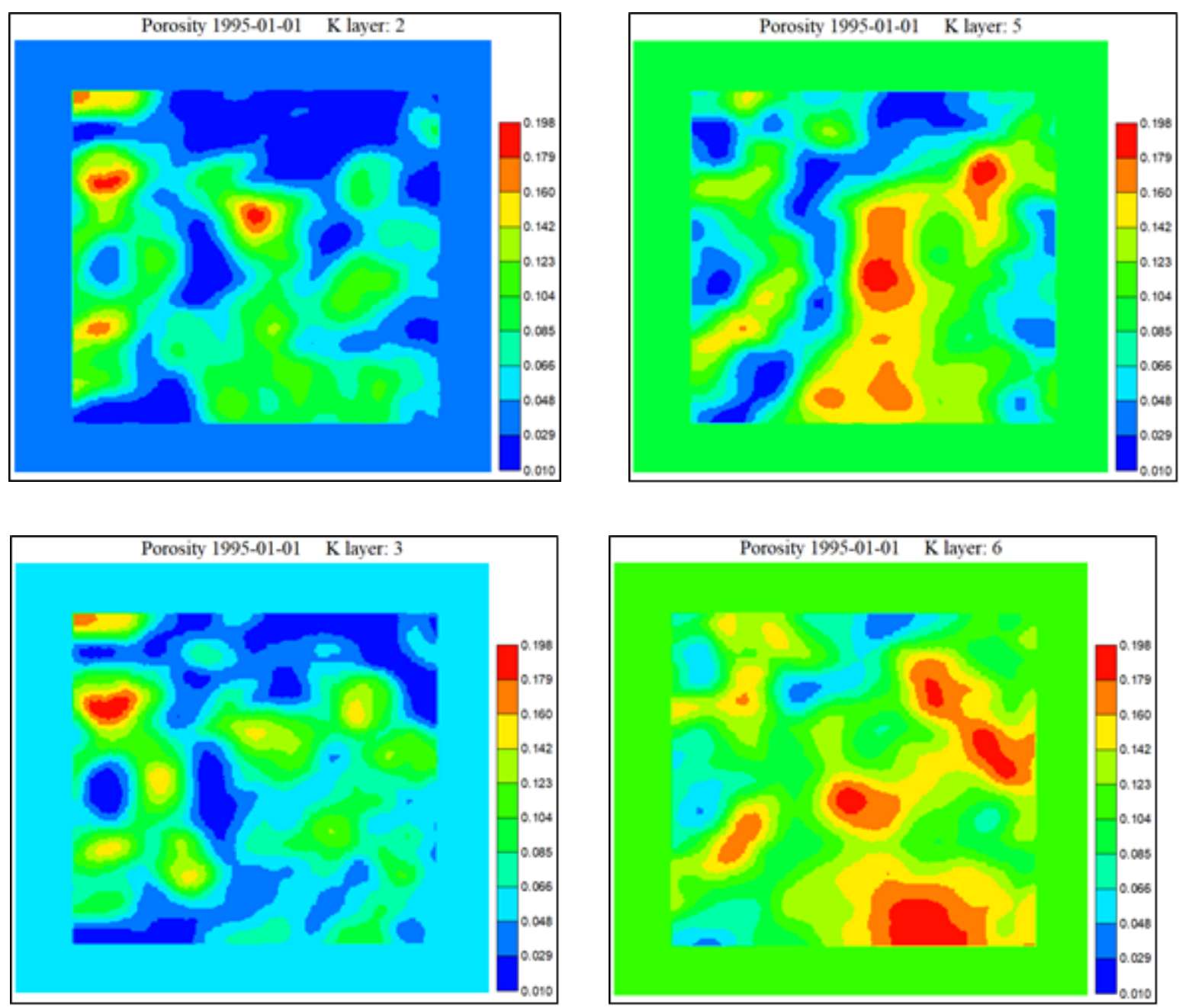

Figure 3-4: Porosity Map Files for All 6 Layers

The porosity distribution maps suggest that the porosity ranges between 0 and $20 \%$ across every layer. 

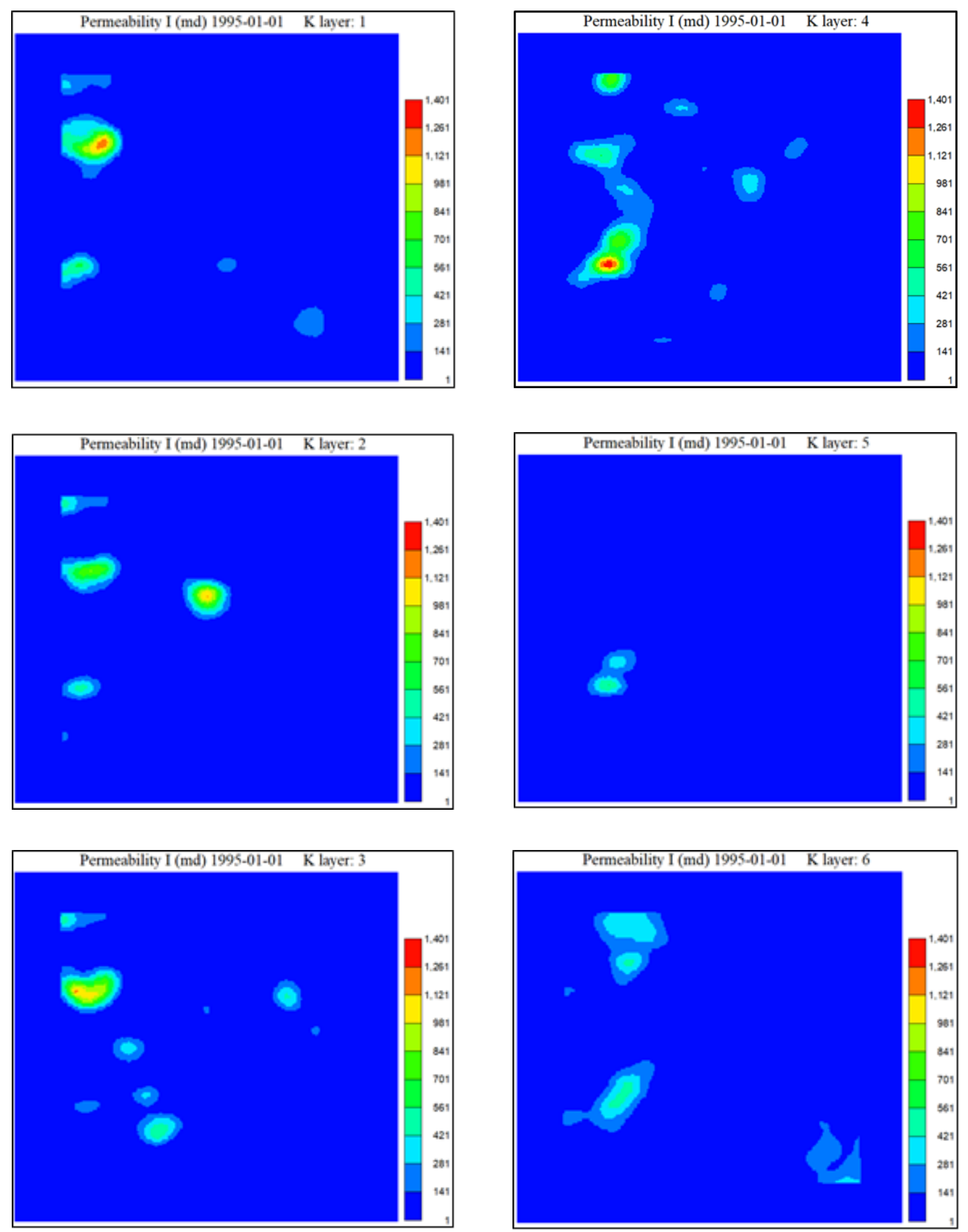

Figure 3-5: Permeability, I (mD) Map Files in All 6 Layers 
The permeability distribution across all layers is very low with most of the values ranging between $1 \mathrm{mD}$ and $150 \mathrm{mD}$. The permeability distribution in the I-direction is equivalent to the permeability distribution in the J-direction.
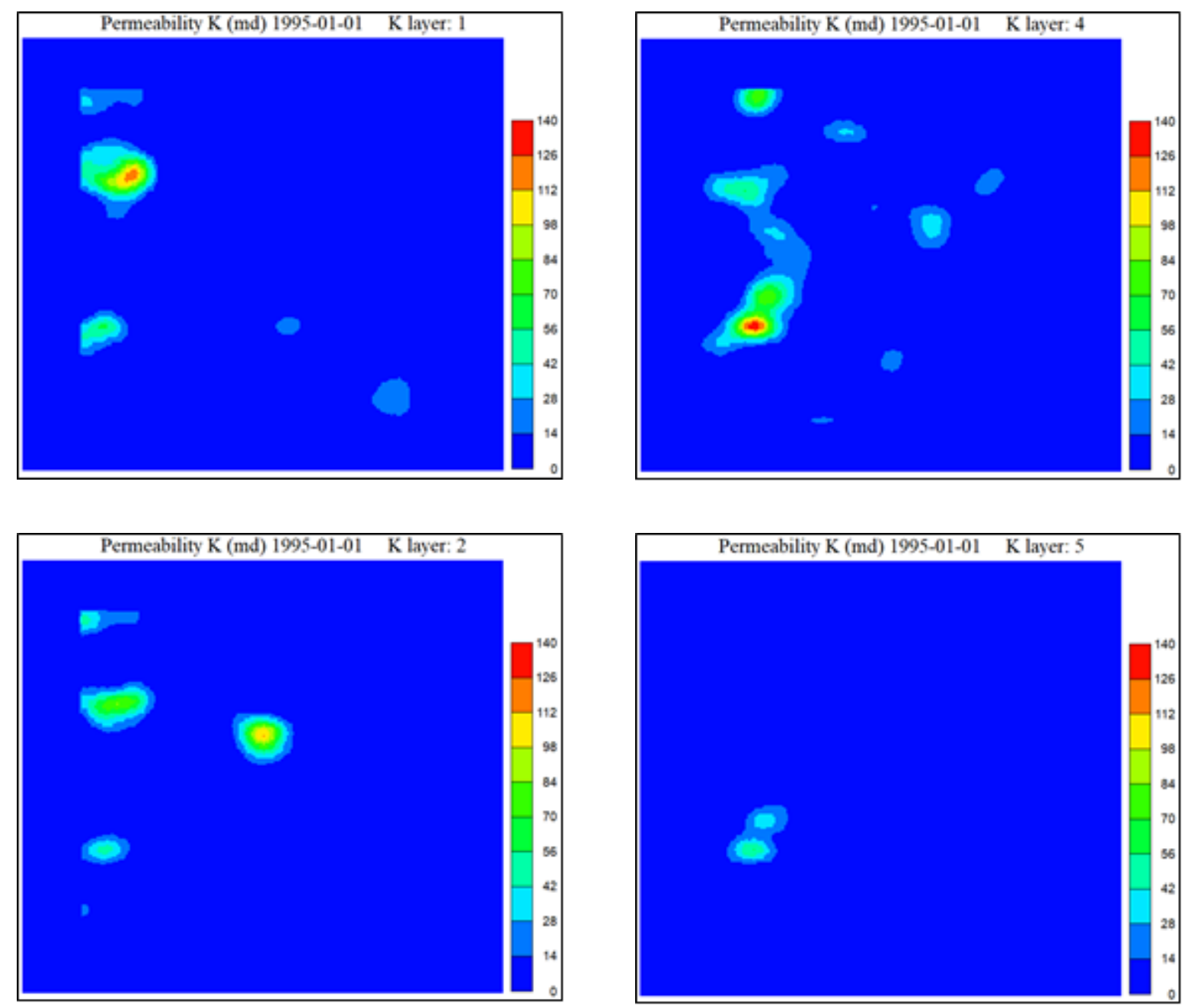

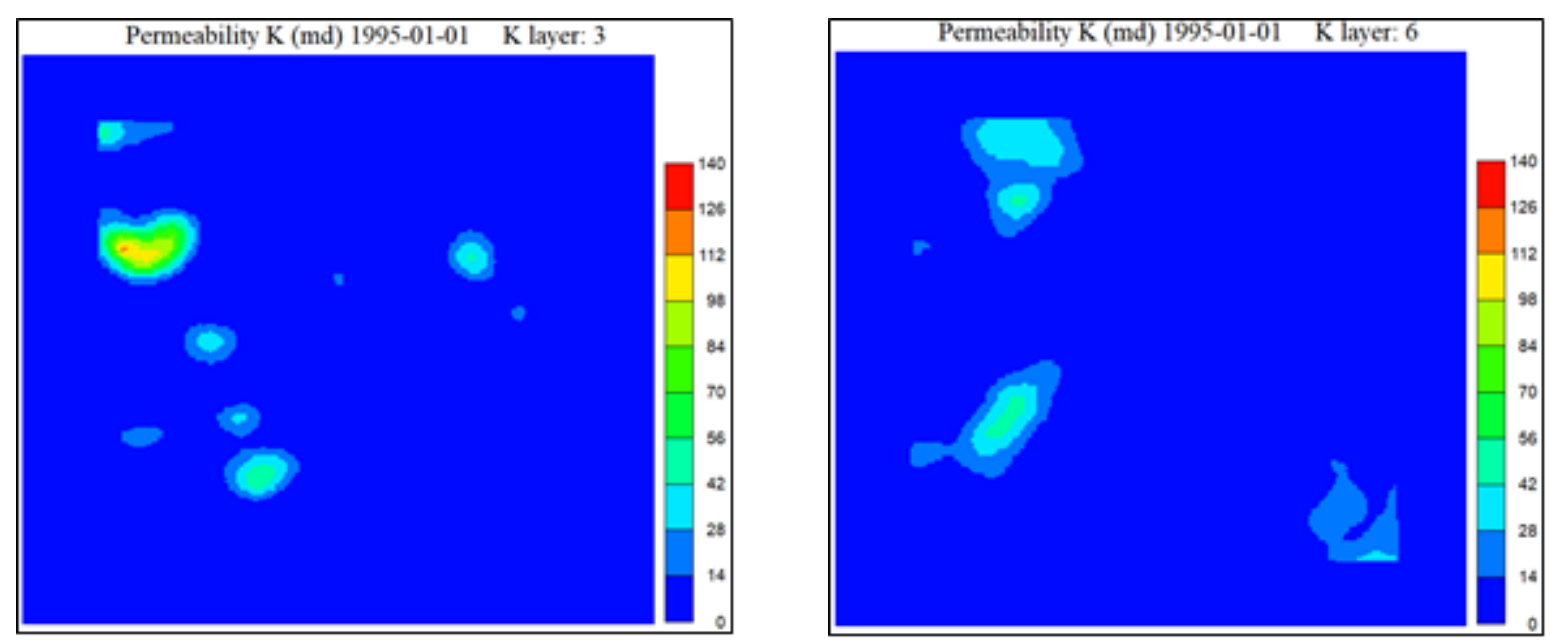

Figure 3-6: Permeability, K (mD) Map Files in All 6 Layers

The permeability distribution in the vertical direction is the lowest ranging from $0 \mathrm{mD}$ to $140 \mathrm{mD}$.
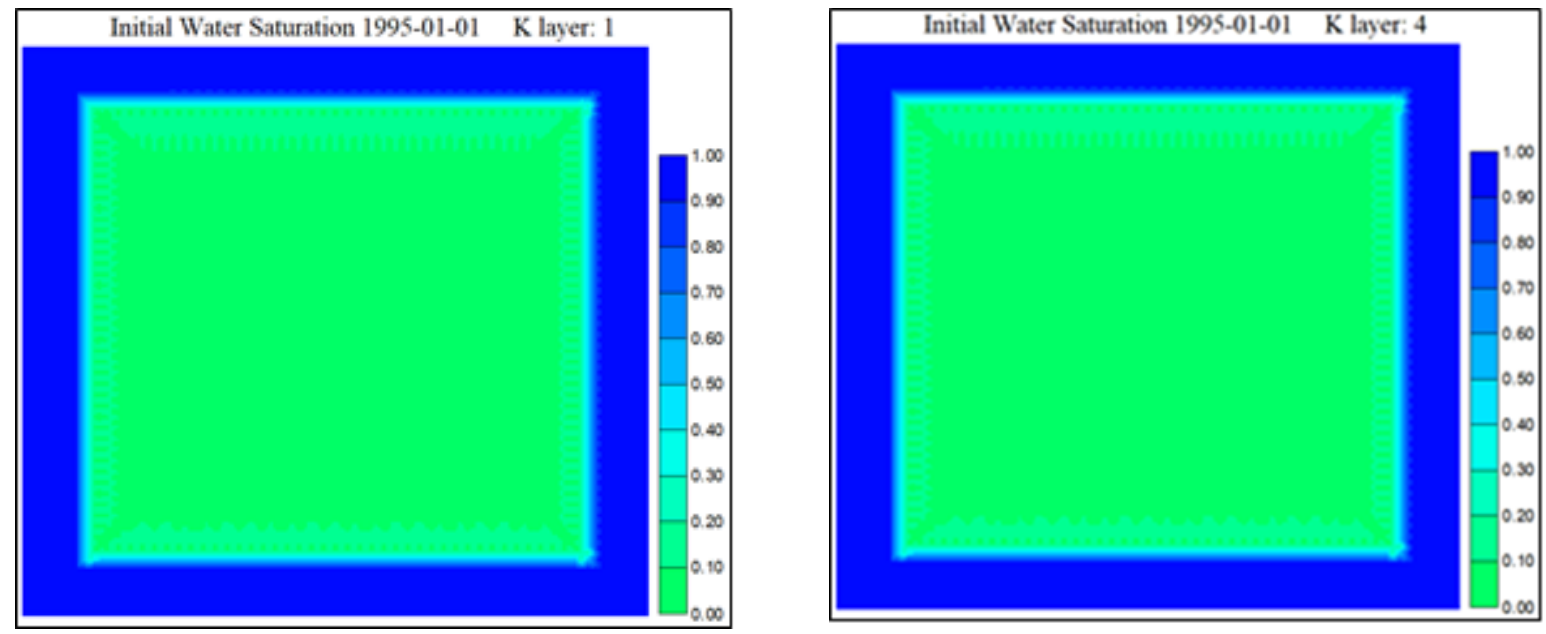

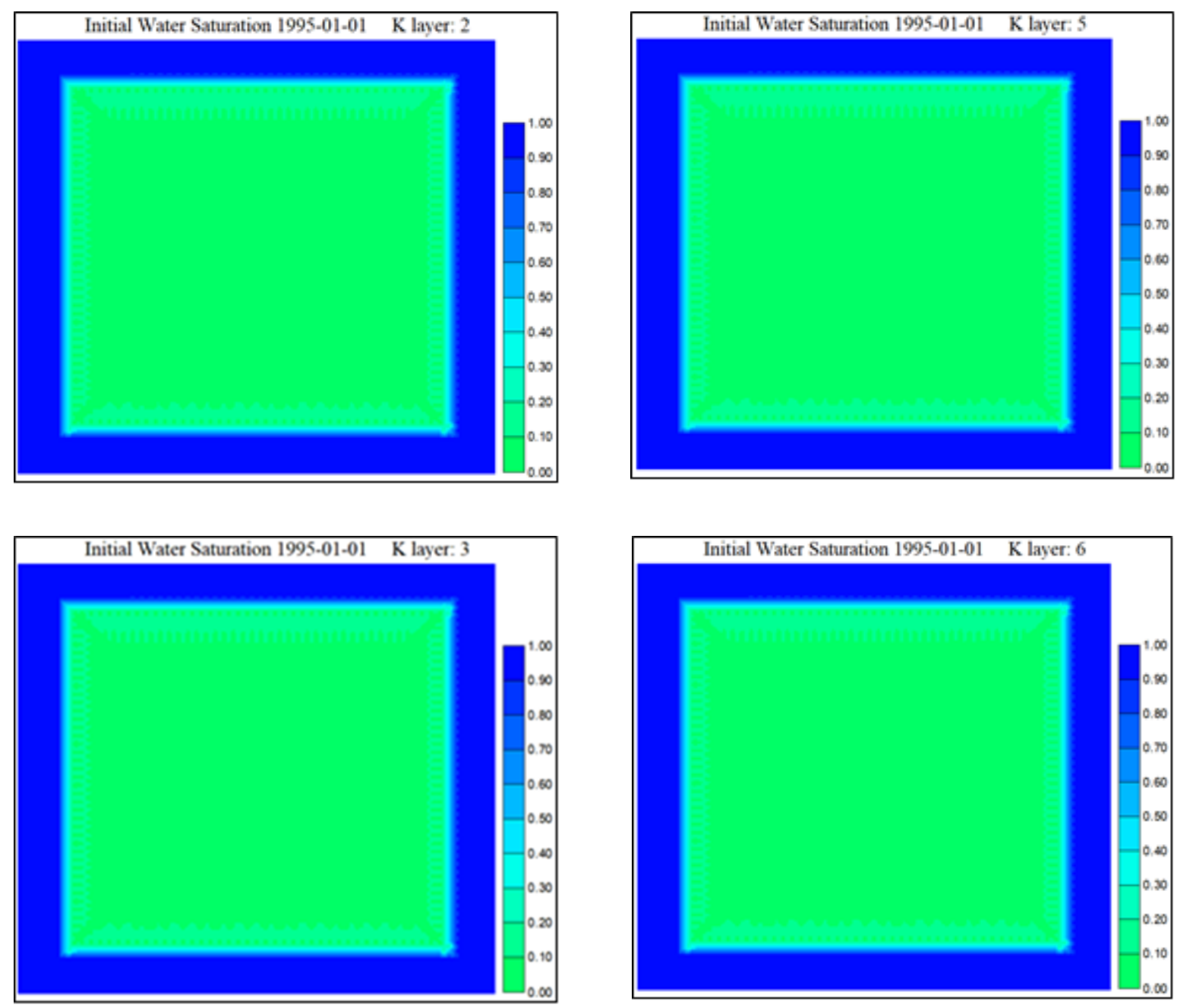

Figure 3-7: Initial Water Saturation Map Files for All 6 Layers

The initial water saturation remains constant throughout all 6 layers. 

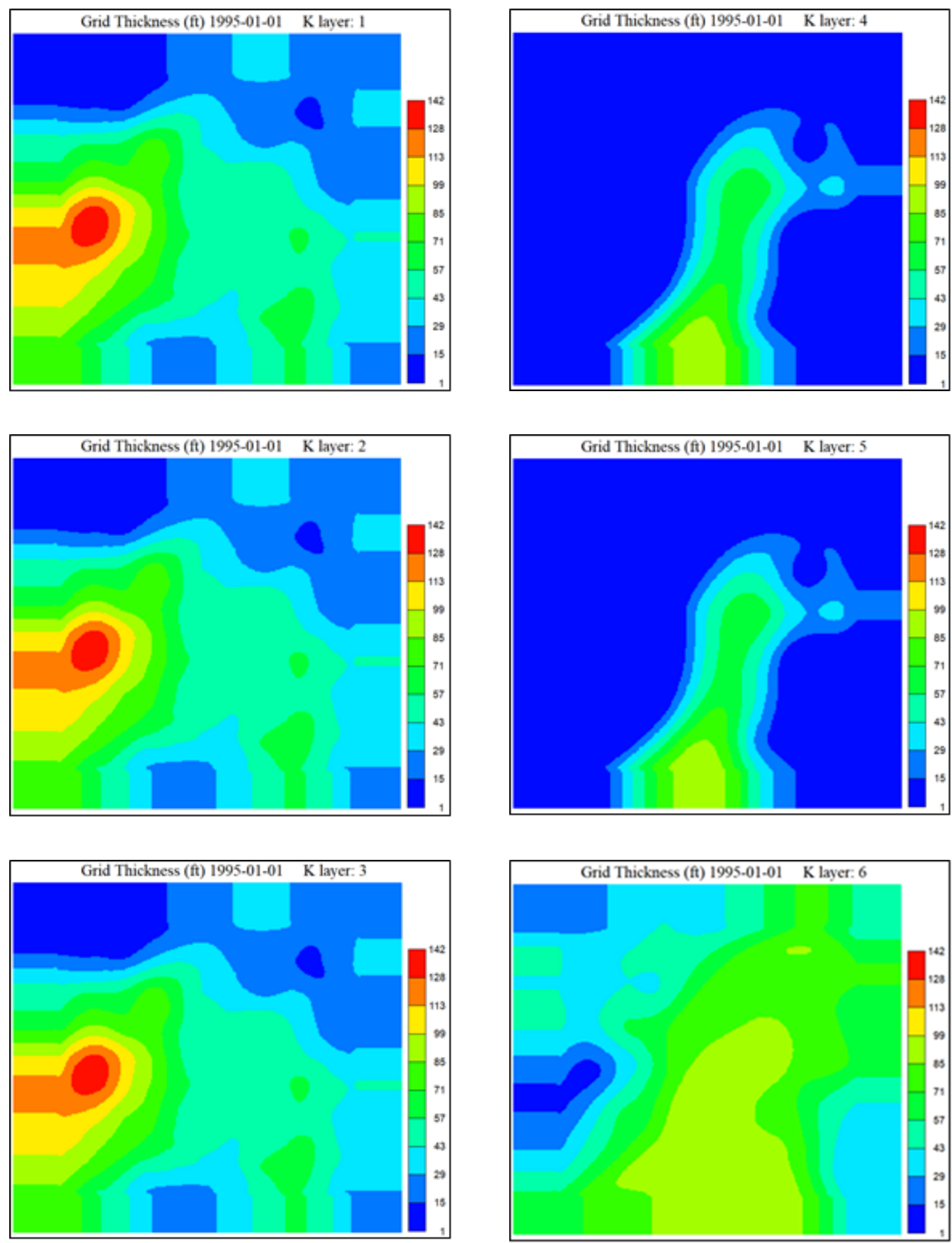

Figure 3-8: Grid Thickness (ft) Map Files for all 6 Layers 
The thickness across the reservoir is constantly changing. However, the layers are thicker in the middle of the reservoir and thinner near the boundaries of the reservoir. Layers 4 and 5 are thinner throughout the entire layer compared to the remaining layers. Layers 1, 2 and 3 follow the same pattern.

\subsubsection{Reservoir Characteristics}

The reservoir is placed on top of a corner point grid system consisting of 260 grid blocks in both I and J directions.

The four corner grid blocks of the reservoir are depicted in Figure 3-9 with their respective centered coordinates.

The length and width of the reservoir are $14,365.05 \mathrm{ft}$ and $13,012.95 \mathrm{ft}$ respectively whereas the reservoir's thickness is constantly changing. See Figure 3-16.

A total of 27,600 grid blocks inherit aquifer property values adjacent to the sides of the

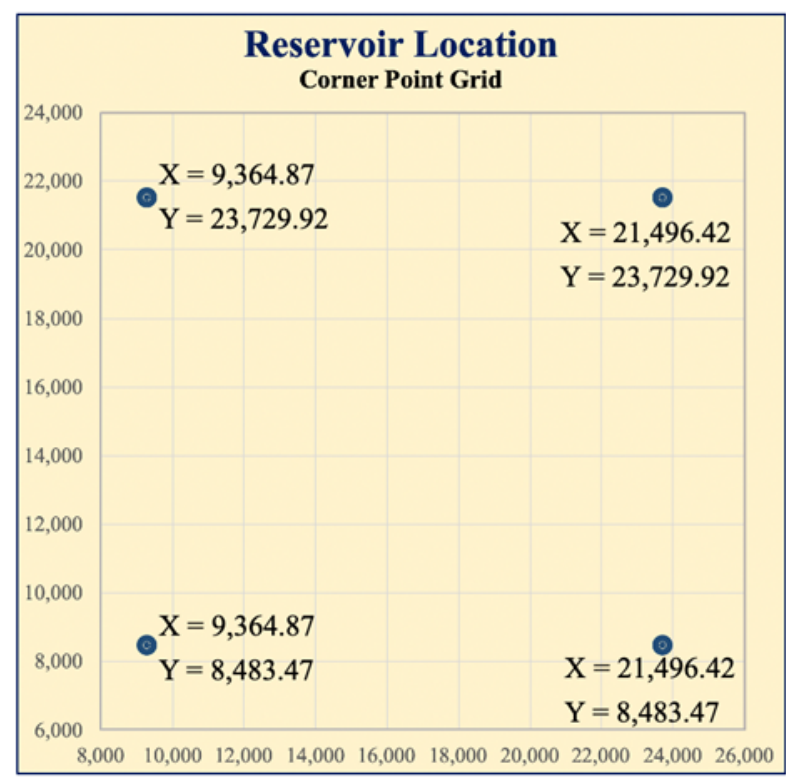

Figure 3-9: Reservoir's Coordinates

reservoir. See the aquifer boundary effect in Figure 3-18. The remaining grid blocks located in the middle of the grid system represent other physical properties of the reservoir.

The rock compressibility is set at $2 * 10^{-6} \mathrm{psi}^{-1}$ which encompasses a range of values representing the majority of consolidated sandstone and limestone data [23]. Moreover, the model does not include any specification of faults or geological units.

\subsubsection{Components}

The reservoir model is an under saturated reservoir that models the flow of oil, gas and water. The properties of each of the flowing components are specified in Table 3-2.

Table 3-2: Fluid Component Characteristics 


\begin{tabular}{|l|l|l|r|l|}
\hline \multicolumn{1}{|c|}{ Description } & \multicolumn{1}{c|}{ KEYWORD } & \multicolumn{1}{c|}{ Option } & \multicolumn{1}{c|}{ Value } & \multicolumn{1}{c|}{ Units } \\
\hline Reservoir Temperature & TRES & STO & 130 & ${ }^{\circ} \mathrm{F}$ \\
\hline Oil Density & DENSITY OIL & Gas gravity (Air=1) & 50.863 & $1 \mathrm{~b} / \mathrm{ft}^{3}$ \\
\hline Gas Density & DENSITY/GRAVITY GAS & 0.65 & \\
\hline Water Density & DENSITY WATER & 62.01 & $1 \mathrm{~b} / \mathrm{ft}^{3}$ \\
\hline Formation Volume Factor & BWI & 1.01332 & \\
\hline Compressibility & CW & & $3.15 \mathrm{E}-06$ & $1 / \mathrm{psi}$ \\
\hline Reference Pressure for FVF & REFPW & 14.696 & $\mathrm{psi}$ \\
\hline Viscosity & VWI & & 0.567336 & $\mathrm{cp}$ \\
\hline Pressure Dependence of CVW & & & 0 & $\mathrm{psi}$ \\
\hline
\end{tabular}

\subsubsection{Rock Fluid Properties}

An imbibition process is modeled by both water injection and incoming water from the aquifer. Theoretically, the water acts as a piston-like displacement to push the oil in the reservoir towards producing wells.
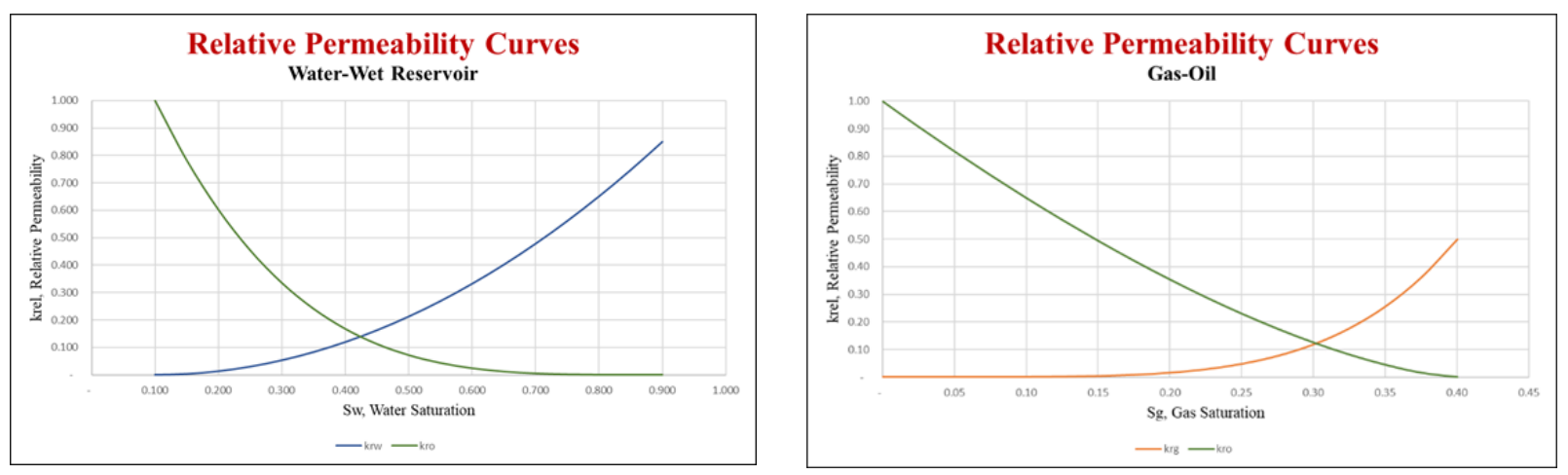

Figure 3-10: Relative Permeability Curves

Relative permeability curves describe the flowing conditions of oil, gas, and water as shown in Figure 3-10.

\subsubsection{Initial Conditions}

Initialization parameters such as such as initial reservoir saturation, water-oil contact, reference pressure and bubble point pressure are specified inside the numerical simulator.

The model has a bubble point pressure set at 1,500psi, suggesting that a two-phase envelope is likely to form at pressure values below the bubble point. Nevertheless, both the aquifer and water 
injection assist the reservoir with enough pressure support to maintain a single phase flow. Only gas production is likely to take place at surface conditions.

\subsubsection{Numerical Controls}

The first and last simulation dates takes place in January $1^{\text {st }}$ of 1995 and January $1^{\text {st }}$ of 2017 respectively, suggesting a simulation of 22 years, 265 months or 8,036 days.

\subsubsection{Wells and Recurrent}

A total of 57 oil producers and 20 water injectors are drilled and perforated on January $1^{\text {st }}$ of 1995 (first day of the simulation).

The well's location in the grid are shown in Figure 3-11 where the oil producers are placed in the middle of the reservoir (light green colored area) from the water injectors positioned inside the aquifer that borders the reservoir (blue area).

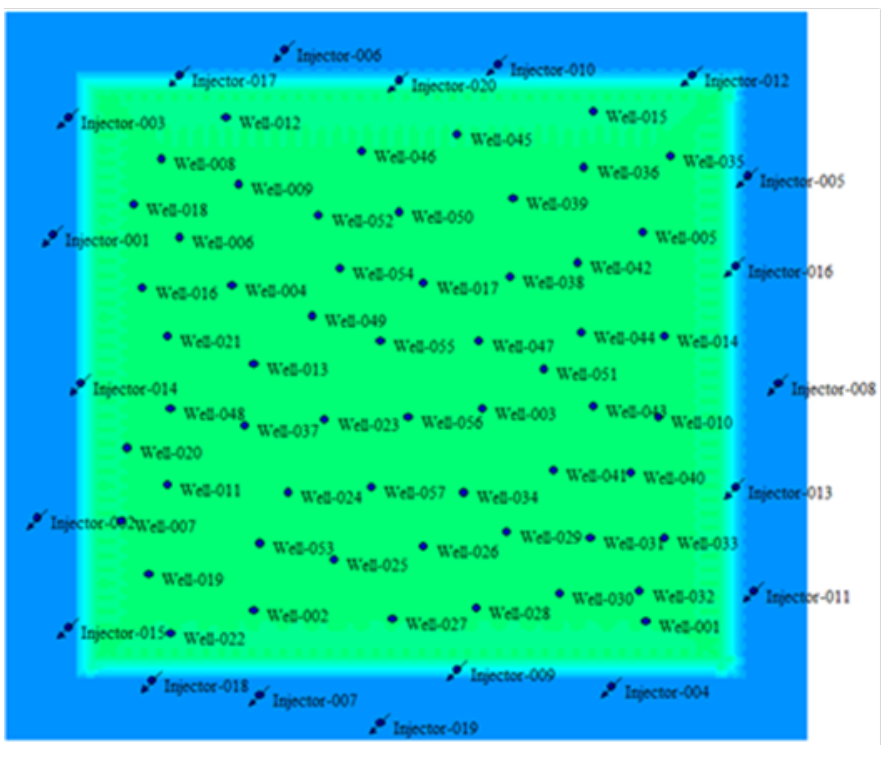

Figure 3-11: Well Locations on Initial Water Saturation Map 


\subsection{Modified Reservoir Model}

The second section of this chapter elaborates on the modifications performed to the original reservoir with efforts to perform a more efficient numerical simulation that approaches real field behaviors. This step was conducted by restructuring the shape of the reservoir from a partial dome to an incline, reducing the number of geological, removing the aquifer boundary effect, adding operational constraints and workover events, and providing a strategic completion plan for each individual well.

\subsubsection{Merging Layers}

In order to reduce the computational work required for each of the tested simulation runs, the 6 original layers included in this model were combined into three layers. See Figure 3-12 and Figure 3-13 for comparison.

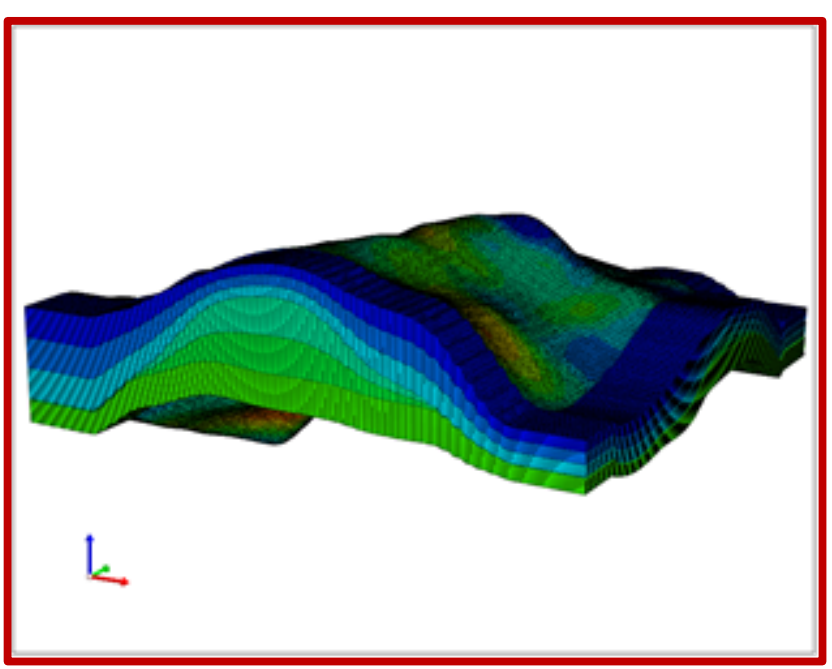

Figure 3-12: Original Model - 6 Geological Layers

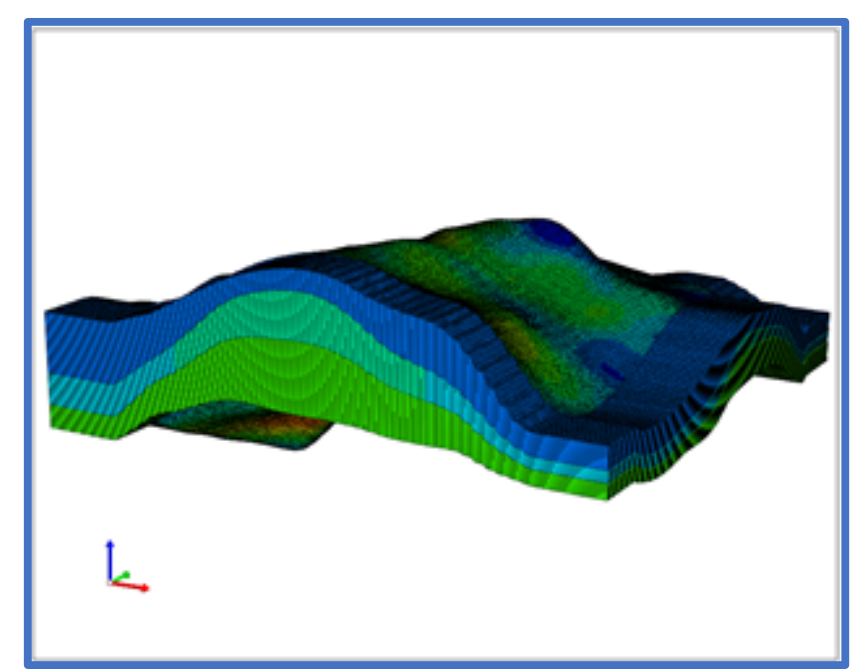

Figure 3-13: Thesis Model - 3 Merged Geological Layers

\section{Methodology:}

This step was accomplished by opening the reservoir model inside the numerical simulator and editing the grid to combine the necessary layers into a single layer as shown in Table 3-3. 
Table 3-3: Combining Layers Into Single Layer

Original Model
$\left.\begin{array}{|l|l|}\hline \text { Layer }(\mathrm{K}=1) \\
\hline \text { Layer }(\mathrm{K}=2) \\
\hline \text { Layer }(\mathrm{K}=3) \\
\hline \text { Layer }(\mathrm{K}=4) \\
\hline \text { Layer }(\mathrm{K}=5) \\
\hline \text { Layer }(\mathrm{K}=6)\end{array}\right\}$\begin{tabular}{|l} 
Thesis Model \\
\hline Layer $(\mathrm{K}=1)$ \\
\hline Layer $(\mathrm{K}=2)$ \\
\hline Layer $(\mathrm{K}=3)$ \\
\hline
\end{tabular}

\subsubsection{Geological Restructuring}

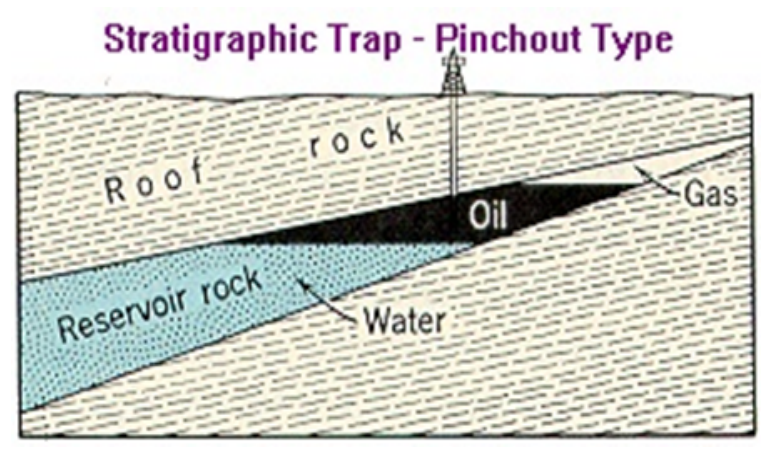

Figure 3-14: Stratigraphic Trap
Reservoir structures are dependent on the geometry of the rocks bounding the reservoir. In the case of the original model, both rock and aquifer properties were bounding the reservoir giving it the characteristics of an anticline/syncline pair (partial-dome).

The reservoir's geological structure was transformed from a partial dome to a stratigraphic trap. See the Figure 3-15 and Figure 3-16 for comparison. 


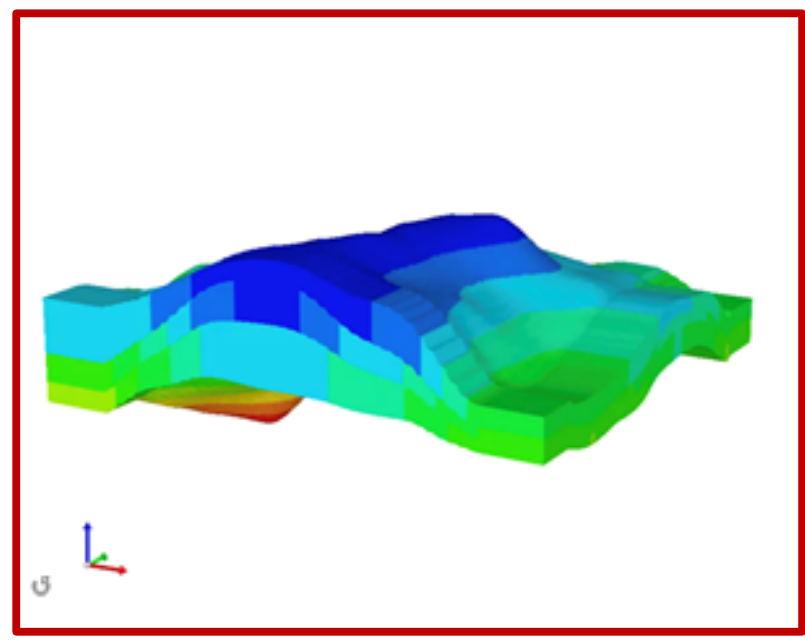

Figure 3-15: Original Model Anticline/Syncline Pair

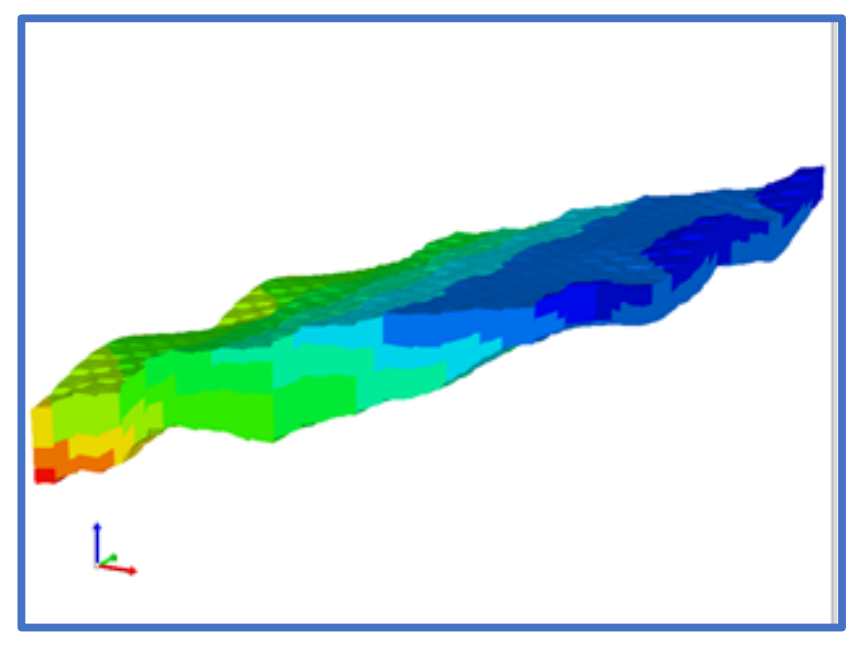

Figure 3-16: Thesis Model - Stratigraphic Trap

\section{Methodology:}

This step was accomplished by creating a new map file inside the numerical simulator. The new map file consisted of 2 important types of information: (1) a range of coordinates (X, Y) referencing a point in the grid system with (2) a corresponding depth for each data point. Figure 3-17 illustrates the X-Coordinates and Y-Coordinates for a total of 24 data points with their respective assigned depths. The 4 red highlighted values represent the corner points of the reservoir. 


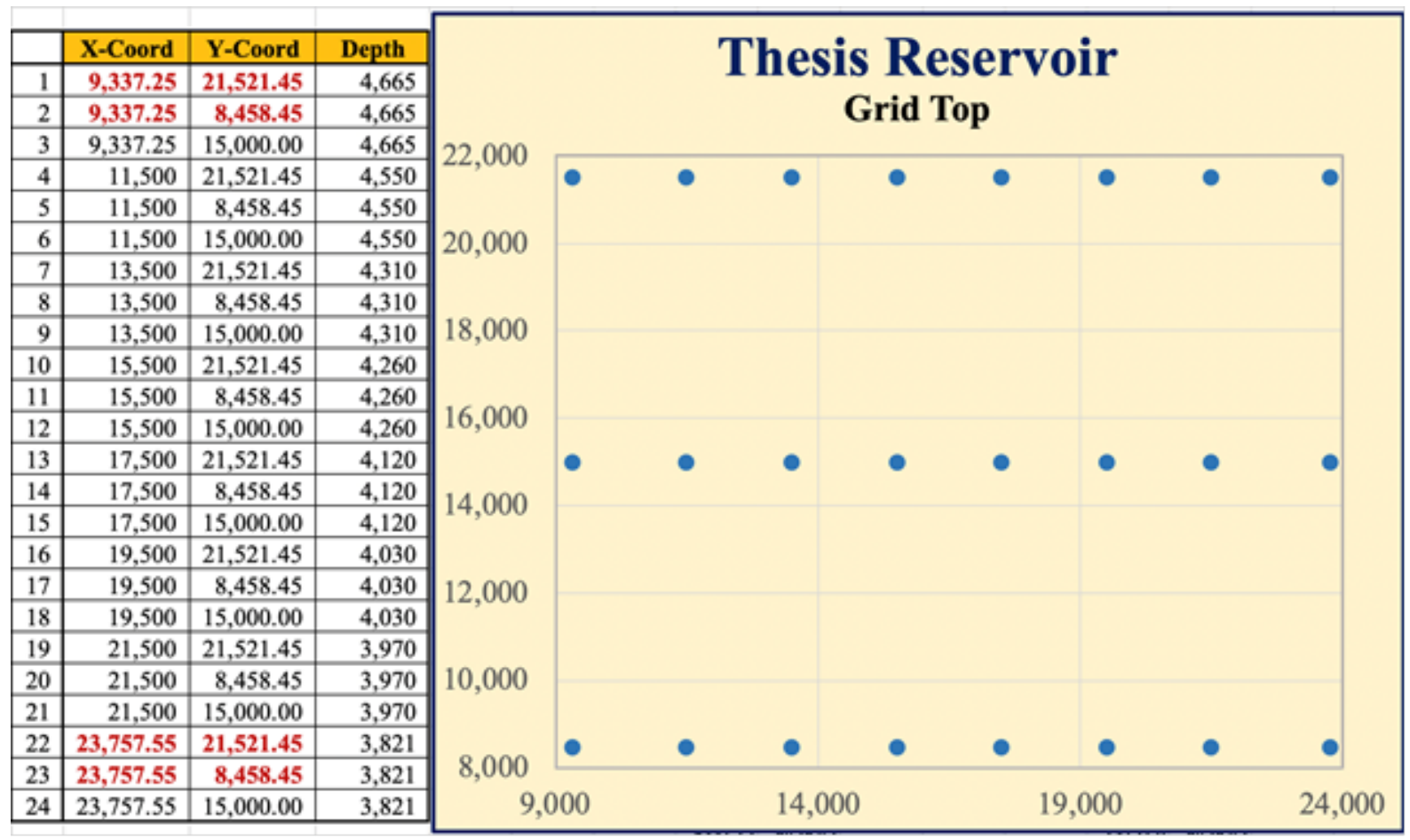

Figure 3-17: Thesis Grid Top Map File

\subsubsection{Removing Aquifer Properties}

The next step was to remove the aquifer boundary effect along the four sides of the reservoir. Notice in Figure 3-12 and Figure 3-13 aquifer property values near the sides of the reservoir create an aquifer boundary effect.

It was physically unrealistic to have an aquifer at the top of an stratigraphic trap considering the density difference between oil and water (Refer to Figure 3-14). Oil is less dense than water and therefore, it is unlikely to model a body of water at the top of the stratigraphic trap reservoir.

\section{Methodology:}

In order to remove the aquifer, the first step was to identify the grid blocks simulating an aquifer boundary effect along the four sides of the reservoir as shown in Figure 3-18. The first and last 30 grid blocks on both the I and J direction shown in color blue, represent the aquifer. 


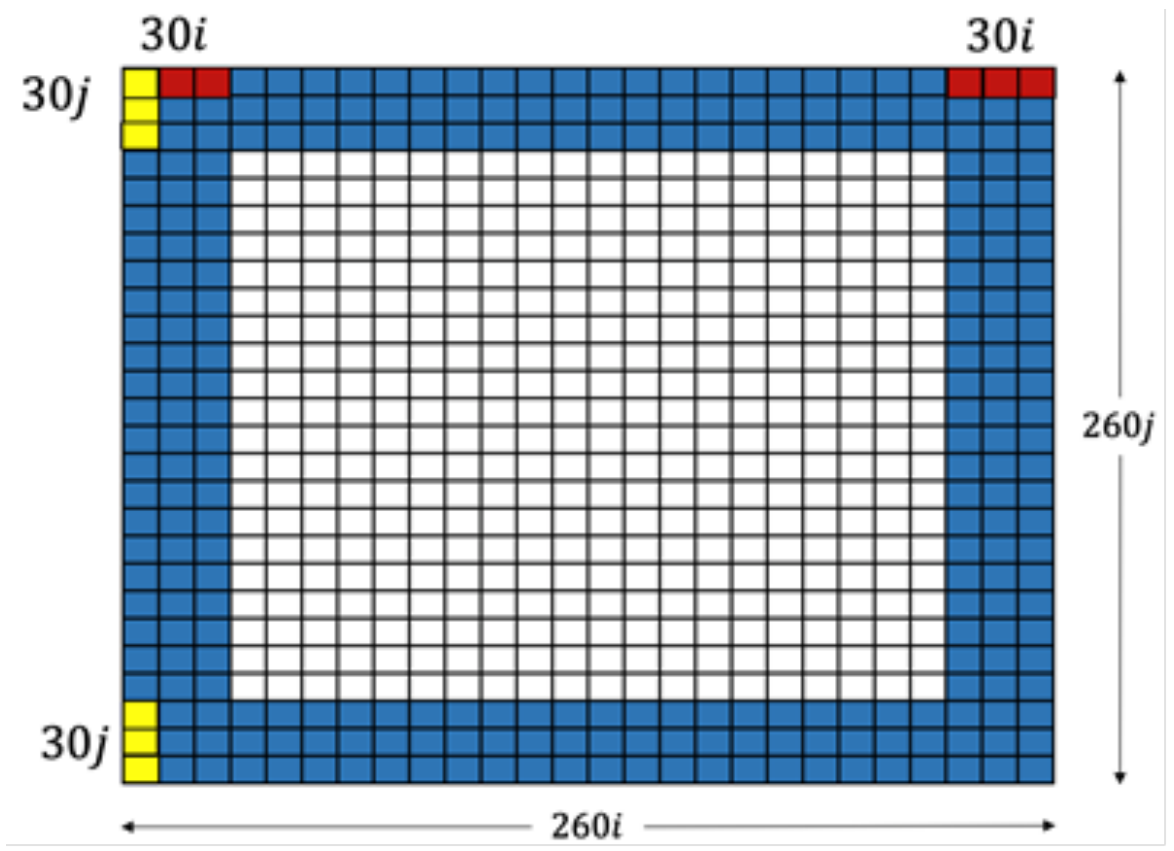

Figure 3-18: Aquifer Boundary Effect

The second step was to place a new $260 \mathrm{i}$ x $260 \mathrm{j}$ grid on top of the reservoir property values of interest shown in white color in Figure 3-18. In order to only cover the white area from Figure $3-18$, the grid block size was reduced from $50.25 \mathrm{ft}$ by $50.05 \mathrm{ft}$ to $42.50 \mathrm{ft}$ by $38.50 \mathrm{ft}$.

This process is explained in more detail in Table 3-4. The number of grids multiplied by the grid size yields the length of the reservoir in both I and J directions. Since the properties of interest (excluding the aquifer property grid blocks) technically cover a $200 \mathrm{i} x 200 \mathrm{j}$ grid as shown in the "Attempted Grid" row on the table, the length of the reservoir shrinks if the grid size is kept as the original. To keep the same number of grids as the original, the grid size is reduced, therefore, covering exactly the area with the reservoir property values of interest. 
Table 3-4: Grid Modification Process

\begin{tabular}{|c|c|r|r|r|}
\hline Grid & Orientation & No. Grids & Grid Size (ft) & Length (ft) \\
\hline \multirow{2}{*}{ Original Grid } & I direction & 260 & 55.25 & $14,365.00$ \\
\cline { 2 - 5 } & J direction & 260 & 50.05 & $13,013.00$ \\
\hline \multirow{2}{*}{ Attempted Grid } & I direction & 200 & 55.25 & $11,050.00$ \\
\cline { 2 - 5 } & J direction & 200 & 50.05 & $10,010.00$ \\
\hline \multirow{2}{*}{ Final Grid } & I direction & 260 & 42.50 & $11,050.00$ \\
\cline { 2 - 5 } & J direction & 260 & 38.50 & $10,010.00$ \\
\hline
\end{tabular}

Once the new grid was placed on top of the reservoir properties of interest, the third step was to export only the properties of interest as a *.msh file. Finally, the exported grid size was changed to the original size to keep the original dimensions of the reservoir model.

\subsubsection{Modified Map Files}

The modified map files (excluding the aquifer boundary effect) for a total of 3 layers are presented below with a constant initial water saturation set at $18 \%$ across the entire reservoir and a nonvertical communication stablished between layers by setting the permeability in the $\mathrm{K}$ direction equal to zero. 

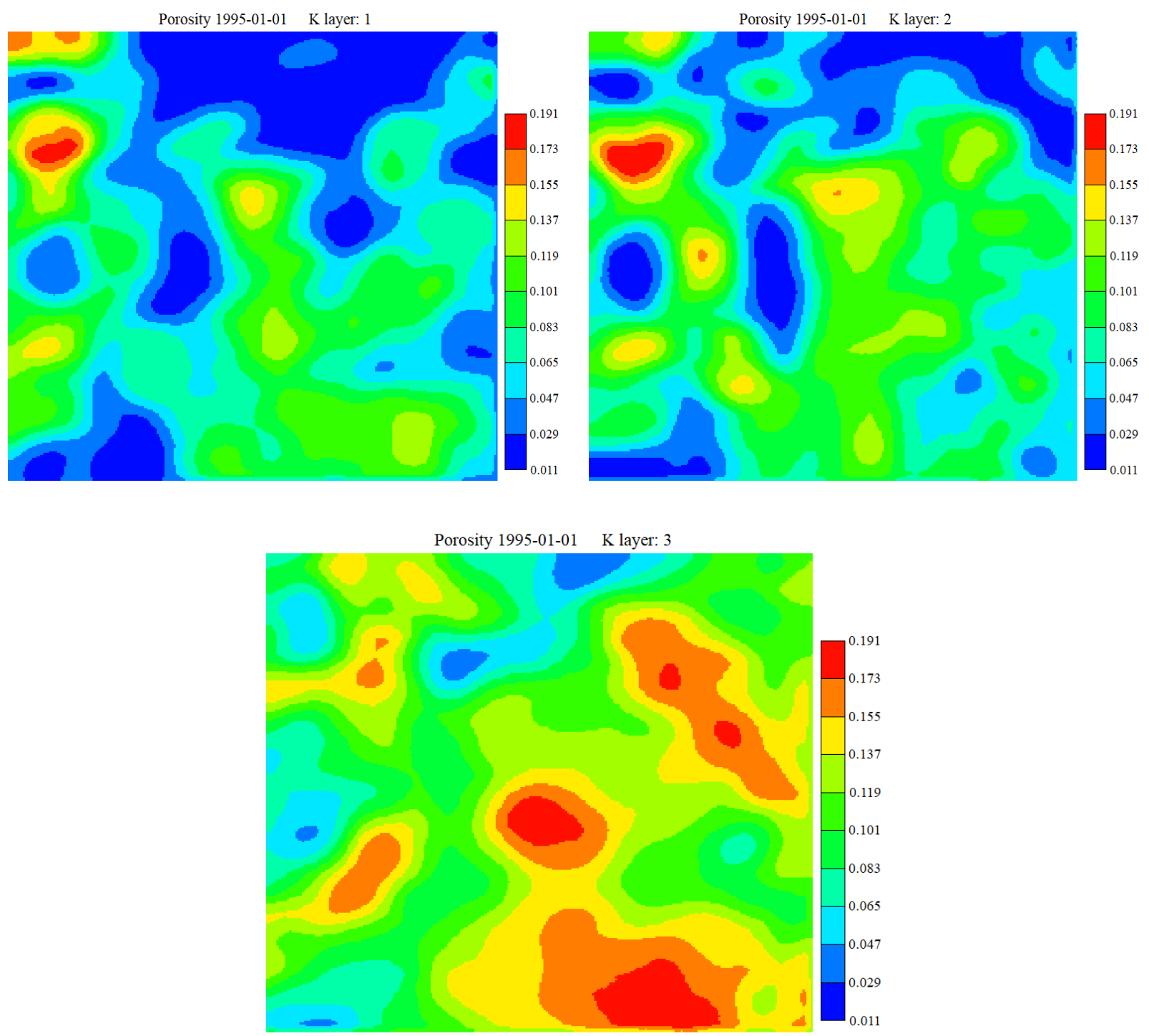

Figure 3-19: Thesis - Porosity Map Files 


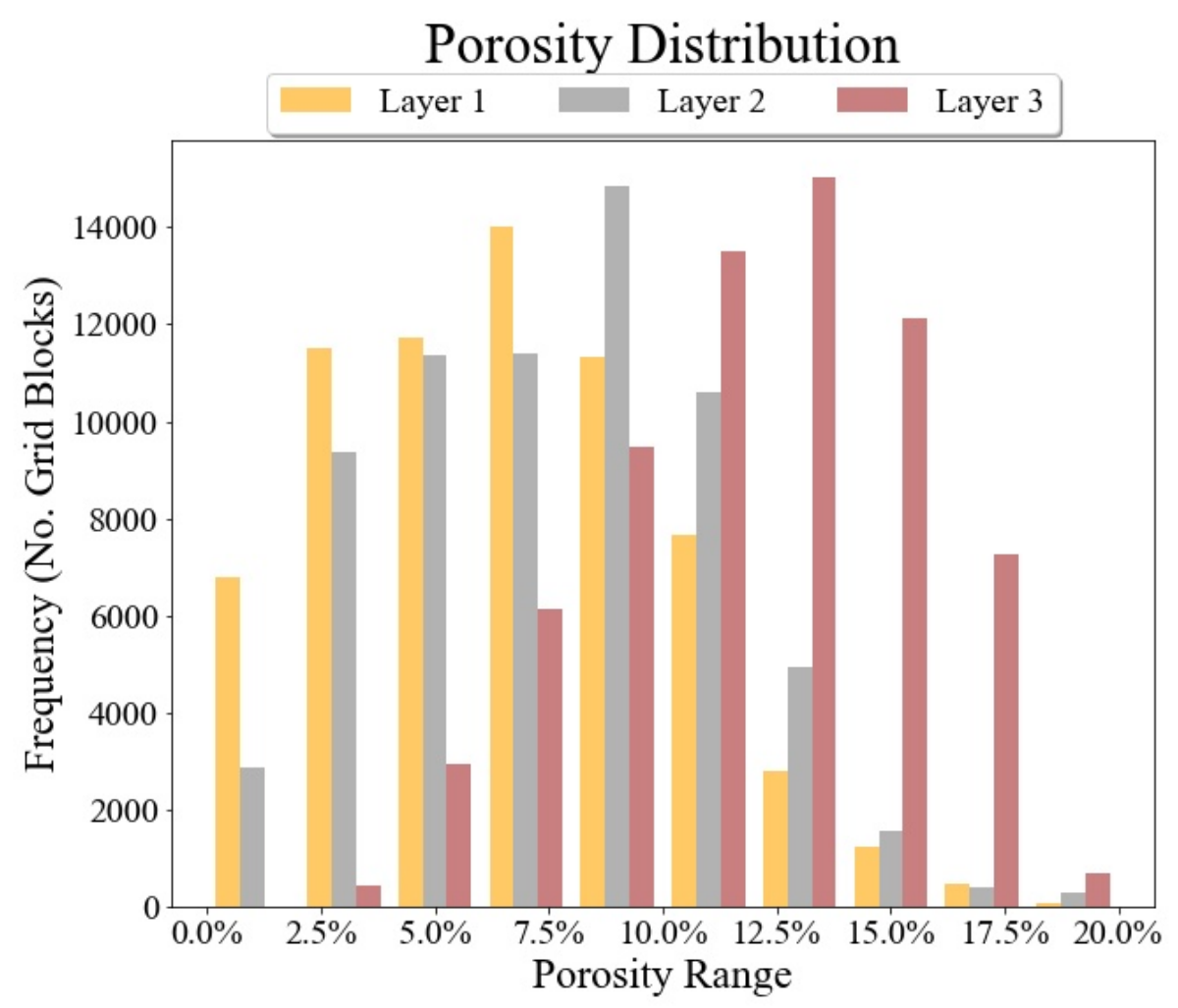

Figure 3-20: Porosity Distribution - 3 Layers

The porosity distribution in the first layer contains the largest number of grid blocks with the lowest porosity values while the third layer contains a larger number of grid blocks with higher porosity values. 

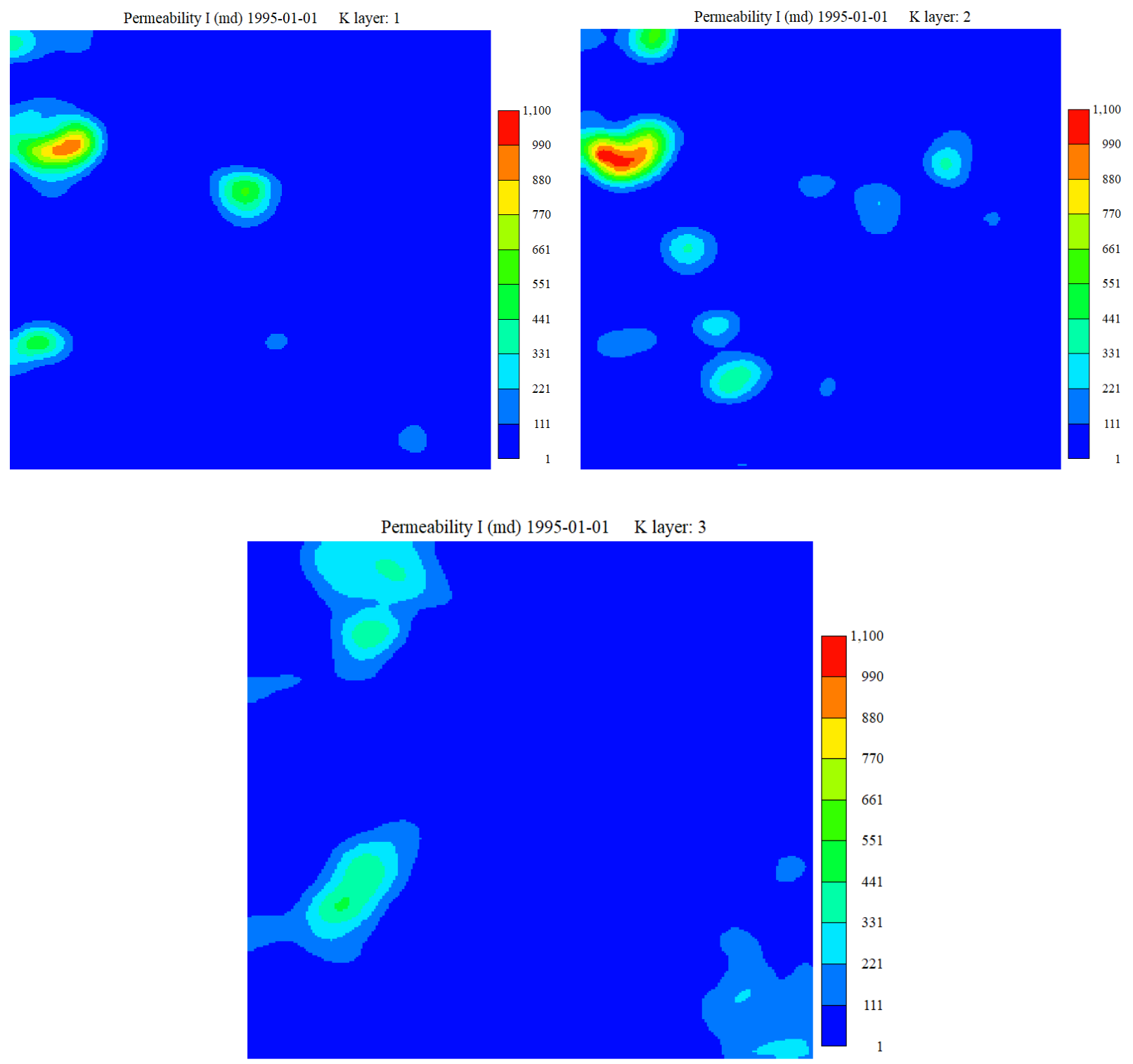

Figure 3-21: Thesis - Permeability, I Map Files 


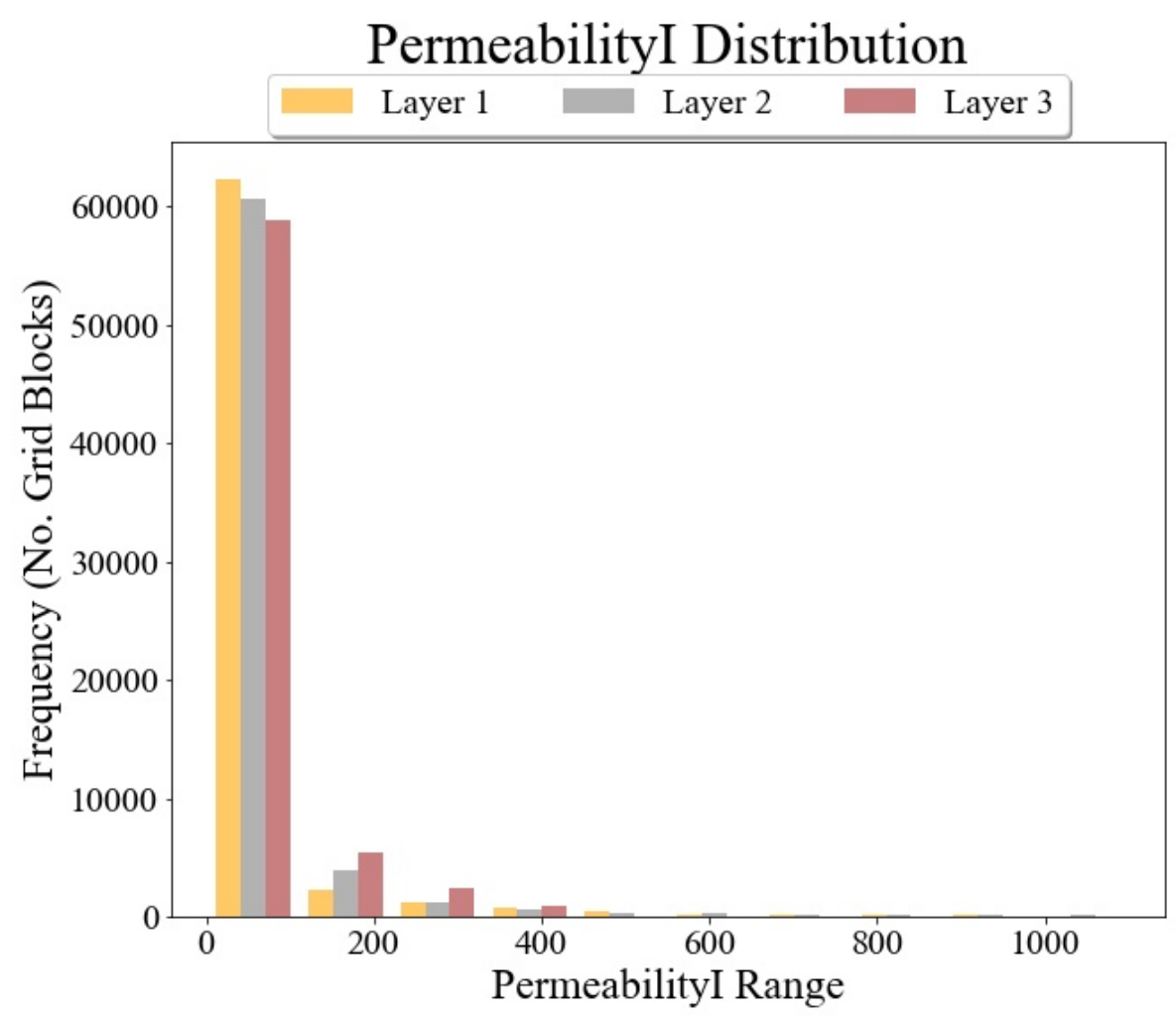

Figure 3-22: Permeability (I, J direction) - 3 Layers

Most of the reservoir in all three layers has a very low permeability. However, some spots in the reservoir have higher permeability values between $200 \mathrm{mD}$ and $400 \mathrm{mD}$. A smaller portion of the reservoir has values with the highest permeability ranging from $500 \mathrm{mD}$ to $1,000 \mathrm{mD}$. The permeability histogram depicted in Figure 3-22. 

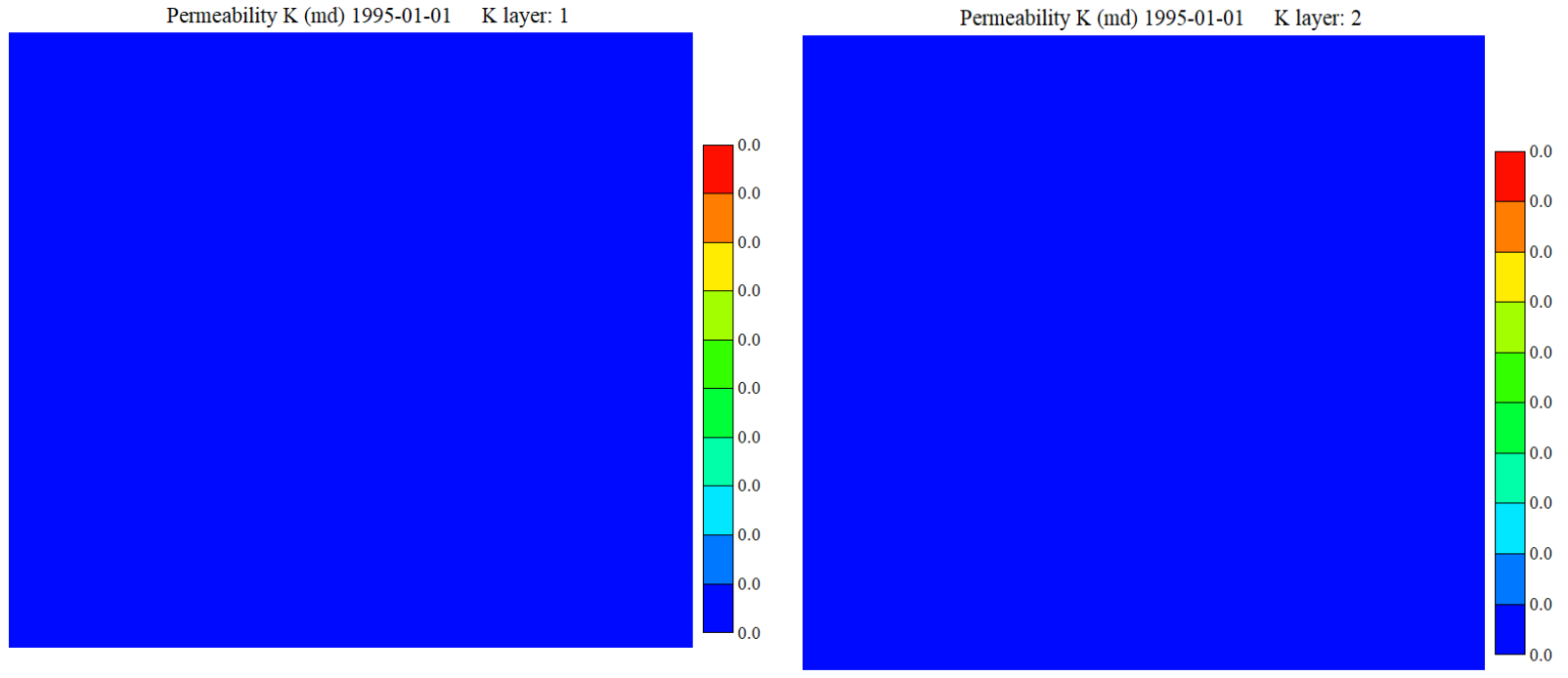

Permeability K (md) 1995-01-01

K layer: 3

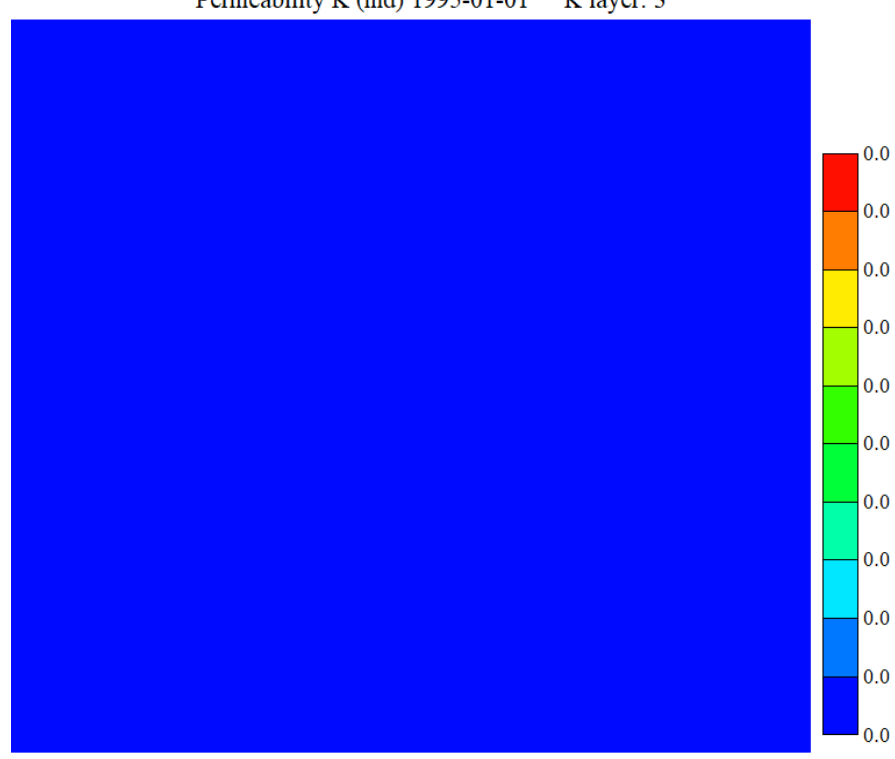

Figure 3-23: Thesis - Permeability, K Map Files 


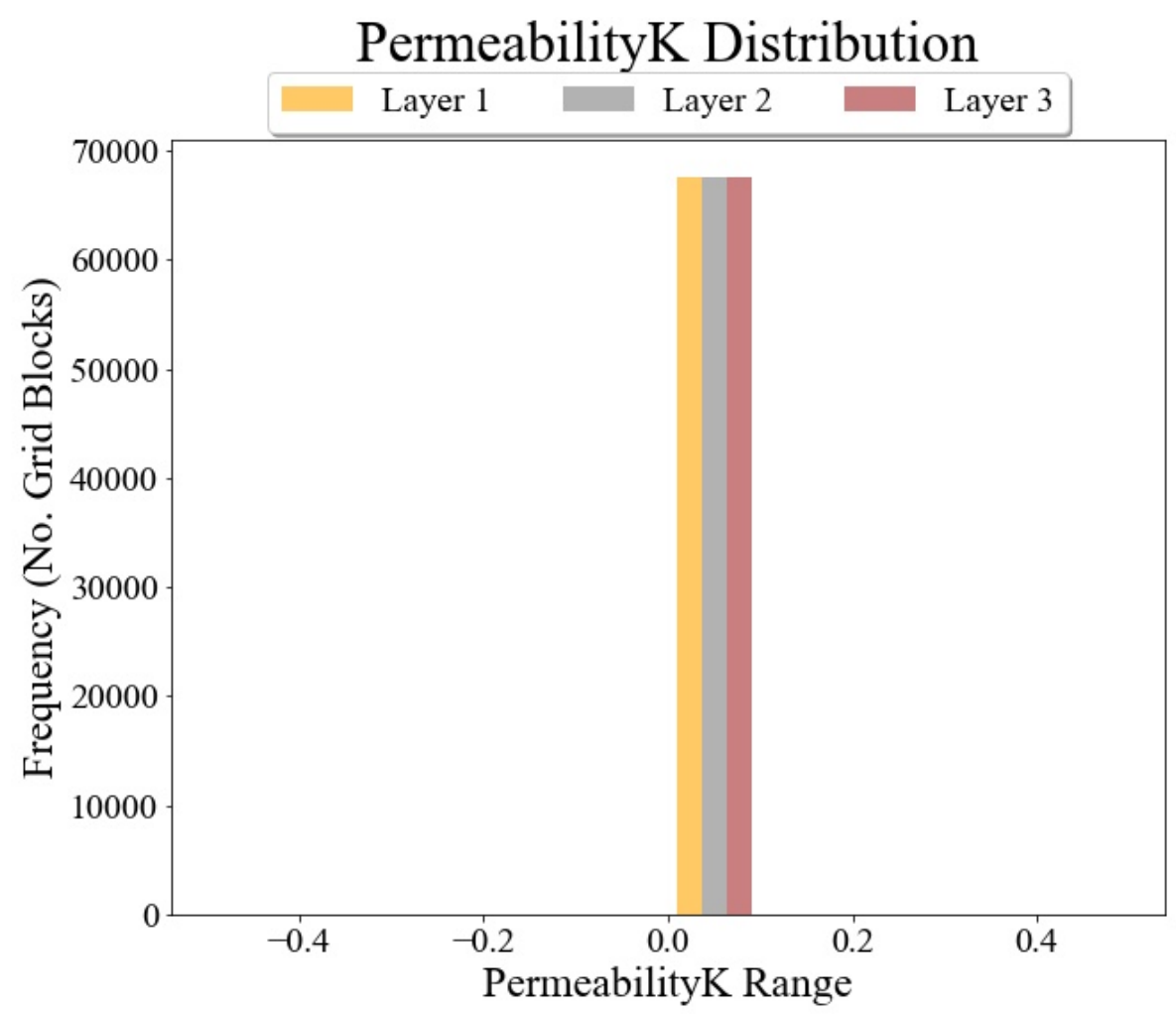

Figure 3-24: Permeability (K-direction) - 3 Layers

The permeability in the vertical direction was assigned to zero to prevent any communication between layers.
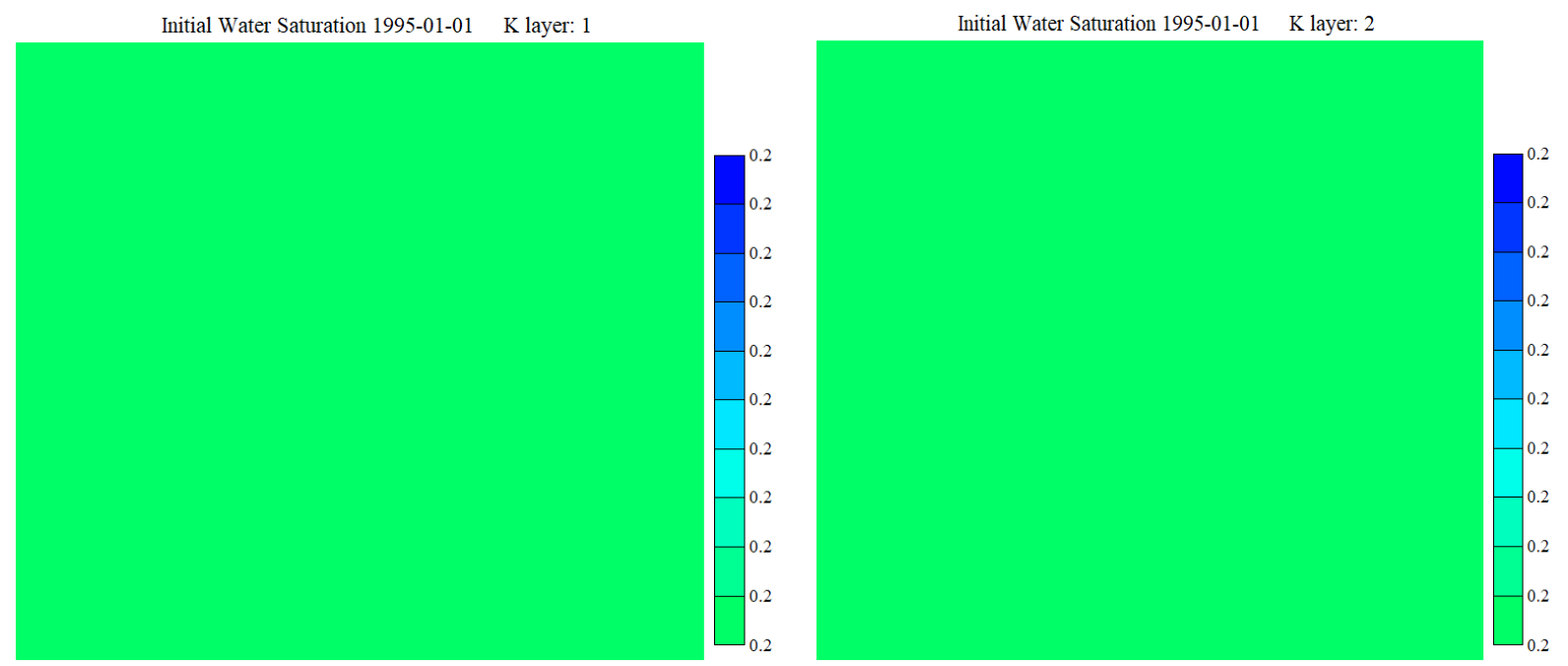


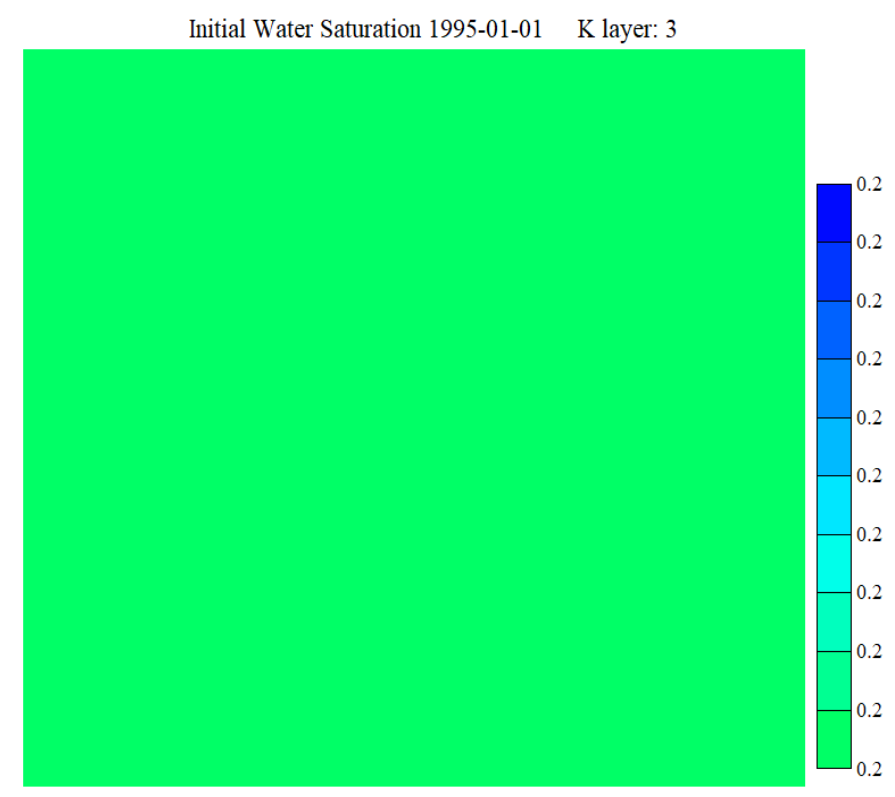

Figure 3-25: Thesis - Initial Water Saturation Map Files

A simple averaging technique was performed to determine a value for the entire reservoir based on all three layers. Table 3-5 summarizes the field characteristics for each layer and for the entire reservoir.

Table 3-5: Field Characteristics

\begin{tabular}{|l|c|c|c|c|}
\hline \multicolumn{1}{|c|}{ Attributes } & Layer 1 & Layer 2 & Layer 3 & Reservoir \\
\hline Avg Porosity & $6.67 \%$ & $7.67 \%$ & $11.95 \%$ & $8.76 \%$ \\
\hline Avg Permeability I, J & $36.93 \mathrm{mD}$ & $49.14 \mathrm{mD}$ & $53.4 \mathrm{mD}$ & $46.49 \mathrm{mD}$ \\
\hline Avg Permeability K & $0 \mathrm{mD}$ & $0 \mathrm{mD}$ & $0 \mathrm{mD}$ & $0 \mathrm{mD}$ \\
\hline Grid Thickness & $1.71 \mathrm{ft}-282.98 \mathrm{ft}$ & $2.84 \mathrm{ft}-143.13 \mathrm{ft}$ & $10.78 \mathrm{ft}-184.45 \mathrm{ft}$ & $1.71 \mathrm{ft}-282.98 \mathrm{ft}$ \\
\hline Formation Depth & $3829.72 \mathrm{ft}-4862.3 \mathrm{ft}$ & $3885.03 \mathrm{ft}-4971.53 \mathrm{ft}$ & $3913.6 \mathrm{ft}-4997.01 \mathrm{ft}$ & $3829.72-4997.01$ \\
\hline
\end{tabular}




\subsubsection{Field Development}

The development of the field consisted of a total of 7 phases. The first phase took place on January $1^{\text {st }}$ of 1995 when a total of 5 oil producers were drilled and completed. A month later, February $2^{\text {nd }}$ of 1995, 2 injectors were drilled and qualified for water injection. The remaining phases are shown in Table 3-6 below.

Table 3-6: Field Development Phases

\begin{tabular}{|c|c|c|c|c|c|}
\hline \multirow{2}{*}{\multicolumn{2}{|c|}{ Phases }} & \multicolumn{2}{|c|}{ Producers } & \multicolumn{2}{|c|}{ Injectors } \\
\hline & & Wells & Dates & Wells & Dates \\
\hline 1 & Phase 1 & Wells 1 - 5 & January 1,1995 & Injector 1 - 2 & February 1, 1995 \\
\hline 2 & Phase 2 & Wells 6 - 20 & January 1, 1998 & Injector $3-6$ & February 1, 1998 \\
\hline 3 & Phase 3 & Wells $21-38$ & January 1,2002 & Injector $7-12$ & February 1, 2002 \\
\hline 4 & Phase $4 a$ & Wells 39 - 42 & January 1,2007 & Injector 13 - 14 & February 1, 2007 \\
\hline 5 & Phase 4b & Wells 43 - 58 & January 1, 2008 & Injector $15-16$ & February 1, 2008 \\
\hline 6 & Phase $4 c$ & Wells 49 - 52 & January 1, 2009 & Injector 17 - 18 & February 1, 2009 \\
\hline 7 & Phase $4 d$ & Wells $53-57$ & January 1,2010 & Injector $19-20$ & February 1,2010 \\
\hline
\end{tabular}

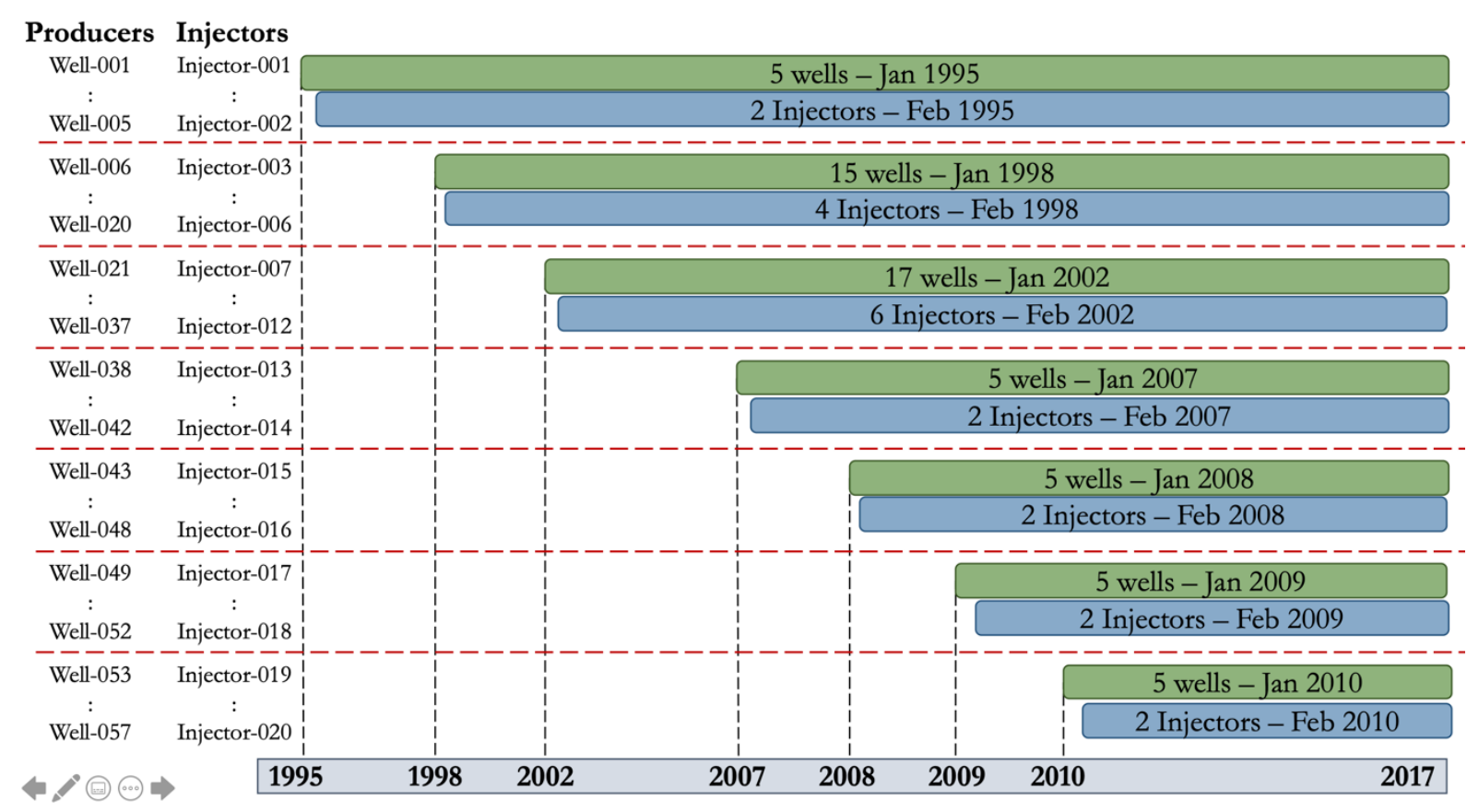

Figure 3-26: Field Development 


\subsubsection{Operational Constraints}

In order to accommodate real-world situations, operating and monitoring constraints were enabled for both producers and injectors inside the numerical simulator. The constraints are described below:

\section{Producers:}

- Operating Constraints:

○ A minimum bottom-hole pressure was set at 1,700 psi, slightly above the bubble point pressure, to keep a single-phase flow.

○ Wells were shut-in when the oil production was less than $30 \mathrm{bbl} / \mathrm{month}$.

- Monitoring Constraints:

- A water cut constraint was used to control the amount of water produced. In real fields, reservoirs that use water injection as a driving mechanism for oil production take into consideration cost analyzes that are associated with the amount of water produced. The water cut was set at $90 \%$, suggesting that wells with higher water production were shut-in.

\section{Injectors:}

- Operating Constraints:

- A maximum bottom-hole pressure constraint was set at 4,000psi to prevent injectors from fracking the formation while providing enough pressure support and water supply [24].

\subsubsection{Workover Events}

Approaching reality through numerical simulation is a difficult task to do. Nevertheless, unexpected delays that often take place in a real field were added to the simulation by implementing shut-in events and reproducing bottom-hole pressure behaviors.

- Random shut-in events: 
A series of daily and monthly random shut-in events were added to producing wells. Roughly $20 \%$ of the months and $15 \%$ of the days were non-productive for each of the existing producers. Water injectors, on the other hand, did not have any limitations as these were active in their respective development phases.

- Bottom-hole pressure fluctuations:

Bottom-hole pressure trends and fluctuations were mimicked in the simulation by randomly fluctuating the bottom-hole pressure trend on a daily and monthly basis within a range of $1,700 \mathrm{psi}-1,900 \mathrm{psi}$ for all producers.

Table 3-7 summarizes the total number of times a well has been shut-in events and the total number of times that the bottom-hole pressure was altered. See "ALTER" and "SHUTIN "columns. 
Table 3-7: Well Events

\begin{tabular}{|l|r|r|r|}
\hline \multirow{2}{*}{ Well Na me e } & \multicolumn{3}{|c|}{ EVENTS } \\
\cline { 2 - 4 } & SHUTIN & ALTER & TOTAL \\
\hline Well-001 & 698 & 6,513 & 7,211 \\
\hline Well-002 & 631 & 6,445 & 7,076 \\
\hline Well-003 & 620 & 6,439 & 7,059 \\
\hline Well-004 & 473 & 5,000 & 5,473 \\
\hline Well-005 & 602 & 6,416 & 7,018 \\
\hline Well-006 & 446 & 4,630 & 5,076 \\
\hline Well-007 & 440 & 4,618 & 5,058 \\
\hline Well-008 & 445 & 4,576 & 5,021 \\
\hline Well-009 & 322 & 3,340 & 3,662 \\
\hline Well-010 & 451 & 4,701 & 5,152 \\
\hline Well-011 & 427 & 4,557 & 4,984 \\
\hline Well-012 & 424 & 4,578 & 5,002 \\
\hline Well-013 & 458 & 4,599 & 5,057 \\
\hline Well-014 & 464 & 4,842 & 5,306 \\
\hline Well-015 & 436 & 4,557 & 4,993 \\
\hline Well-016 & 293 & 3,059 & 3,352 \\
\hline Well-017 & 445 & 4,662 & 5,107 \\
\hline Well-018 & 439 & 4,520 & 4,959 \\
\hline Well-019 & 438 & 4,617 & 5,055 \\
\hline Well-020 & 435 & 4,586 & 5,021 \\
\hline Well-021 & 351 & 3,779 & 4,130 \\
\hline Well-022 & 378 & 3,892 & 4,270 \\
\hline Well-023 & 391 & 3,902 & 4,293 \\
\hline Well-024 & 352 & 3,685 & 4,037 \\
\hline Well-025 & 358 & 3,831 & 4,189 \\
\hline Well-026 & 381 & 3,955 & 4,336 \\
\hline Well-027 & 367 & 3,807 & 4,174 \\
\hline Well-028 & 386 & 3,996 & 4,382 \\
\hline
\end{tabular}

\begin{tabular}{|l|r|r|r|}
\hline \multirow{2}{*}{ Well Na me } & \multicolumn{3}{|c|}{ EVENTS } \\
\cline { 2 - 4 } & SHUTIN & ALTER & TOTAL \\
\hline Well-029 & 388 & 3,983 & 4,371 \\
\hline Well-030 & 389 & 3,940 & 4,329 \\
\hline Well-031 & 380 & 3,889 & 4,269 \\
\hline Well-032 & 394 & 3,929 & 4,323 \\
\hline Well-033 & 385 & 4,006 & 4,391 \\
\hline Well-034 & 367 & 3,913 & 4,280 \\
\hline Well-035 & 372 & 3,901 & 4,273 \\
\hline Well-036 & 379 & 3,906 & 4,285 \\
\hline Well-037 & 381 & 3,836 & 4,217 \\
\hline Well-038 & 276 & 2,901 & 3,177 \\
\hline Well-039 & 277 & 2,913 & 3,190 \\
\hline Well-040 & 285 & 2,913 & 3,198 \\
\hline Well-041 & 281 & 2,911 & 3,192 \\
\hline Well-042 & 284 & 2,920 & 3,204 \\
\hline Well-043 & 258 & 2,645 & 2,903 \\
\hline Well-044 & 245 & 2,627 & 2,872 \\
\hline Well-045 & 206 & 2,242 & 2,448 \\
\hline Well-046 & 119 & 1,272 & 1,391 \\
\hline Well-047 & 246 & 2,633 & 2,879 \\
\hline Well-048 & 221 & 2,336 & 2,557 \\
\hline Well-049 & 232 & 2,338 & 2,570 \\
\hline Well-050 & 219 & 2,326 & 2,545 \\
\hline Well-051 & 228 & 2,335 & 2,563 \\
\hline Well-052 & 202 & 2,089 & 2,291 \\
\hline Well-053 & 196 & 2,059 & 2,255 \\
\hline Well-054 & 198 & 2,058 & 2,256 \\
\hline Well-055 & 198 & 2,059 & 2,257 \\
\hline Well-056 & 207 & 2,074 & 2,281 \\
\hline Well-057 & 195 & 2,059 & 2,254 \\
\hline
\end{tabular}




\subsubsection{Partial Completion Strategy:}

The completion plan for each well was randomly assigned based on the phases at which each well was first introduced to the field. Figure 3-27 shows all the possible completion combinations.

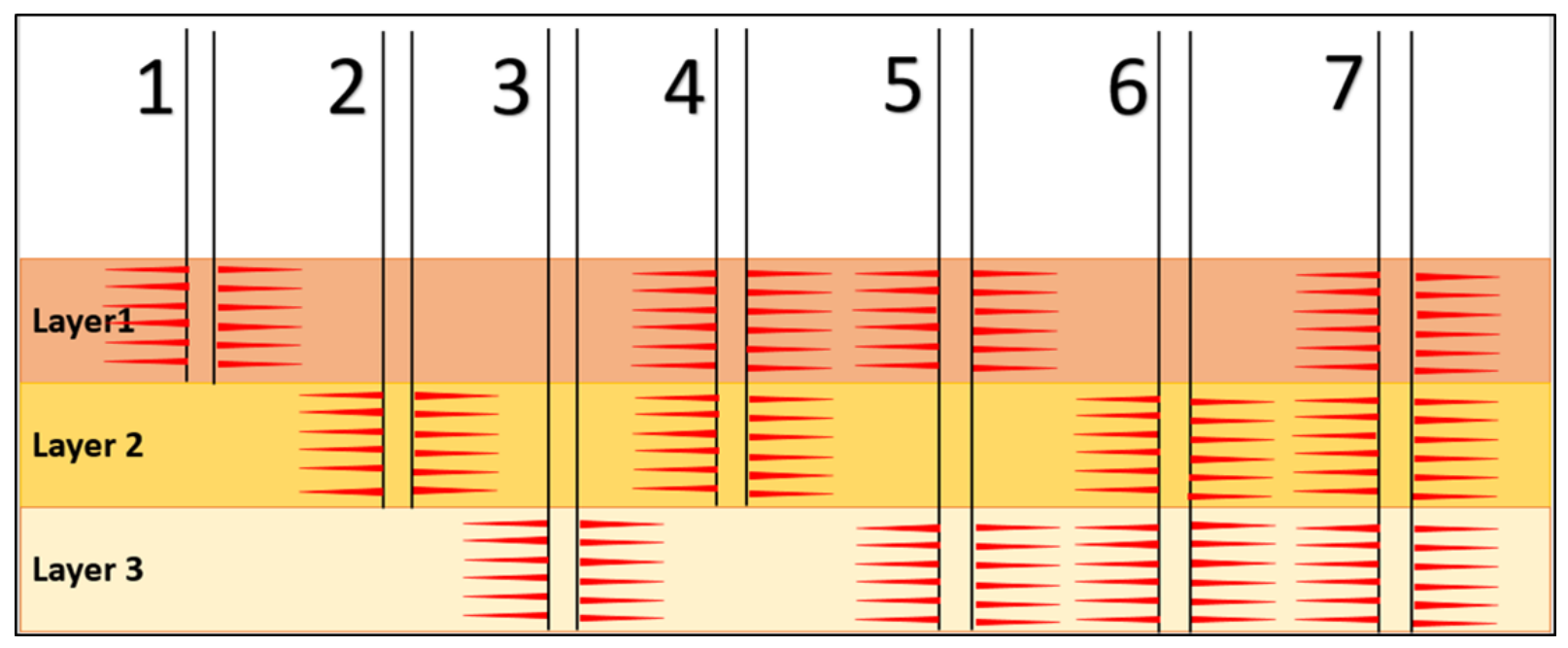

Figure 3-27: Completion Combinations

Out of a total of 57 production wells, 16 wells were unproductive in the first and second layers while 14 wells were unproductive on the third layer. This suggests that $27 \%$ of the layers were unproductive.

A detailed completion timeline of the field is shown in Table 3-8. The green, orange and yellow columns represent the first, second, and third layers of the reservoir respectively. Each layer has a total of 3 columns. The first column contains the dates at which a layer was opened for production while the second column contains the dates at which a layer was closed due to a water cut or production constraint. The third column displays the period of time a layer was producing for. All wells are producing from at least one layer. 


\section{Table 3-8: Field Completion Plan}

\begin{tabular}{|c|c|c|c|c|c|c|}
\hline Well Name & \begin{tabular}{|l|} 
Layer 1 OPEN \\
\end{tabular} & Layer 1 CLOSED & Production Time & Layer 2 OPEN & Layer 2 CLOSED & Production Time \\
\hline Well-001 & 1-Jan-1995 & 1-Apr-2002 & 7 years and 3 months & \begin{tabular}{|c|}
$\mathbf{x}$ \\
\end{tabular} & $\mathbf{x}$ & UNPRODUCTIVE \\
\hline Well-002 & 1-Jan-1995 & 1-Jan-2017 & 22 years & 1-Jan-1998 & 1-Jan-2017 & 19 years \\
\hline Well-003 & $\mathbf{x}$ & $\mathrm{X}$ & UNPRODUCTIVE & 1-Jan-1995 & 1-Jan-2017 & 22 years \\
\hline Well-004 & 1-Jan-1995 & 1-Jan-2012 & 17 years & $\mathbf{X}$ & $\mathbf{x}$ & UNPRODUCTIVE \\
\hline Well-005 & 1-Jan-1995 & 1-Feb-2014 & 19 years and 1 months & 1-Jan-2001 & 1-Feb-2014 & 13 years and 1 months \\
\hline Well-006 & 1-Jan-1998 & 1-Apr-2002 & 4 years and 3 months & 1-Mar-2002 & 1-Apr-2002 & 1 month \\
\hline Well-007 & 1-Jan-1998 & 1-Feb-1999 & 1 years and 1 months & $\mathbf{x}$ & $\mathbf{x}$ & UNPRODUCTIVE \\
\hline Well-008 & $\mathrm{x}$ & $\mathbf{x}$ & UNPRODUCTIVE & 1-Jan-1998 & 1-Jan-2008 & 10 years \\
\hline Well-009 & 1-Jan-1998 & 1-Feb-2009 & 11 years and 1 months & 1-Jan-1998 & 1-Feb-2009 & 11 years and 1 months \\
\hline Well-010 & 1-Jan-1998 & 1-Jan- 2017 & 19 years & $\mathbf{x}$ & $\mathbf{x}$ & UNPRODUCTIVE \\
\hline Well-011 & 1-Jan-1998 & 1-Jan-2004 & 6 years & 1-Jan-2000 & 1-Jan-2004 & 4 years \\
\hline Well-012 & 1-Jan-1998 & 1-Mar-2000 & 2 years and 2 months & 1-Jan-1998 & 1-Mar-2000 & 2 years and 2 months \\
\hline Well-013 & 1-Jan-1998 & 1-Jan-2017 & 19 years & $\mathbf{x}$ & $\mathbf{x}$ & UNPRODUCTIVE \\
\hline Well-014 & 1-Jan-1998 & 1-Apr-2008 & 10 years and 3 months & 1-Jan-1998 & 1-Apr-2008 & 10 years and 3 months \\
\hline Well-015 & $\mathbf{X}$ & $\mathbf{x}$ & UNPRODUCTIVE & 1-Jan-2002 & 1-Jan-2017 & 15 years \\
\hline Well-016 & $\mathbf{x}$ & $\mathbf{x}$ & UNPRODUCTIVE & 1-Jan-1999 & 1-Apr-2001 & 2 years and 3 months \\
\hline Well-017 & $\mathbf{x}$ & $\mathbf{x}$ & UNPRODUCTIVE & 1-Jan-1998 & 1-Jan-2017 & 19 years \\
\hline Well-018 & $\mathbf{x}$ & $\mathbf{x}$ & UNPRODUCTIVE & 1-Jan-1998 & 1-Jul-1998 & 6 months \\
\hline Well-019 & 1-Jan-1999 & 1-Jan-2017 & 18 years & $\mathbf{x}$ & $\mathrm{x}$ & UNPRODUCTIVE \\
\hline Well-020 & 1-Jan-1999 & 1-Aug-2011 & 12 years and 7 months & 1-Jan-1999 & 1-Aug-2011 & 12 years and 7 months \\
\hline Well-021 & 1-Jan-2002 & 1-May-2010 & 8 years and 4 months & $\mathbf{x}$ & $\mathbf{x}$ & UNPRODUCTIVE \\
\hline Well-022 & 1-Jan-2002 & 1-Jan-2017 & 15 years & $\mathbf{x}$ & $\mathbf{x}$ & UNPRODUCTIVE \\
\hline Well-023 & 1-Jan-2002 & 1-Jan- 2017 & 15 years & $\mathbf{x}$ & $\mathbf{x}$ & UNPRODUCTIVE \\
\hline Well-024 & 1-Jan-2002 & 1-Jan-2017 & 15 years & 1-Jan-2002 & 1-Jan-2017 & 15 years \\
\hline Well-025 & 1-Jan-2002 & 1-Jan-2017 & 15 years & $\mathbf{x}$ & $\mathbf{X}$ & UNPRODUCTIVE \\
\hline Well-026 & $\mathbf{x}$ & $\mathbf{x}$ & UNPRODUCTIVE & 1-Jan-2008 & 1-Jul-2009 & 1 year and 6 months \\
\hline Well-027 & 1-Jan-2002 & 1-Jan-2017 & 15 years & $\mathbf{x}$ & $\mathbf{x}$ & UNPRODUCTIVE \\
\hline Well-028 & $\mathbf{x}$ & $\mathbf{x}$ & UNPRODUCTIVE & 1-Jan-2002 & 1-Jan-2005 & 3 years \\
\hline Well-029 & $\mathbf{x}$ & $\mathbf{x}$ & UNPRODUCTIVE & 1-Jan-2002 & 1-Jul-2015 & 13 years and 6 months \\
\hline Well-030 & 1-Jan-2002 & 1-Apr-2011 & 9 years and 3 months & 1-Jan-2002 & 1-Apr-2011 & 9 years and 3 months \\
\hline Well-031 & 1-Jan-2002 & 1-Jan-2017 & 15 years & 1-Jan-2002 & 1-Jan-2017 & 15 years \\
\hline Well-032 & 1-Jan-2002 & 1-Dec-2016 & 14 years and 11 months & 1-Jan-2002 & 1-Dec-2016 & 14 years and 11 months \\
\hline Well-033 & 1-Jan-2004 & 1-Nov-2007 & 3 years and 10 months & 1-Jan-2002 & 1-Nov-2007 & 5 years and 10 months \\
\hline Well-034 & 1-Jan-2002 & 1-Jan- 2017 & 15 years & 1-Jan-2005 & 1-Jan-2017 & 12 years \\
\hline Well-035 & 1-Jan-2004 & 1-Mar-2015 & 11 years and 2 months & 1-Jan-2002 & 1-Mar-2015 & 13 years and 2 months \\
\hline Well-036 & $\mathrm{x}$ & $\mathrm{x}$ & UNPRODUCTIVE & 1-Jan-2002 & 1-Jan-2017 & 15 years \\
\hline Well-037 & $\mathbf{x}$ & $\mathbf{x}$ & UNPRODUCTIVE & 1-Jan-2002 & 1-May-2013 & 11 years and 4 months \\
\hline Well-038 & $\mathbf{X}$ & $\mathbf{x}$ & UNPRODUCTIVE & 1-Jan-2007 & 1-Jan-2017 & 10 years \\
\hline Well-039 & 1-Jan-2007 & 1-Jan-2017 & 10 years & 1-Jan-2007 & 1-Jan-2017 & 10 years \\
\hline Well-040 & 1-Jan-2007 & 1-Jan-2017 & 10 years & $\mathbf{x}$ & $\mathrm{x}$ & UNPRODUCTIVE \\
\hline Well-041 & 1-Jan-2007 & 1-Jan- 2017 & 10 years & $\mathbf{x}$ & $\mathbf{x}$ & UNPRODUCTIVE \\
\hline Well-042 & 1-Jan-2007 & 1-Jan-2017 & 10 years & 1-Jan-2007 & 1-Jan-2017 & 10 years \\
\hline Well-043 & 1-Jan-2008 & 1-Jan-2017 & 9 years & 1-Jan-2014 & 1-Jan-2017 & 3 years \\
\hline Well-044 & 1-Jan-2008 & 1-Jan-2017 & 9 years & 1-Jan-2008 & 1-Jan-2017 & 9 years \\
\hline Well-045 & 1-Jan-2008 & 1-Aug-2015 & 7 years and 7 months & 1-Jan-2008 & 1-Aug-2015 & 7 years and 7 months \\
\hline Well-046 & 1-Jan-2008 & 1-Jan-2012 & 4 years & 1-Jan-2008 & 1-Jan-2012 & 4 years \\
\hline Well-047 & $\mathbf{x}$ & $\mathbf{x}$ & UNPRODUCTIVE & 1-Jan-2008 & 1-Jan-2010 & 2 years \\
\hline Well-048 & 1-Jan-2012 & 1-Jan-2017 & 5 years & $\mathbf{x}$ & $\mathbf{x}$ & UNPRODUCTIVE \\
\hline Well-049 & $\mathbf{x}$ & $\mathbf{x}$ & UNPRODUCTIIE & $\mathbf{x}$ & $\mathbf{x}$ & UNPRODUCTIVE \\
\hline Well-050 & 1-Jan-2009 & 1-Jan-2017 & 8 years & $\mathbf{x}$ & $\mathbf{x}$ & UNPRODUCTIVE \\
\hline Well-051 & $\mathrm{X}$ & $\mathbf{X}$ & UNPRODUCTIVE & 1-Jan-2009 & 1-Jan-2010 & 1 year \\
\hline Well-052 & 1-Jan-2009 & 1-Apr-2016 & 7 years and 3 months & 1-Jan-2009 & 1-Apr-2016 & 7 years and 3 months \\
\hline Well-053 & 1-Jan-2010 & 1-Jan-2017 & 7 years & 1-Jan-2010 & 1-Jan-2017 & 7 years \\
\hline Well-054 & 1-Jan-2010 & 1-Jan-2017 & 7 years & 1-Jan-2010 & 1-Jan-2017 & 7 years \\
\hline Well-055 & 1-Jan-2010 & 1-Jan-2017 & 7 years & 1-Jan-2010 & 1-Jan-2017 & 7 years \\
\hline Well-056 & $\mathrm{x}$ & $\mathrm{x}$ & UNPRODUCTIVE & 1-Jan-2010 & 1-Jan-2017 & 7 years \\
\hline Well-057 & 1-Jan-2010 & 1-Jan-2017 & 7 years & 1-Jan-2010 & 1-Jan-2017 & 7 years \\
\hline Unproductive & \multicolumn{3}{|c|}{16 Wells } & \multicolumn{3}{|c|}{16 Wells } \\
\hline
\end{tabular}




\begin{tabular}{|c|c|c|c|}
\hline Well Name & Layer 3 OPEN & Layer 3 CLOSED & Production Time \\
\hline Well-001 & \begin{tabular}{|c|}
$\mathbf{X}$ \\
\end{tabular} & \begin{tabular}{|l|}
$\mathbf{x}$ \\
\end{tabular} & UNPRODUCTIVE \\
\hline Well-002 & $\mathbf{X}$ & $\mathbf{X}$ & INPRODUCTIVE \\
\hline Well-003 & 1-Jan-1995 & 1-Jan-2017 & 22 years \\
\hline Well-004 & $\mathbf{X}$ & $\mathrm{X}$ & UNPRODUCTIVE \\
\hline Well-005 & 1-Jan-2006 & $1-\mathrm{Feb}-2014$ & 8 years and 1 month \\
\hline Well-006 & 1-Mar-2002 & 1-Apr-2002 & 1 month \\
\hline Well-007 & $\mathbf{x}$ & $\mathrm{x}$ & UNPRODUCTIVE \\
\hline Well-008 & 1-Jan-1999 & 1-Jan-2008 & 9 years \\
\hline Well-009 & 1-Jan-1998 & 1-Feb-2009 & 11 years and 1 month \\
\hline Well-010 & 1-Jan-1998 & 1-Jan-2017 & 19 years \\
\hline Well-011 & $\mathbf{x}$ & $\mathbf{x}$ & UNPRODUCTIVE \\
\hline Well-012 & 1-Jan-1998 & 1-Mar-2000 & 2 years and 2 months \\
\hline Well-013 & $\mathbf{X}$ & $\mathbf{X}$ & UNPRODUCTIVE \\
\hline Well-014 & $\mathbf{x}$ & $\mathbf{x}$ & UNPRODUCTIVE \\
\hline Well-015 & 1-Jan-1998 & 1-Jan-2017 & 19 years \\
\hline Well-016 & 1-Jan-1998 & 1-Apr-2001 & 3 years and 3 months \\
\hline Well-017 & 1-Jan-1998 & 1-Jan- 2017 & 19 years \\
\hline Well-018 & 1-Jan-1998 & 1-Jul-1998 & 6 months \\
\hline Well-019 & $\mathrm{x}$ & $\mathrm{X}$ & UNPRODUCTIVE \\
\hline Well-020 & 1-Jan-1999 & 1-Aug-2011 & 12 years and 7 months \\
\hline Well-021 & 1-Jan-2005 & 1-May-2010 & 5 years and 4 months \\
\hline Well-022 & 1-Jan-2004 & 1-Jan-2017 & 13 years \\
\hline Well-023 & 1-Jan-2005 & 1-Jan-2017 & 12 years \\
\hline Well-024 & $\mathbf{x}$ & $\mathbf{X}$ & UNPRODUCTIVE \\
\hline Well-025 & 1-Jan-2002 & 1-Jan-2017 & 15 years \\
\hline Well-026 & 1-Jan-2002 & 1-Jul-2009 & 7 years and 6 months \\
\hline Well-027 & $\mathrm{X}$ & $\mathrm{X}$ & UNPRODUCTIVE \\
\hline Well-028 & $\mathrm{X}$ & $\mathrm{X}$ & UNPRODUCTIVE \\
\hline Well-029 & 1-Jan-2002 & 1-Jul-2015 & 13 years and 6 months \\
\hline Well-030 & $\mathbf{X}$ & $\mathbf{X}$ & UNPRODUCTIVE \\
\hline Well-031 & 1-Jan-2002 & 1-Jan-2017 & \begin{tabular}{|l|}
15 years \\
\end{tabular} \\
\hline Well-032 & 1-Jan-2002 & 1-Dec-2016 & 14 years and 11 months \\
\hline Well-033 & 1-Jan-2002 & 1-Nov-2007 & 5 years and 10 months \\
\hline Well-034 & 1-Jan-2010 & 1-Jan-2017 & 7 years \\
\hline Well-035 & 1-Jan-2002 & 1-Mar-2015 & 13 years and 2 months \\
\hline Well-036 & 1-Jan-2002 & 1-Jan-2017 & 15 years \\
\hline Well-037 & 1-Jan-2011 & 1-May-2013 & 2 years and 4 months \\
\hline Well-038 & 1-Jan-2007 & 1-Jan-2017 & 10 years \\
\hline Well-039 & 1-Jan-2007 & 1-Jan-2017 & 10 years \\
\hline Well-040 & 1-Jan-2007 & 1-Jan-2017 & 10 years \\
\hline Well-041 & $\mathrm{X}$ & $\mathrm{X}$ & UNPRODUCTIVE \\
\hline Well-042 & $\mathbf{X}$ & $\mathbf{X}$ & UNPRODUCTIVE \\
\hline Well-043 & 1-Jan-2015 & 1-Jan-2017 & 2 years \\
\hline Well-044 & 1-Jan-2008 & 1-Jan-2017 & 9 years \\
\hline Well-045 & 1-Jan-2008 & 1-Aug-2015 & 7 years and 7 months \\
\hline Well-046 & 1-Jan-2008 & 1-Jan-2012 & 4 years \\
\hline Well-047 & 1-Jan-2008 & 1-Jan-2017 & 9 years \\
\hline Well-048 & 1-Jan-2009 & 1-Jan-2017 & 8 years \\
\hline Well-049 & 1-Jan-2009 & 1-Jan-2017 & 8 years \\
\hline Well-050 & 1-Jan-2009 & 1-Jan-2017 & 8 years \\
\hline Well-051 & 1-Jan-2009 & 1-Jan-2017 & 8 years \\
\hline Well-052 & 1-Jan-2009 & 1-Apr-2016 & 7 years and 3 months \\
\hline Well-053 & 1-Jan-2010 & 1-Jan-2017 & 7 years \\
\hline Well-054 & 1-Jan-2010 & 1-Jan-2017 & 7 years \\
\hline Well-055 & 1-Jan-2010 & 1-Jan-2017 & 7 years \\
\hline Well-056 & 1-Jan-2010 & 1-Jan-2017 & 7 years \\
\hline Well-057 & 1-Jan-2010 & 1-Jan-2017 & 7 years \\
\hline Unproductive & \multicolumn{3}{|c|}{14 Wells } \\
\hline
\end{tabular}




\subsection{Available Data}

The total oil, gas, and water production of the field was $6.223 .078 .25 \mathrm{bbl}, 2.597 .680 .627 .59 \mathrm{scf}$, and 3.399.965.94bbl respectively.

Table 3-9: Field Production

\begin{tabular}{|l|r|l|}
\hline \multicolumn{3}{|c|}{ Field Production } \\
\hline \multicolumn{1}{|c|}{ Rate } & \multicolumn{1}{c|}{ Value } & \multicolumn{1}{c|}{ Units } \\
\hline Oil & $6,223,078.25$ & $\mathrm{bbl}$ \\
Gas & $2,597.68$ & $\mathrm{mmscf}$ \\
Water & $3,399,965.94$ & $\mathrm{bbl}$ \\
\hline
\end{tabular}

Individual cumulative oil production ranged from as high as $650,000 \mathrm{bbl}$ to as low as $2,000 \mathrm{bbl}$. Cumulative gas production ranged from $270,000 \mathrm{mscf}$ to $800 \mathrm{mscf}$ and cumulative water production ranged from $660,000 \mathrm{bbl}$ to $500 \mathrm{bbl}$.

Table 3-10: Cumulative Production Statistics on a Well Basis

\begin{tabular}{|l|r|r|r|}
\hline \multicolumn{1}{|c|}{ Rate } & \multicolumn{1}{c|}{ High } & \multicolumn{1}{c|}{ Average } & \multicolumn{1}{c|}{ Low } \\
\hline Oil (bbl) & 650,000 & 110,000 & 2,000 \\
Gas (mmscf) & 270 & 45 & 0.8 \\
Water (bbl) & 660,000 & 60,000 & 500 \\
\hline
\end{tabular}

Figure 3-28 illustrates the different format options in which data can be retrieved to an Excel Spreadsheet. For example, "Well" data is available for a total of 77 wells. Each well contains data for a total of 60 different attributes (See "Data Selection" Figure 3-28). "Layered" data is available for a total of 231 layers (77 wells x 3 layers). Each layer contains data for a total of 50 different attributes. "Special History" data, is available for a total of 3 attributes (Reservoir pressure, oil saturation and water saturation) at grid block locations including the well center grid block (1 WBA) and the surrounding grid blocks ( 8 WBA) in all 3 layers, resulting in a total of 6,238 data points. Moreover, each of the selected properties can be exported on a yearly, quarterly, monthly, or a daily basis as shown in the Report Period tab on the bottom-left corner of Figure 3-28. 


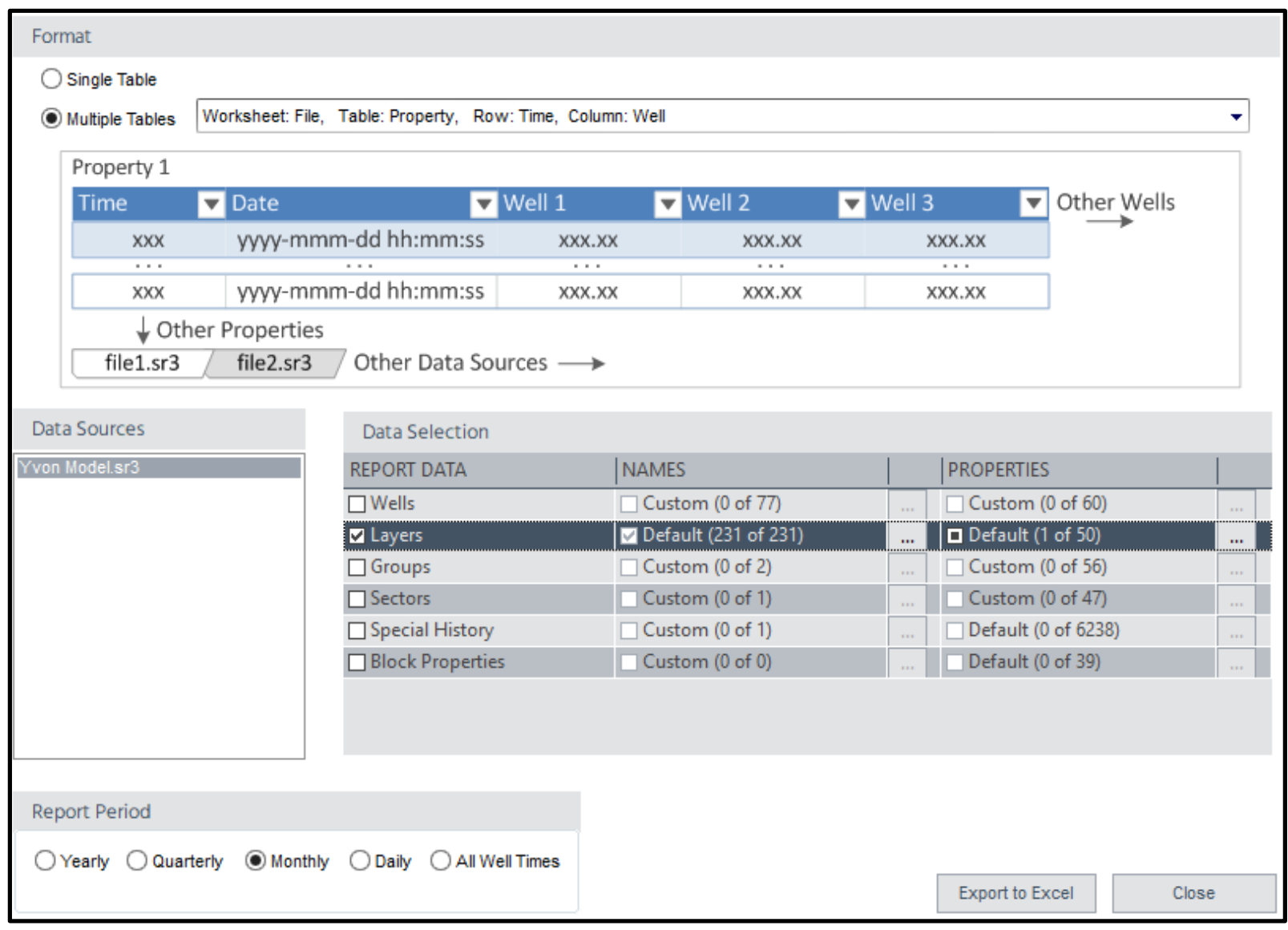

Figure 3-28: Reservoir Simulation Outputs

Below are brief descriptions of the data available for retrieval.

1. Wells: provides data for every well from the date the well is completed until the date the well is abandoned. Approximately 40 attributes options are available for data analysis. See Table 3-11.

Table 3-11: Well Based Reported Data

\begin{tabular}{|l|l|l|l|l|}
\hline \multicolumn{9}{|c|}{ Wells Reported Data } \\
\hline Cumulative Bottom Hole Fluid & Bottom Hole Fluid Rate & Gas Oil Ratio & On Time Fraction & Well BHP Derivative \\
\hline Cumulative Gas Oil Ratio & Fluid Rate & Gas Water Ratio & Period Gas Production & Well Block Pres. Derivative \\
\hline Cumulative Gas & Gas Rate & Oil Gas Ratio & Period Oil Production & Well Block Pressure \\
\hline Cumulative lift gas injected & Lift Gas Rate & Water Gas Ratio & Period Water Production & Well Bottom-hole Pressure \\
\hline Cumulative Liquid & Liquid Rate & Water Oil Ratio & Well Cumulative Open On-time & Well Head Pres. Derivative \\
\hline Cumulative Oil & Oil Rate & Oil Cut & Well Open Fraction & Well Head Pressure \\
\hline Cumulative Water Mass & Water Mass Rate & Water Cut & Well Operating Mode & Well Mobility - Weighted Block P \\
\hline Cumulative Water & Water Rate & & Well State & Well Mobility - Weighted Datum Pressure \\
\hline Cumulative Water Oil Ratio & & & & \\
\hline
\end{tabular}


2. Layer Based Data: provides data for every well at every layer from the date the well is completed until the date the well is abandoned.

Table 3-12: Layer Based Reported Data

\begin{tabular}{|l|l|l|l|l|}
\hline \multicolumn{5}{|c|}{ Layers Repor ted Data } \\
\hline Cumulative Bottom Hole Fluid & Bottom Hole Fluid Rate & Gas Oil Ratio & On Time Fraction & Well Block Pres. Derivative \\
\hline Cumulative Gas Oil Ratio & Fluid Rate & Gas Water Ratio & Period Gas Production & Well Block Pressure \\
\hline Cumulative Gas & Gas Rate & Oil Gas Ratio & Period Oil Production & Well Pressure \\
\hline Cumulative Liquid & Liquid Rate & Water Gas Ratio & Period Water Production & Well Pressure Derivative \\
\hline Cumulative Oil & Oil Rate & Water Oil Ratio & Status $(0=$ Open, 1 = closed, 2= auto $)$ & \\
\hline Cumulative Water Mass & Water Mass Rate & Oil Cut & Well Cumulative Open On-time & \\
\hline Cumulative Water & Water Rate & Water Cut & Well Open Fraction & \\
\hline Cumulative Water Oil Ratio & & & Well Operating Mode & \\
\hline & & & Well State & \\
\hline
\end{tabular}

3. Special History: provides data for every specified grid block location from the beginning of the simulation until the end of the simulation. The specified grid block locations and the properties of interest must be provided prior to running the simulation.

Table 3-13: Special History Reported Data

\begin{tabular}{|l|}
\hline Special History Reported Data \\
\hline Oil Saturation \\
\hline Water Saturation \\
\hline Pressure \\
\hline
\end{tabular}

4. Block Properties: provides data for a specific grid block location by specified by the user. This information can be accessed after running the simulation.

Table 3-14: Block Properties Reported Data

\begin{tabular}{|l|l|l|l|}
\hline \multicolumn{5}{|c|}{ Block Properties Reported Data } \\
\hline Gas Saturation & Krg at Connate Liquid (2) & Low Side Trans Multiplier I & Gas per unit area - Layer \\
\hline Oil Saturation & Kro at Connate Water ST & Low Side Trans Multiplier J & Gas per unit area - Total \\
\hline Water Saturation & Kro at Connate Gas (2) & Low Side Trans Multiplier K & Oil per unit area - Layer \\
\hline Grid Bottom & Krw at Connate Gas (2) & Max Gas-Oil Cap Pres & Oil per unit area - Total \\
\hline Grid Centroid X & Krw at Irreducible Oil ST & Max Water-Oil Cap Pres & Net Pay \\
\hline Grid Centroid Y & Permeability I & Water Cap Pres Shift/Offset & Net Pore Volume \\
\hline Grid Paydepth & Permeability J & Gross Block Volume & Net to Gross Ratio \\
\hline Grid Thickness & Permeability K & Modified Block Volume & \\
\hline Grid Top & Trans Multiplier I & & \\
\hline & Trans Multiplier J & & \\
\hline & Trans Multiplier K & & \\
\hline
\end{tabular}




\section{CHAPTER 4}

\section{DATA-DRIVEN RESERVOIR MODELING}

This chapter is dedicated to the development of five TDM models using IMagine. IMagine is a software that implements artificial intelligence techniques, such as artificial neural networks, genetic algorithms and fuzzy logic to solve oil and gas industry related problems [25].

TDM models were built using data generated from the numerical reservoir model described in section 3.2 to history match and forecast production, reservoir pressure, and water saturation output attributes.

The development and analysis of a TDM consist of the following phases:

1. Data preparation

2. Data import

3. Static modeling

4. Top-down modeling

The first phase focuses on the details of data collection, data cleansing, and data preparation with efforts to properly import formatted and pre-processed data into IMagine.

The second phase briefly mentions the steps taken to successfully import well-based and production rate data into the software.

The third phase elaborates on the pre-modeling analysis that characterizes the reservoir [25].

The fourth phase defines a total five predictive data-driven models that are interconnected in the following order: oil rate, gas rate, water rate, reservoir pressure and water saturation. Figure 4-1 illustrates the order in which the predictive models are presented. 


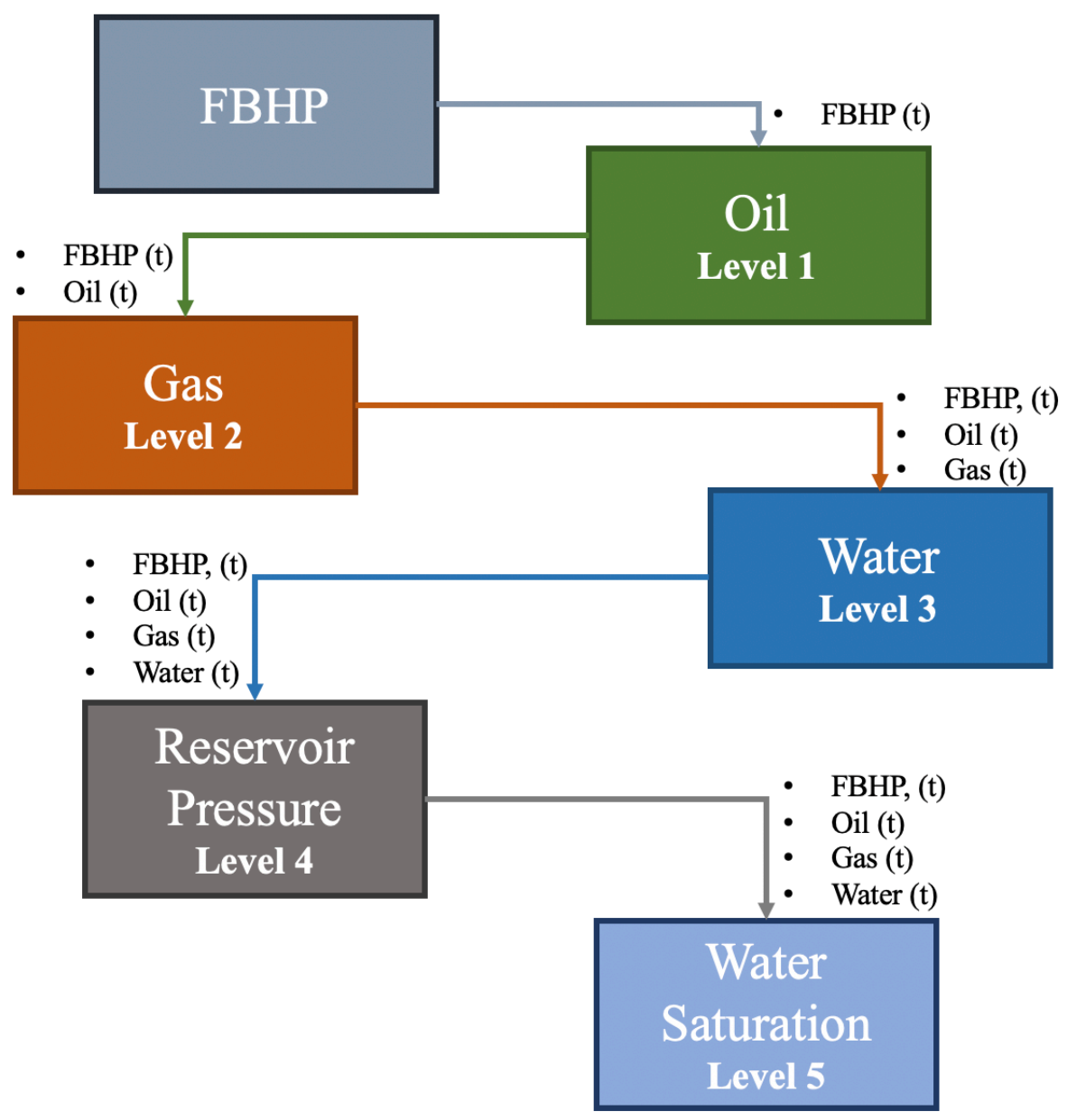

Figure 4-1: Top-Down Model Levels

\subsection{Data Preparation}

Well-based and production rate data were imported into IMagine. The well-based data is further classified into static and dynamic datasets. The formatting of each dataset is explained in detail in the following section.

\subsubsection{Data Formatting}

In the data preparation process, information was arranged in standardized tabular formats. The static dataset was organized with columns representing static properties and rows representing all 
the wells in the field (producers and injectors). A single static file (*.csv) was enough to provide all the static information regarding the reservoir. An example of the static file imported into the software is shown in Figure 4-2.

On the other hand, one dynamic dataset constituted the values of a single property that changed over time. All dynamic properties were saved in separate .*csv files with a common formatting structure depicted in Figure 4-3, where columns represent a series of dates and rows represent all the wells.

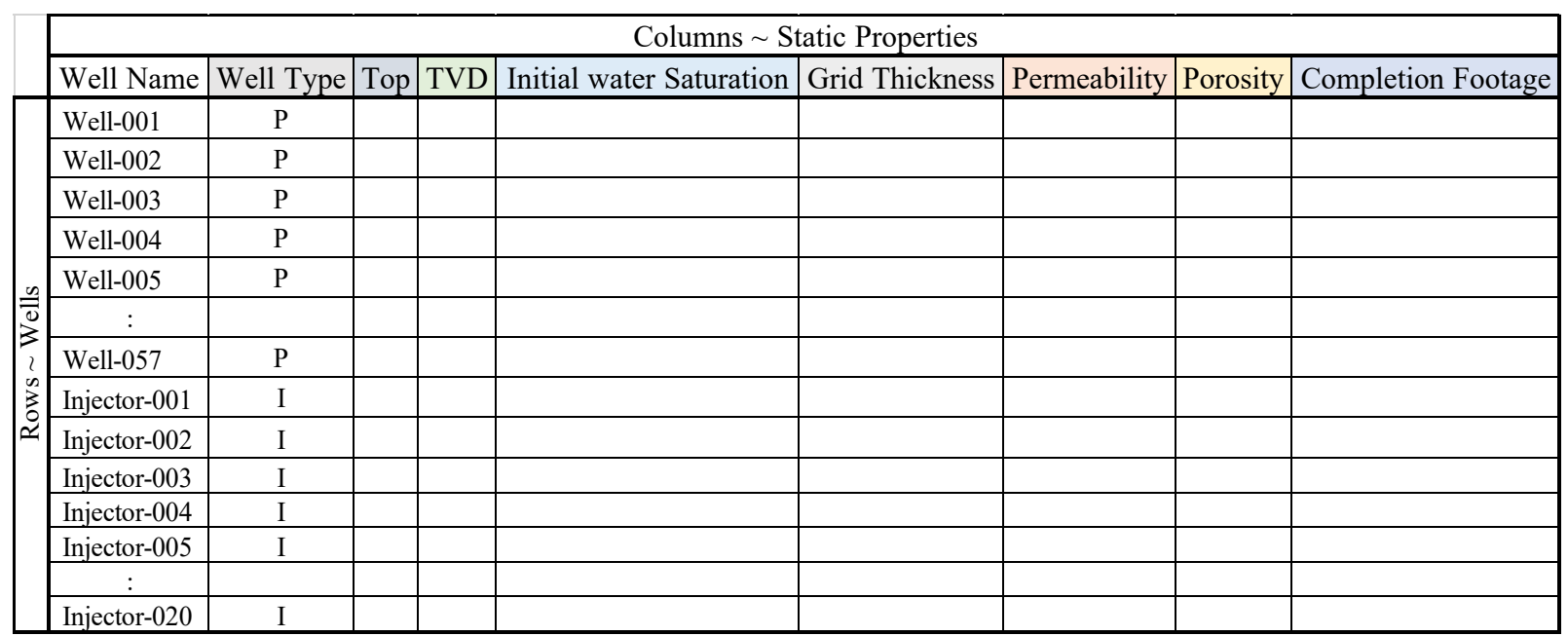

Figure 4-2: Static Dataset Format

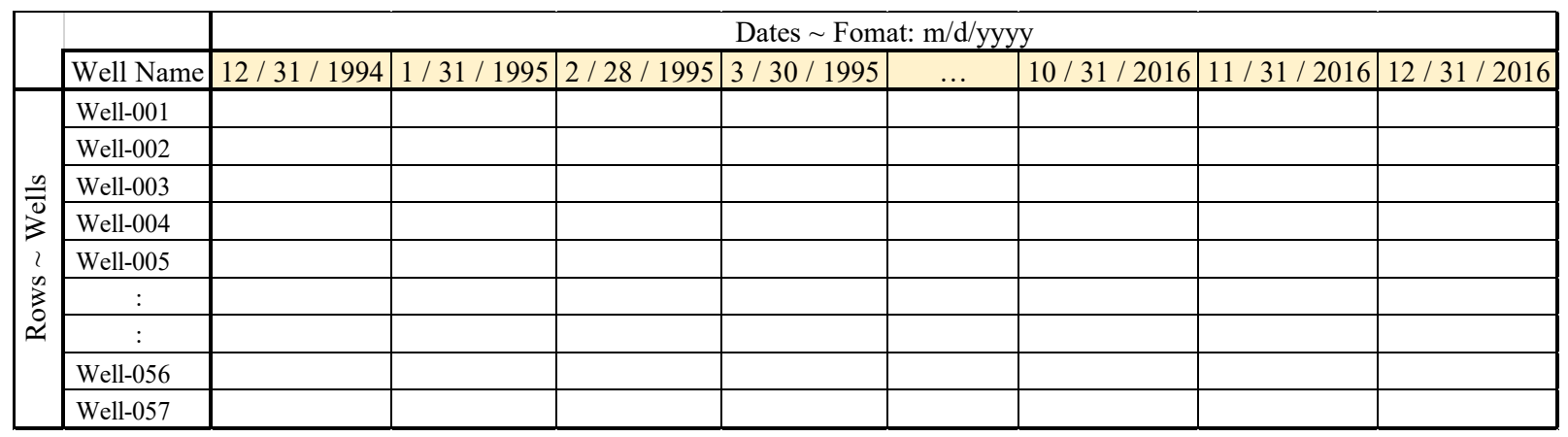

Figure 4-3: Dynamic Dataset Format 


\subsubsection{Data Collection}

The data collected from the numerical simulation results output file contained static, dynamic and production rate data as previously mentioned in section 3.3.

\subsubsection{Static Data}

Static properties were exported as text files, cleansed and transformed into the required table format by means of Python coding (See Figure 4-2). As the simulation data was exported per layer, it was necessary to average the reservoir properties with respect to the open layers in order to determine one value per well. A single value was provided for each well to meet the formatting requirements on a well basis rather than a layer basis. This was accomplished by using the weight average method with respect to grid thickness (See Eq. 4-3). Furthermore, the top and TVD values from each well were selected according to the upper most open layer and the lower most open layer. In a similar fashion, completion footage was calculated with respect to the grid thickness of completed layers.

Figure 4-4 illustrates the static file imported in the final spatio-temporal database.

\begin{tabular}{|c|c|c|c|c|c|c|c|c|c|c|c|c|}
\hline Well Name & Well Type & $\mathbf{X}$ & $\mathbf{Y}$ & Top (ft) & TVD (ft) & Swi (\%) & Thickness (ft) & Permeability I (mD) & Permeability J (mD) & Permeability K (mD) & Porosity (\%) & Completion (ft) \\
\hline \begin{tabular}{|l|} 
Well-001 \\
\end{tabular} & $\mathrm{P}$ & $20,829.25$ & $10,610.60$ & $4,004.90$ & $4,211.24$ & 18.0 & 206.34 & 36.43 & 36.43 & - & 11.18 & 98.90 \\
\hline Well-002 & $\mathrm{P}$ & $13,812.50$ & $10,810.80$ & $4,349.40$ & $4,523.80$ & 18.0 & 278.49 & 97.16 & 97.16 & - & 9.99 & 174.41 \\
\hline Well-003 & $\mathrm{P}$ & $17,901.00$ & $14,414.40$ & $4,207.09$ & $4,463.09$ & 18.0 & 351.18 & 24.37 & 24.37 & - & 12.74 & 256.00 \\
\hline Well-004 & $\mathrm{P}$ & $13,425.75$ & $16,616.60$ & $4,359.73$ & $4,501.79$ & 18.0 & 270.32 & 8.59 & 8.59 & - & 6.45 & 142.06 \\
\hline Well-005 & $\mathrm{P}$ & $20,774.00$ & $17,567.55$ & $4,008.85$ & $4,168.94$ & 18.0 & 160.09 & 73.74 & 73.74 & - & 13.57 & 160.09 \\
\hline Well-006 & P & $12,486.50$ & $17,467.45$ & $4,414.25$ & $4,522.52$ & 18.0 & 203.63 & 22.14 & 22.14 & - & 7.11 & 108.28 \\
\hline Well-007 & P & $11,436.75$ & $12,412.40$ & $4,451.80$ & $4,668.08$ & 18.0 & 355.62 & 113.65 & 113.65 & - & 12.26 & 216.28 \\
\hline Well-008 & $\mathrm{P}$ & $12,155.00$ & $18,868.85$ & $4,446.39$ & $4,497.73$ & 18.0 & 74.79 & 201.27 & 201.27 & - & 12.36 & 51.34 \\
\hline Well-009 & $\mathrm{P}$ & $13,536.25$ & $18,418.40$ & $4,364.87$ & $4,483.22$ & 18.0 & 118.35 & 6.72 & 6.72 & - & 5.06 & 118.35 \\
\hline Well-010 & $\mathrm{P}$ & $21,050.25$ & $14,264.25$ & $3,983.99$ & $4,191.32$ & 18.0 & 207.33 & 18.42 & 18.42 & - & 9.83 & 160.33 \\
\hline : & & & & & & 0.0 & & & & & - & \\
\hline : & & & & & & 0.0 & & & & & - & \\
\hline Injector-001 & I & $10,221.25$ & $17,517.50$ & $4,498.05$ & $4,687.33$ & 18.0 & 189.28 & 524.22 & 524.22 & - & 15.33 & - \\
\hline Injector-002 & I & $9,945.00$ & $12,462.45$ & $4,512.25$ & $4,866.24$ & 18.0 & 353.99 & 259.46 & 259.46 & - & 12.61 & - \\
\hline Injector-003 & I & $10,497.50$ & $19,619.60$ & $4,516.81$ & $4,556.03$ & 18.0 & 39.23 & 7.77 & 7.77 & - & 4.72 & - \\
\hline Injector-004 & I & $20,221.50$ & $9,459.45$ & $4,020.33$ & $4,286.60$ & 18.0 & 266.27 & 38.61 & 38.61 & - & 12.60 & - \\
\hline Injector-005 & I & $22,652.50$ & $18,568.55$ & $3,963.58$ & $4,128.50$ & 18.0 & 164.92 & 5.46 & 5.46 & - & 7.28 & - \\
\hline Injector-006 & II & $14,365.00$ & $20,820.80$ & $4,297.07$ & $4,380.93$ & 18.0 & 83.86 & 55.67 & 55.67 & - & 6.95 & - \\
\hline Injector-007 & I & $13,923.00$ & $9,309.30$ & $4,322.86$ & $4,615.16$ & 18.0 & 292.29 & 12.05 & 12.05 & - & 8.36 & - \\
\hline Injector-008 & I & $23,205.00$ & $14,864.85$ & $3,846.95$ & $4,021.04$ & 18.0 & 174.09 & 25.10 & 25.10 & - & 10.23 & - \\
\hline Injector-009 & I & $17,459.00$ & $9,759.75$ & $4,141.38$ & $4,490.02$ & 18.0 & 348.64 & 40.67 & 40.67 & - & 14.07 & - \\
\hline Injector-010 & I & $18,177.25$ & $20,570.55$ & $4,103.18$ & $4,253.32$ & 18.0 & 150.15 & 3.13 & 3.13 & - & 4.36 & - \\
\hline : & & & & & & & & & & & & \\
\hline : & & & & & & & & & & & & \\
\hline
\end{tabular}

Figure 4-4: Formatted Static Data

A visual representation of the static data and the retrieving process is shown in Figure 2-1. 


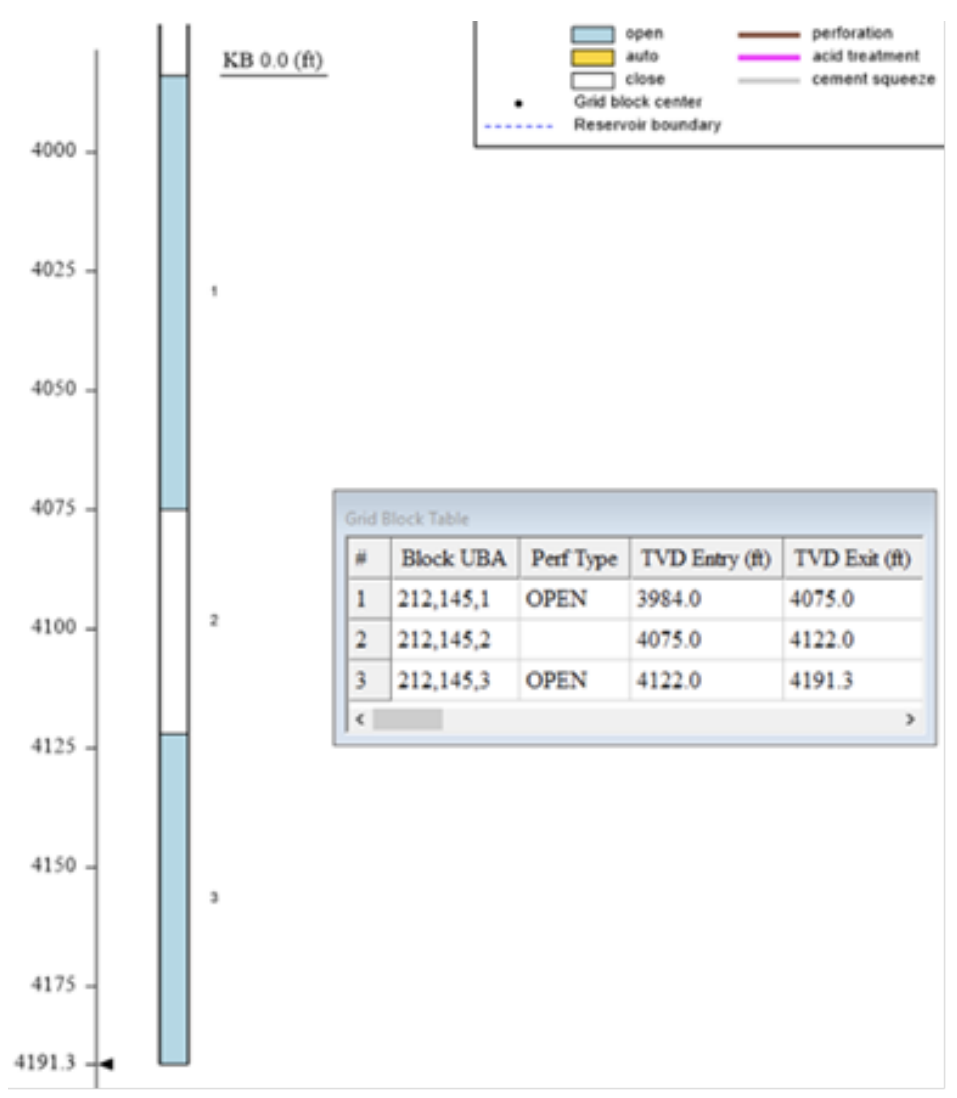

Figure 4-5: Wellbore Diagram

The Grid Block Table presented in Figure 4-5 contains information illustrated in the diagram to the left of the table. The "Block UBA" column provides information regarding well location (X, Y, Z Coordinates). The second column "Perf Type" provides completion information. If a layer is completed it is denoted as "OPEN" and is colored in light blue in the well trajectory diagram shown in Figure 4-5. The top and bottom depths of each layer are provided in the "TVD Entry (ft)" and "TVD Exit (ft)" columns respectively. The thickness of each layer is calculated by taking the difference between the top and bottom depths of any layer.

A diagram for each well is provided with well location and trajectory, well type, top and bottom of the formation, top and bottom of each layer, completion, grid thickness and more. Porosity, permeability, initial water saturation and other property values were available in a text file format at each grid block. 


\subsubsection{Dynamic Data}

After examining all the potential information available for the development of a data-driven model, it was concluded that the most meaningful data was found in the layered and the special history report formats presented in Figure 3-28. The main reason for retrieving data on a layer basis was the nature of the partial completion plan implemented in the numerical reservoir simulation.

Both layered and special history formats are described below:

1. Special History: contains data for all the simulation time steps (January $1^{\text {st }}, 1995$ - January $\left.1^{\text {st }}, 2017\right)$.

- Oil Saturation (fraction)

- Water Saturation (fraction)

- Reservoir pressure (psi)

2. Layer Based: contains data only for time steps a well produces. The life of a well is determined by a minimum production constraint and a maximum water cut percentage.

- Oil production rate (bbl/month)

- Gas production rate $\left(f t^{3} /\right.$ month $)$

- Water production rate (bbl/month)

- Well block pressure (psi) - Reservoir pressure (psi)

- Well pressure (psi) - Flowing bottom-hole pressure (psi)

Figure 4-6 illustrates the format structure of the exported data while Figure 4-3 shows the required table format for the generation of a well-constructed spatio-temporal database. 


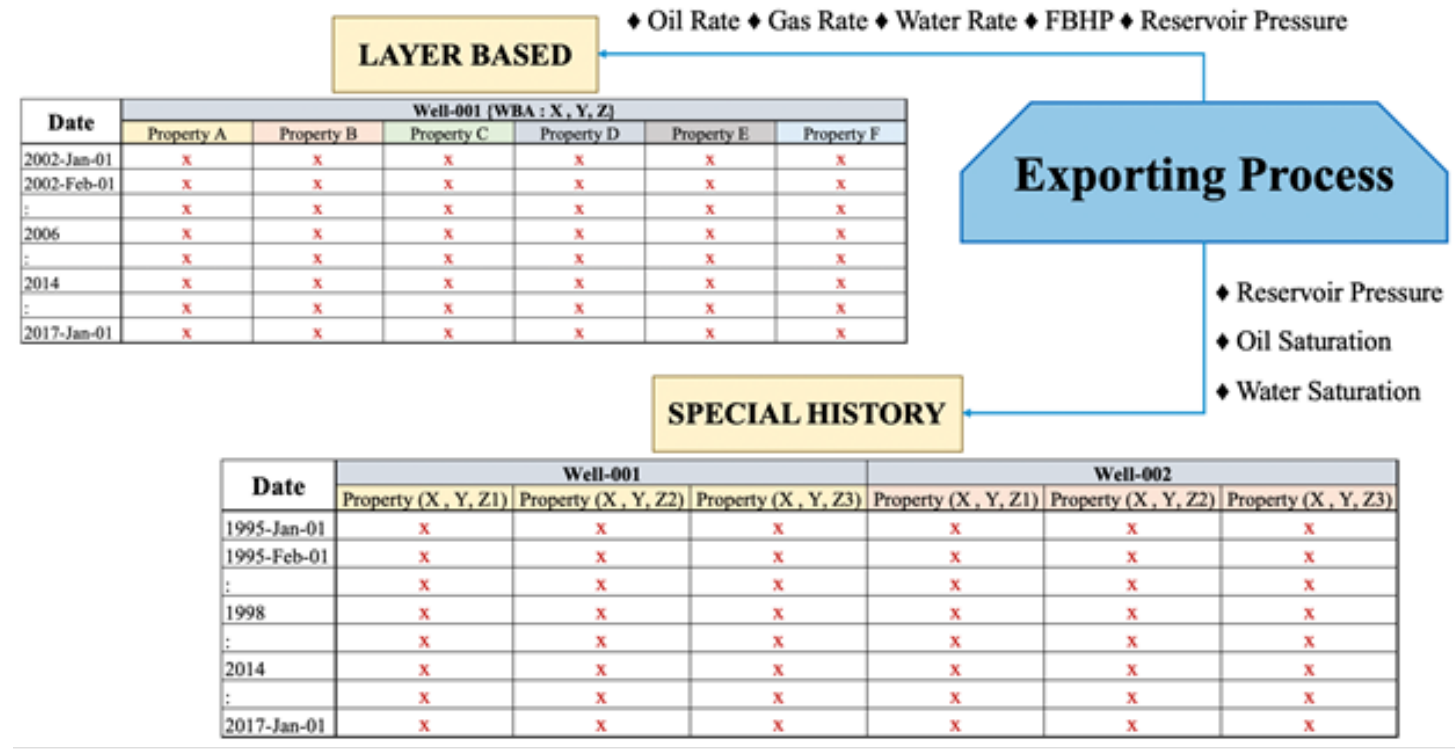

Figure 4-6: Primary Data Exporting Formats

Moreover, static properties such as porosity and permeability changed as a function of time and were therefore formatted and included into the dynamic dataset.

\subsubsection{Data Cleansing}

Erroneous or incomplete data impacts the learning process during the development of predictive models.

After inspecting the layer based and special history data exported, misleading values, such as negative or exponentially small numbers, were encountered in oil, gas, and water production datasets at random timesteps. Such values were replaced with zeros if the well continued to produce and if the layer was completed.

A secondary cleaning procedure was based on oil production. When oil production was zero, it was important to communicate to the neural network that there was no gas and/or water production. Therefore, at timesteps were oil production was zero, gas and water production were set to zero accordingly.

Due to the fact that the data was exported on a layer basis, it was necessary to bring the data back to a well basis as this was the required format for the recreation of the spatio-temporal database 
earlier described in section 4.1.1. Simple average of completed and productive layers was not an accurate approach to communicate the contribution of fluid flow through porous media to the neural network. For reservoir properties a weighted average method was determined by permeability and thickness. Flowing bottom-hole pressure was weight averaged on thickness.

The impact of using a weight average against a simple average is explained in Figure 4-7.

\section{Simple average:}

$$
\begin{gathered}
P_{r}=\frac{P_{r 1}+P_{r 2}+P_{r 3}}{3} \\
P_{r}=\frac{3,560+1,320+2,380}{3} \\
P_{r}=2,420 p s i
\end{gathered}
$$

Weighted Average:

$$
\begin{aligned}
& P_{r}=\frac{P_{r 1} *\left(h_{1} * k_{1}\right)+P_{r 2} *\left(h_{2} * k_{2}\right)+P_{r 3} *\left(h_{3} * k_{3}\right)}{\left(h_{1} * k_{1}+h_{2} * k_{2}+h_{3} * k_{3}\right)} \\
& P_{r}=\frac{3,560 *(58 * 14)+1,320 *(8 * 2)+2,380 *(28 * 7)}{(58 * 14+8 * 2+28 * 7)} \quad P_{r 1}=1,320 p s i \\
& P_{r}=\frac{3,378,320}{1,024}
\end{aligned}
$$

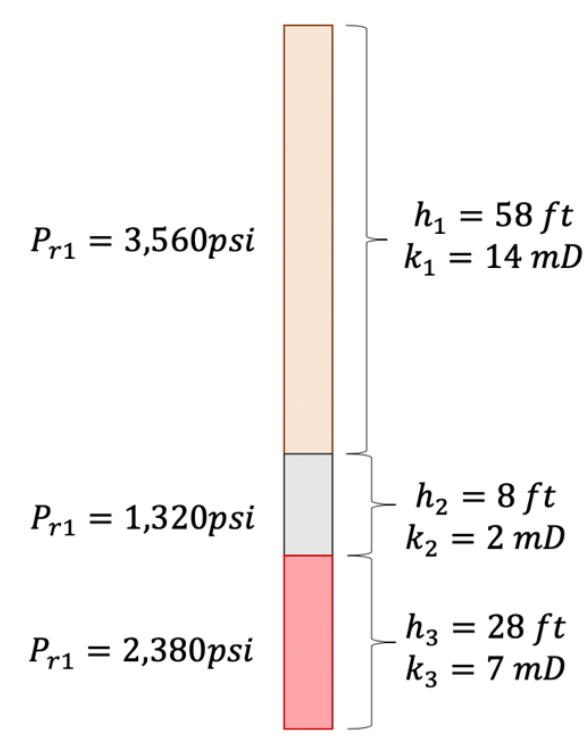

$$
\begin{aligned}
& P_{r}=3,299.14 p s i
\end{aligned}
$$

Figure 4-7: Simple Average Methods vs Weight Average Method Example

In summary:

- Well production was the summation of the production from all layers.

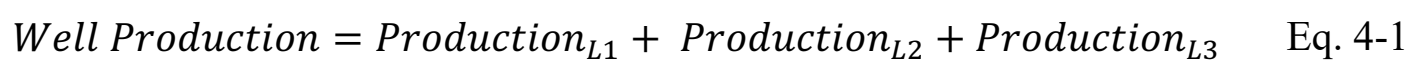

- Reservoir properties, including porosity, permeability, and reservoir pressure, were weight averaged based on $\mathrm{KH}$ (permeability and thickness) 
$\left(\right.$ Property $_{A v g}=\frac{\operatorname{Prop}_{L 1} *\left(K_{L 1} * H_{L 1}\right)+\operatorname{Prop}_{L 2} *\left(K_{L 2} * H_{L 2}\right)+\operatorname{Prop}_{L 3} *\left(K_{L 3} * H_{L 3}\right)}{\left(\left(K_{L 1} * H_{L 1}\right)+\left(K_{L 2} * H_{L 2}\right)+\left(K_{L 3} * H_{L 3}\right)\right)}$

Eq. $4-2$

- Surface properties, including flowing bottom-hole pressure, were weight averaged based on $\mathrm{H}$ (thickness).

$$
\text { (Property }_{A v g}=\frac{\operatorname{Prop}_{L 1} *\left(H_{L 1}\right)+\operatorname{Prop}_{L 2} *\left(H_{L 2}\right)+\operatorname{Prop}_{L 3} *\left(H_{L 3}\right)}{\left(\left(H_{L 1}\right)+\left(H_{L 2}\right)+\left(H_{L 3}\right)\right)}
$$

\subsection{Data Import}

Importing well-based and production rate data was the first step in the recreation of a final spatiotemporal database to be used in the development of predictive data-driven models.

The arrangement of the final database imported into IMagine with all static, dynamic and production rate data is depicted in Figure 4-8. 


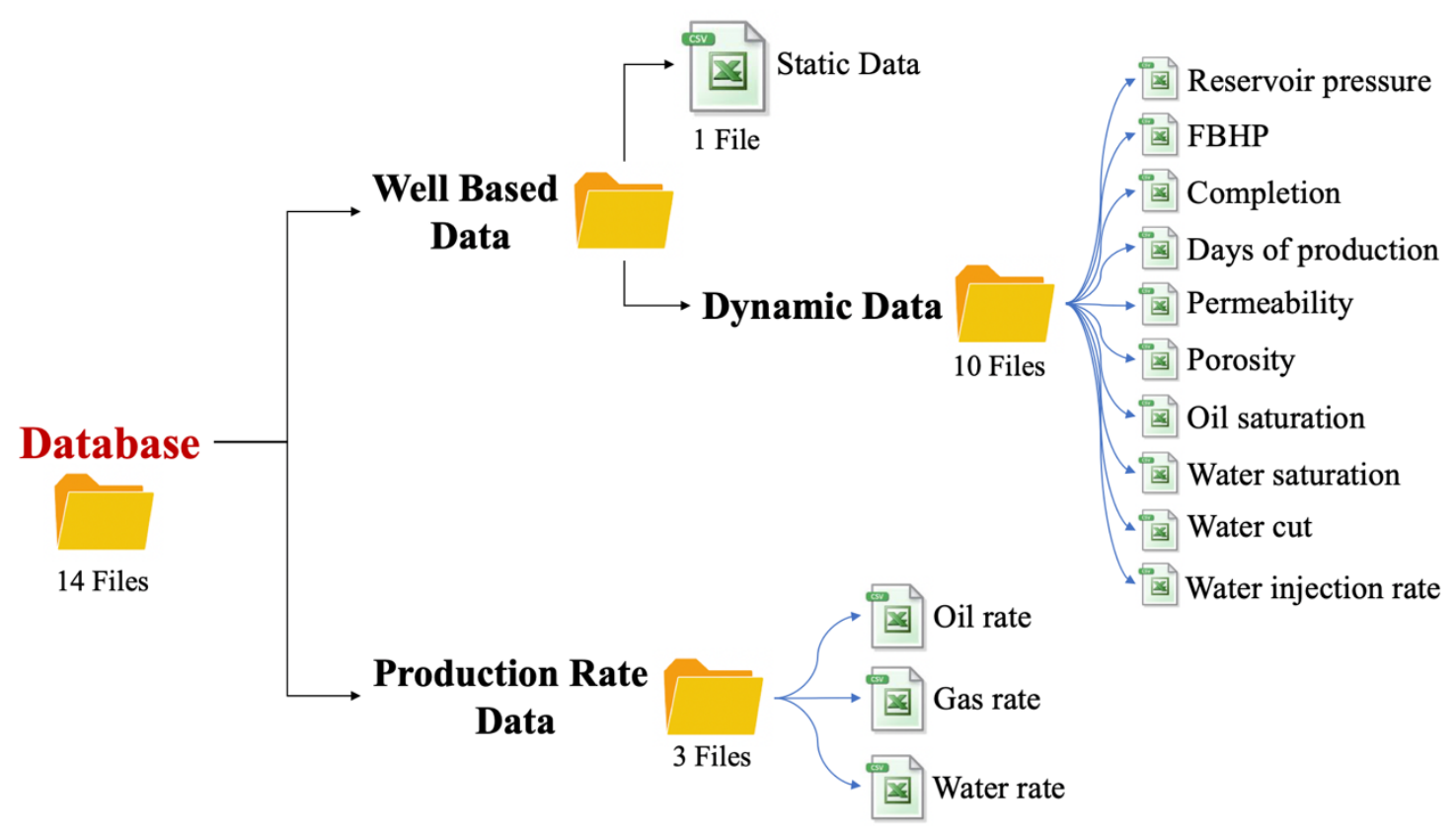

Figure 4-8: Spatio-temporal Database

The total number of static, dynamic, and production attributes was 12, 10 and 3 respectively. Dynamic and production data was provided on a monthly basis encompassing a total of 265 months starting in January $1^{\text {st }}$ of 1995 and ending in January $1^{\text {st }}$ of 2017.

\subsection{Static Modeling}

Static modeling focuses on efficiently performing pre-modeling analysis with efforts to map and define the reservoir. This is accomplished by defining the grid and boundary of the reservoir, performing spatial interpolation to assign reservoir property values to the entire grid system, and by performing volumetric and geostatistic calculations.

\subsubsection{Grid and Boundary}

The grid area was set as 5 acres. The boundary of the reservoir was drawn as closely as possible to the boundary of the numerical reservoir model (See Figure 4-9). 


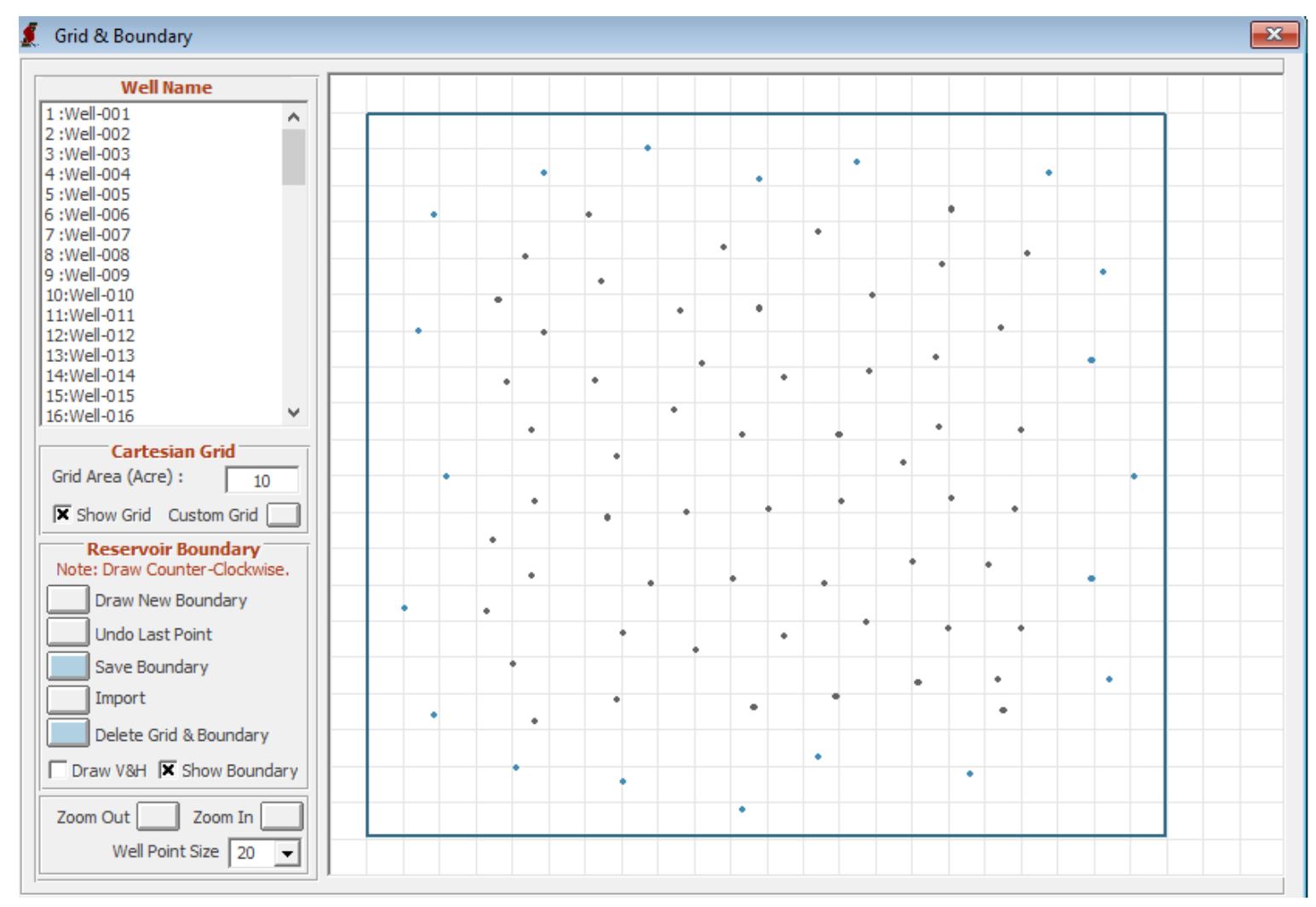

Figure 4-9: Grid and Boundary

\subsubsection{Geostatistics}

In this module, reservoir properties at each grid block were populated based on the values provided at each well location. Inverse distance weighting method was the preferred interpolation technique used to generate distribution maps for both static and dynamic properties imported into the software. 


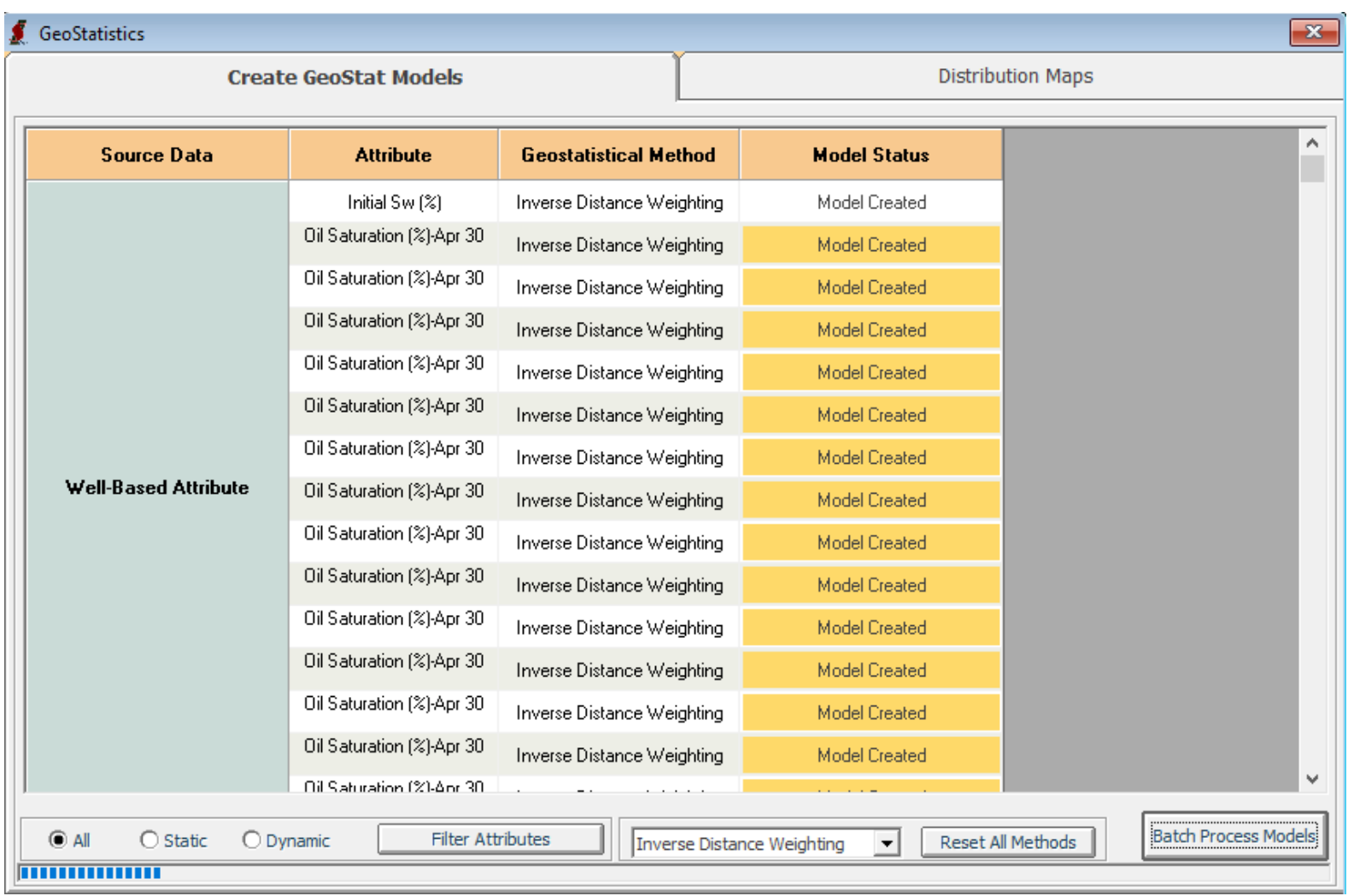

Figure 4-10: Static and Dynamic Spatial-Interpolation Using Inverse Distance Weighting Method

\subsubsection{Reservoir Delineation}

In this module, effective drainage was determined for each well in the reservoir. 


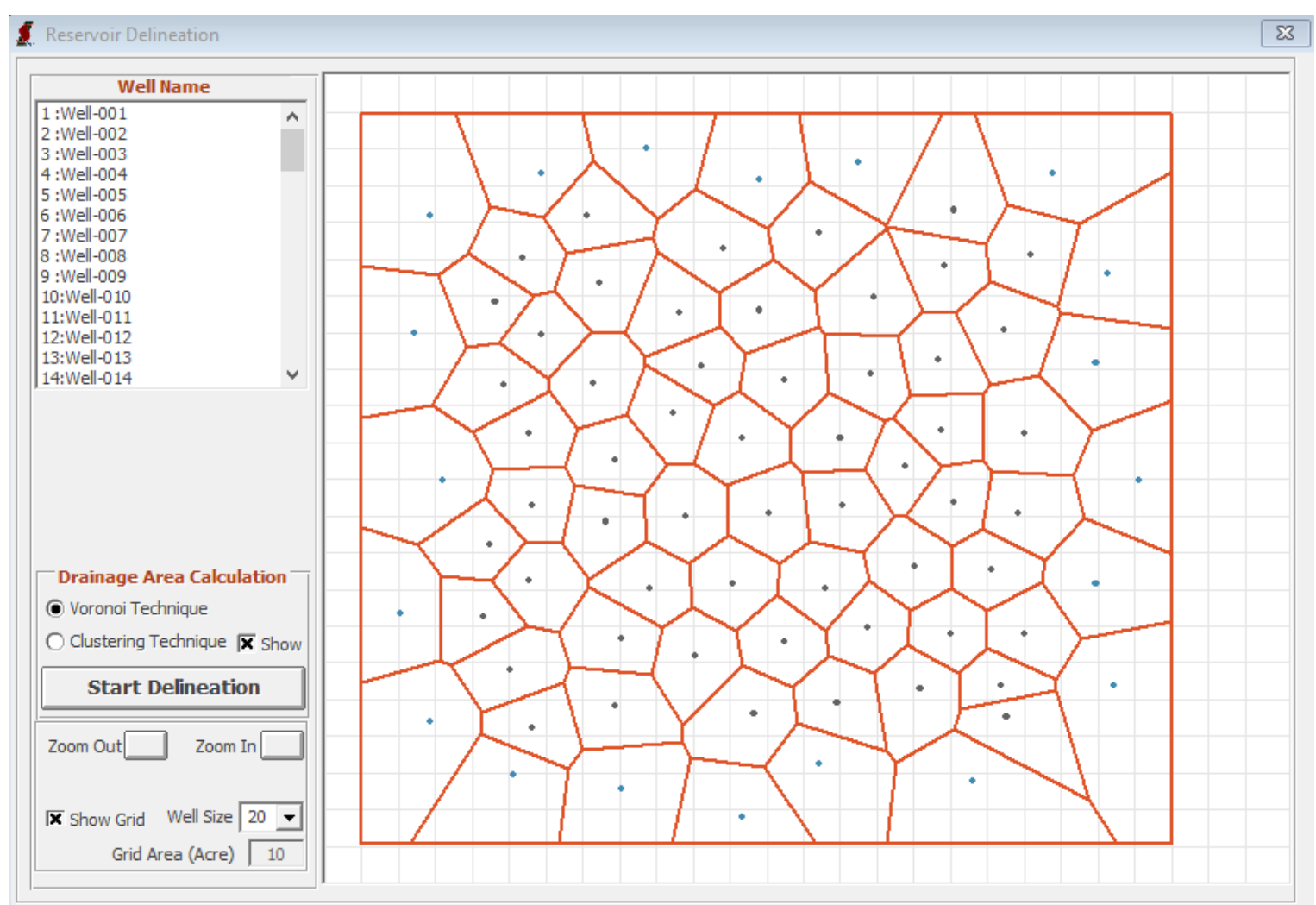

Figure 4-11: Reservoir Delineation using Voronoi Technique

\subsubsection{Volumetric}

Volumetric and geostatistic calculations were performed using reservoir property values previously determined in section 4.3.2. These calculations are necessary to fill information that was not previously imported, such as initial oil in place, initial gas in place, temperature, saturations, etc. 


\subsection{Top-Down Modeling}

Top-down models are often composed of one or more interconnected predictive models that are history matched and deployed under different operational conditions.

Two datasets are often used in top-down reservoir modeling:

1. Development dataset

2. Deployment dataset

The development dataset partially or entirely uses available data to train, calibrate and validate the model through the application of artificial neural networks. The "development" is also referred to as history match. Once the TDM model is validated in time, it can be used for forecasting purposes. This is also referred to as the deployment dataset which includes time ranges beyond the development dataset [17]. Figure 4-12 illustrates an example of development and deployment time ranges.

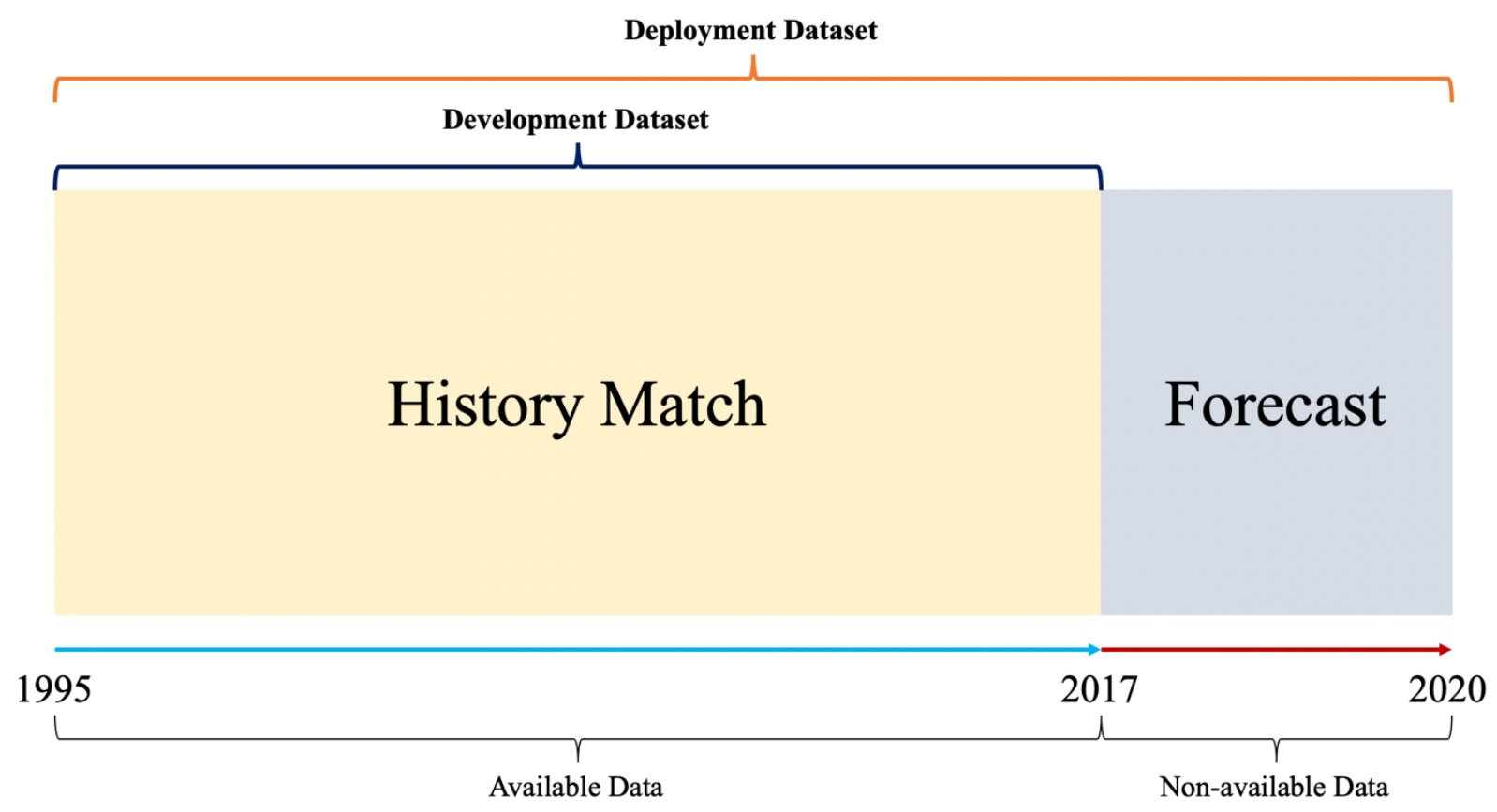

Figure 4-12: Top-Down Modeling - History Match and Forecast

Due to the lack of data beyond January $1^{\text {st }}$ of 2017 , validation of the TDM's forecast was not possible. However, forecasting was performed on data ranges where TDM predictions could be compared against the numerical simulation data. 


\subsubsection{Build and History Match}

A total of five different TDM models were built with efforts to history match oil, gas, and water production, reservoir pressure and water saturation distributions. Only two TDM models were further deployed on a blind dataset to evaluate their forecast performance.

Each TDM model was characterized by the partitioning type implemented, the input attributes used in the neural network development, and the number of records used in the training, calibration, and validation datasets.

The first TDM implemented a random partitioning approach. Due to the nature of the partitioning method used, the model had the lowest degree of confidence. The second TDM was built using a mixed partitioning method in which the last year (January $1^{\text {st }}, 2016$ - January $1^{\text {st }}, 2017$ ) of the development dataset was used as a blind history match. The third TDM resembled the partitioning type from the second scenario. However, the last 2 years (January $1^{\text {st }}, 2015$ - January $1^{\text {st }}, 2017$ ) of the development dataset were used as a blind history match. The fourth TDM performed 1 year of blind history-matching (January $1^{\text {st }}, 2015$ - December $31^{\text {st }}, 2015$ ) and 1 year of forecasting (January $1^{\text {st }}, 2016$ - January $\left.1^{\text {st }}, 2017\right)$. The fifth TDM performed 1 year of blind history matching (January $1^{\text {st }}, 2014$ - December $31^{\text {st }}, 2014$ ) and 2 years of forecasting (January $1^{\text {st }}, 2015$ - January $\left.1^{\text {st }}, 2017\right)$.

Table 4-1 briefly summarizes each of the scenarios to be discussed in more detail. "MP" and "RP" are abbreviations for "Mixed Partitioning" and "Random Partitioning" respectively. "1V", "2V" are short for "1-year validation" and "2-year validation" while " $1 F$ " and " $2 F$ " refer to "1-year forecast" and "2-year forecast" respectively.

Table 4-1: History Match and Forecast Scenarios - Description

\begin{tabular}{|c|c|c|c|c|c|c|}
\hline Scenario & Name & Partitioning & Training & Calibration & Validation & Forecast \\
\hline 1 & RP TDM & Random & $80 \%$ & $10 \%$ & $10 \%$ & - \\
\hline 2 & MP TDM 1V & Mixed & $80 \%$ & $20 \%$ & 1 Year & - \\
\hline 3 & MP TDM 2V & Mixed & $80 \%$ & $20 \%$ & 2 Years & - \\
\hline 4 & MP TDM 1V 1F & Mixed & $80 \%$ & $20 \%$ & 1 year & 1 Year \\
\hline 5 & MP TDM 1V 2F & Mixed & $80 \%$ & $20 \%$ & 1 year & 2 Years \\
\hline
\end{tabular}

Each TDM model built will be described into detail in the following sections. 


\subsubsection{Scenario 1 - Random Partitioning TDM}

The first scenario was conducted to test the most basic partitioning approach while sacrificing the robustness and degree of confidence of the model.

\section{Data-Driven Dataset Generation:}

The TDM model incorporated five interconnected data-driven models previously discussed and illustrated in Figure 4-1. The development and deployment datasets consisted of the same time ranges, from January $1^{\text {st }}$ of 1995 until January $1^{\text {st }}$ of 2017, suggesting that no forecasting was performed.

\begin{tabular}{|llllllllll|}
\multicolumn{10}{c|}{$\begin{array}{c}\text { Development Dataset } \\
\text { Training, Calibration and Validation Datasets }\end{array}$} \\
\hline 1995 & 2009 & 2010 & 2011 & 2012 & 2013 & 2014 & 2015 & 2016 & 2017 \\
\hline
\end{tabular}

Figure 4-13: Scenario 1 - Development Dataset

Data-driven datasets for each predictive model were generated by including candidate attributes from the focal well, 2 offset producers, and 2 offset injectors (neighboring information was included to account for the influence of production and water injection with respect to the focal well).

Attribute selection for both focal and offset wells was performed at different timesteps where the current and previous timestep were denoted as " $\mathrm{t}$ " and " $\mathrm{t}-1$ " respectively. The model output was to be predicted at time " $\mathrm{t}$ " based on previous information at timesteps of "t-1". However, a set of operational conditions determines the outcome of the model output. Therefore, operational conditions such as completion, flowing bottom-hole pressure, and water injection were provided at the current timestep of " $t$ ".

Once the development and deployment datasets were established and all candidate attributes were selected at their respective timesteps, oil, gas, water, reservoir pressure and water saturation datadriven datasets were compiled, cleansed based on zero oil production at the timestep of " $t$ " and sorted in chronological order.

\section{Data-Driven Model Development:}


Data-driven modeling uses artificial neural networks to build well-trained predictive models capable of learning from data and predicting possible outcomes.

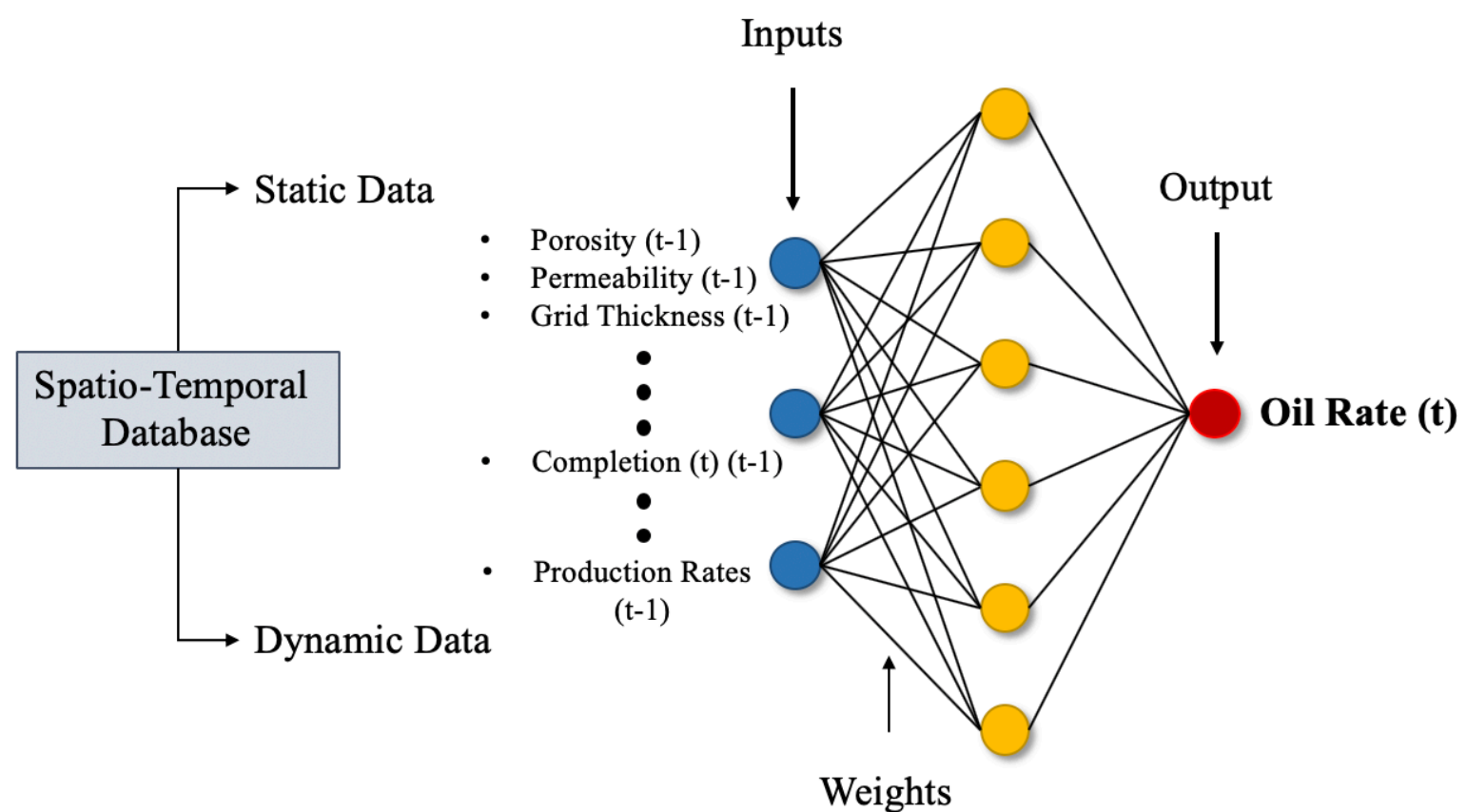

Figure 4-14: Neural Network Data Preparation - Oil Model

Each data-driven dataset was further compiled into a spatio-temporal database by reducing the number of attributes to be used in the neural network development (KPI analysis was used as a guiding tool to identify the most influential attributes on the output attributes (APPENDIX B: Key Performance Indicators). Figure 4-14 illustrates an example input attributes used to predict an output value.

Figure 4-15 shows the input attributes included in the neural network development of each datadriven model. 
Scenario 1 - TDM Input Attributes 


\section{Oil Rate}

\begin{tabular}{|c|c|c|c|c|c|}
\hline \multicolumn{3}{|c|}{ FOCAL WELL } & \multicolumn{3}{|c|}{ OFFSET WELLS } \\
\hline \multicolumn{3}{|c|}{ Static Attributes } & \multicolumn{3}{|c|}{ Static Attributes } \\
\hline Rank & \begin{tabular}{|l|} 
Attribute \\
\end{tabular} & DOI & Rank & Attribute & DOI \\
\hline & Porh(1-sw) & 100 & & Porh(1-sw)(1I) & 91 \\
\hline & Porosity (\%) & 90 & & Top (ft)(1I) & 90 \\
\hline & TVD $(\mathrm{ft})$ & 52 & & TVD $(\mathrm{ft})(1 \mathrm{I})$ & 73 \\
\hline & Pay Thickness (ft) & 23 & 67 & Top (ft)(2P) & 65 \\
\hline \multicolumn{3}{|c|}{4} & 97 & TVD (ft)(1P) & 55 \\
\hline & & & & $\mathrm{X} /$ Longitude $(1 \mathrm{P})$ & 52 \\
\hline \multicolumn{3}{|c|}{ Dynamic Attributes } & $111 \mathrm{I}$ & Pay thickness (ft)(1P) & 50 \\
\hline & Oil Rate (t-1) & 100 & \multicolumn{3}{|c|}{7} \\
\hline & Gas Rate $(\mathrm{t}-1)$ & 100 & & & \\
\hline & Permeability I(t-1) & 49 & \multicolumn{3}{|c|}{ Dynamic Attributes } \\
\hline & Time & 48 & & FBH Pressure $(p s i)(t)(1 \mathrm{I})$ & 100 \\
\hline \multicolumn{3}{|c|}{4} & & Distance $(\mathrm{t}-1)(2 \mathrm{P})$ & 97 \\
\hline & & & $3 \mathrm{I}$ & FBH Pressure $(\mathrm{psi})(\mathrm{t}-1)(1 \mathrm{I})$ & 96 \\
\hline \multicolumn{2}{|c|}{ TOTAL ATTRIBUTES } & \multirow[t]{2}{*}{25} & $4 \mathrm{I}$ & Reservoir Pressure (psi)(t-1)(1I) & 96 \\
\hline & & & & Distance $(\mathrm{t})(2 \mathrm{P})$ & 96 \\
\hline & & & & FBH Pressure (psi)(t)(2I) & 93 \\
\hline & & & $7 \mathrm{H}$ & FBH Pressure $(\mathrm{psi})(\mathrm{t}-1)(2 \mathrm{I})$ & 92 \\
\hline & & & $8 \mathrm{1}$ & Reservoir Pressure $(\mathrm{psi})(\mathrm{t}-1)(2 \mathrm{I})$ & 92 \\
\hline & & & 99 & Water Saturation (\%)(t-1)(2I) & 87 \\
\hline & & & 10 & Oil Saturation $(\%)(\mathrm{t}-1)(2 \mathrm{I})$ & 87 \\
\hline & & & & 10 & \\
\hline
\end{tabular}

\section{Water Rate}

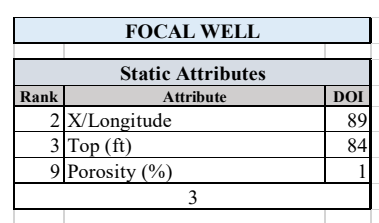

Dynamic Attributes

1 Water Rate (t-1)

2 Oil Saturation (\%)(t-1)

3 Water Saturation (\%)(t-1)

4 Permeability I(t-1)

15 Oil Rate $(\mathrm{t})$

16 Gas Rate (t)

6

TOTAL ATTRIBUTES

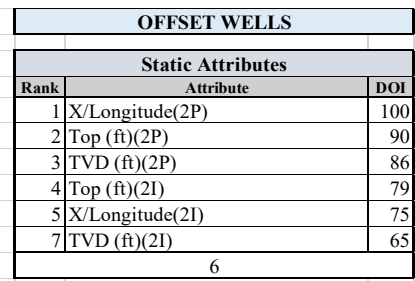

Dynamic Attributes

\begin{tabular}{|c|l|l|}
\hline 1 & Water Saturation (\%)(t-1)(1P) & 100 \\
\hline
\end{tabular} 2 Oil Saturation (\%)(t-1)(1P) 3 Distance(t)(1I)

12 Permeability I(t-1)(2P) 15 Permeability I $(\mathrm{t}-1)(2 \mathrm{I})$ 5

\section{Gas Rate}

\begin{tabular}{|c|c|c|c|c|c|}
\hline \multicolumn{3}{|c|}{ FOCAL WELL } & \multicolumn{3}{|c|}{ OFFSET WELLS } \\
\hline \multicolumn{3}{|c|}{ Static Attributes } & \multicolumn{3}{|c|}{ Static Attributes } \\
\hline Rank & Attribute & DOI & Rank & \begin{tabular}{|c|} 
Attribute \\
\end{tabular} & DOI \\
\hline & Porh(1-sw) & 100 & & Completion $(\mathrm{ft})(1 \mathrm{P})$ & 100 \\
\hline & Porosity (\%) & 90 & & Porh(1-sw)(1I) & 91 \\
\hline \multicolumn{3}{|c|}{2} & & Top (ft)(1I) & 90 \\
\hline & & & & $\mathrm{X} /$ Longitude $(1 \mathrm{I})$ & 84 \\
\hline \multicolumn{3}{|c|}{ Dynamic Attributes } & 5 & TVD $(\mathrm{ft})(1 \mathrm{I})$ & 73 \\
\hline \multicolumn{2}{|r|}{\begin{tabular}{l|l|}
1 & Oil Rate $(\mathrm{t})$ \\
\end{tabular}} & 100 & & Y/Latitude(1I) & 56 \\
\hline & Oil Rate (t-1) & 60 & \multicolumn{3}{|c|}{6} \\
\hline & Gas Rate $(\mathrm{t}-1)$ & 60 & & & \\
\hline & Permeability I(t-1) & 29 & \multicolumn{3}{|c|}{ Dynamic Attributes } \\
\hline \multicolumn{3}{|c|}{4} & & FBH Pressure (psi)(t)(1I) & 100 \\
\hline & & & & Distance $(\mathrm{t}-1)(2 \mathrm{P})$ & 97 \\
\hline \multicolumn{2}{|c|}{ TOTAL ATTRIBUTES } & 22 & & FBH Pressure $(\mathrm{psi})(\mathrm{t}-1)(1 \mathrm{I})$ & 96 \\
\hline & & & & Reservoir Pressure (psi)(t-1)(1I) & 96 \\
\hline & & & & Distance $(\mathrm{t})(2 \mathrm{P})$ & 96 \\
\hline & & & & FBH Pressure $(p s i)(t)(2 I)$ & 93 \\
\hline & & & & FBH Pressure $(\mathrm{psi})(\mathrm{t}-1)(2 \mathrm{I})$ & 92 \\
\hline & & & & Reservoir Pressure (psi)(t-1)(2I) & 92 \\
\hline & & & 9 & Water Saturation $(\%)(\mathrm{t}-1)(2 \mathrm{I})$ & 87 \\
\hline & & & 10 & Oil Saturation $(\%)(\mathrm{t}-1)(2 \mathrm{I})$ & 87 \\
\hline & & & & 10 & \\
\hline
\end{tabular}

\section{Reservoir Pressure}

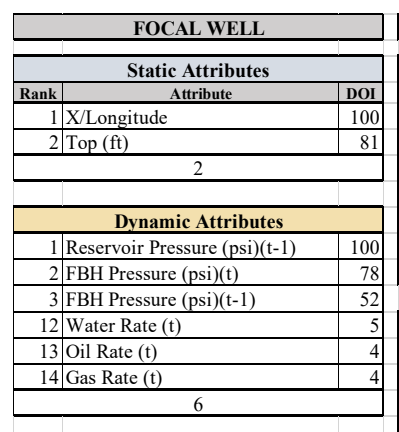

TOTAL ATTRIBUTES

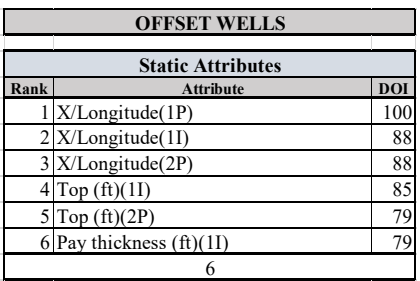

Dynamic Attributes

\begin{tabular}{|l|l|}
\hline Reservoir Pressure (psi)(t-1)(1P) & 100 \\
\hline
\end{tabular} 2 FBH Pressure $(\mathrm{psi})(\mathrm{t}-1)(1 \mathrm{P})$ 3 FBH Pressure (psi)(t)(1P)

Water Saturation

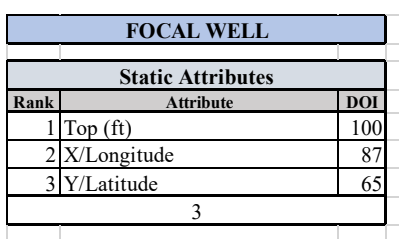

Dynamic Attributes

\begin{tabular}{|r|l|r|}
\hline \multicolumn{3}{|c|}{ Dynamic Attributes } \\
\hline 1 & Oil Saturation (\%)(t-1) & 100 \\
\hline 2 & Water Saturation (\%)(t-1) & 100 \\
\hline 4 Reservoir Pressure (psi)(t) & 23 \\
\hline 5 Water Rate (t) & 18 \\
\hline 10 & Oil Rate (t) & 8 \\
\hline 11 & Gas Rate (t) \\
\hline \multicolumn{2}{|c|}{6} \\
\hline \multicolumn{2}{|c|}{6} \\
\hline
\end{tabular}

TOTAL ATTRIBUTES

\begin{tabular}{|c|c|c|}
\hline \multicolumn{3}{|c|}{ OFFSET WELLS } \\
\hline \multicolumn{3}{|c|}{ Static Attributes } \\
\hline Rank & Attribute & DOI \\
\hline & $\mathrm{X} /$ Longitude $(2 \mathrm{P})$ & 100 \\
\hline & Top (ft)(2P) & 97 \\
\hline & Y/Latitude(1P) & 79 \\
\hline & $\mathrm{X} /$ Longitude $(1 \mathrm{P})$ & 74 \\
\hline & 4 & \\
\hline
\end{tabular}

Dynamic Attributes

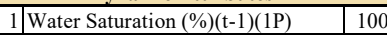
2 Oil Saturation (\%)(t-1)(1P) 100 2

Figure 4-15: Scenario 1 - TDM Input Attributes 
The finalized spatio-temporal database was partitioned into training, calibration, and validation datasets. The number of records pertaining to each partition dataset is represented in Figure 4-16.

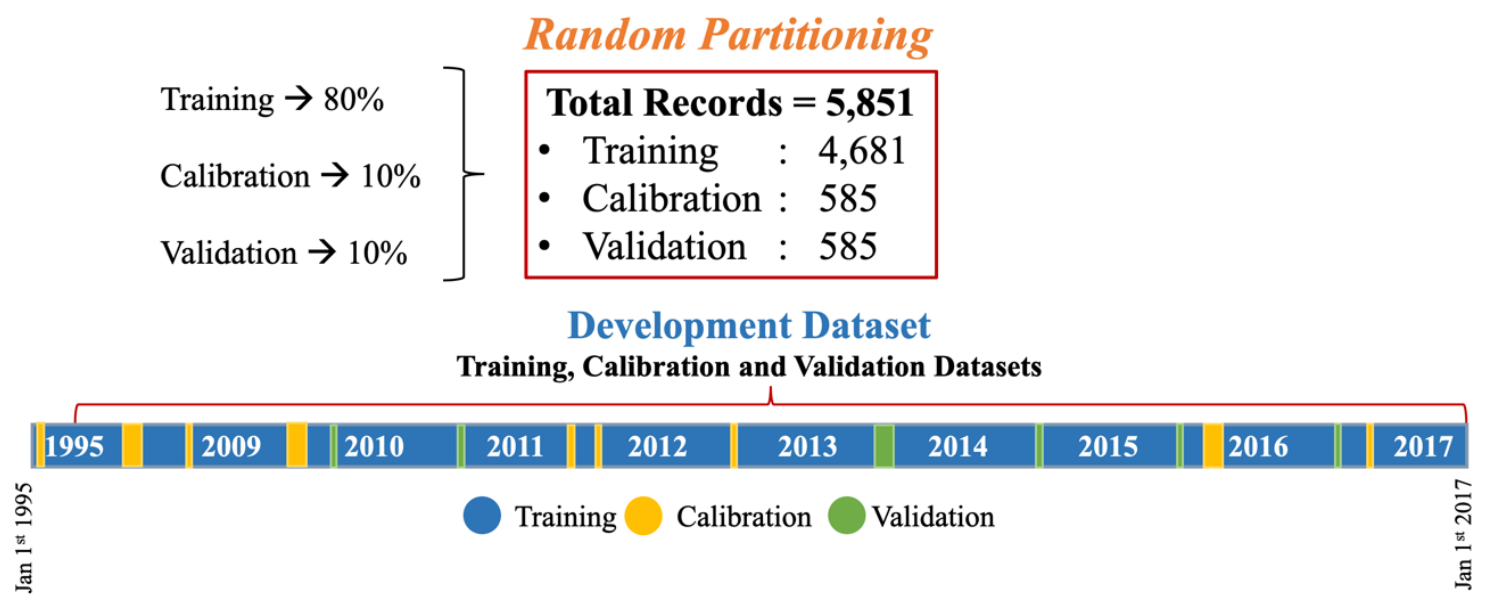

Figure 4-16: Scenario 1 - Neural Network Data Partitioning

The quality of the estimated results from each trained model is graphically and numerically presented in Figure 4-17. The linearity of the cross plots along with a high $R^{2}$ confirms the quality of the trained network. 


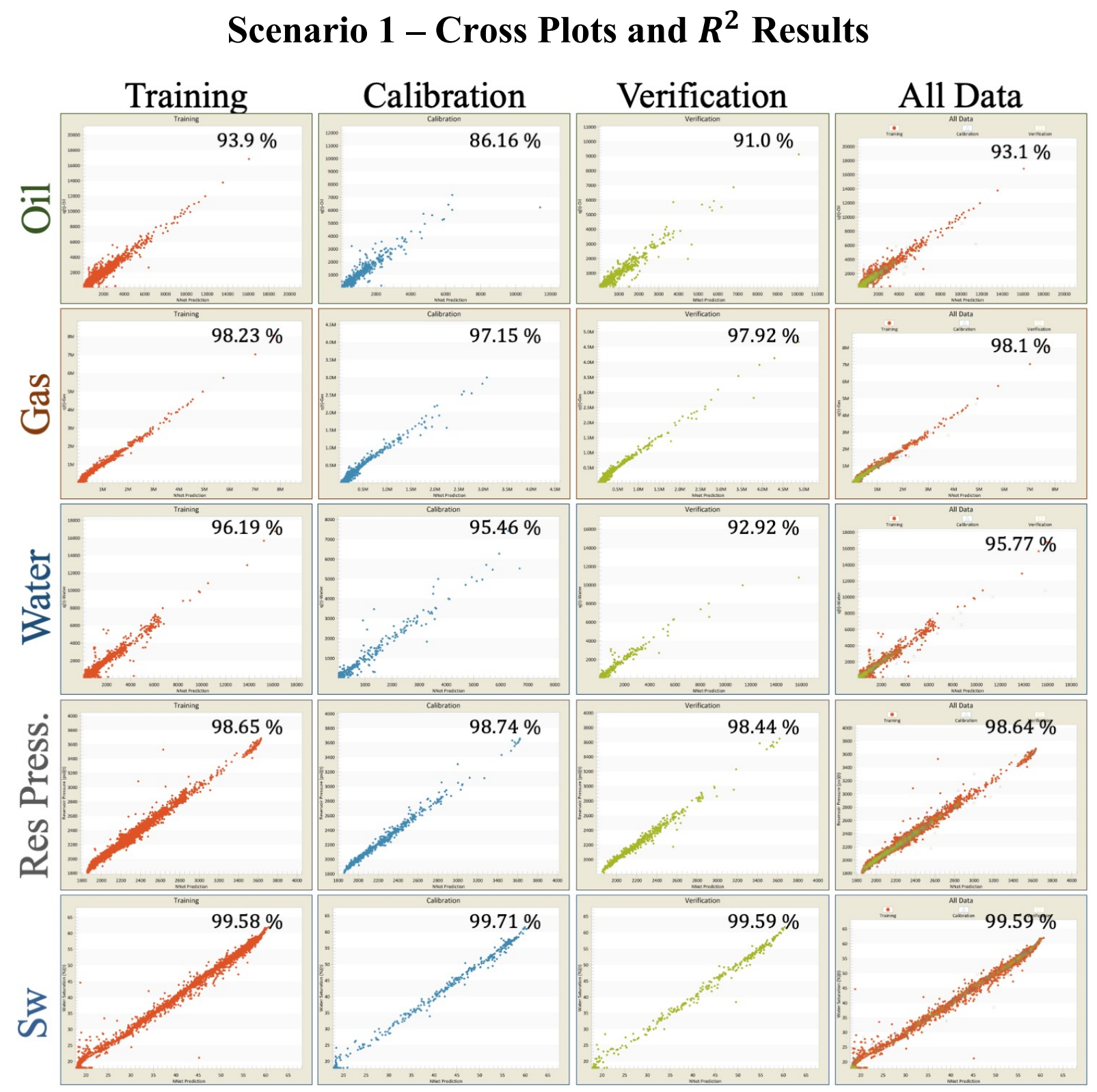

Figure 4-17: Scenario 1 - Partitioning Cross Plot Results 


\subsubsection{Scenario 2-Mixed Partitioning (1 Year Validation)}

Mixed partitioning was the method used in the development of the second TDM model. This suggests that once the model is validated, it has a higher degree of confidence associated with the top-down model forecast [17]. Nevertheless, the purpose of the model was solely to perform blind history-matching in time.

\section{Comprehensive Data-Driven Dataset Generation:}

The recreation of five predictive data-driven datasets included candidate attributes from the focal well and offset wells ( 2 offset producers and 2 offset injectors). The development dataset included time ranges from January $1^{\text {st }}$ of 1995 to January $1^{\text {st }}$ of 2017, suggesting forecast in time was not performed. Once attribute selection was performed and development and deployment time ranges were established, data-driven datasets were generated, cleansed based on oil at time " $\mathrm{t}$ " and sorted in a chronological order.

\begin{tabular}{|llllllllll|r|}
\multicolumn{1}{c|}{$\begin{array}{c}\text { Development Dataset } \\
\text { Training, Calibration and Validation Datasets }\end{array}$} \\
\hline 1995 & 2009 & 2010 & 2011 & 2012 & 2013 & 2014 & 2015 & 2016 & 2017 \\
\hline
\end{tabular}

Figure 4-18: Scenario 2 - Development Dataset

\section{Data-Driven Model Development:}

All the generated data-driven datasets were further compiled by selecting the most influential attributes from KPI analysis (Refer to APPENDIX B: Key Performance Indicators). A list of the final input attributes used in the neural network development is shown in Figure 4-19. 


\section{Scenario 2 - TDM Input Attributes}

\section{Oil Rate}

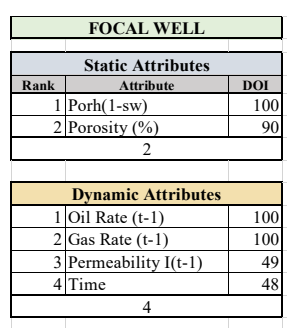

\begin{tabular}{|l|r|}
\hline & \\
\hline TOTAL ATTRIBUTES & 24 \\
\hline
\end{tabular}

\section{Water Rate}

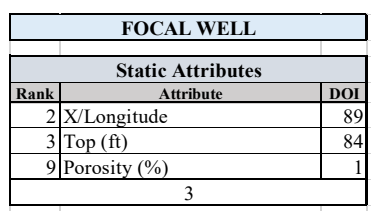

Dynamic Attributes 1 $\mathrm{q}(\mathrm{t}-1)$-Water

\begin{tabular}{l|l}
1 & $\mathrm{q}(\mathrm{t}-1)$-Water \\
\hline & Oil Saturation $(\%)(\mathrm{t}-1)$
\end{tabular}

3 Water Saturation (\%)(t-1)

4 Permeability I(t-1)

15 Oil Rate (t)

16 Gas Rate (t)

TOTAL ATTRIBUTES

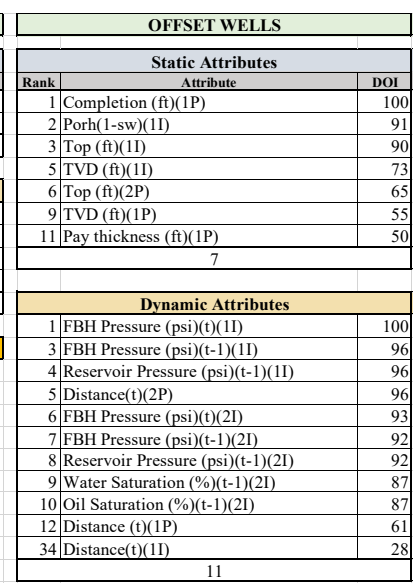

\begin{tabular}{|c|c|c|}
\hline \multicolumn{3}{|c|}{ OFFSET WELLS } \\
\hline \multicolumn{3}{|c|}{ Static Attributes } \\
\hline Rank & \begin{tabular}{|c|} 
Attribute \\
\end{tabular} & DOI \\
\hline & $\mathrm{X} /$ Longitude $(2 \mathrm{P})$ & 100 \\
\hline & Top $(\mathrm{ft})(2 \mathrm{P})$ & 90 \\
\hline & TVD (ft)(2P) & 86 \\
\hline & Top $(\mathrm{ft})(2 \mathrm{I})$ & 79 \\
\hline & $\mathrm{X} /$ Longitude(2I) & 75 \\
\hline & TVD $(\mathrm{ft})(2 \mathrm{I})$ & 65 \\
\hline \multicolumn{3}{|c|}{ 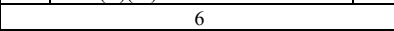 } \\
\hline \multicolumn{3}{|c|}{ Dynamic Attributes } \\
\hline & Water Saturation $(\%)(\mathrm{t}-1)(1 \mathrm{P})$ & 100 \\
\hline & Oil Saturation (\%)(t-1)(1P) & 100 \\
\hline & Distance $(\mathrm{t})(1 \mathrm{I})$ & 92 \\
\hline 12 & Permeability I(t-1)(2P) & 42 \\
\hline 15 & Permeability I(t-1)(2I) & 39 \\
\hline
\end{tabular}

\section{Gas Rate}

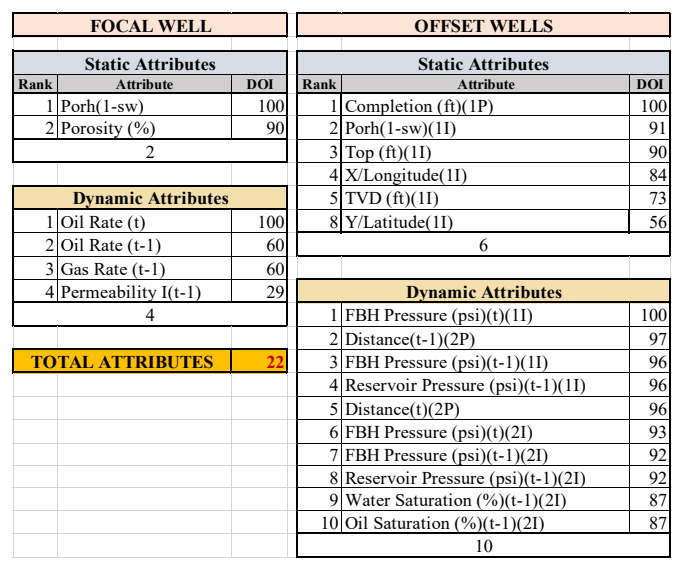

\section{Reservoir Pressure}

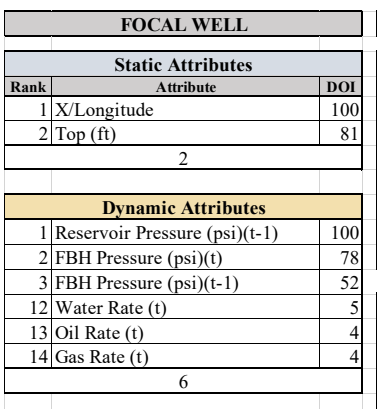

TOTAL ATTRIBUTES

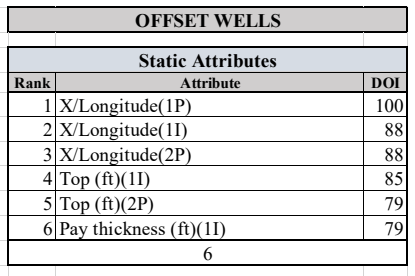

Dynamic Attributes

Reservoir Pressure (psi)(t-1)(1P)

2 FBH Pressure $(\mathrm{psi})(\mathrm{t}-1)(1 \mathrm{P})$

3 FBH Pressure $(\mathrm{psi})(\mathrm{t})(1 \mathrm{P})$

\section{Water Saturation}

\begin{tabular}{|c|c|c|}
\hline \multicolumn{3}{|c|}{ FOCAL WELL } \\
\hline \multicolumn{3}{|c|}{ Static Attributes } \\
\hline Rank & Attribute & DOI \\
\hline 1 & Top $(\mathrm{ft})$ & 100 \\
\hline & $\mathrm{X} /$ Longitude & 87 \\
\hline & Y/Latitude & 65 \\
\hline \multicolumn{3}{|c|}{ 1 } \\
\hline \multicolumn{3}{|c|}{ Dynamic Attributes } \\
\hline 1 & Oil Saturation $(\%)(\mathrm{t}-1)$ & 100 \\
\hline 2 & Water Saturation $(\%)(\mathrm{t}-1)$ & 100 \\
\hline 4 & Reservoir Pressure $(\mathrm{psi})(\mathrm{t})$ & 23 \\
\hline 5 & Water Rate $(\mathrm{t})$ & 18 \\
\hline 10 & Oil Rate $(\mathrm{t})$ & 8 \\
\hline 11 & Gas Rate $(\mathrm{t})$ & 8 \\
\hline \multicolumn{3}{|c|}{ 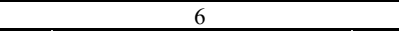 } \\
\hline
\end{tabular}

\begin{tabular}{|c|c|c|}
\hline \multicolumn{3}{|c|}{ OFFSET WELLS } \\
\hline \multicolumn{3}{|c|}{ Static Attributes } \\
\hline Rank & Attribute & DOI \\
\hline & $\mathrm{X} /$ Longitude $(2 \mathrm{P})$ & 100 \\
\hline 2 & Top $(\mathrm{ft})(2 \mathrm{P})$ & 97 \\
\hline 3 & Y/Latitude(1P) & 79 \\
\hline 4 & $\mathrm{X} /$ Longitude $(1 \mathrm{P})$ & 74 \\
\hline & 4 & \\
\hline
\end{tabular}

Dynamic Attributes

\begin{tabular}{l|l|l|}
1 & Water Saturation $(\%)(\mathrm{t}-1)(1 \mathrm{P})$ & 100 \\
\hline
\end{tabular}

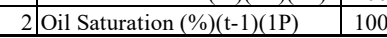
2

TOTAL ATTRIBUTES 
Figure 4-19: Scenario 1 - TDM Input Attributes

Each compiled dataset, also referred to as the spatio-temporal database, was partitioned into training, calibration and validation datasets. While the training and calibration datasets were completely randomized, the validation dataset comprised records pertaining to the last year of the dataset (January $1^{\text {st }}, 2016$ - January $1^{\text {st }}, 2017$ ). The number of records pertaining to each partition dataset is represented in Figure 4-20.

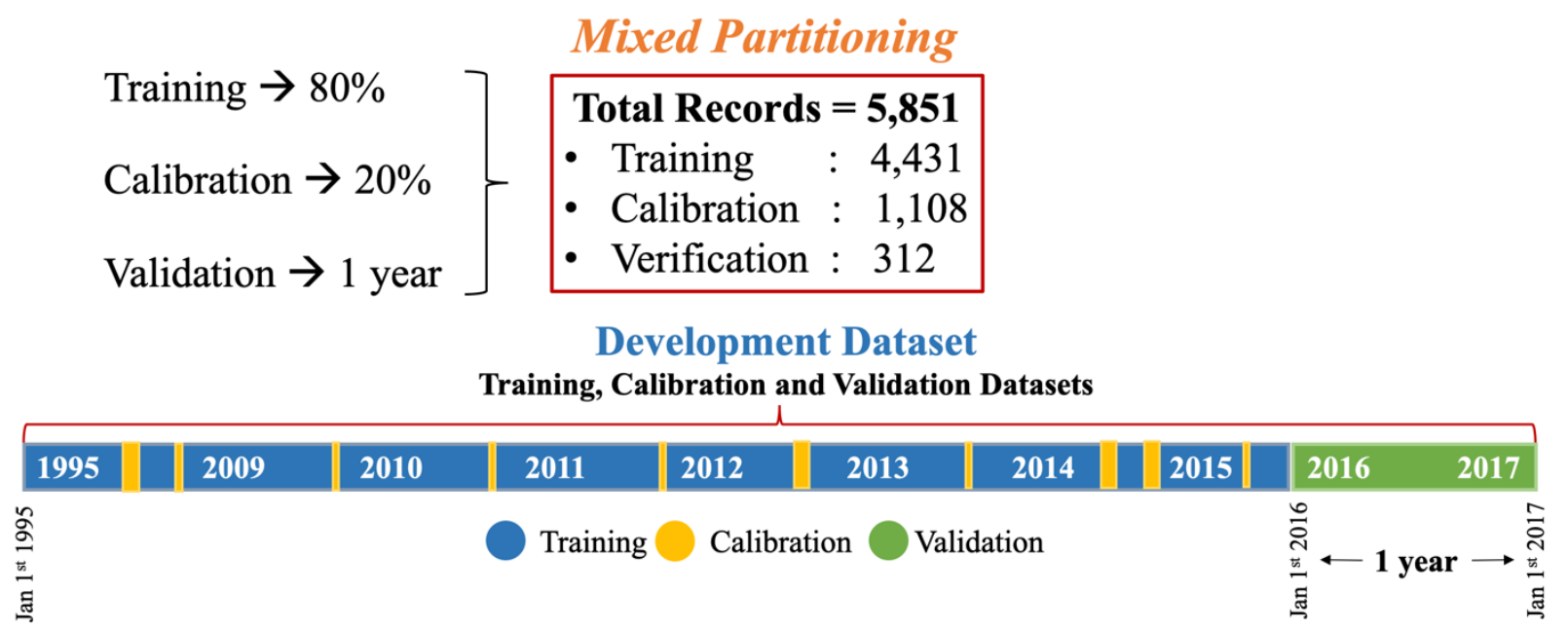

Figure 4-20: Scenario 2 - Neural Network Data Partitioning

Estimated results from each data-driven model are graphically and numerically presented in Figure 4-21. Overall, the training, calibration, and validation datasets display satisfactory results. However, the oil model had a lower $R^{2}$ value for the calibration and validation datasets. 


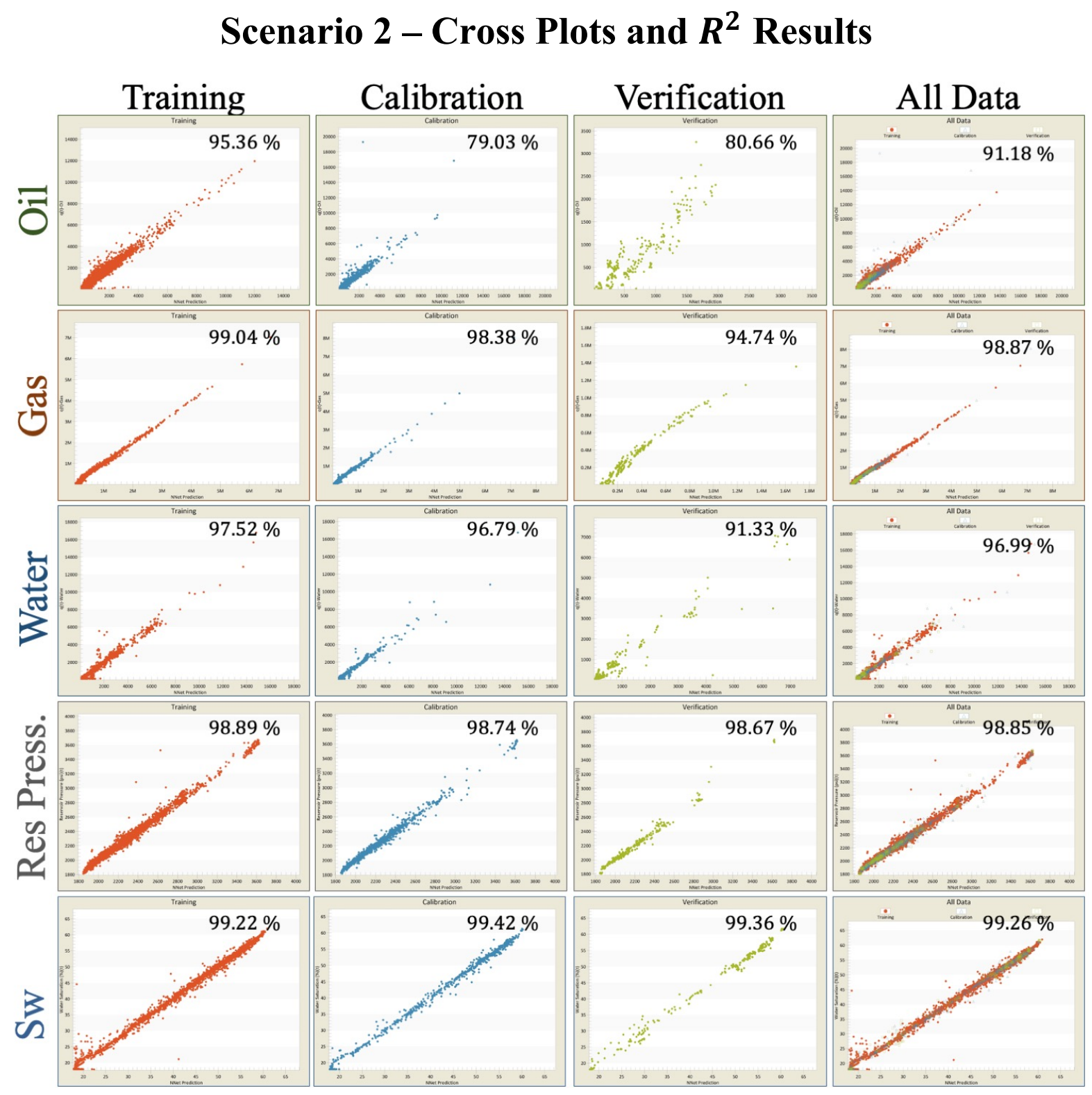

Figure 4-21: Scenario 2 - Partitioning Cross Plot Results 


\subsubsection{Scenario 3-Mixed Partitioning (2 Year Validation)}

The third scenario used a similar approach to the second scenario. However, the number of records used in the training and calibration process was decreased while the number of records in the validation dataset was increased. This approach was taken to evaluate the TDM performance on the blind validation dataset with fewer data records in the training dataset.

\section{Comprehensive Data-Driven Dataset Generation:}

The development and deployment dataset comprised of time ranges from January $1^{\text {st }}$ of 1995 to January $1^{\text {st }}$ of 2017, suggesting that no forecasting was performed.

\begin{tabular}{|c|c|c|c|c|c|c|c|c|c|}
\hline \multicolumn{10}{|c|}{$\begin{array}{l}\text { Development Dataset } \\
\text { Training, Calibration and Validation Datasets }\end{array}$} \\
\hline 1995 & 2009 & 2010 & 2011 & 2012 & 2013 & 2014 & 2015 & 2016 & 2017 \\
\hline
\end{tabular}

Figure 4-22: Scenario 3 - Development Dataset

\section{Data-Driven Model Development:}

The data-driven datasets were further compiled by selecting the most influential attributes from KPI analysis (Refer to APPENDIX B: Key Performance Indicators). The list of attributes used as inputs to the neural network is shown in Figure 4-23. 


\section{Scenario 3 - TDM Input Attributes}

\section{Oil Rate}

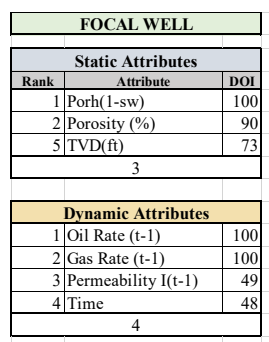

\begin{tabular}{|l|l|}
\hline TOTAL ATTRIBUTES & 25 \\
\hline
\end{tabular}

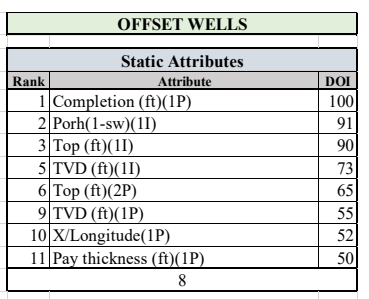

Dynamic Attributes

1 FBH Pressure (psi)(t)(1I)

2 Distance(t-1)(2P)

3 FBH Pressure (psi)(t-1)(1I)

4 Reservoir Pressure (psi)(t-1)(11)

5 Distance $(\mathrm{t})(2 \mathrm{P})$

6 FBH Pressure $(\mathrm{psi})(\mathrm{t})(2 \mathrm{I})$

7 FBH Pressure (psi)(t-1)(2I)

8 Reservoir Pressure (psi)(t-1)(2I)

9 Water Saturation (\%)(t-1)(2I

10 Oil Saturation (\%)(t-1)(2)

\section{Gas Rate}

\begin{tabular}{|c|c|c|c|c|c|}
\hline \multicolumn{3}{|c|}{ FOCAL WELL } & \multicolumn{3}{|c|}{ OFFSET WELLS } \\
\hline \multicolumn{3}{|c|}{ Static Attributes } & \multicolumn{3}{|c|}{ Static Attributes } \\
\hline Rank & Attribute & DOI & Rank & Attribute & DOI \\
\hline & Porh(1-sw) & 100 & & Completion (ft)(1P) & 100 \\
\hline & Porosity (\%) & 90 & & Porh(1-sw)(1I) & 91 \\
\hline \multicolumn{3}{|c|}{2} & & Top (ft)(1I) & 90 \\
\hline & & & & $\mathrm{X} /$ Longitude(1I) & 84 \\
\hline \multicolumn{3}{|c|}{ Dynamic Attributes } & & TVD (ft)(1I) & 73 \\
\hline & Oil Rate (t) & 100 & \multicolumn{3}{|c|}{$x_{1}=$} \\
\hline & Oil Rate $(\mathrm{t}-1)$ & 60 & & & \\
\hline & Gas Rate (t-1) & 60 & \multicolumn{3}{|c|}{ Dynamic Attributes } \\
\hline & Permeability I(t-1) & 29 & & FBH Pressure (psi)(t)(1I) & 100 \\
\hline \multicolumn{3}{|c|}{4} & & Distance(t-1)(2P) & 97 \\
\hline & & & & FBH Pressure (psi)(t-1)(1I) & 96 \\
\hline \multirow{8}{*}{ TOTA } & AL ATTRIBUTES & 21 & & Reservoir Pressure (psi)(t-1)(1I) & 96 \\
\hline & & & & Distance $(\mathrm{t})(2 \mathrm{P})$ & 96 \\
\hline & & & & FBH Pressure $(\mathrm{psi})(\mathrm{t})(2 \mathrm{I})$ & 93 \\
\hline & & & & FBH Pressure $(\mathrm{psi})(\mathrm{t}-1)(2 \mathrm{I})$ & 92 \\
\hline & & & & Reservoir Pressure (psi)(t-1)(2I) & 92 \\
\hline & & & & Water Saturation (\%)(t-1)(2I) & 87 \\
\hline & & & & Oil Saturation (\%)(t-1)(2I) & 87 \\
\hline & & & \multicolumn{3}{|c|}{10} \\
\hline
\end{tabular}

\section{Reservoir Pressure}

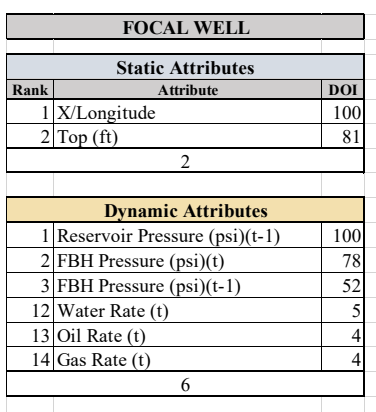

TOTAL ATTRIBUTES

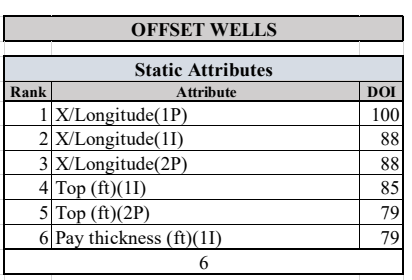

Dynamic Attributes Reservoir Pressure (psi)(t-1)(1P) 100 FBH Pressure (psi)(t-1)(1P) \begin{tabular}{l|l}
2 & FBH Pressure (psi)(t-1)(1P) \\
3 & FBH Pressure (psi)(t)(1P)
\end{tabular}

3 Distance $(\mathrm{t})(1 \mathrm{I})$

\section{Water Saturation}

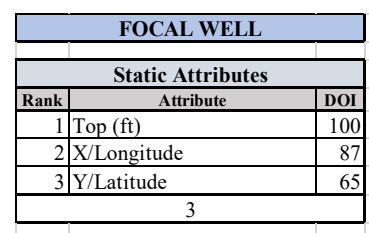

Dynamic Attributes

\begin{tabular}{|r|l|r|}
\hline 1 & Oil Saturation $(\%)(\mathrm{t}-1)$ & 100 \\
\hline 2 & Water Saturation $(\%)(\mathrm{t}-1)$ & 100 \\
\hline 4 & Reservoir Pressure $(\mathrm{psi})(\mathrm{t})$ & 23 \\
\hline 5 & Water Rate $(\mathrm{t})$ & 18 \\
\hline 10 & Oil Rate $(\mathrm{t})$ & 8 \\
\hline 11 & Gas Rate $(\mathrm{t})$ & 8 \\
\hline \multicolumn{2}{|c|}{6} \\
\hline \multicolumn{2}{|c|}{6} \\
\hline
\end{tabular}

\begin{tabular}{|l|l|}
\hline TOTAL ATTRIBUTES & 15 \\
\hline
\end{tabular}

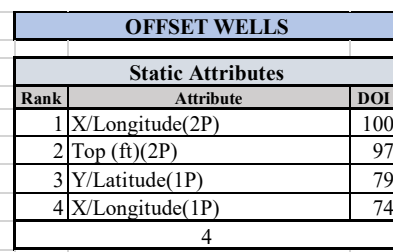

Dynamic Attributes

1 Water Saturation (\%)(t-1)(1P) 100 2 Oil Saturation (\%)(t-1)(1P) 100 2 
Figure 4-23: Scenario 3 - TDM Input Attributes 
The training and calibration datasets were randomly assigned. The validation dataset consisted of data records pertaining to the last 2 years of the development dataset (January $1^{\text {st }}, 2015$ - January $1^{\text {st }}$, 2017). See Figure 4-24.

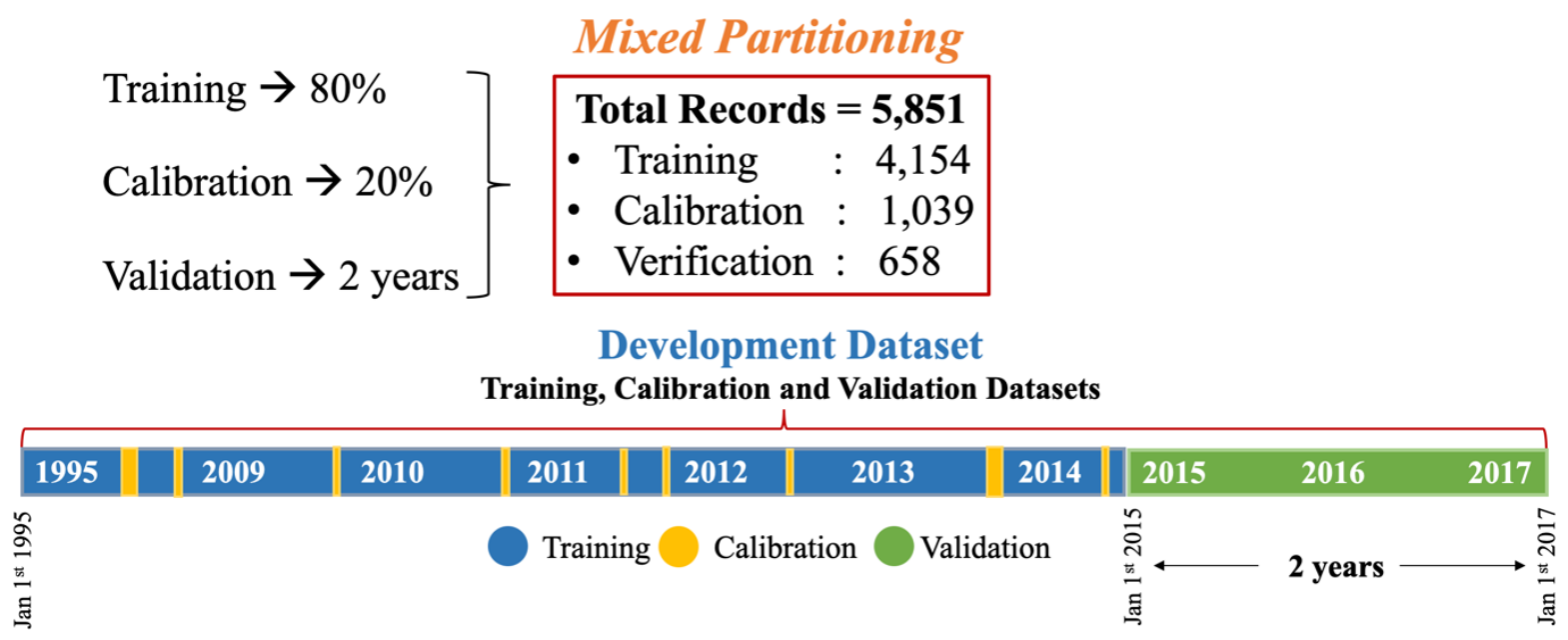

Figure 4-24: Scenario 3 - Neural Network Data Partitioning

Cross plots and $R^{2}$ values served as a graphical and numerical measurement to determine the quality of the trained data-driven models. Figure 4-25 suggests that the overall performance for the training, calibration, and validation datasets was satisfactory. However, the oil model presented data records spread over the validation cross plot as well as lower $R^{2}$ values for both the calibration and validation datasets. 


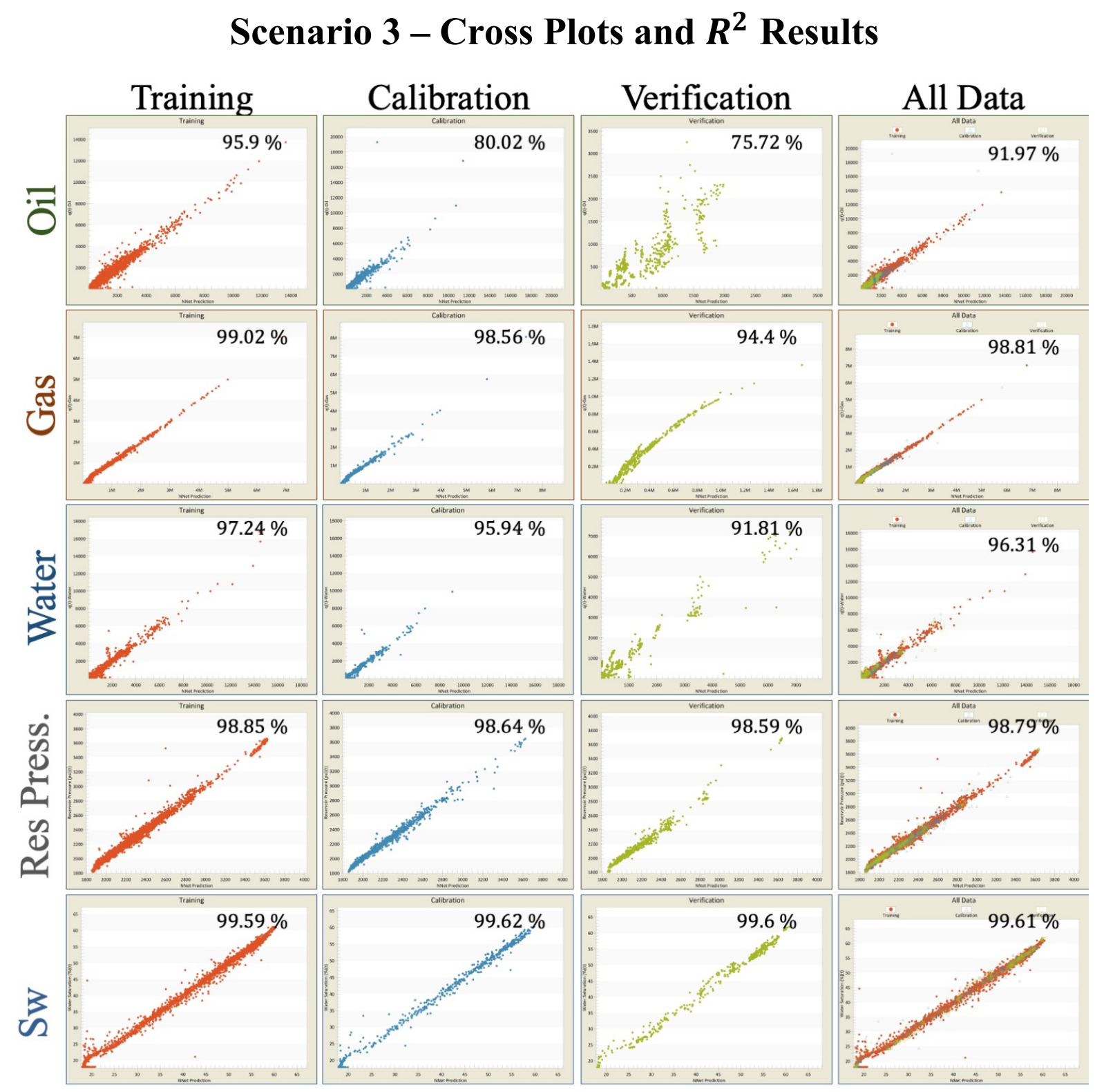

Figure 4-25: Scenario 3 - Partitioning Cross Plot Results 


\subsubsection{Scenario 4-Mixed Partitioning (1 Year Forecast)}

The fourth scenario was developed with efforts to history match and forecast production, reservoir pressure and water saturation distributions. Once the model was graphically and numerically validated, the TDM was deployed on a blind dataset that was not included in the spatio-temporal database.

\section{Comprehensive Data-Driven Dataset Generation:}

Candidate attributes were selected at appropriate timesteps to recreate comprehensive data-driven datasets for each predictive model.

The development dataset consisted of time ranges from January $1^{\text {st }}$ of 1995 until December $31^{\text {st }}$ of 2015. On the other hand, the deployment dataset consisted of time ranges from January $1^{\text {st }}$ of 1995 until January $1^{\text {st }}$ of 2017, suggesting that the TDM model forecasted production, reservoir pressure and water saturation distributions under a variety of operating conditions (i.e. water injection rates, days of production, and flowing bottom-hole pressure). Figure 4-26 illustrates the time ranges for both the development and deployment datasets.

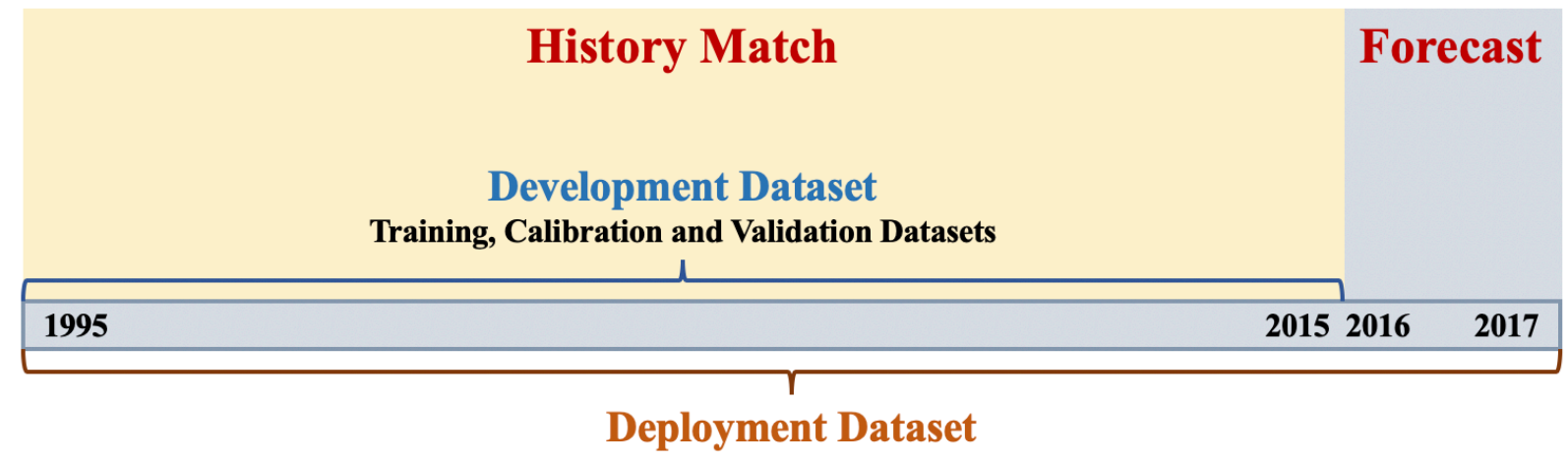

Figure 4-26: Scenario 4: Development and Deployment Datasets

\section{Data-Driven Model Development:}

The comprehensive datasets were compiled by reducing the number of potential input attributes to be used in the final spatio-temporal database. KPI analysis provided some insight regarding the most influential attributes with respect to the output attribute (Refer to APPENDIX B: Key Performance Indicators). A larger number of inputs were included in the development of each 
predictive model in order to provide more information to the neural network. A list of the input attributes is provided below: 


\section{Scenario 4 - TDM Input Attributes}

\section{Oil Rate}

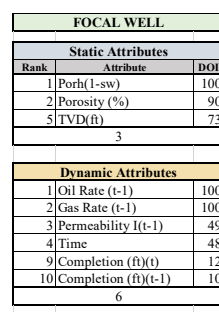

\begin{tabular}{|l|l|}
\hline TOTALATTRIBUTES & 3 \\
\hline
\end{tabular}
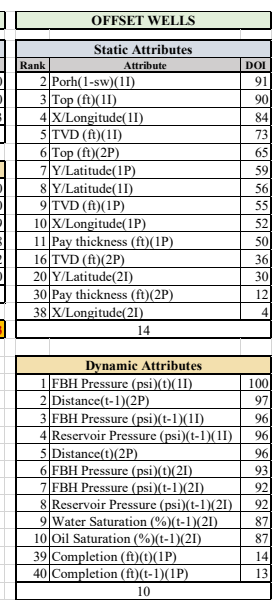

Water Rate

\begin{tabular}{|c|c|c|}
\hline \multicolumn{3}{|c|}{ FOCAL WELL } \\
\hline \multicolumn{3}{|c|}{ Static Attributes } \\
\hline Rank & \begin{tabular}{|c|} 
Attribute \\
\end{tabular} & DOI \\
\hline 1 & Permeability (md) & 100 \\
\hline 2 & $\mathrm{X} /$ Longitude & 89 \\
\hline 3 & Top (ft) & 84 \\
\hline & 3 & \\
\hline
\end{tabular}

Dynamic Attributes

\begin{tabular}{r|l|r|} 
& Q $(\mathrm{t}-1)$-Water & 100 \\
\hline 2 & Oil Saturation (\%)(t-1) & 78 \\
3 & Water Saturation (\%)(t-1) & 78 \\
\hline 4 & Permeability I(t-1) & 72 \\
\hline 15 & Oil Rate $(\mathrm{t})$ & 1 \\
\hline 16 & Gas Rate $(\mathrm{t})$ & 1 \\
\hline \multicolumn{2}{|c|}{6} \\
\hline \multicolumn{2}{|c|}{6}
\end{tabular}

TOTAL ATTRIBUTES

\begin{tabular}{l|l}
15 & Permeability I(t-1)(2I) \\
\hline
\end{tabular}

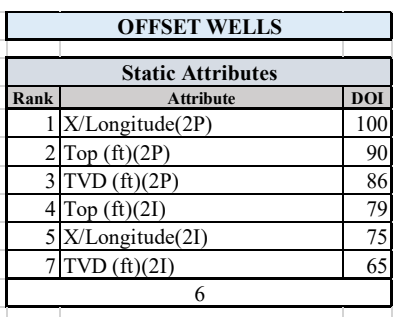

Dynamic Attributes

\begin{tabular}{l|l|l|}
\hline 1 & Water Saturation $(\%)(\mathrm{t}-1)(1 \mathrm{P})$ & 100 \\
\hline
\end{tabular}

2 Oil Saturation (\%)(t-1)(1P) 100 3 Distance(t)(1I)

12 Permeability I(t-1)(2P)
Gas Rate

\begin{tabular}{|c|c|c|c|c|c|}
\hline \multicolumn{3}{|c|}{ FOCAL WELL } & \multicolumn{3}{|c|}{ OFFSET WELLS } \\
\hline \multicolumn{3}{|c|}{ Static Attributes } & \multicolumn{3}{|c|}{ Static Attributes } \\
\hline Rank & \begin{tabular}{|l|} 
Attribute \\
\end{tabular} & DOI & Rank & \begin{tabular}{|c|} 
Attribute \\
\end{tabular} & DOI \\
\hline & Porh(1-sw) & 100 & & Completion (ft)(1P) & 100 \\
\hline & Porosity (\%) & 90 & & Porh(1-sw)(1I) & 91 \\
\hline \multicolumn{3}{|c|}{2} & & Top (ft)(1I) & 90 \\
\hline & & & & $\mathrm{X} /$ Longitude(1I) & 84 \\
\hline \multicolumn{3}{|c|}{ Dynamic Attributes } & & TVD (ft)(1I) & 73 \\
\hline & \begin{tabular}{|l|} 
Oil Rate $(\mathrm{t})$ \\
\end{tabular} & 100 & & Y/Latitude(1I) & 56 \\
\hline & Oil Rate $(\mathrm{t}-1)$ & 60 & \multicolumn{3}{|c|}{6} \\
\hline & Gas Rate $(\mathrm{t}-1)$ & 60 & & & \\
\hline & Permeability I $(\mathrm{t}-1)$ & 29 & \multicolumn{3}{|c|}{ Dynamic Attributes } \\
\hline \multicolumn{3}{|c|}{4} & & FBH Pressure $(\mathrm{psi})(\mathrm{t})(1 \mathrm{I})$ & 100 \\
\hline & & & & Distance $(\mathrm{t}-1)(2 \mathrm{P})$ & 97 \\
\hline \multirow[t]{9}{*}{ TOTA } & AL ATTRIBUTES & 22 & & FBH Pressure (psi)(t-1)(1I) & 96 \\
\hline & & & & Reservoir Pressure $(\mathrm{psi})(\mathrm{t}-1)(1 \mathrm{I})$ & 96 \\
\hline & & & & Distance $(\mathrm{t})(2 \mathrm{P})$ & 96 \\
\hline & & & & FBH Pressure $(\mathrm{psi})(\mathrm{t})(2 \mathrm{I})$ & 93 \\
\hline & & & & FBH Pressure (psi)(t-1)(2I) & 92 \\
\hline & & & & Reservoir Pressure $(\mathrm{psi})(\mathrm{t}-1)(2 \mathrm{I})$ & 92 \\
\hline & & & & Water Saturation $(\%)(\mathrm{t}-1)(2 \mathrm{I})$ & 87 \\
\hline & & & & Oil Saturation (\%)(t-1)(2I) & 87 \\
\hline & & & \multicolumn{3}{|c|}{10} \\
\hline
\end{tabular}

\section{Reservoir Pressure}

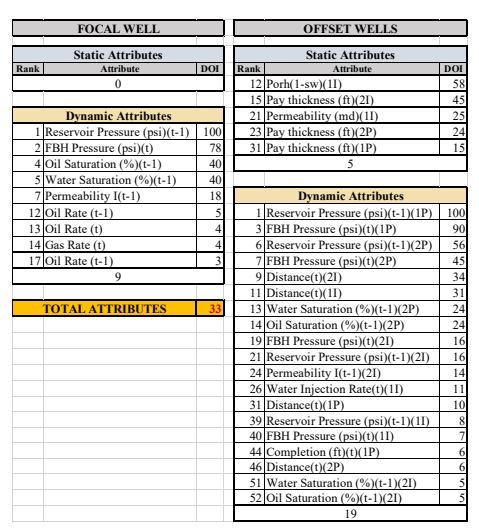

\section{Water Saturation}
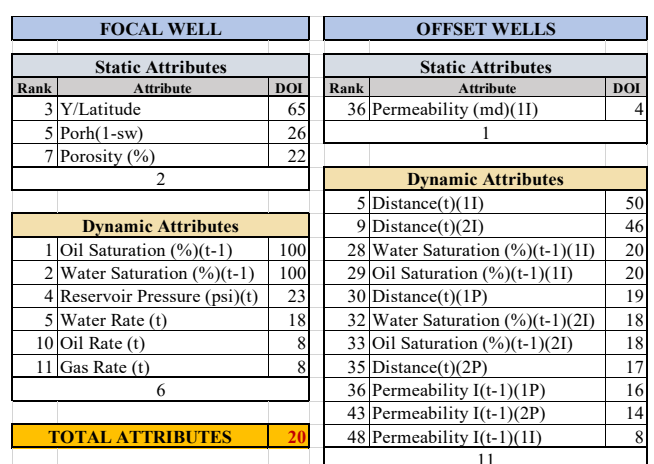

Dynamic Attributes \begin{tabular}{l|l}
5 & Distance $(\mathrm{t})(1 \mathrm{II})$ \\
\hline 9 & Distance $(\mathrm{t})(2 \mathrm{I})$ \\
\hline
\end{tabular}

28 Water Saturation (\%)(t-1)(1I)

29 Oil Saturation $(\%)(\mathrm{t}-1)(1 \mathrm{I})$

30 Distance $(\mathrm{t})(1 \mathrm{P})$

32 Water Saturation (\%)(t-1)(2I)

33 Oil Saturation $(\%)(\mathrm{t}-1)(2 \mathrm{I})$

35 Distance $(\mathrm{t})(2 \mathrm{P})$

36 Permeability I(t-1)(1P)

43 Permeability I(t-1)(2P)

48 Permeability I(t-1)(1I) 11 
Figure 4-27: Scenario 4 - TDM Input Attributes

Each spatio-temporal database was partitioned into the training, calibration, and validation datasets. The training and calibration dataset records were randomly assigned while the validation dataset included data records pertaining to the last year of the development dataset (January $1^{\text {st }}$, 2015 - December $\left.31^{\text {st }}, 2015\right)$. The number of records pertaining to each partition dataset is represented in Figure 4-28.

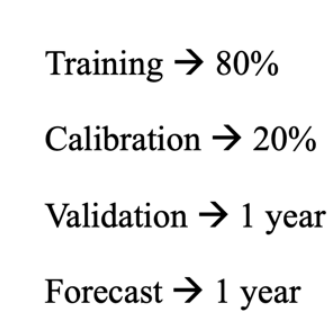

\section{Mixed Partitioning}

Total Records $=\mathbf{5 , 5 3 9}$

- Training : 4,154

- Calibration : 1,039

- Validation : 346

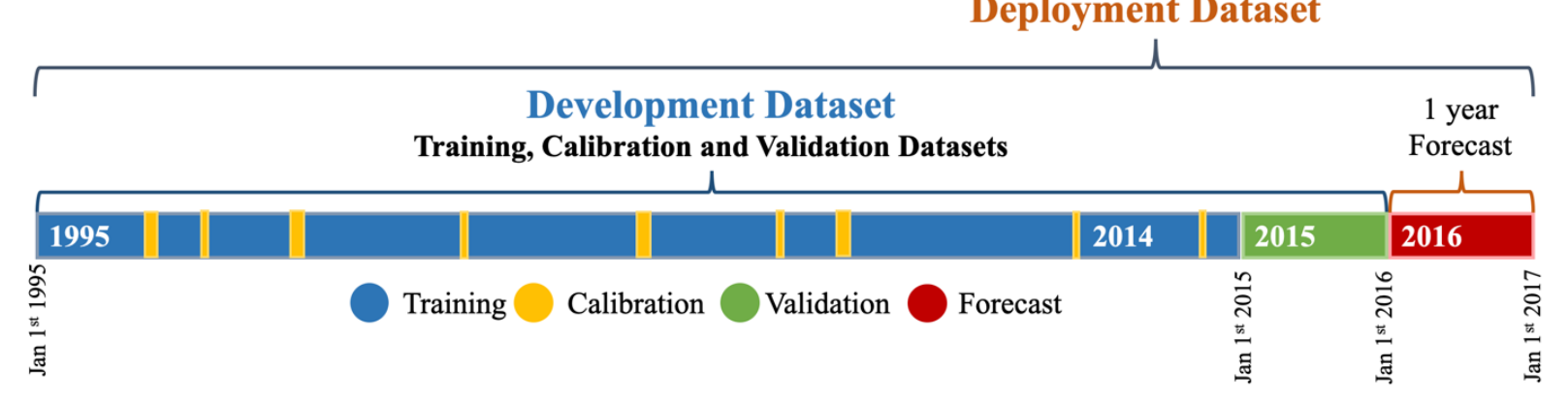

Figure 4-28: Scenario 4 - Neural Network Data Partitioning

Graphical and numerical correlations between the data-driven models' estimated values and the actual data are displayed in Figure 4-29. The figure shows that the lowest calibration and validation $R^{2}$ values pertain to the oil model. Acceptable $R^{2}$ values and linearity from the cross plots confirm a good quality trained network [25]. 


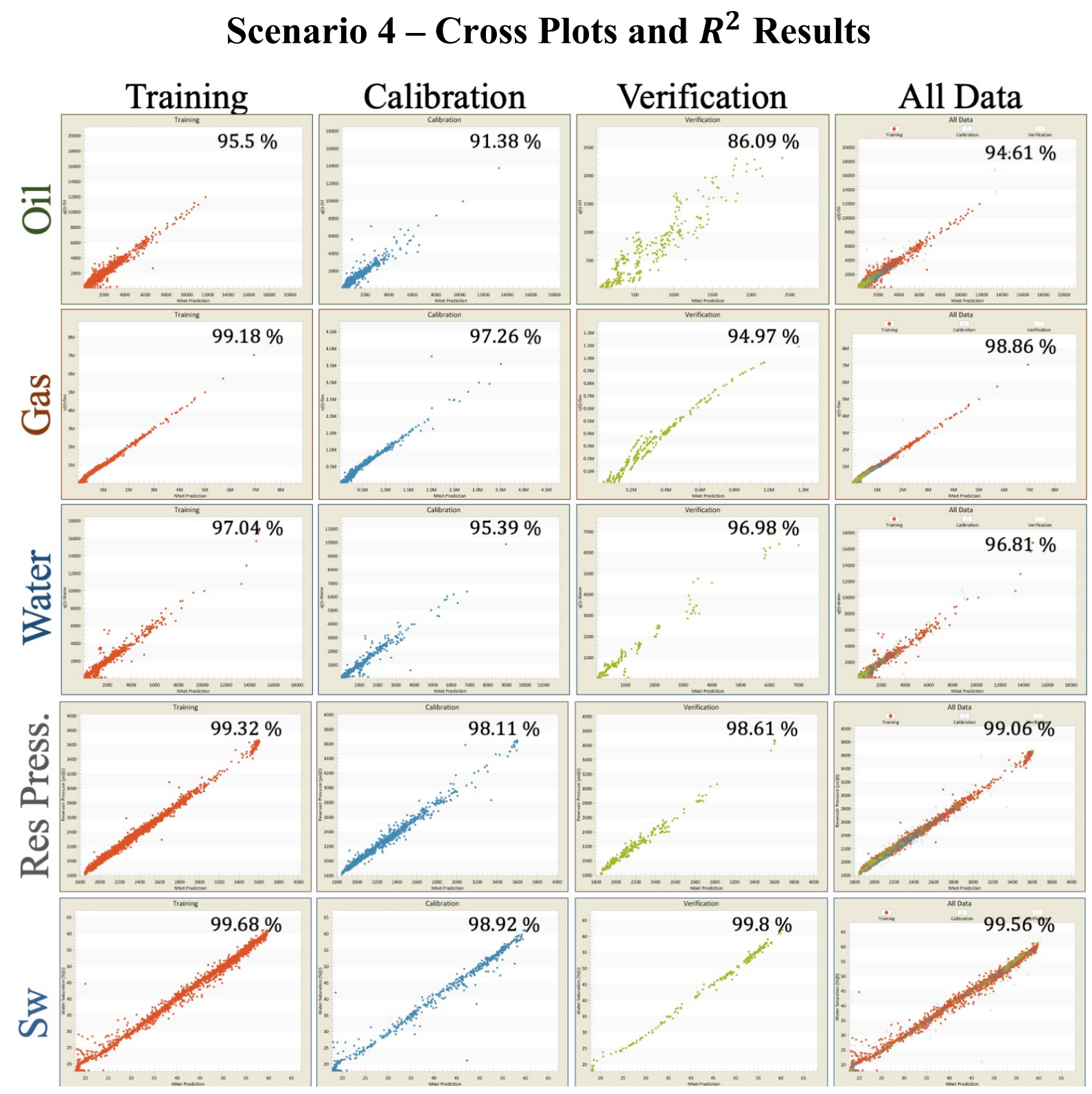

Figure 4-29: Scenario 4 - Partitioning Cross Plot Results 


\subsubsection{Scenario 5-Mixed Partitioning (2 Year Forecast)}

The fifth scenario followed a similar approach to scenario 4 . However, the forecasting time range was increased from 1 year to 2 years.

\section{Comprehensive Data-Driven Dataset Generation:}

Candidate attributes for the focal and offset wells ( 2 offset producers and 2 offset injectors) were selected at appropriate timesteps of " $\mathrm{t}$ " and "t-1". Furthermore, the development dataset was composed of records from January $1^{\text {st }}$ of 1995 until December $31^{\text {st }}$ of 2014 while the deployment dataset ranged from January $1^{\text {st }}$ of 1995 to January $1^{\text {st }}$ of 2017.

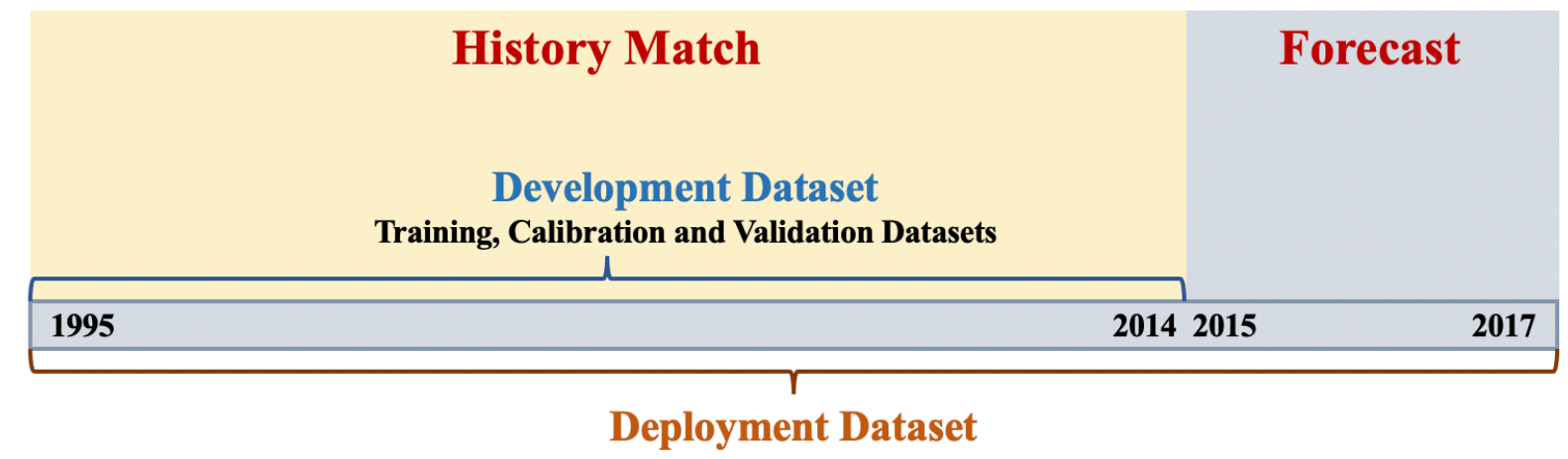

Figure 4-30: Scenario 5 - Development and Deployment Datasets

\section{Data-Driven Model Development:}

Neural network input attributes, displayed in Figure 4-31, were selected according to the KPI analysis performed (Refer to APPENDIX B: Key Performance Indicators). 


\section{Scenario 5 - TDM Input Attributes}

\section{Oil Rate}

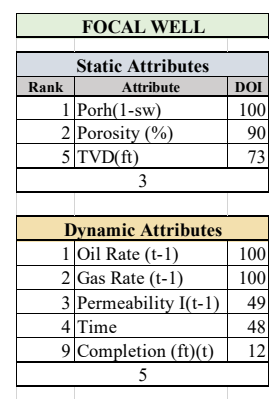

\begin{tabular}{|l|l|}
\hline TOTAL ATTRIBUTES & 25 \\
\hline
\end{tabular}

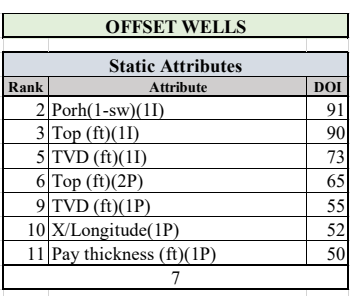

Dynamic Attributes

\begin{tabular}{l|l|l}
1 & FBH Pressure $(\mathrm{psi})(\mathrm{t})(\mathrm{I})$ \\
\hline &
\end{tabular}

2 Distance $(\mathrm{t}-1)(2 \mathrm{P})$

3 FBH Pressure (psi)(t-1)(1I)

4 Reservoir Pressure (psi)(t-1)(1I)

5 Distance $(\mathrm{t})(2 \mathrm{P})$

6 FBH Pressure (psi)(t)(2I)

7 FBH Pressure (psi)(t-1)(2I)

8 Reservoir Pressure (psi)(t-1)(2I)

9 Water Saturation $(\%)(\mathrm{t}-1)(2)$

10 Oil Saturation (\%)(t-1)(2I)

\section{Gas Rate}

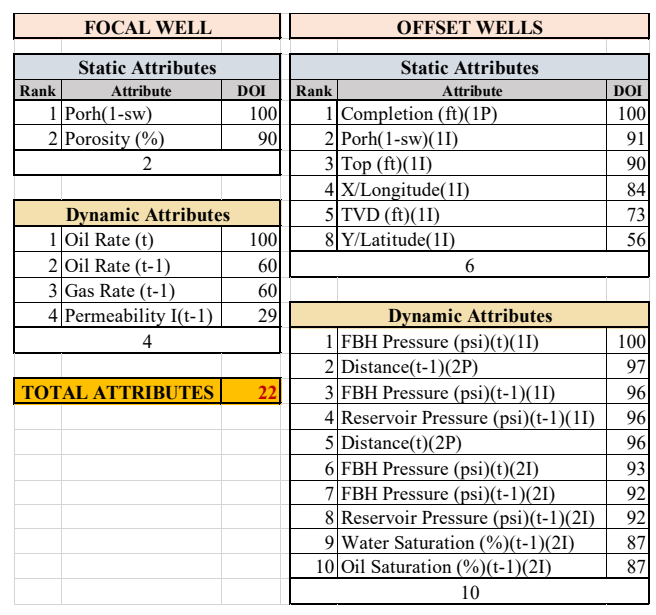

\section{Reservoir Pressure}

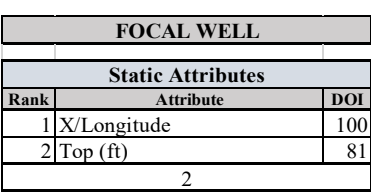

Dynamic Attributes

\begin{tabular}{l|l|l|}
1 & Reservoir Pressure (psi)(t-1) & 100 \\
\hline
\end{tabular} 2 FBH Pressure $(\mathrm{psi})(\mathrm{t})$

3 FBH Pressure (psi)(t-1)

12 Water Rate (t)

13 Oil Rate (t)

14 Gas Rate (t)

\begin{tabular}{l|l}
2 & Oil Saturation $(\%)(t-1)($ \\
3 & Distance $(\mathrm{t})(1 \mathrm{I})$
\end{tabular}

12 Permeability I(t-1)(2P)

15 Permeability I(t-1)(2I)
TOTAL ATTRIBUTES

\begin{tabular}{|c|c|c|}
\hline \multicolumn{3}{|c|}{ OFFSET WELLS } \\
\hline \multicolumn{3}{|c|}{ Static Attributes } \\
\hline Rank & $\begin{array}{c}\text { Attribute } \\
\end{array}$ & DOI \\
\hline & $\mathrm{X} /$ Longitude $(1 \mathrm{P})$ & 100 \\
\hline 2 & $\mathrm{X} /$ Longitude(1I) & 88 \\
\hline 3 & $\mathrm{X} /$ Longitude $(2 \mathrm{P})$ & 88 \\
\hline 4 & Top $(\mathrm{ft})(1 \mathrm{I})$ & 85 \\
\hline 5 & Top (ft)(2P) & 79 \\
\hline & Pay thickness (ft)(1I) & 79 \\
\hline \multicolumn{3}{|c|}{6} \\
\hline \multicolumn{3}{|c|}{ Dynamic Attributes } \\
\hline 1 & Reservoir Pressure $(\mathrm{psi})(\mathrm{t}-1)(1 \mathrm{P})$ & 100 \\
\hline 2 & FBH Pressure (psi)(t-1)(1P) & 91 \\
\hline 3 & FBH Pressure $(\mathrm{psi})(\mathrm{t})(1 \mathrm{P})$ & 90 \\
\hline \multicolumn{3}{|c|}{3} \\
\hline
\end{tabular}

\section{Water Saturation}

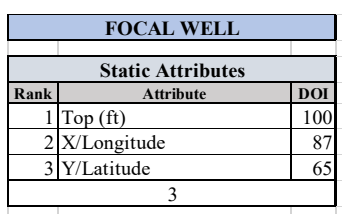

Dynamic Attributes

Oil Saturation (\%)(t-1)

2 Water Saturation (\%)(t-1) 100

4 Reservoir Pressure (psi)(t) 23

5 Water Rate (t)

10 Oil Rate (t)

11 Gas Rate ( $\mathrm{t})$

\begin{tabular}{|l|l|} 
TOTAL ATTRIBUTES & 15 \\
\hline
\end{tabular}

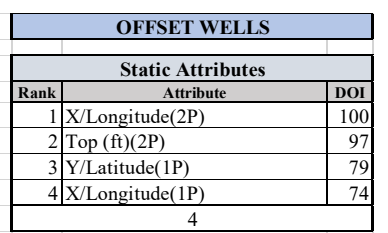

Dynamic Attributes \begin{tabular}{|l|l|l|}
\hline \multicolumn{3}{|c|}{ Dynamic Attributes } \\
\hline 1 & Water Saturation (\%)(t-1)(1P) & 100 \\
\hline 2 & Oil Saturation (\%)(t-1)(1P) & 100 \\
\hline
\end{tabular} 
Figure 4-31: Scenario 5 - TDM Input Attributes 
The spatio-temporal database was partitioned into three different datasets. The training and calibration datasets were randomly assigned while the validation dataset consisted of records pertaining to the last year of the dataset (January $1^{\text {st }}, 2014-$ December $\left.31^{\text {st }}, 2014\right)$.

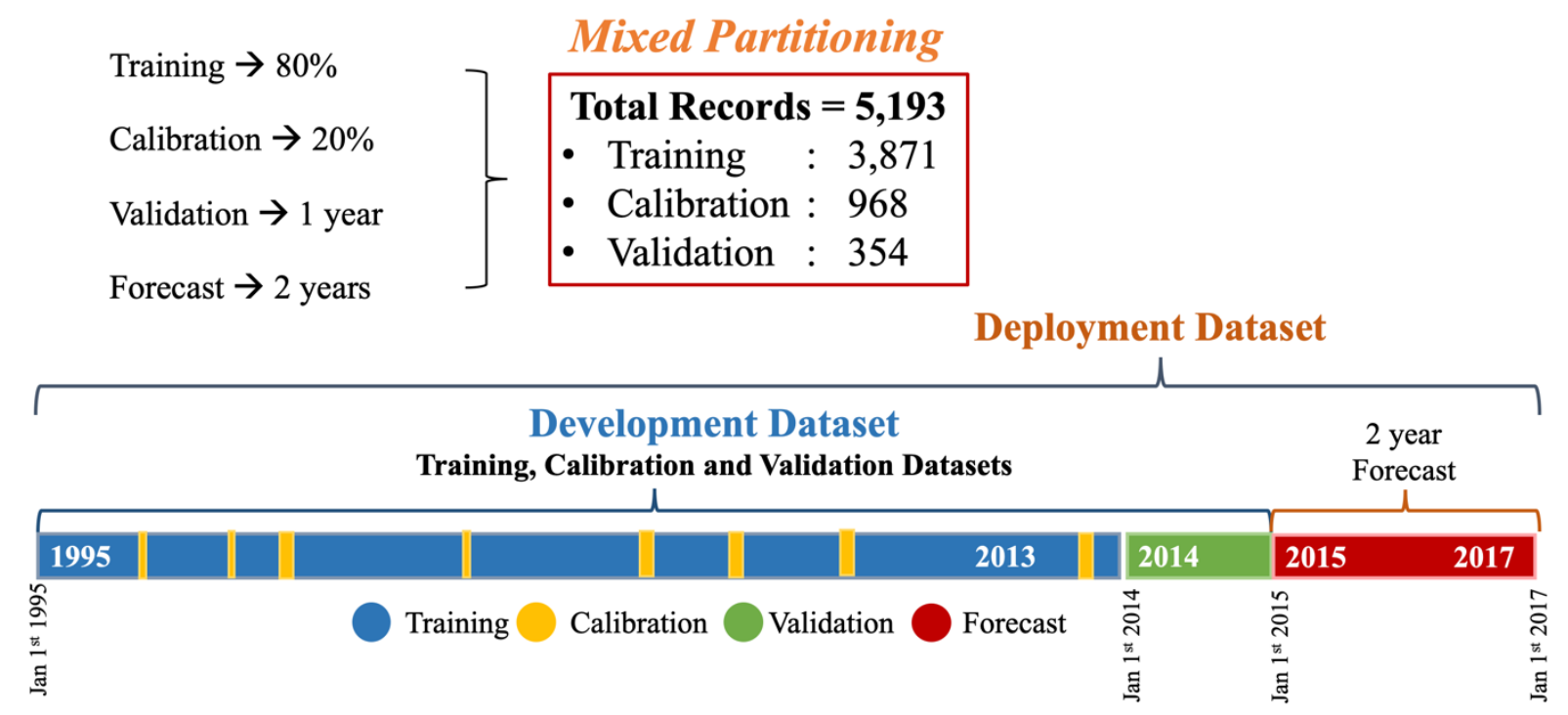

Figure 4-32: Scenario 5 - Neural Network Data Partitioning 


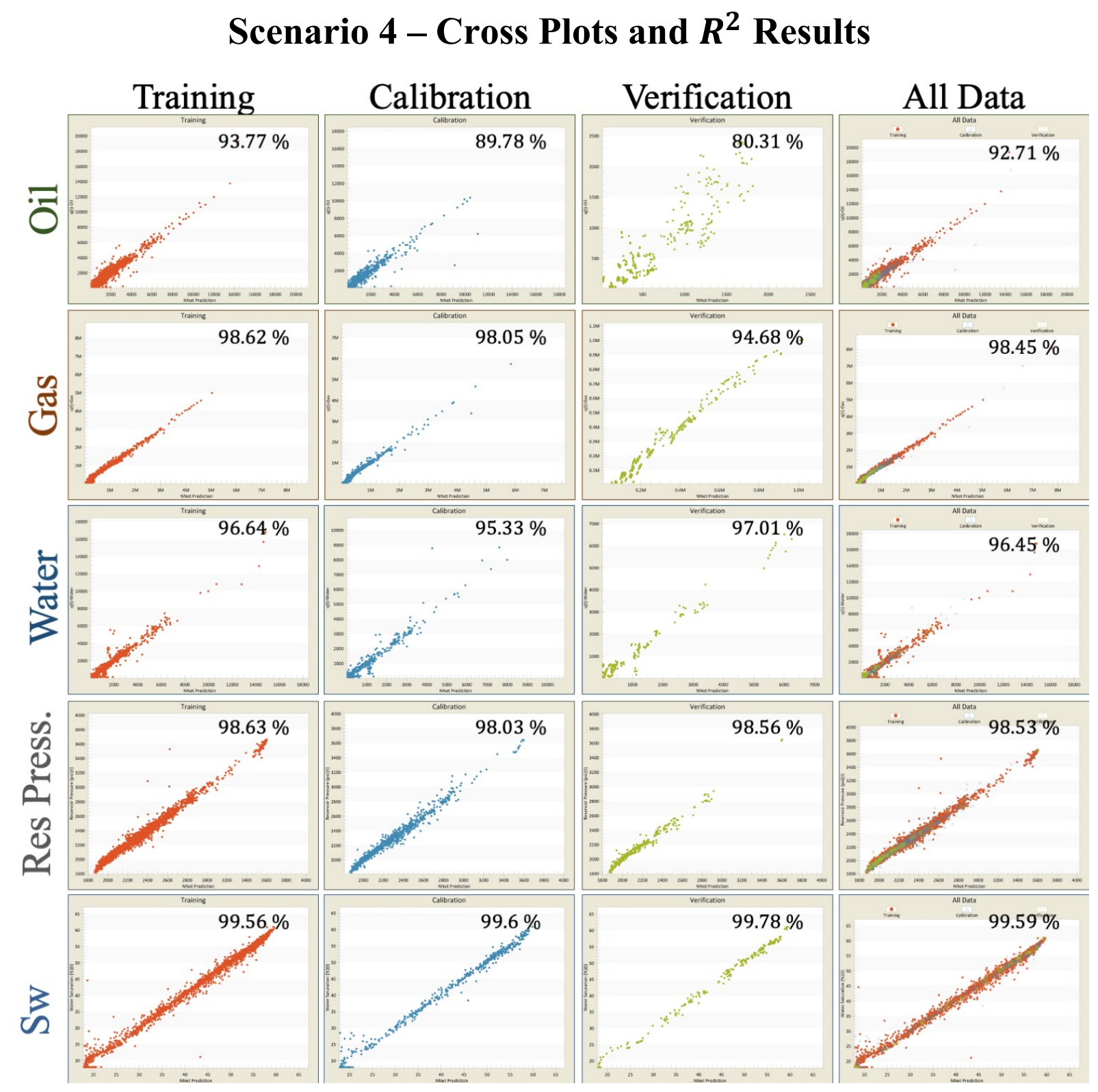

Figure 4-33: Scenario 5 - Partitioning Cross Plot Results 


\subsubsection{Summary of Conducted Scenarios}

The number of records used in the training, calibration, and validation datasets for all five TDM models is shown in Table 4-2.

Table 4-2: Partitioning No. of Records

\begin{tabular}{|l|l|r|r|r|r|r|}
\hline Scenario No. & $\begin{array}{c}\text { TDM Model } \\
\text { Name }\end{array}$ & \multicolumn{5}{|c|}{ TDM Partitioning Records } \\
\hline Scenario 1 & RP TDM & 4,681 & 585 & 585 & - & 5,851 \\
\hline Scenario 2 & MP TDM 1V & 4,431 & 1,108 & 312 & - & 5,851 \\
\hline Scenario 3 & MP TDM 2V & 4,154 & 1,039 & 658 & - & 5,851 \\
\hline Scenario 4 & MP TDM 1V 1B & 4,154 & 1,039 & 346 & 312 & 5,539 \\
\hline Scenario 5 & MP TDM 1V 2B & 3,871 & 968 & 354 & 658 & 5,193 \\
\hline
\end{tabular}

Moreover, the number of epochs that the neural network was exposed to during the training process and the number of input attributes used in the development of the neural network are summarized in Table 4-3.

Table 4-3: Predictive Model Input Attributes and No. of Epochs Summary

\begin{tabular}{|c|c|c|c|c|c|c|}
\hline & \multirow{2}{*}{$\begin{array}{c}\text { Predictive } \\
\text { Model }\end{array}$} & \multicolumn{5}{|c|}{ TDM Models } \\
\hline & & $\begin{array}{l}\text { Scenario } 1 \\
\text { RP TDM }\end{array}$ & $\begin{array}{c}\text { Scenario } 2 \\
\text { MP TDM 1V }\end{array}$ & $\begin{array}{c}\text { Scenario } 3 \\
\text { MP TDM 2V }\end{array}$ & $\begin{array}{c}\text { Scenario } 4 \\
\text { MP TDM 1V 1F }\end{array}$ & $\begin{array}{c}\text { Scenario } 5 \\
\text { MP TDM 1V 2F }\end{array}$ \\
\hline \multirow{5}{*}{ No. Inputs } & Oil (77) & 25 & 24 & 25 & 35 & 25 \\
\hline & Gas (77) & 22 & 22 & 21 & 22 & 22 \\
\hline & Water (79) & 21 & 20 & 20 & 21 & 20 \\
\hline & Res Press. (83) & 17 & 17 & 17 & 33 & 17 \\
\hline & Water Sat (86) & 15 & 15 & 15 & 20 & 15 \\
\hline \multirow{5}{*}{ No. Epochs } & Oil & 18,297 & 30,905 & 33,256 & 18,637 & 18,609 \\
\hline & Gas & 15,949 & 33,052 & 33,113 & 32,068 & 32,628 \\
\hline & Water & 10,636 & 37,938 & 22,443 & 18,814 & 19,501 \\
\hline & Res Press. & 27,379 & 43,524 & 35,646 & 12,829 & 18,882 \\
\hline & Water Sat & 9,985 & 31,138 & 13,206 & 15,013 & 15,168 \\
\hline
\end{tabular}

The performance of each predictive model was evaluated graphically and numerically through different criteria, including cross plots and different evaluation metrics summarized in Table 4-4 and Table 4-5. 
Table 4-4: TDM Model R.Squared Results

\begin{tabular}{|c|c|c|c|c|c|c|}
\hline \multirow[b]{2}{*}{ Partition } & \multirow{2}{*}{$\begin{array}{c}\text { Predictive } \\
\text { Data-Driven } \\
\text { Model }\end{array}$} & \multicolumn{5}{|c|}{ TDM Models } \\
\hline & & $\begin{array}{c}\text { Scenario } 1 \\
\text { RP TDM }\end{array}$ & $\begin{array}{c}\text { Scenario } 2 \\
\text { MP TDM 1V }\end{array}$ & $\begin{array}{c}\text { Scenario } 3 \\
\text { MP TDM 2V }\end{array}$ & $\begin{array}{c}\text { Scenario } 4 \\
\text { MP TDM 1V 1F }\end{array}$ & $\begin{array}{c}\text { Scenario } 5 \\
\text { MP TDM 1V 2F }\end{array}$ \\
\hline \multirow{5}{*}{ Training } & Oil Rate & $93.90 \%$ & $95.36 \%$ & $95.90 \%$ & $95.50 \%$ & $93.77 \%$ \\
\hline & Gas Rate & $98.23 \%$ & $99.04 \%$ & $99.02 \%$ & $99.18 \%$ & $98.62 \%$ \\
\hline & Water Rate & $96.19 \%$ & $97.52 \%$ & $97.24 \%$ & $97.04 \%$ & $96.64 \%$ \\
\hline & Reservoir Pressure & $99.30 \%$ & $98.89 \%$ & $98.85 \%$ & $99.32 \%$ & $98.63 \%$ \\
\hline & Water Saturation & $99.68 \%$ & $99.22 \%$ & $99.59 \%$ & $99.68 \%$ & $99.56 \%$ \\
\hline \multirow{5}{*}{ Calibration } & Oil Rate & $86.16 \%$ & $79.03 \%$ & $80.02 \%$ & $91.38 \%$ & $89.78 \%$ \\
\hline & Gas Rate & $97.15 \%$ & $98.38 \%$ & $98.56 \%$ & $97.26 \%$ & $98.05 \%$ \\
\hline & Water Rate & $95.46 \%$ & $96.79 \%$ & $95.94 \%$ & $95.39 \%$ & $95.33 \%$ \\
\hline & Reservoir Pressure & $97.33 \%$ & $98.74 \%$ & $98.64 \%$ & $98.11 \%$ & $98.03 \%$ \\
\hline & Water Saturation & $98.92 \%$ & $99.42 \%$ & $99.62 \%$ & $98.92 \%$ & $99.60 \%$ \\
\hline \multirow{5}{*}{ Validation } & Oil Rate & $91.00 \%$ & $80.66 \%$ & $75.72 \%$ & $86.09 \%$ & $80.31 \%$ \\
\hline & Gas Rate & $97.92 \%$ & $94.74 \%$ & $94.40 \%$ & $94.97 \%$ & $94.69 \%$ \\
\hline & Water Rate & $92.92 \%$ & $91.33 \%$ & $91.81 \%$ & $96.98 \%$ & $97.01 \%$ \\
\hline & Reservoir Pressure & $97.98 \%$ & $98.67 \%$ & $98.59 \%$ & $98.61 \%$ & $98.56 \%$ \\
\hline & Water Saturation & $99.81 \%$ & $99.36 \%$ & $99.60 \%$ & $99.81 \%$ & $99.78 \%$ \\
\hline \multirow{5}{*}{ All Cases } & Oil Rate & $93.10 \%$ & $91.18 \%$ & $91.97 \%$ & $94.61 \%$ & $92.71 \%$ \\
\hline & Gas Rate & $98.10 \%$ & $98.87 \%$ & $98.81 \%$ & $98.86 \%$ & $98.45 \%$ \\
\hline & Water Rate & $95.77 \%$ & $96.99 \%$ & $96.31 \%$ & $96.81 \%$ & $96.45 \%$ \\
\hline & Reservoir Pressure & $98.83 \%$ & $98.85 \%$ & $98.79 \%$ & $99.06 \%$ & $98.53 \%$ \\
\hline & Water Saturation & $99.56 \%$ & $99.26 \%$ & $99.61 \%$ & $99.56 \%$ & $99.59 \%$ \\
\hline
\end{tabular}

Table 4-5: TDM Model MAE Results

\begin{tabular}{|c|c|c|c|c|c|c|}
\hline \multirow[b]{2}{*}{ Partition } & \multirow{2}{*}{$\begin{array}{c}\text { Predictive } \\
\text { Data-Driven } \\
\text { Model }\end{array}$} & \multicolumn{5}{|c|}{ TDM Models } \\
\hline & & $\begin{array}{c}\text { Scenario } 1 \\
\text { RP TDM } \\
\end{array}$ & $\begin{array}{c}\text { Scenario } 2 \\
\text { MP TDM 1V } \\
\end{array}$ & $\begin{array}{c}\text { Scenario } 3 \\
\text { MP TDM 2V } \\
\end{array}$ & $\begin{array}{c}\text { Scenario } 4 \\
\text { MP TDM 1V 1F }\end{array}$ & $\begin{array}{c}\text { Scenario } 5 \\
\text { MP TDM 1V 2F }\end{array}$ \\
\hline \multirow{5}{*}{ Training } & Oil Rate & 198.84 & 169.13 & 167.65 & 160.99 & 204.87 \\
\hline & Gas Rate & $50,510.60$ & $37,996.02$ & $38,185.97$ & $36,443.51$ & $45,092.99$ \\
\hline & Water Rate & 98.49 & 72.09 & 82.90 & 81.76 & 86.51 \\
\hline & Reservoir Pressure & 23.74 & 20.64 & 20.90 & 19.74 & 23.71 \\
\hline & Water Saturation & 0.54 & 0.84 & 0.50 & 0.45 & 0.50 \\
\hline \multirow{5}{*}{ Calibration } & Oil Rate & 217.99 & 210.84 & 199.90 & 190.77 & 238.87 \\
\hline & Gas Rate & $55,661.31$ & $39,483.52$ & $44,222.94$ & $39,919.65$ & $50,828.20$ \\
\hline & Water Rate & 97.31 & 71.61 & 80.87 & 85.98 & 95.36 \\
\hline & Reservoir Pressure & 24.58 & 23.28 & 22.64 & 26.64 & 29.33 \\
\hline & Water Saturation & 0.54 & 0.81 & 0.50 & 0.58 & 0.50 \\
\hline \multirow{5}{*}{ Validation } & Oil Rate & 202.26 & 191.61 & 201.33 & 161.98 & 191.73 \\
\hline & Gas Rate & $52,756.45$ & $46,679.03$ & $46,865.99$ & $43,517.47$ & $48,850.92$ \\
\hline & Water Rate & 116.98 & 174.22 & 189.33 & 119.58 & 136.30 \\
\hline & Reservoir Pressure & 23.01 & 23.29 & 25.06 & 27.45 & 24.75 \\
\hline & Water Saturation & 0.55 & 0.87 & 0.69 & 0.49 & 0.53 \\
\hline \multirow{5}{*}{ All Cases } & Oil Rate & 201.10 & 178.22 & 177.16 & 166.64 & 210.31 \\
\hline & Gas Rate & $51,250.13$ & $38,740.72$ & $40,234.14$ & $37,537.44$ & $46,213.72$ \\
\hline & Water Rate & 100.22 & 77.45 & 94.51 & 84.92 & 91.55 \\
\hline & Reservoir Pressure & 23.75 & 21.28 & 21.68 & 21.16 & 24.83 \\
\hline & Water Saturation & 0.54 & 0.84 & 0.52 & 0.48 & 0.50 \\
\hline
\end{tabular}




\section{CHAPTER 5}

\section{RESULTS AND DISCUSSION}

A total of five different TDM models were built from data generated from a numerical reservoir model.

Each TDM was composed of five interconnected predictive models that were trained, calibrated and validated in order to history match oil, gas, and water production, reservoir pressure and water saturation distributions while varying the number of input attributes and partitioning method. The last two TDM models were further deployed on a blind dataset to evaluate their forecast performance.

\subsection{Entire Field:}

The TDM's entire field performance was evaluated by comparing the cumulative production rates from the TDM model and the actual numerical reservoir model. Table 5-1 suggests that scenarios 1, 4, and 5 overestimated the field's oil, gas, and water cumulative productions as shown in Figure 5-1, Figure 5-4, and Figure 5-5 respectively. The second scenario underestimated the total field's oil production by $0.99 \%$ and water production by $1.84 \%$, while the gas production was overestimated by $2.18 \%$ as displayed in Figure $5-2$. The third scenario overestimated the field's oil and gas total production by $0.90 \%$ and $2.37 \%$ respectively, while it underestimated the field's water cumulative production by $3.83 \%$ as shown in Figure $5-3$.

Table 5-1: History Match - Cumulative Field Production Comparison

\begin{tabular}{|l|r|r|r|r|r|r|}
\hline \multirow{2}{*}{$\begin{array}{c}\text { Numerical Reservoir Model } \\
\text { Cumulative Production }\end{array}$} & \multicolumn{4}{|c|}{ TDM Model - Entire Field Cumulative Production } \\
\cline { 2 - 7 } & \multicolumn{1}{c|}{ Scenario 1 } & \multicolumn{1}{c|}{ Scenario 2 } & \multicolumn{1}{c|}{ Scenario 3 } & \multicolumn{1}{c|}{ Scenario 4 } & Scenario 5 \\
\hline Oil & $6,223,078 \mathrm{bbl}$ & $-1.13 \%$ & $0.99 \%$ & $-0.90 \%$ & $-1.29 \%$ & $-0.52 \%$ \\
Gas & $2,597,680,628 \mathrm{scf}$ & $-1.74 \%$ & $-2.18 \%$ & $-2.37 \%$ & $-1.84 \%$ & $-2.03 \%$ \\
Water & $3,399,966 \mathrm{bbl}$ & $-2.56 \%$ & $1.84 \%$ & $3.83 \%$ & $-0.72 \%$ & $-0.26 \%$ \\
\hline
\end{tabular}


Table 5-2, on the other hand, provides a cumulative production comparison that takes into account forecasted production from the last two TDM models. The table indicates that the fourth TDM significantly overestimated the forecasted oil, gas, and water productions by $12.76 \%, 10.57 \%$, and $21.69 \%$ respectively (See Figure 5-4). This was primarily attributed to wells 036, 038, 039, 042, 050, 052, 054 and 055 that, despite having an accurate history match, had poor forecast results when compared to the actual data. The production profiles of each of these wells is found in Appendix F: Scenario 4 - Mixed Partitioning TDM (1 Year Forecast) .

The last TDM had a more accurate forecasting performance, although each predictive model was trained for a fewer number of epochs and with a fewer number of input attributes that are summarized in Table 4-3. The field's cumulative gas and water production were overestimated by $1.52 \%$ and $2.05 \%$ respectively while the oil was underestimated by $5.32 \%$ (See Figure 5-5).

Table 5-2: History Match and Forecast - Cumulative Field Production

\begin{tabular}{|l|r|r|r|r|r|r|}
\hline \multirow{2}{*}{$\begin{array}{c}\text { Numerical } \\
\text { Cumulative Production }\end{array}$} & \multicolumn{3}{|c|}{ TDM Model - Entire Field Cumulative Production } \\
\cline { 2 - 7 } & Scenario 1 & Scenario 2 & Scenario 3 & \multicolumn{1}{c|}{ Scenario 4 } & Scenario 5 \\
\hline Oil & $6,223,078$ bbl & $-1.13 \%$ & $0.99 \%$ & $-0.90 \%$ & $-12.76 \%$ & $5.32 \%$ \\
Gas & $2,597,680,628$ scf & $-1.74 \%$ & $-2.18 \%$ & $-2.37 \%$ & $-10.57 \%$ & $-1.52 \%$ \\
Water & $3,399,966$ bbl & $-2.56 \%$ & $1.84 \%$ & $3.83 \%$ & $-21.69 \%$ & $-2.05 \%$ \\
\hline
\end{tabular}

Entire field production profiles for all TDM models are illustrated below: 


\section{Scenario 1 - Random Partitioning TDM}

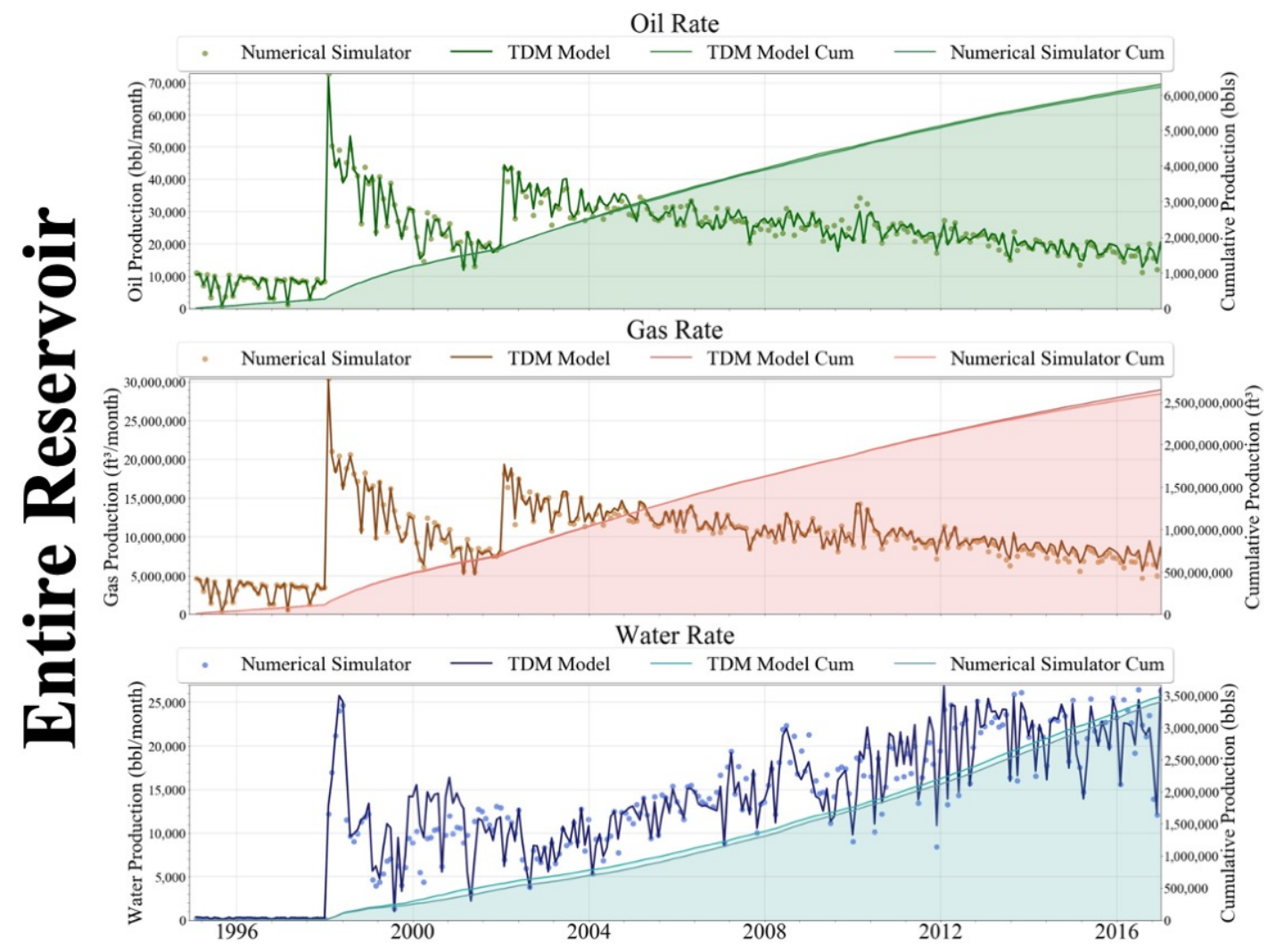

Figure 5-1: Scenario 1 - Entire Field Production Profiles 


\section{Scenario 2 - Mixed Partitioning TDM (1 Year Validation)}

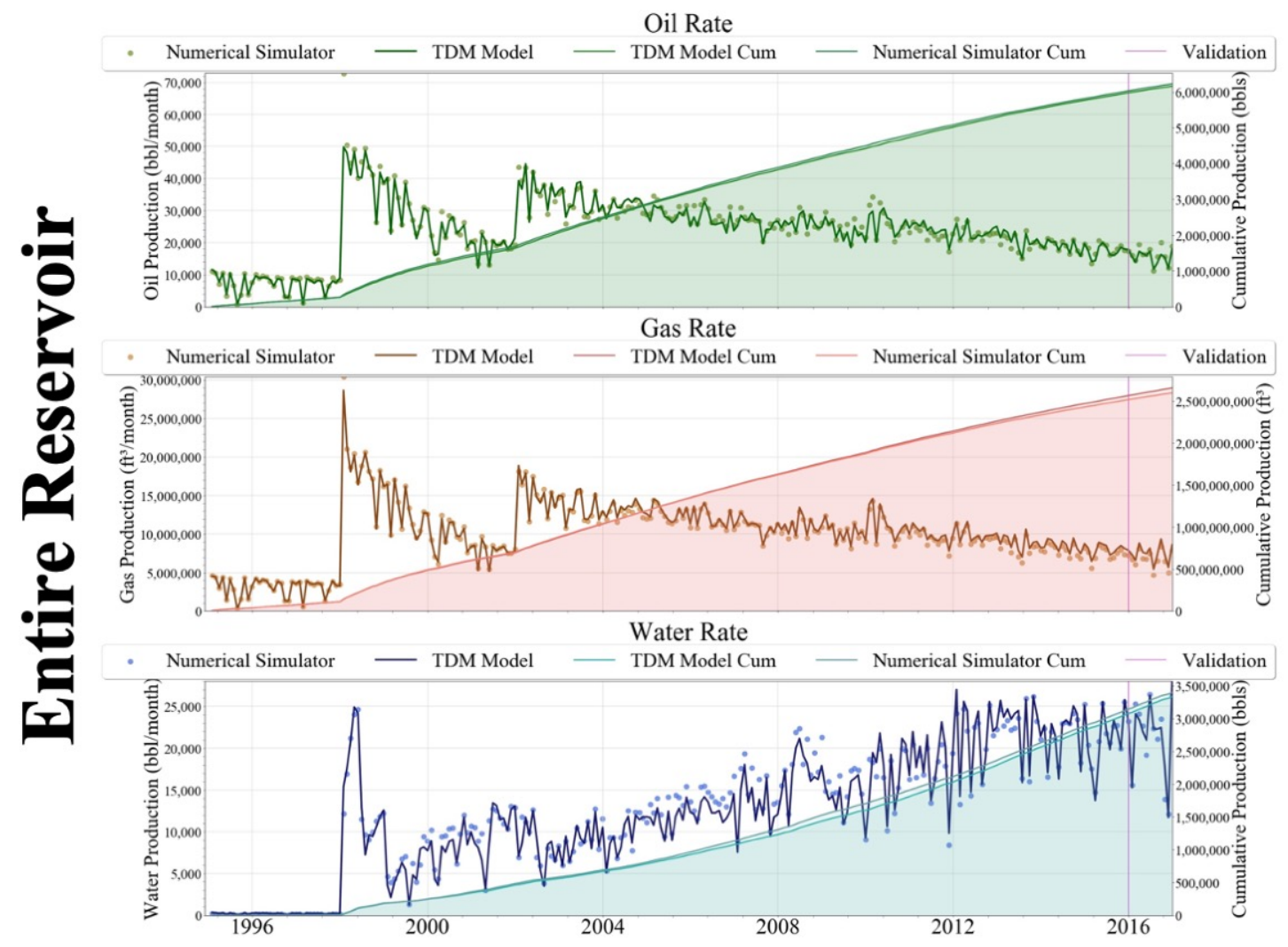

Figure 5-2: Scenario 2 - Entire Field Production Profiles 


\section{Scenario 3 - Mixed Partitioning TDM (2 Year Validation)}

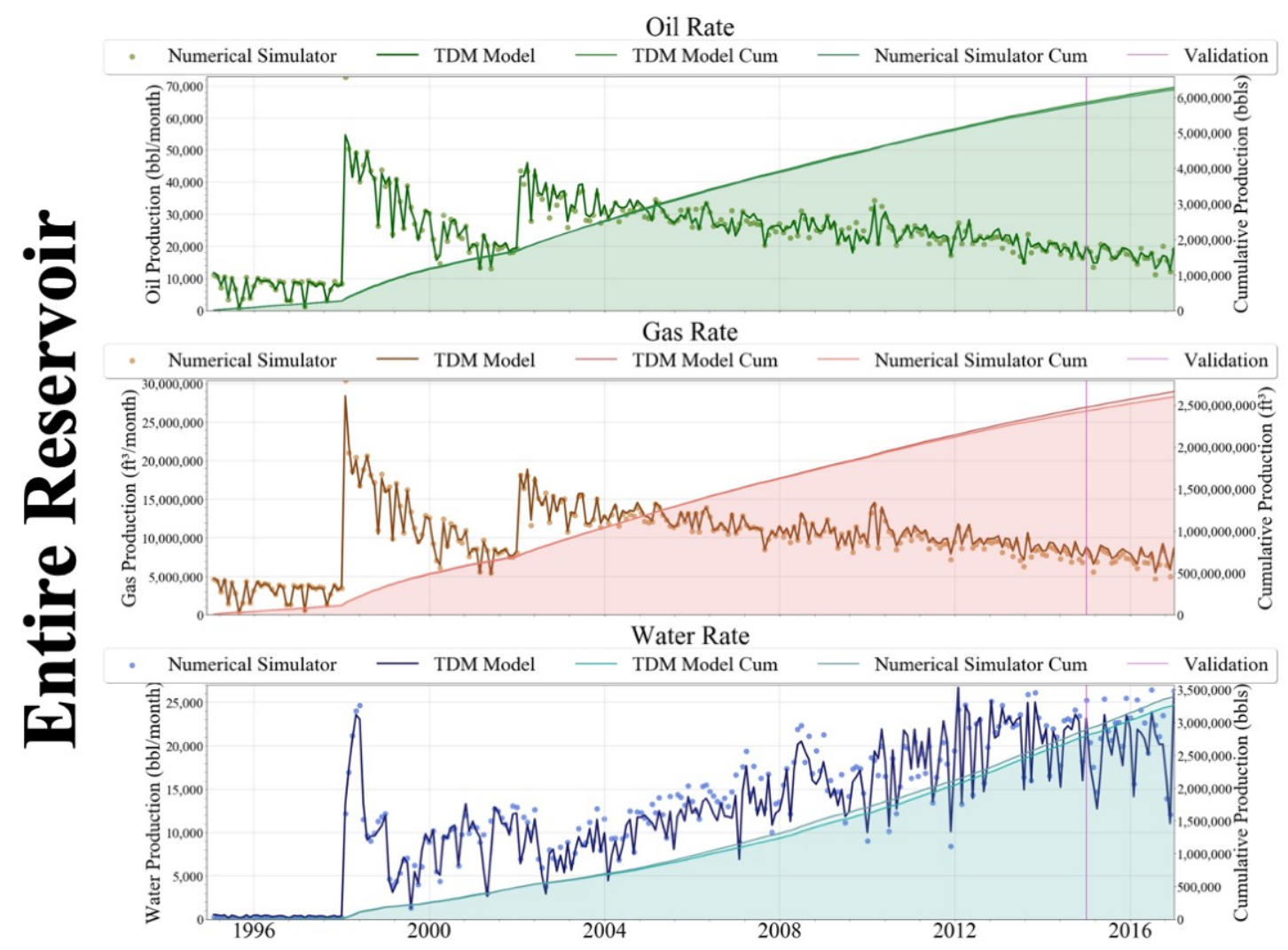

Figure 5-3: Scenario 3 - Entire Field Production Profiles 


\section{Scenario 4 - Mixed Partitioning TDM (1 Year Forecast)}

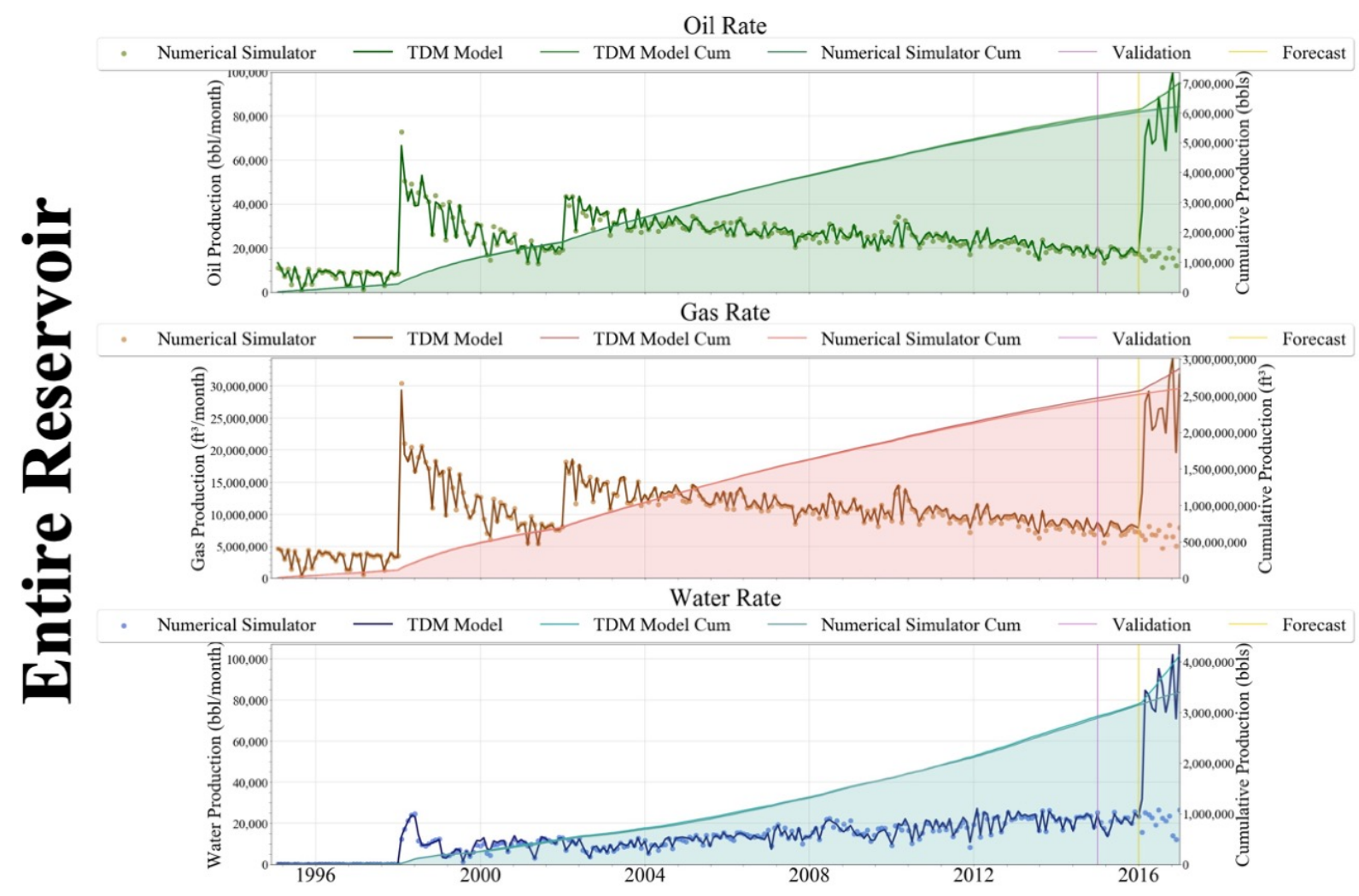

Figure 5-4: Scenario 4 - Entire Field Production Profiles 


\section{Scenario 5 - Mixed Partitioning TDM (2 Year Validation)}

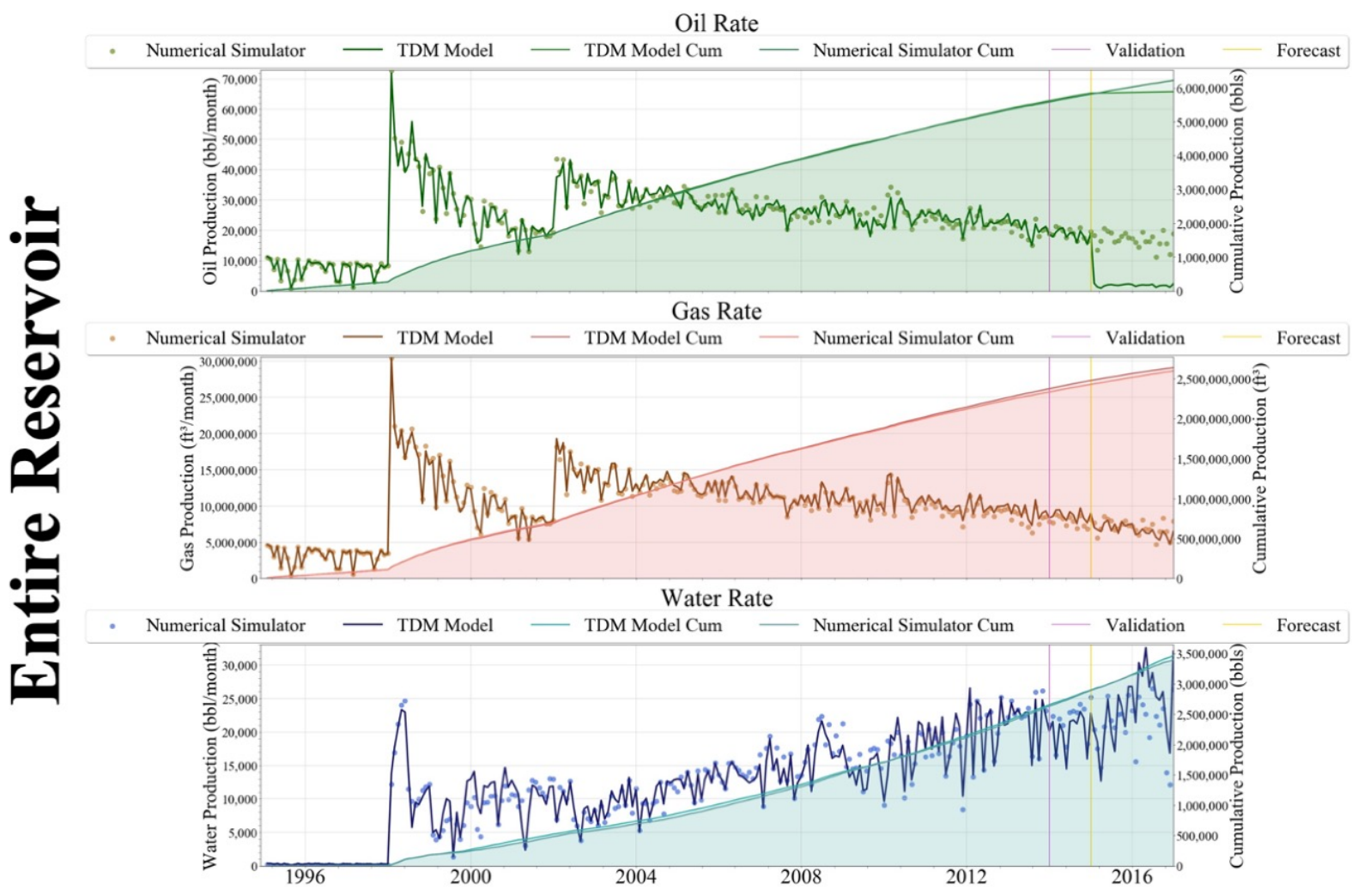

Figure 5-5: Scenario 5 - Entire Field Production Profiles 
Furthermore, heat maps were generated to visualize reservoir pressure and water saturation distributions at different points in time by interpolating between the values reported at the well locations. Cubic interpolation was the preferred method as it provided the smoothest distribution maps against linear and nearest neighbor interpolations that resulted in distribution discontinuities. Figure 5-7 and Figure 5-8 shows distribution maps at selected timesteps during blind validation and forecast. For example, if the second scenario performed blind history-matching from January $1^{\text {st }}$ of 2016 until January $1^{\text {st }}$ of 2017 , the most appropriate timestep to visualize the reservoir pressure and water saturation distributions during the blind validation was in June of 2016.

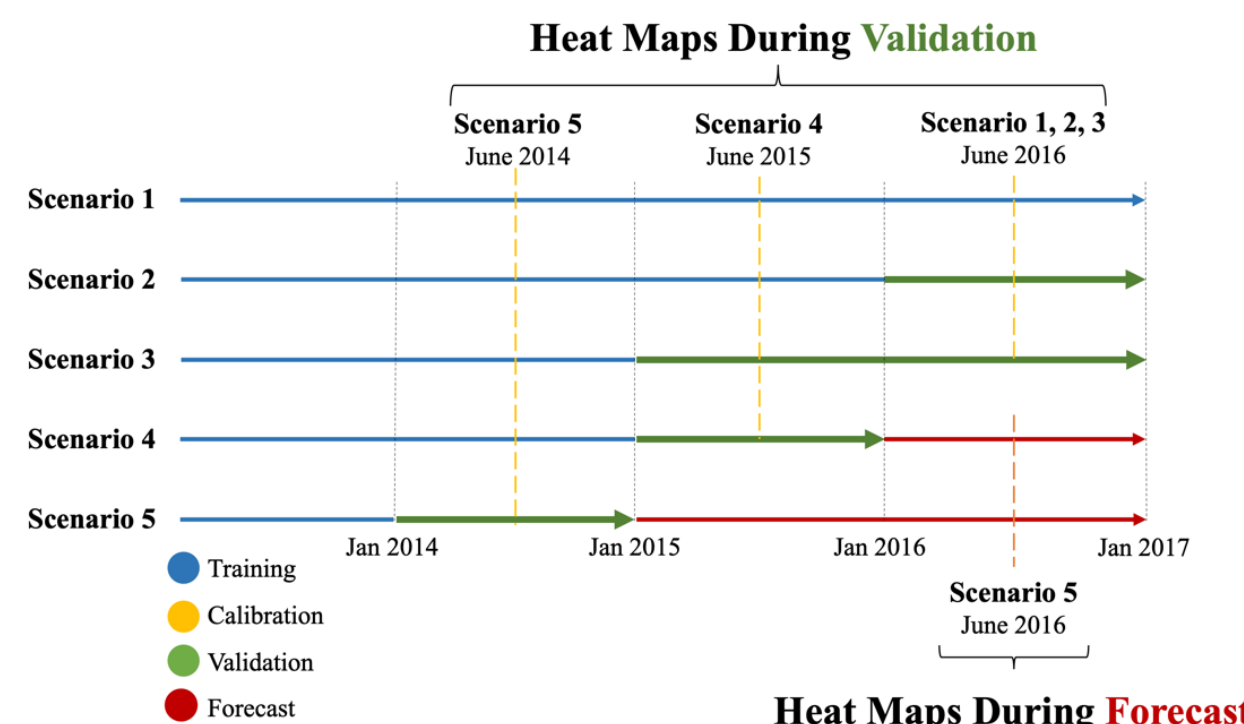

Figure 5-6: Selected Dates for Distribution Maps During Validation and Forecast

Water saturation distribution maps had higher percentage error near the boundaries of the reservoir. This was potentially influenced by the following:

a. The difference between the numerical reservoir boundary and the TDM's reservoir boundary. As it was previously described in section 4.3.1, the TDM boundary was manually drawn as closely as possible to the numerical reservoir boundary. This approach resulted in a misleading interpolation near the boundary of the reservoir.

b. Wells with a shorter production life located near the boundaries of the reservoir had less data to obtain an appropriate trend. 
c. Water saturation values from the neural network were not reported at timesteps when oil production was zero. As a matter of fact, a forward filling technique was used to fill missing values.

Moreover, the percentage error for the 2-year-forecast TDM was lower for both reservoir pressure and water saturation distributions. As it will be discussed in upcoming sections, the 2-year-forecast TDM had a better forecasting performance overall when compared to the 1-year-forecast TDM. This is potentially related to the input attributes used in the development of each predictive model. 


\section{Distribution Maps During Validation}

\section{Scenario 1 - Random Partitioning TDM}

Reservoir Pressure (psi) at 2016-06-30
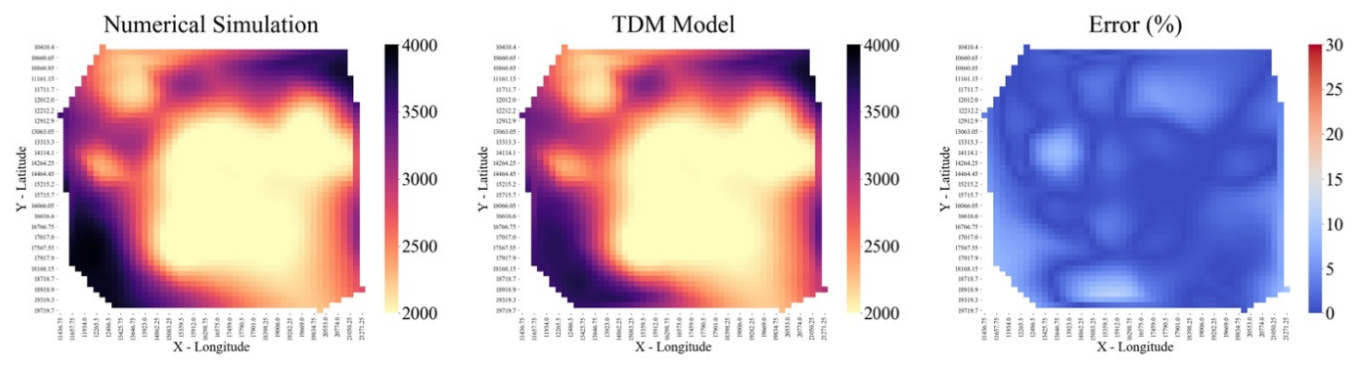

Water Saturation (\%) at 2016-06-30
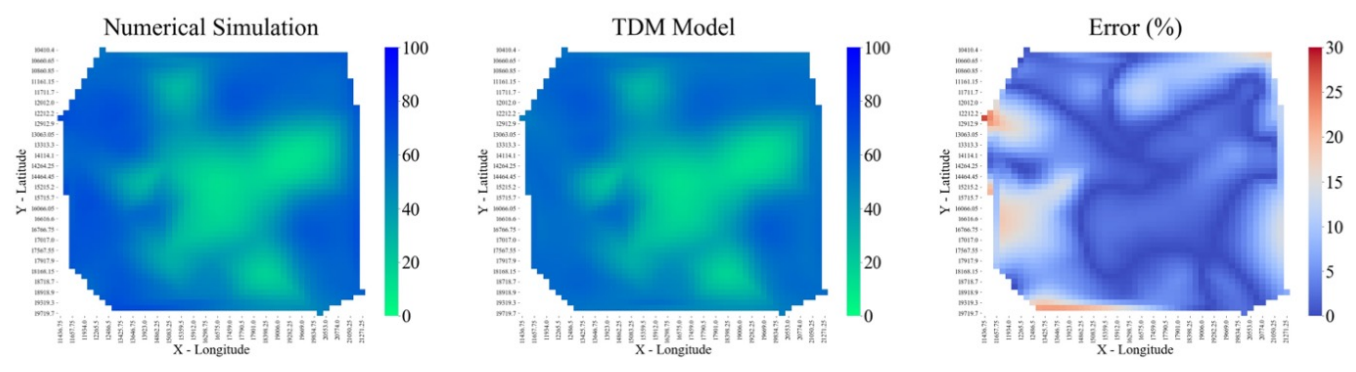

\section{Scenario 2 - Mixed Partitioning TDM (1 Year Validation)}

Reservoir Pressure (psi) at 2016-06-30
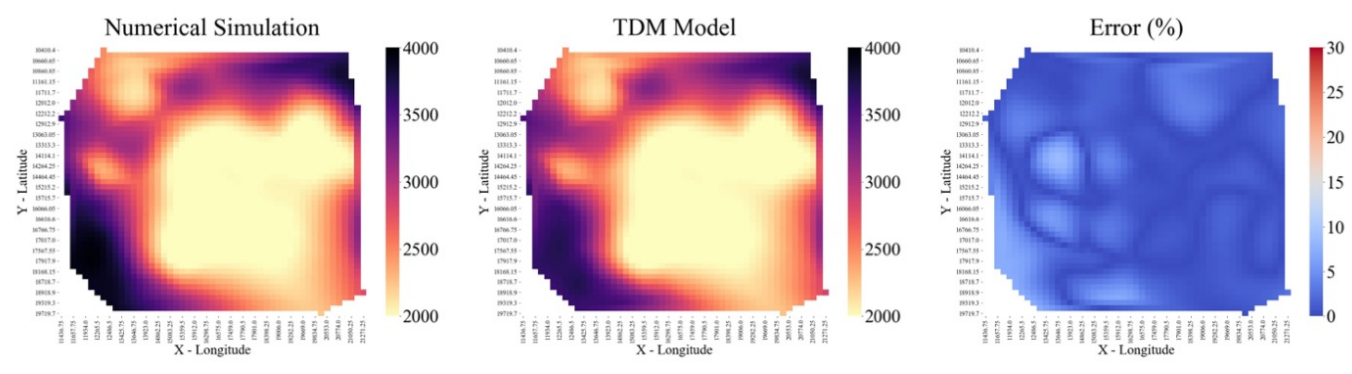

Water Saturation (\%) at 2016-06-30
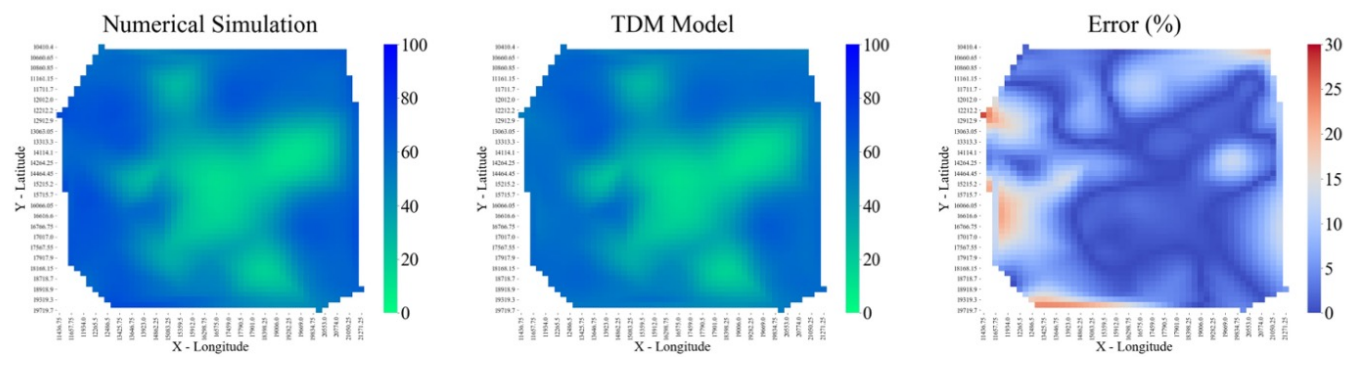


\section{Scenario 3 - Mixed Partitioning TDM (2 Year Validation)}

Reservoir Pressure (psi) at 2016-06-30
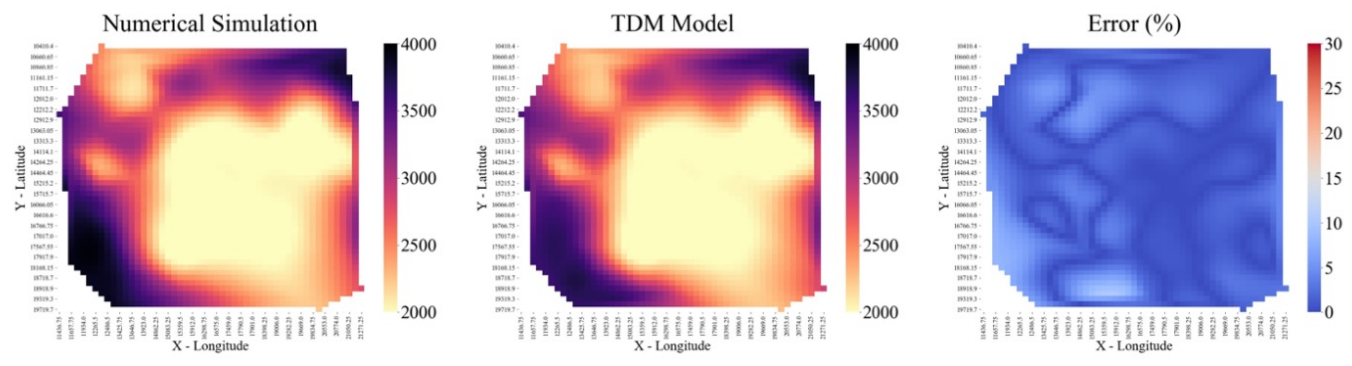

Water Saturation (\%) at 2016-06-30
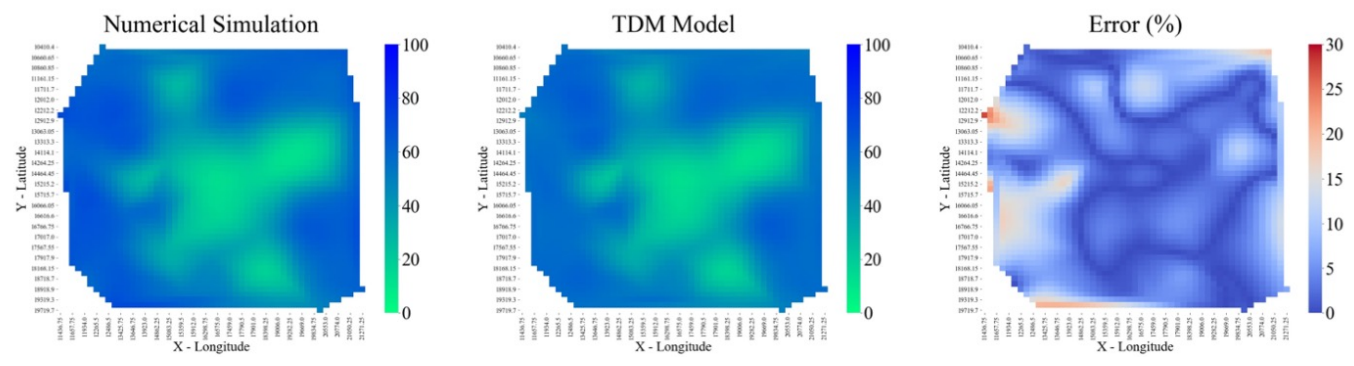

\section{Scenario 4 - Mixed Partitioning TDM (1 Year Forecast)}

Reservoir Pressure (psi) at 2015-06-30
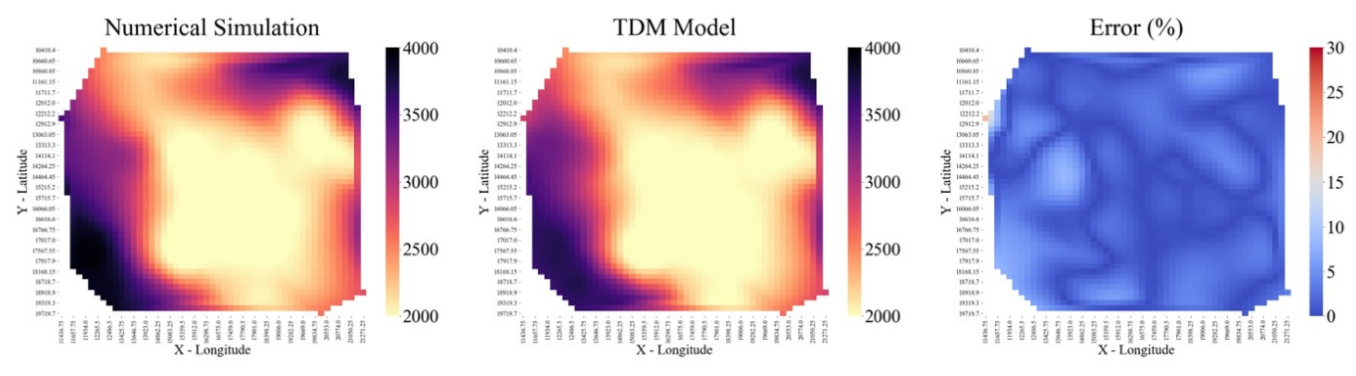

Water Saturation (\%) at 2015-06-30
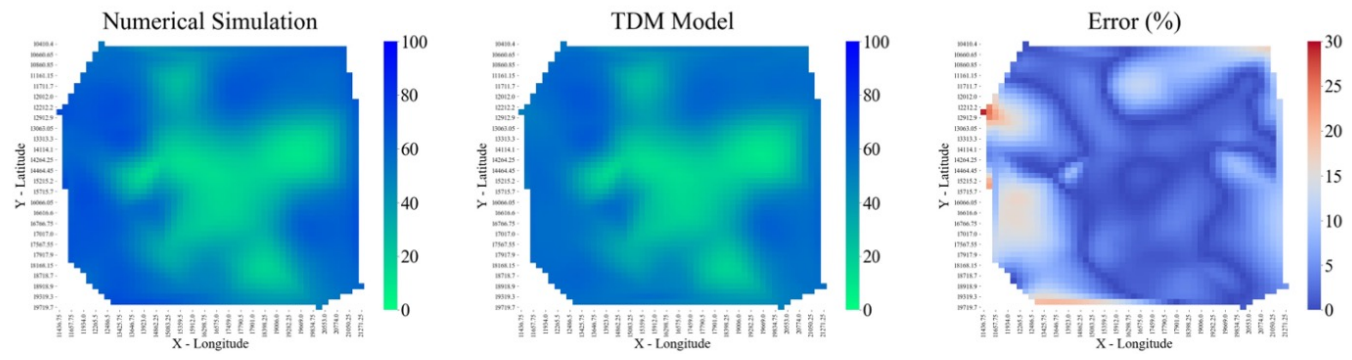


\section{Scenario 5 - Mixed Partitioning TDM (2 Year Forecast)}

Reservoir Pressure (psi) at 2014-06-30
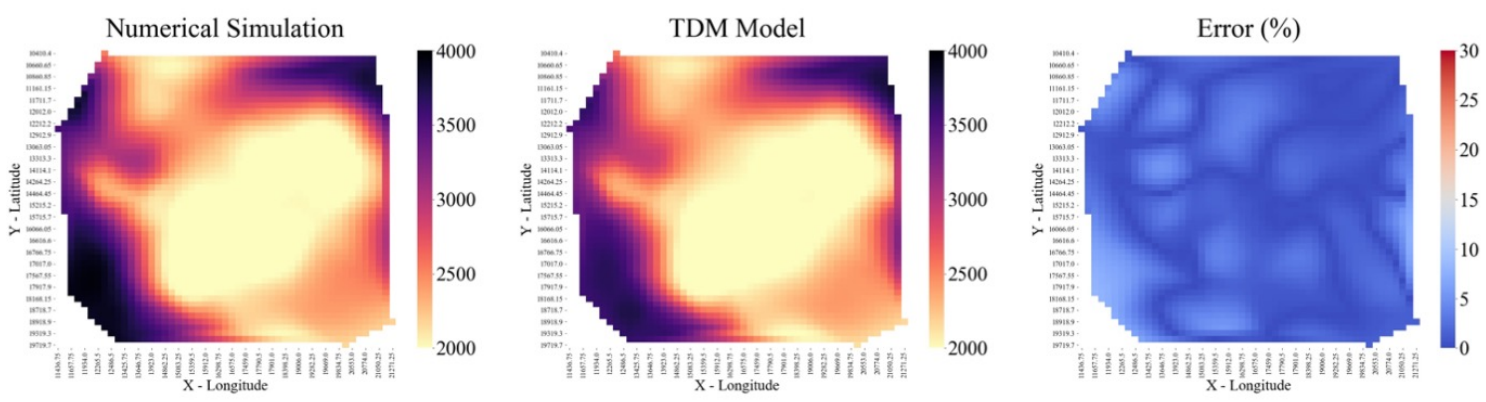

Water Saturation (\%) at 2014-06-30
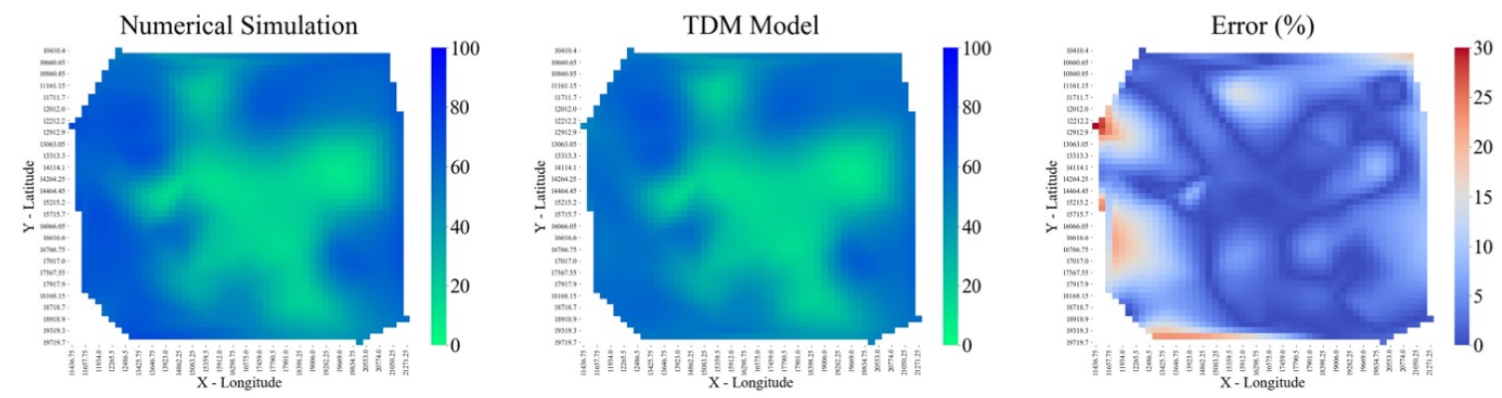

Figure 5-7: Distribution Maps During Validation 


\section{Distribution Maps During Forecast}

\section{Scenario 4 - Mixed Partitioning TDM (1 Year Forecast)}

Reservoir Pressure (psi) at 2016-06-30
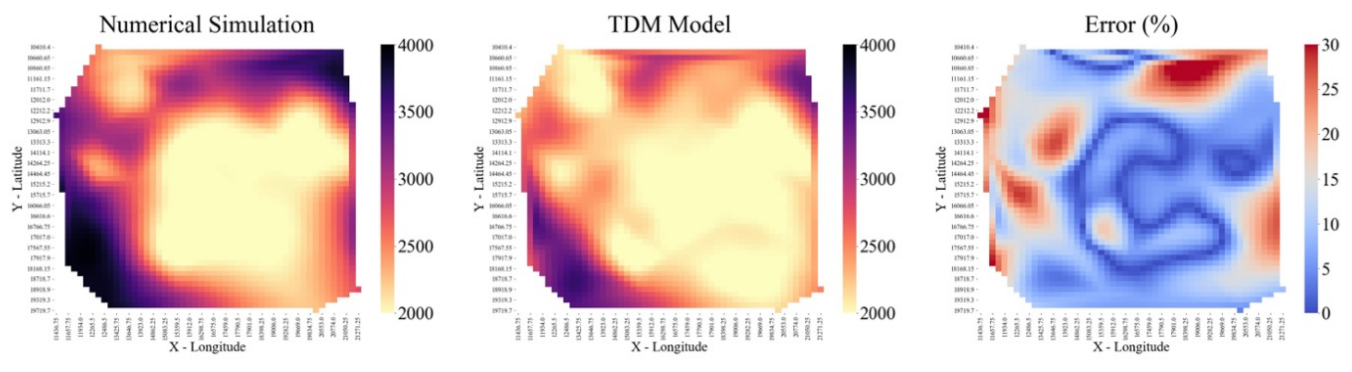

Water Saturation (\%) at 2016-06-30
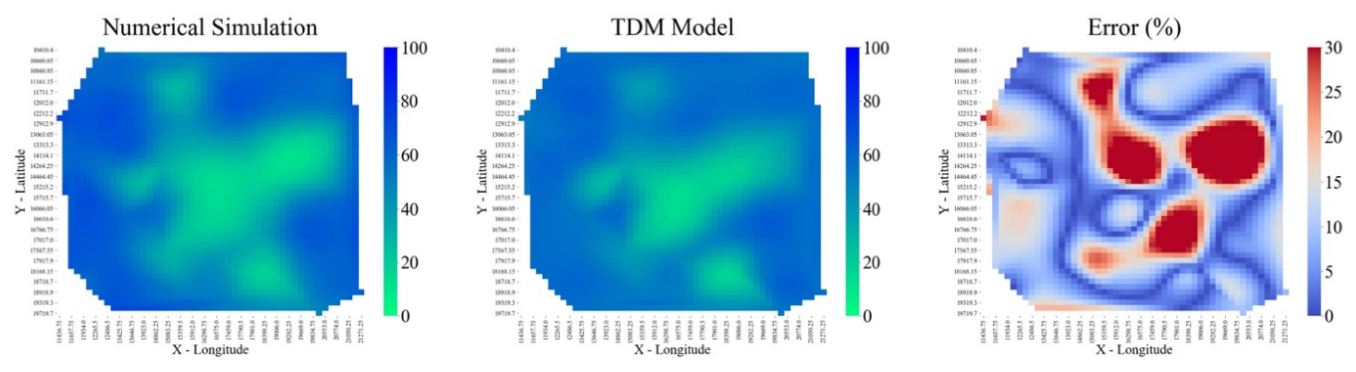

\section{Scenario 5 - Mixed Partitioning TDM (2 Year Forecast)}

Reservoir Pressure (psi) at 2016-06-30
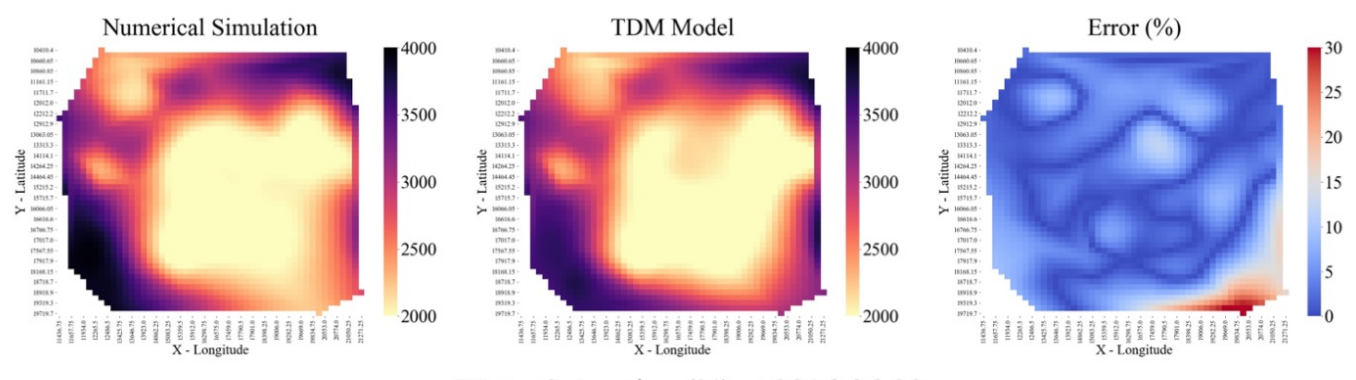

Water Saturation (\%) at 2016-06-30
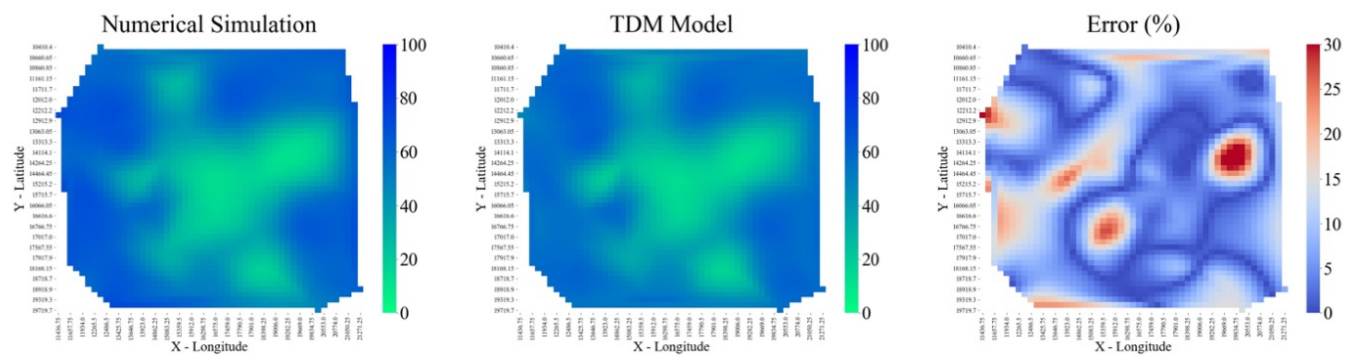

Figure 5-8: Distribution Maps During Forecast 


\subsection{Well by Well:}

Although high $R^{2}$ and low MSE described the quality of the trained networks, these criteria were re-evaluated by visually inspecting the history match of production profiles both individually and collectively.

\subsubsection{Individual Production Analysis:}

Oil, gas, and water production rates were evaluated on an individual well by well basis and labeled as having and "good", "average" or "poor" match against the actual production rates. Wells with a good match had a close if not an exact match against the actual production rate being evaluated. Figure 5-9 displays examples of individual production profiles with a good history match. Wells with an average prediction were able to match production for some portions of time while at other instances, the predictions did not match the simulation data as closely. Examples of average predictions are displayed in Figure 5-10. Wells with a poor match had were unable to closely follow the actual production trend. Examples of poor predictions are displayed in Figure 5-11. 


\section{Good History Match of Individual Production Rates}

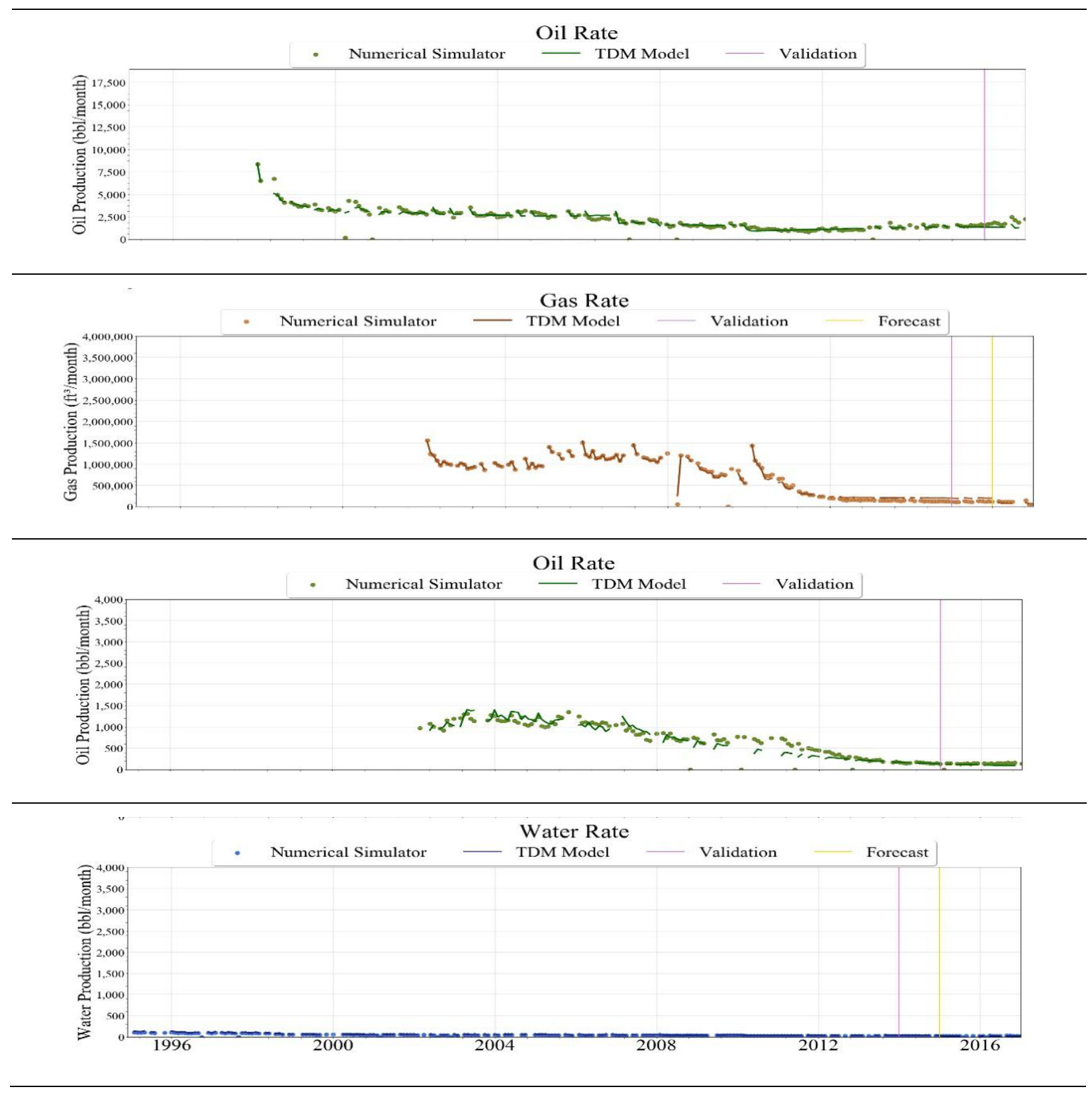

Figure 5-9: Good History Match of Individual Production Profiles 


\section{Average History Match of Individual Production Rates}

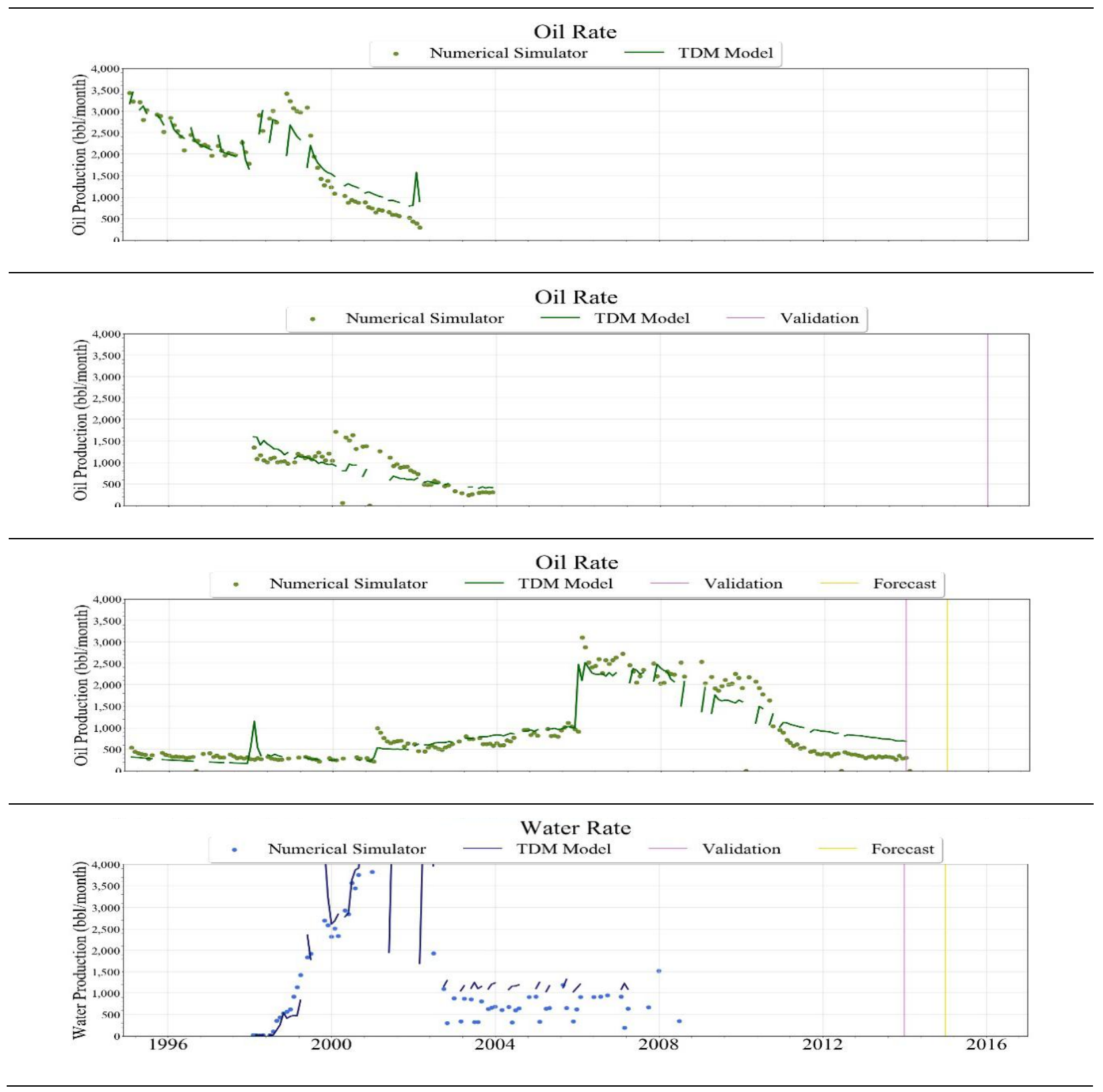

Figure 5-10: Average History Match of Individual Production Profiles 


\section{Poor History Match of Individual Production Rates}

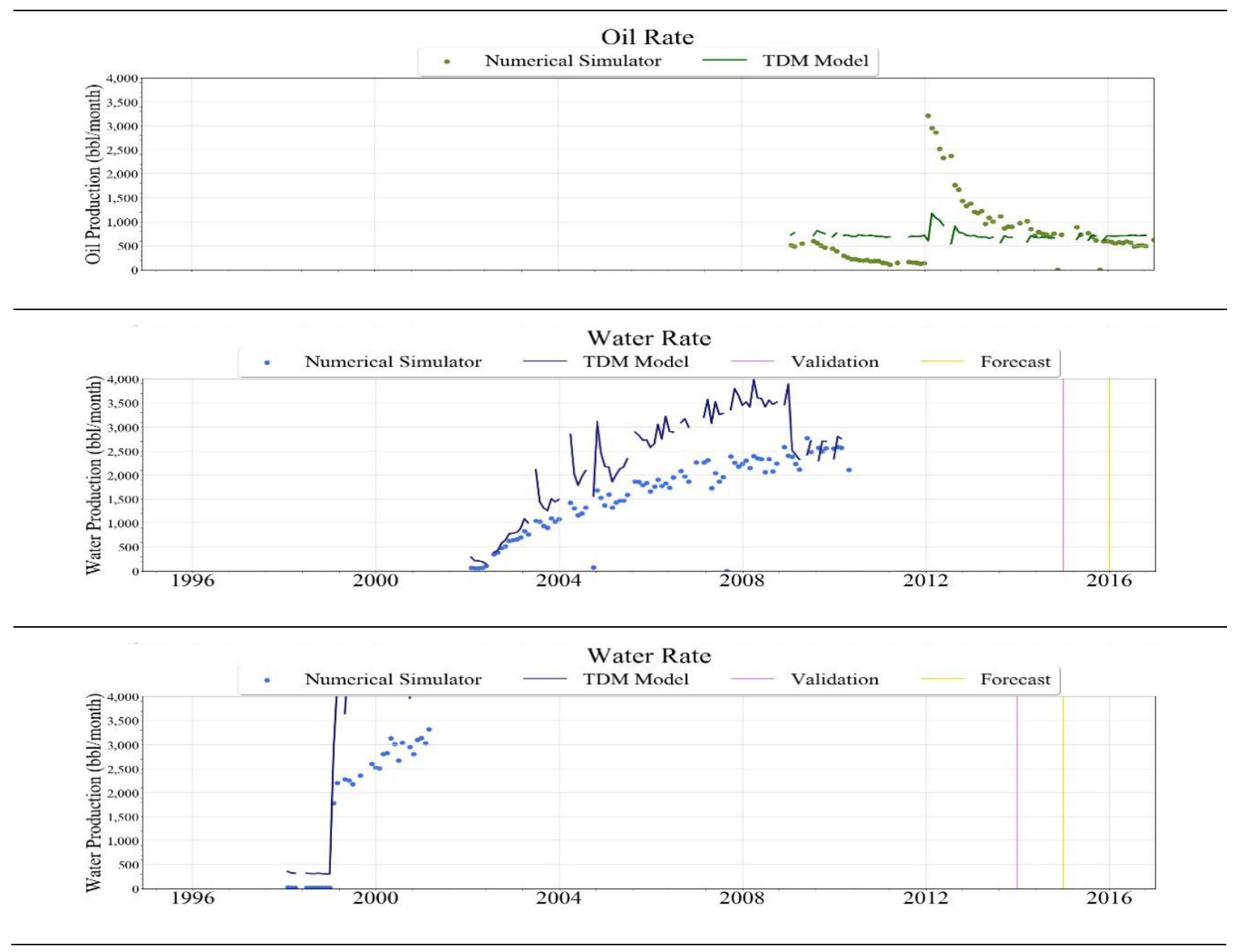

Figure 5-11: Poor History Match of Individual Production Profiles 
Table 5-3 provides the number or percentage of wells with good, average, and poor history match of three production rates for every TDM model. Overall, more than $70 \%$ of the wells presented good history matches for every production rate.

The fourth TDM model had the highest percentage of wells with a good history match of oil production while the second TDM had the highest number of wells with good water predictions. The gas rate, on the other hand, remained highly accurate across all the TDM models. Moreover, the number of wells with poor history matches did not exceed $2 \%$.

Table 5-3: History Match Accuracy of Individual Production Rates

\begin{tabular}{|c|c|c|c|c|c|c|c|c|c|c|c|}
\hline \multirow{2}{*}{\multicolumn{2}{|c|}{$\begin{array}{c}\text { History Match } \\
\text { Accuracy }\end{array}$}} & \multicolumn{2}{|c|}{ Scenario 1} & \multicolumn{2}{|c|}{ Scenario 2} & \multicolumn{2}{|c|}{ Scenario 3} & \multicolumn{2}{|c|}{ Scenario 4} & \multicolumn{2}{|c|}{ Scenario 5} \\
\hline & & No. Wels & Percentage & No. Wels & Percentage & No. Wels & Percentage & No. Wels & Percentage & No. Wels & Percentage \\
\hline \multirow{3}{*}{ Oil } & Good & 42 & $74 \%$ & 40 & $70 \%$ & 42 & $74 \%$ & 51 & $89 \%$ & 40 & $70 \%$ \\
\hline & Average & 14 & $25 \%$ & 17 & $30 \%$ & 15 & $26 \%$ & 6 & $11 \%$ & 17 & $30 \%$ \\
\hline & Poor & 1 & $2 \%$ & 0 & $0 \%$ & 0 & $0 \%$ & 0 & $0 \%$ & 0 & $0 \%$ \\
\hline \multirow{3}{*}{ Gas } & Good & 57 & $100 \%$ & 57 & $100 \%$ & 57 & $100 \%$ & 57 & $100 \%$ & 57 & $100 \%$ \\
\hline & Average & 0 & $0 \%$ & 0 & $0 \%$ & 0 & $0 \%$ & 0 & $0 \%$ & 0 & $0 \%$ \\
\hline & Poor & 0 & $0 \%$ & 0 & $0 \%$ & 0 & $0 \%$ & 0 & $0 \%$ & 0 & $0 \%$ \\
\hline \multirow{3}{*}{ Water } & Good & 46 & $81 \%$ & 52 & $91 \%$ & 47 & $82 \%$ & 50 & $88 \%$ & 50 & $88 \%$ \\
\hline & Average & 11 & $19 \%$ & 4 & $7 \%$ & 9 & $16 \%$ & 5 & $9 \%$ & 6 & $11 \%$ \\
\hline & Poor & 0 & $0 \%$ & 1 & $2 \%$ & 1 & $2 \%$ & 2 & $4 \%$ & 1 & $2 \%$ \\
\hline
\end{tabular}

In a similar fashion, Table 5-4 provides the number or percentage of wells with good, average, and poor forecast of three production rates for the TDM models that were deployed on a blind dataset. The fourth TDM had a total of 35 wells with production from January $1^{\text {st }}, 2016$ until January $1^{\text {st }}$, 2017 (1-year forecast) while the fifth scenario had a total of 38 wells with production from January $1^{\text {st }}, 2015$ until January $1^{\text {st }}, 2017$ (2-year-forecast). The table suggests that the fifth TDM (2-yearforecast) had a higher number of wells with good forecast production rates. The fifth TDM also had a lower number of wells with poor forecast performance. 
Table 5-4: Forecast of Individual Production Rates

\begin{tabular}{|c|c|c|c|c|c|}
\hline \multirow{2}{*}{\multicolumn{2}{|c|}{$\begin{array}{c}\text { Forecast Production } \\
\text { Accuracy }\end{array}$}} & \multicolumn{2}{|c|}{ Scenario 4} & \multicolumn{2}{|c|}{ Scenario 5} \\
\hline & & No. Wels & Percentage & No. Wels & Percentage \\
\hline \multirow{3}{*}{ Oil } & Good & 15 & $44 \%$ & 21 & $57 \%$ \\
\hline & Average & 6 & $18 \%$ & 14 & $38 \%$ \\
\hline & Poor & 13 & $38 \%$ & 2 & $5 \%$ \\
\hline \multirow{3}{*}{ Gas } & Good & 24 & $71 \%$ & 32 & $86 \%$ \\
\hline & Average & 1 & $3 \%$ & 5 & $14 \%$ \\
\hline & Poor & 9 & $26 \%$ & 0 & $0 \%$ \\
\hline \multirow{3}{*}{ Water } & Good & 20 & $59 \%$ & 27 & $73 \%$ \\
\hline & Average & 4 & $12 \%$ & 10 & $27 \%$ \\
\hline & Poor & 10 & $29 \%$ & 0 & $0 \%$ \\
\hline
\end{tabular}

\subsubsection{Collective Production Analysis:}

Production rates were collectively evaluated and labeled as having an "good", "average", or "poor" history match of production. Example of wells with a good, average, and poor predictions are shown in Figure 5-12, Figure 5-13, and Figure 5-14 respectively. Furthermore, the last two TDM models were evaluated based on their forecast predictions. Figure 5-15, Figure 5-16, and Figure 5-17, illustrate wells with good, average, and poor forecast production. 


\section{Acceptable History Match of Production}

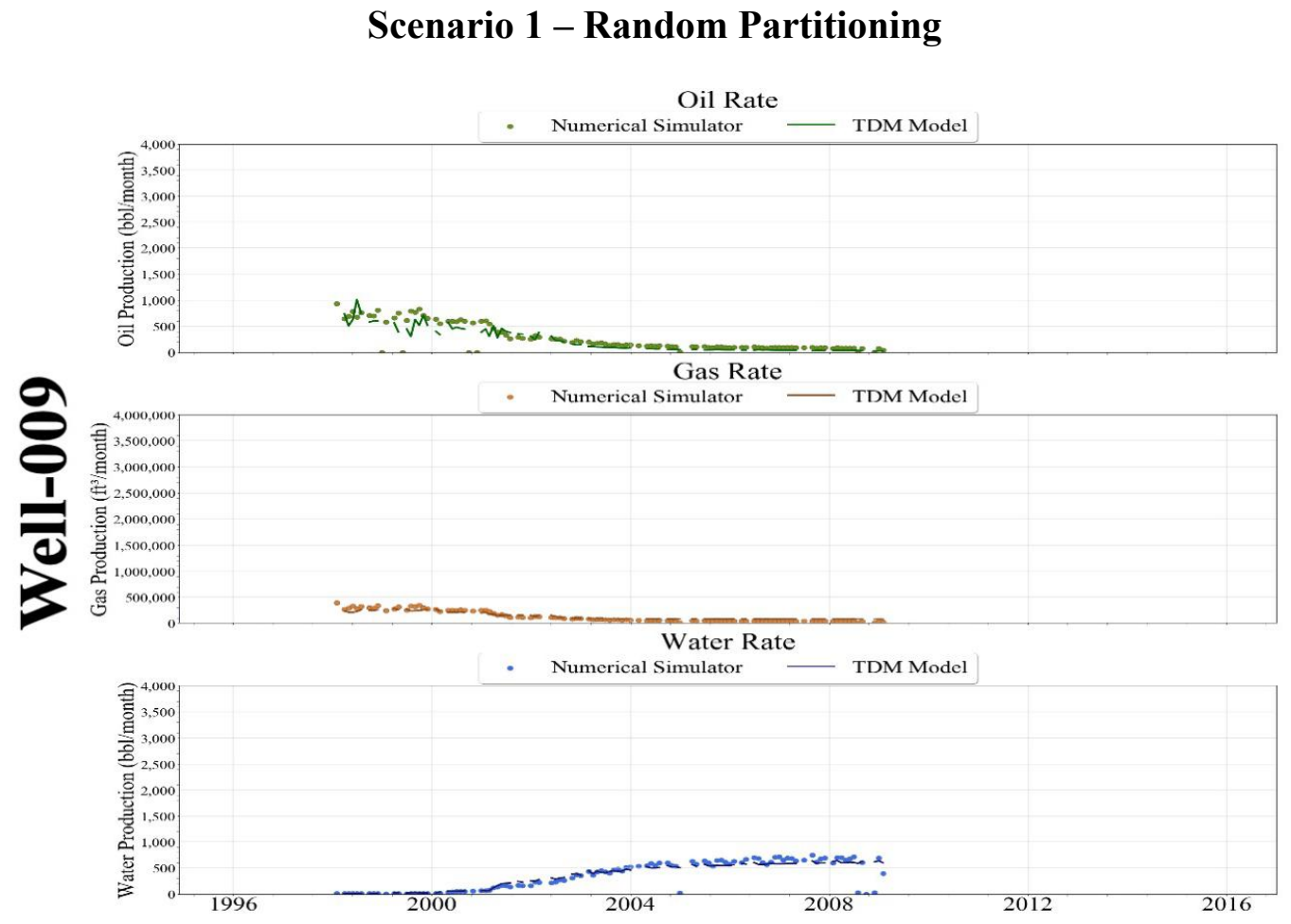

Scenario 2 - Mixed Partitioning TDM (1 Year Validation)

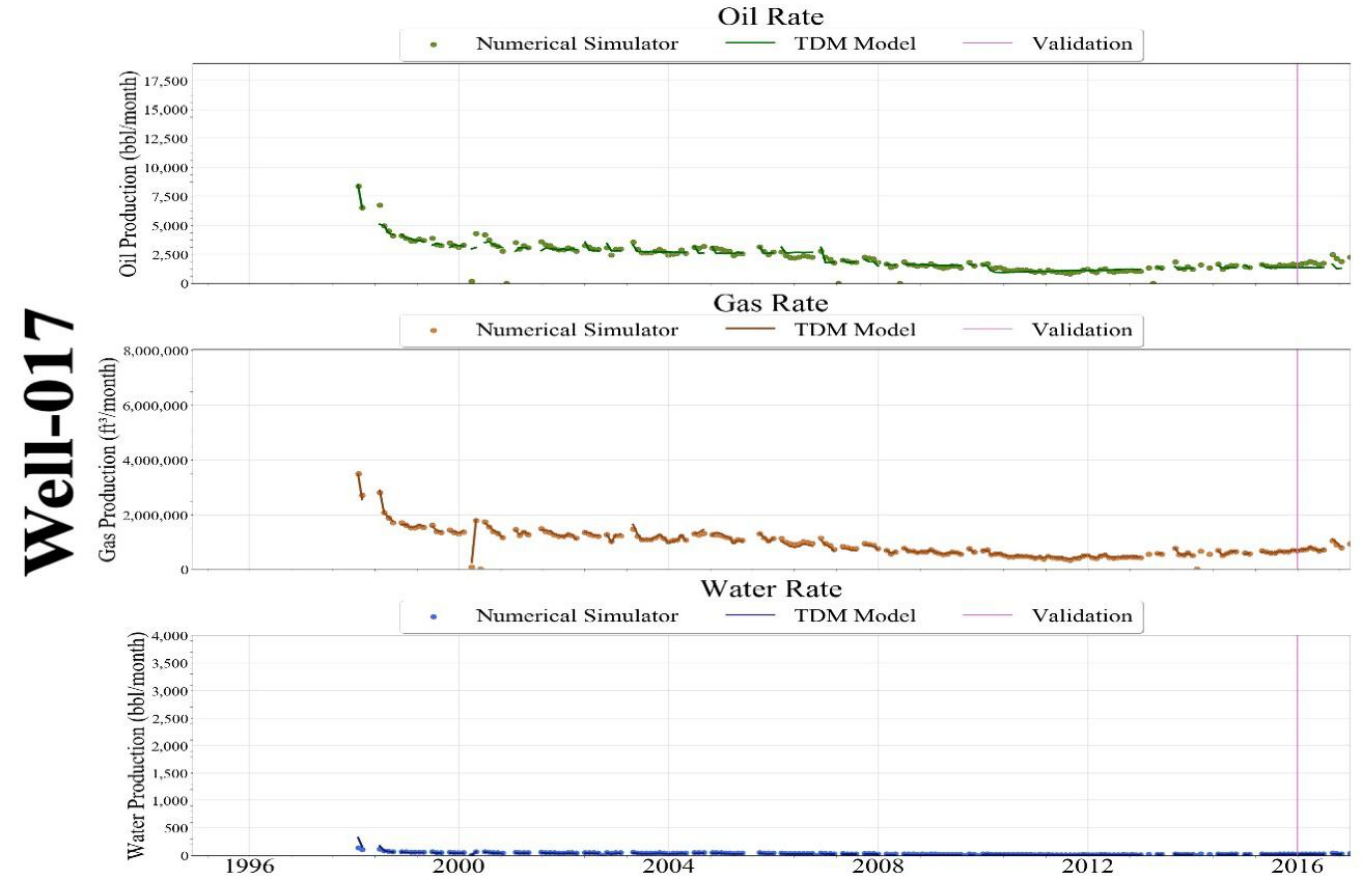




\section{Scenario 3 - Mixed Partitioning TDM (2 Year Validation)}

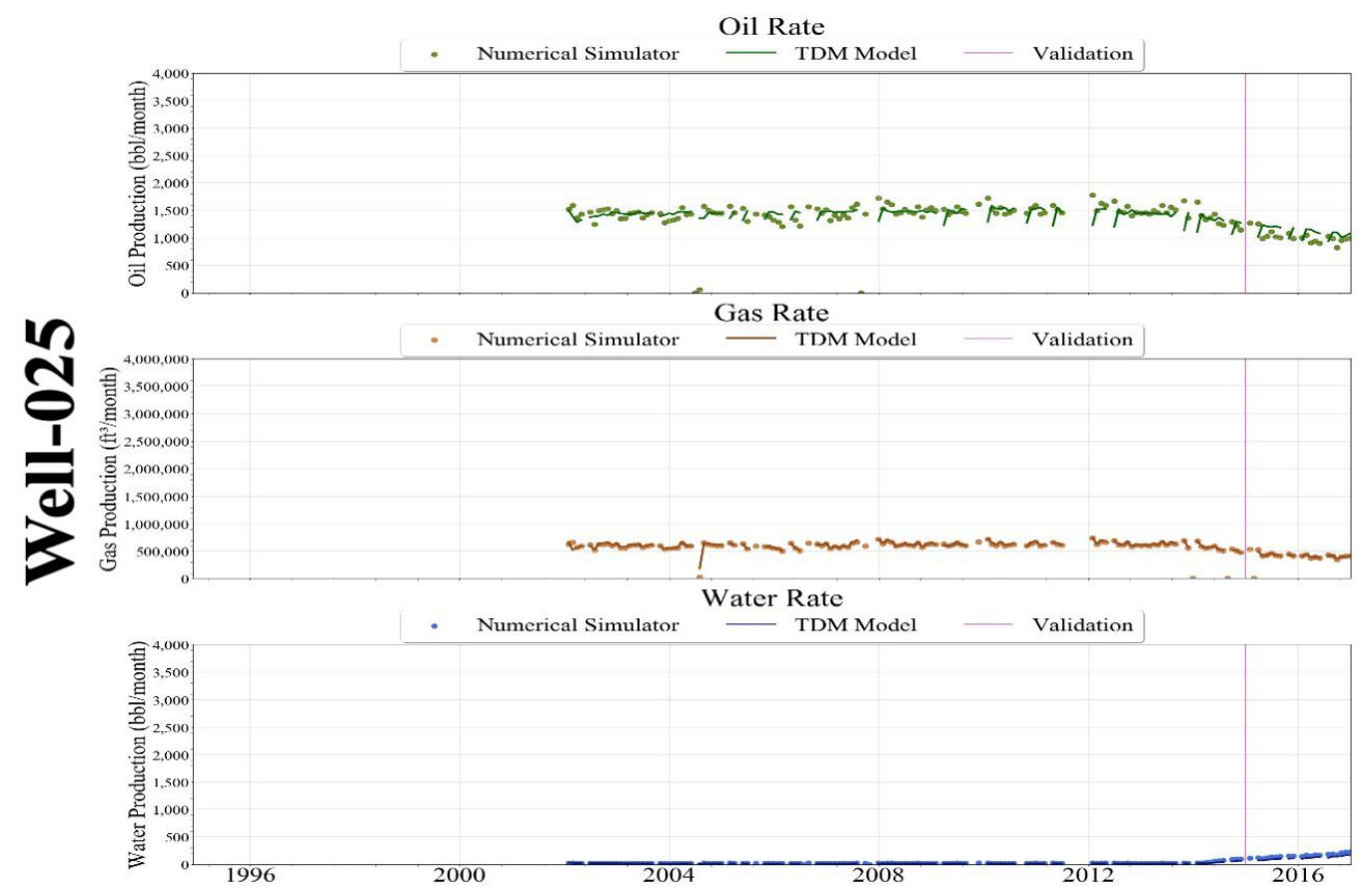

\section{Scenario 4 - Mixed Partitioning TDM (1 Year Forecast)}

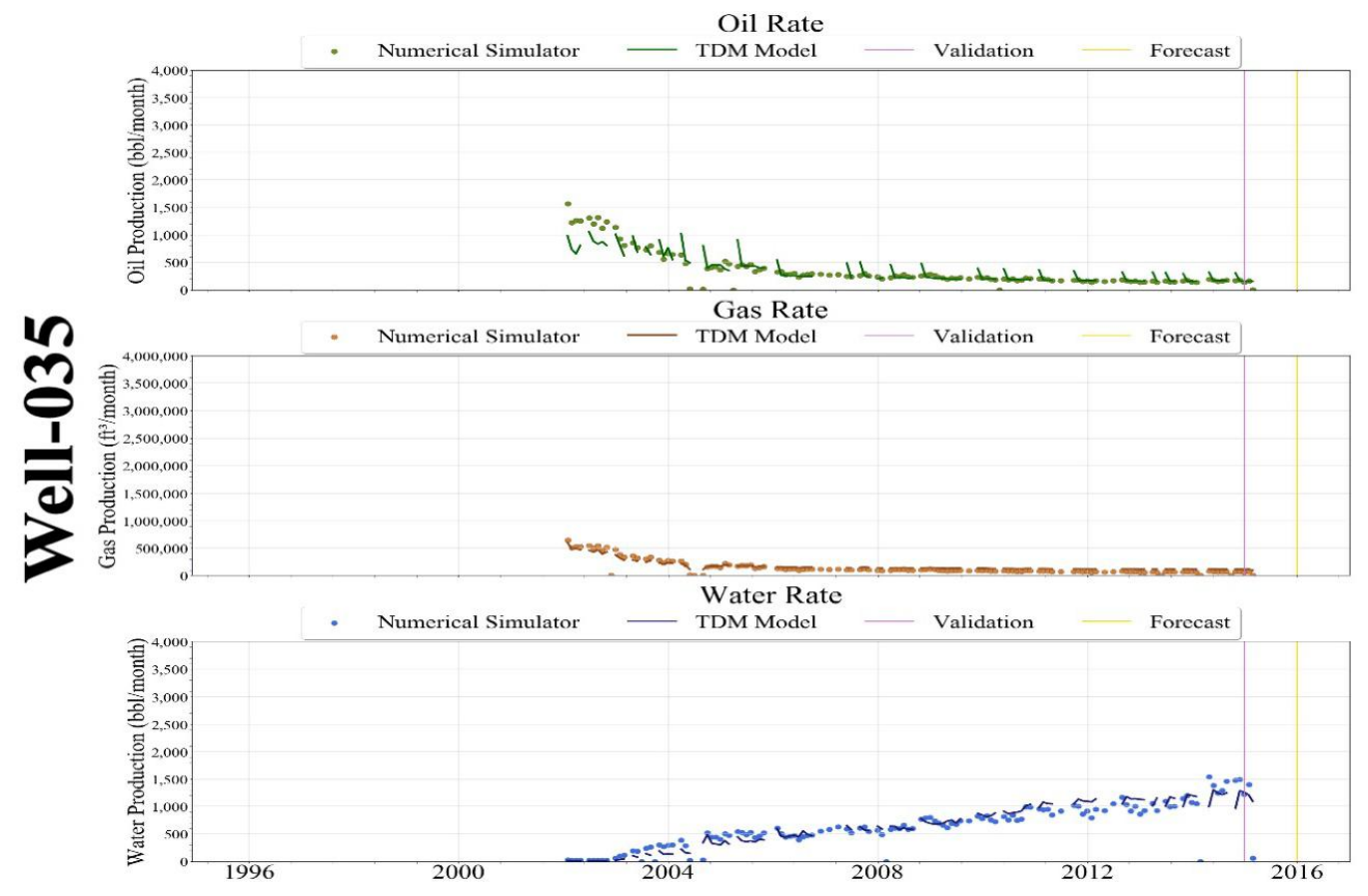




\section{Scenario 5 - Mixed Partitioning TDM (2 Year Forecast)}

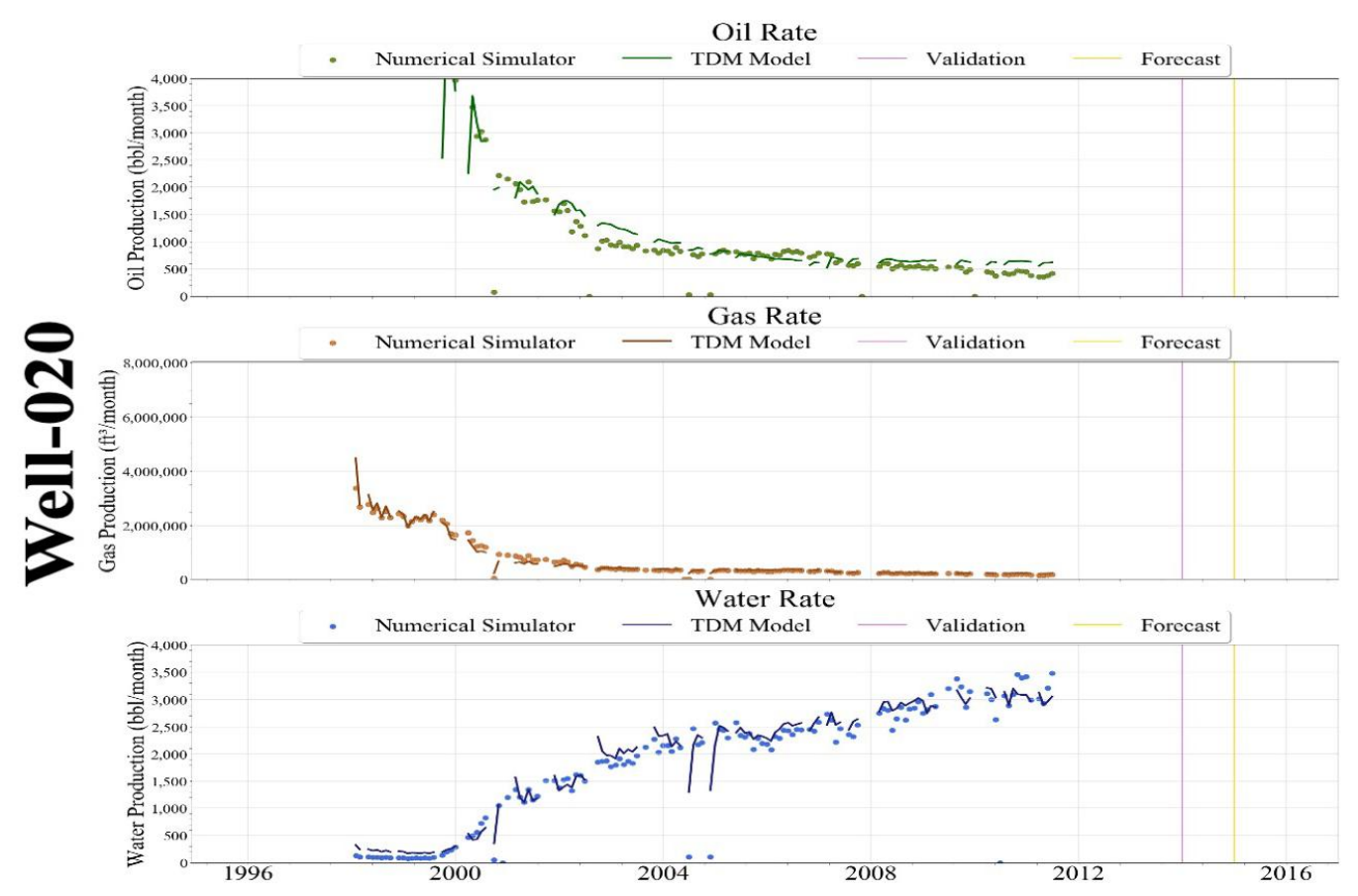

Figure 5-12: Acceptable History Match of Production 


\section{Average History Match of Production}

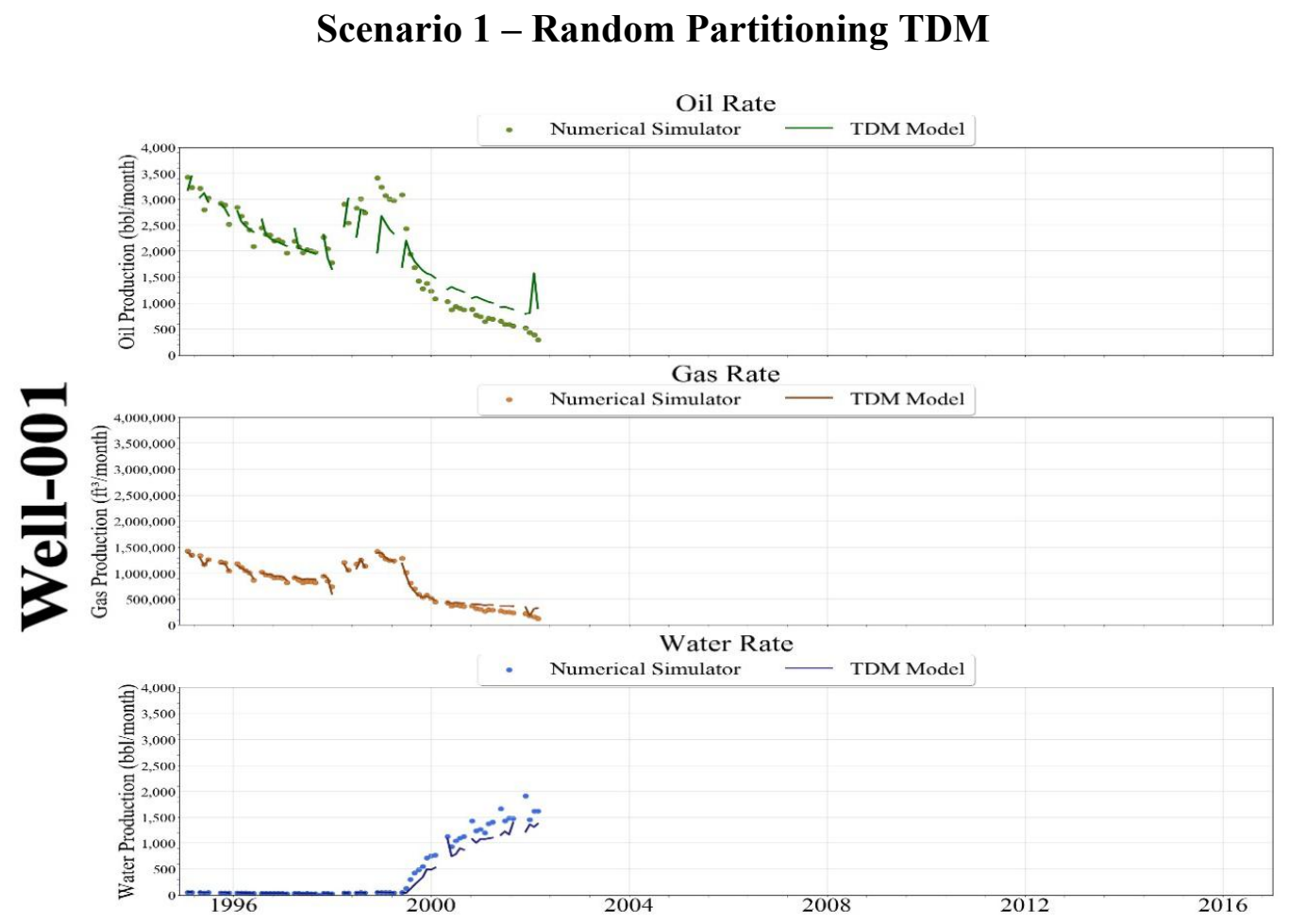

Scenario 2 - Mixed Partitioning TDM (1 Year Validation)

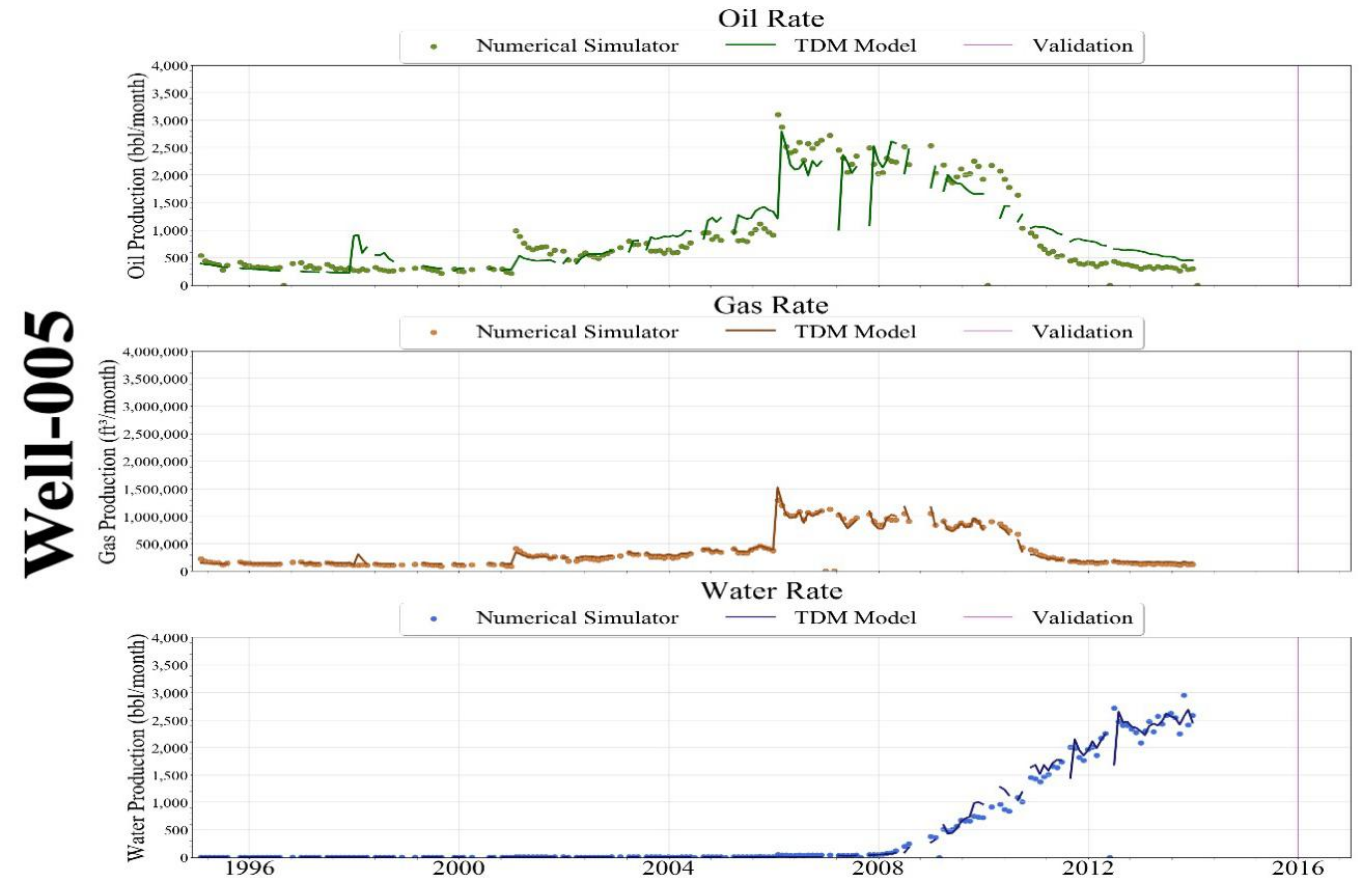


Scenario 3 - Mixed Partitioning TDM (2 Year Validation)

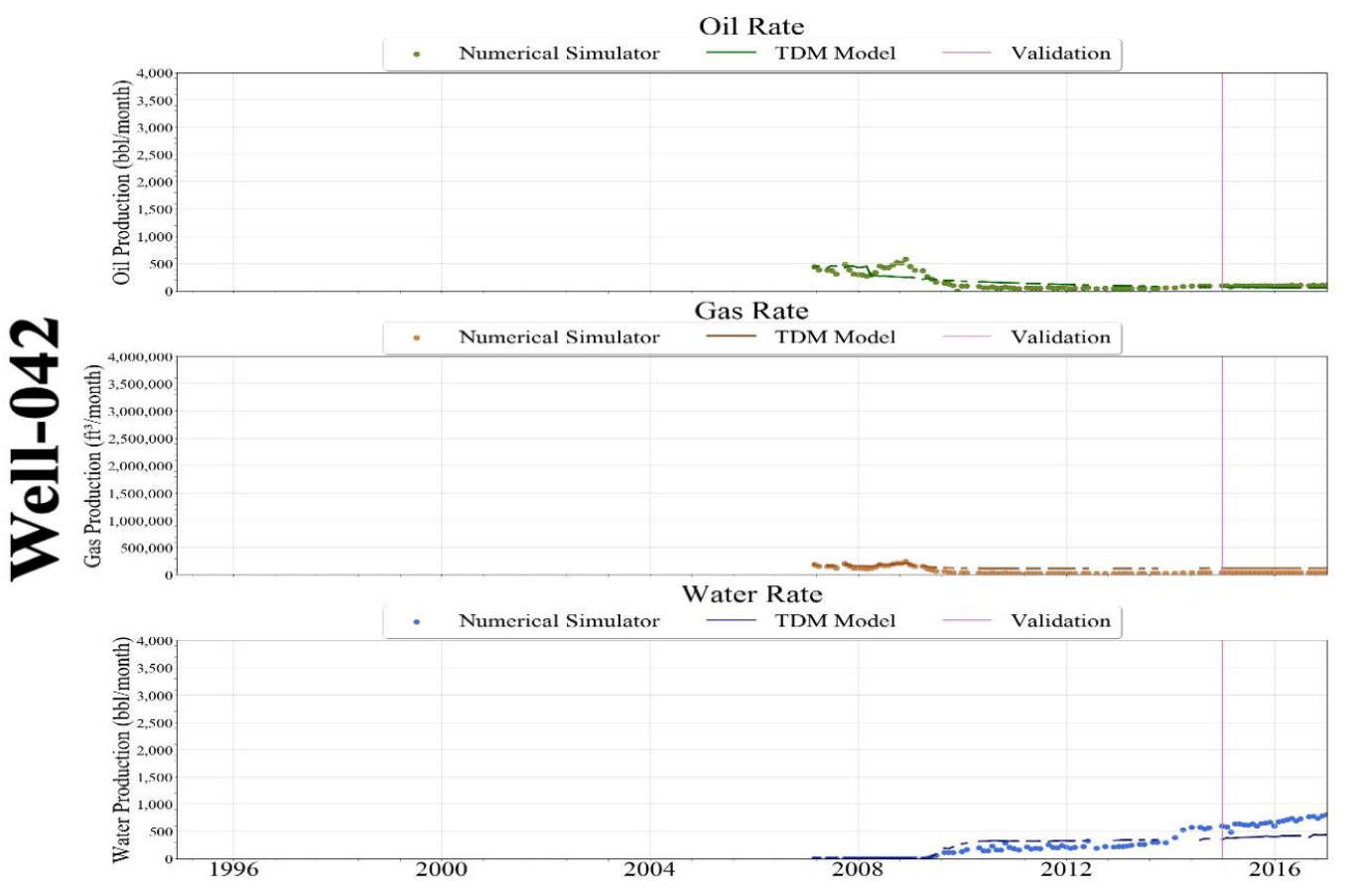

Scenario 4 - Mixed Partitioning TDM (1 Year Forecast)

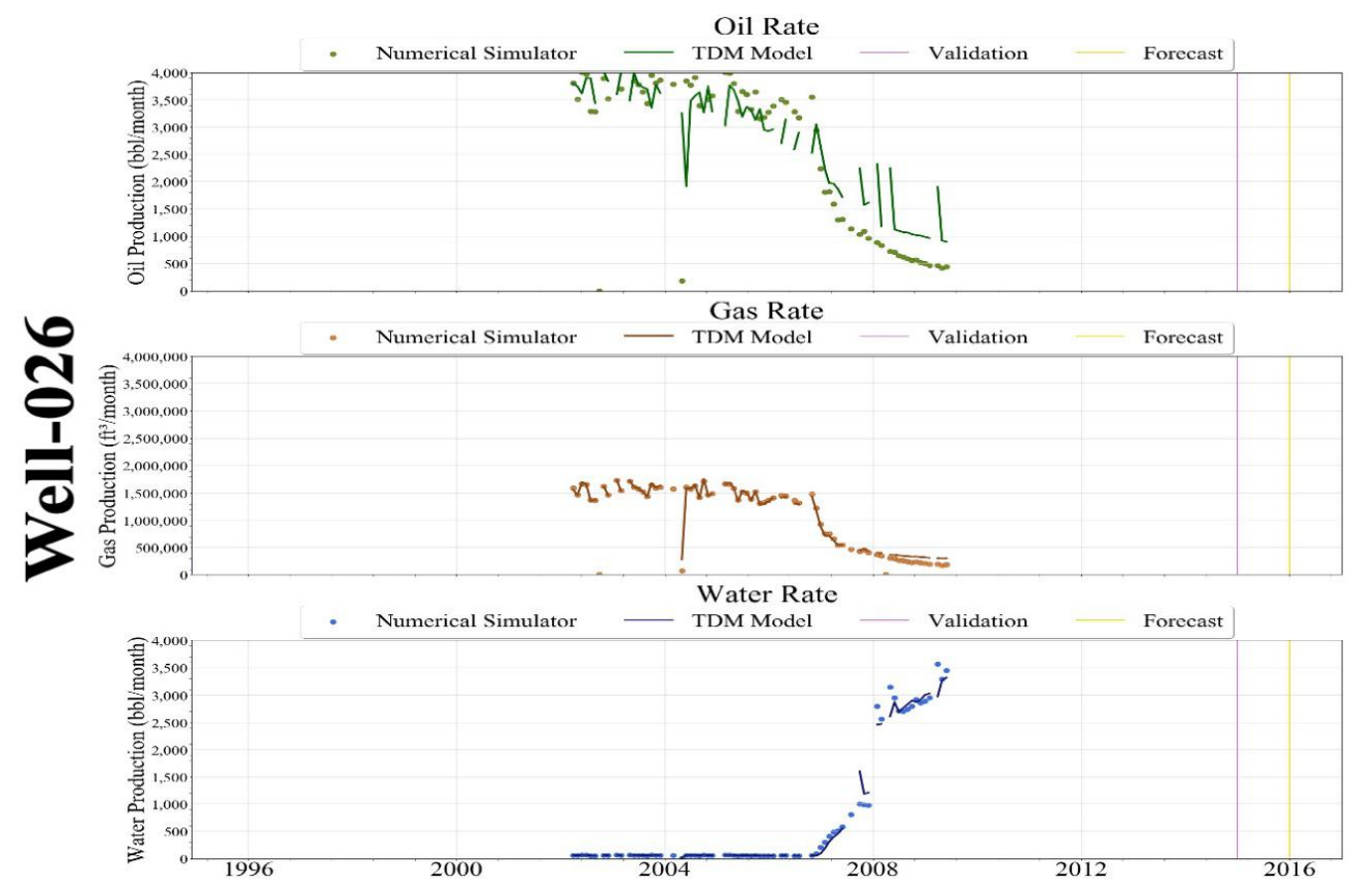




\section{Scenario 5 - Mixed Partitioning TDM (2 Year Forecast)}

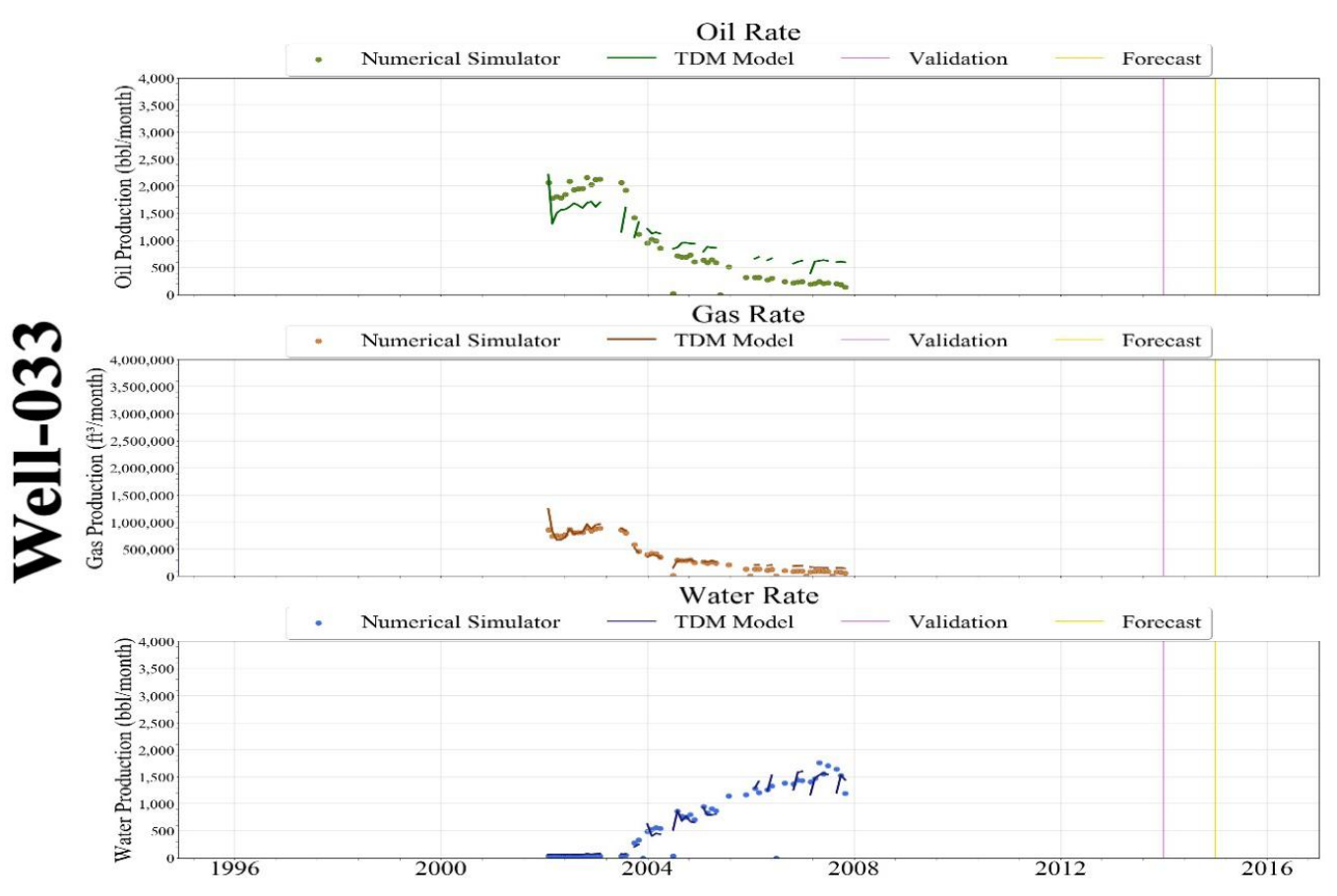

Figure 5-13: Average History Match of Production 


\section{Poor History Match of Production}

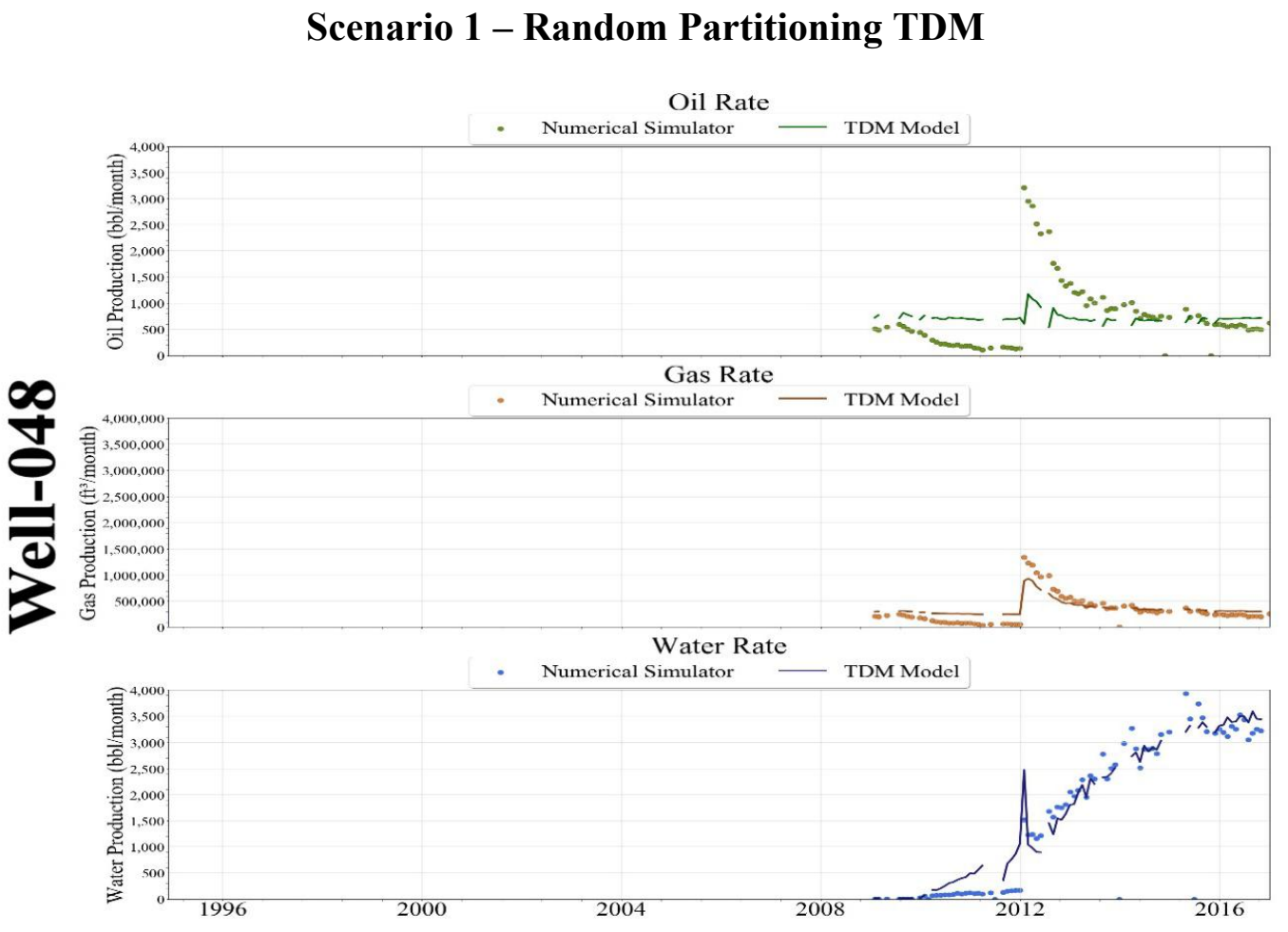

Scenario 2 - Mixed Partitioning TDM (1 Year Validation)

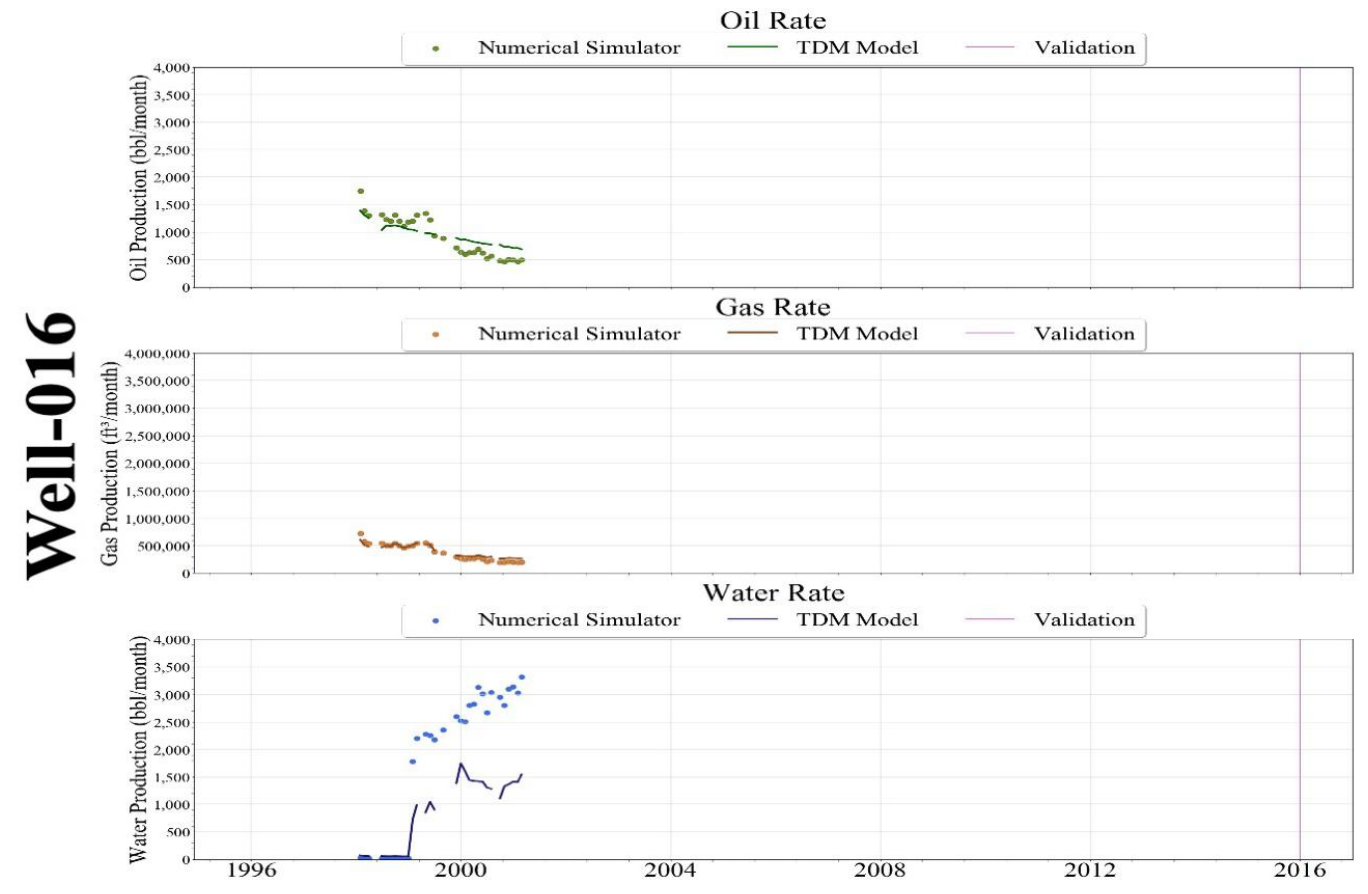




\section{Scenario 3 - Mixed Partitioning TDM (2 Year Validation)}

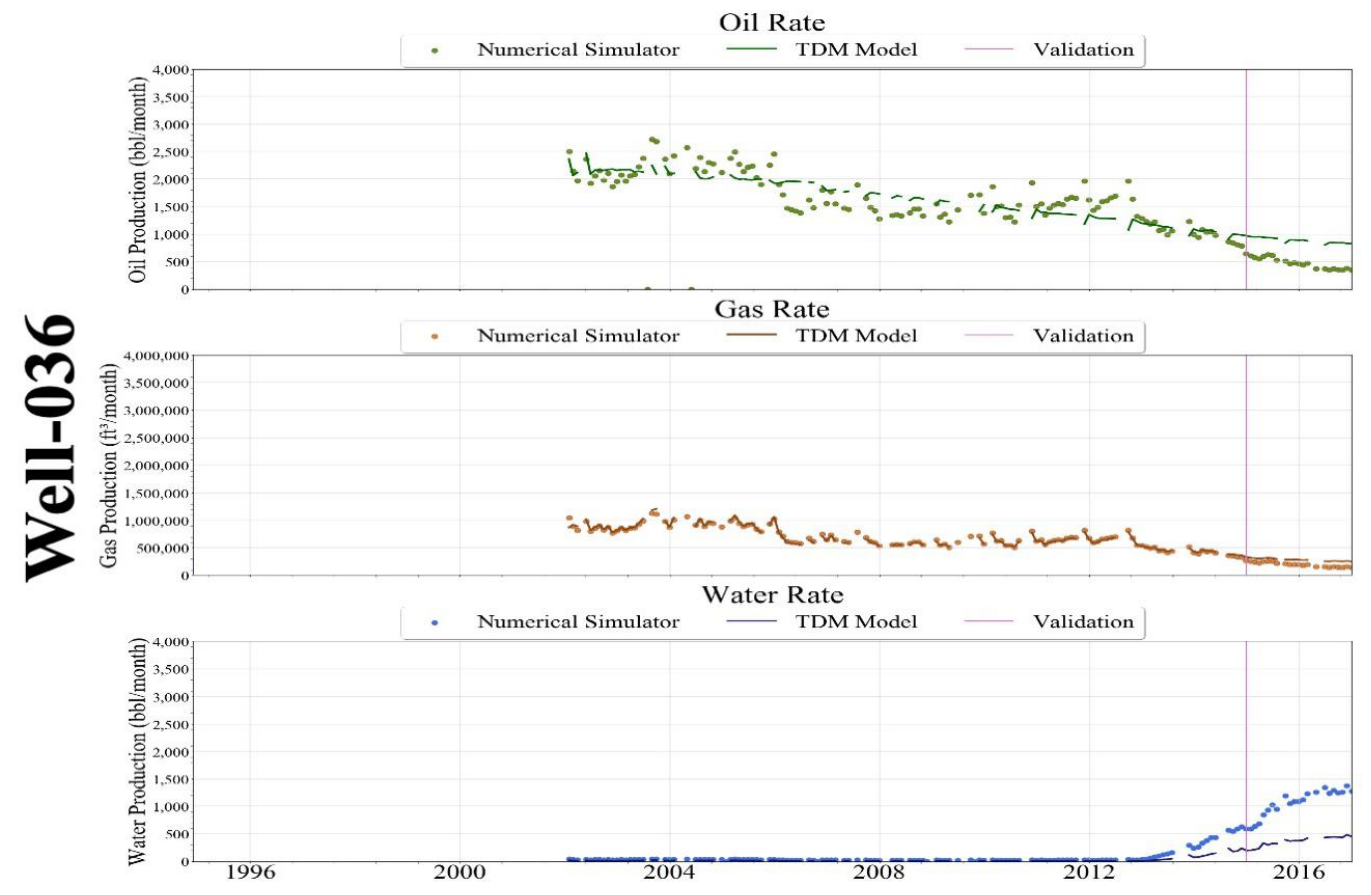

\section{Scenario 5 - Mixed Partitioning TDM (2 Year Forecast)}

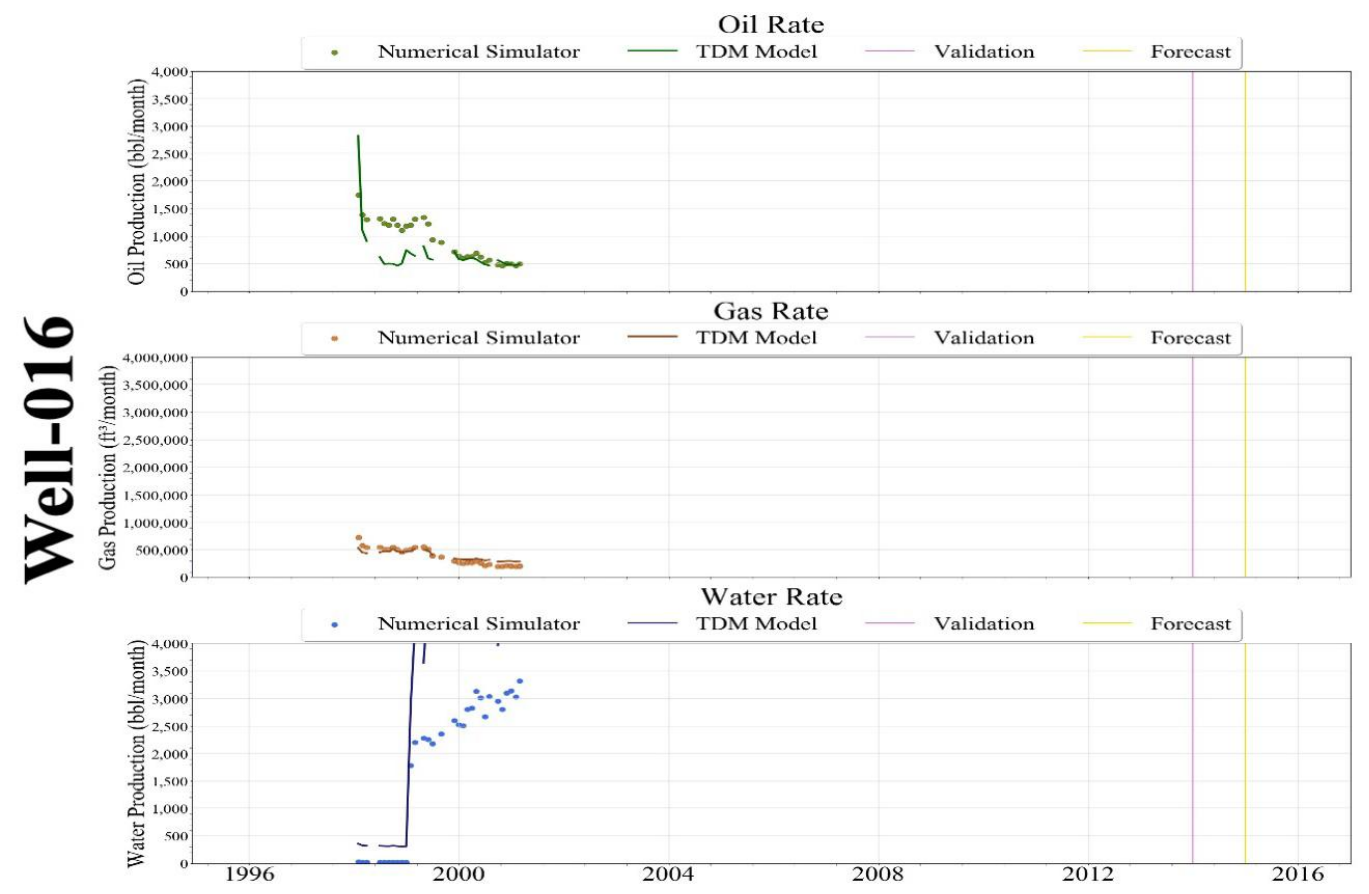

Figure 5-14: Poor Production History Match 


\section{Good Forecast Production}

\section{Scenario 4 - Mixed Partitioning TDM (1 Year Forecast)}

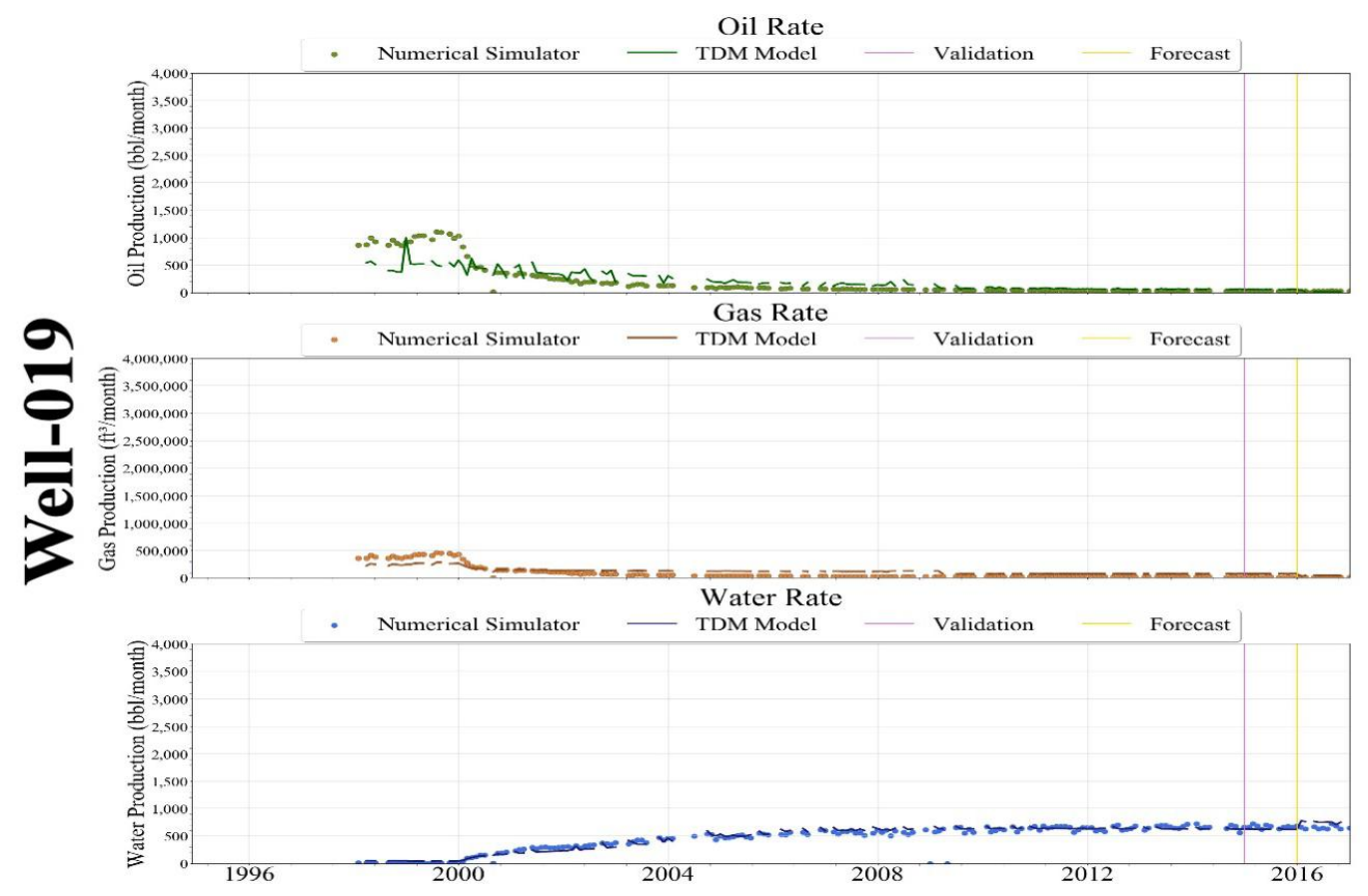

\section{Scenario 5 - Mixed Partitioning TDM (2 Year Forecast)}

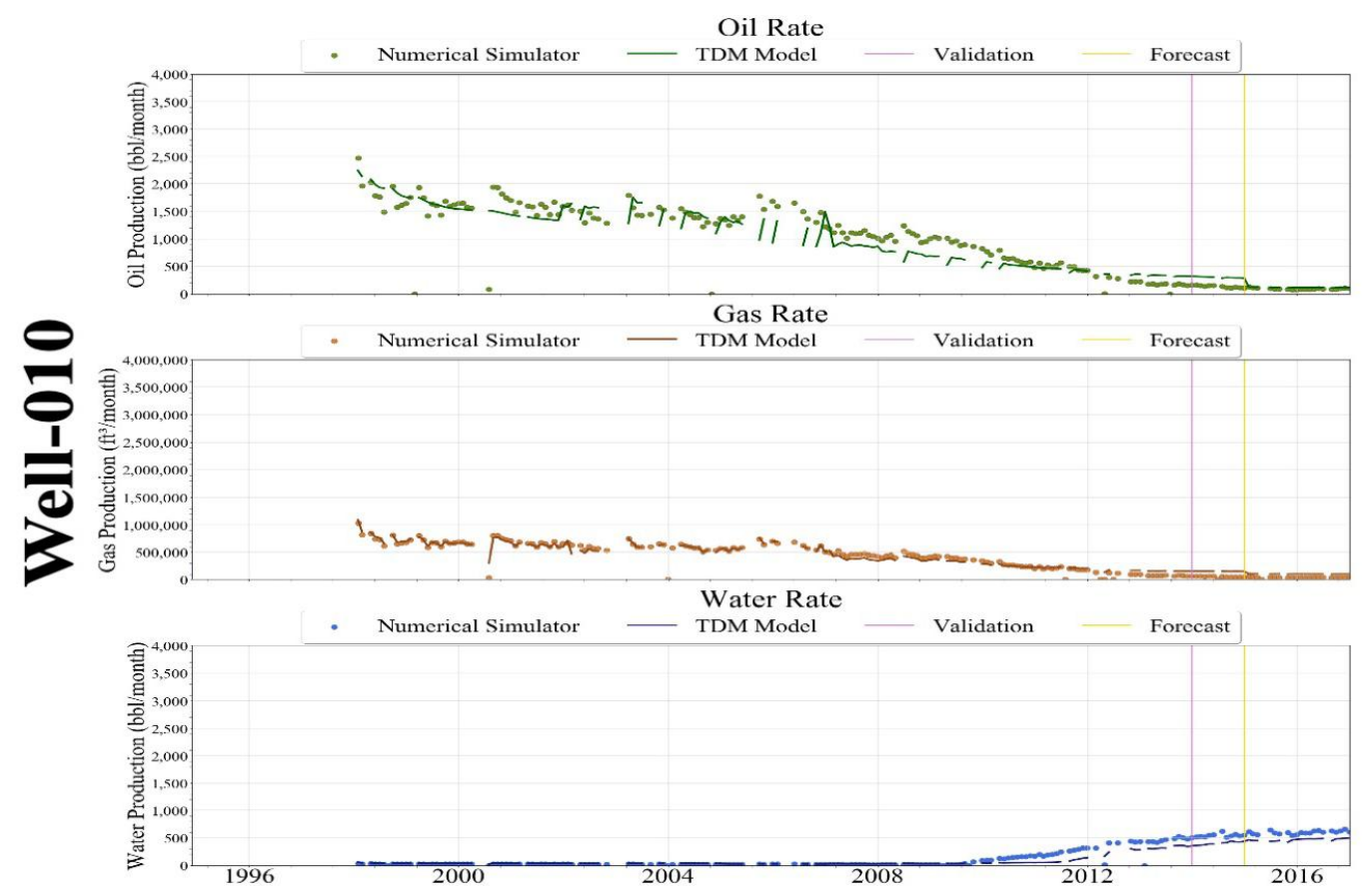


Figure 5-15: Good Forecast Production 


\section{Average Production Forecast}

\section{Scenario 4 - Mixed Partitioning TDM (1 Year Forecast)}

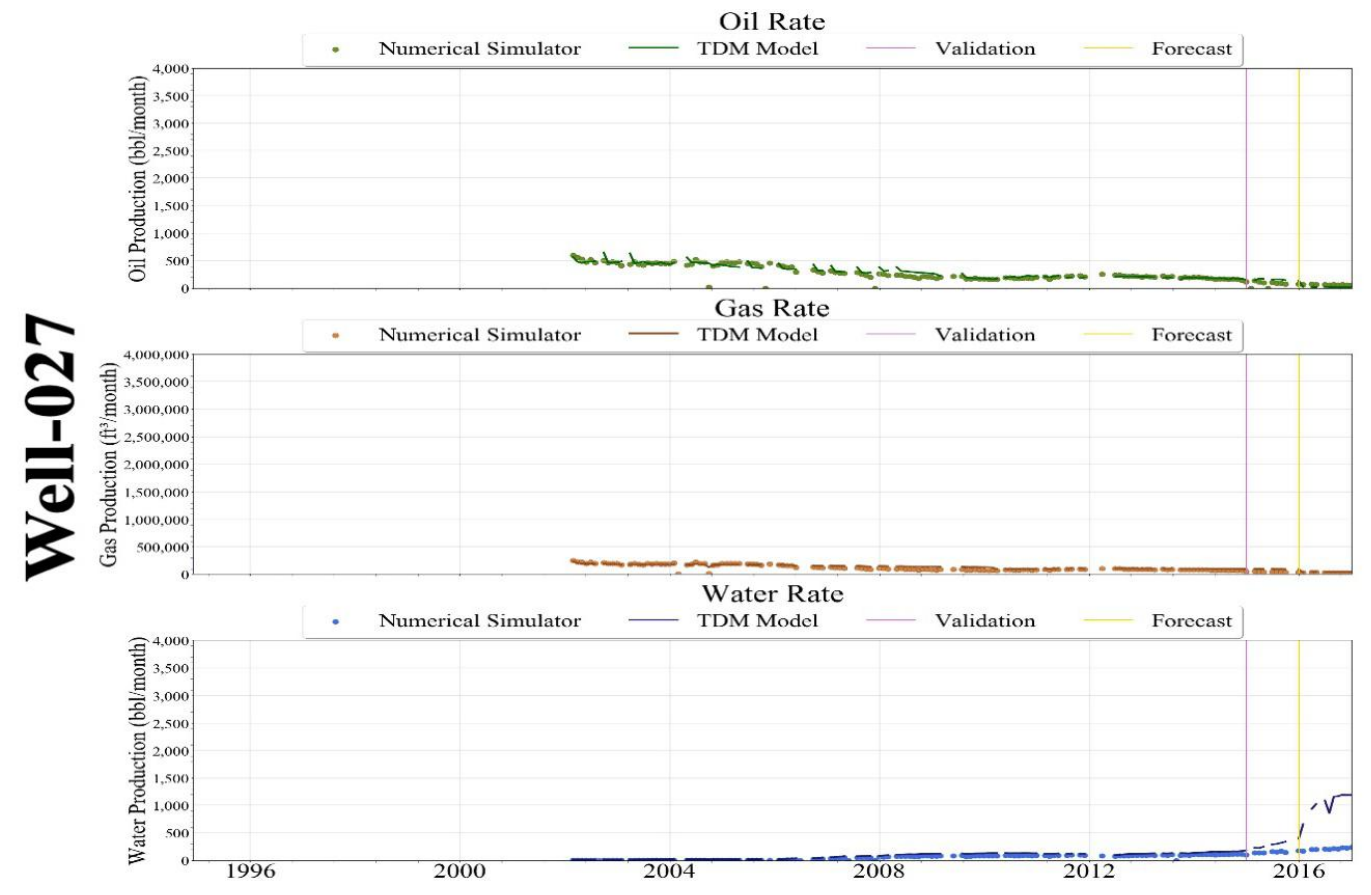

Scenario 5 - Mixed Partitioning TDM (2 Year Forecast)

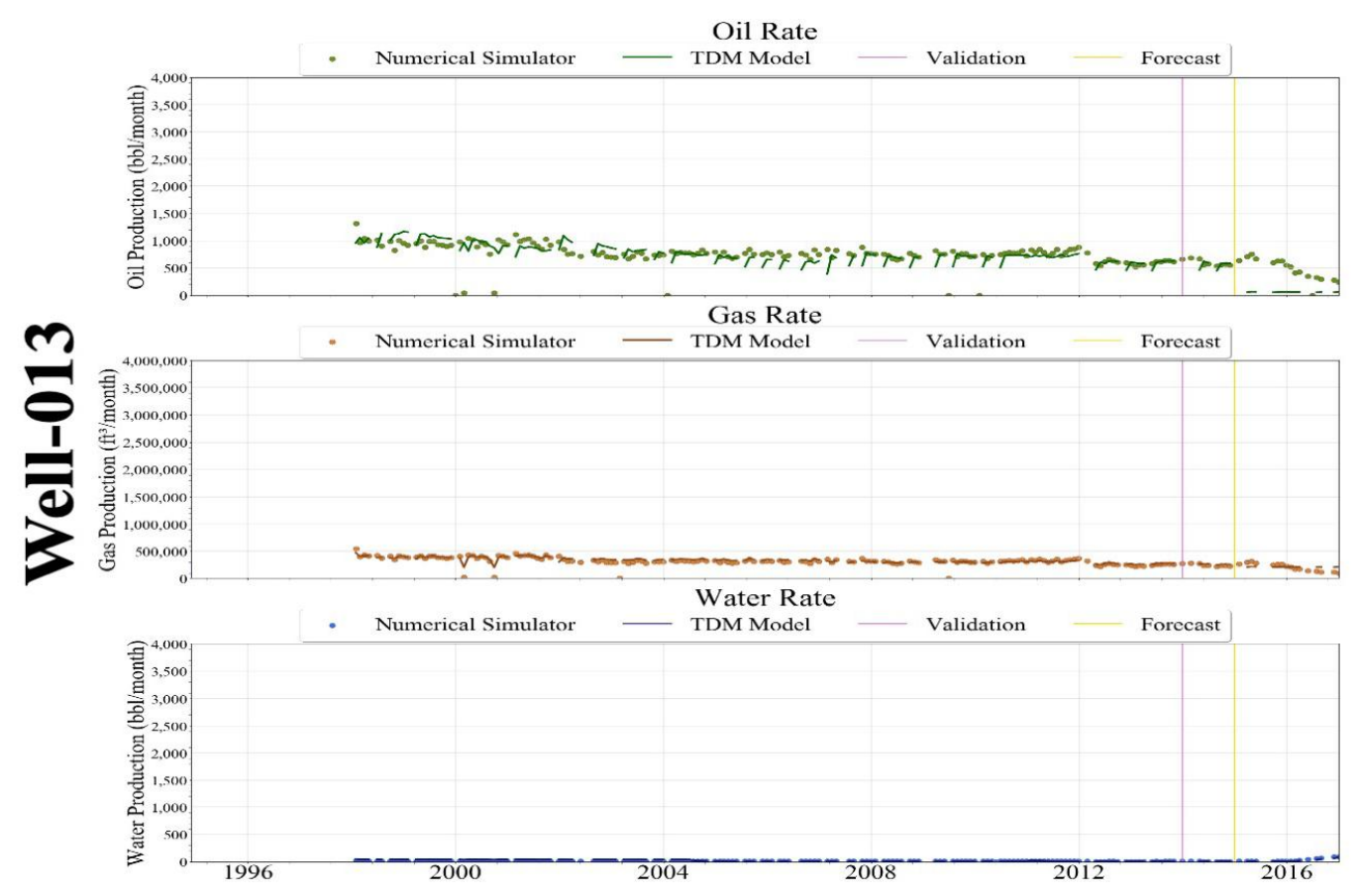


Figure 5-16: Average Forecast Production 


\section{Poor Production Forecast}

\section{Scenario 4 - Mixed Partitioning TDM (1 Year Forecast)}

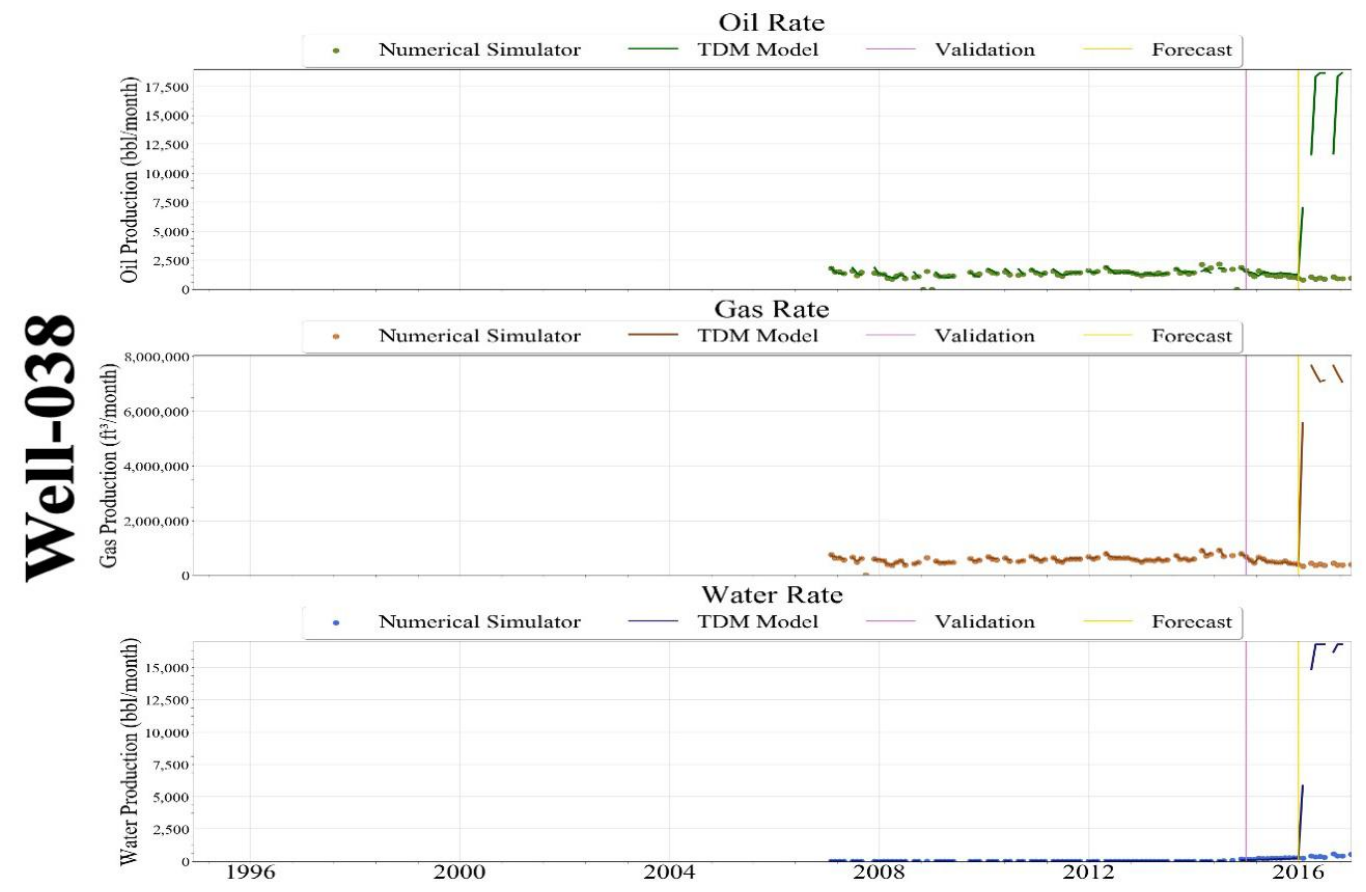

Scenario 5 - Mixed Partitioning TDM (2 Year Forecast)

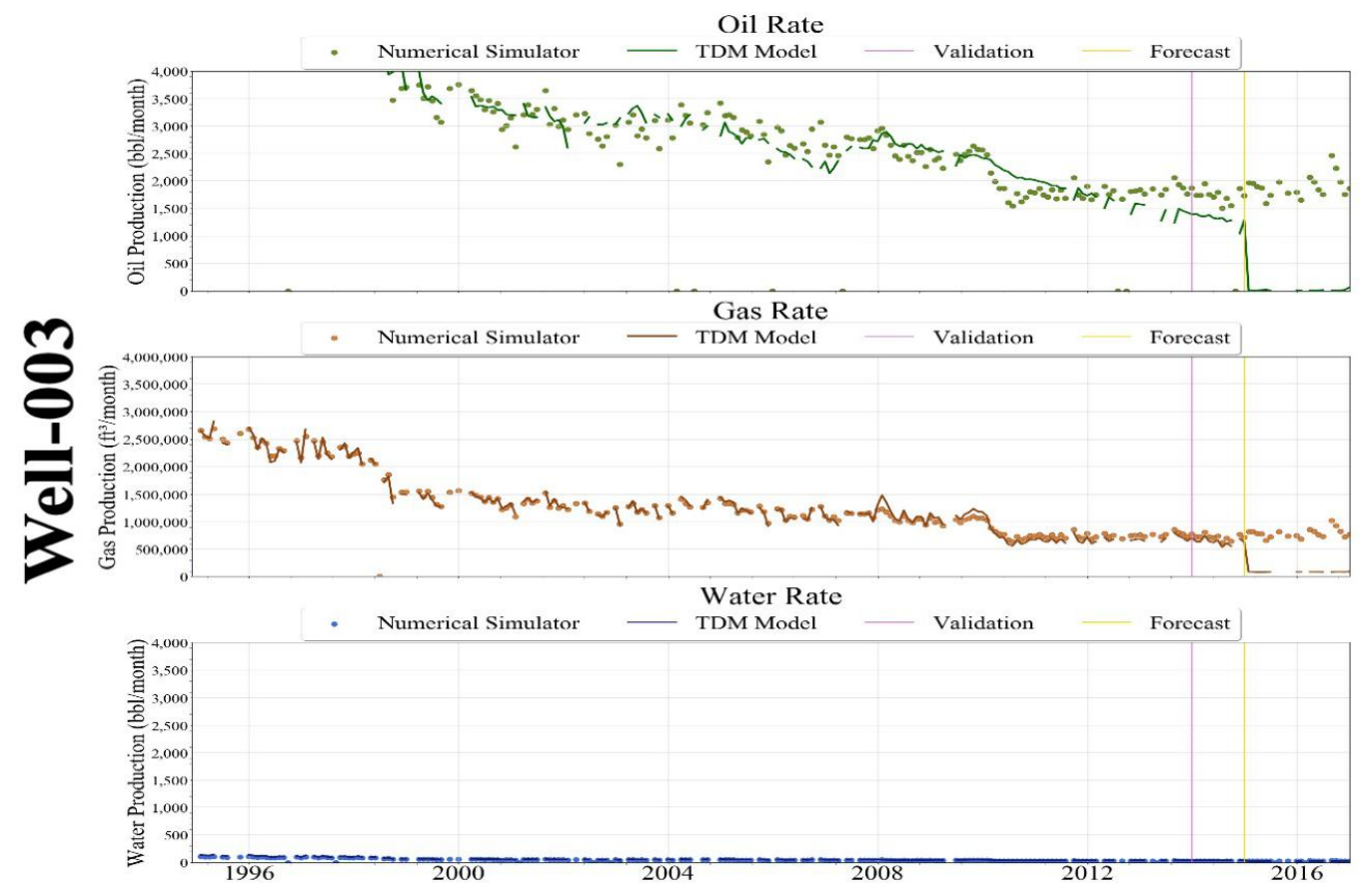




\section{Figure 5-17: Poor Production Forecast}

Production rates for every well were collectively evaluated. Table 5-5 provides both the number and percentage of wells with good, average, and poor history match for every TDM model.

Table 5-5: History Match Production Accuracy

\begin{tabular}{|c|c|c|c|c|c|c|c|c|c|c|}
\hline \multirow{2}{*}{$\begin{array}{c}\text { History Match } \\
\text { Accuracy } \\
\text { Overall Production }\end{array}$} & \multicolumn{2}{|c|}{ Scenario 1} & \multicolumn{2}{|c|}{ Scenario 2} & \multicolumn{2}{|c|}{ Scenario 3} & \multicolumn{2}{|c|}{ Scenario 4} & \multicolumn{2}{|c|}{ Scenario 5} \\
\hline & No. Wels & Percentage & No. Wels & Percentage & No. Wels & Percentage & No. Wels & Percentage & No. Wels & Percentage \\
\hline Good & 28 & $49 \%$ & 28 & $49 \%$ & 22 & $39 \%$ & 40 & $69 \%$ & 29 & $51 \%$ \\
\hline Average & 28 & $49 \%$ & 27 & $47 \%$ & 32 & $56 \%$ & 17 & $29 \%$ & 27 & $47 \%$ \\
\hline Poor & 1 & $2 \%$ & 2 & $4 \%$ & 3 & $5 \%$ & 0 & $0 \%$ & 1 & $2 \%$ \\
\hline
\end{tabular}

The TDM with 1-year forecast used a higher number of input attributes in the development of each predictive model and was trained for a higher number of epochs. The statistics suggest that $89 \%$ of the wells in the field had good history match of oil production, 100\% had a good history match of gas production, and $88 \%$ had a good history match of water production. After the model was deployed on a blind dataset, $44 \%$ of the wells had a good oil production forecast, $71 \%$ had a good gas production forecast, and 59\% with had a good water production forecast.

The TDM with 2-year-forecast, was trained for a fewer number of epochs and with fewer input attributes. Although the percentage of wells with good history match of production was lower than the TDM with 1-year forecast, Table 5-6 suggests that the overall performance during forecast were more reasonable.

Table 5-6: Production Forecast

\begin{tabular}{|l|c|c|c|c|}
\hline \multicolumn{1}{c|}{$\begin{array}{c}\text { Forecast } \\
\begin{array}{c}\text { Accuracy } \\
\text { Overall Production }\end{array}\end{array}$} & \multicolumn{2}{|c|}{ Scenario 4 } & \multicolumn{2}{c|}{ Scenario 5 } \\
\cline { 2 - 5 } & No. Wels & Percentage & No. Wels & Percentage \\
\hline Good & 10 & $29 \%$ & 11 & $30 \%$ \\
\hline Average & 11 & $32 \%$ & 19 & $51 \%$ \\
\hline Poor & 13 & $38 \%$ & 7 & $19 \%$ \\
\hline
\end{tabular}




\section{CHAPTER 6}

\section{CONCLUSIONS}

Sufficient data was generated from a numerical reservoir simulation model that recreated complexities from real-industry applications. The purpose of this thesis was to implement artificial intelligence and machine learning techniques via Top Down Modeling to history match and forecast oil, gas, and water production, reservoir pressure and water saturation distributions.

The thesis was accomplished by collecting, cleansing, and transforming the generated data into a useful standardized format to proceed with building a total of five TDMs composed of five interconnected predictive models. Each predictive model was trained, calibrated, and validated to ensure the teaching process was a success.

Linearity of cross plots and evaluation metrics, such as high $R^{2}$ and low MAE values, were graphical and numerical measurements used as an indication of the quality of the trained networks. Moreover, a visual inspection of the history-matched and forecasted production data vs the simulation data was conducted to once again verify the quality of the developed TDMs.

The different TDM models developed suggest that well-trained networks are capable of historymatching past production data as well as reservoir pressure and water saturation distributions using random and mixed partitioning methods.

The most accurate history-matched results were achieved by the 1-year forecast TDM trained with a higher number of input attributes than the other TDMs. The results indicate that $89 \%$ of wells had a good history match of oil production, nearly $100 \%$ of wells had a good history match of gas production, and $88 \%$ of wells had a good history match of water production. When considering all three plots' quality at once, $66 \%$ of the wells had a good history match of production.

The 2-year-forecast TDM resulted in lower percentages of wells with good history matches for oil, gas, and water production rates. Similarly, the number of wells was lower when evaluating the production rates collectively. However, the neural network's prediction during forecast resulted in $53 \%$ of accuracy for oil, $86 \%$ for gas, and $73 \%$ for water. The quality of the forecast when 
evaluating the three production rates collectively resulted in $30 \%$ of the wells with a good forecast, $51 \%$ had an average forecast, and $19 \%$ had a poor forecast.

\subsection{Future Work}

Due to time limitations in the development of different predictive models, the history match and blind history matches were validated while the TDM models with forecast are yet to be improved and validated. The quality of the TDM models is subject to the importance of quantity and quality of data used in the development of a TDM [26].

Moreover, the application of feature selection methods highly impacts the accuracy of predictive models during blind history-matching and forecasting. The TDM models that were deployed on blind datasets can result in a more reliable forecast by investigating efficient sets of input attributes. Additionally, the error near the boundaries of the water saturation distribution maps was potentially attributed to forward filling unreported values at the well locations at timesteps when there was no oil production. These events can be addressed by implementing interpolation techniques that take into account time and space. 


\section{Works Cited}

[1] Reporting Oil and Gas, "The Exploration and Producion Life Cycle of Oil and Gas," 29 June 2016. [Online]. Available: http://www.reportingoilandgas.org/the-exploration-andproduction-life-cycle-of-oil-and-gas/.

[2] S. D. Mohaghegh, Shale Analytics, Morgantown: Springer, 2017.

[3] Intelligent Solutions Inc, "Automated History Matching," January 2019. [Online]. Available: http://www.intelligentsolutionsinc.com/Blogs/Blog06-AutoHM.shtml.

[4] F. Sirois and F. Grilli, "Potential and limits of numerical modelling for supporting the development of HTS devices," 29 May 2017. [Online]. Available: https://arxiv.org/pdf/1412.2312.pdf.

[5] F. Hellman, "Numerical Methods for Darcy Flow Problems with Rough and Uncertain Data," Acta Universitatis Upsaliensis Uppsala, 2017.

[6] L. Y. K. Ding, "Performance and Process Simulation," in Laser Shock Peening, Woodhead Publishing, 2006, pp. 133-150.

[7] G. Avansi and D. Schiozer, "A New Approach to History Matching Using Reservoir Characterization and Reservoir Simulation Integrated Studies," Society of Petroleum Engineers, p. 29, 2015.

[8] Wikipedia, "Artificial Intelligence," 8 March 2020. [Online]. Available: https://en.wikipedia.org/wiki/Artificial_intelligence.

[9] C. Das, "What is machine learning and types of machine learning - Part-1," 21 May 2017. [Online]. Available: https://towardsdatascience.com/what-is-machine-learning-and-typesof-machine-learning-andrews-machine-learning-part-1-9cd9755bc647. 
[10] Intelligent Solutions Inc, "Modeling Physics with Artificial Intelligece \& Machine Learning," $\quad 2019 . \quad$ August $\quad$ Available: http://www.intelligentsolutionsinc.com/Blogs/Blog07-Physics.shtml.

[11] J. Hardwood and D. P. Wilkin, "Nerve Impulse," 30 November 2012. [Online]. Available: https://www.ck12.org/biology/nerve-impulse/lesson/Nerve-Cells-and-Nerve-Impulses-MS$\mathrm{LS} /$.

[12] Mindmajix Technologies Inc, "What Is Artificial Neural Network And How It Works," 5 April 2017. [Online]. Available: https://mindmajix.com/artificial-neural-network-and-howit-works.

[13] A. S. Walia, "Activation functions and its types - Which is better?," 29 May 2017. [Online]. Available: https://towardsdatascience.com/activation-functions-and-its-types-which-isbetter-a9a5310cc8f.

[14] Course Hero, "The Math Behind Neural Networks (01)," 18 November 2018. [Online]. Available: https://www.youtube.com/watch?v=RiqWATOoos8.

[15] J. Brownlee, "A Gentle Introduction to Backpropagation Through Time," 23 June 2017. [Online]. Available: https://machinelearningmastery.com/gentle-introductionbackpropagation-time/.

[16] M. Kuhn and K. Johnson, Applied Predictive Modeling, 2013: Springer.

[17] S. Mohaghegh, Data Driven Reservoir Modeling, Society of Petroleum Engineers, 2017.

[18] S. Asiri, "Data Mining in Brief," 23 December 2017. [Online]. Available: https://towardsdatascience.com/data-mining-in-brief-26483437f178.

[19] A. Kaplan and M. Haenlein, Business Horizons, Elsevier, 2019. 
[20] Y. Alatrach, "Data-Driven Vs. Traditional Reservoir Numerical Models: A Case Study Comparison of Applicabiblity, Practicality and Performance," Society of Petroleum Engineers, Abu Dhabi, 2019.

[21] A. H. Salaheldin Elkatatny and A. Abdulraheem, "Application of Artificial Intelligence Techniques to Predict the Well Productivity of Fishbone Wells," MDPI, Dhahran, 2019.

[22] F. Alenezi and S. Mohaghegh, "A Data-Driven Smart Proxy Model for A Comprehensive Reservoir Simulation," IEEE, 2016.

[23] W. Lyons, G. B. Plisga and L. Michael, "Rock Compressibility (Chapter 5)," in Standard Handbook of Petroleum and Natural Gas Engineering, Elsevier, 2016, p. 1822.

[24] Schlumberger, "Fracture Gradient," 2020. [Online]. Available: https://www.glossary.oilfield.slb.com/en/Terms/f/fracture_gradient.aspx.

[25] Intelligent Solutions, Inc, "Top-Down Intelligent Reservoir Modeling," 2018.

[26] Intelligent Solutions, Inc., "Top-Down, Intelligent Reservoir Models," Intelligent Solutions, Inc., Morgantown, 2011.

[28] G. A. Polizel, G. D. Avansi and D. J. Schiozer, "Use of Proxy Models in Risk Analysis of Petroleum Fields," Society of Petroleum Engineers, p. 19, 2017.

[29] G. A. Polizel, G. D. Avansi and D. J. Schiozer, "Use of Proxy Models in Risk Analysis of Petroleum Fields," Society of Petroleum Engineers, p. 19, 2017.

[30] F. Alenezi and S. Mohaghegh, "Developing a Smart Proxy for the SACROC Water-Flooding Numerical Reservoir Simulation Model," Society of Petroleum Engineers, p. 12, 2017.

[31] Computer Modeling Group Ltd, "Builder Simulation Model Building," 2019. [Online]. Available:

file://C:/Program\%20Files\%20(x86)/CMG/Manuals/2018.10/BUILDER/Default.htm. 


\section{APPENDIX}

\section{Appendix A: Well Biography}

The following plots provide information regarding the focal well and its offset producers and injectors. The plots include production profiles (oil, gas and water), water cut, bottom-hole pressure behavior, completion footage and the well's location.

The focal well is shown in color red, the offset producers are shown in green and the offset injectors are shown in blue in the map located at the bottom-left of the graph. The plot convention is located at the top-left of the graph.

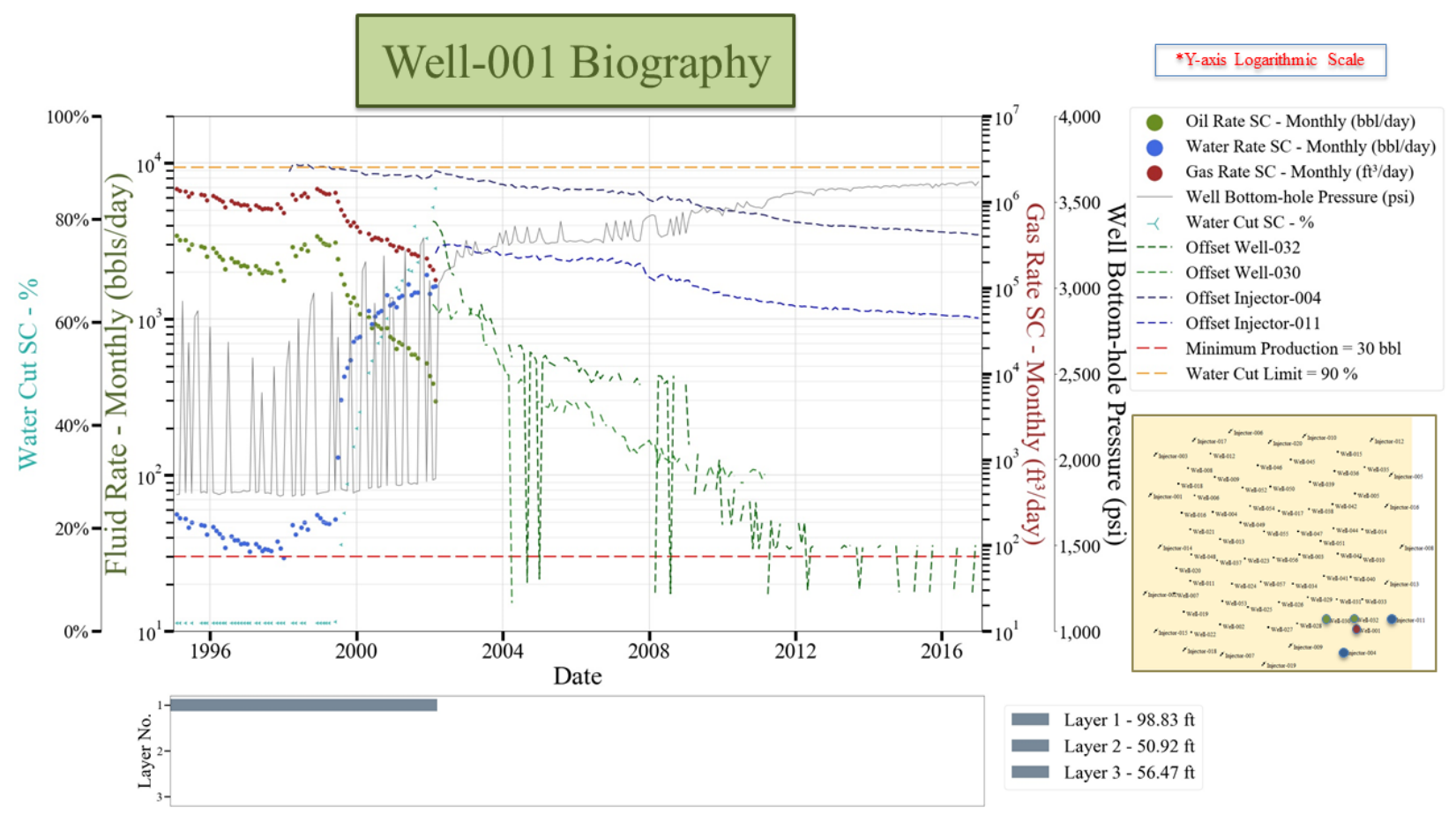

Figure 7-1: Well-001 Biography 


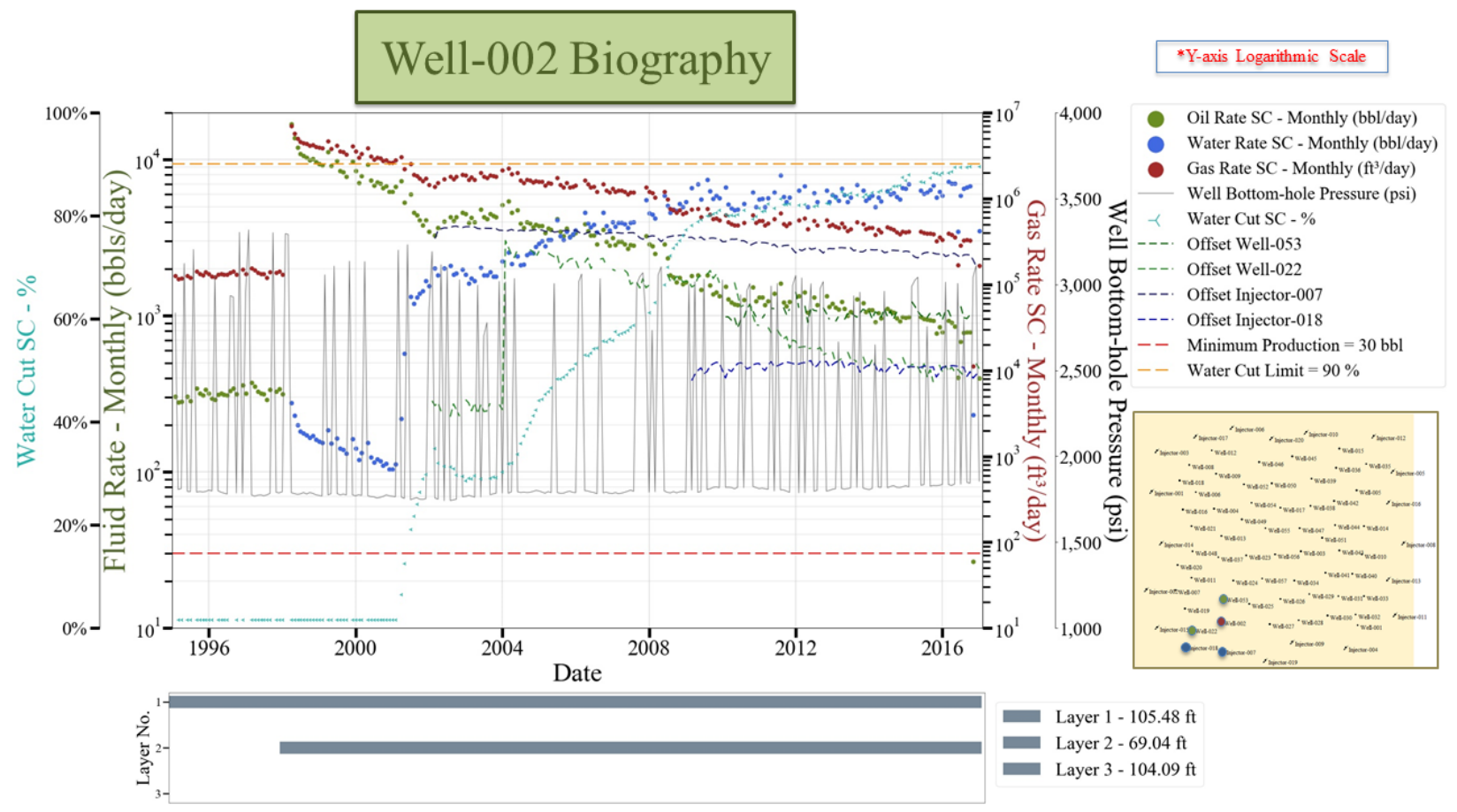

Figure 7-2: Well-002 Biography

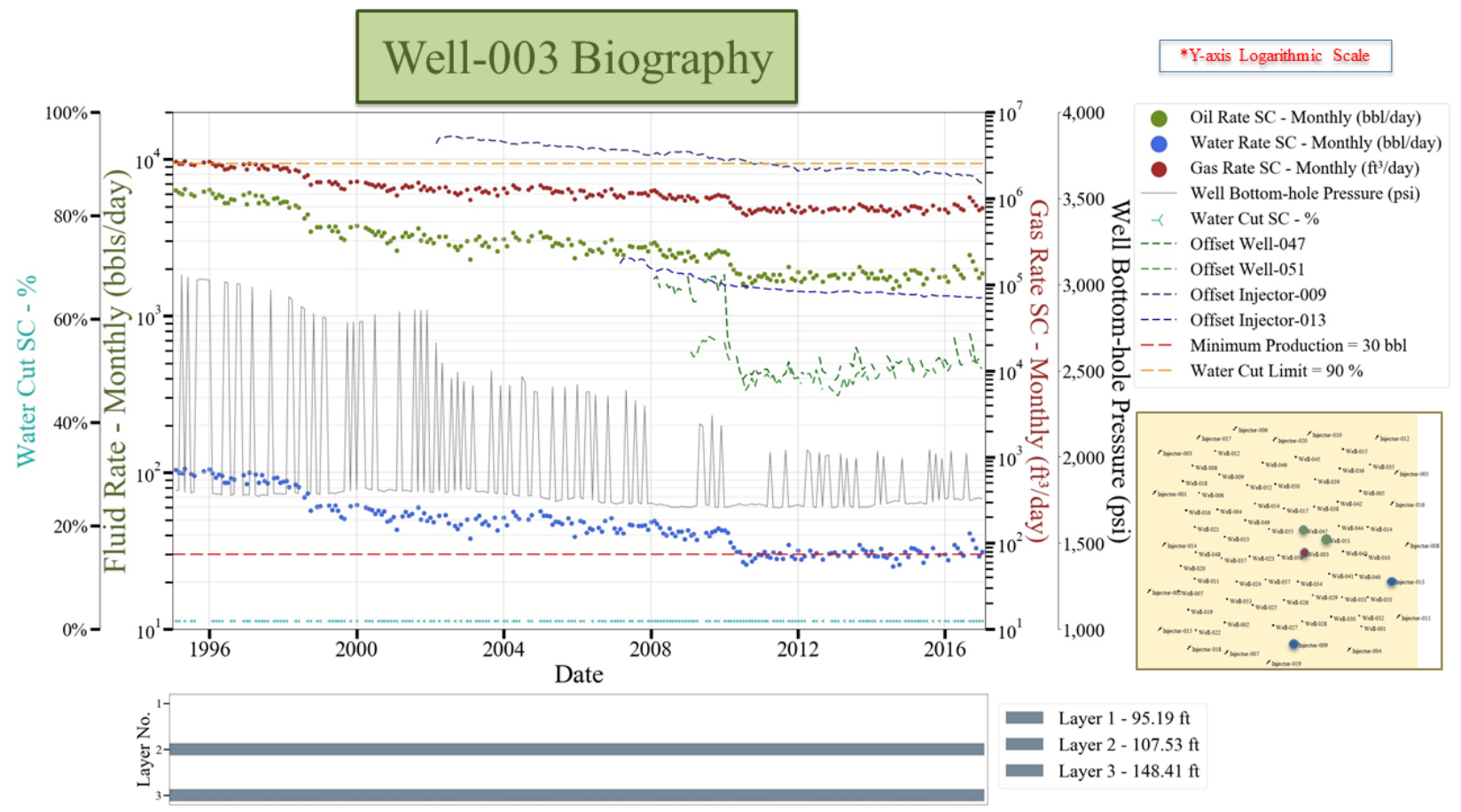

Figure 7-3: Well-003 Biography 


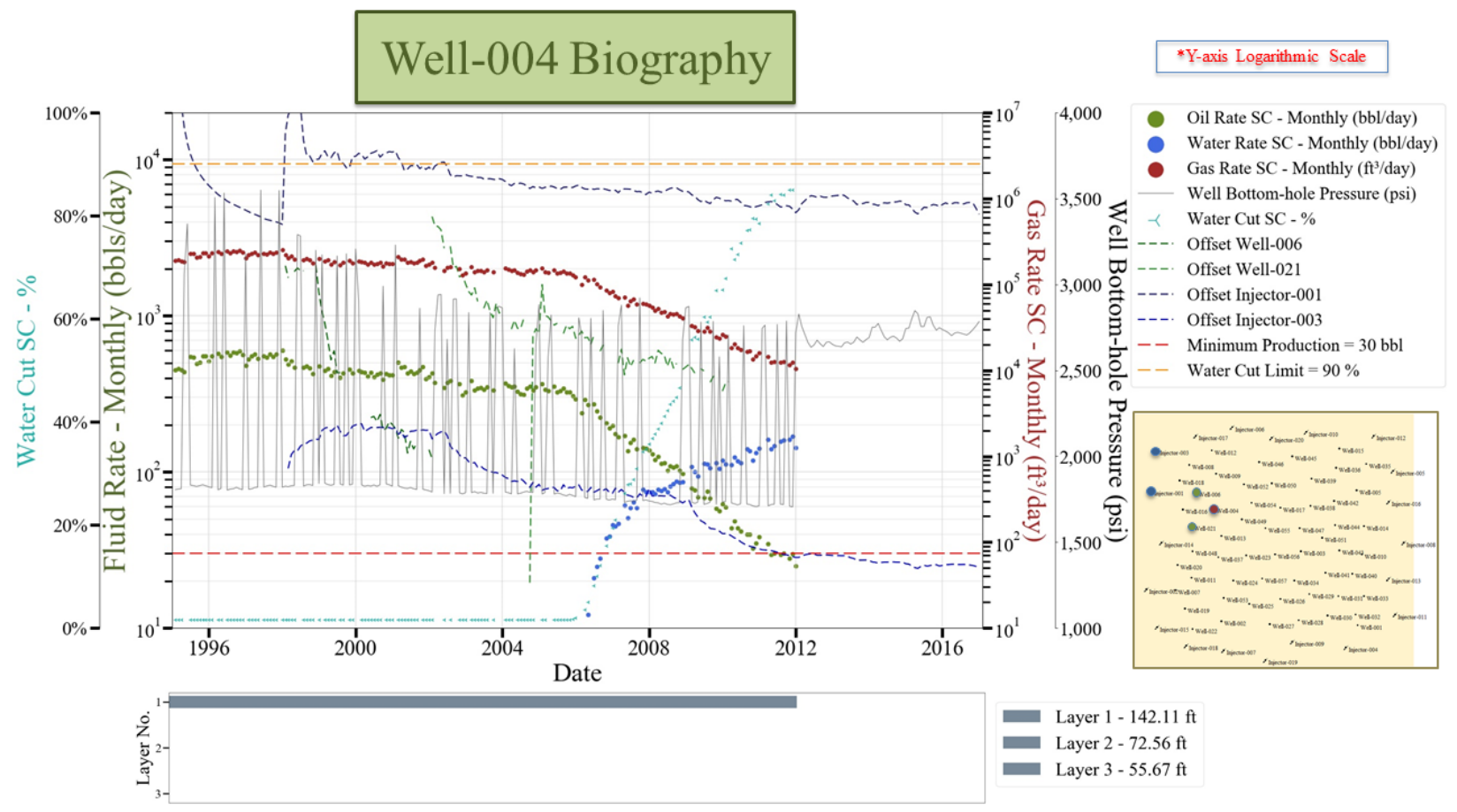

Figure 7-4: Well-004 Biography

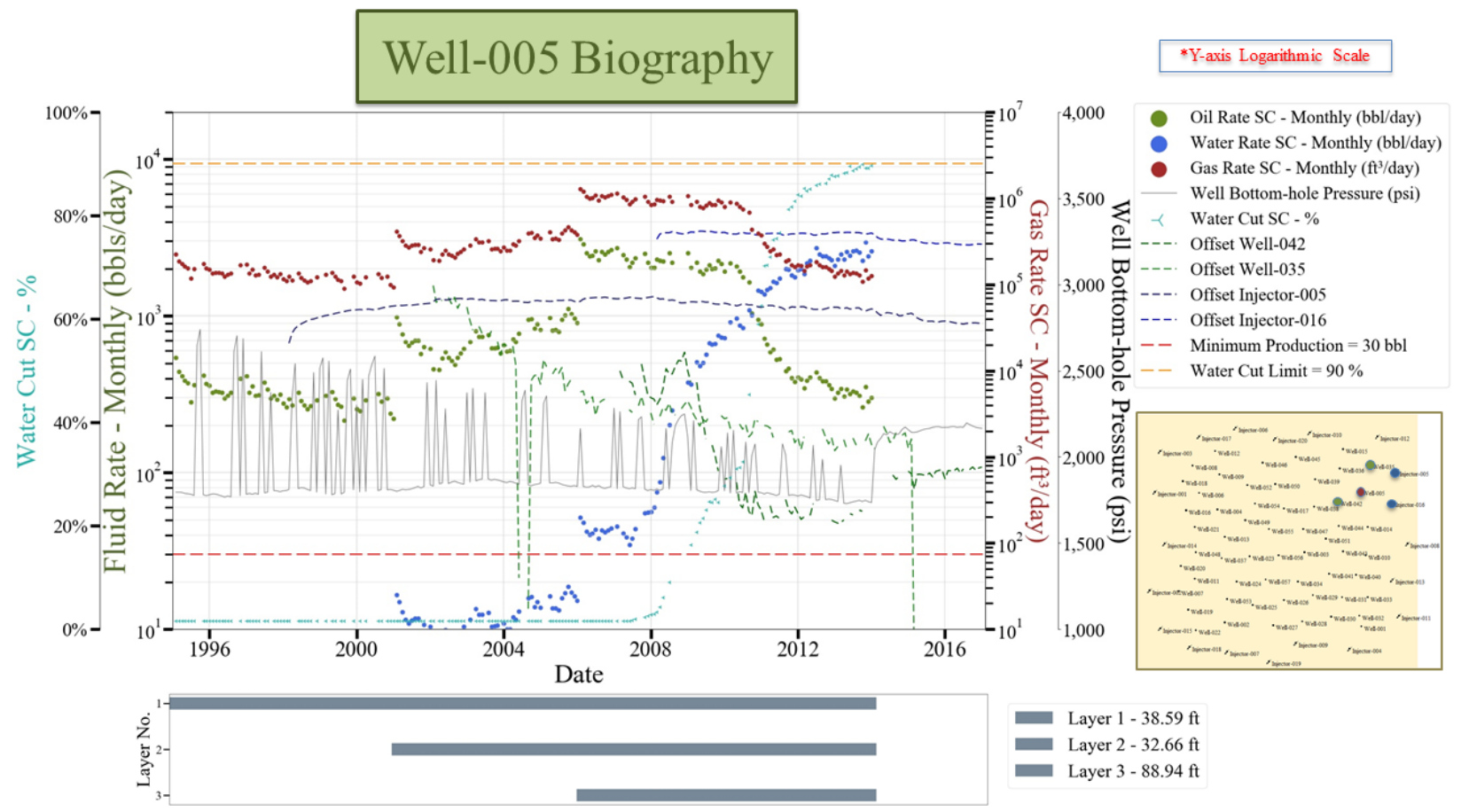

Figure 7-5: Well-005 Biography 


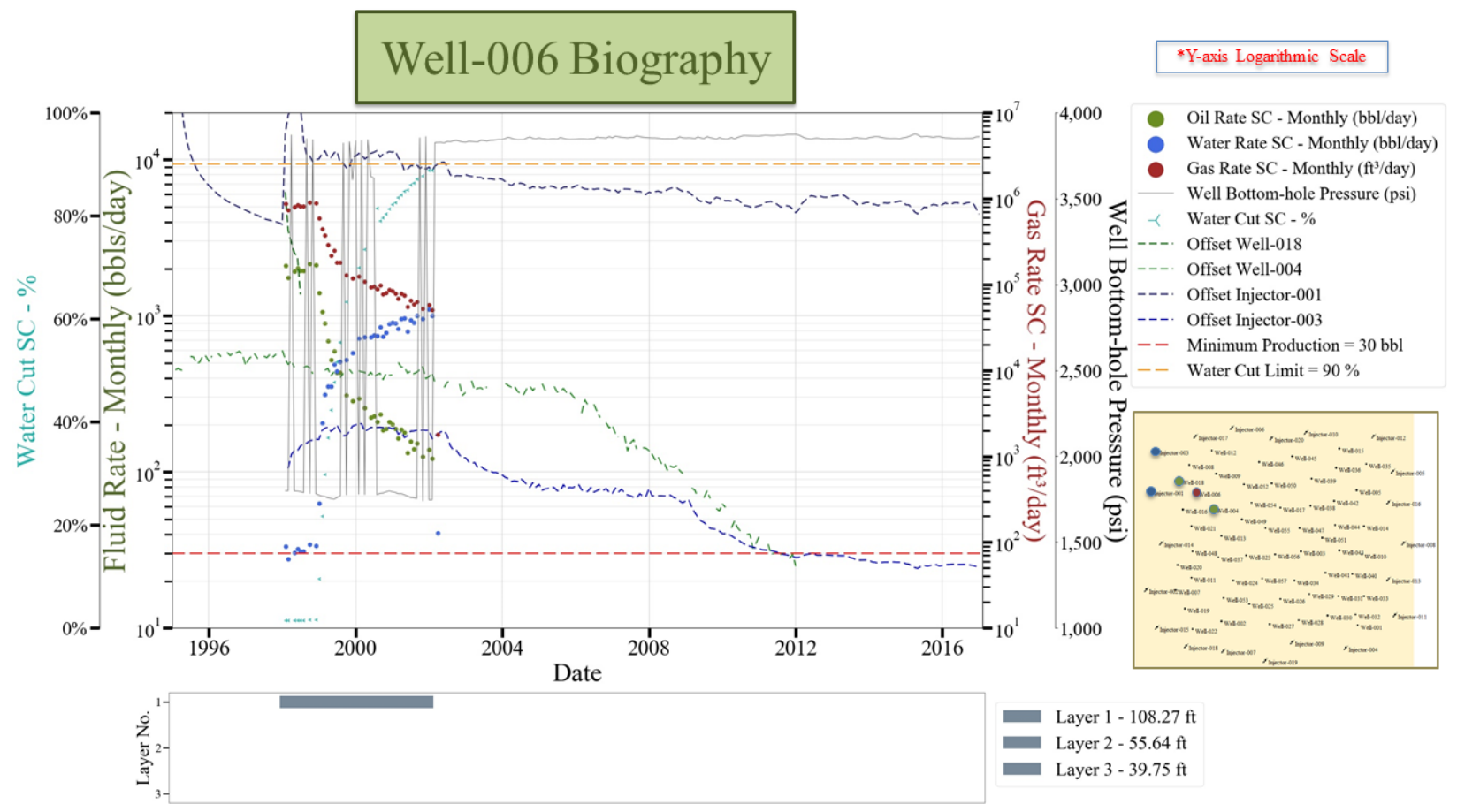

Figure 7-6: Well-006 Biography

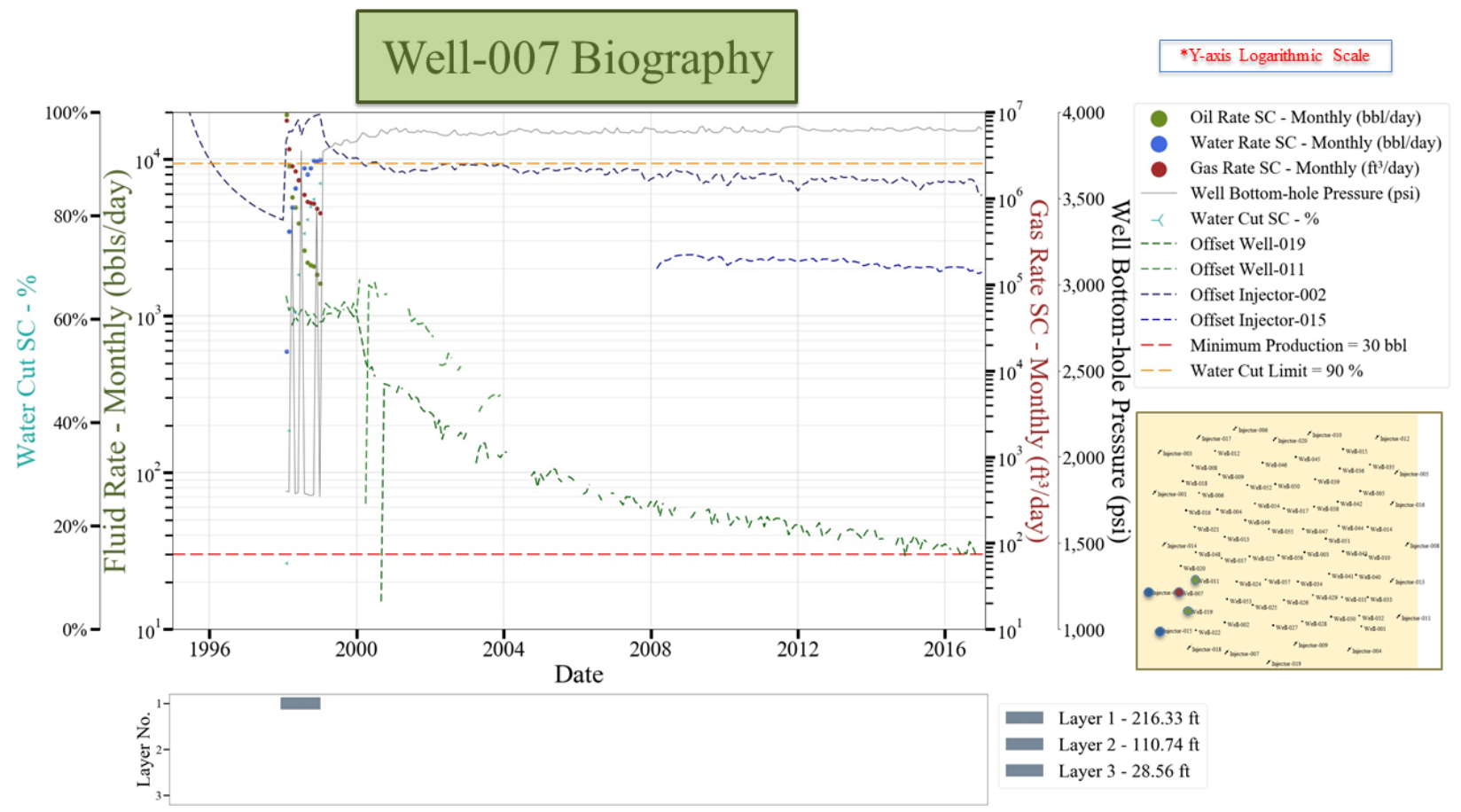

Figure 7-7: Well-007 Biography 


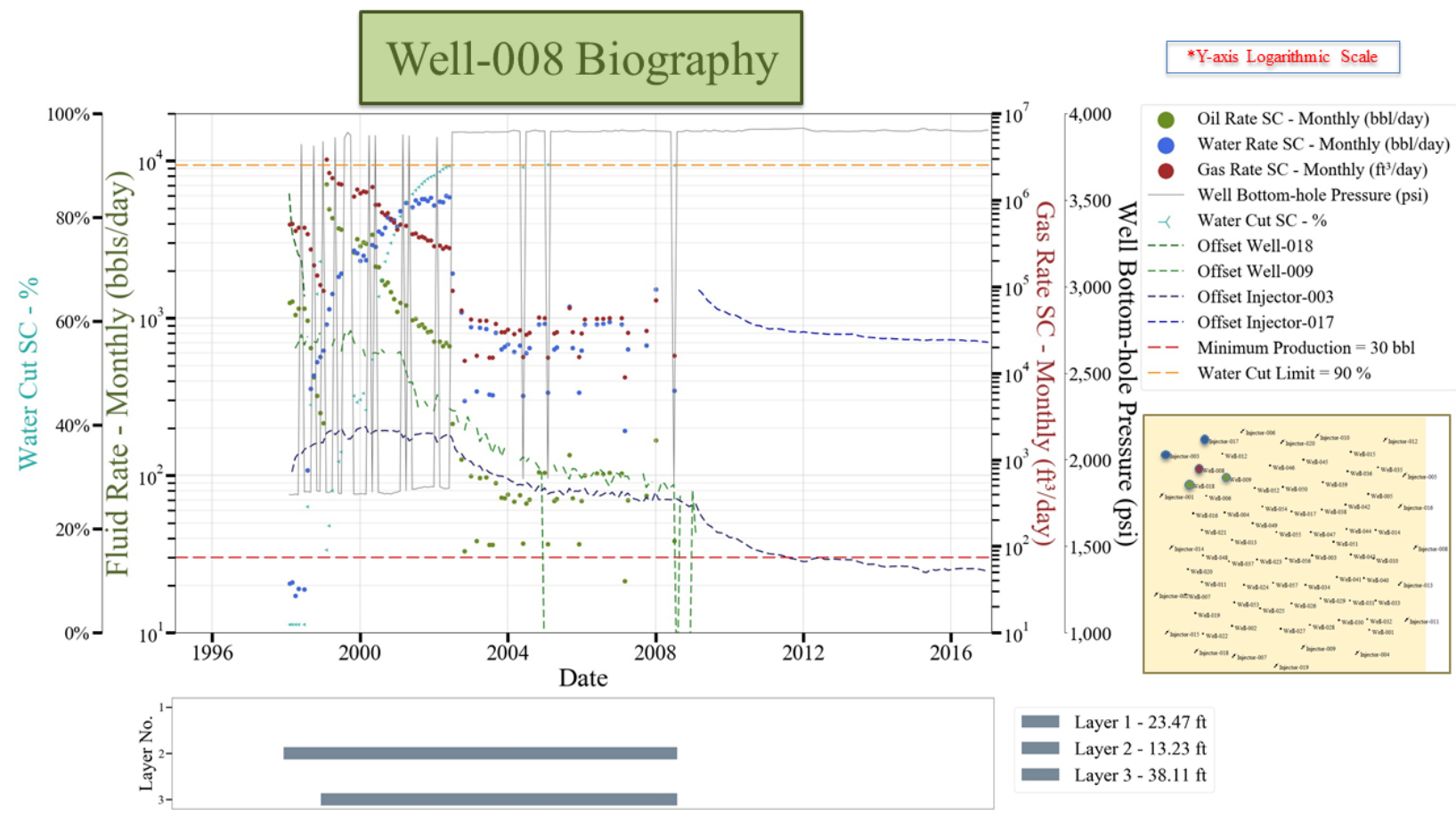

Figure 7-8: Well-008 Biography

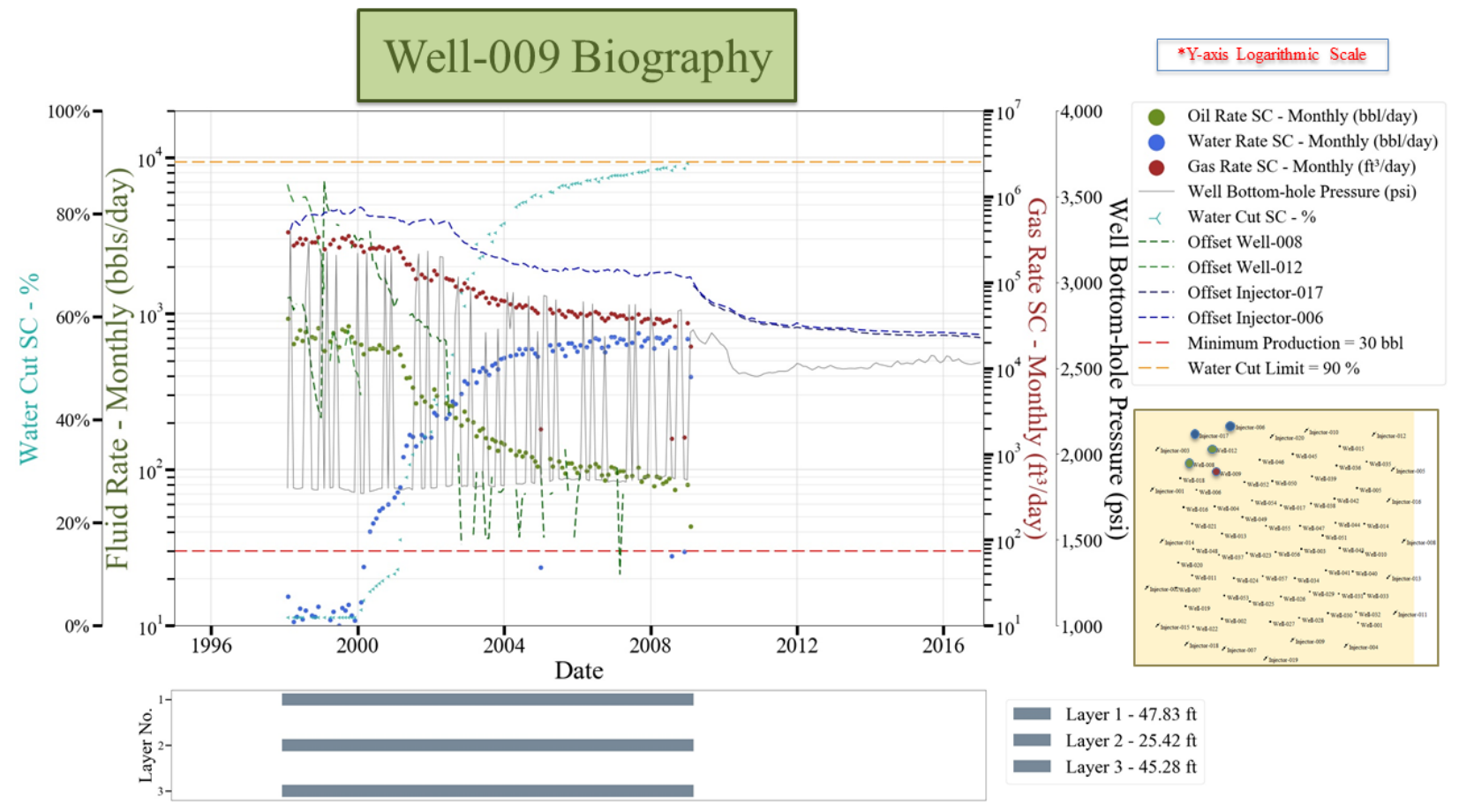

Figure 7-9: Well-009 Biography 


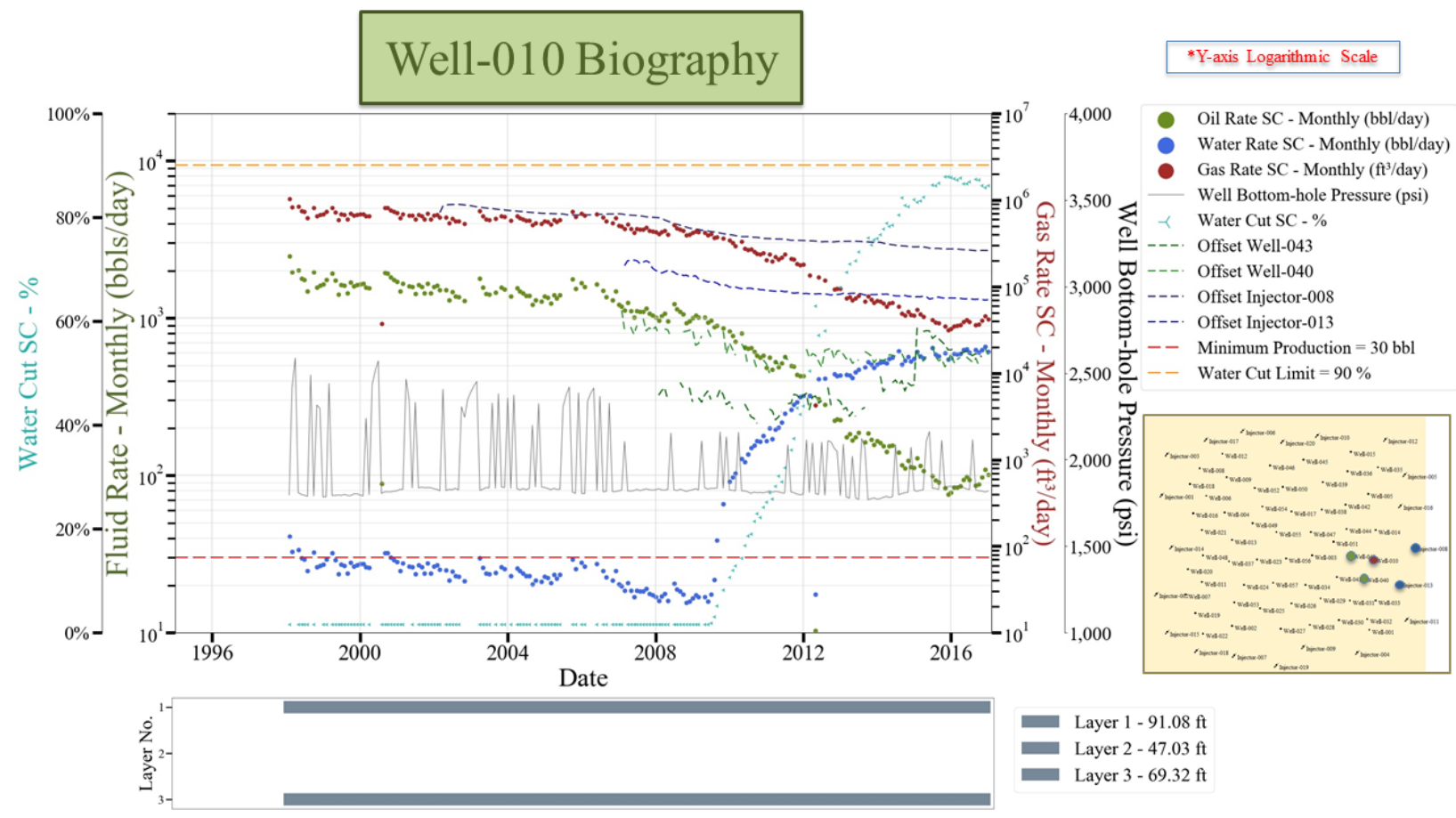

Figure 7-10: Well-010 Biography

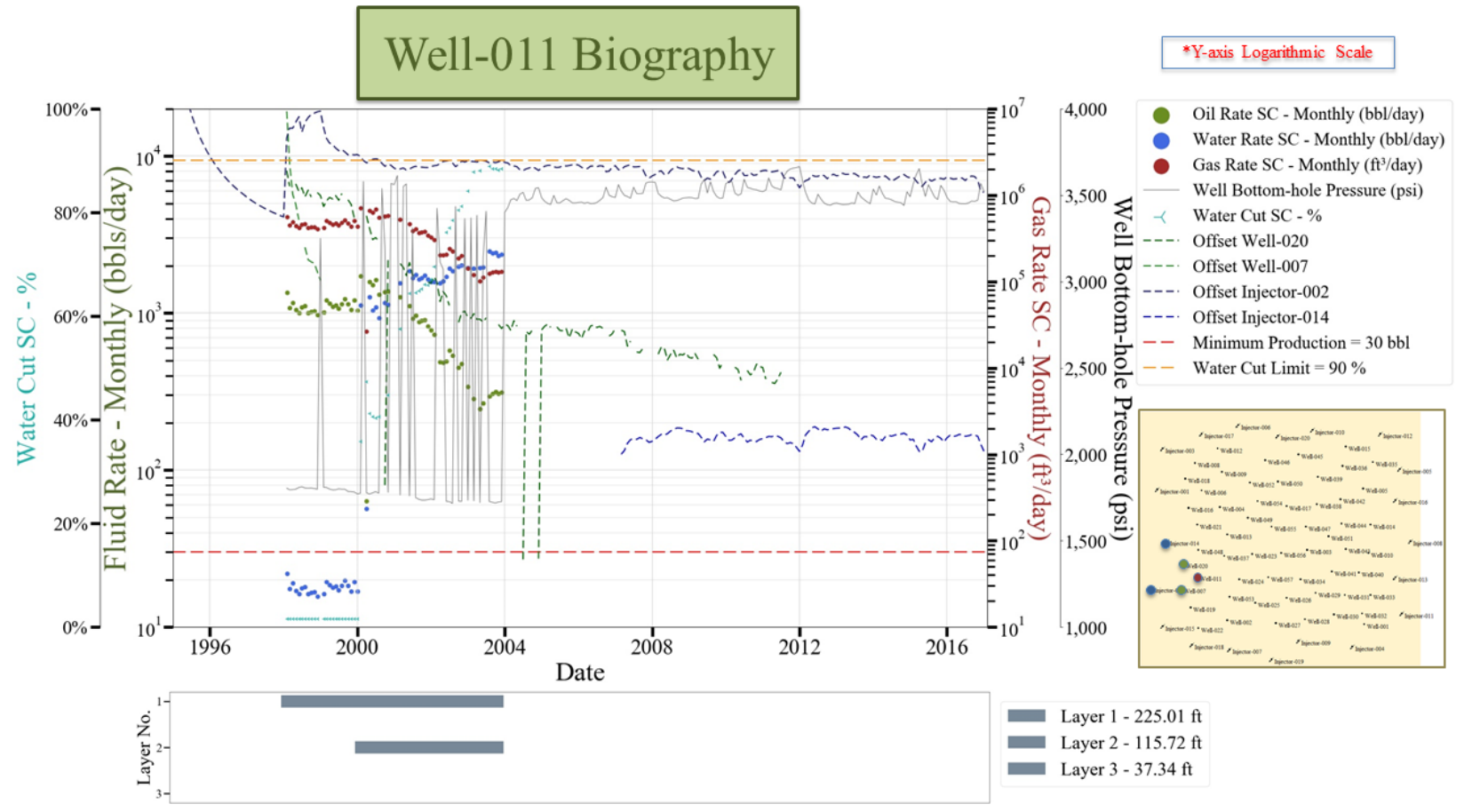

Figure 7-11: Well-011 Biography 


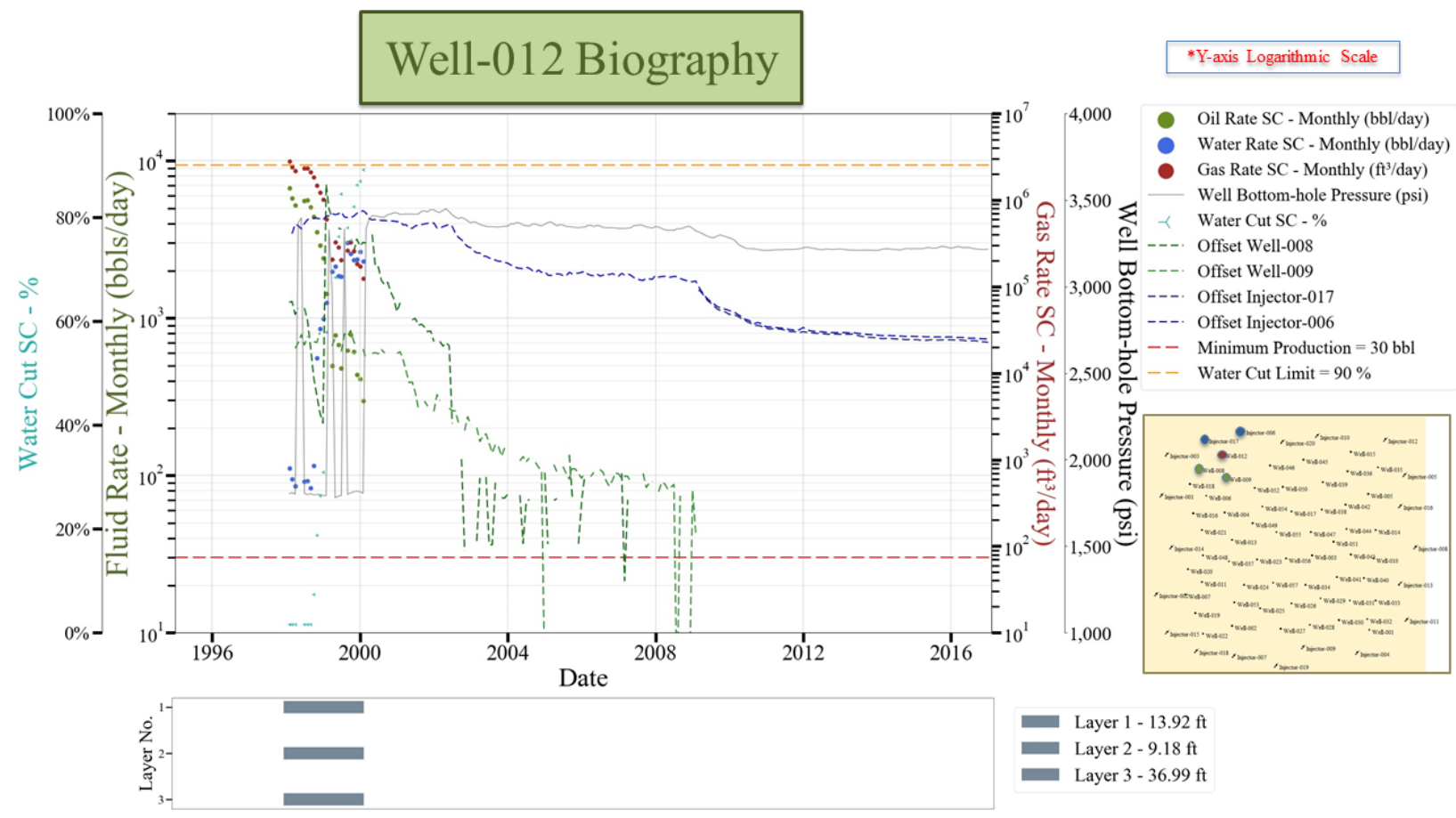

Figure 7-12: Well-012 Biography

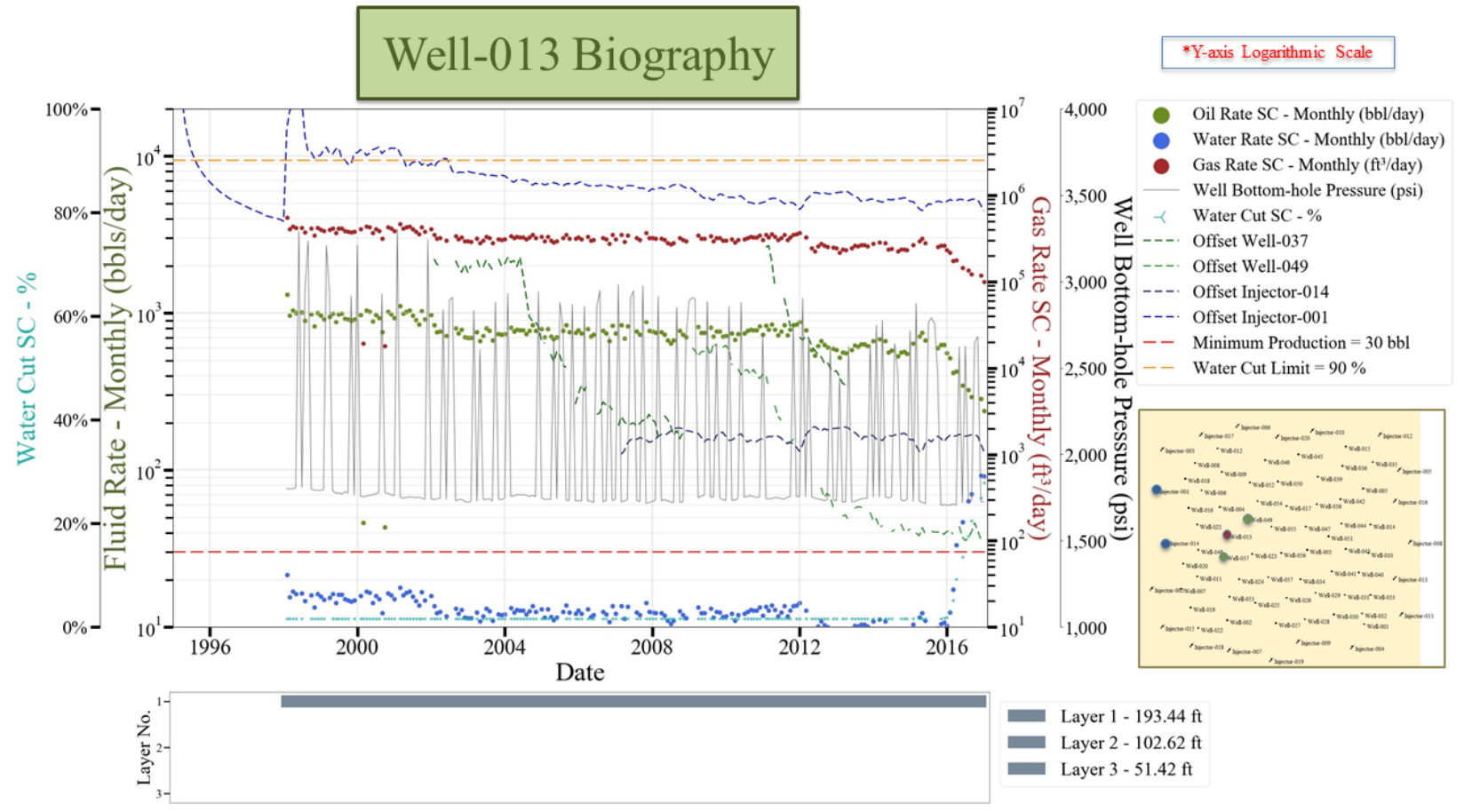

Figure 7-13: Well-013 Biography 


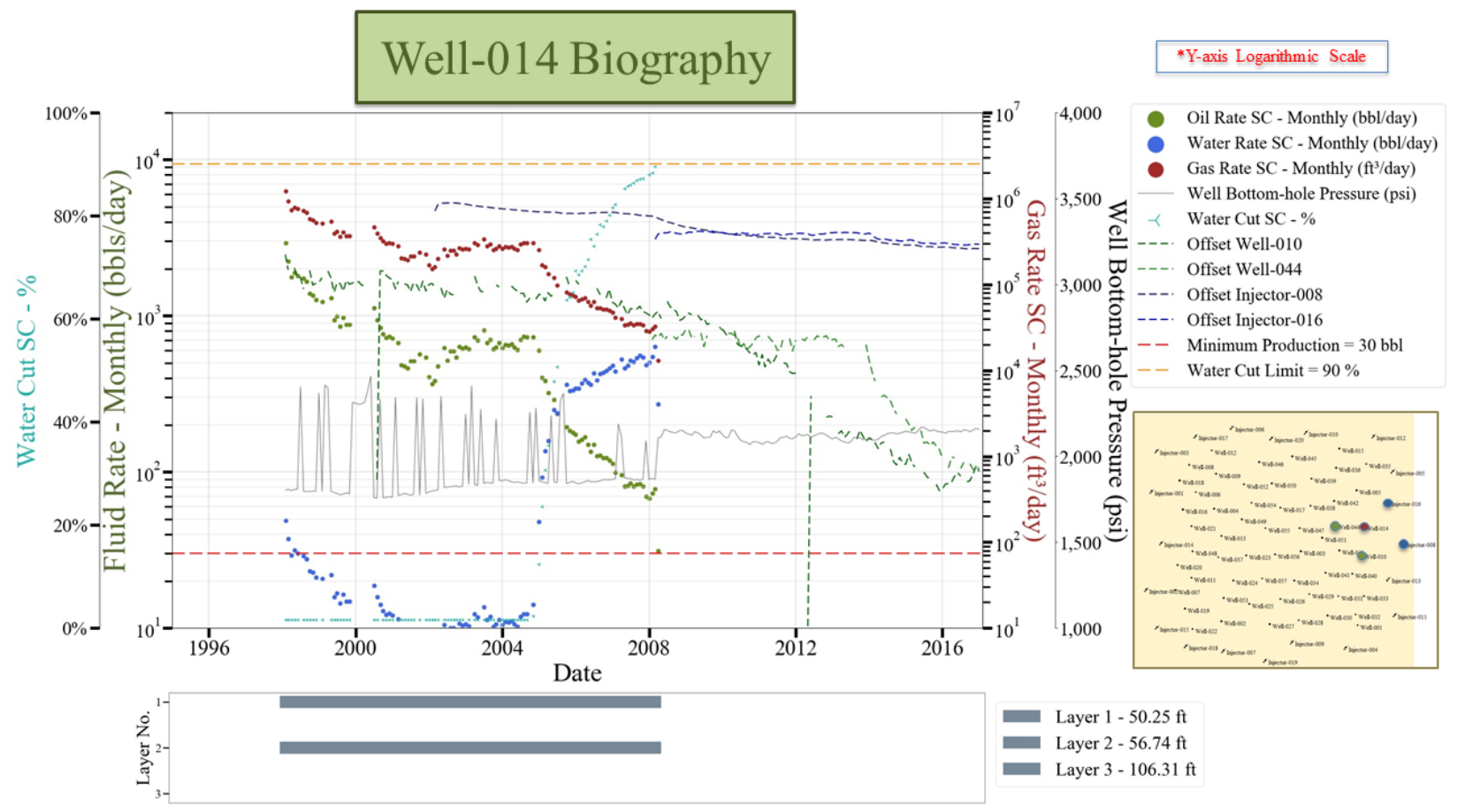

Figure 7-14: Well-014 Biography

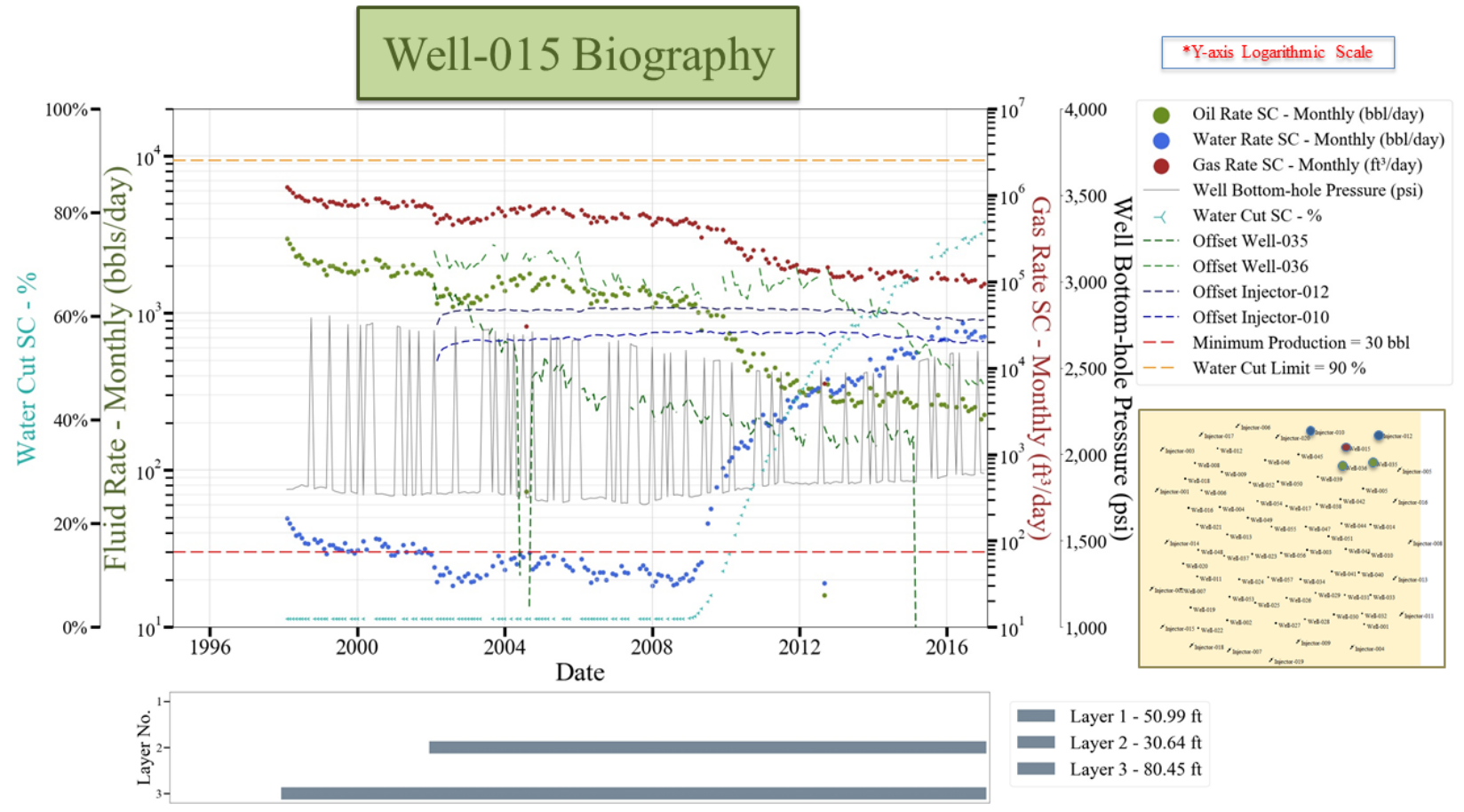

Figure 7-15: Well-015 Biography 


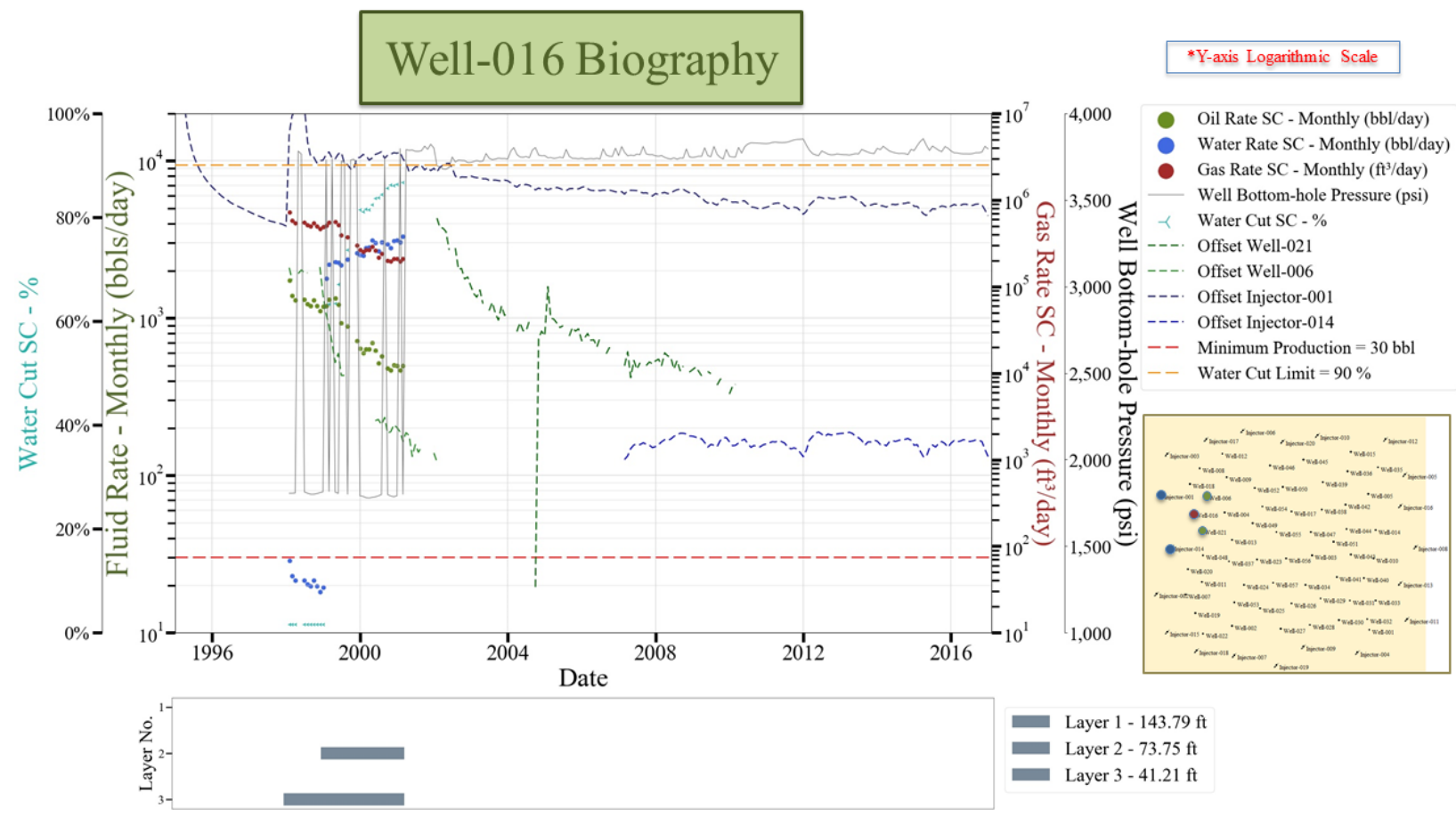

Figure 7-16: Well-016 Biography

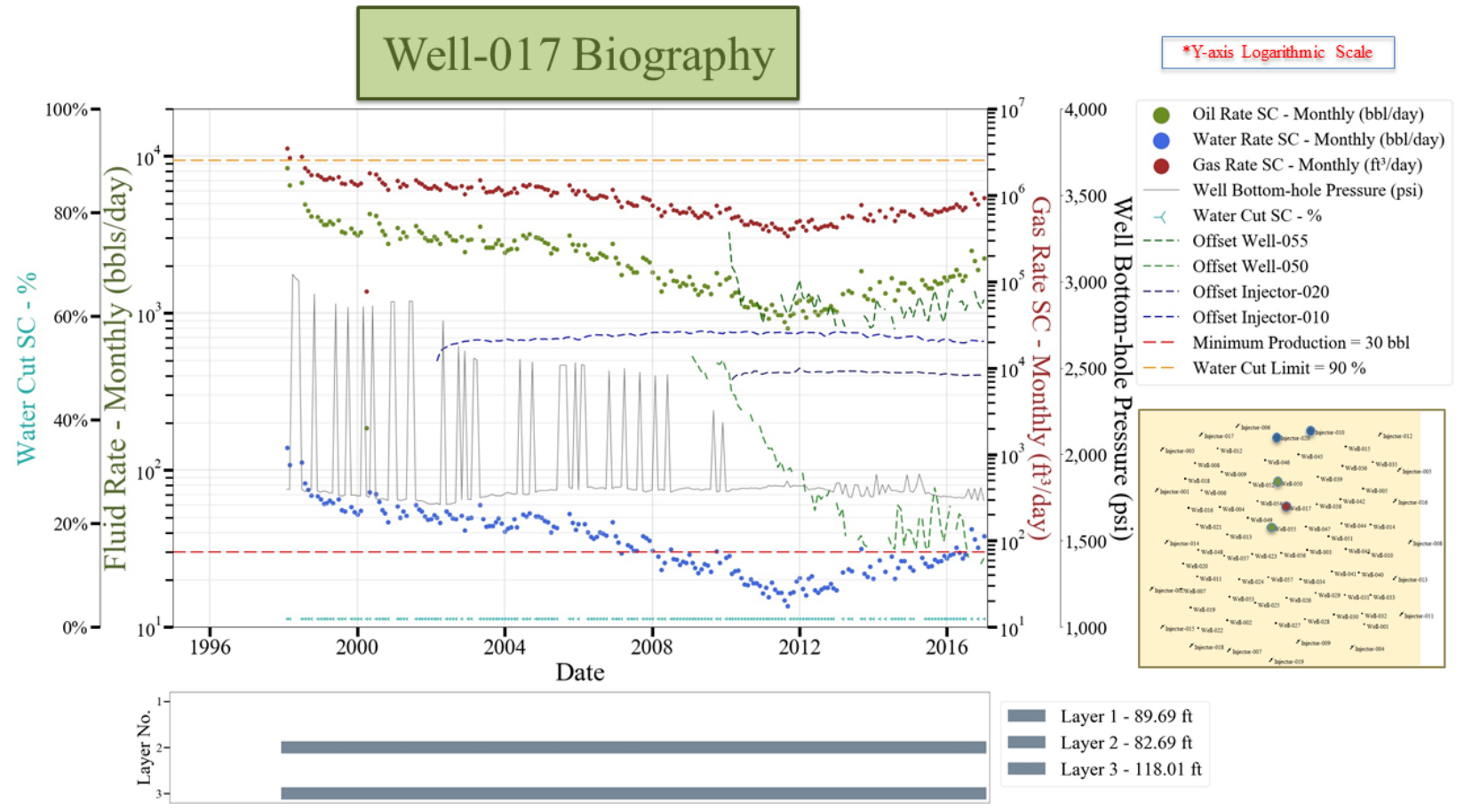

Figure 7-17: Well-017 Biography 


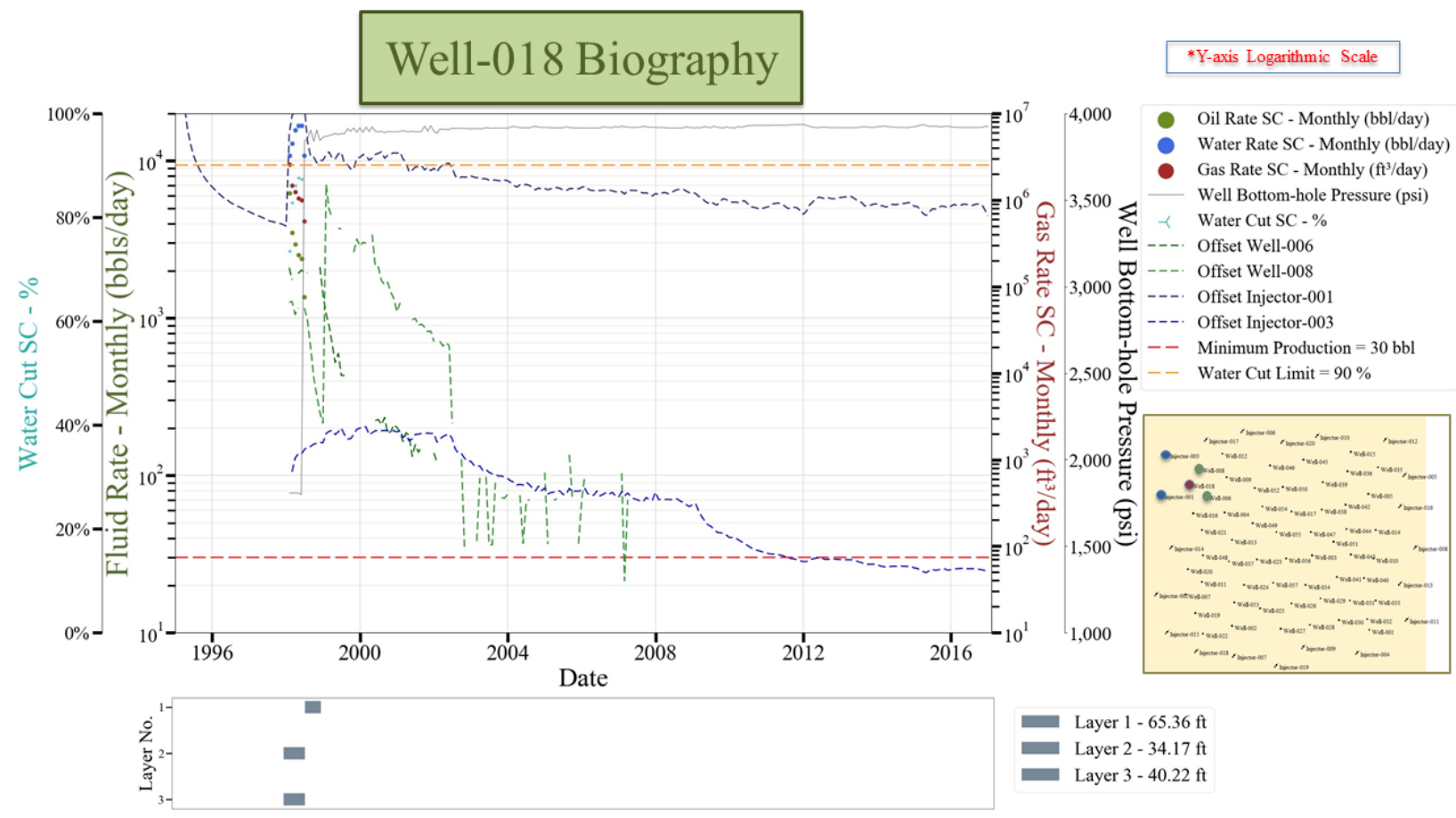

Figure 7-18: Well-018 Biography

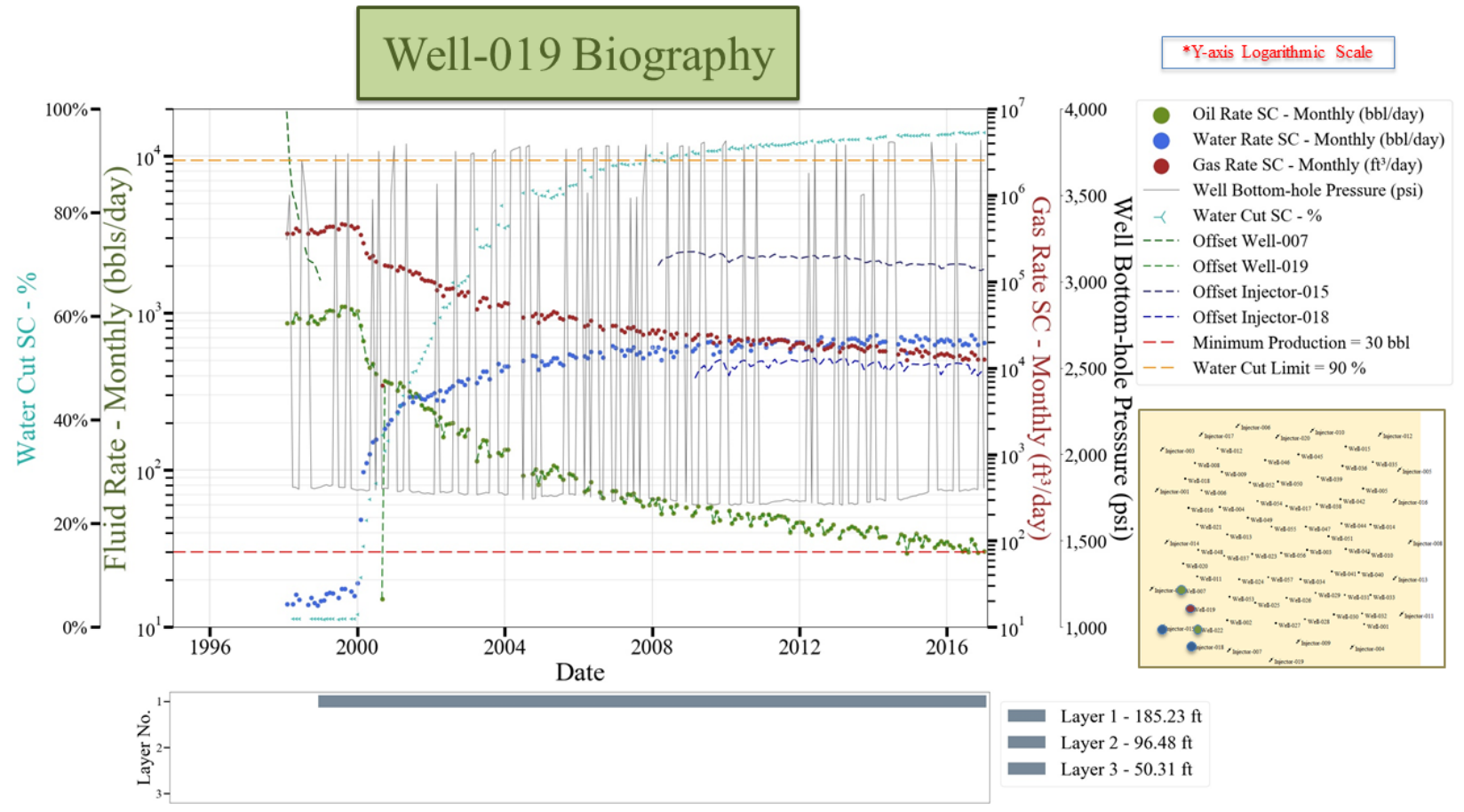

Figure 7-19: Well-019 Biography 


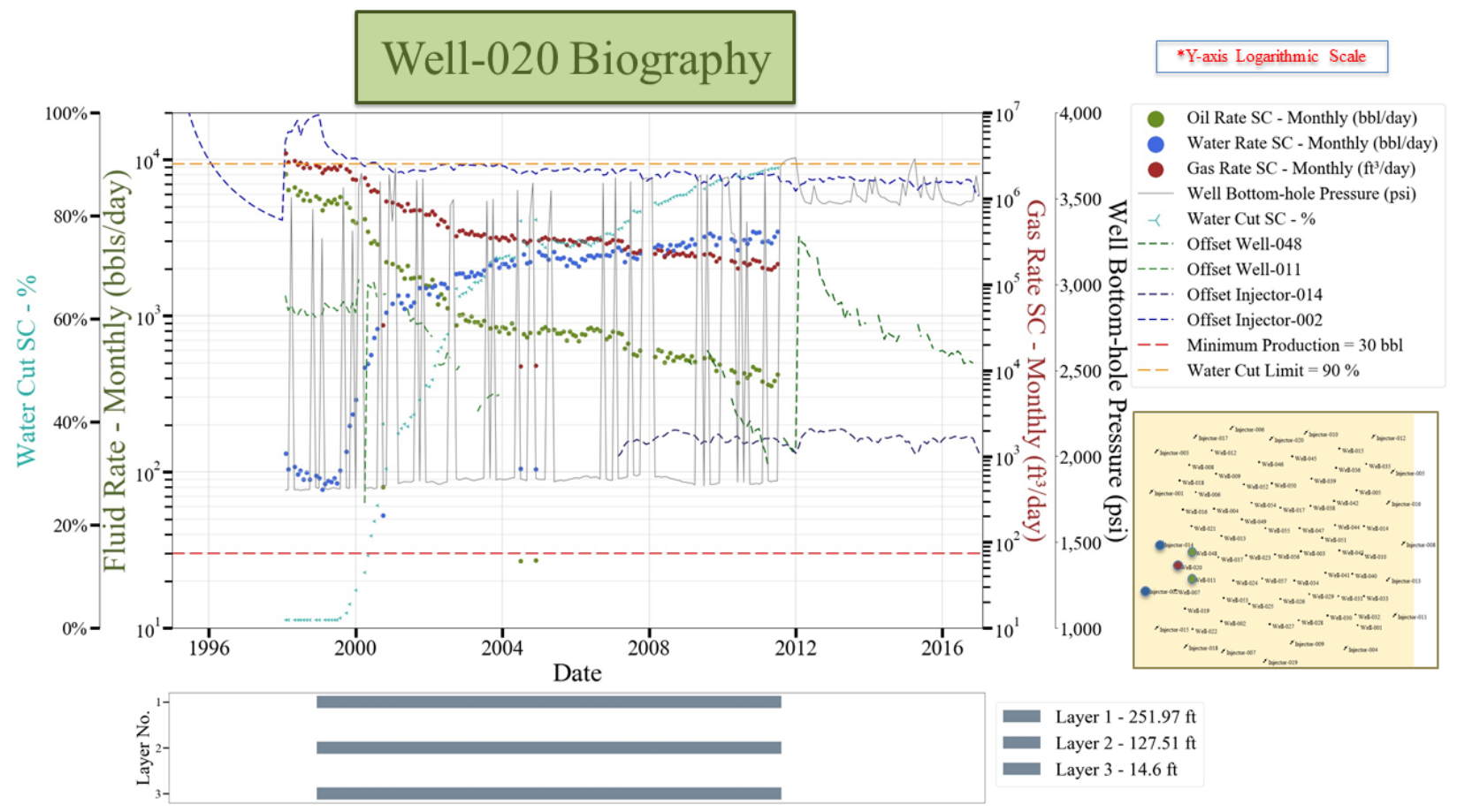

Figure 7-20: Well-020 Biography

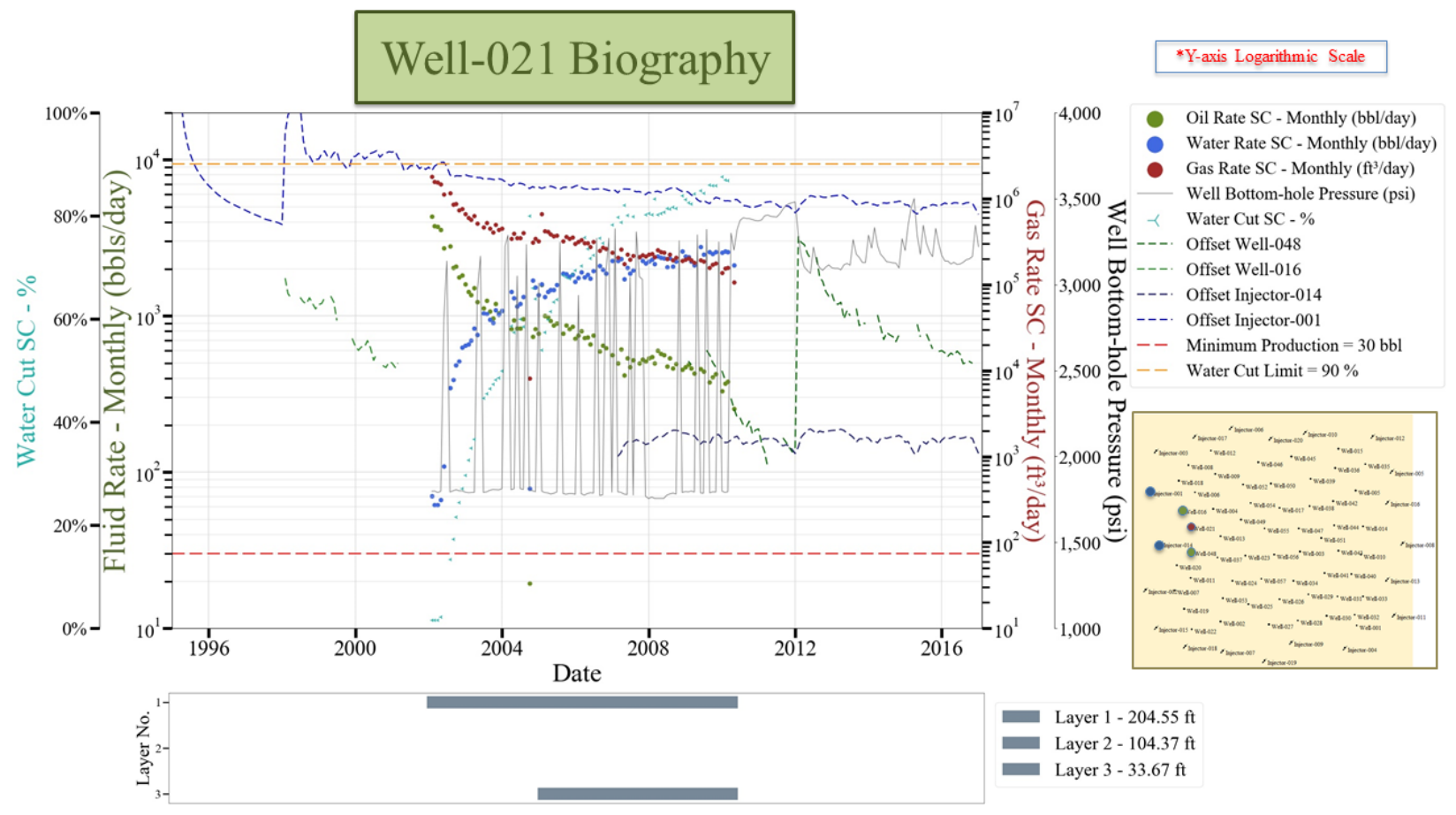

Figure 7-21: Well-021 Biography 


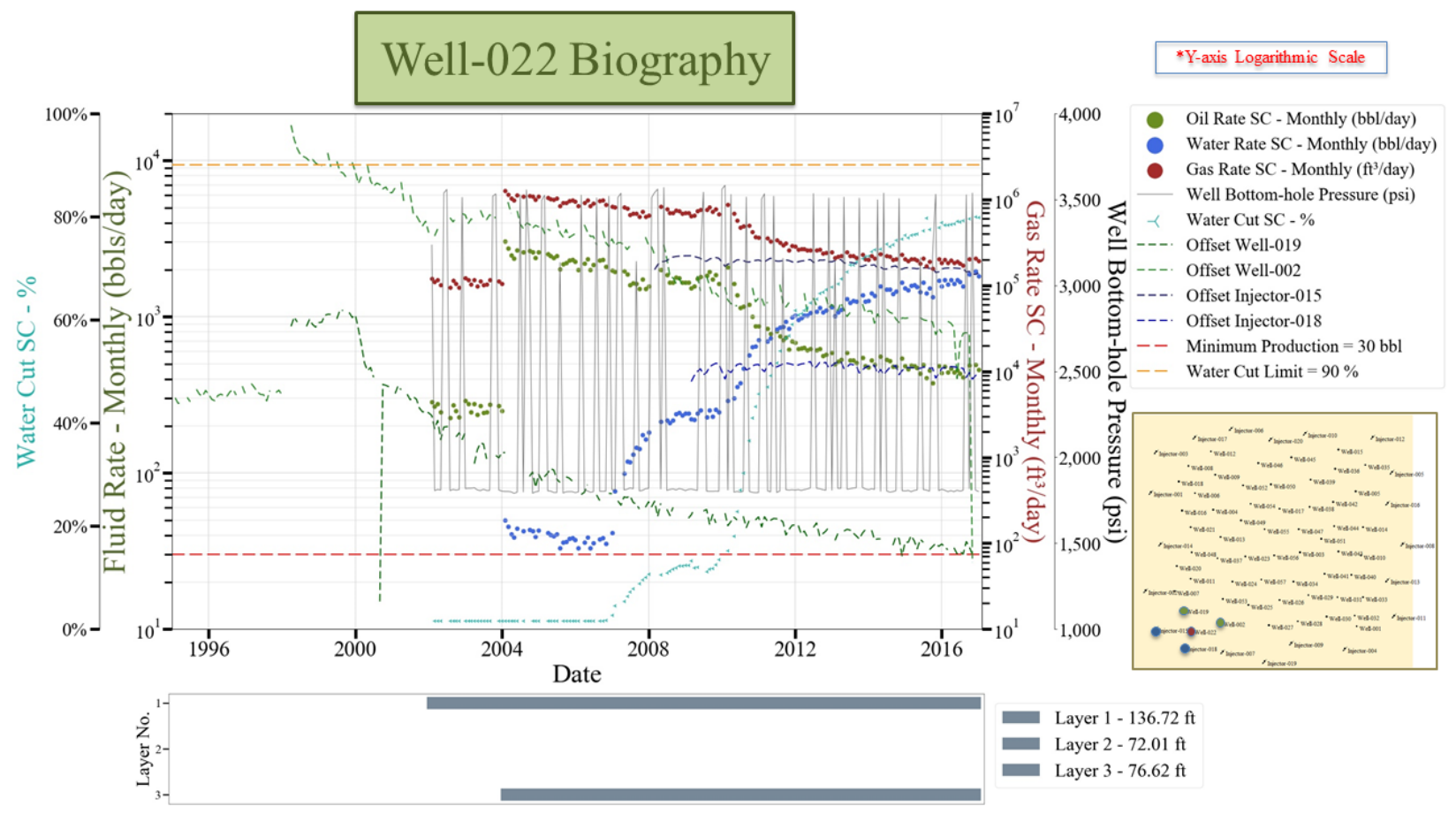

Figure 7-22: Well-022 Biography

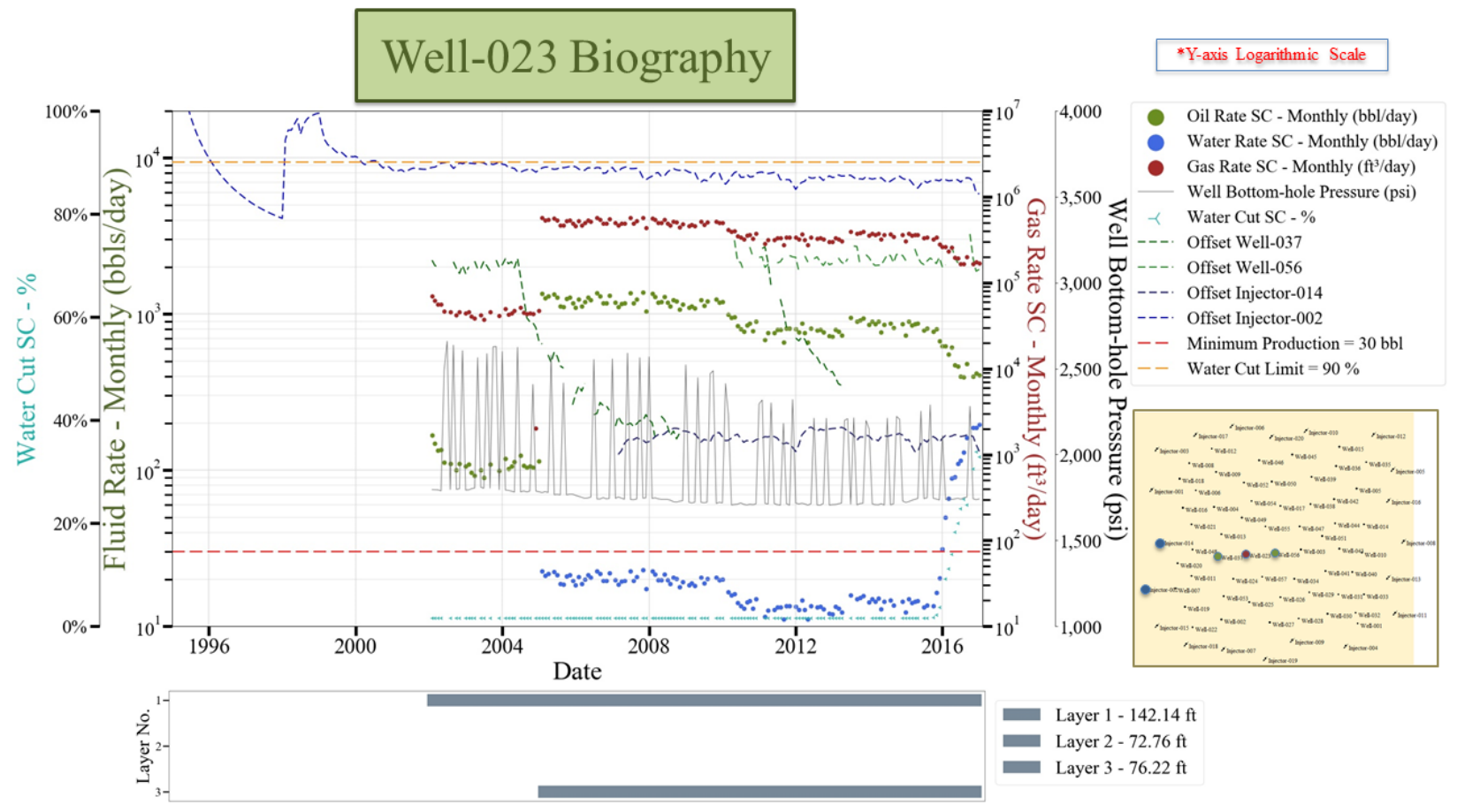

Figure 7-23: Well-023 Biography 


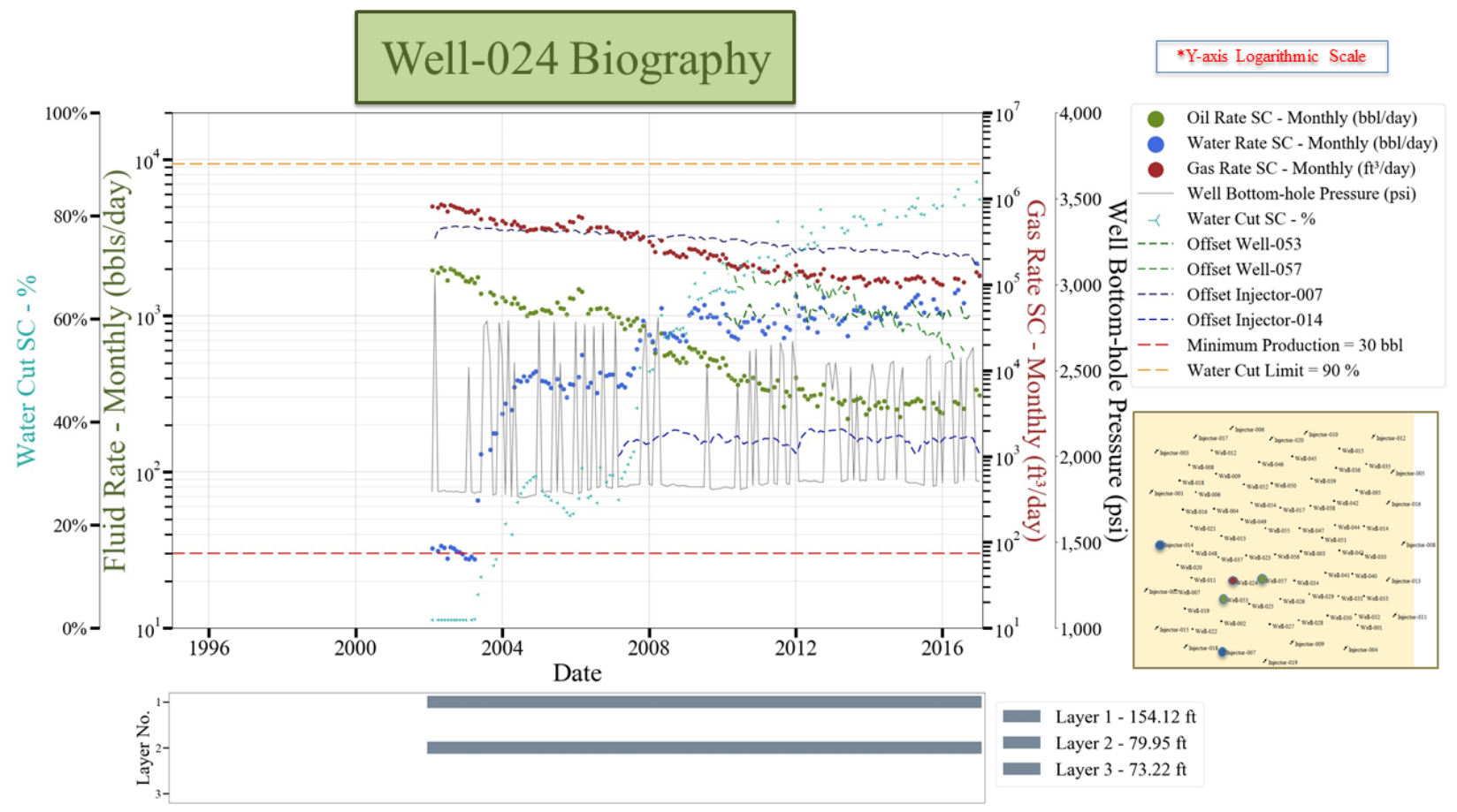

Figure 7-24: Well-024 Biography

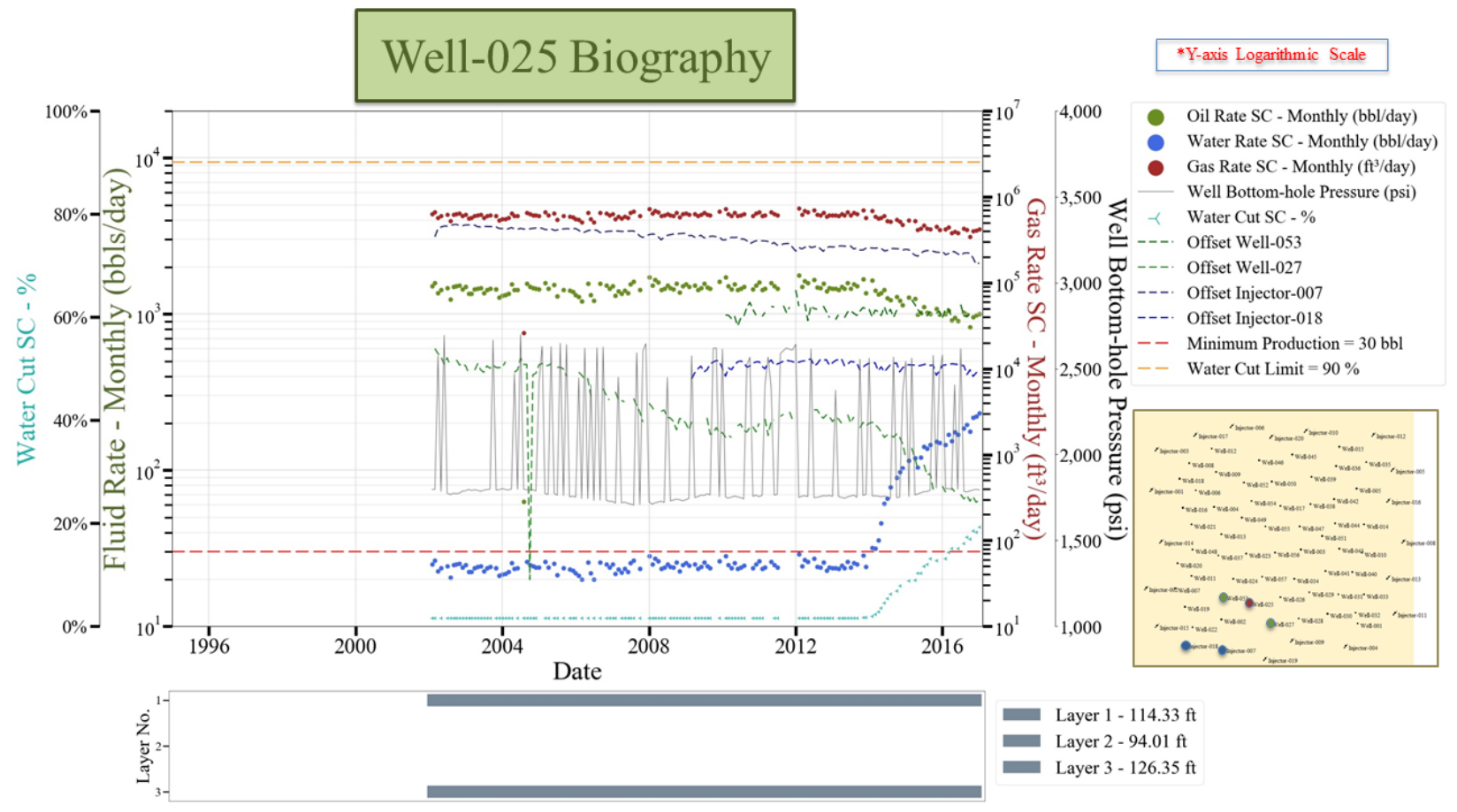

Figure 7-25: Well-025 Biography 


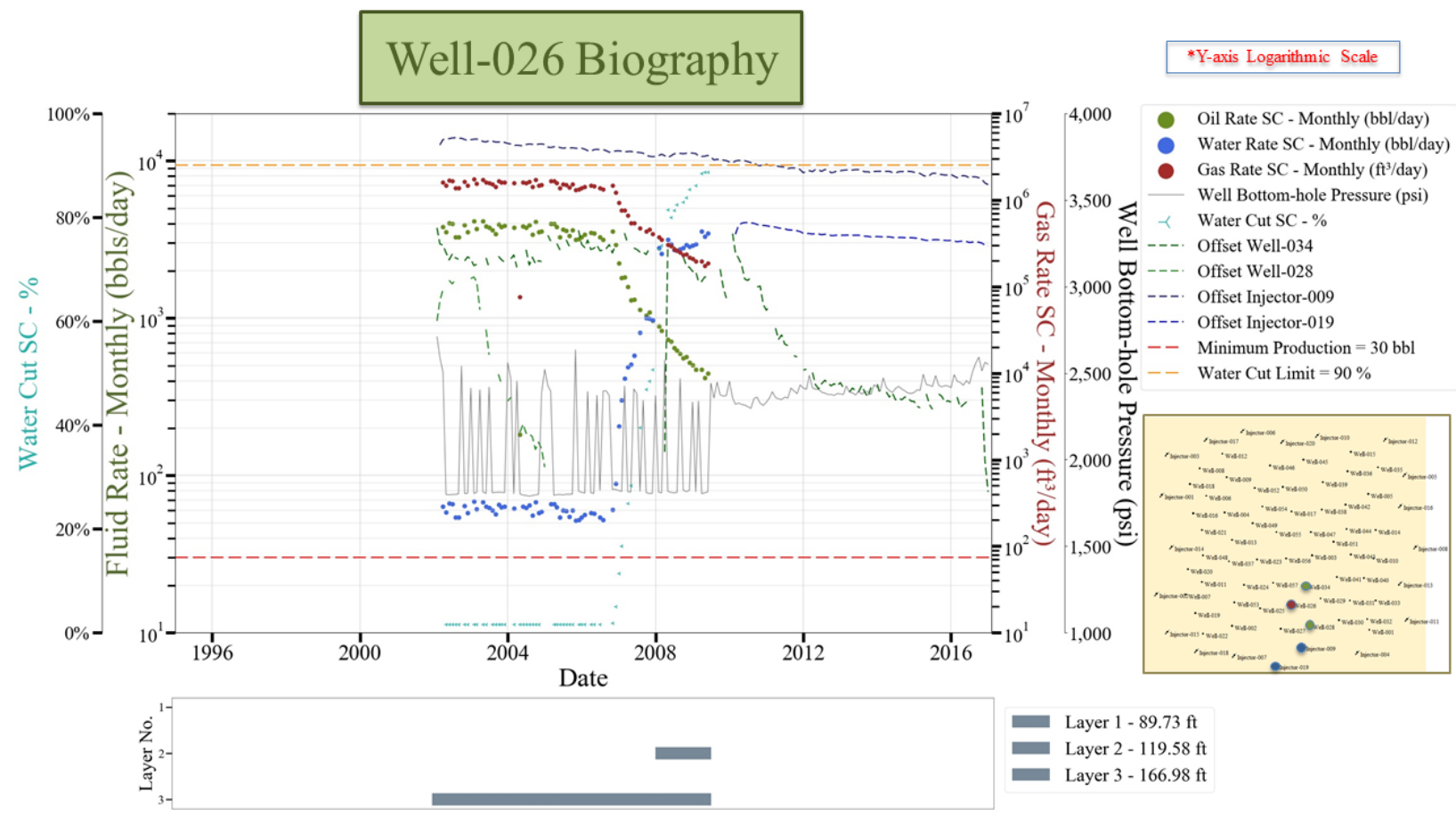

Figure 7-26: Well-026 Biography

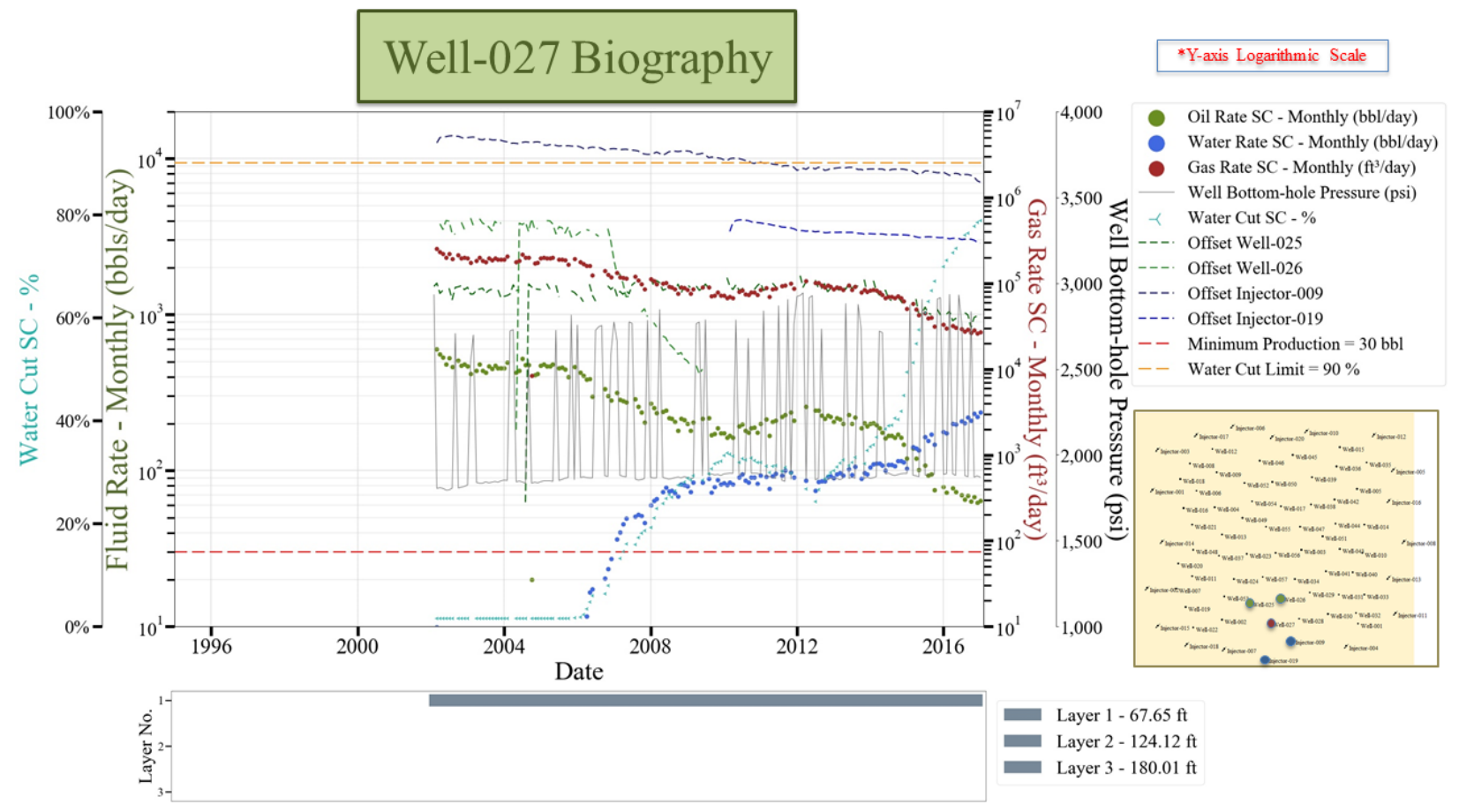

Figure 7-27: Well-027 Biography 


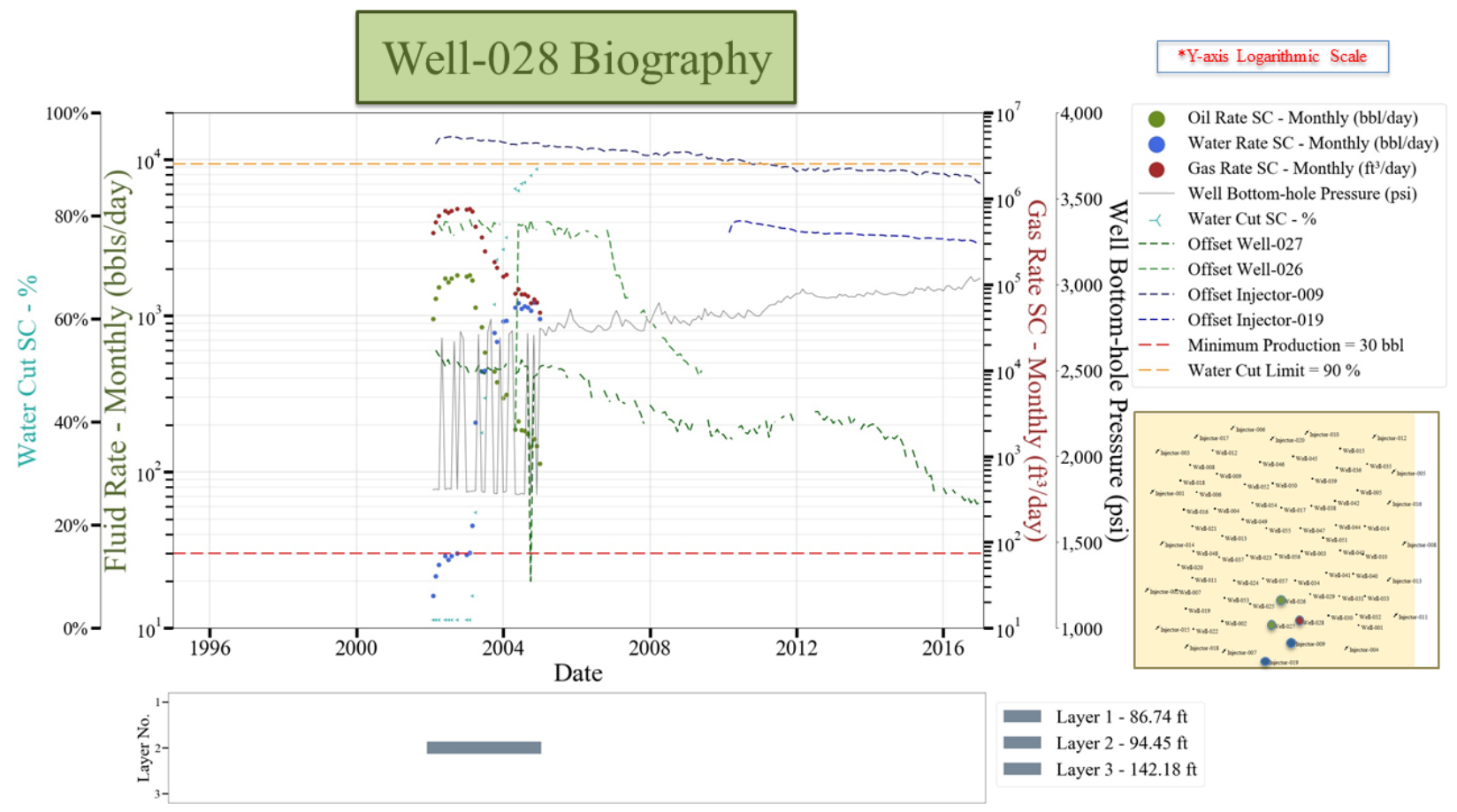

Figure 7-28: Well-028 Biography

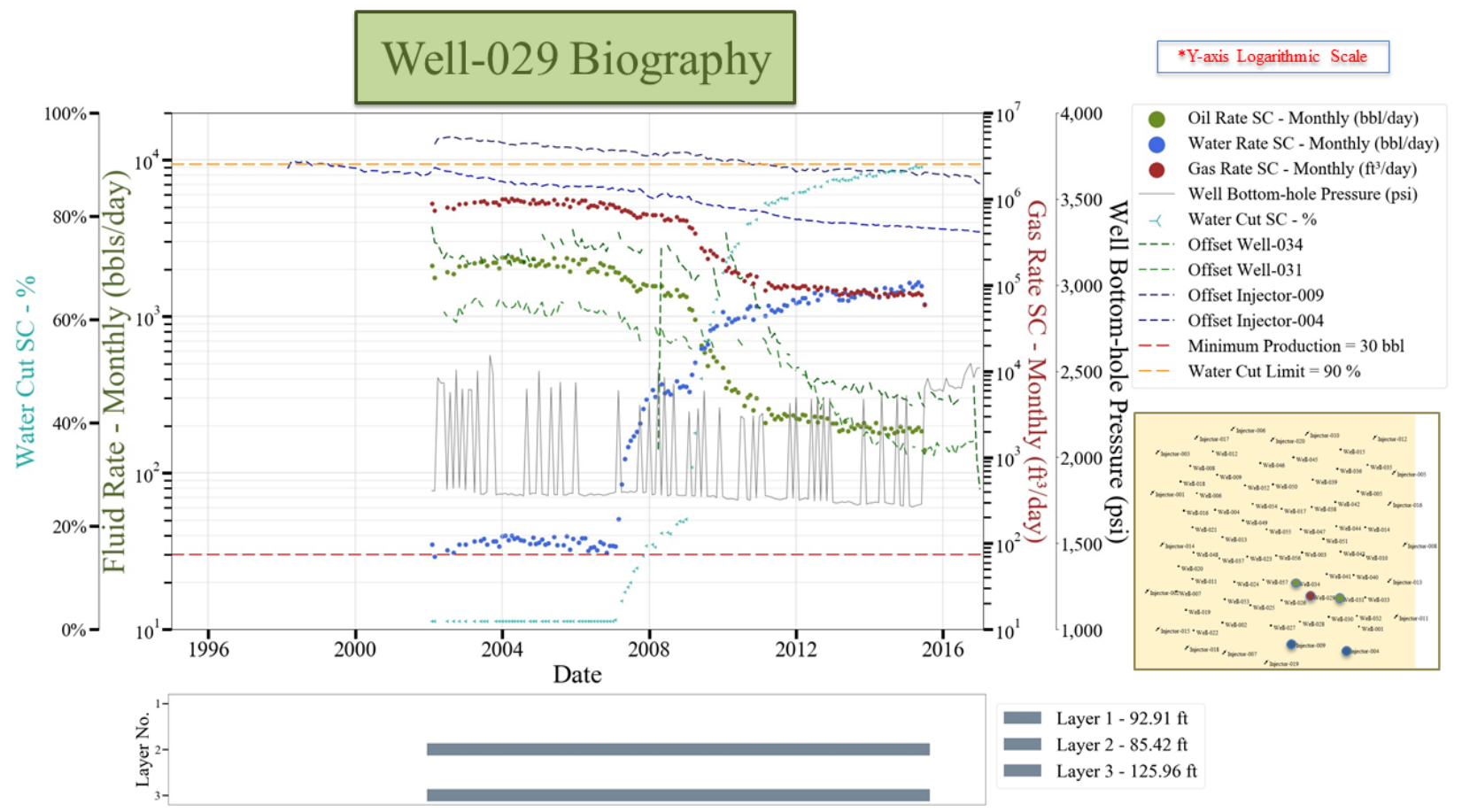

Figure 7-29: Well-029 Biography 


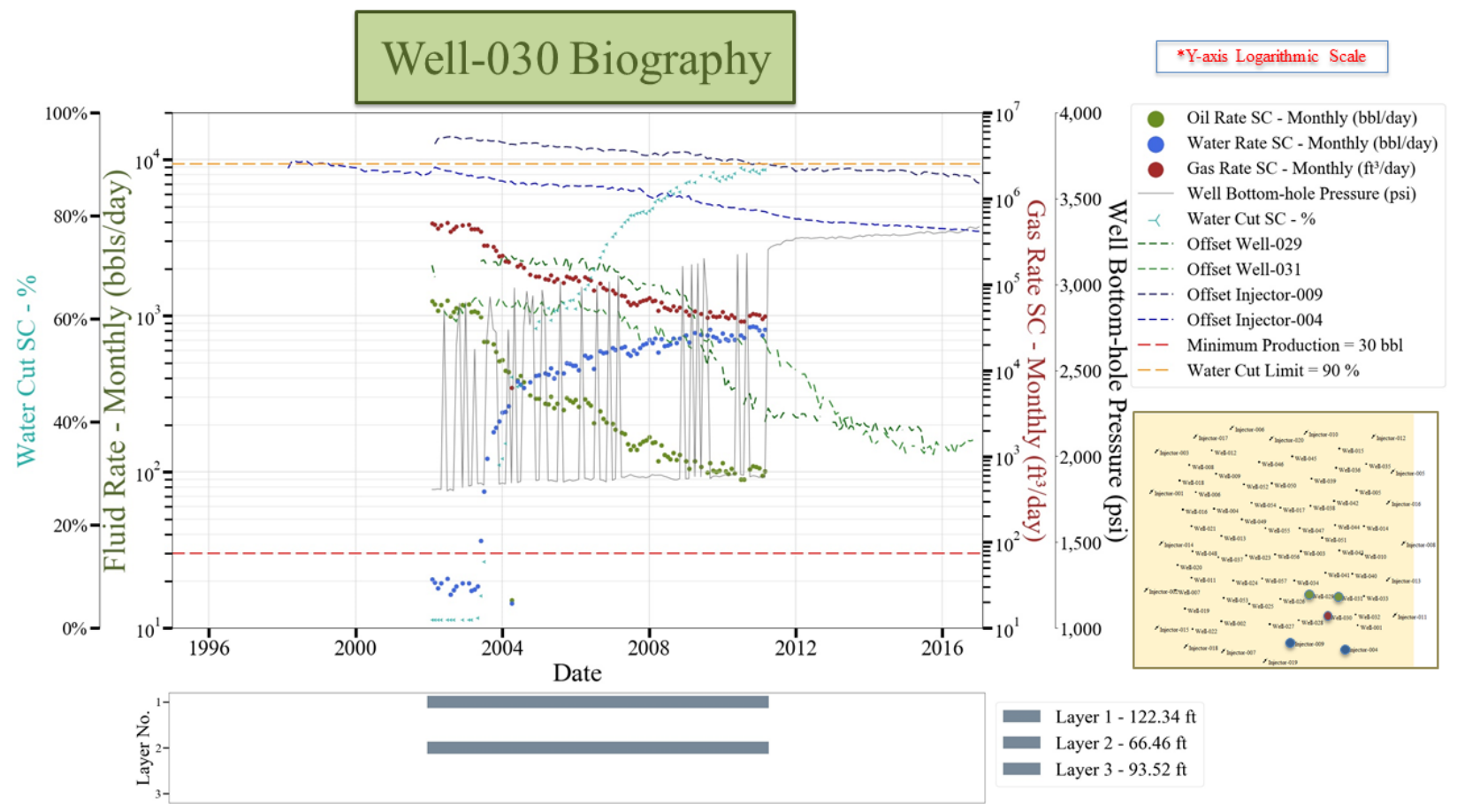

Figure 7-30: Well-030 Biography

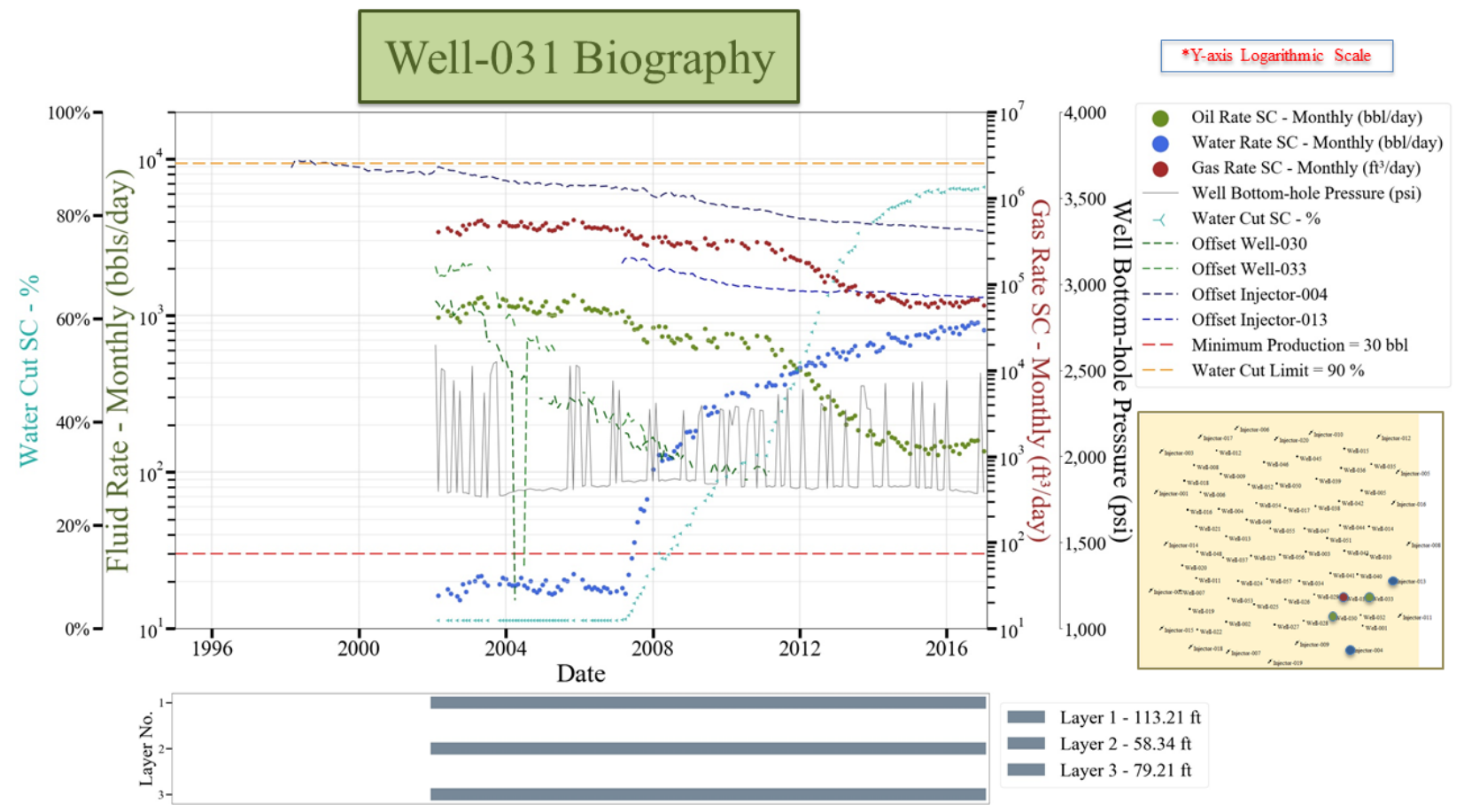

Figure 7-31: Well-031 Biography 


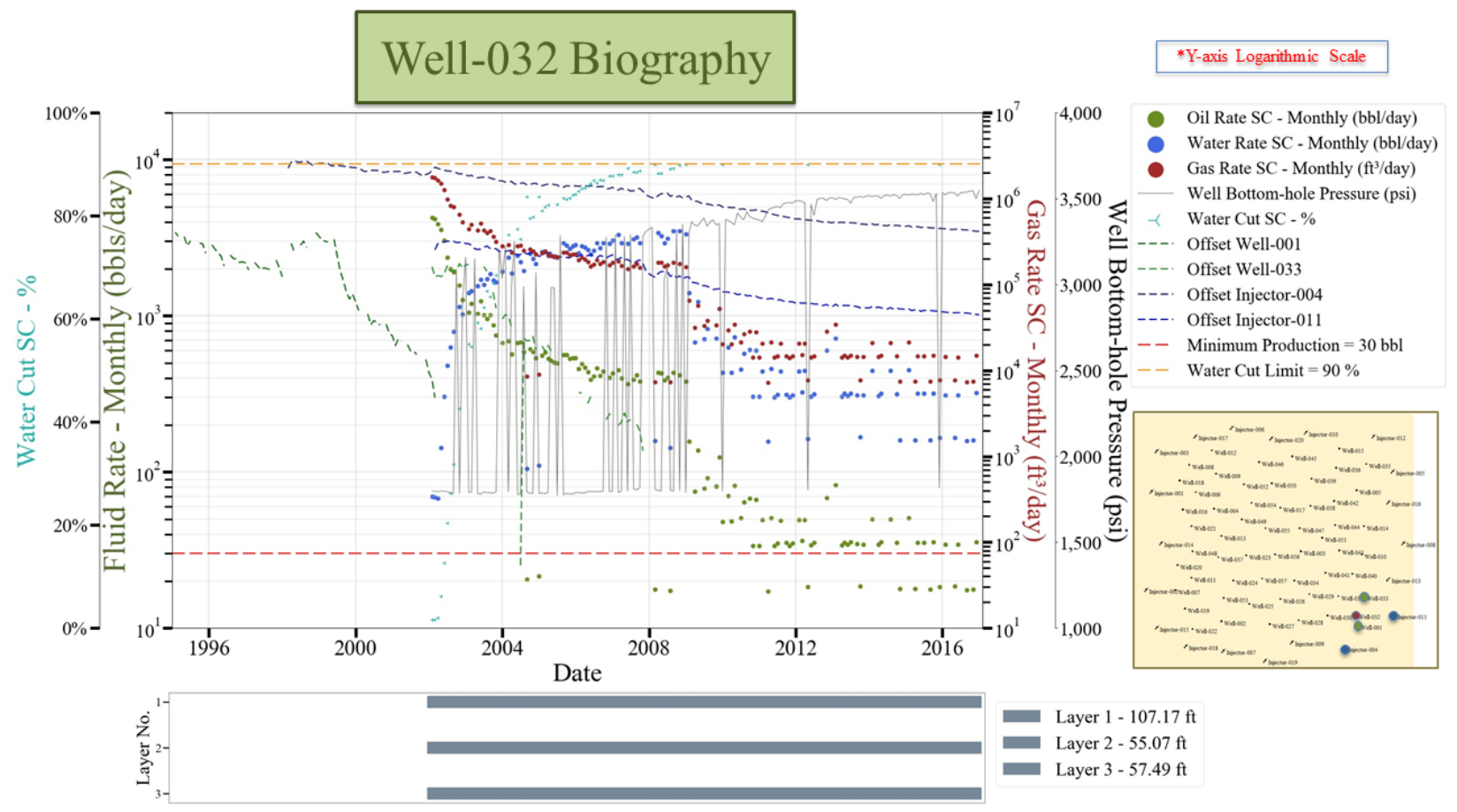

Figure 7-32: Well-032 Biography

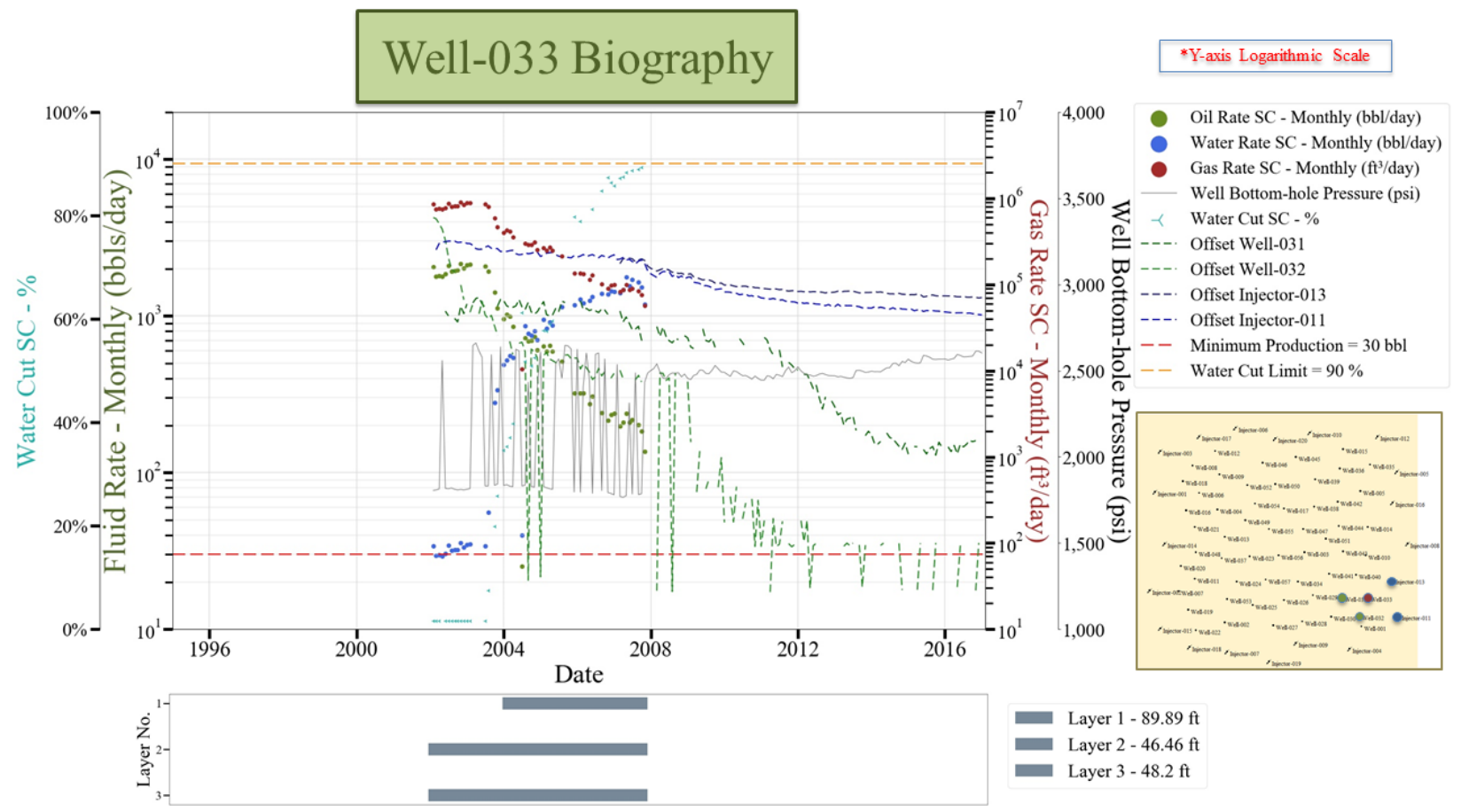

Figure 7-33: Well-033 Biography 


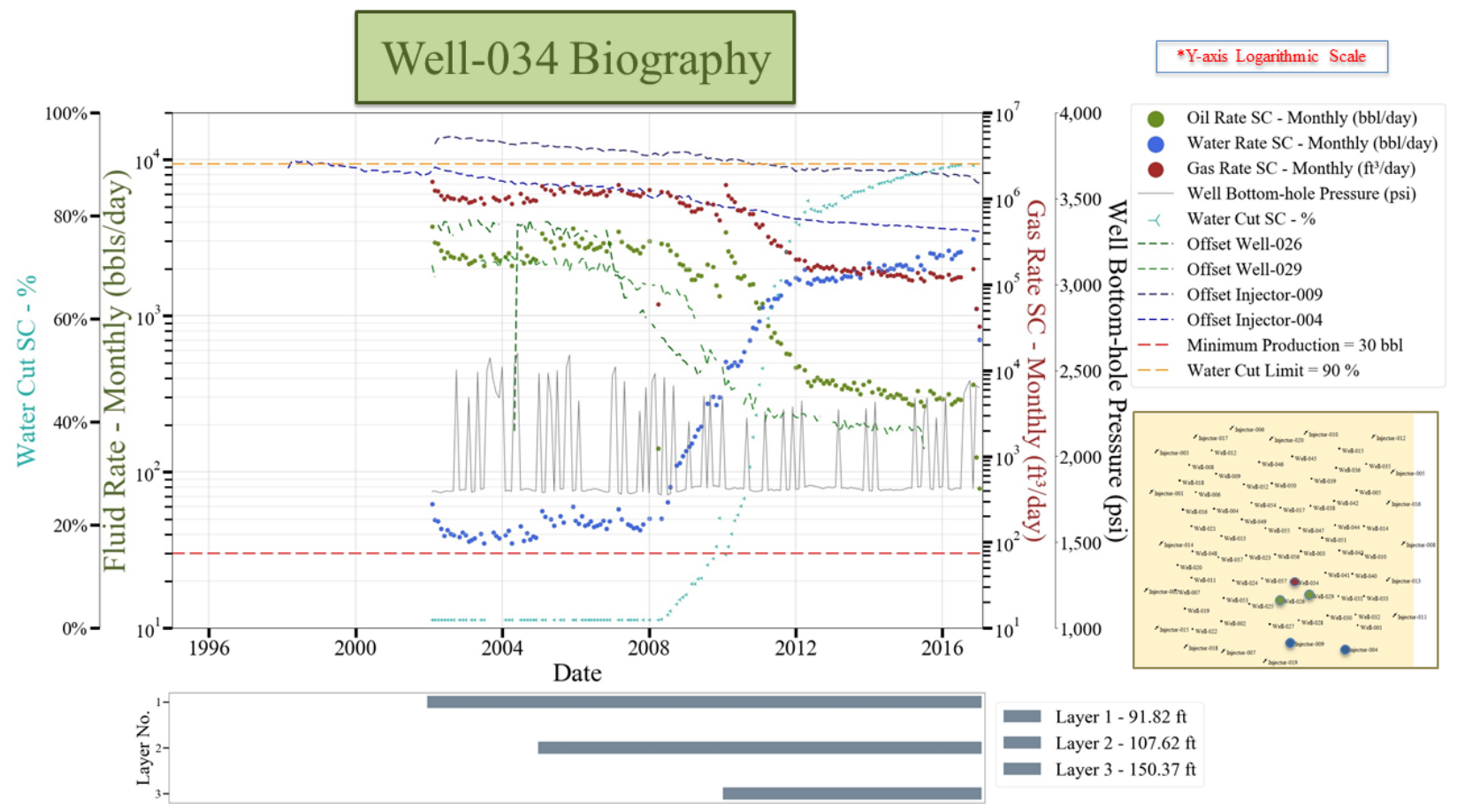

Figure 7-34: Well-034 Biography

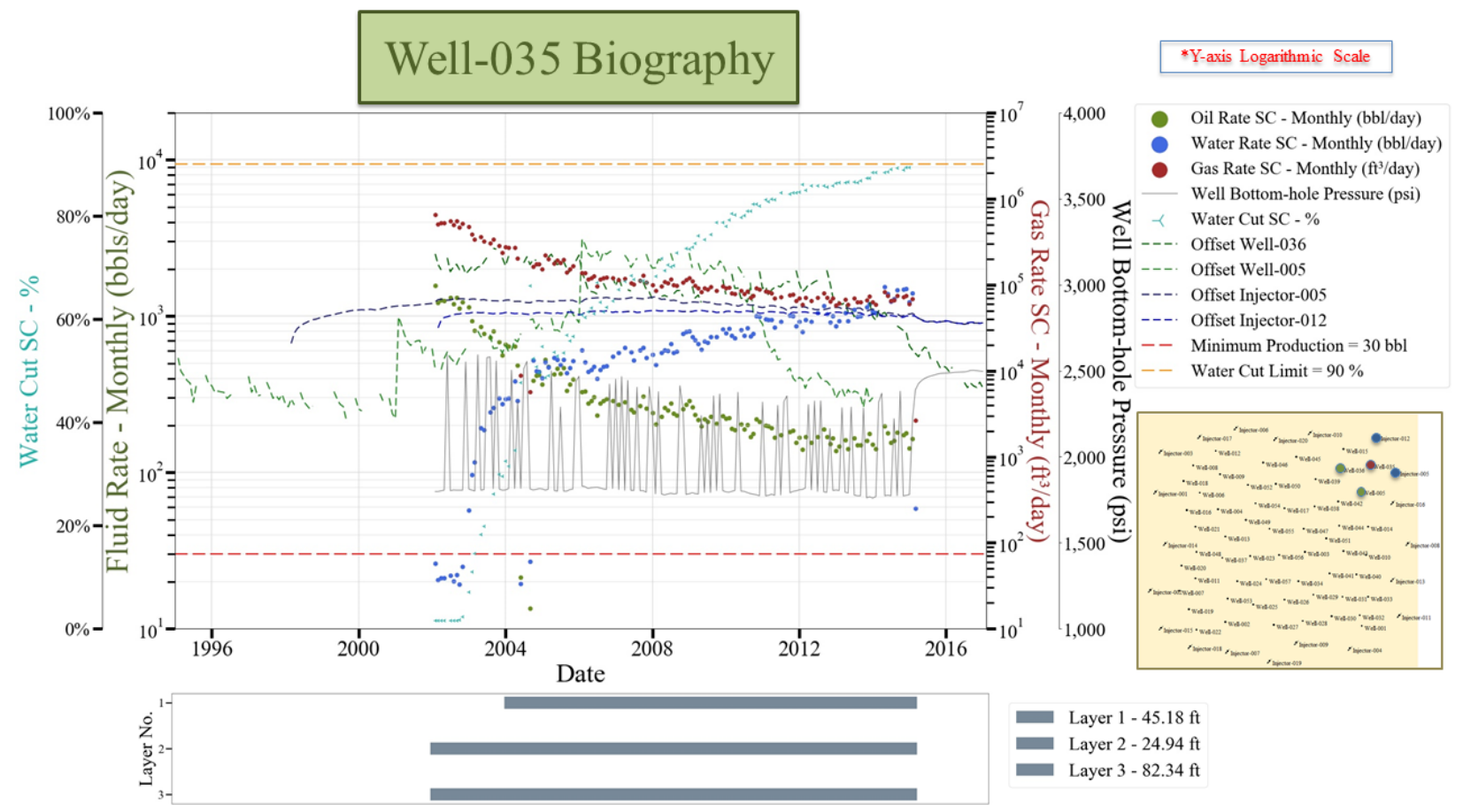

Figure 7-35: Well-035 Biography 


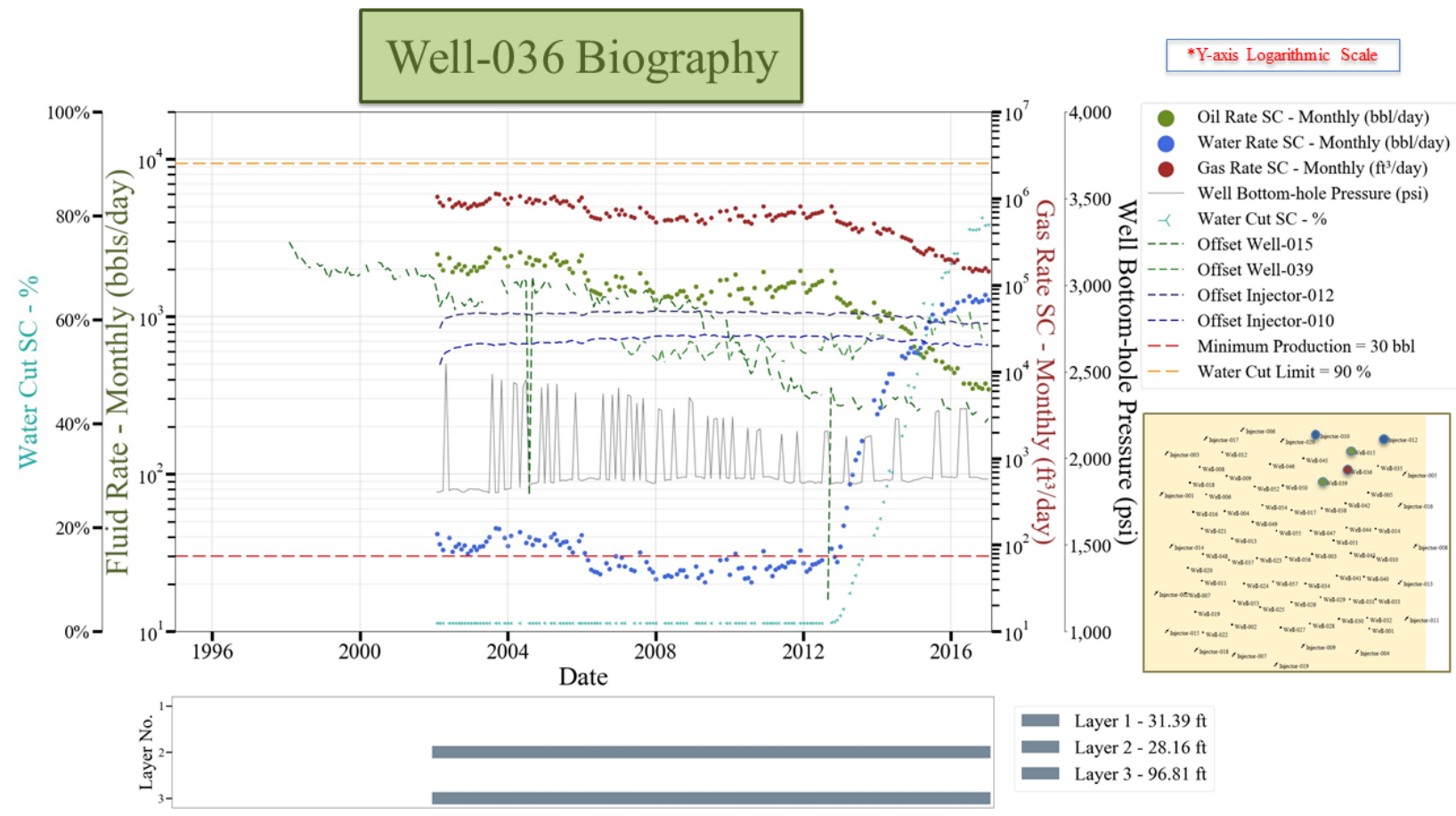

Figure 7-36: Well-036 Biography

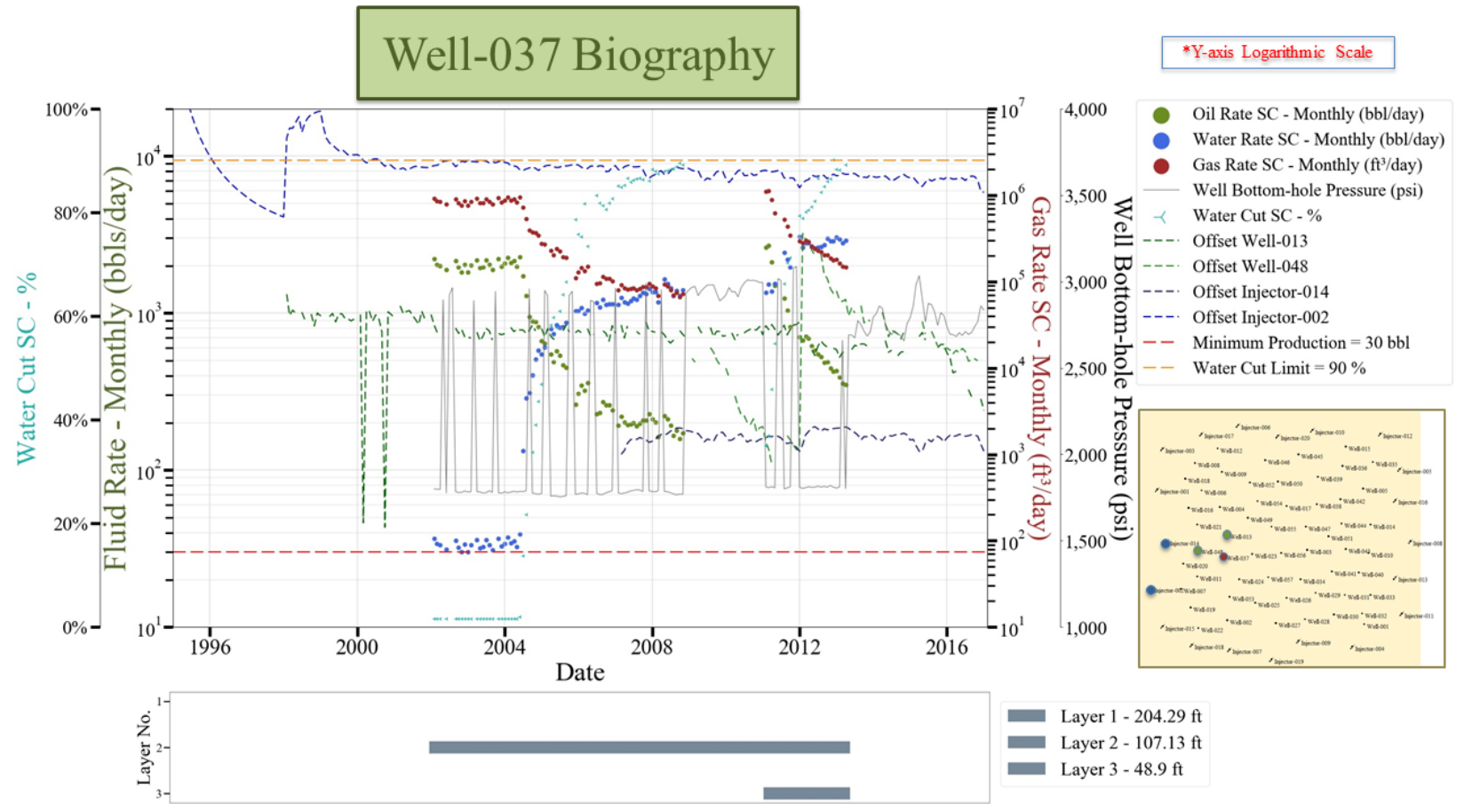

Figure 7-37: Well-037 Biography 


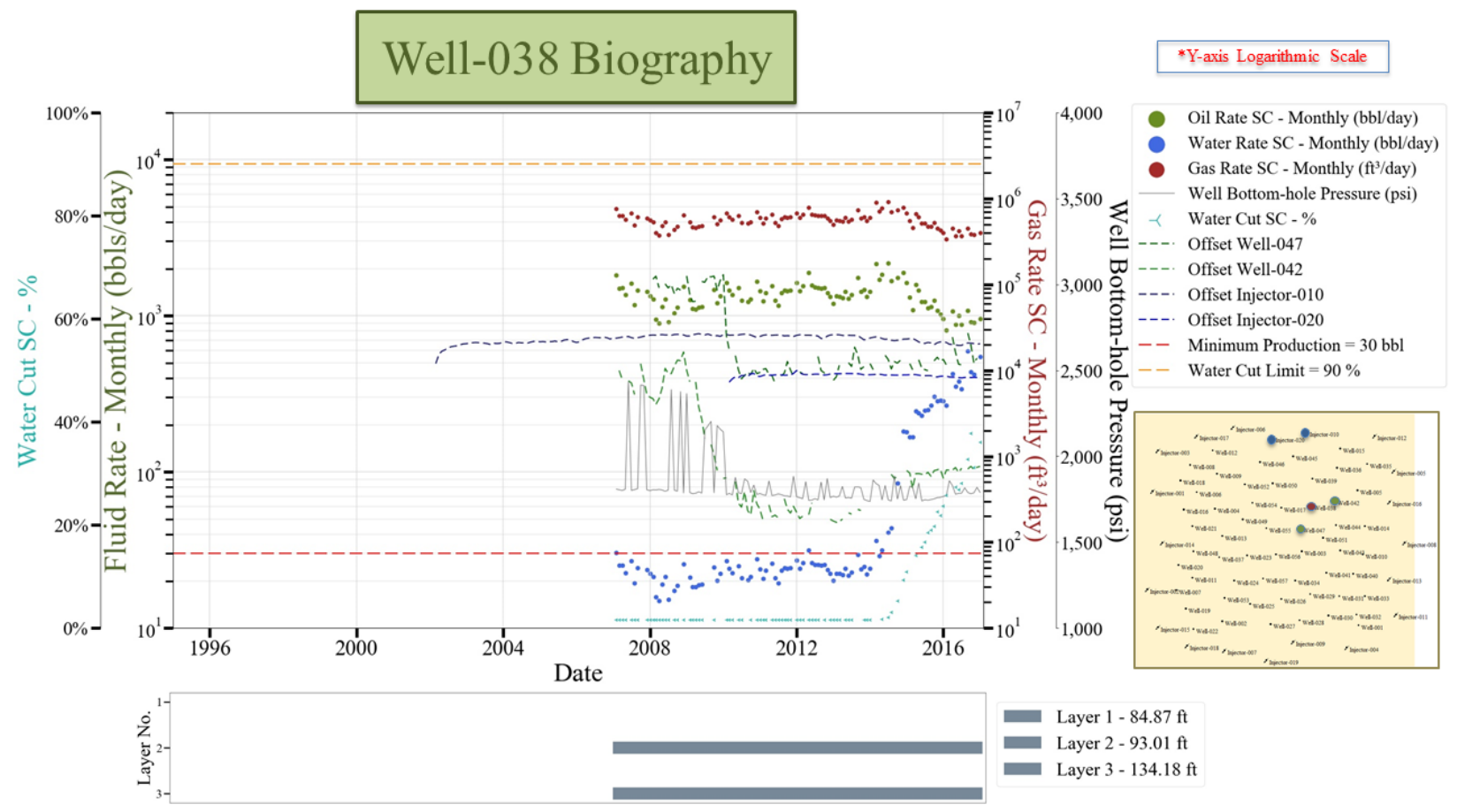

Figure 7-38: Well-038 Biography

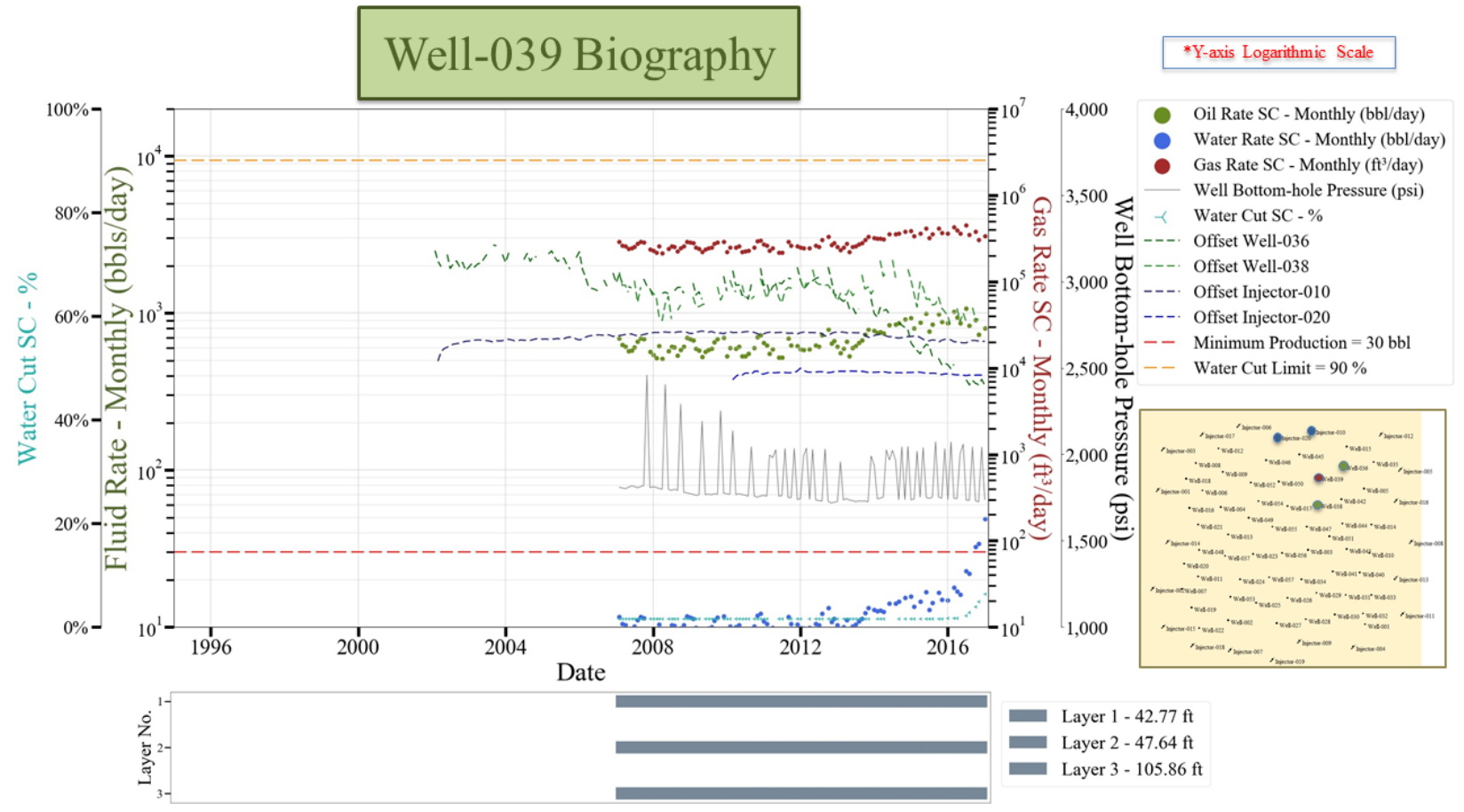

Figure 7-39: Well-039 Biography 


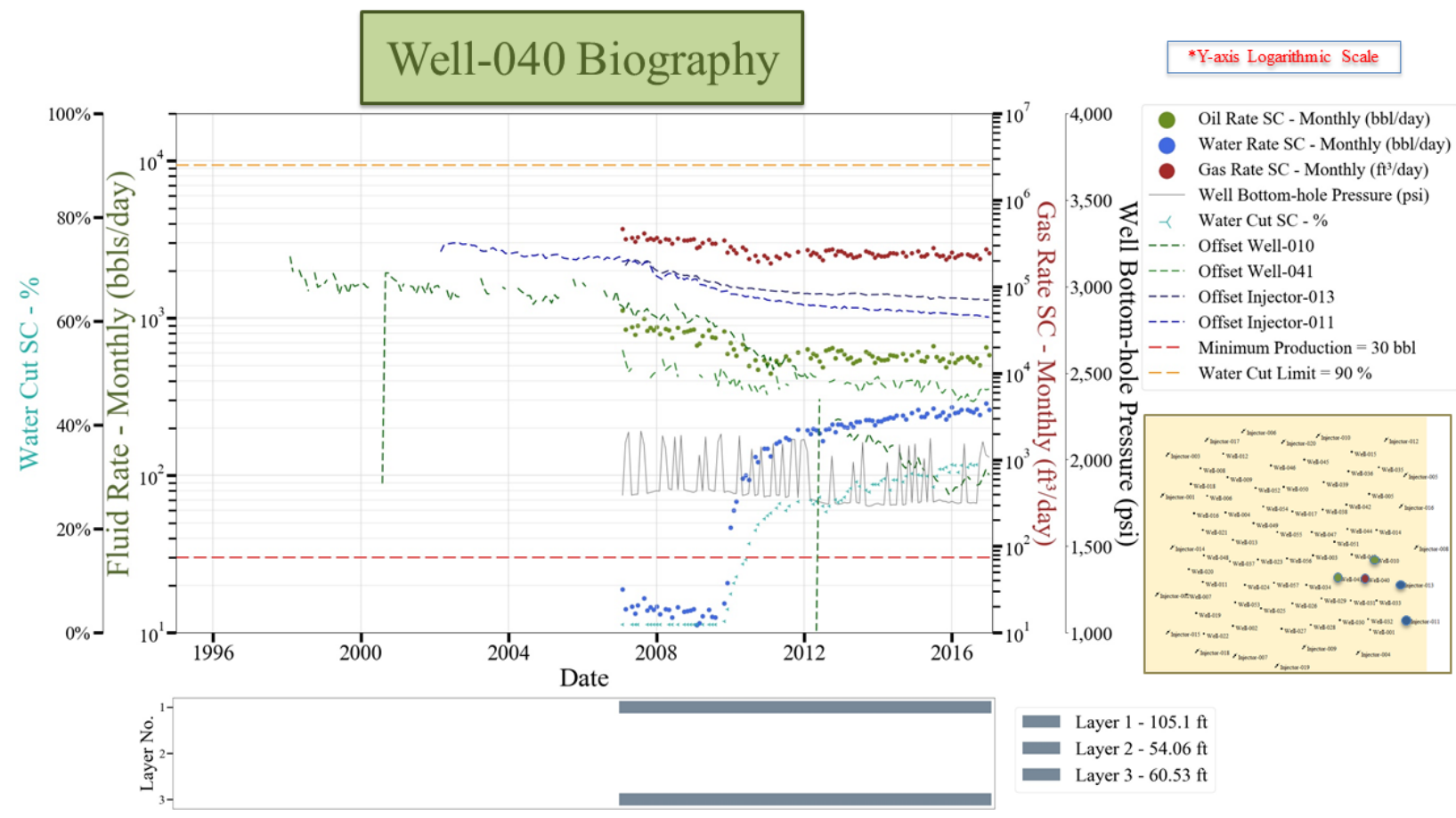

Figure 7-40: Well-040 Biography

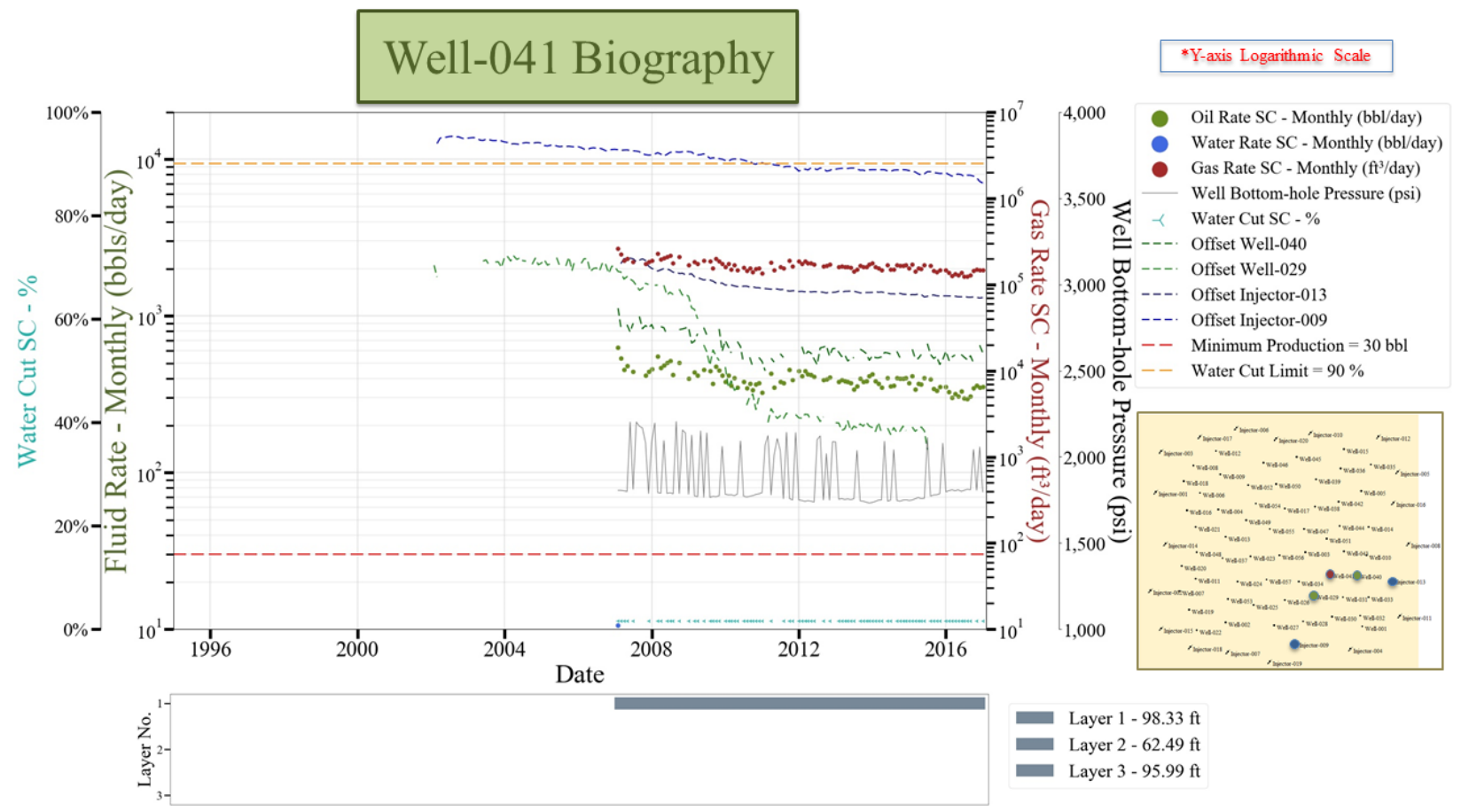

Figure 7-41: Well-041 Biography 


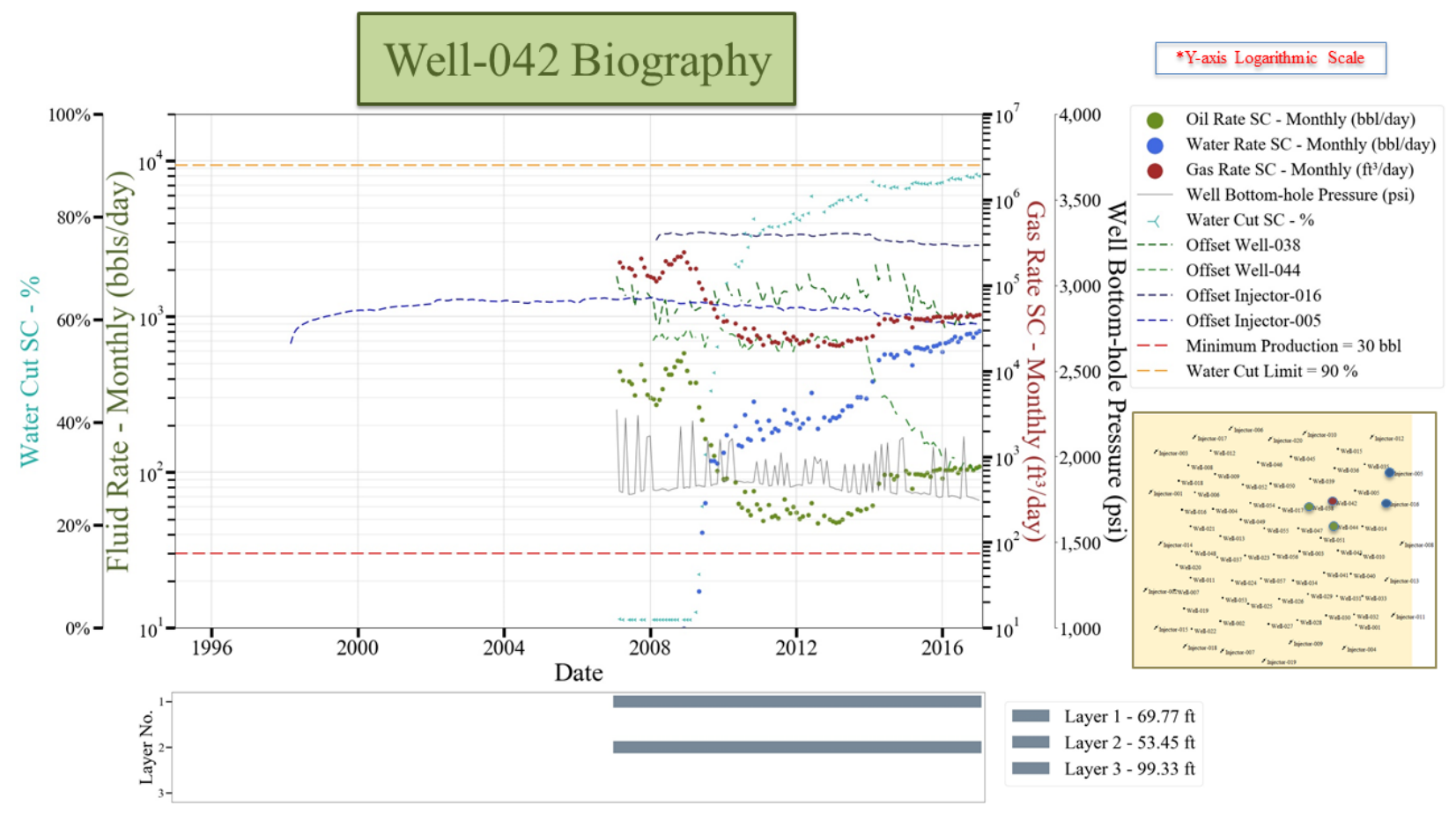

Figure 7-42: Well-042 Biography

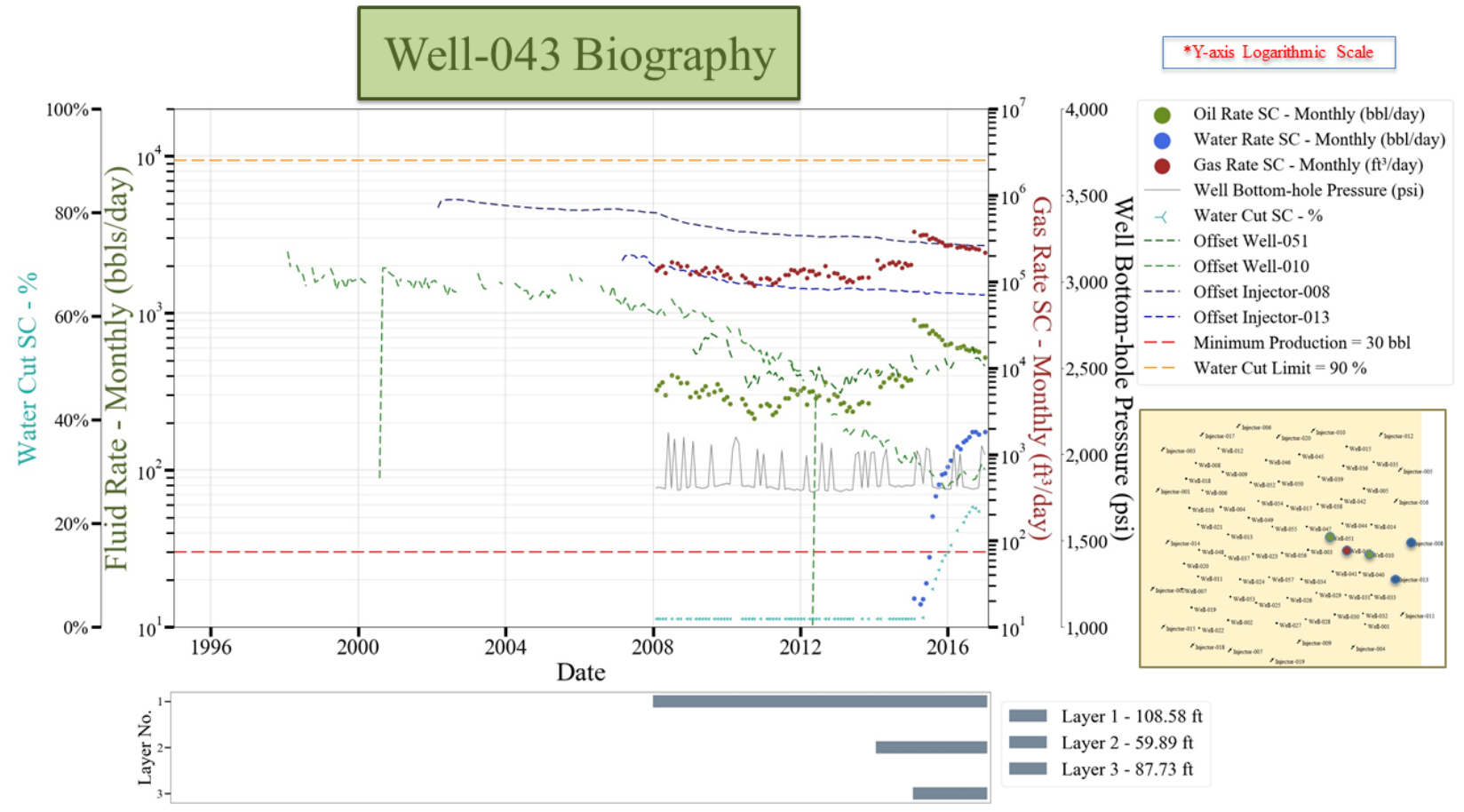

Figure 7-43: Well-043 Biography 


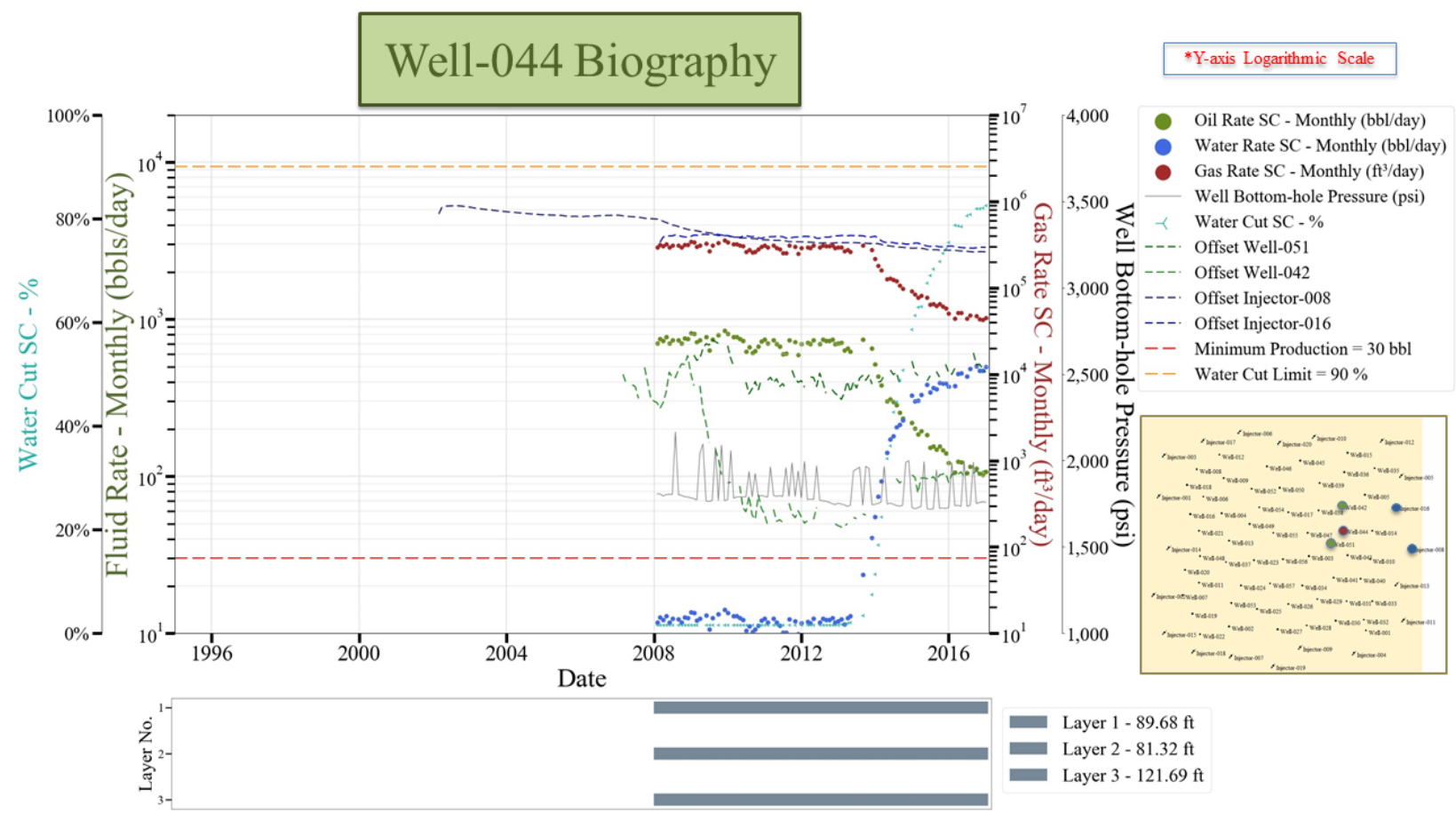

Figure 7-44: Well-044 Biography

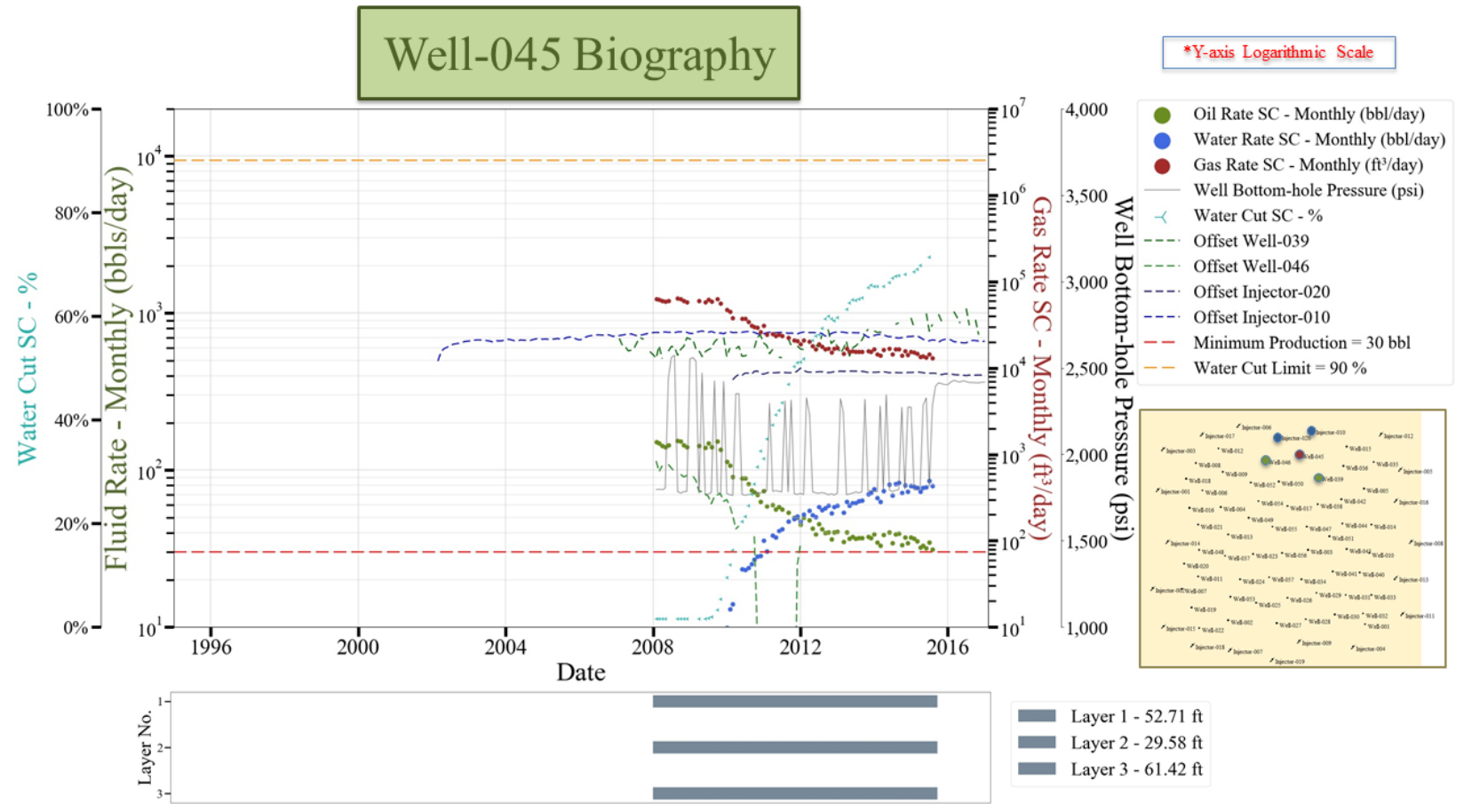

Figure 7-45: Well-045 Biography 


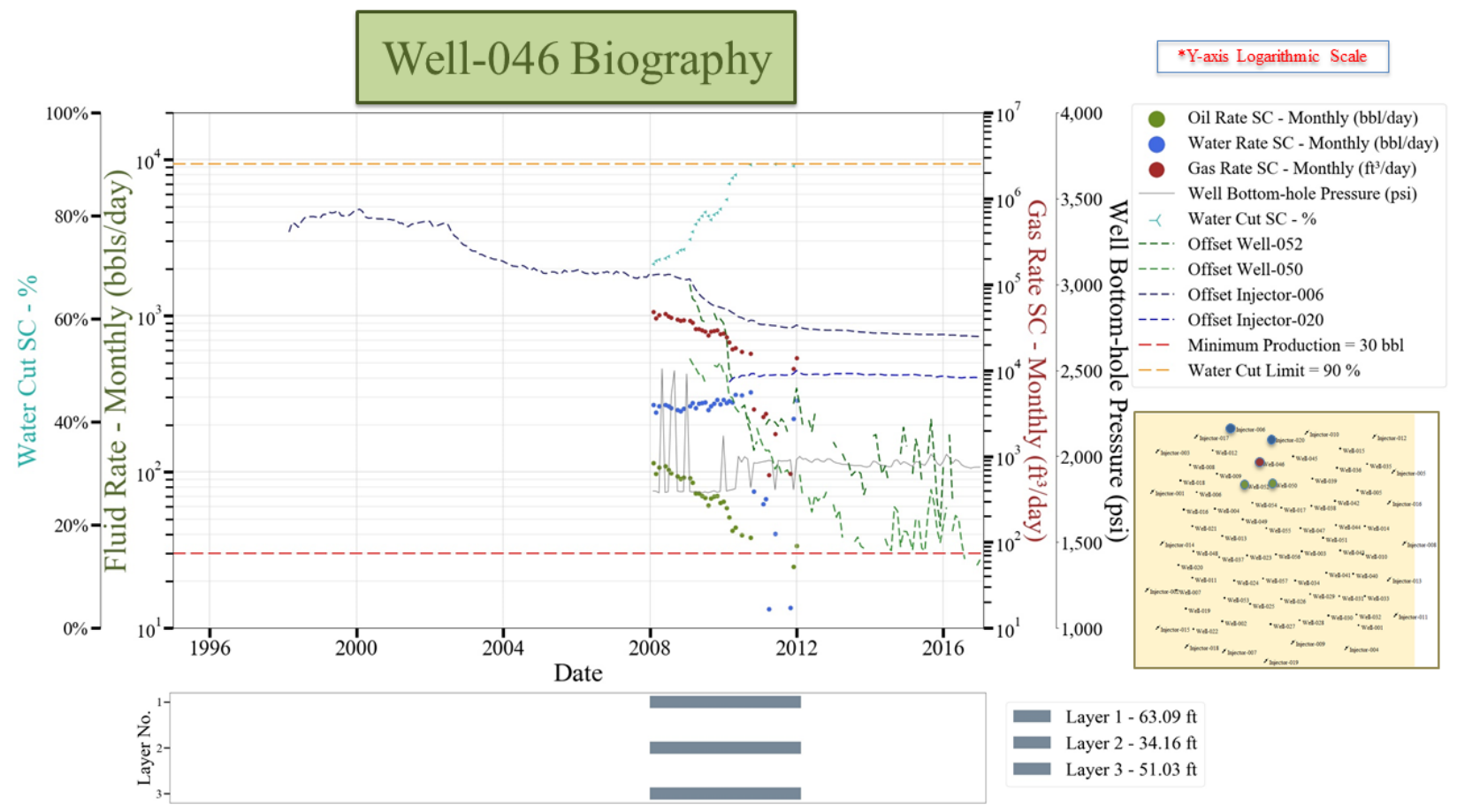

Figure 7-46: Well-046 Biography

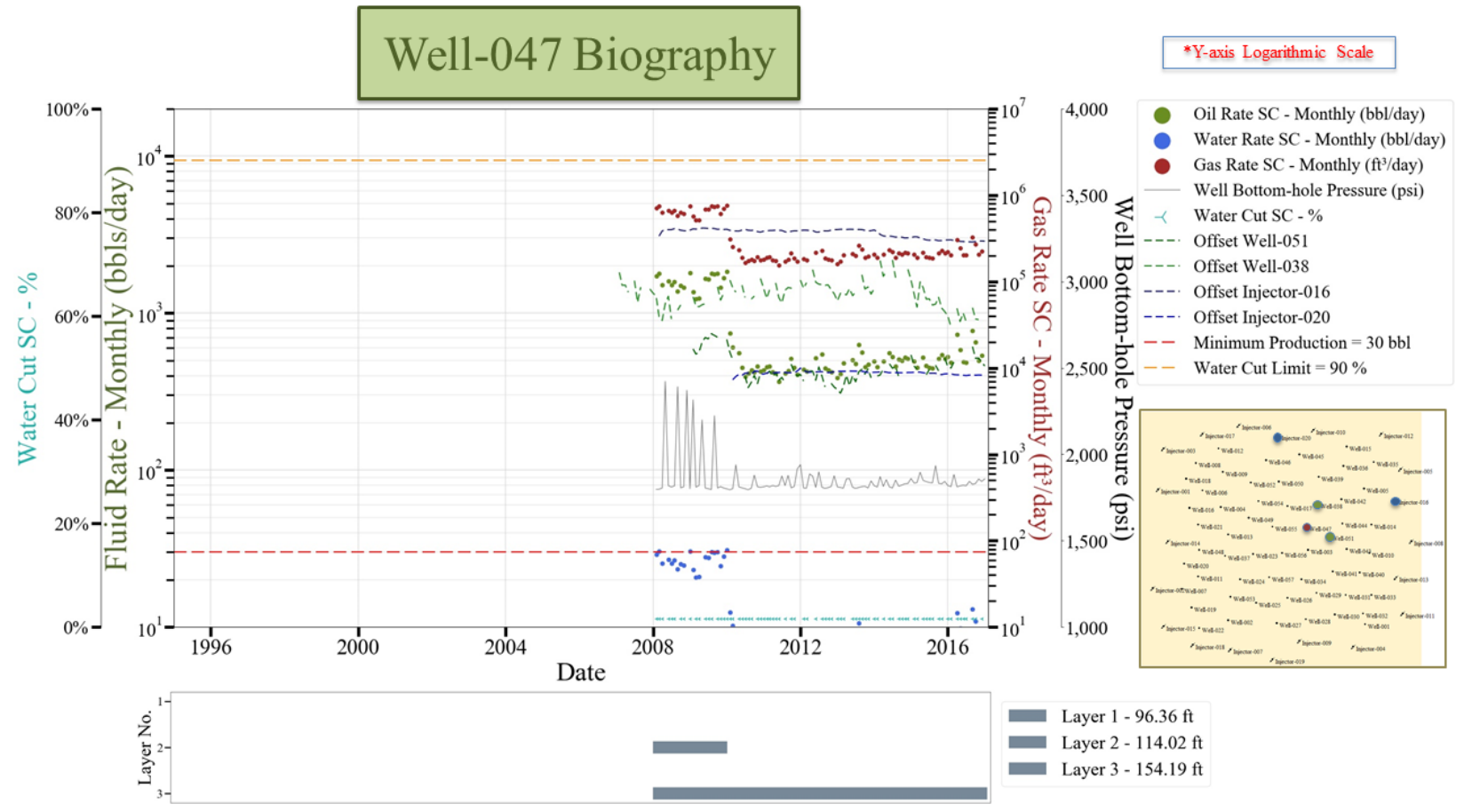

Figure 7-47: Well-047 Biography 


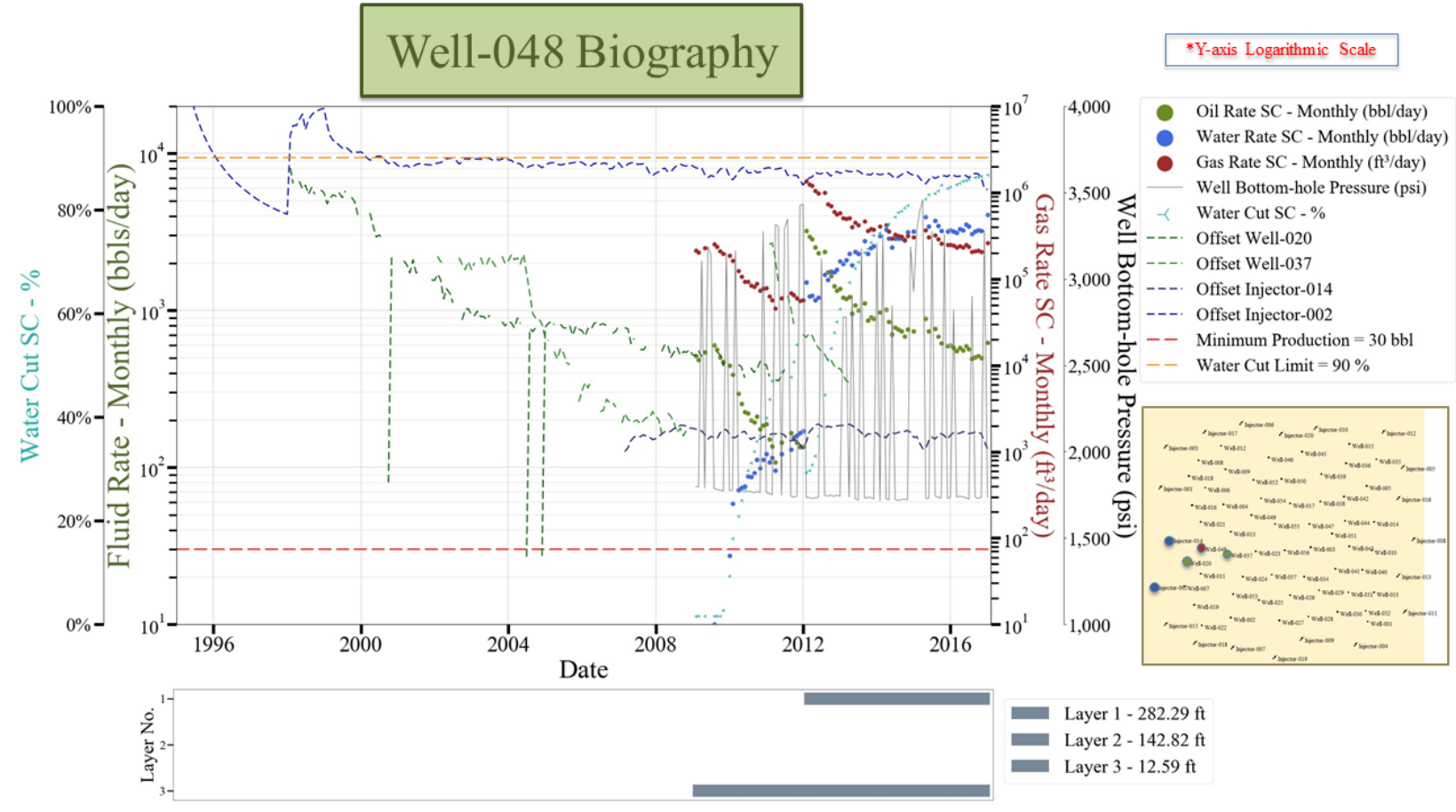

Figure 7-48: Well-048 Biography

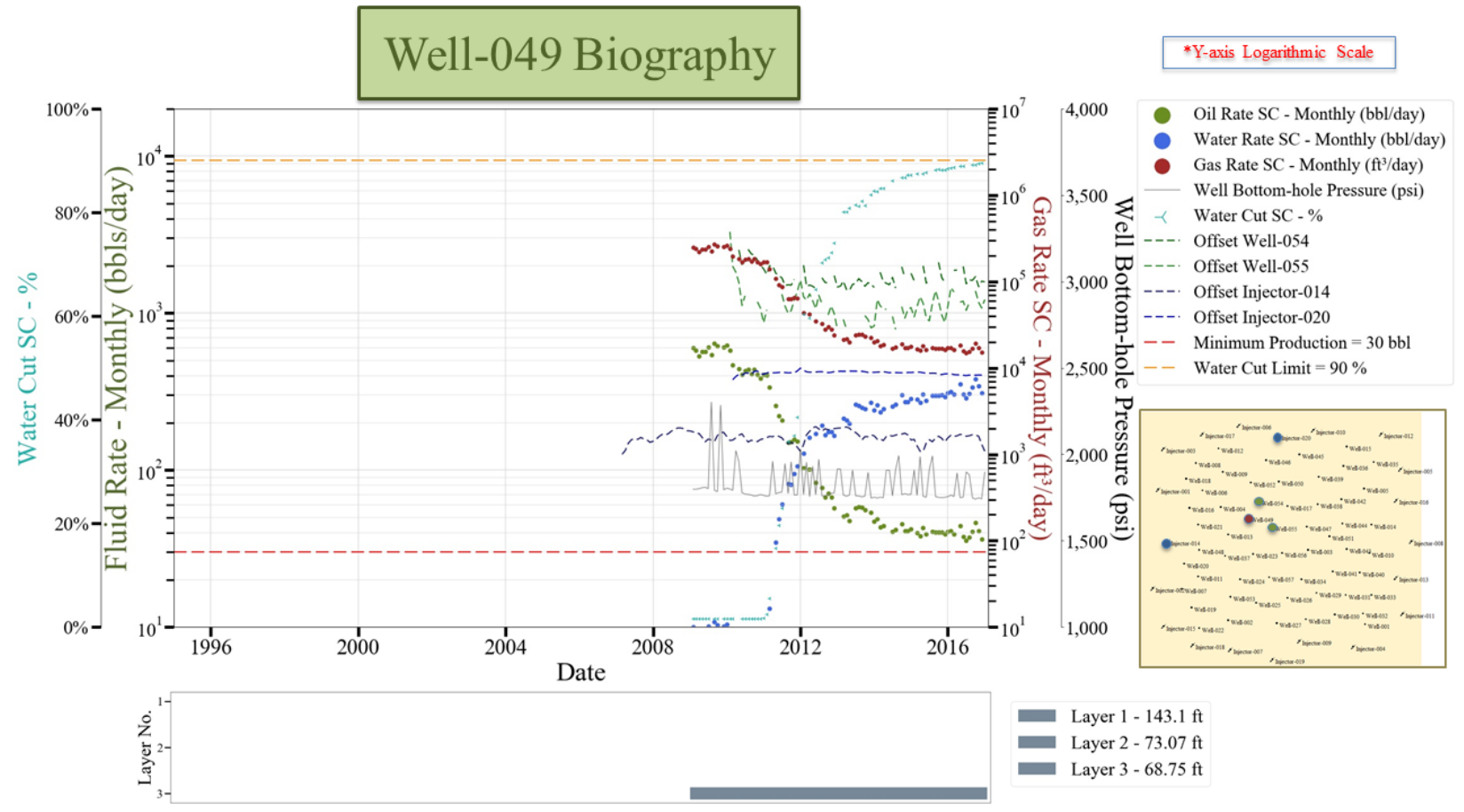

Figure 7-49: Well-049 Biography 


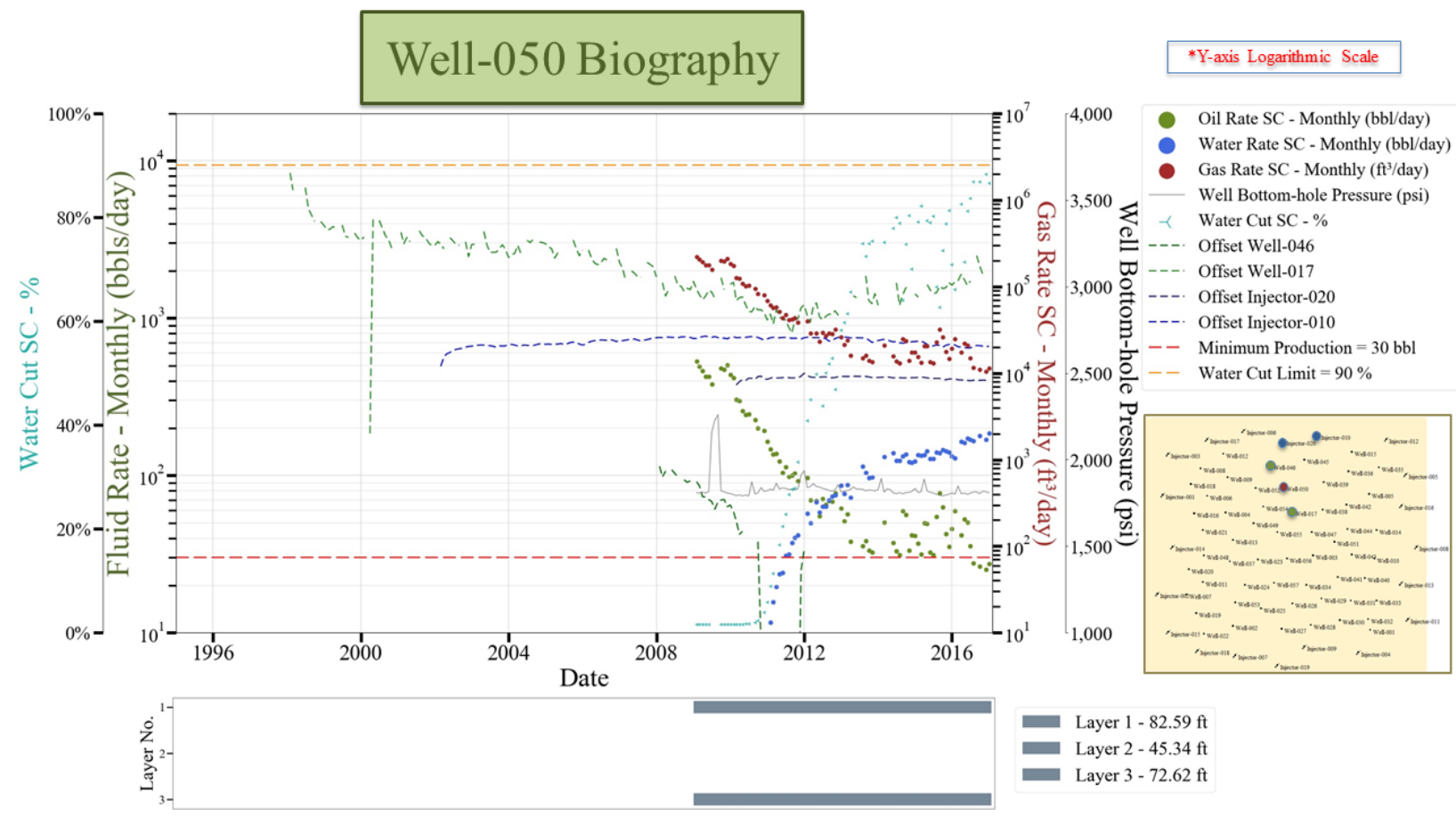

Figure 7-50: Well-050 Biography

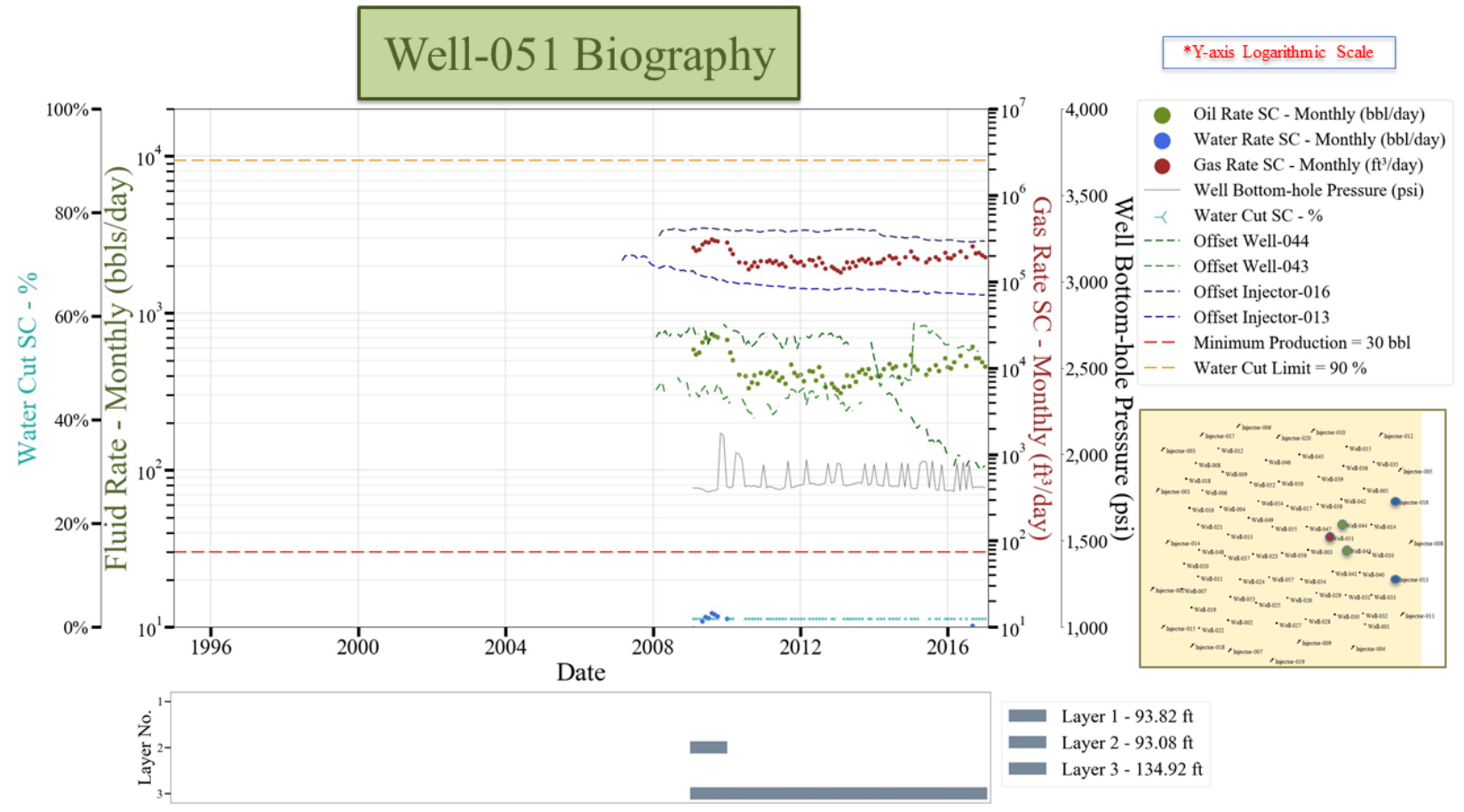

Figure 7-51: Well-051 Biography 


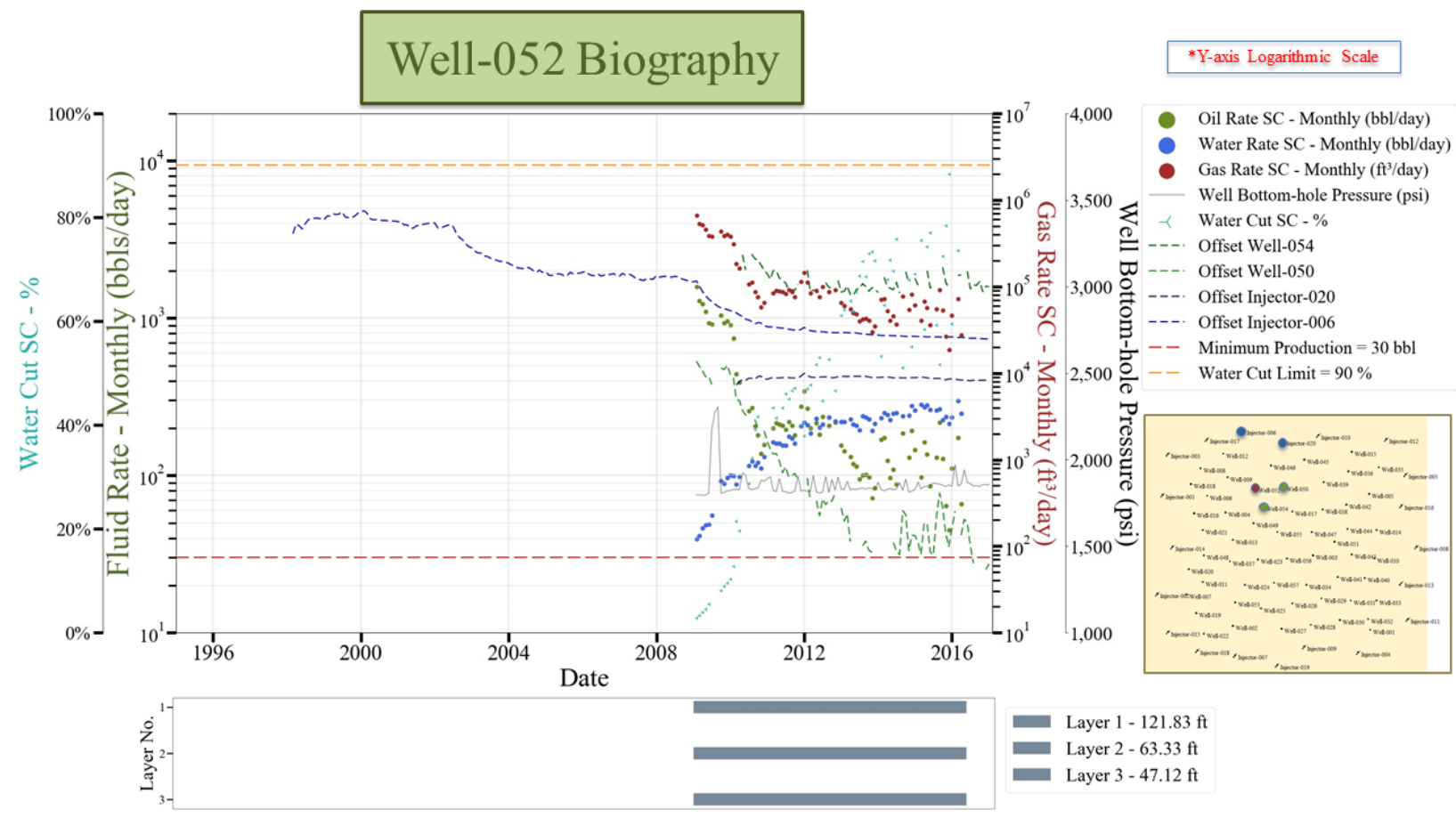

Figure 7-52: Well-052 Biography

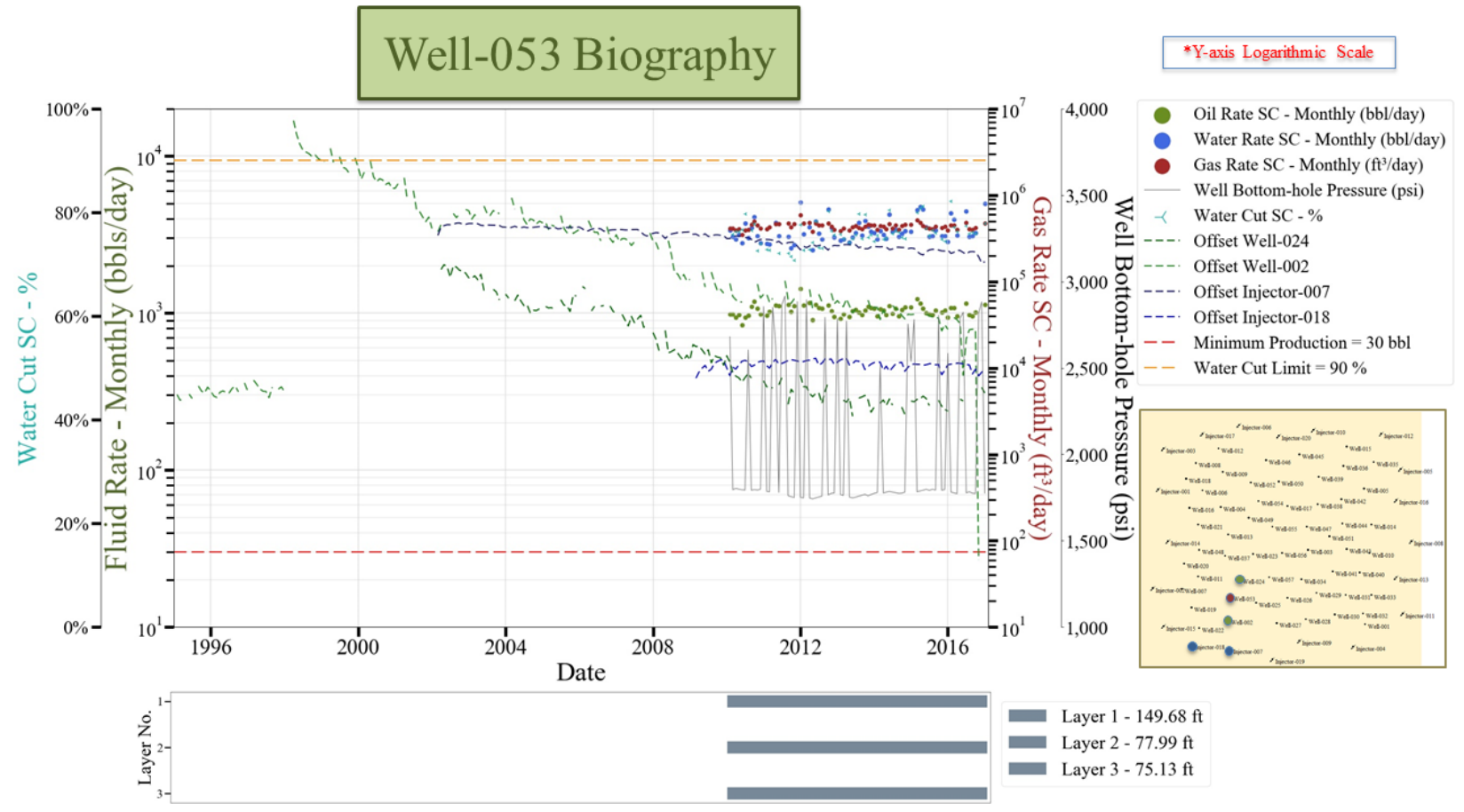

Figure 7-53: Well-053 Biography 


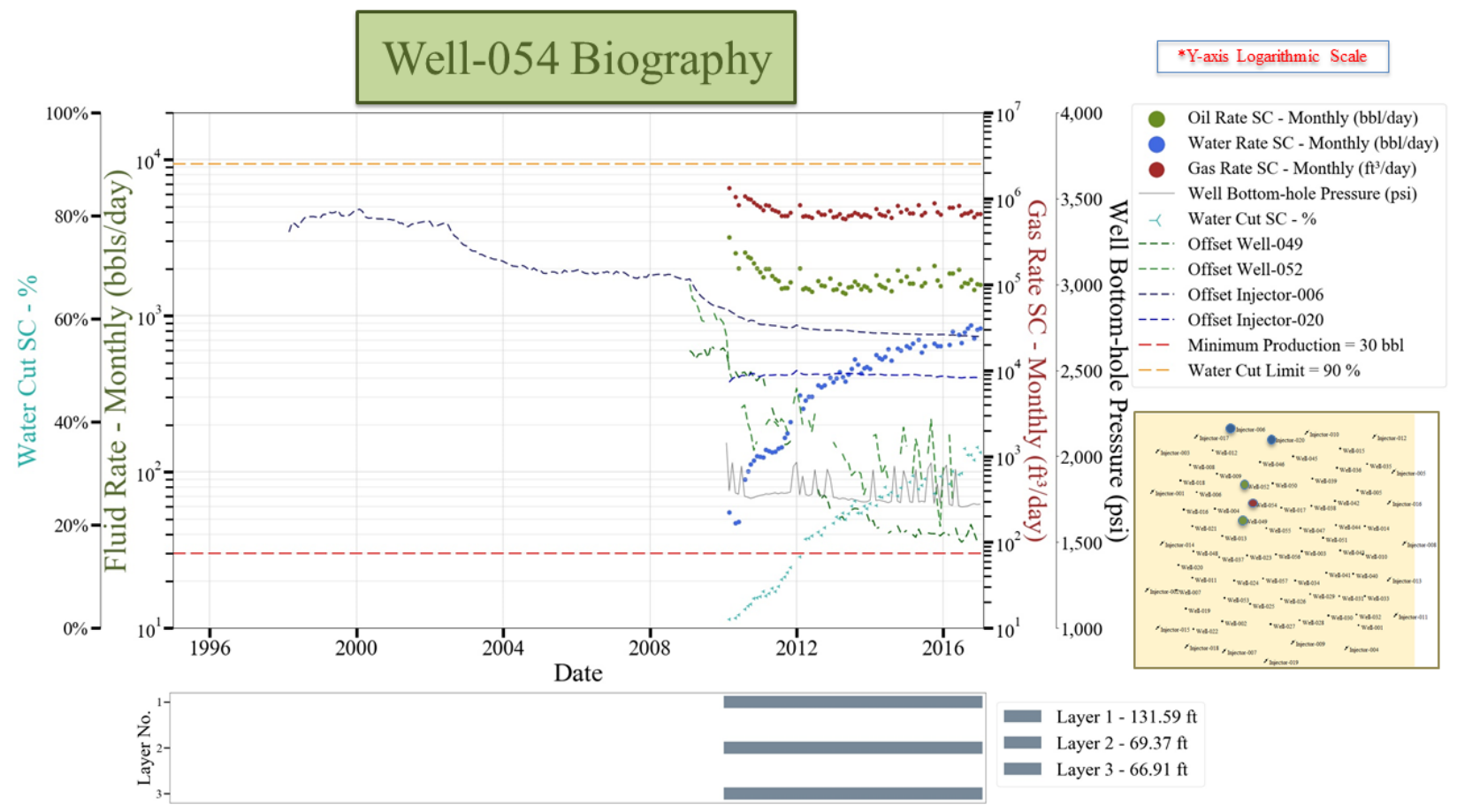

Figure 7-54: Well-054 Biography

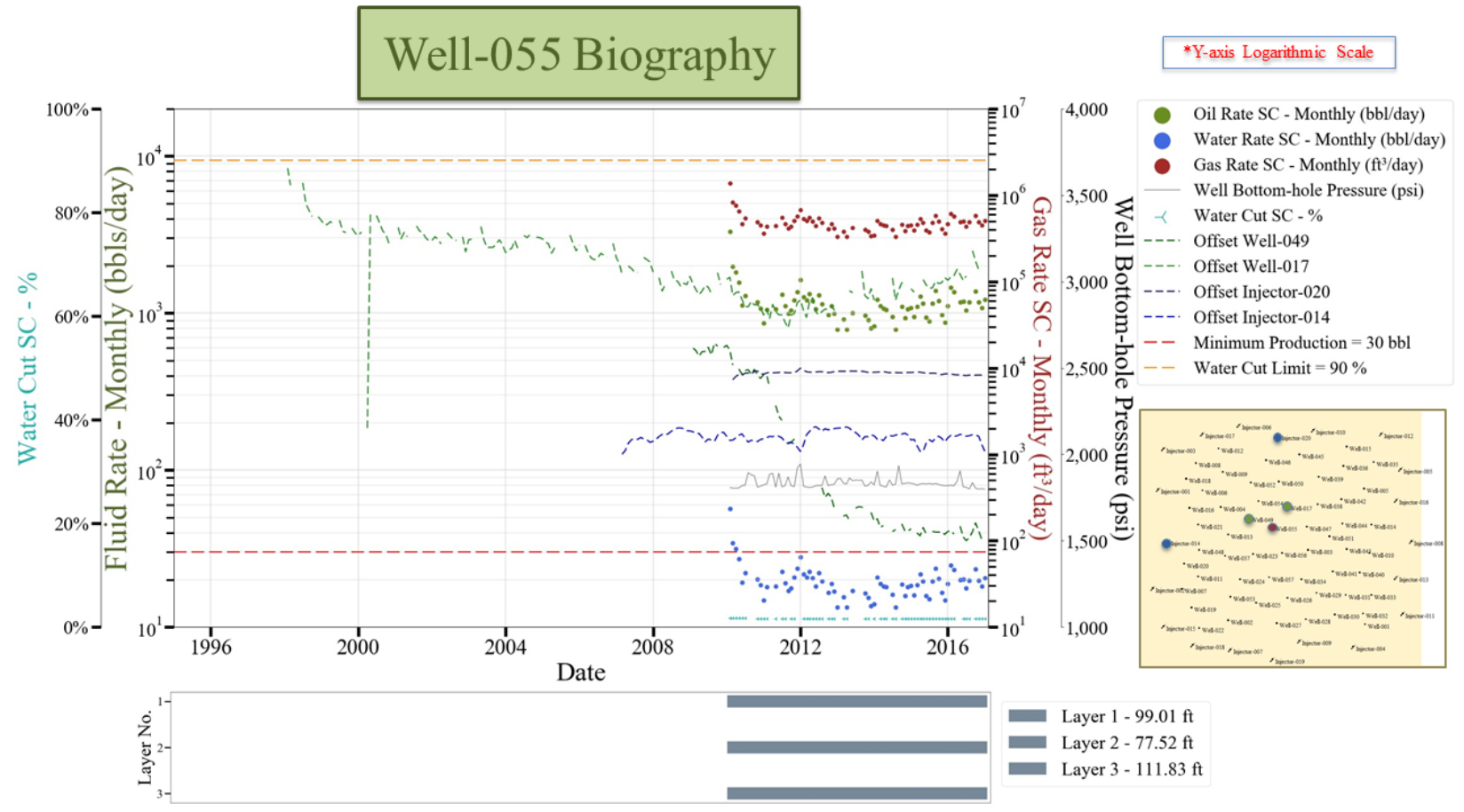

Figure 7-55: Well-055 Biography 


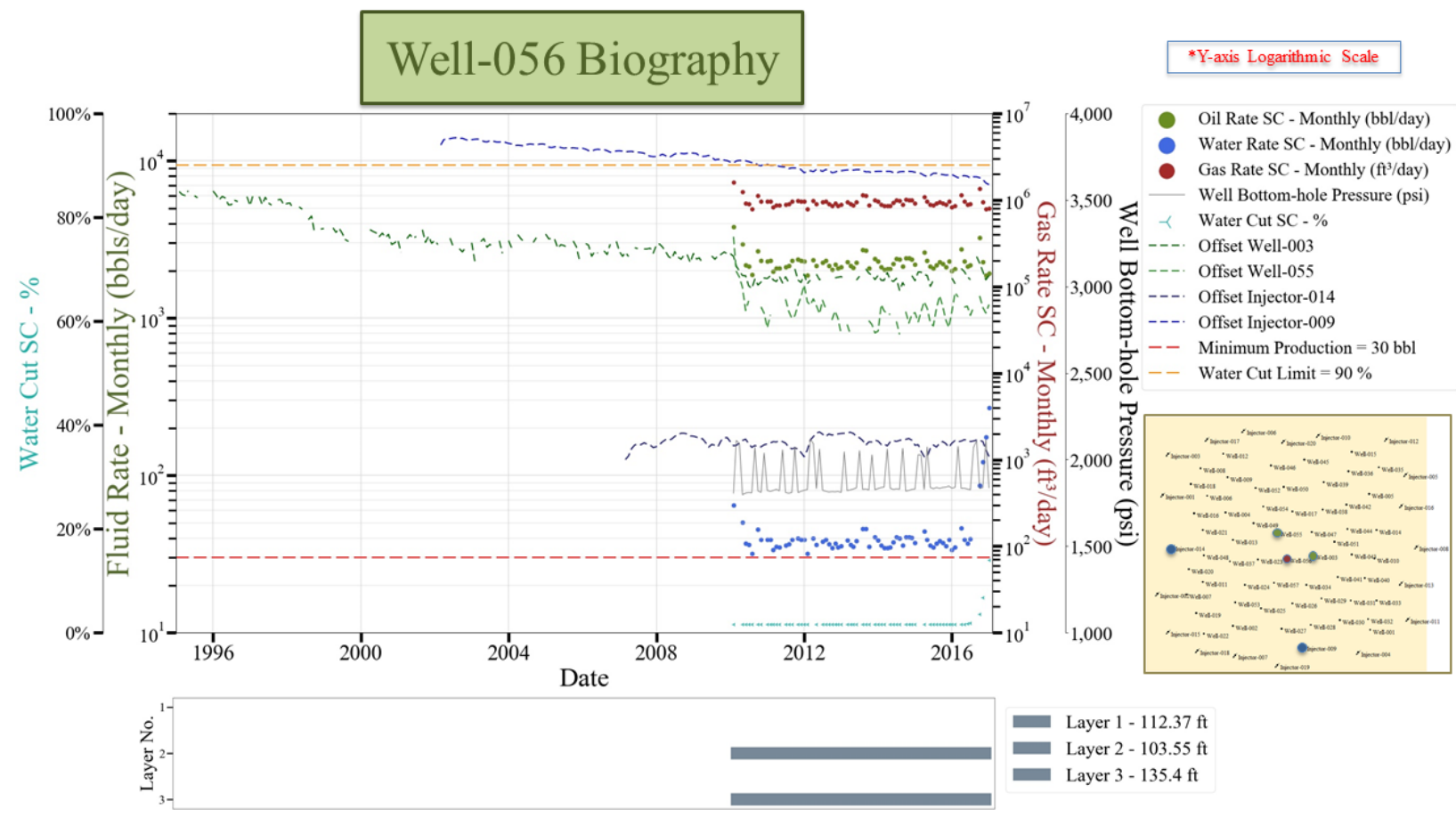

Figure 7-56: Well-056 Biography

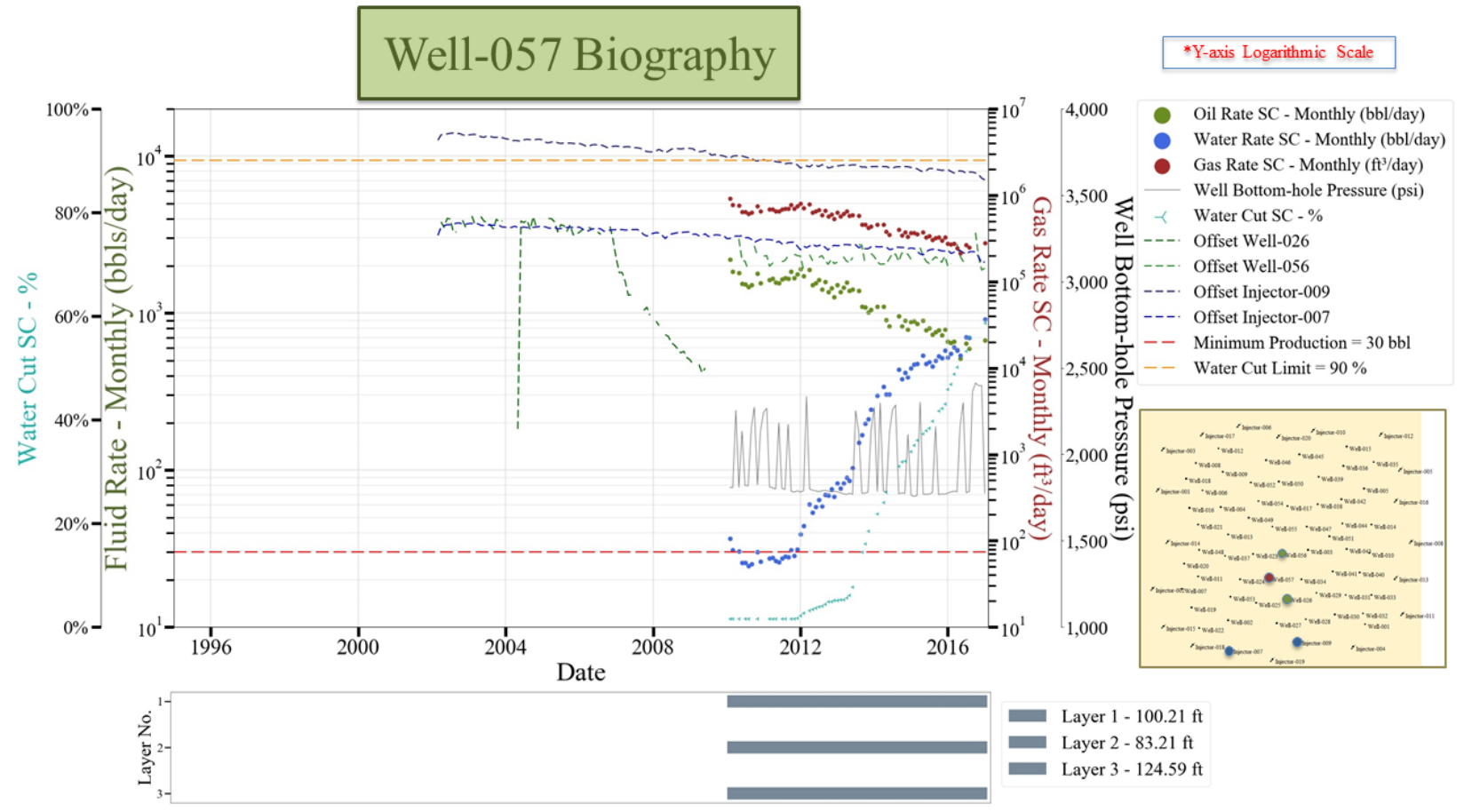

Figure 7-57: Well-057 Biography 


\section{APPENDIX B: Key Performance Indicators}

Four different KPI analysis were performed as a guiding tool to identify the most influential input attributes with respect to an output attribute of interest. The first and second KPI targeted the focal well's static and dynamic attributes while the third and fourth KPI targeted the offset wells' static and dynamic attributes respectively.

\subsection{Oil Rate}

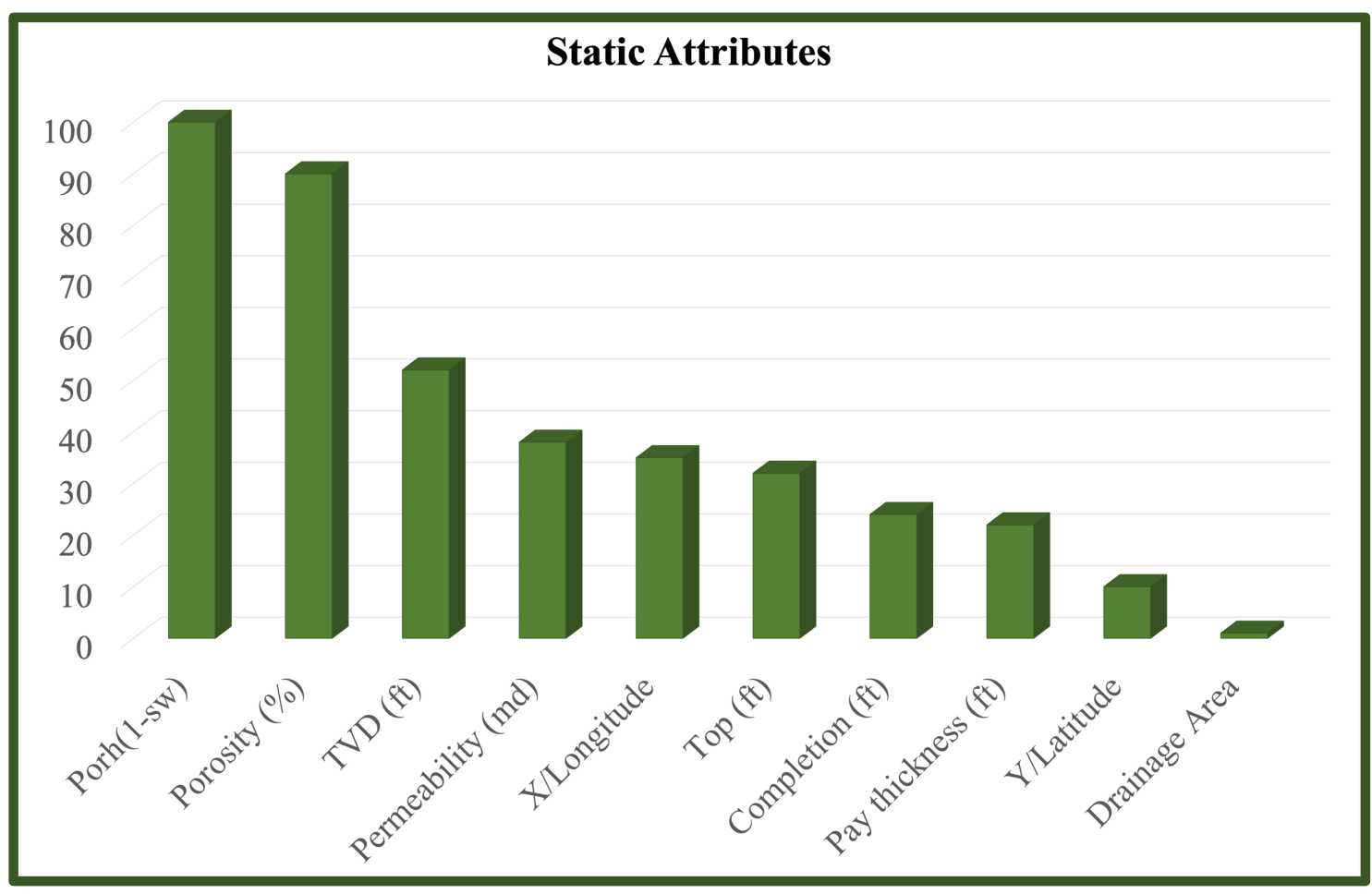

Figure 8-1: Oil Rate - Focal Static Attributes KPI 


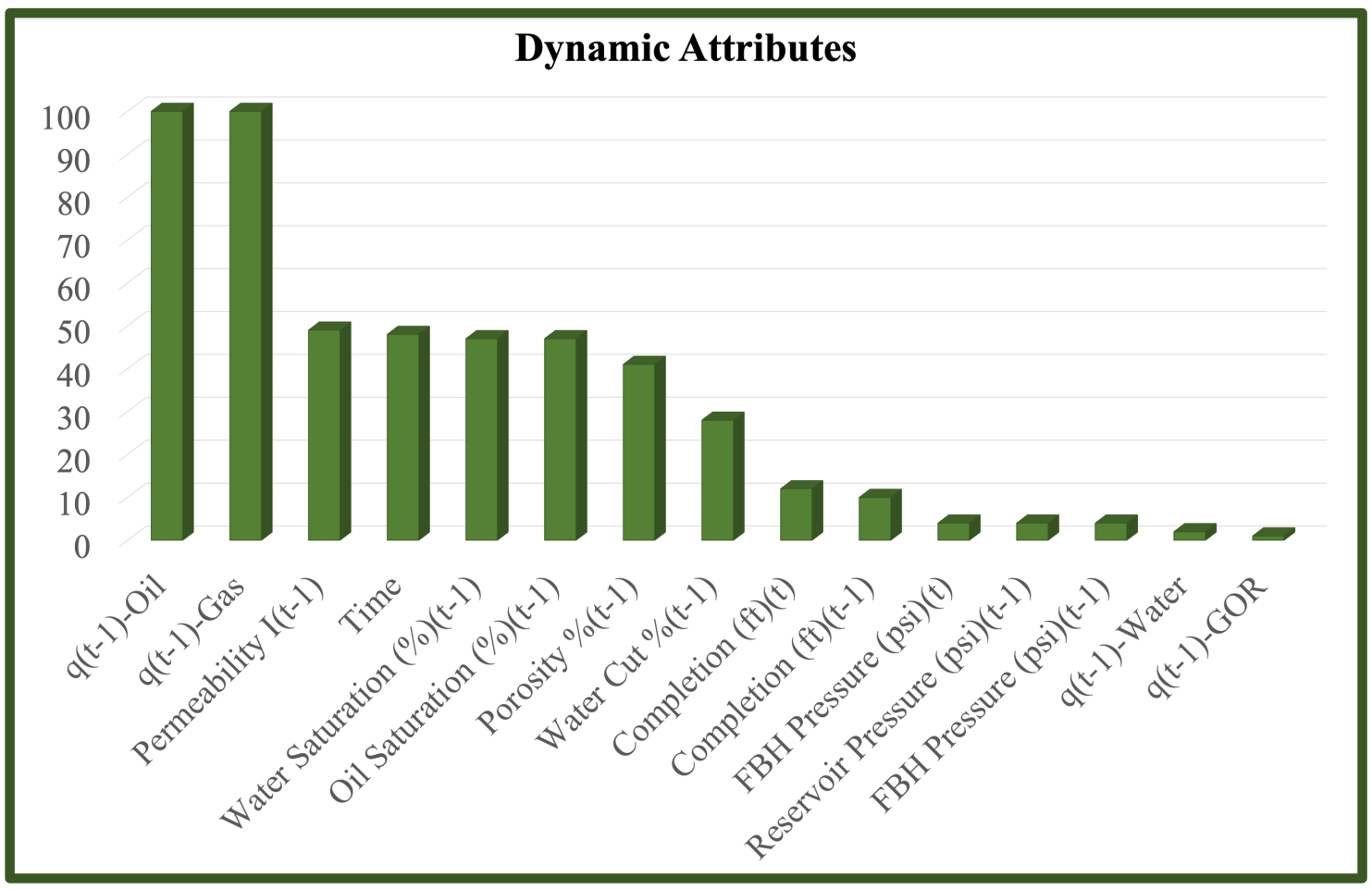

Figure 8-2: Oil Rate - Focal Dynamic Attributes KPI

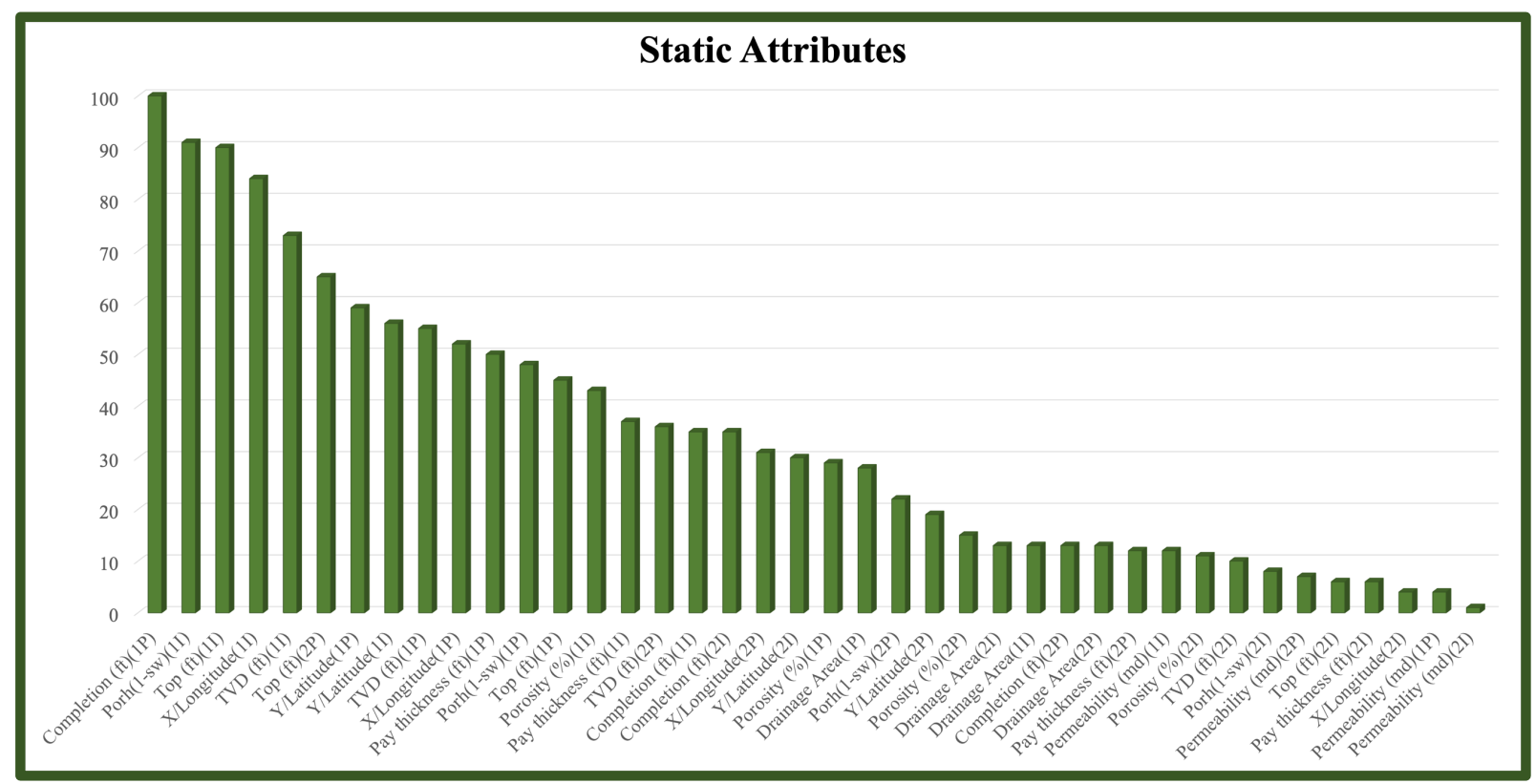

Figure 8-3: Oil Rate - Offset Static Attributes KPI 


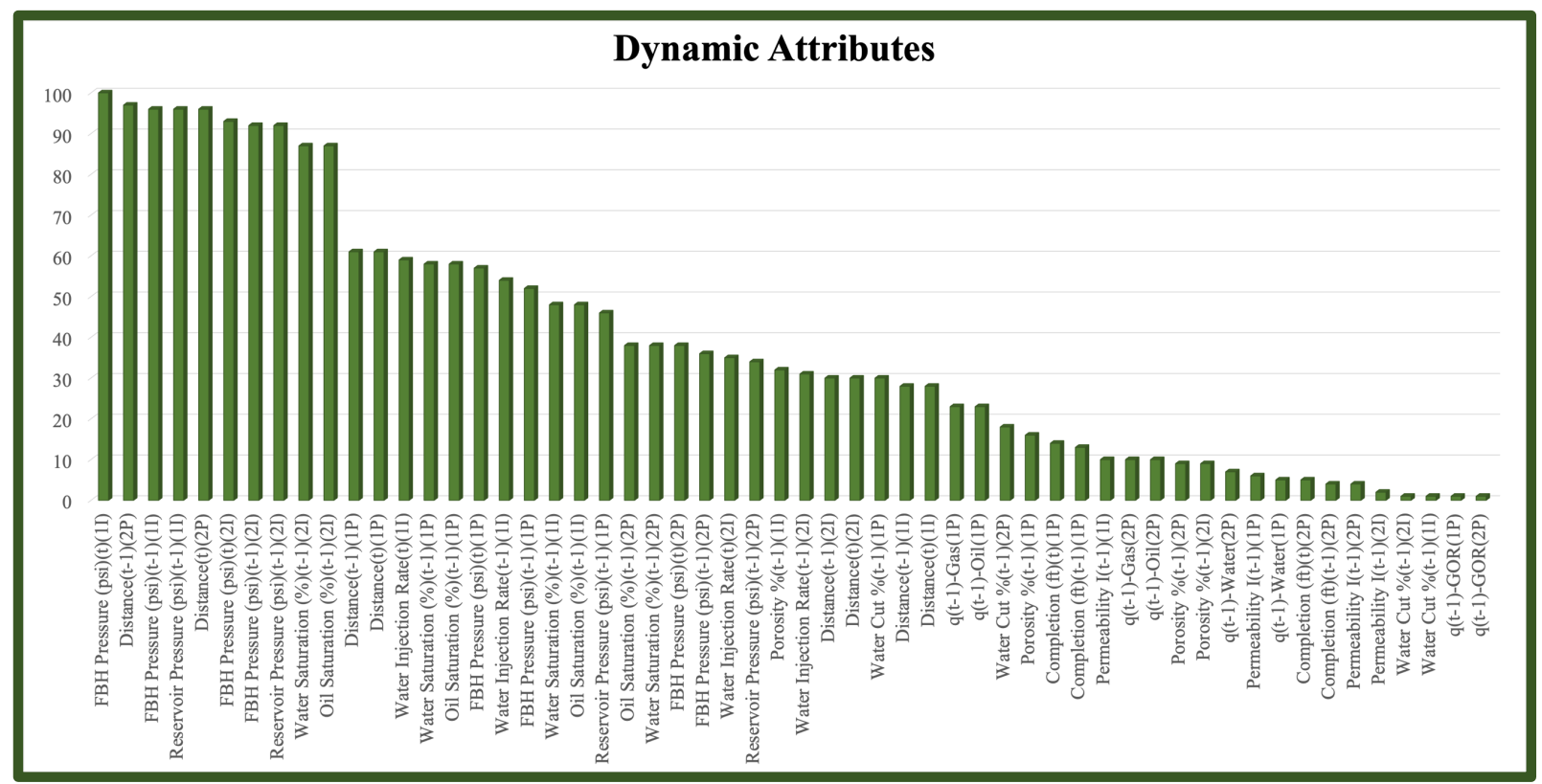

Figure 8-4: Oil Rate - Offset Dynamic Attributes KPI 


\subsection{Gas Rate}

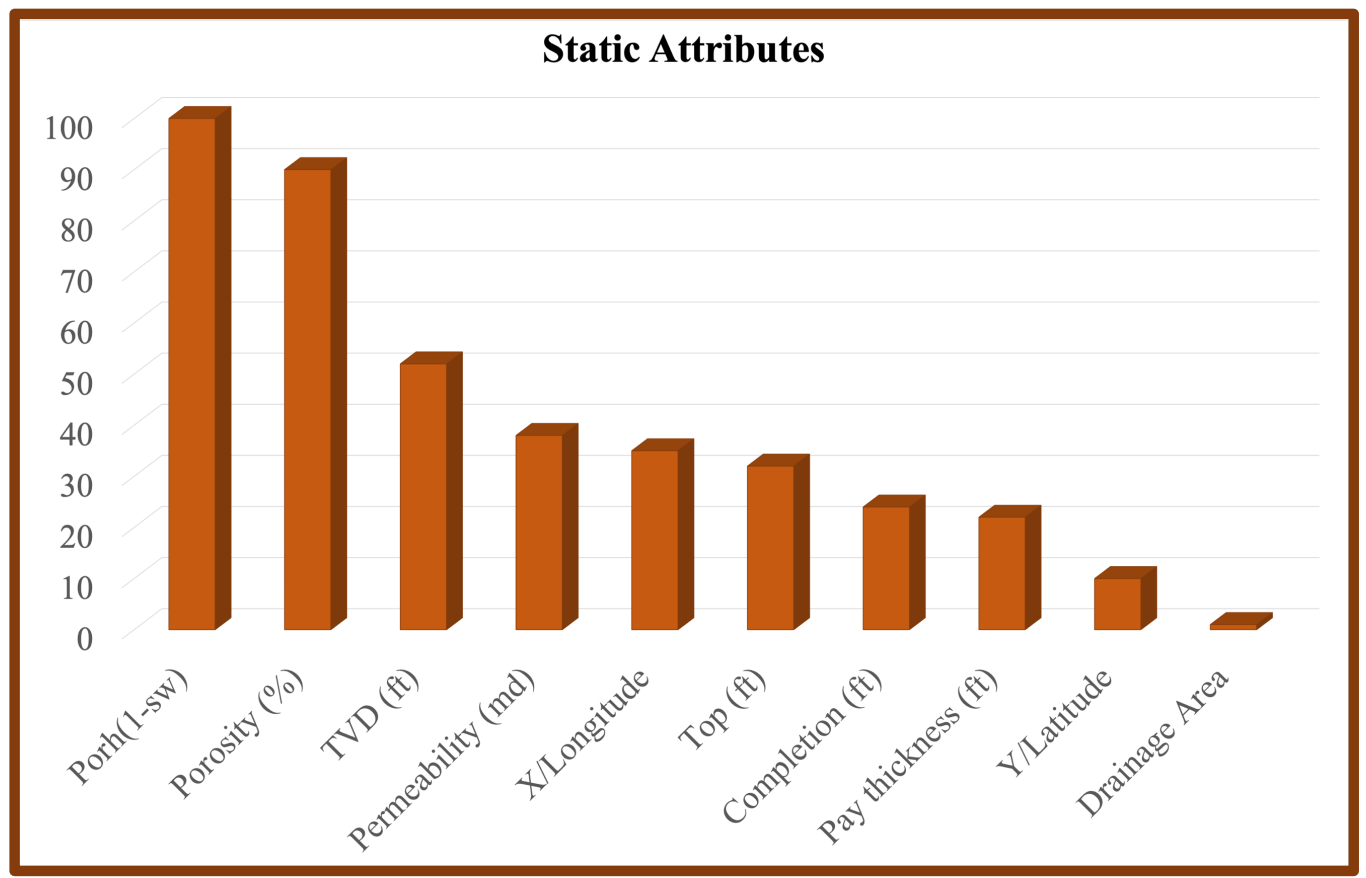

Figure 8-5: Gas Rate - Focal Static Attributes KPI

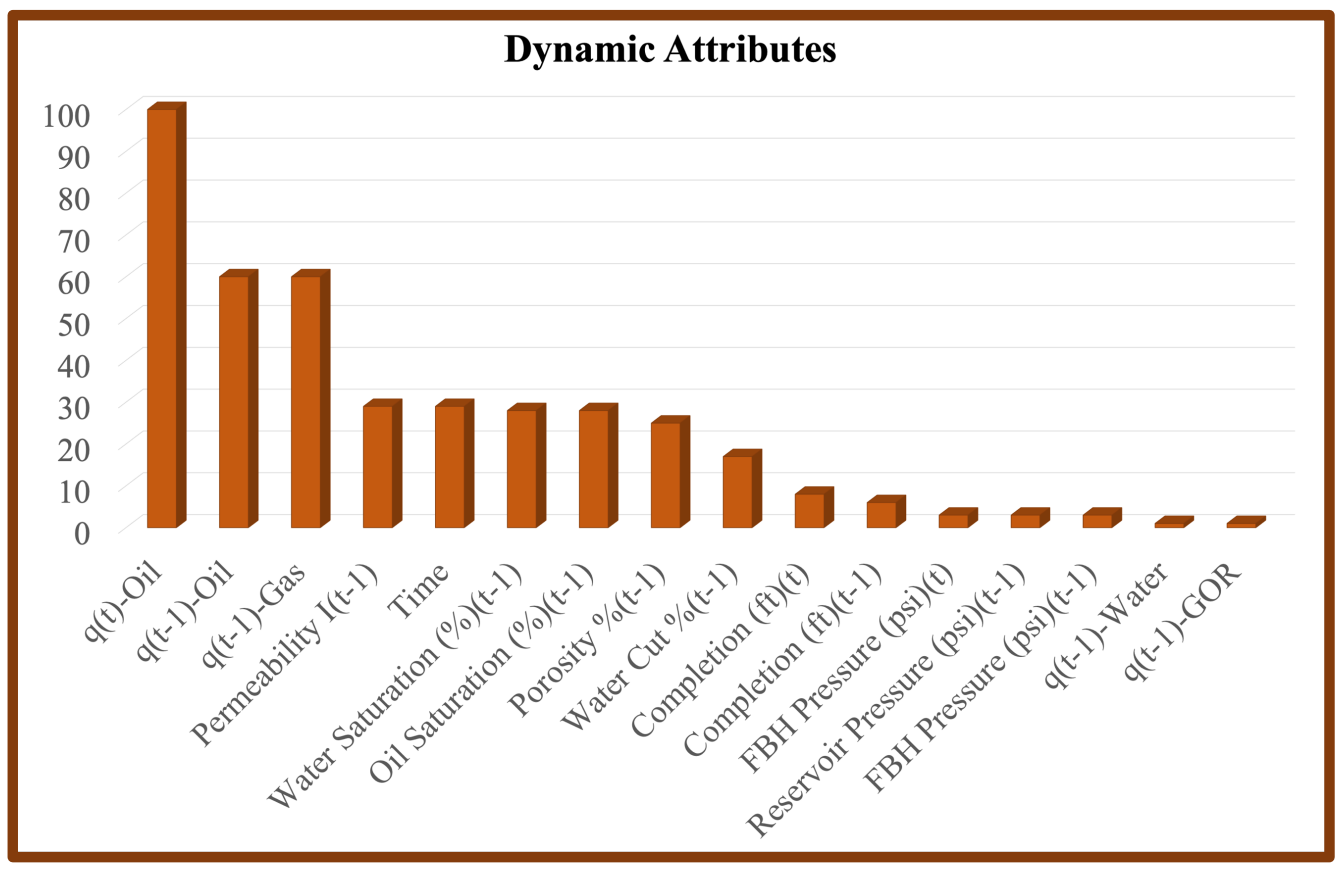

Figure 8-6: Gas Rate - Focal Dynamic Attributes KPI 


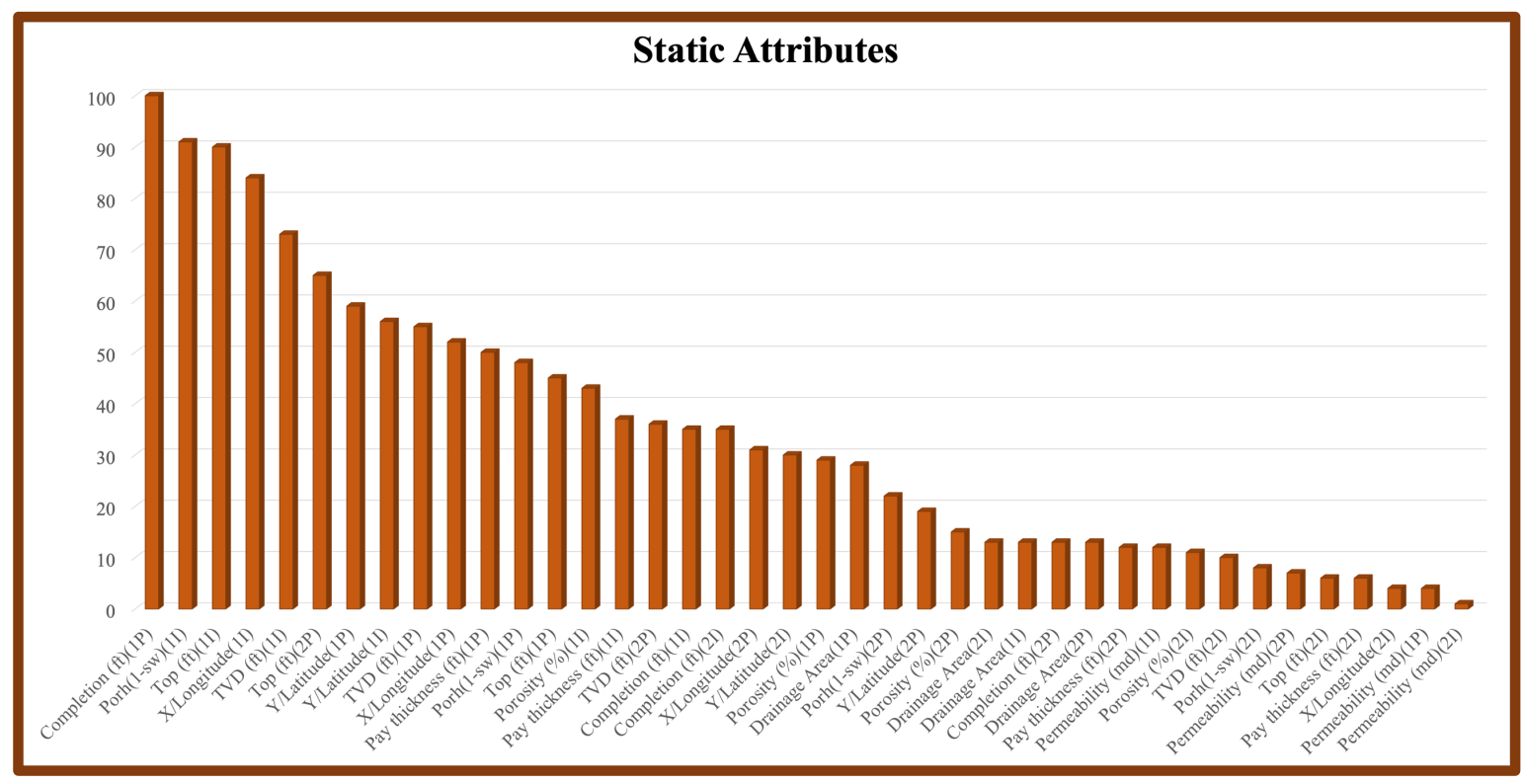

Figure 8-7: Gas Rate - Offset Static Attributes KPI

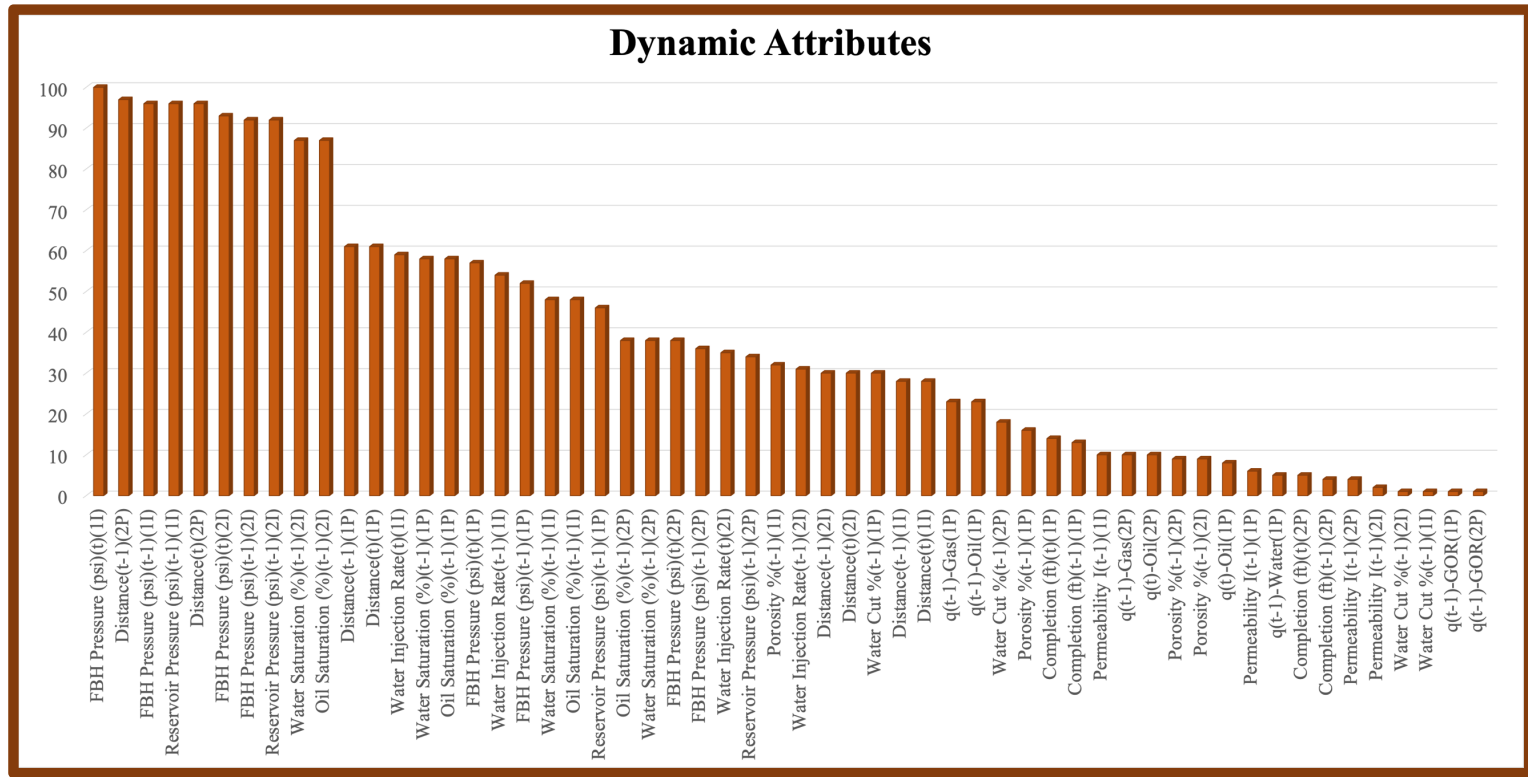

Figure 8-8: Gas Rate - Offset Dynamic Attributes KPI 


\subsection{Water Rate}

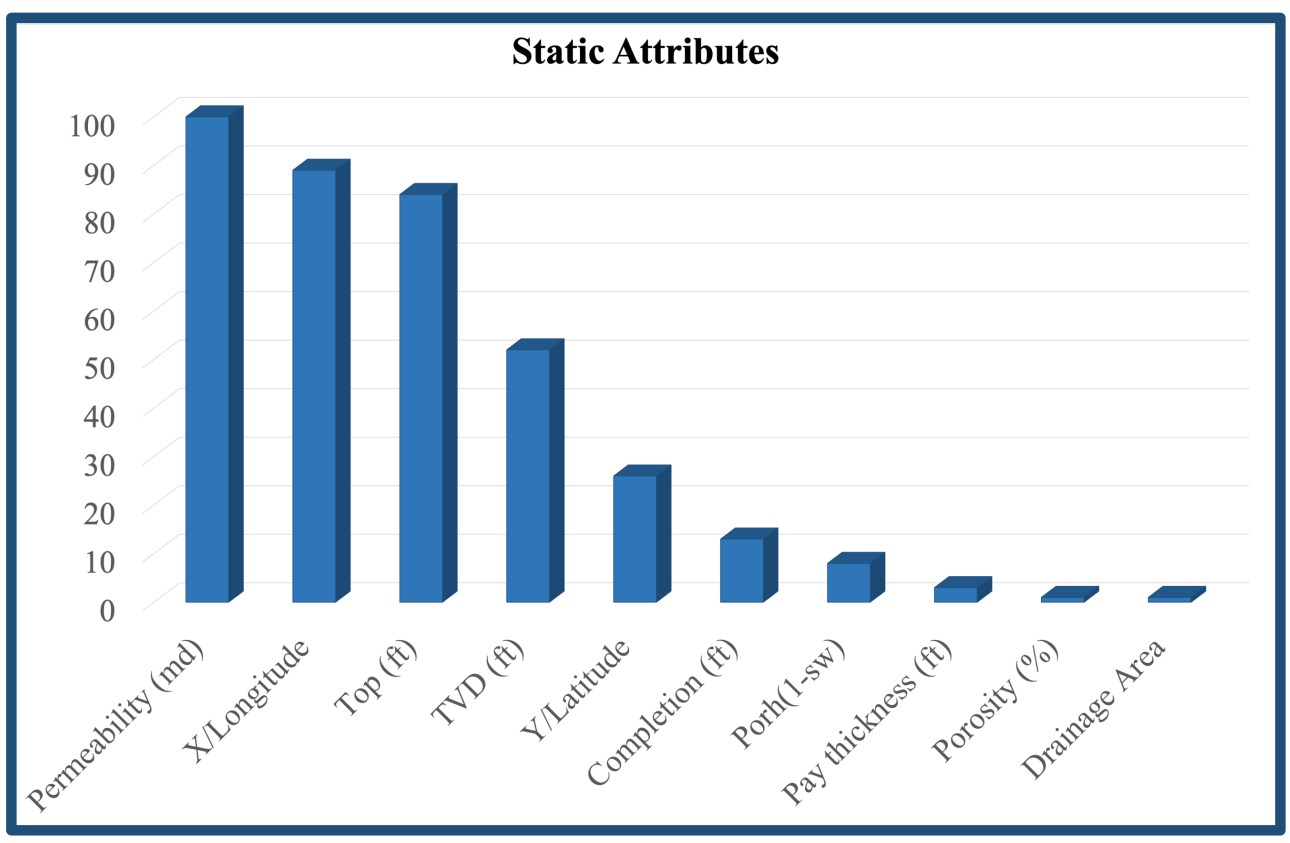

Figure 8-9: Water Rate - Focal Static Attributes KPI

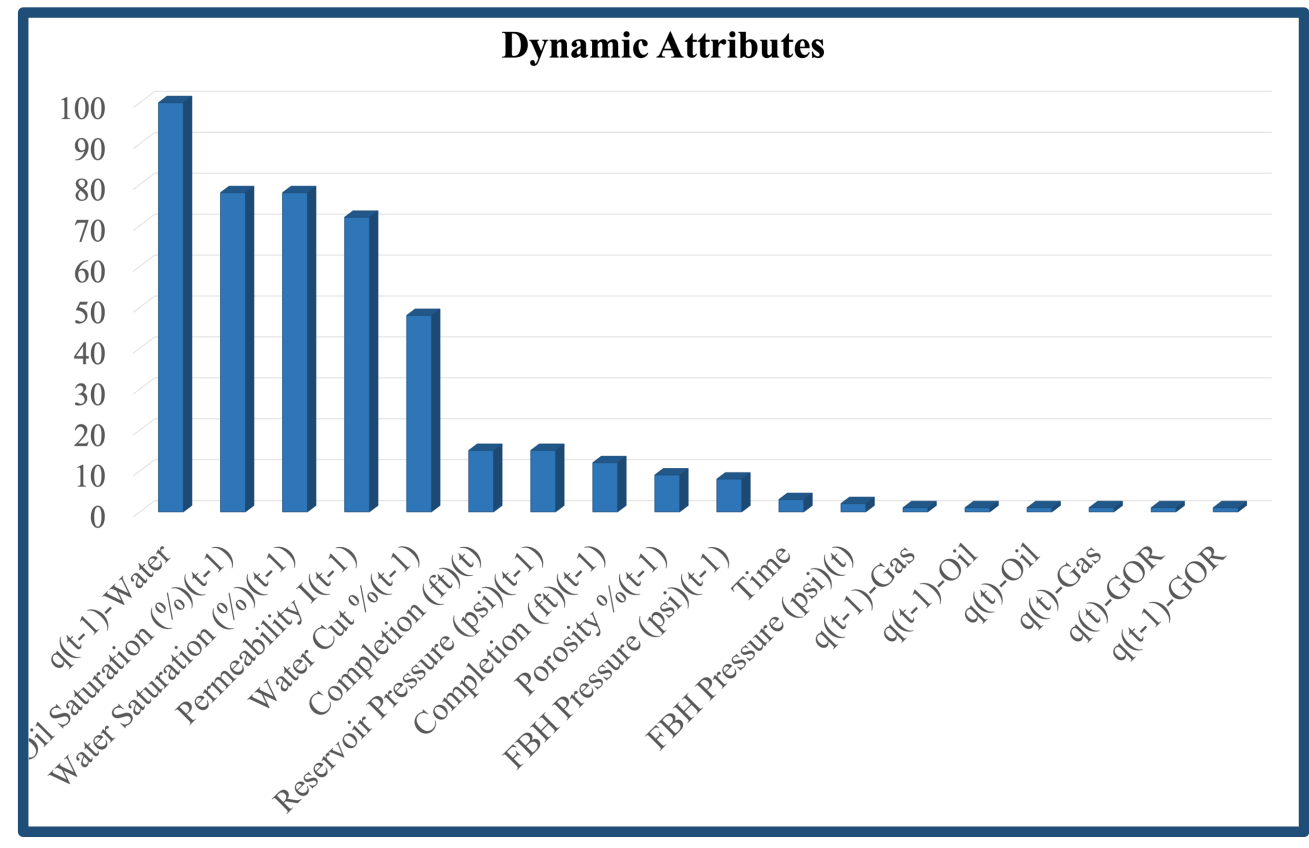

Figure 8-10: Water Rate - Focal Dynamic Attributes KPI 


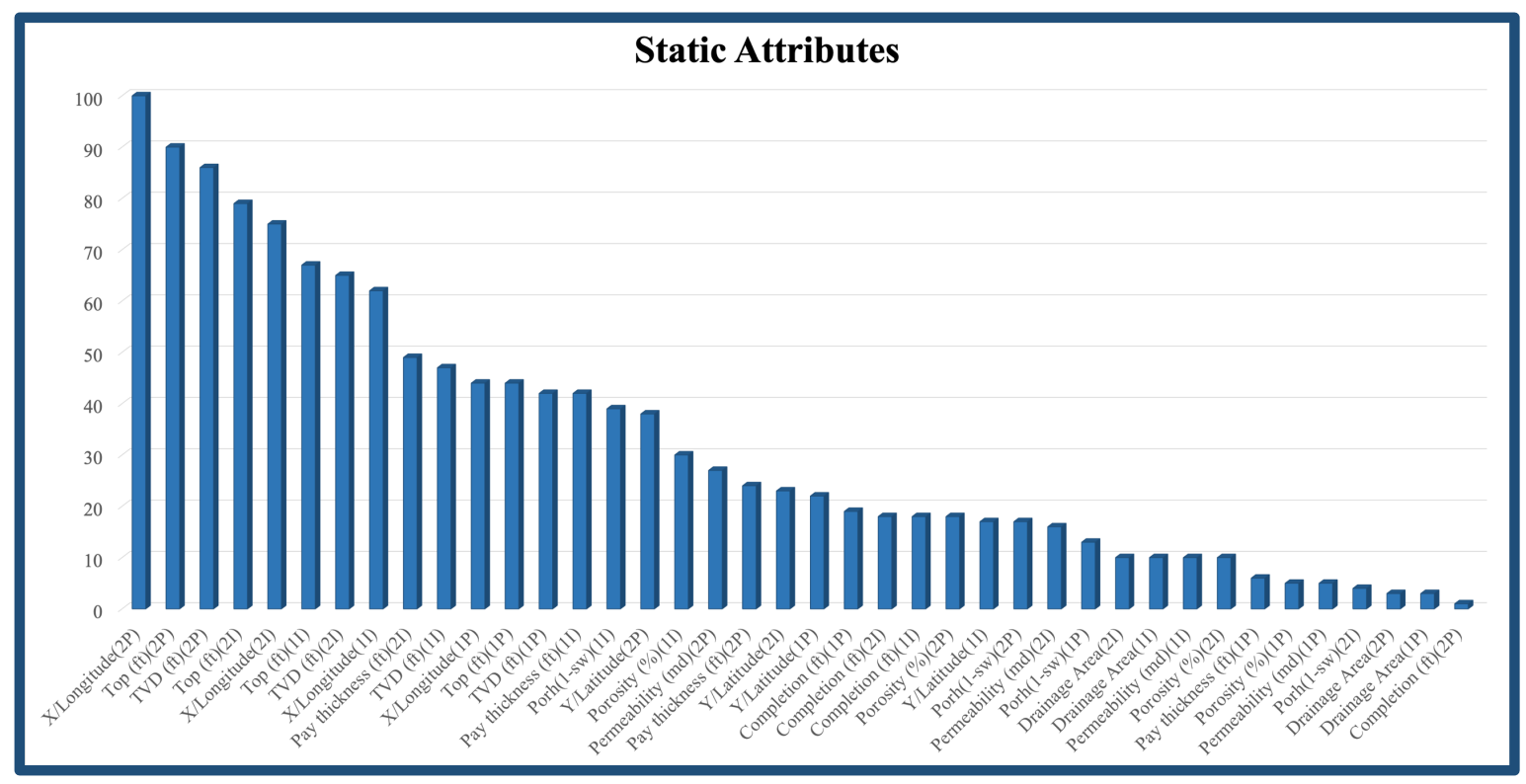

Figure 8-11: Water Rate - Offset Static Attributes KPI

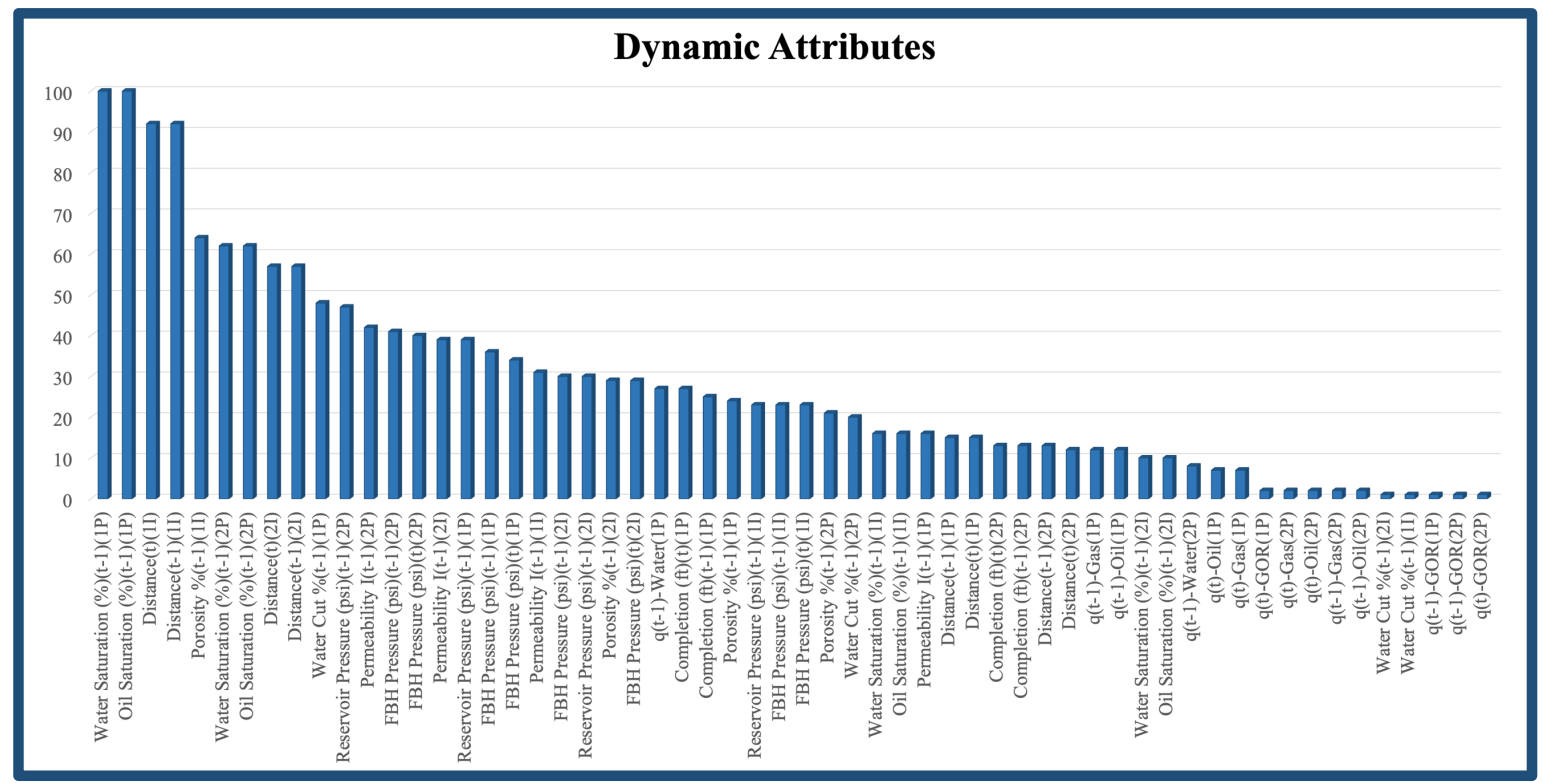

Figure 8-12: Water Rate - Offset Dynamic Attributes KPI 


\subsection{Reservoir Pressure}

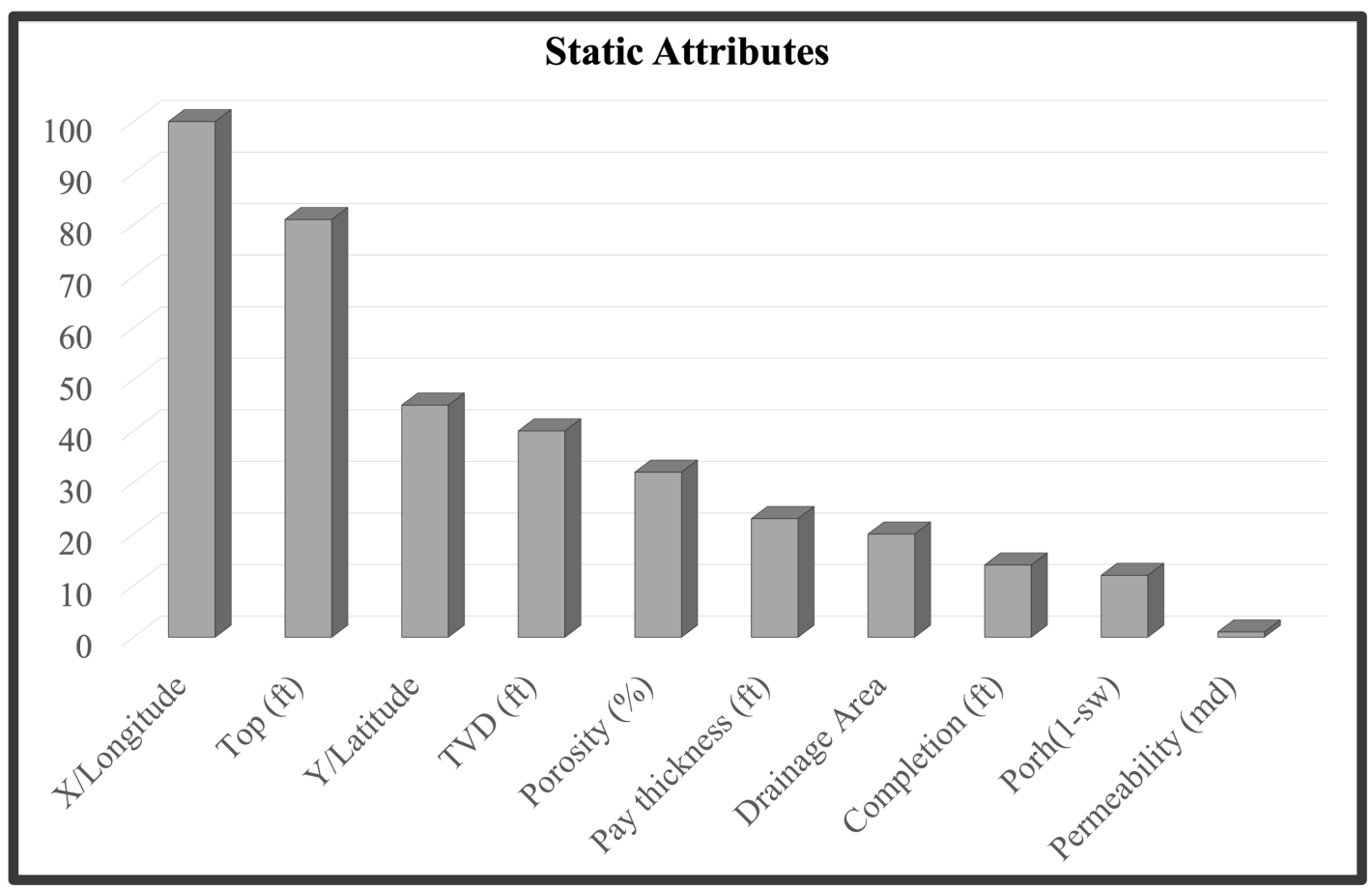

Figure 8-13: Reservoir Pressure - Focal Static Attributes KPI

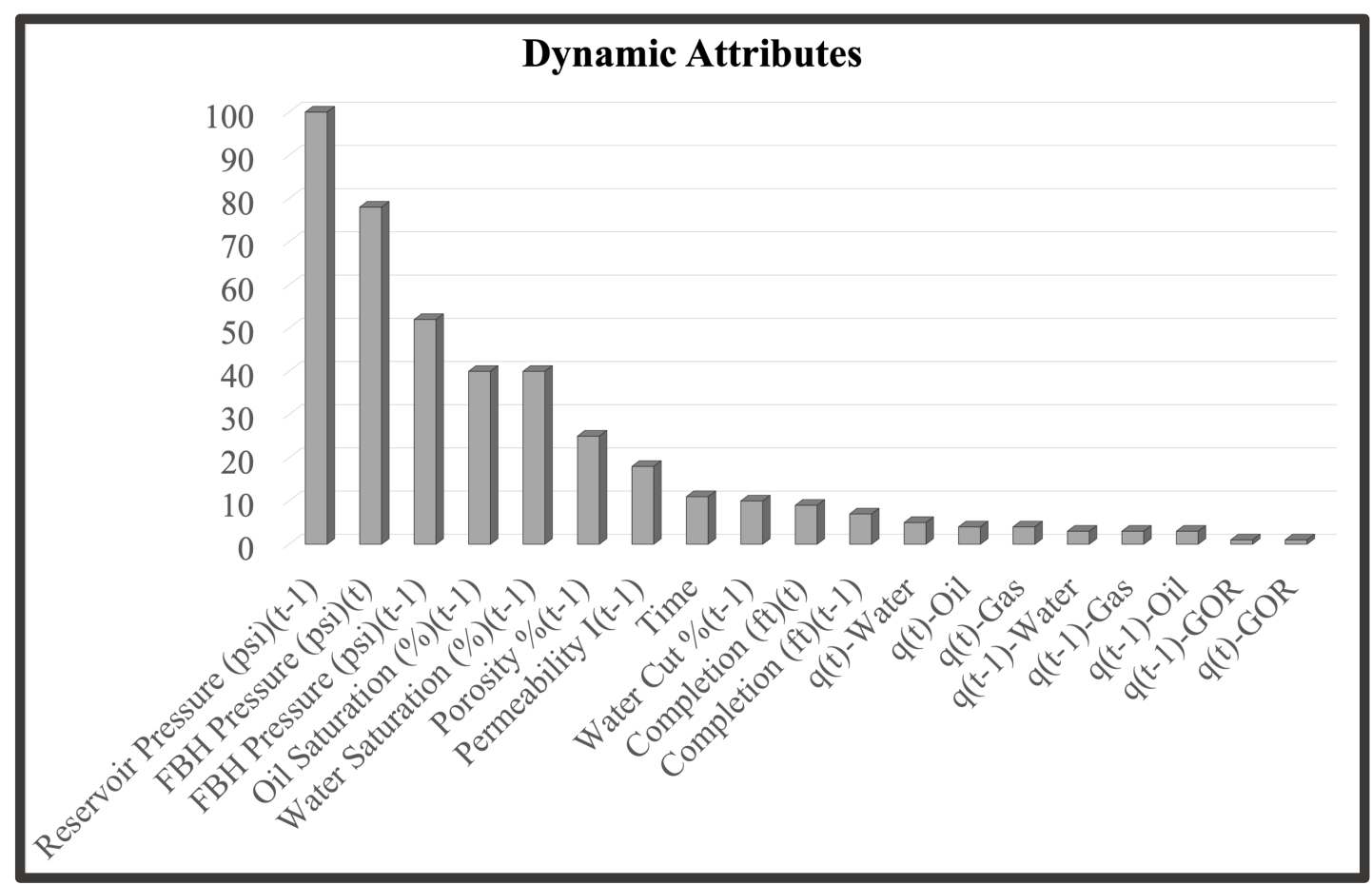

Figure 8-14: Reservoir Pressure - Focal Dynamic Attributes KPI 


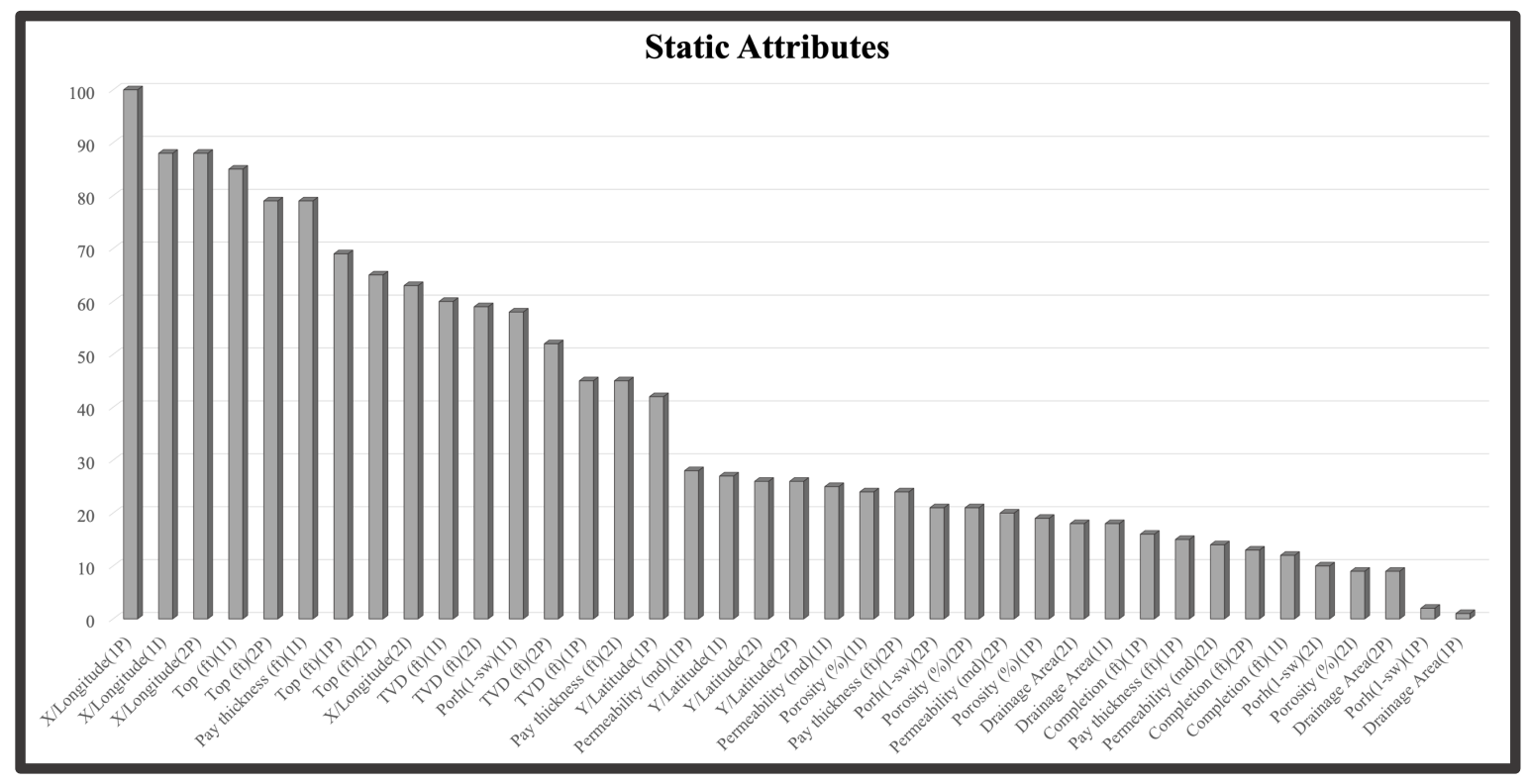

Figure 8-15: Reservoir Pressure - Offset Static Attributes KPI

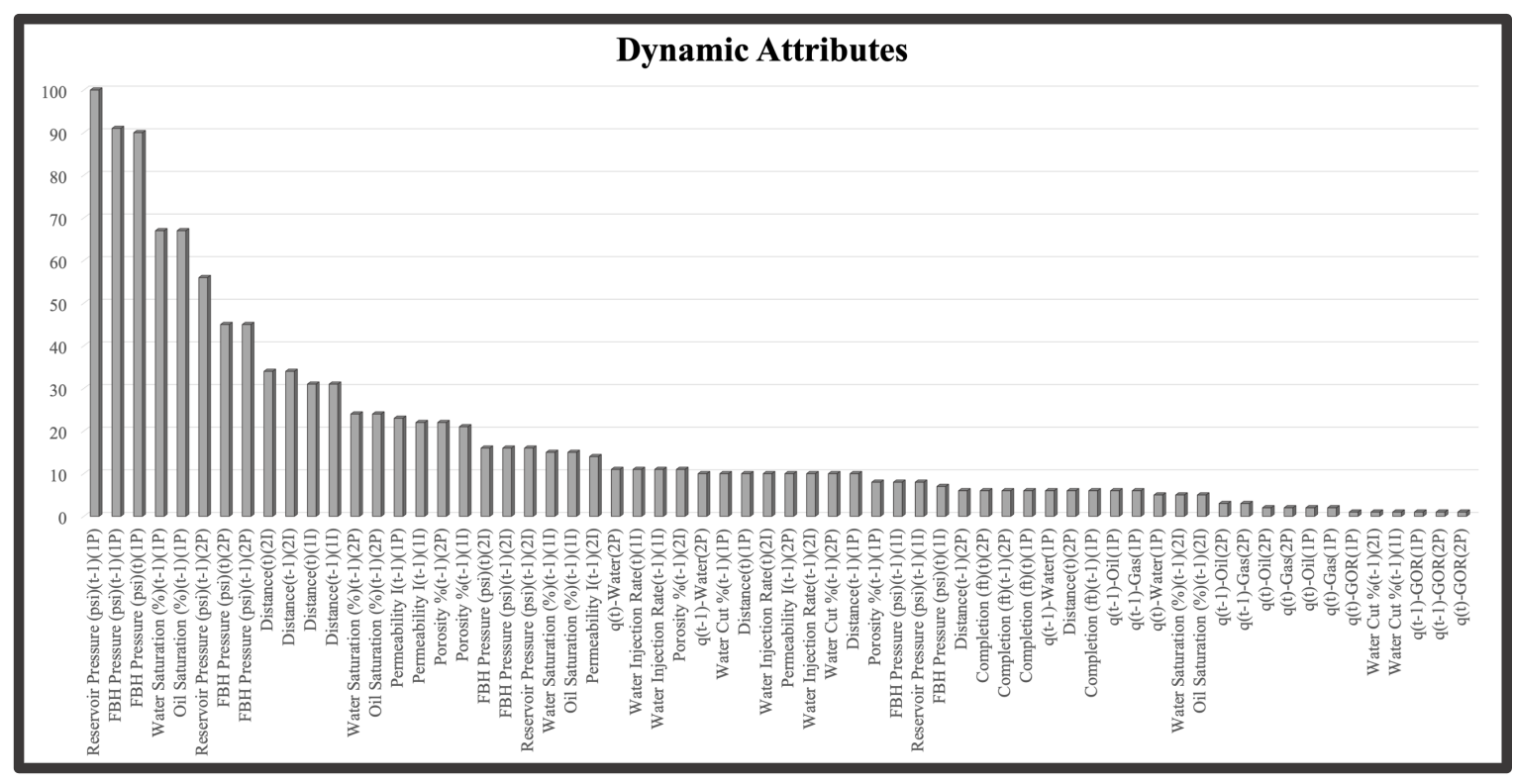

Figure 8-16: Reservoir Pressure - Offset Dynamic Attributes KPI 


\subsection{Water Saturation}

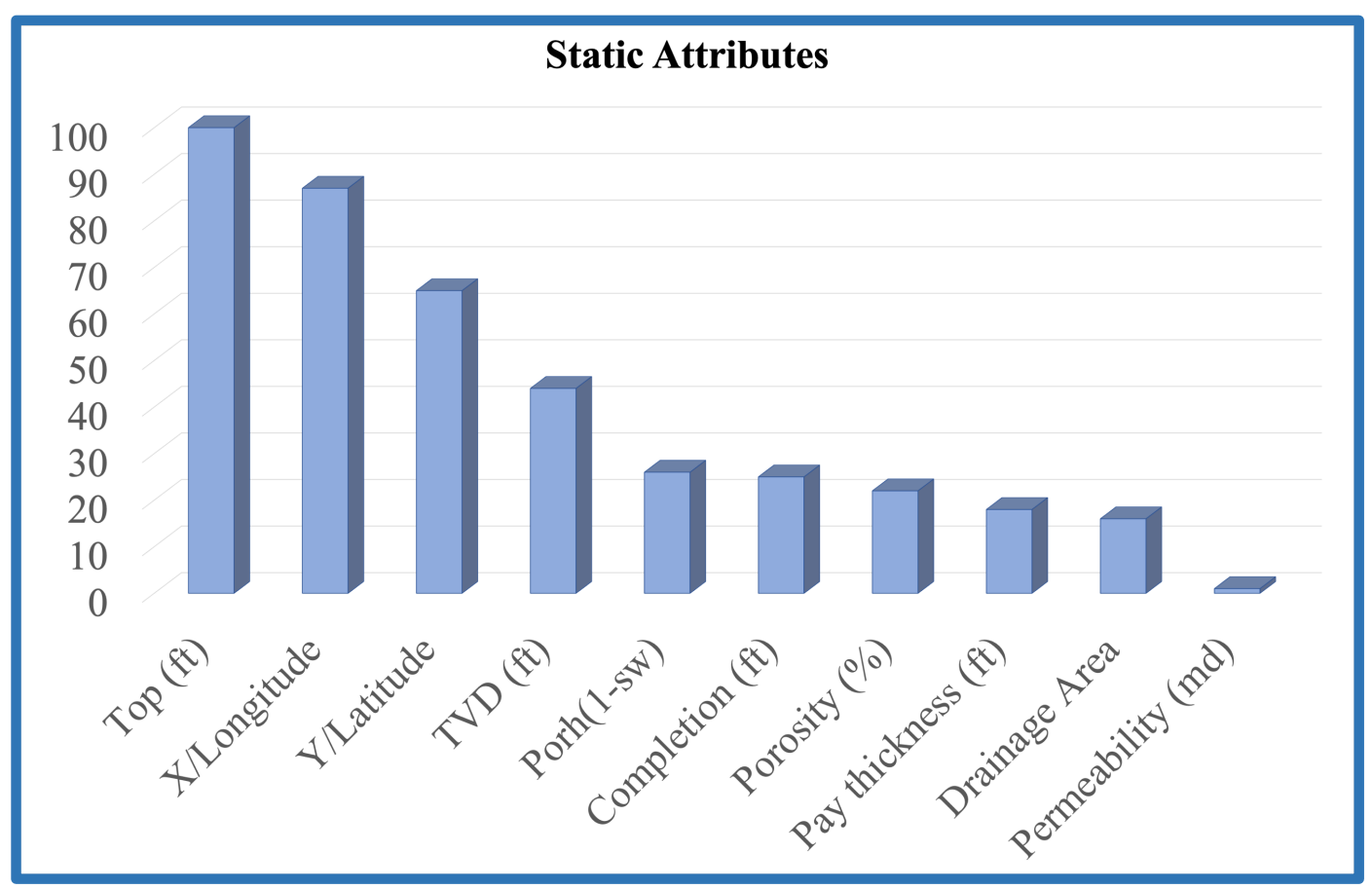

Figure 8-17: Water Saturation - Focal Static Attributes KPI

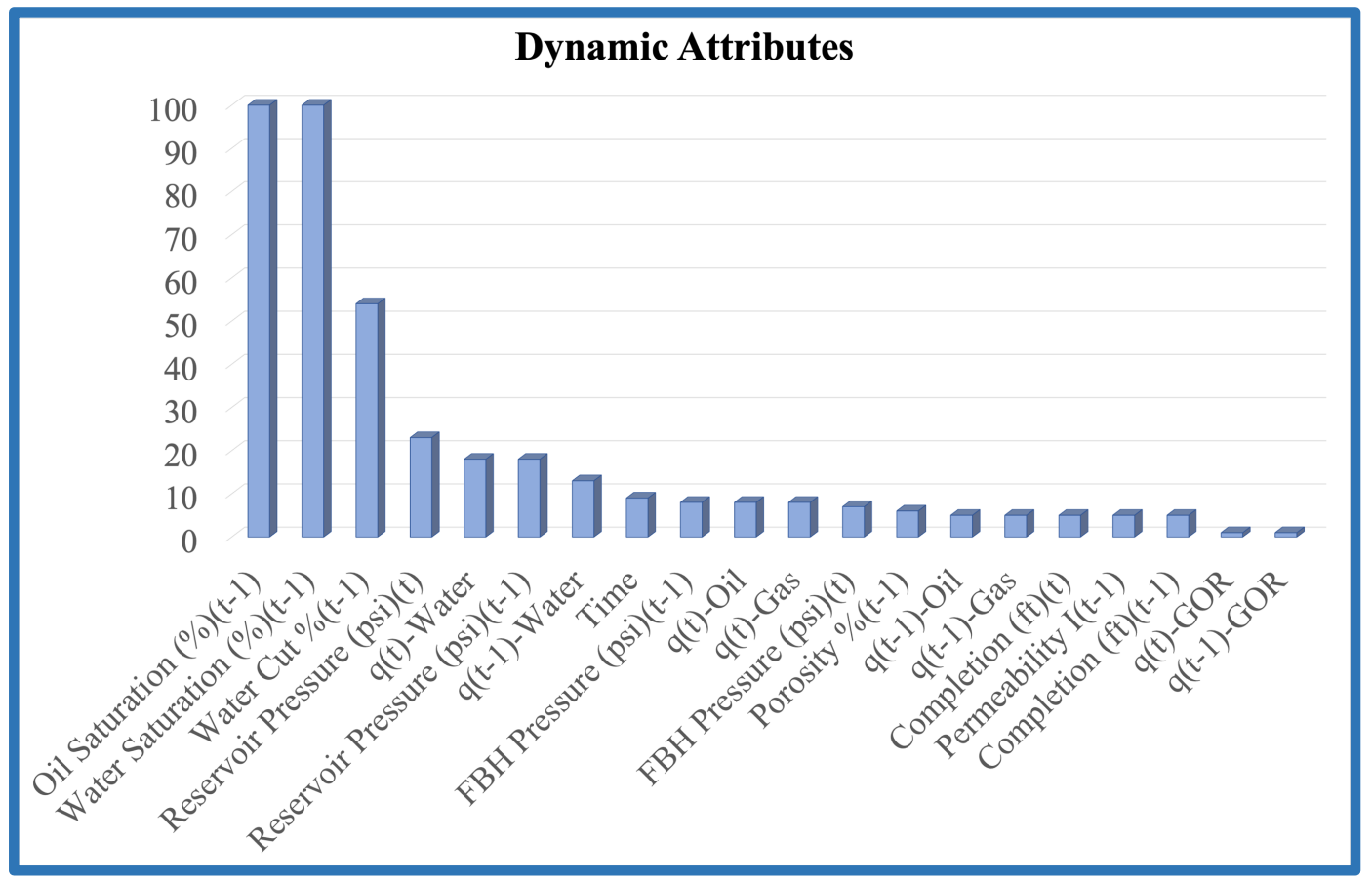

Figure 8-18: Water Saturation - Focal Dynamic Attributes KPI 


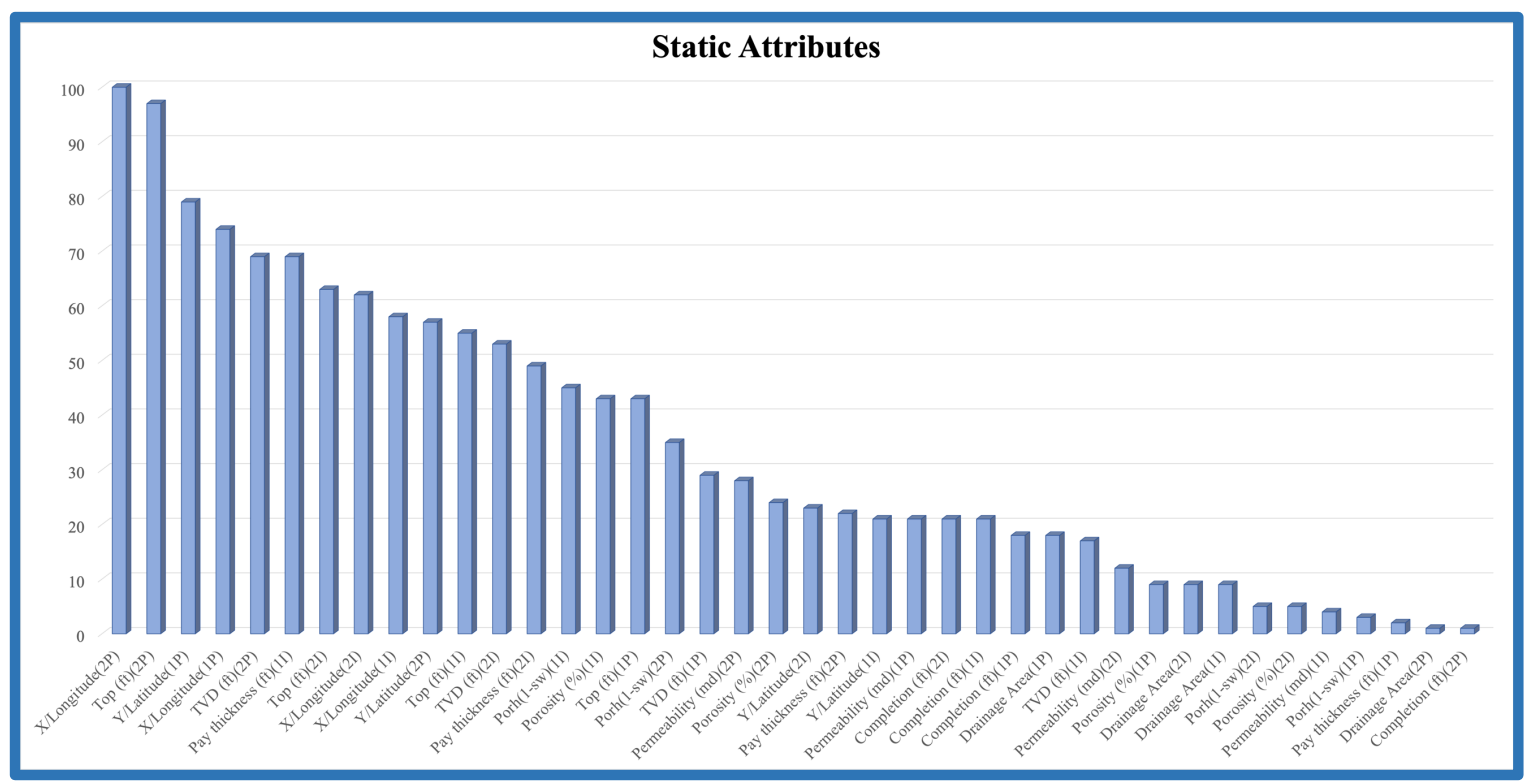

Figure 8-19: Water Saturation - Offset Static Attributes KPI

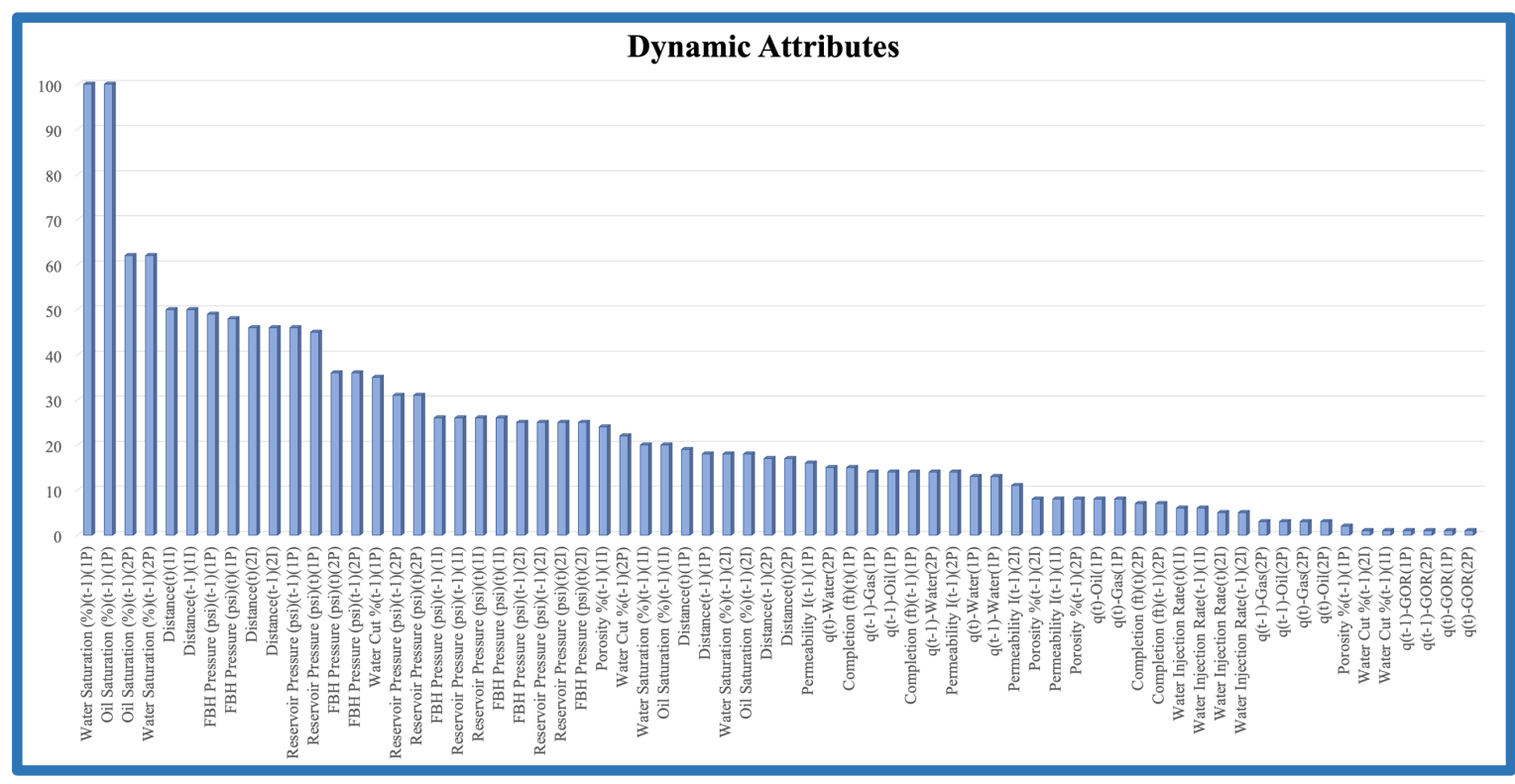

Figure 8-20: Water Saturation - Focal Dynamic Attributes KPI 


\section{APPENDIX C: Scenario 1 - Random Partitioning TDM}

\subsection{Input Attributes}

The number of input attributes used in the development of each data-driven model was based on KPI analysis and domain expertise. The following tables provide a list of static and dynamic attributes for both the focal and offset wells. Each table is composed of three columns that indicate the ranking, name of the input attribute, and its degree of influence (DOI) with respect to the output model.

\subsubsection{Oil Predictive Model}

The oil model consisted of a total of 25 input attributes for the development of the neural network. 8 attributes provided static and dynamic information regarding the focal well while 17 attributes provided static and dynamic information from the offset wells.

Flowing bottom-hole pressure and reservoir pressure from 2 offset injectors have a high degree of influence (DOI) on oil production. Similarly, static attributes from the first injector influenced the oil production.

\section{Oil Model - Input Attributes}

\begin{tabular}{|c|c|c|c|c|c|}
\hline \multicolumn{3}{|c|}{ FOCAL WELL } & \multicolumn{3}{|c|}{ OFFSET WELLS } \\
\hline \multicolumn{3}{|c|}{ Static Attributes } & \multicolumn{3}{|c|}{ Static Attributes } \\
\hline Rank & Attribute & DOI & Rank & Attribute & DOI \\
\hline 1 & Porh(1-sw) & 100 & 2 & Porh $(1-\mathrm{sw})(1 \mathrm{I})$ & 91 \\
\hline 2 & Porosity (\%) & 90 & 3 & Top $(\mathrm{ft})(1 \mathrm{I})$ & 90 \\
\hline 3 & TVD (ft) & 52 & 5 & TVD $(\mathrm{ft})(1 \mathrm{I})$ & 73 \\
\hline 8 & Pay Thickness (ft) & 23 & 6 & Top $(\mathrm{ft})(2 \mathrm{P})$ & 65 \\
\hline \multicolumn{3}{|c|}{4} & 9 & TVD $(\mathrm{ft})(1 \mathrm{P})$ & 55 \\
\hline & & & 10 & $\mathrm{X} /$ Longitude $(1 \mathrm{P})$ & 52 \\
\hline \multicolumn{3}{|c|}{ Dynamic Attributes } & 11 & Pay thickness $(\mathrm{ft})(1 \mathrm{P})$ & 50 \\
\hline & Oil Rate (t-1) & 100 & \multicolumn{3}{|c|}{7} \\
\hline 2 & Gas Rate (t-1) & 100 & & & \\
\hline 3 & Permeability I(t-1) & 49 & \multicolumn{3}{|c|}{ Dynamic Attributes } \\
\hline & Time & 48 & 1 & FBH Pressure $(\mathrm{psi})(\mathrm{t})(1 \mathrm{I})$ & 100 \\
\hline \multicolumn{3}{|c|}{4} & 2 & Distance $(\mathrm{t}-1)(2 \mathrm{P})$ & 97 \\
\hline & & & 3 & FBH Pressure $(\mathrm{psi})(\mathrm{t}-1)(1 \mathrm{I})$ & 96 \\
\hline \multirow[t]{8}{*}{ TOT } & AL ATTRIBUTES & 25 & 4 & Reservoir Pressure $(\mathrm{psi})(\mathrm{t}-1)(1 \mathrm{I})$ & 96 \\
\hline & & & 5 & Distance $(\mathrm{t})(2 \mathrm{P})$ & 96 \\
\hline & & & 6 & FBH Pressure $(\mathrm{psi})(\mathrm{t})(2 \mathrm{I})$ & 93 \\
\hline & & & 7 & FBH Pressure (psi)(t-1)(2I) & 92 \\
\hline & & & 8 & Reservoir Pressure $(\mathrm{psi})(\mathrm{t}-1)(2 \mathrm{I})$ & 92 \\
\hline & & & 9 & Water Saturation $(\%)(\mathrm{t}-1)(2 \mathrm{I})$ & 87 \\
\hline & & & 10 & Oil Saturation $(\%)(\mathrm{t}-1)(2 \mathrm{I})$ & 87 \\
\hline & & & \multicolumn{3}{|c|}{10} \\
\hline
\end{tabular}

Figure 9-1: Scenario 1 - Oil Model Input Attributes 


\subsubsection{Gas Predictive Model}

The gas model consisted of 22 total input attributes. Higher DOI was attributed to offset injector dynamic properties. Moreover, static attributes from the first injector had higher influence on gas production.

\section{Gas Model - Input Attributes}

\begin{tabular}{|c|c|c|c|c|c|}
\hline \multicolumn{3}{|c|}{ FOCAL WELL } & \multicolumn{3}{|c|}{ OFFSET WELLS } \\
\hline \multicolumn{3}{|c|}{ Static Attributes } & \multicolumn{3}{|c|}{ Static Attributes } \\
\hline Rank & Attribute & DOI & Rank & Attribute & DOI \\
\hline 1 & Porh(1-sw) & 100 & 1 & Completion (ft)(1P) & 100 \\
\hline 2 & Porosity $(\%)$ & 90 & 2 & Porh(1-sw)(1I) & 91 \\
\hline \multicolumn{3}{|c|}{2} & 3 & Top (ft)(1I) & 90 \\
\hline & & & 4 & $\mathrm{X} /$ Longitude(1I) & 84 \\
\hline \multicolumn{3}{|c|}{ Dynamic Attributes } & 5 & TVD (ft)(1I) & 73 \\
\hline 1 & Oil Rate $(\mathrm{t})$ & 100 & 8 & Y/Latitude(1I) & 56 \\
\hline 2 & Oil Rate (t-1) & 60 & \multicolumn{3}{|c|}{$\mathrm{C}_{\mathrm{C}}$} \\
\hline 3 & Gas Rate (t-1) & 60 & & & \\
\hline 4 & Permeability I(t-1) & 29 & \multicolumn{3}{|c|}{ Dynamic Attributes } \\
\hline \multicolumn{3}{|c|}{4} & 1 & FBH Pressure (psi)(t)(1I) & 100 \\
\hline & & & 2 & Distance $(\mathrm{t}-1)(2 \mathrm{P})$ & 97 \\
\hline \multicolumn{2}{|c|}{ TOTAL ATTRIBUTES } & \multirow[t]{2}{*}{22} & 3 & FBH Pressure (psi)(t-1)(1I) & 96 \\
\hline & & & 4 & Reservoir Pressure (psi)(t-1)(1I) & 96 \\
\hline & & & 5 & Distance $(\mathrm{t})(2 \mathrm{P})$ & 96 \\
\hline & & & 6 & FBH Pressure $(\mathrm{psi})(\mathrm{t})(2 \mathrm{I})$ & 93 \\
\hline & & & 7 & FBH Pressure $(\mathrm{psi})(\mathrm{t}-1)(2 \mathrm{I})$ & 92 \\
\hline & & & 8 & Reservoir Pressure (psi)(t-1)(2I) & 92 \\
\hline & & & 9 & Water Saturation $(\%)(\mathrm{t}-1)(2 \mathrm{I})$ & 87 \\
\hline & & & 10 & Oil Saturation $(\%)(\mathrm{t}-1)(2 \mathrm{I})$ & 87 \\
\hline & & & & 10 & \\
\hline
\end{tabular}

Figure 9-2: Scenario 1 - Gas Model Input Attributes 


\subsubsection{Water Predictive Model}

The water model consisted of 22 total input attributes. Dynamic saturations from the closest producer had a higher DOI on water production. Furthermore, top and TVD from the second closest producer and injector seemed to contribute more towards water production.

\section{Water Model - Input Attributes}

\begin{tabular}{|c|c|c|}
\hline \multicolumn{3}{|c|}{ FOCAL WELL } \\
\hline \multicolumn{3}{|c|}{ Static Attributes } \\
\hline Rank & Attribute & DOI \\
\hline 2 & $\mathrm{X} /$ Longitude & 89 \\
\hline 3 & Top (ft) & 84 \\
\hline & Porosity (\%) & 1 \\
\hline \multicolumn{3}{|c|}{3} \\
\hline \multicolumn{3}{|c|}{ Dynamic Attributes } \\
\hline 1 & Water Rate (t-1) & 100 \\
\hline 2 & Oil Saturation $(\%)(\mathrm{t}-1)$ & 78 \\
\hline 3 & Water Saturation $(\%)(t-1)$ & 78 \\
\hline 4 & Permeability I(t-1) & 72 \\
\hline 15 & Oil Rate $(\mathrm{t})$ & 1 \\
\hline 16 & Gas Rate $(\mathrm{t})$ & 1 \\
\hline \multicolumn{3}{|c|}{6} \\
\hline
\end{tabular}

TOTAL ATTRIBUTES

\begin{tabular}{|c|c|c|}
\hline \multicolumn{3}{|c|}{ OFFSET WELLS } \\
\hline \multicolumn{3}{|c|}{ Static Attributes } \\
\hline Rank & Attribute & DOI \\
\hline 1 & $\mathrm{X} /$ Longitude $(2 \mathrm{P})$ & 100 \\
\hline 2 & Top (ft)(2P) & 90 \\
\hline 3 & TVD (ft)(2P) & 86 \\
\hline 4 & Top $(\mathrm{ft})(2 \mathrm{I})$ & 79 \\
\hline 5 & $\mathrm{X} /$ Longitude(2I) & 75 \\
\hline 7 & TVD (ft)(2I) & 65 \\
\hline \multicolumn{3}{|c|}{6} \\
\hline
\end{tabular}

\section{Dynamic Attributes}

\begin{tabular}{|r|l|r|}
1 & Water Saturation $(\%)(\mathrm{t}-1)(1 \mathrm{P})$ & 100 \\
2 & Oil Saturation $(\%)(\mathrm{t}-1)(1 \mathrm{P})$ & 100 \\
3 & Distance(t)(1I) & 92 \\
12 & Permeability I(t-1)(2P) & 42 \\
\hline 15 & Permeability I(t-1)(2I) & 39 \\
\hline \multicolumn{2}{|c|}{5} &
\end{tabular}
5

Figure 9-3: Scenario 1 - Water Model Input Attributes 


\subsubsection{Reservoir Pressure Predictive Model}

The water model consisted of a total of 17 input attributes. Offset positioning from the offset wells, flowing bottom-hole pressure and reservoir pressure from the closest producer had higher DOI on reservoir pressure.

\section{Reservoir Pressure Model - Input Attributes}

\begin{tabular}{|r|l|r|}
\hline \multicolumn{3}{|c|}{ FOCAL WELL } \\
\hline \multicolumn{2}{|c|}{ Static Attributes } \\
\hline \multicolumn{2}{|c|}{ Attribute } & DOI \\
\hline Rank & \multicolumn{2}{|c|}{100} \\
\hline 1 & X/Longitude \\
\hline 2 & Top (ft) \\
\hline \multicolumn{2}{|c|}{ Dynamic Attributes } \\
\hline \multicolumn{3}{|c|}{} \\
\hline 1 & Reservoir Pressure (psi)(t-1) & 100 \\
\hline 2 & FBH Pressure (psi)(t) & 78 \\
\hline 3 & FBH Pressure (psi)(t-1) & 52 \\
\hline 12 & Water Rate (t) & 5 \\
\hline 13 & Oil Rate (t) & 4 \\
\hline 14 & Gas Rate (t) & 4 \\
\hline \multicolumn{2}{|c|}{6} & \\
\hline
\end{tabular}

\begin{tabular}{|c|c|c|}
\hline \multicolumn{3}{|c|}{ OFFSET WELLS } \\
\hline \multicolumn{3}{|c|}{ Static Attributes } \\
\hline Rank & Attribute & DOI \\
\hline 1 & $\mathrm{X} /$ Longitude(1P) & 100 \\
\hline 2 & $\mathrm{X} /$ Longitude(1I) & 88 \\
\hline 3 & $\mathrm{X} /$ Longitude(2P) & 88 \\
\hline 4 & Top (ft)(1I) & 85 \\
\hline 5 & Top (ft)(2P) & 79 \\
\hline 6 & Pay thickness (ft)(1I) & 79 \\
\hline \multicolumn{3}{|c|}{6} \\
\hline \multicolumn{3}{|c|}{ Dynamic Attributes } \\
\hline 1 & Reservoir Pressure (psi)(t-1)(1P) & 100 \\
\hline 2 & FBH Pressure (psi)(t-1)(1P) & 91 \\
\hline 3 & FBH Pressure (psi)(t)(1P) & 90 \\
\hline \multicolumn{3}{|c|}{3} \\
\hline
\end{tabular}

TOTAL ATTRIBUTES

Figure 9-4: Scenario 1 - Reservoir Pressure Model Input Attributes 


\subsubsection{Water Saturation Predictive Model}

The water model consisted of a total of 17 input attributes. Positioning from the offset producers, and dynamic saturations from the closest producer had a higher DOI on water saturation.

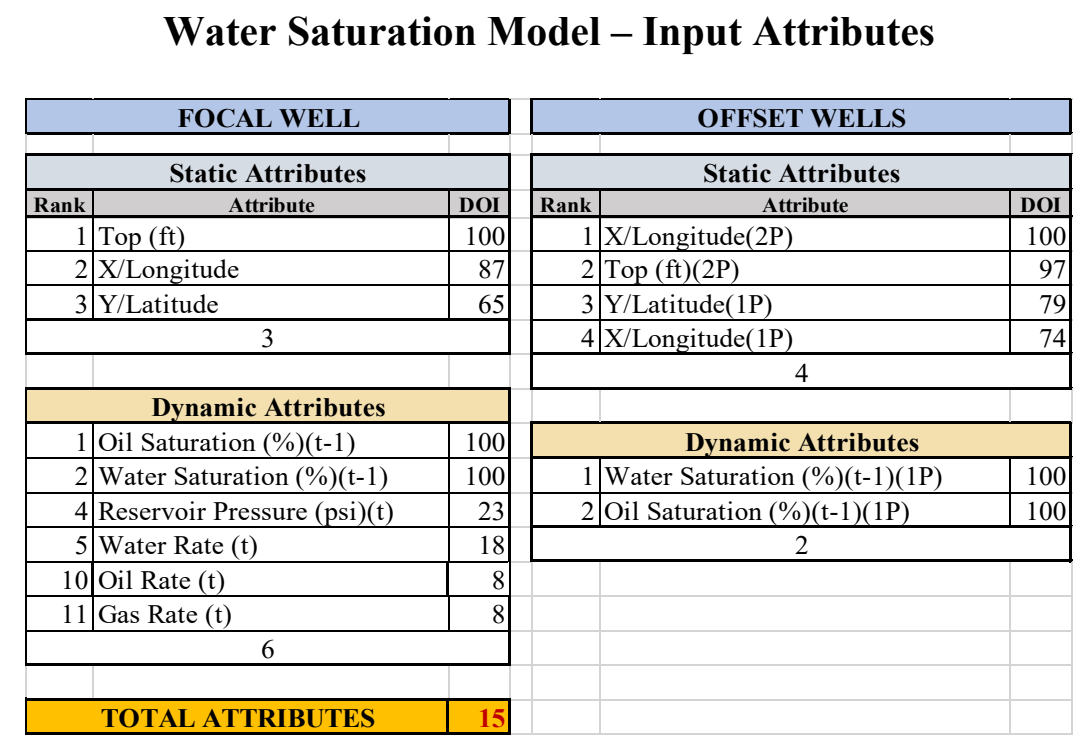

Figure 9-5: Scenario 1 - Water Saturation Model Input Attributes 


\subsection{Production Profile Plots}

\subsubsection{Entire Reservoir}

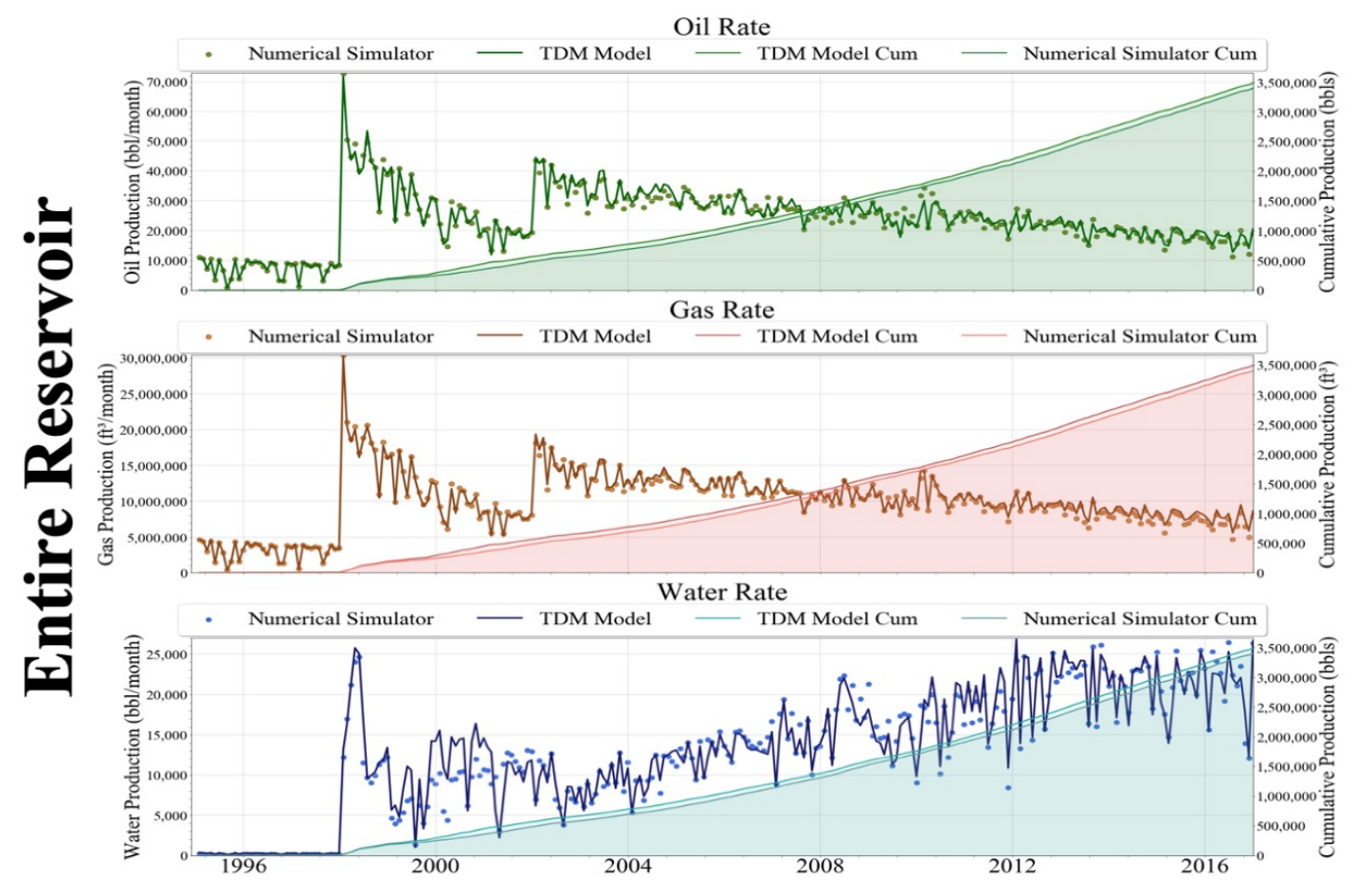

Figure 9-6: Scenario 1 - Entire Field Production 


\subsubsection{Good History Match of Production}

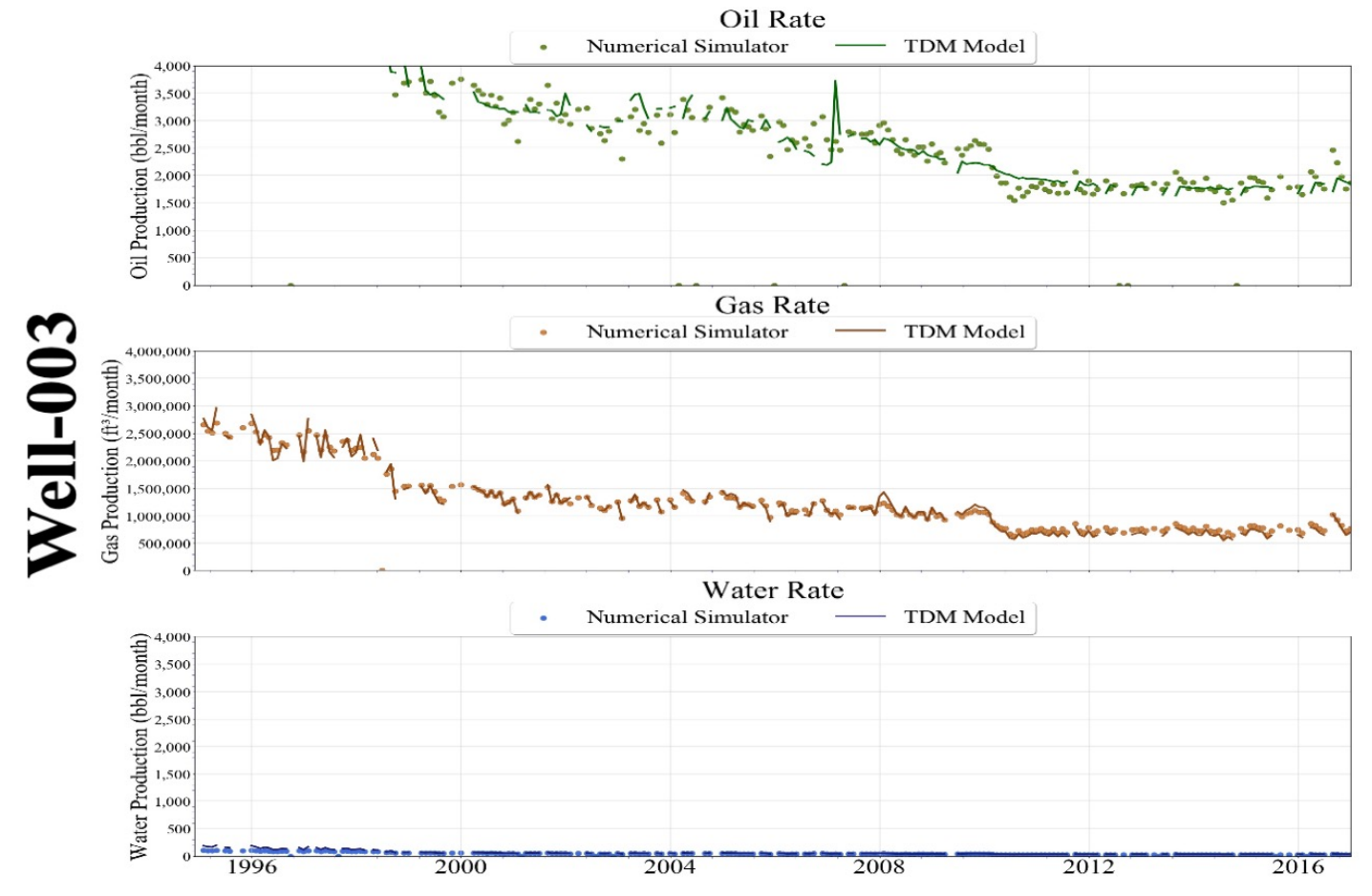

Figure 9-7: Scenario 1 - Well-003 Production History Match

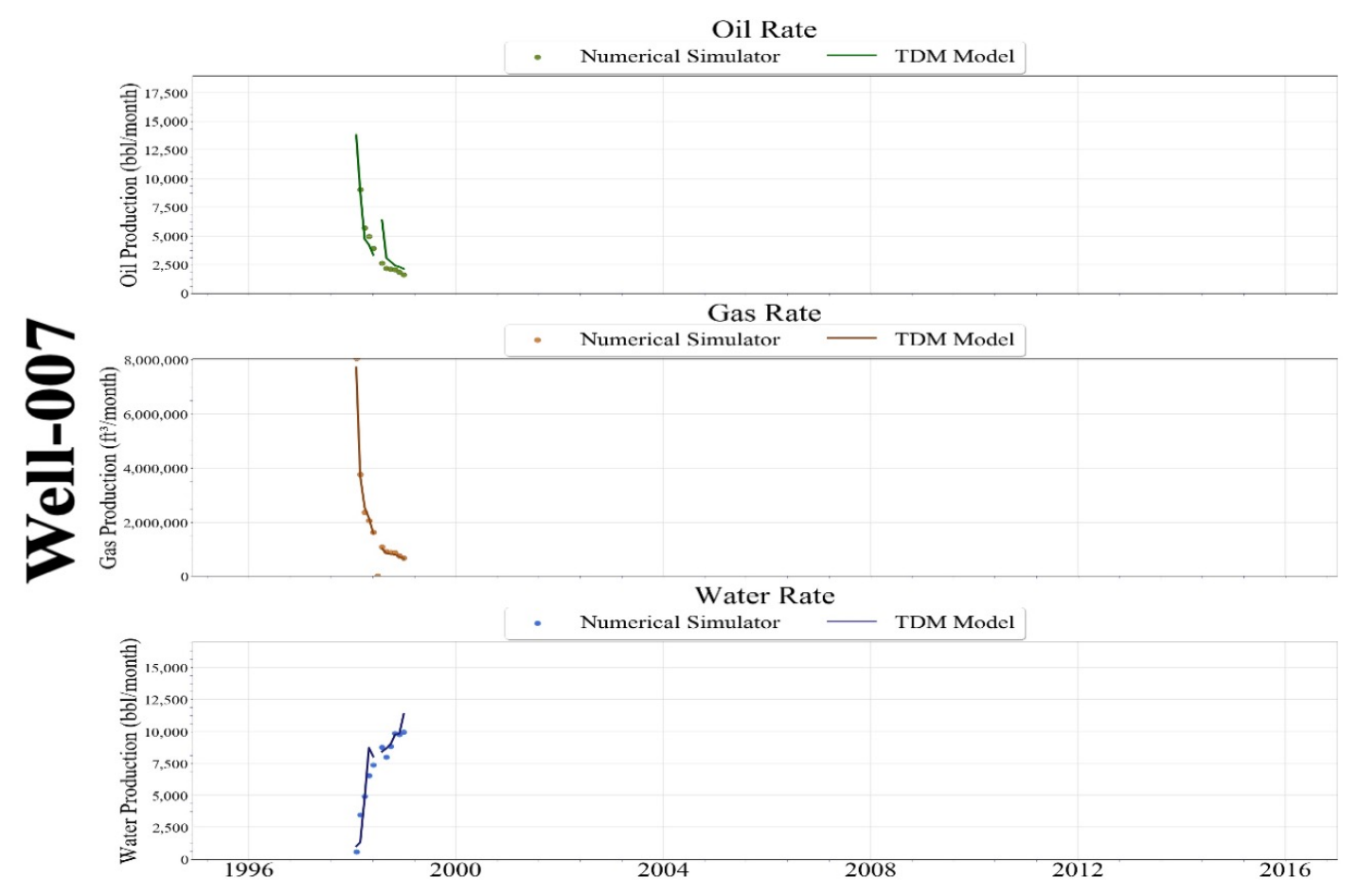

Figure 9-8: Scenario 1 - Well-007 Production History Match 

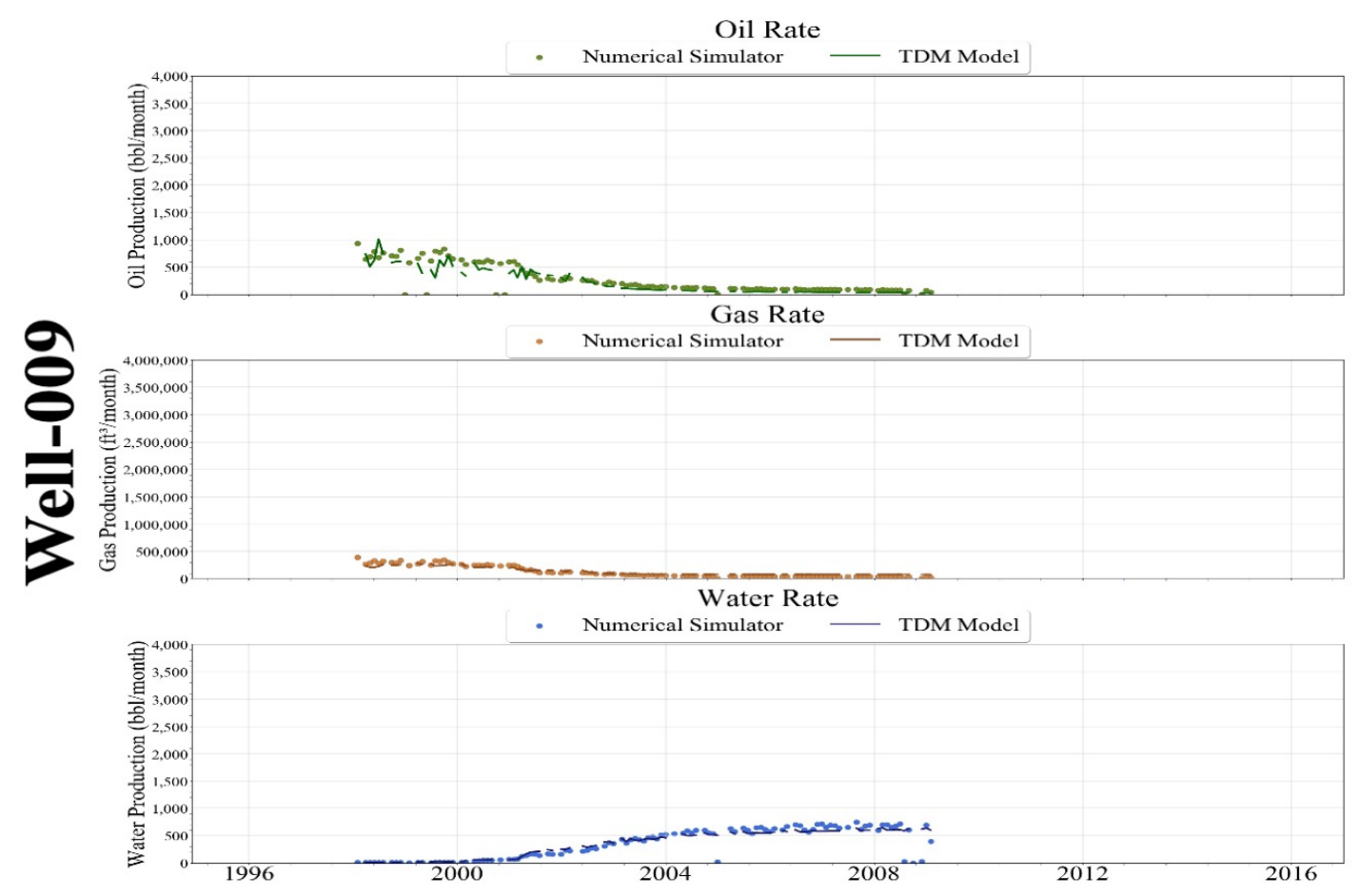

Figure 9-9: Scenario 1 - Well-009 Production History Match

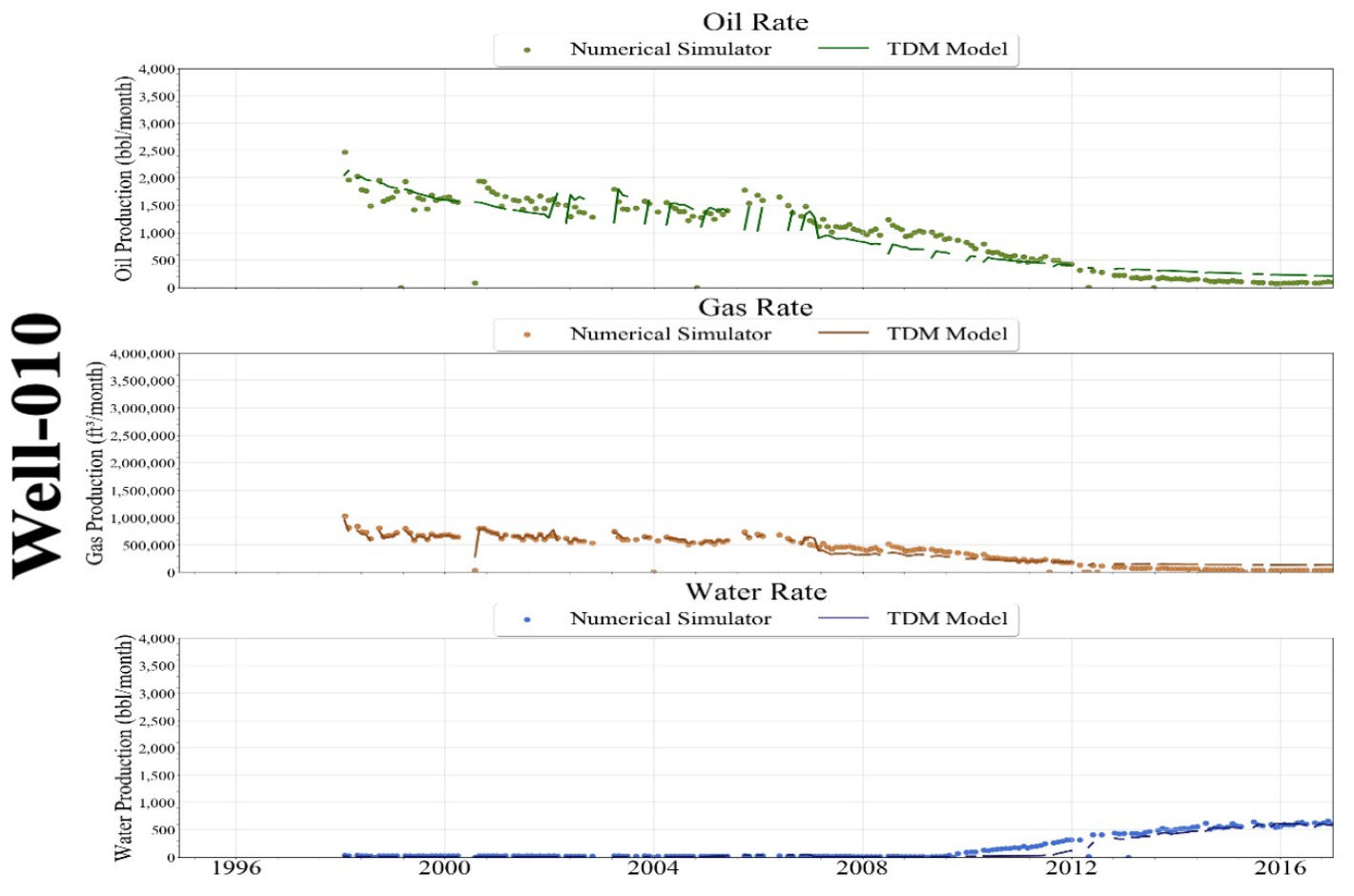

Figure 9-10: Scenario 1 - Well-010 Production History Match 


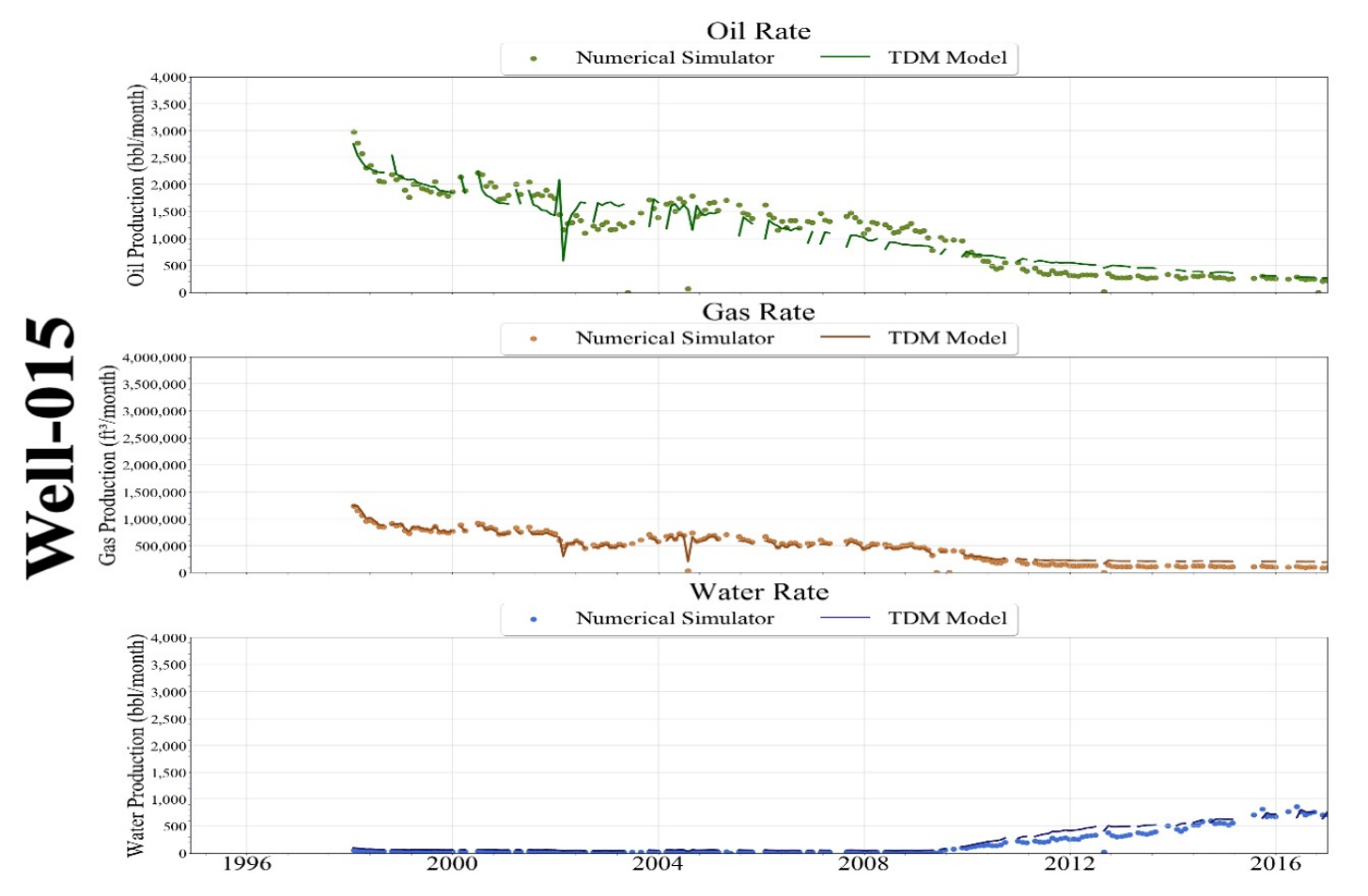

Figure 9-11: Scenario 1 - Well-015 Production History Match

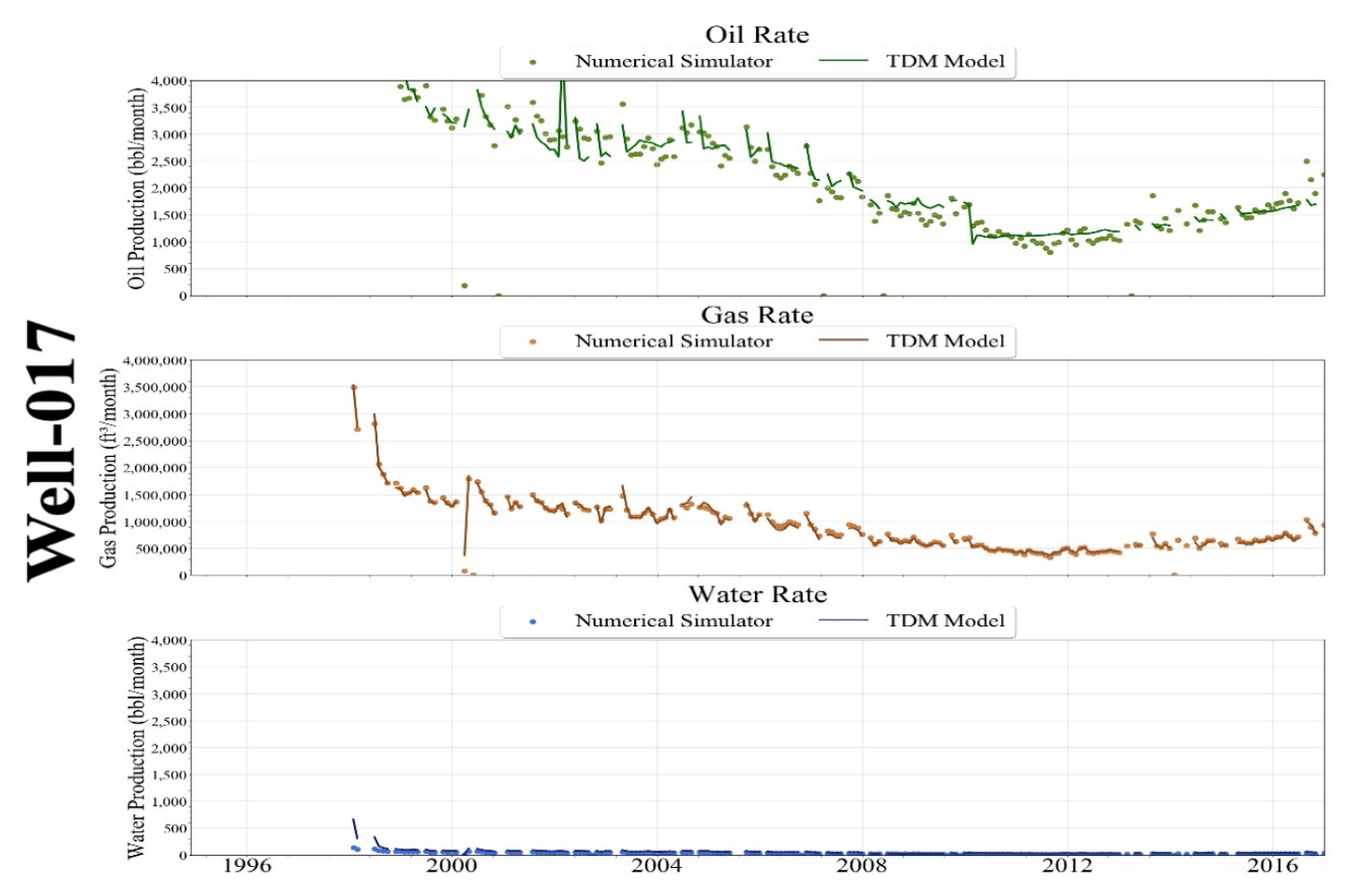

Figure 9-12: Scenario 1 - Well-017 Production History Match 


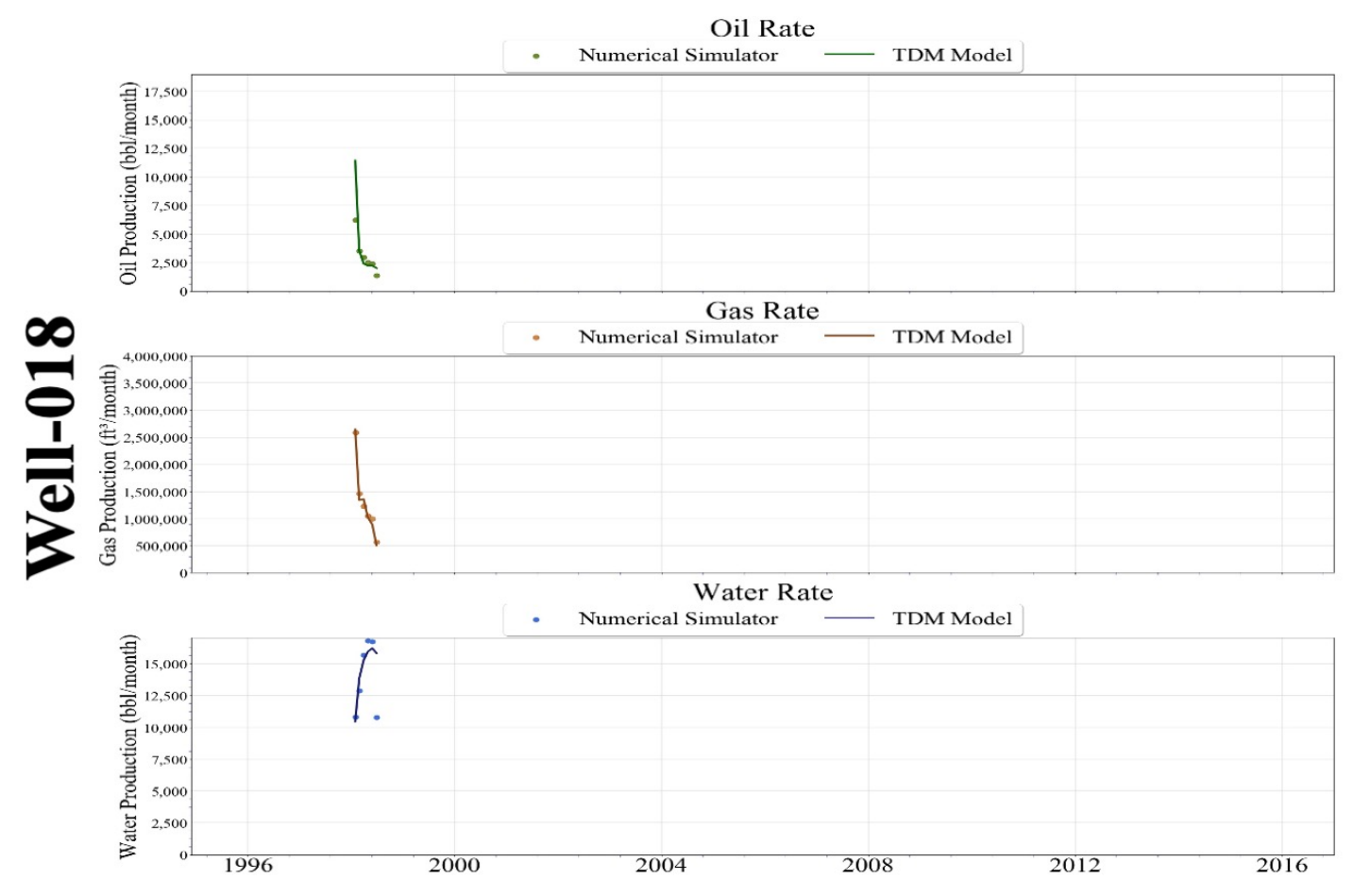

Figure 9-13: Scenario 1 - Well-018 Production History Match

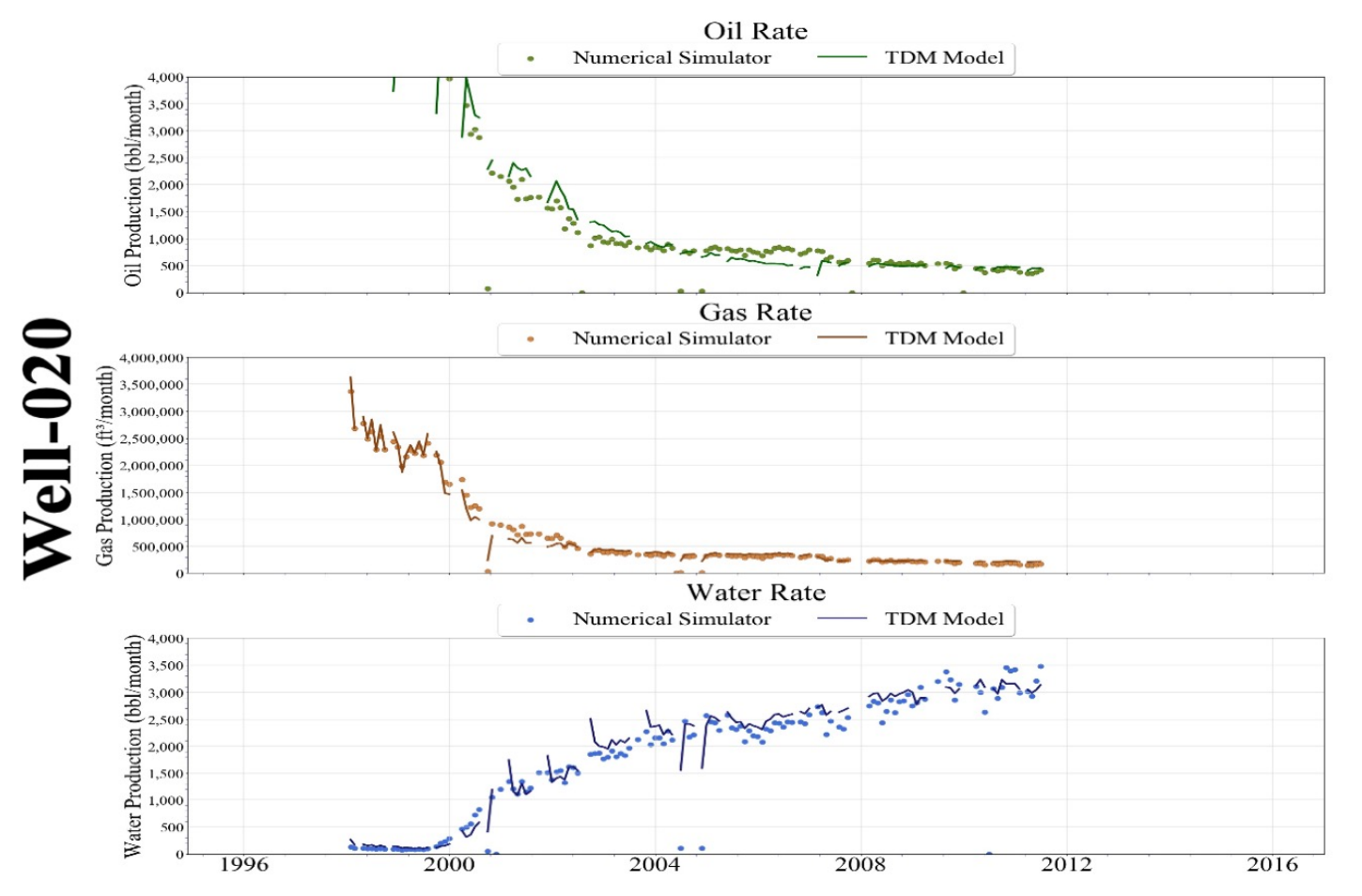

Figure 9-14: Scenario 1 - Well-020 Production History Match 


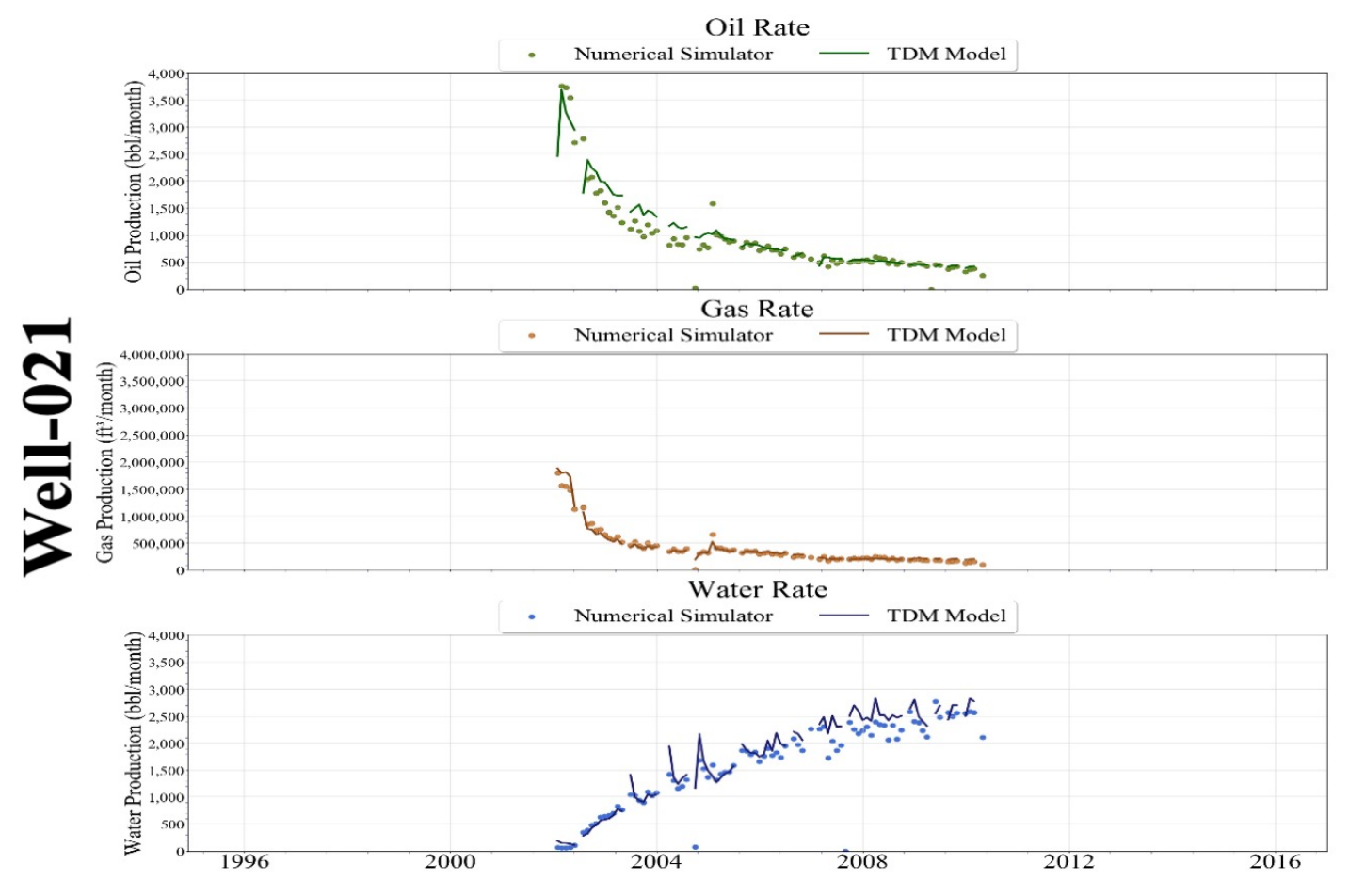

Figure 9-15: Scenario 1 - Well-021 Production History Match

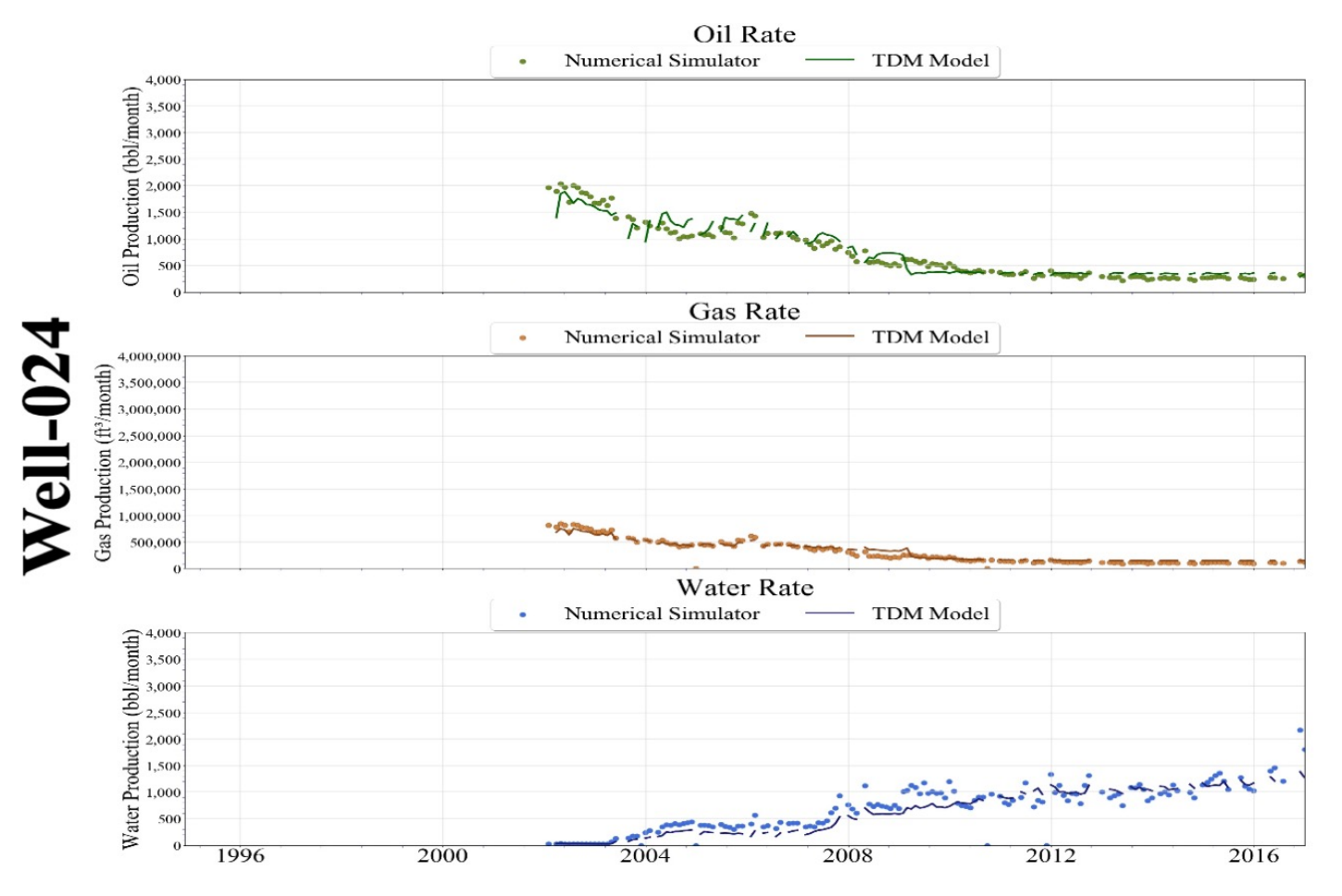

Figure 9-16: Scenario 1 - Well-024 Production History Match 


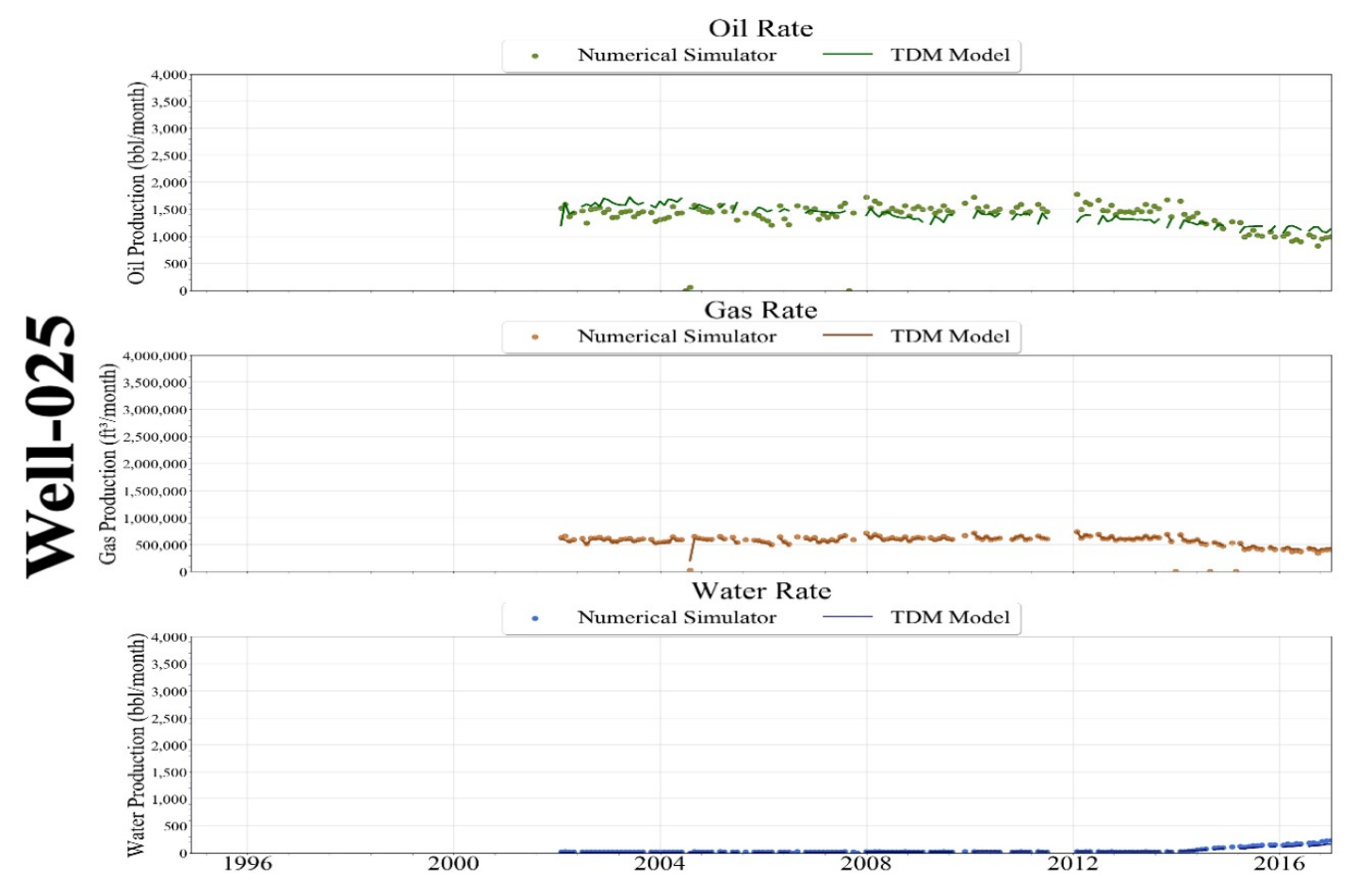

Figure 9-17: Scenario 1 - Well-025 Production History Match

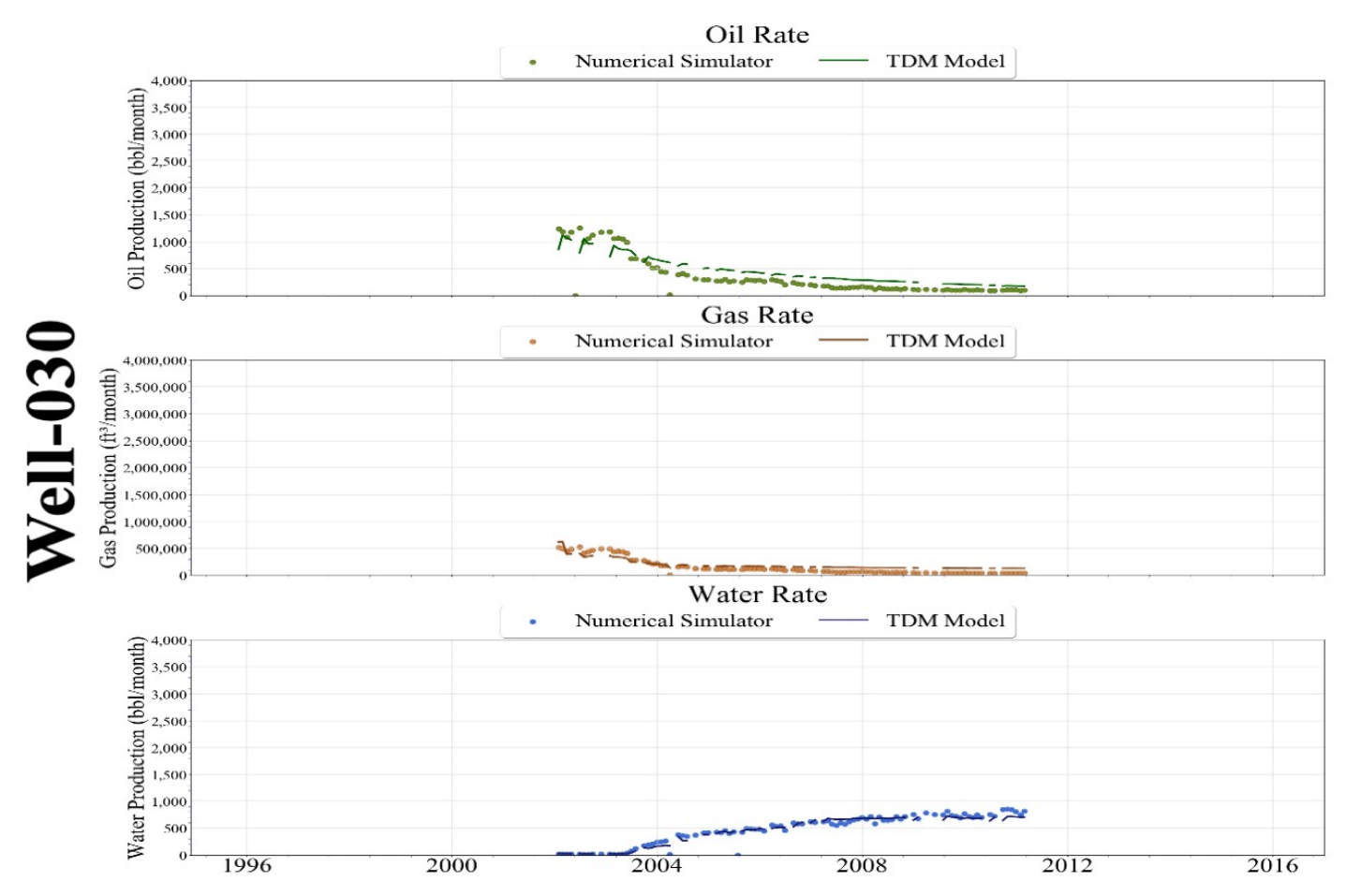

Figure 9-18: Scenario 1 - Well-030 Production History Match 


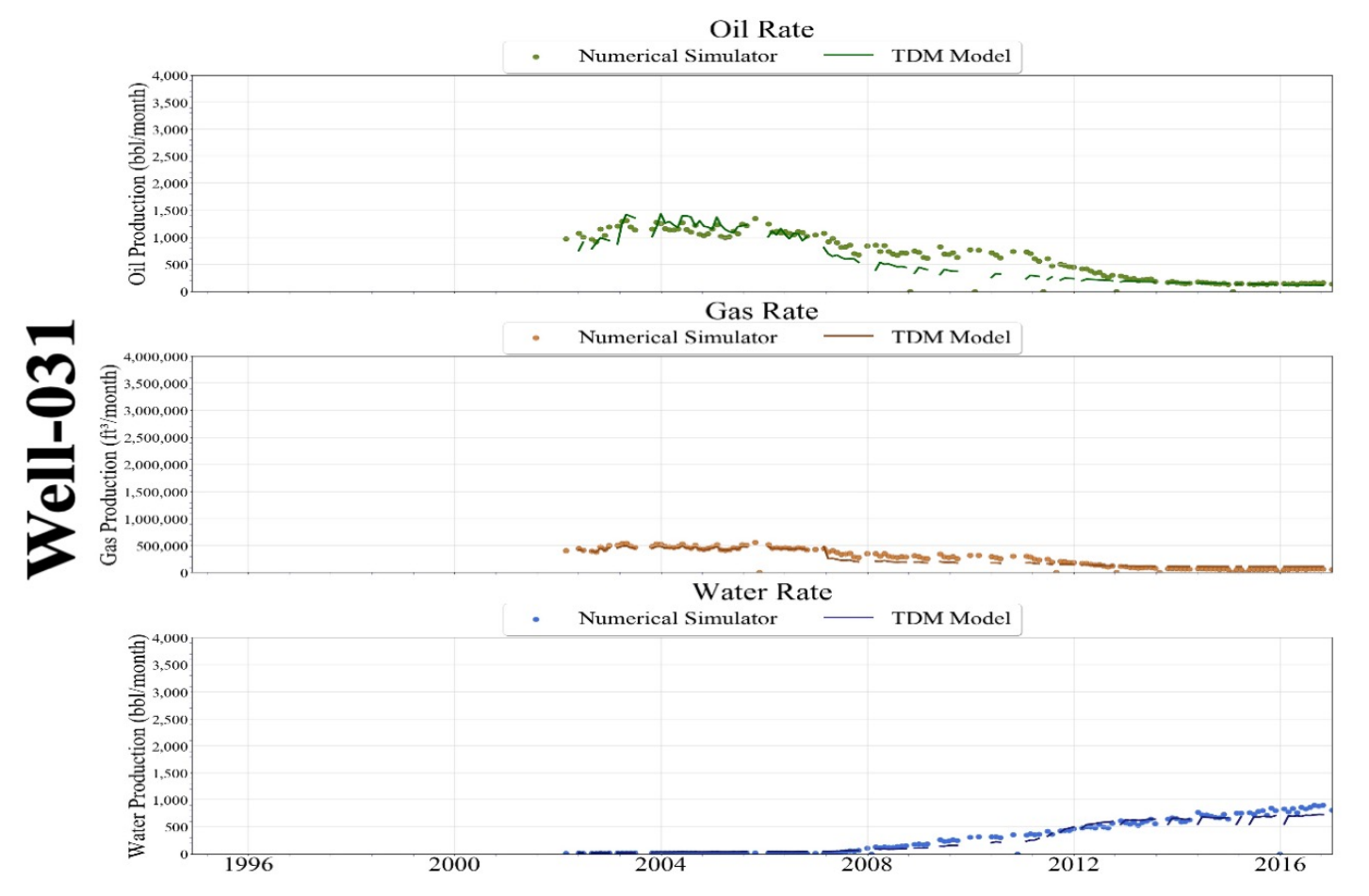

Figure 9-19: Scenario 1 - Well-031 Production History Match

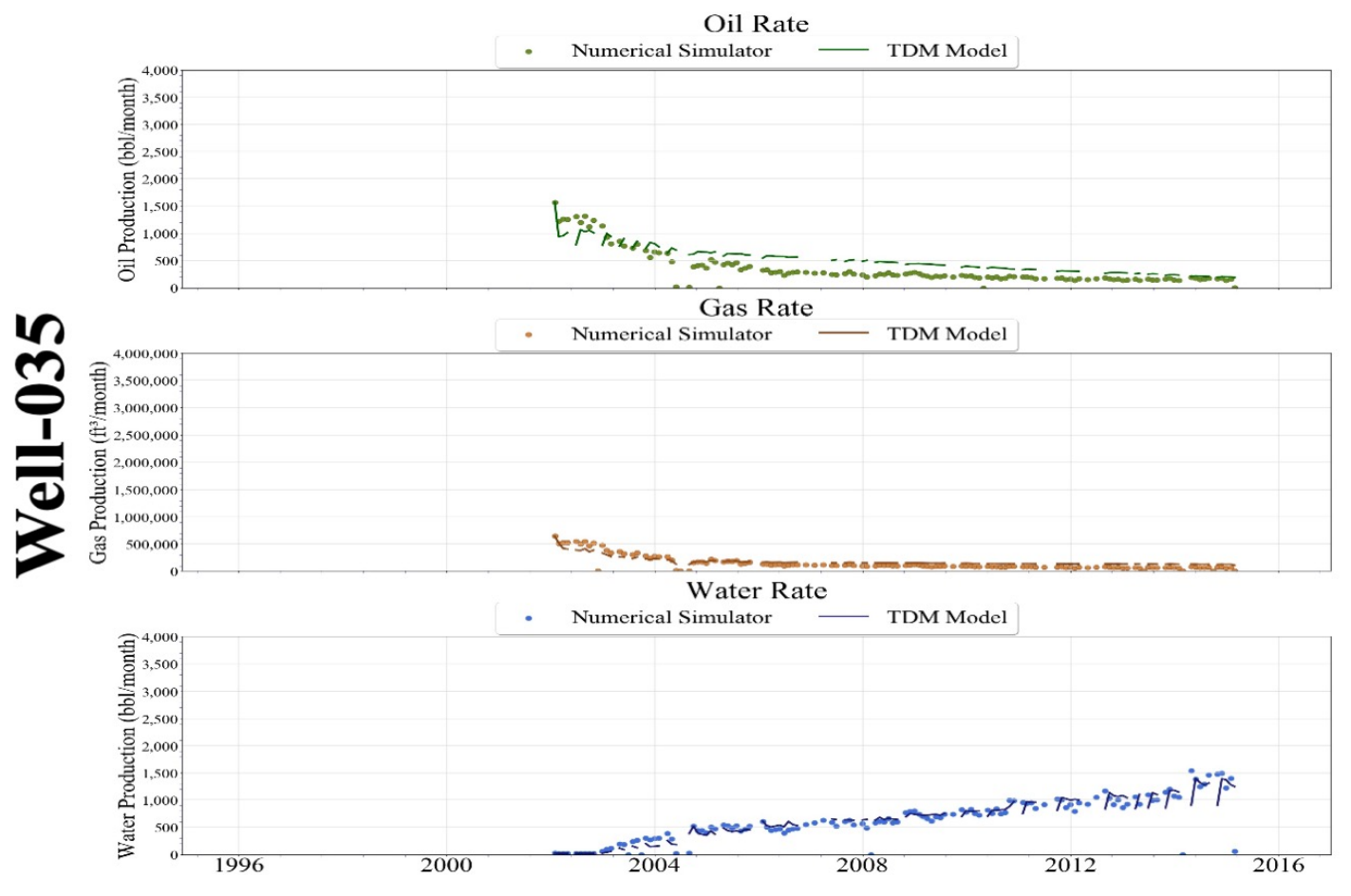

Figure 9-20: Scenario 1 - Well-035 Production History Match 


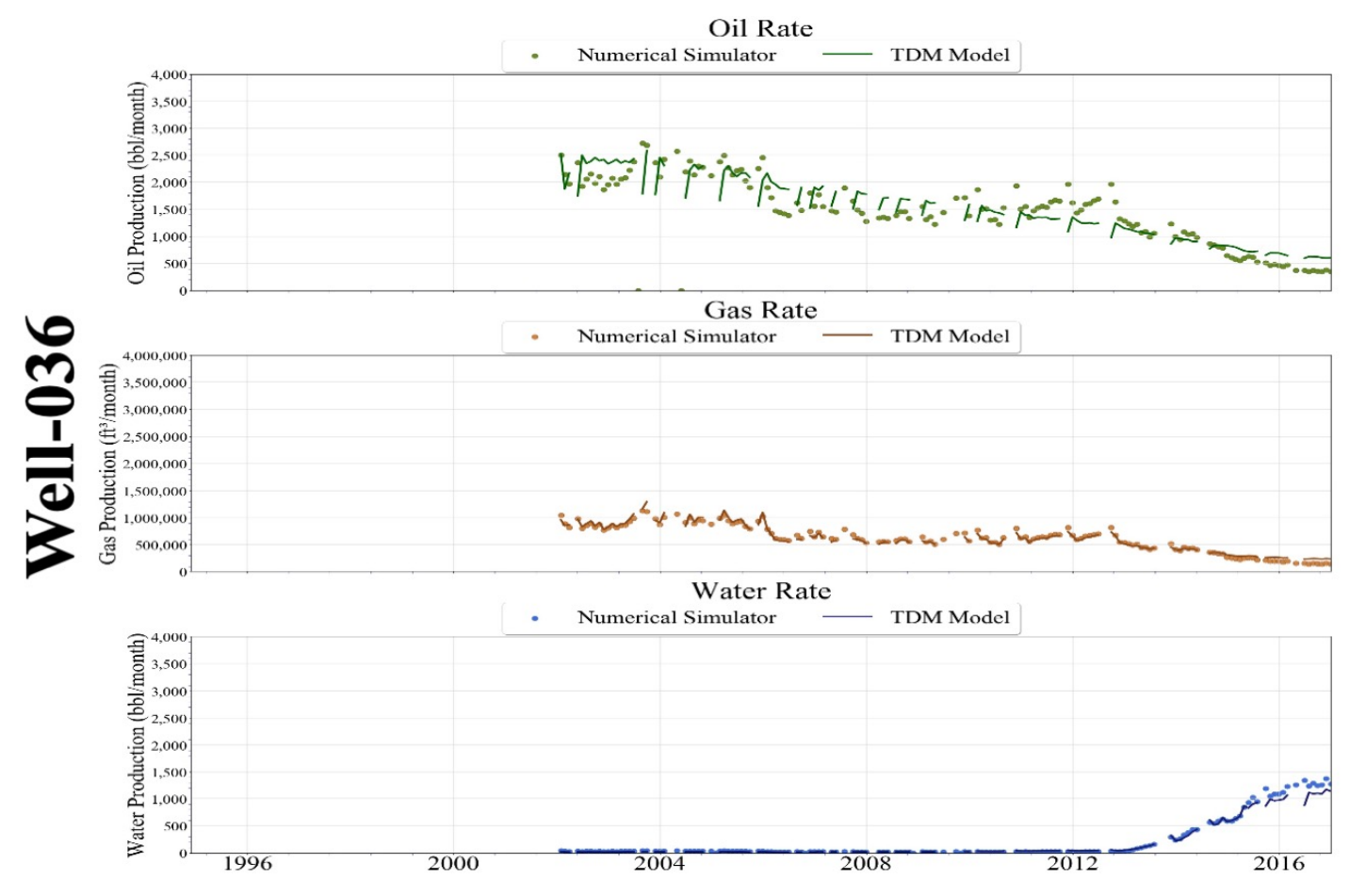

Figure 9-21: Scenario 1 - Well-036 Production History Match

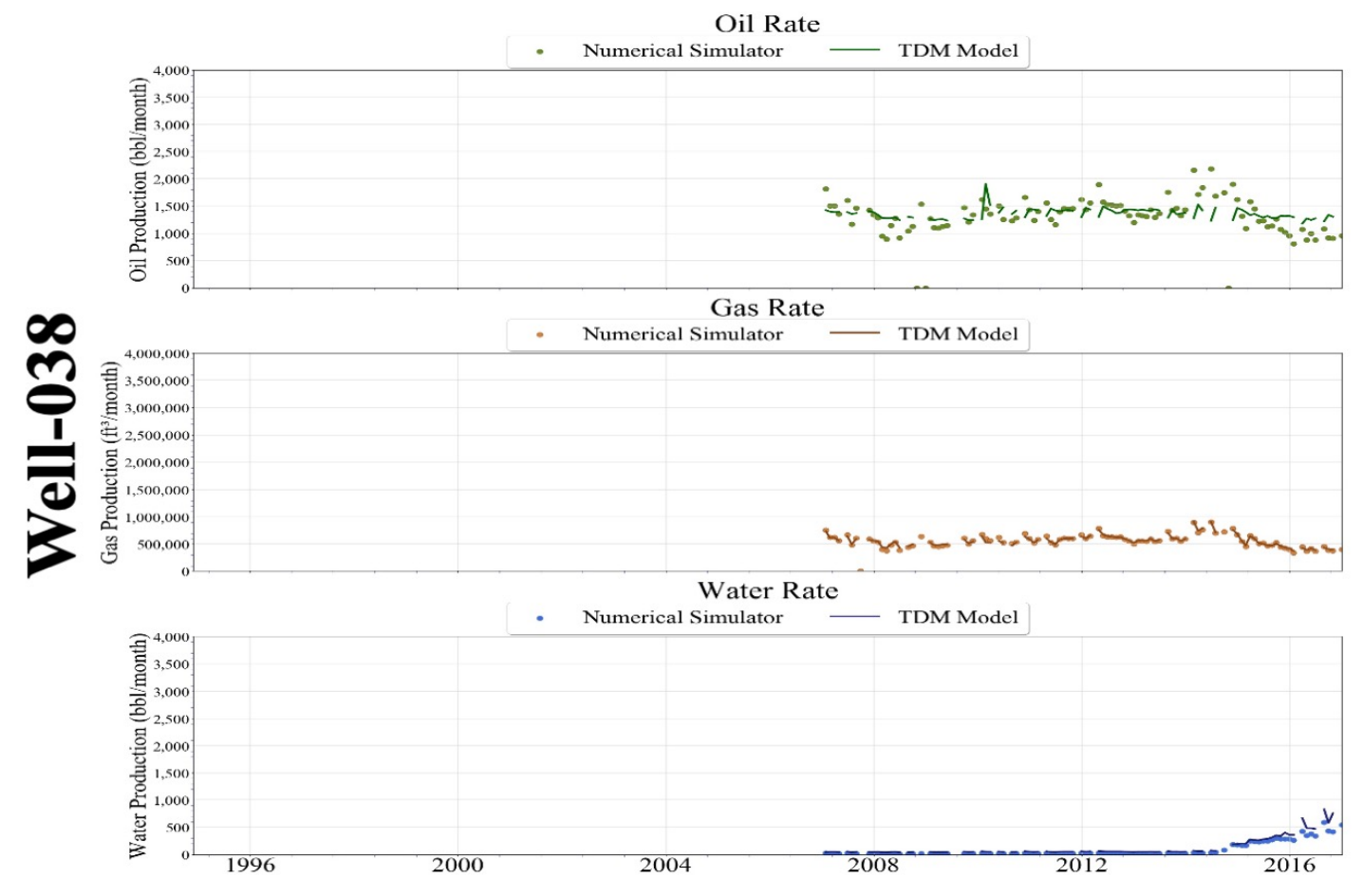

Figure 9-22: Scenario 1 - Well-038 Production History Match 
Oil Rate

Numerical Simulator — TDM Model

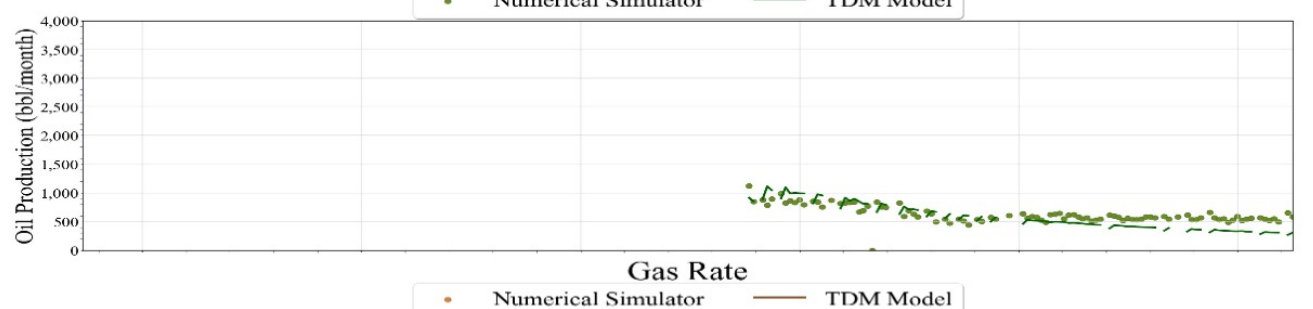

Numerical Simulator — TDM Model

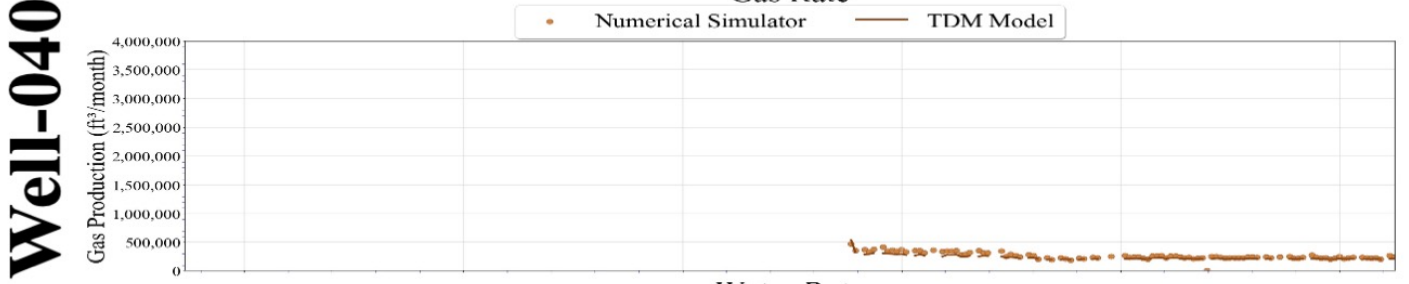

Water Rate

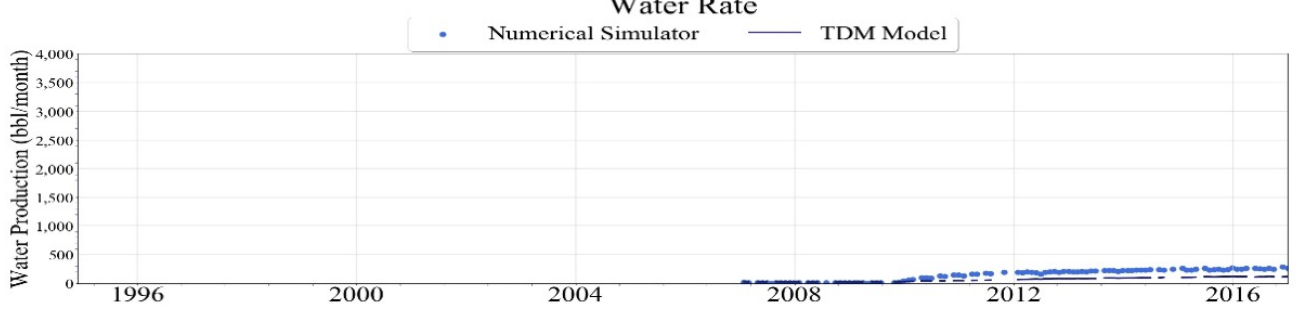

Figure 9-23: Scenario 1 - Well-040 Production History Match

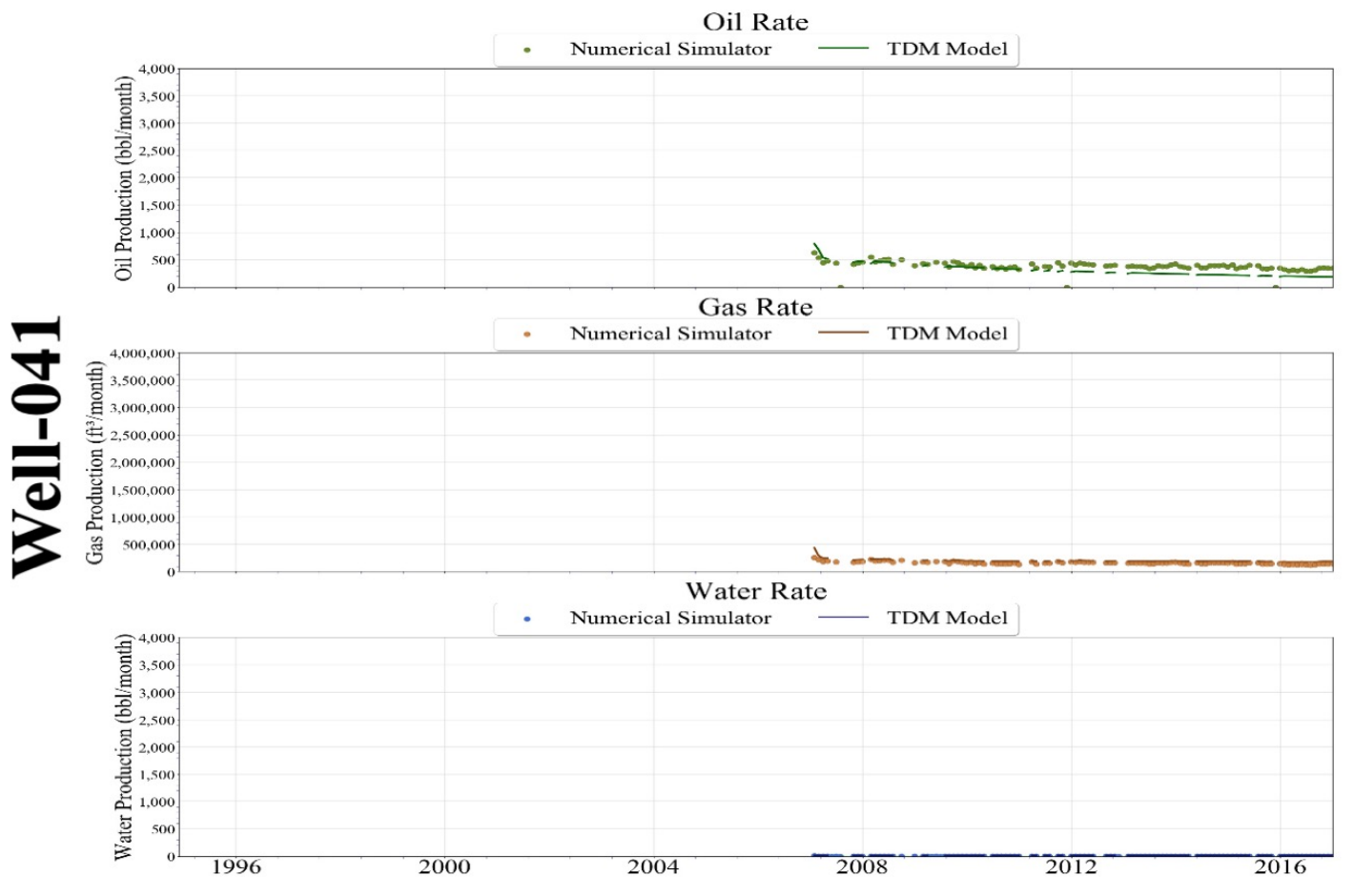

Figure 9-24: Scenario 1 - Well-041 Production History Match 


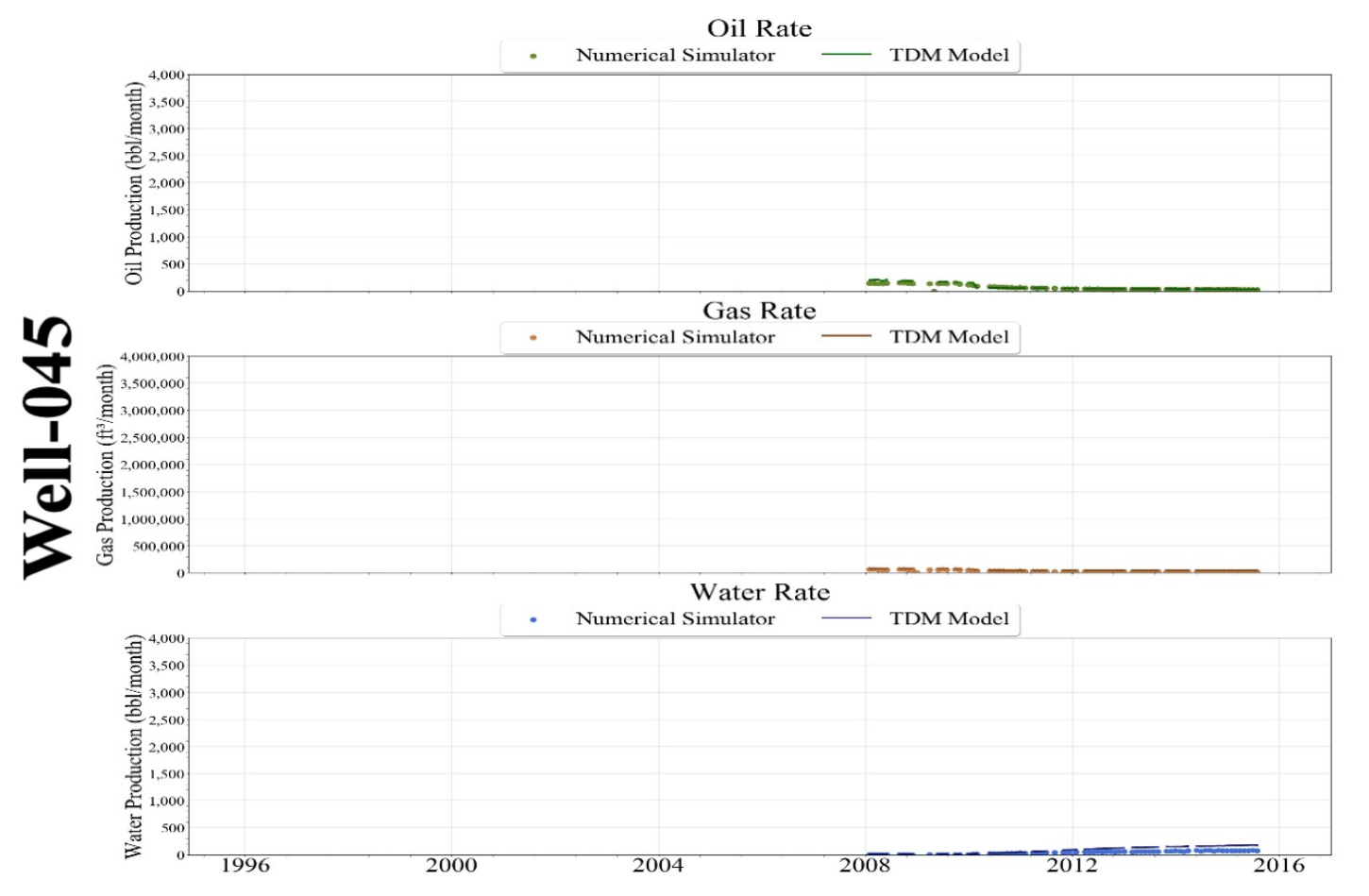

Figure 9-25: Scenario 1 - Well-045 Production History Match

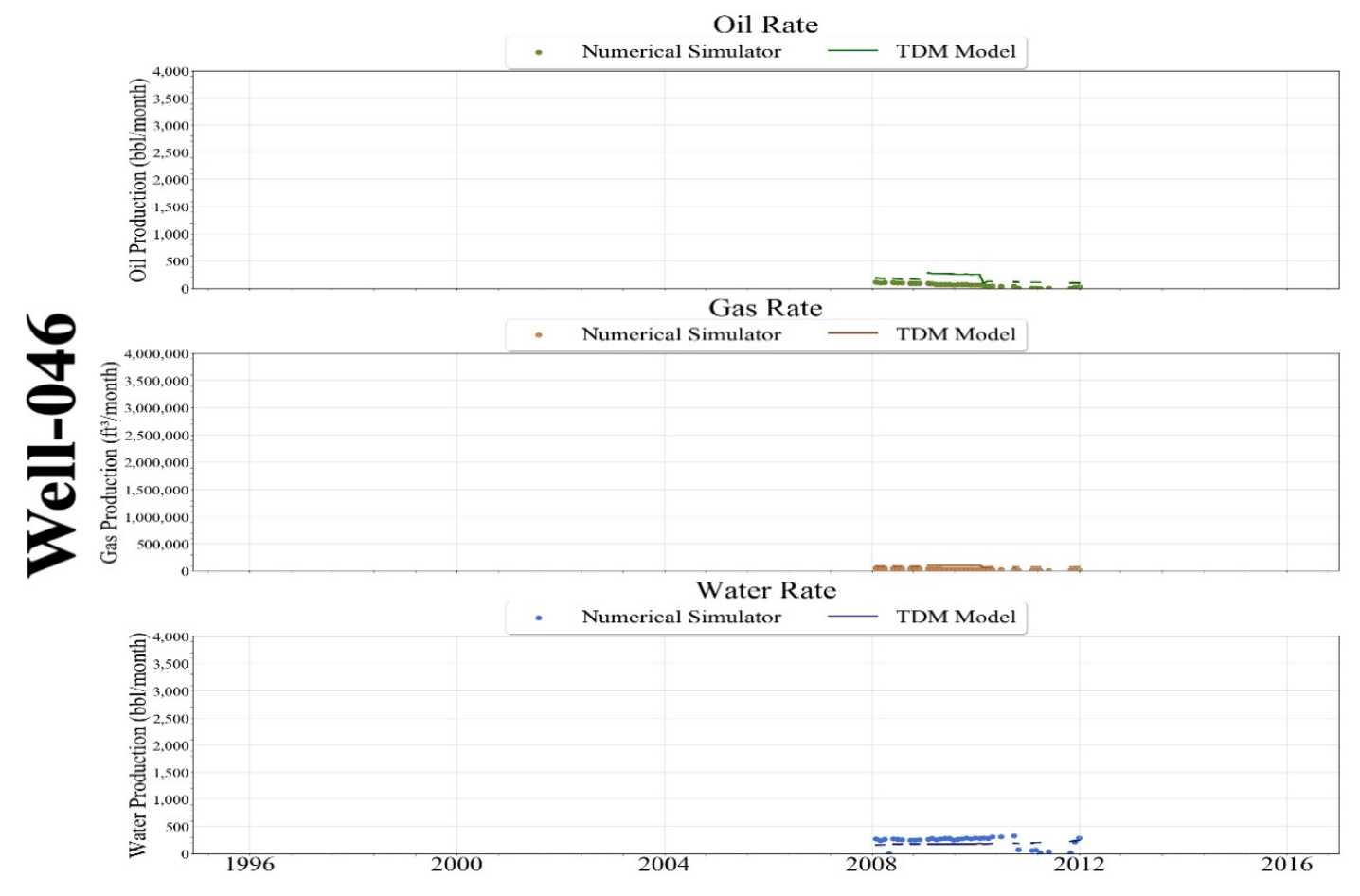

Figure 9-26: Scenario 1 - Well-046 Production History Match 


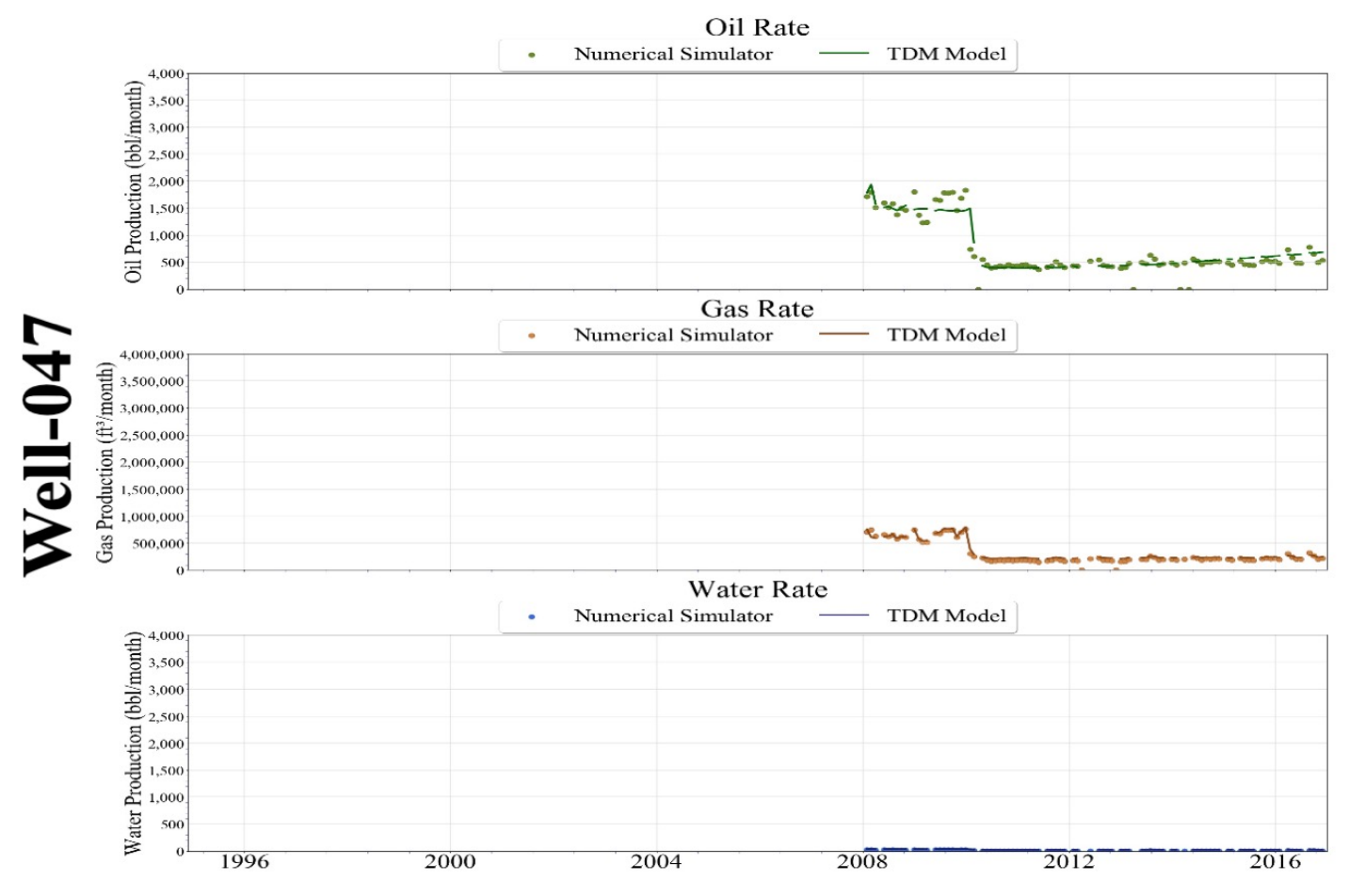

Figure 9-27: Scenario 1 - Well-047 Production History Match

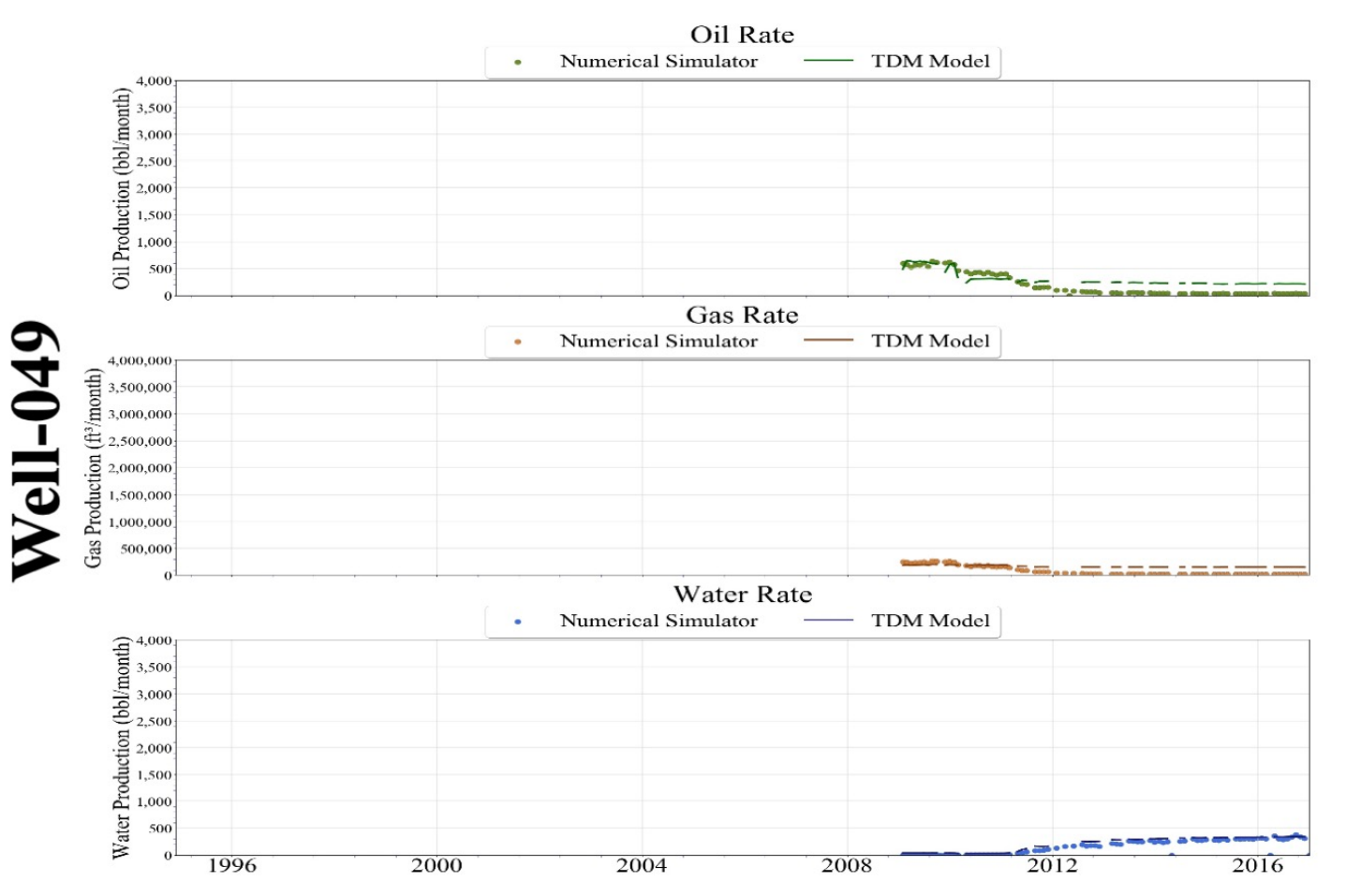

Figure 9-28: Scenario 1 - Well-049 Production History Match 


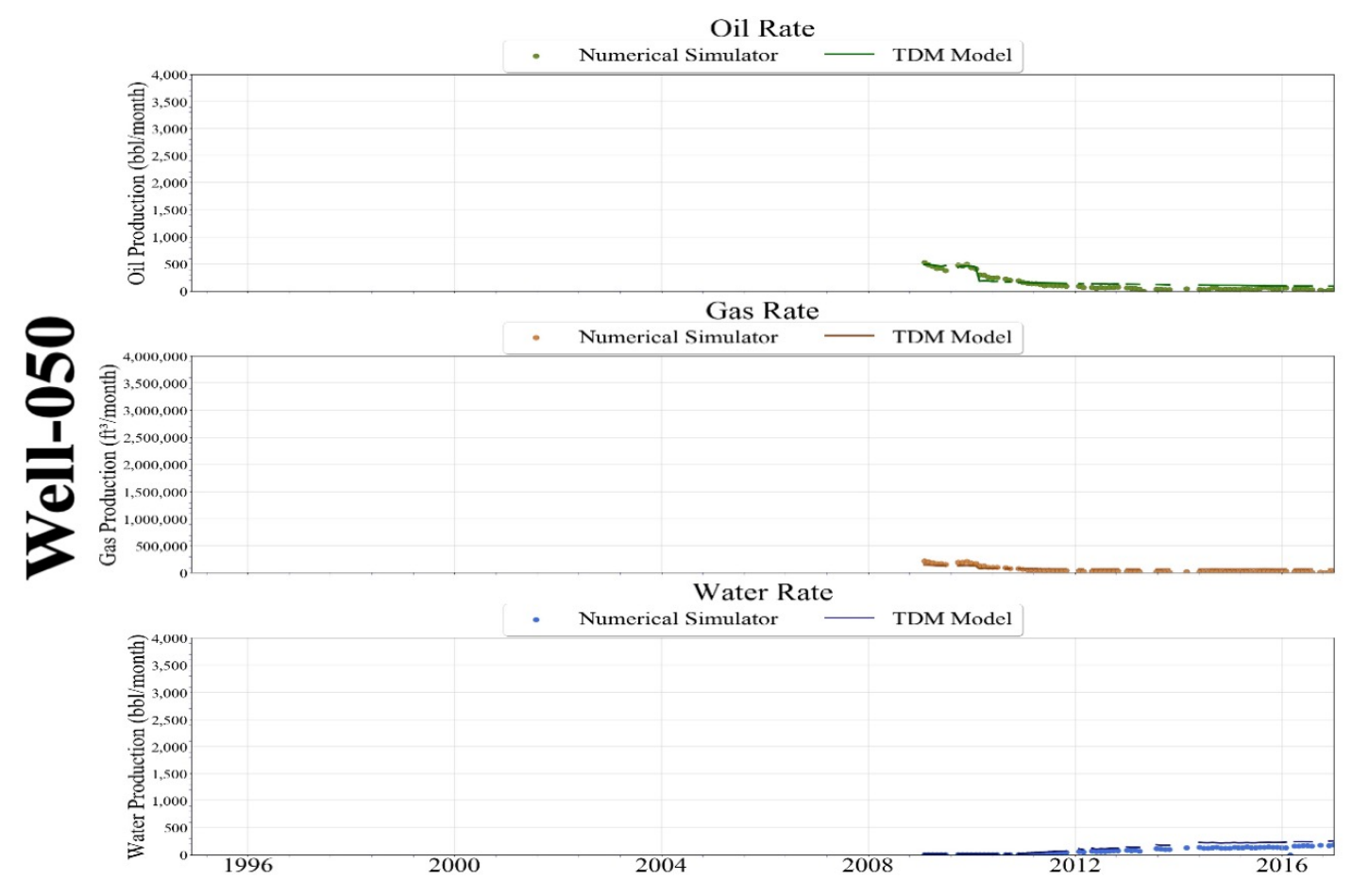

Figure 9-29: Scenario 1 - Well-050 Production History Match

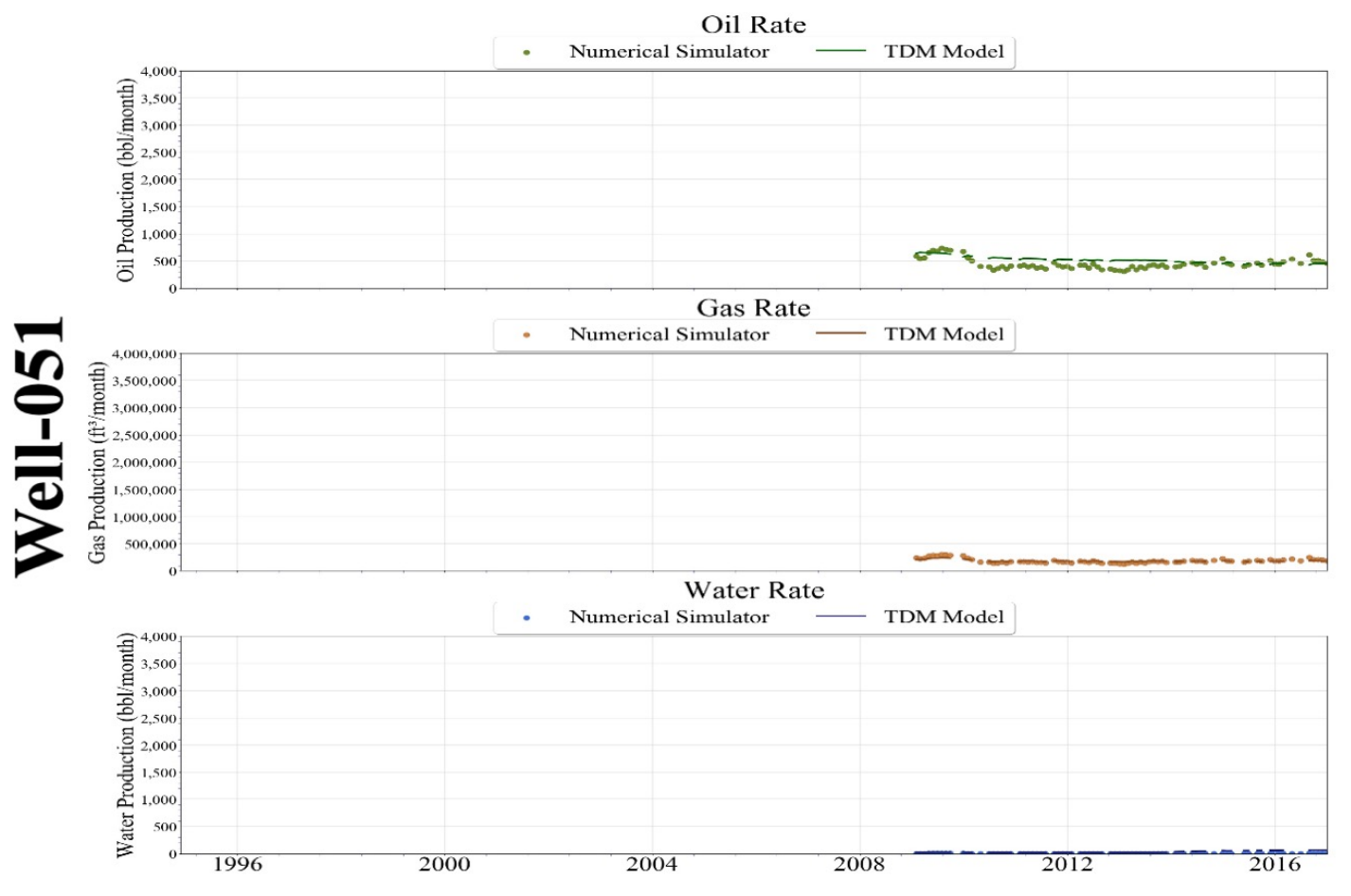

Figure 9-30: Scenario 1 - Well-051 Production History Match 


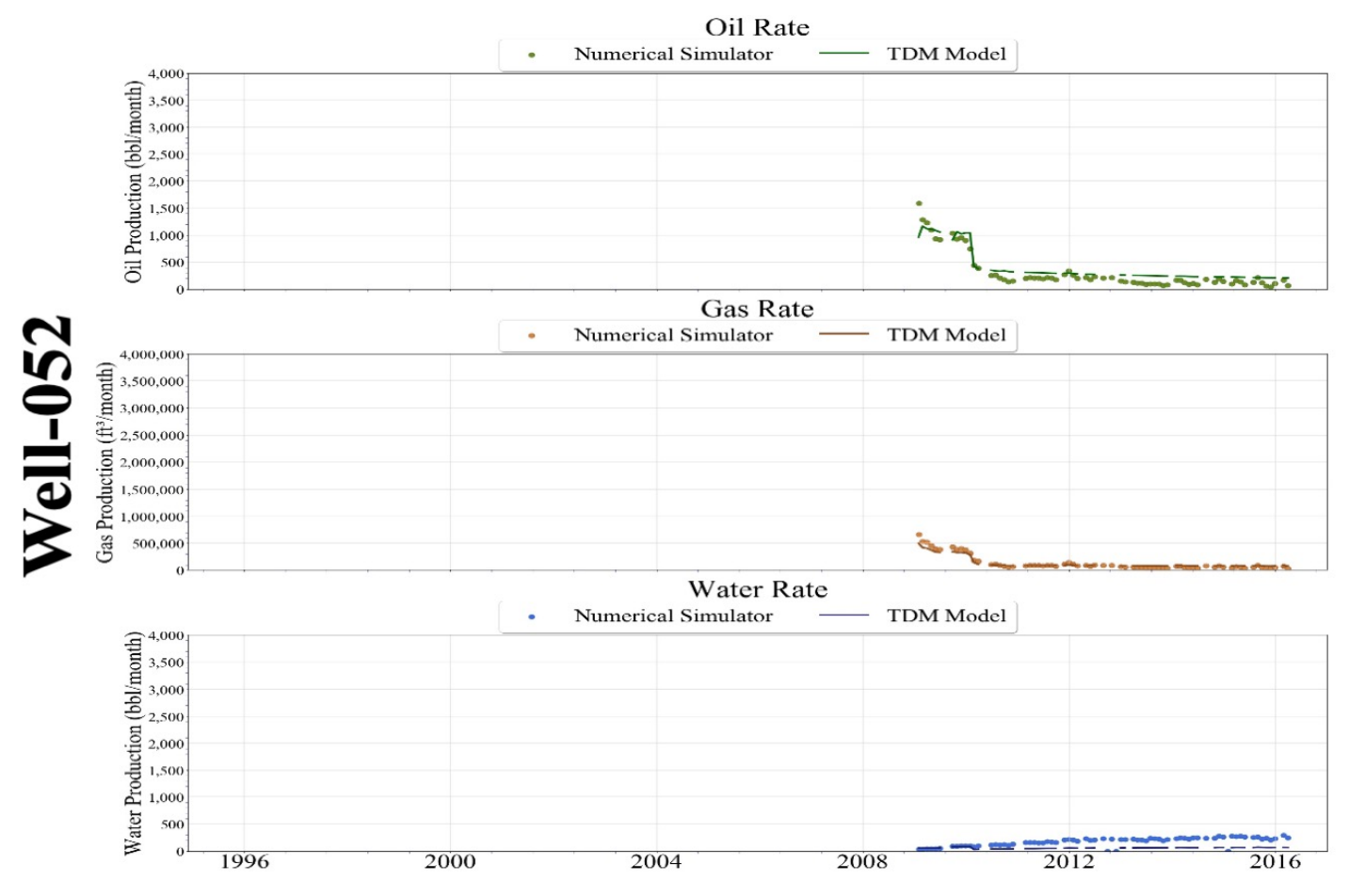

Figure 9-31: Scenario 1 - Well-052 Production History Match

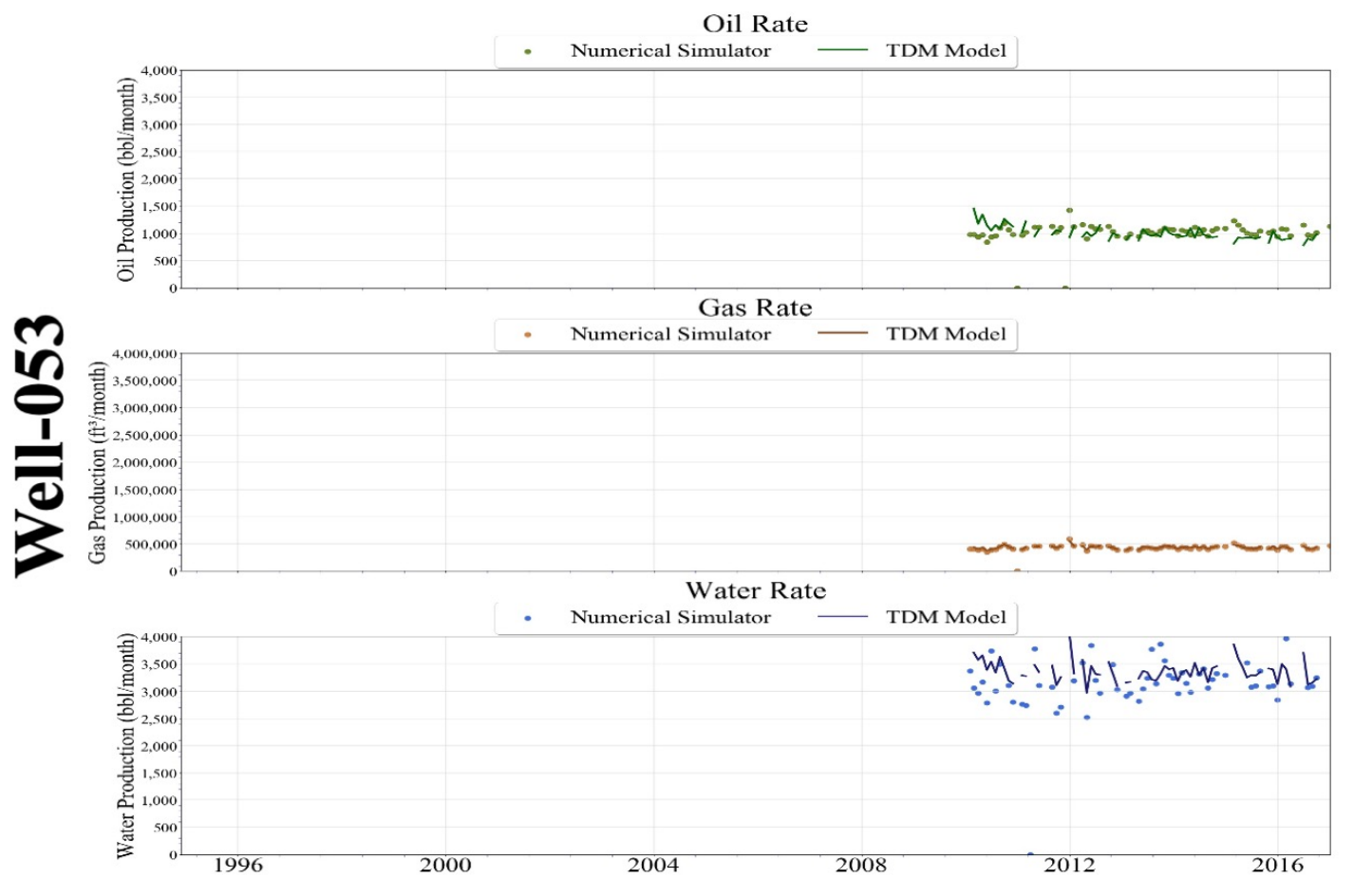

Figure 9-32: Scenario 1 - Well-053 Production History Match 


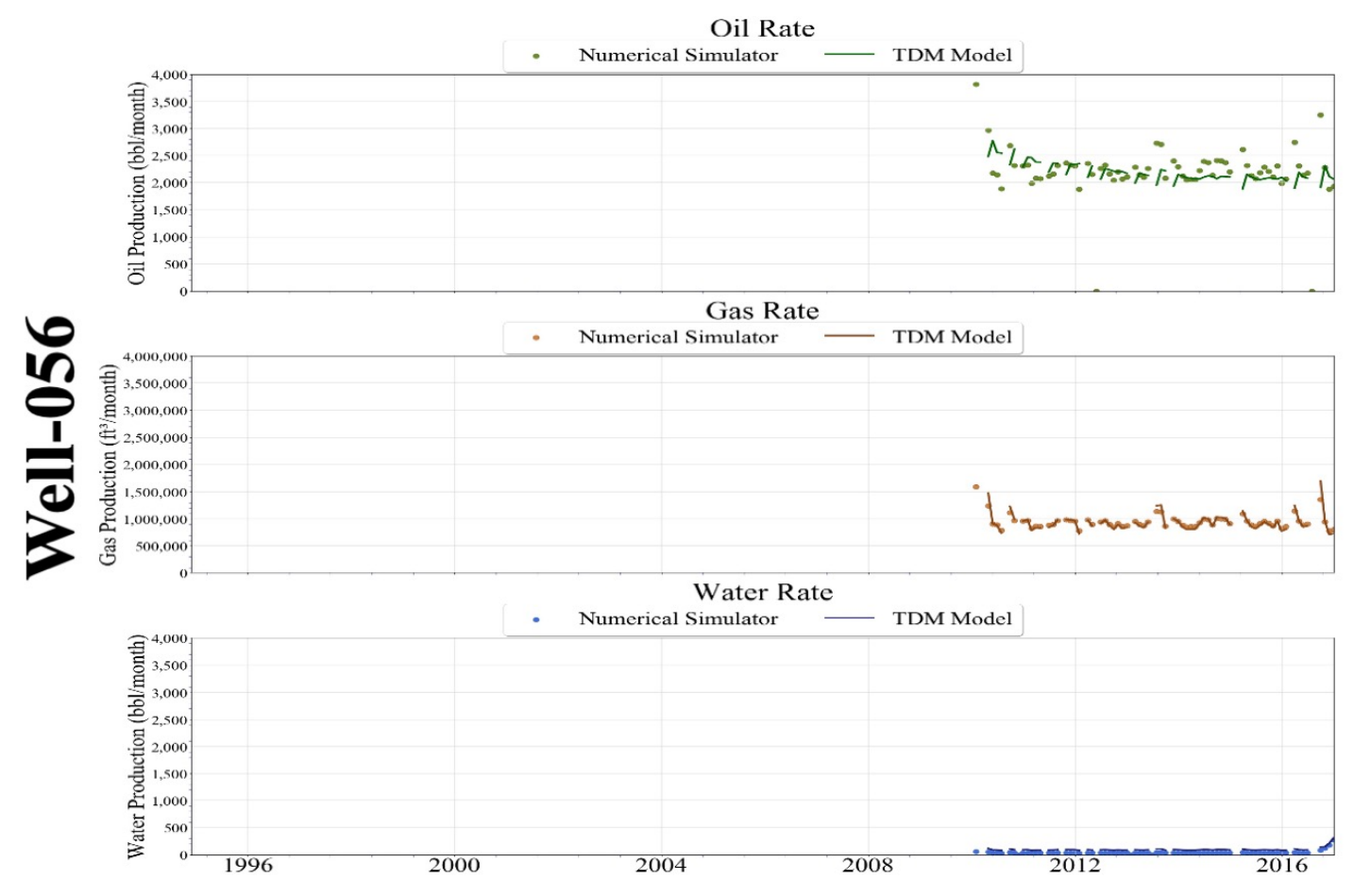

Figure 9-33: Scenario 1 - Well-056 Production History Match

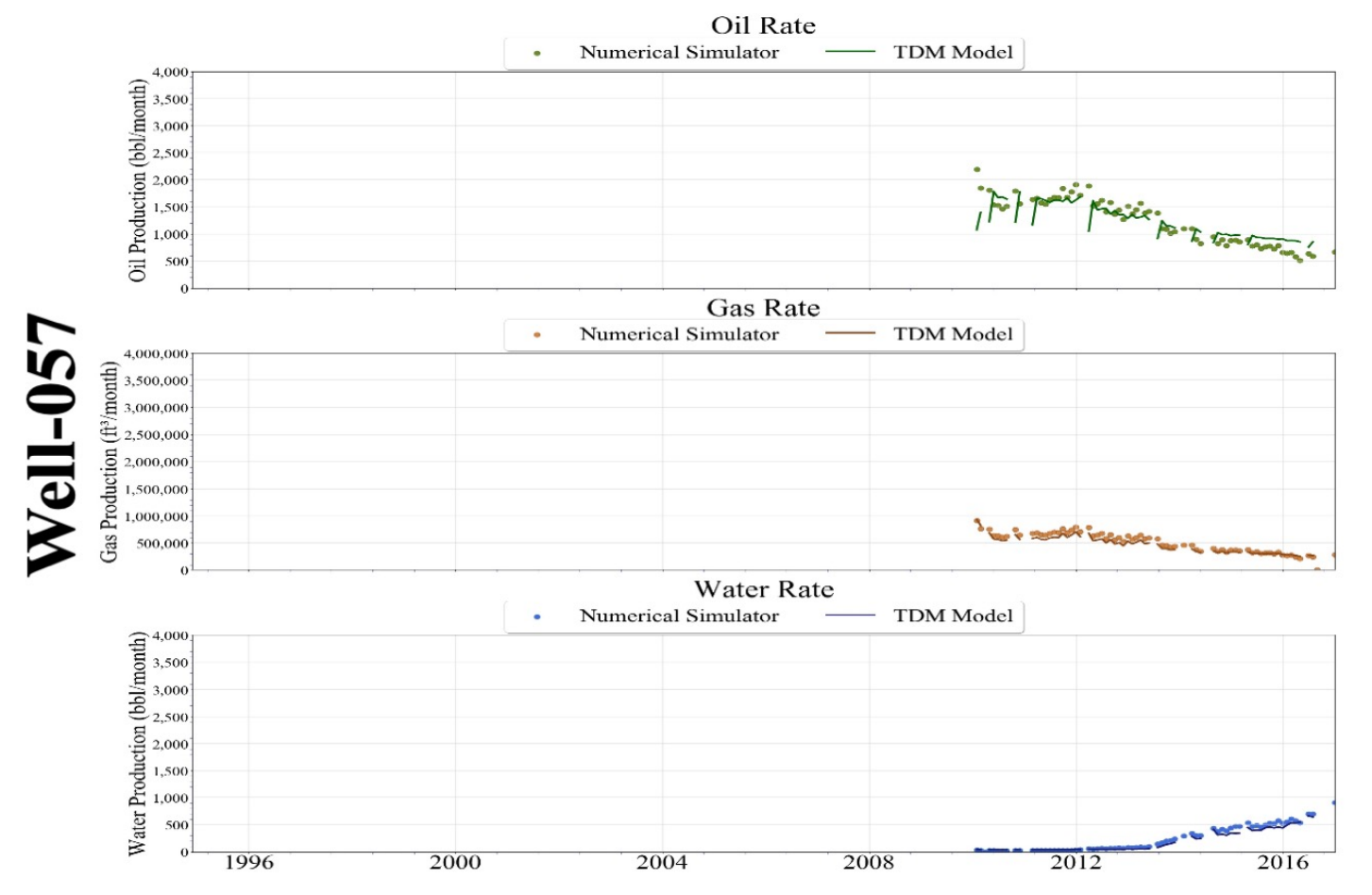

Figure 9-34: Scenario 1 - Well-057 Production History Match 


\subsubsection{Average History Match of Production}

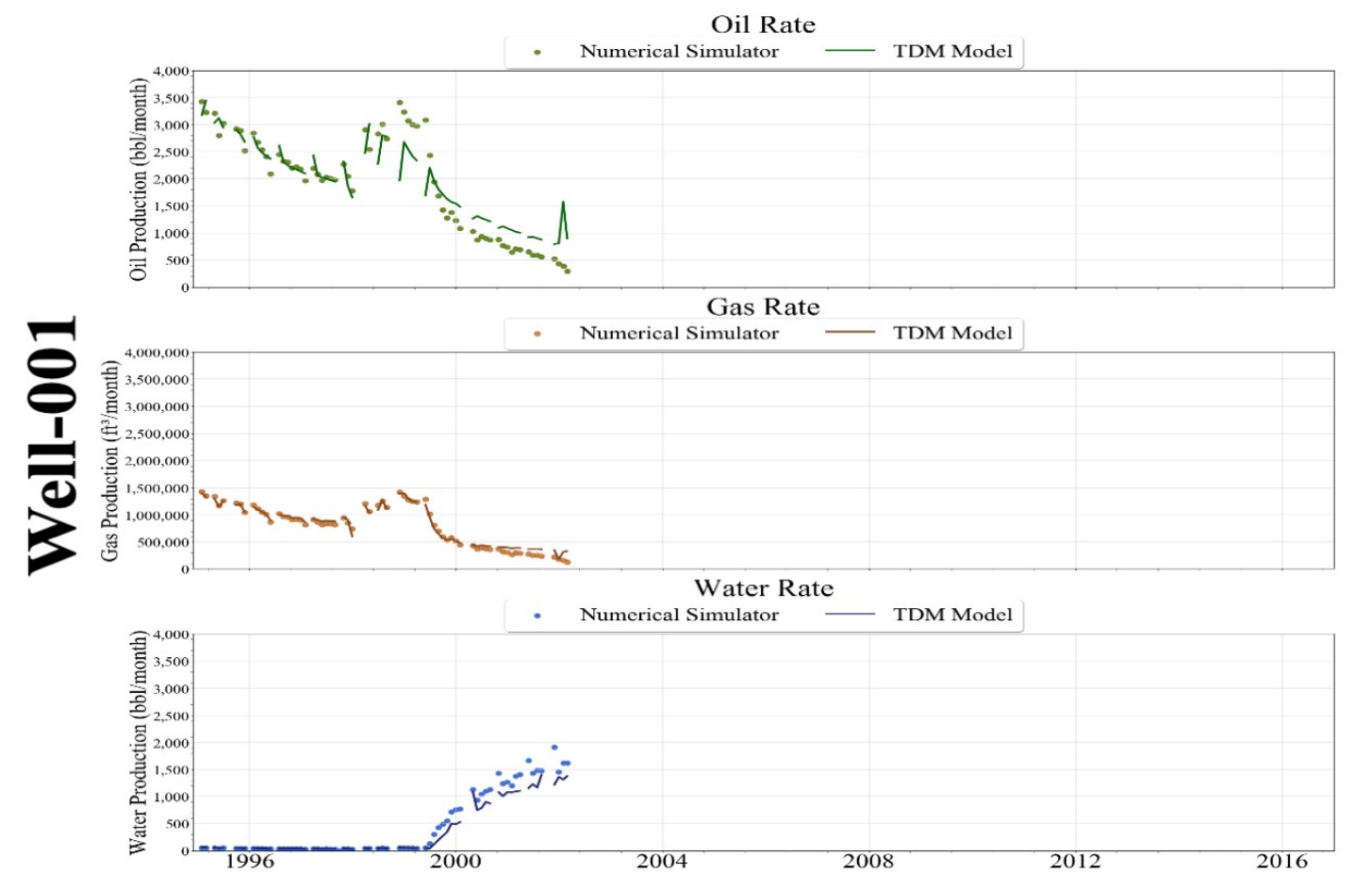

Figure 9-35: Scenario 1 - Well-001 Production History Match 


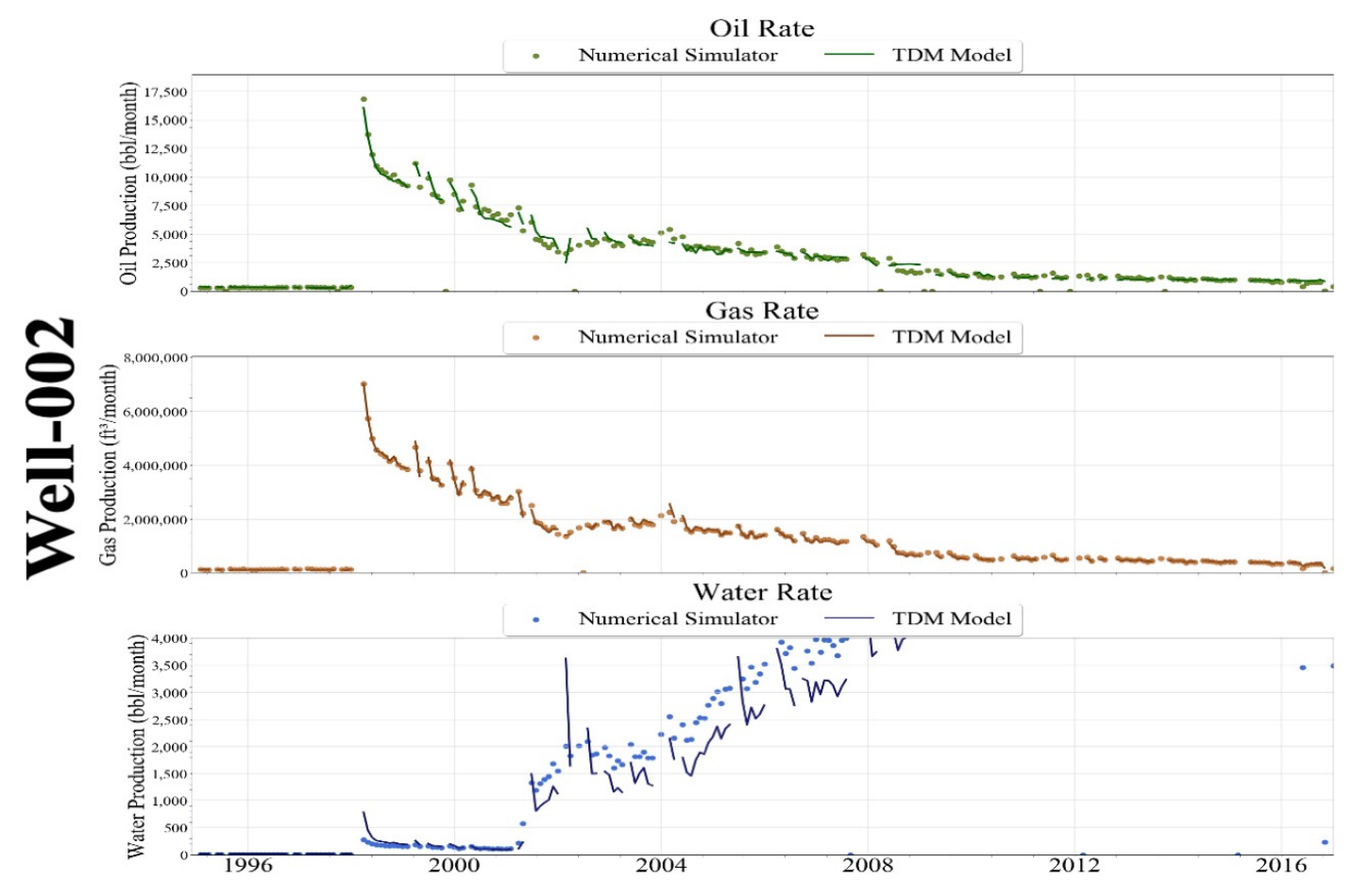

Figure 9-36: Scenario 1 - Well-002 Production History Match

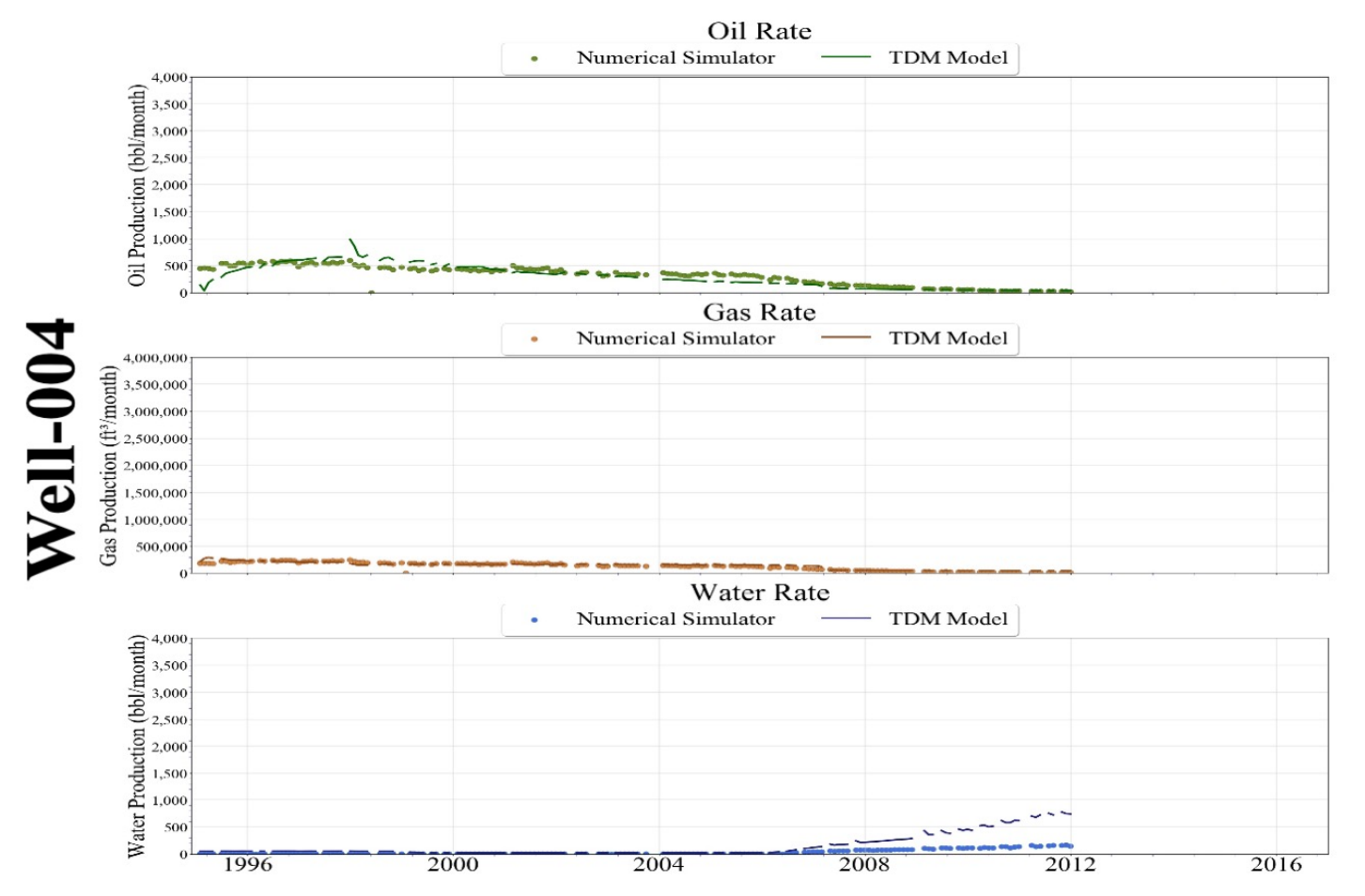

Figure 9-37: Scenario 1 - Well-004 Production History Match 


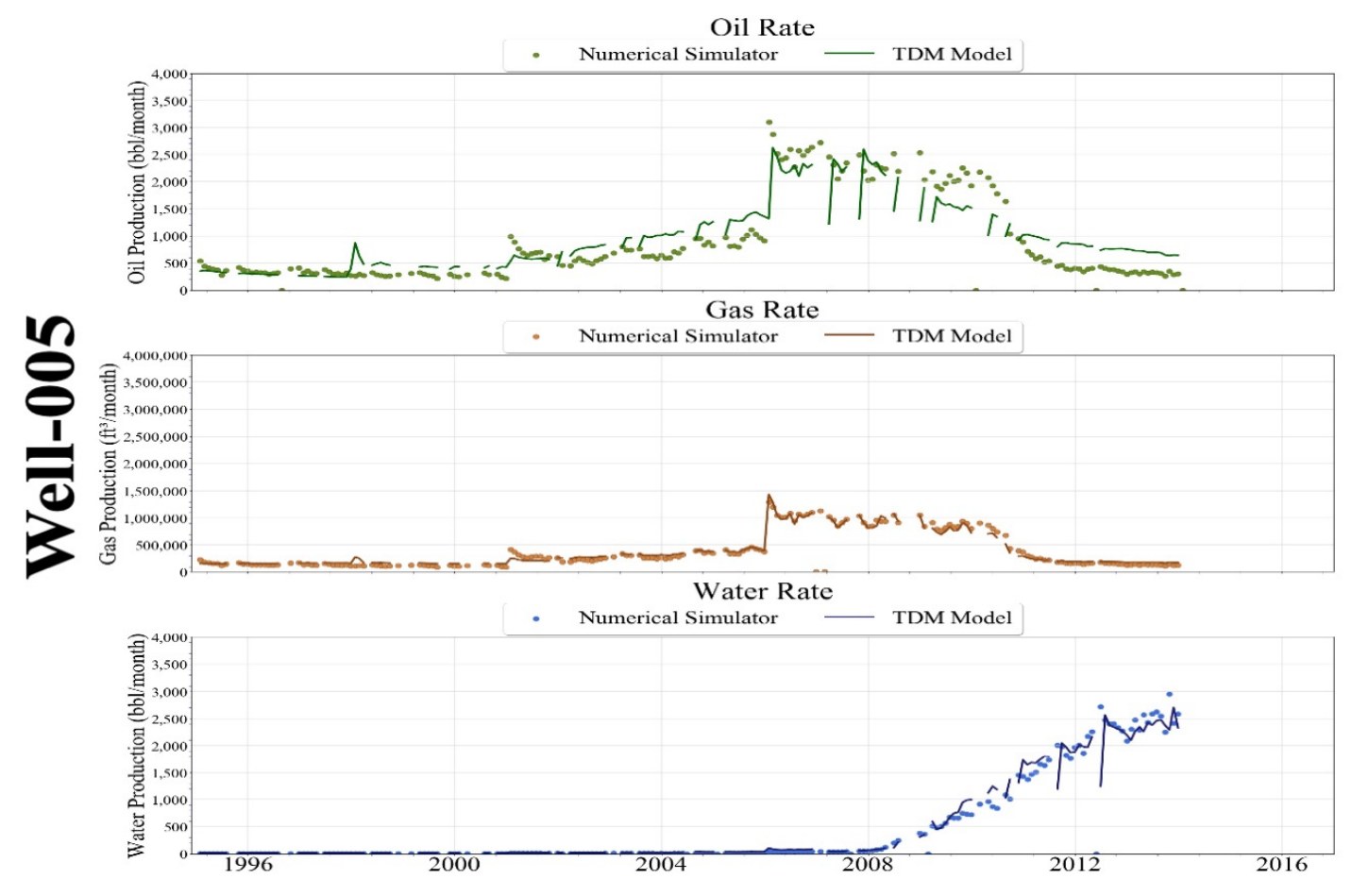

Figure 9-38: Scenario 1 - Well-005 Production History Match

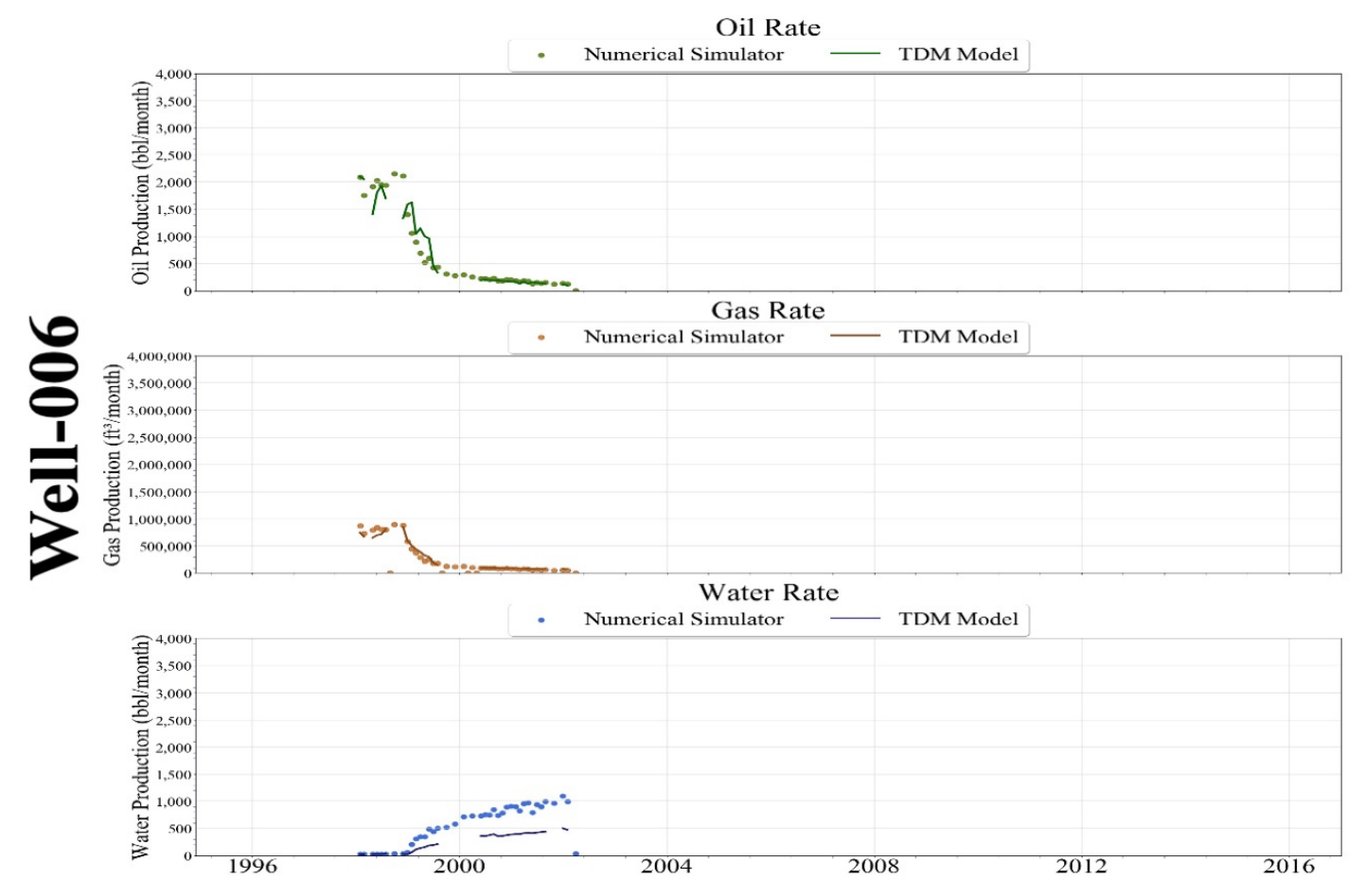

Figure 9-39: Scenario 1 - Well-006 Production History Match 


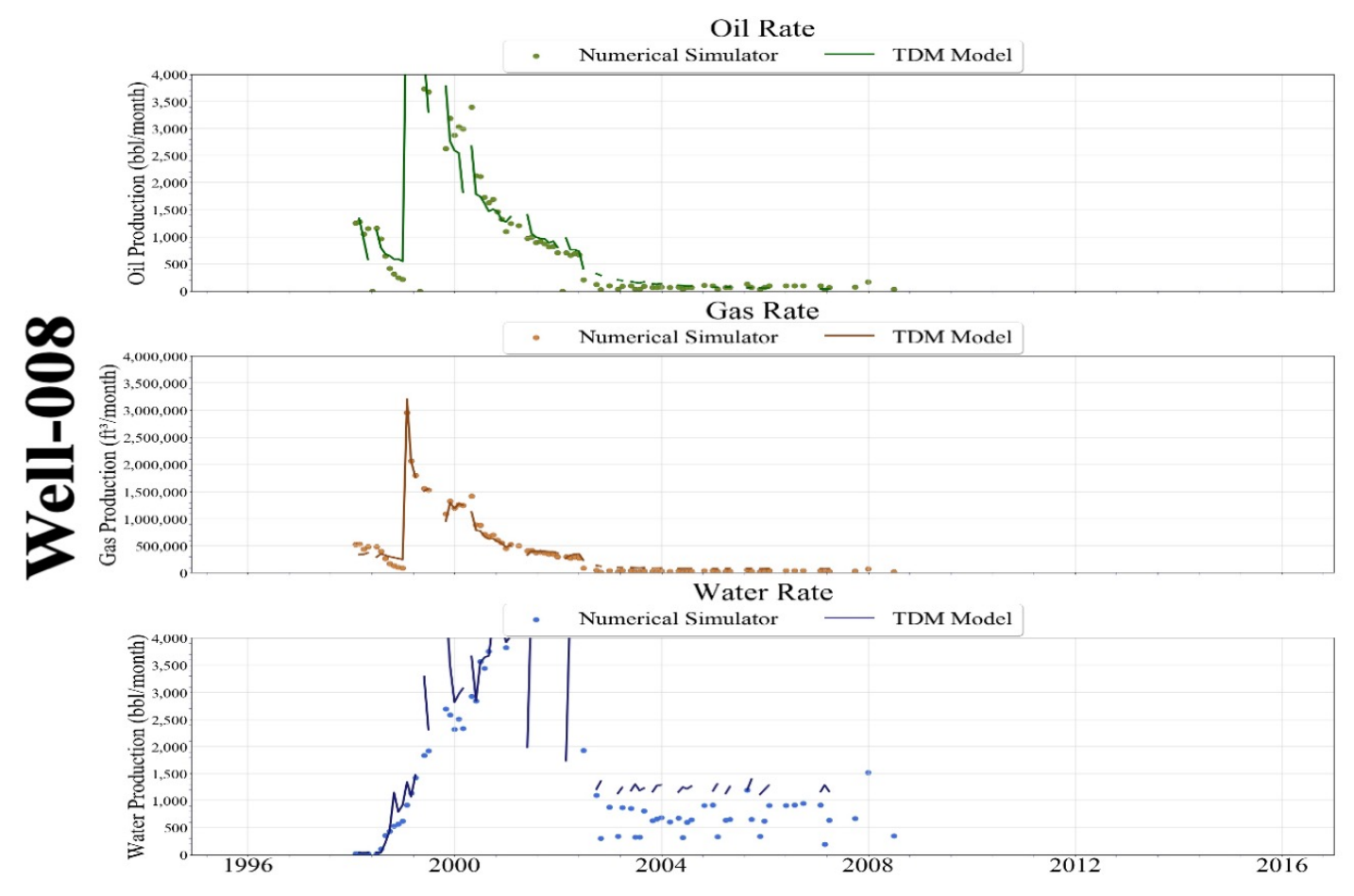

Figure 9-40: Scenario 1-Well-008 Production History Match

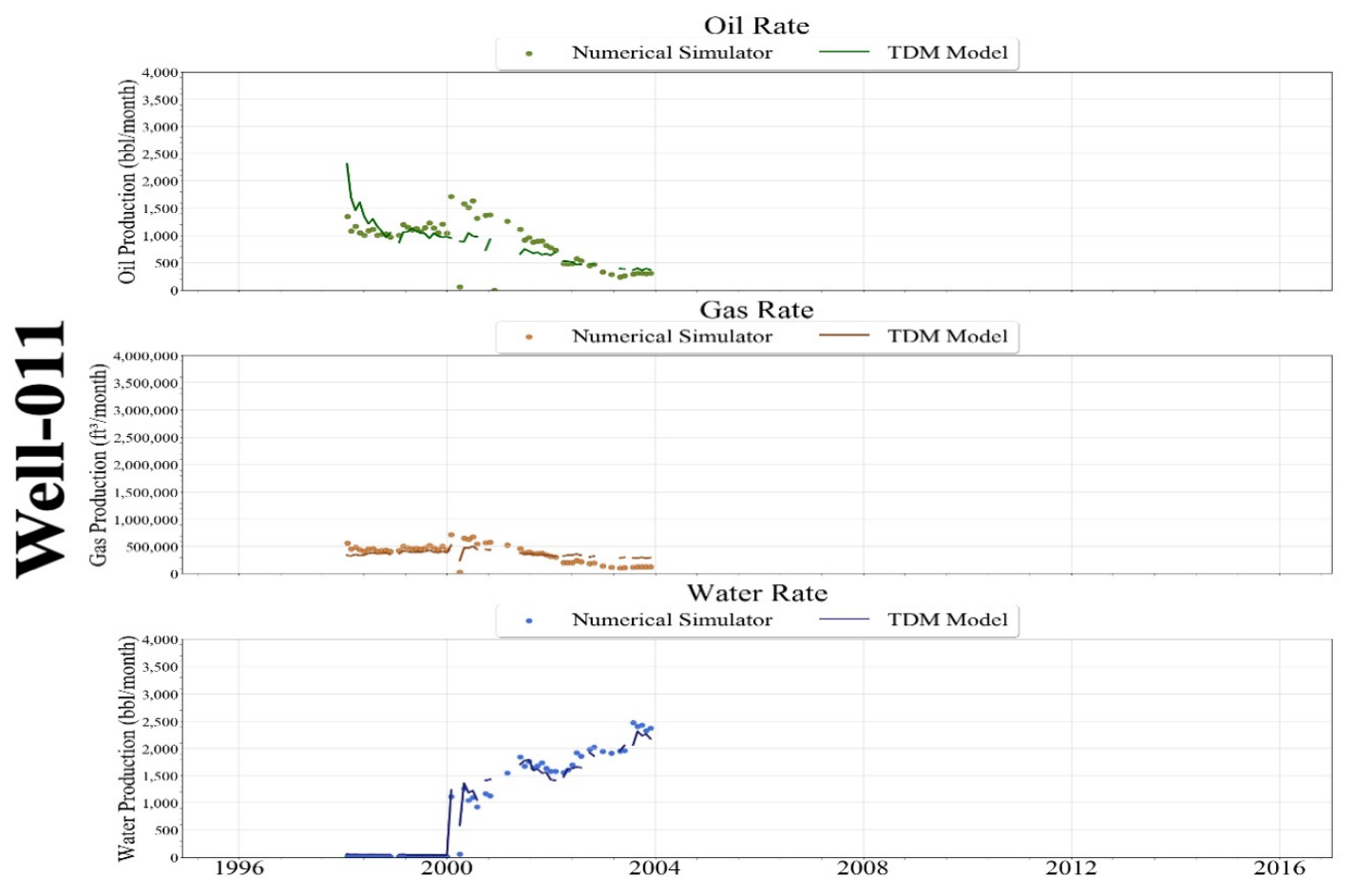

Figure 9-41: Scenario 1 - Well-011 Production History Match 


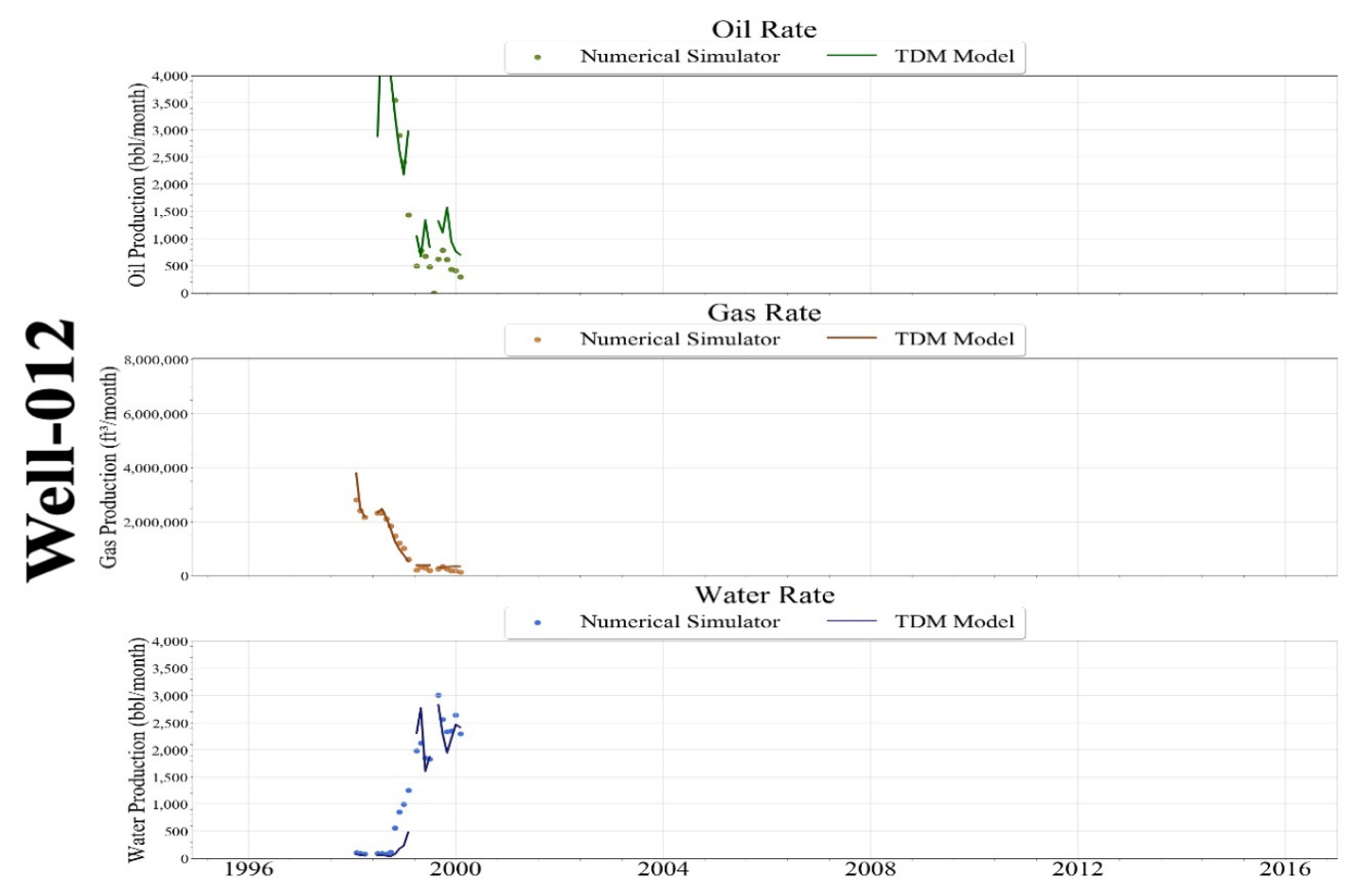

Figure 9-42: Scenario 1 - Well-012 Production History Match

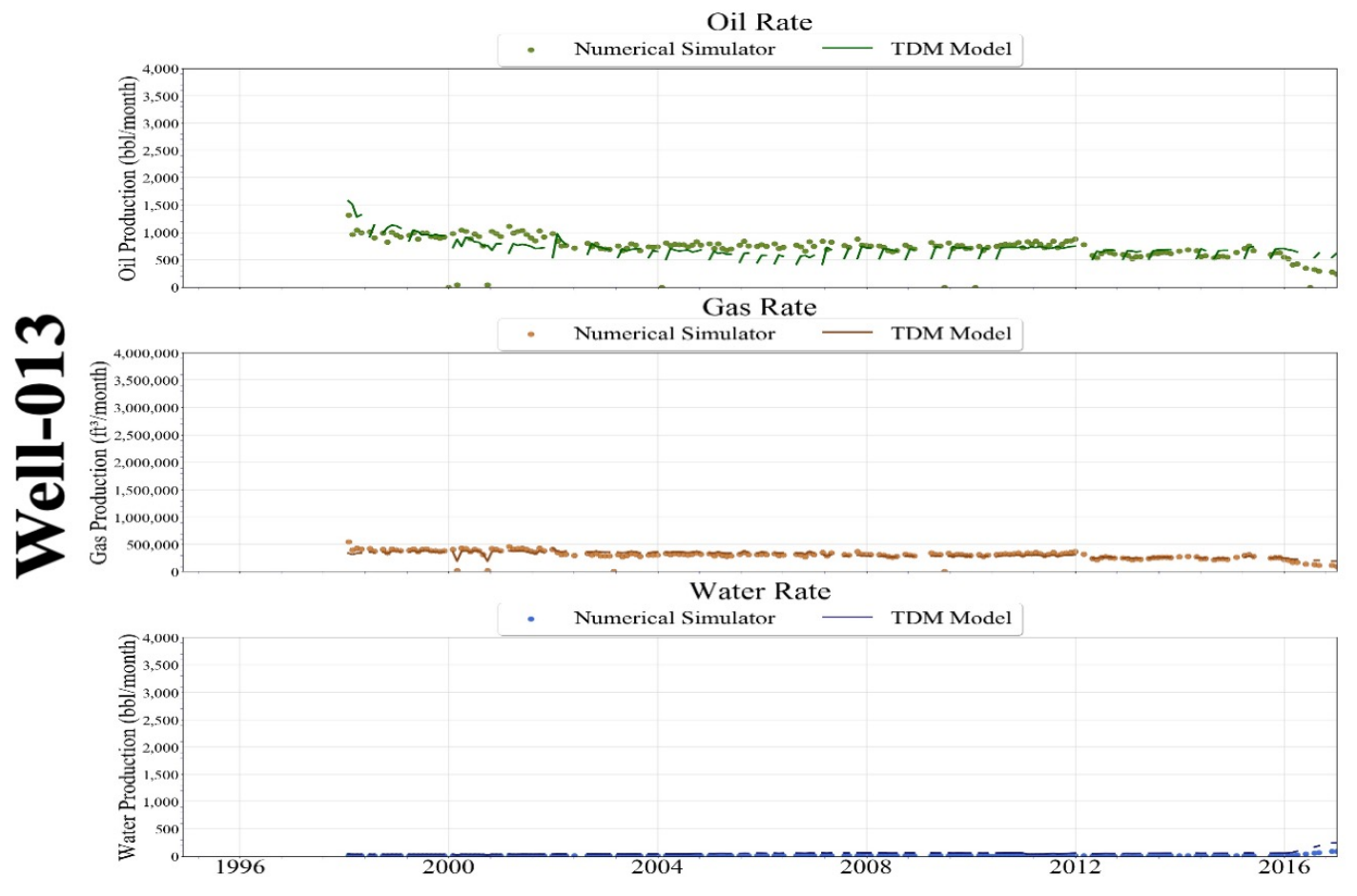

Figure 9-43: Scenario 1 - Well-013 Production History Match 


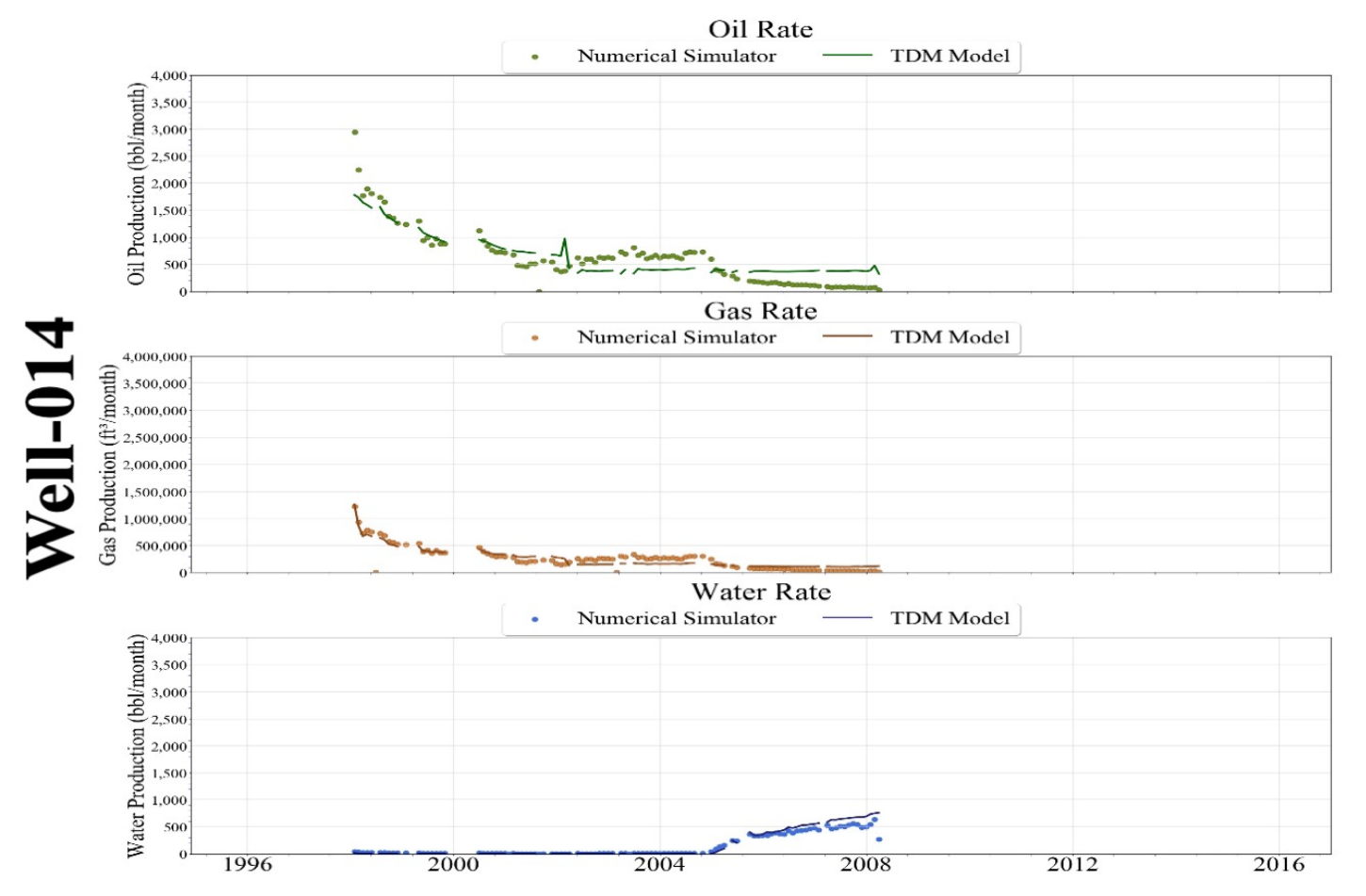

Figure 9-44: Scenario 1 - Well-014 Production History Match

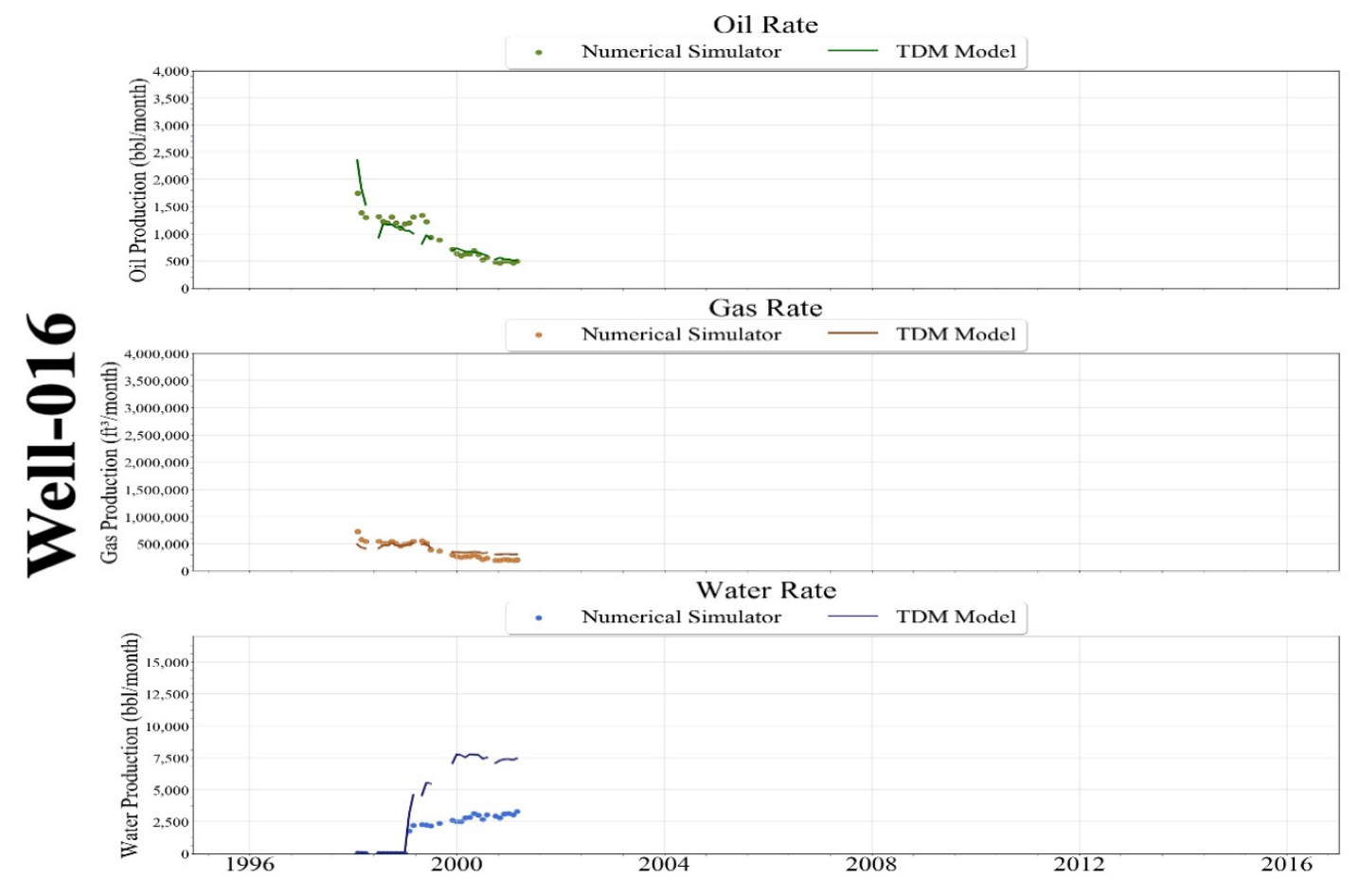

Figure 9-45: Scenario 1 - Well-016 Production History Match 


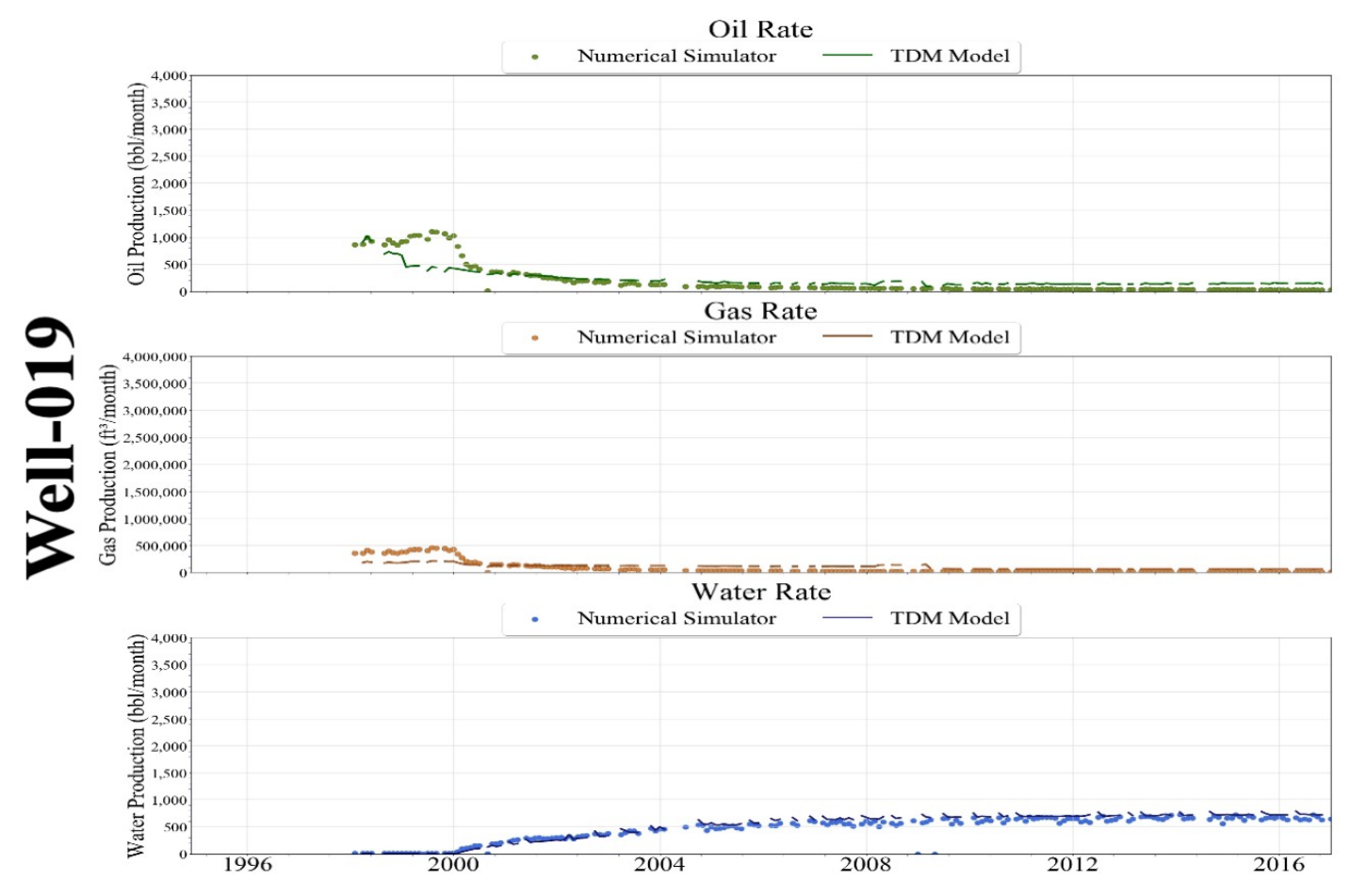

Figure 9-46: Scenario 1 - Well-019 Production History Match

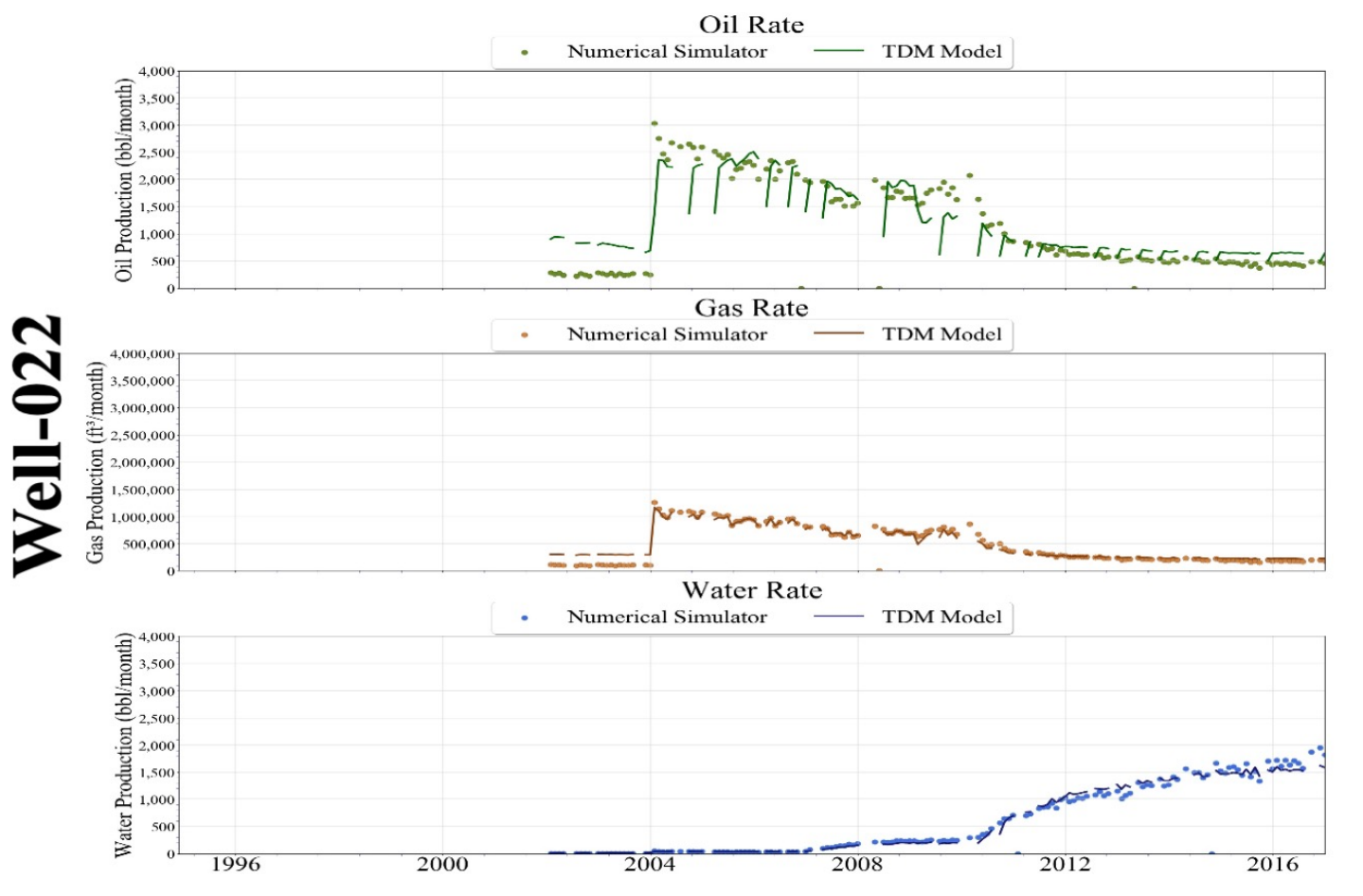

Figure 9-47: Scenario 1 - Well-022 Production History Match 


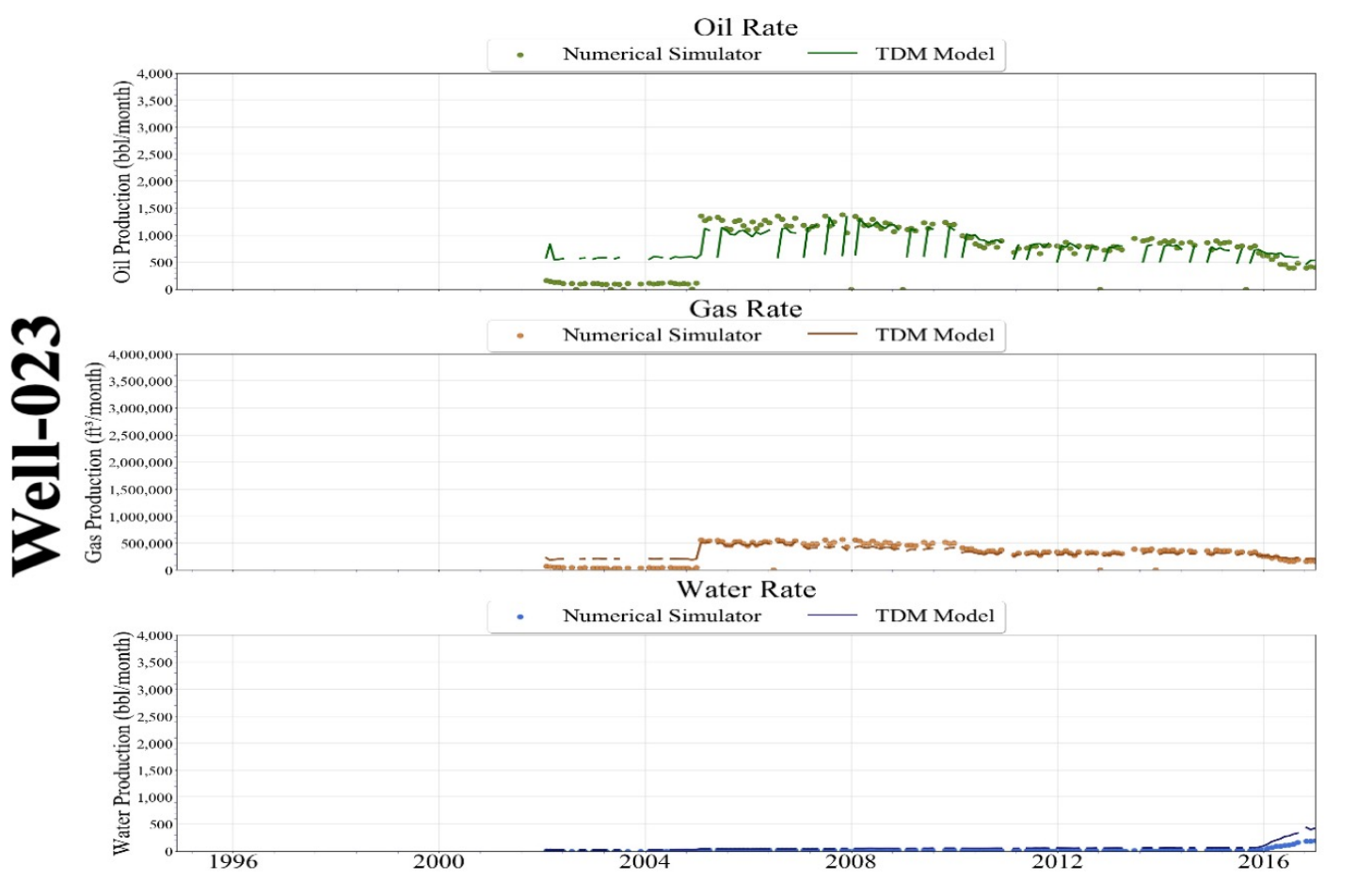

Figure 9-48: Scenario 1 - Well-023 Production History Match

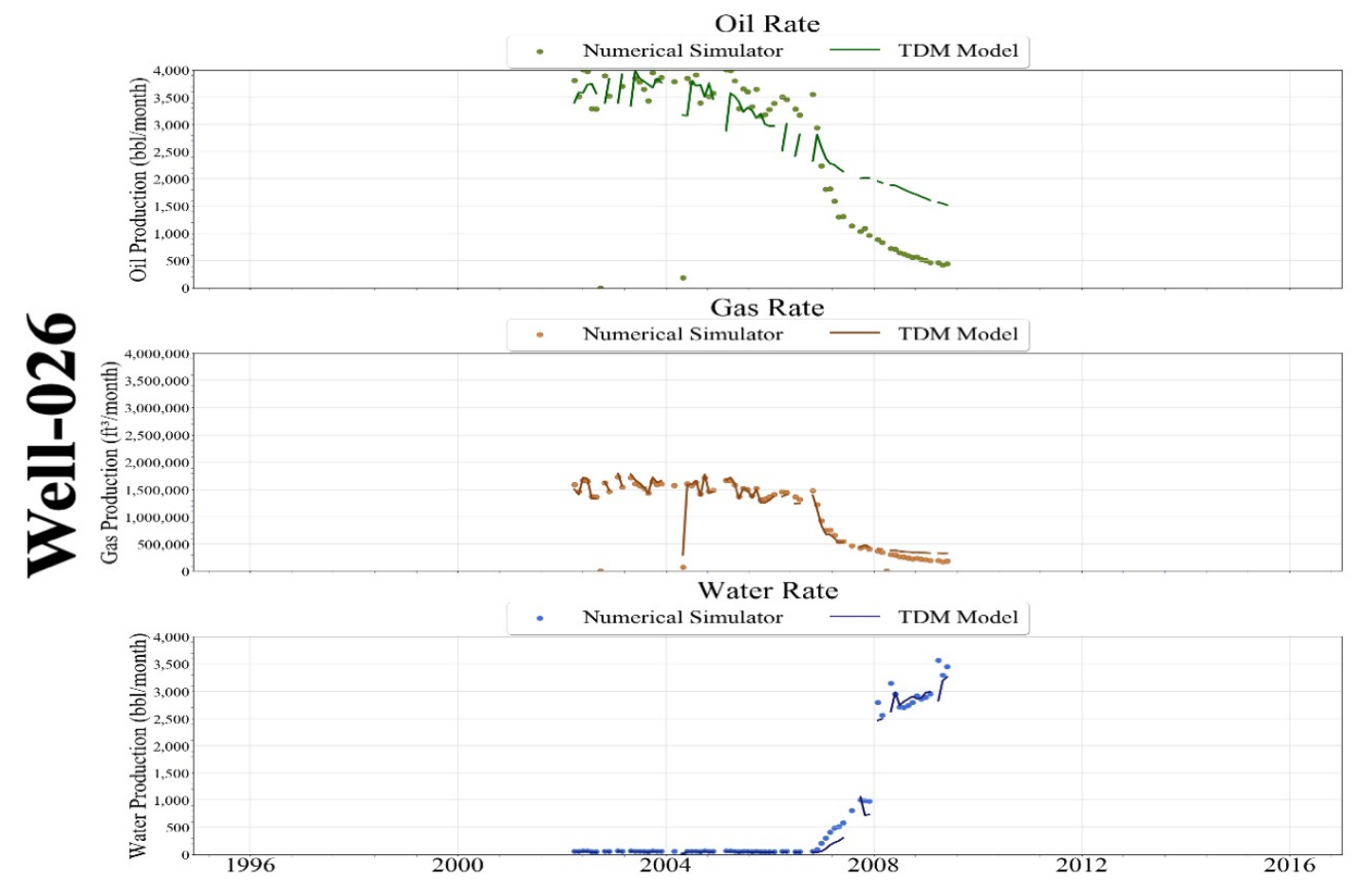

Figure 9-49: Scenario 1 - Well-026 Production History Match 


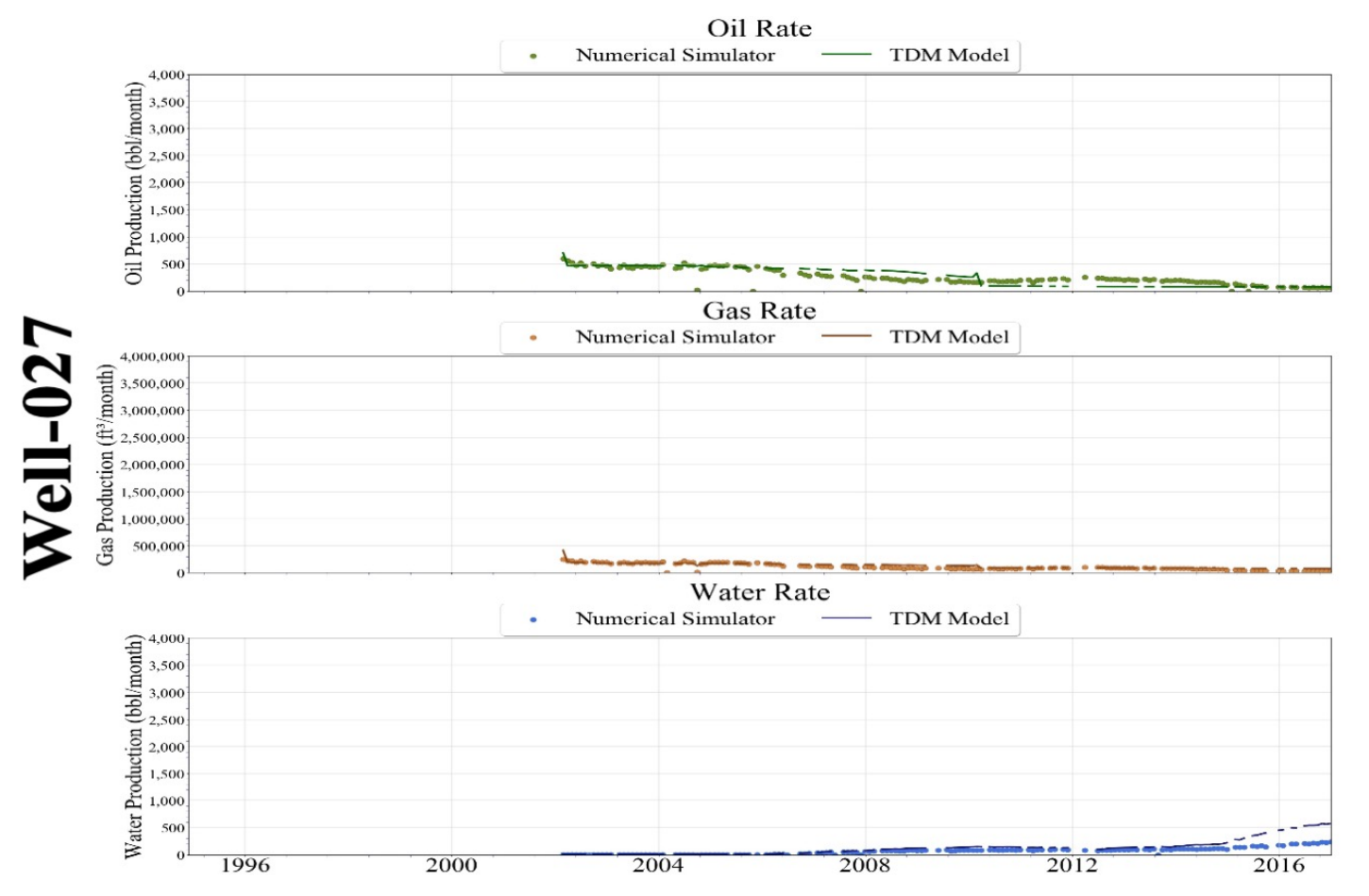

Figure 9-50: Scenario 1 - Well-027 Production History Match

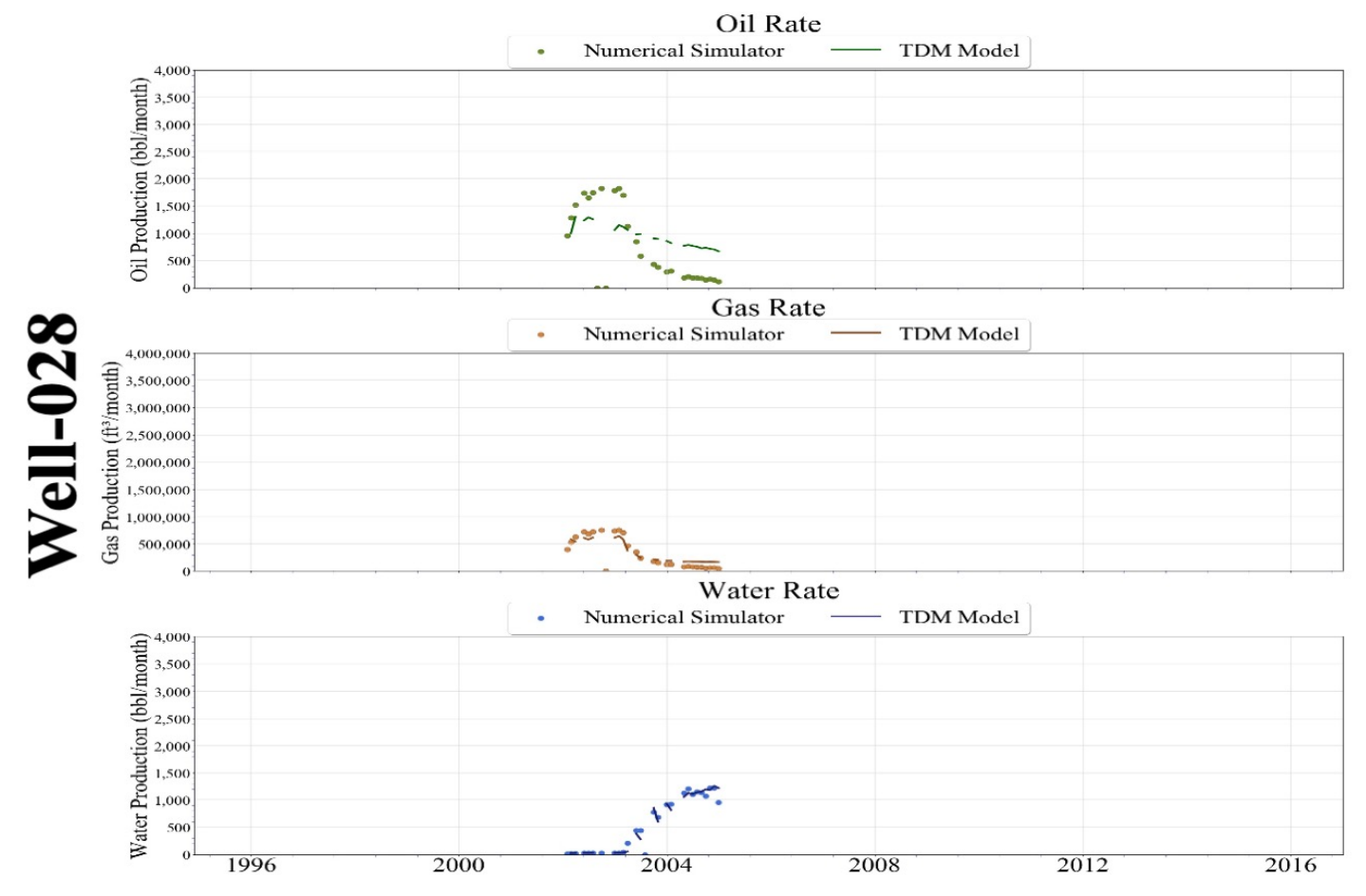

Figure 9-51: Scenario 1-Well-028 Production History Match 


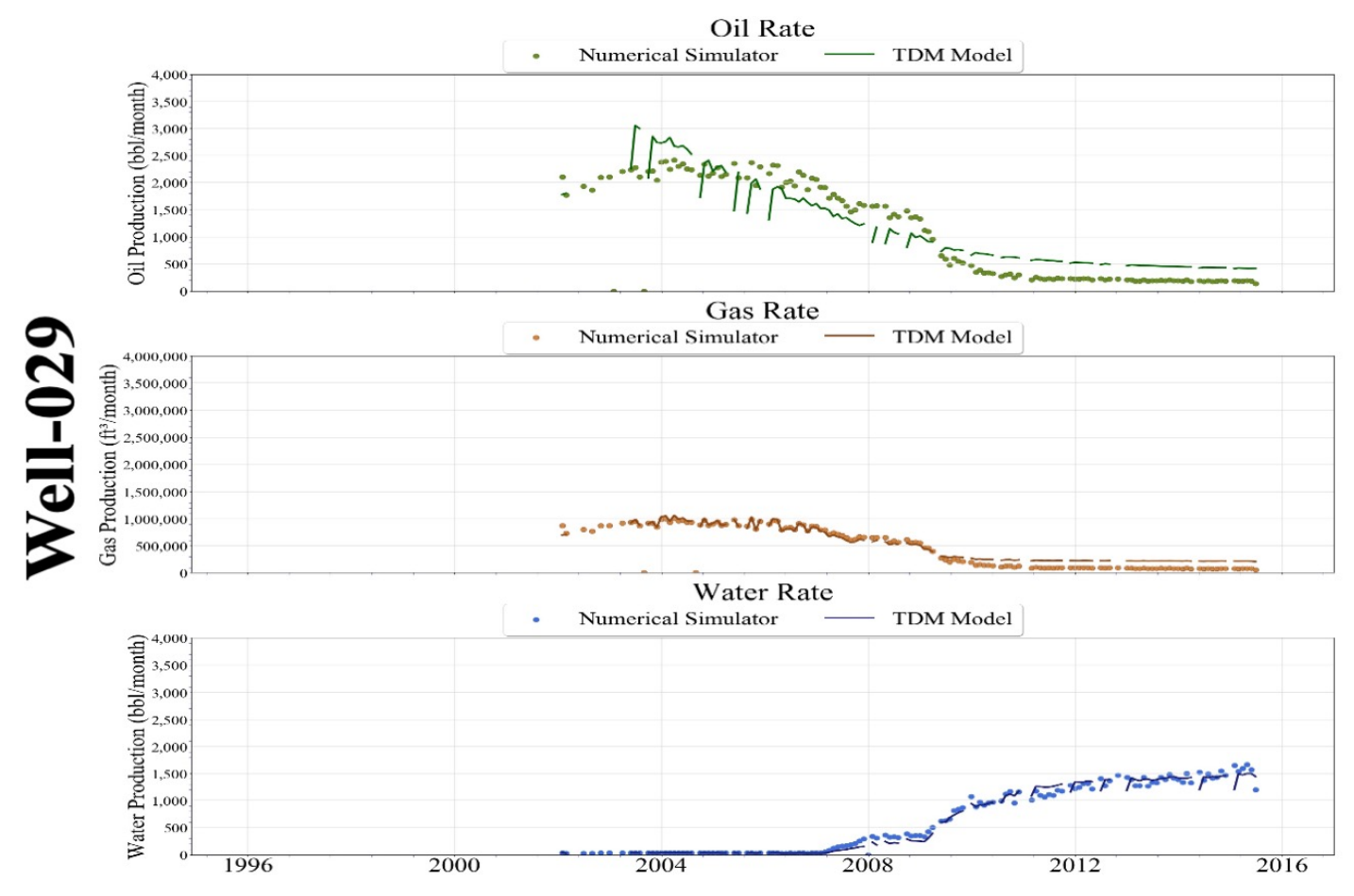

Figure 9-52: Scenario 1 - Well-029 Production History Match

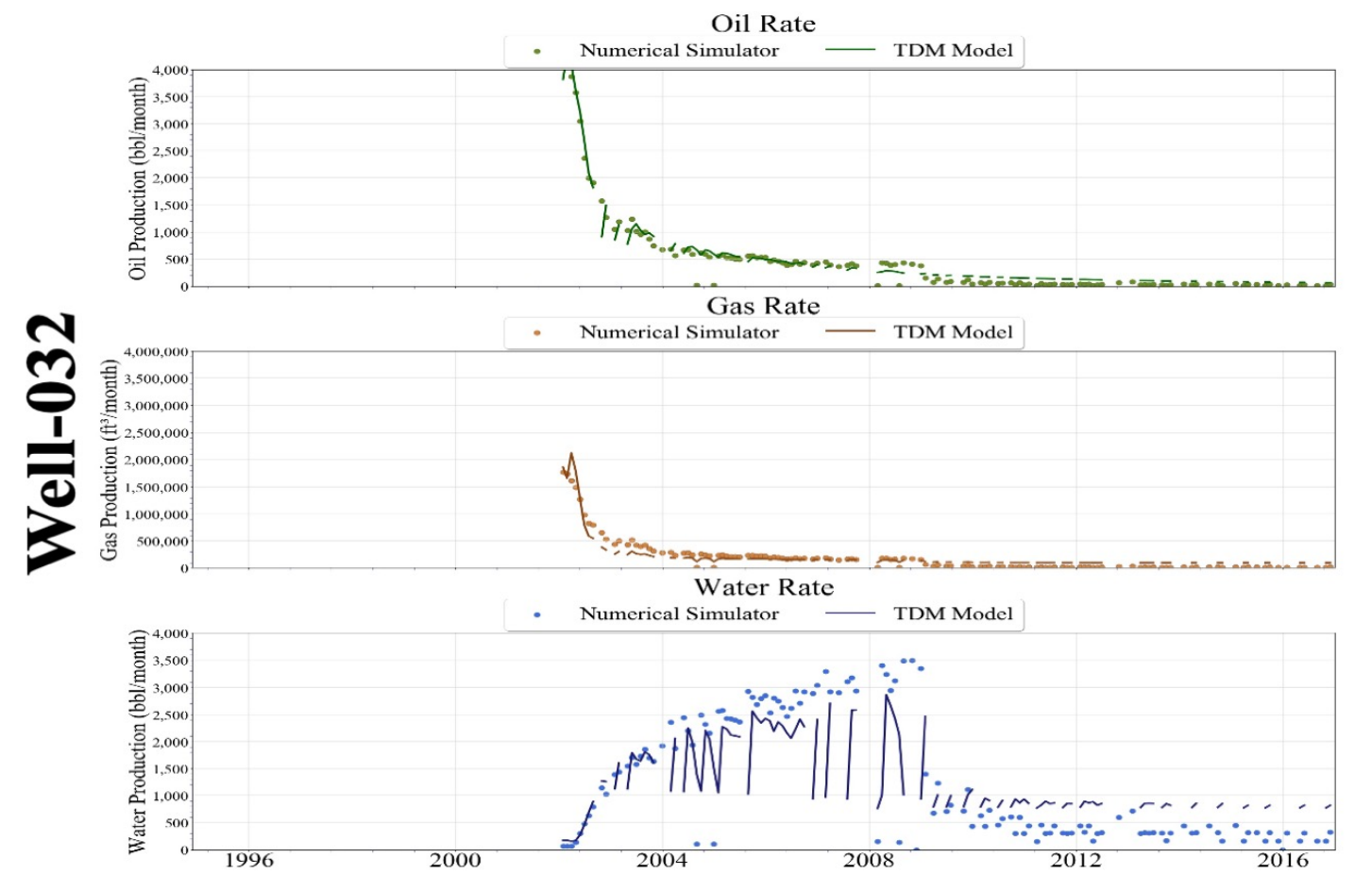

Figure 9-53: Scenario 1 - Well-032 Production History Match 


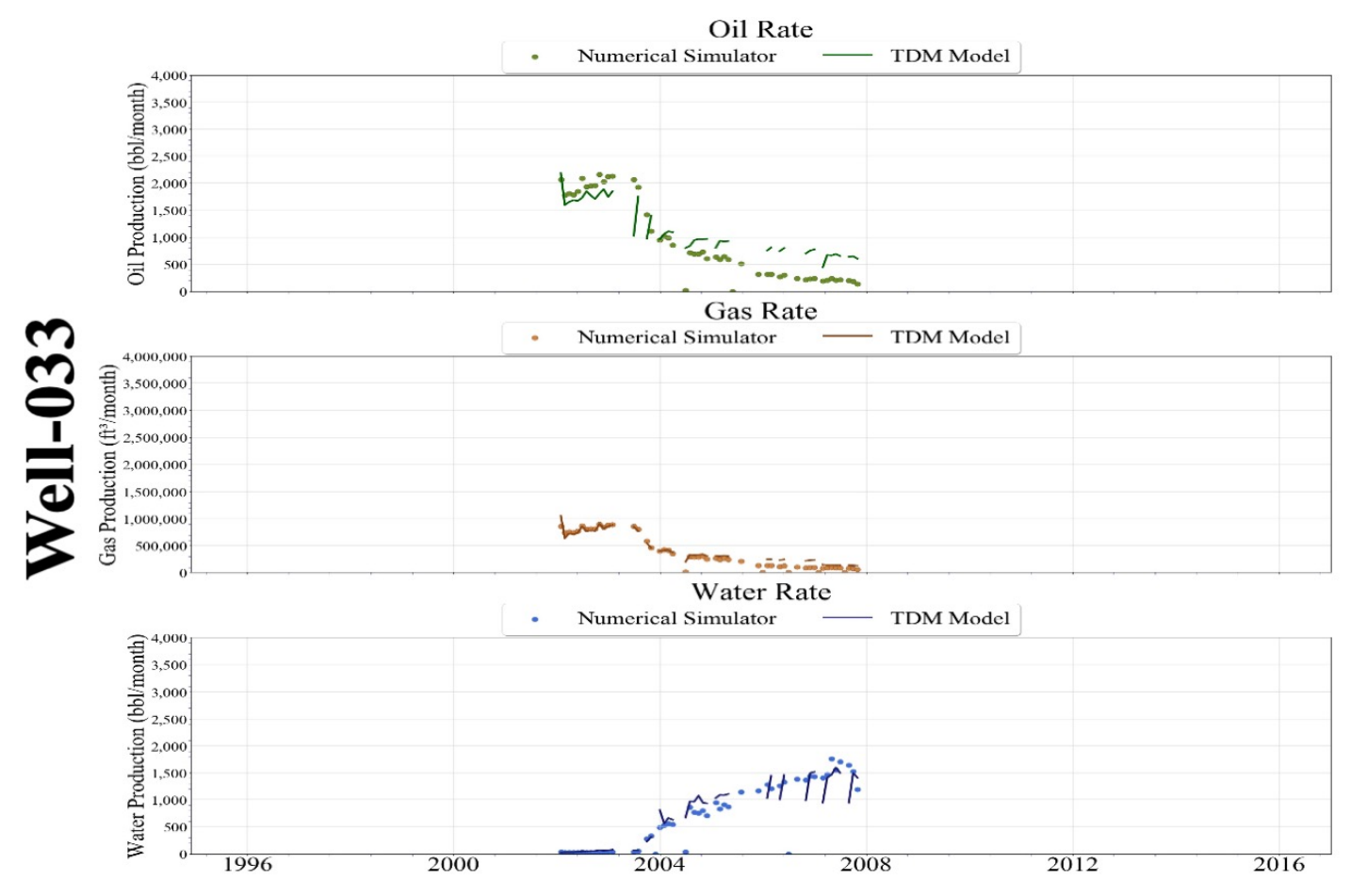

Figure 9-54: Scenario 1 - Well-033 Production History Match

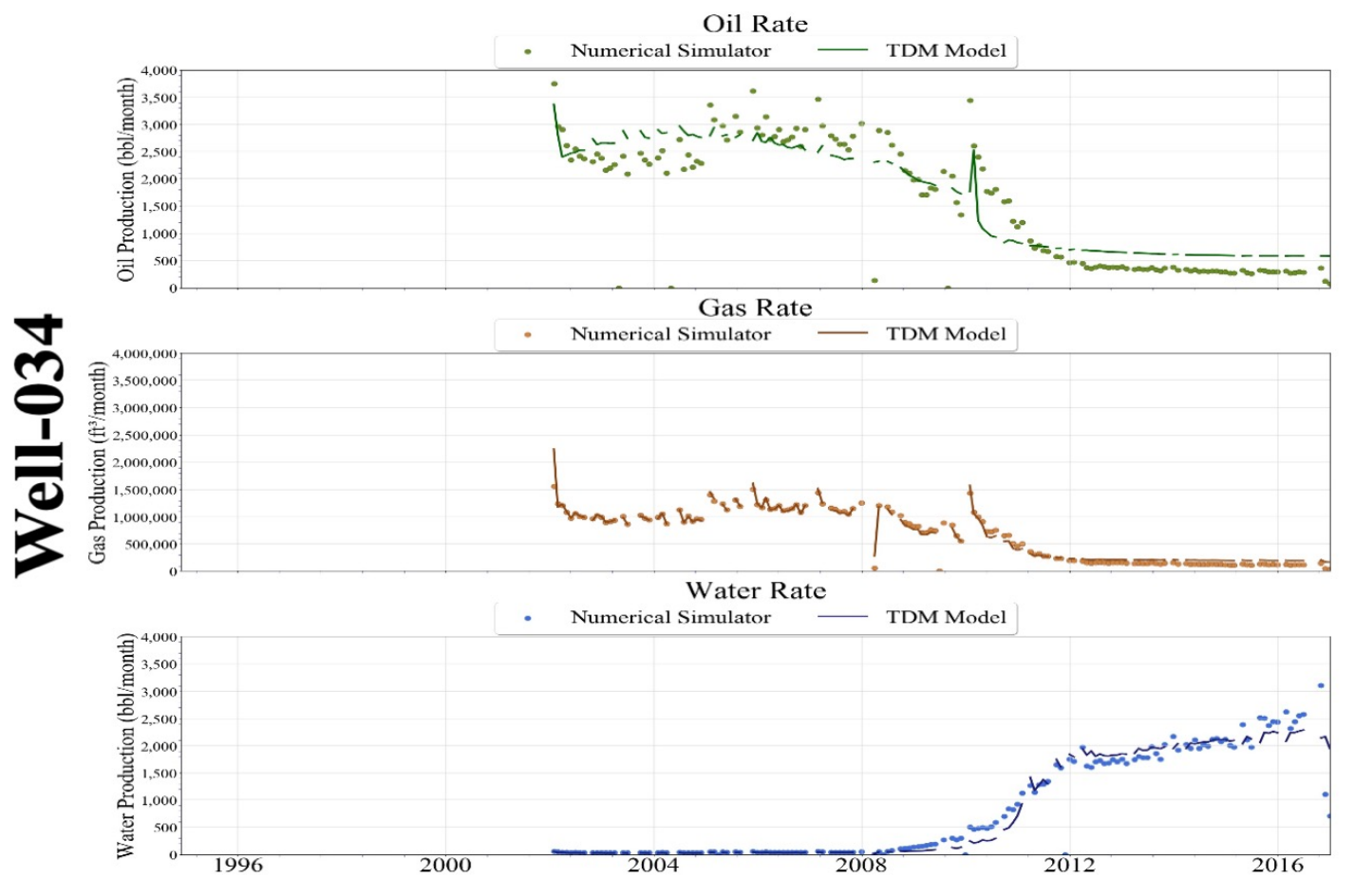

Figure 9-55: Scenario 1 - Well-034 Production History Match 


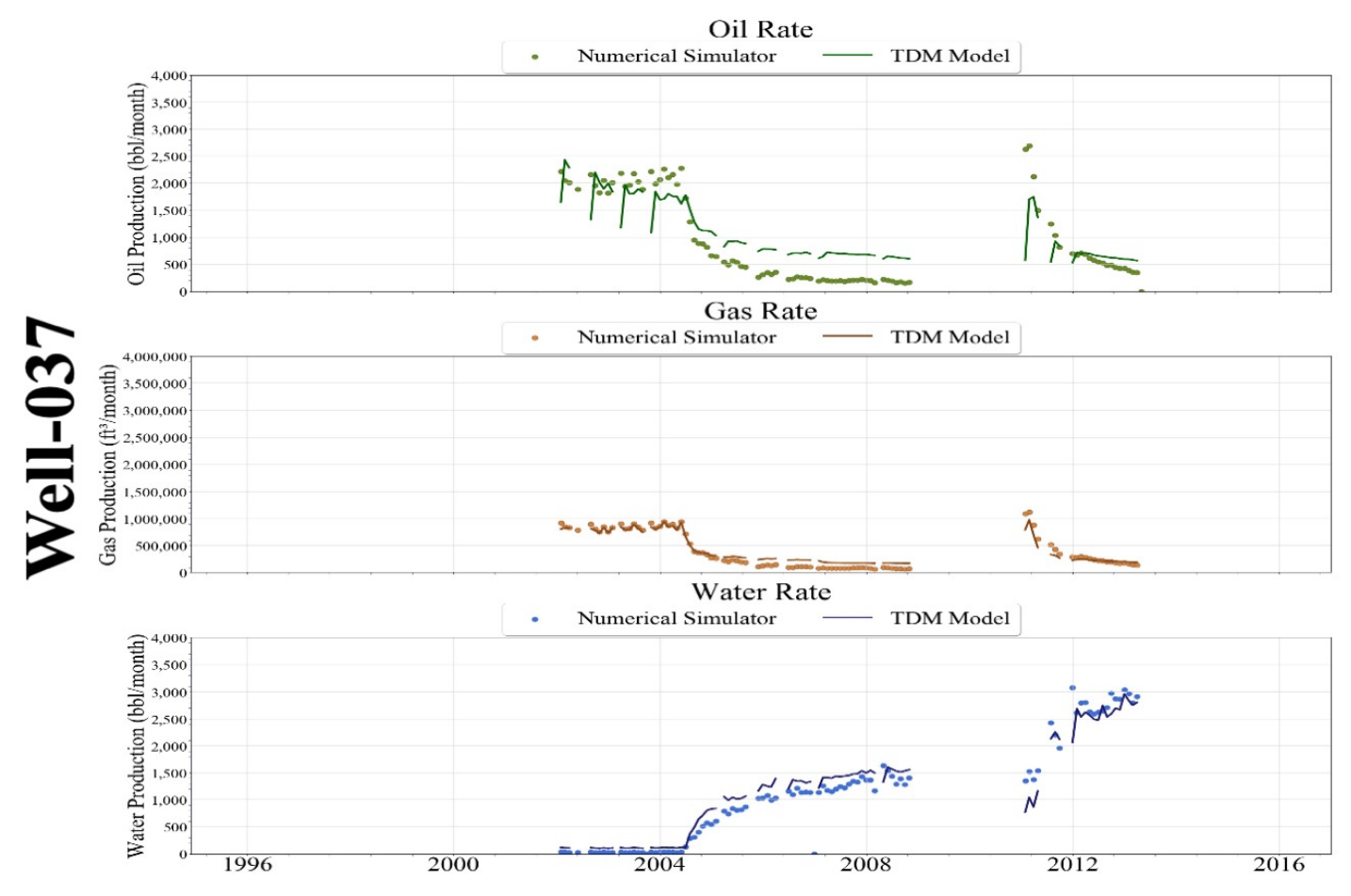

Figure 9-56: Scenario 1 - Well-037 Production History Match

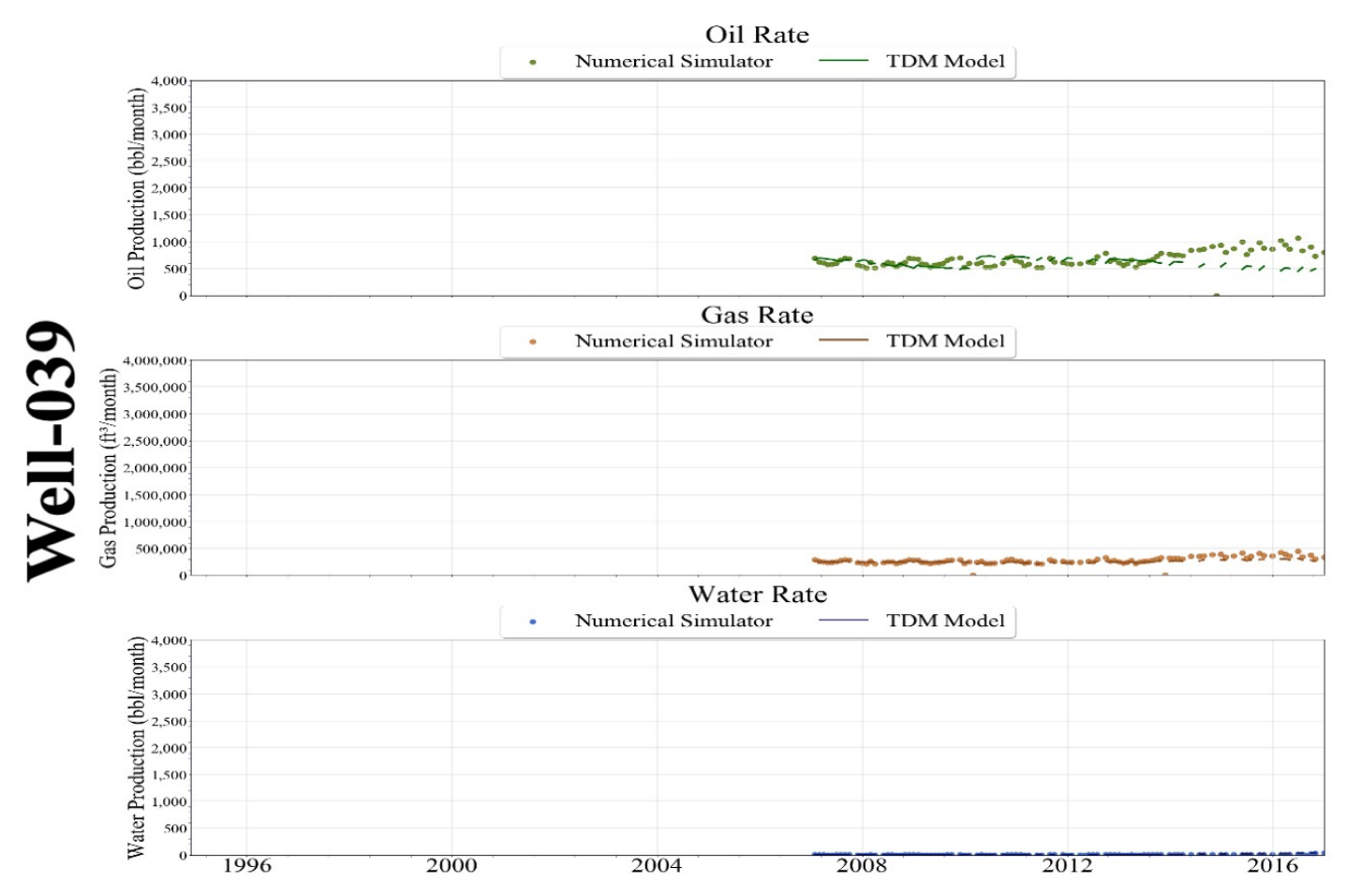

Figure 9-57: Scenario 1 - Well-039 Production History Match 


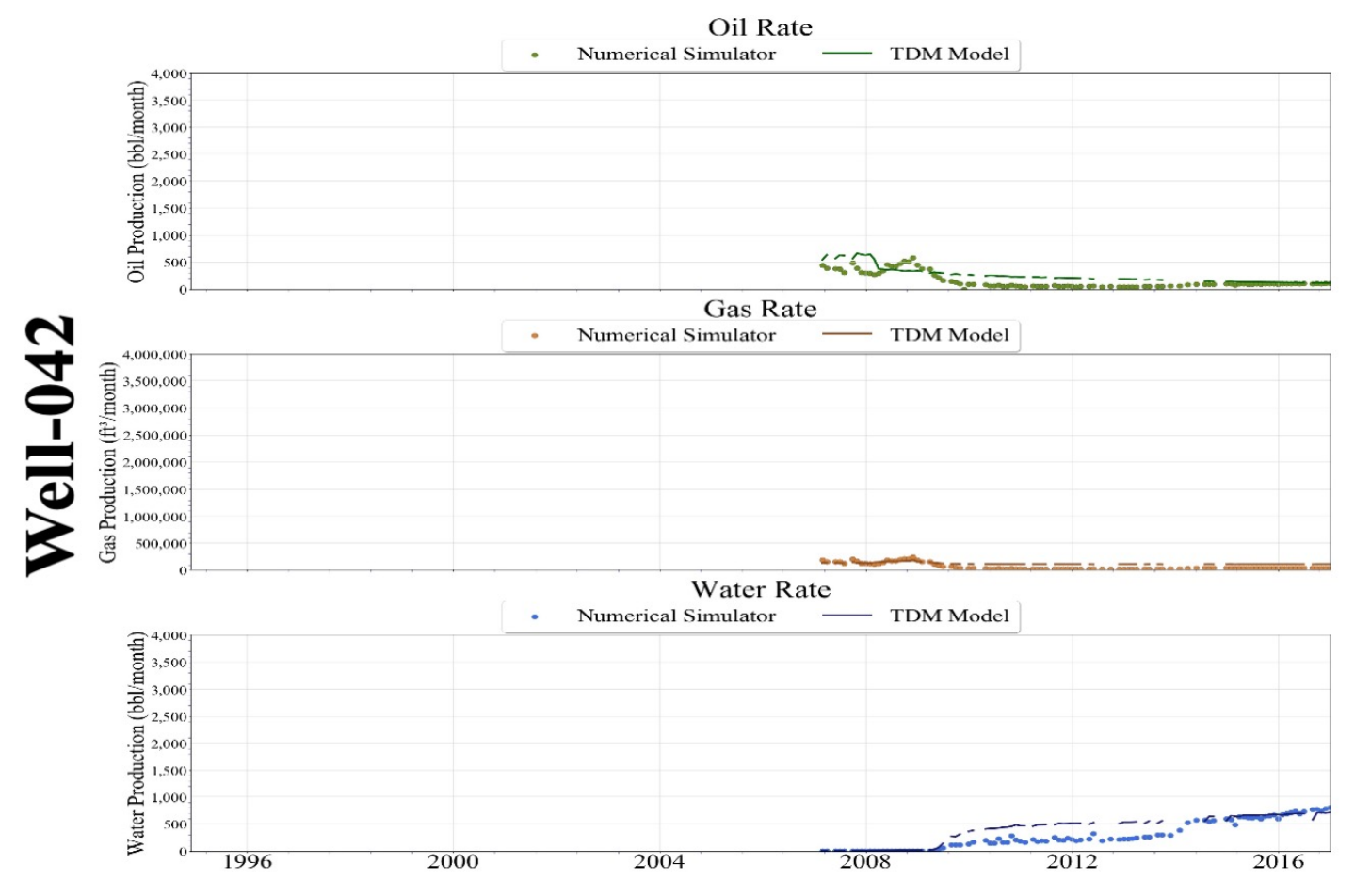

Figure 9-58: Scenario 1 - Well-042 Production History Match

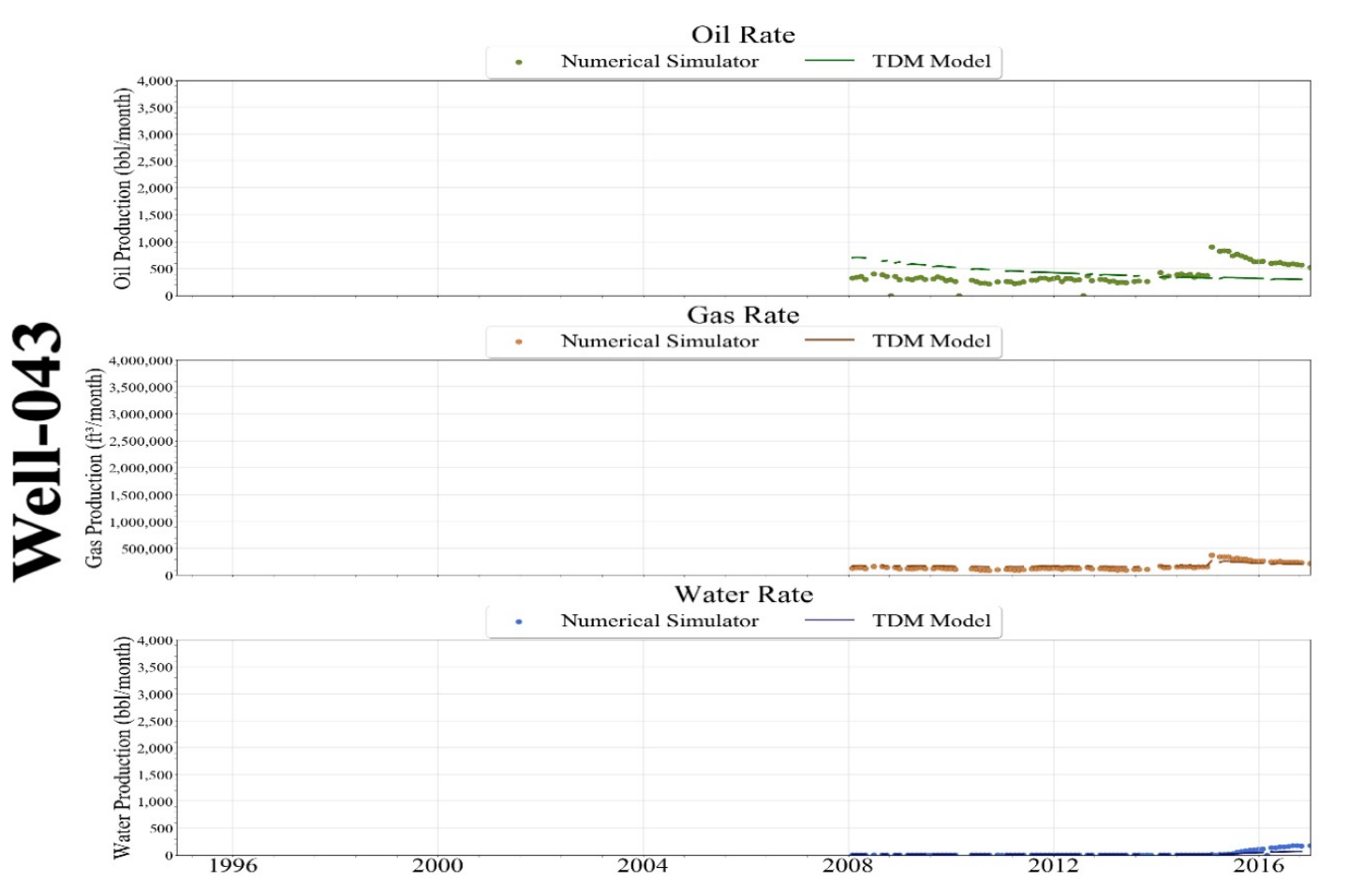

Figure 9-59: Scenario 1 - Well-043 Production History Match 


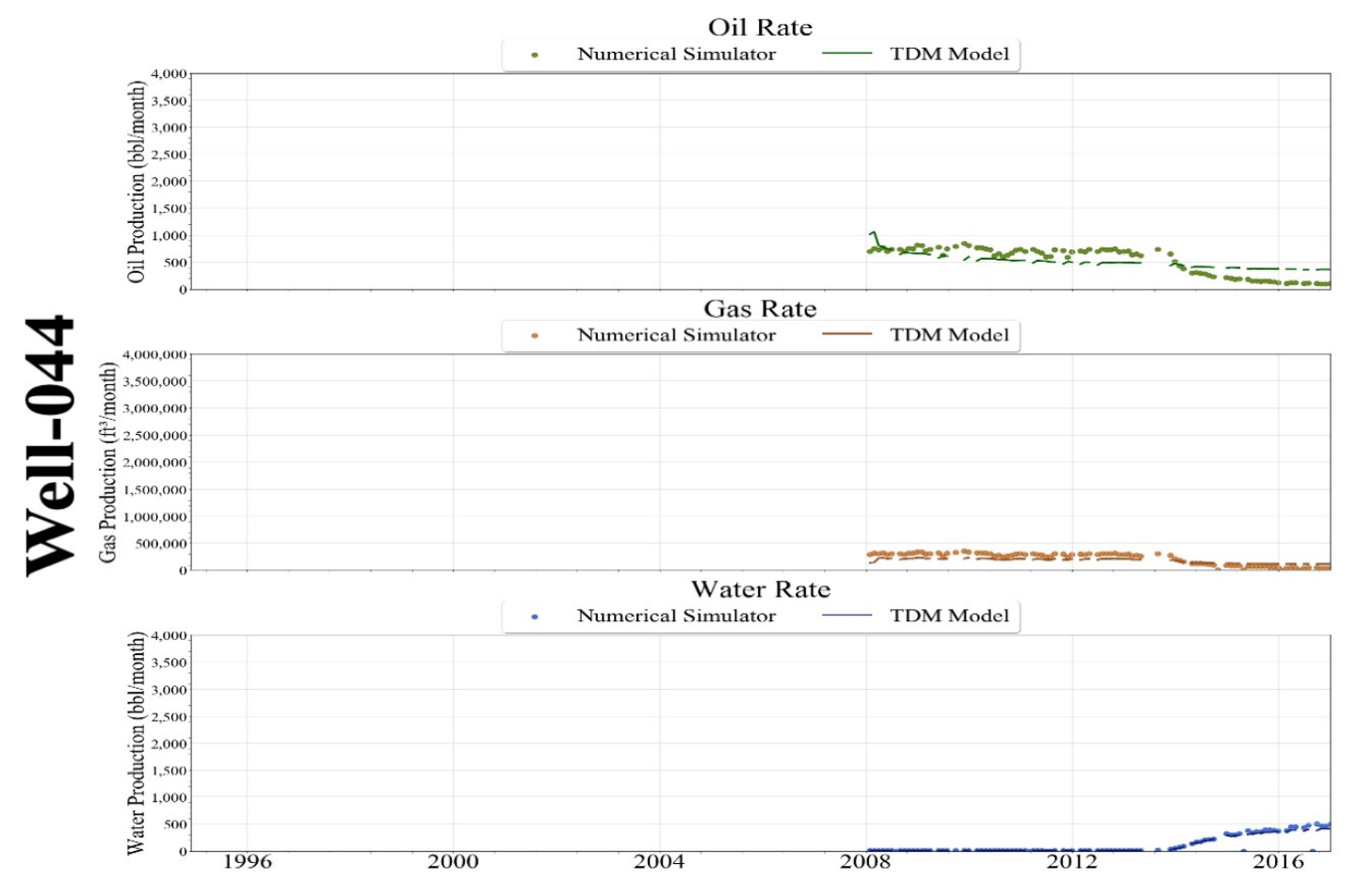

Figure 9-60: Scenario 1 - Well-044 Production History Match

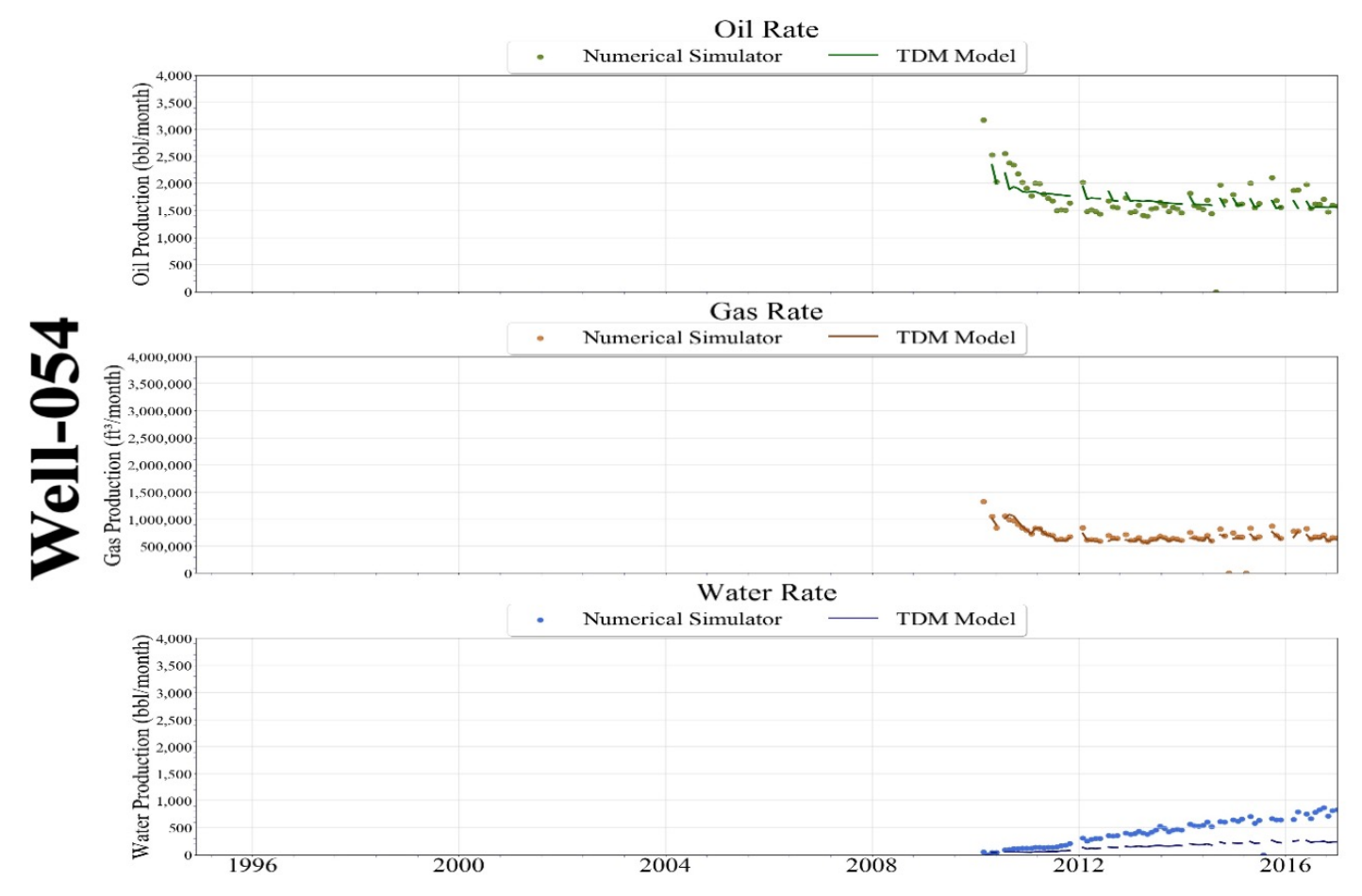

Figure 9-61: Scenario 1 - Well-054 Production History Match 


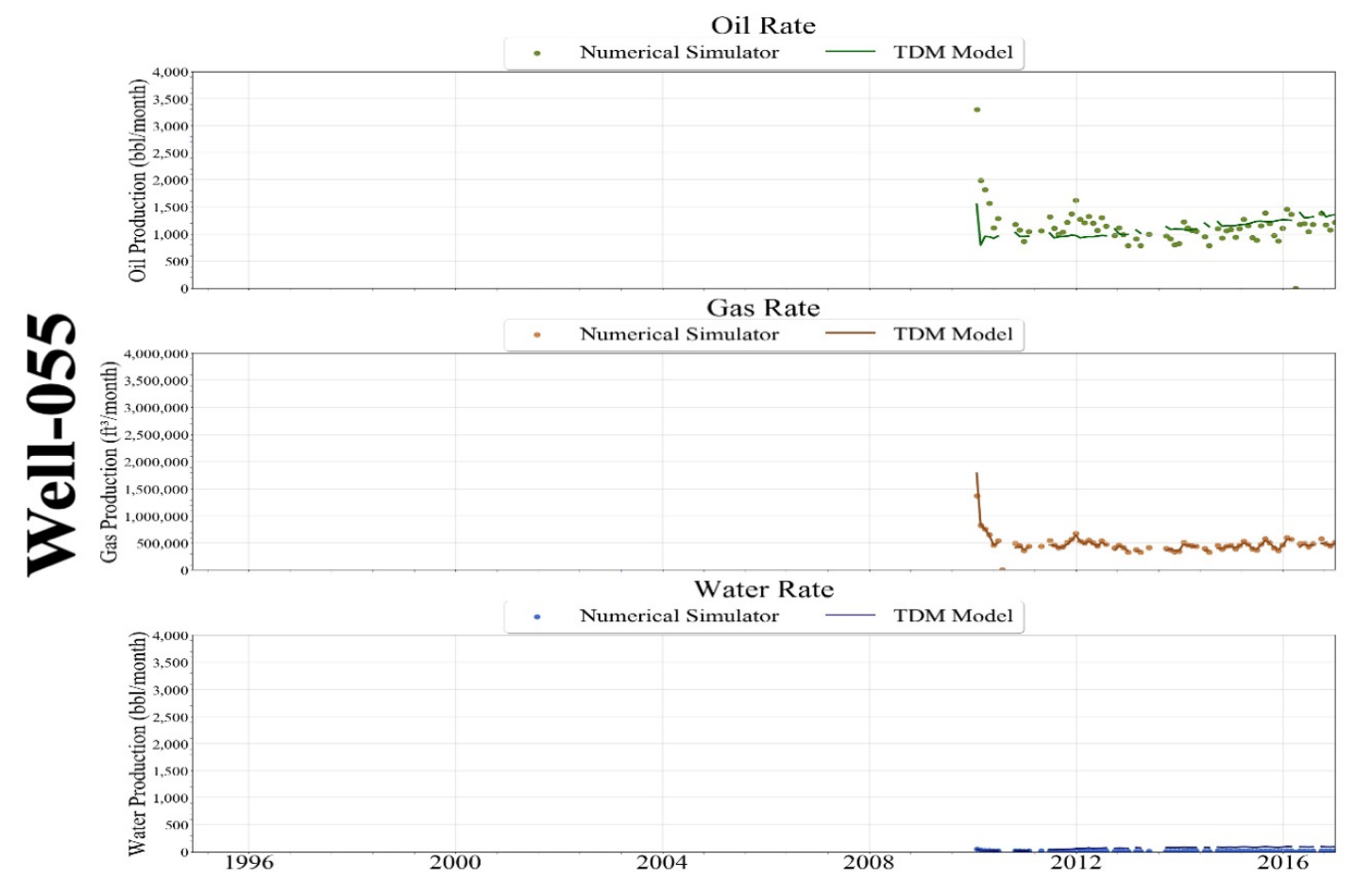

Figure 9-62: Scenario 1 - Well-055 Production History Match 


\subsubsection{Poor History Match of Production}

$2 \%$ of the wells had poor history match when compared to the actual numerical simulation production data.

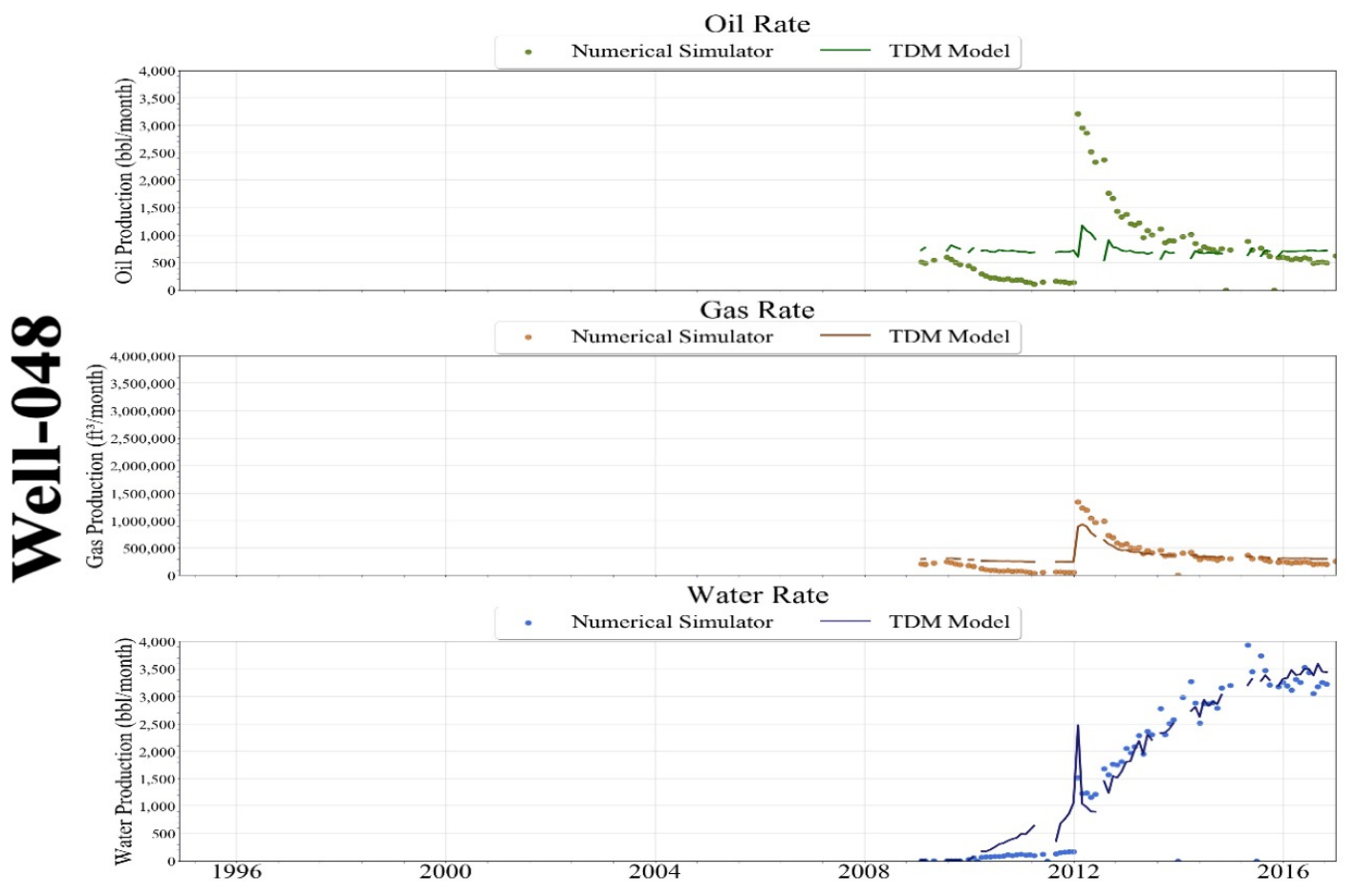

Figure 9-63: Scenario 1 - Well-048 Production History Match 


\subsection{Distribution Maps}

Distribution maps are presented at different timesteps, including the months of January, June, and December of 2014, and the months of June and December of years 2015 and 2016.

Reservoir Pressure (psi) at 2014-01-31
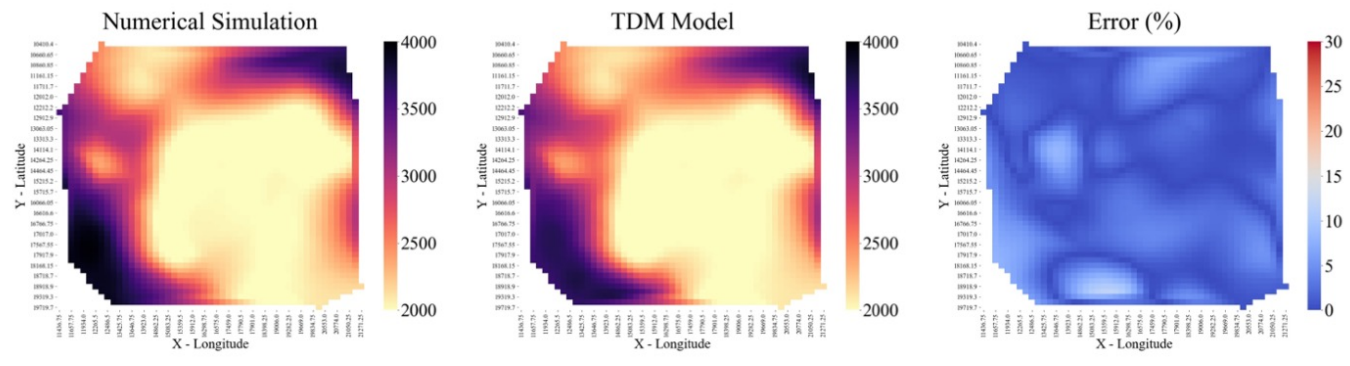

Water Saturation (\%) at 2014-01-31
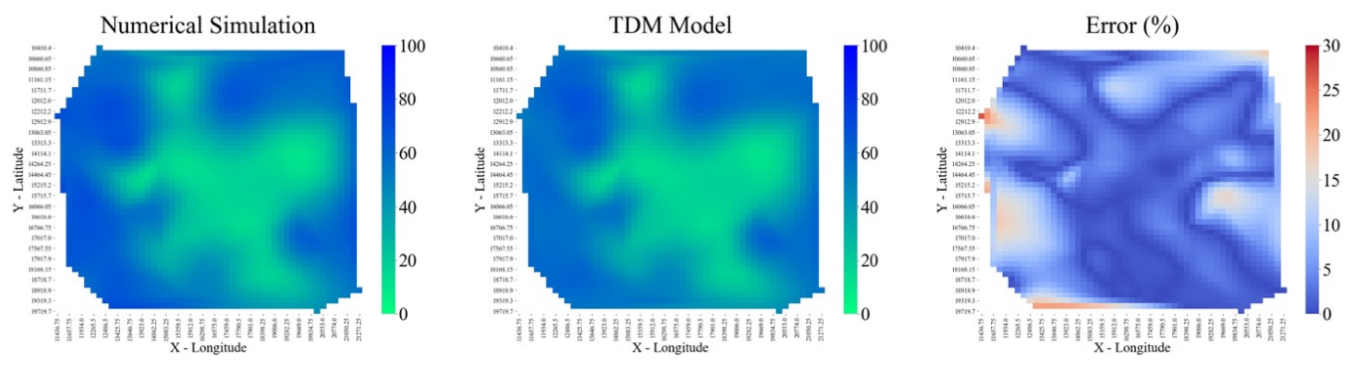

Reservoir Pressure (psi) at 2014-06-30
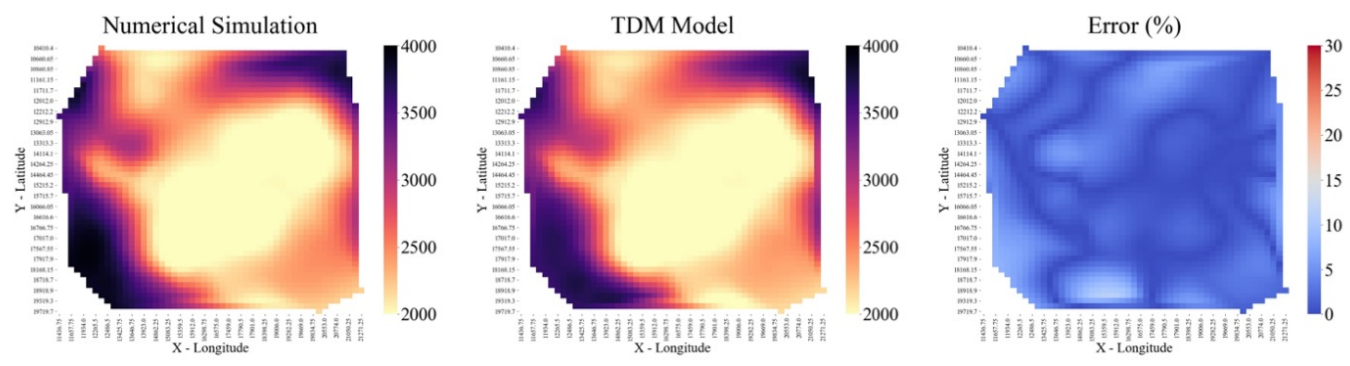

Water Saturation (\%) at 2014-06-30
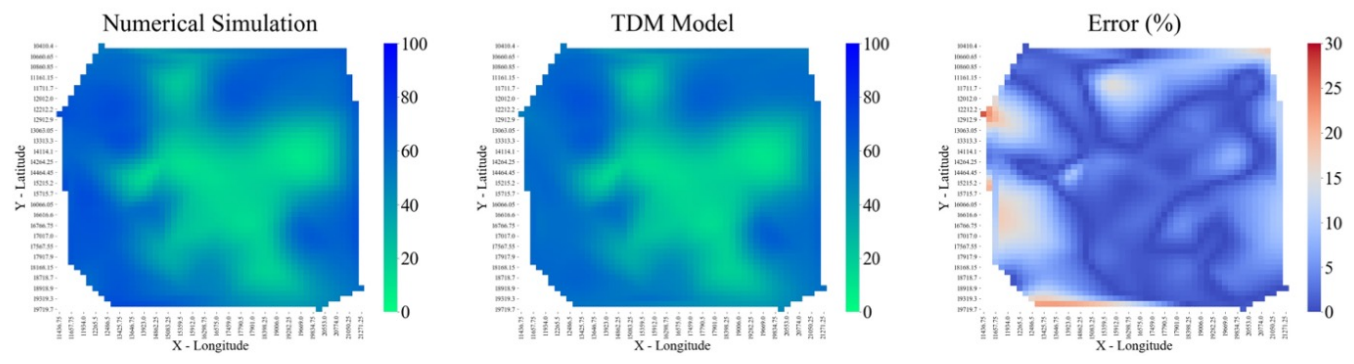
Reservoir Pressure (psi) at 2014-12-31
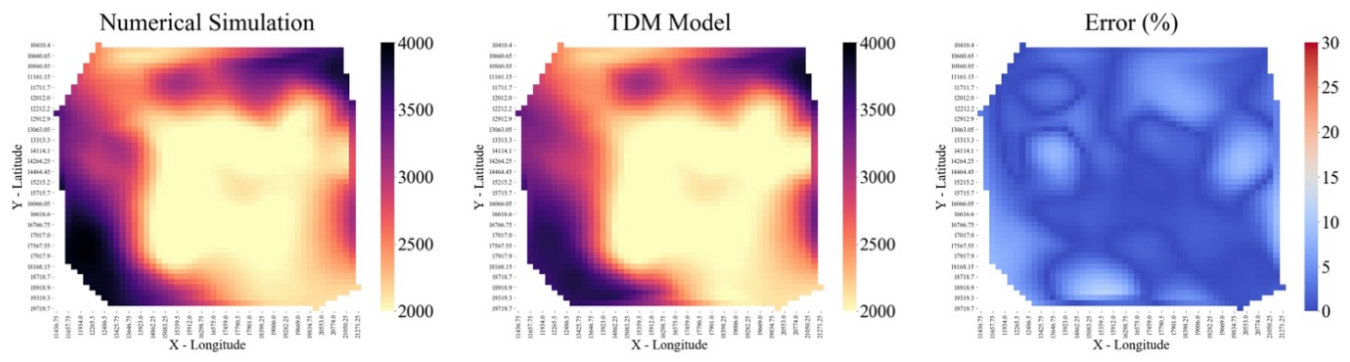

Water Saturation (\%) at 2014-12-31
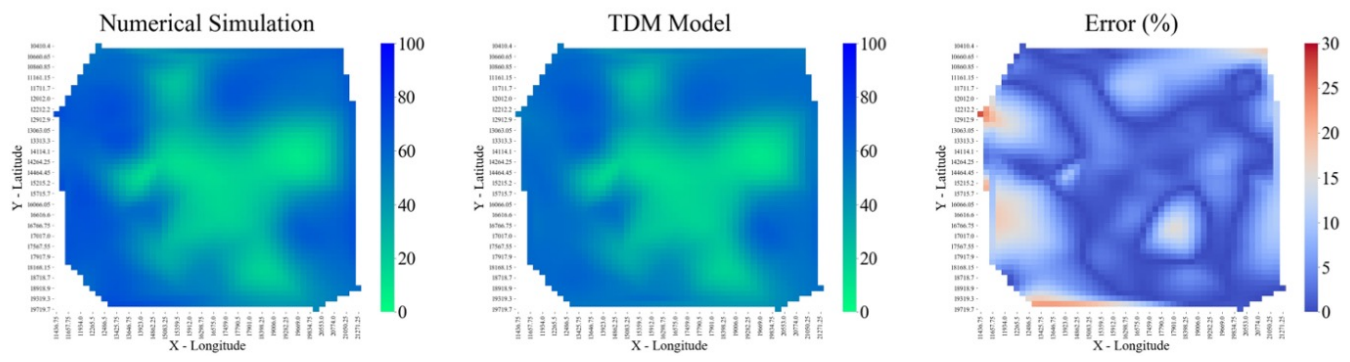

Reservoir Pressure (psi) at 2015-06-30
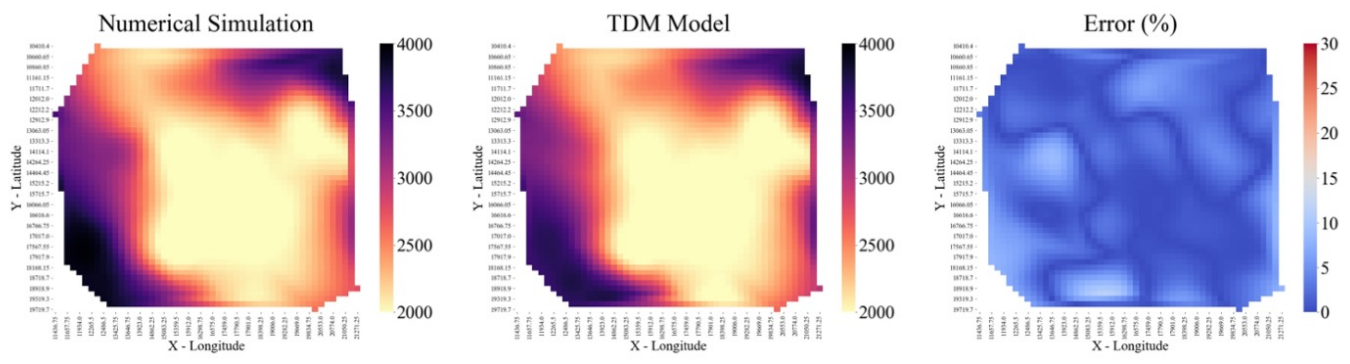

Water Saturation (\%) at 2015-06-30
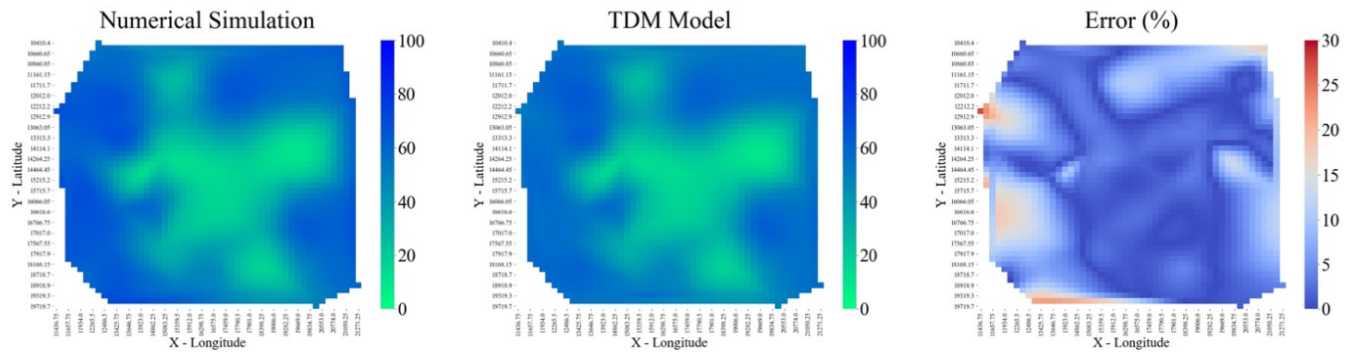
Reservoir Pressure (psi) at 2015-12-31
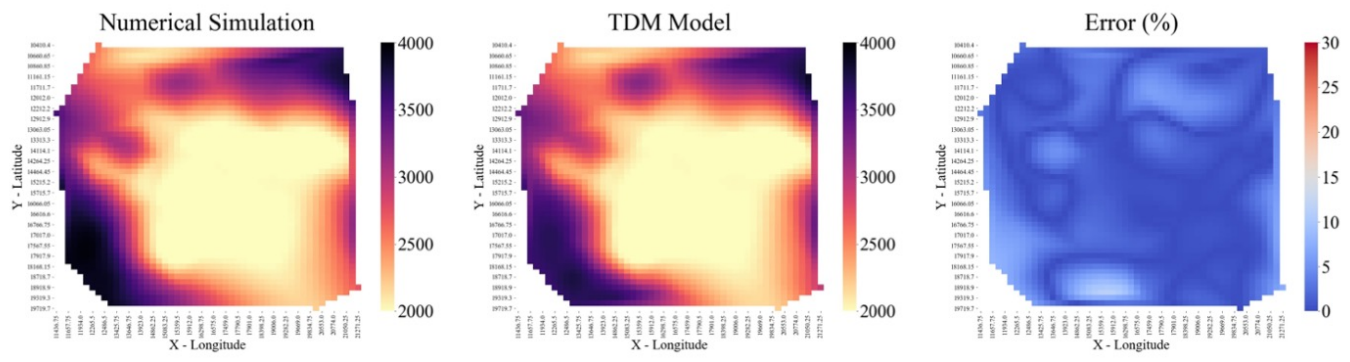

Water Saturation (\%) at 2015-12-31
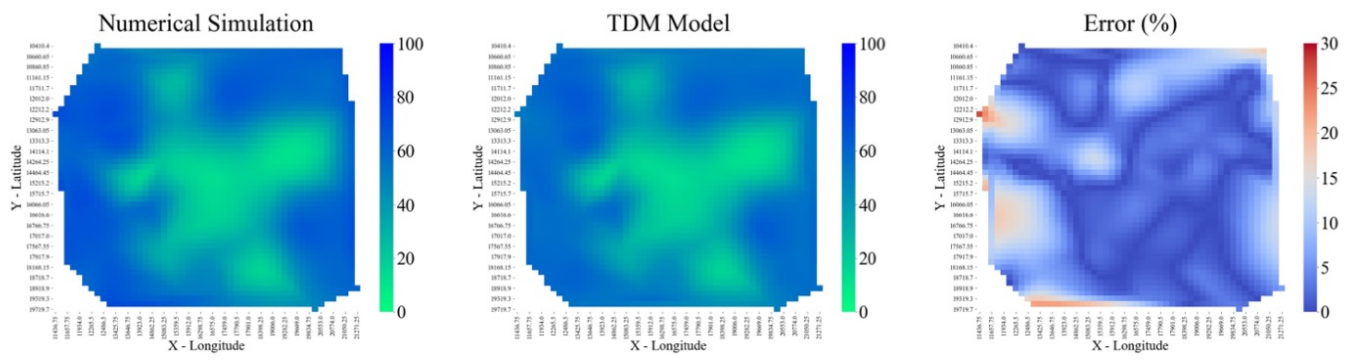

Reservoir Pressure (psi) at 2016-06-30
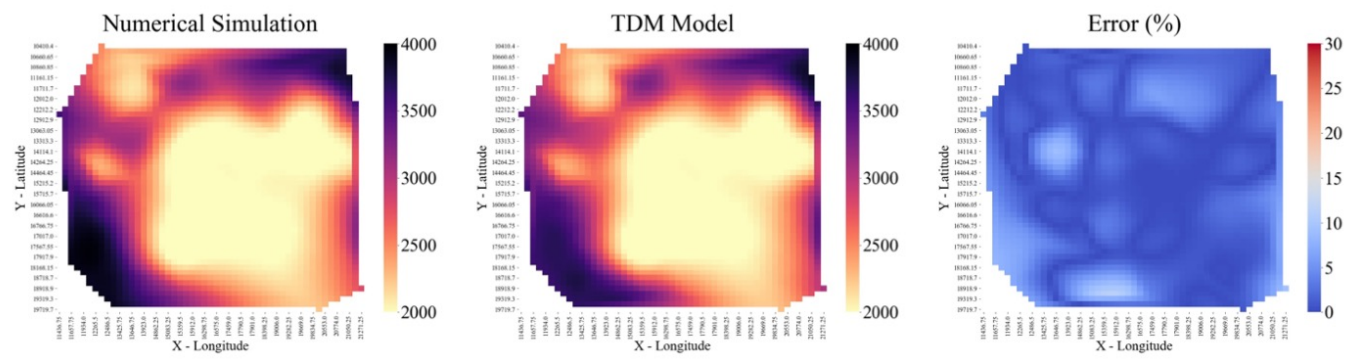

Water Saturation (\%) at 2016-06-30
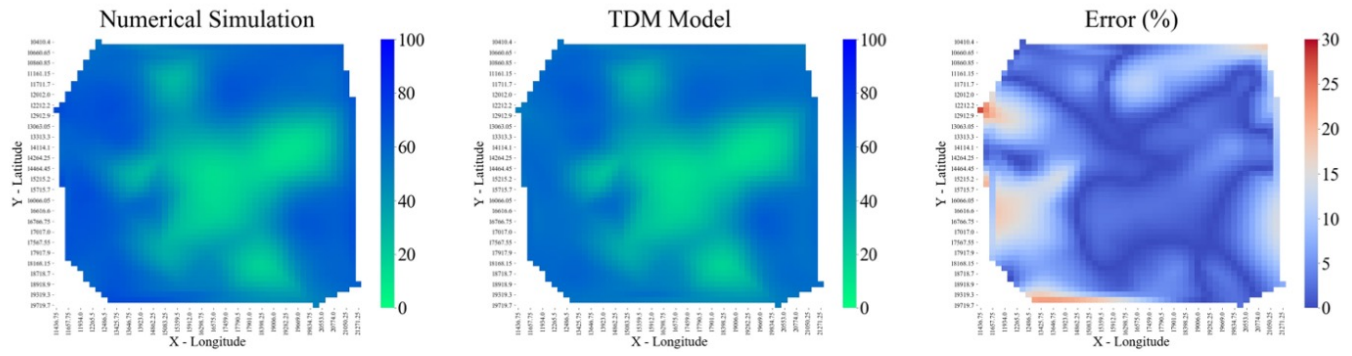
Reservoir Pressure (psi) at 2016-12-31
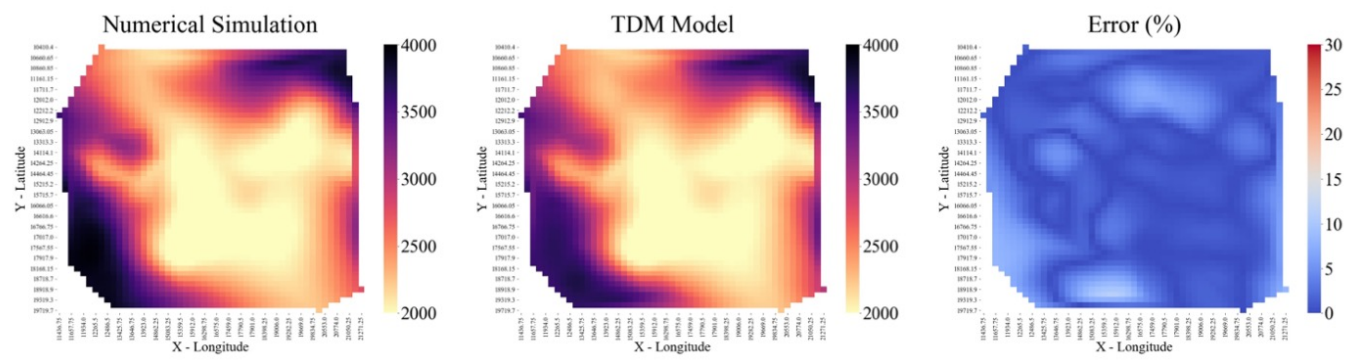

Water Saturation (\%) at 2016-12-31
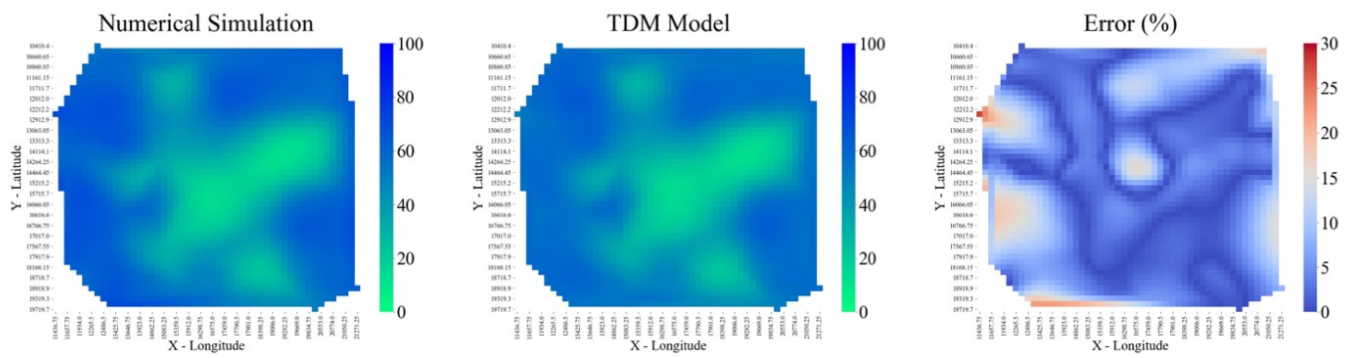

Figure 9-64: Scenario 1 - Distribution Maps at Different Timesteps 


\section{Appendix D: Scenario 2 - Mixed Partitioning TDM (1 Year Validation)}

\subsection{Input Attributes}

The number of input attributes used in the development of each data-driven model was based on KPI analysis and domain expertise. The following tables provide a list of static and dynamic attributes for both the focal and offset wells. Each table is composed of three columns that indicate the ranking, name of the input attribute, and its degree of influence (DOI) with respect to the output model.

\subsubsection{Oil Predictive Model}

Oil Model - Input Attributes

\begin{tabular}{|c|c|c|c|c|c|}
\hline \multicolumn{3}{|c|}{ FOCAL WELL } & \multicolumn{3}{|c|}{ OFFSET WELLS } \\
\hline \multicolumn{3}{|c|}{ Static Attributes } & \multicolumn{3}{|c|}{ Static Attributes } \\
\hline Rank & Attribute & DOI & Rank & Attribute & DOI \\
\hline 1 & Porh(1-sw) & 100 & 1 & Completion $(\mathrm{ft})(1 \mathrm{P})$ & 100 \\
\hline 2 & Porosity (\%) & 90 & 2 & Porh(1-sw)(1I) & 91 \\
\hline \multicolumn{3}{|c|}{2} & 3 & Top $(\mathrm{ft})(1 \mathrm{I})$ & 90 \\
\hline & & & 5 & TVD (ft)(1I) & 73 \\
\hline \multicolumn{3}{|c|}{ Dynamic Attributes } & 6 & Top (ft)(2P) & 65 \\
\hline & Oil Rate (t-1) & 100 & 9 & TVD (ft)(1P) & 55 \\
\hline 2 & Gas Rate (t-1) & 100 & 11 & Pay thickness $(\mathrm{ft})(1 \mathrm{P})$ & 50 \\
\hline 3 & Permeability I(t-1) & 49 & \multicolumn{3}{|c|}{7} \\
\hline 4 & Time & 48 & & & \\
\hline \multicolumn{3}{|c|}{4} & \multicolumn{3}{|c|}{ Dynamic Attributes } \\
\hline & & & 1 & FBH Pressure $(\mathrm{psi})(\mathrm{t})(1 \mathrm{I})$ & 100 \\
\hline \multirow[t]{11}{*}{ TOT } & AL ATTRIBUTES & 24 & 3 & FBH Pressure (psi)(t-1)(1I) & 96 \\
\hline & & & 4 & Reservoir Pressure $(\mathrm{psi})(\mathrm{t}-1)(1 \mathrm{I})$ & 96 \\
\hline & & & 5 & Distance $(\mathrm{t})(2 \mathrm{P})$ & 96 \\
\hline & & & 6 & FBH Pressure $(\mathrm{psi})(\mathrm{t})(2 \mathrm{I})$ & 93 \\
\hline & & & 7 & FBH Pressure $(\mathrm{psi})(\mathrm{t}-1)(2 \mathrm{I})$ & 92 \\
\hline & & & 8 & Reservoir Pressure (psi)(t-1)(2I) & 92 \\
\hline & & & 9 & Water Saturation $(\%)(\mathrm{t}-1)(2 \mathrm{I})$ & 87 \\
\hline & & & 10 & Oil Saturation $(\%)(\mathrm{t}-1)(2 \mathrm{I})$ & 87 \\
\hline & & & 12 & Distance $(\mathrm{t})(1 \mathrm{P})$ & 61 \\
\hline & & & 34 & Distance $(\mathrm{t})(1 \mathrm{I})$ & 28 \\
\hline & & & & 11 & \\
\hline
\end{tabular}

Figure 10-1: Scenario 2 - Oil Model Input Attributes 


\subsubsection{Gas Predictive Model}

\section{Gas Model - Input Attributes}

\begin{tabular}{|c|c|c|c|c|c|}
\hline \multicolumn{3}{|c|}{ FOCAL WELL } & \multicolumn{3}{|c|}{ OFFSET WELLS } \\
\hline \multicolumn{3}{|c|}{ Static Attributes } & \multicolumn{3}{|c|}{ Static Attributes } \\
\hline Rank & Attribute & DOI & Rank & $\begin{array}{c}\text { Attribute } \\
\end{array}$ & DOI \\
\hline 1 & Porh(1-sw) & 100 & 1 & Completion $(\mathrm{ft})(1 \mathrm{P})$ & 100 \\
\hline 2 & Porosity (\%) & 90 & 2 & Porh $(1-\mathrm{sw})(1 \mathrm{I})$ & 91 \\
\hline \multicolumn{3}{|c|}{2} & 3 & Top $(\mathrm{ft})(1 \mathrm{I})$ & 90 \\
\hline & & & 4 & $\mathrm{X} /$ Longitude(1I) & 84 \\
\hline \multicolumn{3}{|c|}{ Dynamic Attributes } & 5 & TVD $(\mathrm{ft})(1 \mathrm{I})$ & 73 \\
\hline & Oil Rate $(\mathrm{t})$ & 100 & 8 & Y/Latitude(1I) & 56 \\
\hline 2 & Oil Rate $(\mathrm{t}-1)$ & 60 & \multicolumn{3}{|c|}{ Cr } \\
\hline 3 & Gas Rate $(\mathrm{t}-1)$ & 60 & & & \\
\hline 4 & Permeability I(t-1) & 29 & \multicolumn{3}{|c|}{ Dynamic Attributes } \\
\hline \multicolumn{3}{|c|}{4} & 1 & FBH Pressure $(\mathrm{psi})(\mathrm{t})(1 \mathrm{I})$ & 100 \\
\hline & & \multirow{3}{*}{22} & 2 & Distance $(\mathrm{t}-1)(2 \mathrm{P})$ & 97 \\
\hline \multicolumn{2}{|c|}{ TOTAL ATTRIBUTES } & & 3 & FBH Pressure $(\mathrm{psi})(\mathrm{t}-1)(1 \mathrm{I})$ & 96 \\
\hline & & & 4 & Reservoir Pressure $(\mathrm{psi})(\mathrm{t}-1)(1 \mathrm{I})$ & 96 \\
\hline & & & 5 & Distance $(\mathrm{t})(2 \mathrm{P})$ & 96 \\
\hline & & & 6 & FBH Pressure $(\mathrm{psi})(\mathrm{t})(2 \mathrm{I})$ & 93 \\
\hline & & & 7 & FBH Pressure $(\mathrm{psi})(\mathrm{t}-1)(2 \mathrm{I})$ & 92 \\
\hline & & & 8 & Reservoir Pressure $(\mathrm{psi})(\mathrm{t}-1)(2 \mathrm{I})$ & 92 \\
\hline & & & 9 & Water Saturation $(\%)(\mathrm{t}-1)(2 \mathrm{I})$ & 87 \\
\hline & & & 10 & Oil Saturation $(\%)(\mathrm{t}-1)(2 \mathrm{I})$ & 87 \\
\hline & & & \multicolumn{3}{|c|}{10} \\
\hline
\end{tabular}

Figure 10-2: Scenario 2 - Gas Model Input Attributes 


\subsubsection{Water Predictive Model}

\section{Water Model - Input Attributes}

\begin{tabular}{|r|l|r|}
\hline \multicolumn{3}{|c|}{ FOCAL WELL } \\
\hline \multicolumn{3}{|c|}{ Static Attributes } \\
\hline \multicolumn{2}{|c|}{ Attribute } & DOI \\
\hline Rank & \multicolumn{1}{|c|}{89} \\
\hline 2 & X/Longitude & 84 \\
\hline 3 & Top (ft) & 1 \\
\hline 9 & Porosity (\%) \\
\hline \multicolumn{2}{|c|}{3} & \\
\hline
\end{tabular}

\begin{tabular}{|r|l|r|}
\hline \multicolumn{3}{|c|}{ Dynamic Attributes } \\
\hline 1 & $\mathrm{q}(\mathrm{t}-1)$-Water & 100 \\
\hline 2 & Oil Saturation $(\%)(\mathrm{t}-1)$ & 78 \\
\hline 3 & Water Saturation $(\%)(\mathrm{t}-1)$ & 78 \\
\hline 4 & Permeability I(t-1) & 72 \\
\hline 15 & Oil Rate $(\mathrm{t})$ & 1 \\
\hline 16 & Gas Rate $(\mathrm{t})$ & 1 \\
\hline \multicolumn{2}{|c|}{6} \\
\hline
\end{tabular}

TOTAL ATTRIBUTES 20

OFFSET WELLS
\begin{tabular}{|r|l|r|}
\hline \multicolumn{3}{|c|}{ Static Attributes } \\
\hline \multicolumn{3}{|c|}{ Attribute } \\
\hline Rank & \multicolumn{1}{|c|}{ DOI } \\
\hline 1 & X/Longitude(2P) & 100 \\
\hline 2 & Top $(\mathrm{ft})(2 \mathrm{P})$ & 90 \\
\hline 3 & TVD $(\mathrm{ft})(2 \mathrm{P})$ & 86 \\
\hline 4 & Top $(\mathrm{ft})(2 \mathrm{I})$ & 79 \\
\hline 5 & $\mathrm{X} /$ Longitude(2I) & 75 \\
\hline 7 & $\mathrm{TVD}(\mathrm{ft})(2 \mathrm{I})$ & 65 \\
\hline \multicolumn{2}{|c|}{6} \\
\hline
\end{tabular}

\begin{tabular}{|r|l|r|}
\hline \multicolumn{3}{|c|}{ Dynamic Attributes } \\
\hline 1 & Water Saturation (\%)(t-1)(1P) & 100 \\
\hline 2 & Oil Saturation (\%)(t-1)(1P) & 100 \\
\hline 3 & Distance(t)(1I) & 92 \\
\hline 12 & Permeability I(t-1)(2P) & 42 \\
\hline 15 & Permeability I(t-1)(2I) & 39 \\
\hline \multicolumn{2}{|c|}{5} & \\
\hline
\end{tabular}

Figure 10-3: Scenario 2 - Water Model Input Attributes 


\subsubsection{Reservoir Pressure Predictive Model}

\begin{tabular}{|c|c|c|c|c|c|}
\hline \multicolumn{3}{|c|}{ FOCAL WELL } & \multicolumn{3}{|c|}{ OFFSET WELLS } \\
\hline \multicolumn{3}{|c|}{ Static Attributes } & \multicolumn{3}{|c|}{ Static Attributes } \\
\hline Rank & Attribute & DOI & \begin{tabular}{|l|} 
Rank \\
\end{tabular} & $\begin{array}{c}\text { Attribute } \\
\end{array}$ & DOI \\
\hline & $\mathrm{X} /$ Longitude & 100 & \begin{tabular}{|l|}
1 \\
\end{tabular} & $\mathrm{X} /$ Longitude $(1 \mathrm{P})$ & 100 \\
\hline 2 & Top $(\mathrm{ft})$ & 81 & 2 & $\mathrm{X} /$ Longitude(1I) & 88 \\
\hline \multicolumn{3}{|c|}{2} & 3 & $\mathrm{X} /$ Longitude $(2 \mathrm{P})$ & 88 \\
\hline & & & 4 & Top $(\mathrm{ft})(1 \mathrm{I})$ & 85 \\
\hline \multicolumn{3}{|c|}{ Dynamic Attributes } & 5 & Top (ft)(2P) & 79 \\
\hline 1 & Reservoir Pressure $(\mathrm{psi})(\mathrm{t}-1)$ & 100 & 6 & Pay thickness (ft)(1I) & 79 \\
\hline 2 & FBH Pressure $(\mathrm{psi})(\mathrm{t})$ & 78 & \multicolumn{3}{|c|}{6} \\
\hline 3 & FBH Pressure (psi)(t-1) & 52 & & & \\
\hline 12 & Water Rate $(\mathrm{t})$ & 5 & \multicolumn{3}{|c|}{ Dynamic Attributes } \\
\hline 13 & Oil Rate $(\mathrm{t})$ & 4 & 1 & Reservoir Pressure $(\mathrm{psi})(\mathrm{t}-1)(1 \mathrm{P})$ & 100 \\
\hline 14 & Gas Rate $(\mathrm{t})$ & 4 & 2 & FBH Pressure $(\mathrm{psi})(\mathrm{t}-1)(1 \mathrm{P})$ & 91 \\
\hline \multicolumn{3}{|c|}{ ( } & 3 & FBH Pressure $(\mathrm{psi})(\mathrm{t})(1 \mathrm{P})$ & 90 \\
\hline & & & \multicolumn{3}{|c|}{3} \\
\hline
\end{tabular}

Figure 10-4: Scenario 2 - Reservoir Pressure Model Input Attributes 


\subsubsection{Water Saturation Predictive Model}

\begin{tabular}{|c|c|c|c|c|c|}
\hline \multicolumn{3}{|c|}{ FOCAL WELL } & \multicolumn{3}{|c|}{ OFFSET WELLS } \\
\hline \multicolumn{3}{|c|}{ Static Attributes } & \multicolumn{3}{|c|}{ Static Attributes } \\
\hline Rank & Attribute & DOI & Rank & \begin{tabular}{|c|} 
Attribute \\
\end{tabular} & DOI \\
\hline & Top (ft) & 100 & & $\mathrm{X} /$ Longitude $(2 \mathrm{P})$ & 100 \\
\hline 2 & $\mathrm{X} /$ Longitude & 87 & 2 & Top $(\mathrm{ft})(2 \mathrm{P})$ & 97 \\
\hline 3 & Y/Latitude & 65 & 3 & Y/Latitude(1P) & 79 \\
\hline \multicolumn{3}{|c|}{3} & & $\mathrm{X} /$ Longitude $(1 \mathrm{P})$ & 74 \\
\hline & & & \multicolumn{3}{|c|}{4} \\
\hline \multicolumn{3}{|c|}{ Dynamic Attributes } & & & \\
\hline 1 & Oil Saturation $(\%)(\mathrm{t}-1)$ & 100 & \multicolumn{3}{|c|}{ Dynamic Attributes } \\
\hline 2 & Water Saturation $(\%)(\mathrm{t}-1)$ & 100 & 1 & Water Saturation $(\%)(\mathrm{t}-1)(1 \mathrm{P})$ & 100 \\
\hline 4 & Reservoir Pressure (psi)(t) & 23 & & Oil Saturation $(\%)(\mathrm{t}-1)(1 \mathrm{P})$ & 100 \\
\hline 5 & Water Rate $(\mathrm{t})$ & 18 & \multicolumn{3}{|c|}{2} \\
\hline 10 & Oil Rate $(\mathrm{t})$ & 8 & & & \\
\hline 11 & Gas Rate $(\mathrm{t})$ & 8 & & & \\
\hline \multicolumn{3}{|c|}{6} & & & \\
\hline & TOTAL ATTRIBUTES & 15 & & & \\
\hline
\end{tabular}

Figure 10-5: Scenario 2 - Water Saturation Model Input Attributes 


\subsection{Production Profile Plots}

\subsubsection{Entire Reservoir}

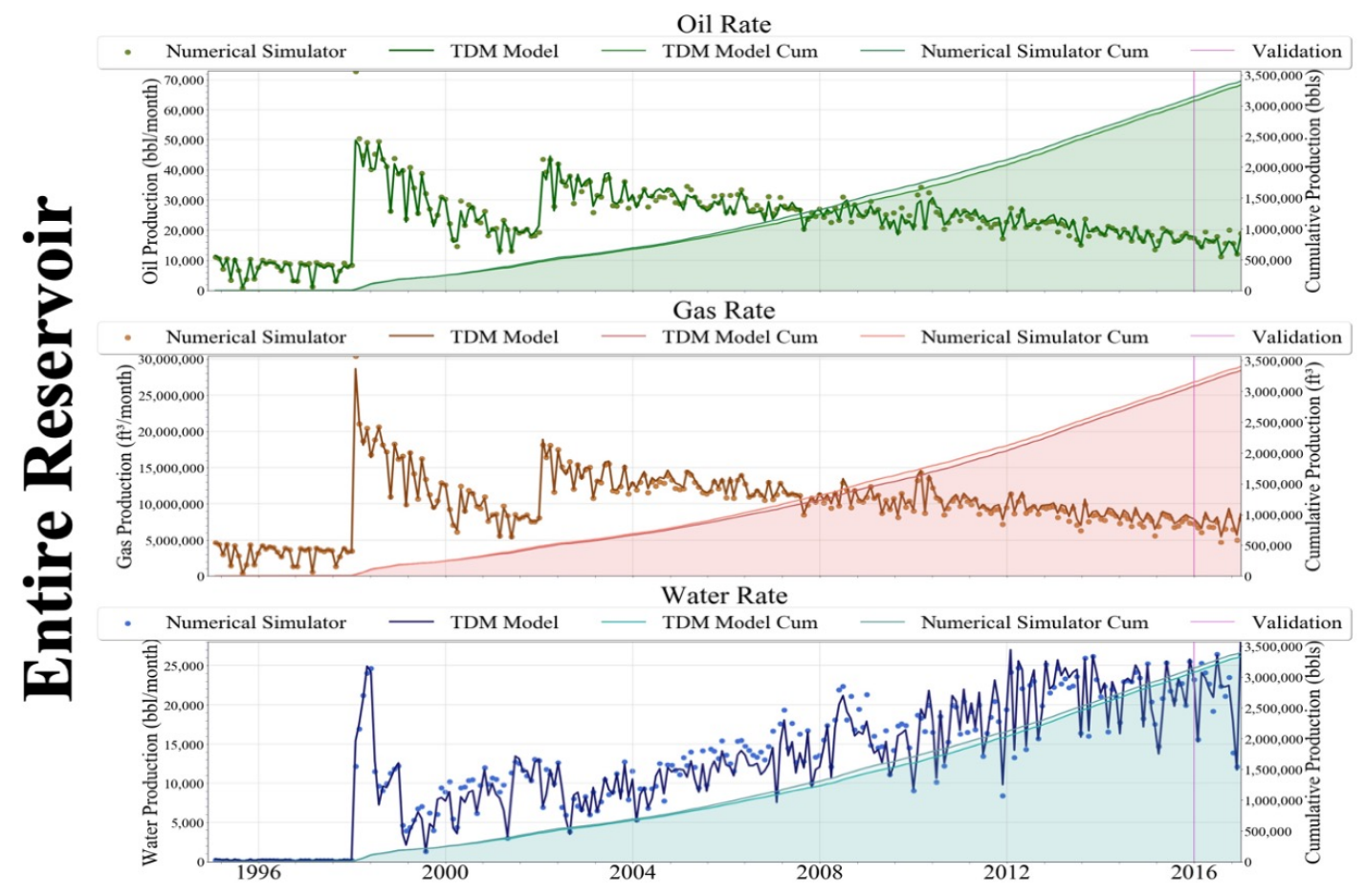

Figure 10-6: Scenario 2 - Entire Field Production 


\subsubsection{Good History Match of Production}

The following wells had excellent if not close history matches for oil, gas, and water production. The TDM predictions follow the actual production trend and have established a good relationship between input and output attributes.

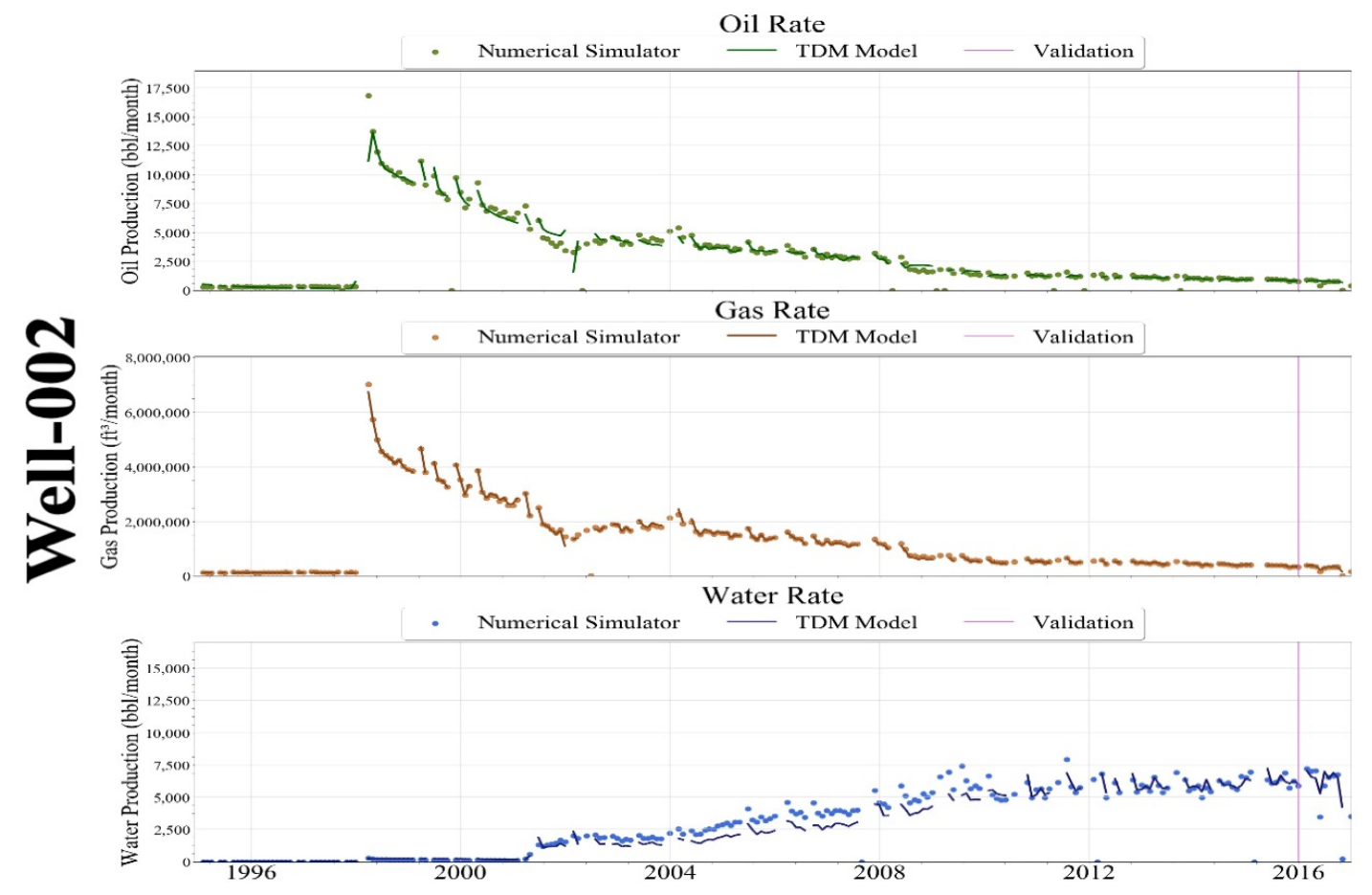

Figure 10-7: Scenario 2 - Well-002 Production History Match 
Oil Rate
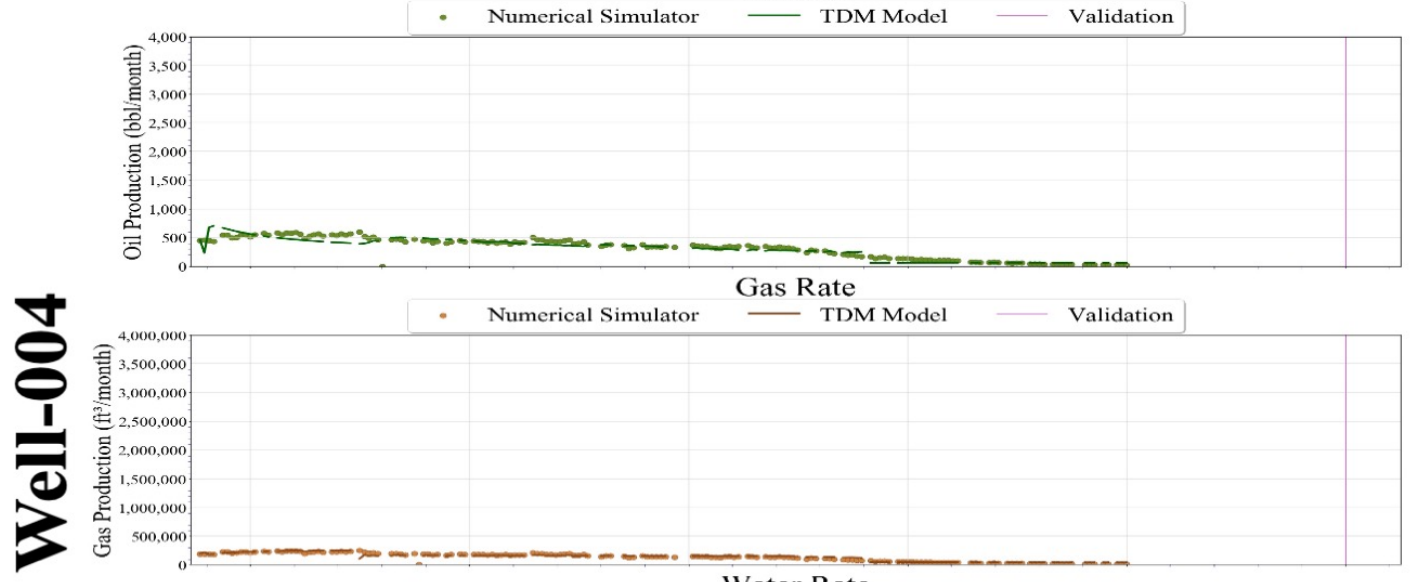

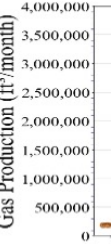

TDM Model

Validation

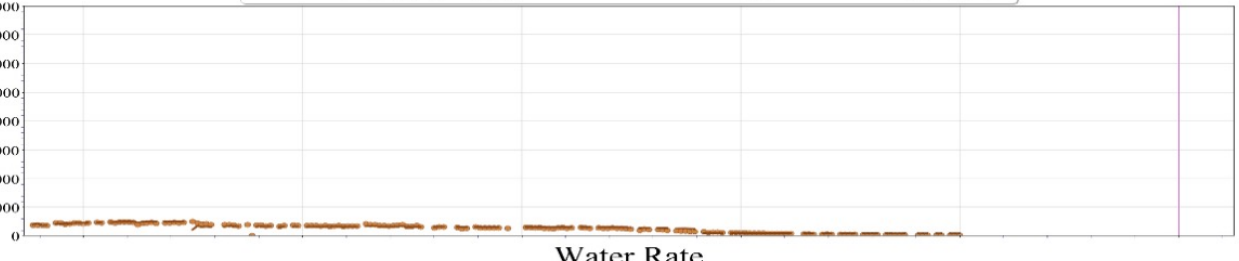

Water Rate

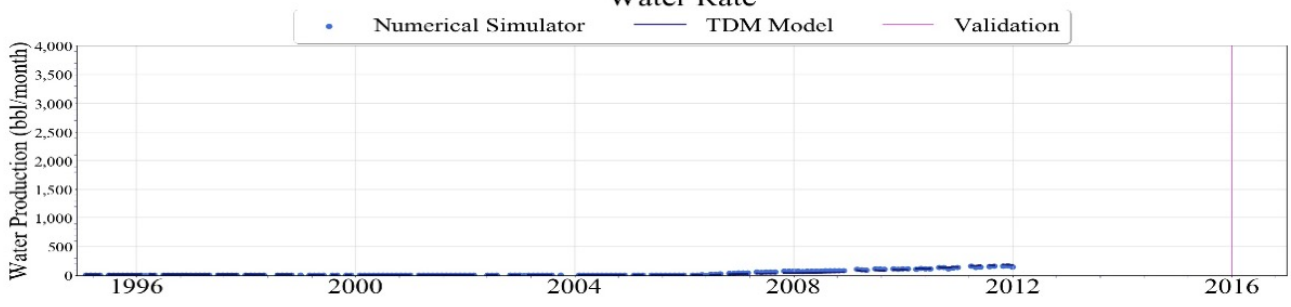

Figure 10-8: Scenario 2 - Well-004 Production History Match
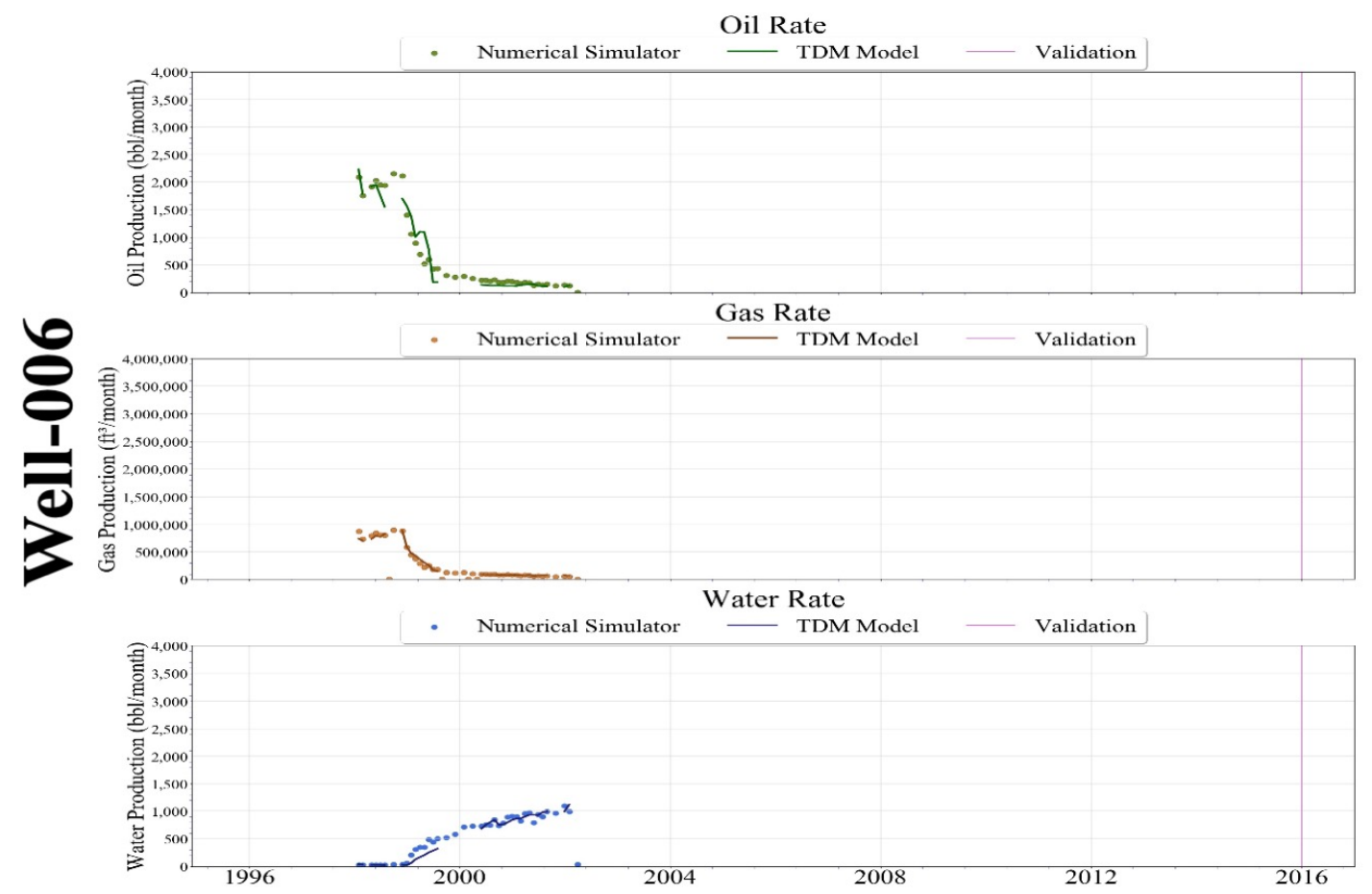

Figure 10-9: Scenario 2 - Well-006 Production History Match 


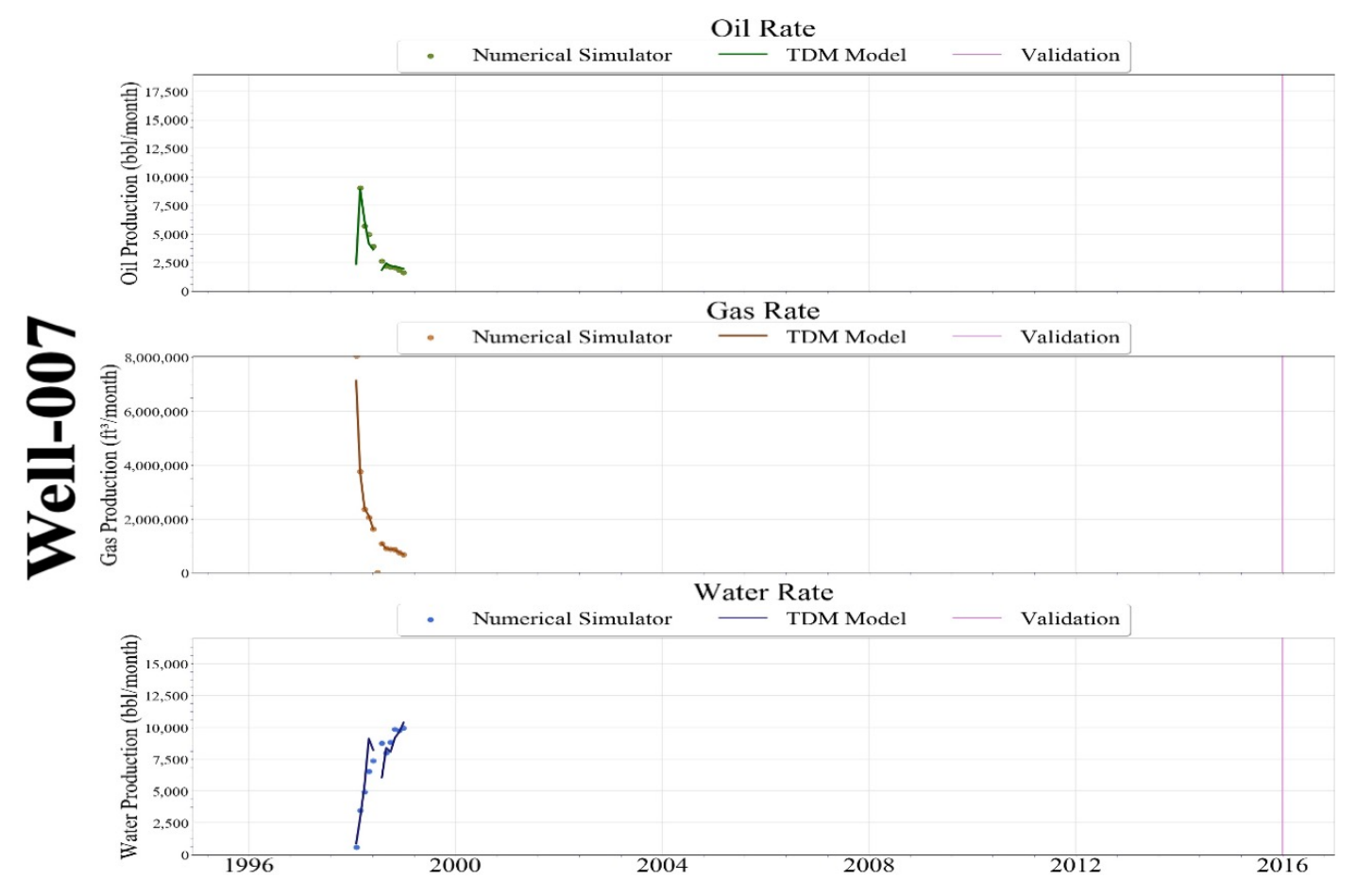

Figure 10-10: Scenario 2 - Well-007 Production History Match

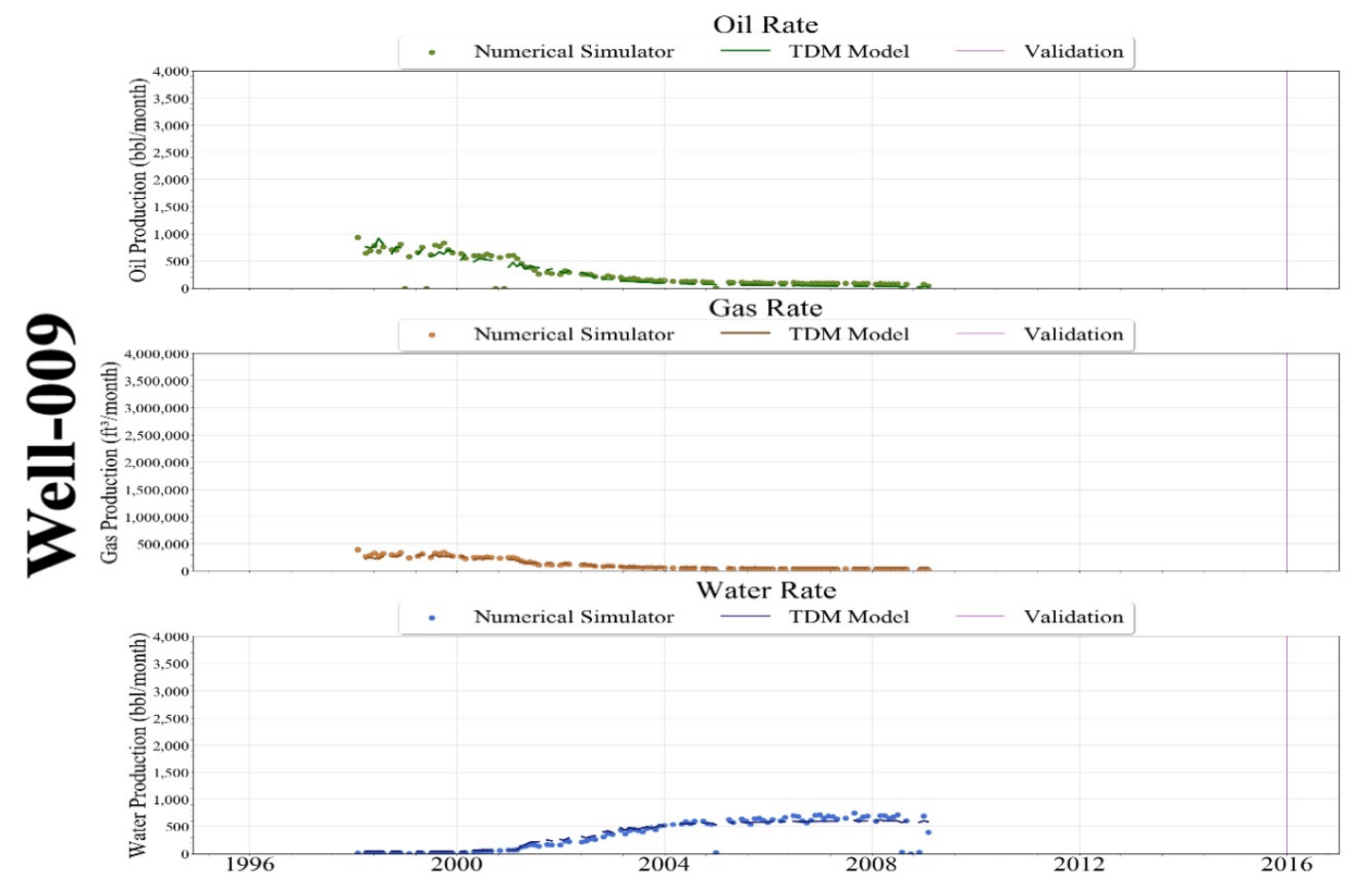

Figure 10-11: Scenario 2 - Well-009 Production History Match 


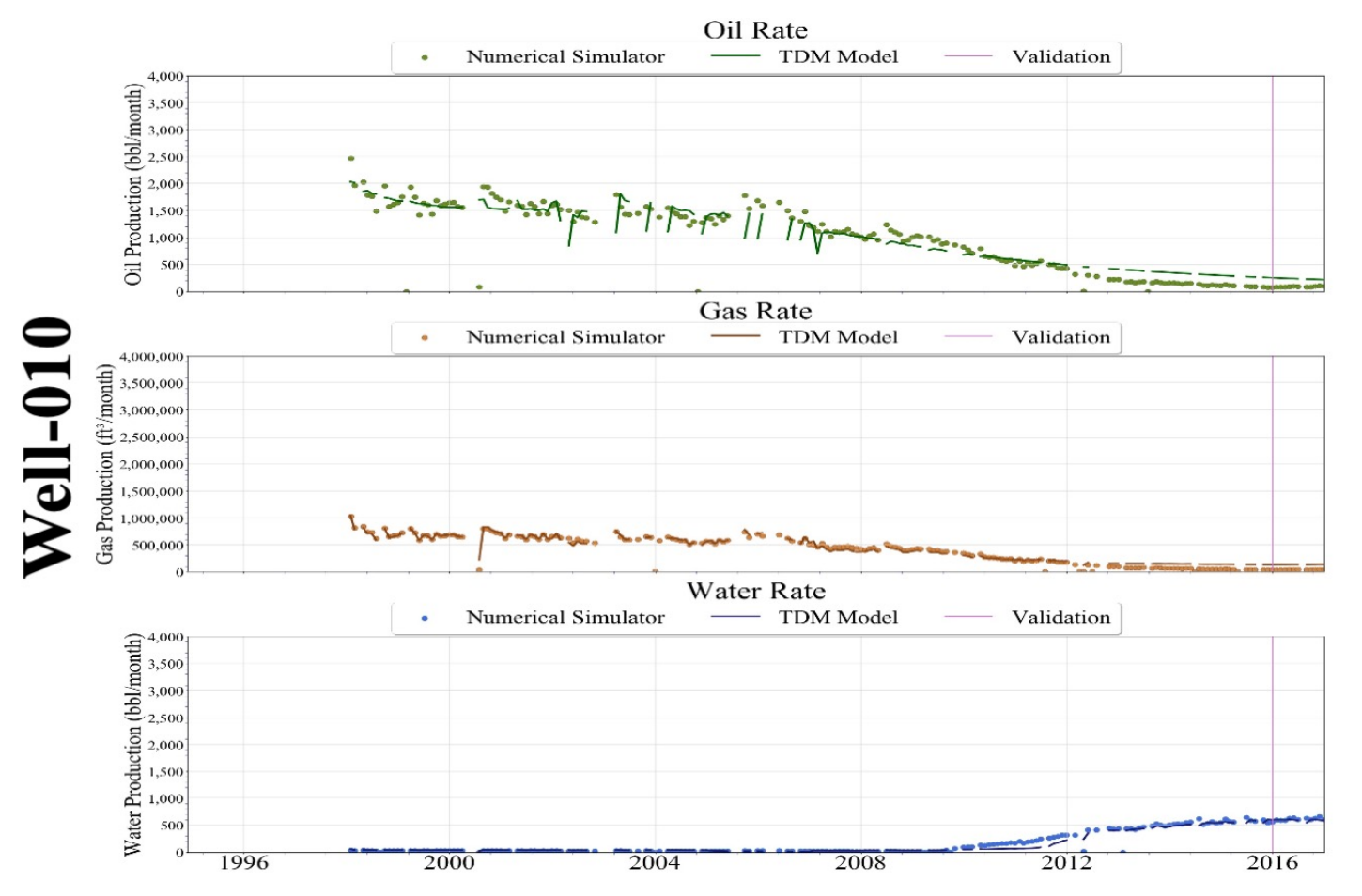

Figure 10-12: Scenario 2 - Well-010 Production History Match

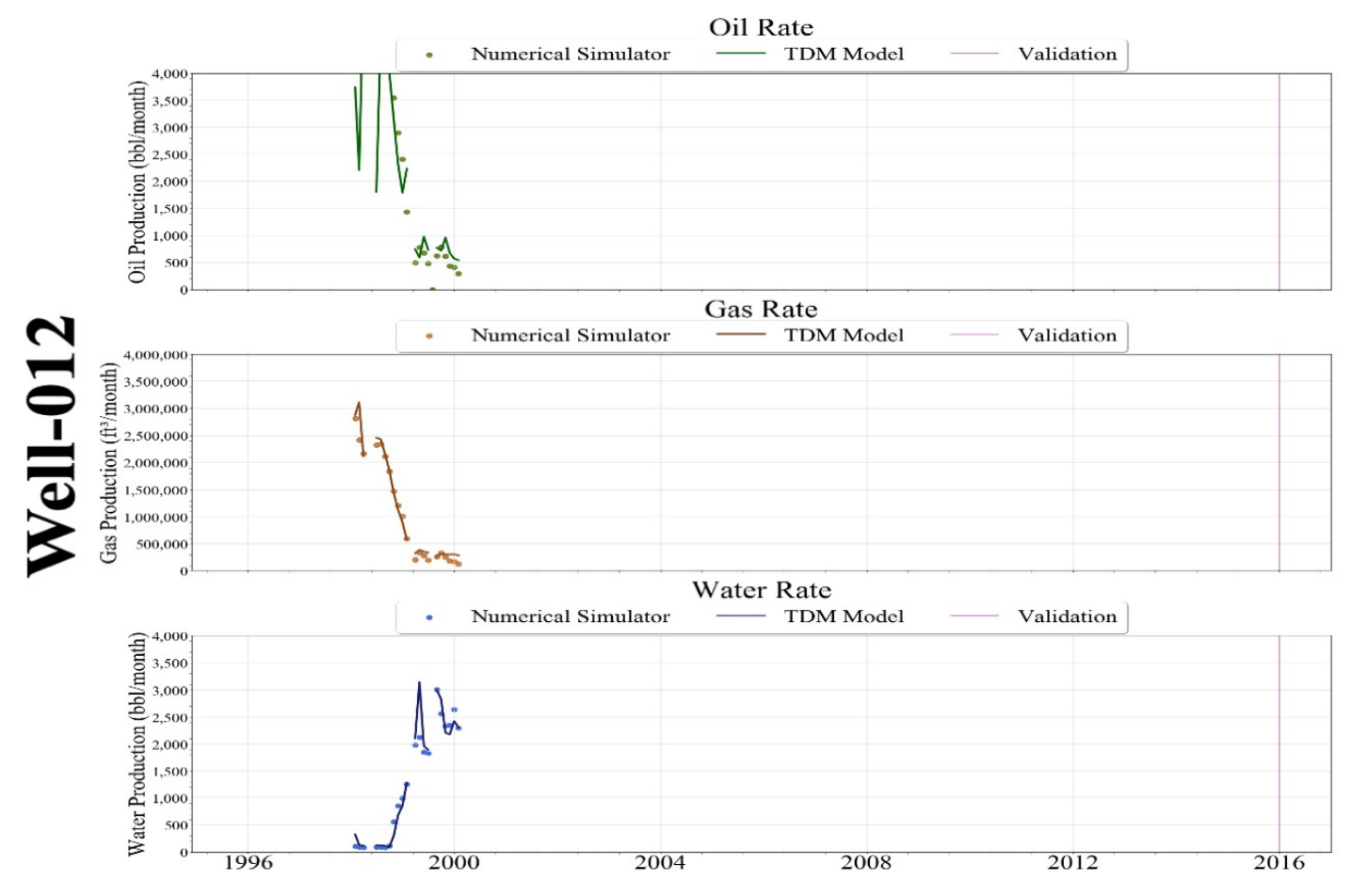

Figure 10-13: Scenario 2 - Well-012 Production History Match 


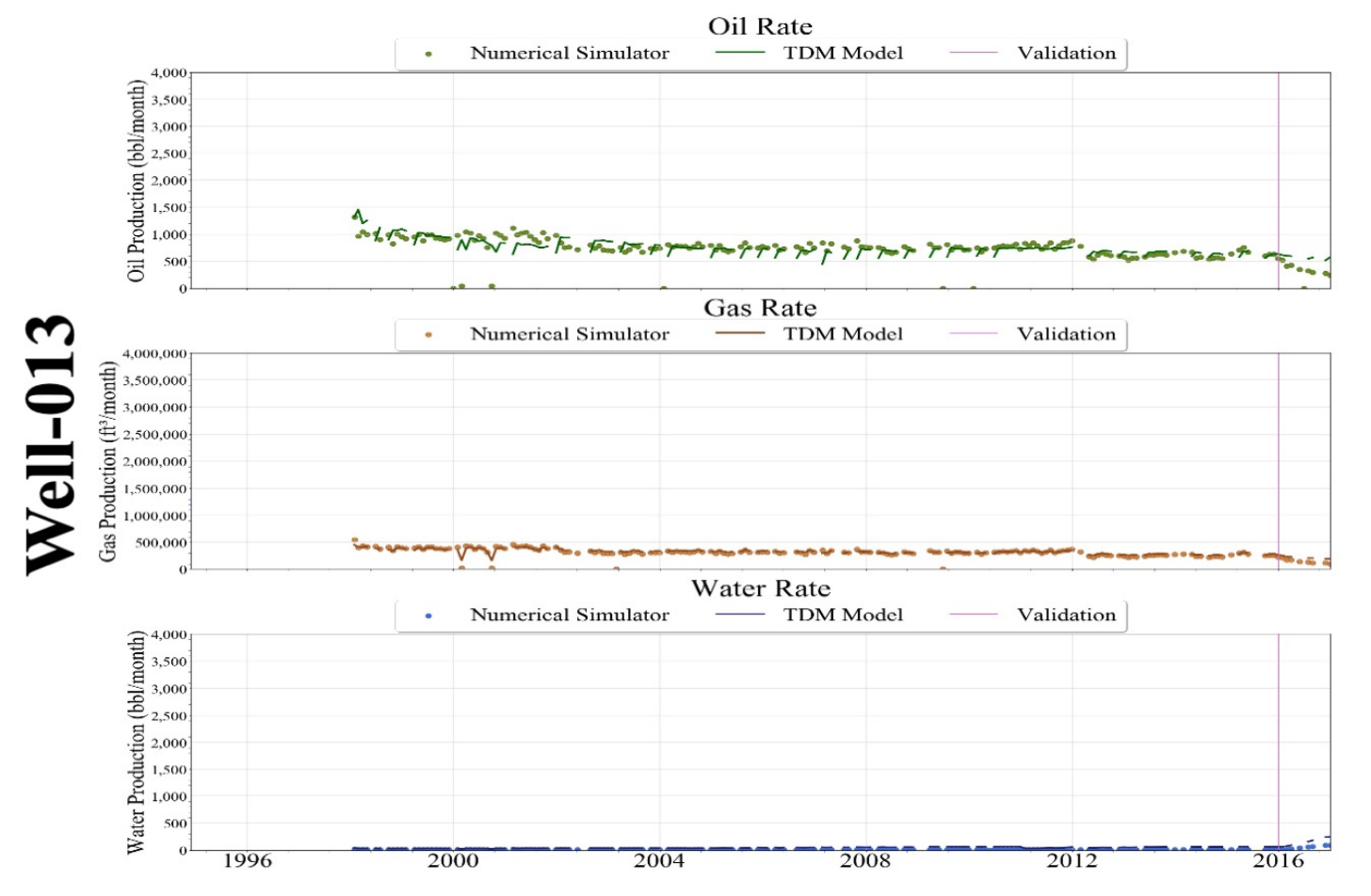

Figure 10-14: Scenario 2 - Well-013 Production History Match

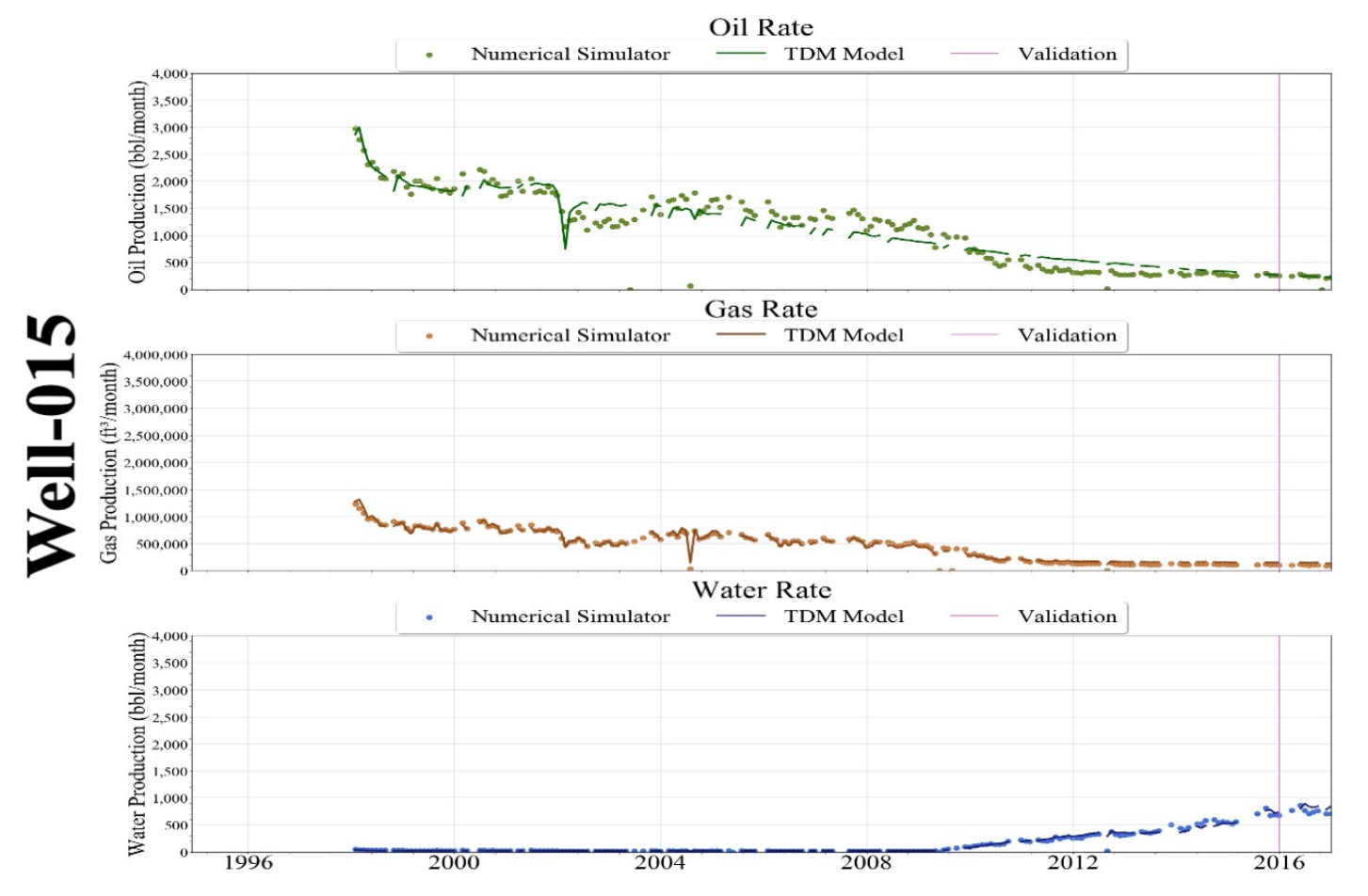

Figure 10-15: Scenario 2 - Well-015 Production History Match 


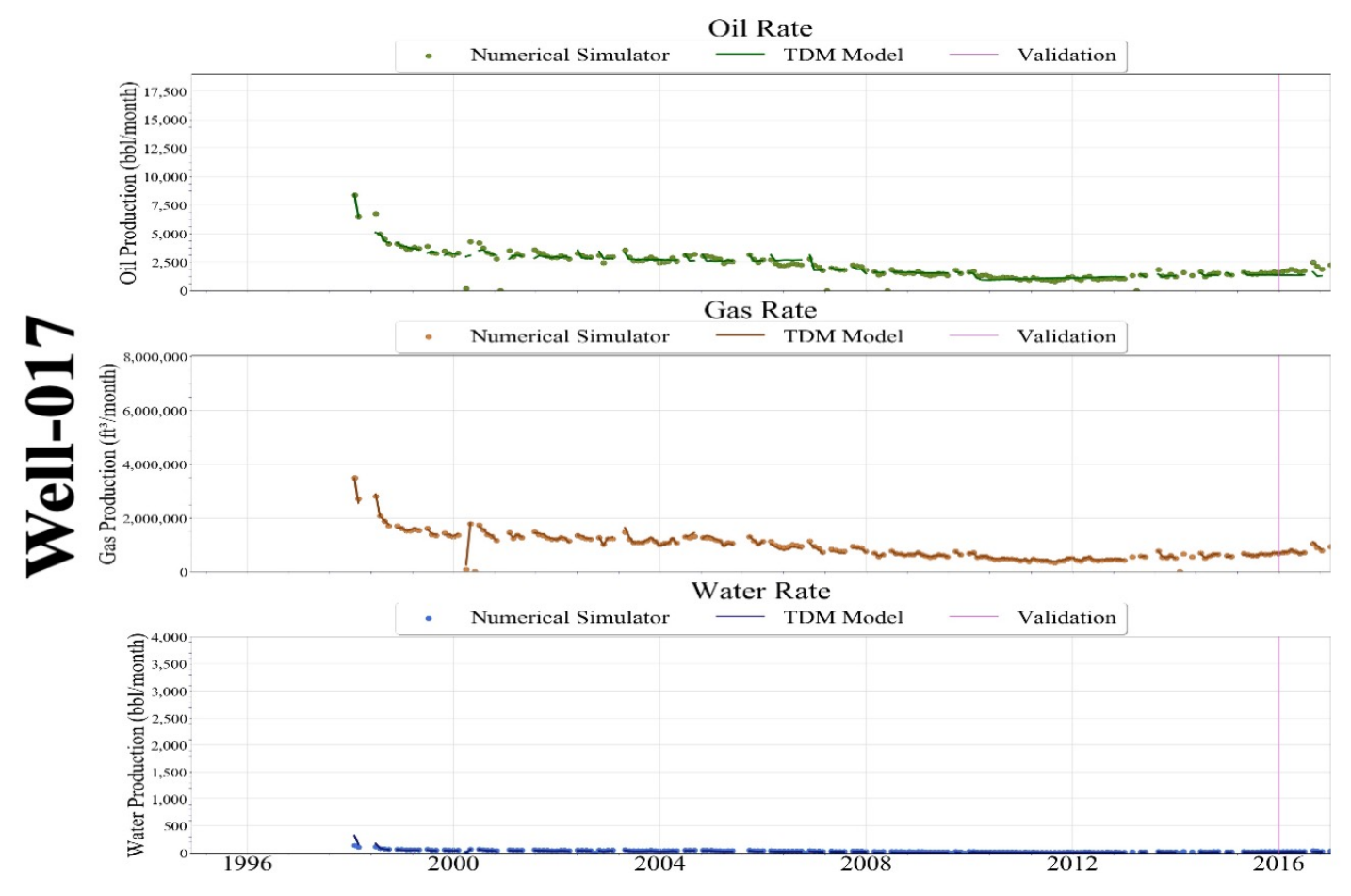

Figure 10-16: Scenario 2 - Well-017 Production History Match

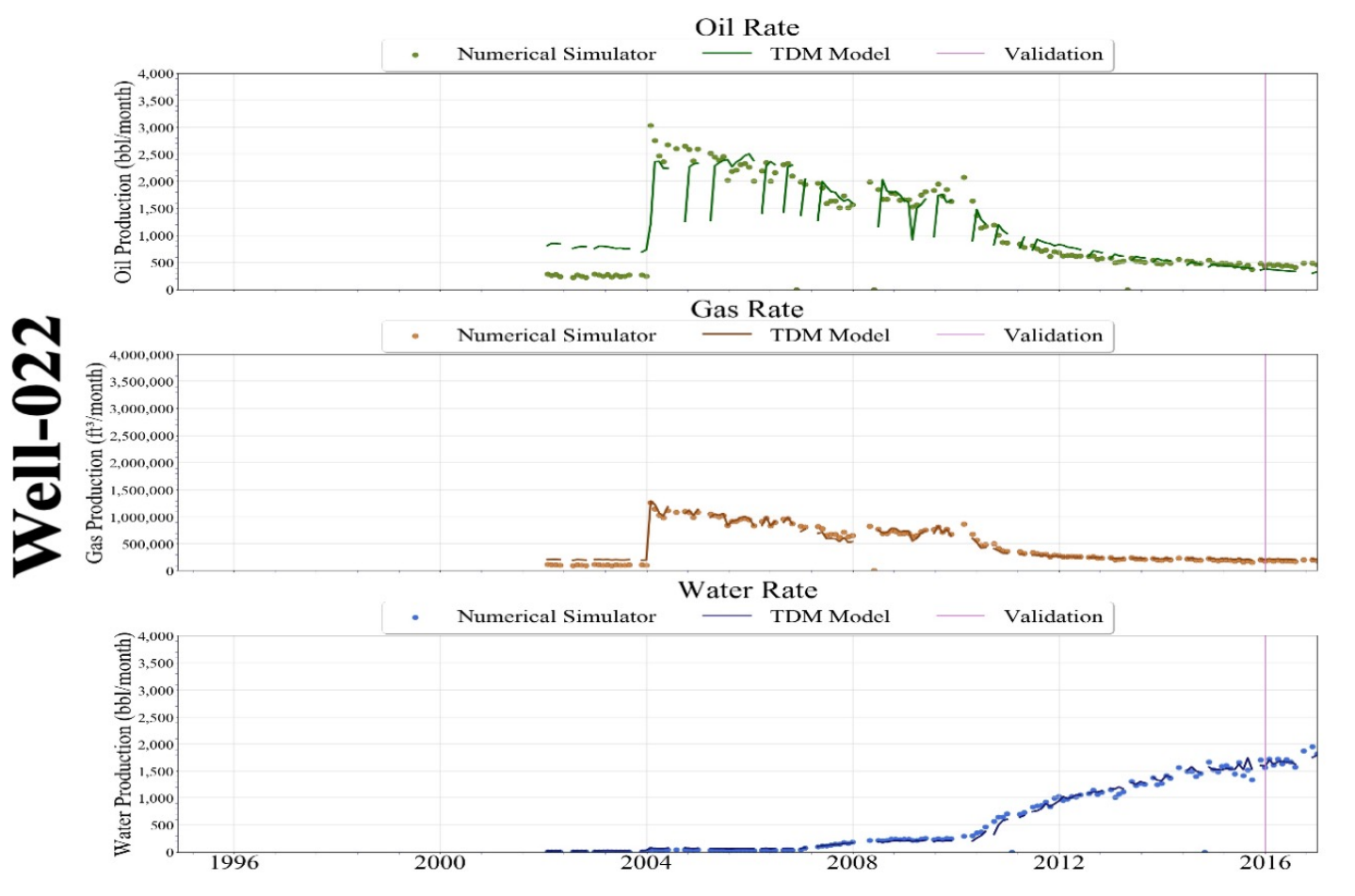

Figure 10-17: Scenario 2 - Well-022 Production History Match 


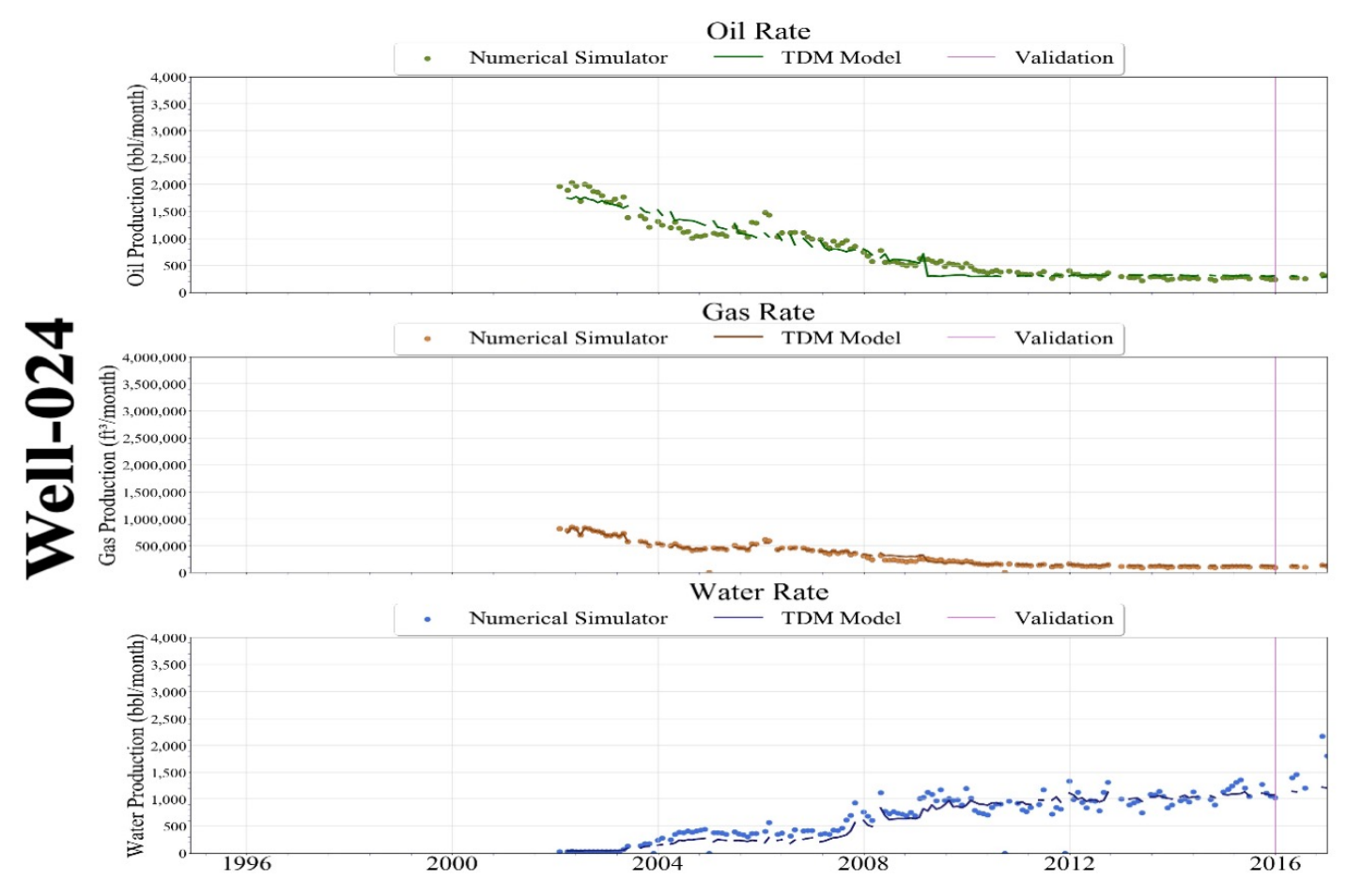

Figure 10-18: Scenario 2 - Well-024 Production History Match

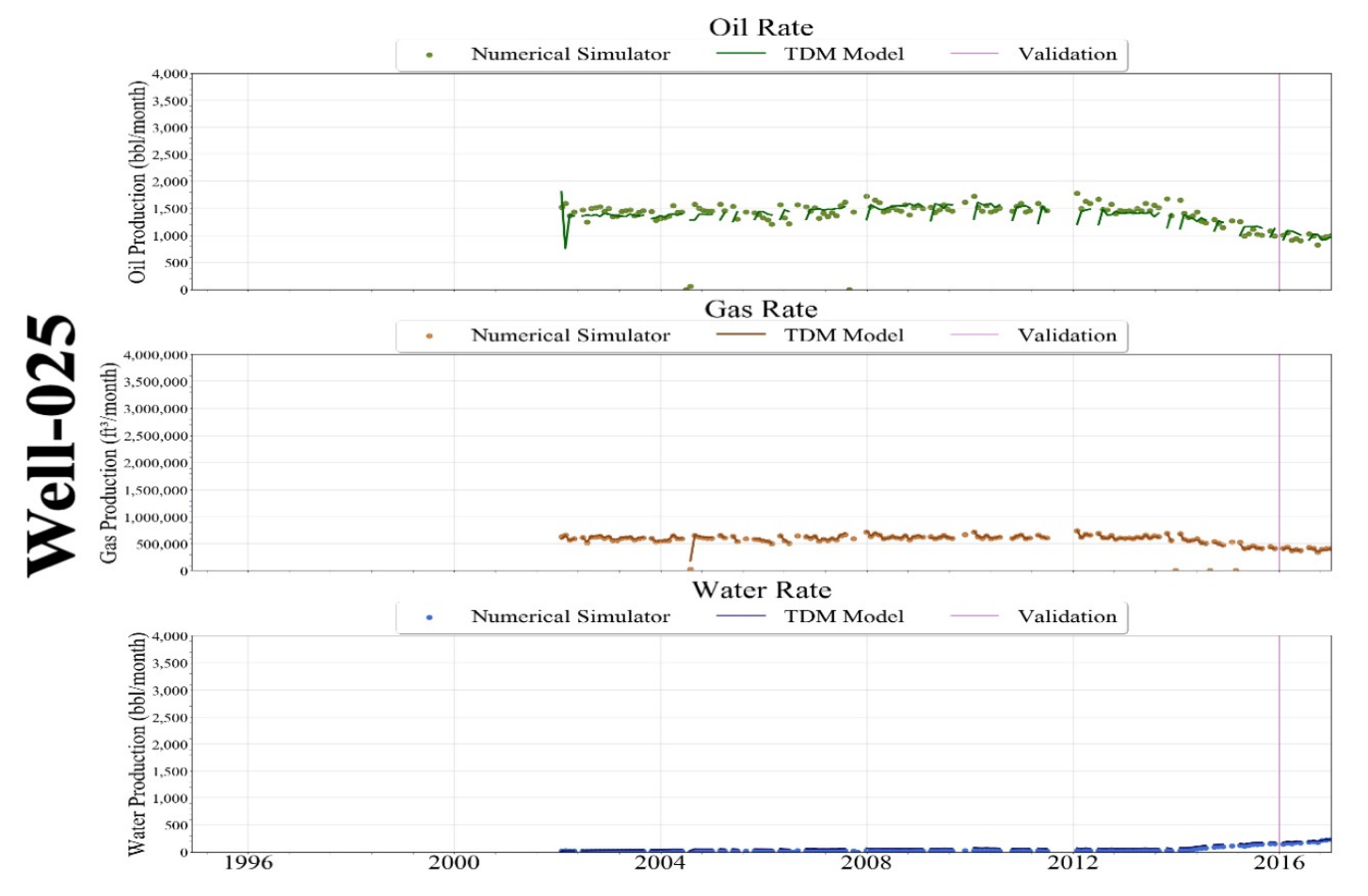

Figure 10-19: Scenario 2 - Well-025 Production History Match 


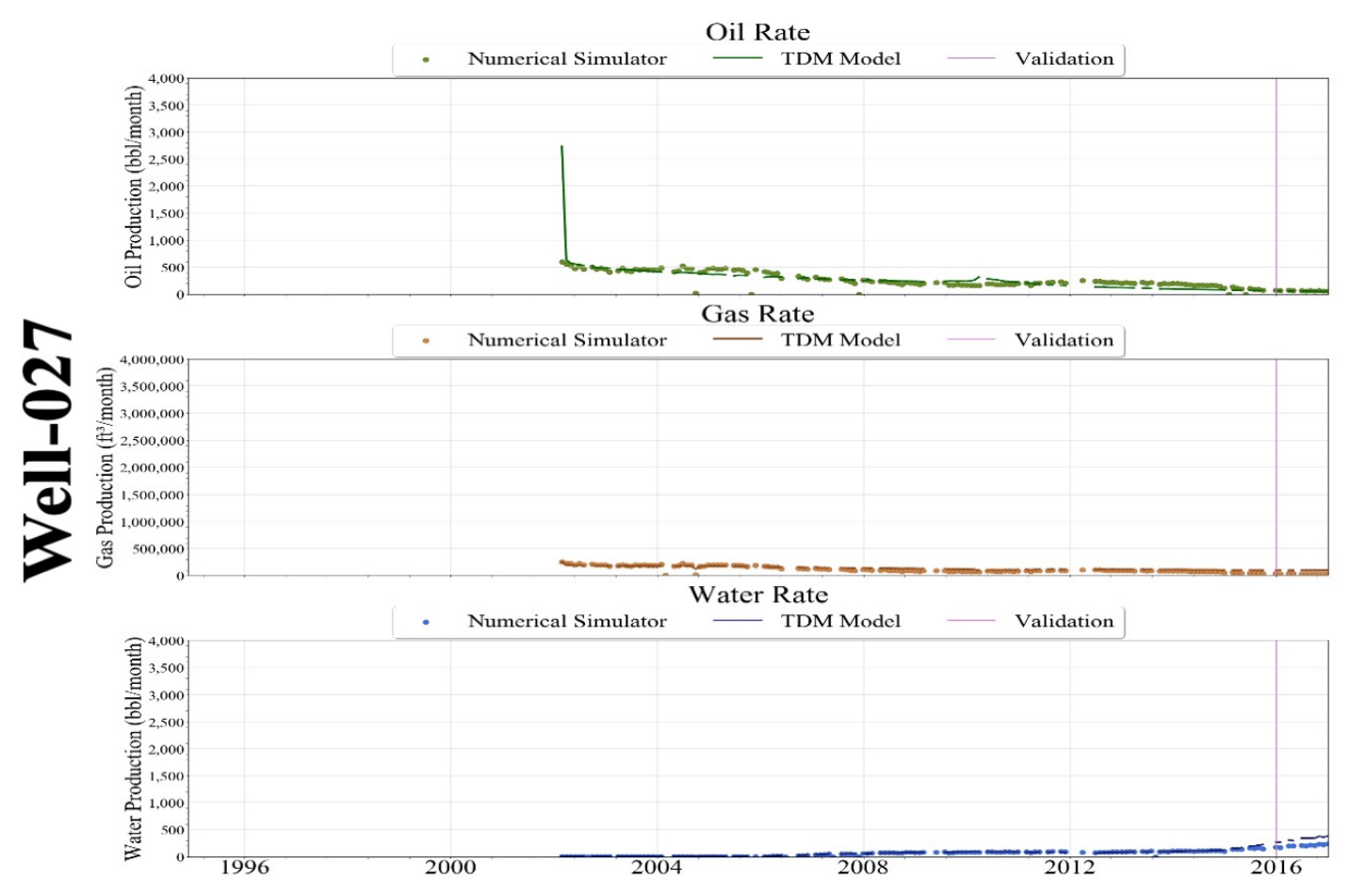

Figure 10-20: Scenario 2 - Well-027 Production History Match

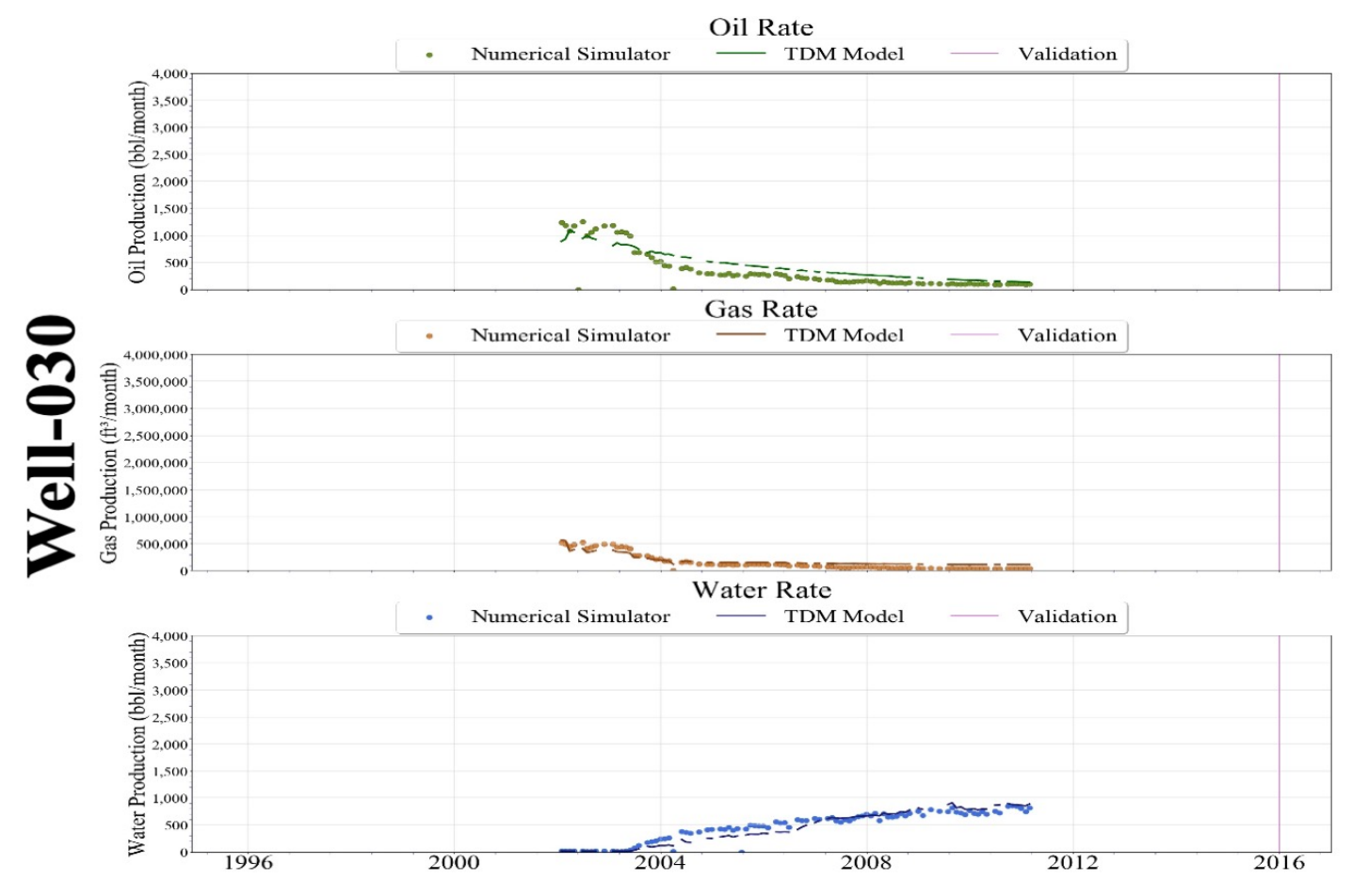

Figure 10-21: Scenario 2 - Well-030 Production History Match 


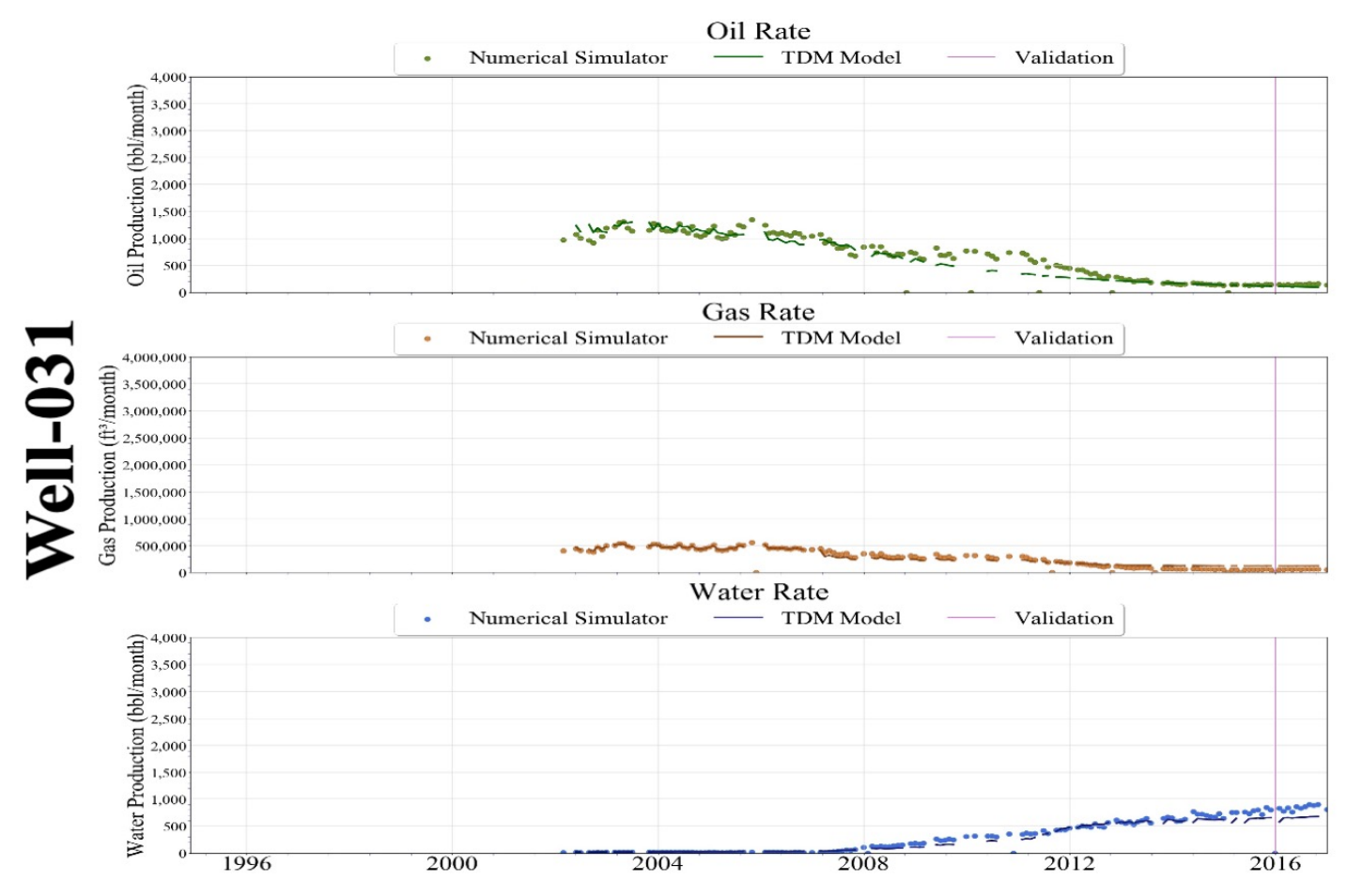

Figure 10-22: Scenario 2 - Well-031 Production History Match

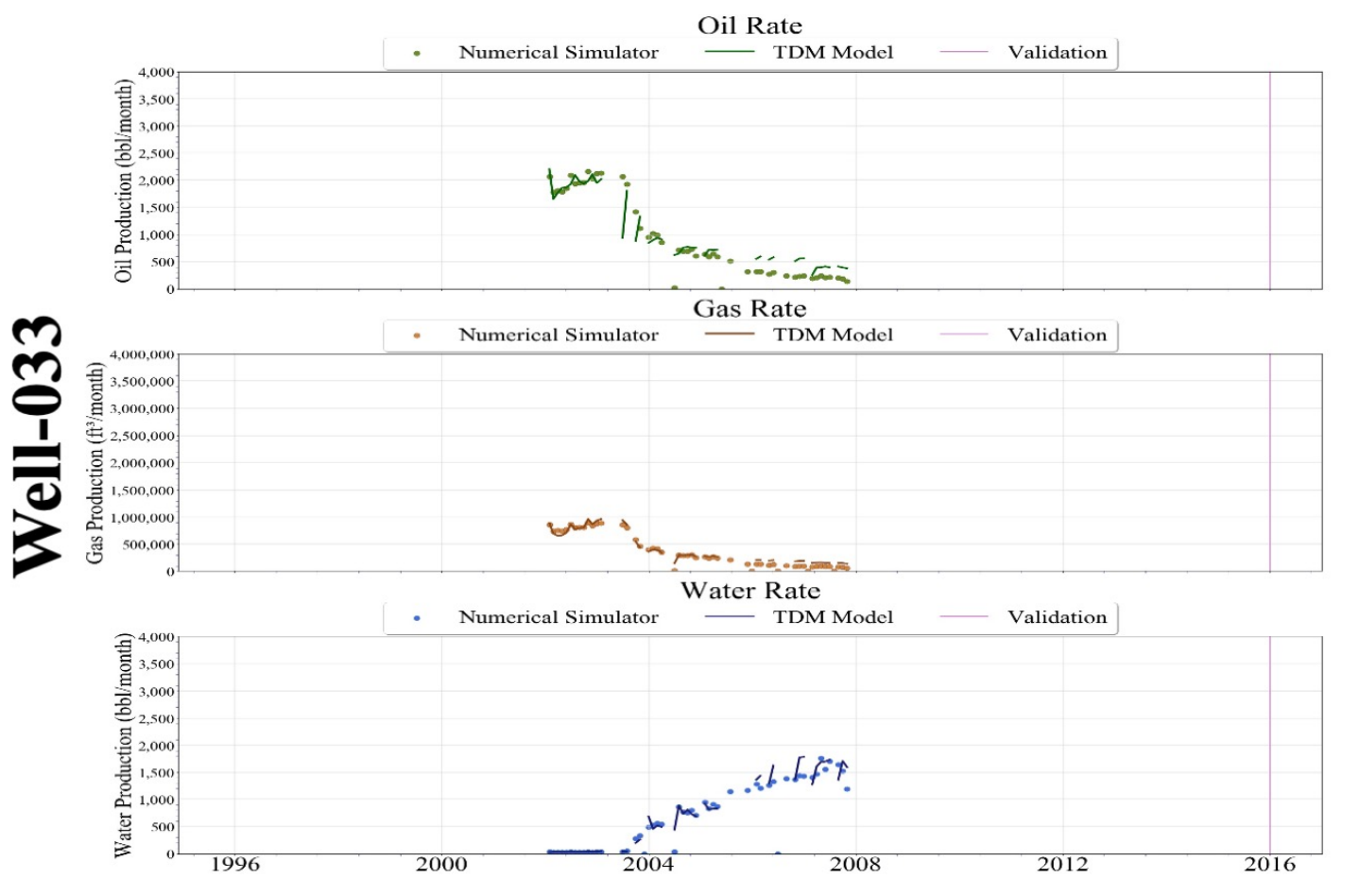

Figure 10-23: Scenario 2 - Well-033 Production History Match 


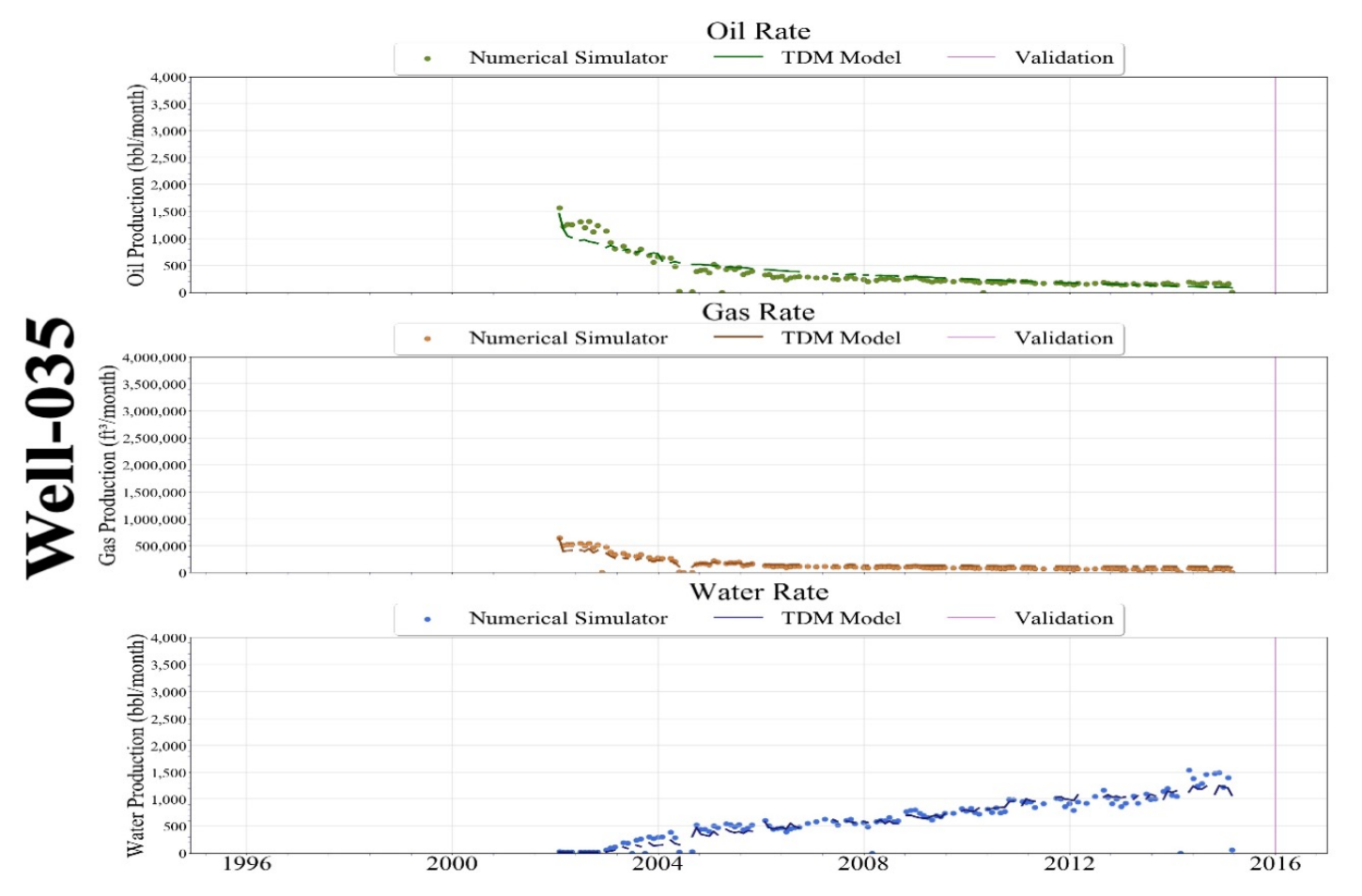

Figure 10-24: Scenario 2 - Well-035 Production History Match

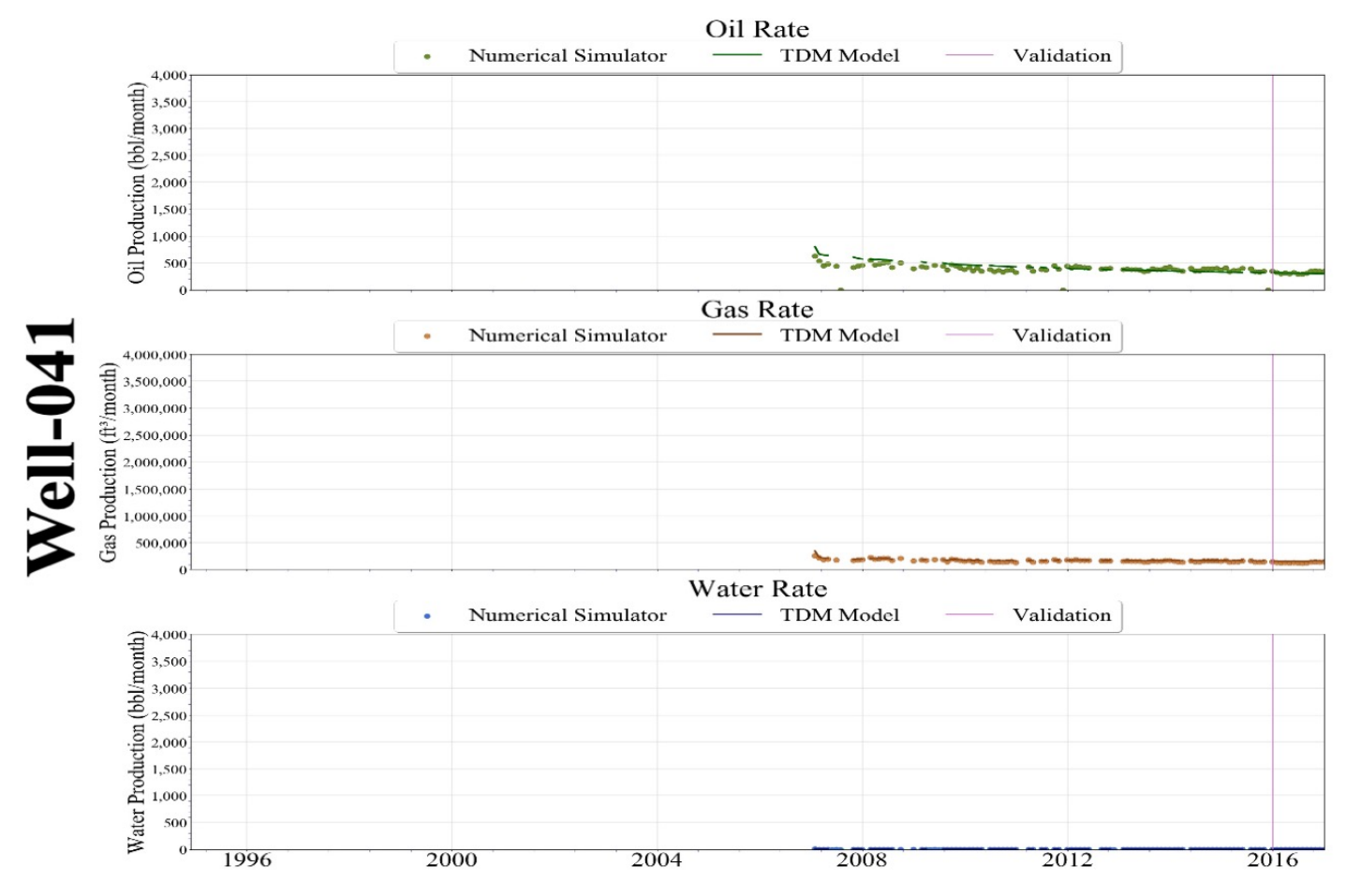

Figure 10-25: Scenario 2 - Well-041 Production History Match 


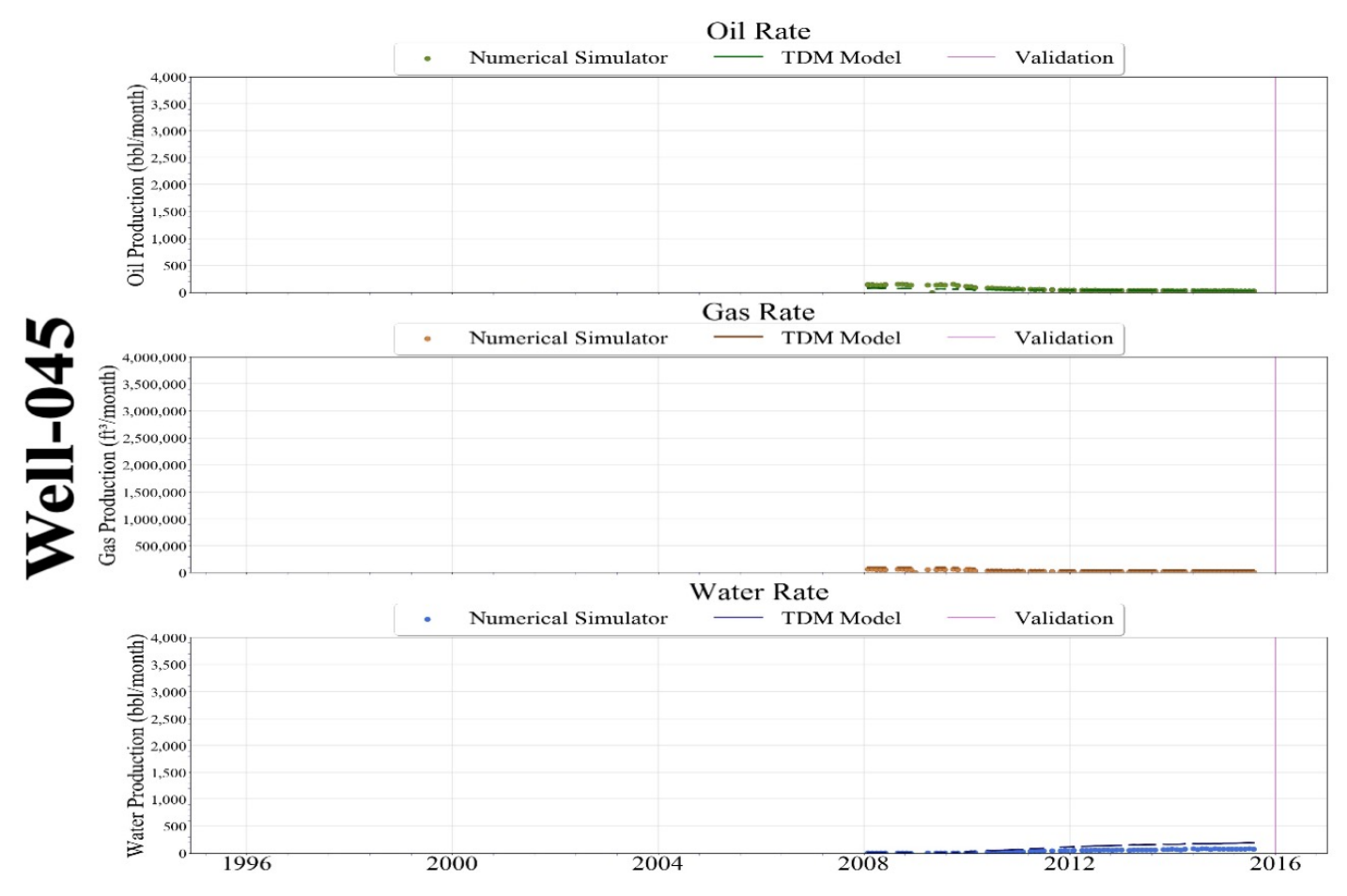

Figure 10-26: Scenario 2 - Well-045 Production History Match

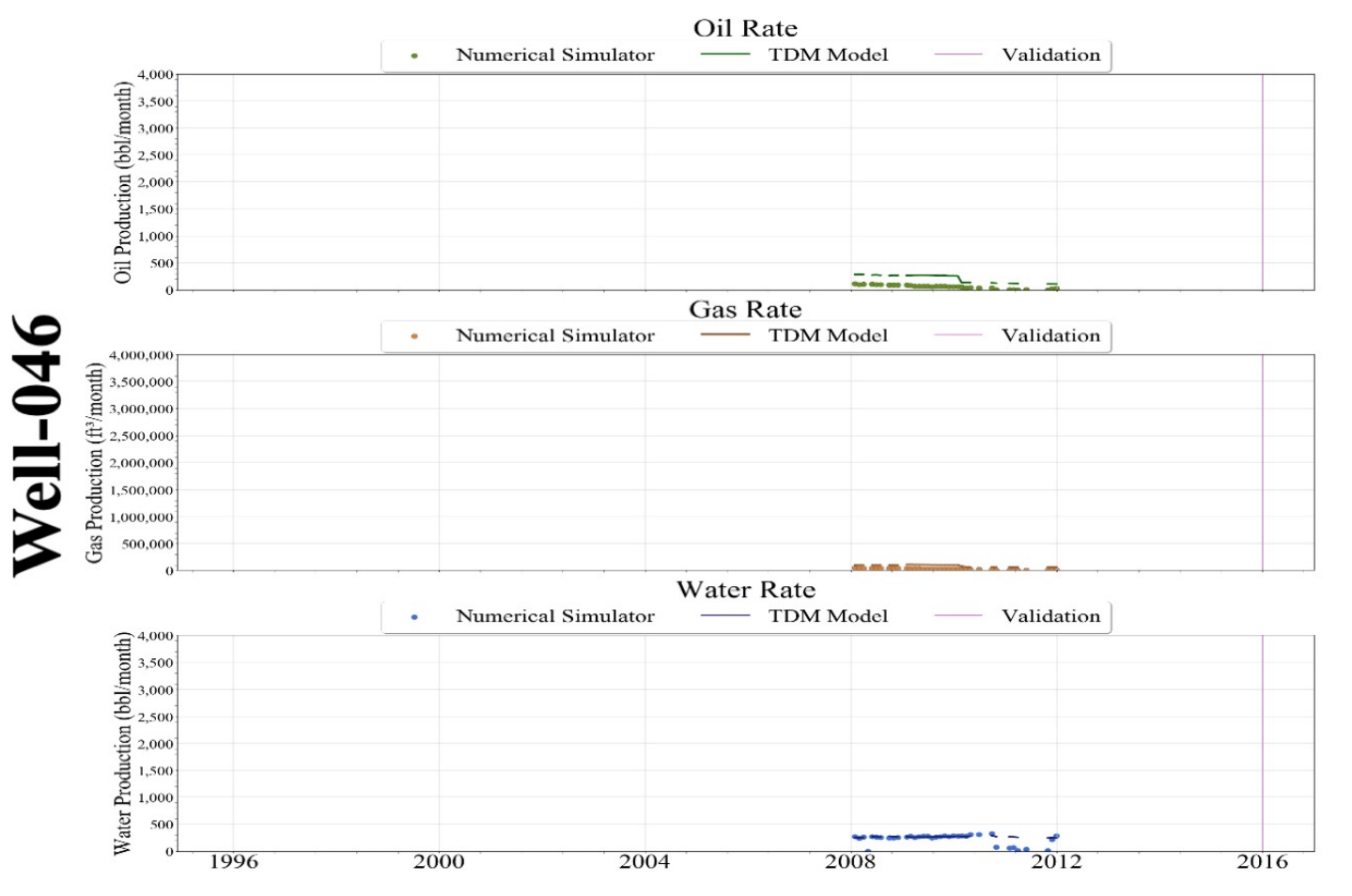

Figure 10-27: Scenario 2 - Well-046 Production History Match 


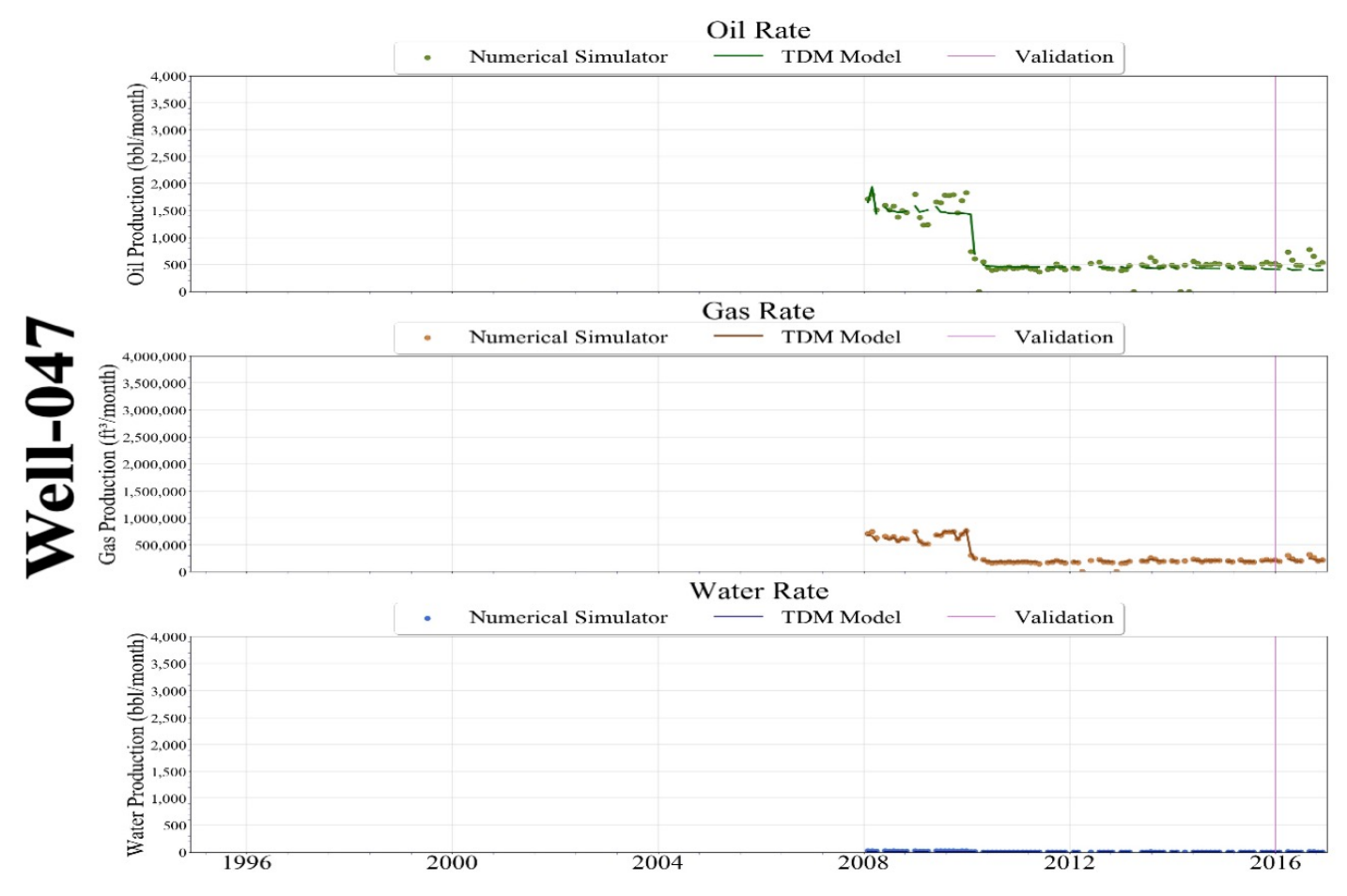

Figure 10-28: Scenario 2 - Well-047 Production History Match

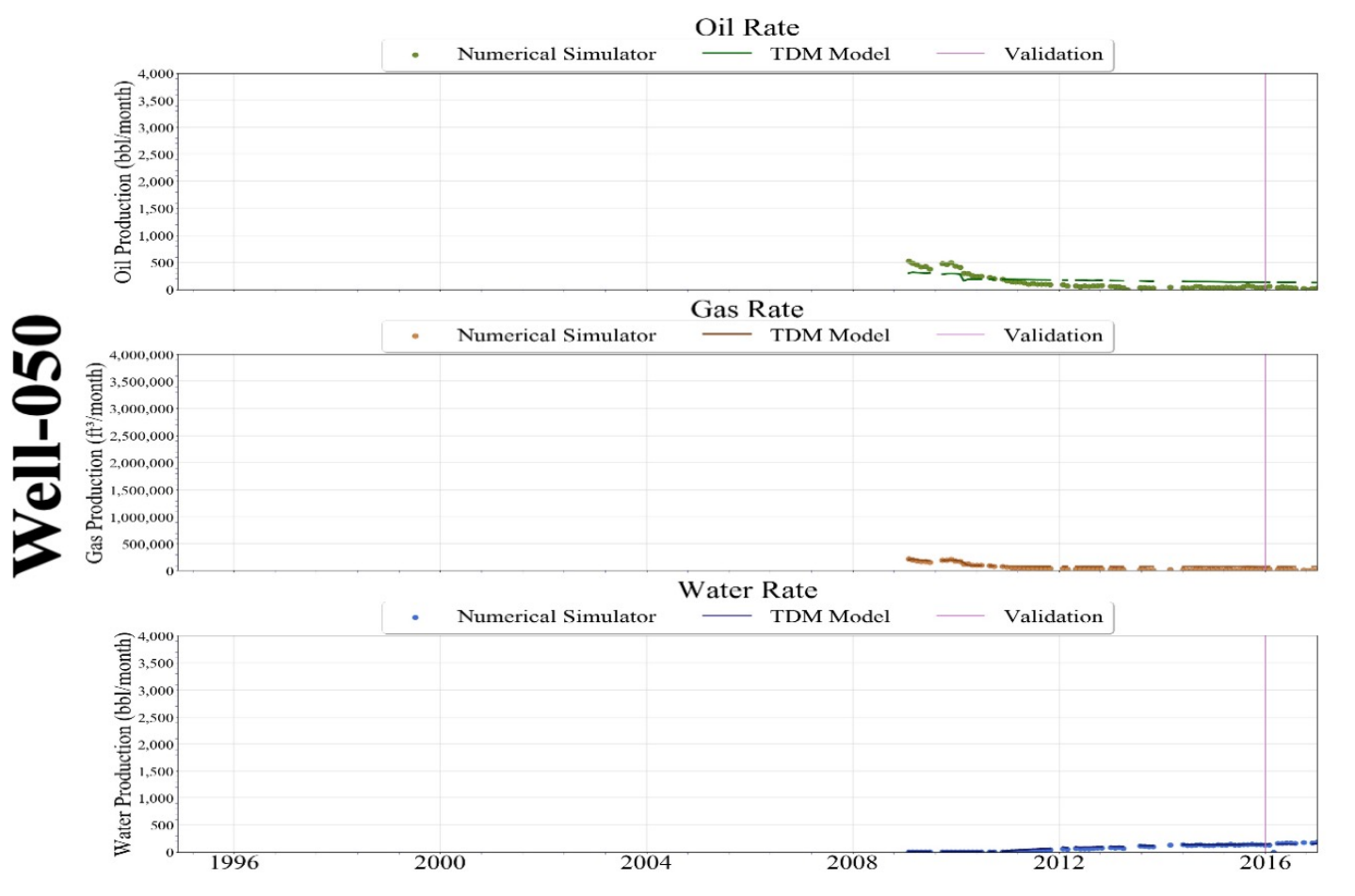

Figure 10-29: Scenario 2 - Well-050 Production History Match 


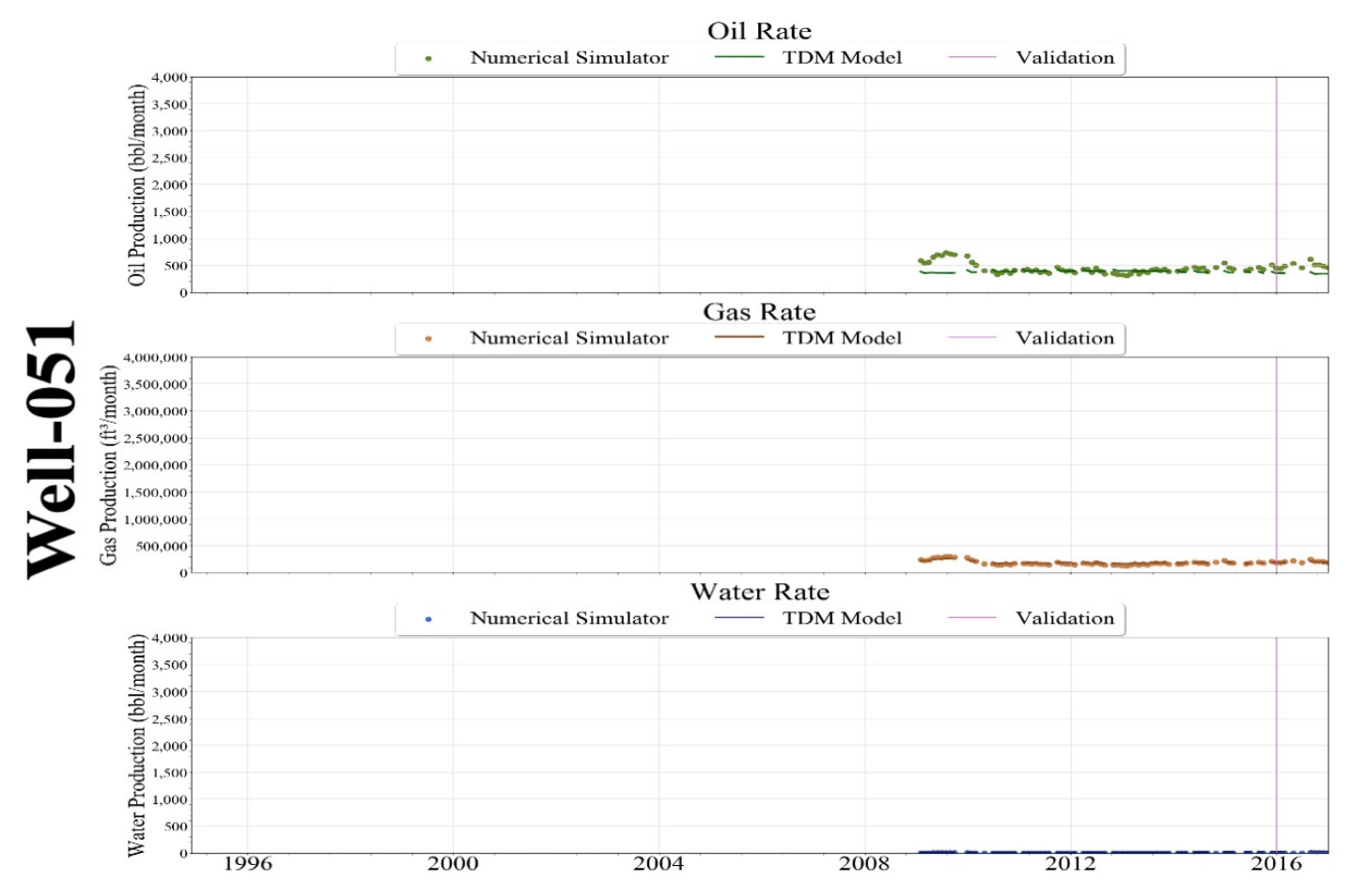

Figure 10-30: Scenario 2 - Well-051 Production History Match

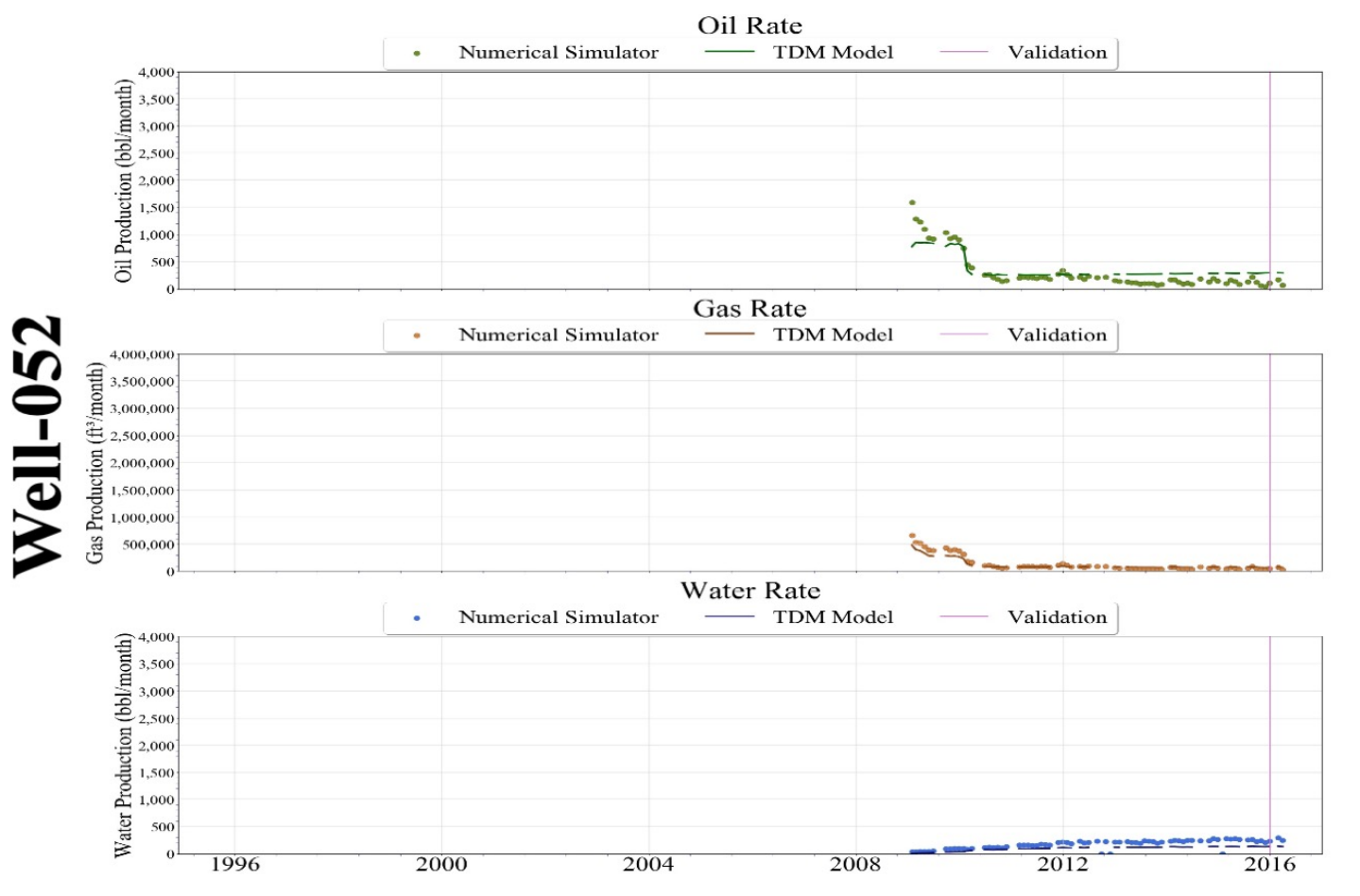

Figure 10-31: Scenario 2 - Well-052 Production History Match 


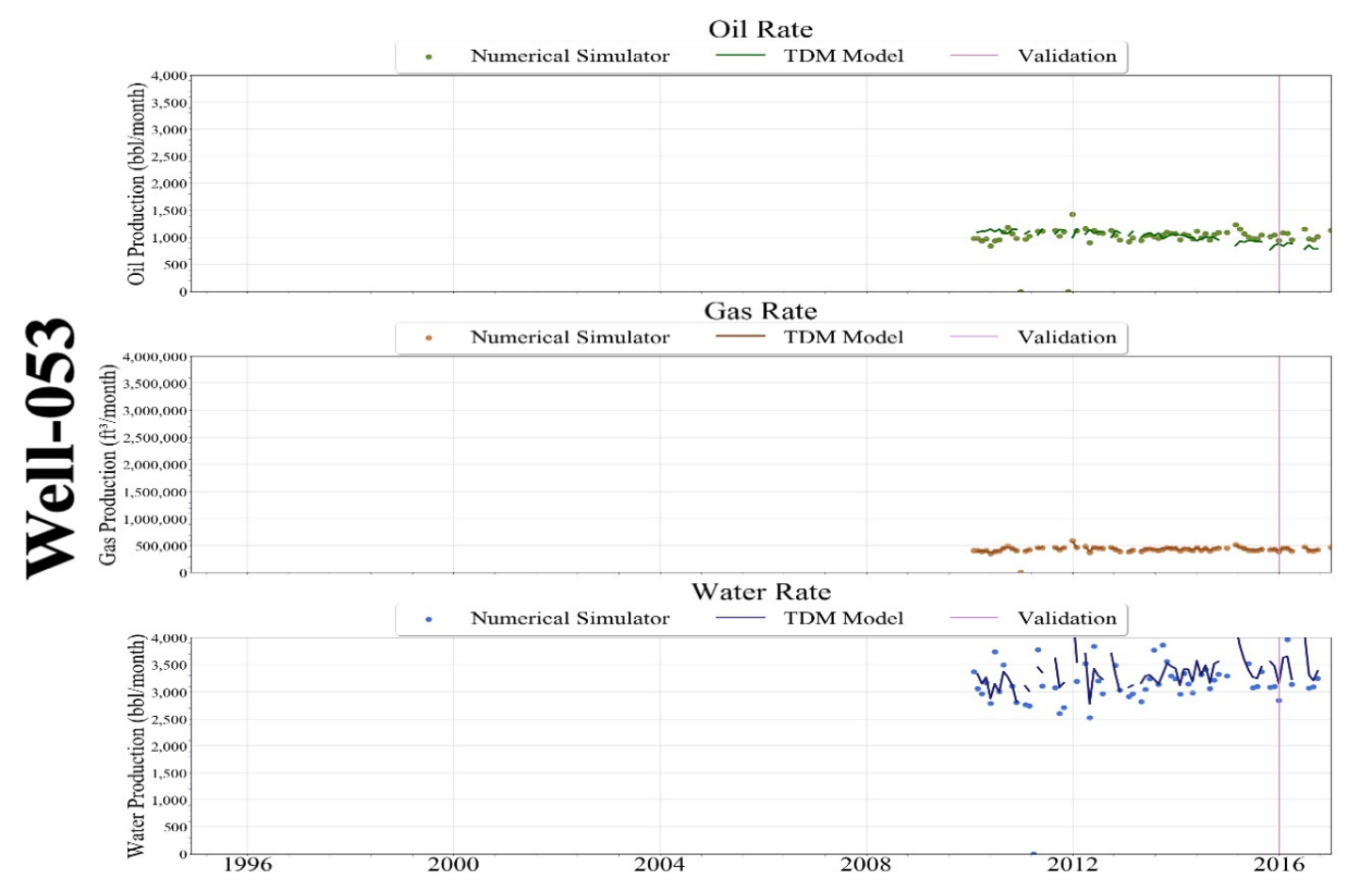

Figure 10-32: Scenario 2 - Well-053 Production History Match

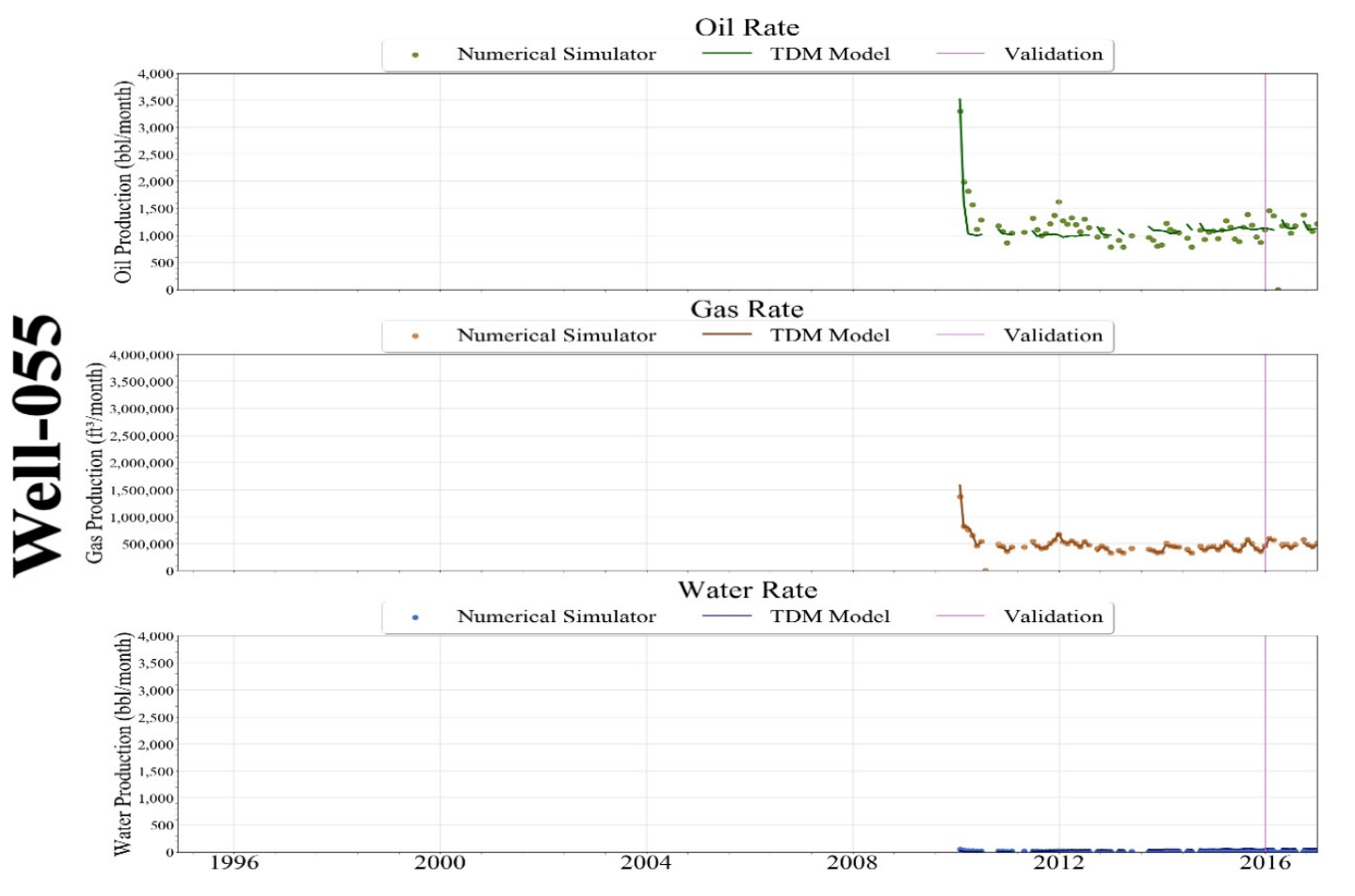

Figure 10-33: Scenario 2 - Well-055 Production History Match 


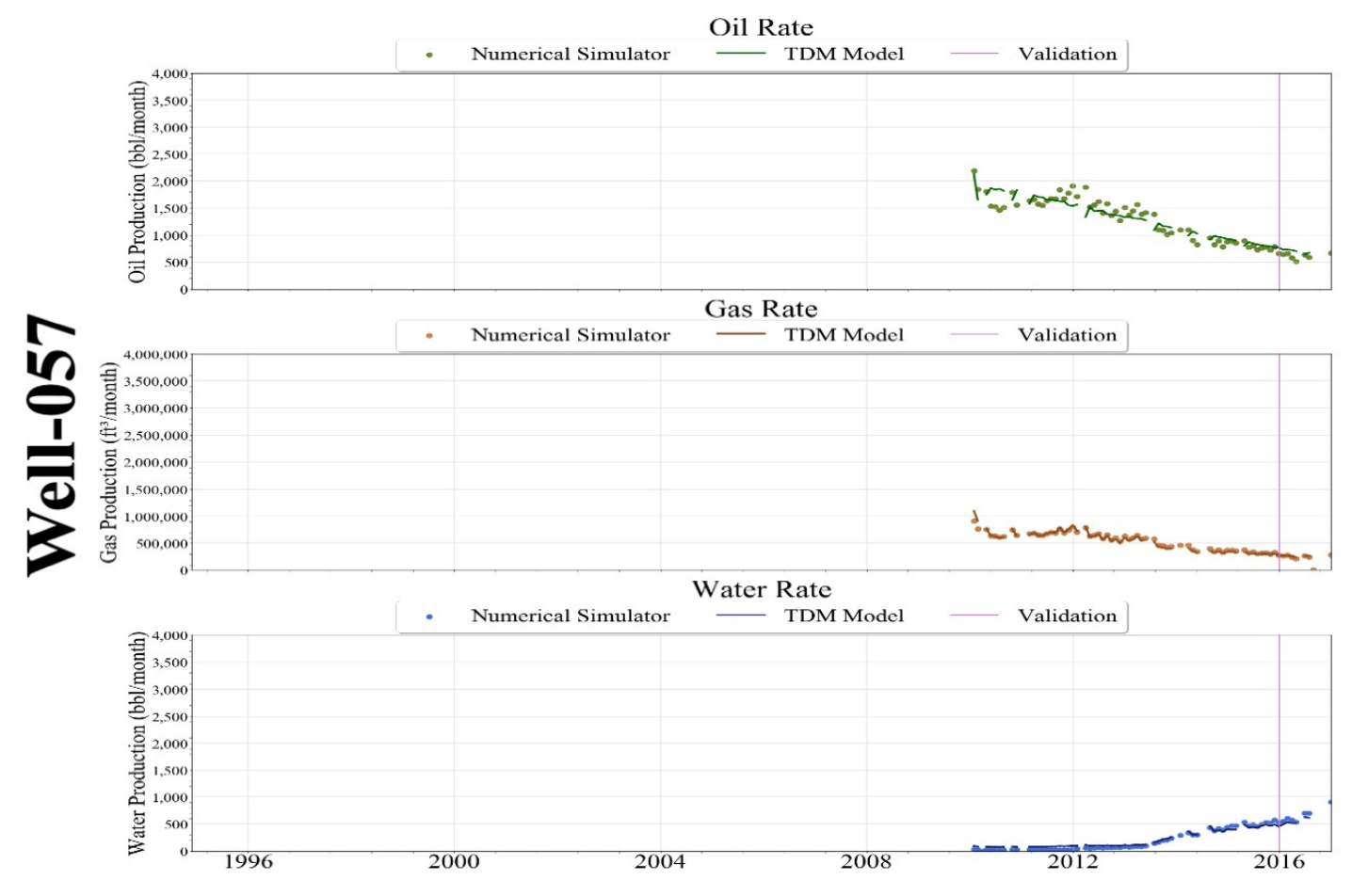

Figure 10-34: Scenario 2 - Well-057 Production History Match

\subsubsection{Average History Match of Production}

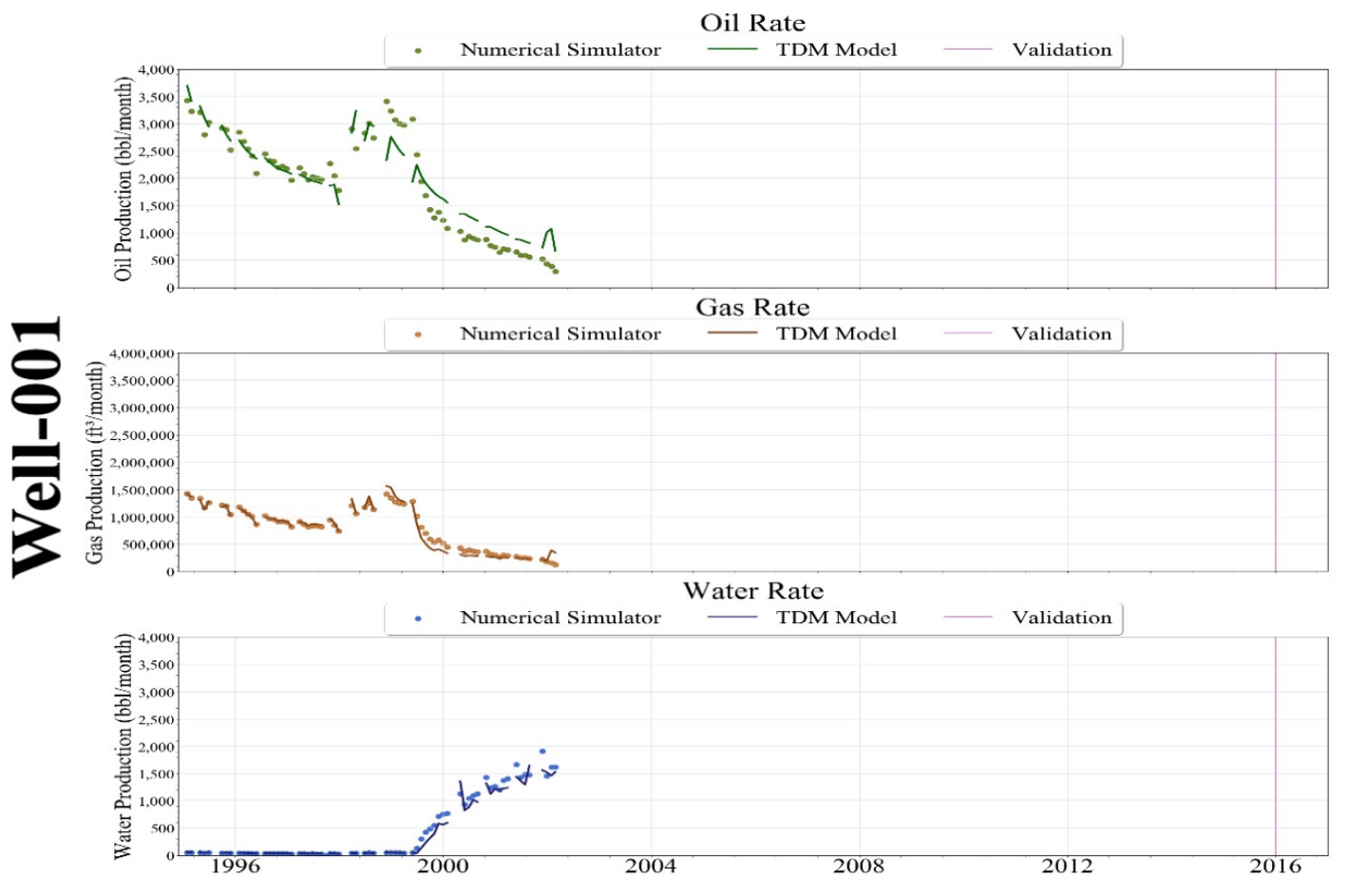

Figure 10-35: Scenario 2 - Well-001 Production History Match 


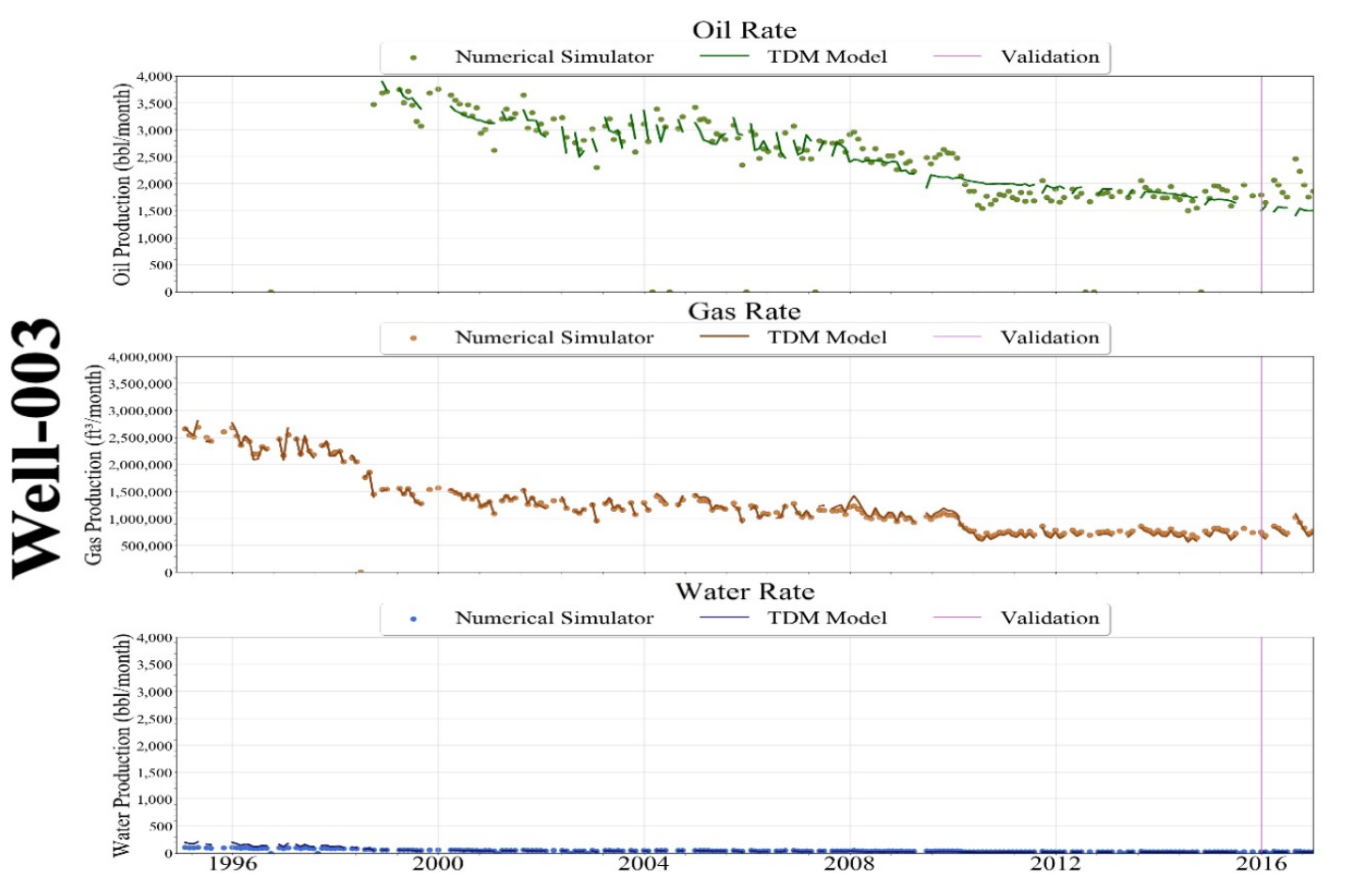

Figure 10-36: Scenario 2 - Well-003 Production History Match

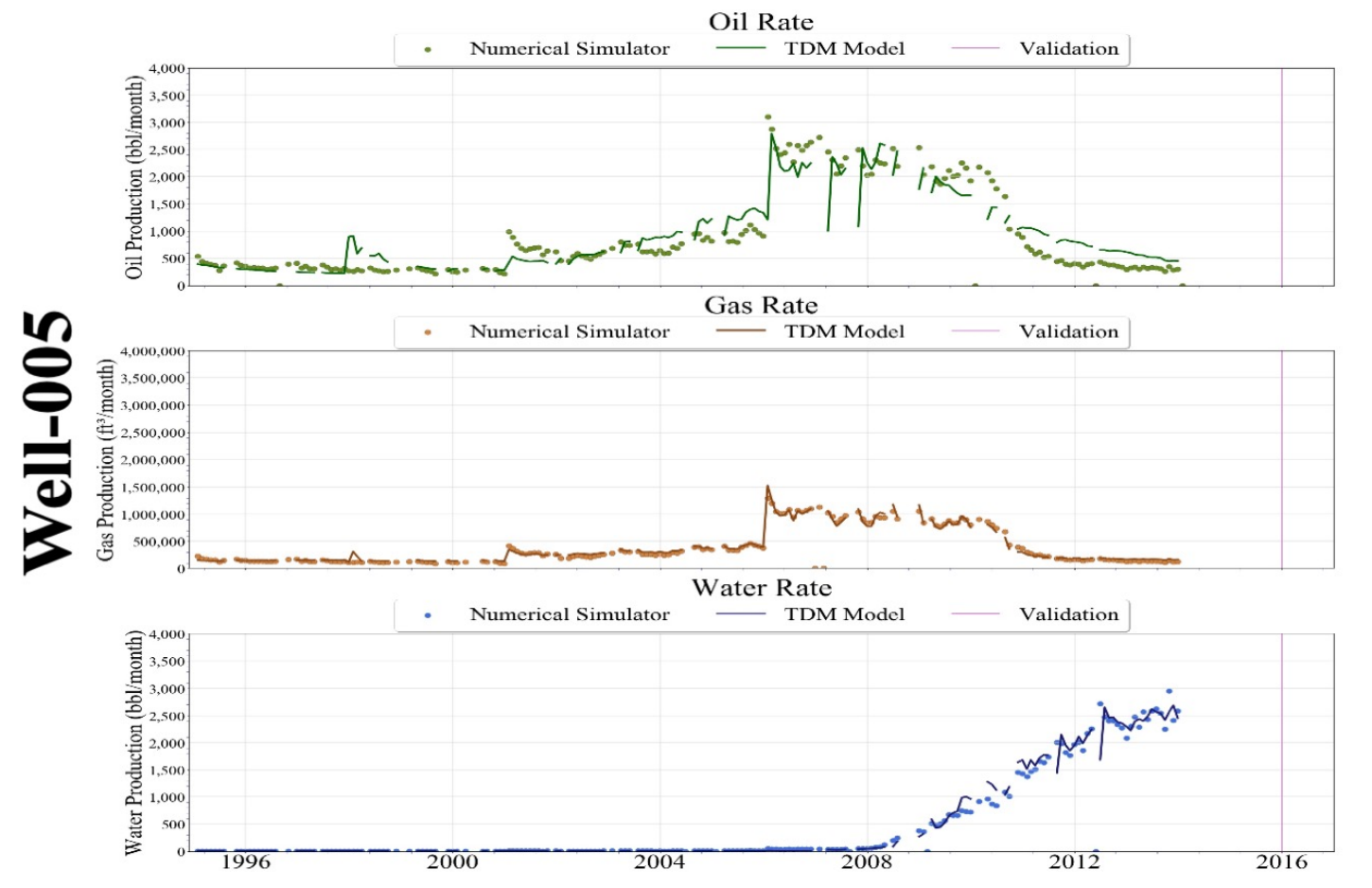

Figure 10-37: Scenario 2 - Well-005 Production History Match 


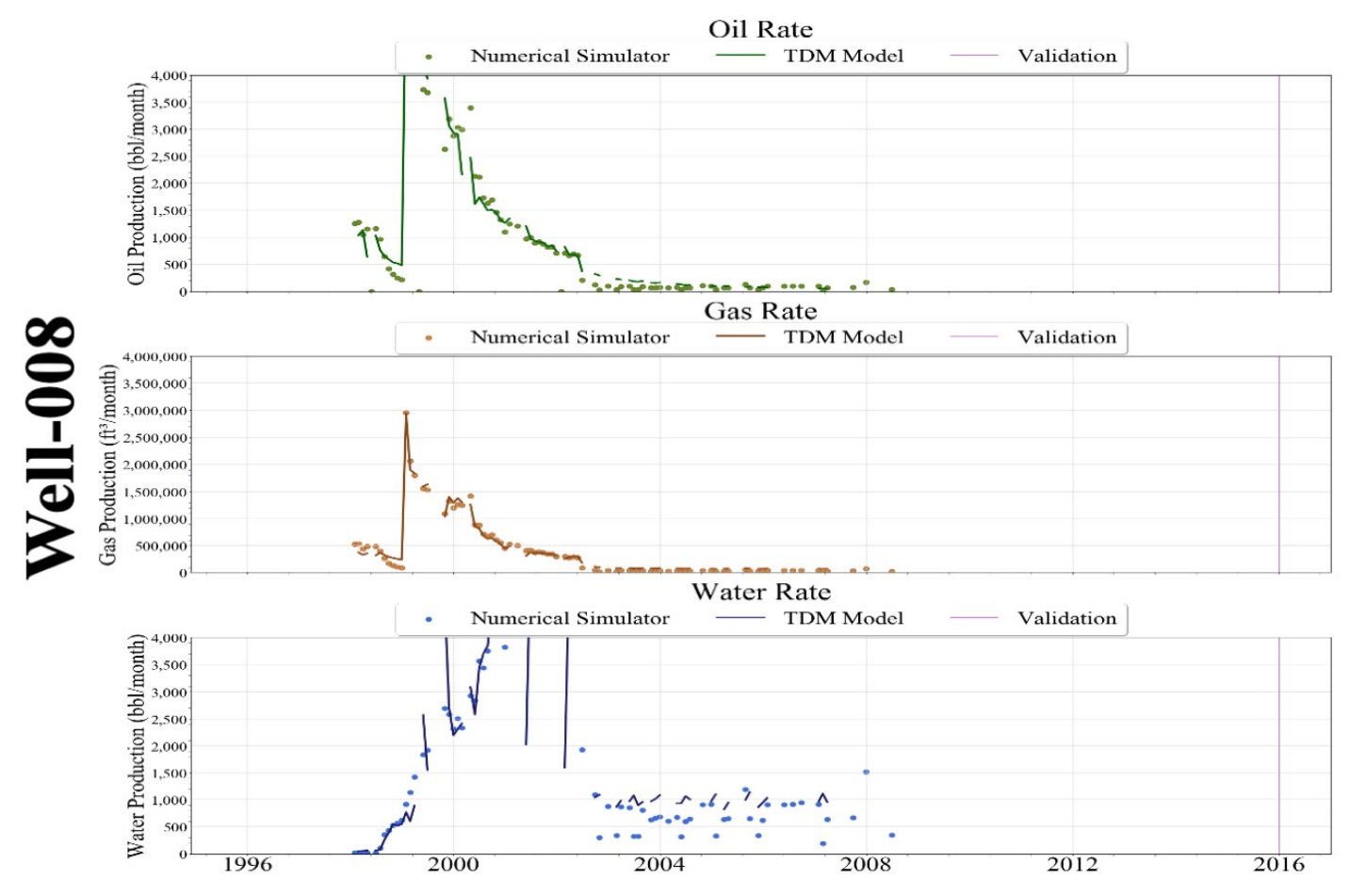

Figure 10-38: Scenario 2 - Well-008 Production History Match

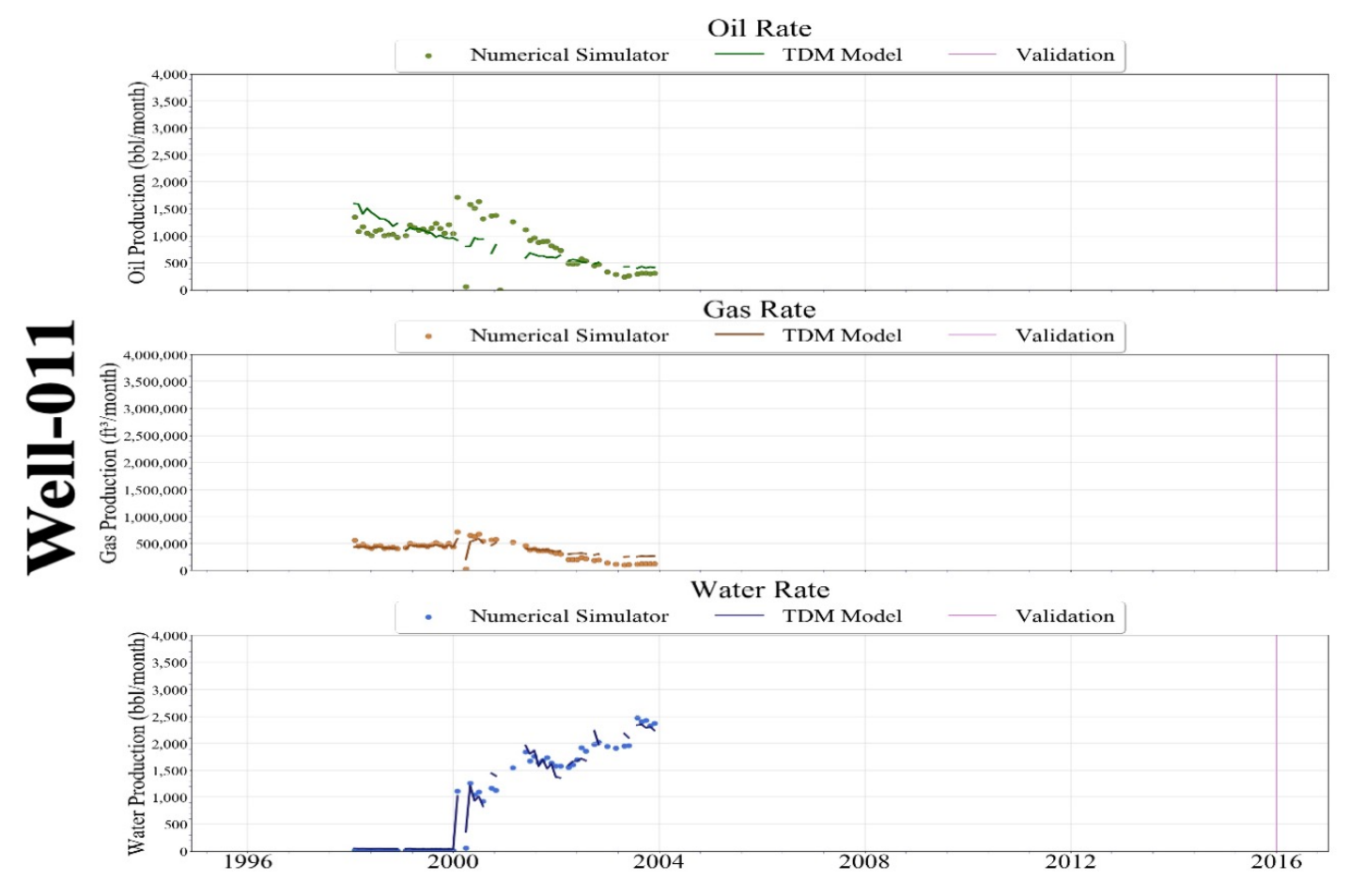

Figure 10-39: Scenario 2 - Well-011 Production History Match 


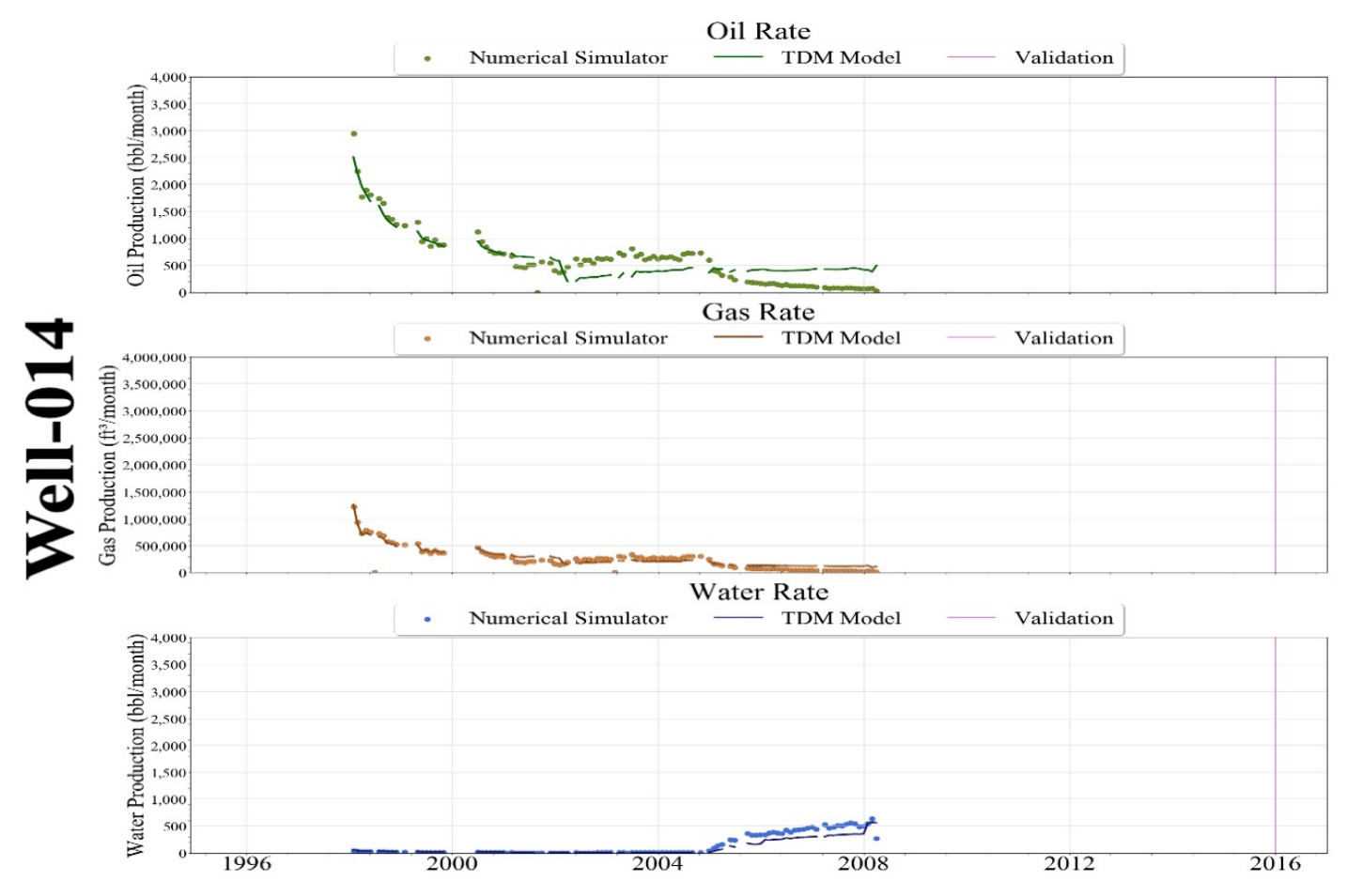

Figure 10-40: Scenario 2 - Well-014 Production History Match

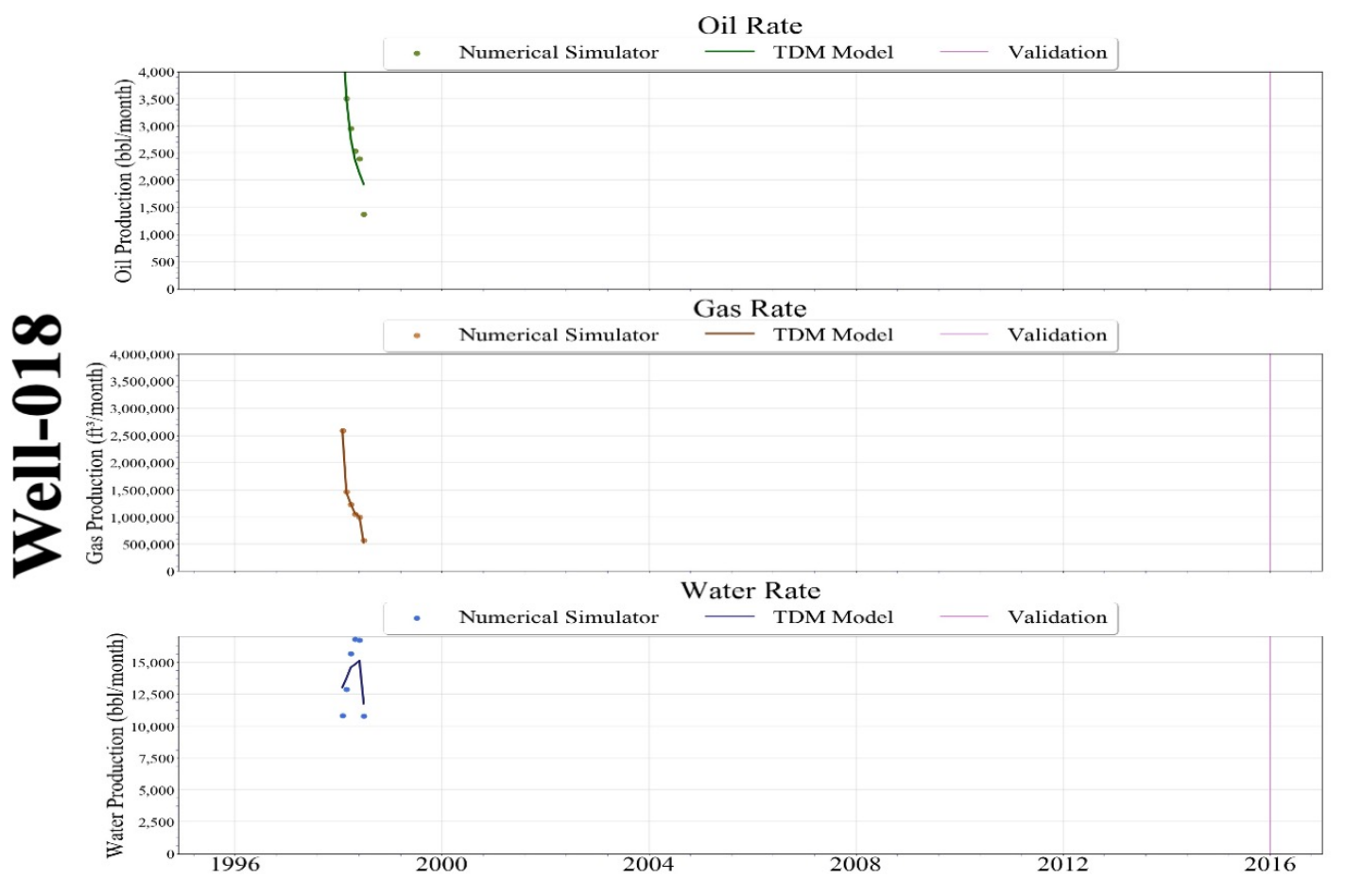

Figure 10-41: Scenario 2 - Well-018 Production History Match 


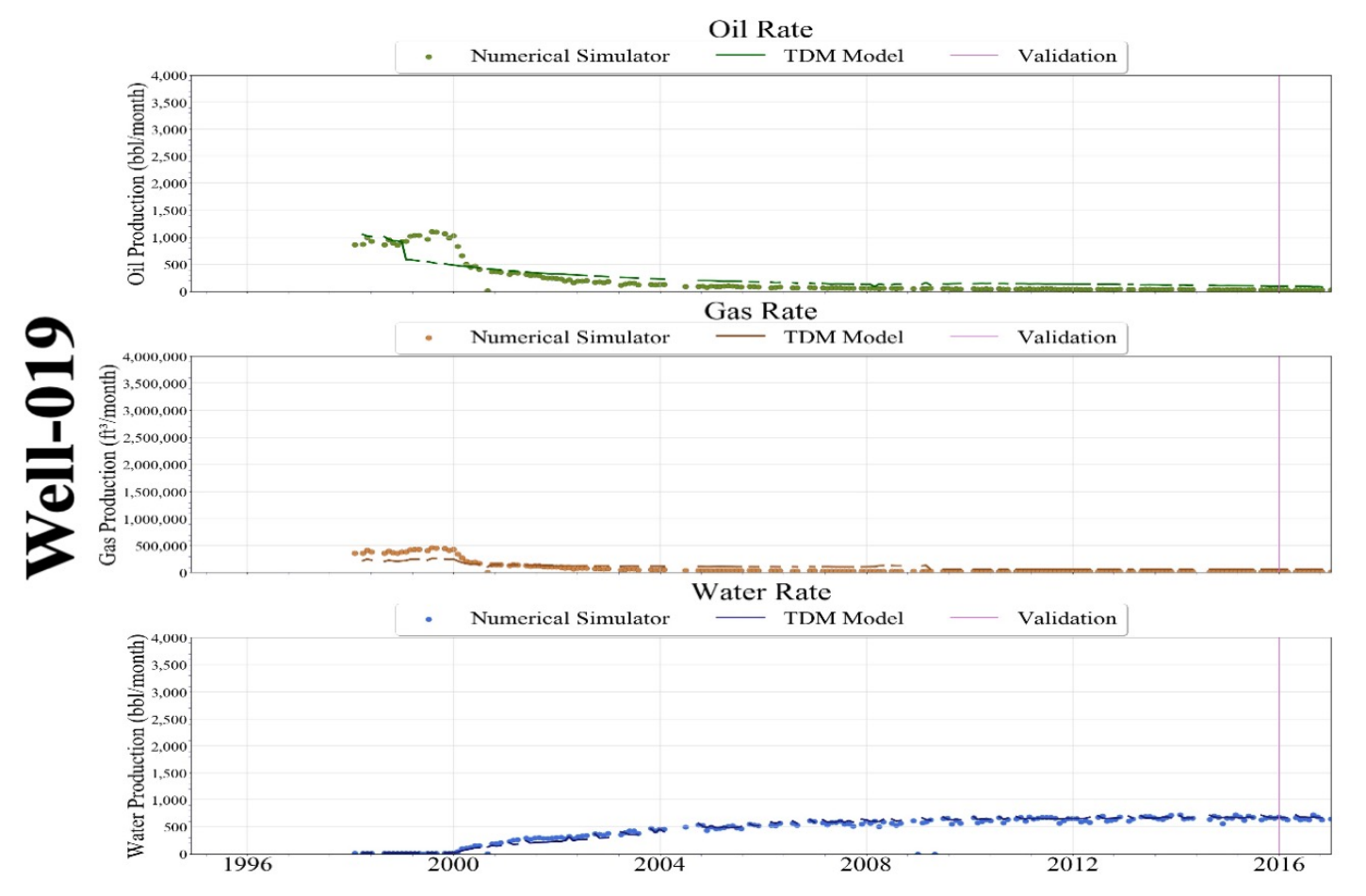

Figure 10-42: Scenario 2 - Well-019 Production History Match

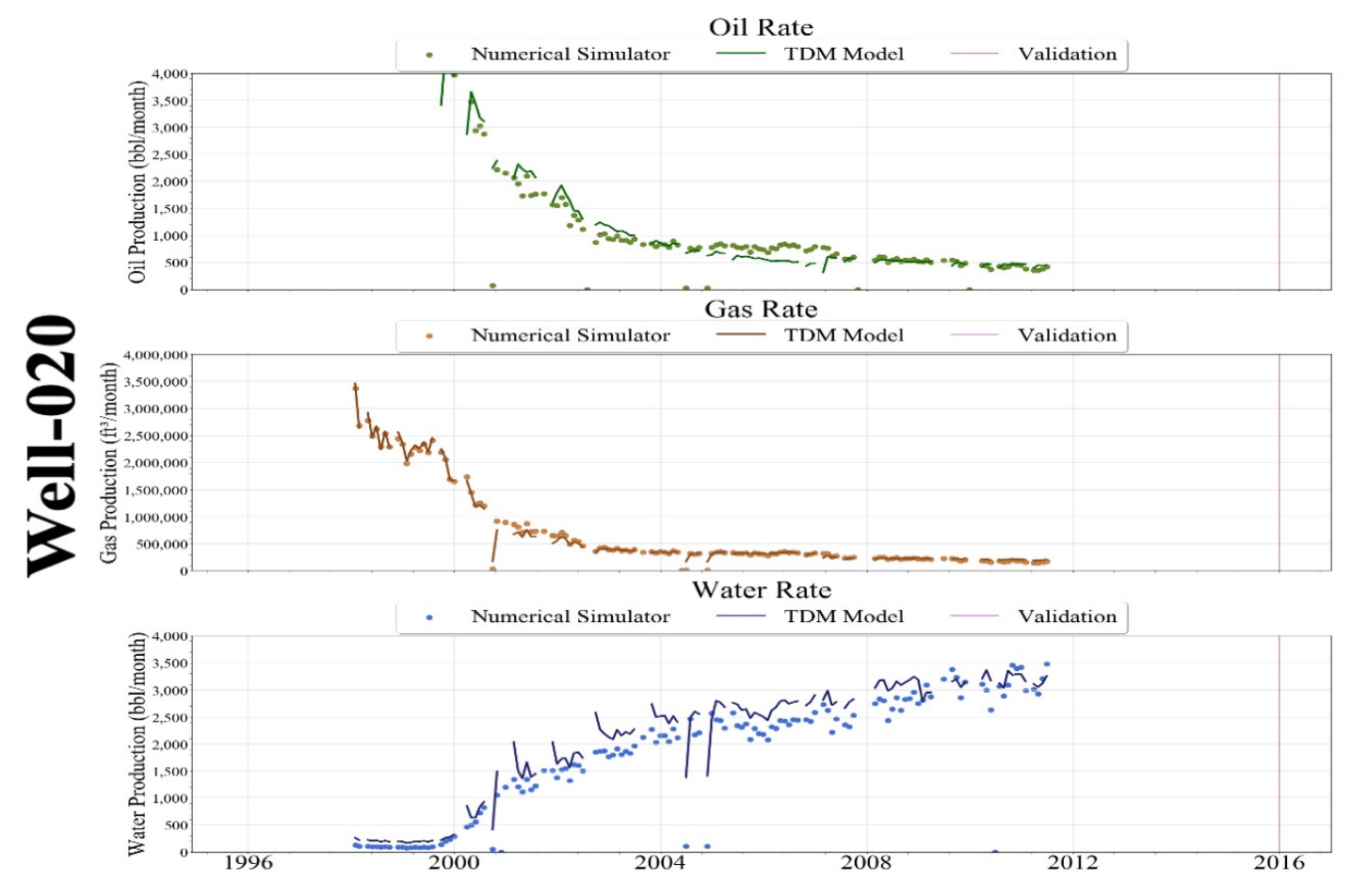

Figure 10-43: Scenario 2 - Well-020 Production History Match 


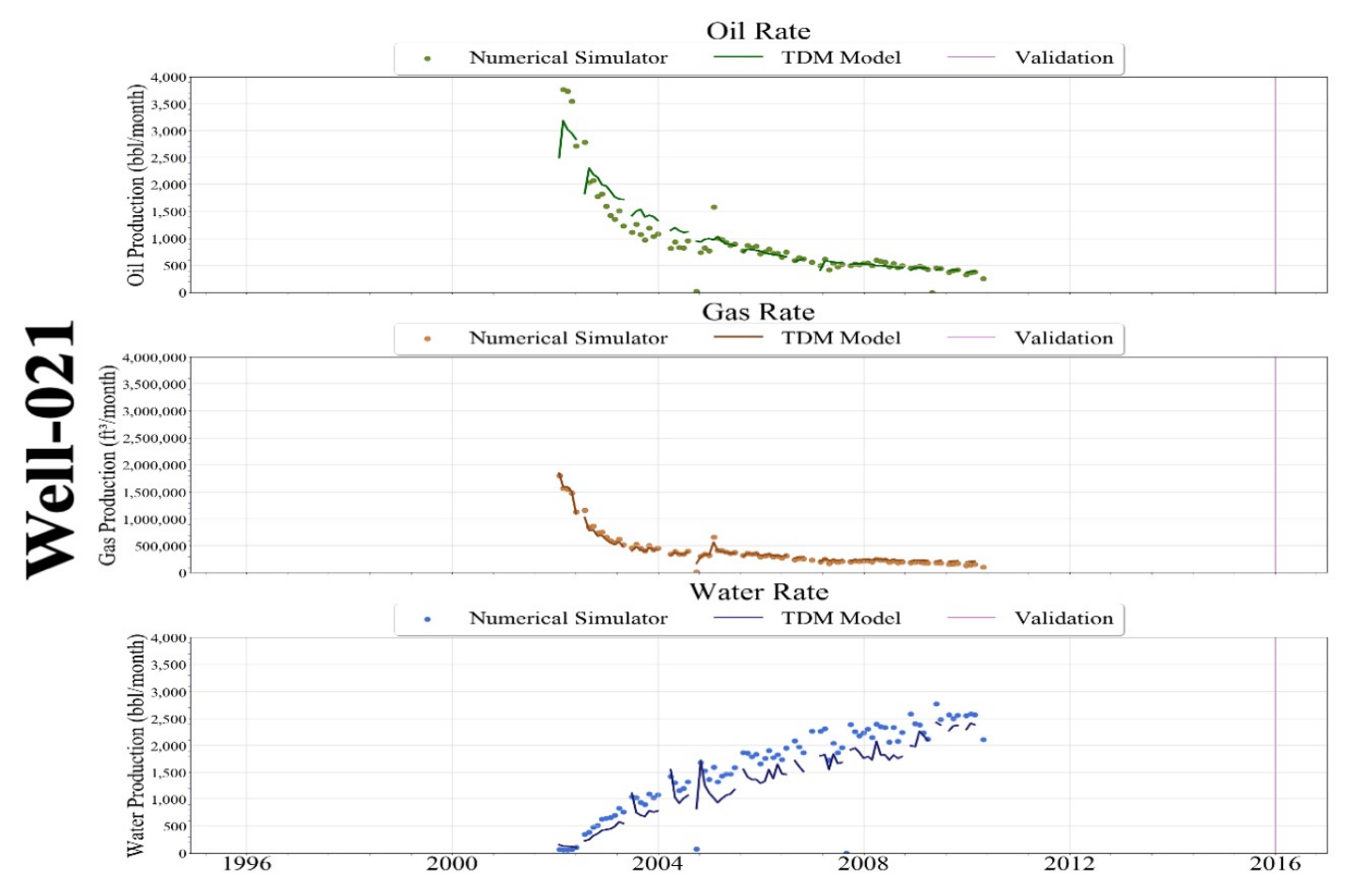

Figure 10-44: Scenario 2 - Well-021 Production History Match

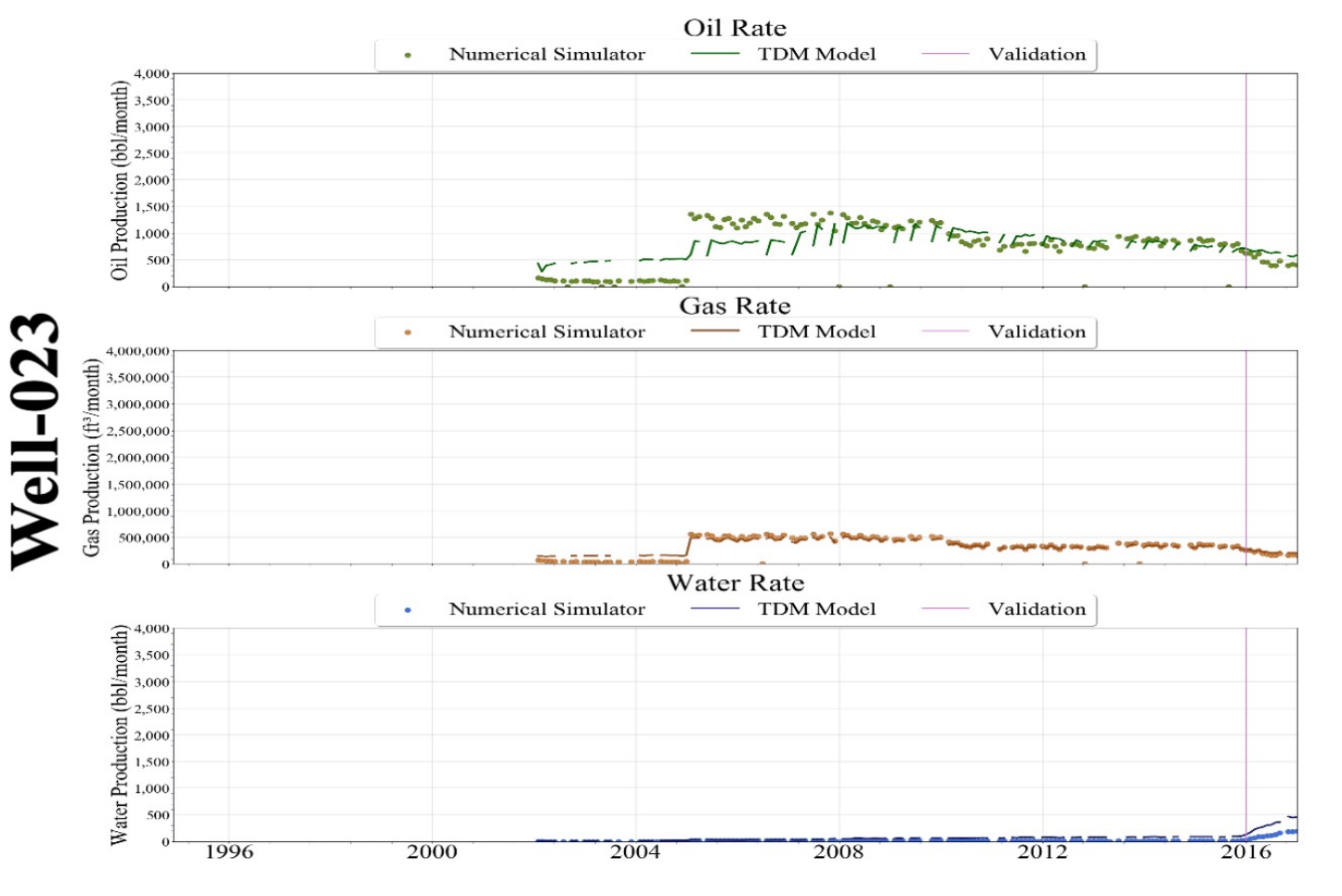

Figure 10-45: Scenario 2 - Well-023 Production History Match 


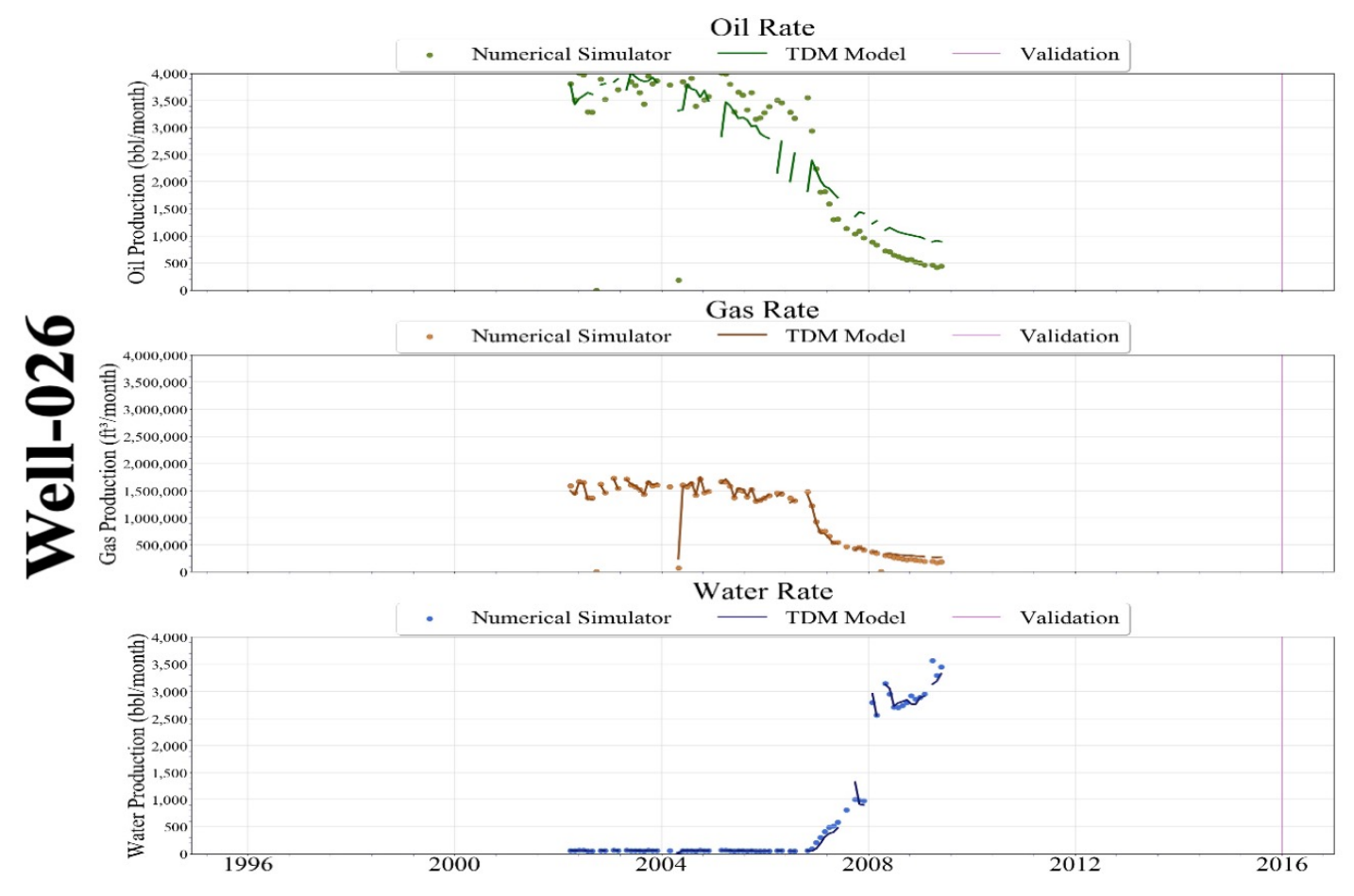

Figure 10-46: Scenario 2 - Well-026 Production History Match

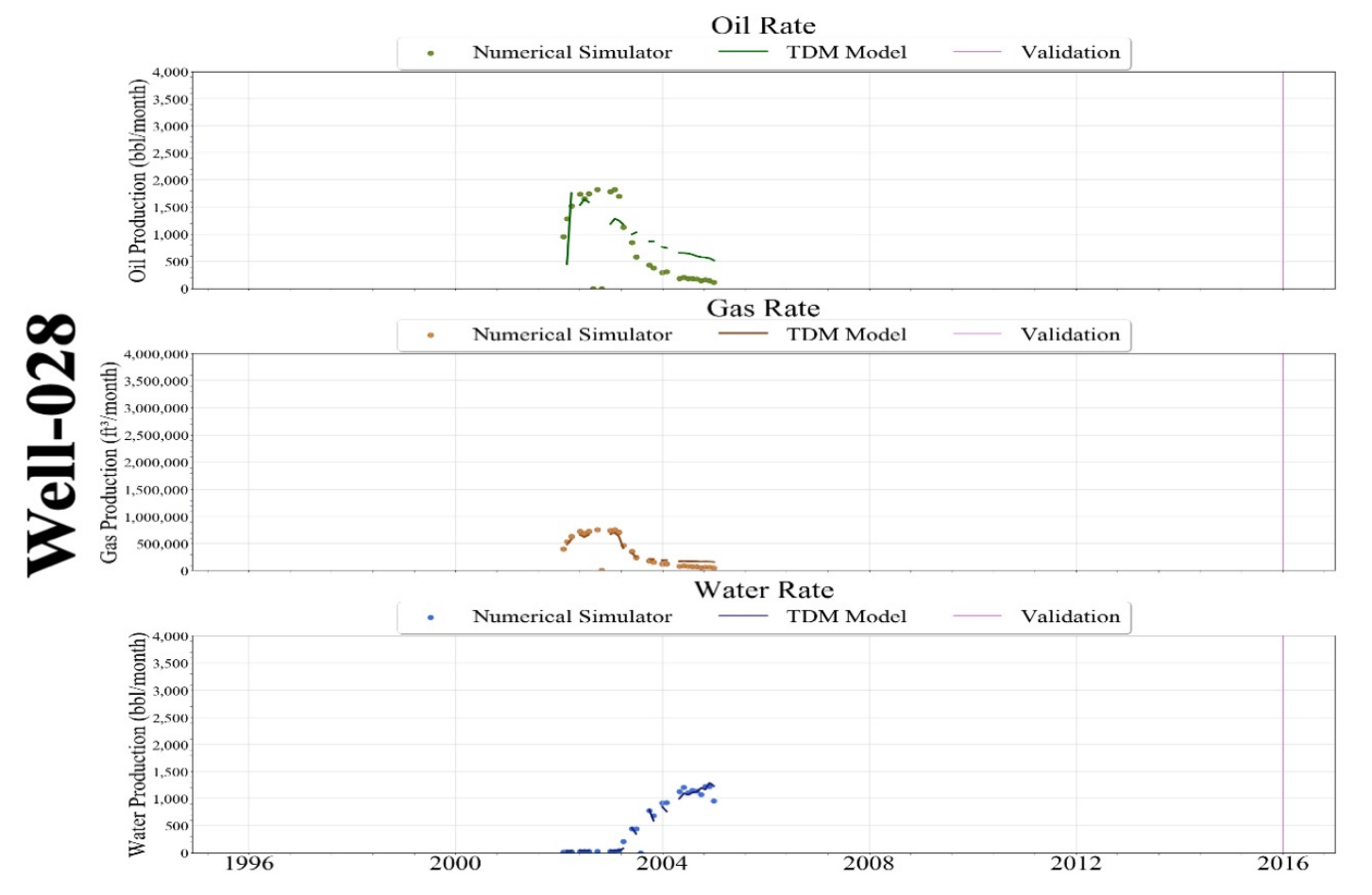

Figure 10-47: Scenario 2 - Well-028 Production History Match 


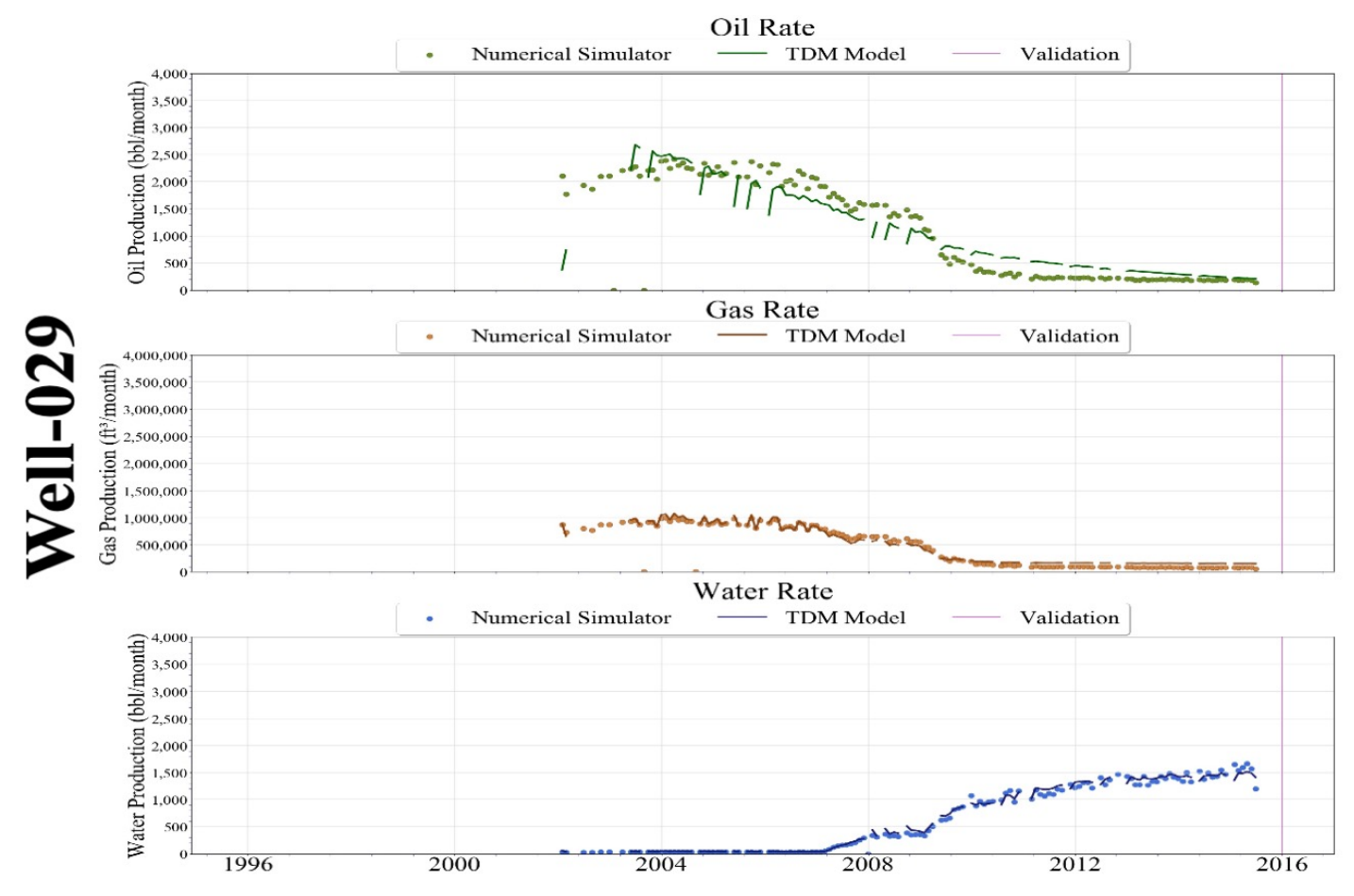

Figure 10-48: Scenario 2 - Well-029 Production History Match

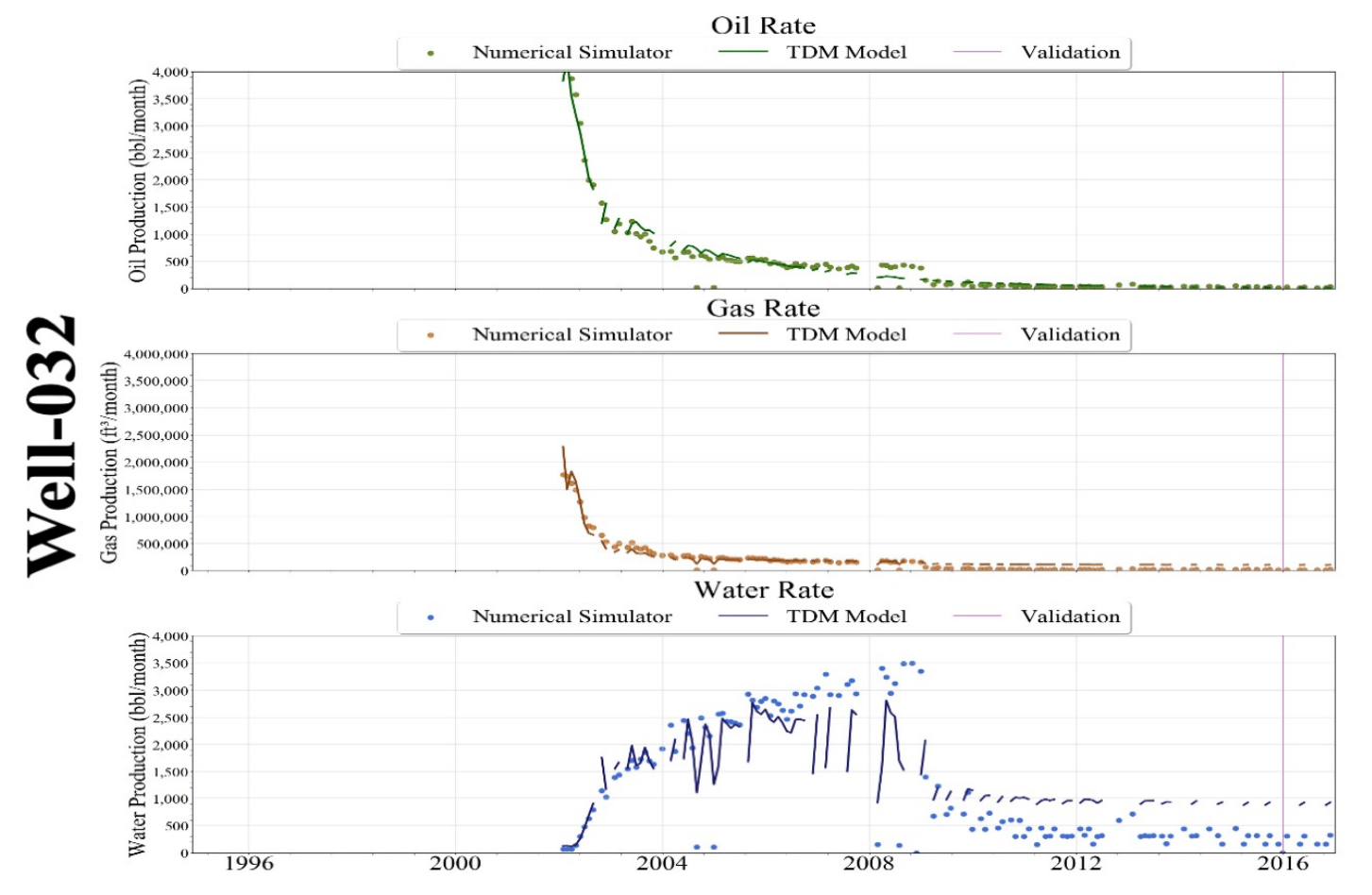

Figure 10-49: Scenario 2 - Well-032 Production History Match 


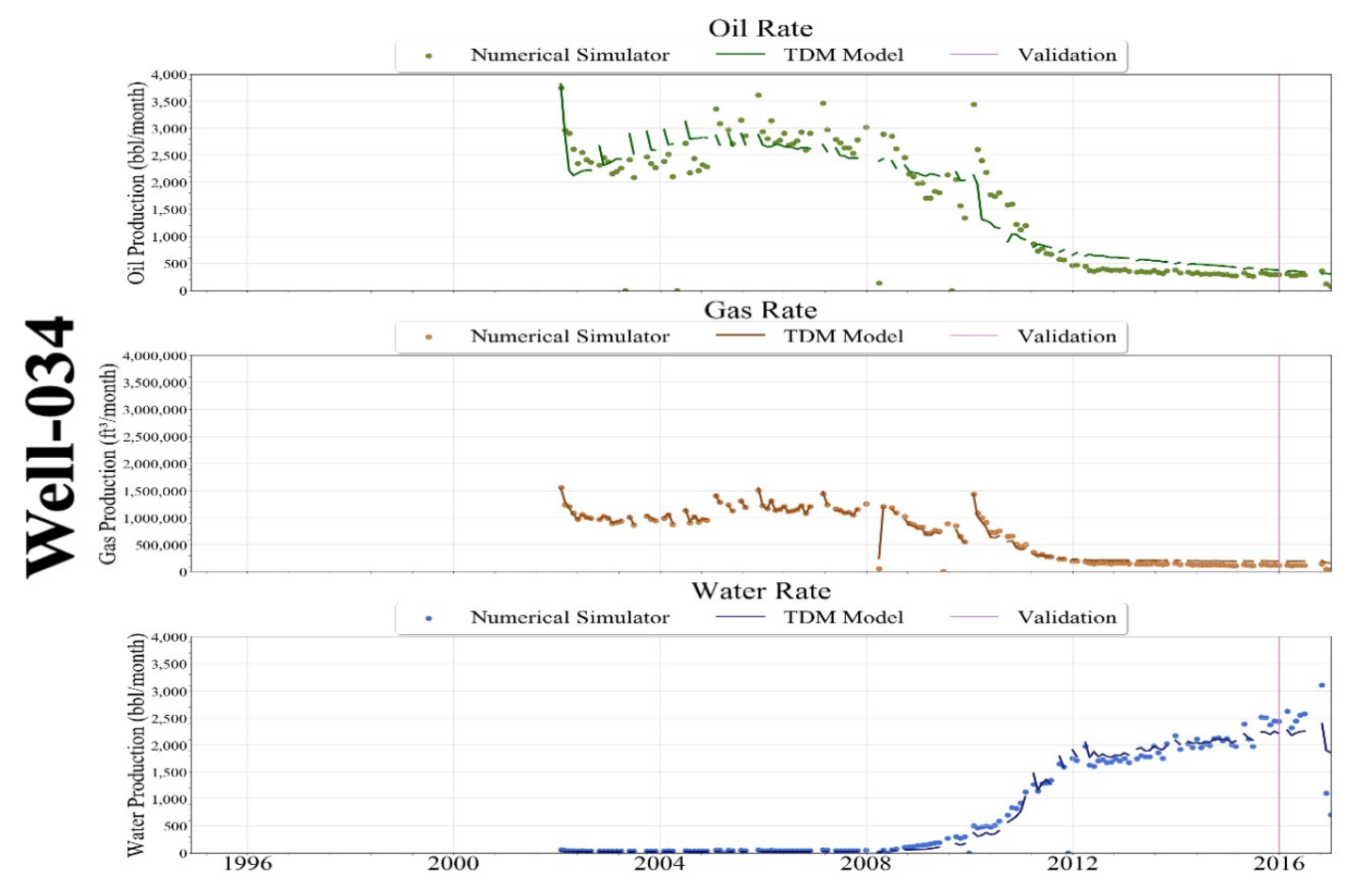

Figure 10-50: Scenario 2 - Well-034 Production History Match

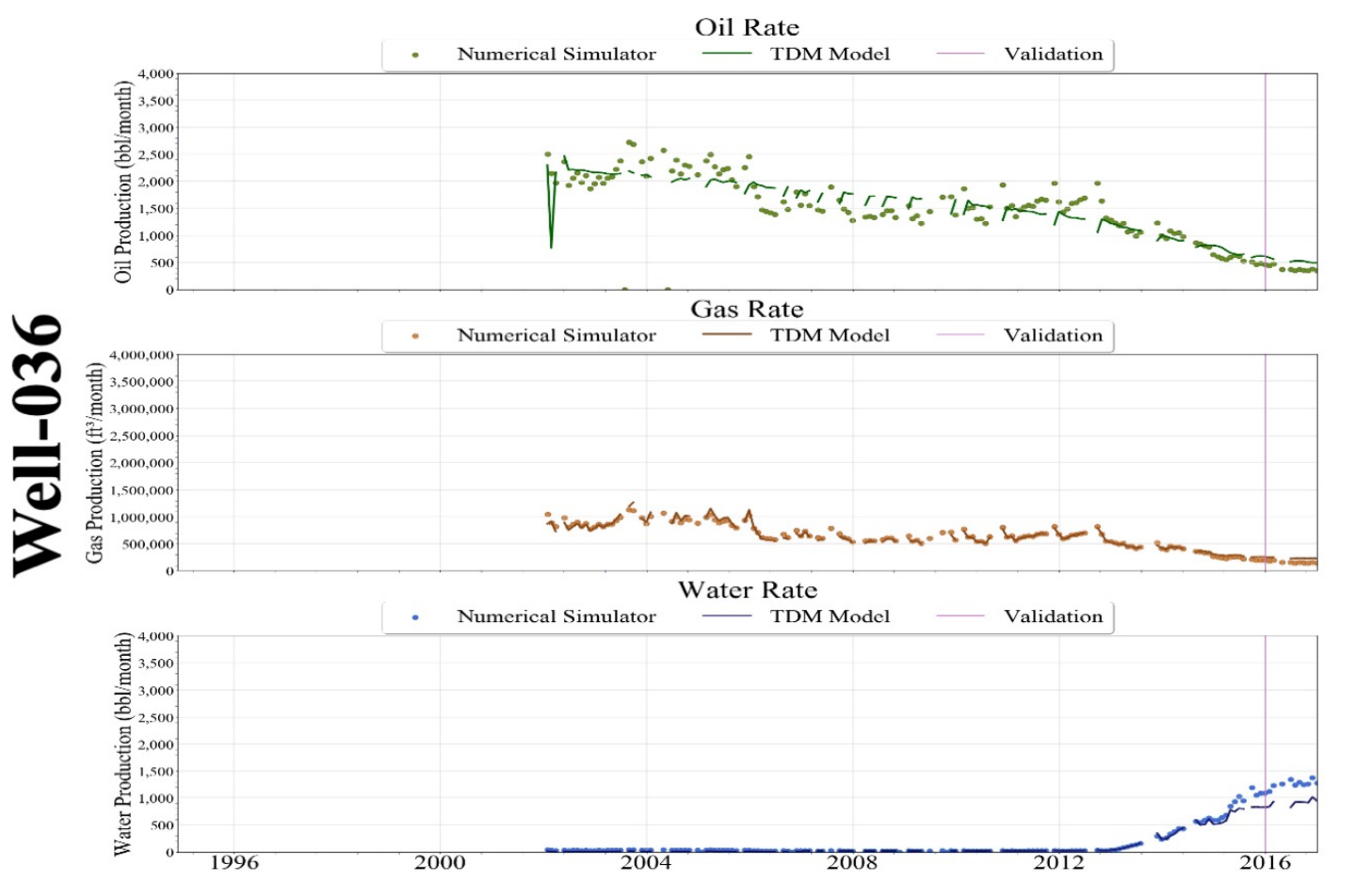

Figure 10-51: Scenario 2 - Well-036 Production History Match 


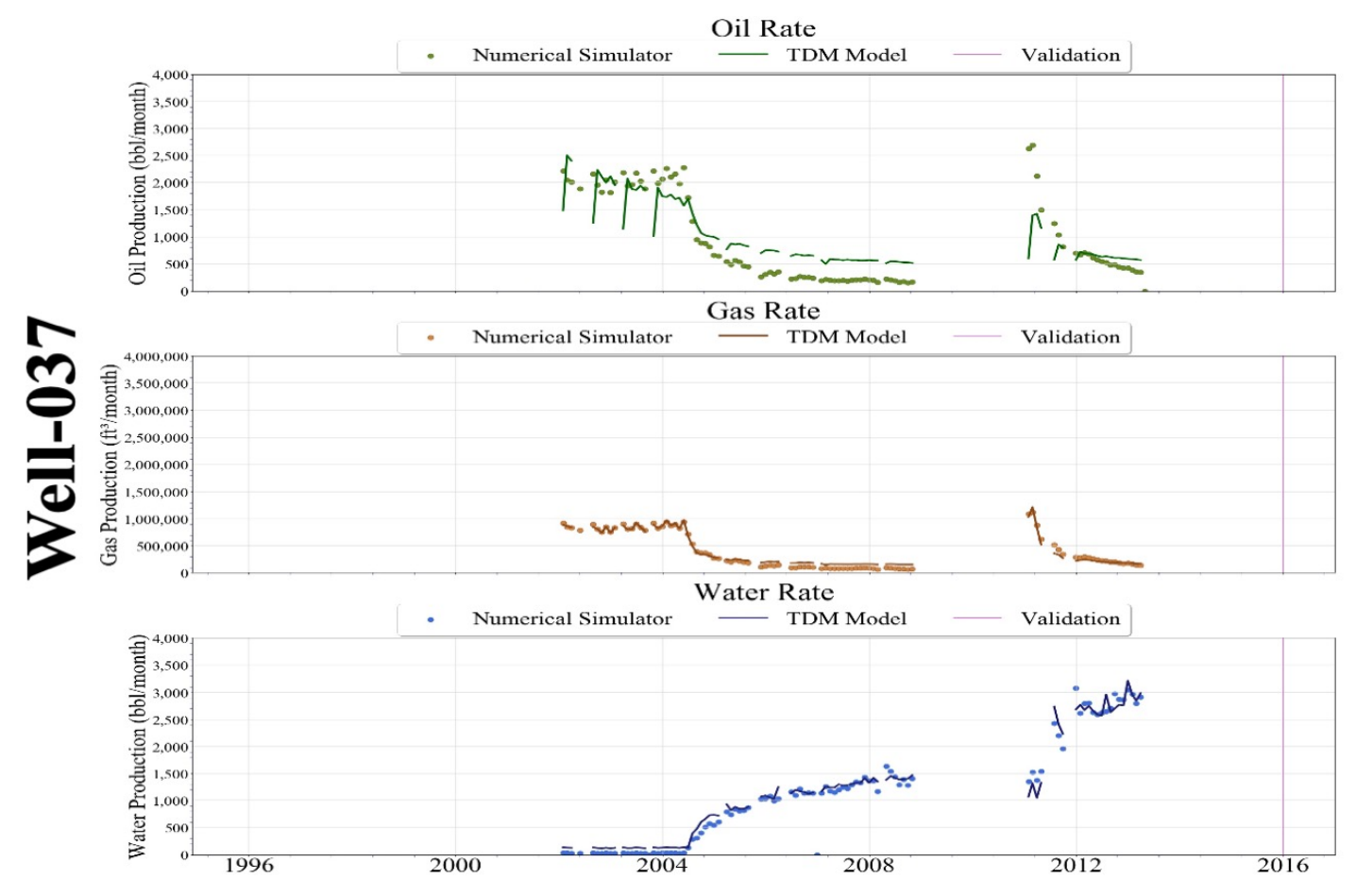

Figure 10-52: Scenario 2 - Well-037 Production History Match

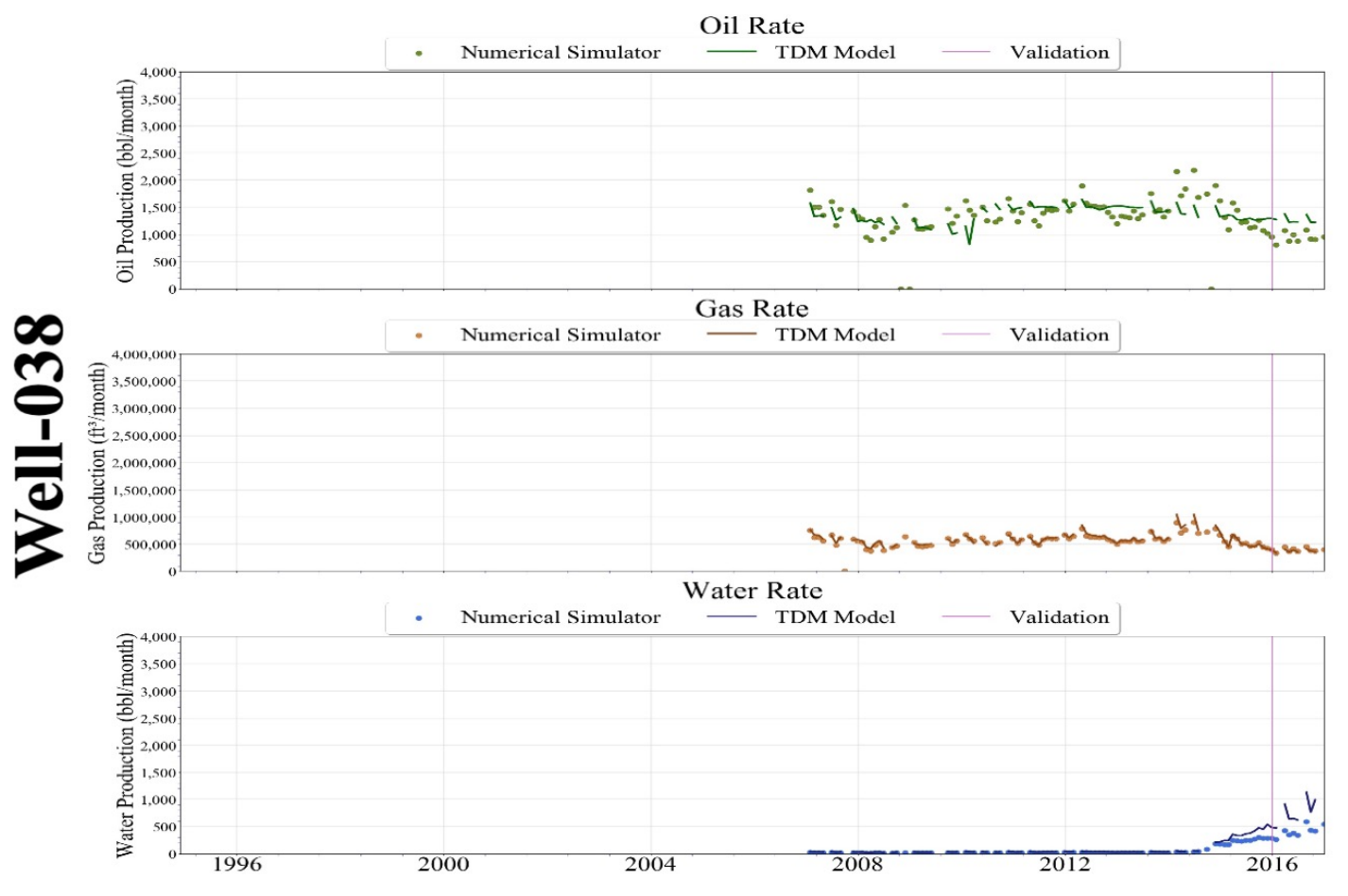

Figure 10-53: Scenario 2 - Well-038 Production History Match 


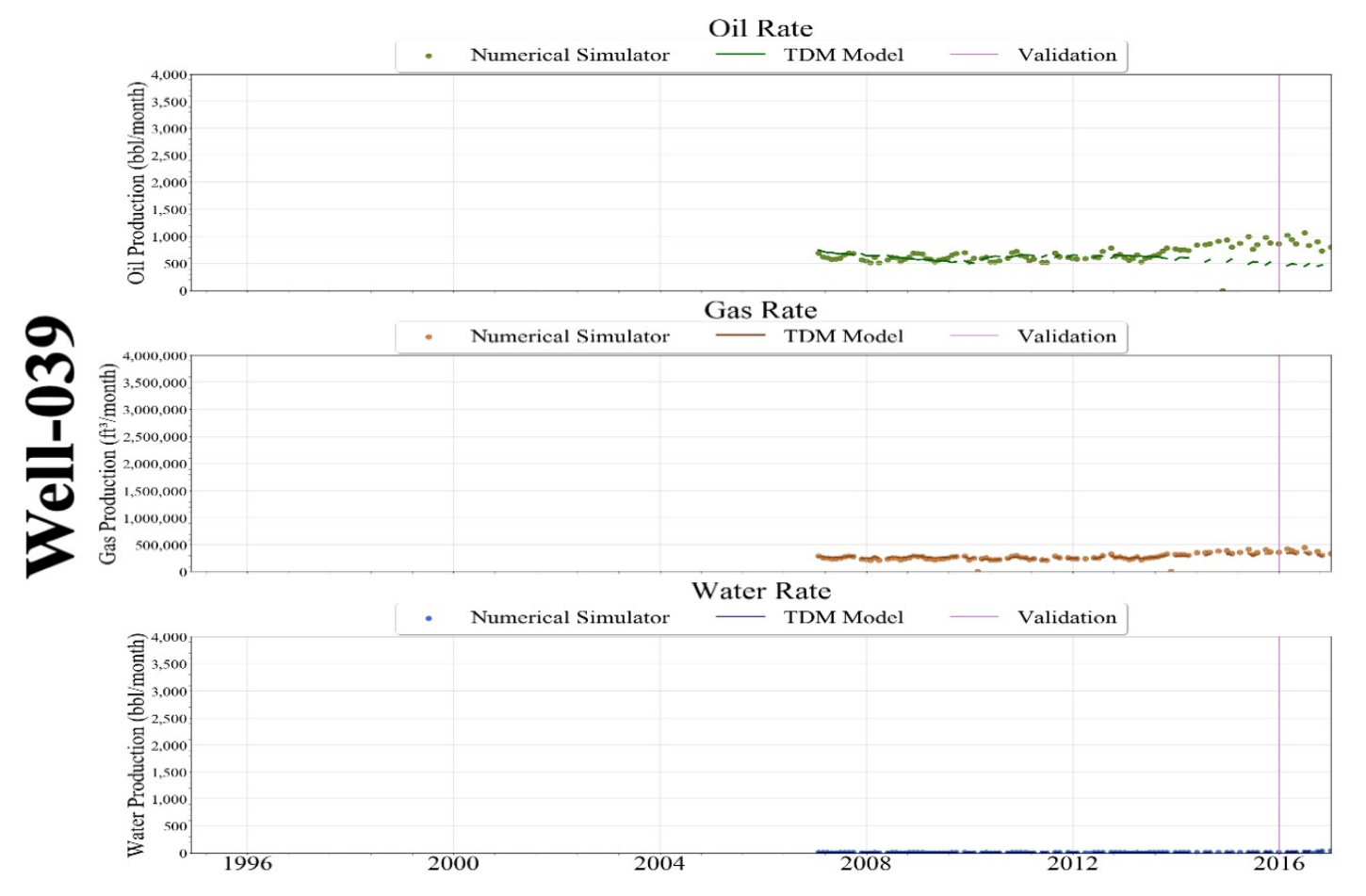

Figure 10-54: Scenario 2 - Well-039 Production History Match

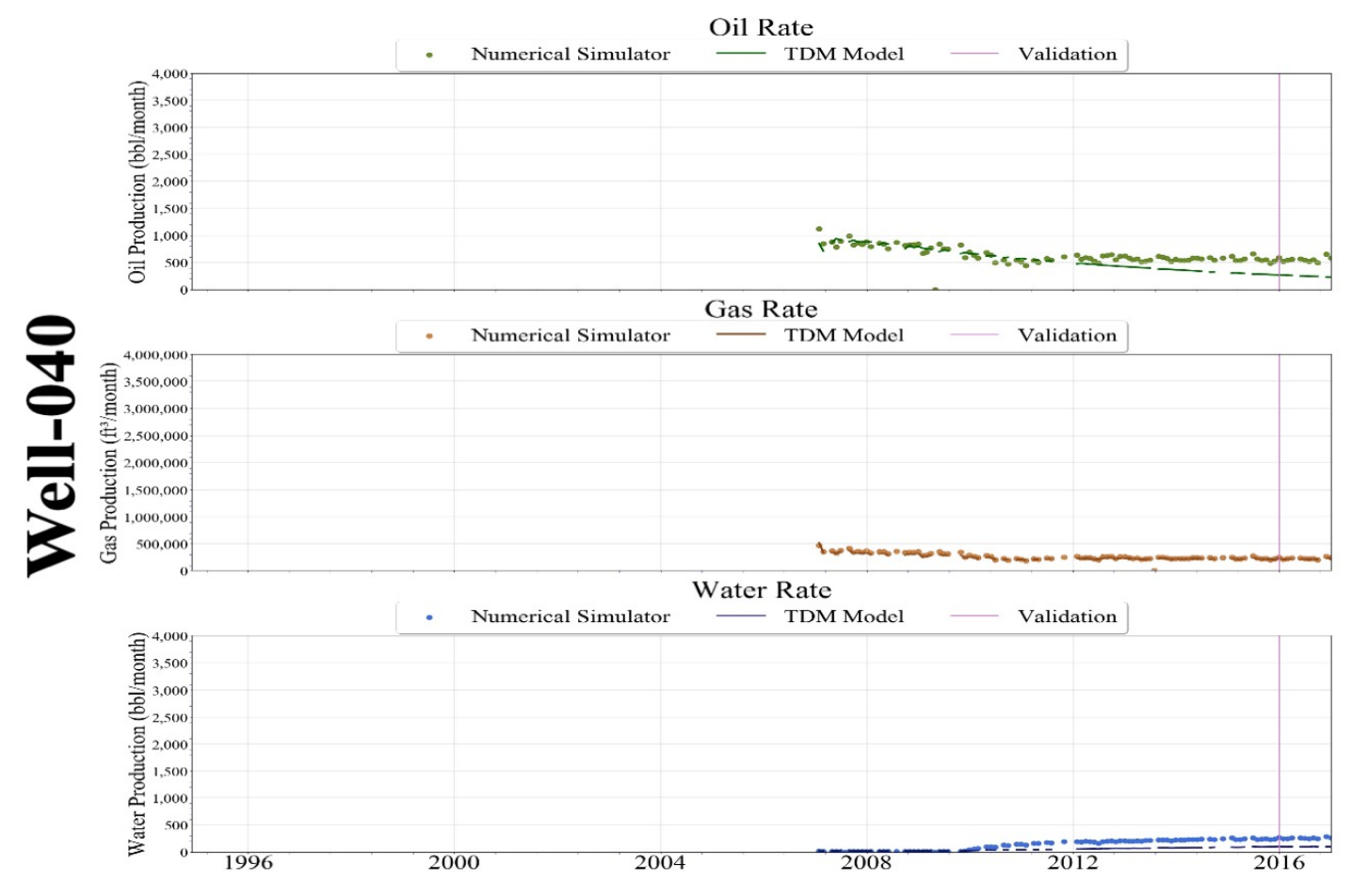

Figure 10-55: Scenario 2 - Well-040 Production History Match 


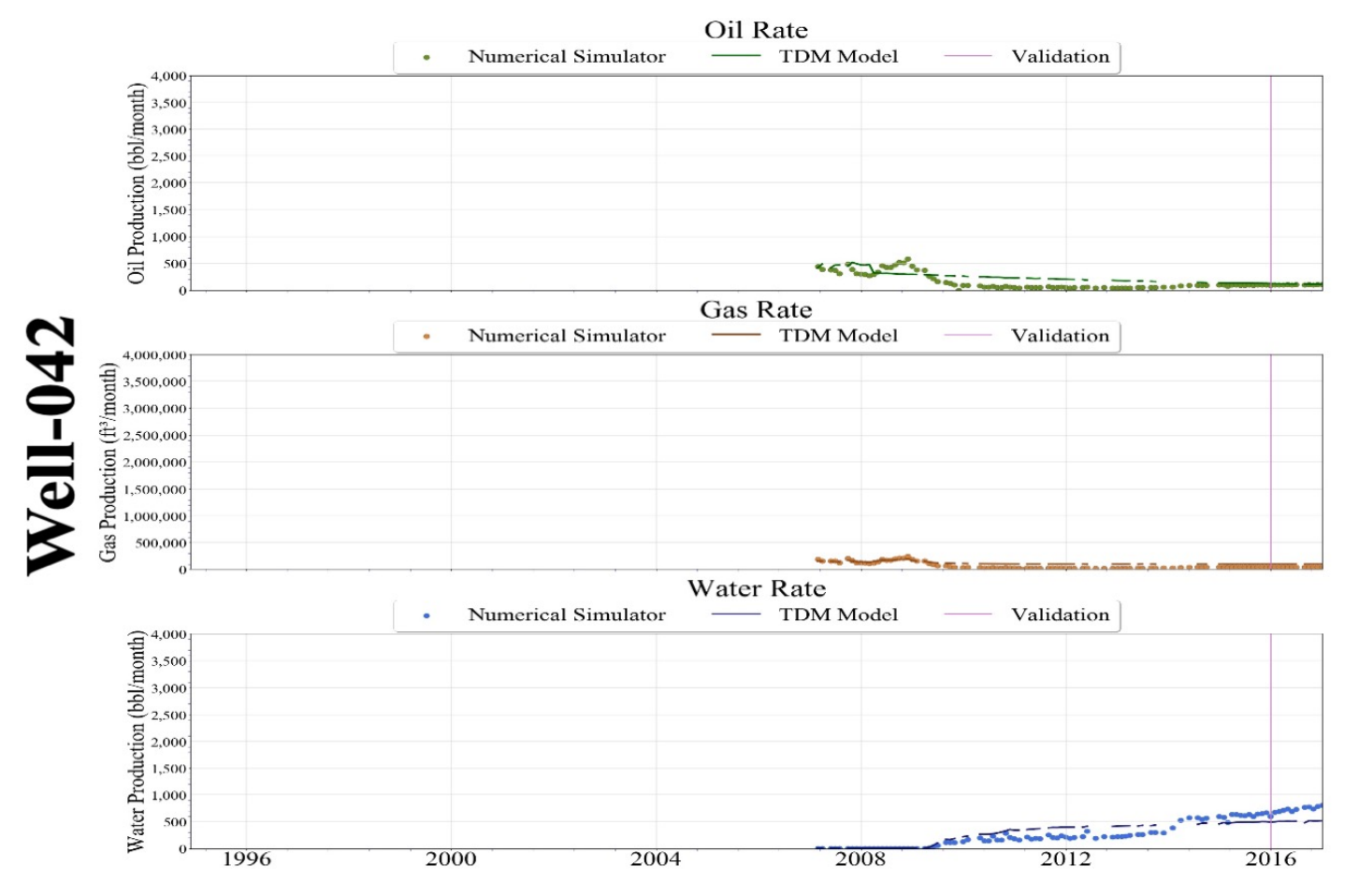

Figure 10-56: Scenario 2 - Well-042 Production History Match

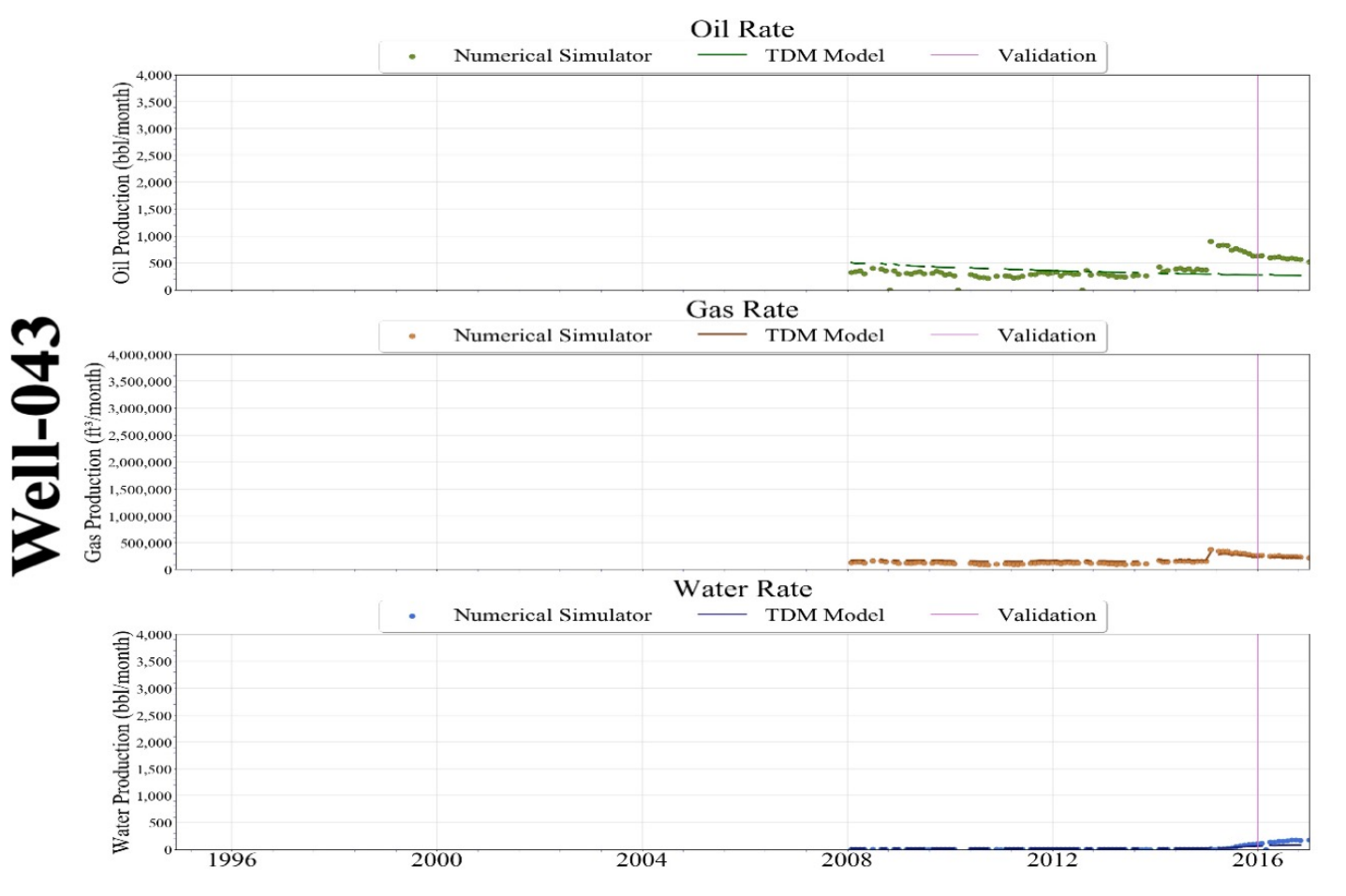

Figure 10-57: Scenario 2 - Well-043 Production History Match 


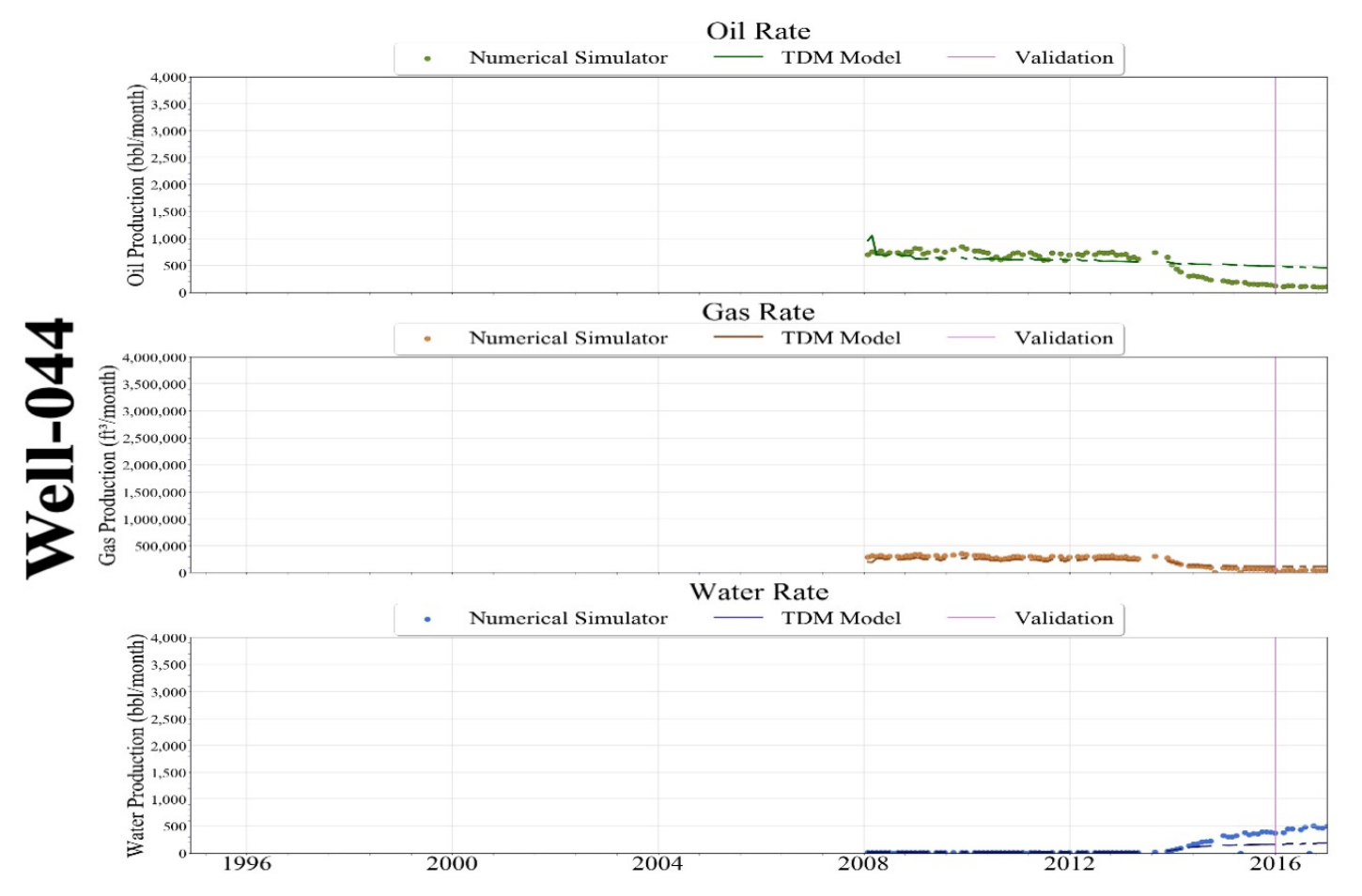

Figure 10-58: Scenario 2 - Well-044 Production History Match

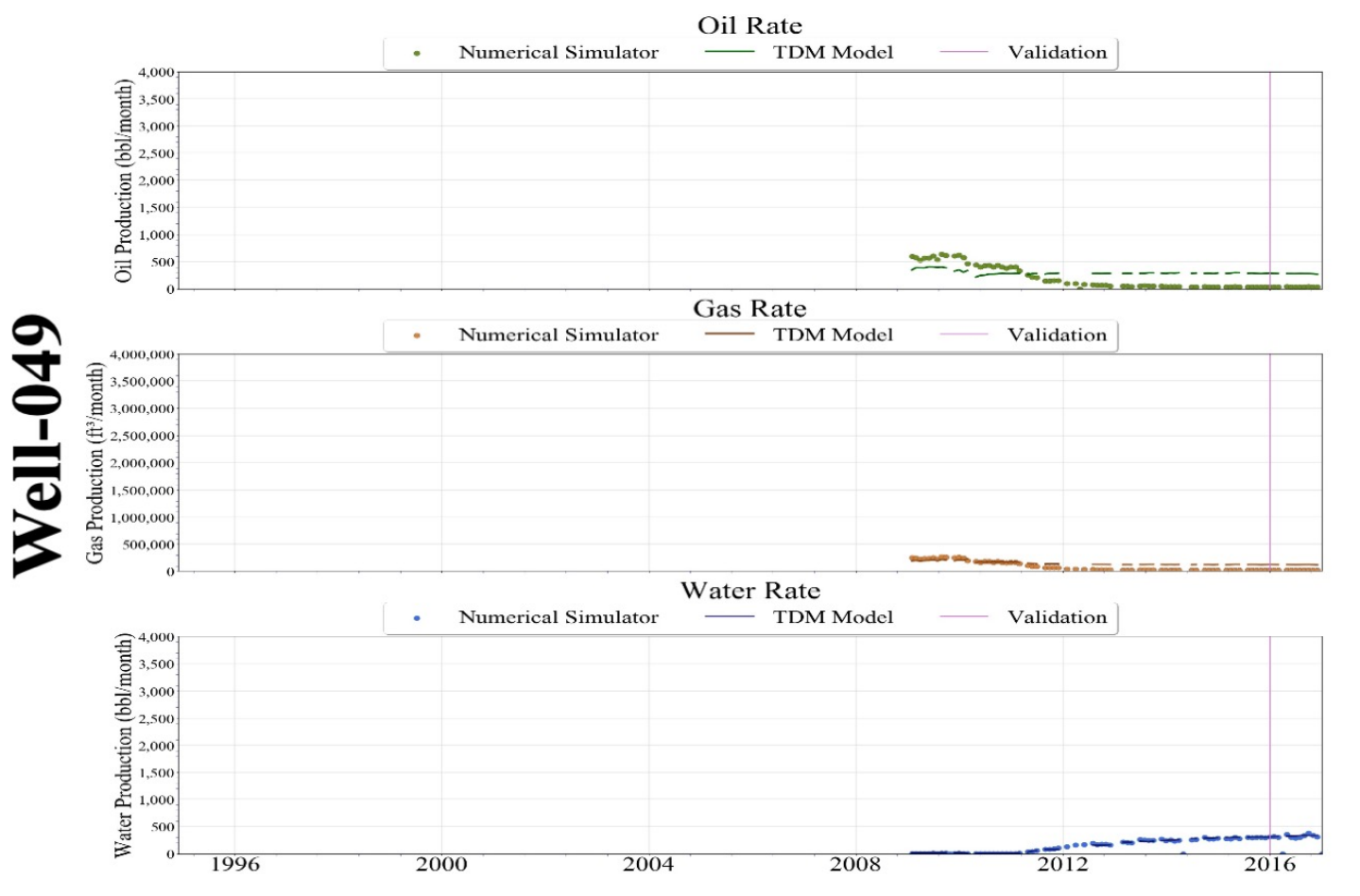

Figure 10-59: Scenario 2 - Well-049 Production History Match 


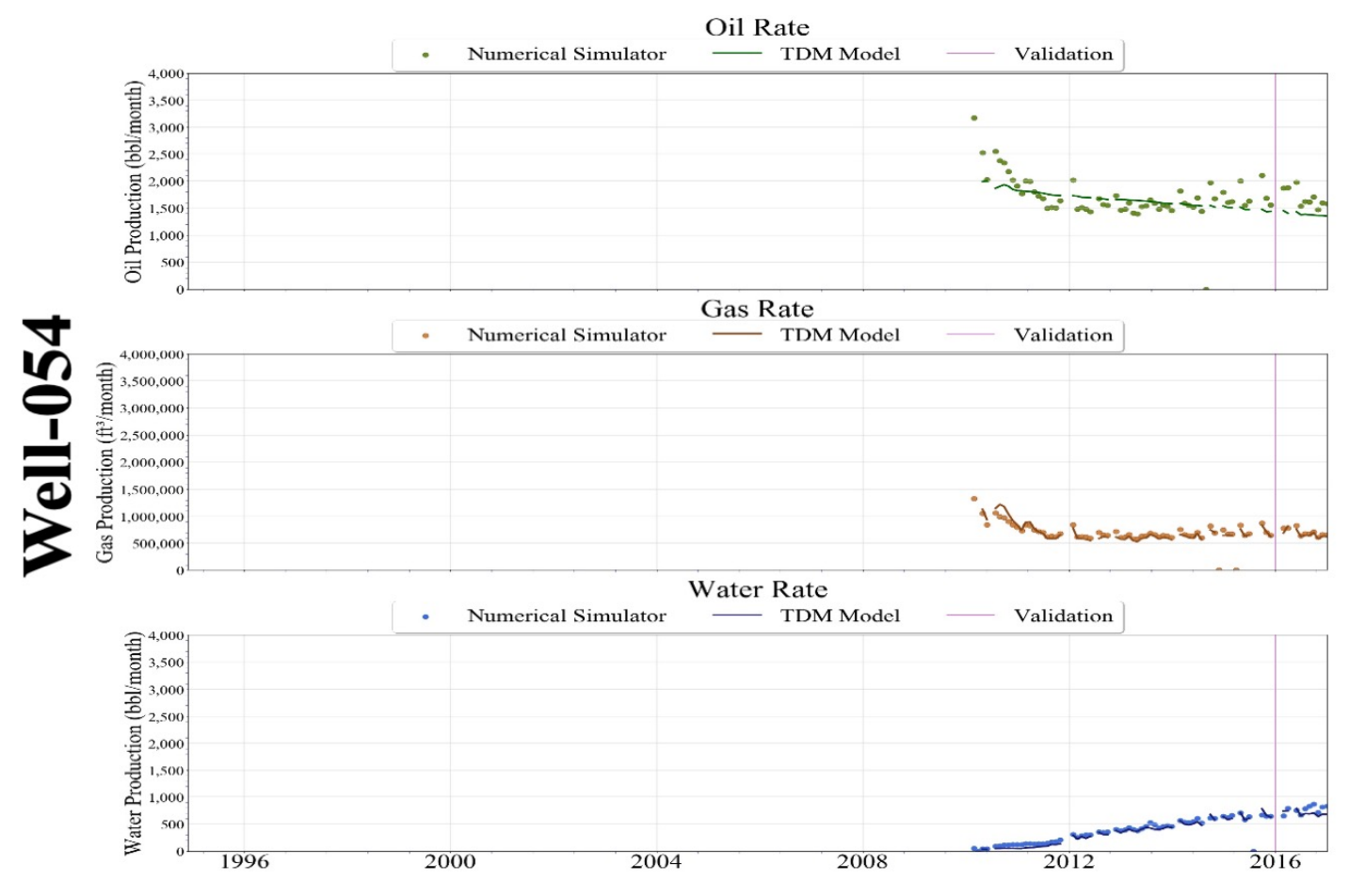

Figure 10-60: Scenario 2 - Well-054 Production History Match

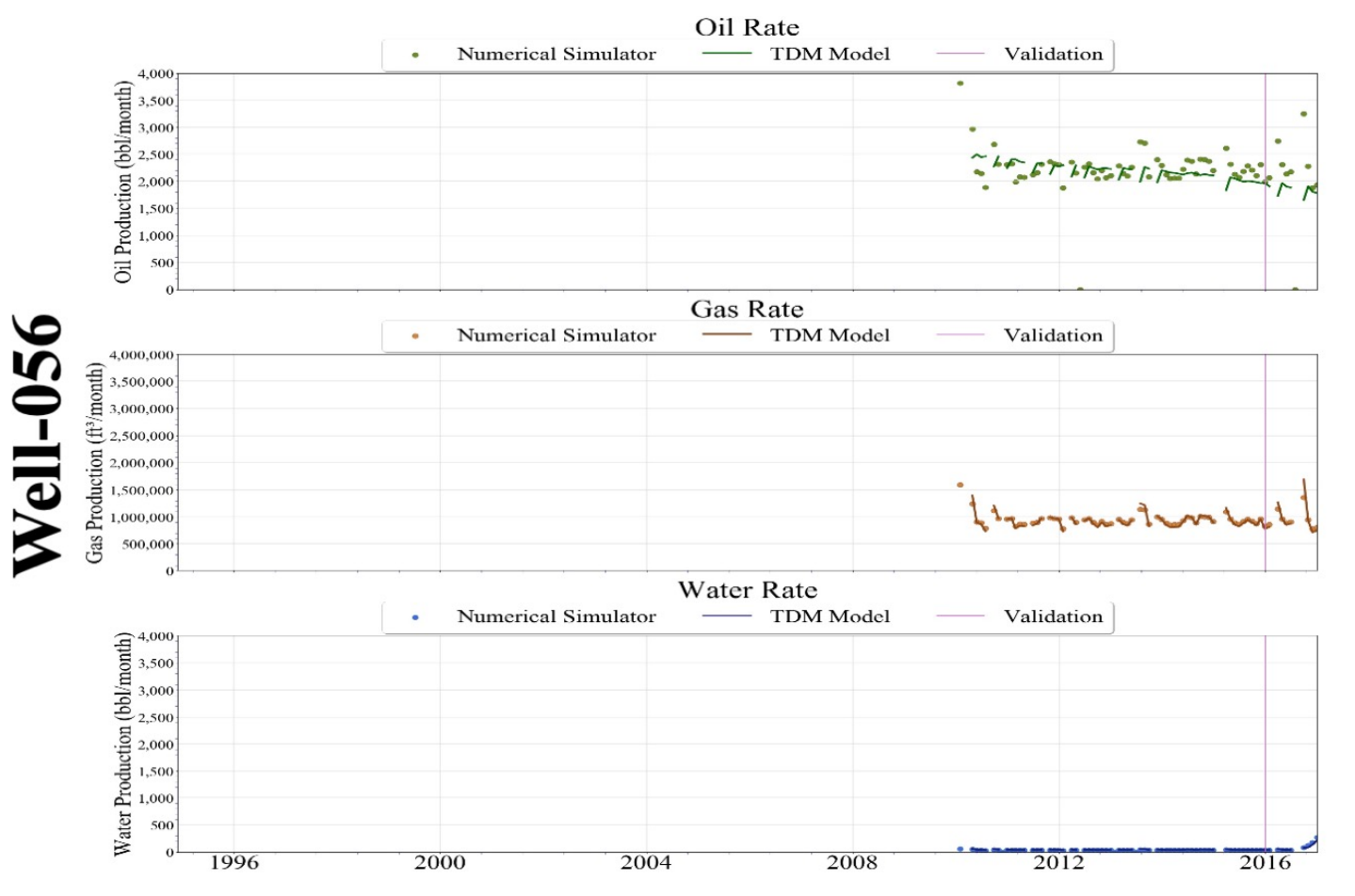

Figure 10-61: Scenario 2 - Well-056 Production History Match 


\subsubsection{Poor History Match of Production}

The water predictions from well-016 are significantly distant from the actual water production. Although the oil predictions are close to the actual oil production, the oil trend is decreasing rather than fluctuating. The combination of the oil and water predictions result in an overall poor history match.

Although the oil and water predictions of well-048 follow the actual production trend, these are inconsistent trend at the beginning and at the end of the well's life.

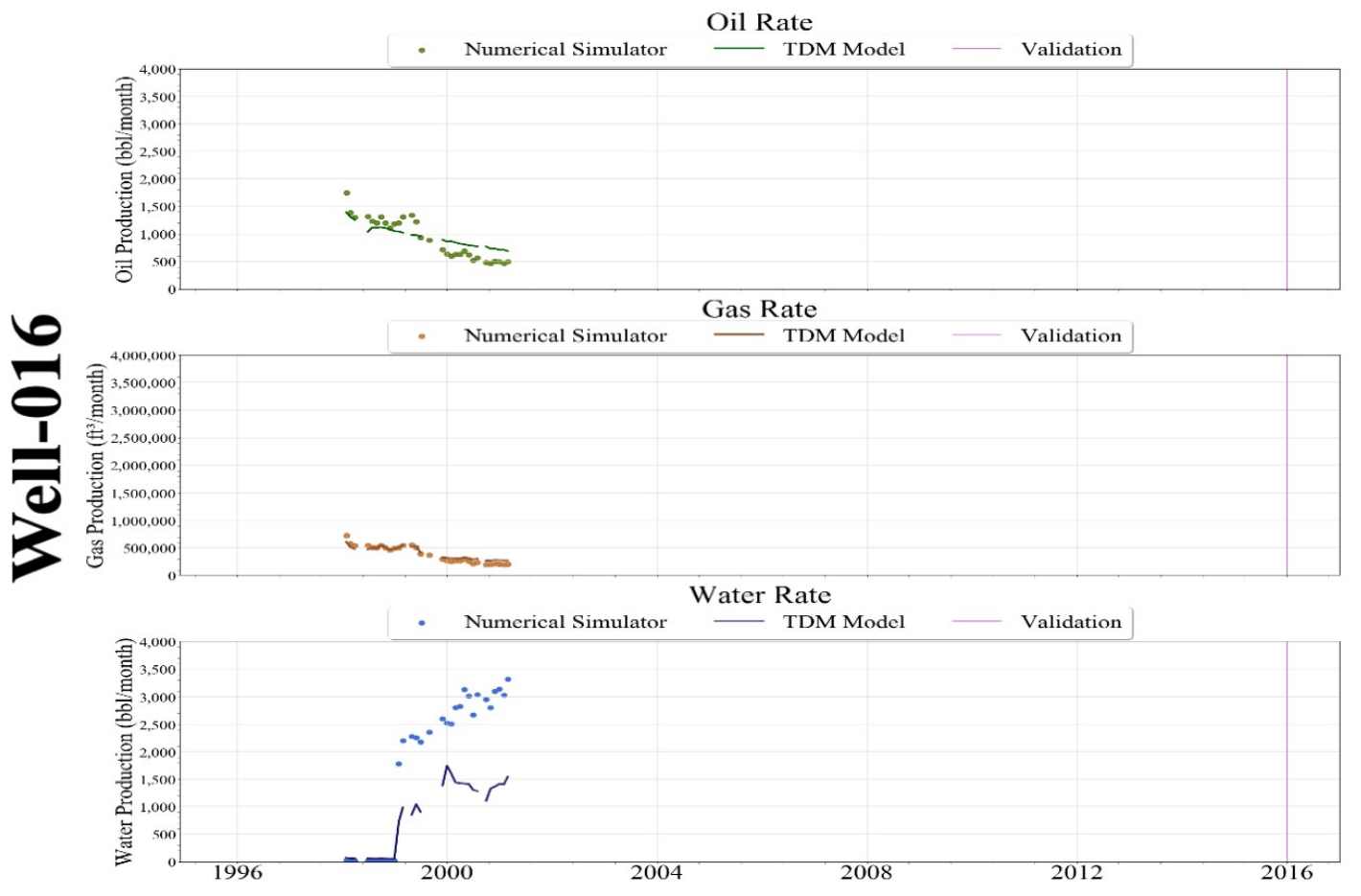

Figure 10-62: Scenario 2 - Well-016 Production History Match 


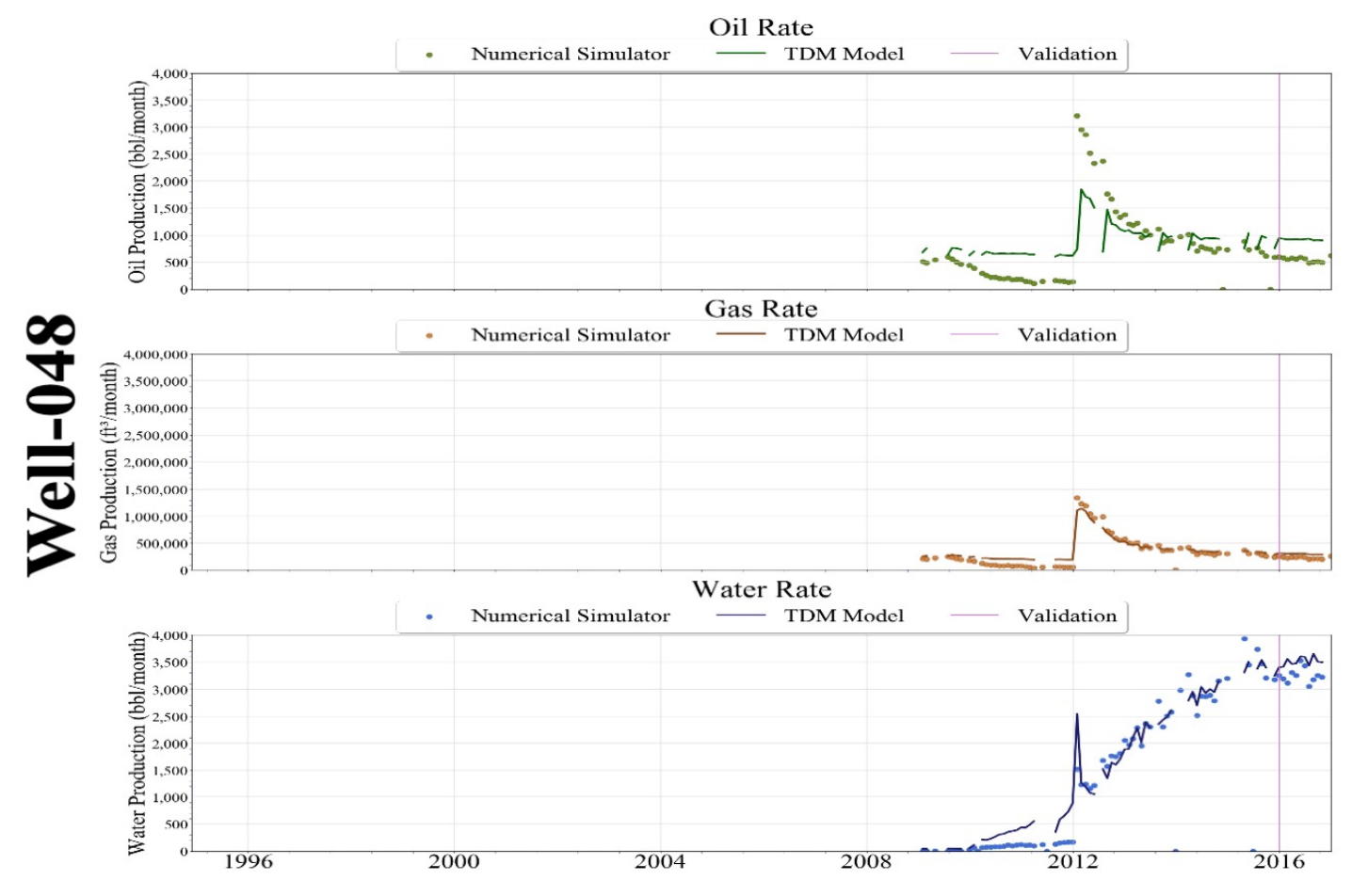

Figure 10-63: Scenario 2 - Well-048 Production History Match 


\subsection{Distribution Maps}

Distribution maps are presented at different timesteps, including the months of January, June, and December of 2014, and the months of June and December of years 2015 and 2016.

Reservoir Pressure (psi) at 2014-01-31
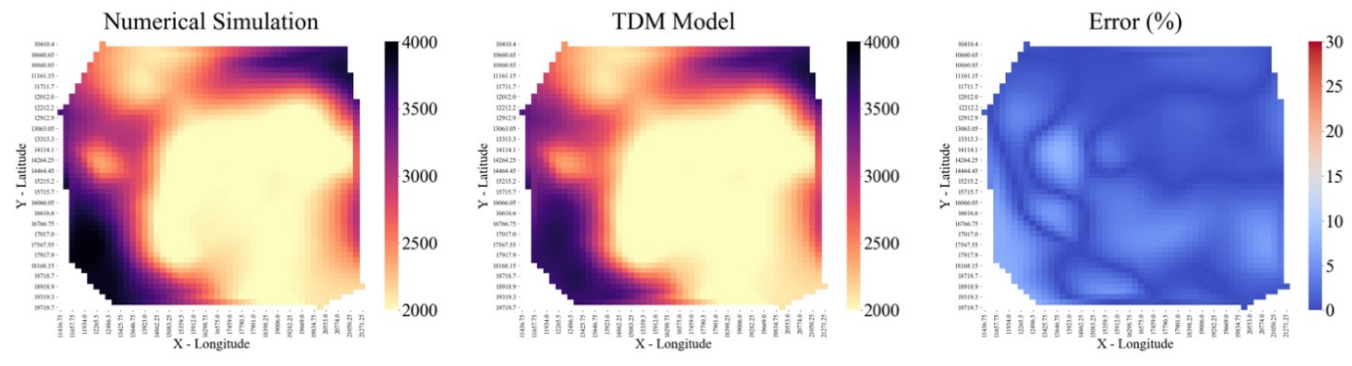

Water Saturation (\%) at 2014-01-31
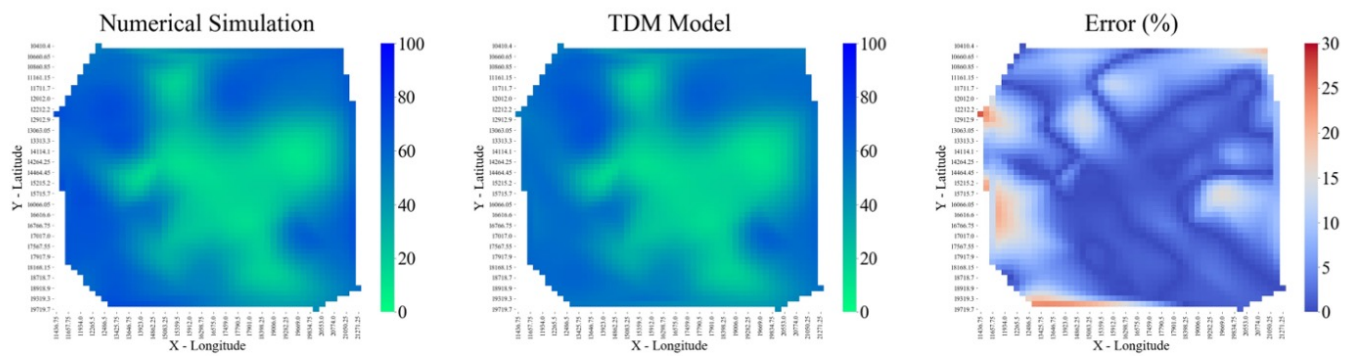

Reservoir Pressure (psi) at 2014-06-30
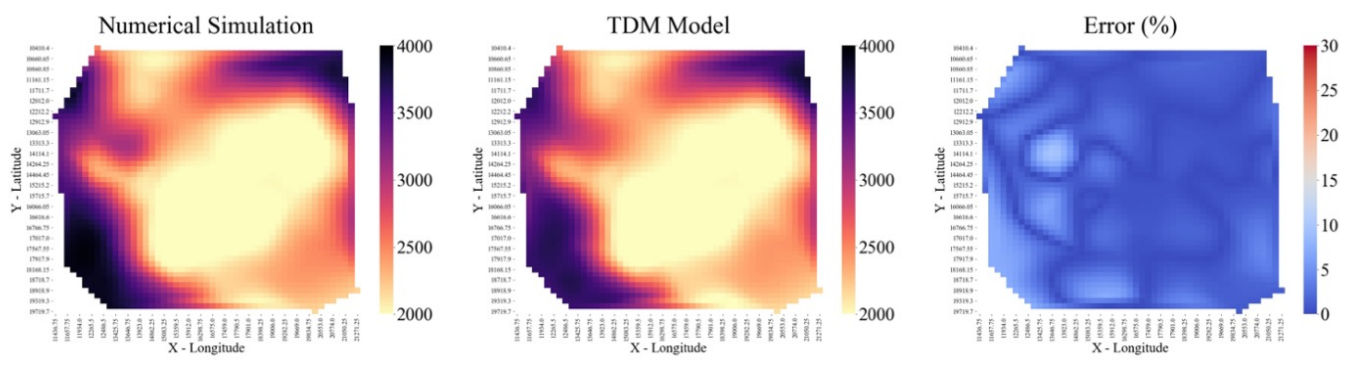

Water Saturation (\%) at 2014-06-30
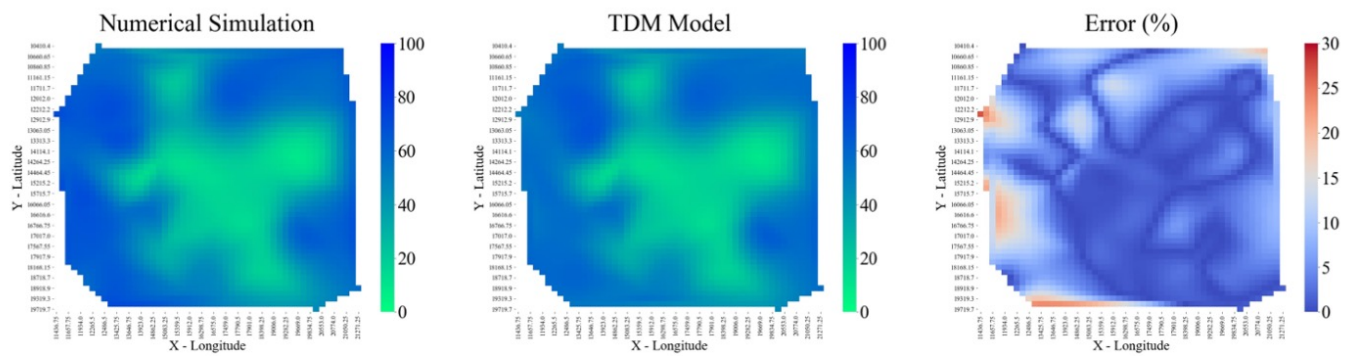
Reservoir Pressure (psi) at 2014-12-31
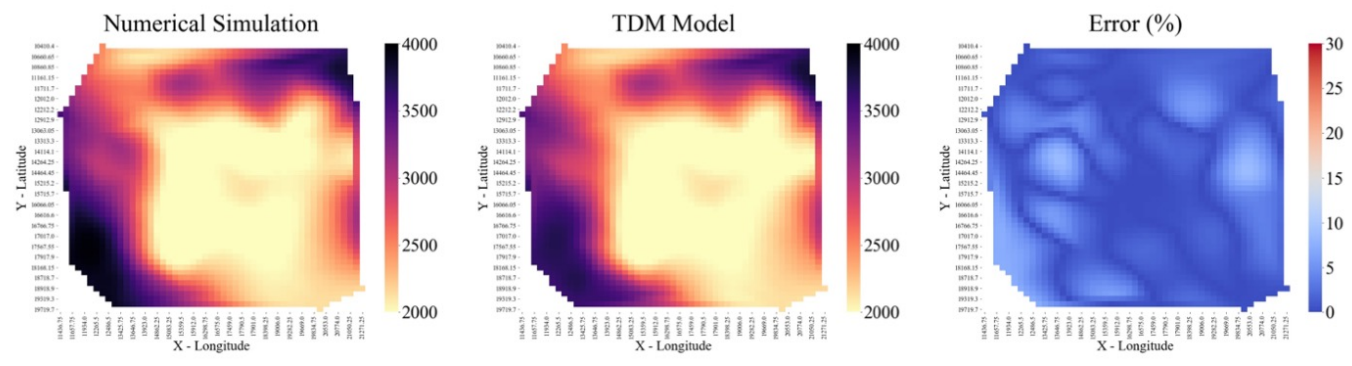

Water Saturation (\%) at 2014-12-31
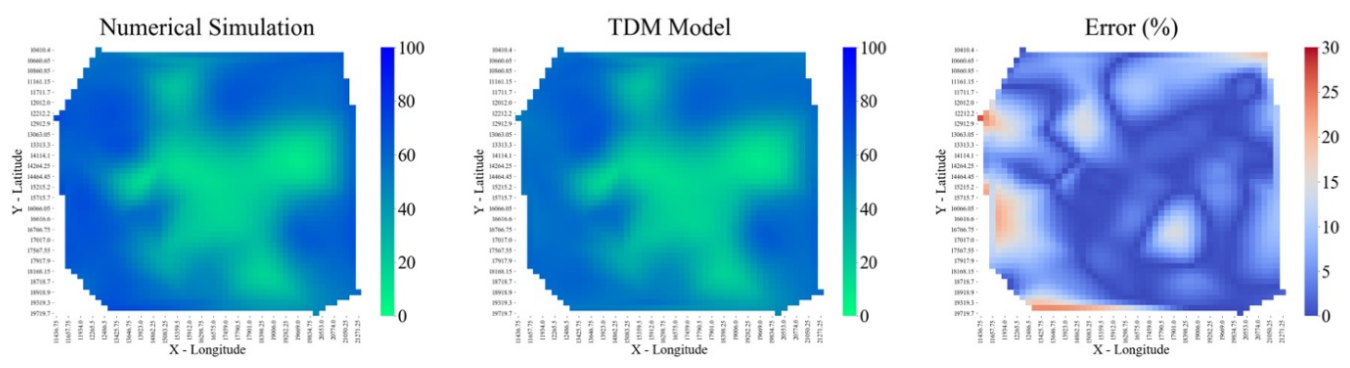

Reservoir Pressure (psi) at 2015-06-30
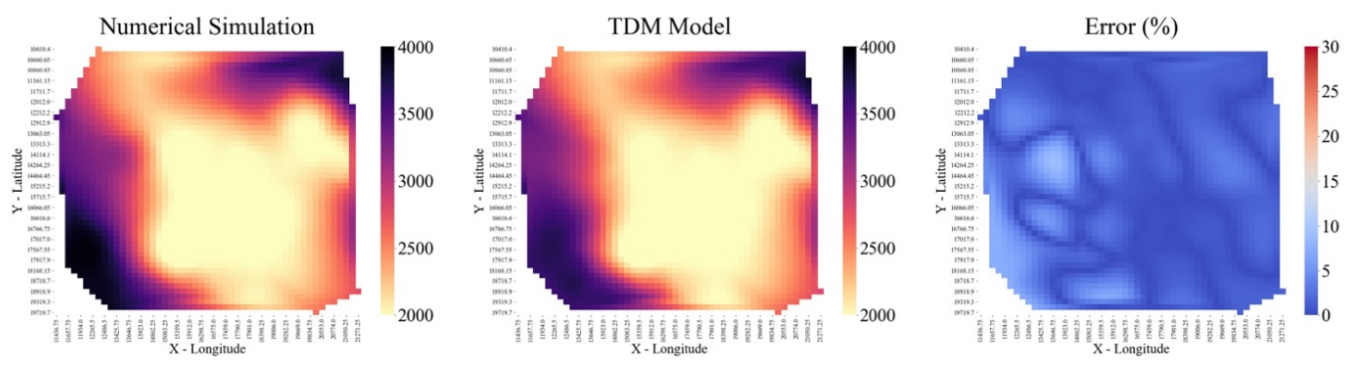

Water Saturation (\%) at 2015-06-30
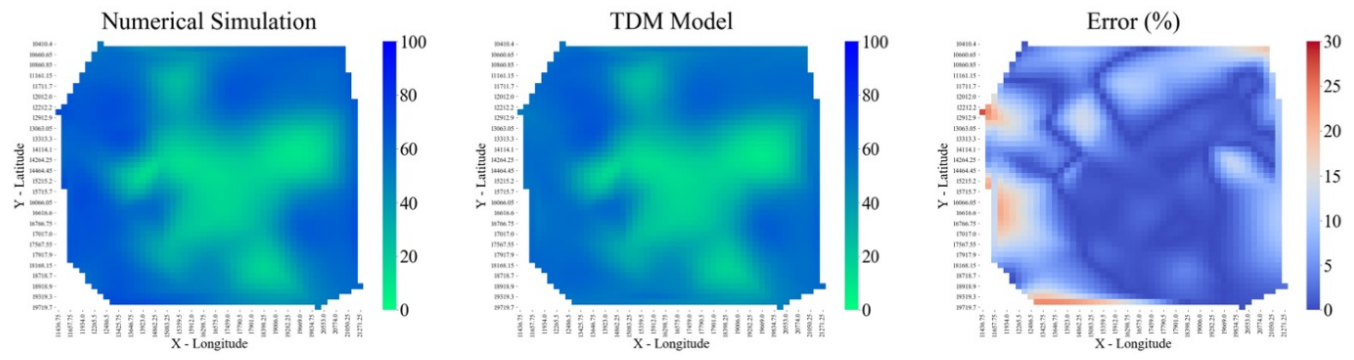
Reservoir Pressure (psi) at 2015-12-31
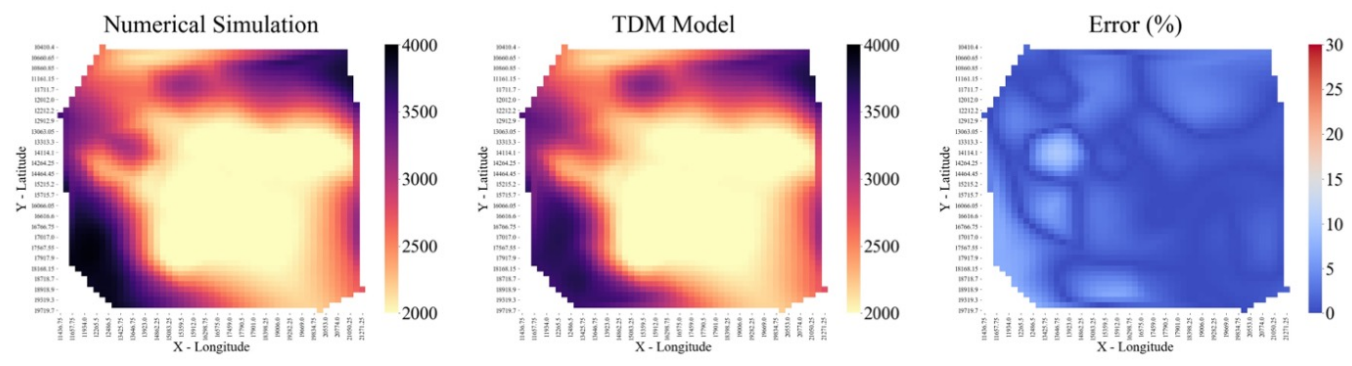

Water Saturation (\%) at 2015-12-31
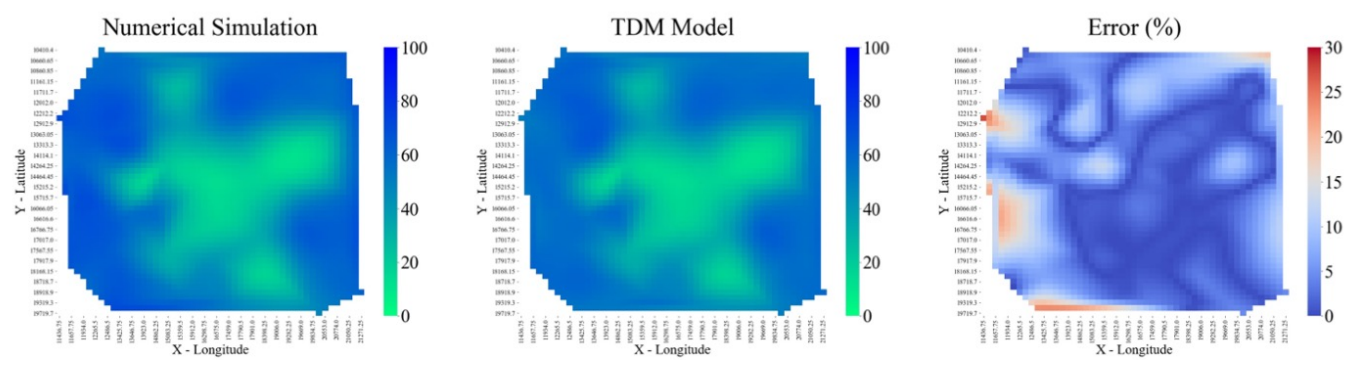

Reservoir Pressure (psi) at 2016-06-30
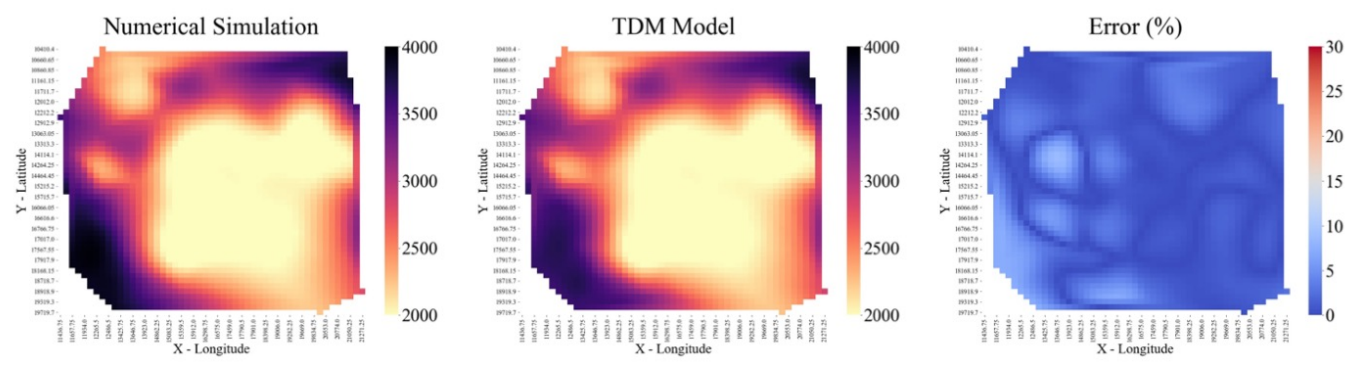

Water Saturation (\%) at 2016-06-30
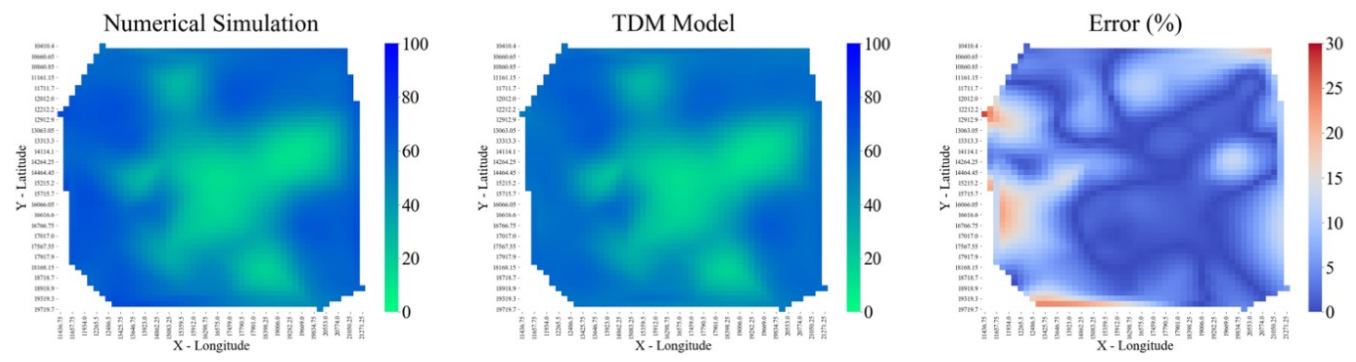
Reservoir Pressure (psi) at 2016-12-31
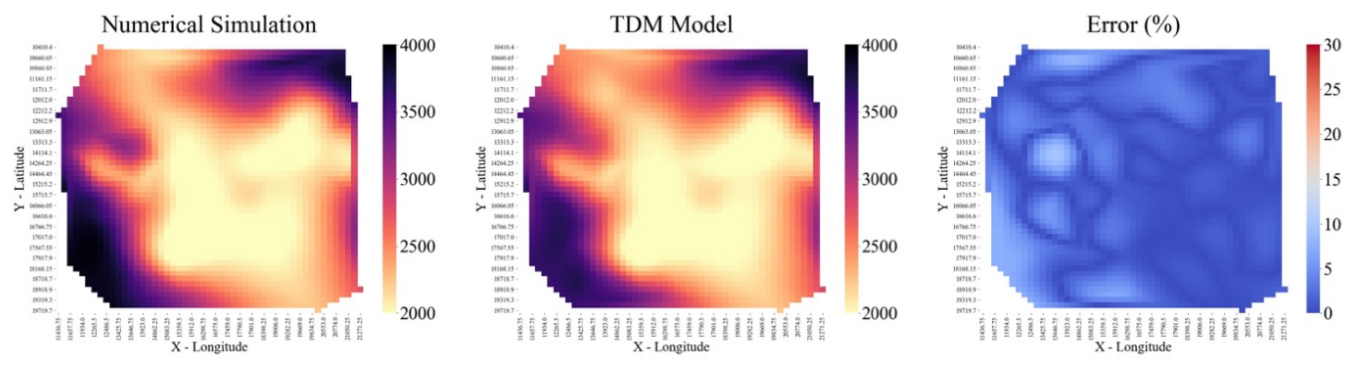

Water Saturation (\%) at 2016-12-31
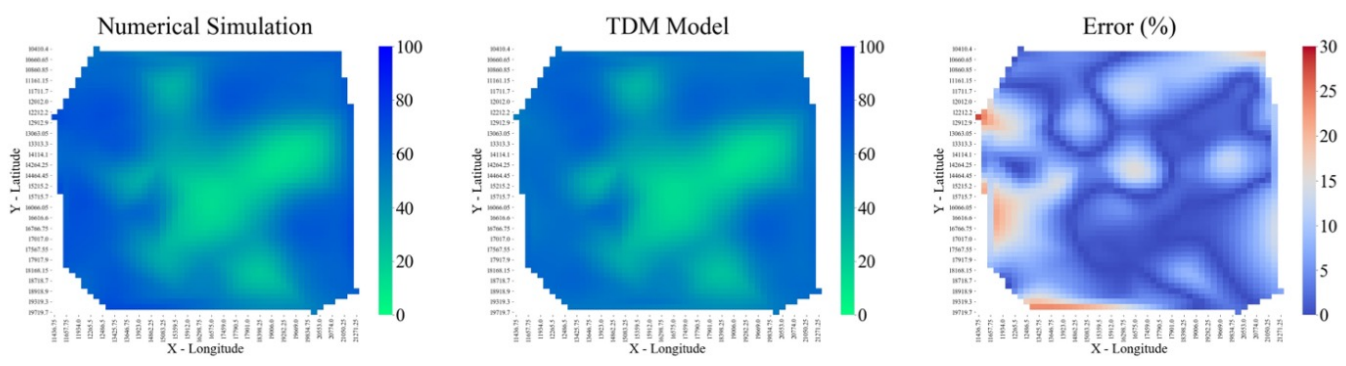

Figure 10-64: Scenario 2 - Distribution Maps at Different Timesteps 


\section{Appendix E: Scenario 3: Mixed Partitioning TDM (2 Year Validation)}

\subsection{Input Attributes}

The number of input attributes used in the development of each data-driven model was based on KPI analysis and domain expertise. The following tables provide a list of static and dynamic attributes for both the focal and offset wells. Each table is composed of three columns that indicate the ranking, name of the input attribute, and its degree of influence (DOI) with respect to the output model.

\subsubsection{Oil Predictive Model}

Oil Model - Input Attributes

\begin{tabular}{|c|c|c|c|c|c|}
\hline \multicolumn{3}{|c|}{ FOCAL WELL } & \multicolumn{3}{|c|}{ OFFSET WELLS } \\
\hline \multicolumn{3}{|c|}{ Static Attributes } & \multicolumn{3}{|c|}{ Static Attributes } \\
\hline Rank & Attribute & DOI & Rank & Attribute & DOI \\
\hline 1 & Porh(1-sw) & 100 & 1 & Completion (ft)(1P) & 100 \\
\hline 2 & Porosity (\%) & 90 & 2 & Porh(1-sw)(1I) & 91 \\
\hline 5 & TVD $(\mathrm{ft})$ & 73 & 3 & Top (ft)(1I) & 90 \\
\hline \multicolumn{3}{|c|}{3} & 5 & TVD $(\mathrm{ft})(1 \mathrm{I})$ & 73 \\
\hline & & & 6 & Top (ft)(2P) & 65 \\
\hline \multicolumn{3}{|c|}{ Dynamic Attributes } & 9 & TVD (ft)(1P) & 55 \\
\hline 1 & Oil Rate (t-1) & 100 & 10 & $\mathrm{X} /$ Longitude(1P) & 52 \\
\hline 2 & Gas Rate (t-1) & 100 & 11 & Pay thickness $(\mathrm{ft})(1 \mathrm{P})$ & 50 \\
\hline 3 & Permeability I(t-1) & 49 & \multicolumn{3}{|c|}{8} \\
\hline 4 & Time & 48 & & & \\
\hline \multicolumn{3}{|c|}{4} & \multicolumn{3}{|c|}{ Dynamic Attributes } \\
\hline & & & 1 & FBH Pressure $(\mathrm{psi})(\mathrm{t})(1 \mathrm{I})$ & 100 \\
\hline \multicolumn{2}{|c|}{ TOTAL ATTRIBUTES } & 25 & 2 & Distance $(\mathrm{t}-1)(2 \mathrm{P})$ & 97 \\
\hline & & & 3 & FBH Pressure $(\mathrm{psi})(\mathrm{t}-1)(1 \mathrm{I})$ & 96 \\
\hline & & & 4 & Reservoir Pressure $(\mathrm{psi})(\mathrm{t}-1)(1 \mathrm{I})$ & 96 \\
\hline & & & 5 & Distance $(\mathrm{t})(2 \mathrm{P})$ & 96 \\
\hline & & & 6 & FBH Pressure $(p s i)(t)(2 I)$ & 93 \\
\hline & & & 7 & FBH Pressure (psi)(t-1)(2I) & 92 \\
\hline & & & 8 & Reservoir Pressure (psi)(t-1)(2I) & 92 \\
\hline & & & 9 & Water Saturation $(\%)(\mathrm{t}-1)(2 \mathrm{I})$ & 87 \\
\hline & & & 10 & Oil Saturation $(\%)(\mathrm{t}-1)(2 \mathrm{I})$ & 87 \\
\hline & & & & 10 & \\
\hline
\end{tabular}

Figure 11-1: Scenario 3 - Oil Model Input Attributes 


\subsubsection{Gas Predictive Model}

\section{Gas Model - Input Attributes}

\begin{tabular}{|c|c|c|c|c|c|}
\hline \multicolumn{3}{|c|}{ FOCAL WELL } & \multicolumn{3}{|c|}{ OFFSET WELLS } \\
\hline \multicolumn{3}{|c|}{ Static Attributes } & \multicolumn{3}{|c|}{ Static Attributes } \\
\hline Rank & Attribute & DOI & Rank & $\begin{array}{c}\text { Attribute } \\
\end{array}$ & DOI \\
\hline 1 & Porh(1-sw) & 100 & 1 & Completion $(\mathrm{ft})(1 \mathrm{P})$ & 100 \\
\hline 2 & Porosity $(\%)$ & 90 & 2 & Porh $(1-\mathrm{sw})(1 \mathrm{I})$ & 91 \\
\hline \multicolumn{3}{|c|}{2} & 3 & Top (ft)(1I) & 90 \\
\hline & & & 4 & $\mathrm{X} /$ Longitude(1I) & 84 \\
\hline \multicolumn{3}{|c|}{ Dynamic Attributes } & 5 & $\operatorname{TVD}(\mathrm{ft})(1 \mathrm{I})$ & 73 \\
\hline 1 & Oil Rate $(\mathrm{t})$ & 100 & \multicolumn{3}{|c|}{ 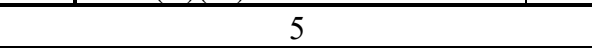 } \\
\hline 2 & Oil Rate (t-1) & 60 & & & \\
\hline 3 & Gas Rate (t-1) & 60 & \multicolumn{3}{|c|}{ Dynamic Attributes } \\
\hline 4 & Permeability I(t-1) & 29 & 1 & FBH Pressure $(p s i)(t)(1 \mathrm{I})$ & 100 \\
\hline \multicolumn{3}{|c|}{4} & 2 & Distance $(\mathrm{t}-1)(2 \mathrm{P})$ & 97 \\
\hline & & & 3 & FBH Pressure $(\mathrm{psi})(\mathrm{t}-1)(1 \mathrm{I})$ & 96 \\
\hline \multicolumn{2}{|c|}{ TOTAL ATTRIBUTES } & 21 & 4 & Reservoir Pressure $(\mathrm{psi})(\mathrm{t}-1)(1 \mathrm{I})$ & 96 \\
\hline & & & 5 & Distance $(\mathrm{t})(2 \mathrm{P})$ & 96 \\
\hline & & & 6 & FBH Pressure $(\mathrm{psi})(\mathrm{t})(2 \mathrm{I})$ & 93 \\
\hline & & & 7 & FBH Pressure (psi)(t-1)(2I) & 92 \\
\hline & & & 8 & Reservoir Pressure $(\mathrm{psi})(\mathrm{t}-1)(2 \mathrm{I})$ & 92 \\
\hline & & & 9 & Water Saturation $(\%)(\mathrm{t}-1)(2 \mathrm{I})$ & 87 \\
\hline & & & 10 & Oil Saturation $(\%)(\mathrm{t}-1)(2 \mathrm{I})$ & 87 \\
\hline & & & & 10 & \\
\hline
\end{tabular}

Figure 11-2: Scenario 3 - Gas Model Input Attributes 


\subsubsection{Water Predictive Model}

\section{Water Model - Input Attributes}

\begin{tabular}{|c|c|c|c|c|c|}
\hline \multicolumn{3}{|c|}{ FOCAL WELL } & \multicolumn{3}{|c|}{ OFFSET WELLS } \\
\hline \multicolumn{3}{|c|}{ Static Attributes } & \multicolumn{3}{|c|}{ Static Attributes } \\
\hline Rank & Attribute & DOI & Rank & Attribute & DOI \\
\hline & Permeability (md) & 100 & 1 & $\mathrm{X} /$ Longitude $(2 \mathrm{P})$ & 100 \\
\hline 2 & $\mathrm{X} /$ Longitude & 89 & 2 & Top (ft)(2P) & 90 \\
\hline 3 & Top $(\mathrm{ft})$ & 84 & 3 & TVD (ft)(2P) & 86 \\
\hline \multicolumn{3}{|c|}{3} & 4 & Top $(\mathrm{ft})(2 \mathrm{I})$ & 79 \\
\hline & & & 5 & $\mathrm{X} /$ Longitude(2I) & 75 \\
\hline \multicolumn{3}{|c|}{ Dynamic Attributes } & 7 & TVD $(\mathrm{ft})(2 \mathrm{I})$ & 65 \\
\hline & $\mathrm{q}(\mathrm{t}-1)$-Water & 100 & \multicolumn{3}{|c|}{6} \\
\hline 2 & Oil Saturation $(\%)(\mathrm{t}-1)$ & 78 & & & \\
\hline 3 & Water Saturation $(\%)(\mathrm{t}-1)$ & 78 & \multicolumn{3}{|c|}{ Dynamic Attributes } \\
\hline 4 & Permeability I(t-1) & 72 & 1 & Water Saturation $(\%)(\mathrm{t}-1)(1 \mathrm{P})$ & 100 \\
\hline 15 & Oil Rate $(\mathrm{t})$ & 1 & 2 & Oil Saturation (\%)(t-1)(1P) & 100 \\
\hline 16 & Gas Rate $(\mathrm{t})$ & 1 & 3 & Distance $(\mathrm{t})(1 \mathrm{I})$ & 92 \\
\hline \multicolumn{3}{|c|}{6} & 12 & Permeability I(t-1)(2P) & 42 \\
\hline & & & 15 & Permeability I(t-1)(2I) & 39 \\
\hline & TOTAL ATTRIBUTES & 20 & \multicolumn{3}{|c|}{5} \\
\hline
\end{tabular}

Figure 11-3: Scenario 3 - Water Model Input Attributes 


\subsubsection{Reservoir Pressure Predictive Model}

\begin{tabular}{|c|c|c|c|c|c|}
\hline \multicolumn{3}{|c|}{ FOCAL WELL } & \multicolumn{3}{|c|}{ OFFSET WELLS } \\
\hline \multicolumn{3}{|c|}{ Static Attributes } & \multicolumn{3}{|c|}{ Static Attributes } \\
\hline Rank & Attribute & DOI & Rank & Attribute & DOI \\
\hline 1 & $\mathrm{X} /$ Longitude & 100 & 1 & $\mathrm{X} /$ Longitude $(1 \mathrm{P})$ & 100 \\
\hline & Top $(\mathrm{ft})$ & 81 & 2 & $\mathrm{X} /$ Longitude(1I) & 88 \\
\hline \multicolumn{3}{|c|}{2} & 3 & $\mathrm{X} /$ Longitude $(2 \mathrm{P})$ & 88 \\
\hline & & & 4 & Top $(\mathrm{ft})(1 \mathrm{I})$ & 85 \\
\hline \multicolumn{3}{|c|}{ Dynamic Attributes } & 5 & Top $(\mathrm{ft})(2 \mathrm{P})$ & 79 \\
\hline 1 & Reservoir Pressure (psi)(t-1) & 100 & 6 & Pay thickness (ft)(1I) & 79 \\
\hline 2 & FBH Pressure $(p s i)(t)$ & 78 & \multicolumn{3}{|c|}{6} \\
\hline 3 & FBH Pressure $(\mathrm{psi})(\mathrm{t}-1)$ & 52 & & & \\
\hline 12 & Water Rate $(\mathrm{t})$ & 5 & \multicolumn{3}{|c|}{ Dynamic Attributes } \\
\hline 13 & Oil Rate $(\mathrm{t})$ & 4 & 1 & Reservoir Pressure $(\mathrm{psi})(\mathrm{t}-1)(1 \mathrm{P})$ & 100 \\
\hline 14 & Gas Rate $(\mathrm{t})$ & 4 & 2 & FBH Pressure $(\mathrm{psi})(\mathrm{t}-1)(1 \mathrm{P})$ & 91 \\
\hline \multicolumn{3}{|c|}{6} & 3 & FBH Pressure $(\mathrm{psi})(\mathrm{t})(1 \mathrm{P})$ & 90 \\
\hline & & & \multicolumn{3}{|c|}{3} \\
\hline
\end{tabular}

Figure 11-4: Scenario 3 - Reservoir Pressure Model Input Attributes 


\subsubsection{Water Saturation Predictive Model}

\begin{tabular}{|c|c|c|c|c|c|}
\hline \multicolumn{3}{|c|}{ FOCAL WELL } & \multicolumn{3}{|c|}{ OFFSET WELLS } \\
\hline \multicolumn{3}{|c|}{ Static Attributes } & \multicolumn{3}{|c|}{ Static Attributes } \\
\hline Rank & Attribute & DOI & Rank & Attribute & DOI \\
\hline 1 & Top (ft) & 100 & 1 & $\mathrm{X} /$ Longitude(2P) & 100 \\
\hline 2 & $\mathrm{X} /$ Longitude & 87 & 2 & Top (ft)(2P) & 97 \\
\hline & Y/Latitude & 65 & 3 & Y/Latitude(1P) & 79 \\
\hline \multicolumn{3}{|c|}{$\lambda_{1}$} & & $\mathrm{X} /$ Longitude $(1 \mathrm{P})$ & 74 \\
\hline & & & \multicolumn{3}{|c|}{4} \\
\hline \multicolumn{3}{|c|}{ Dynamic Attributes } & & & \\
\hline 1 & Oil Saturation $(\%)(\mathrm{t}-1)$ & 100 & \multicolumn{3}{|c|}{ Dynamic Attributes } \\
\hline 2 & Water Saturation $(\%)(\mathrm{t}-1)$ & 100 & 1 & Water Saturation $(\%)(\mathrm{t}-1)(1 \mathrm{P})$ & 100 \\
\hline 4 & Reservoir Pressure $(\mathrm{psi})(\mathrm{t})$ & 23 & 2 & Oil Saturation $(\%)(\mathrm{t}-1)(1 \mathrm{P})$ & 100 \\
\hline 5 & Water Rate $(\mathrm{t})$ & 18 & \multicolumn{3}{|c|}{2} \\
\hline 10 & Oil Rate $(\mathrm{t})$ & 8 & & & \\
\hline 11 & Gas Rate $(\mathrm{t})$ & 8 & & & \\
\hline \multicolumn{3}{|c|}{6} & & & \\
\hline & OTAL ATTRIBUTES & 15 & & & \\
\hline
\end{tabular}

Figure 11-5: Scenario 3 - Water Saturation Model Input Attributes 


\subsection{Production Profile Plots}

\subsubsection{Entire Reservoir}

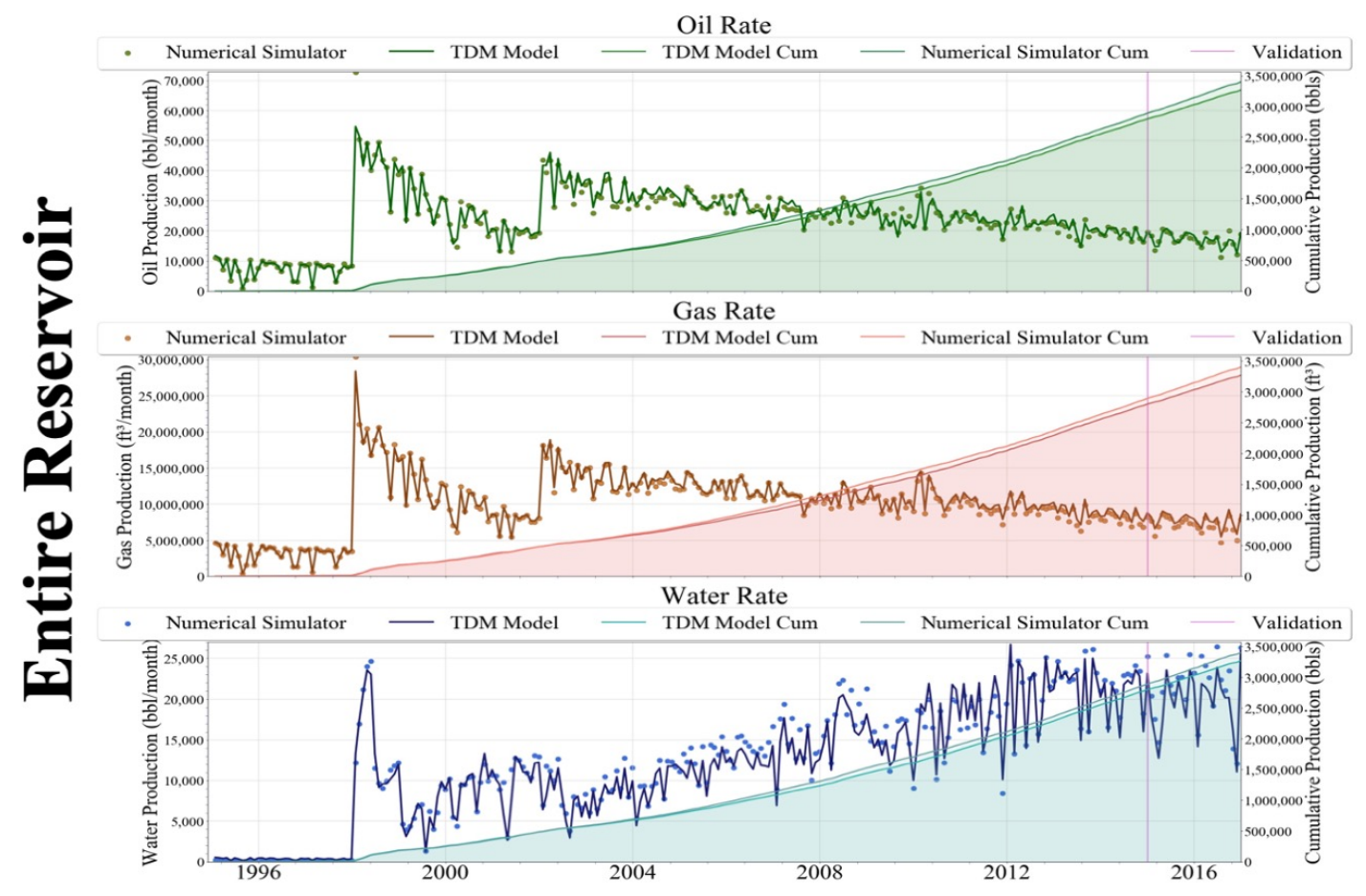

Figure 11-6: Scenario 3 - Entire Field Production 


\subsubsection{Good History Match of Production}

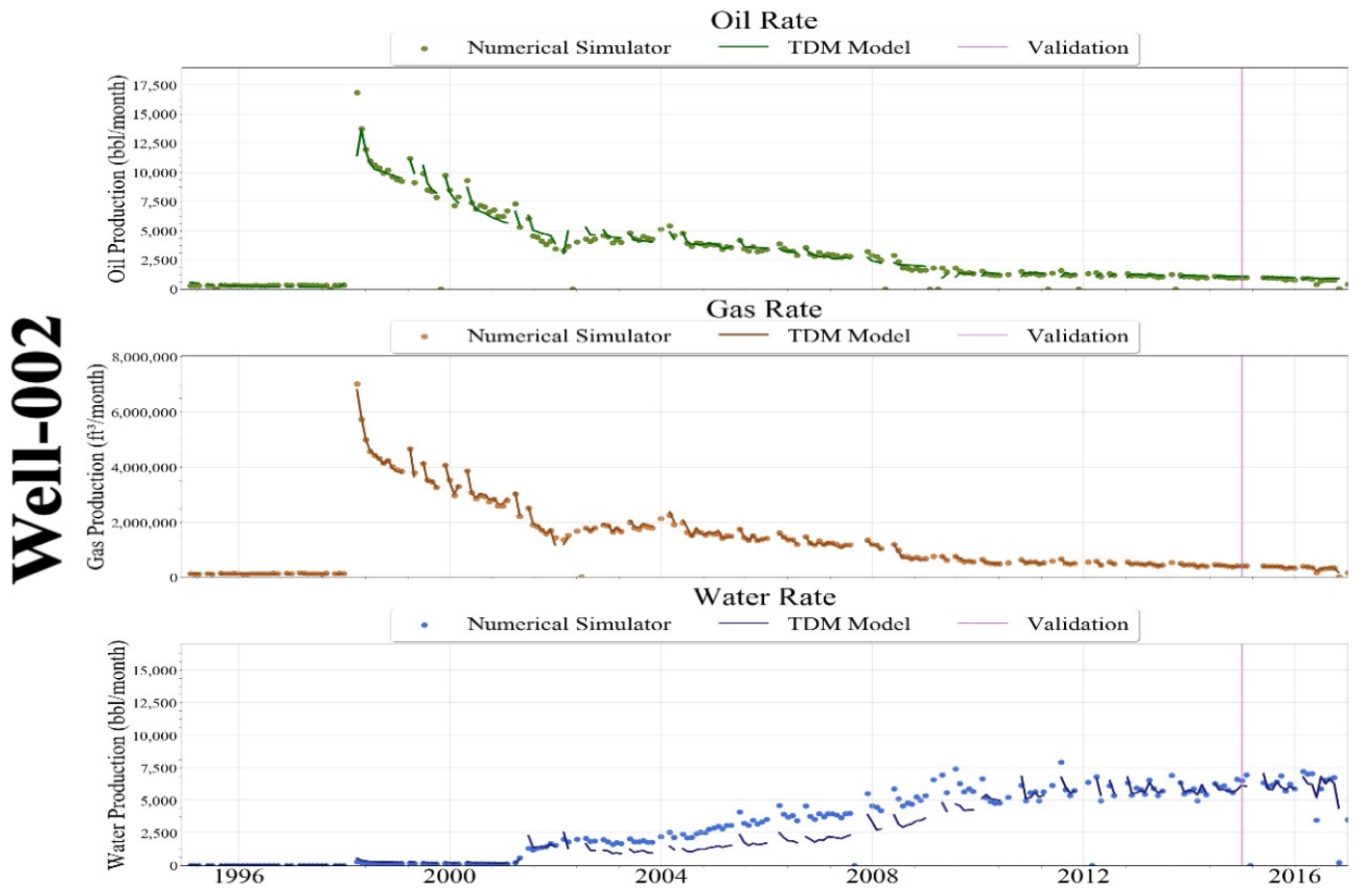

Figure 11-7: Scenario 3 - Well-002 Production History Match

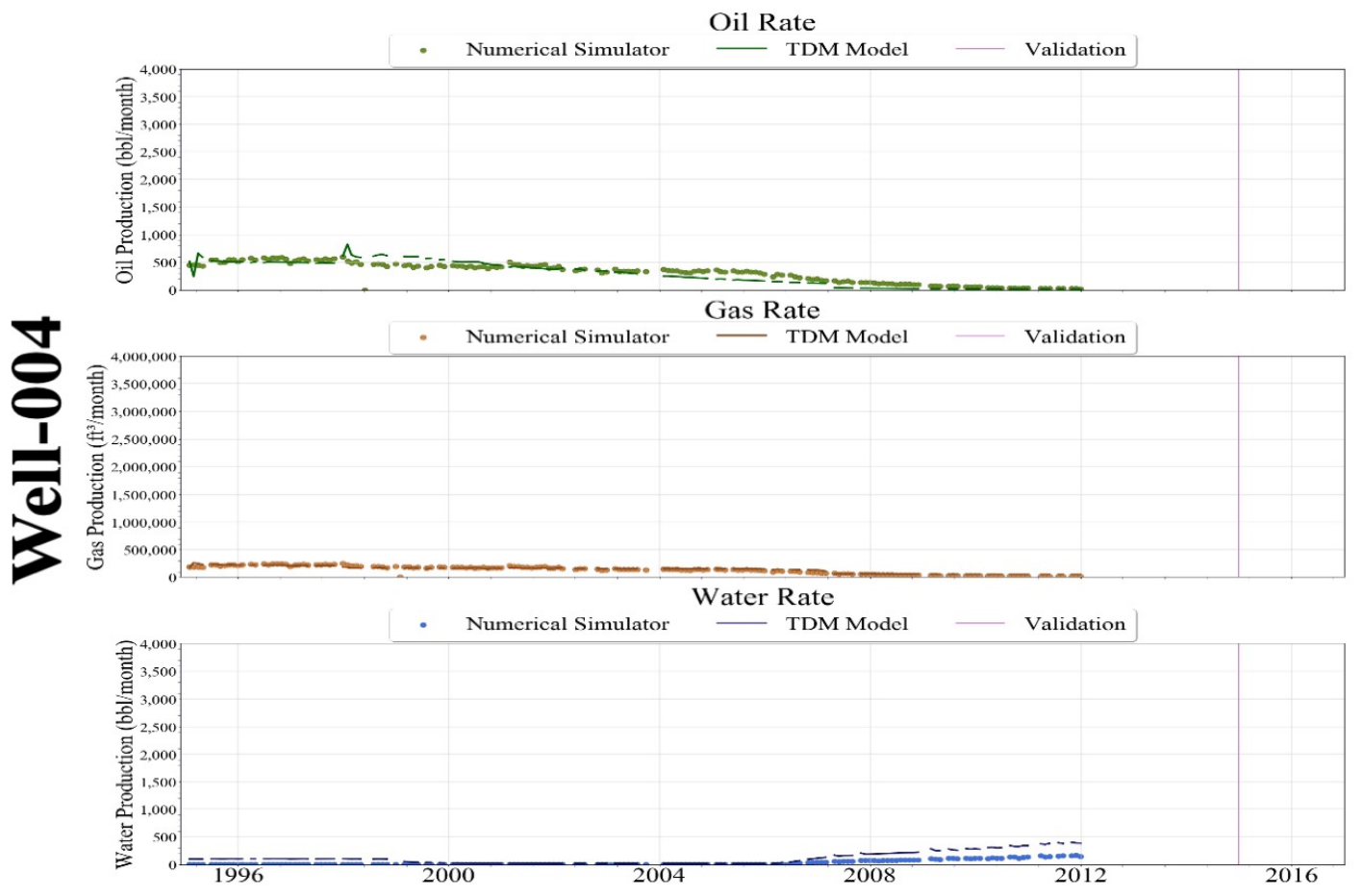

Figure 11-8: Scenario 3 - Well-004 Production History Match 


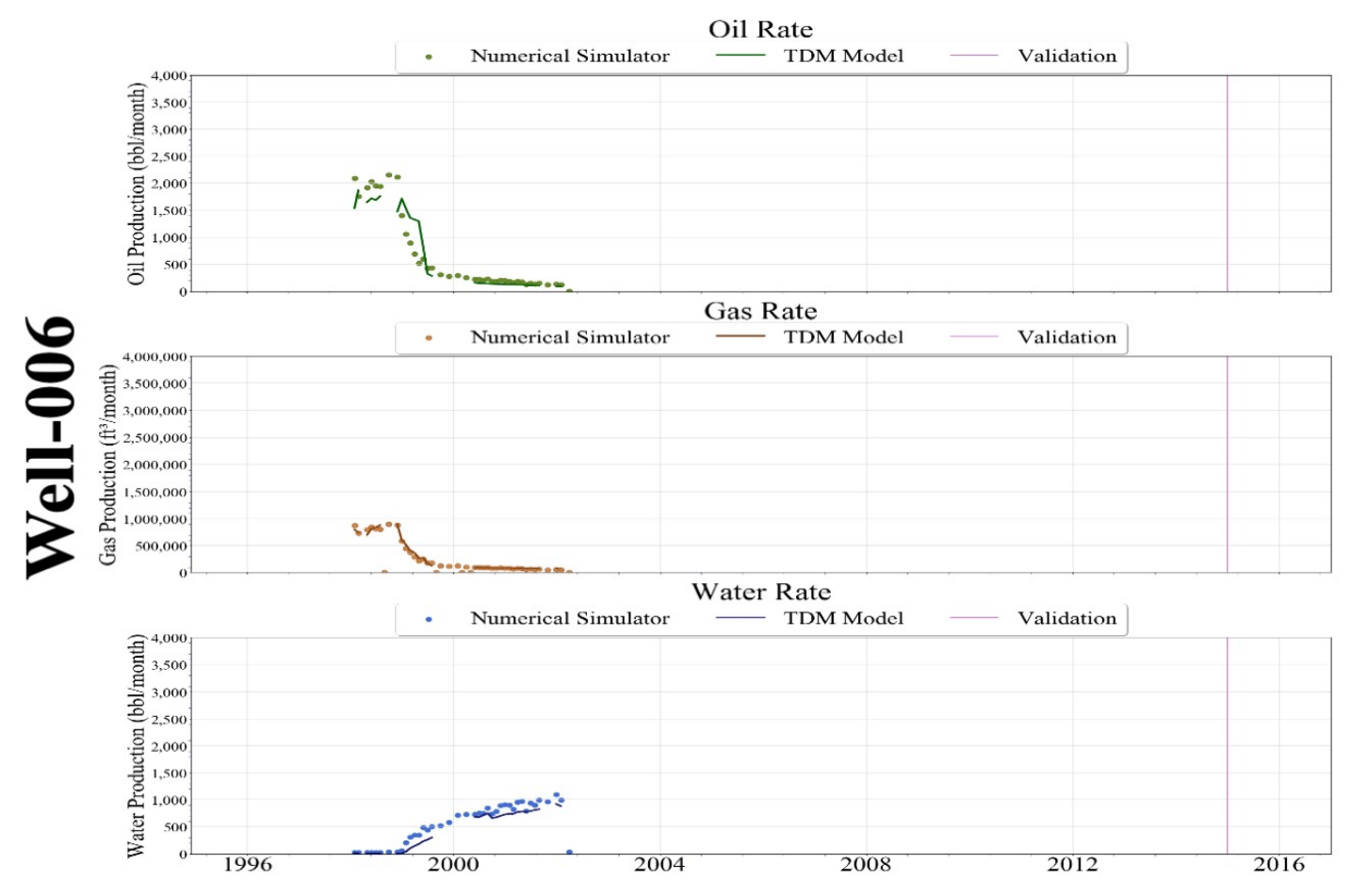

Figure 11-9: Scenario 3 - Well-006 Production History Match

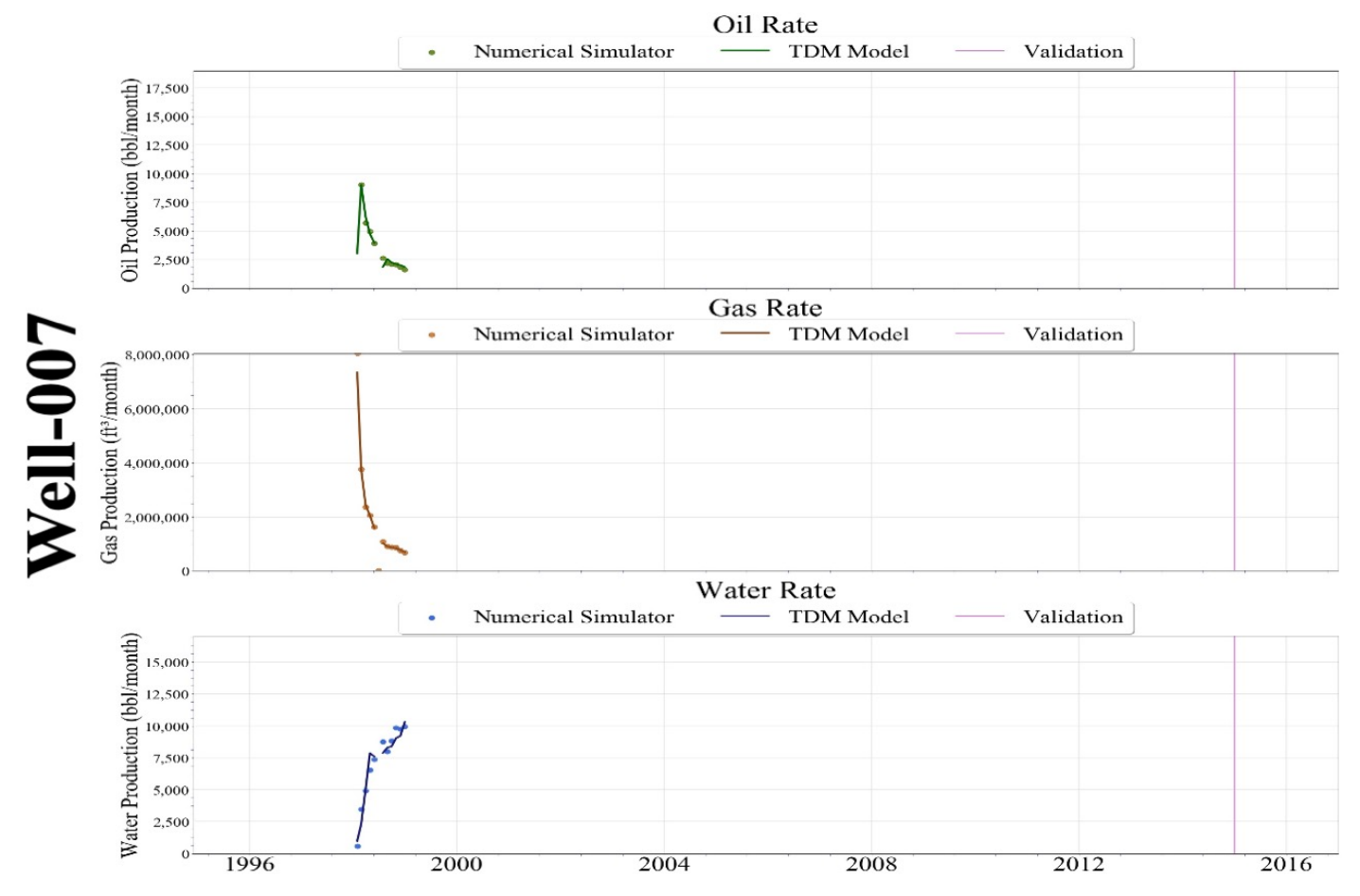

Figure 11-10: Scenario 3 - Well-007 Production History Match 


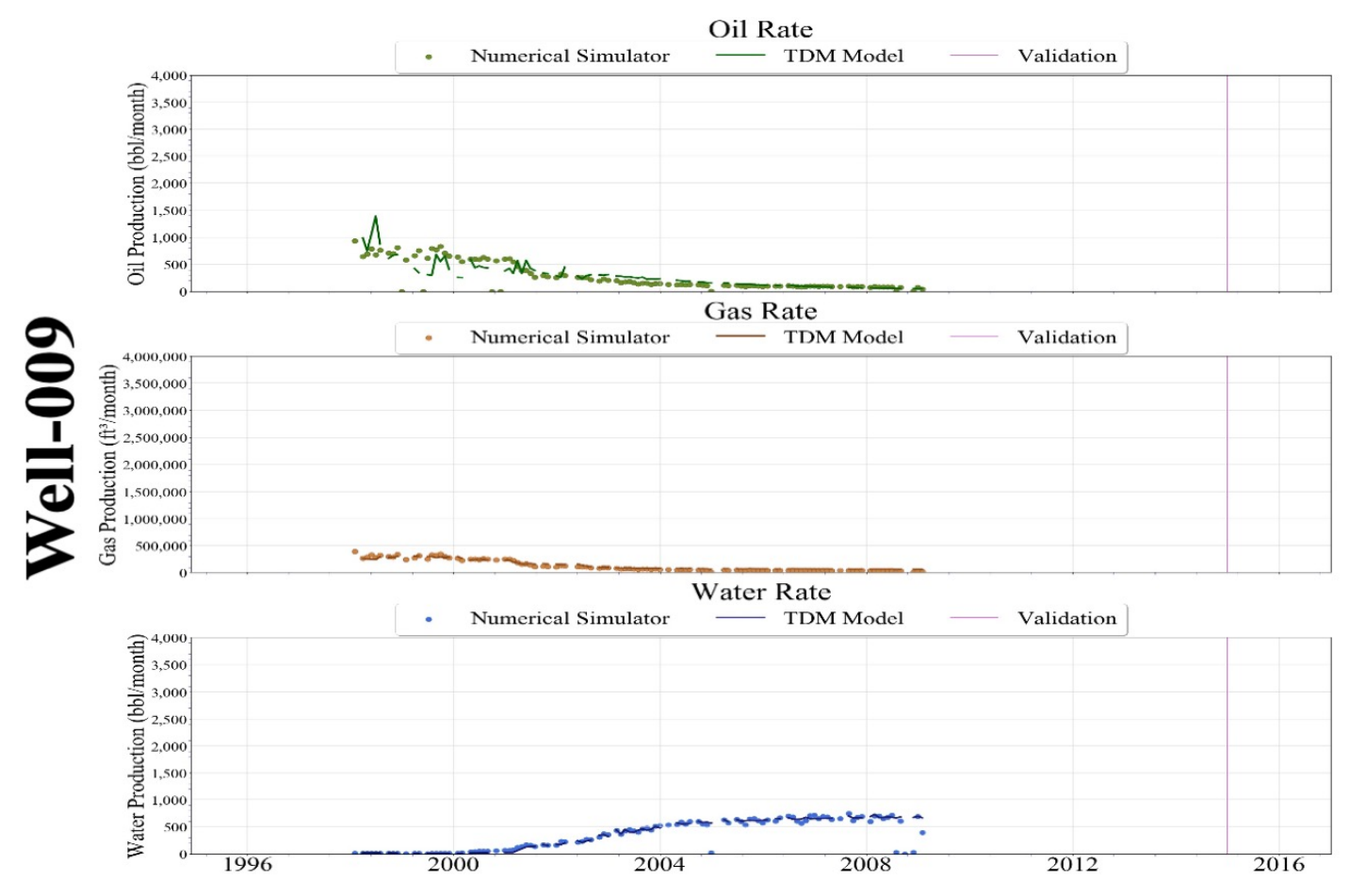

Figure 11-11: Scenario 3 - Well-009 Production History Match

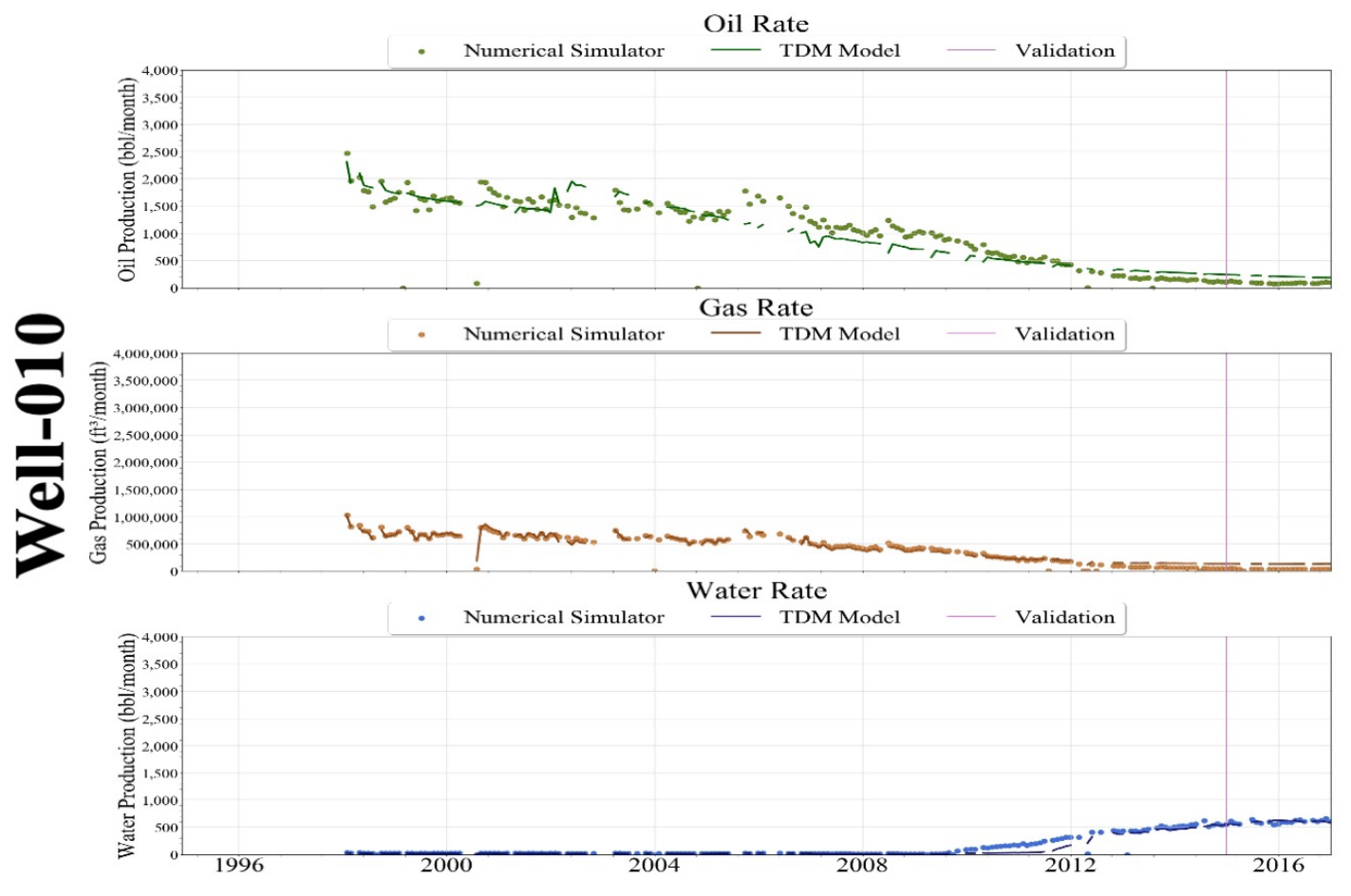

Figure 11-12: Scenario 3 - Well-010 Production History Match 


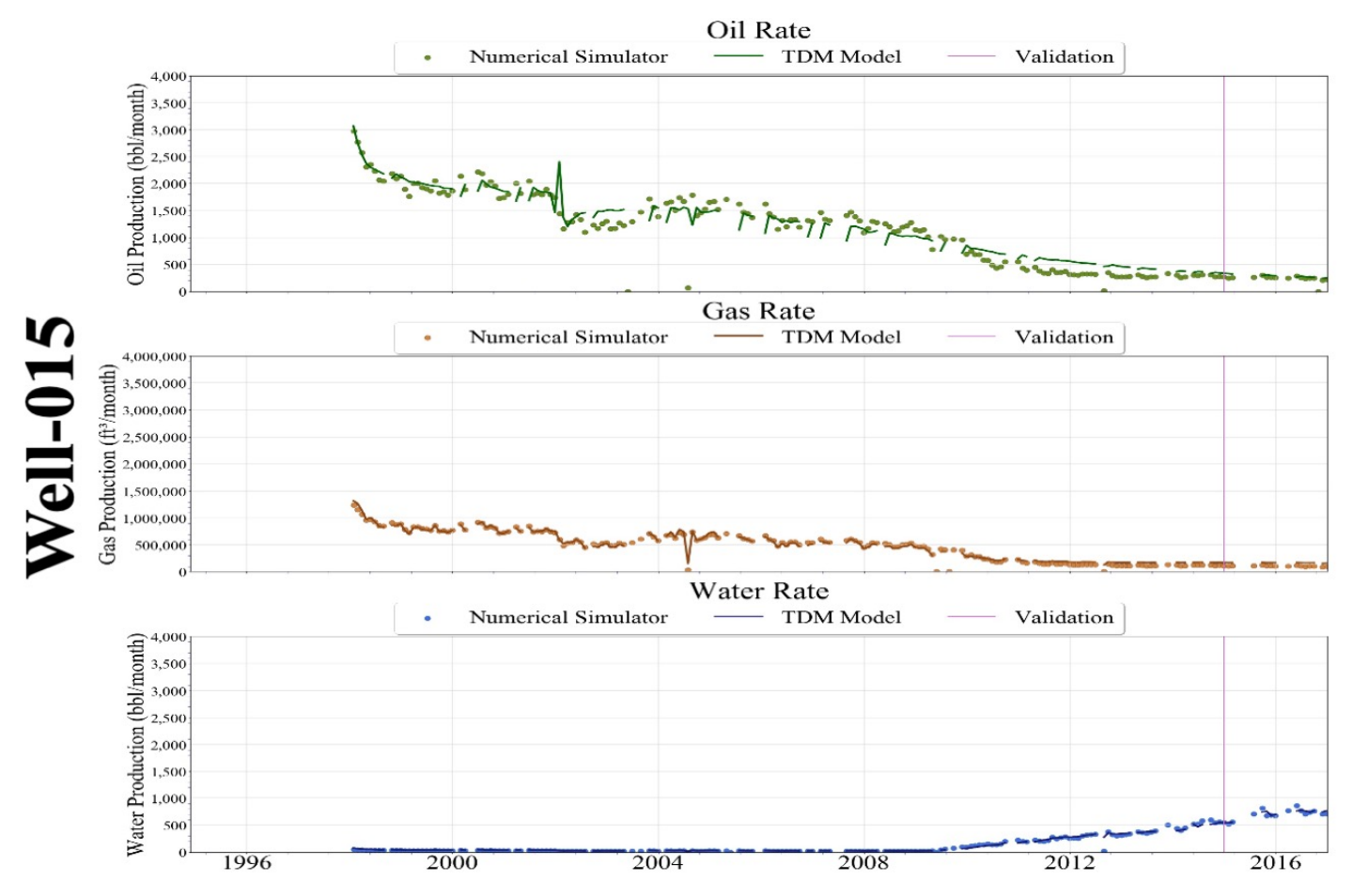

Figure 11-13: Scenario 3 - Well-015 Production History Match

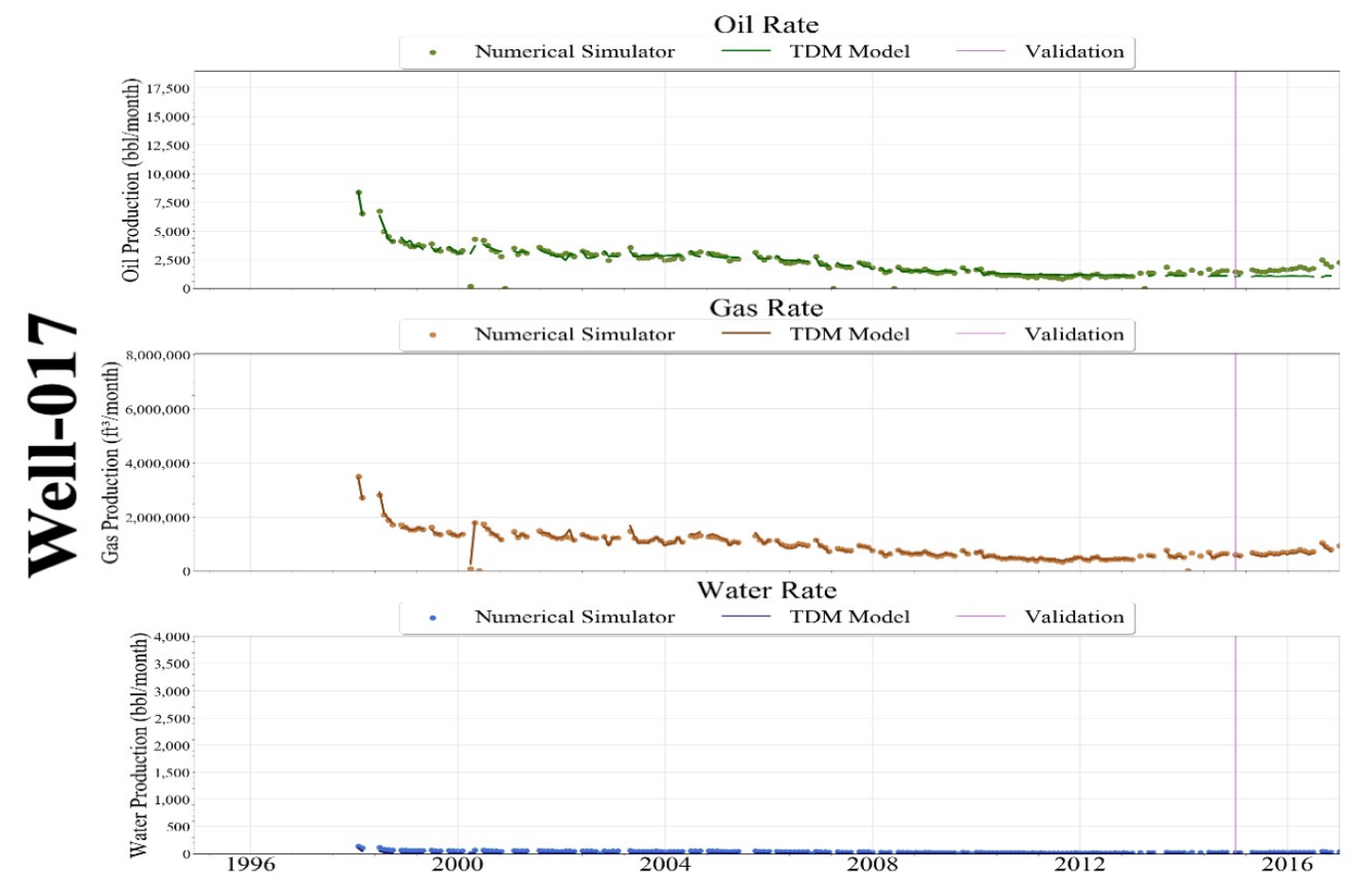

Figure 11-14: Scenario 3 - Well-017 Production History Match 


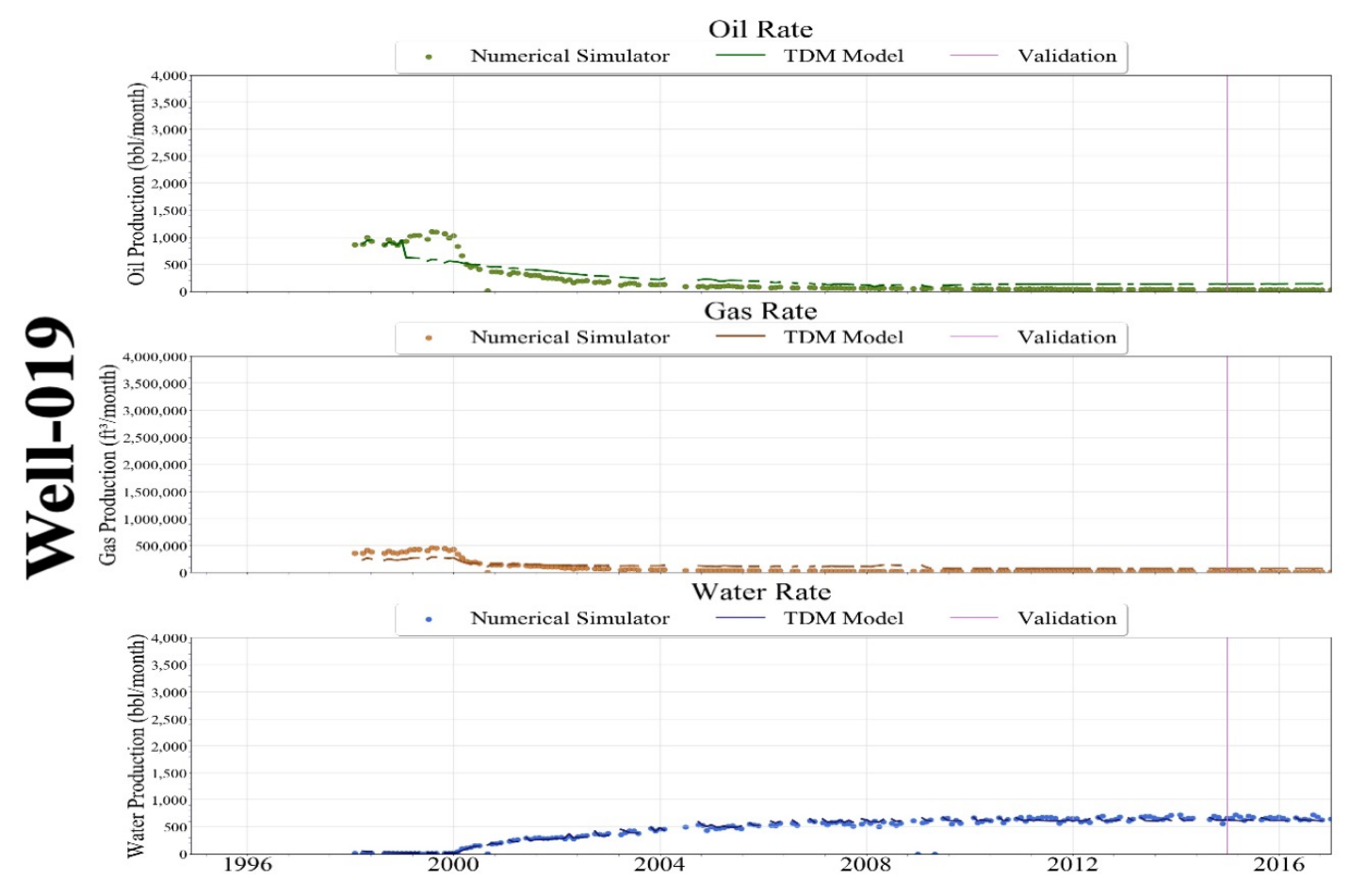

Figure 11-15: Scenario 3 - Well-019 Production History Match

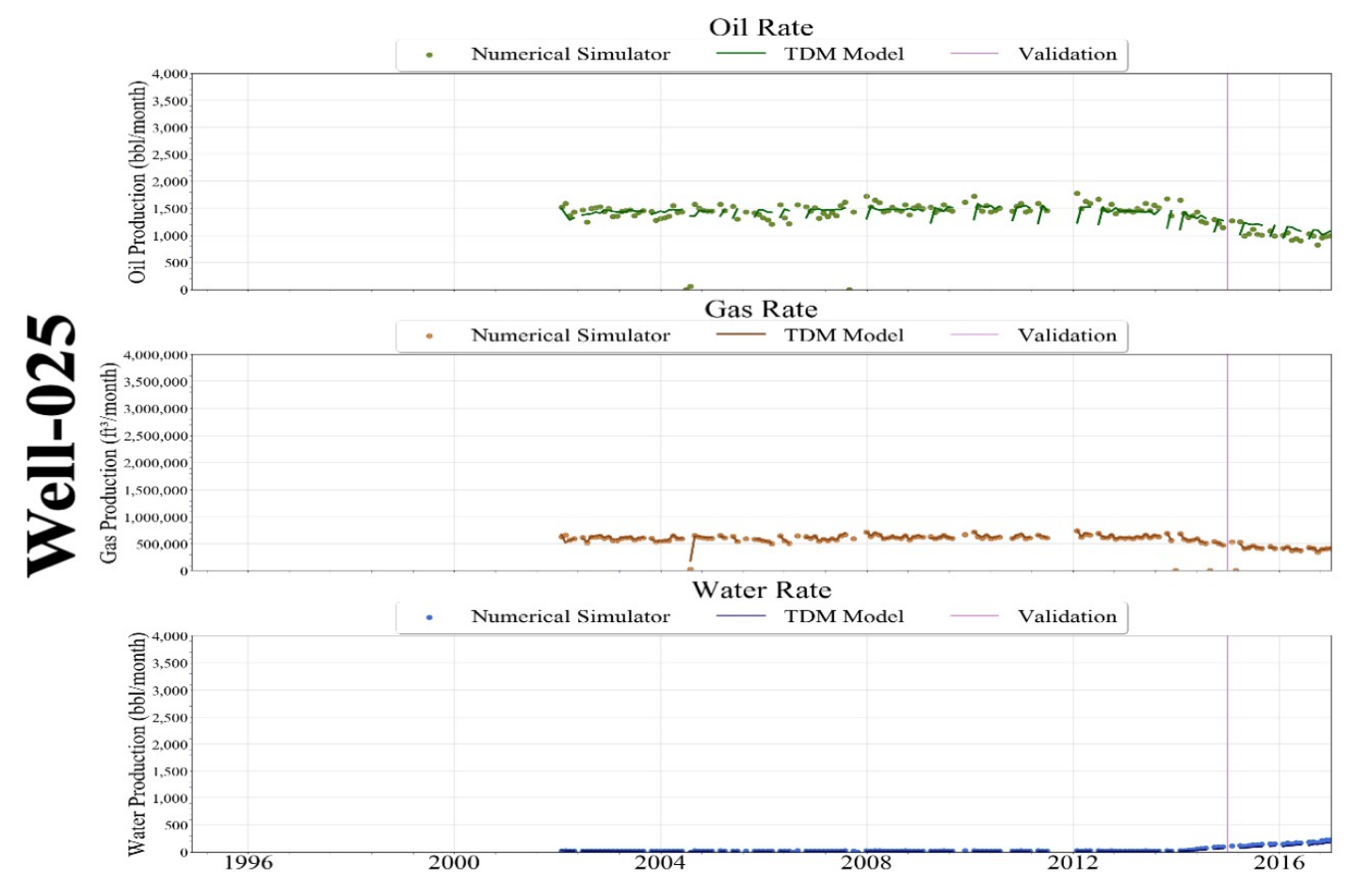

Figure 11-16: Scenario 3 - Well-025 Production History Match 
Oil Rate
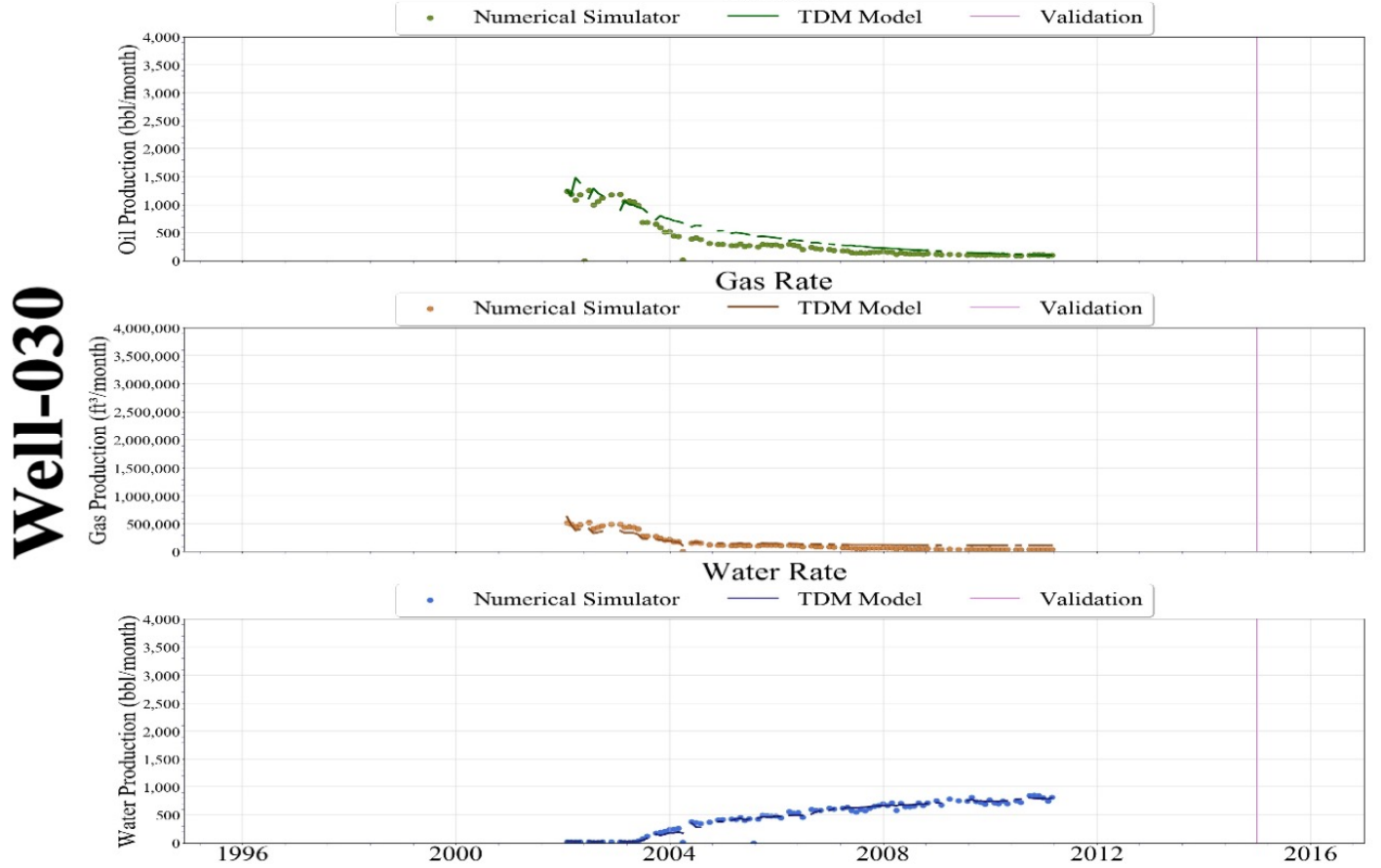

Figure 11-17: Scenario 3 - Well-030 Production History Match
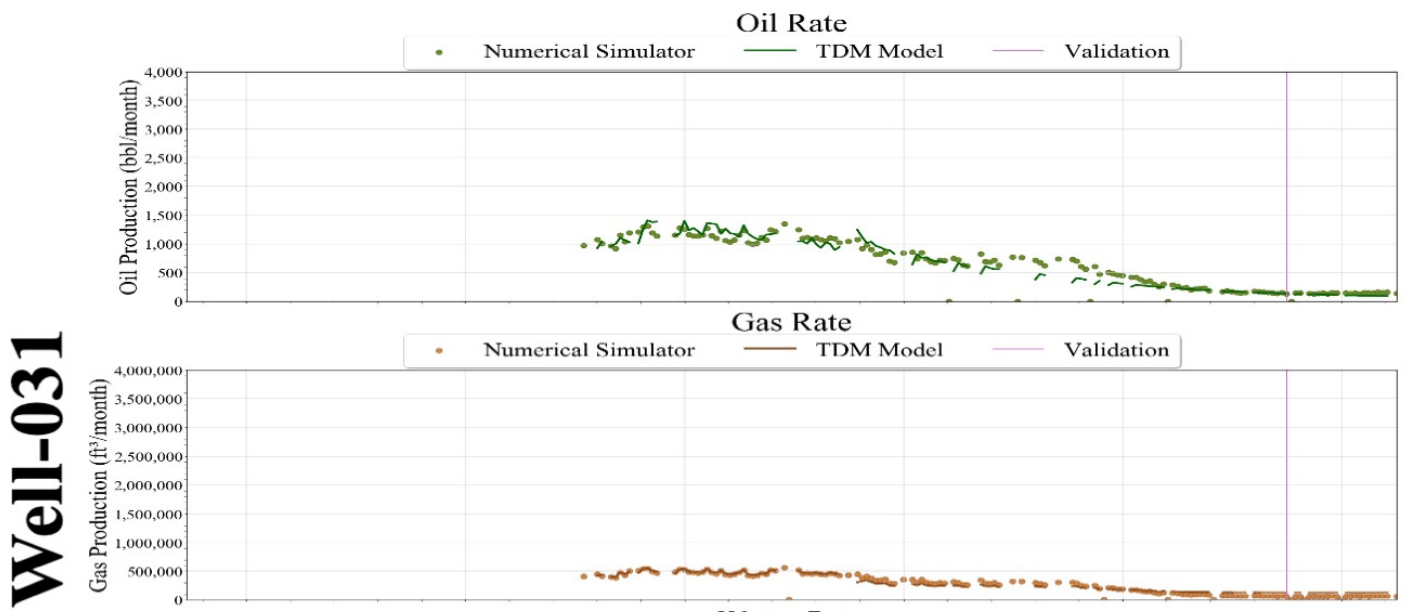

Water Rate

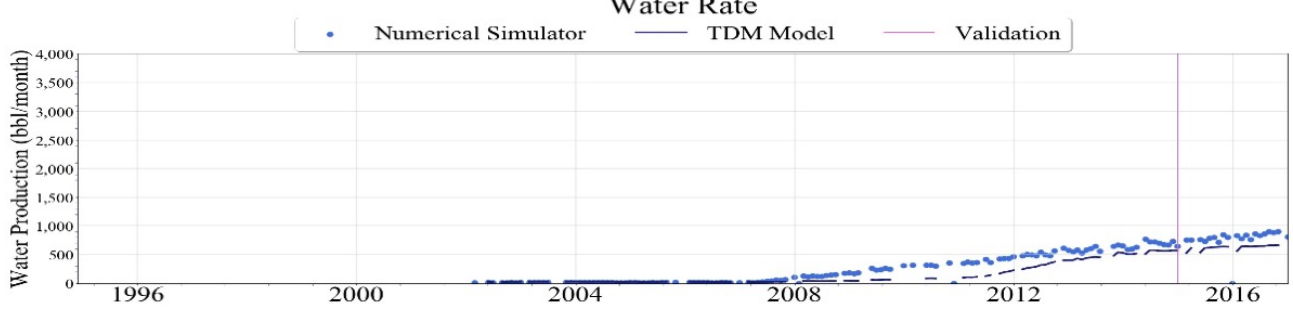

Figure 11-18: Scenario 3 - Well-031 Production History Match 


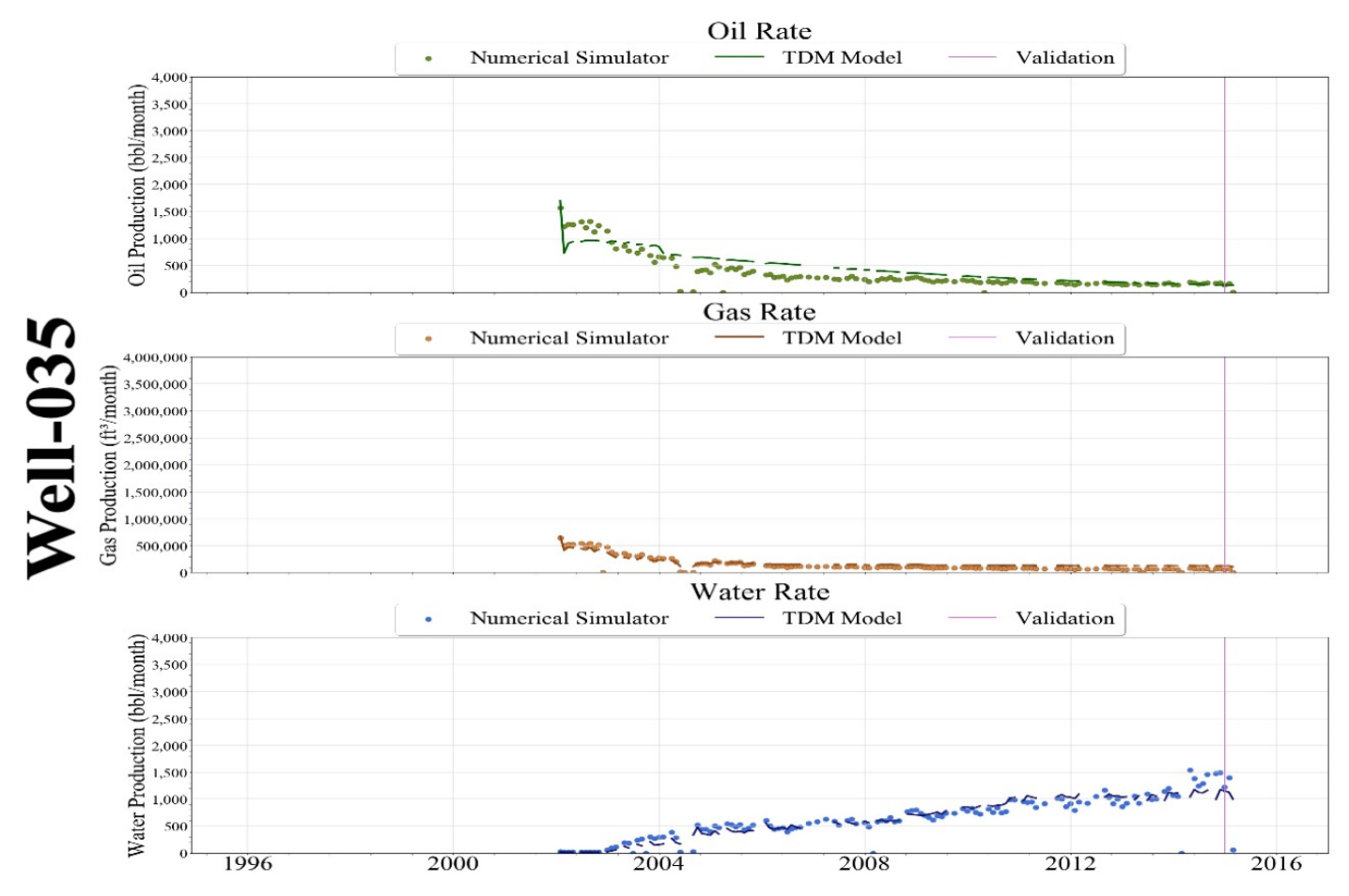

Figure 11-19: Scenario 3 - Well-035 Production History Match

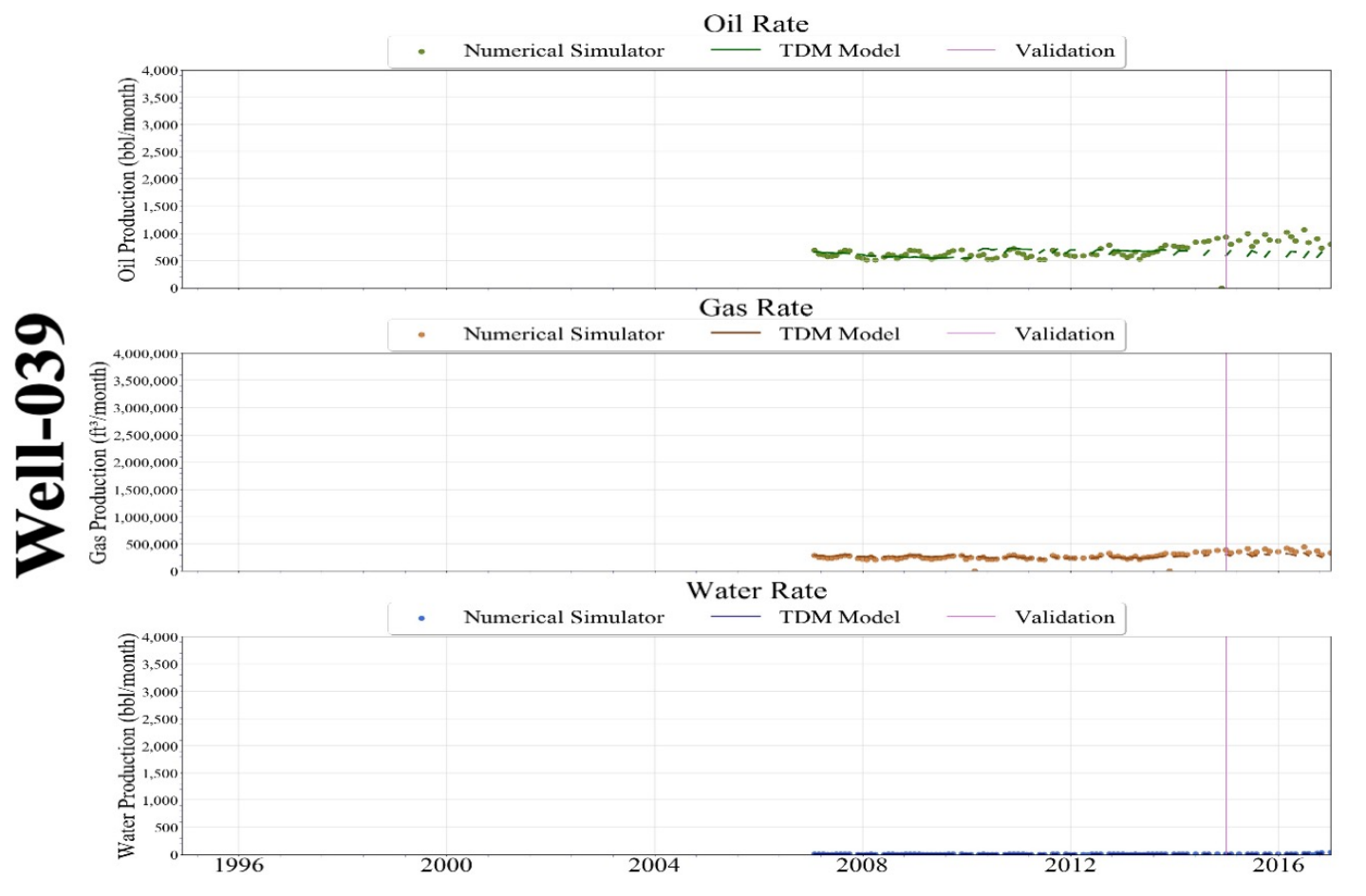

Figure 11-20: Scenario 3 - Well-039 Production History Match 


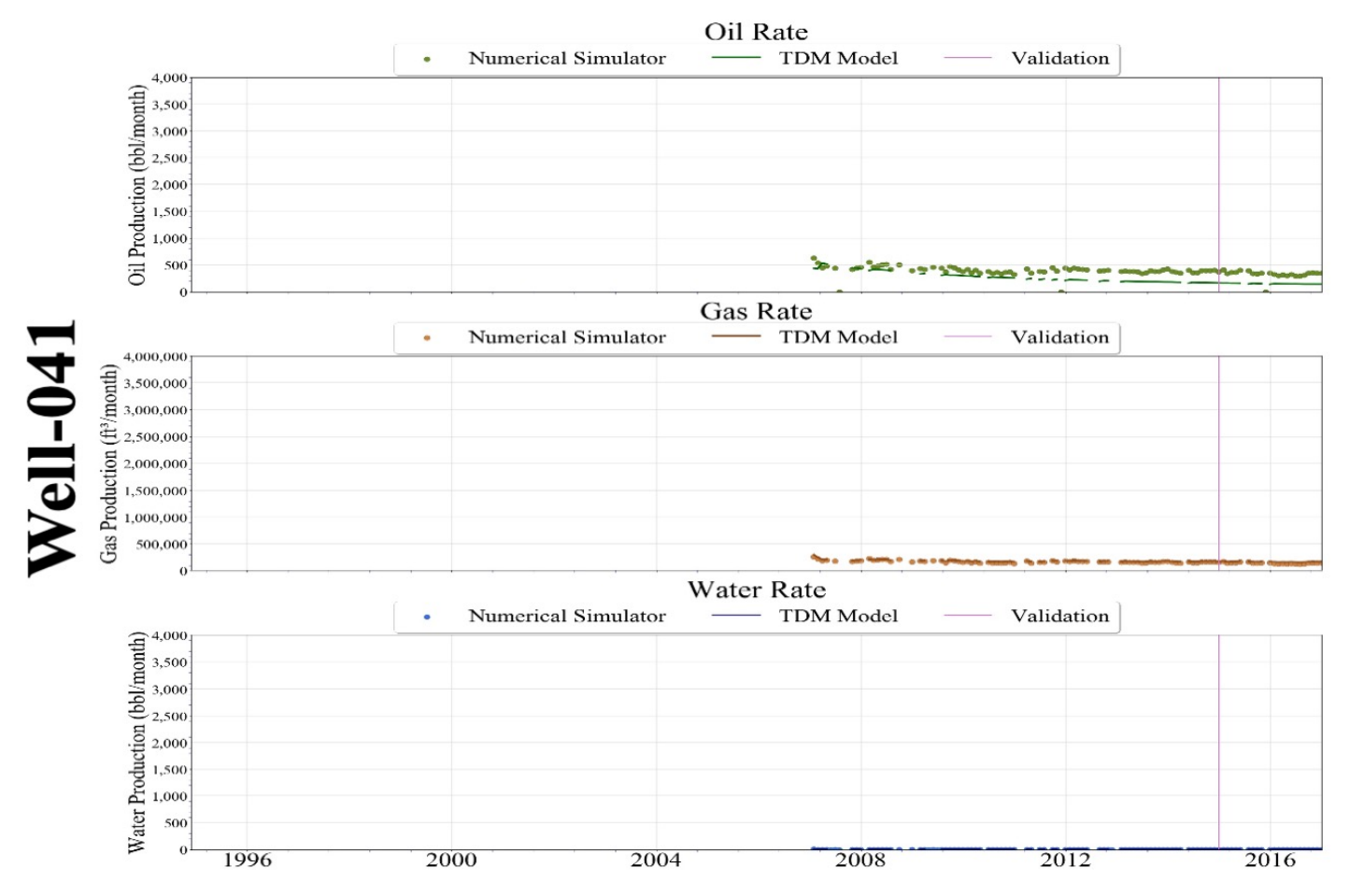

Figure 11-21: Scenario 3 - Well-041 Production History Match

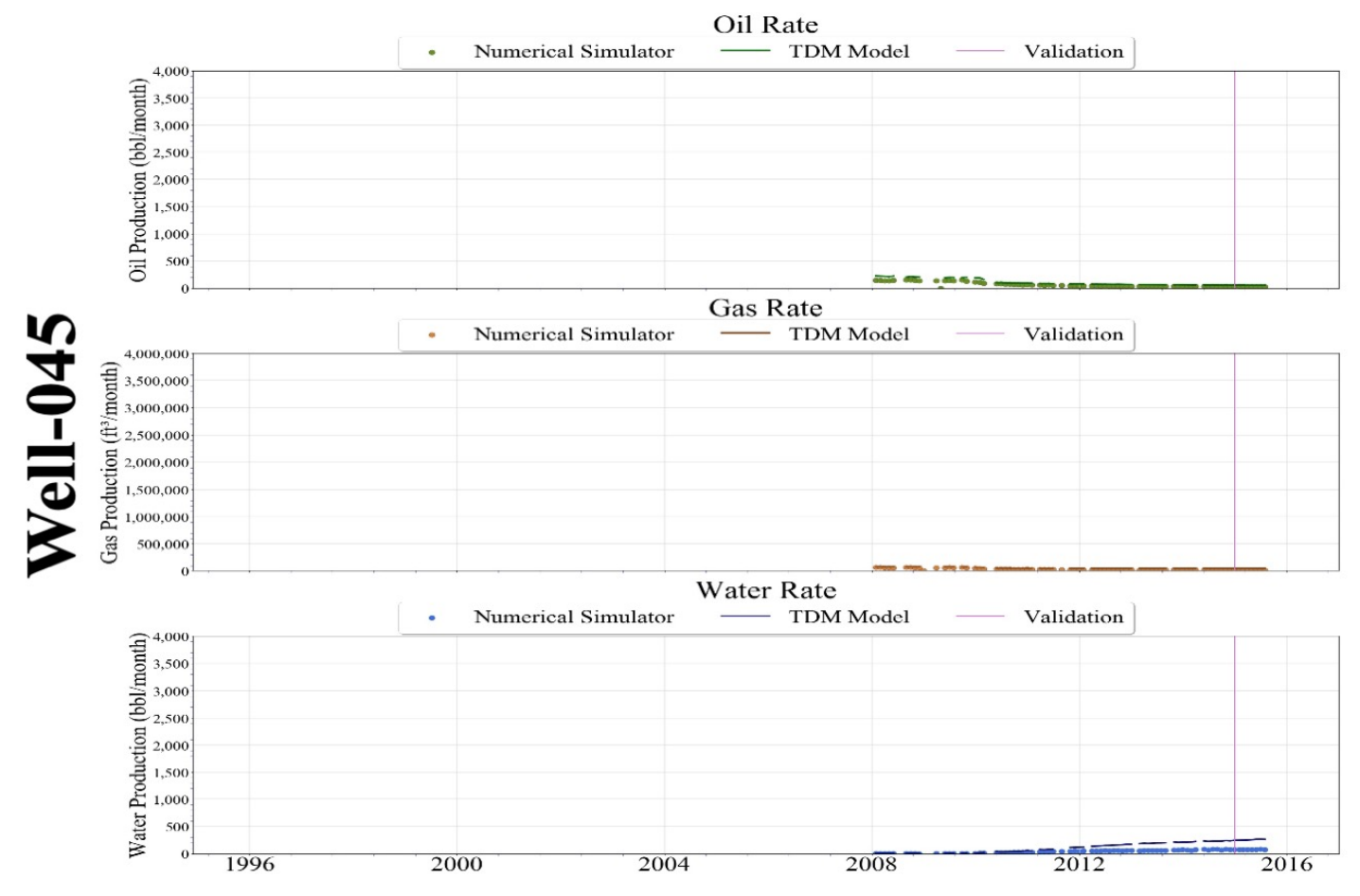

Figure 11-22: Scenario 3 - Well-045 Production History Match 


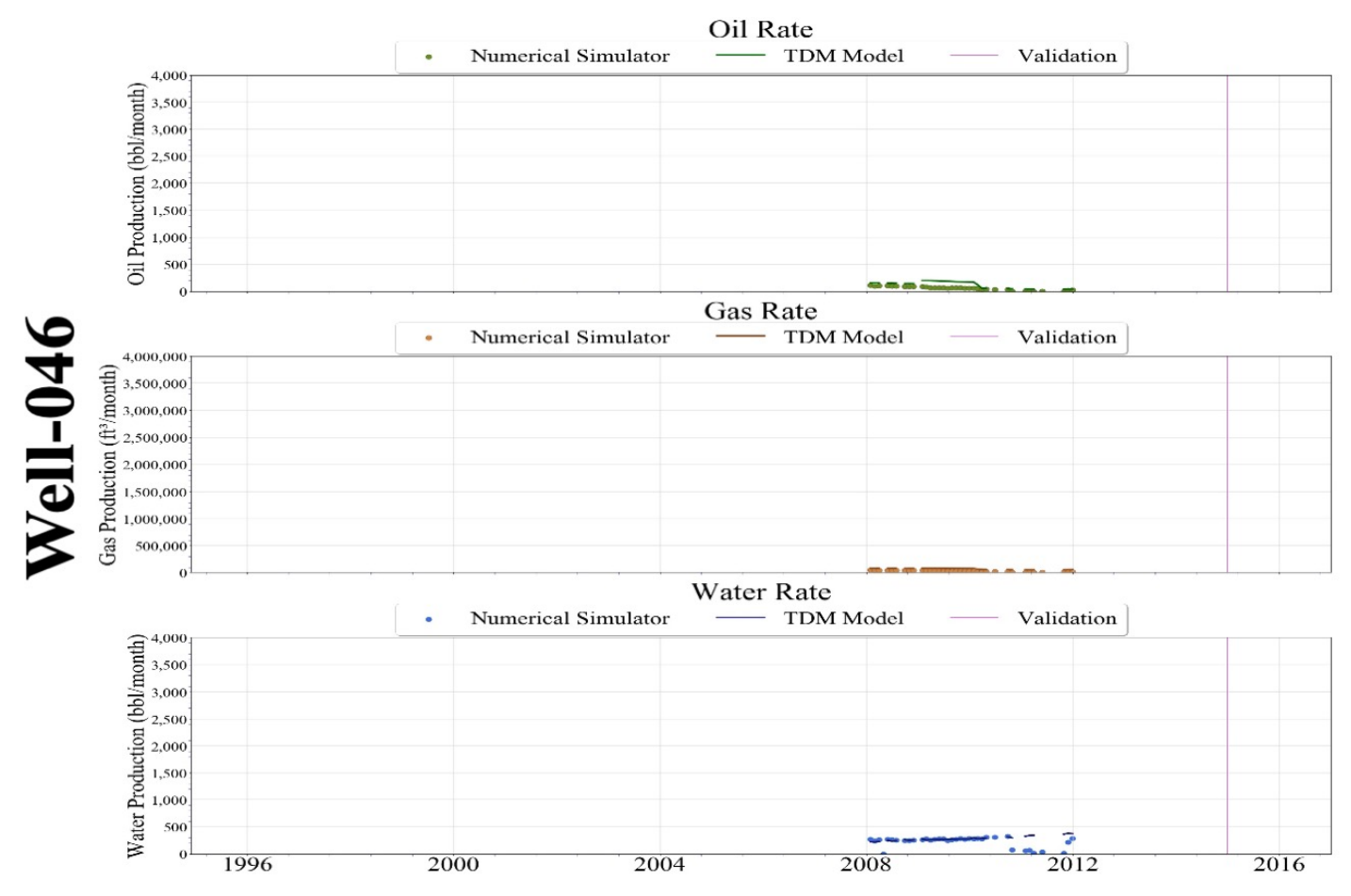

Figure 11-23: Scenario 3 - Well-046 Production History Match

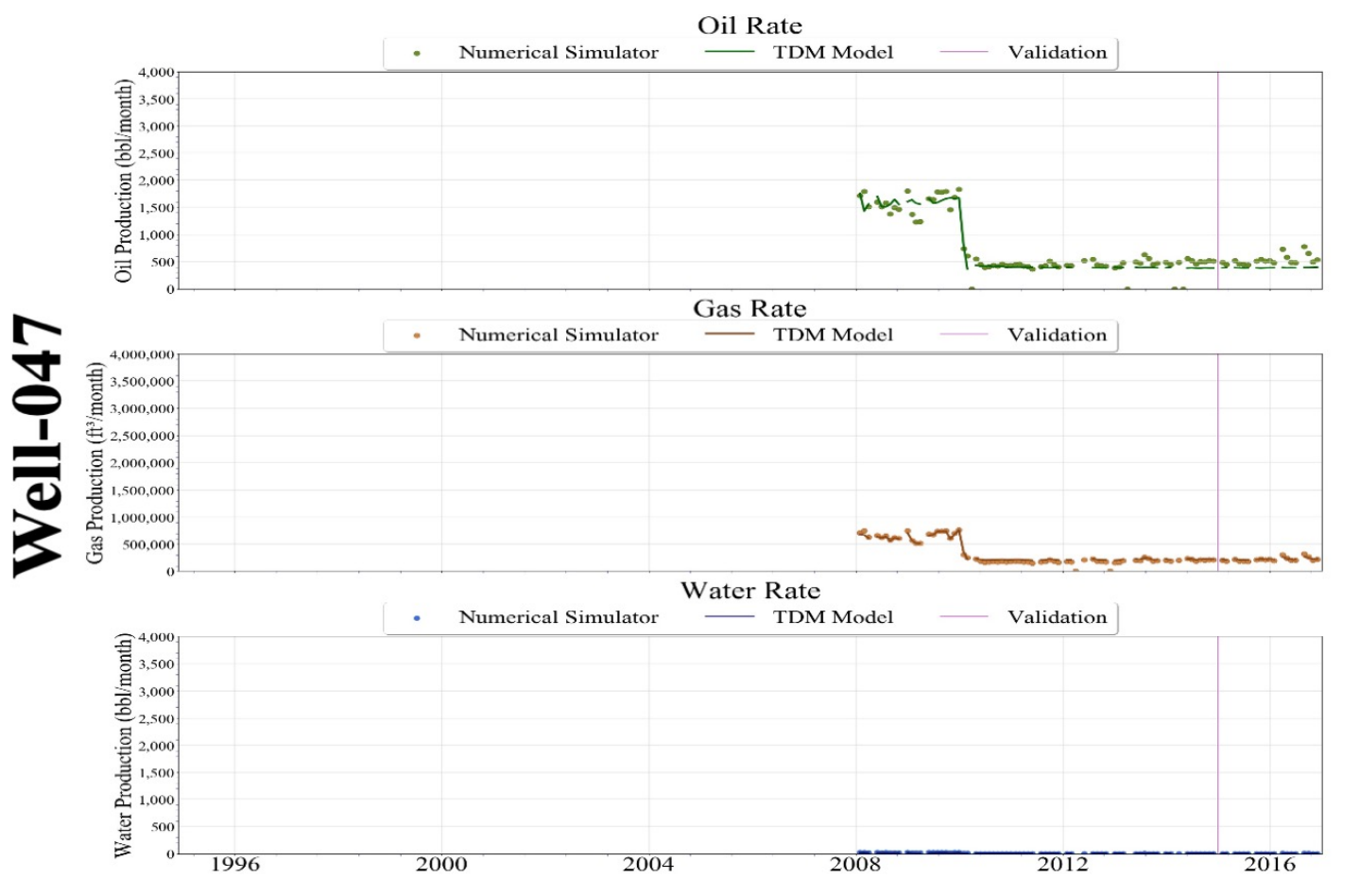

Figure 11-24: Scenario 3 - Well-047 Production History Match 


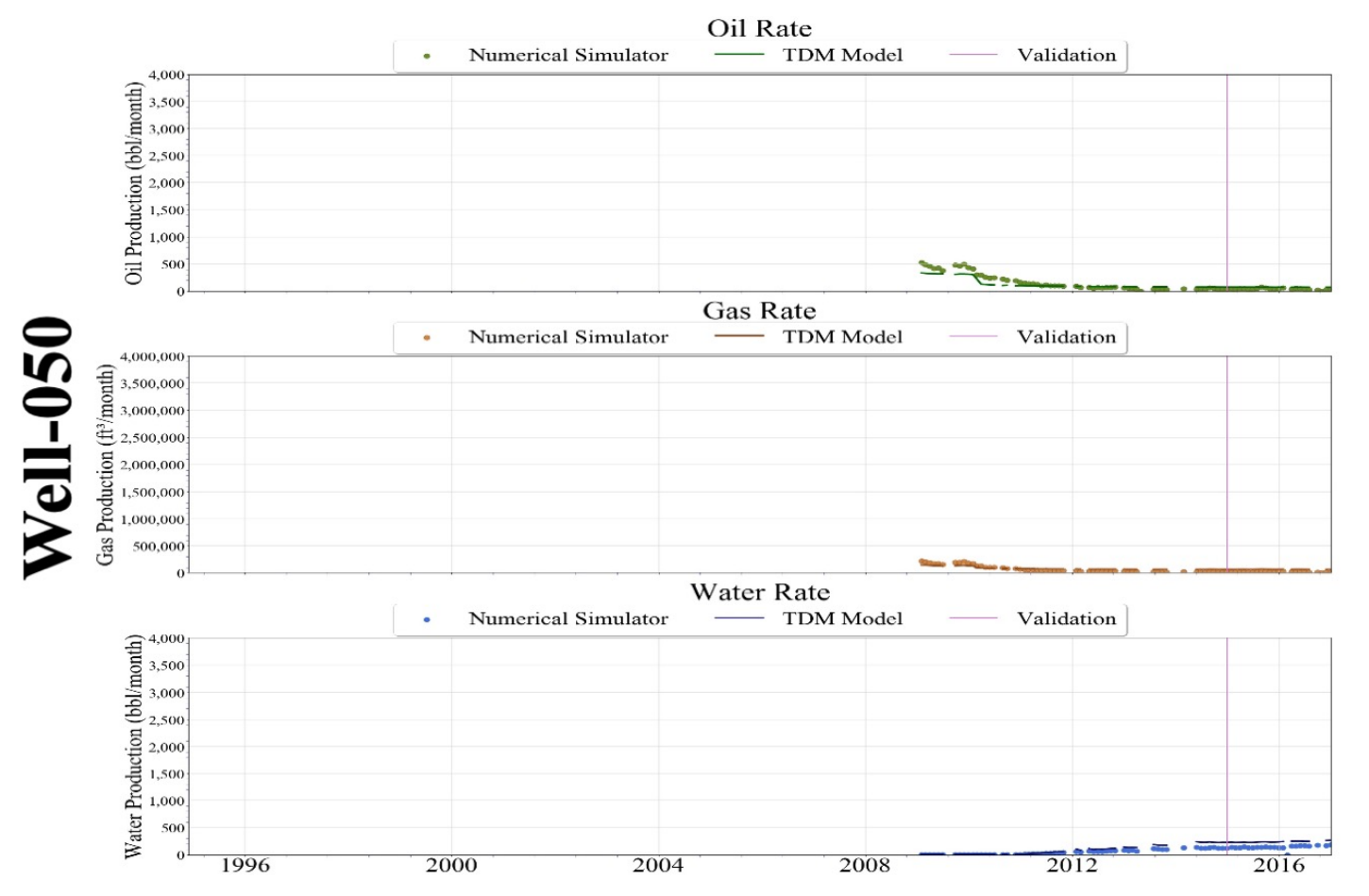

Figure 11-25: Scenario 3 - Well-050 Production History Match

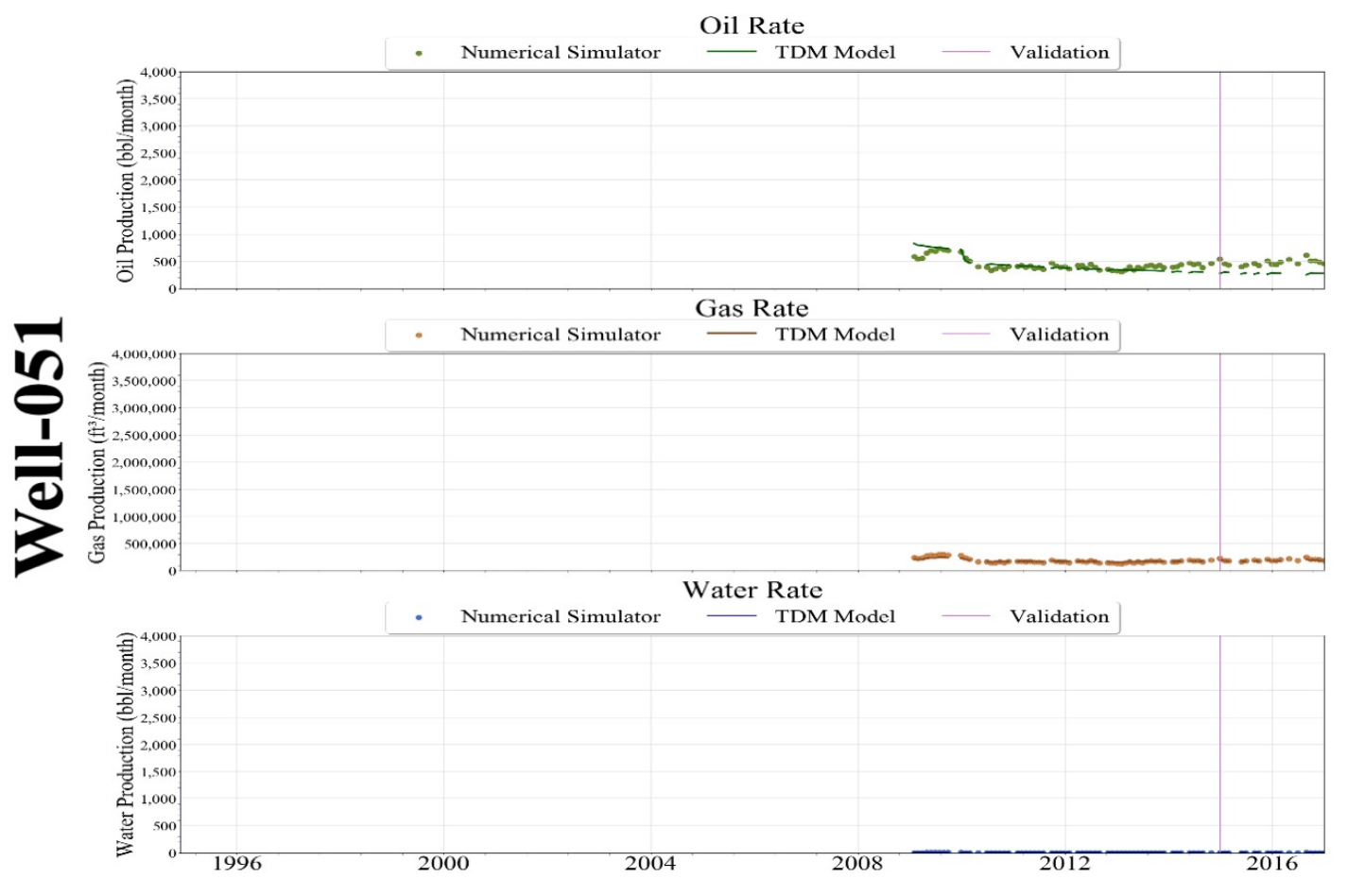

Figure 11-26: Scenario 3 - Well-051 Production History Match 


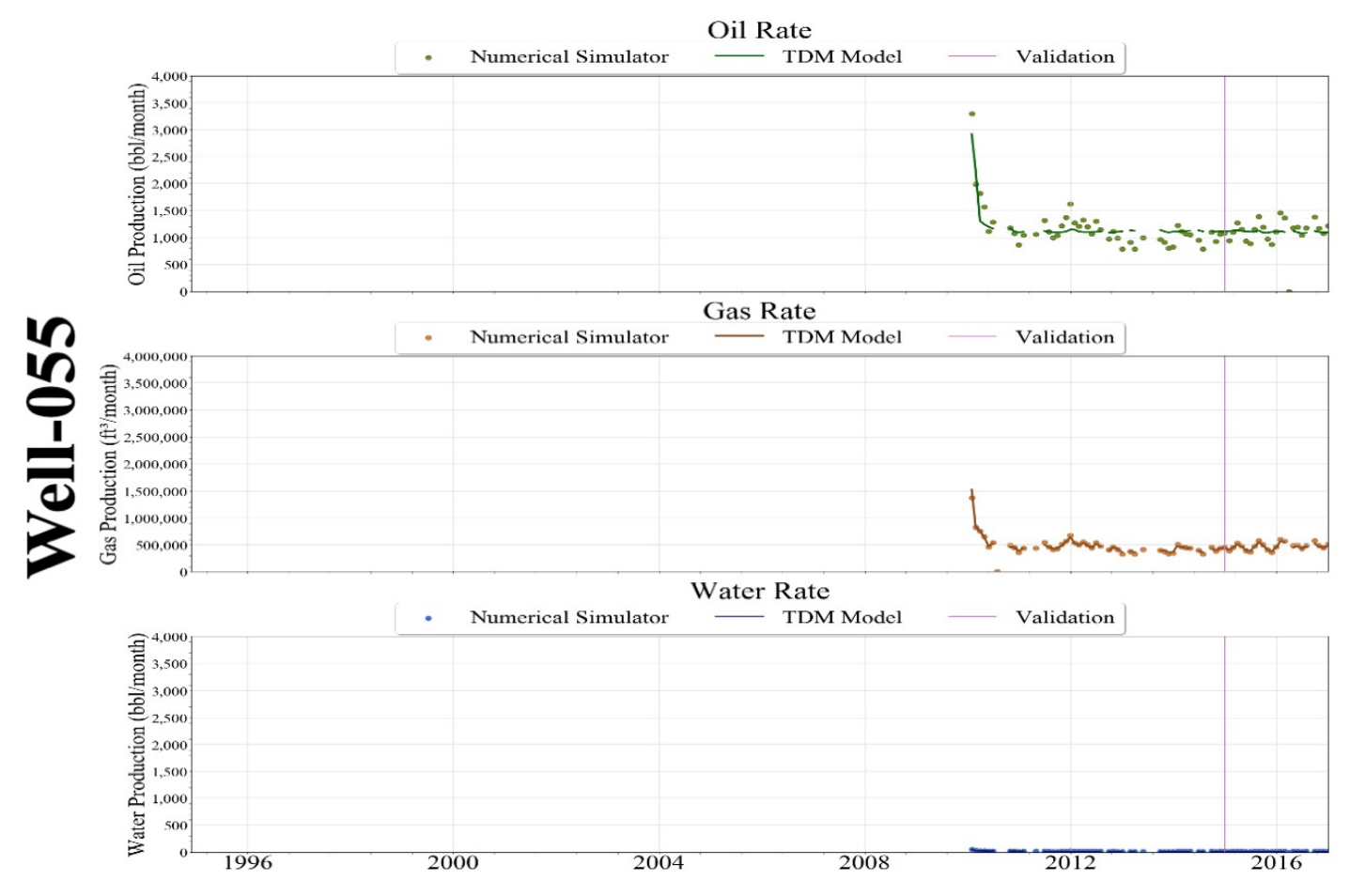

Figure 11-27: Scenario 3 - Well-055 Production History Match

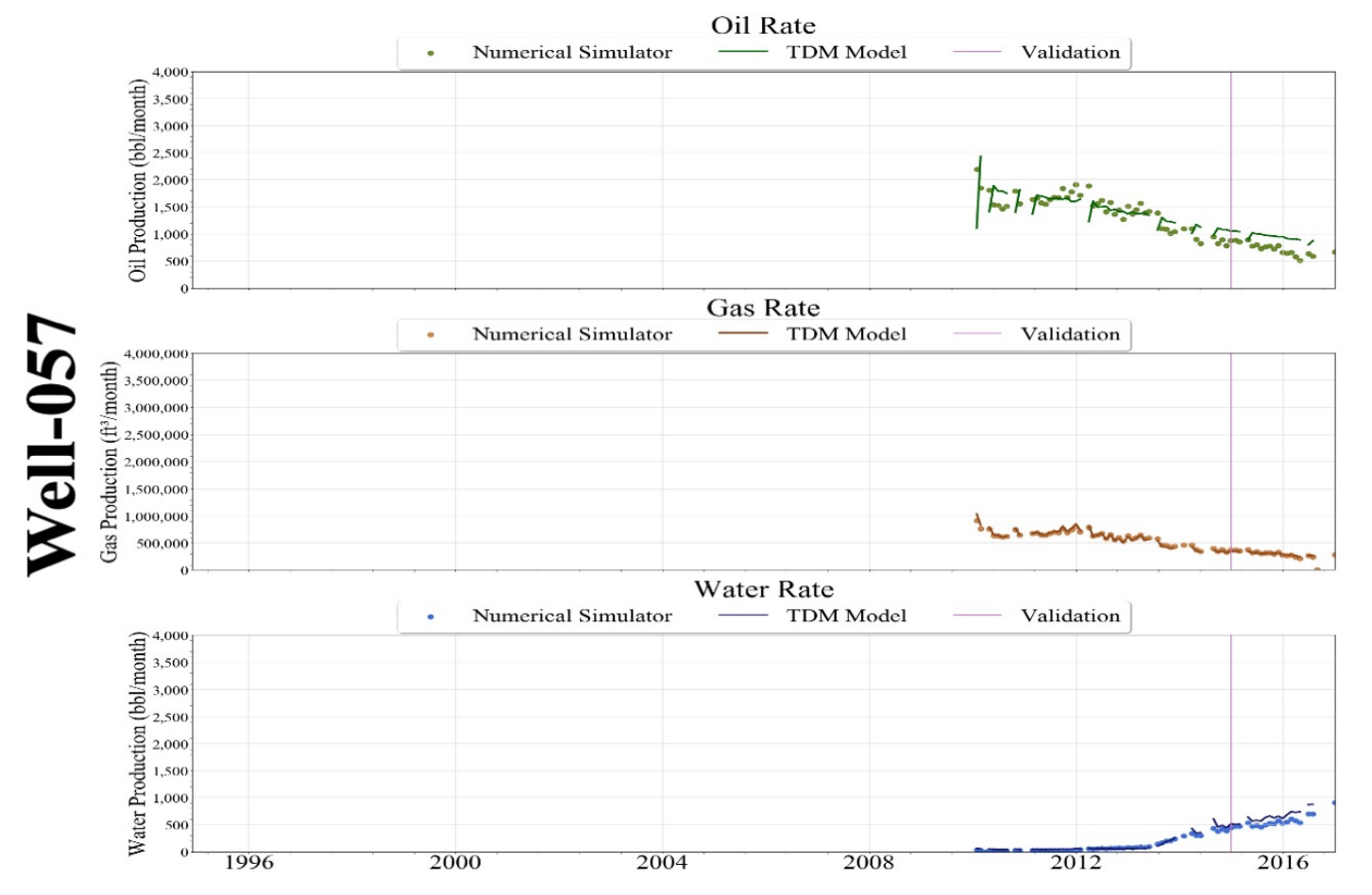

Figure 11-28: Scenario 3 - Well-057 Production History Match 


\subsubsection{Average History Match of Production}

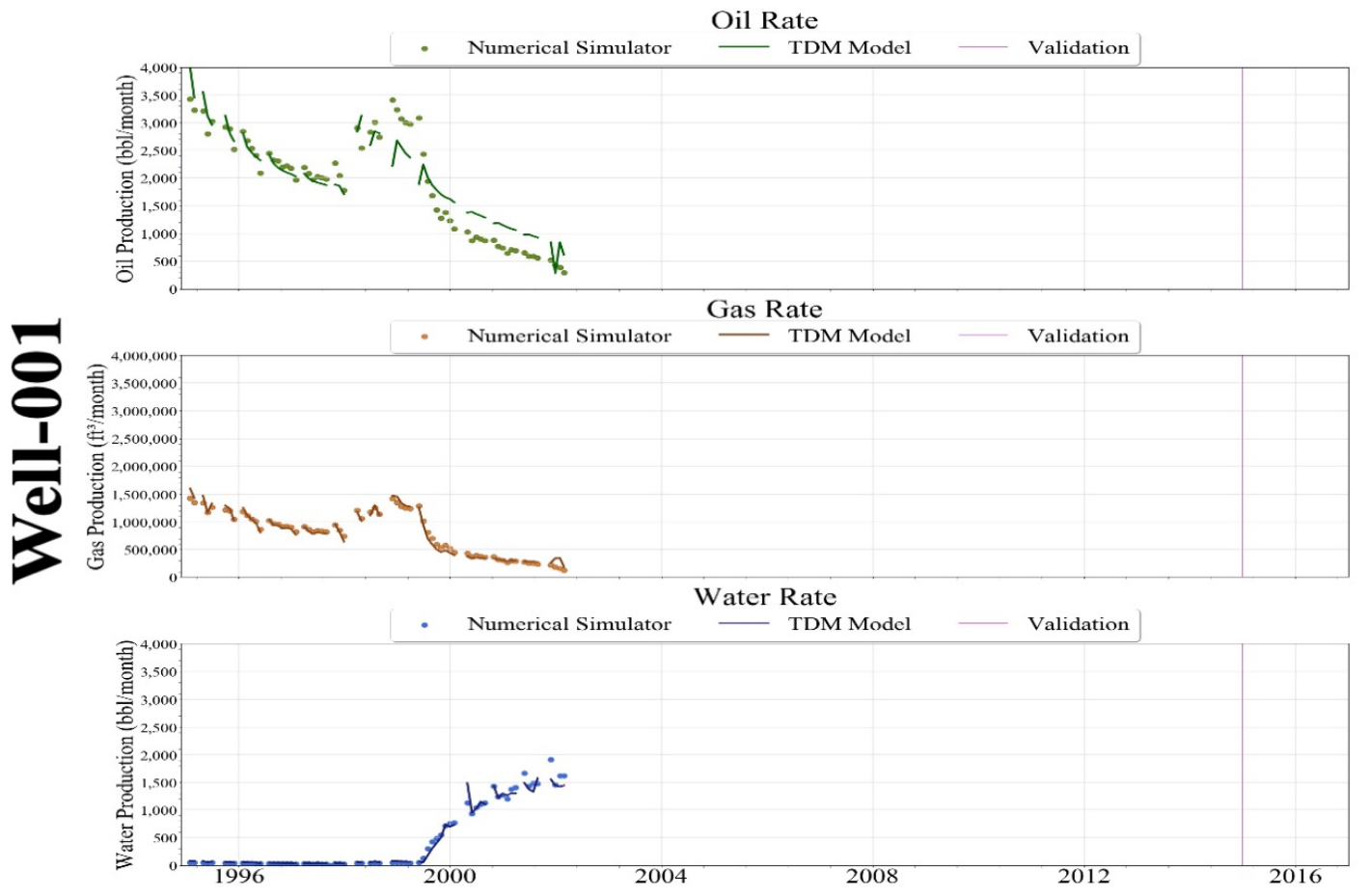

Figure 11-29: Scenario 3 - Well-001 Production History Match

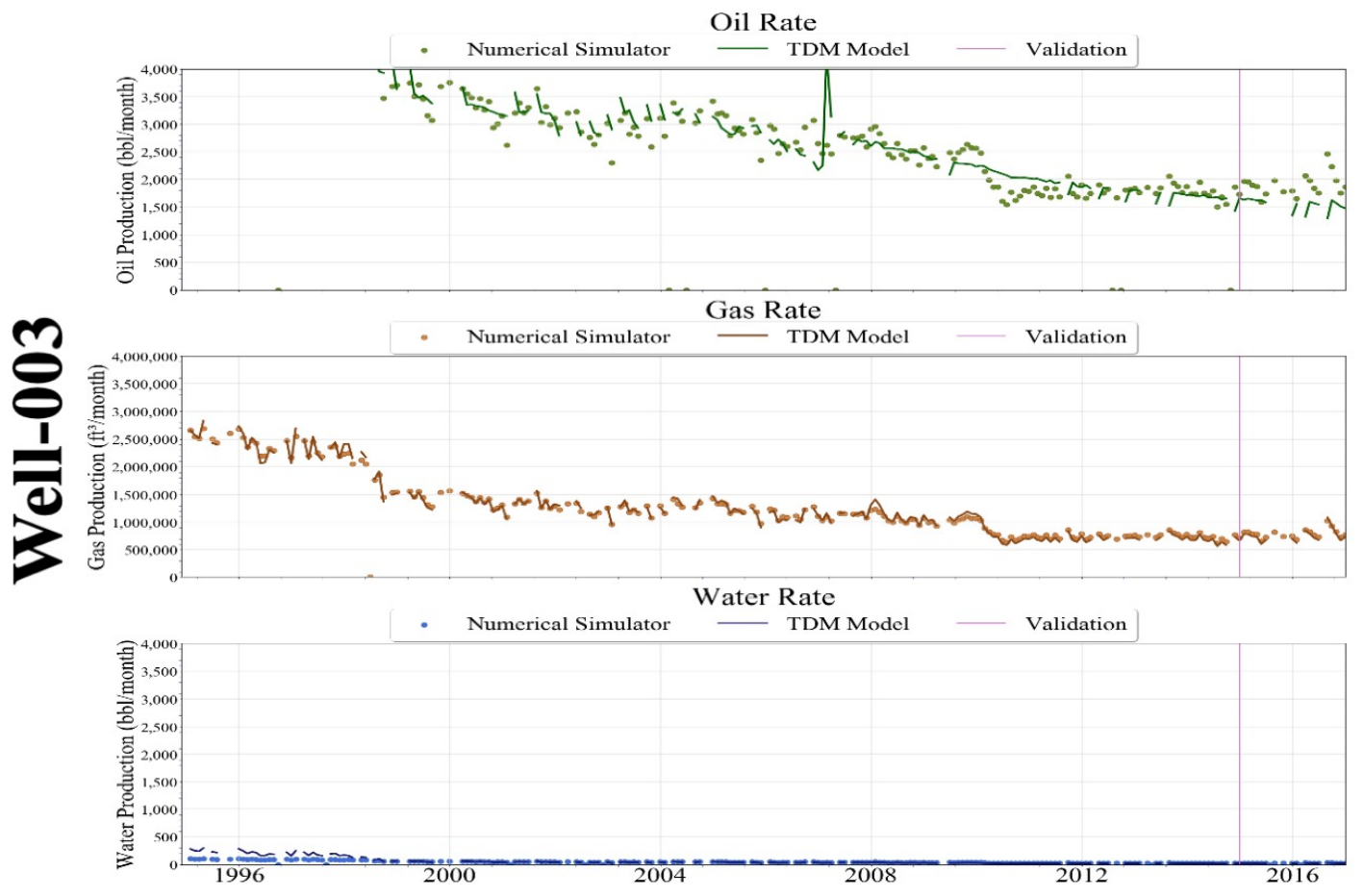

Figure 11-30: Scenario 3 - Well-003 Production History Match 


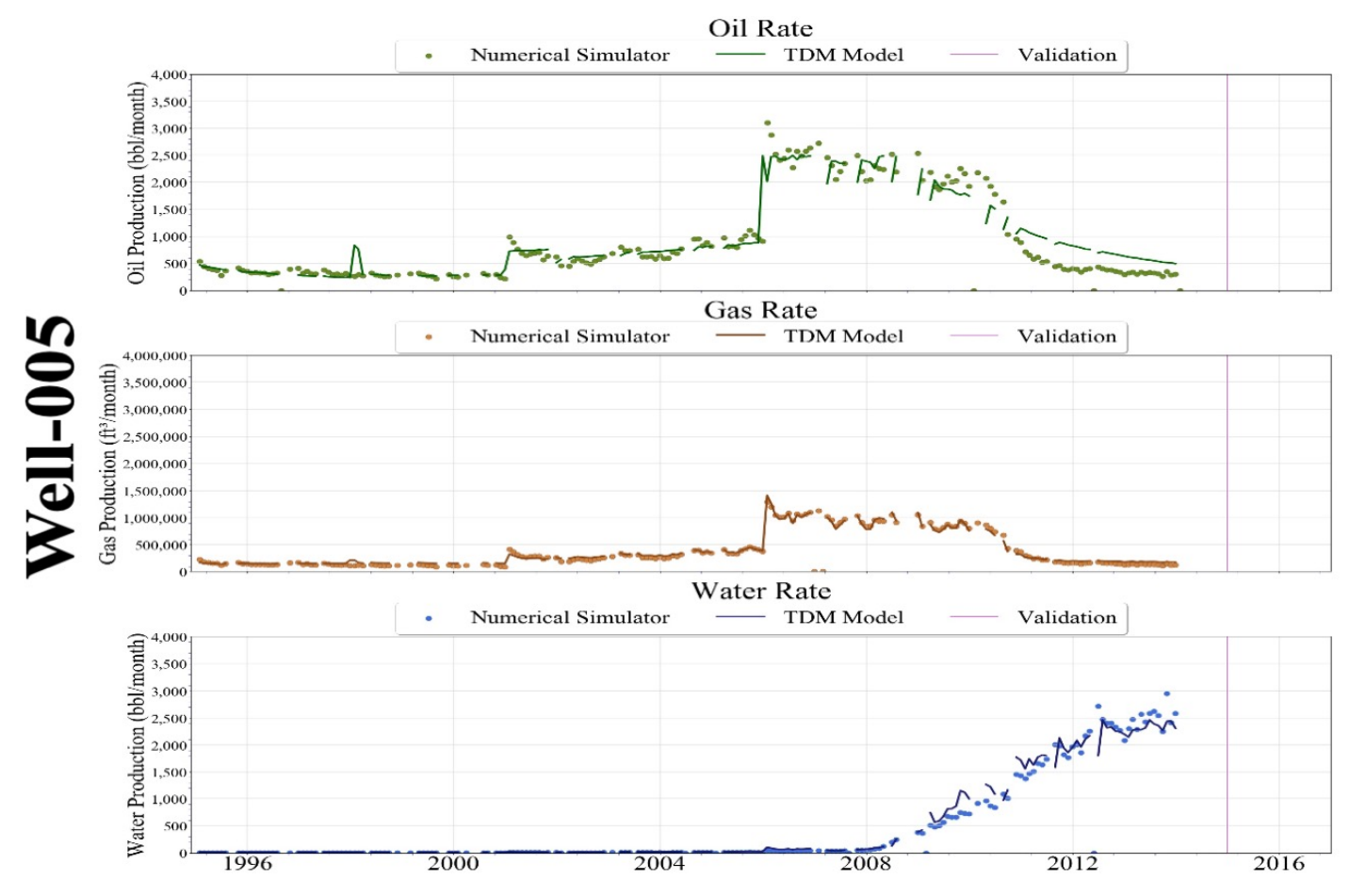

Figure 11-31: Scenario 3 - Well-005 Production History Match

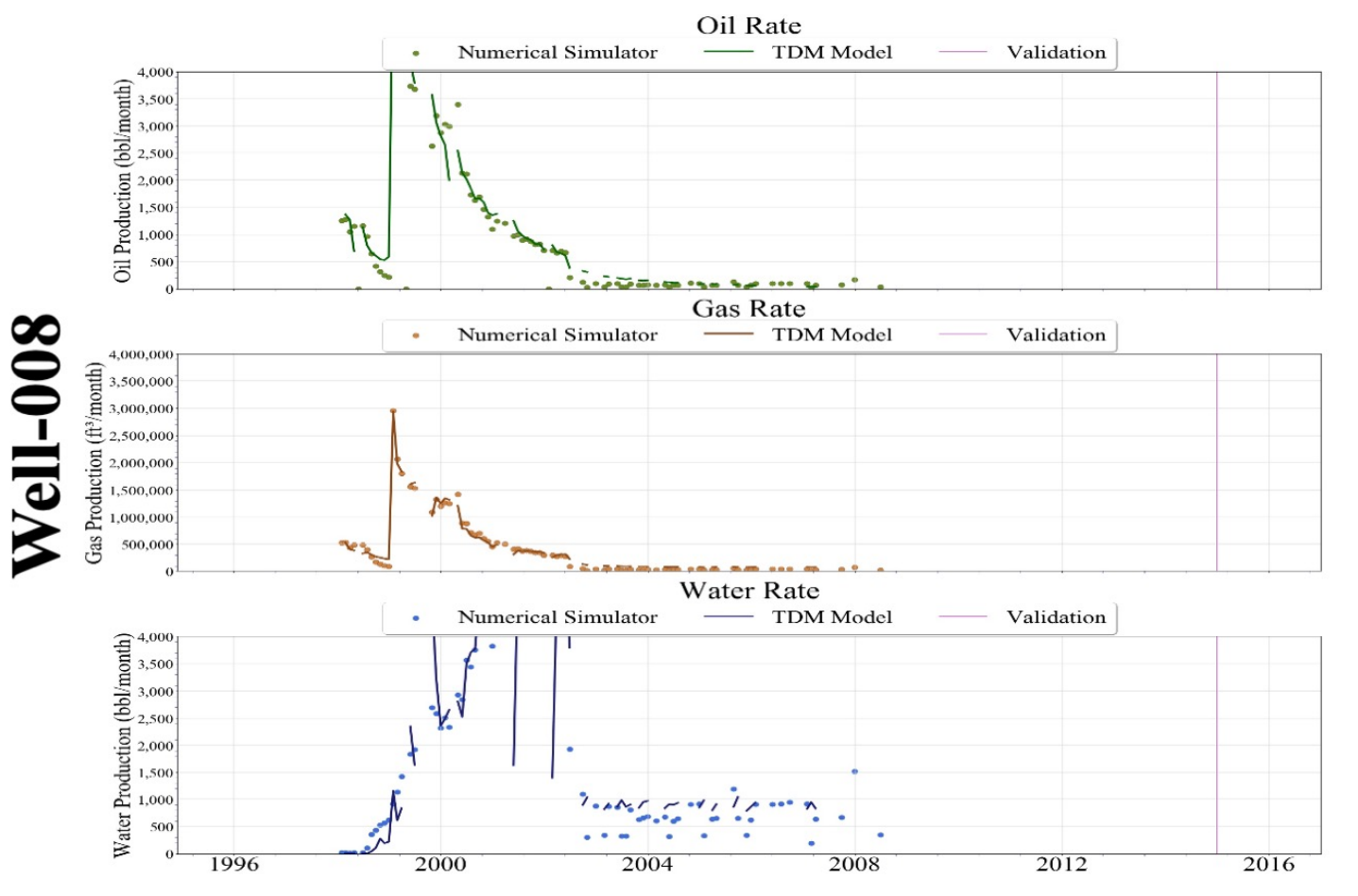

Figure 11-32: Scenario 3 - Well-008 Production History Match 


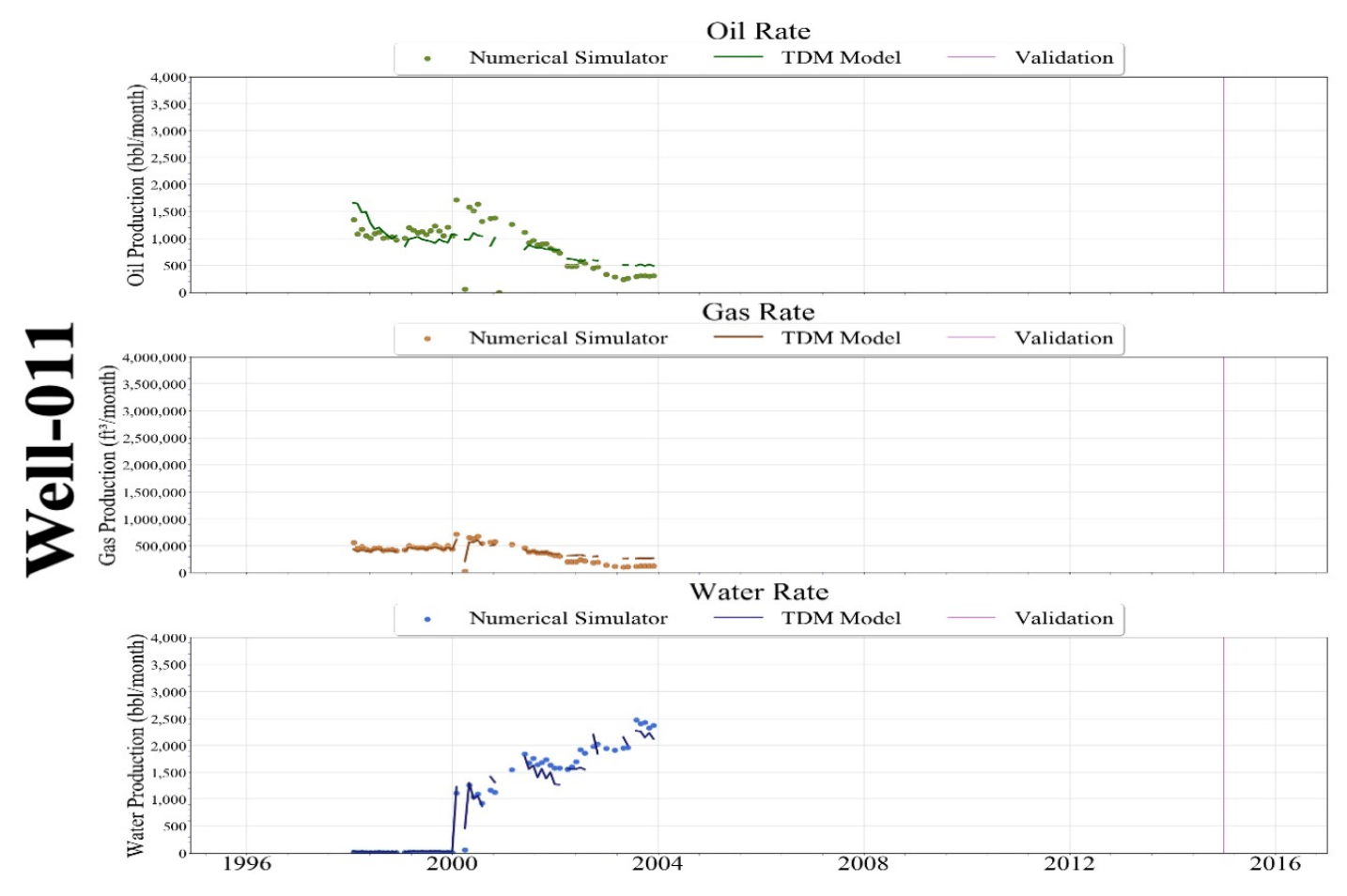

Figure 11-33: Scenario 3 - Well-011 Production History Match

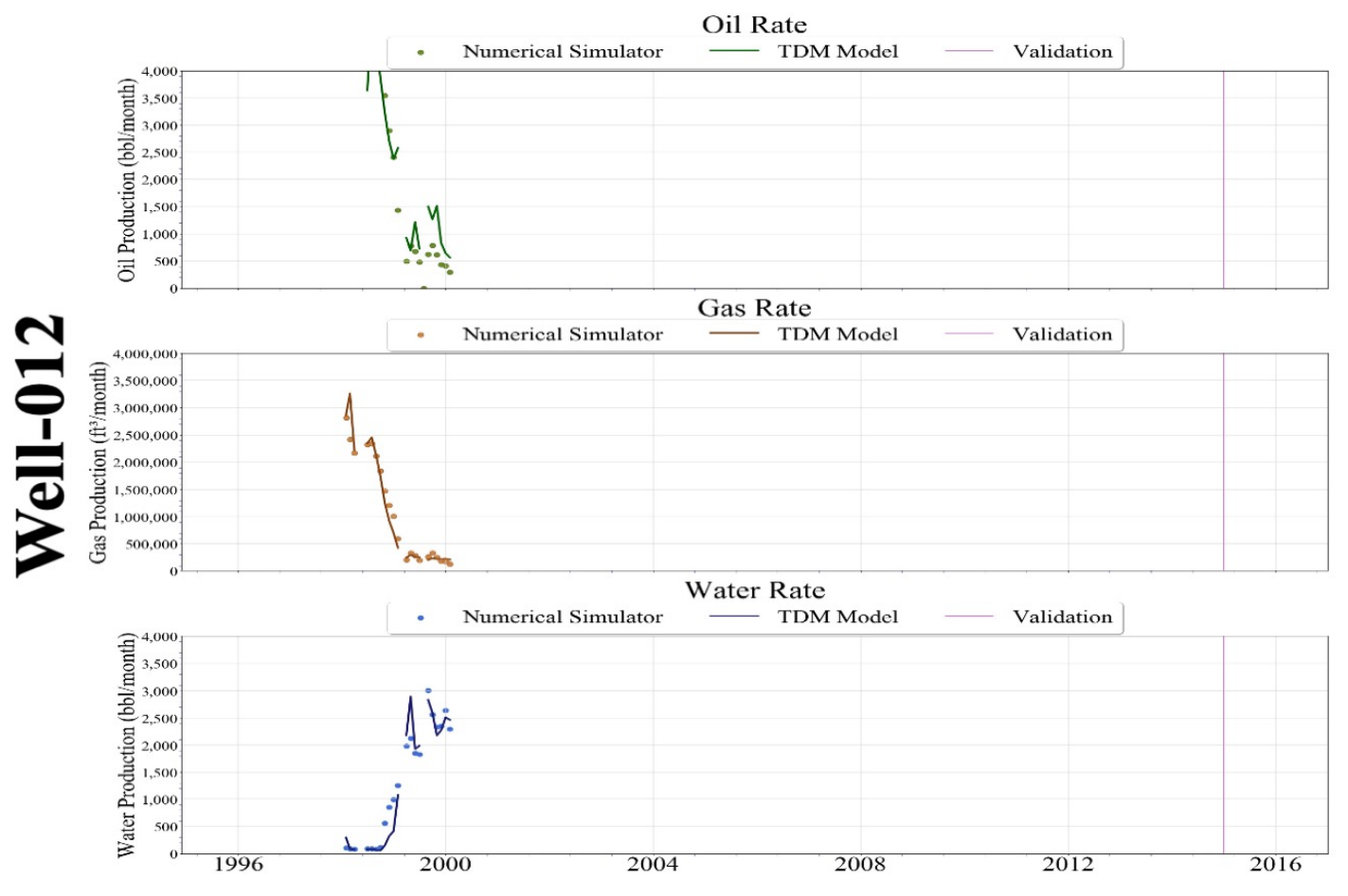

Figure 11-34: Scenario 3 - Well-012 Production History Match 


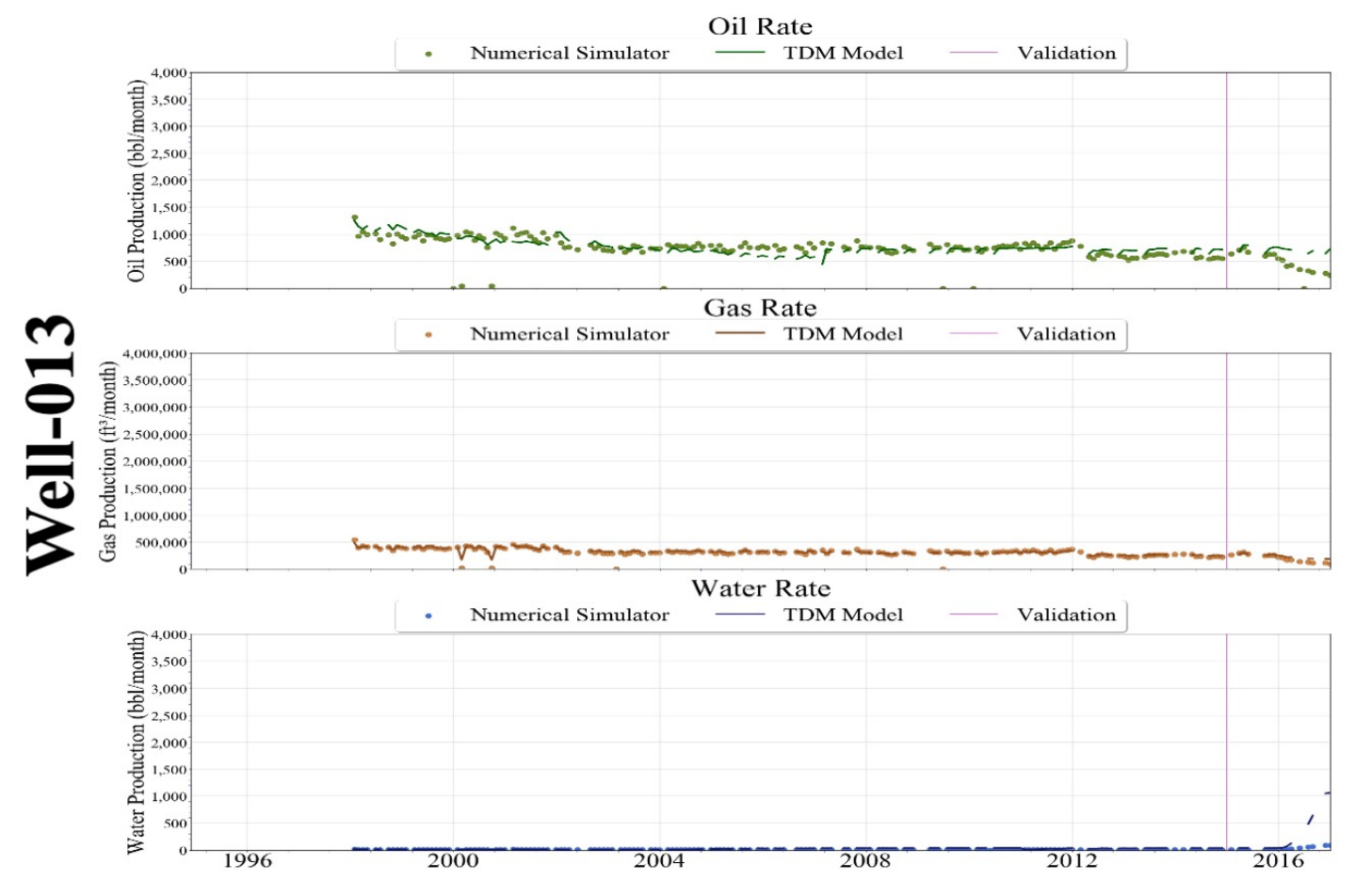

Figure 11-35: Scenario 3 - Well-013 Production History Match

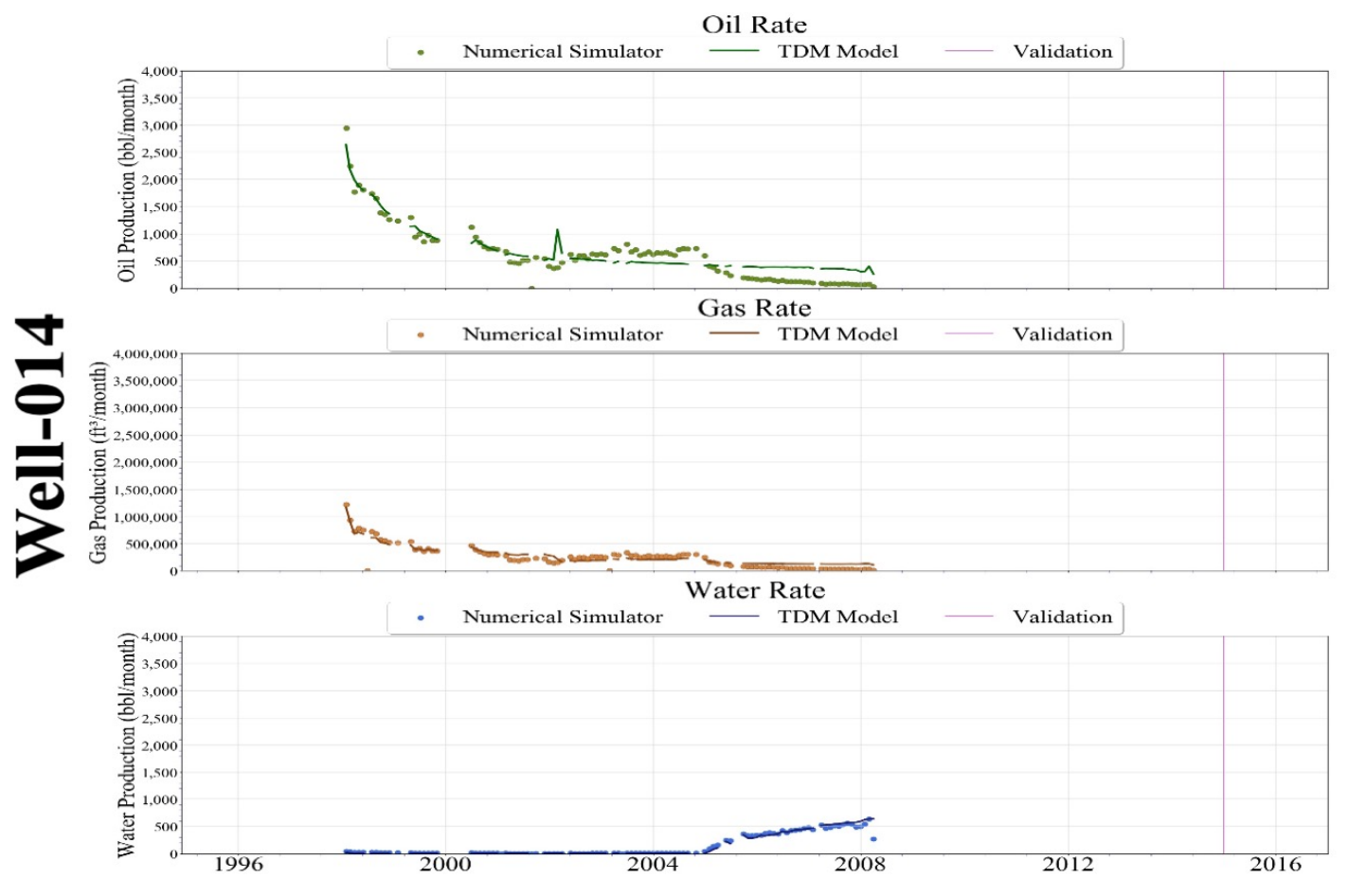

Figure 11-36: Scenario 3 - Well-014 Production History Match 


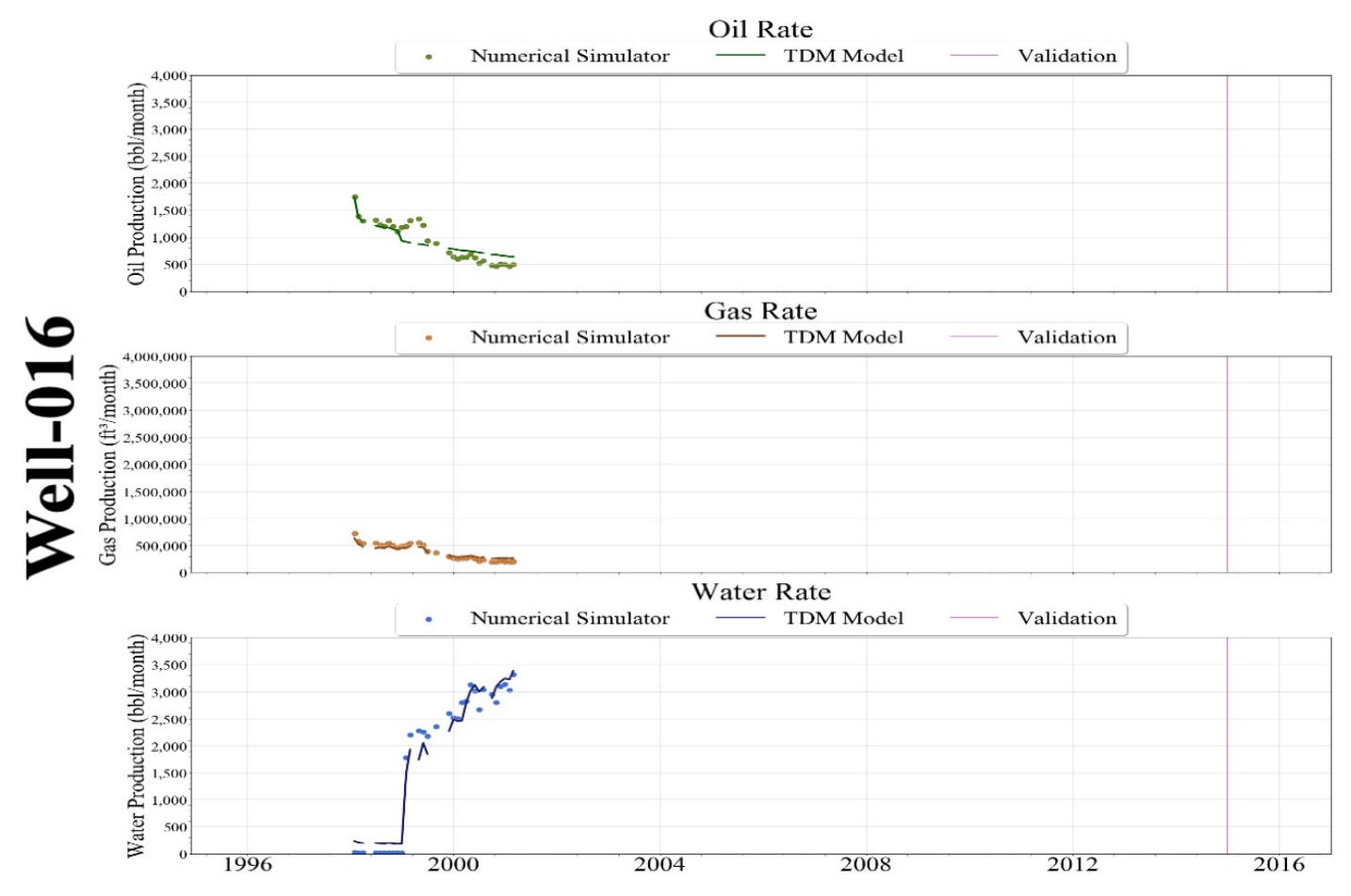

Figure 11-37: Scenario 3 - Well-016 Production History Match

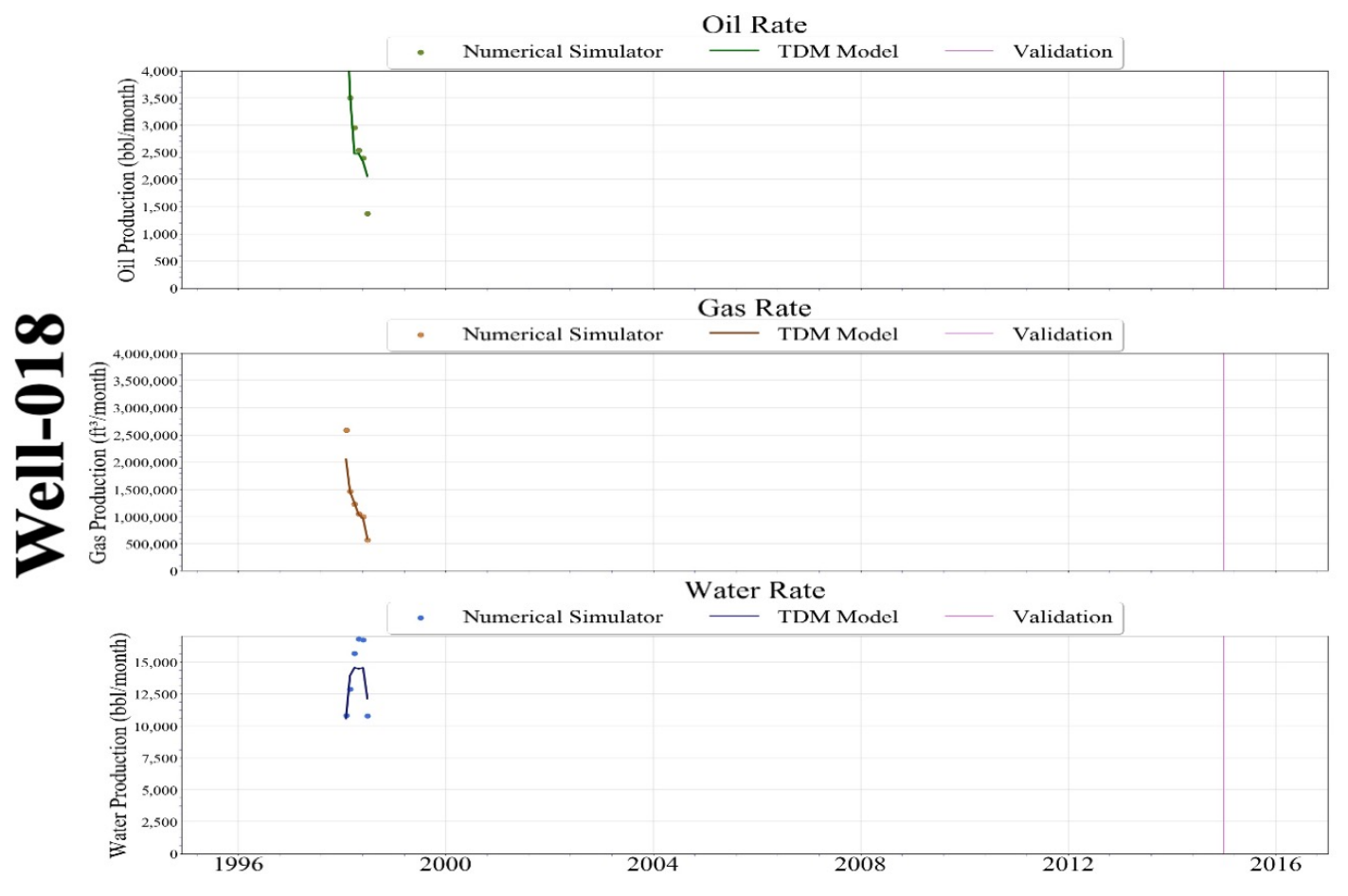

Figure 11-38: Scenario 3 - Well-018 Production History Match 


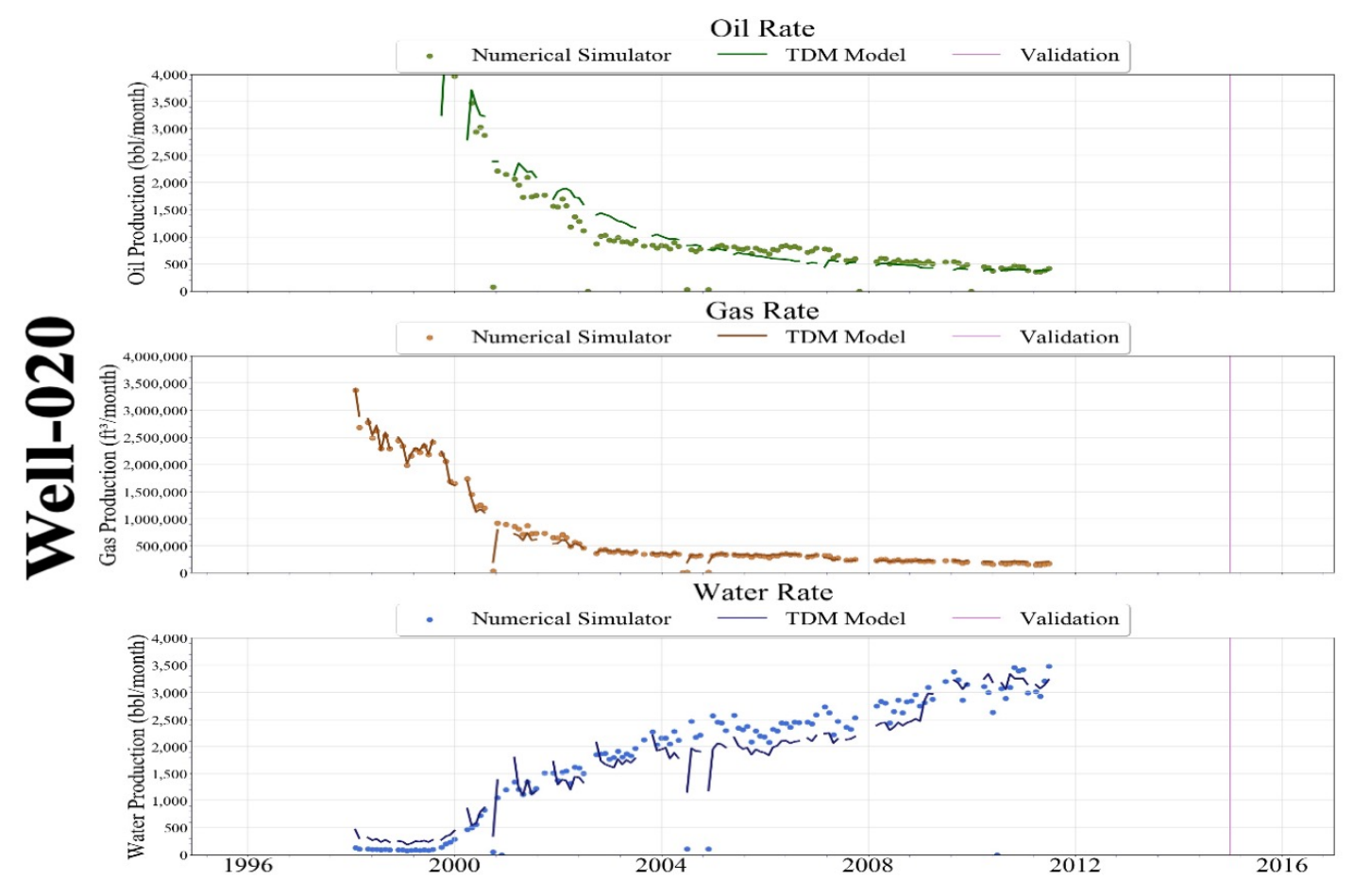

Figure 11-39: Scenario 3 - Well-020 Production History Match

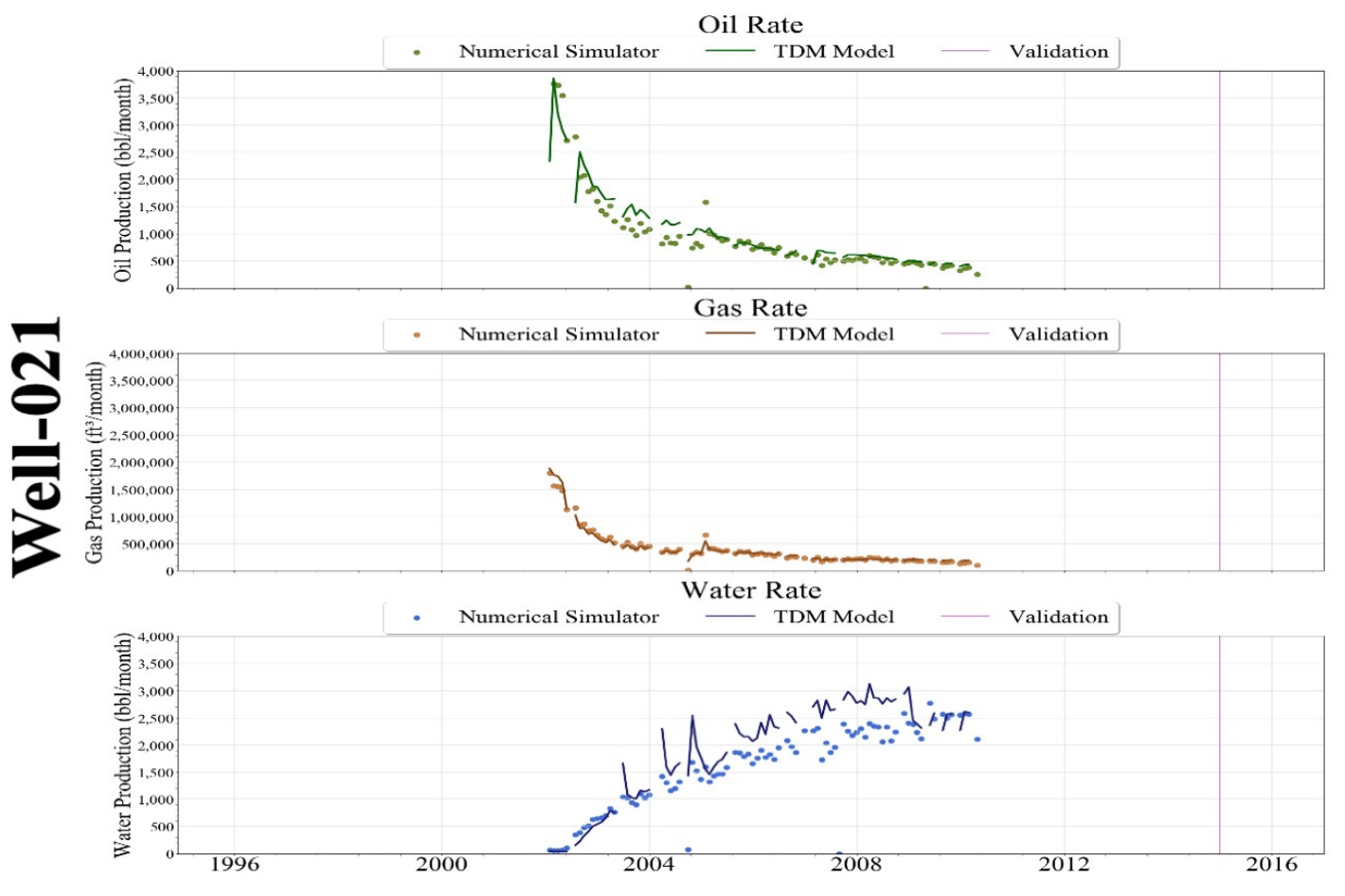

Figure 11-40: Scenario 3 - Well-021 Production History Match 
Oil Rate
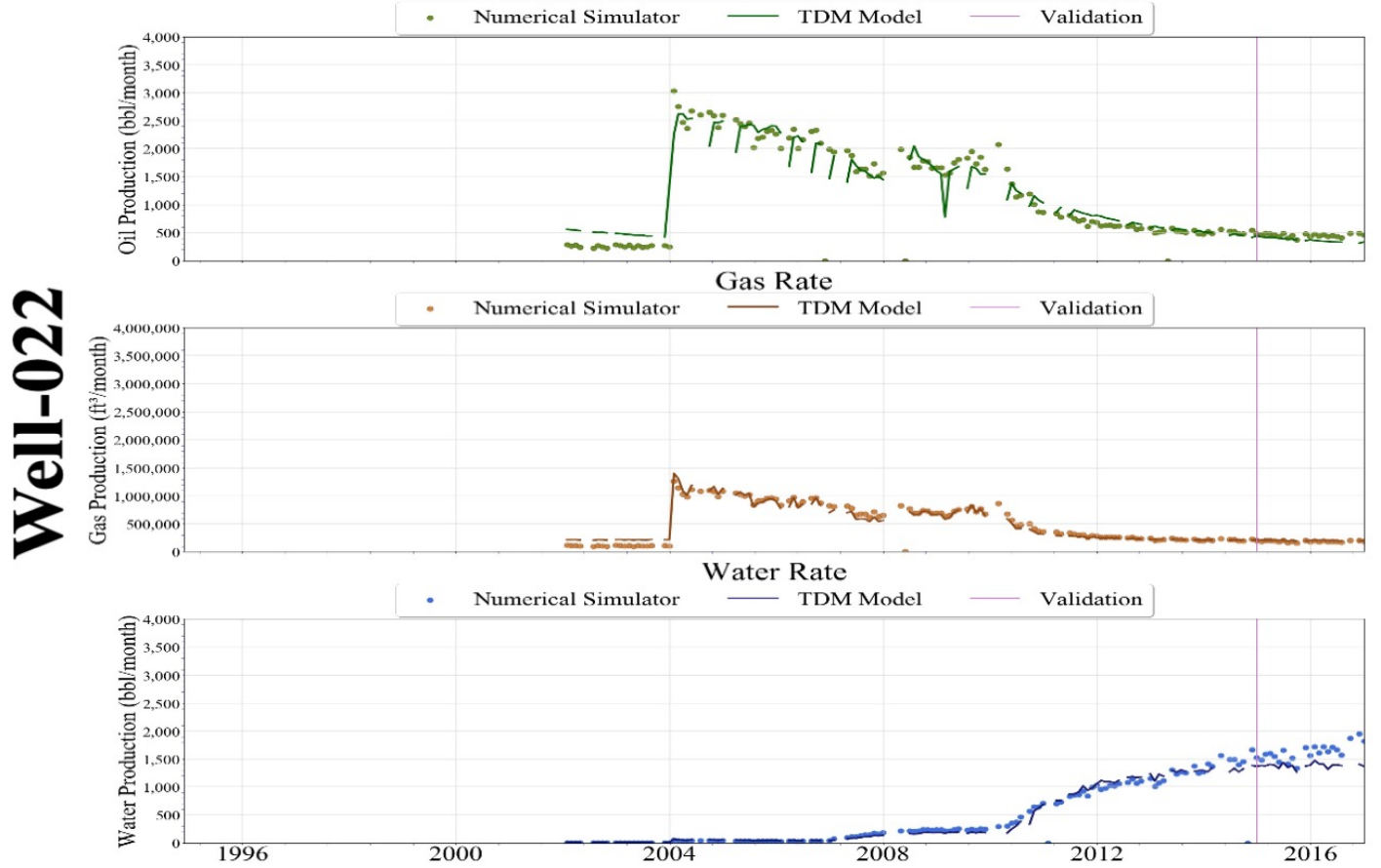

Figure 11-41: Scenario 3 - Well-022 Production History Match
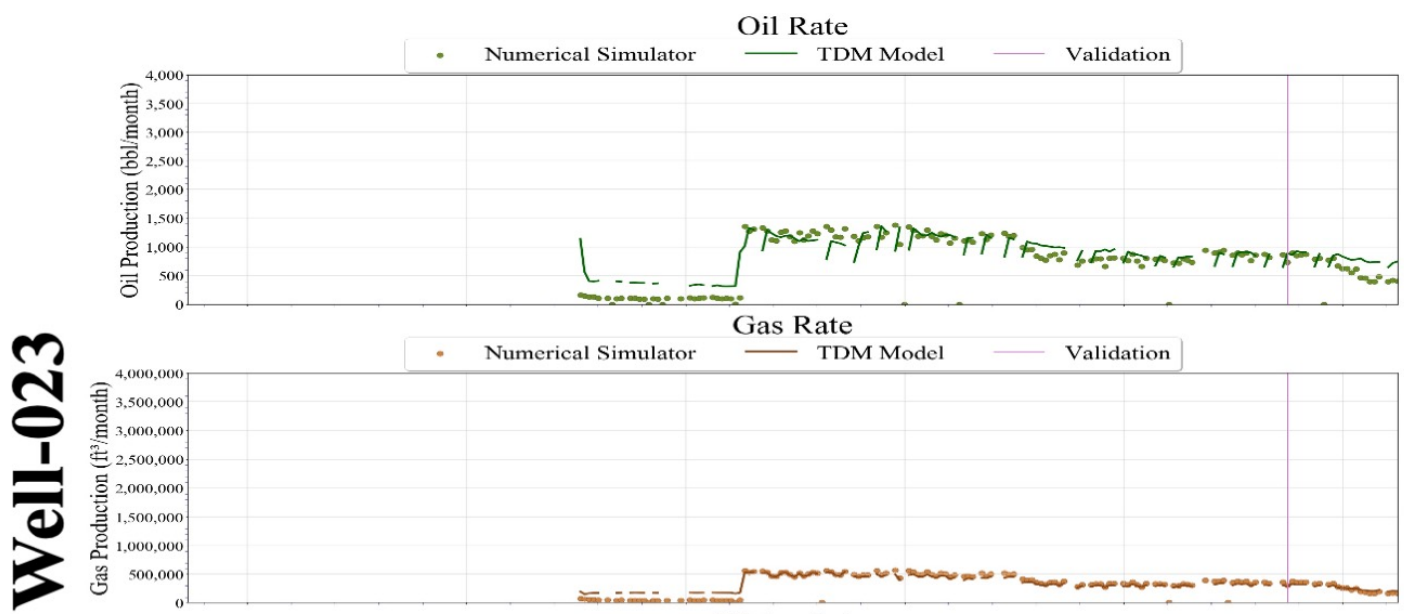

Water Rate

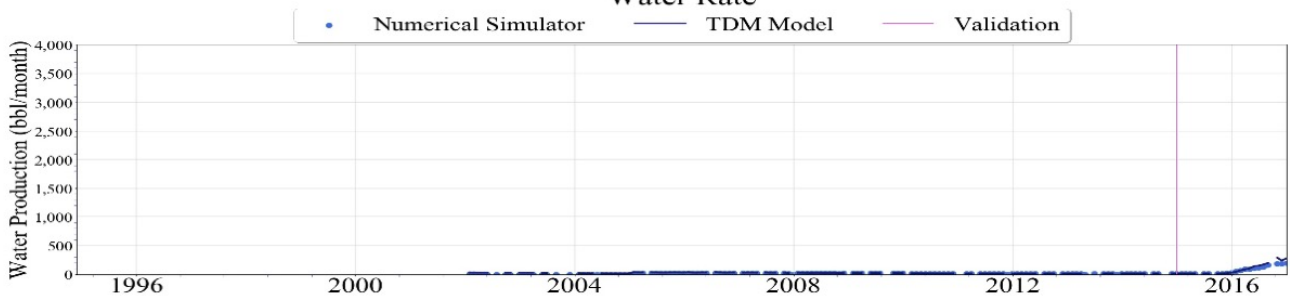

Figure 11-42: Scenario 3 - Well-023 Production History Match 


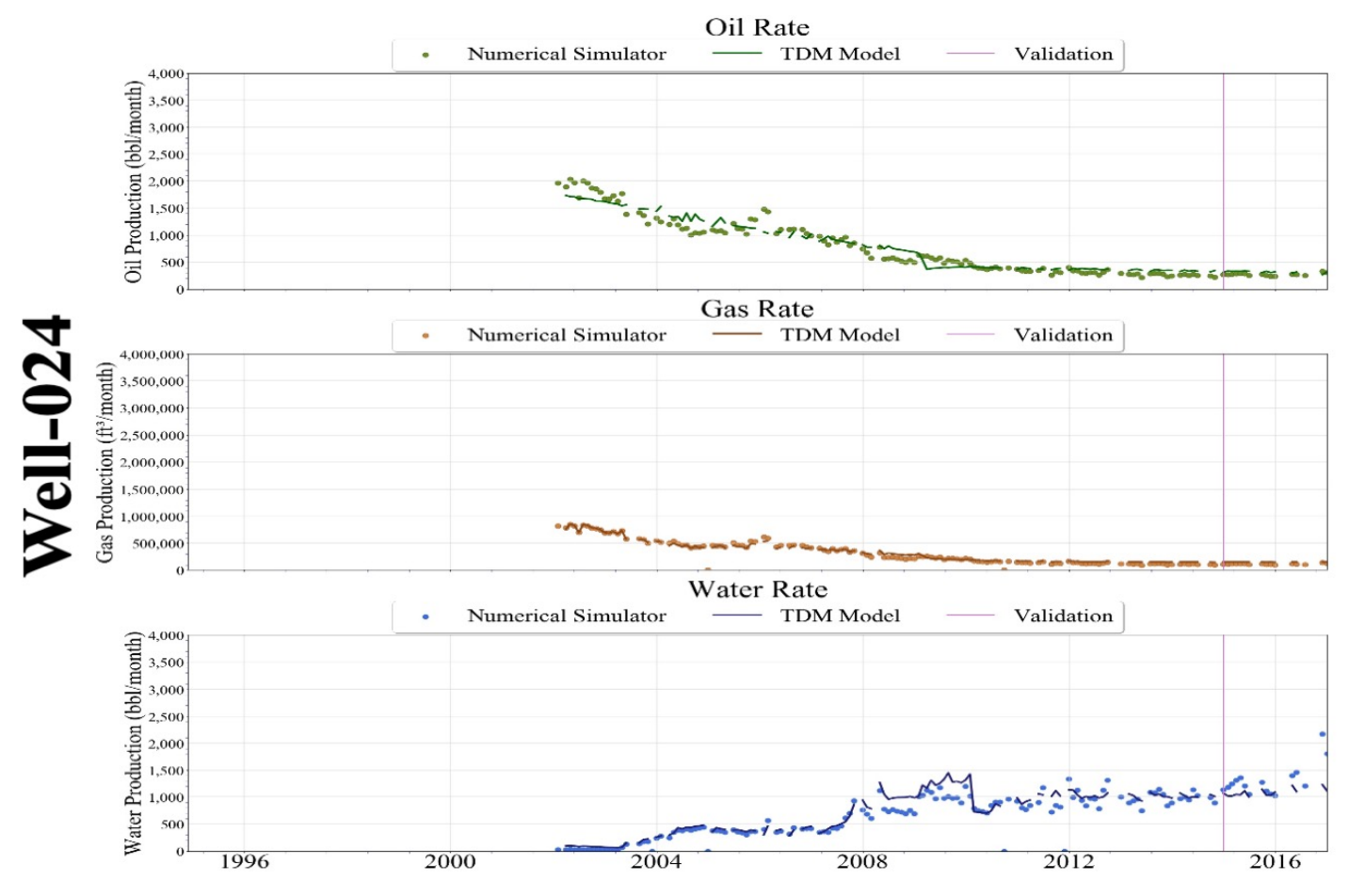

Figure 11-43: Scenario 3 - Well-024 Production History Match

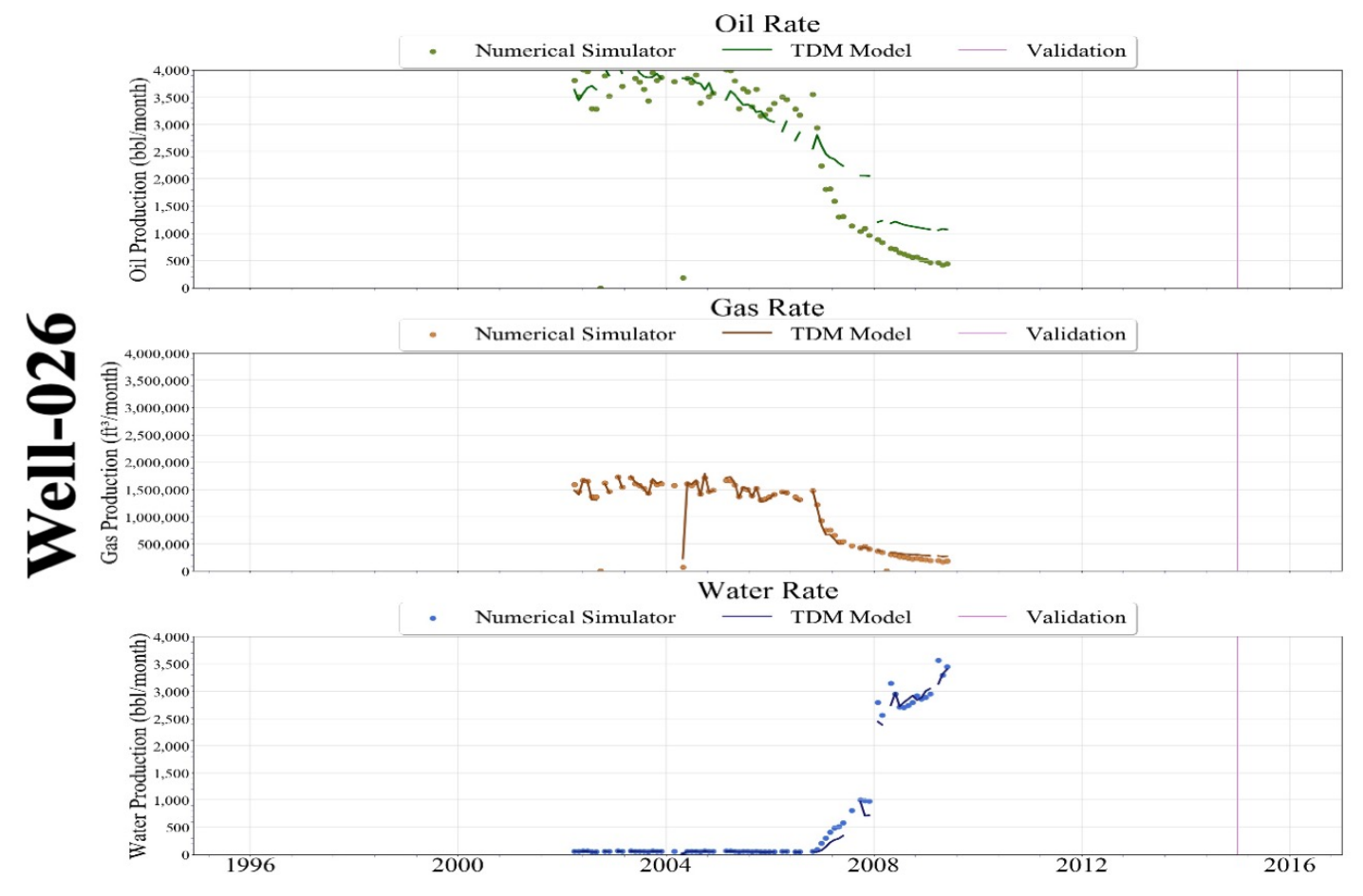

Figure 11-44: Scenario 3 - Well-026 Production History Match 


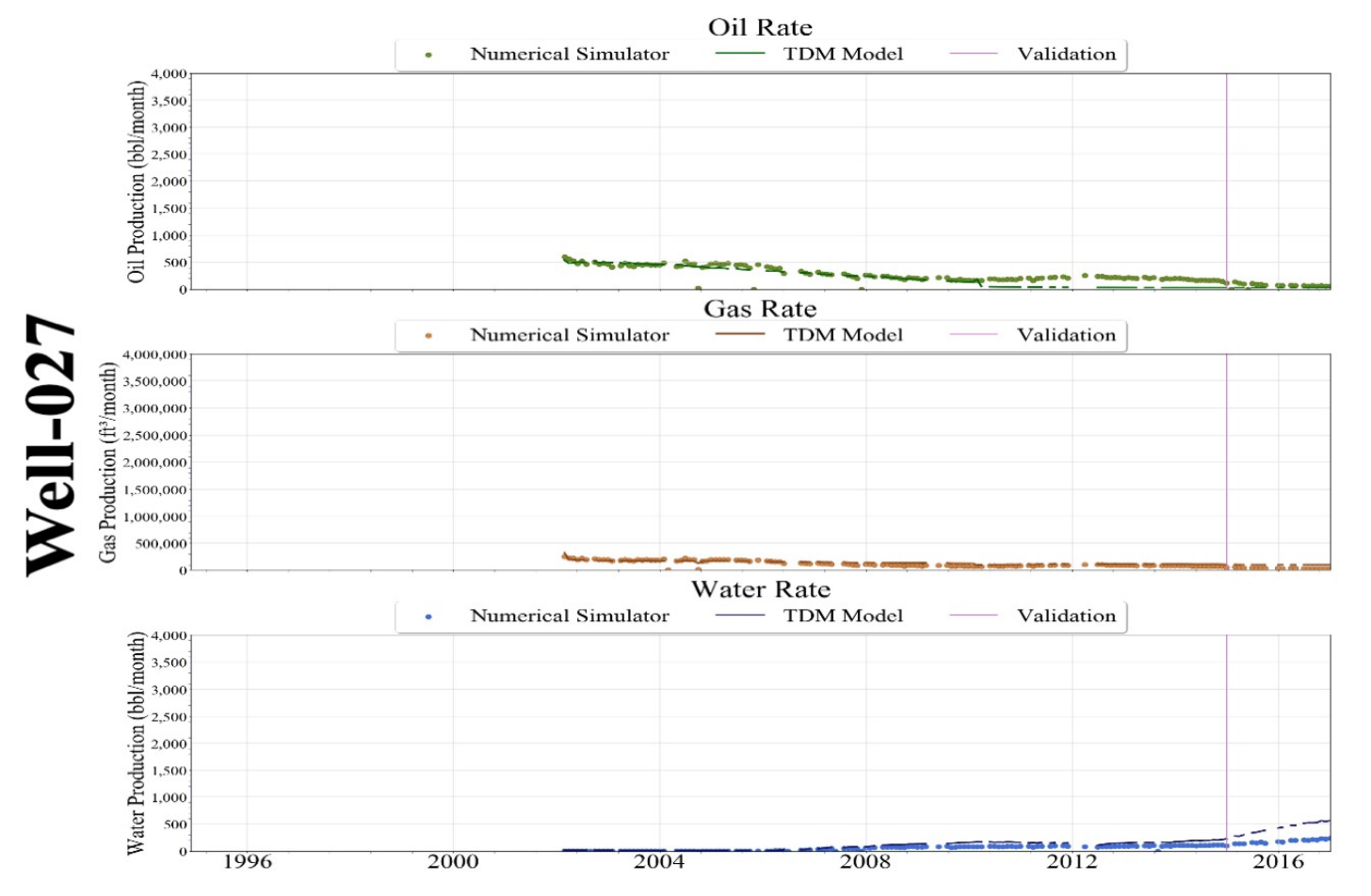

Figure 11-45: Scenario 3 - Well-027 Production History Match

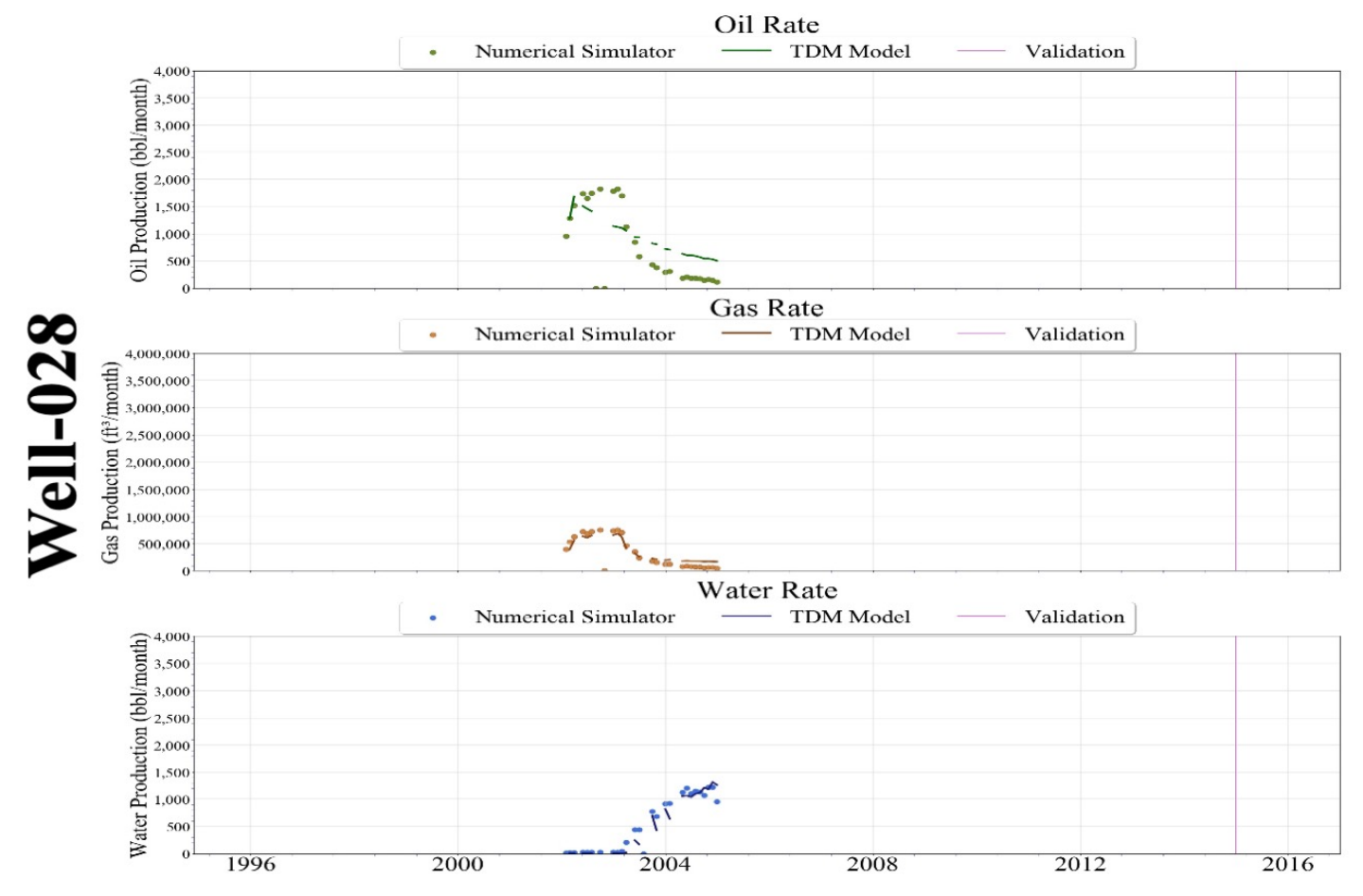

Figure 11-46: Scenario 3 - Well-028 Production History Match 


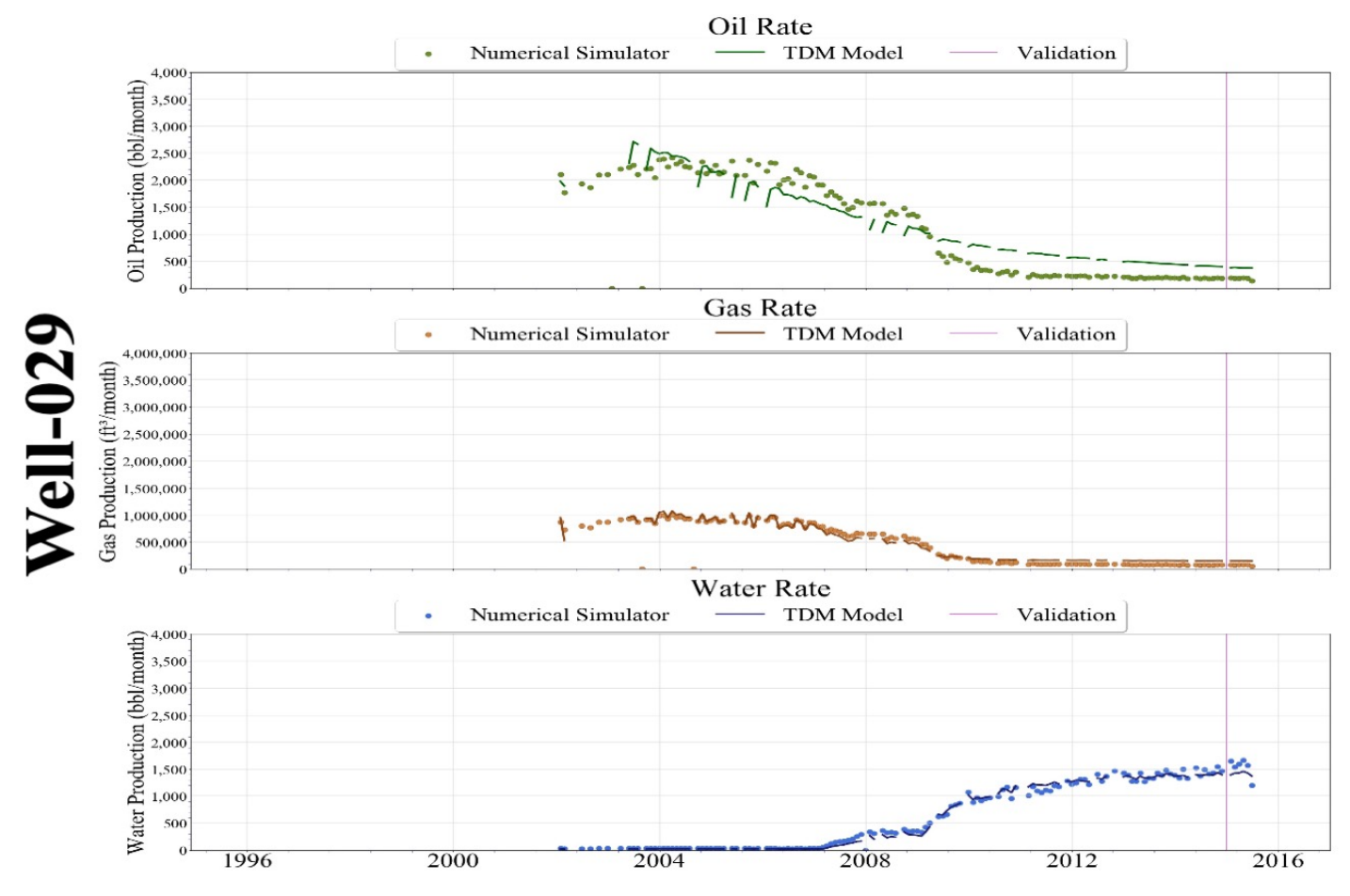

Figure 11-47: Scenario 3 - Well-029 Production History Match

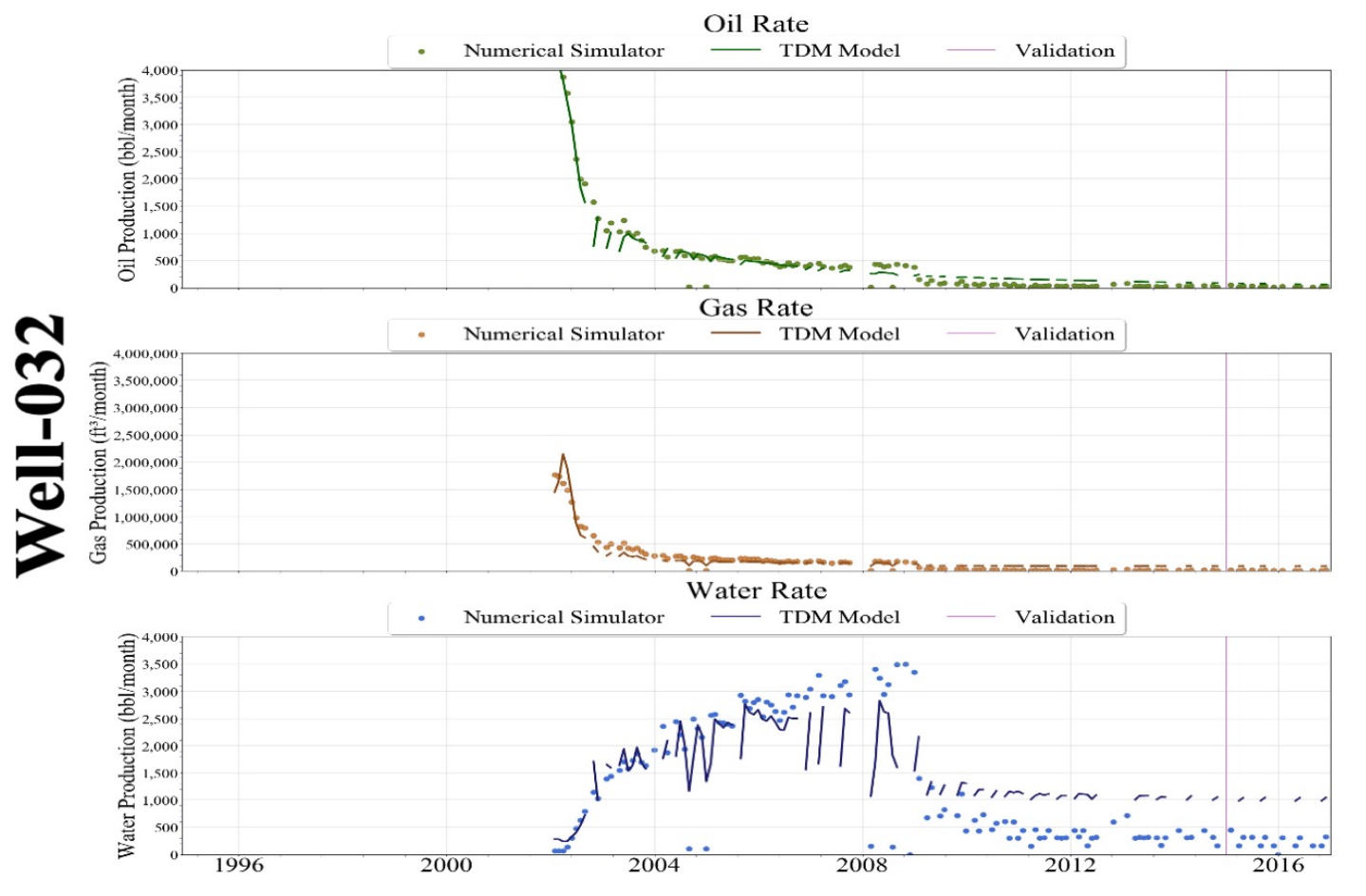

Figure 11-48: Scenario 3 - Well-032 Production History Match 


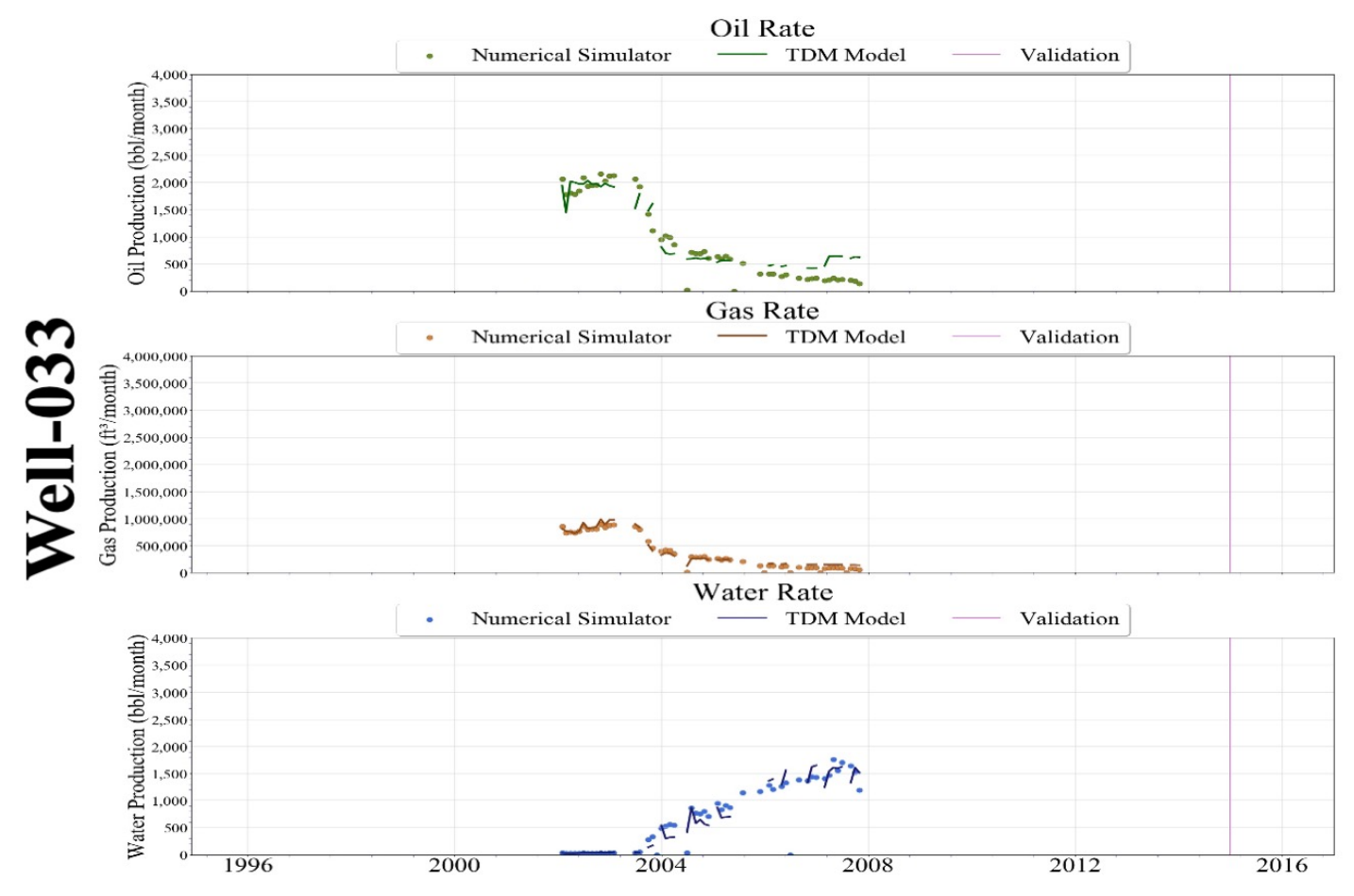

Figure 11-49: Scenario 3 - Well-033 Production History Match

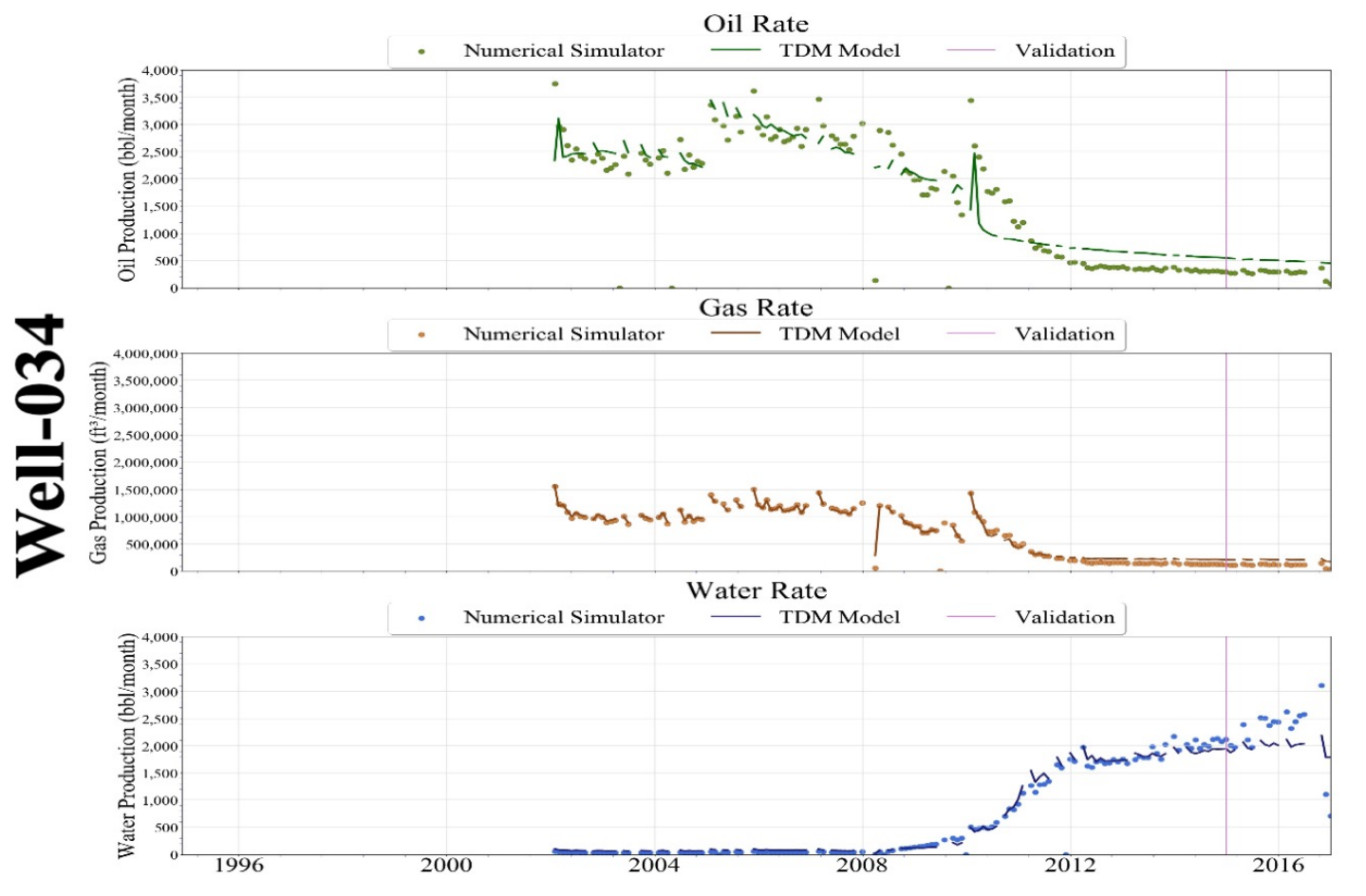

Figure 11-50: Scenario 3 - Well-034 Production History Match 


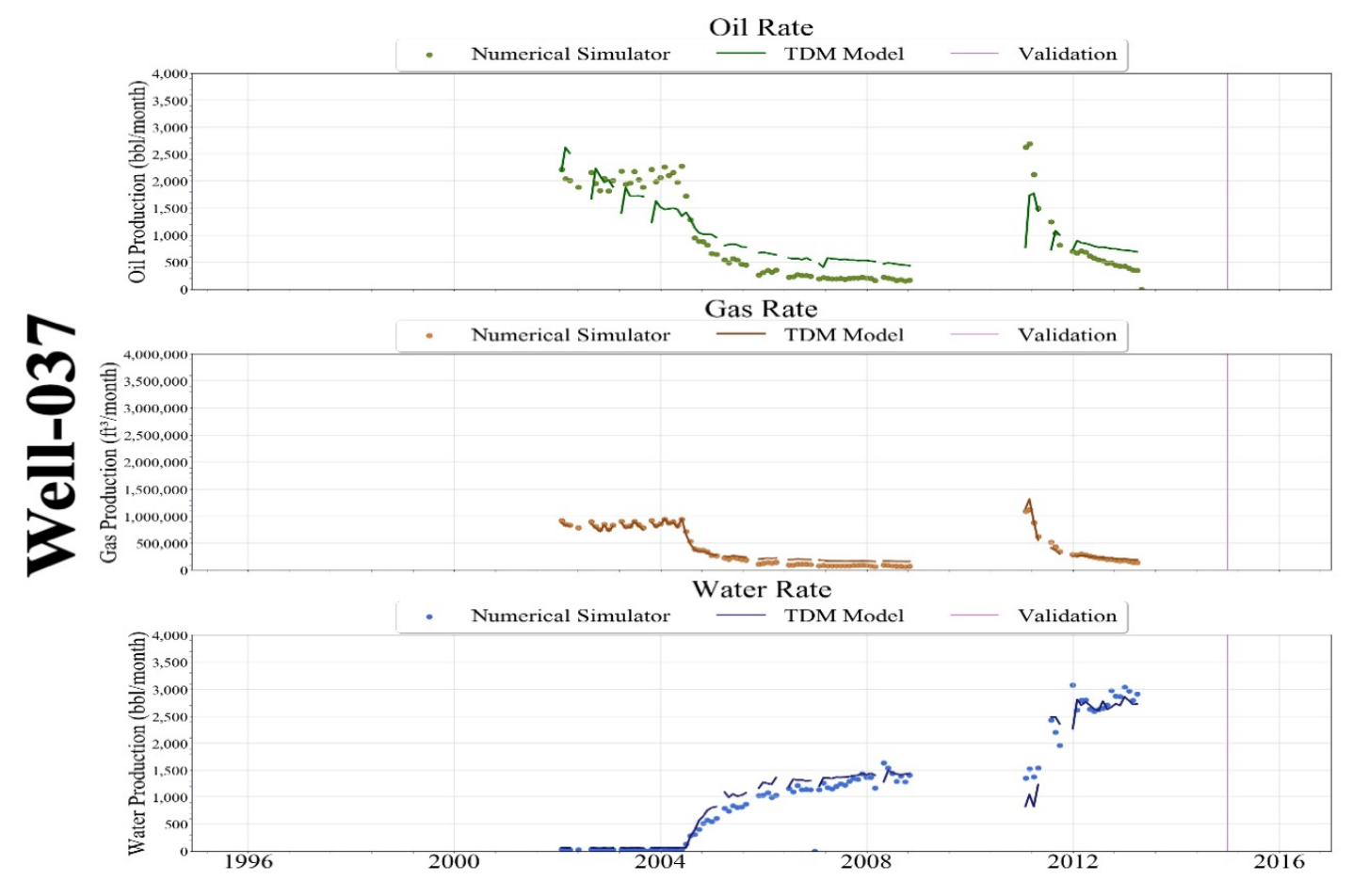

Figure 11-51: Scenario 3 - Well-037 Production History Match

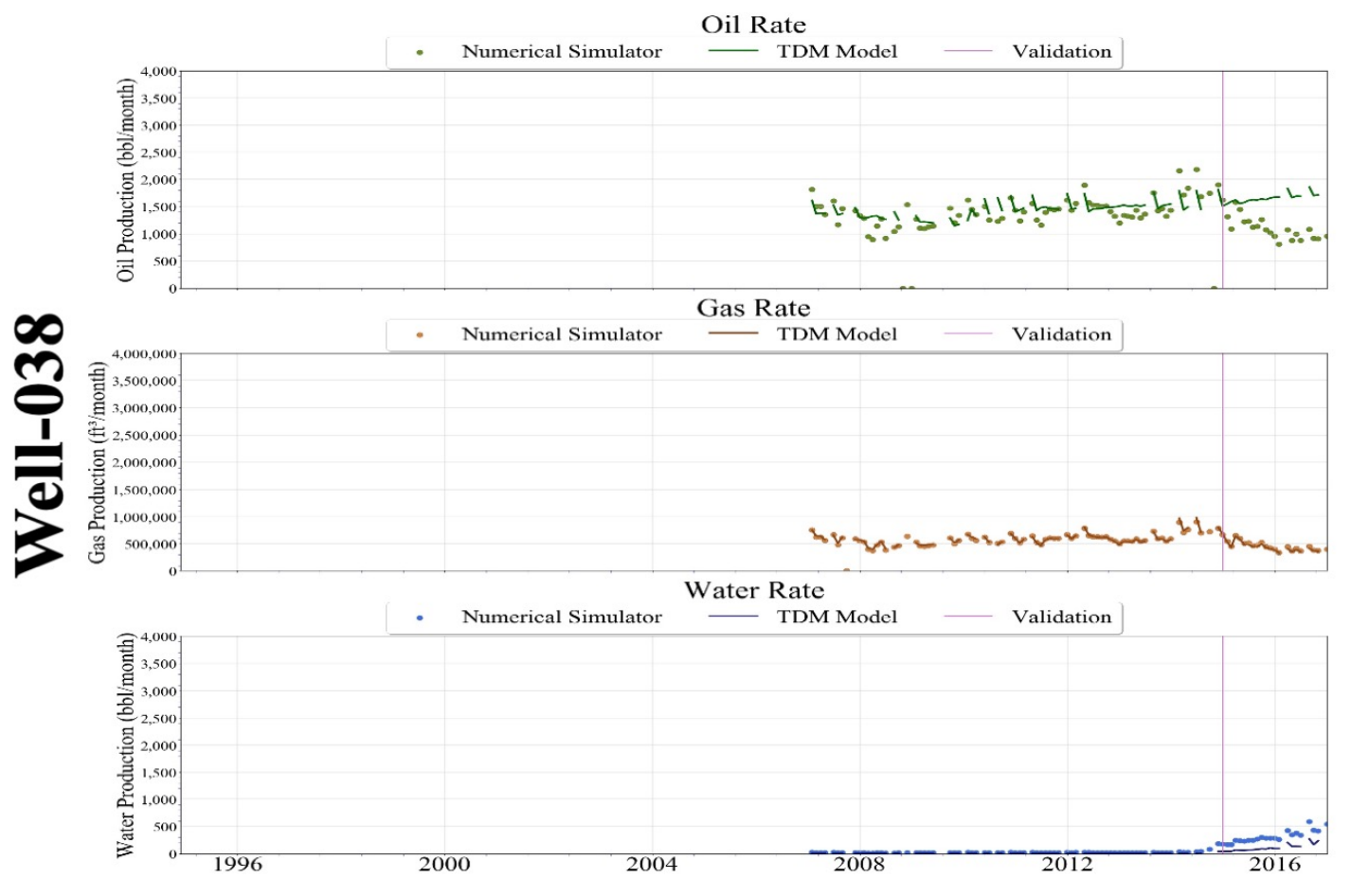

Figure 11-52: Scenario 3 - Well-038 Production History Match 


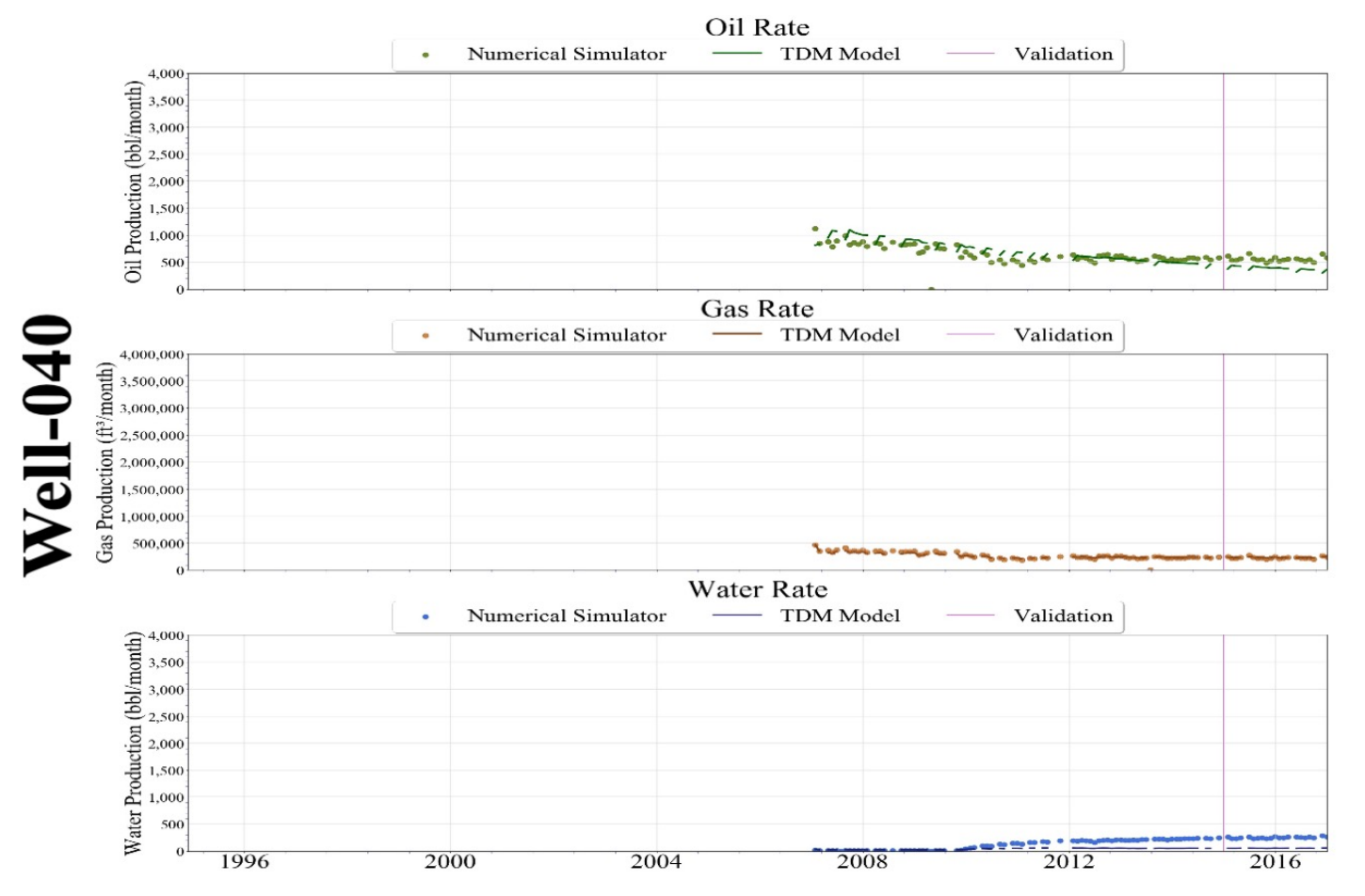

Figure 11-53: Scenario 3 - Well-040 Production History Match

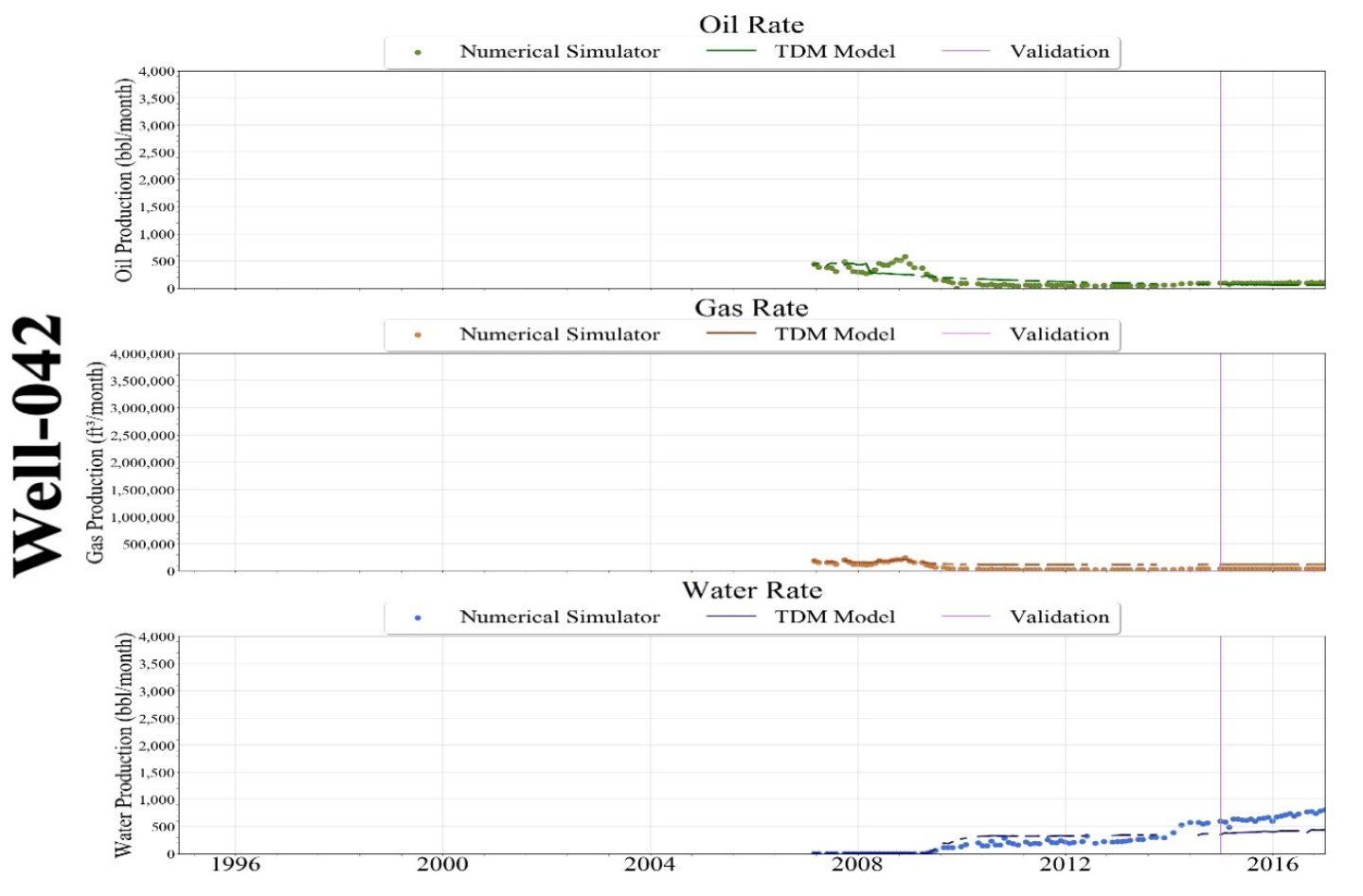

Figure 11-54: Scenario 3 - Well-042 Production History Match 


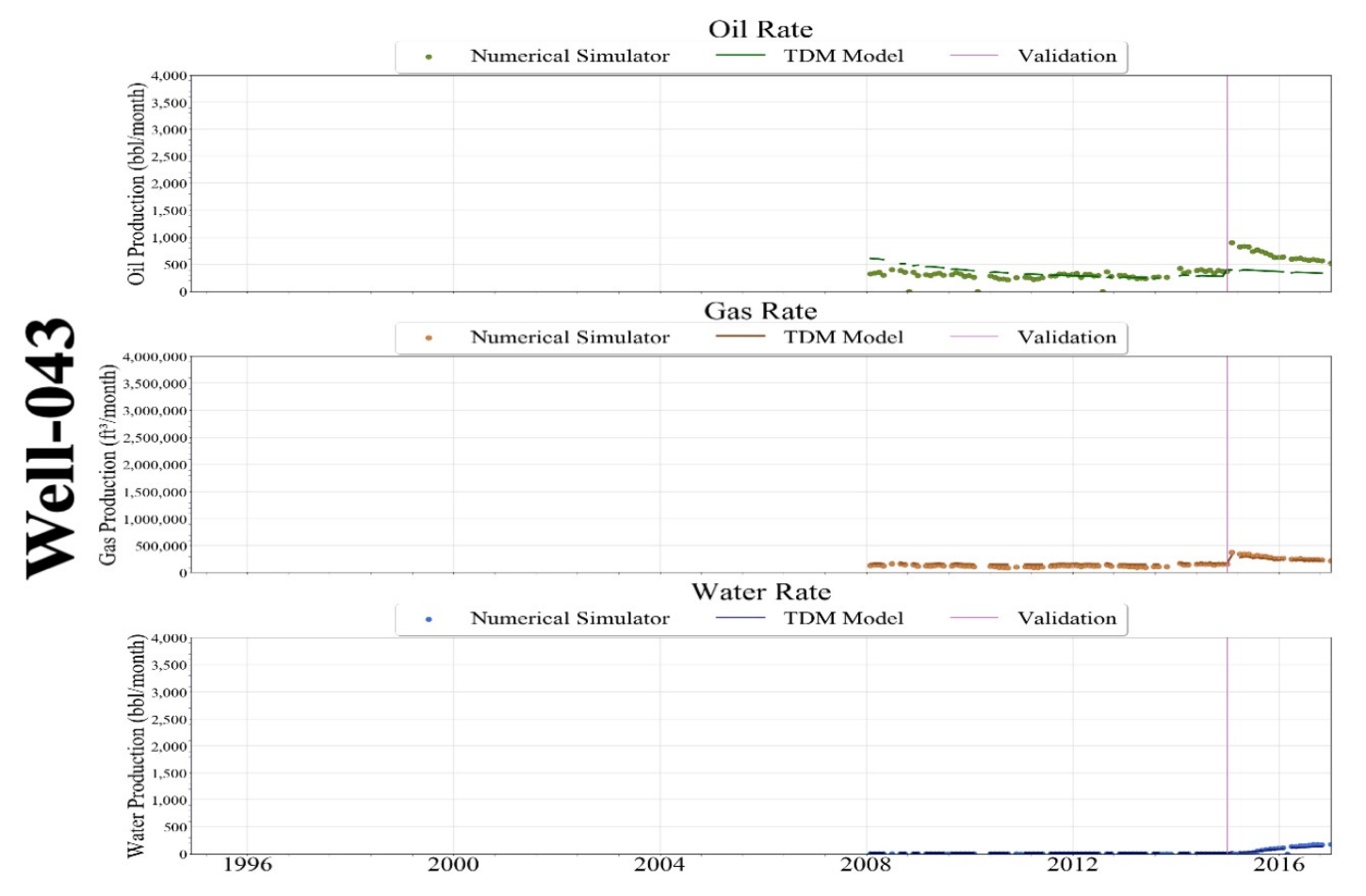

Figure 11-55: Scenario 3 - Well-043 Production History Match

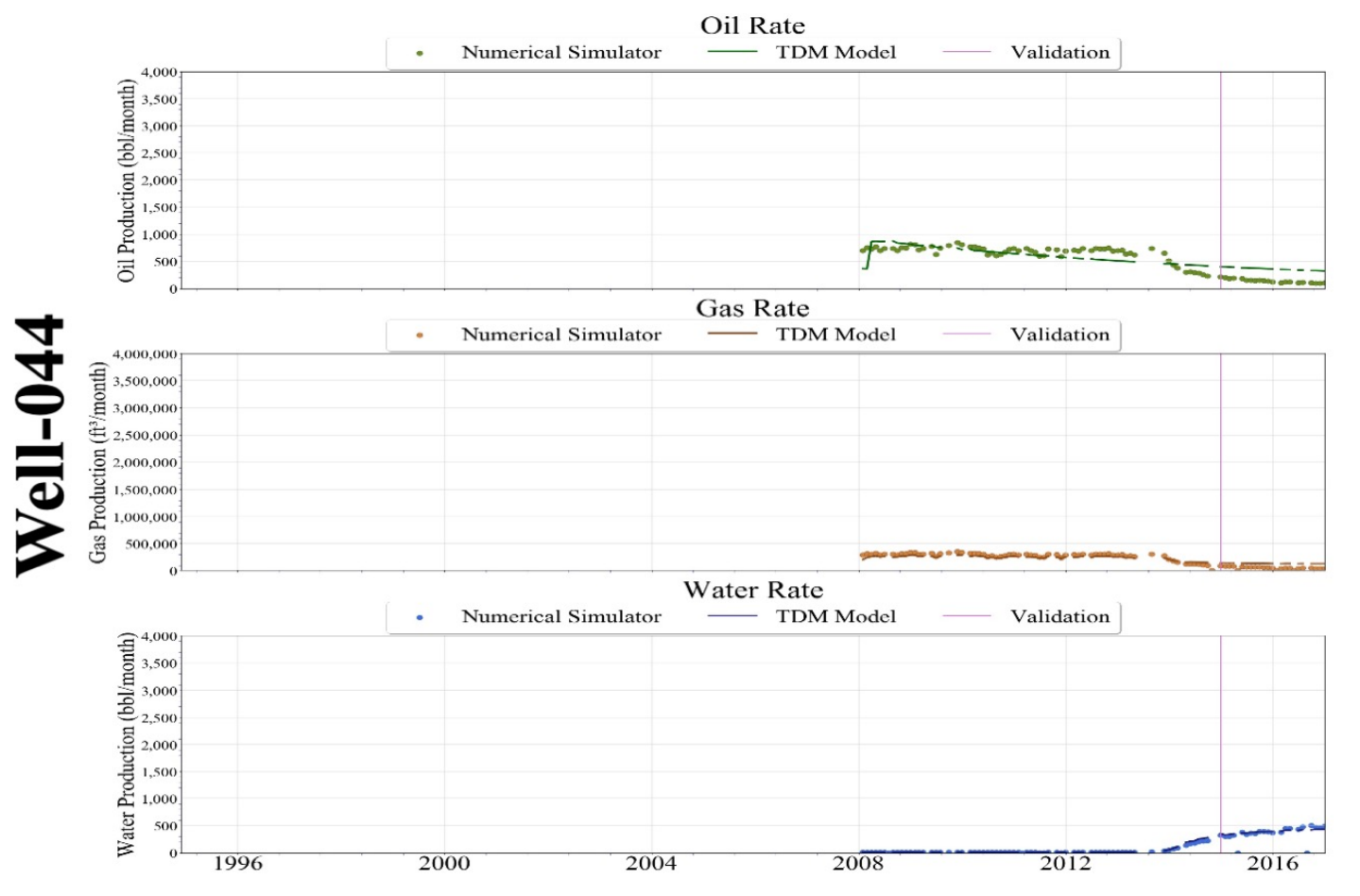

Figure 11-56: Scenario 3 - Well-044 Production History Match 


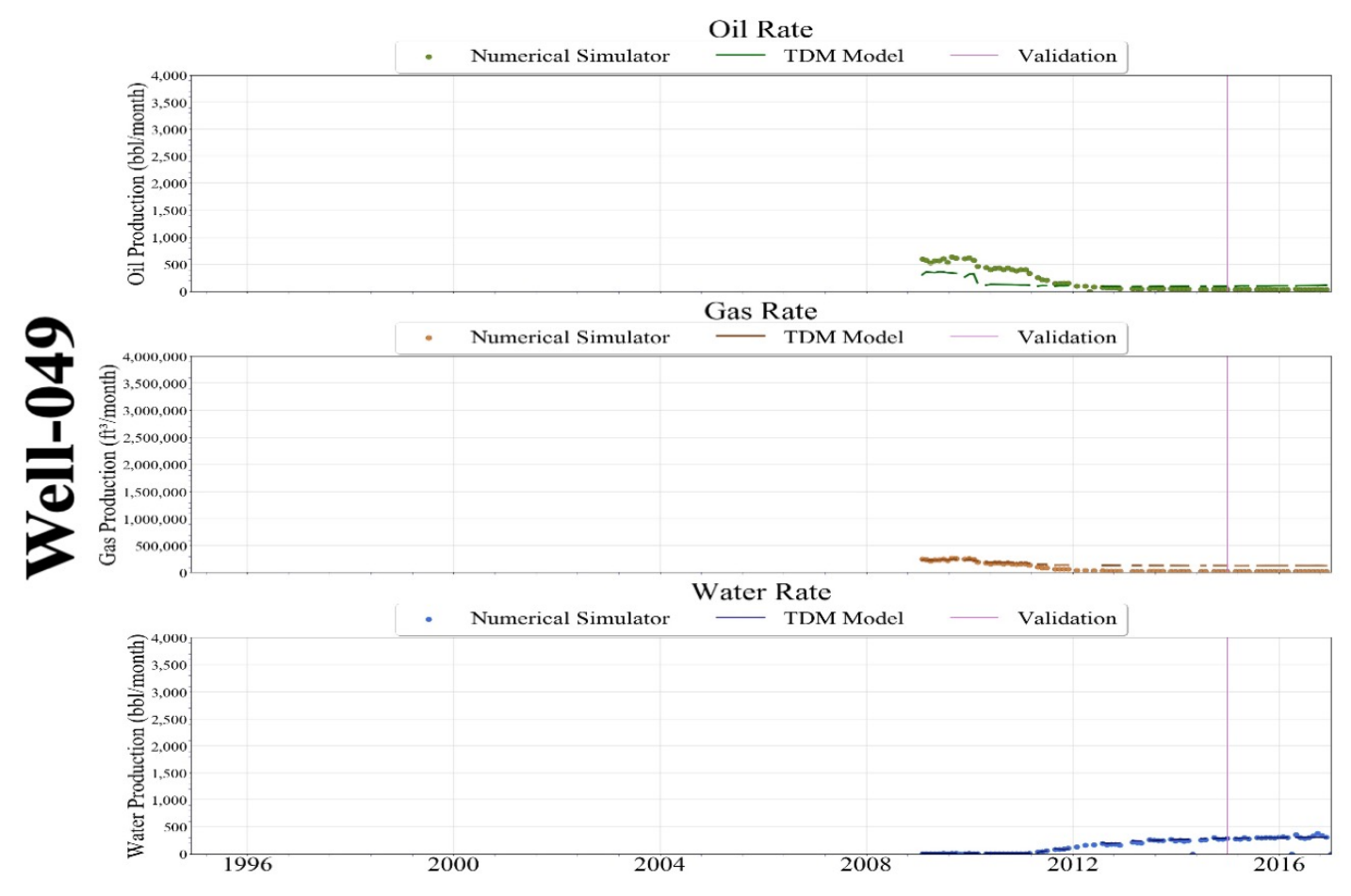

Figure 11-57: Scenario 3 - Well-049 Production History Match

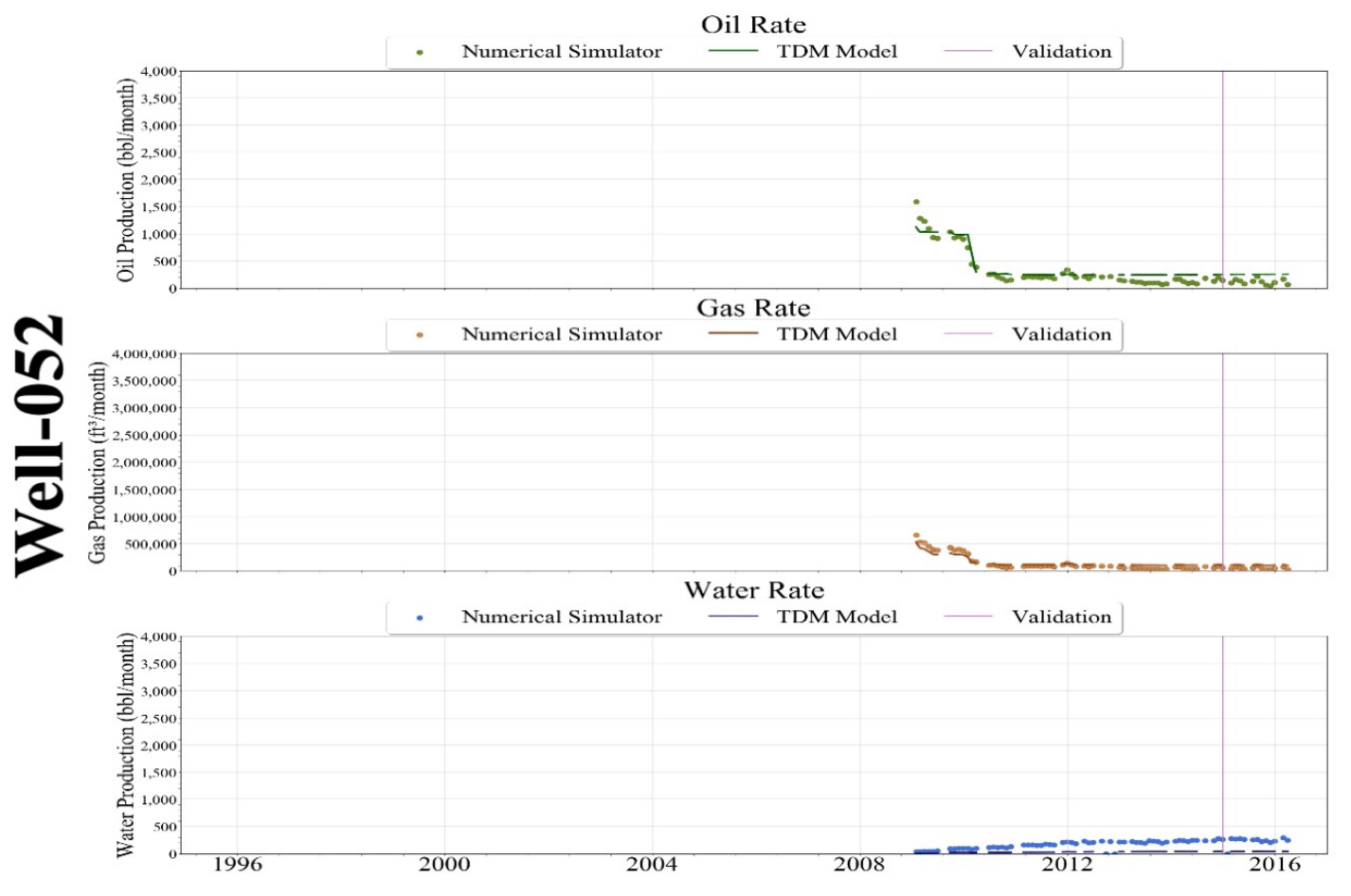

Figure 11-58: Scenario 3 - Well-052 Production History Match 


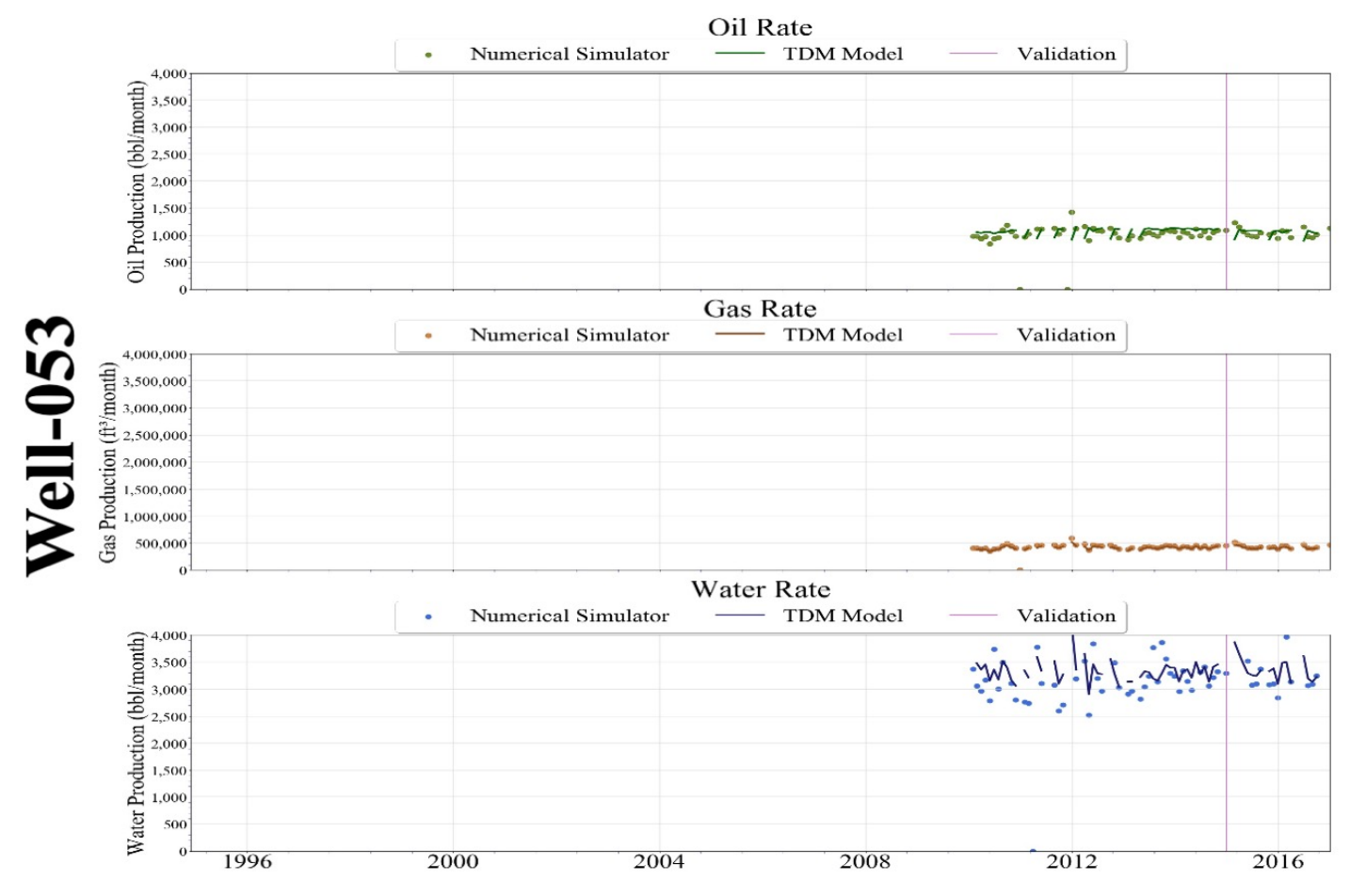

Figure 11-59: Scenario 3 - Well-053 Production History Match

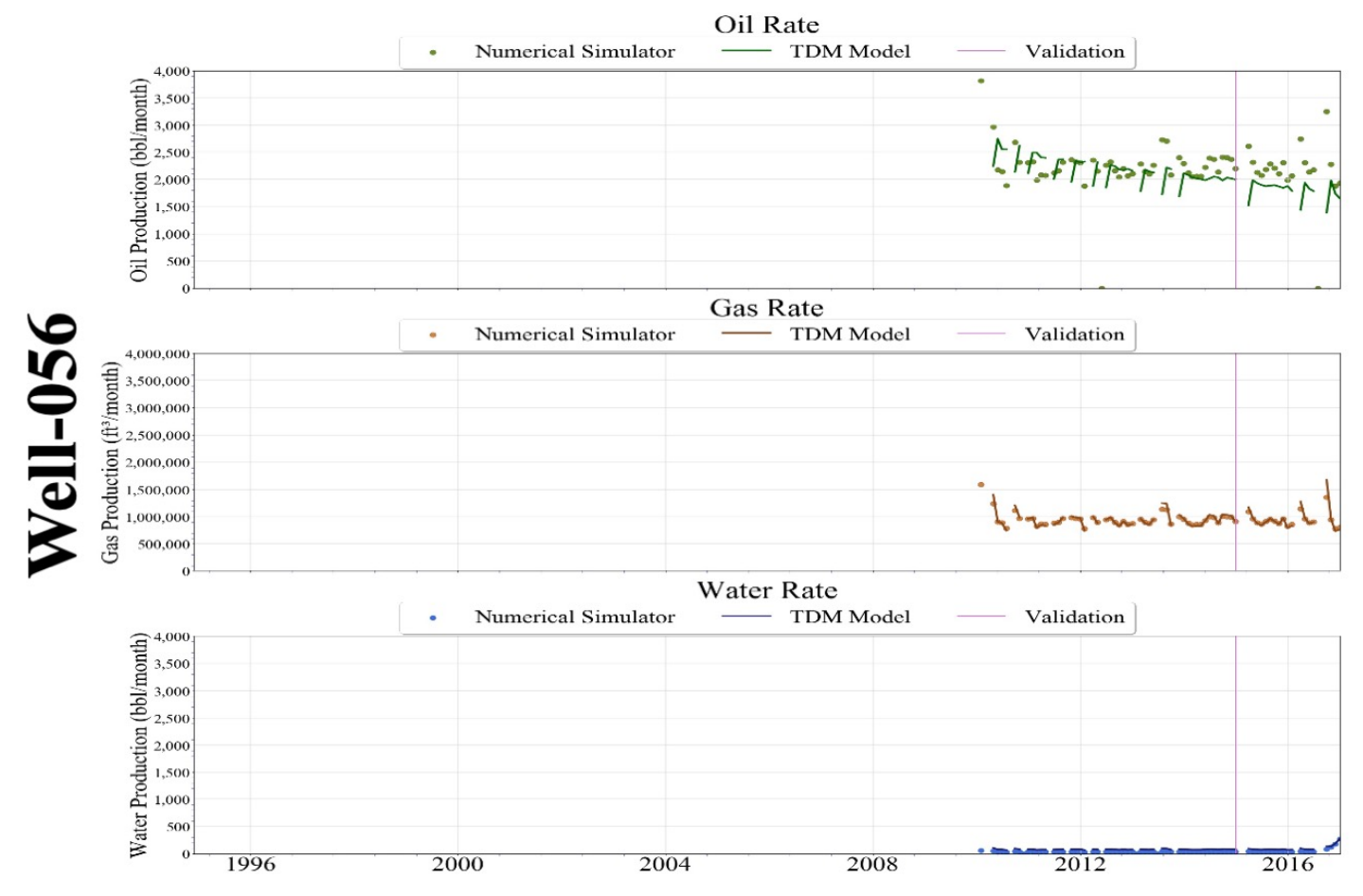

Figure 11-60: Scenario 3 - Well-056 Production History Match 


\subsubsection{Poor History Match of Production}

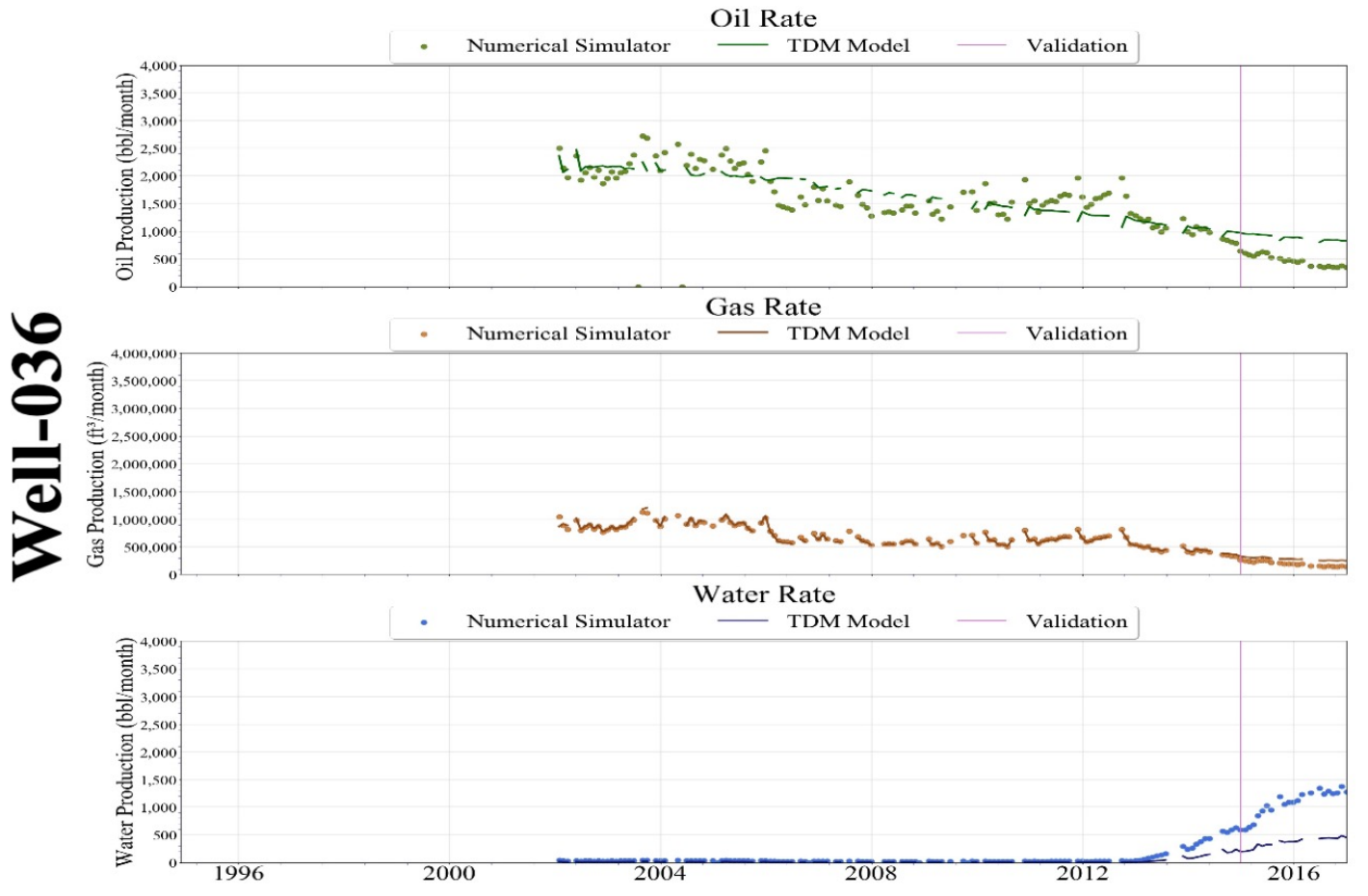

Figure 11-61: Scenario 3 - Well-036 Production History Match

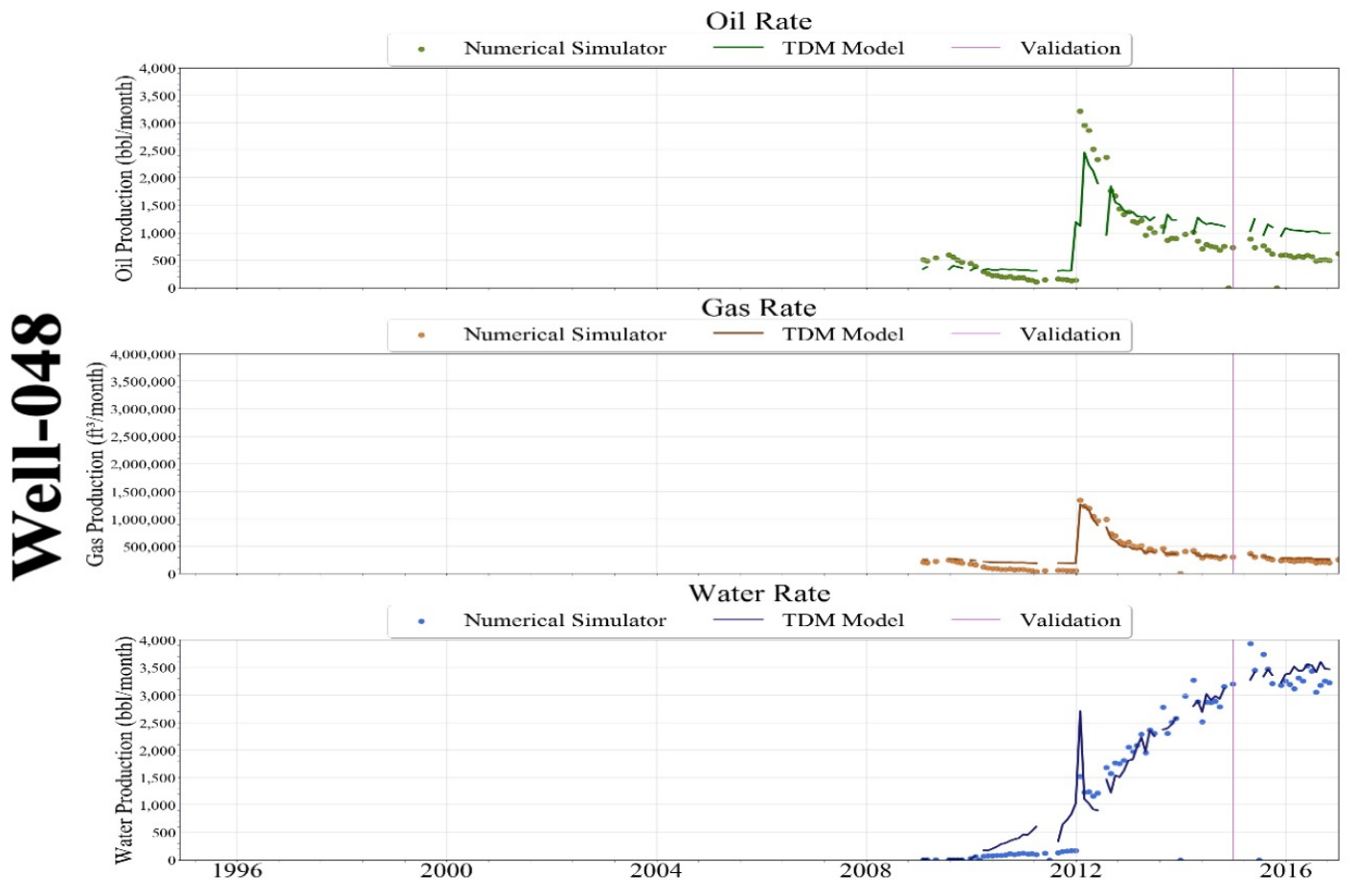

Figure 11-62: Scenario 3 - Well-048 Production History Match 


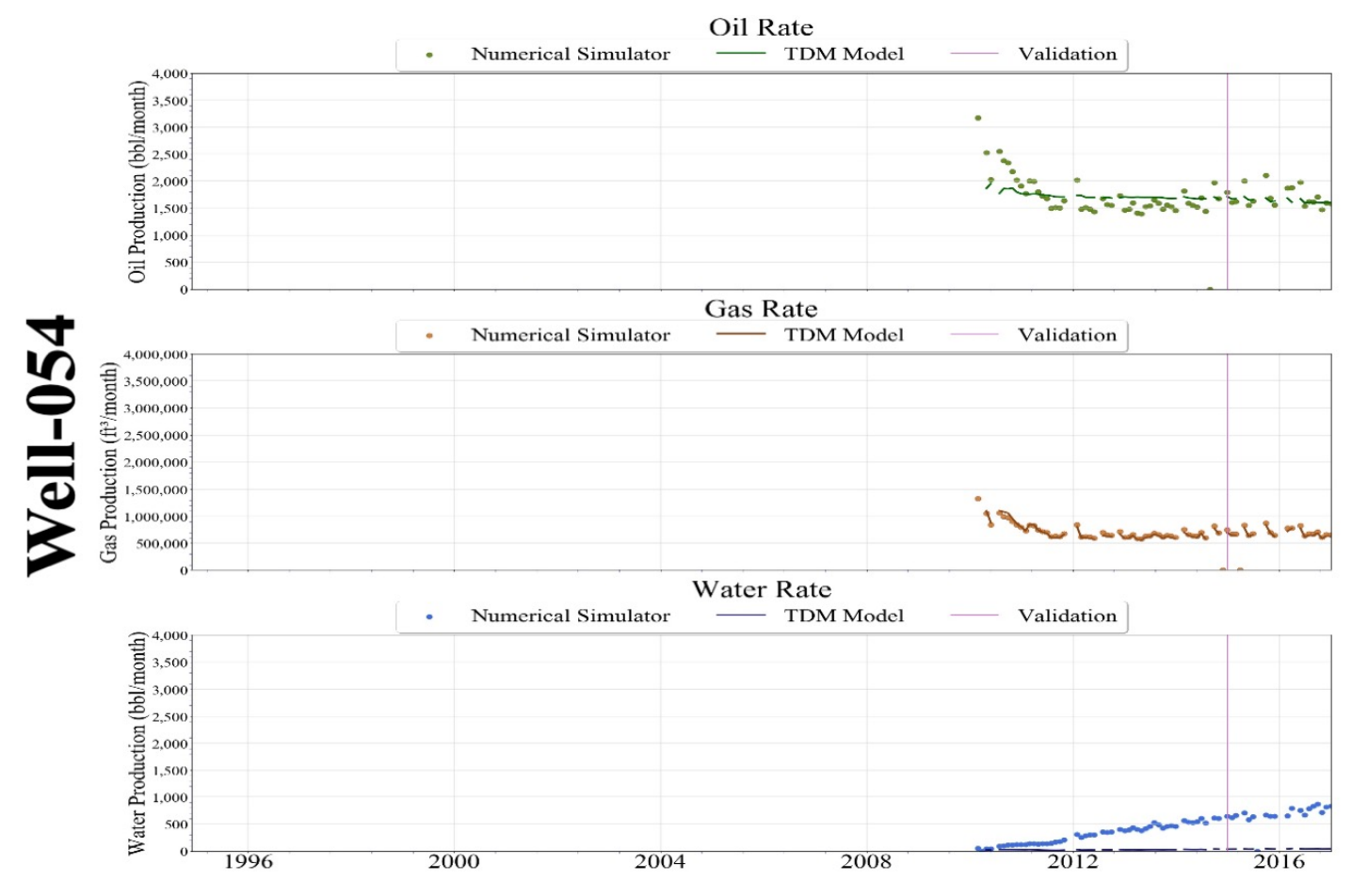

Figure 11-63: Scenario 3 - Well-054 Production History Match 


\subsection{Distribution Maps}

Distribution maps are presented at different timesteps, including the months of January, June, and December of 2014, and the months of June and December of years 2015 and 2016.

Reservoir Pressure (psi) at 2014-01-31
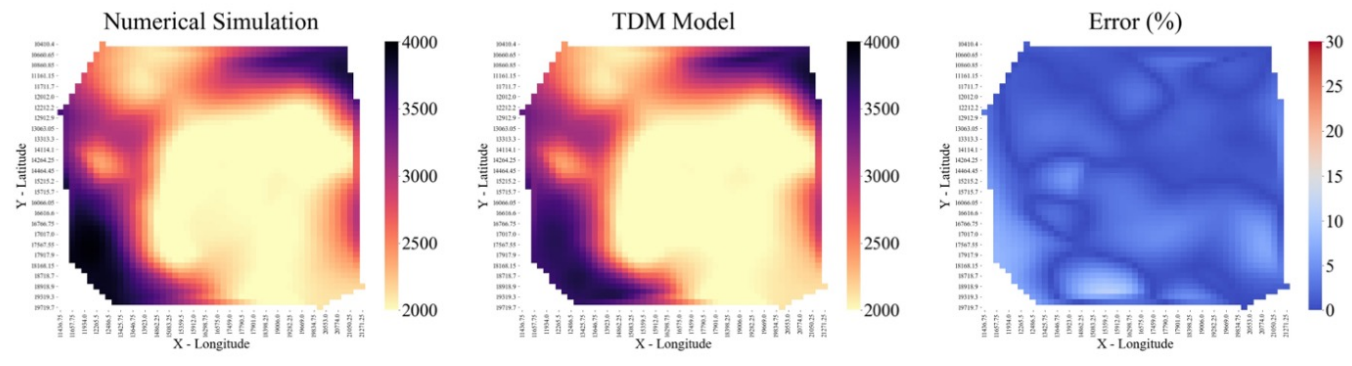

Water Saturation (\%) at 2014-01-31
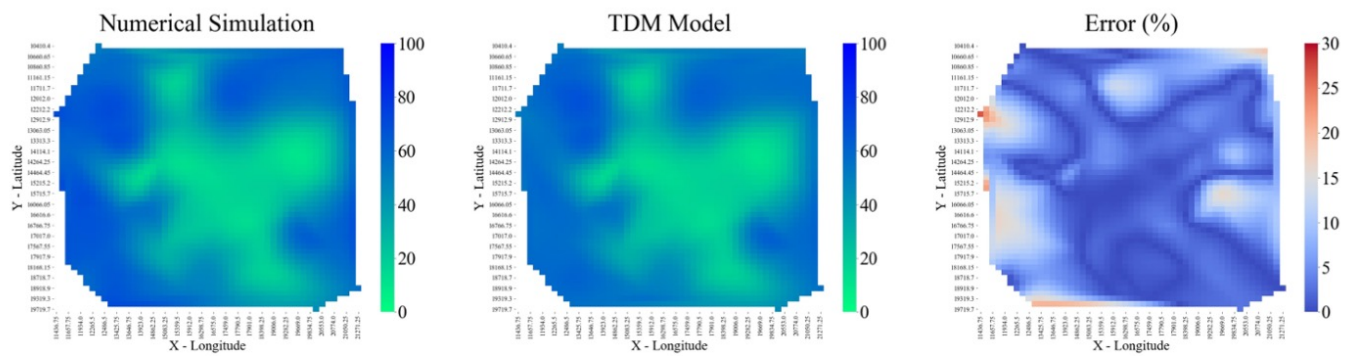

Reservoir Pressure (psi) at 2014-06-30
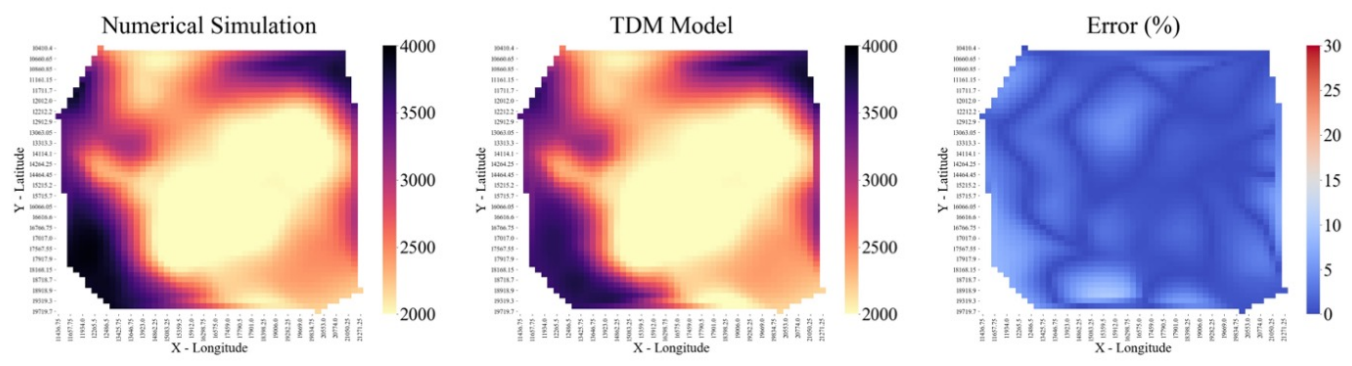

Water Saturation (\%) at 2014-06-30
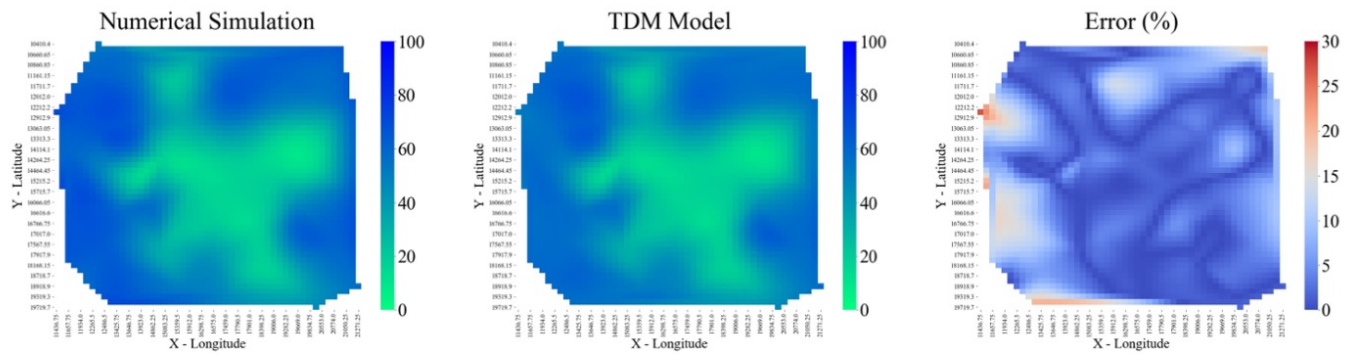
Reservoir Pressure (psi) at 2014-12-31
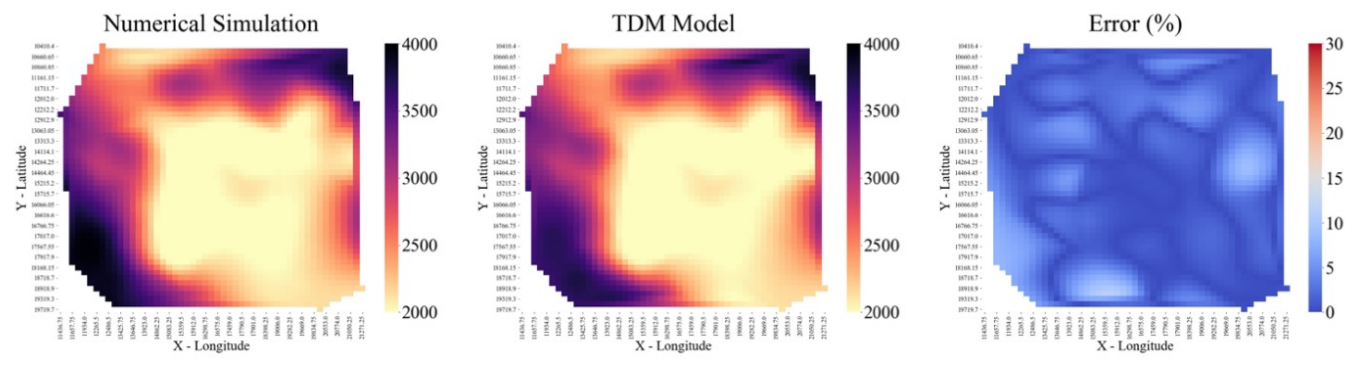

Water Saturation (\%) at 2014-12-31
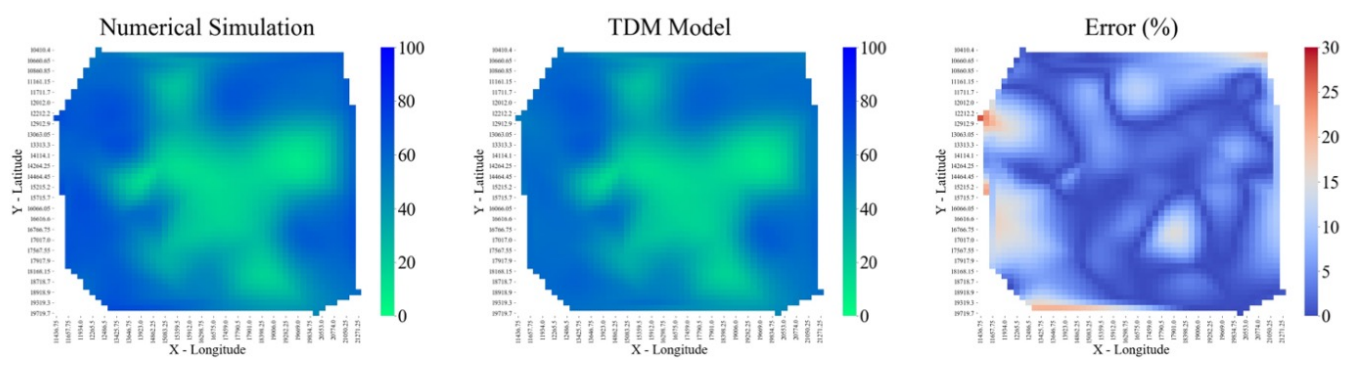

Reservoir Pressure (psi) at 2015-06-30
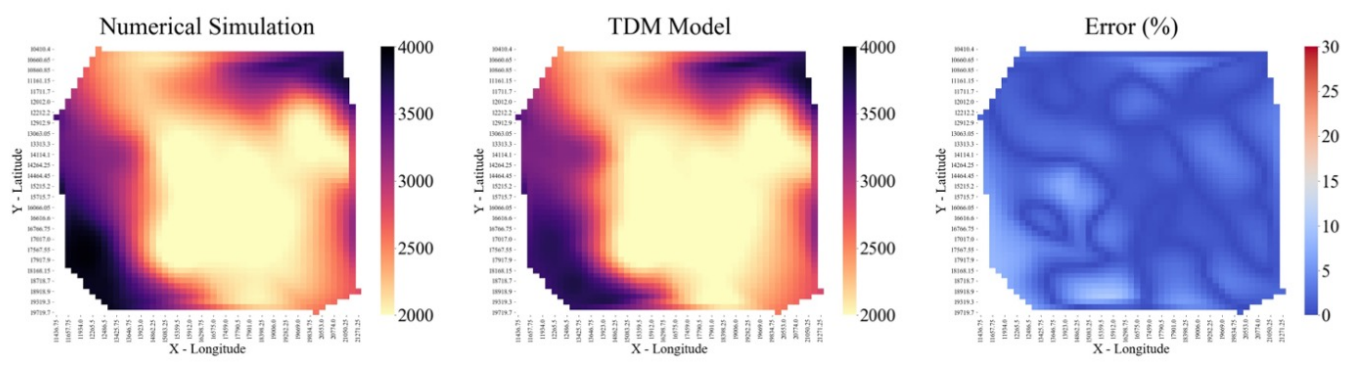

Water Saturation (\%) at 2015-06-30
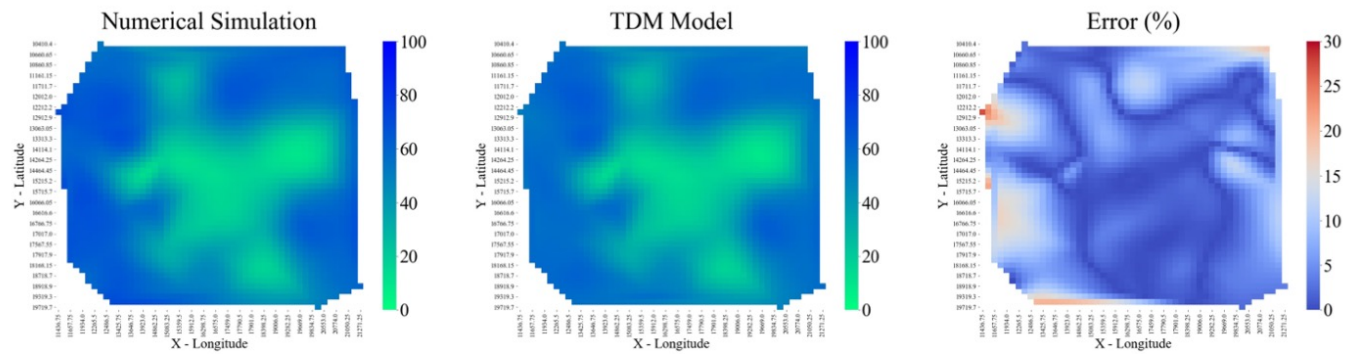
Reservoir Pressure (psi) at 2015-12-31
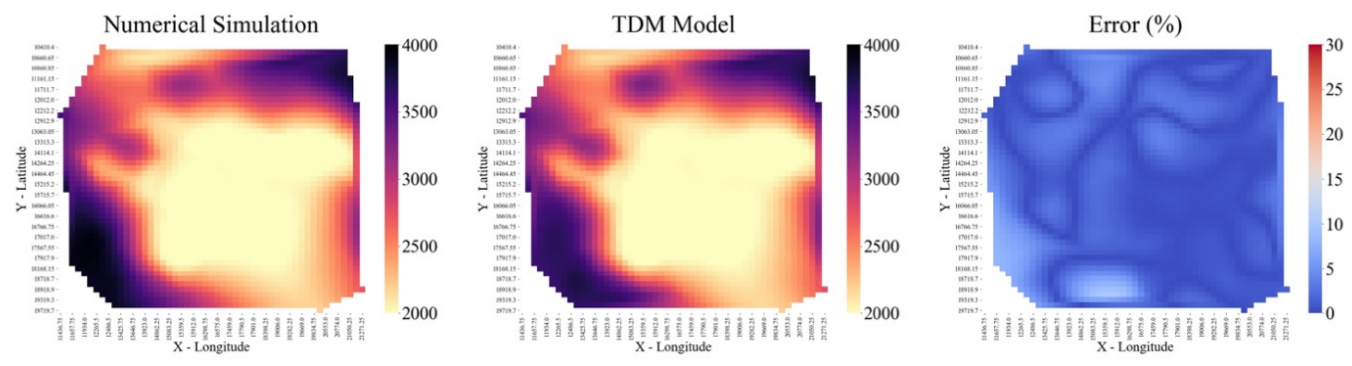

Water Saturation (\%) at 2015-12-31
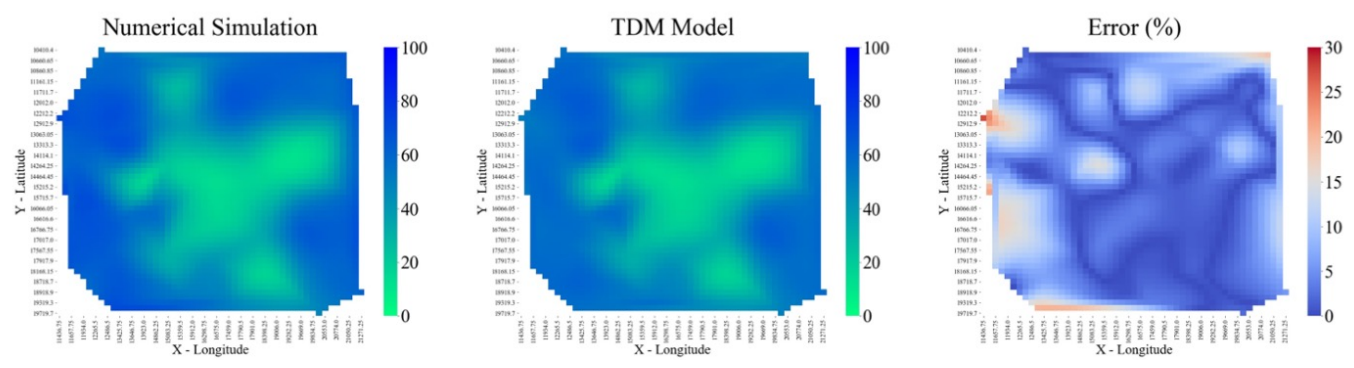

Reservoir Pressure (psi) at 2016-06-30
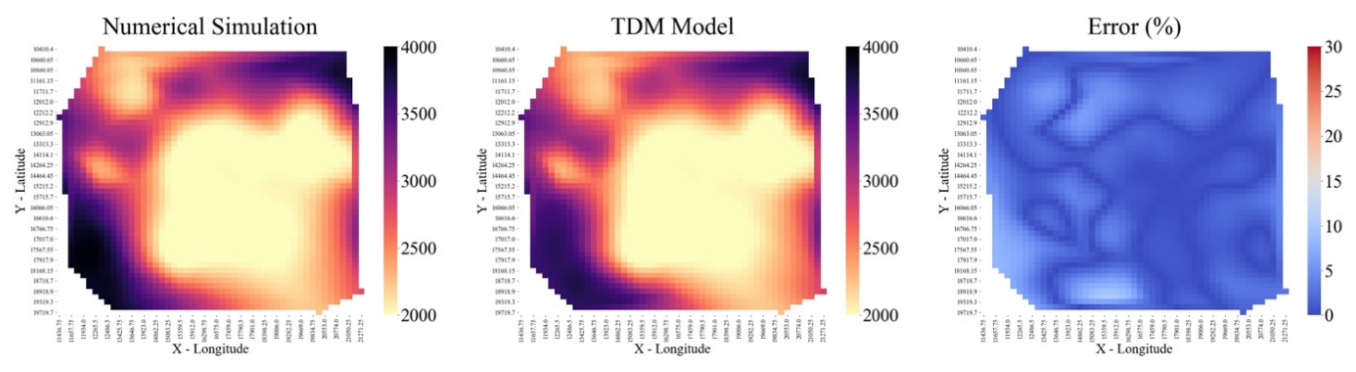

Water Saturation (\%) at 2016-06-30
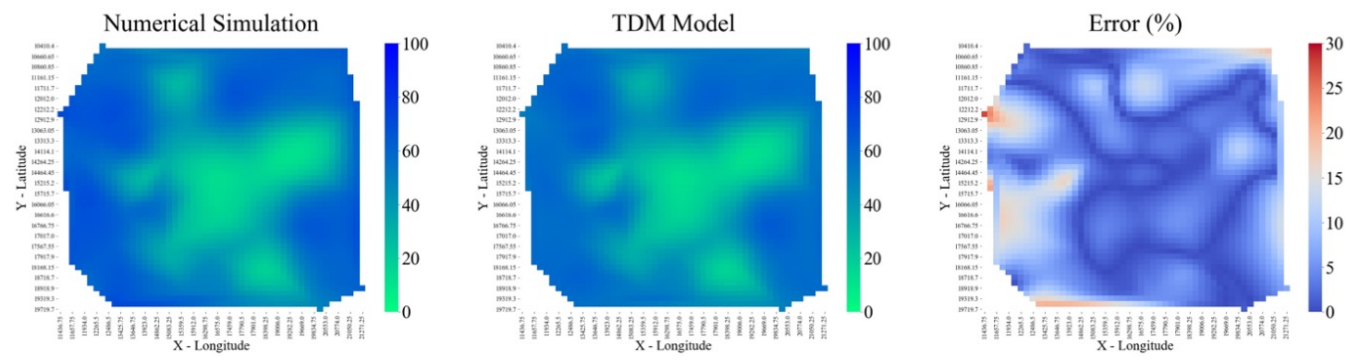
Reservoir Pressure (psi) at 2016-12-31
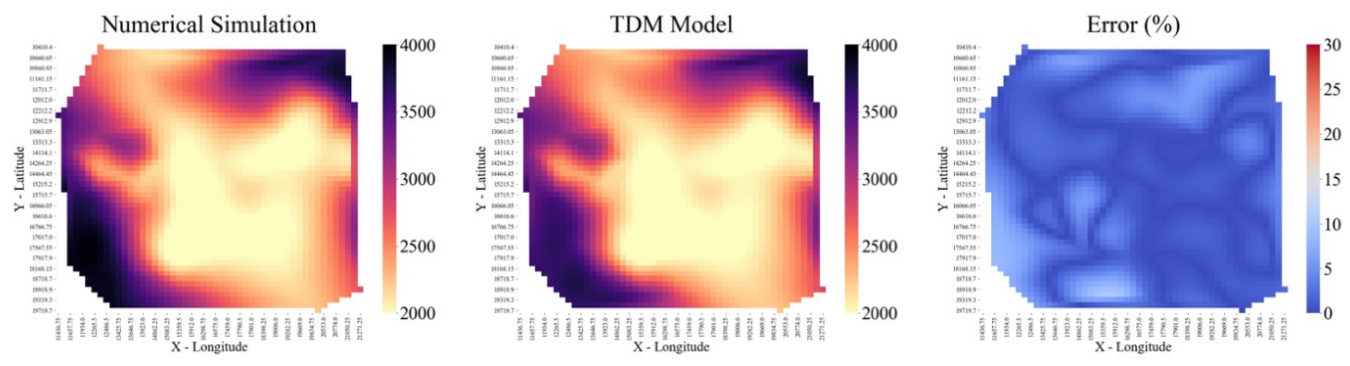

Water Saturation (\%) at 2016-12-31
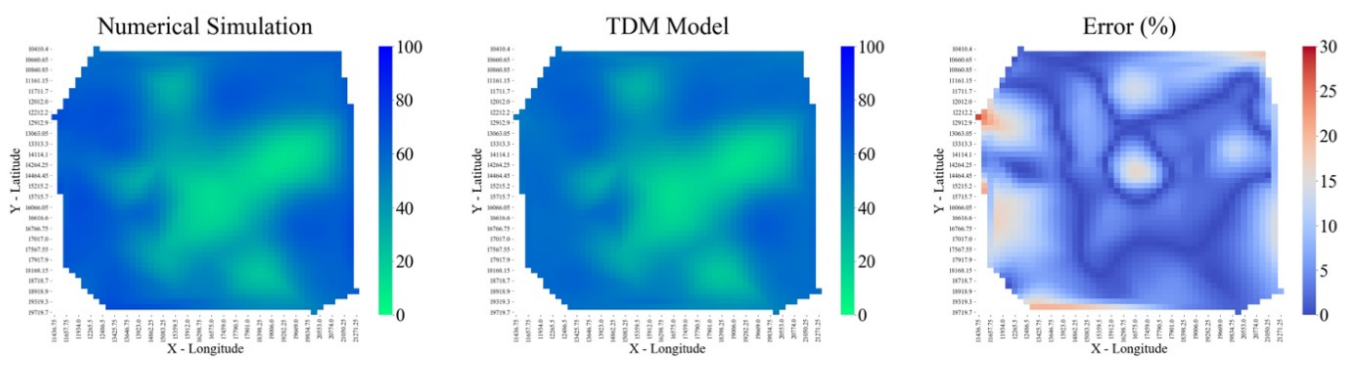

Figure 11-64: Scenario 3 - Distribution Maps at Different Timesteps 


\section{Appendix F: Scenario 4 - Mixed Partitioning TDM (1 Year Forecast)}

\subsection{Input Attributes}

The number of input attributes used in the development of each data-driven model was based on KPI analysis and domain expertise. The following tables provide a list of static and dynamic attributes for both the focal and offset wells. Each table is composed of three columns that indicate the ranking, name of the input attribute, and its degree of influence (DOI) with respect to the output model.

\subsubsection{Oil Predictive Model}

Oil Model - Input Attributes

\begin{tabular}{|r|l|r|}
\hline \multicolumn{3}{|c|}{ FOCAL WELL } \\
\hline \multicolumn{3}{|c|}{ Static Attributes } \\
\hline Rank & Attribute & DOI \\
\hline 1 & Porh(1-sw) & 100 \\
\hline 2 & Porosity (\%) & 90 \\
\hline 5 & TVD(ft) & 73 \\
\hline \multicolumn{3}{|c|}{3} \\
\hline \multicolumn{3}{|c|}{ Dynamic Attributes } \\
\hline 1 & Oil Rate (t-1) & 100 \\
\hline 2 & Gas Rate (t-1) & 100 \\
\hline 3 & Permeability I(t-1) & 49 \\
\hline 4 & Time & 48 \\
\hline 9 & Completion (ft)(t) & 12 \\
\hline 10 & Completion (ft)(t-1) & 10 \\
\hline \multicolumn{3}{|c|}{6} \\
\hline
\end{tabular}

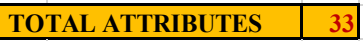

\begin{tabular}{|c|c|c|}
\hline \multicolumn{3}{|c|}{ OFFSET WELLS } \\
\hline \multicolumn{3}{|c|}{ Static Attributes } \\
\hline Rank & Attribute & DOI \\
\hline 2 & Porh(1-sw)(1I) & 91 \\
\hline 3 & Top (ft)(1I) & 90 \\
\hline 4 & $\mathrm{X} /$ Longitude(1I) & 84 \\
\hline 5 & TVD (ft)(1I) & 73 \\
\hline 6 & Top $(\mathrm{ft})(2 \mathrm{P})$ & 65 \\
\hline 7 & Y/Latitude(1P) & 59 \\
\hline 8 & Y/Latitude(1I) & 56 \\
\hline 9 & TVD (ft)(1P) & 55 \\
\hline 10 & $\mathrm{X} /$ Longitude(1P) & 52 \\
\hline 11 & Pay thickness (ft)(1P) & 50 \\
\hline 16 & TVD $(\mathrm{ft})(2 \mathrm{P})$ & 36 \\
\hline 20 & Y/Latitude(2I) & 30 \\
\hline 30 & Pay thickness (ft)(2P) & 12 \\
\hline 38 & $\mathrm{X} /$ Longitude(2I) & 4 \\
\hline & 14 & \\
\hline
\end{tabular}

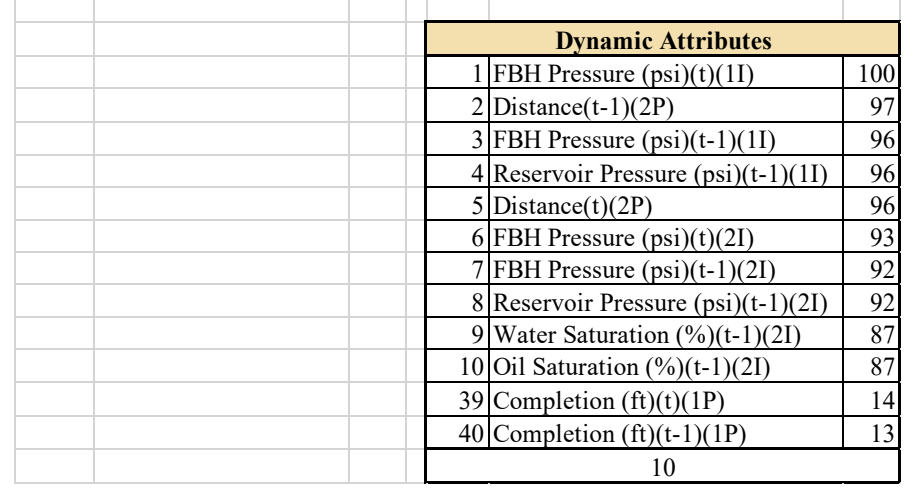

Figure 12-1: Scenario 4 - Oil Model Input Attributes 


\subsubsection{Gas Predictive Model}

\section{Gas Model - Input Attributes}

\begin{tabular}{|c|c|c|c|c|c|}
\hline \multicolumn{3}{|c|}{ FOCAL WELL } & \multicolumn{3}{|c|}{ OFFSET WELLS } \\
\hline \multicolumn{3}{|c|}{ Static Attributes } & \multicolumn{3}{|c|}{ Static Attributes } \\
\hline Rank & Attribute & DOI & Rank & Attribute & DOI \\
\hline 1 & Porh(1-sw) & 100 & 1 & Completion $(\mathrm{ft})(1 \mathrm{P})$ & 100 \\
\hline 2 & Porosity (\%) & 90 & 2 & Porh(1-sw)(1I) & 91 \\
\hline \multicolumn{3}{|c|}{2} & 3 & Top (ft)(1I) & 90 \\
\hline & & & 4 & $\mathrm{X} /$ Longitude(1I) & 84 \\
\hline \multicolumn{3}{|c|}{ Dynamic Attributes } & 5 & $\operatorname{TVD}(\mathrm{ft})(1 \mathrm{I})$ & 73 \\
\hline 1 & Oil Rate $(\mathrm{t})$ & 100 & 8 & Y/Latitude(1I) & 56 \\
\hline 2 & Oil Rate (t-1) & 60 & \multicolumn{3}{|c|}{6} \\
\hline 3 & Gas Rate $(\mathrm{t}-1)$ & 60 & & & \\
\hline 4 & Permeability I(t-1) & 29 & \multicolumn{3}{|c|}{ Dynamic Attributes } \\
\hline \multicolumn{3}{|c|}{4} & 1 & FBH Pressure (psi)(t)(1I) & 100 \\
\hline & & & 2 & Distance $(\mathrm{t}-1)(2 \mathrm{P})$ & 97 \\
\hline \multirow[t]{9}{*}{ TOTA } & AL ATTRIBUTES & 22 & 3 & FBH Pressure (psi)(t-1)(1I) & 96 \\
\hline & & & 4 & Reservoir Pressure $(\mathrm{psi})(\mathrm{t}-1)(1 \mathrm{I})$ & 96 \\
\hline & & & 5 & Distance $(\mathrm{t})(2 \mathrm{P})$ & 96 \\
\hline & & & 6 & FBH Pressure $(p s i)(t)(2 I)$ & 93 \\
\hline & & & 7 & FBH Pressure (psi)(t-1)(2I) & 92 \\
\hline & & & 8 & Reservoir Pressure $(\mathrm{psi})(\mathrm{t}-1)(2 \mathrm{I})$ & 92 \\
\hline & & & 9 & Water Saturation $(\%)(\mathrm{t}-1)(2 \mathrm{I})$ & 87 \\
\hline & & & 10 & Oil Saturation $(\%)(\mathrm{t}-1)(2 \mathrm{I})$ & 87 \\
\hline & & & \multicolumn{3}{|c|}{10} \\
\hline
\end{tabular}

Figure 12-2: Scenario 4 - Gas Model Input Attributes 


\subsubsection{Water Predictive Model}

\section{Water Model - Input Attributes}

\begin{tabular}{|c|c|c|}
\hline \multicolumn{3}{|c|}{ FOCAL WELL } \\
\hline \multicolumn{3}{|c|}{ Static Attributes } \\
\hline Rank & Attribute & DOI \\
\hline 1 & Permeability (md) & 100 \\
\hline 2 & $\mathrm{X} /$ Longitude & 89 \\
\hline 3 & Top (ft) & 84 \\
\hline \multicolumn{3}{|c|}{3} \\
\hline \multicolumn{3}{|c|}{ Dynamic Attributes } \\
\hline & $\mathrm{q}(\mathrm{t}-1)$-Water & 100 \\
\hline 2 & Oil Saturation $(\%)(\mathrm{t}-1)$ & 78 \\
\hline 3 & Water Saturation $(\%)(\mathrm{t}-1)$ & 78 \\
\hline 4 & Permeability I(t-1) & 72 \\
\hline 15 & Oil Rate (t) & 1 \\
\hline 16 & Gas Rate $(\mathrm{t})$ & 1 \\
\hline & 6 & \\
\hline
\end{tabular}

\begin{tabular}{|l|l|}
\hline TOTAL ATTRIBUTES & 20 \\
\hline
\end{tabular}

\begin{tabular}{|c|c|c|}
\hline \multicolumn{3}{|c|}{ OFFSET WELLS } \\
\hline \multicolumn{3}{|c|}{ Static Attributes } \\
\hline Rank & Attribute & DOI \\
\hline 1 & $\mathrm{X} /$ Longitude(2P) & 100 \\
\hline 2 & Top (ft)(2P) & 90 \\
\hline 3 & TVD (ft)(2P) & 86 \\
\hline 4 & Top (ft)(2I) & 79 \\
\hline 5 & $\mathrm{X} /$ Longitude(2I) & 75 \\
\hline 7 & $\operatorname{TVD}(\mathrm{ft})(2 \mathrm{I})$ & 65 \\
\hline & 6 & \\
\hline
\end{tabular}

Dynamic Attributes

1 Water Saturation (\%)(t-1)(1P) 100

2 Oil Saturation $(\%)(\mathrm{t}-1)(1 \mathrm{P}) \quad 100$

3 Distance (t)(1I)

12 Permeability I $(\mathrm{t}-1)(2 \mathrm{P})$

15 Permeability I(t-1)(2I)

Figure 12-3: Scenario 4 - Water Model Input Attributes 


\subsubsection{Reservoir Pressure Predictive Model}

\section{Reservoir Pressure Model - Input Attributes}

\begin{tabular}{|c|c|c|}
\hline \multicolumn{3}{|c|}{ FOCAL WELL } \\
\hline \multicolumn{3}{|c|}{ Static Attributes } \\
\hline Rank & Attribute & DOI \\
\hline \multicolumn{3}{|c|}{0} \\
\hline \multicolumn{3}{|c|}{ Dynamic Attributes } \\
\hline 1 & Reservoir Pressure (psi)(t-1) & 100 \\
\hline 2 & FBH Pressure $(\mathrm{psi})(\mathrm{t})$ & 78 \\
\hline 4 & Oil Saturation $(\%)(\mathrm{t}-1)$ & 40 \\
\hline 5 & Water Saturation $(\%)(\mathrm{t}-1)$ & 40 \\
\hline 7 & Permeability I(t-1) & 18 \\
\hline 12 & Oil Rate (t-1) & 5 \\
\hline 13 & Oil Rate (t) & 4 \\
\hline 14 & Gas Rate $(\mathrm{t})$ & 4 \\
\hline 17 & Oil Rate (t-1) & 3 \\
\hline \multicolumn{3}{|c|}{9} \\
\hline
\end{tabular}

\begin{tabular}{|l|r|}
\hline TOTAL ATTRIBUTES & 33 \\
\hline
\end{tabular}

\begin{tabular}{|c|c|c|}
\hline \multicolumn{3}{|c|}{ OFFSET WELLS } \\
\hline \multicolumn{3}{|c|}{ Static Attributes } \\
\hline Rank & Attribute & DOI \\
\hline 12 & Porh(1-sw)(1I) & 58 \\
\hline 15 & Pay thickness (ft)(2I) & 45 \\
\hline 21 & Permeability $(\mathrm{md})(1 \mathrm{I})$ & 25 \\
\hline 23 & Pay thickness (ft)(2P) & 24 \\
\hline 31 & Pay thickness $(\mathrm{ft})(1 \mathrm{P})$ & 15 \\
\hline \multicolumn{3}{|c|}{5} \\
\hline
\end{tabular}

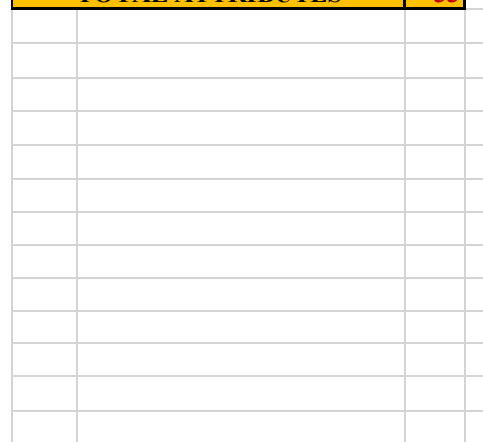

,

13 Water Saturation $(\%)(\mathrm{t}-1)(2 \mathrm{P})$

14 Oil Saturation $(\%)(\mathrm{t}-1)(2 \mathrm{P})$

19 FBH Pressure (psi)(t)(2I)

21 Reservoir Pressure (psi)(t-1)(2I)

24 Permeability I(t-1)(2I)

26 Water Injection Rate(t)(1I)

31 Distance $(\mathrm{t})(1 \mathrm{P})$

39 Reservoir Pressure (psi)(t-1)(1I)

40 FBH Pressure (psi)(t)(1I)

44 Completion $(\mathrm{ft})(\mathrm{t})(1 \mathrm{P})$

46 Distance $(\mathrm{t})(2 \mathrm{P})$

51 Water Saturation $(\%)(\mathrm{t}-1)(2 \mathrm{I})$

52 Oil Saturation $(\%)(\mathrm{t}-1)(2 \mathrm{I})$

19

Figure 12-4: Scenario 4 - Reservoir Pressure Model Input Attributes 


\subsubsection{Water Saturation Predictive Model}

Water Saturation Model - Input Attributes

\begin{tabular}{|c|c|c|c|c|c|}
\hline \multicolumn{3}{|c|}{ FOCAL WELL } & \multicolumn{3}{|c|}{ OFFSET WELLS } \\
\hline \multicolumn{3}{|c|}{ Static Attributes } & \multicolumn{3}{|c|}{ Static Attributes } \\
\hline Rank & Attribute & DOI & Rank & $\begin{array}{c}\text { Attribute } \\
\end{array}$ & DOI \\
\hline & Y/Latitude & 65 & 36 & Permeability (md)(1I) & 4 \\
\hline & Porh(1-sw) & 26 & \multicolumn{3}{|c|}{1} \\
\hline & Porosity $(\%)$ & 22 & & & \\
\hline \multicolumn{3}{|c|}{2} & \multicolumn{3}{|c|}{ Dynamic Attributes } \\
\hline & & & & Distance $(\mathrm{t})(1 \mathrm{I})$ & 50 \\
\hline \multicolumn{3}{|c|}{ Dynamic Attributes } & 9 & Distance $(\mathrm{t})(2 \mathrm{I})$ & 46 \\
\hline & Oil Saturation $(\%)(\mathrm{t}-1)$ & 100 & 28 & Water Saturation $(\%)(\mathrm{t}-1)(1 \mathrm{I})$ & 20 \\
\hline 2 & Water Saturation $(\%)(\mathrm{t}-1)$ & 100 & 29 & Oil Saturation $(\%)(\mathrm{t}-1)(1 \mathrm{I})$ & 20 \\
\hline & Reservoir Pressure (psi)(t) & 23 & 30 & Distance $(\mathrm{t})(1 \mathrm{P})$ & 19 \\
\hline & Water Rate $(\mathrm{t})$ & 18 & 32 & Water Saturation $(\%)(\mathrm{t}-1)(2 \mathrm{I})$ & 18 \\
\hline & Oil Rate $(\mathrm{t})$ & 8 & 33 & Oil Saturation $(\%)(\mathrm{t}-1)(2 \mathrm{I})$ & 18 \\
\hline & Gas Rate $(\mathrm{t})$ & 8 & 35 & Distance $(\mathrm{t})(2 \mathrm{P})$ & 17 \\
\hline \multicolumn{3}{|c|}{6} & 36 & Permeability I(t-1)(1P) & 16 \\
\hline & & & 43 & Permeability I(t-1)(2P) & 14 \\
\hline \multirow{2}{*}{\multicolumn{2}{|c|}{ TOTAL ATTRIBUTES }} & 20 & 48 & Permeability I(t-1)(1I) & 8 \\
\hline & & & \multicolumn{3}{|c|}{11} \\
\hline
\end{tabular}

Figure 12-5: Scenario 4 - Water Saturation Model Input Attributes 


\subsection{Production Profile Plots}

\subsubsection{Entire Reservoir}

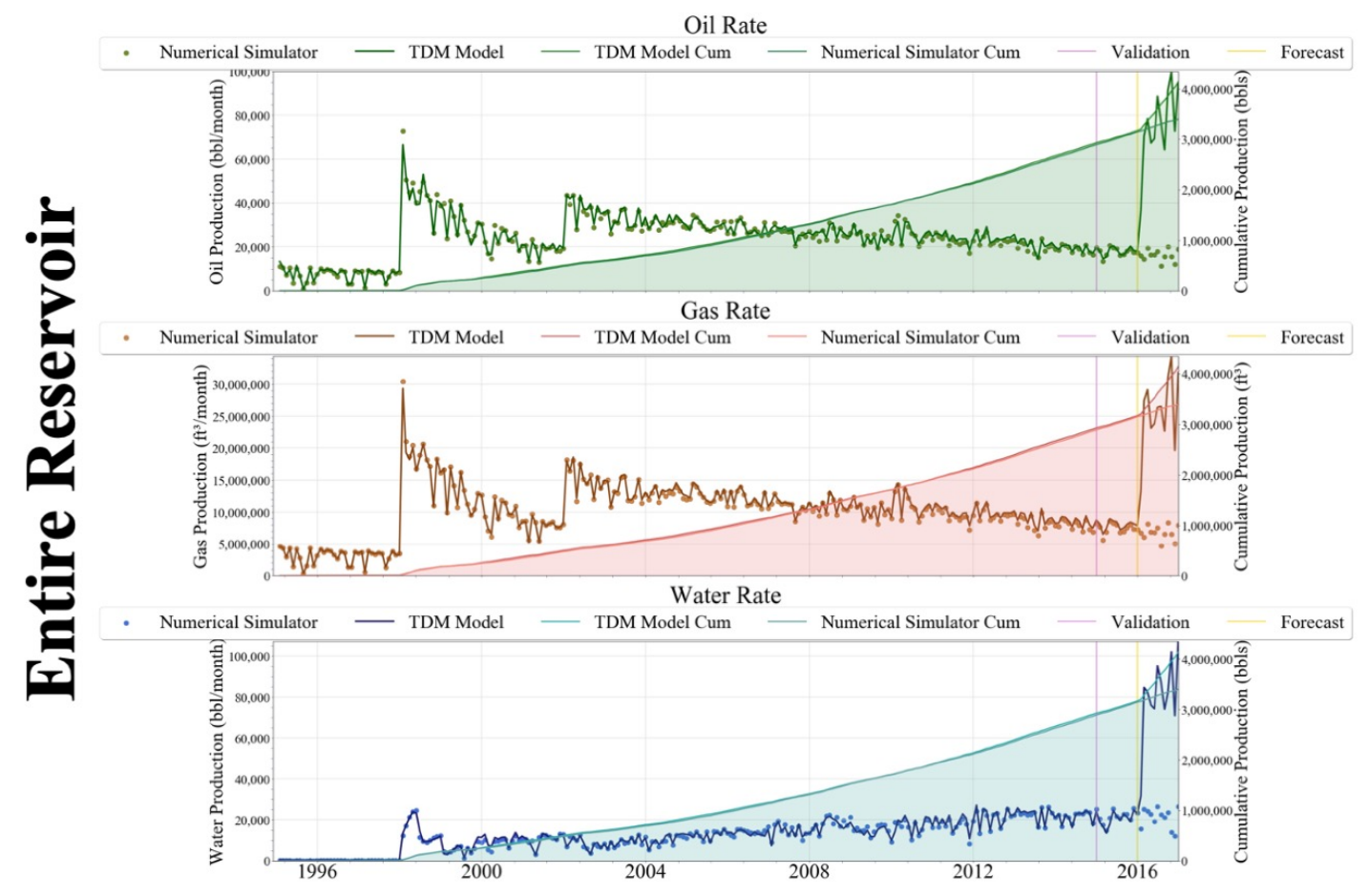

Figure 12-6: Scenario 4 - Entire Field Production 


\subsubsection{Good History Match of Production}

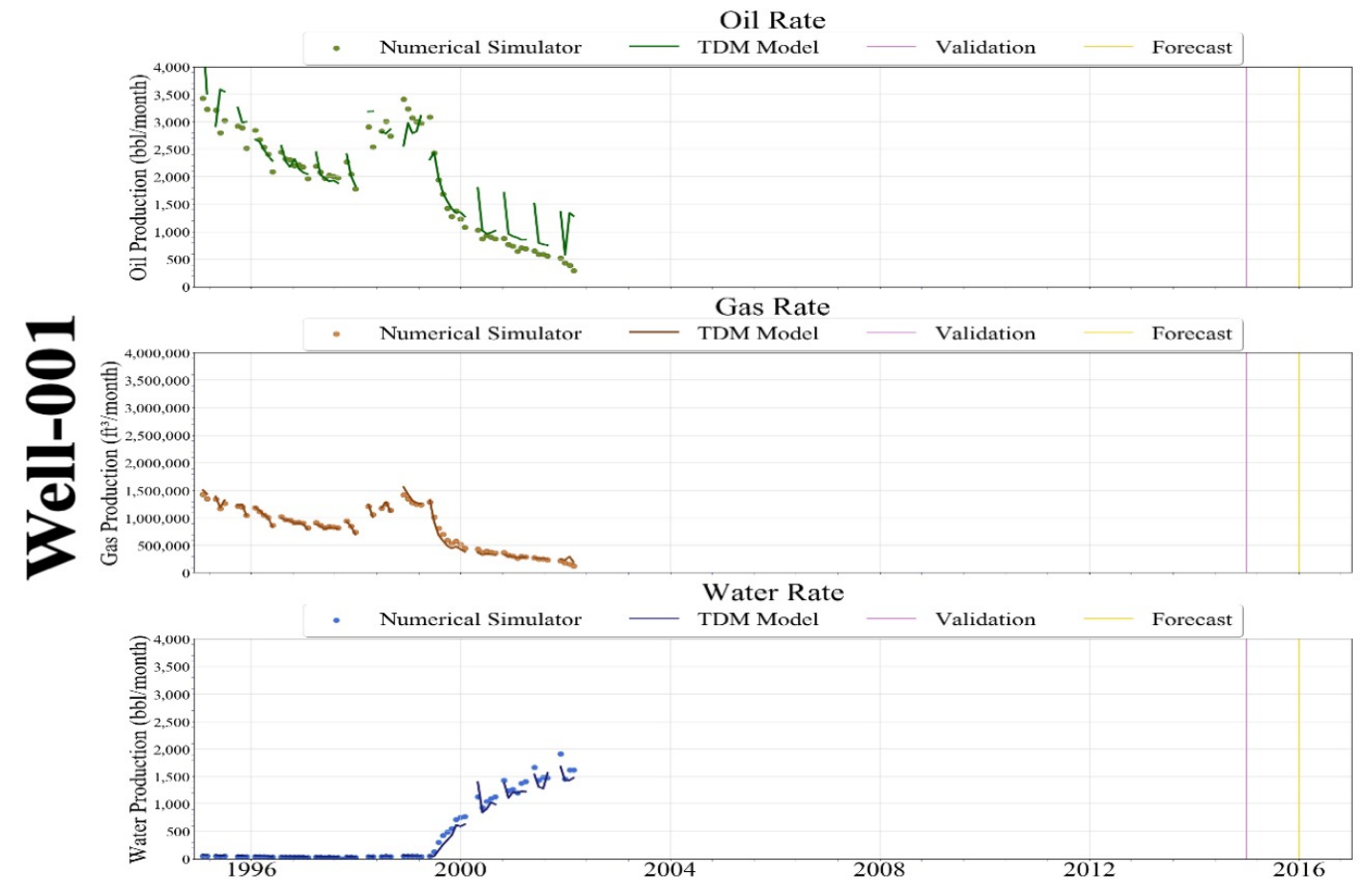

Figure 12-7: Scenario 4 - Well-001 Production History Match

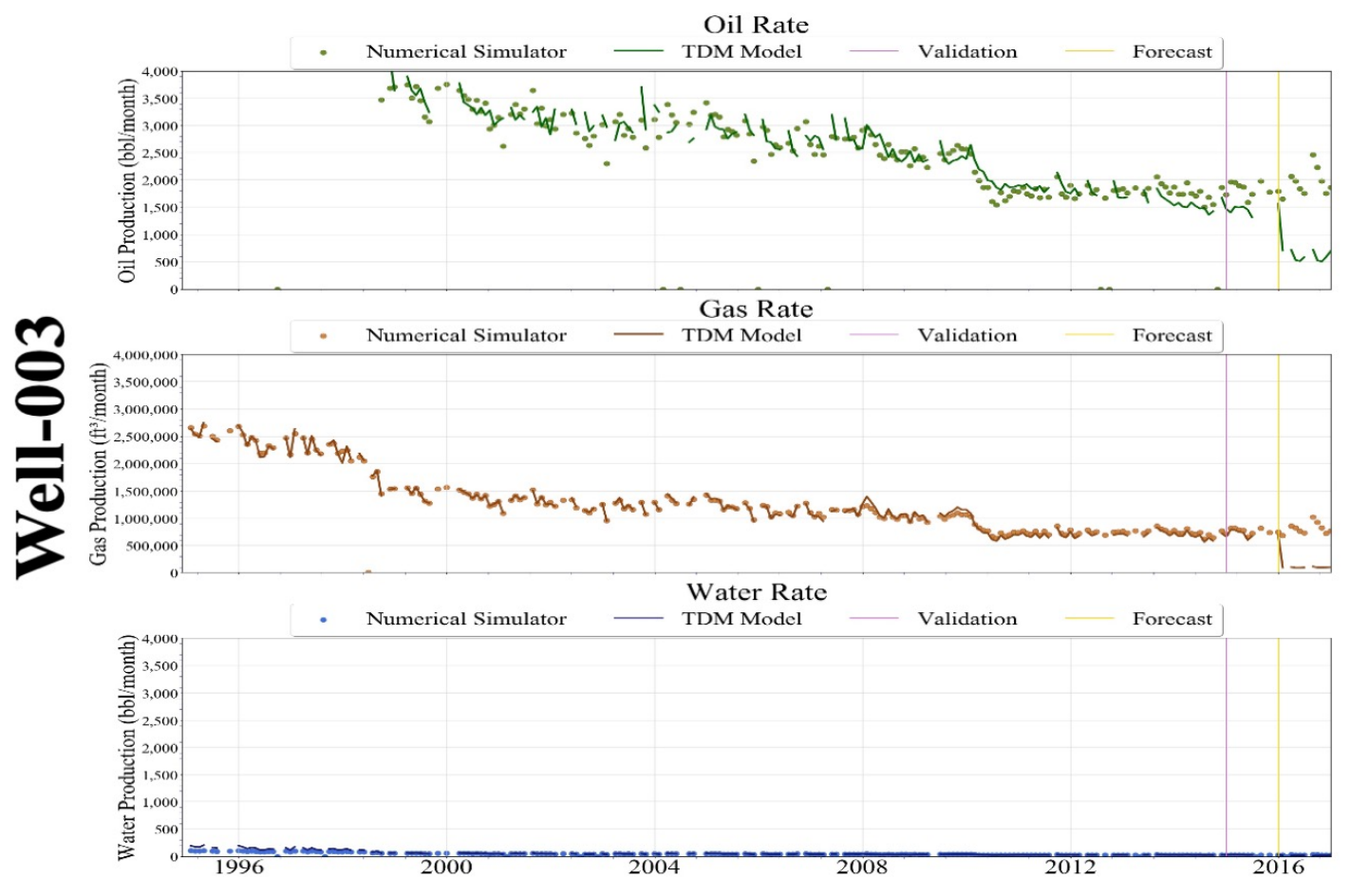

Figure 12-8: Scenario 4 - Well-003 Production History Match 


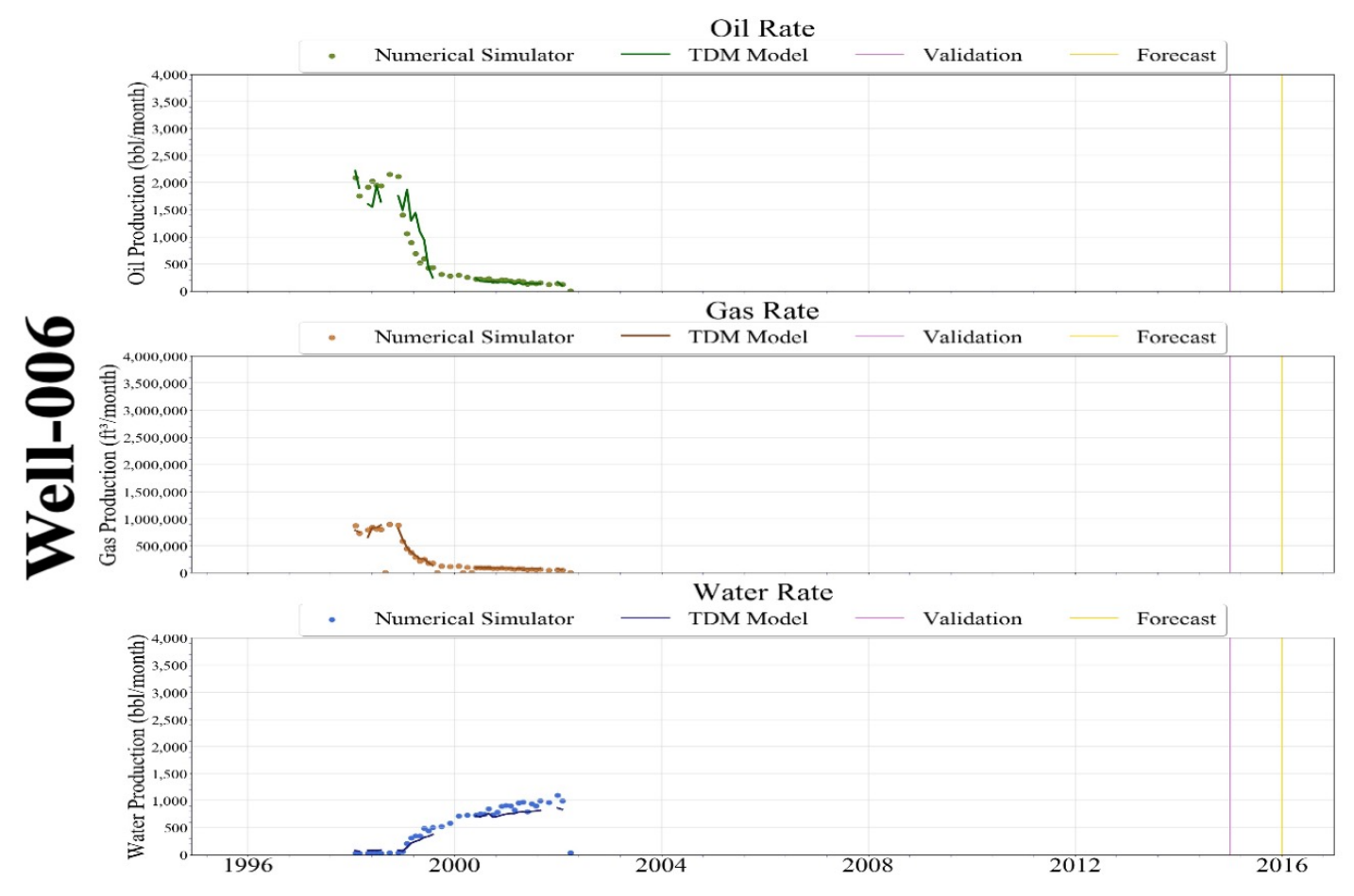

Figure 12-9: Scenario 4 - Well-006 Production History Match

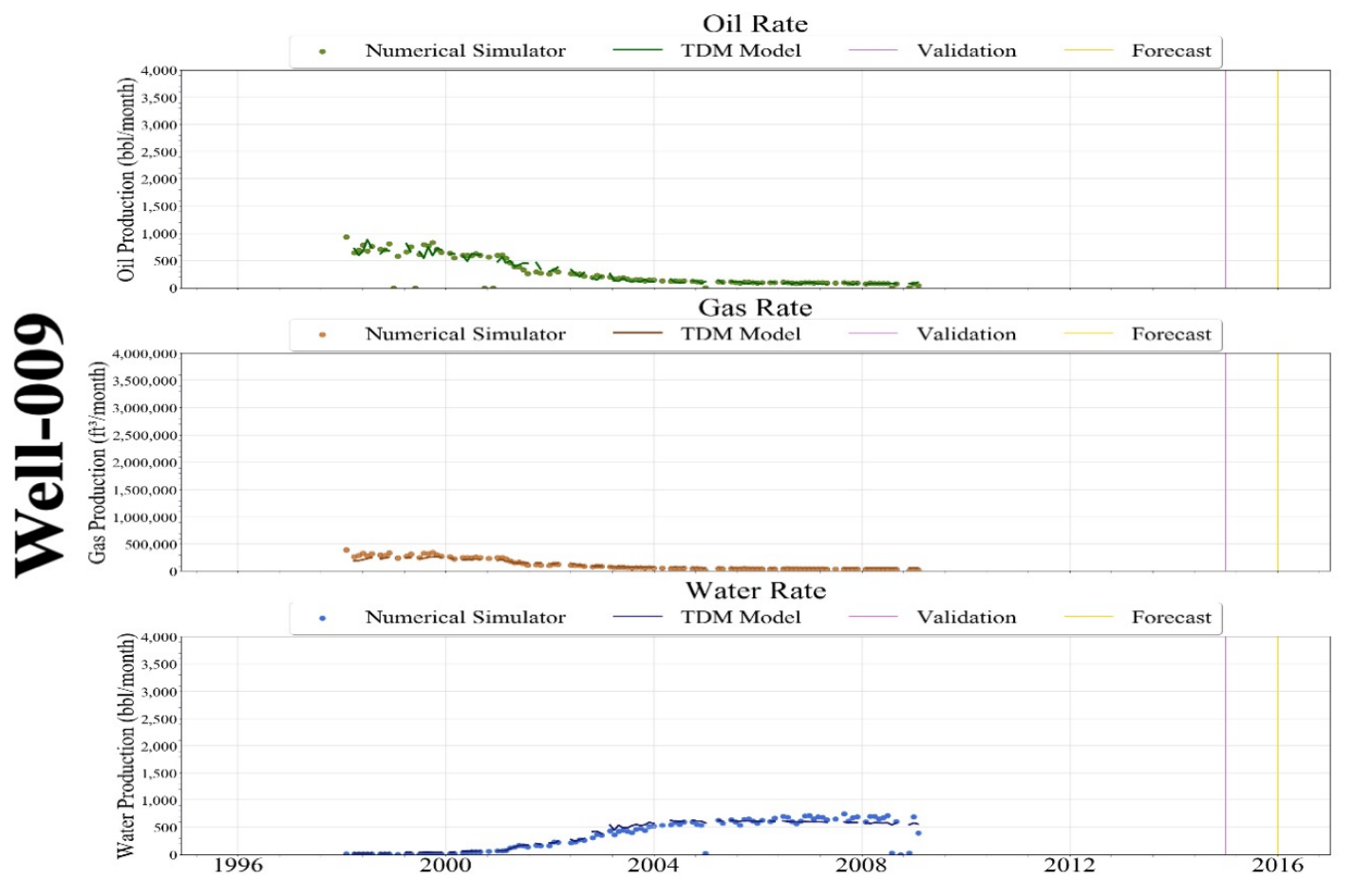

Figure 12-10: Scenario 4 - Well-009 Production History Match 


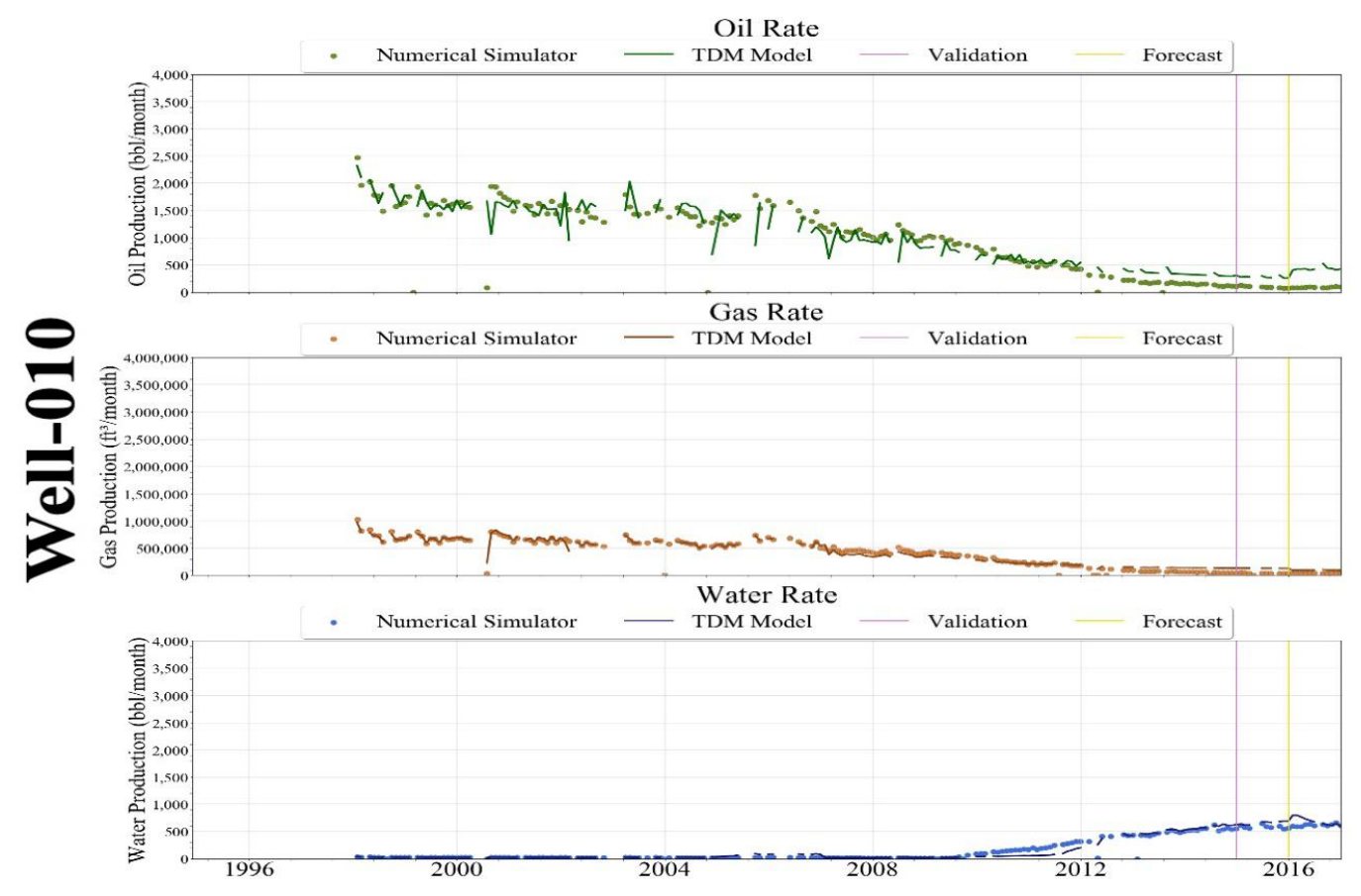

Figure 12-11: Scenario 4 - Well-010 Production History Match

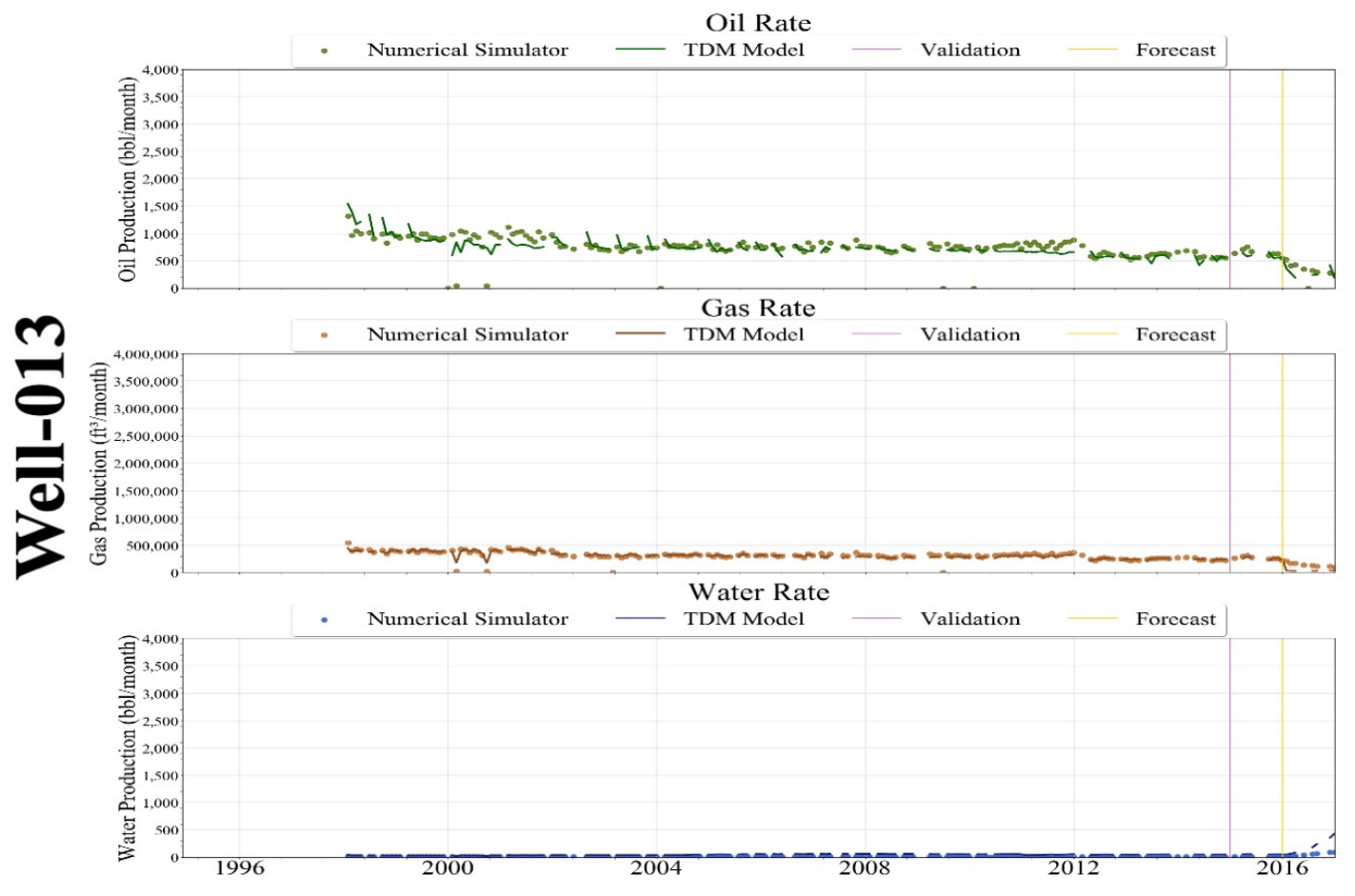

Figure 12-12: Scenario 4 - Well-013 Production History Match 


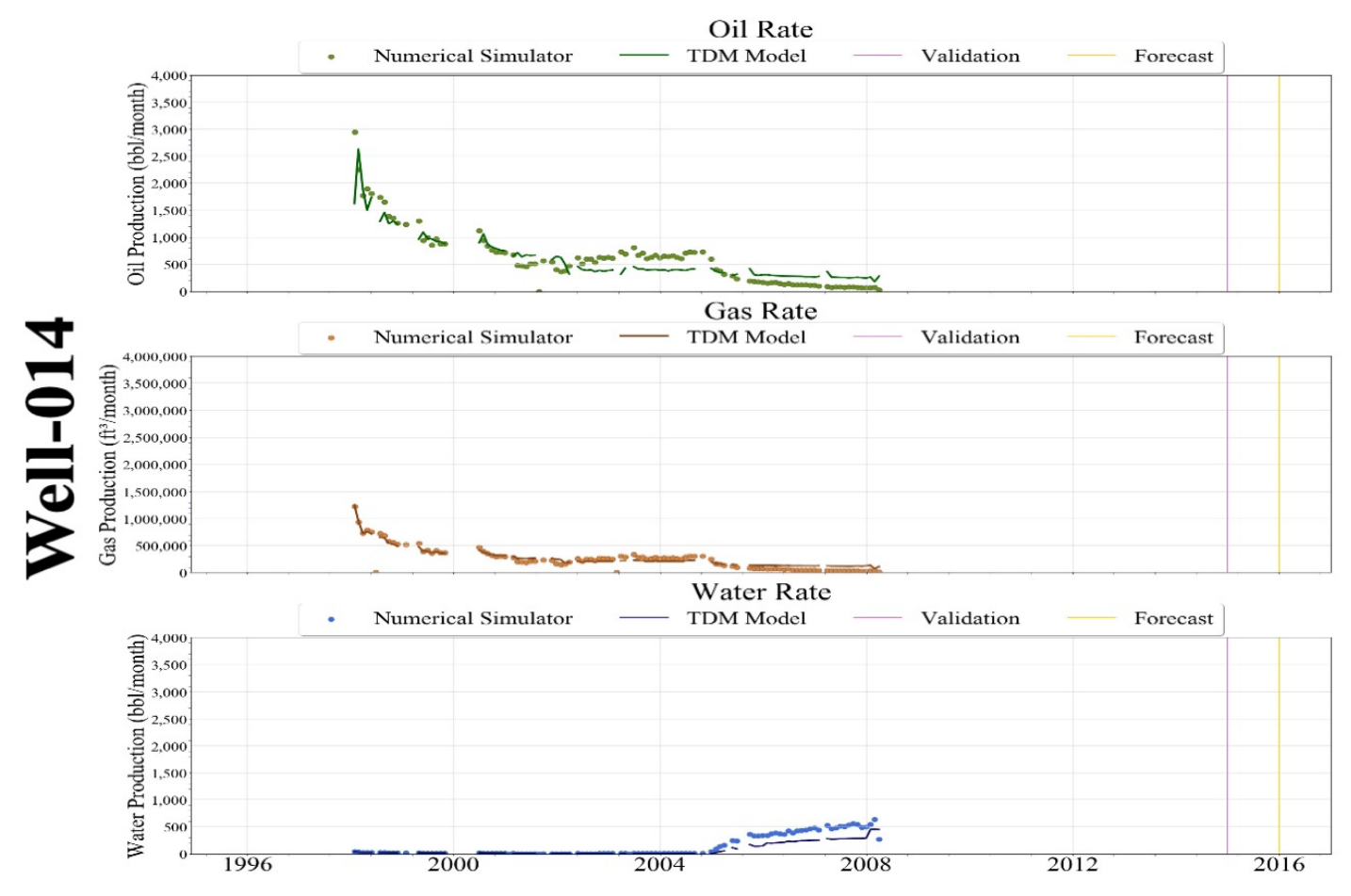

Figure 12-13: Scenario 4 - Well-014 Production History Match

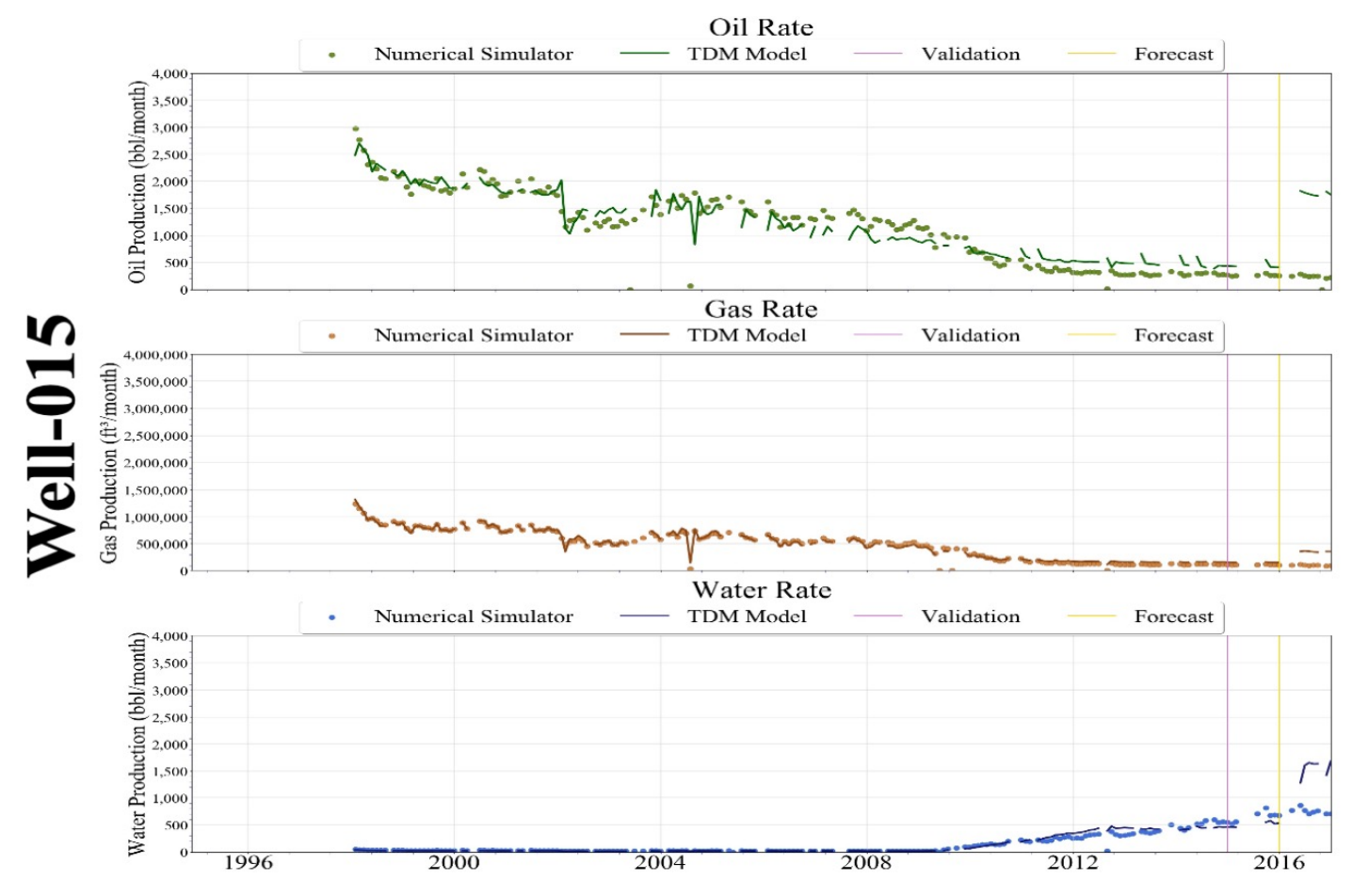

Figure 12-14: Scenario 4 - Well-015 Production History Match 


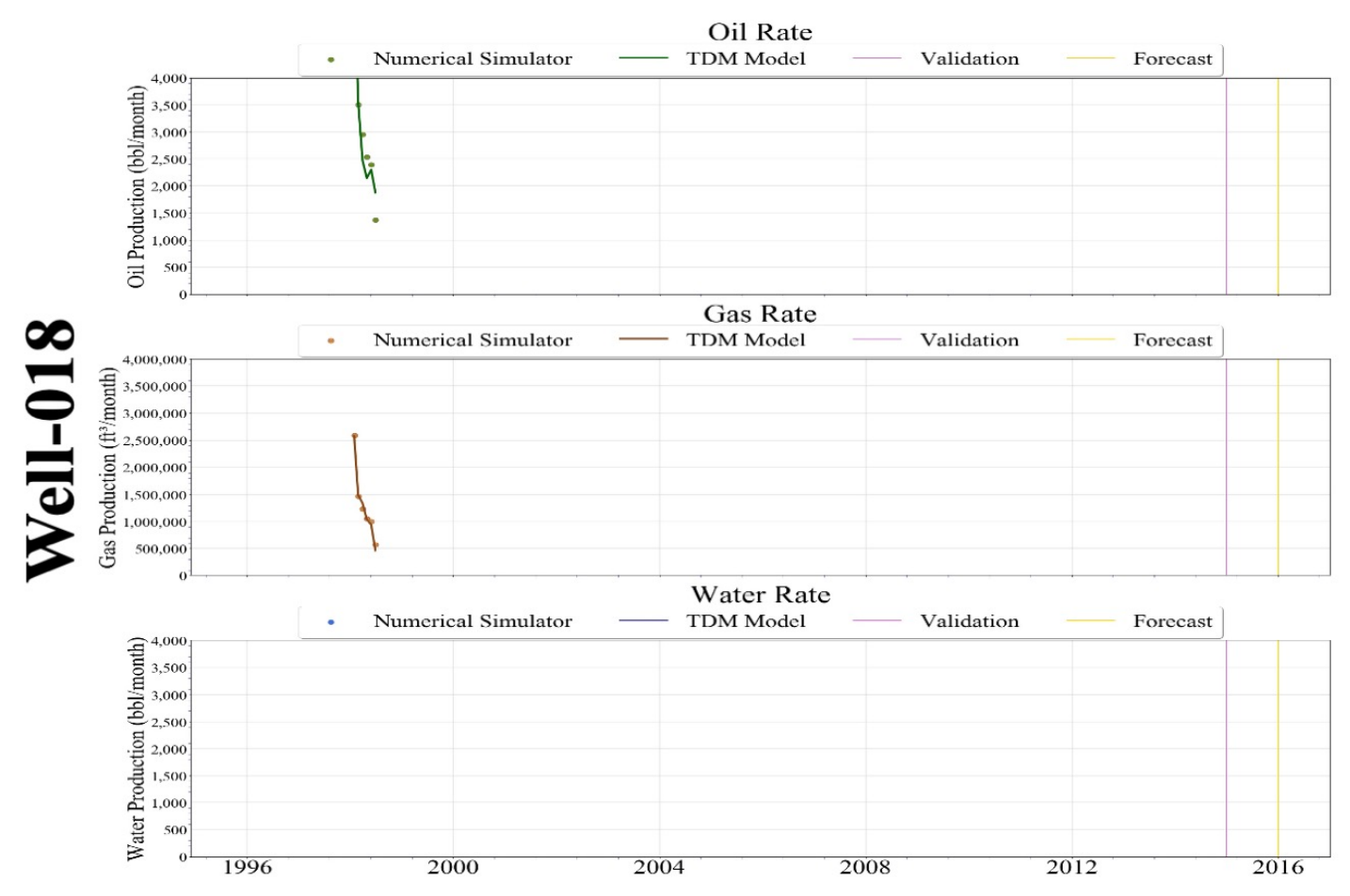

Figure 12-15: Scenario 4 - Well-018 Production History Match

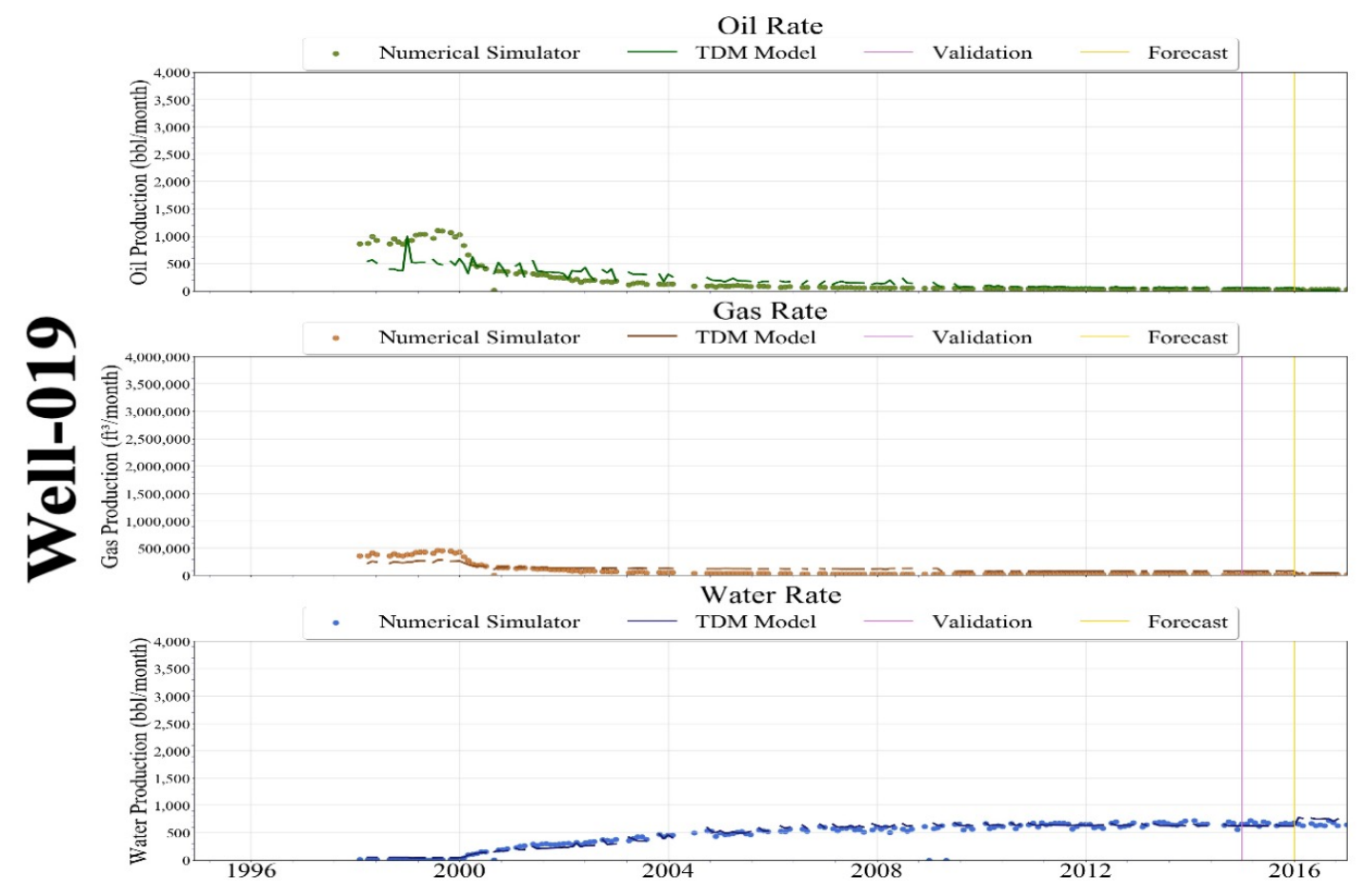

Figure 12-16: Scenario 4 - Well-019 Production History Match 


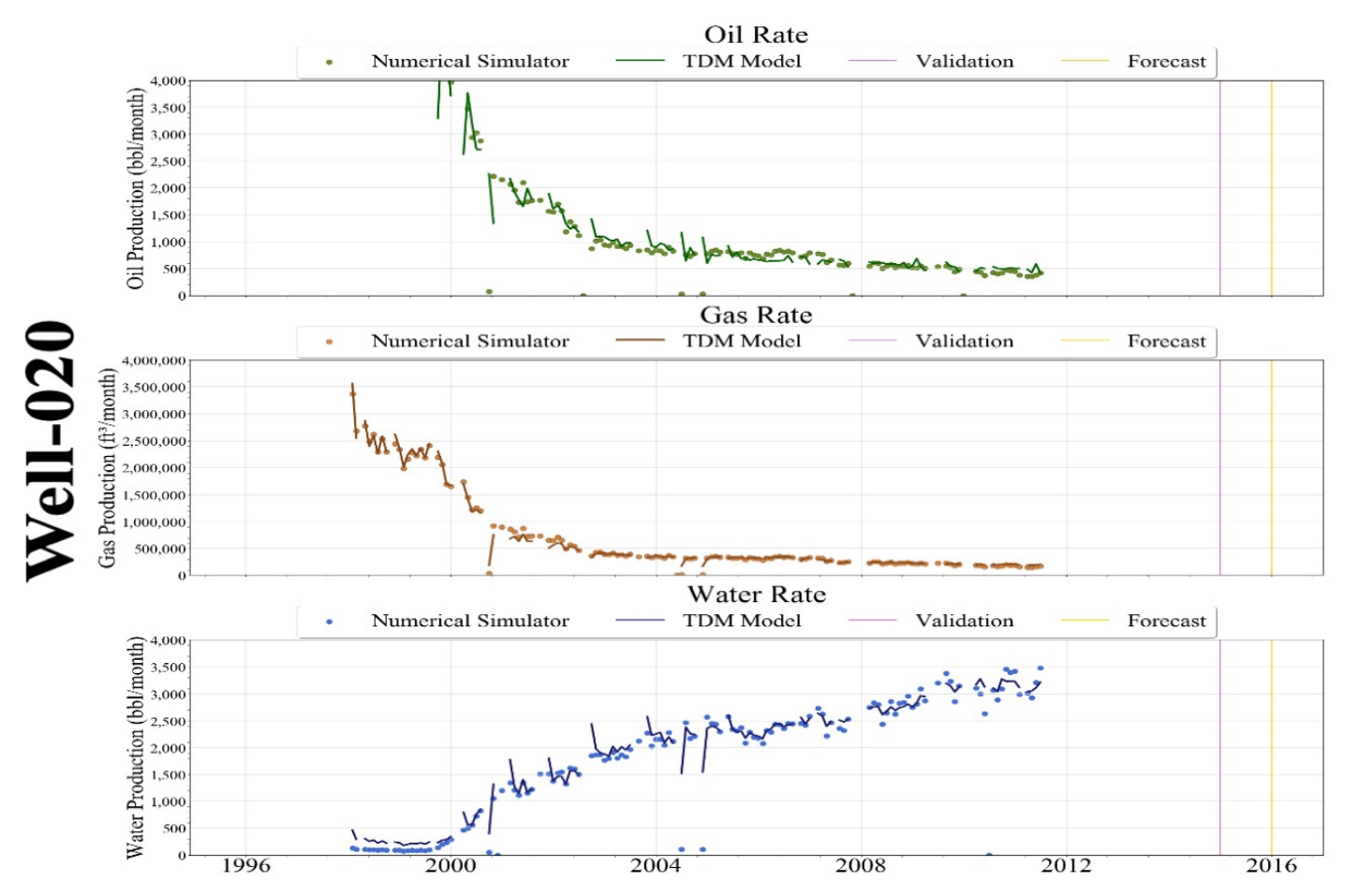

Figure 12-17: Scenario 4 - Well-020 Production History Match

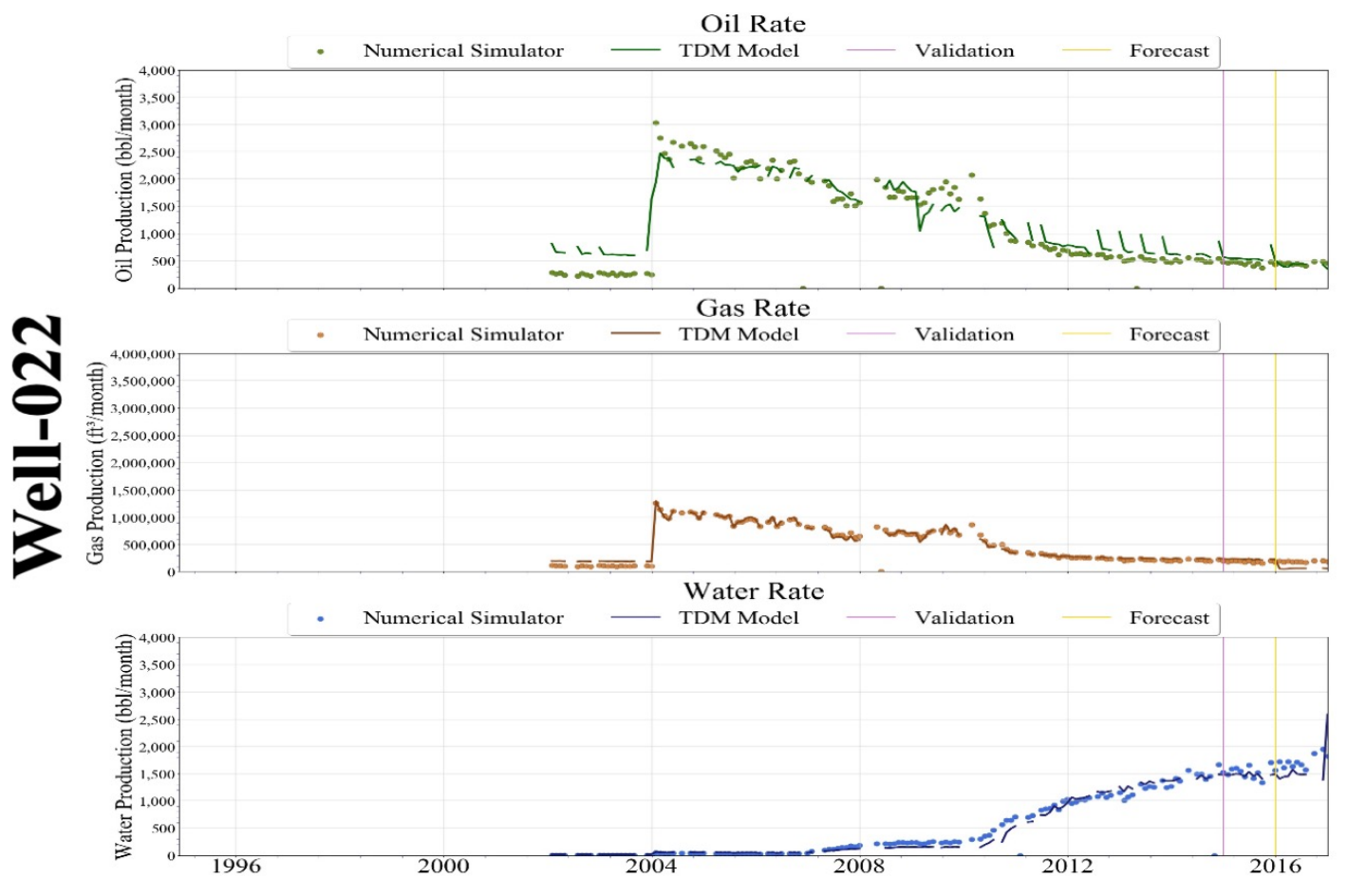

Figure 12-18: Scenario 4 - Well-022 Production History Match 


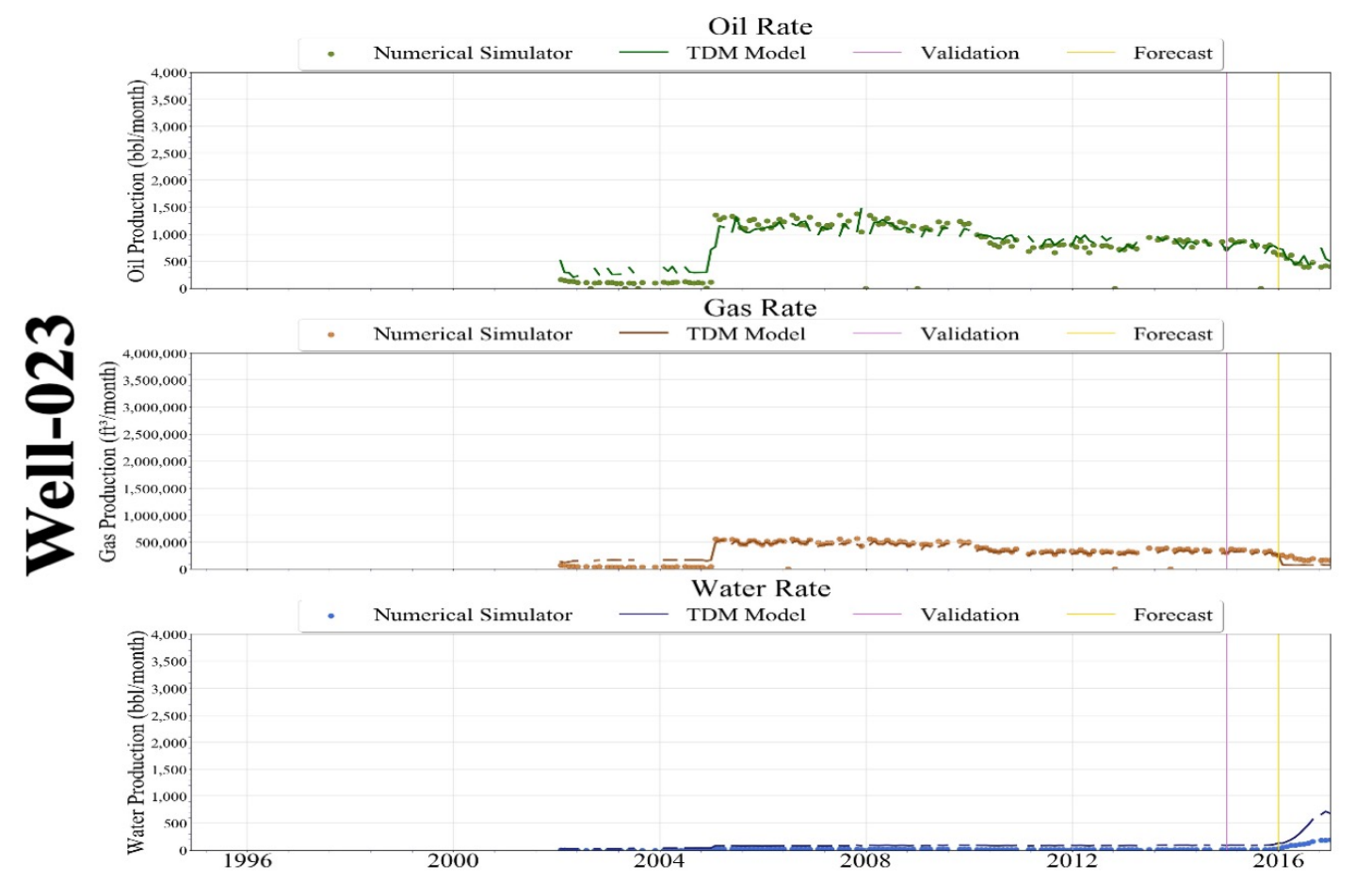

Figure 12-19: Scenario 4 - Well-023 Production History Match

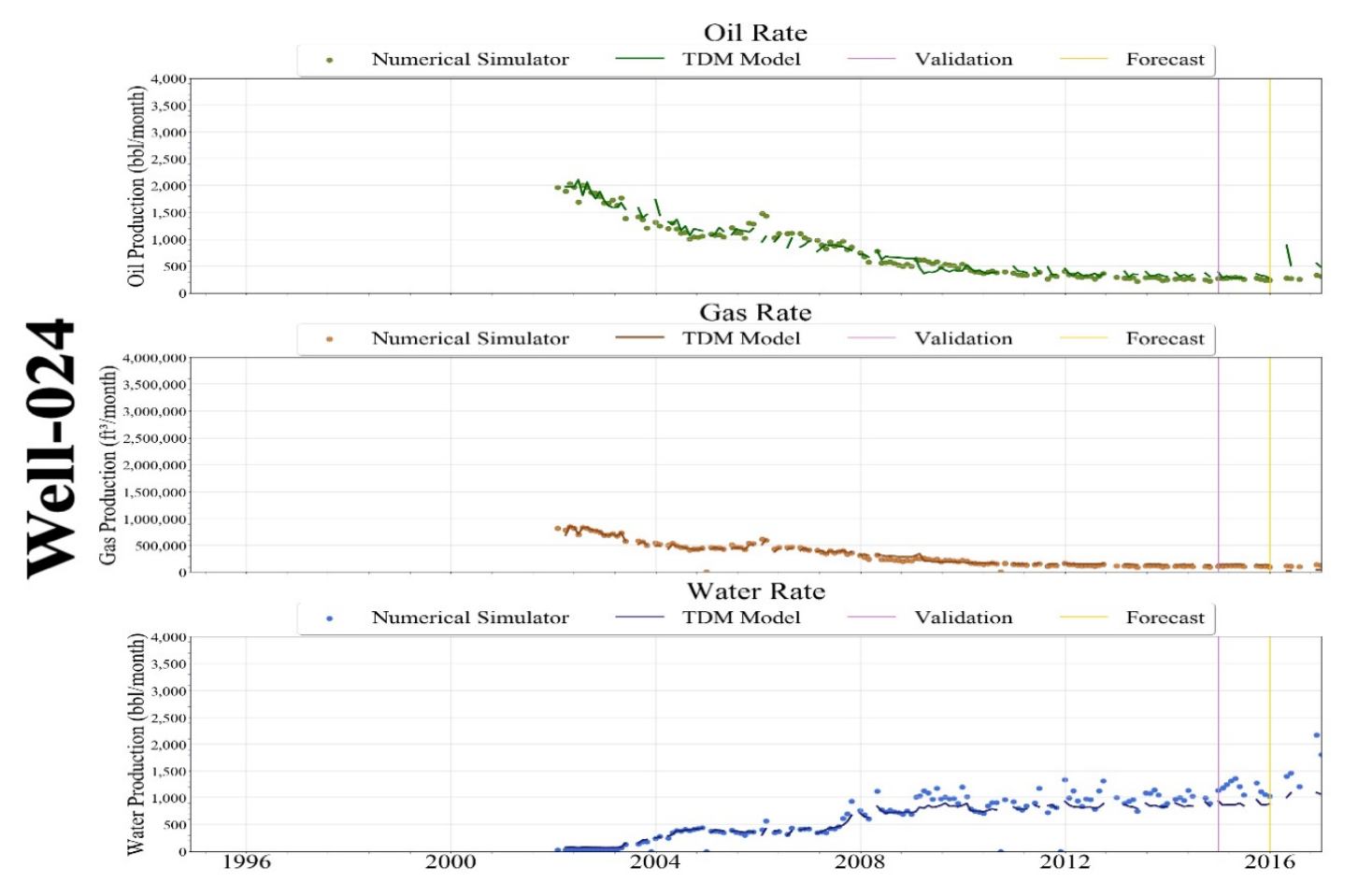

Figure 12-20: Scenario 4 - Well-024 Production History Match 


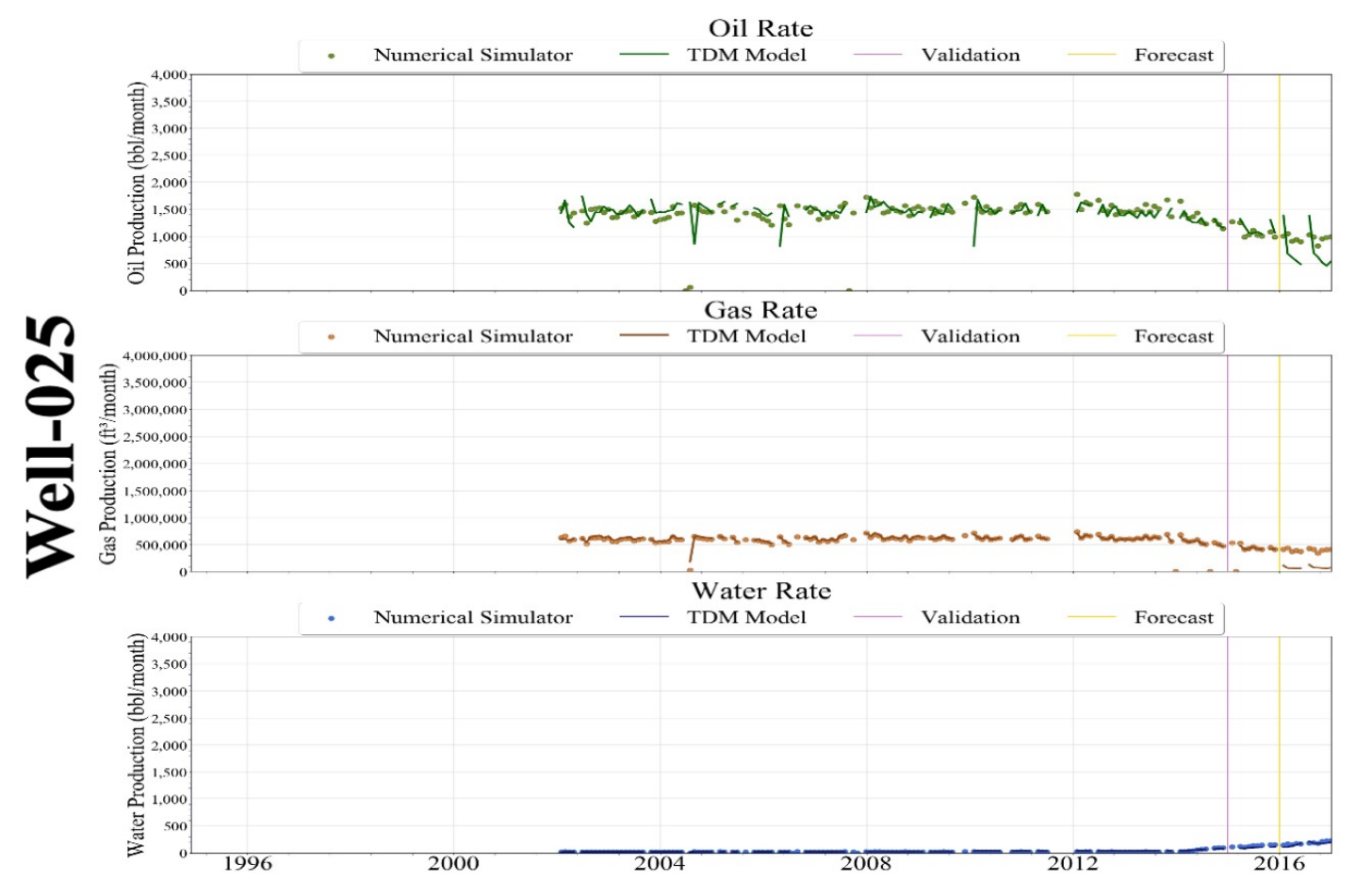

Figure 12-21: Scenario 4 - Well-025 Production History Match

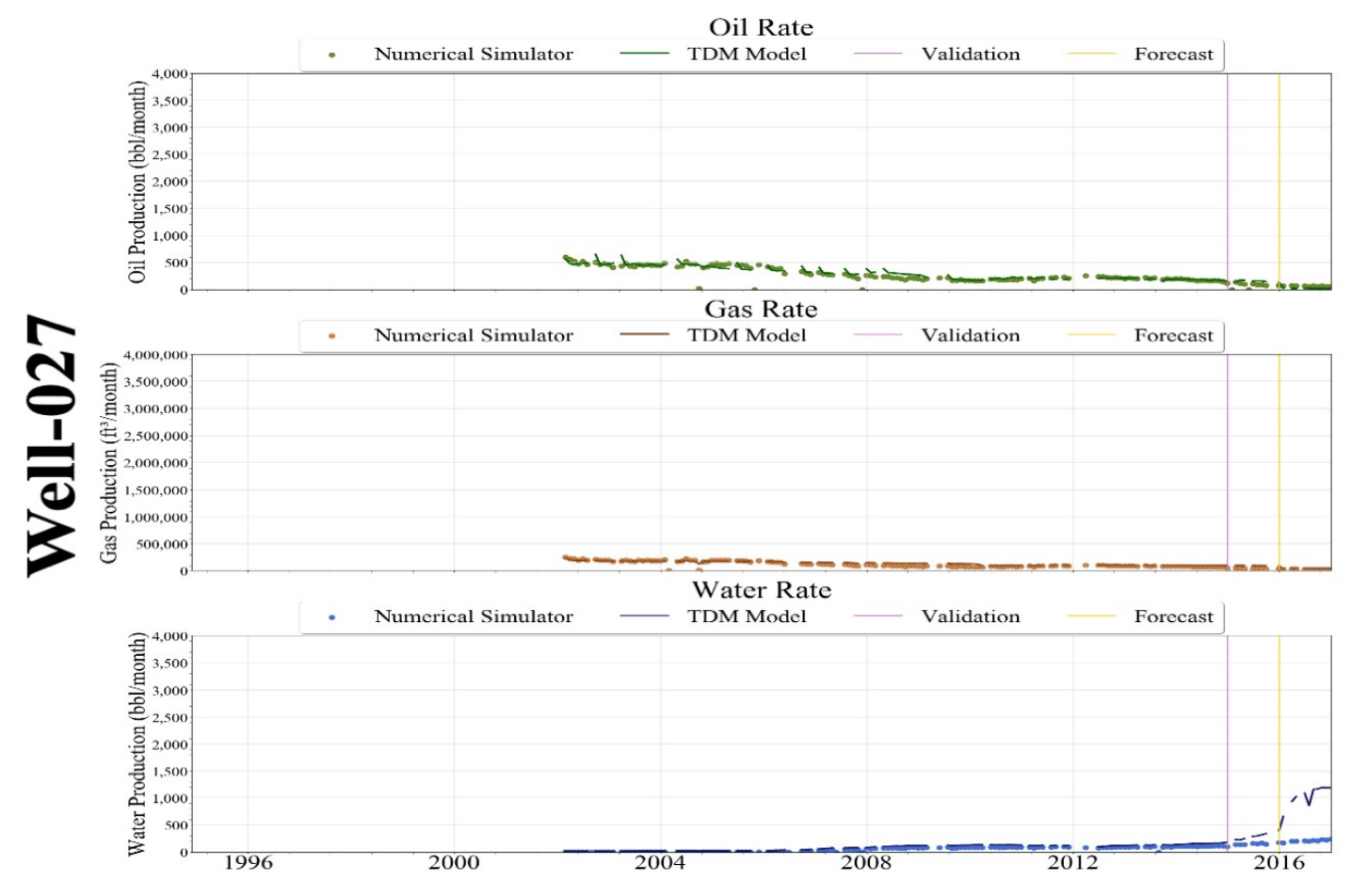

Figure 12-22: Scenario 4 - Well-027 Production History Match 


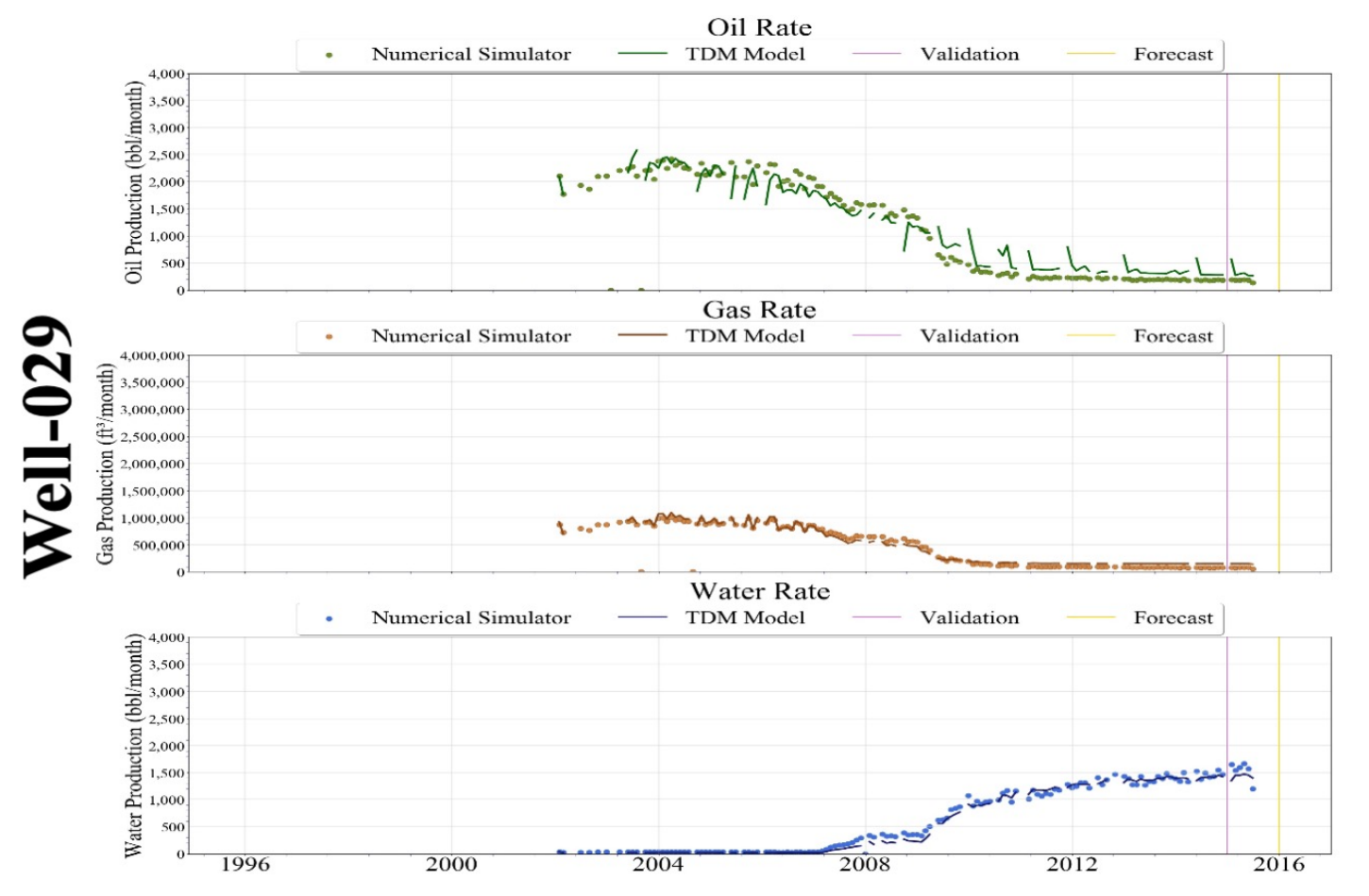

Figure 12-23: Scenario 4 - Well-029 Production History Match

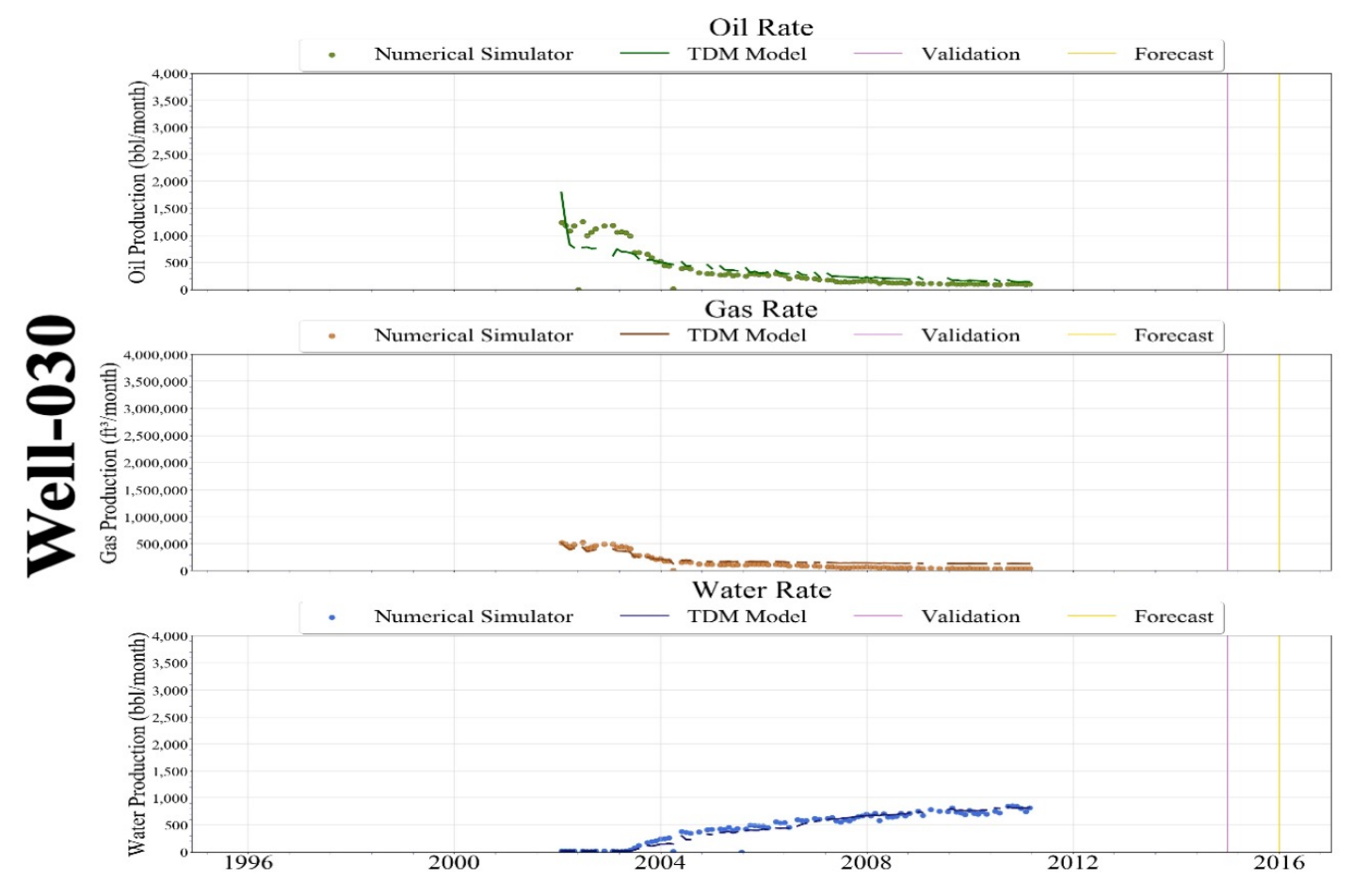

Figure 12-24: Scenario 4 - Well-030 Production History Match 


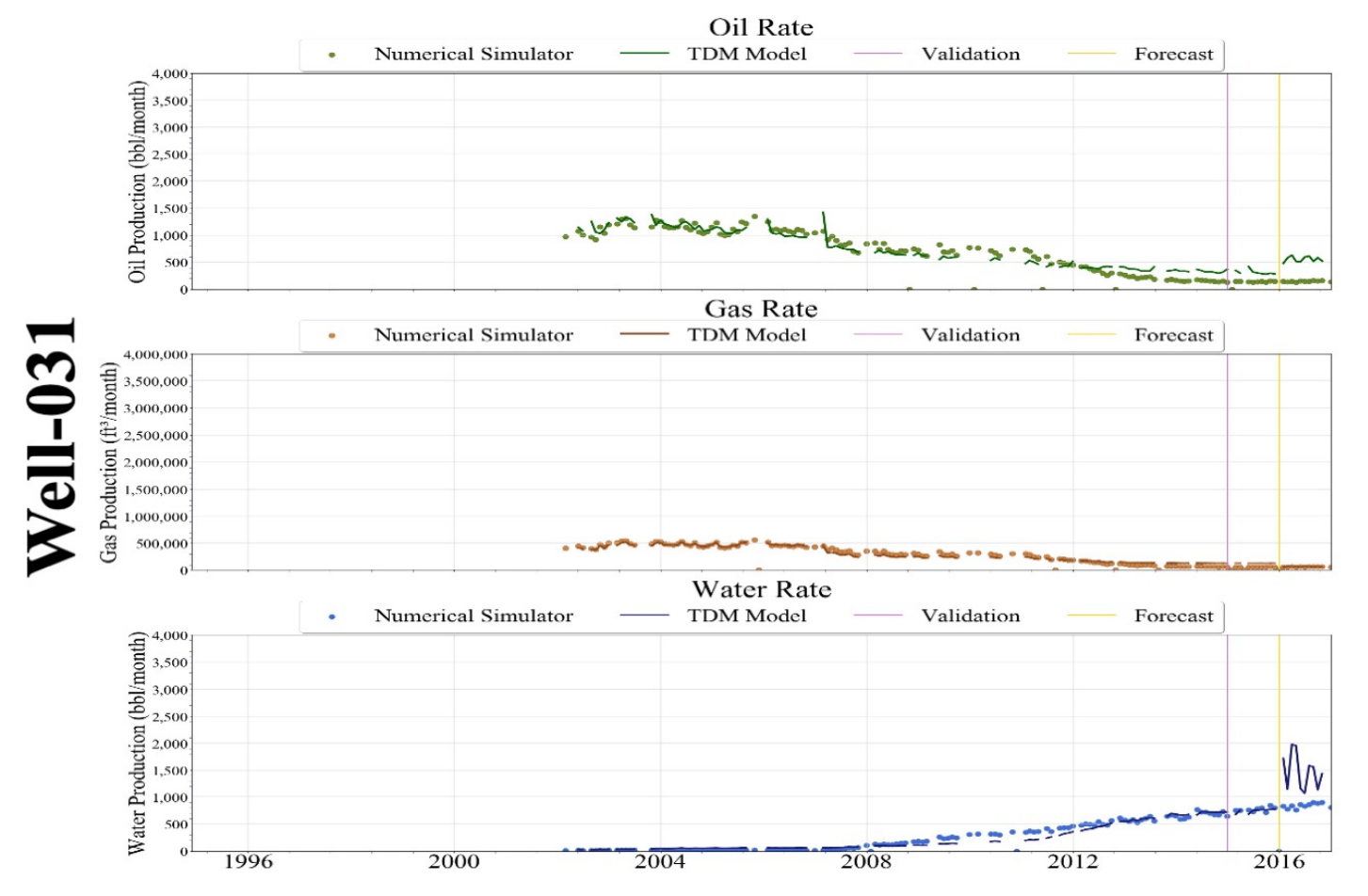

Figure 12-25: Scenario 4 - Well-031 Production History Match

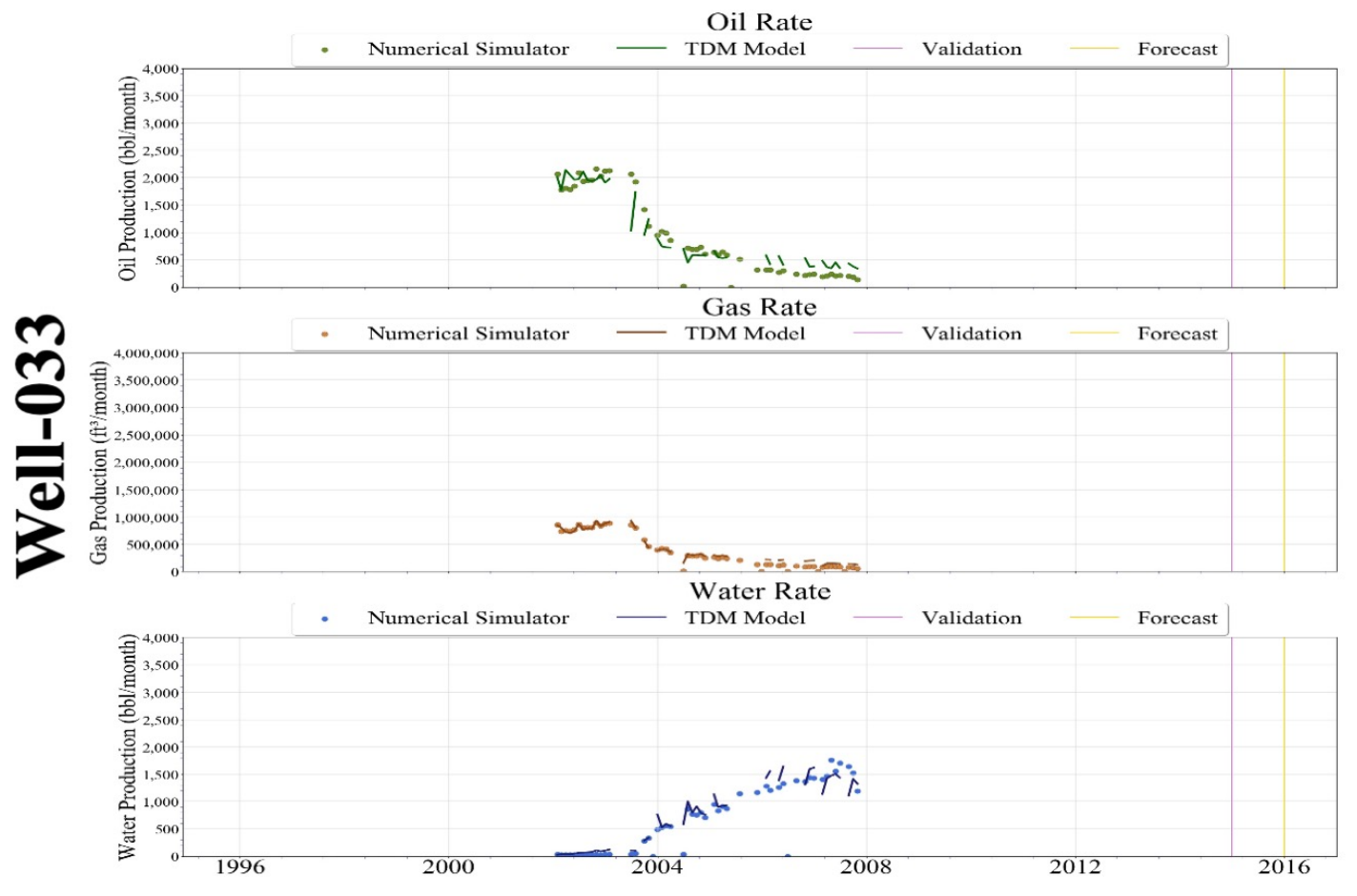

Figure 12-26: Scenario 4 - Well-033 Production History Match 


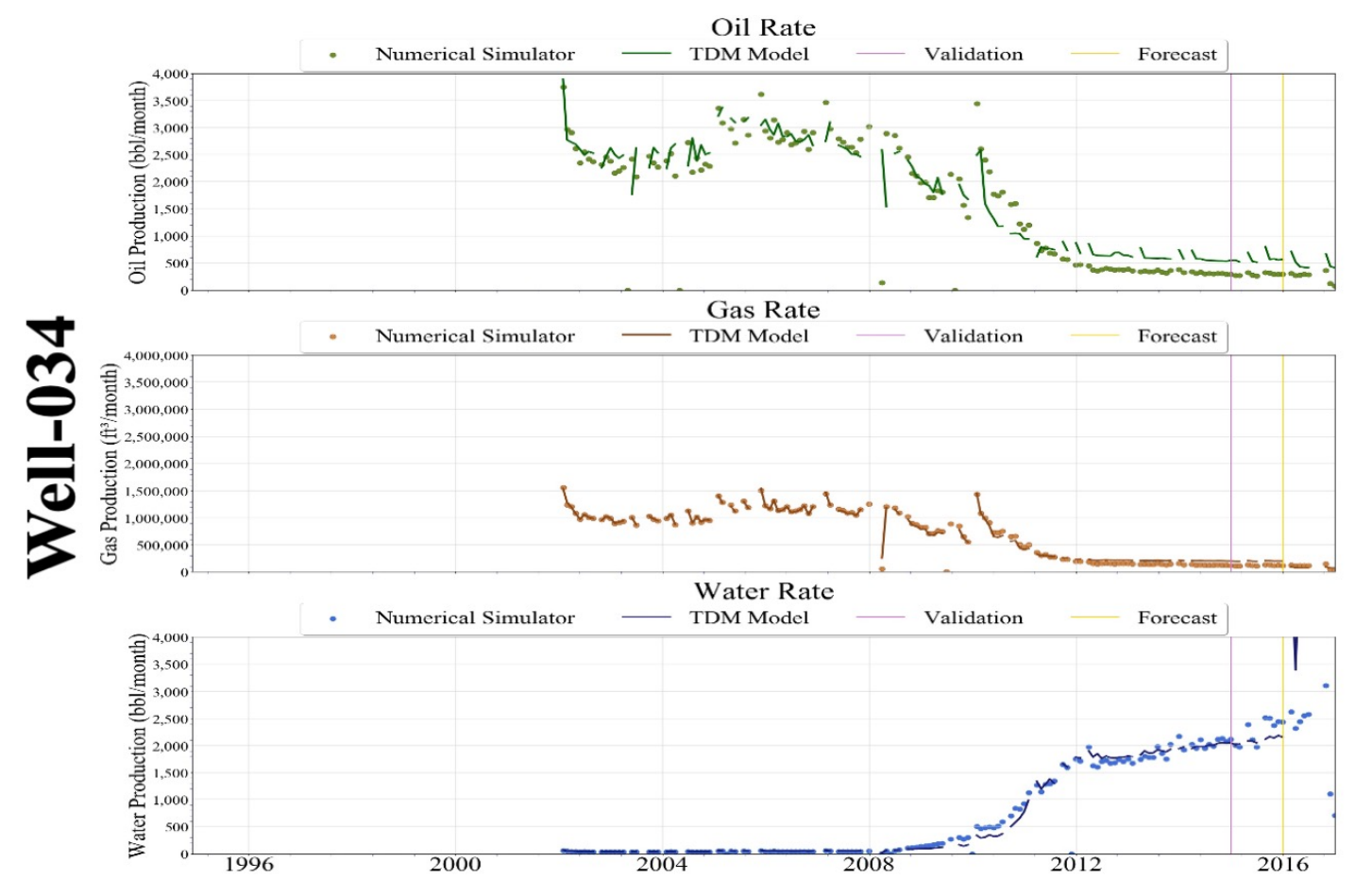

Figure 12-27: Scenario 4 - Well-034 Production History Match

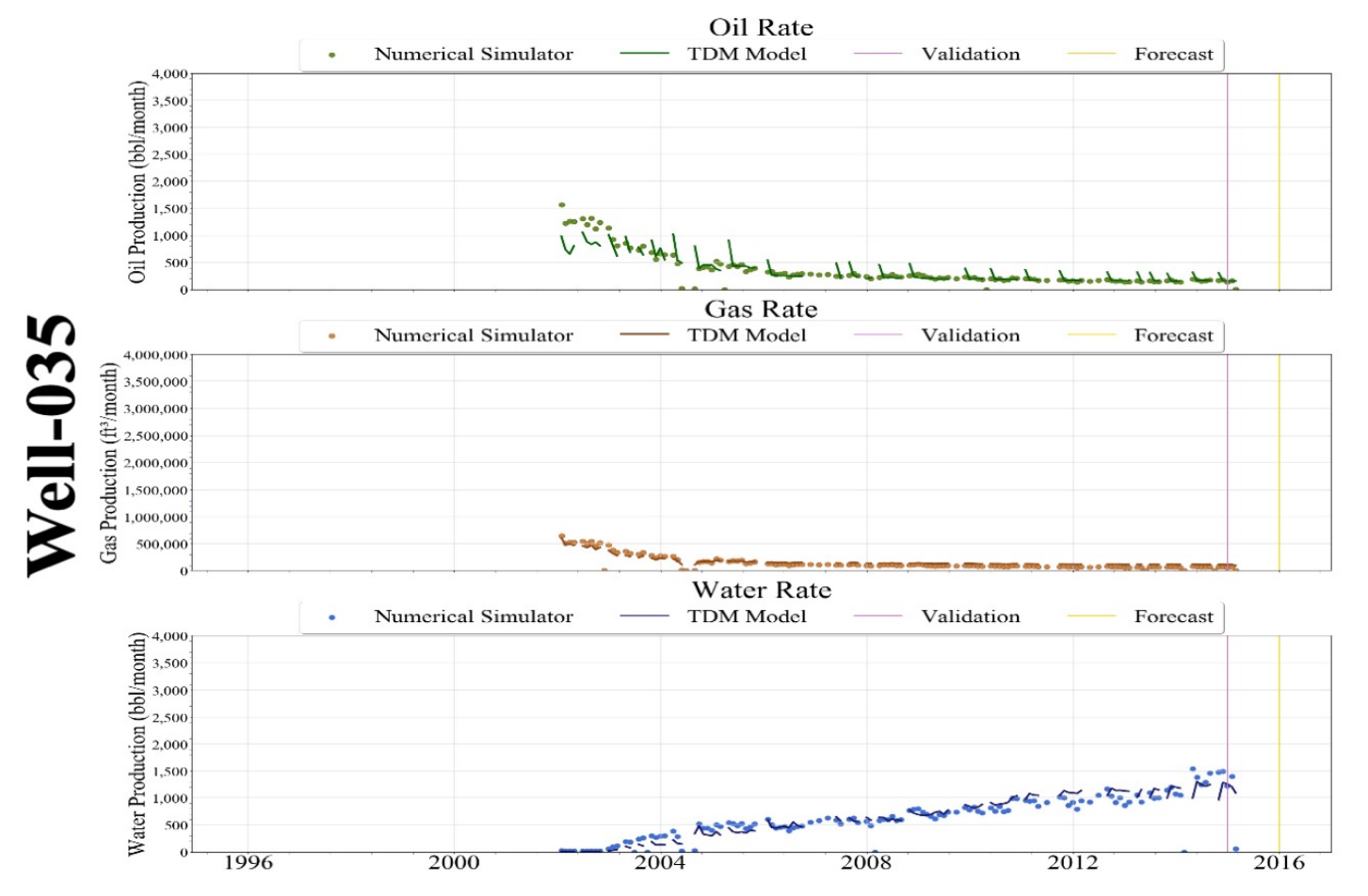

Figure 12-28: Scenario 4 - Well-035 Production History Match 


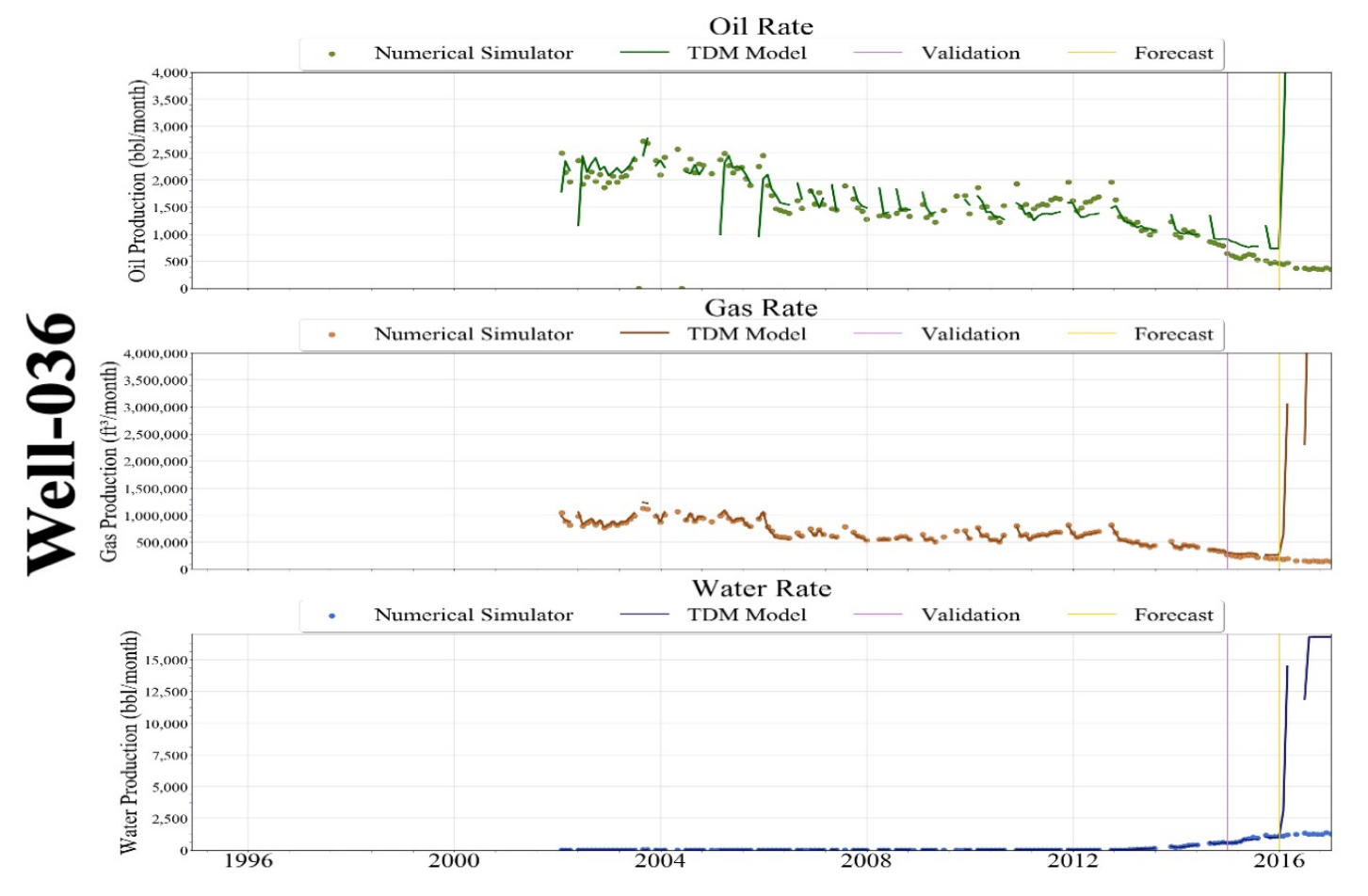

Figure 12-29: Scenario 4 - Well-036 Production History Match

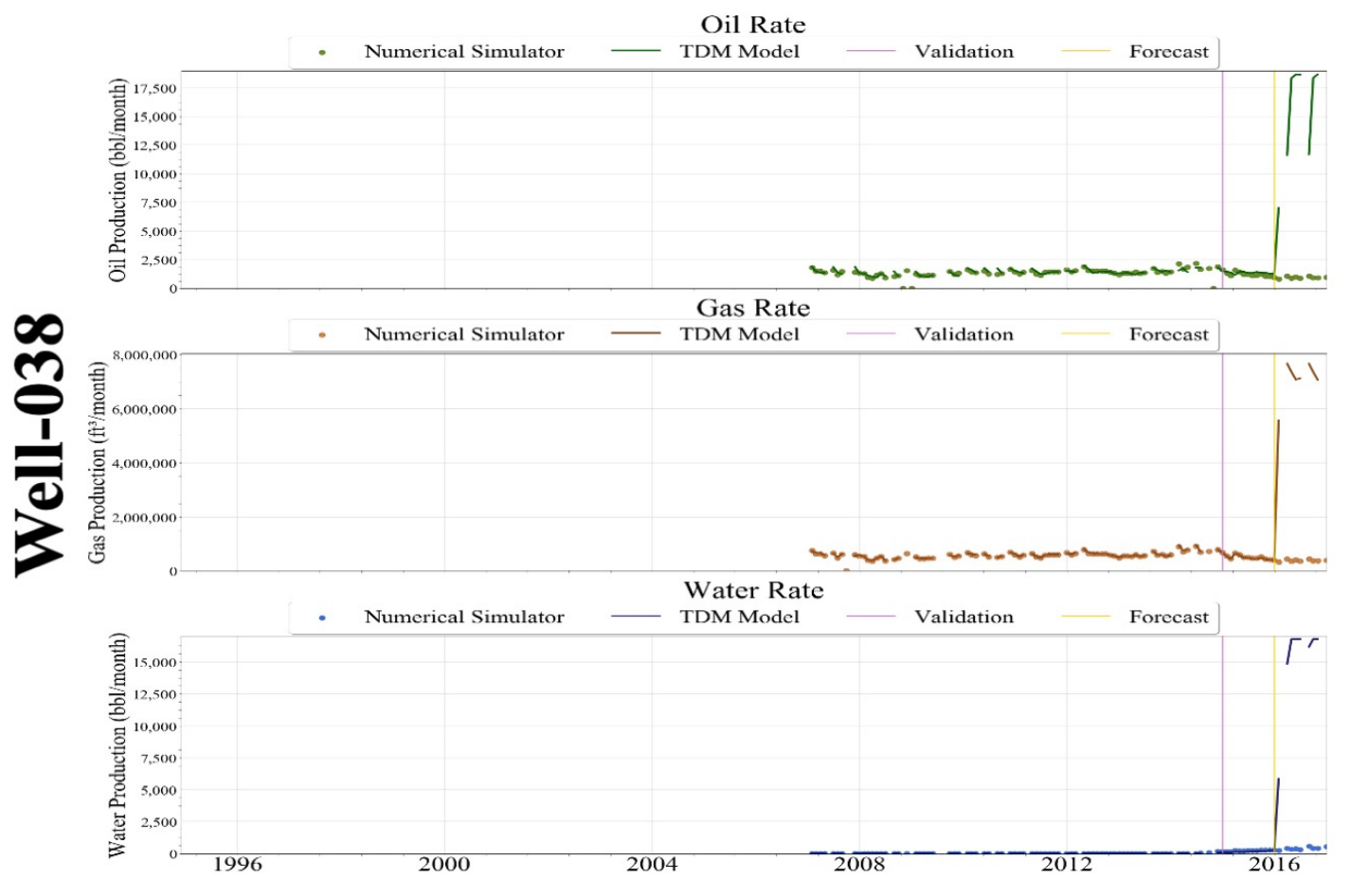

Figure 12-30: Scenario 4 - Well-038 Production History Match 


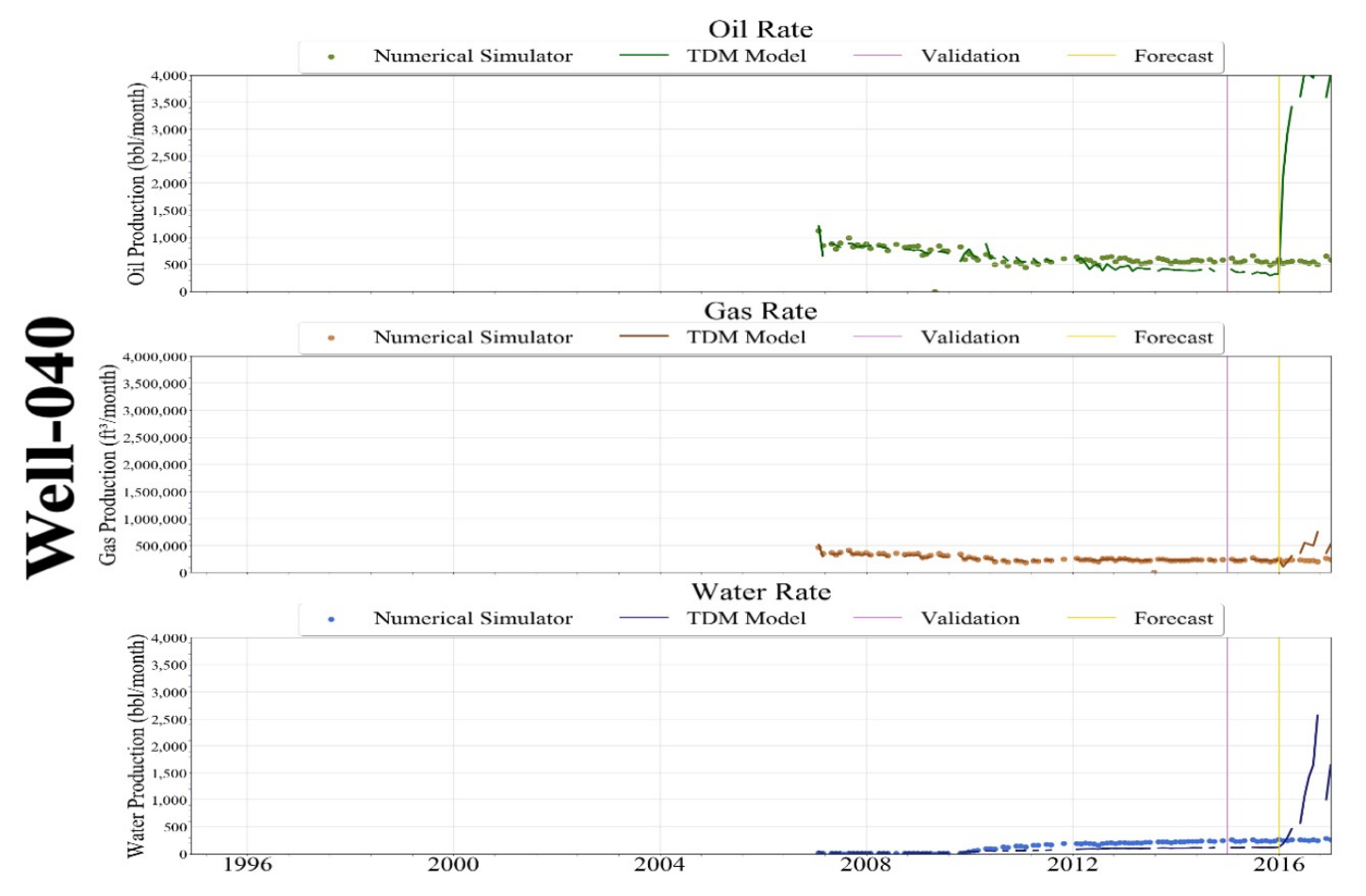

Figure 12-31: Scenario 4 - Well-040 Production History Match

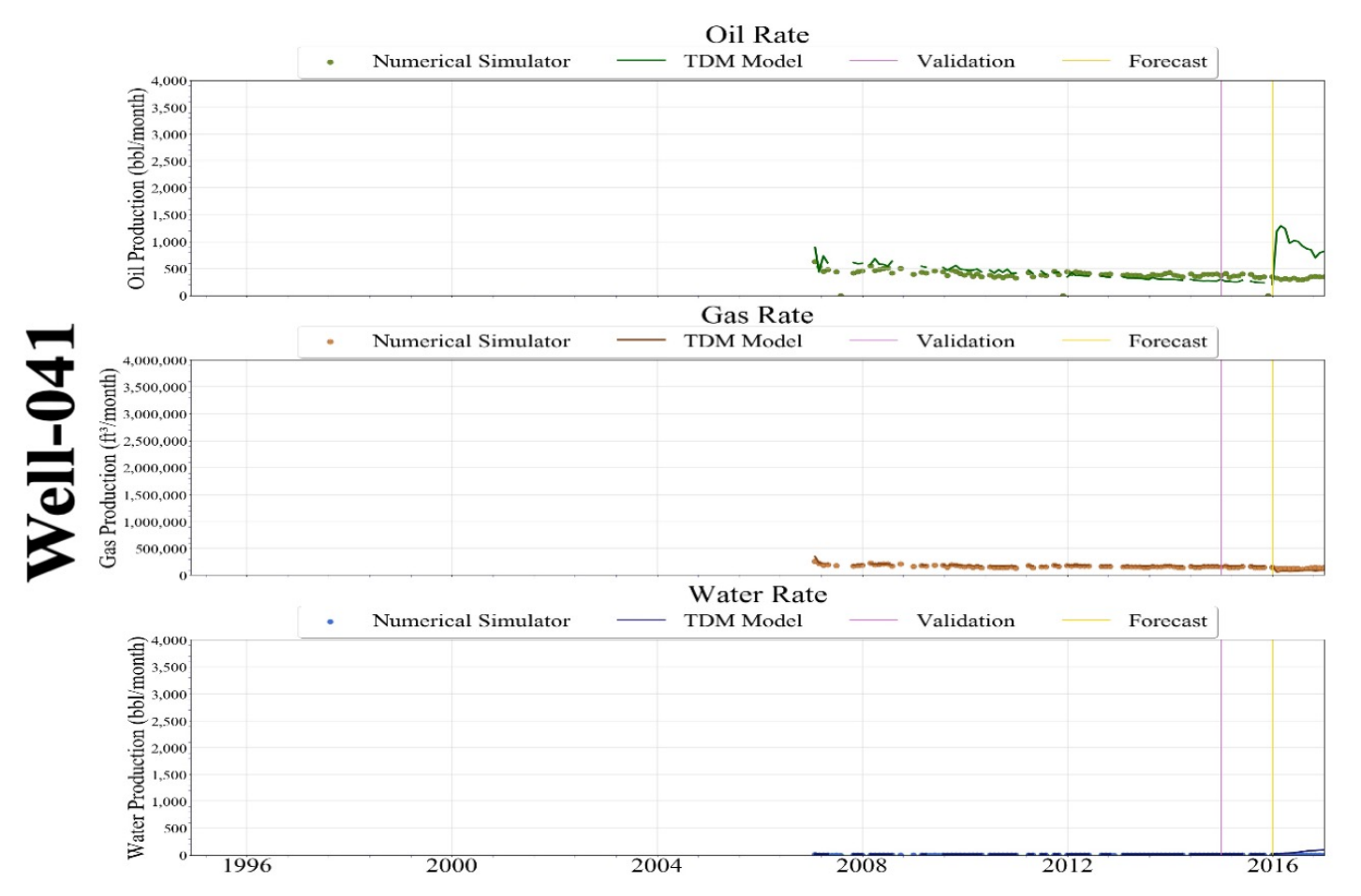

Figure 12-32: Scenario 4 - Well-041 Production History Match 


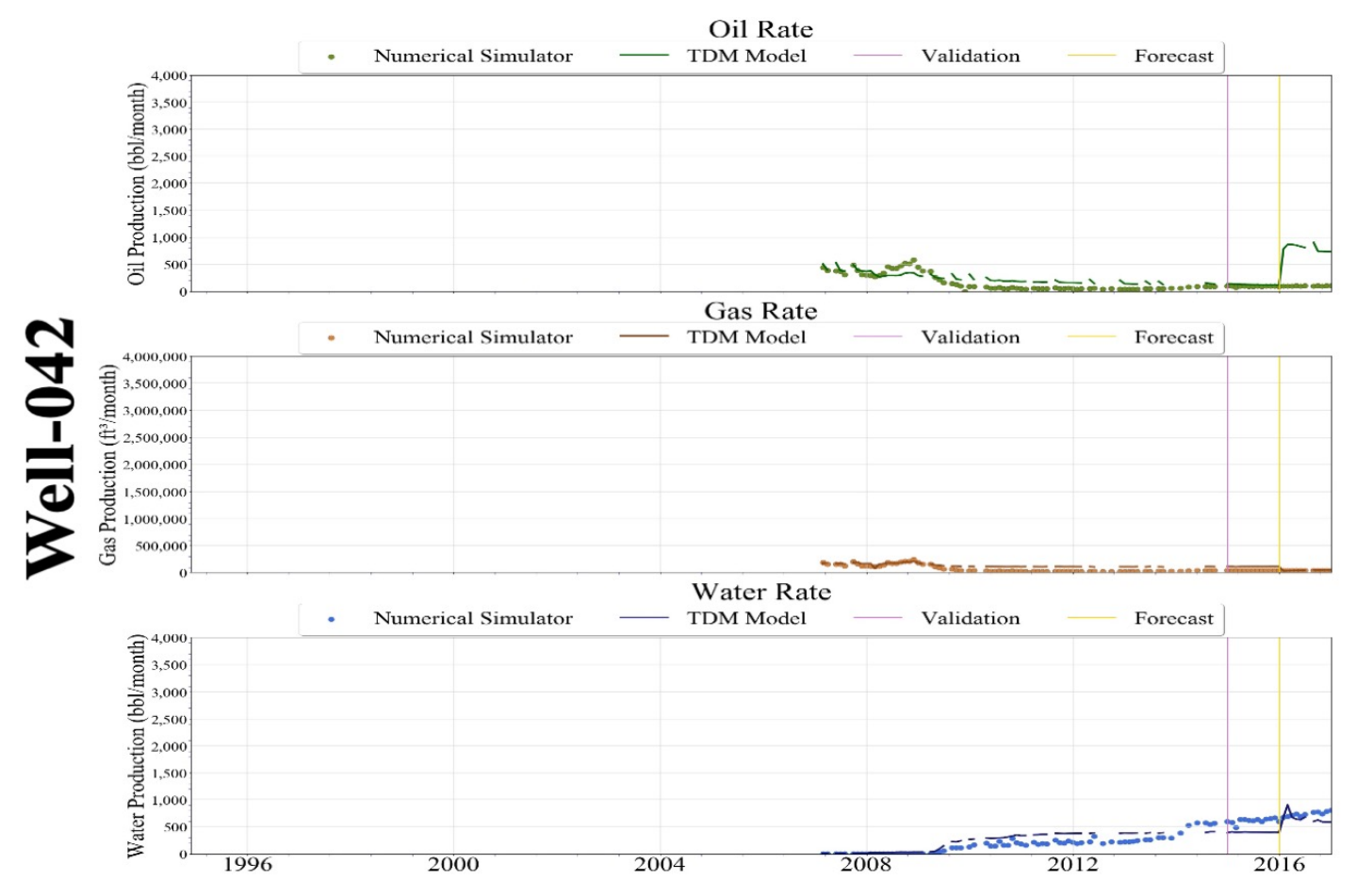

Figure 12-33: Scenario 4 - Well-042 Production History Match

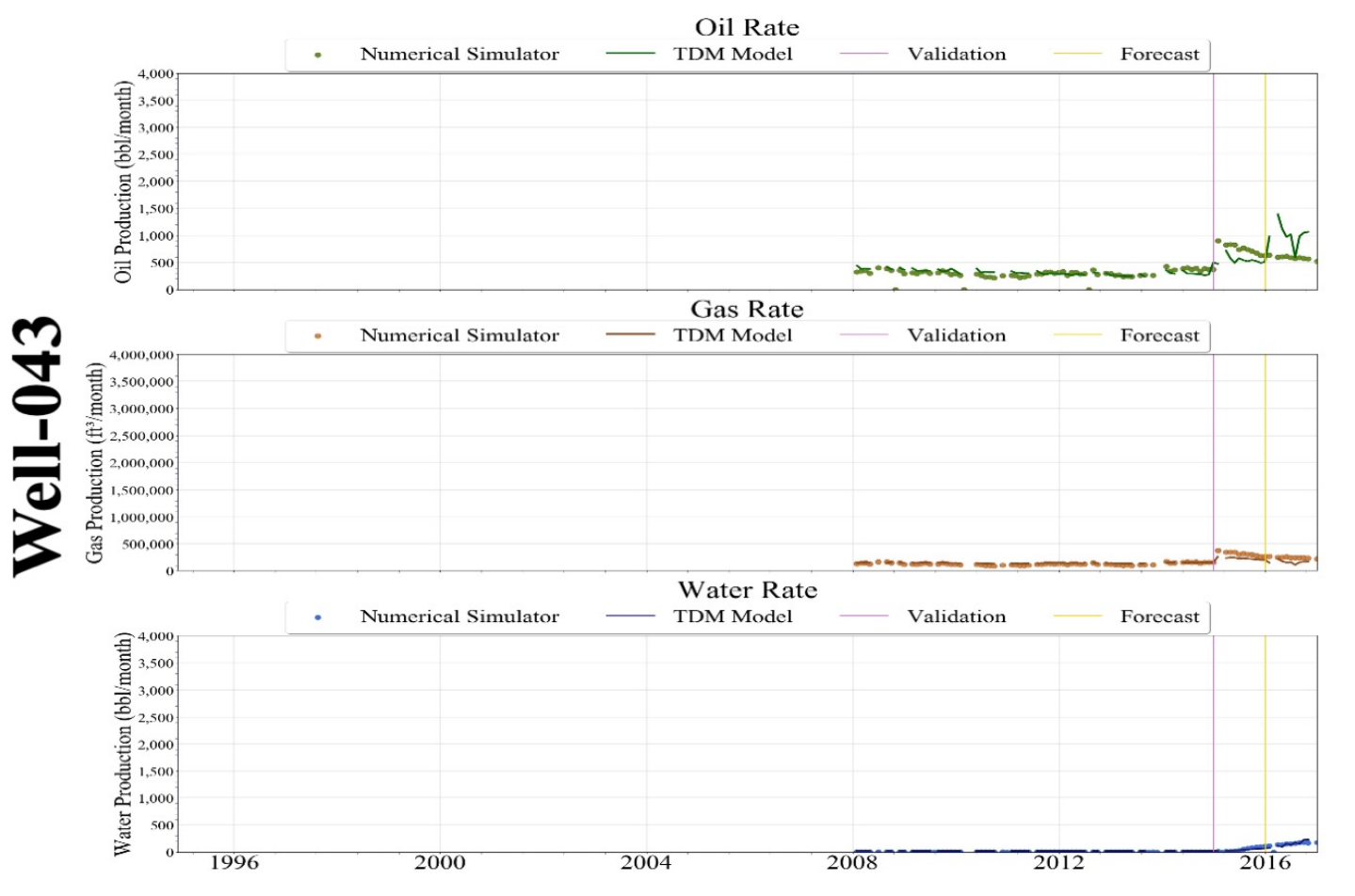

Figure 12-34: Scenario 4 - Well-043 Production History Match 


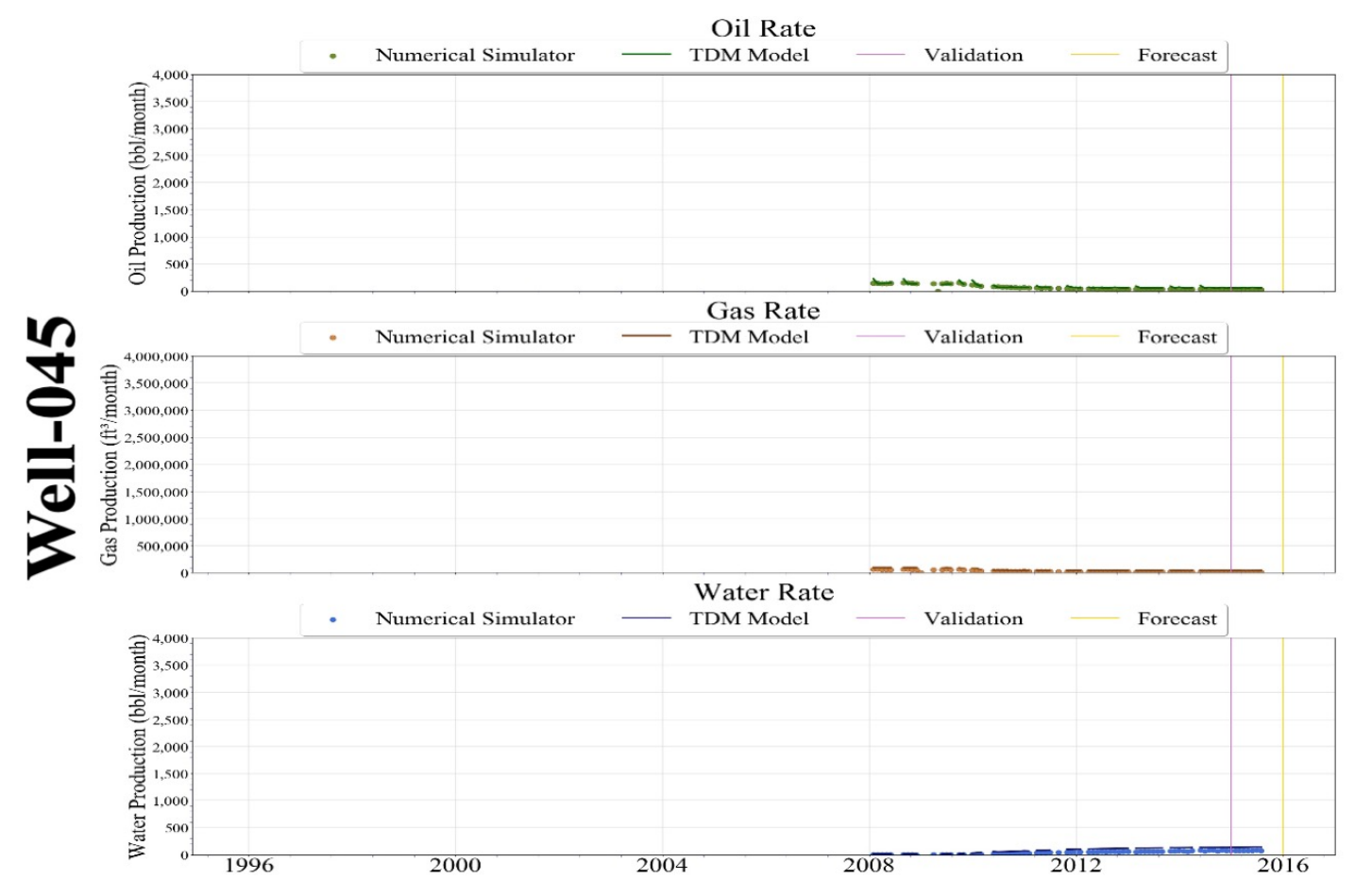

Figure 12-35: Scenario 4 - Well-045 Production History Match

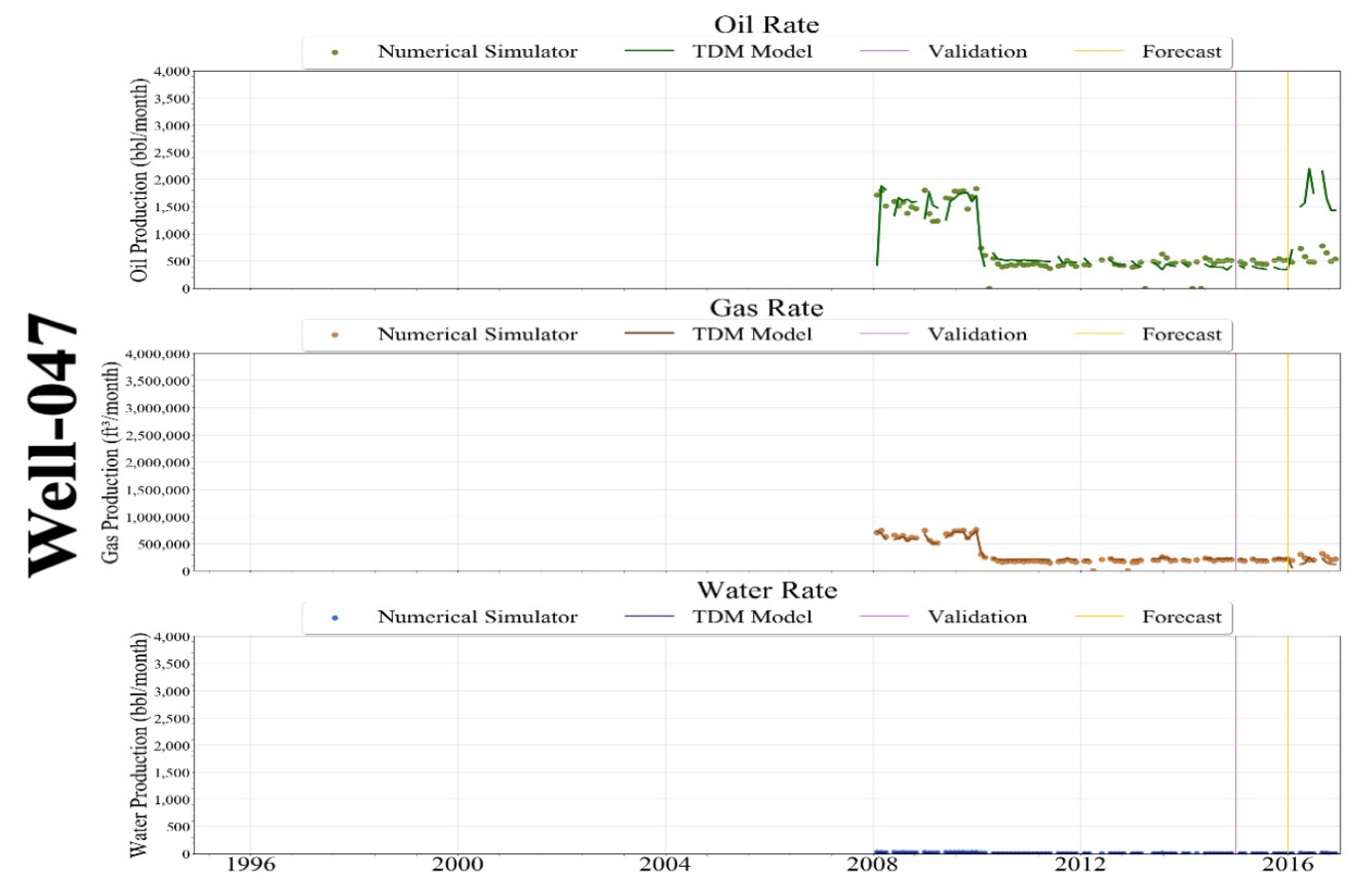

Figure 12-36: Scenario 4 - Well-047 Production History Match 


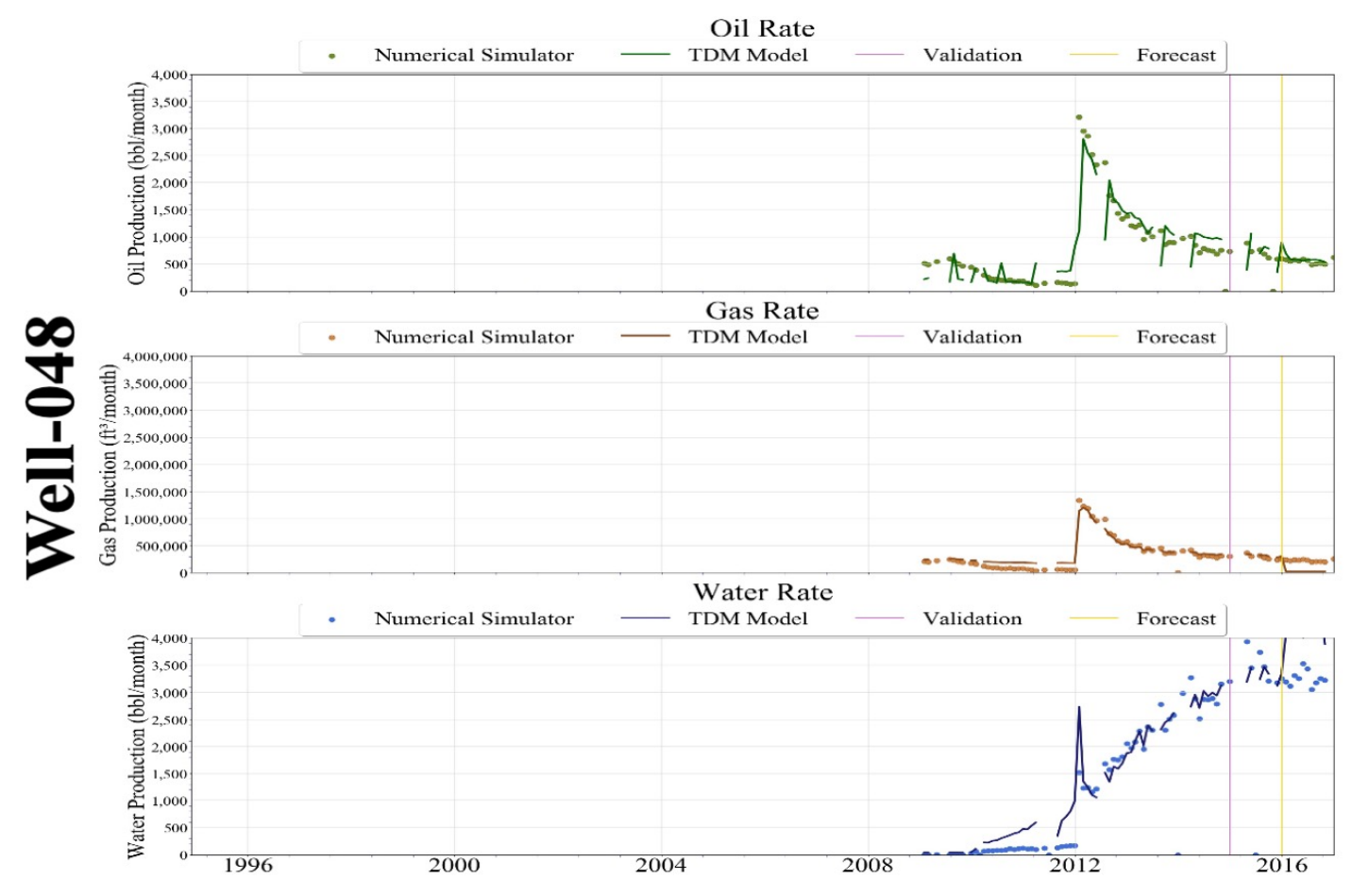

Figure 12-37: Scenario 4 - Well-048 Production History Match

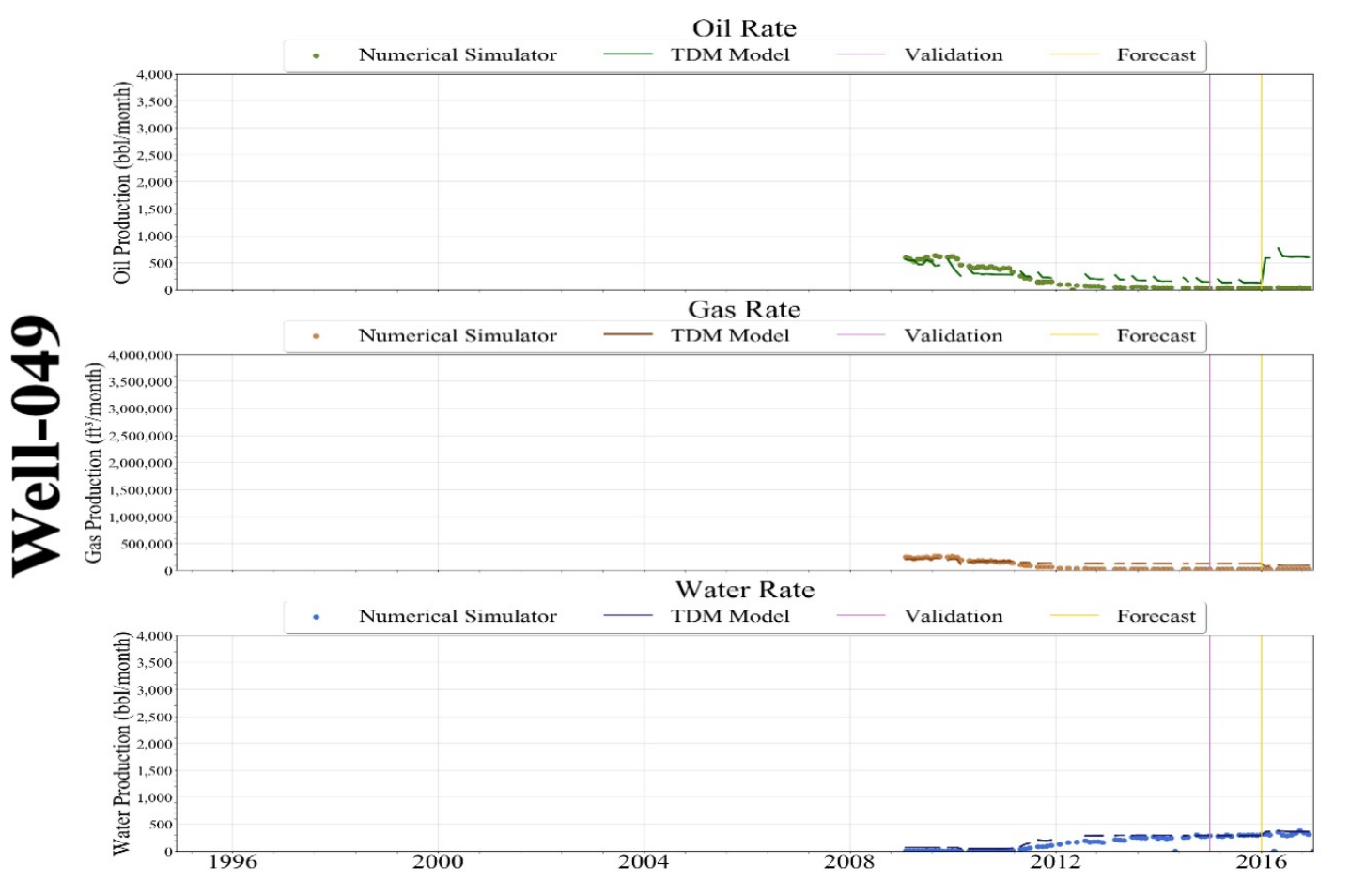

Figure 12-38: Scenario 4 - Well-049 Production History Match 


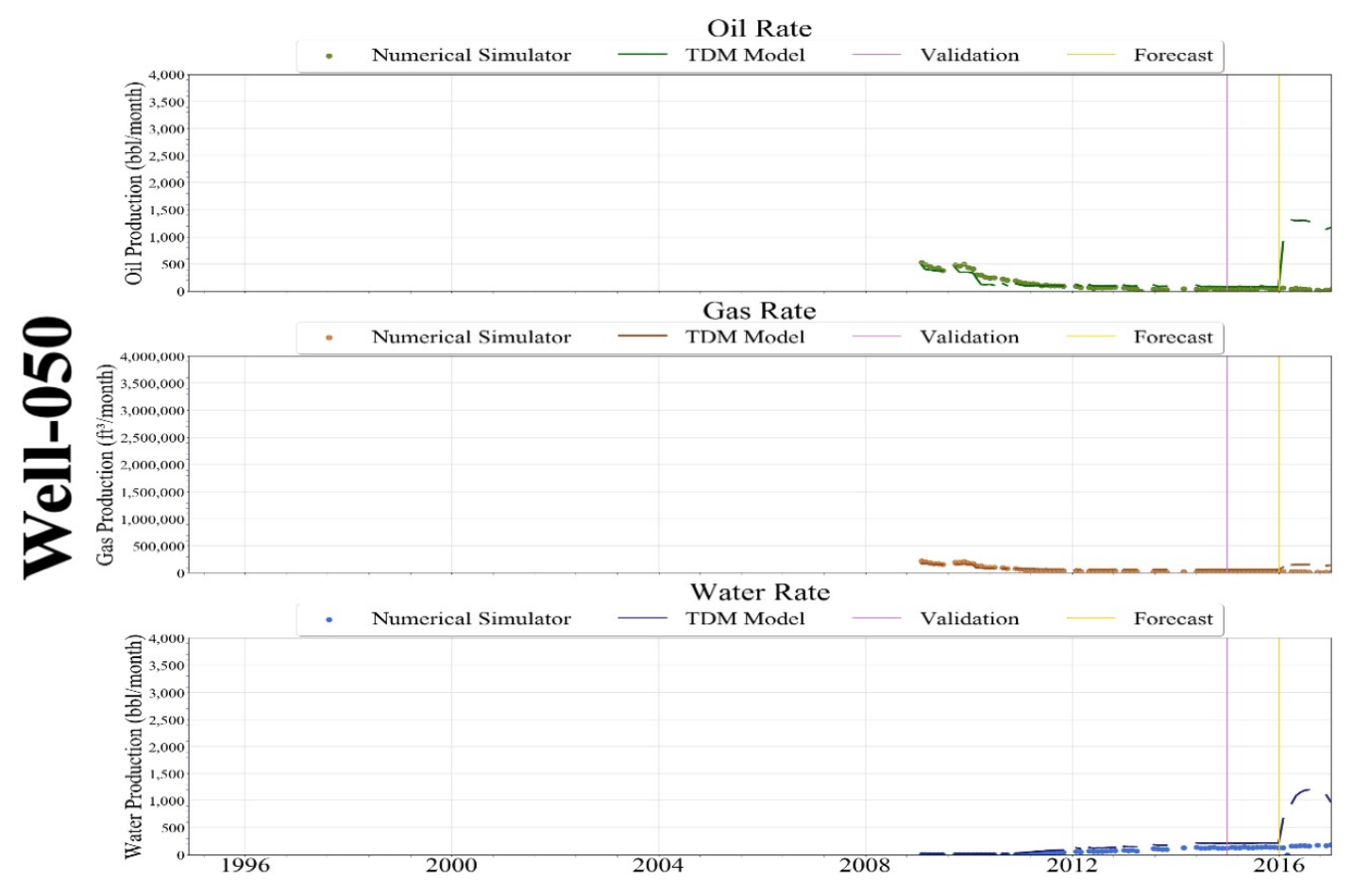

Figure 12-39: Scenario 4 - Well-050 Production History Match

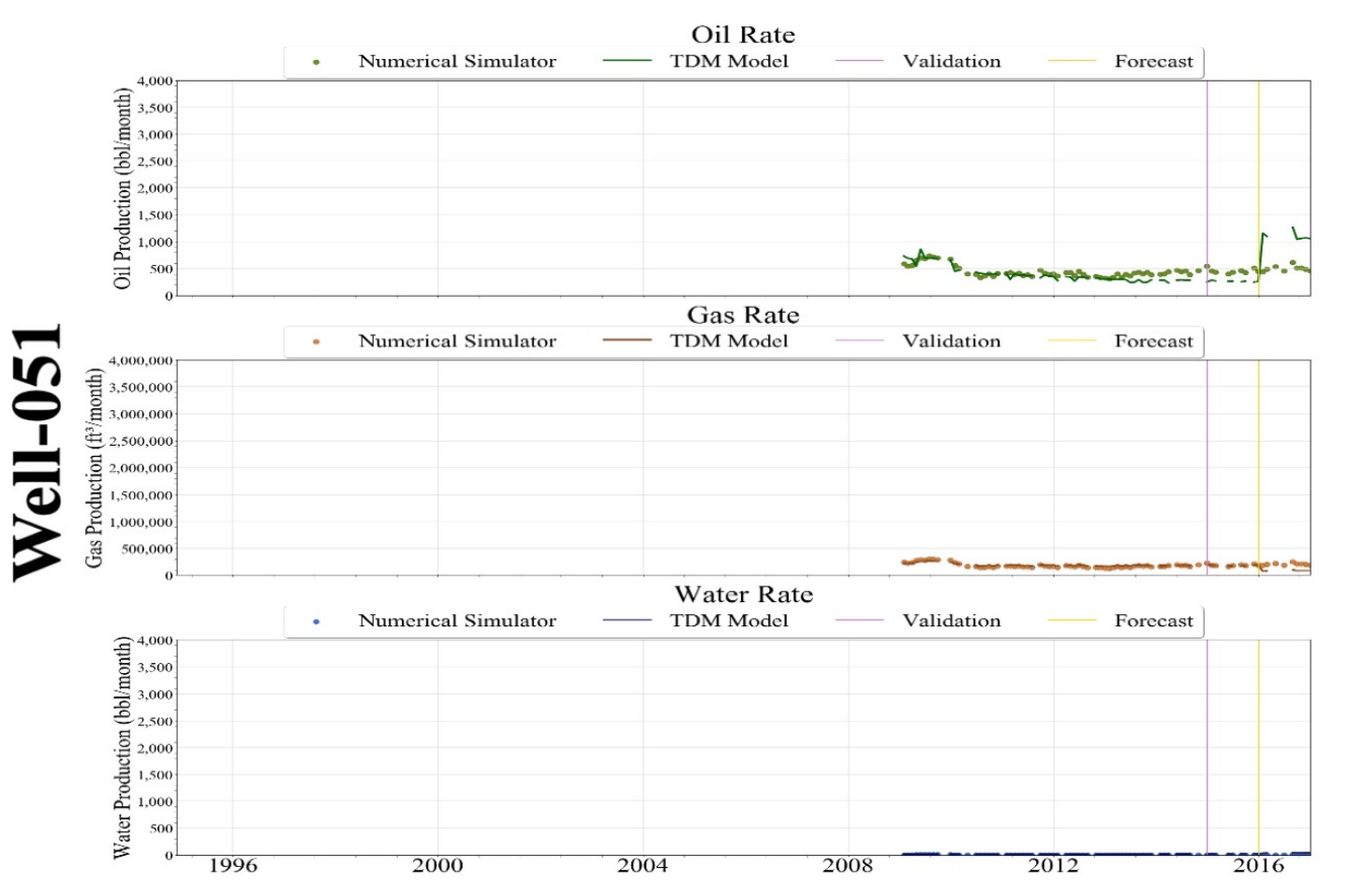

Figure 12-40: Scenario 4 - Well-051 Production History Match 


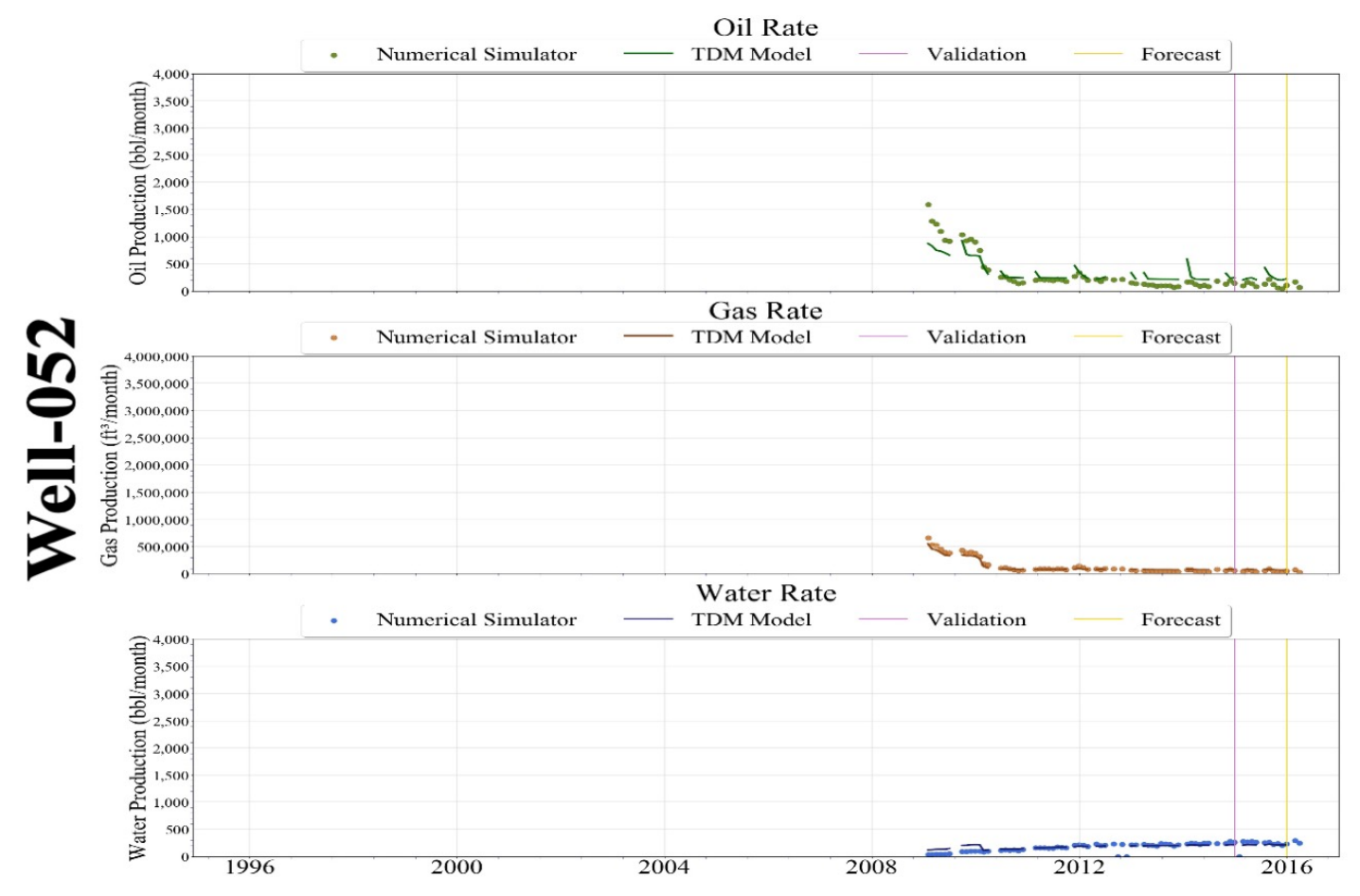

Figure 12-41: Scenario 4 - Well-052 Production History Match

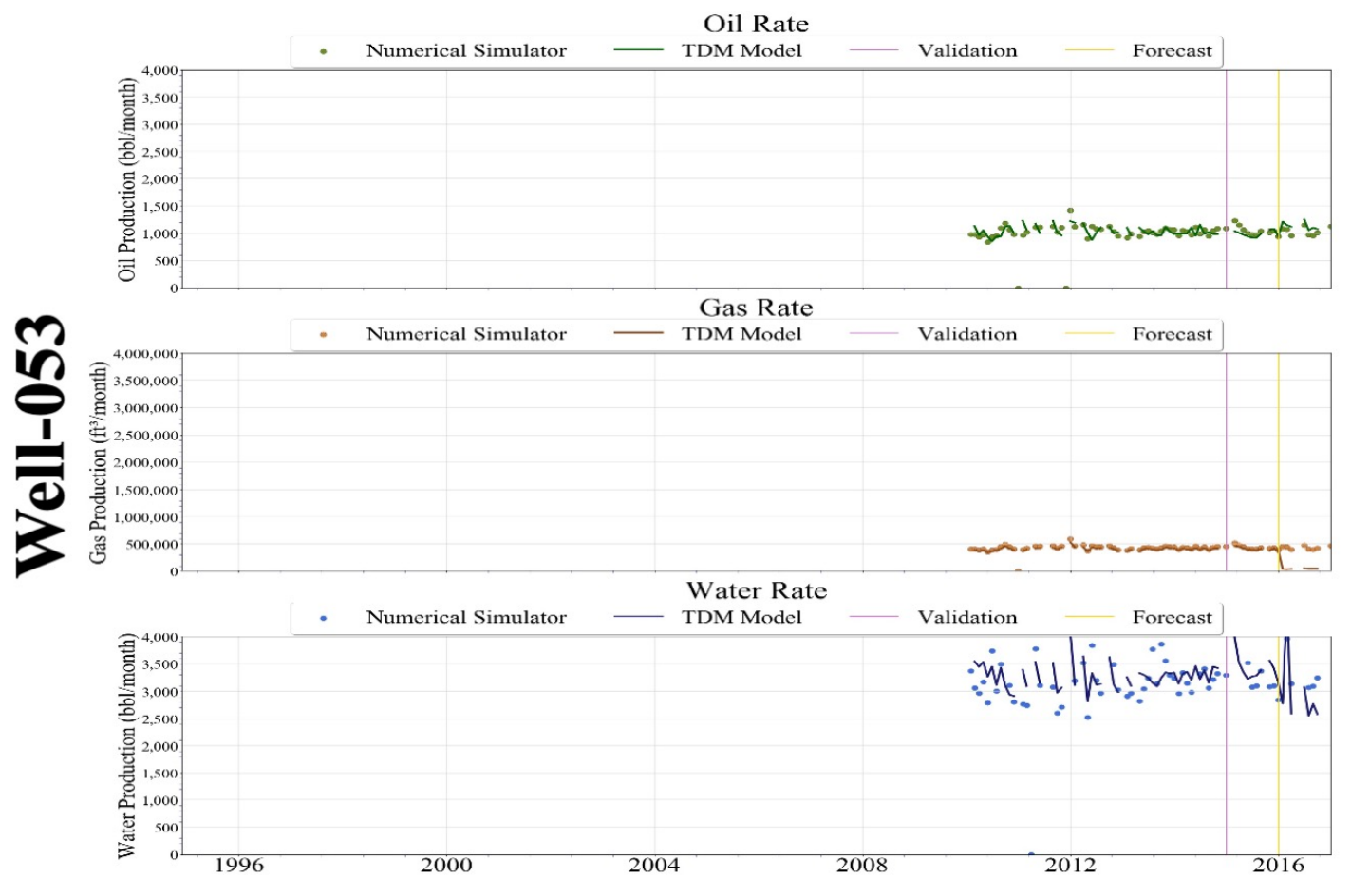

Figure 12-42: Scenario 4 - Well-053 Production History Match 


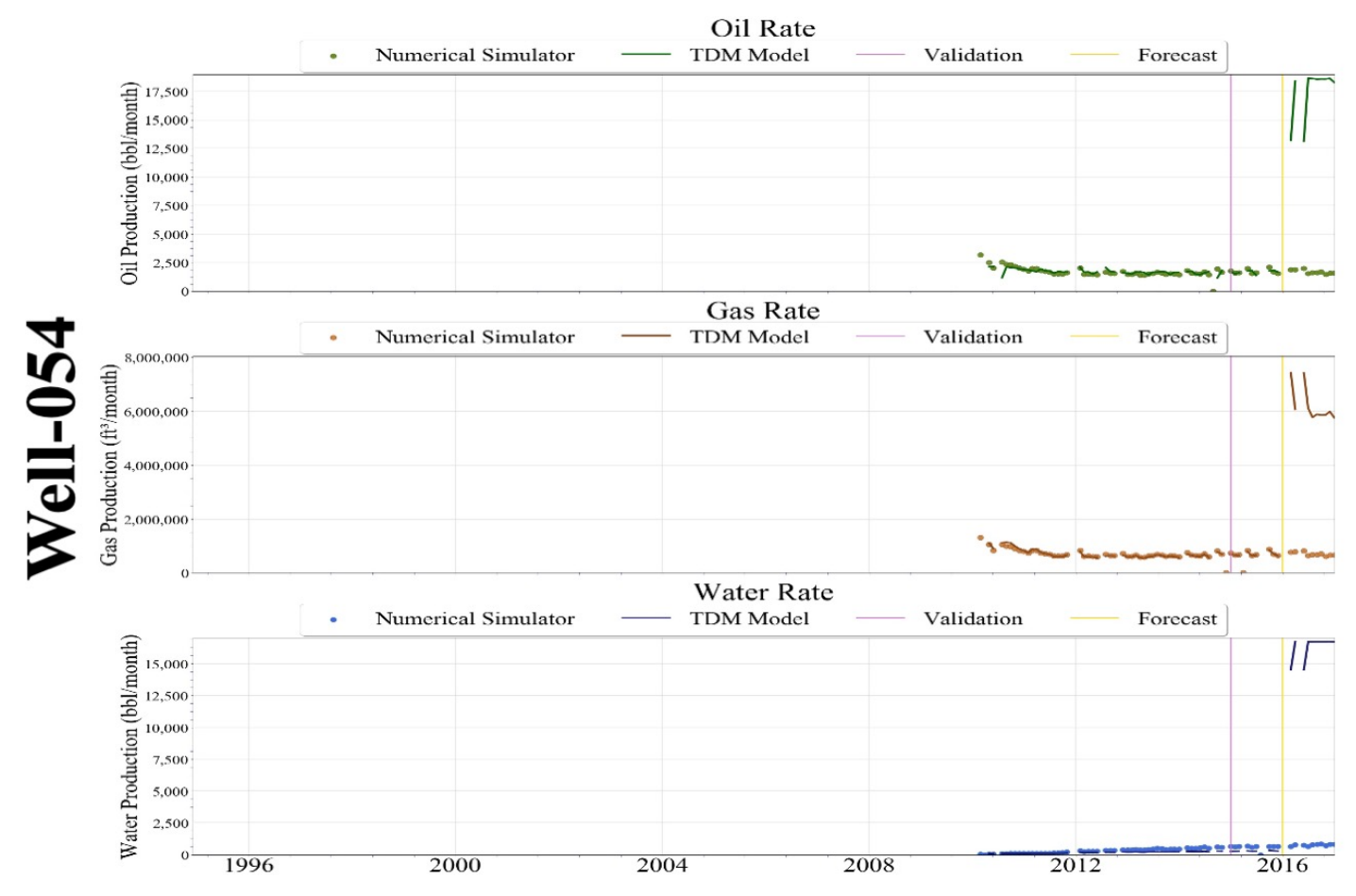

Figure 12-43: Scenario 4 - Well-054 Production History Match

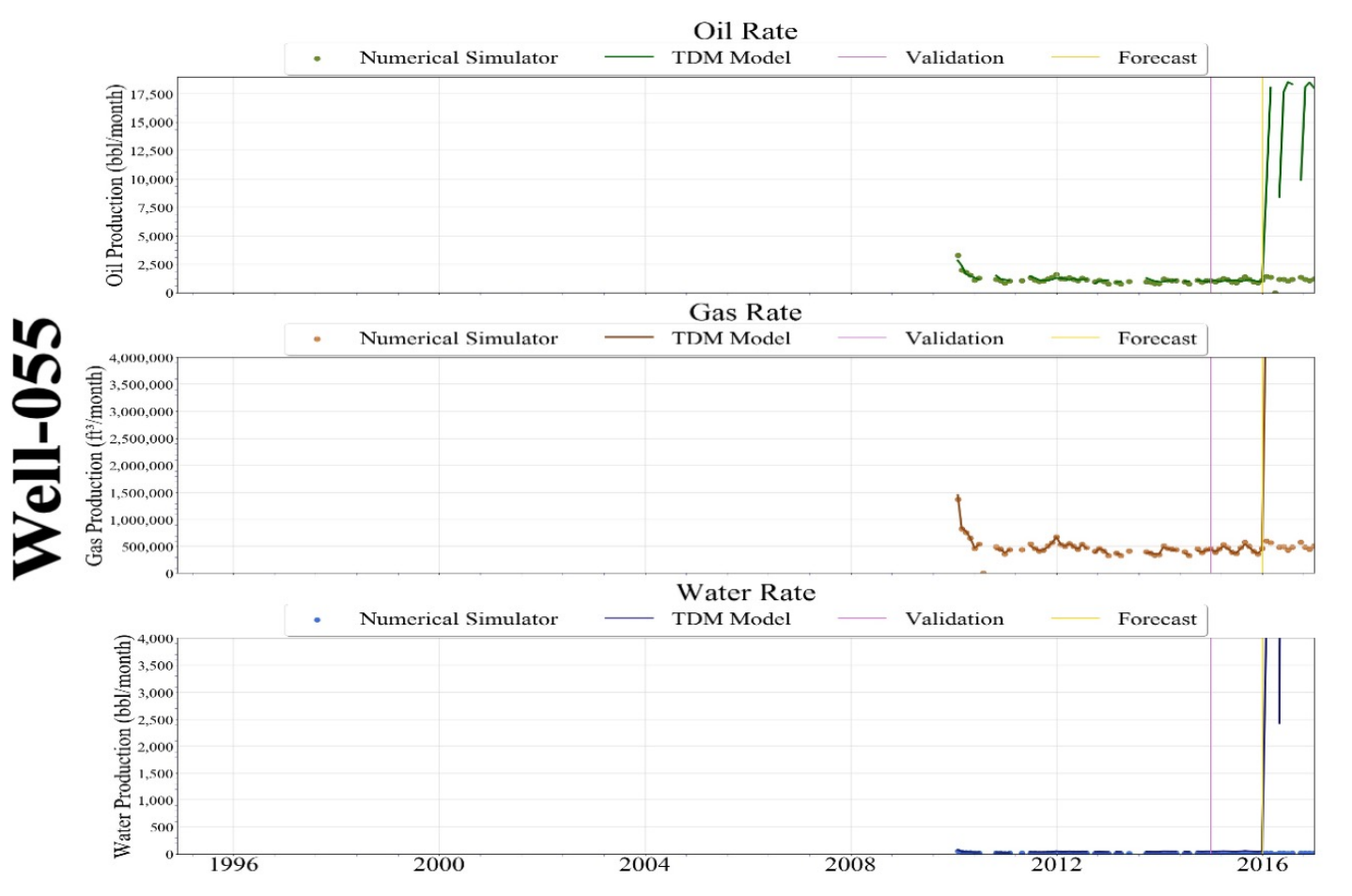

Figure 12-44: Scenario 4 - Well-055 Production History Match 


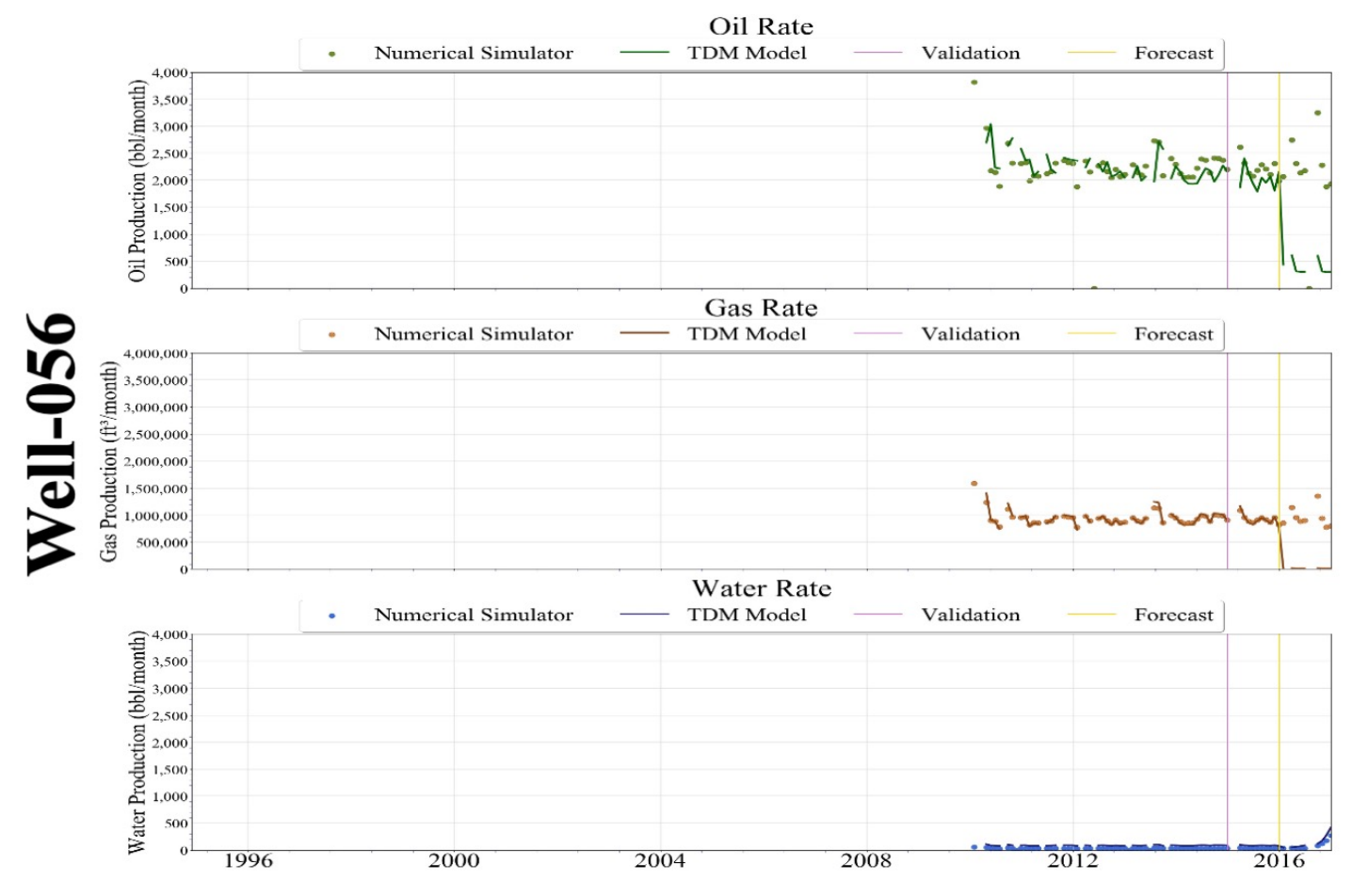

Figure 12-45: Scenario 4 - Well-056 Production History Match

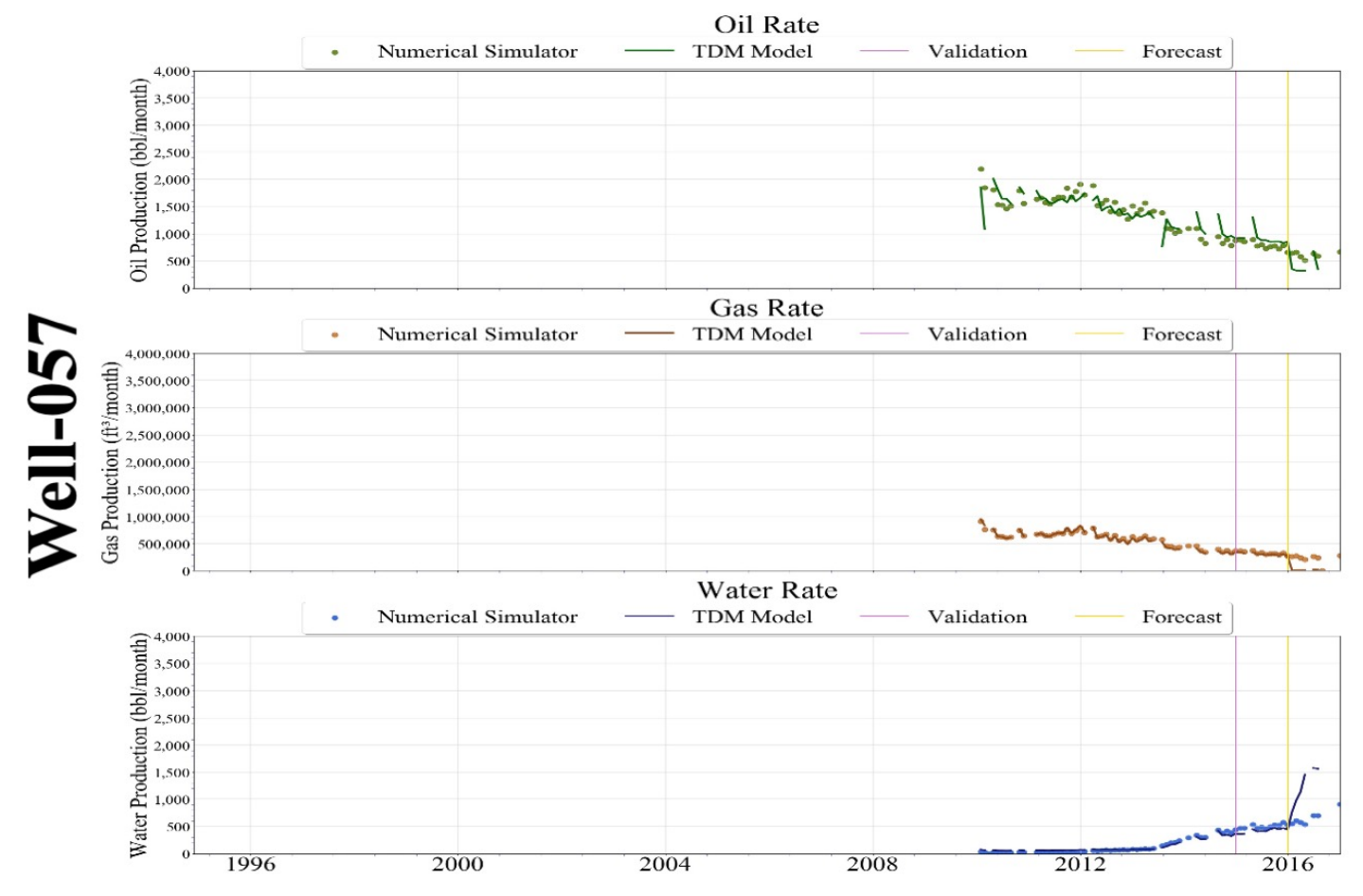

Figure 12-46: Scenario 4 - Well-057 Production History Match 


\subsubsection{Average History Match of Production}

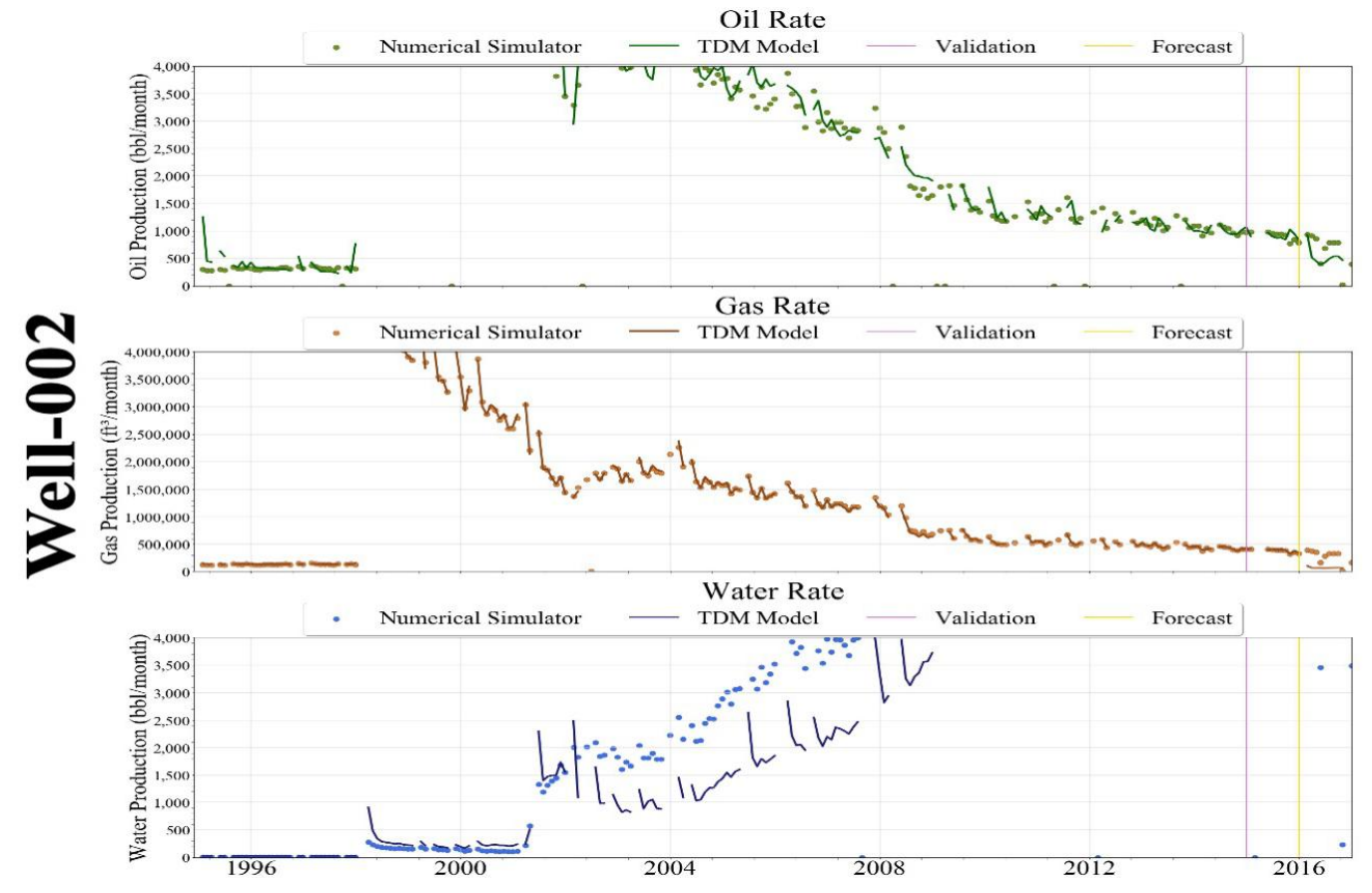

Figure 12-47: Scenario 4 - Well-002 Production History Match

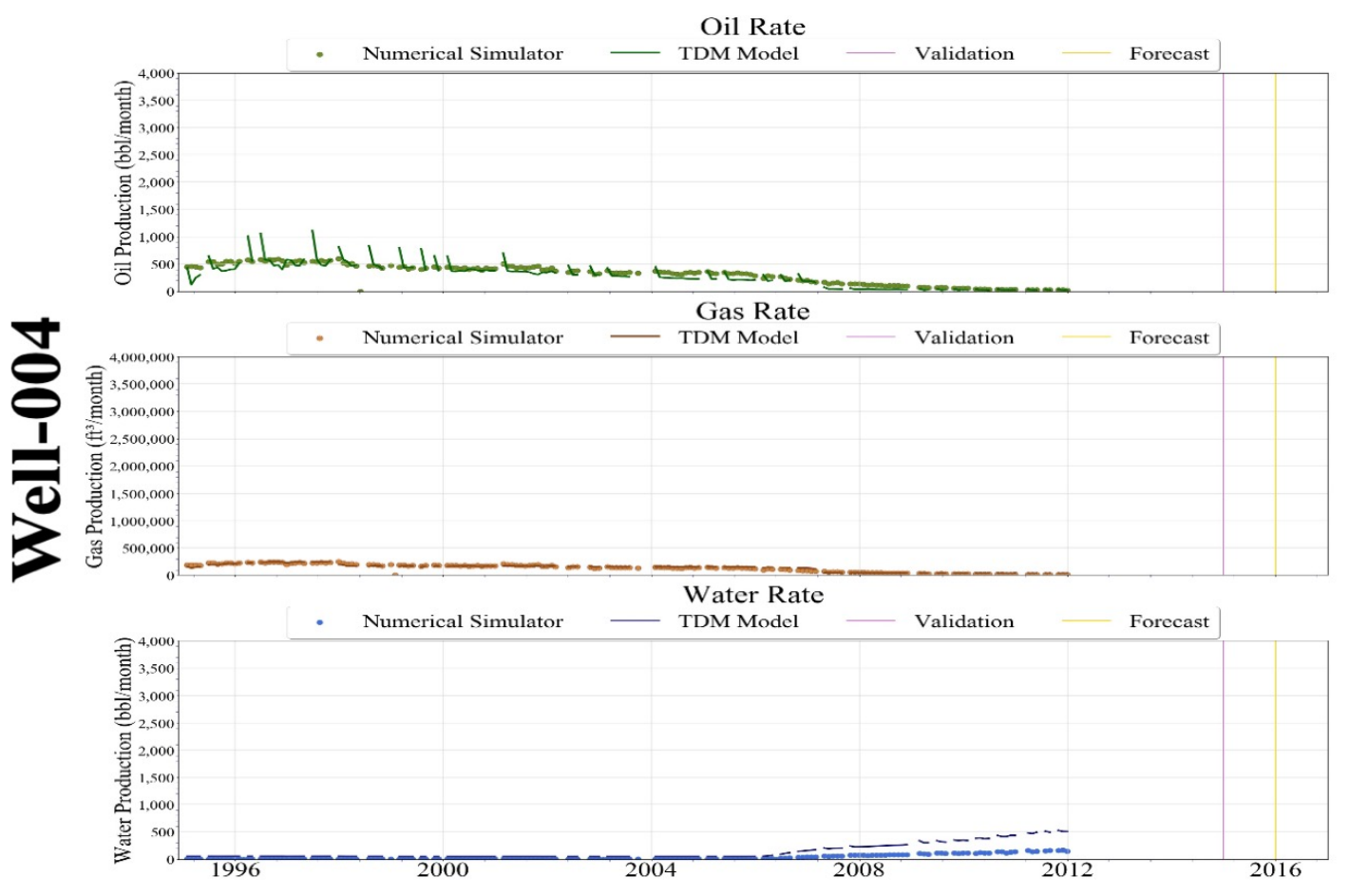

Figure 12-48: Scenario 4 - Well-004 Production History Match 


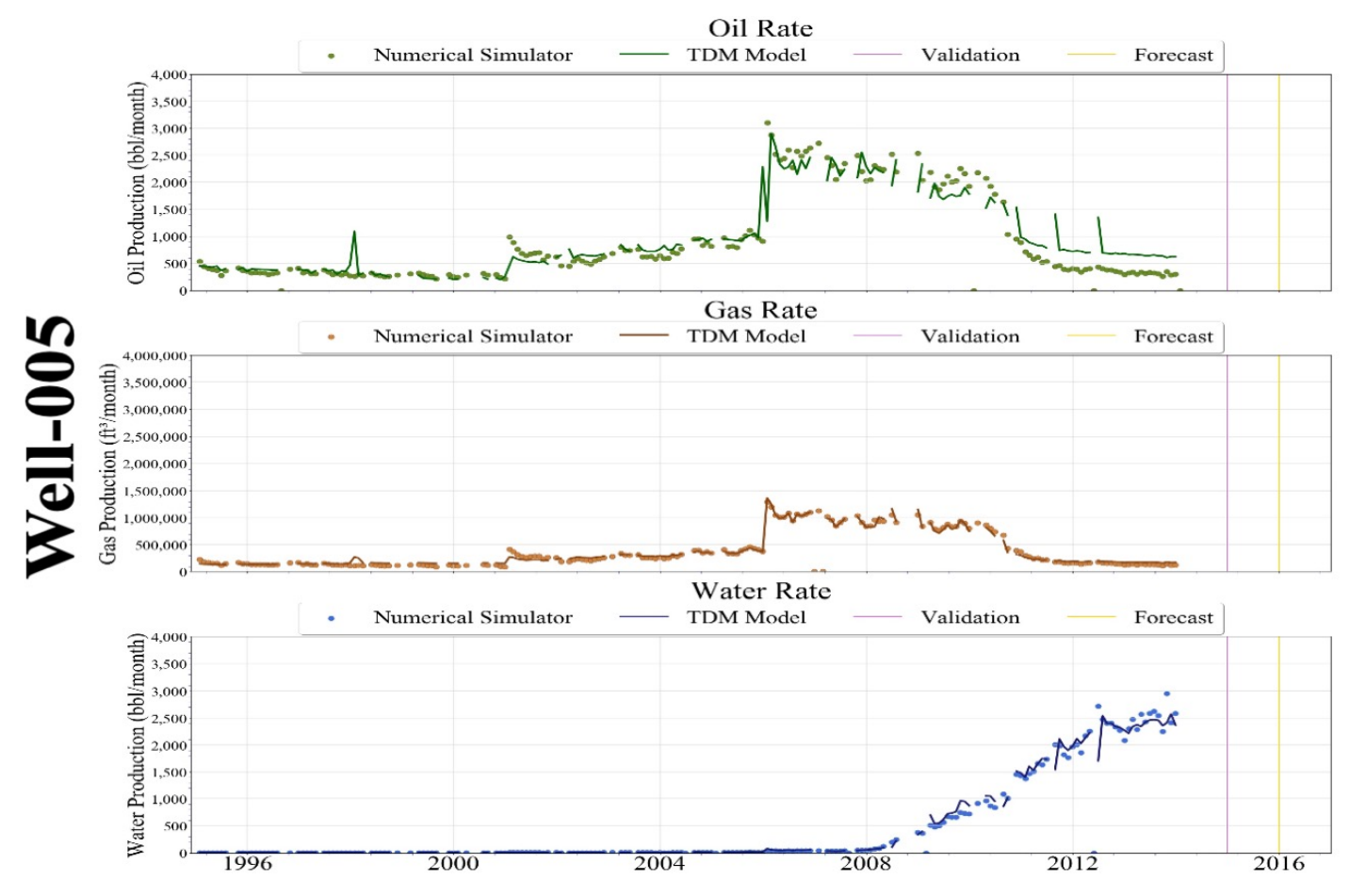

Figure 12-49: Scenario 4 - Well-005 Production History Match

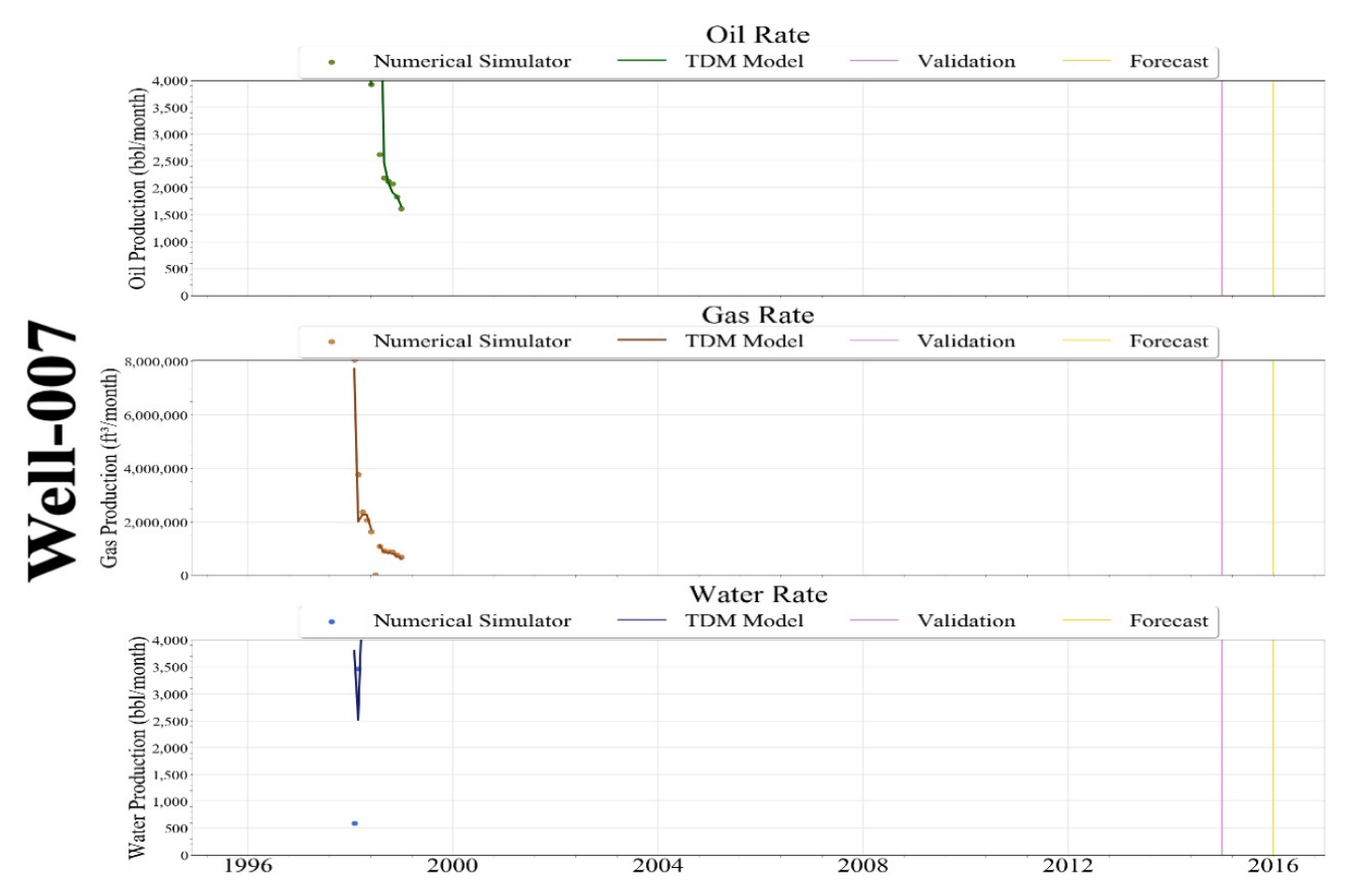

Figure 12-50: Scenario 4 - Well-007 Production History Match 


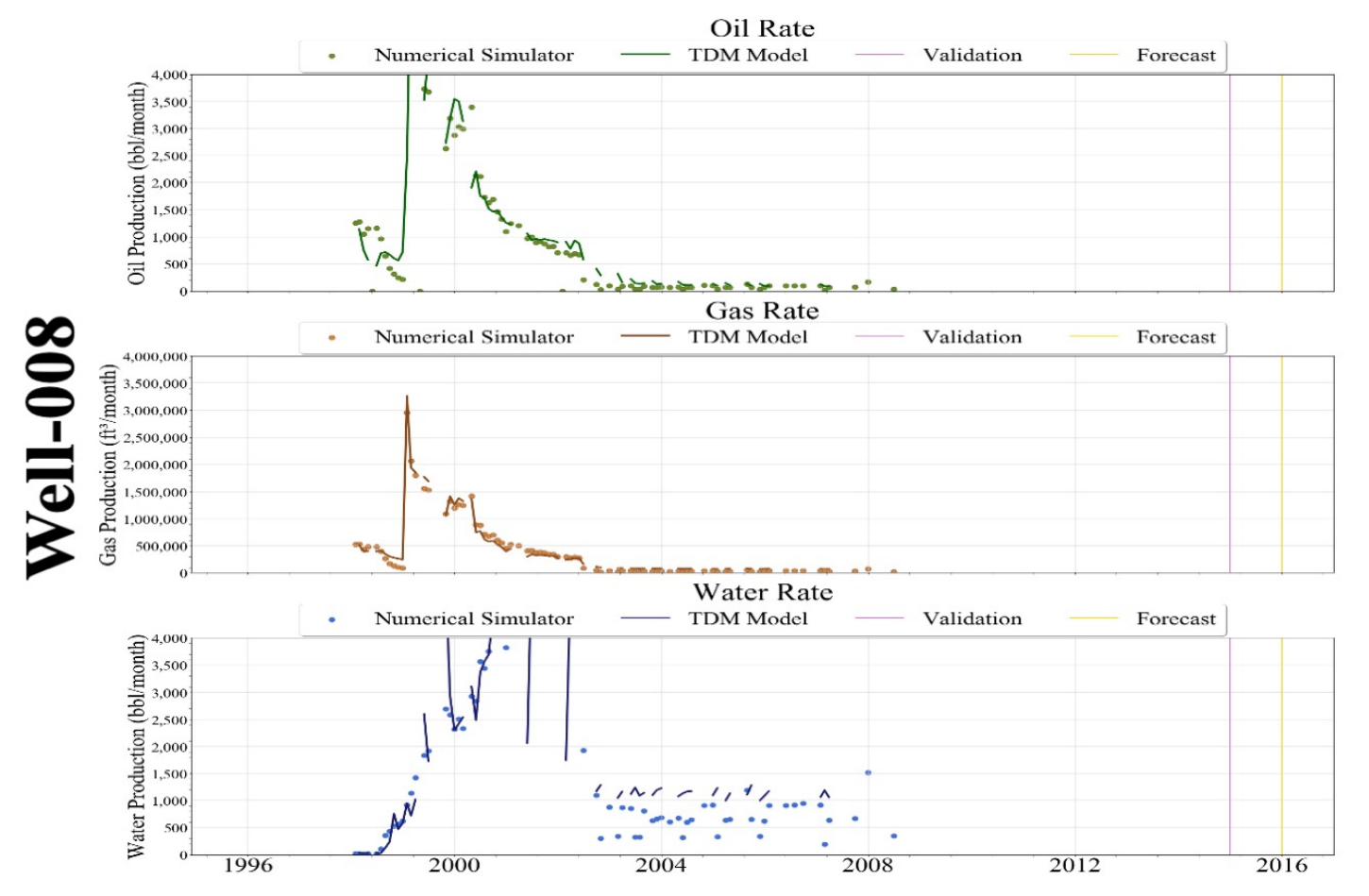

Figure 12-51: Scenario 4 - Well-008 Production History Match

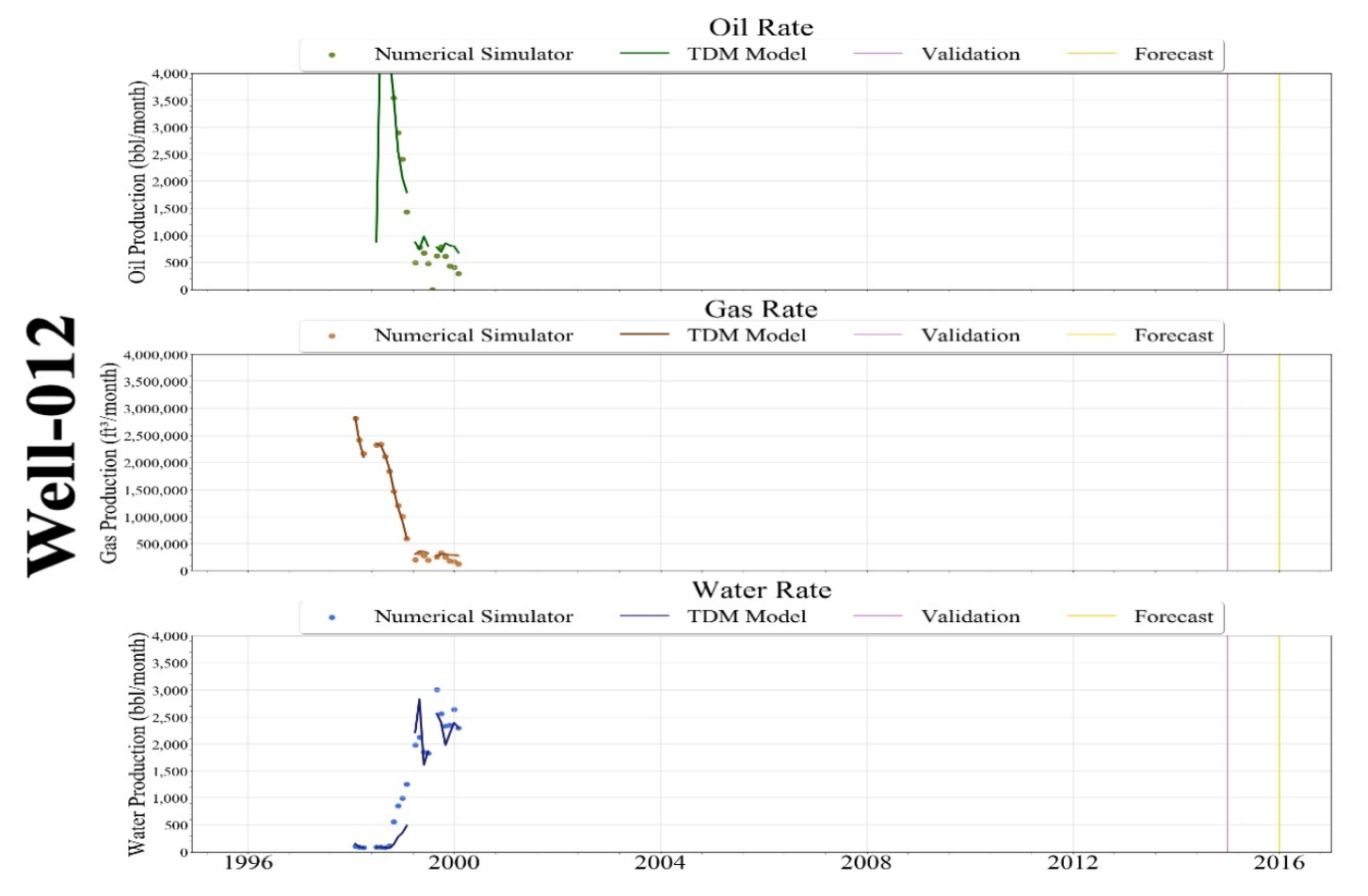

Figure 12-52: Scenario 4 - Well-012 Production History Match 


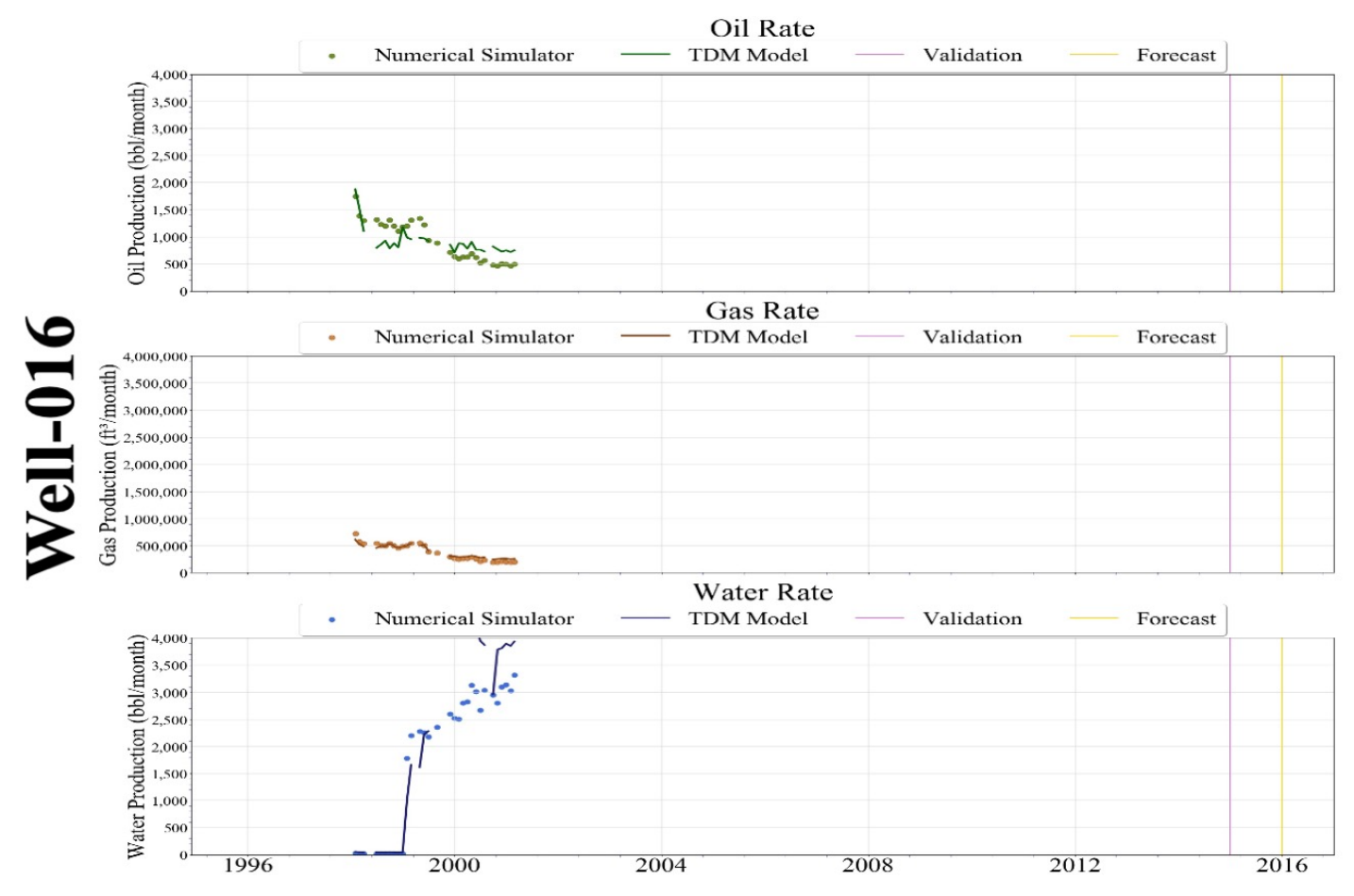

Figure 12-53: Scenario 4 - Well-016 Production History Match

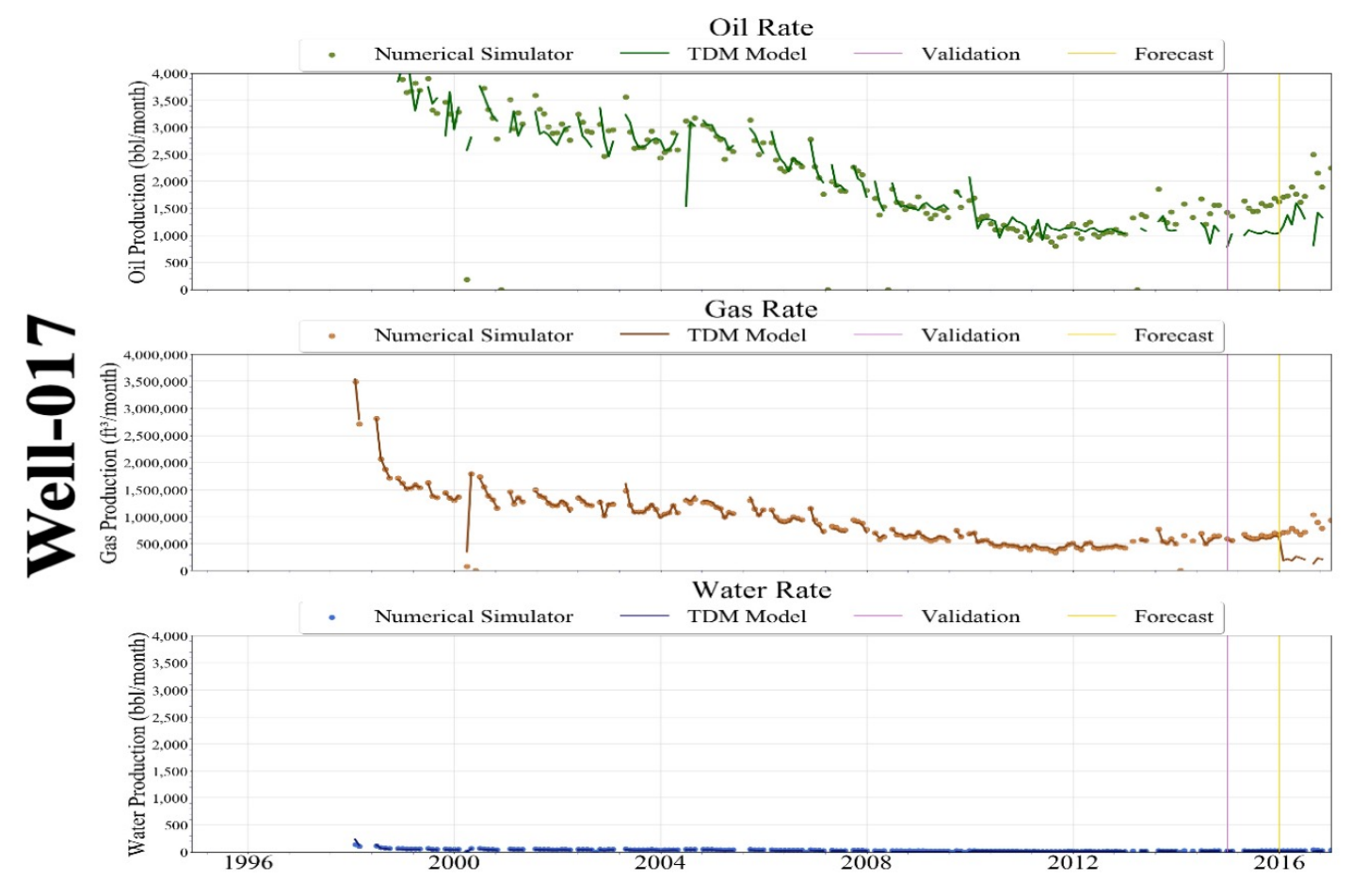

Figure 12-54: Scenario 4 - Well-017 Production History Match 


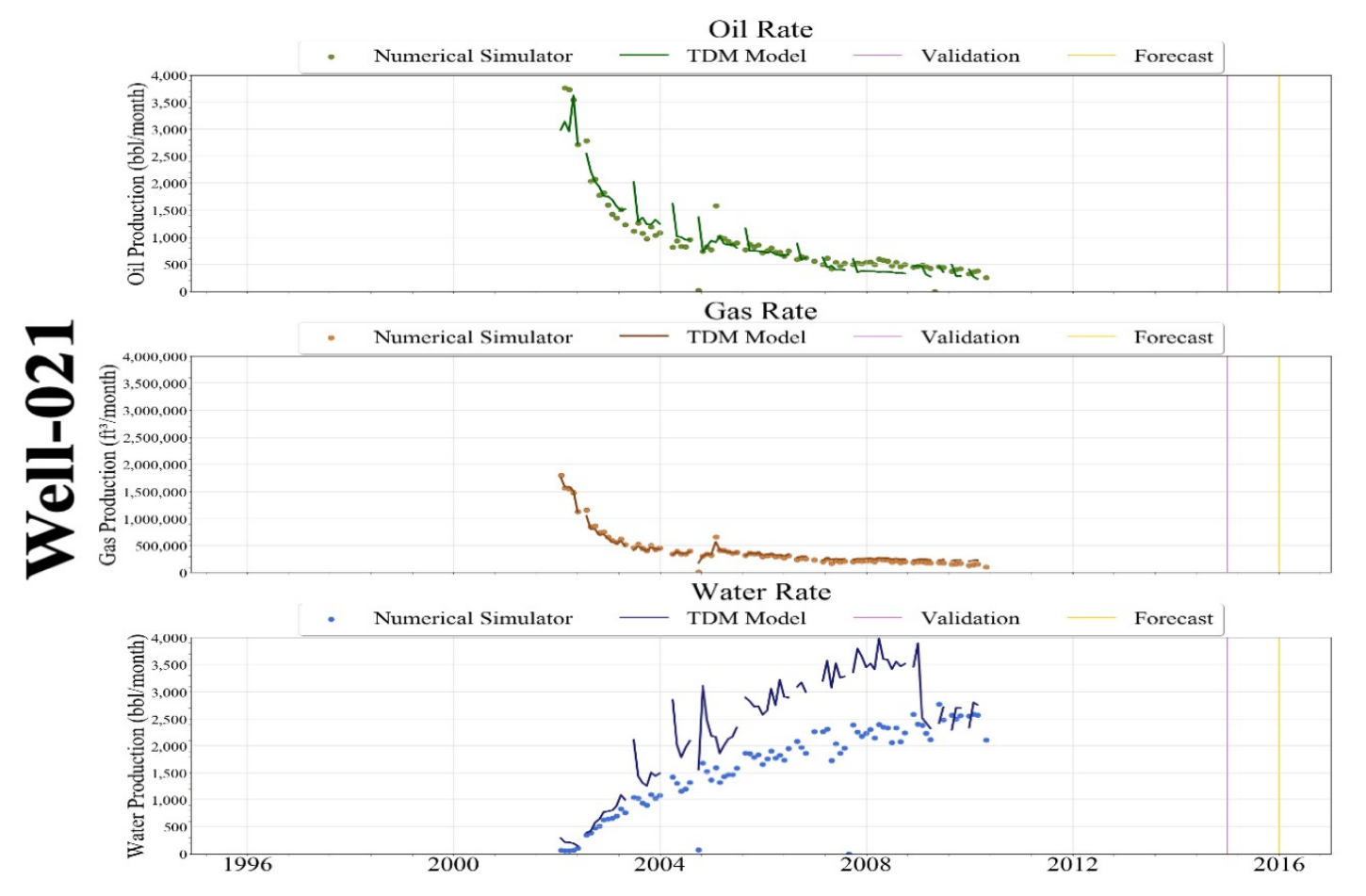

Figure 12-55: Scenario 4 - Well-021 Production History Match

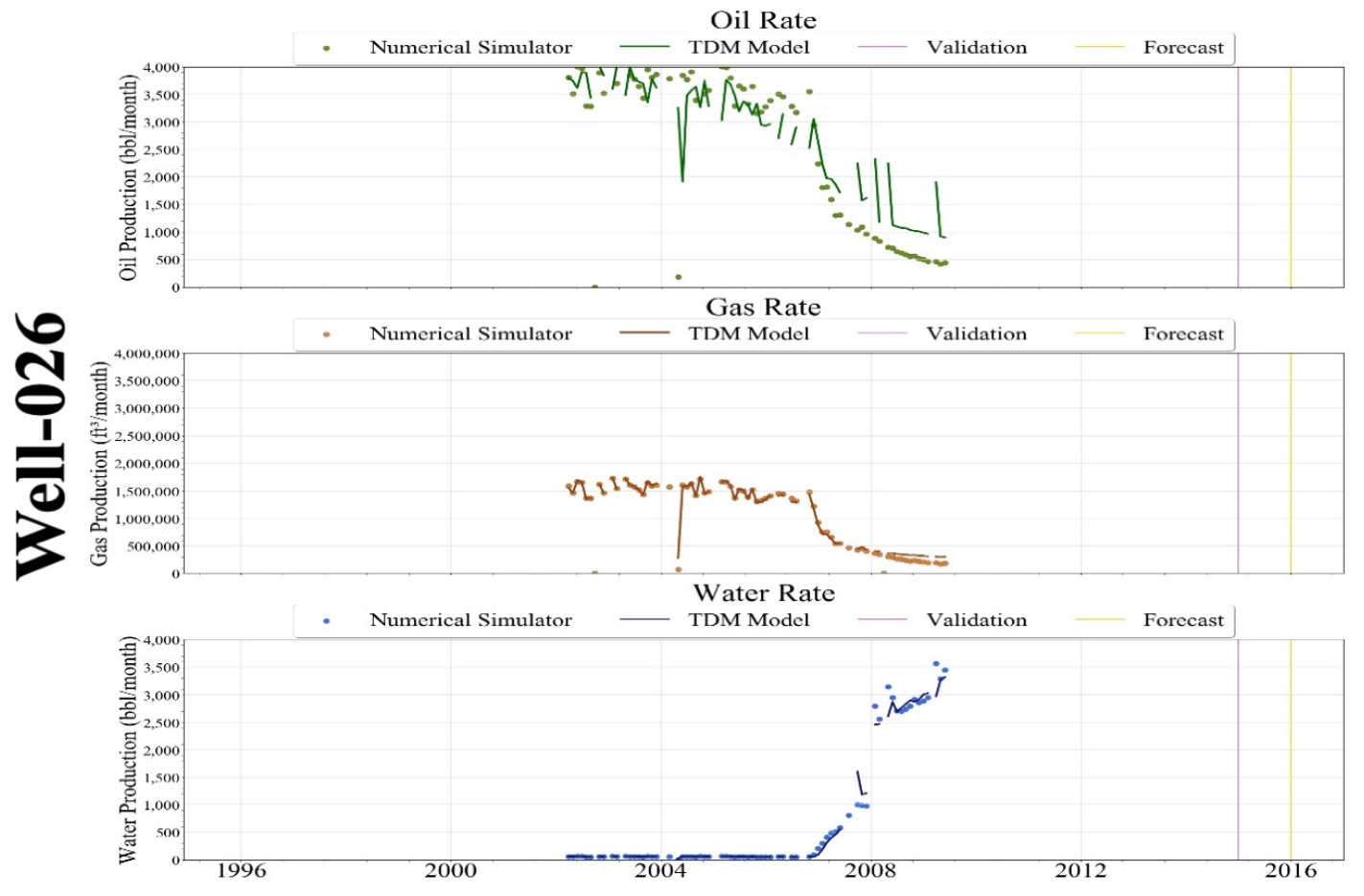

Figure 12-56: Scenario 4 - Well-026 Production History Match 


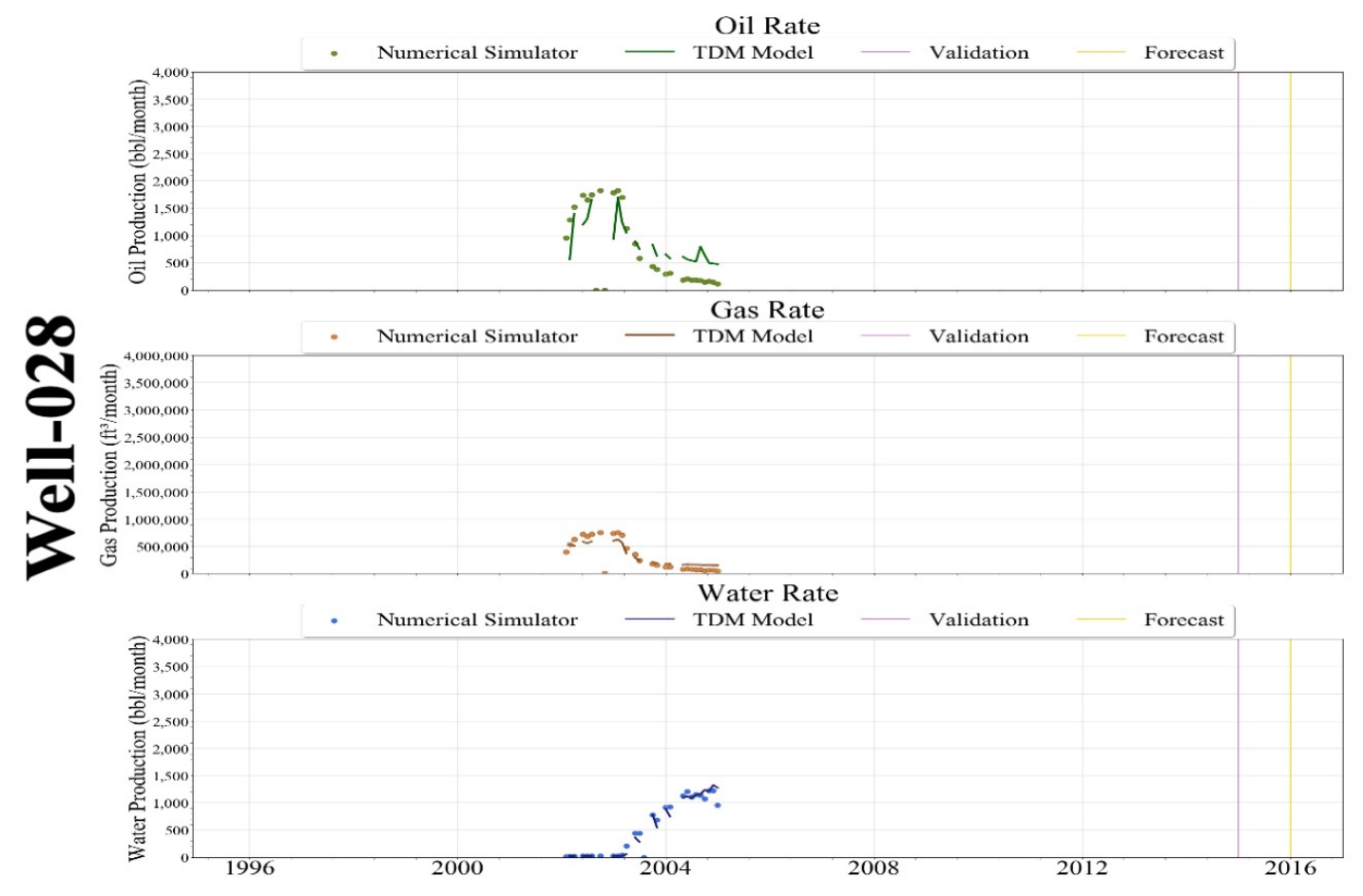

Figure 12-57: Scenario 4 - Well-028 Production History Match

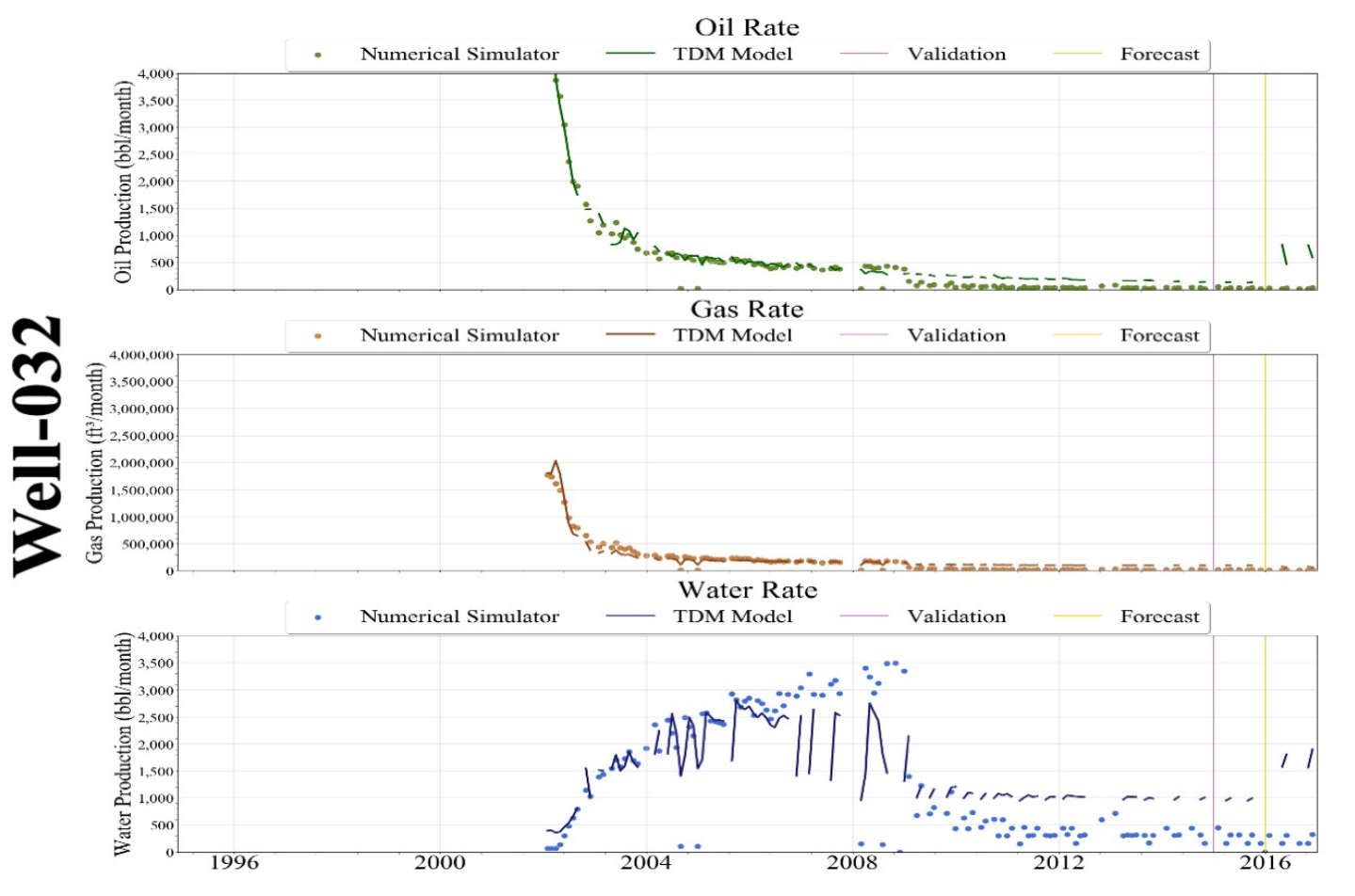

Figure 12-58: Scenario 4 - Well-032 Production History Match 


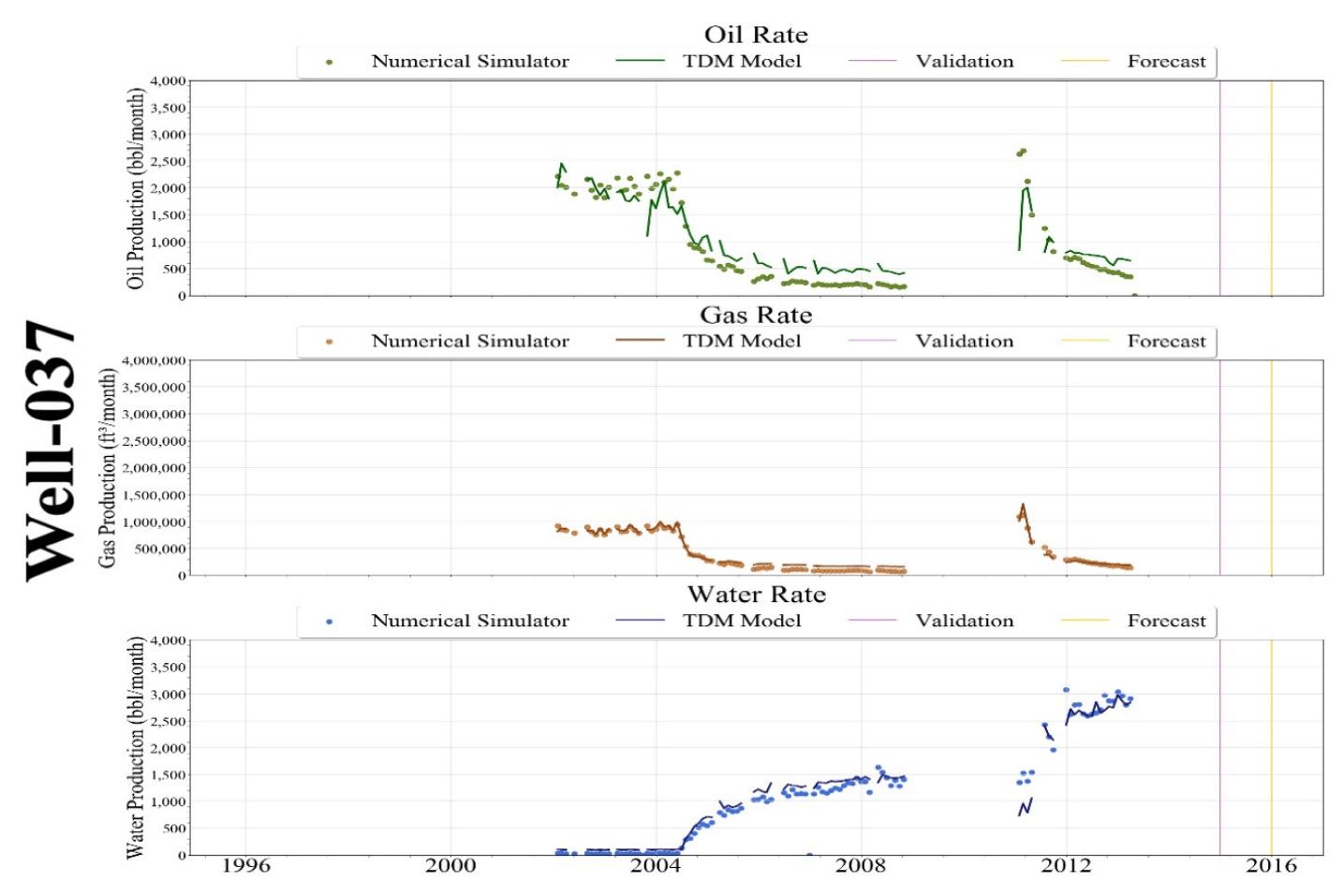

Figure 12-59: Scenario 4 - Well-037 Production History Match

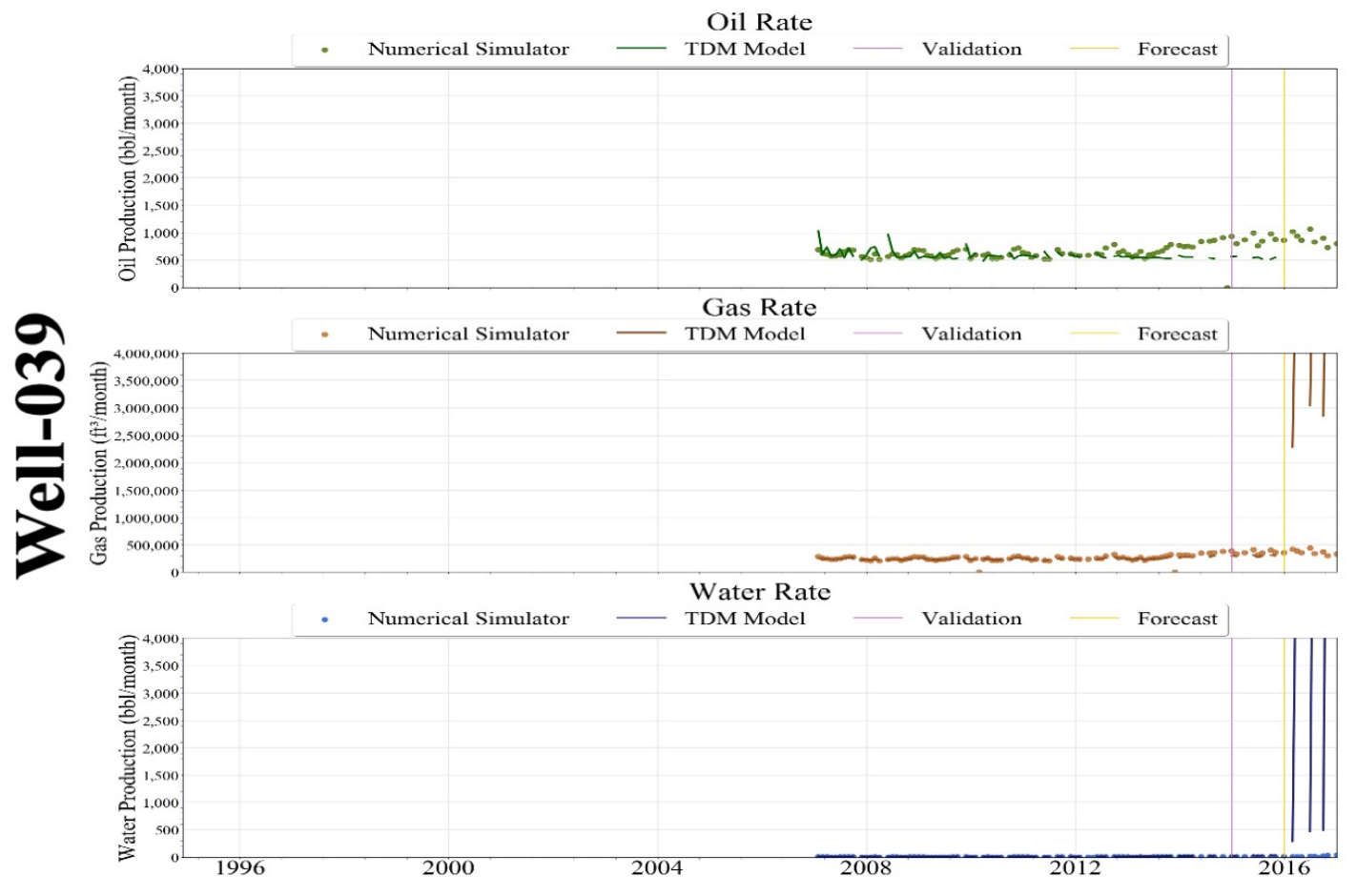

Figure 12-60: Scenario 4 - Well-039 Production History Match 


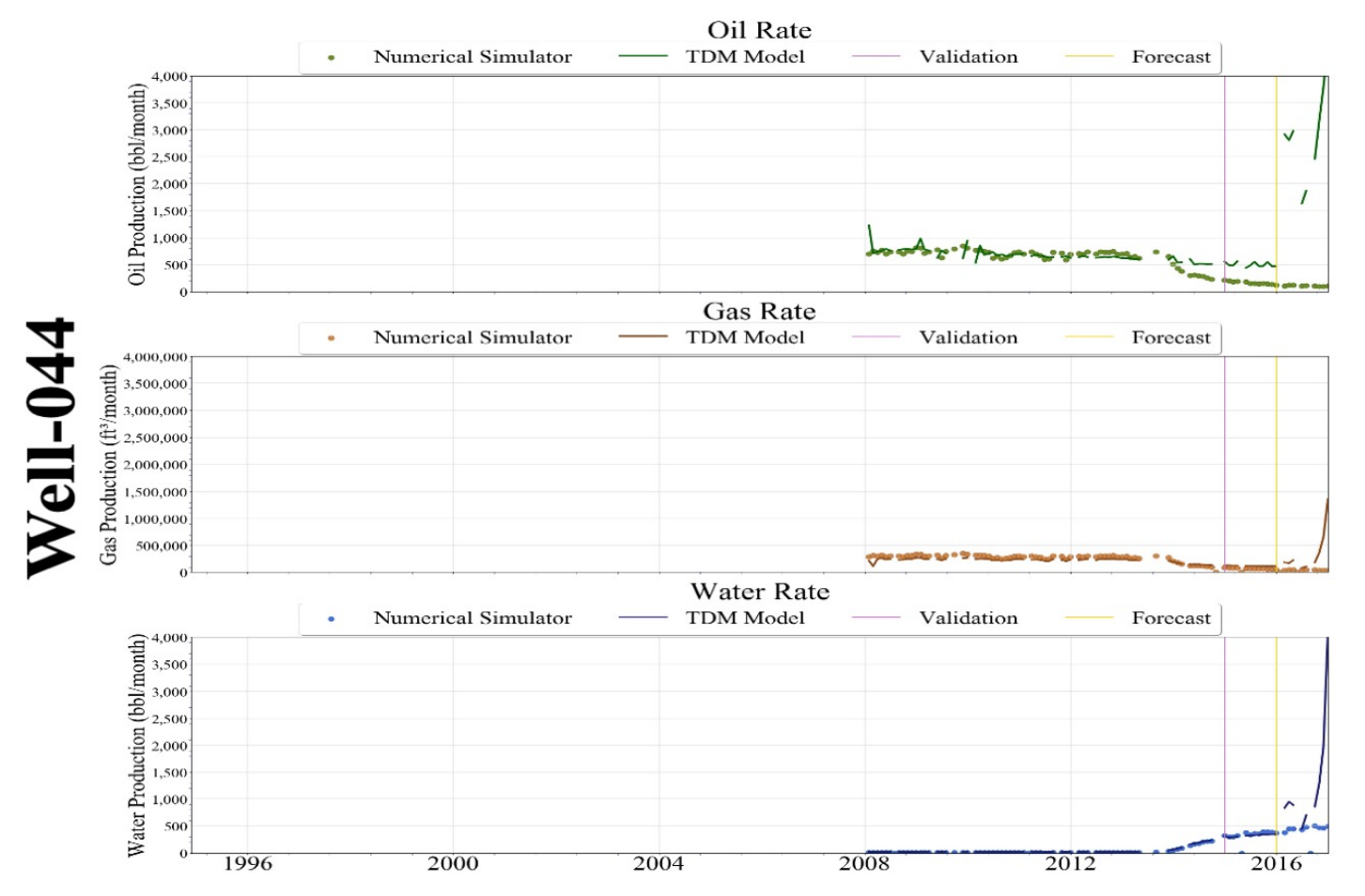

Figure 12-61: Scenario 4 - Well-044 Production History Match

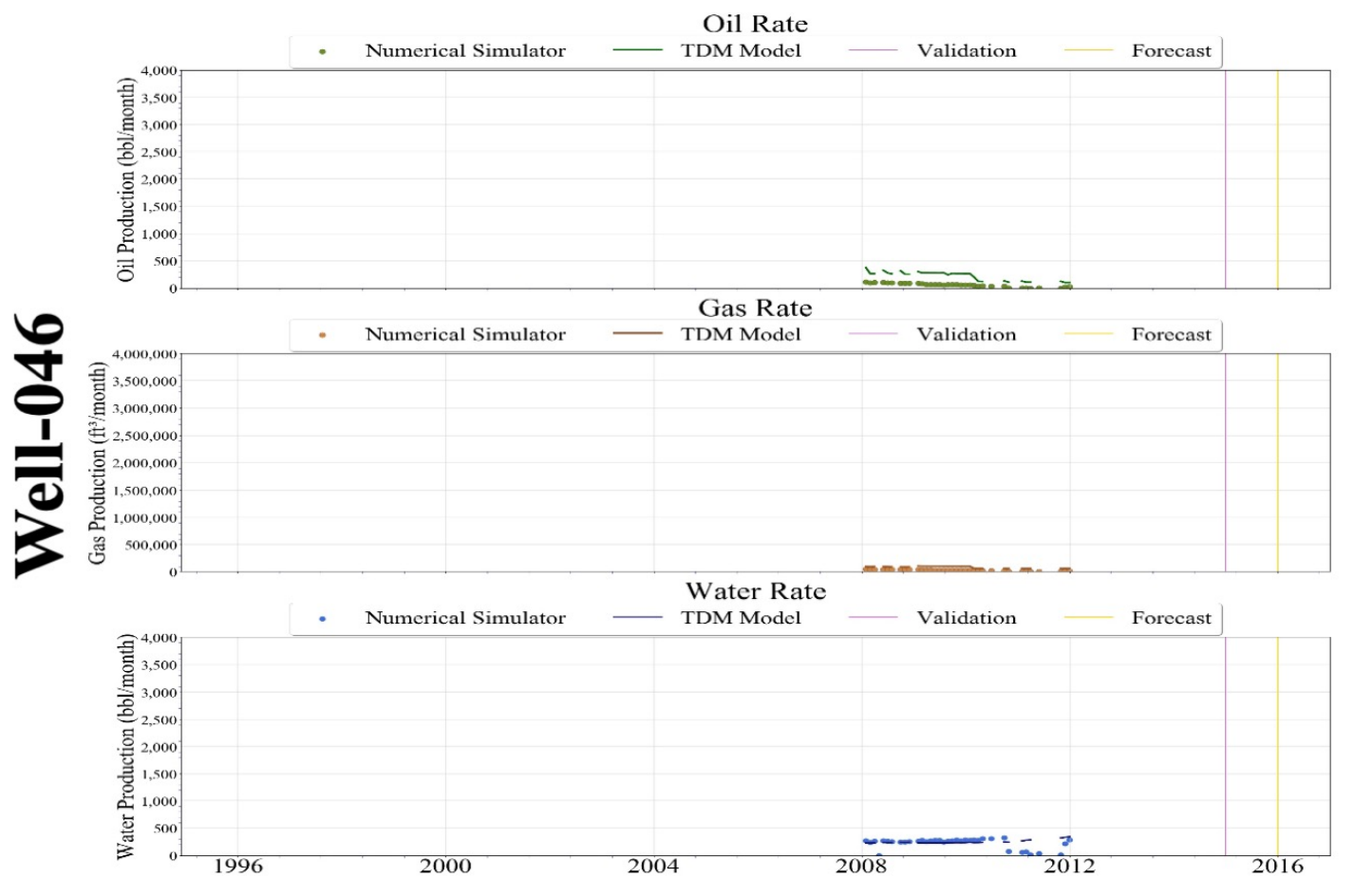

Figure 12-62: Scenario 4 - Well-046 Production History Match 


\subsubsection{Poor History Match of Production}

Poor results were not visually inspected during the blind history match time period. 


\subsubsection{Good Forecast Production}

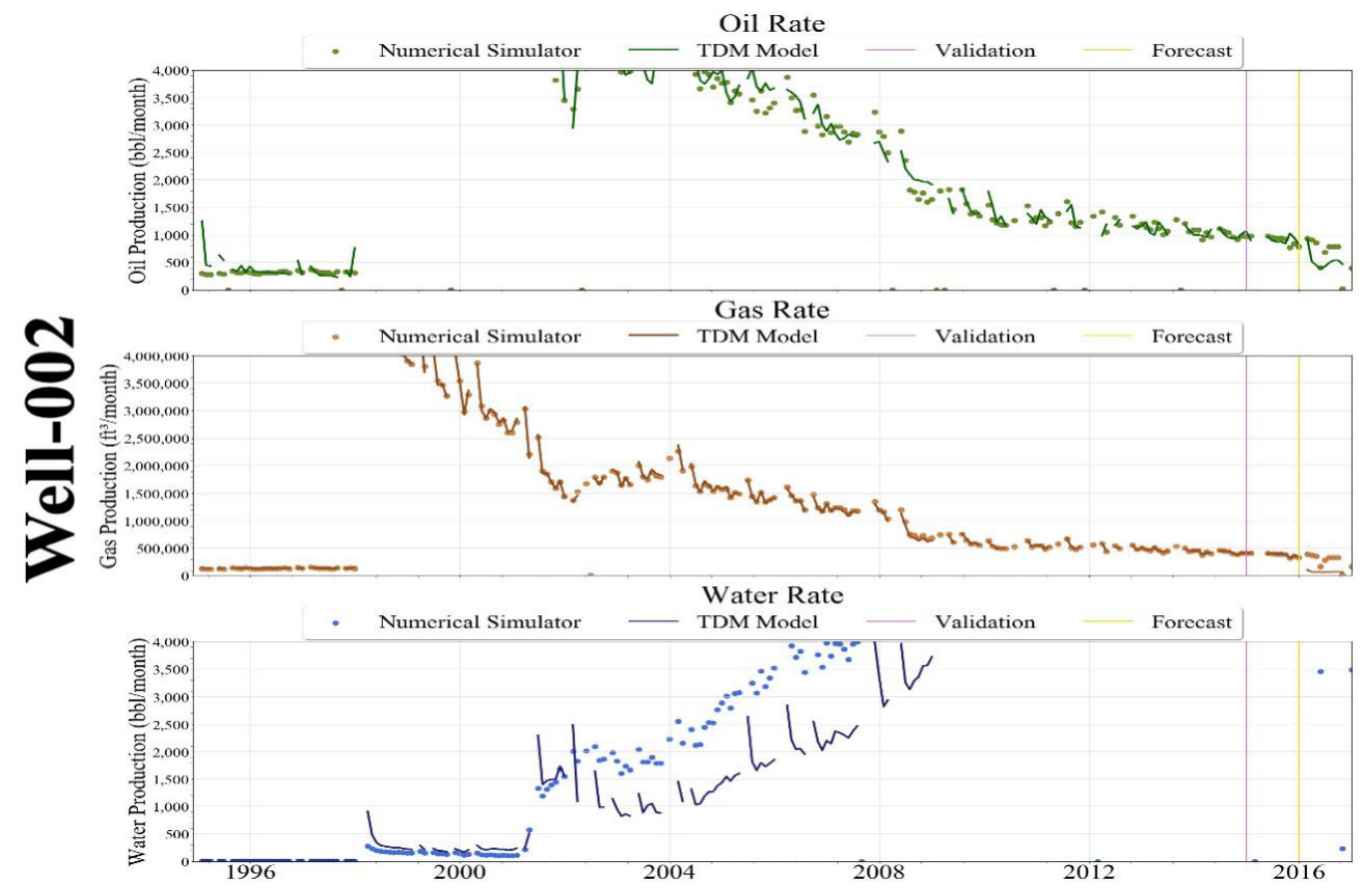

Figure 12-63: Scenario 4 - Well-002 Forecast Production

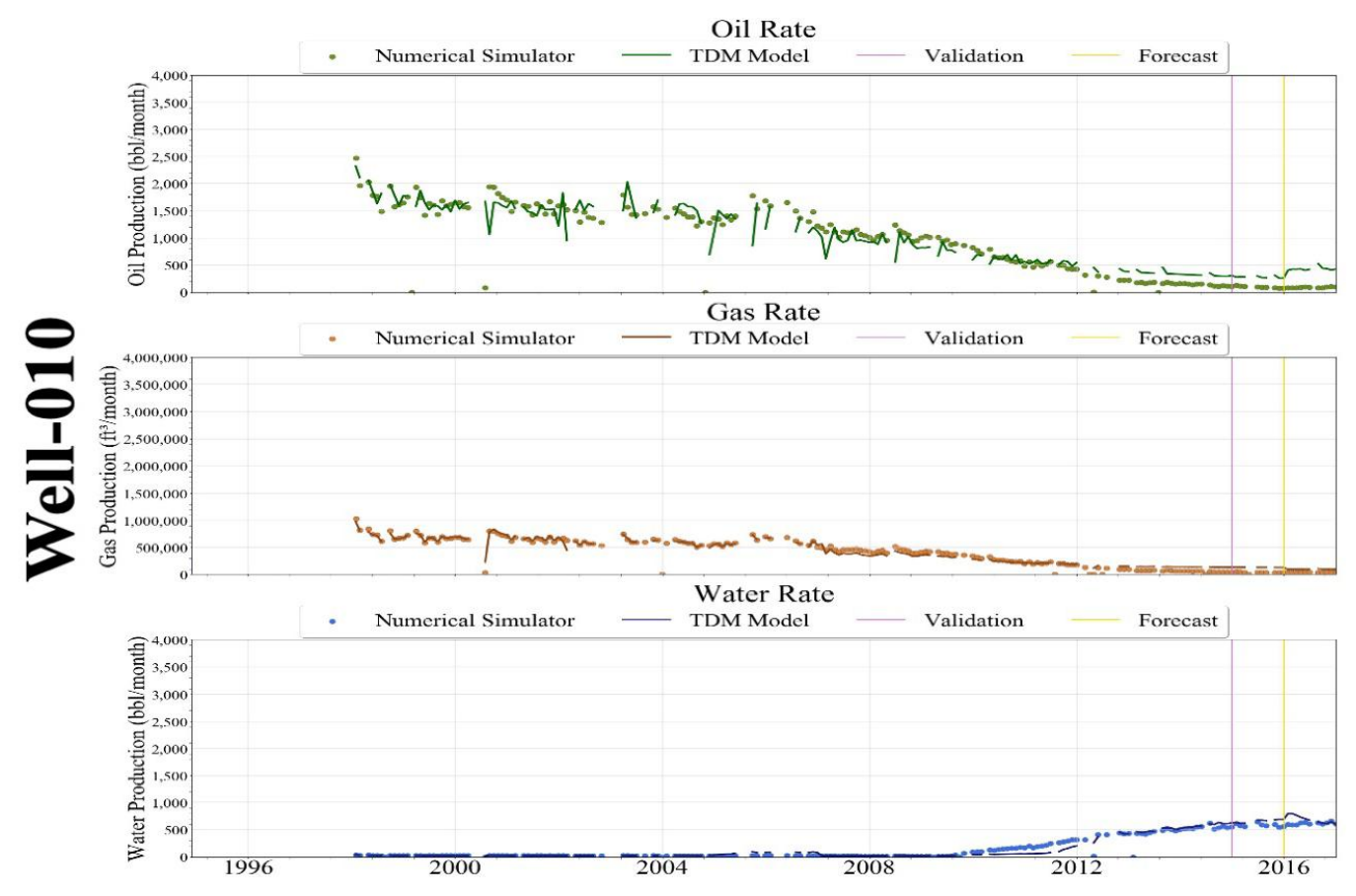

Figure 12-64: Scenario 4 - Well-010 Forecast Production 


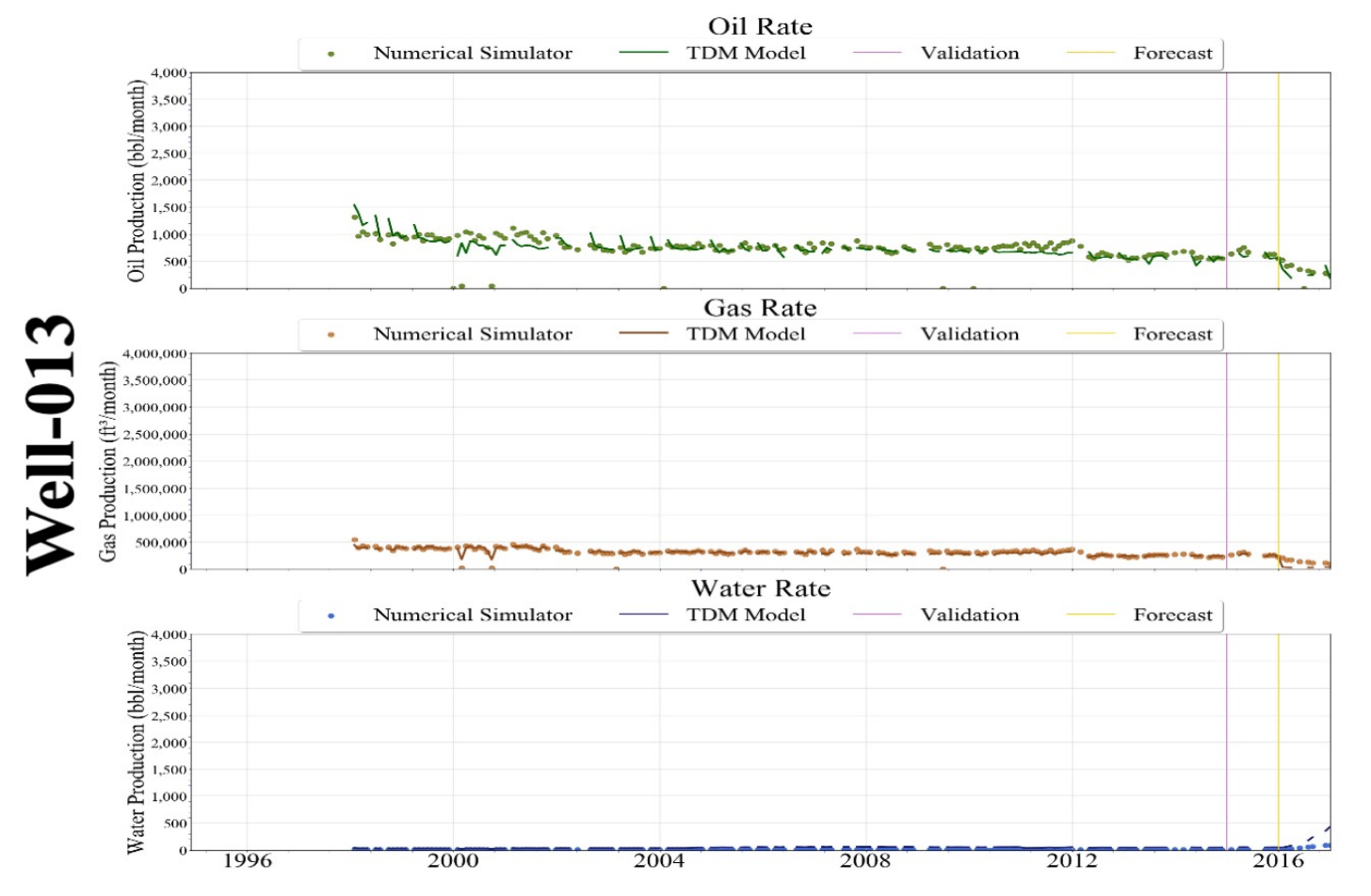

Figure 12-65: Scenario 4 - Well-013 Forecast Production

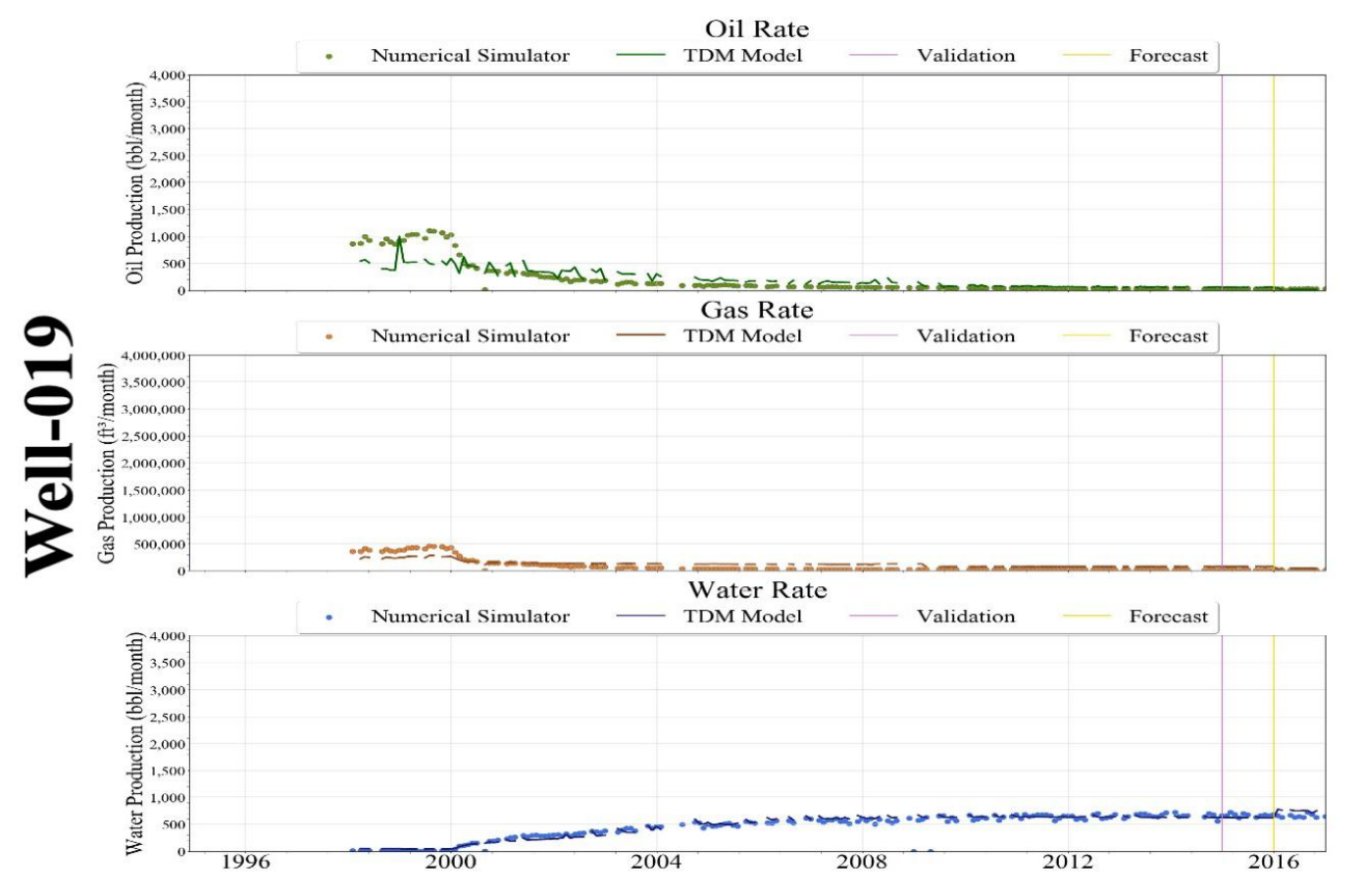

Figure 12-66: Scenario 4 - Well-019 Forecast Production 


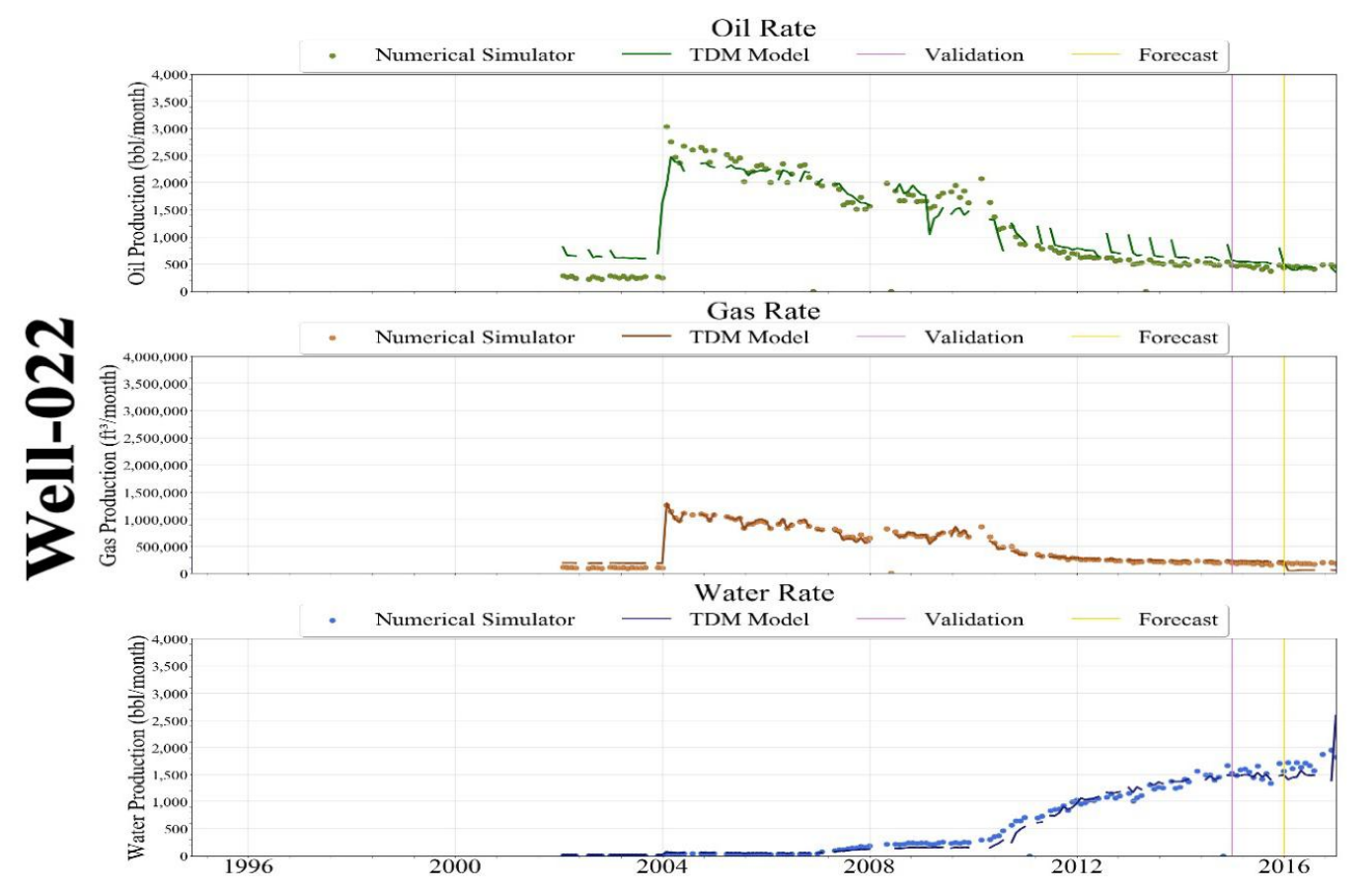

Figure 12-67: Scenario 4 - Well-022 Forecast Production

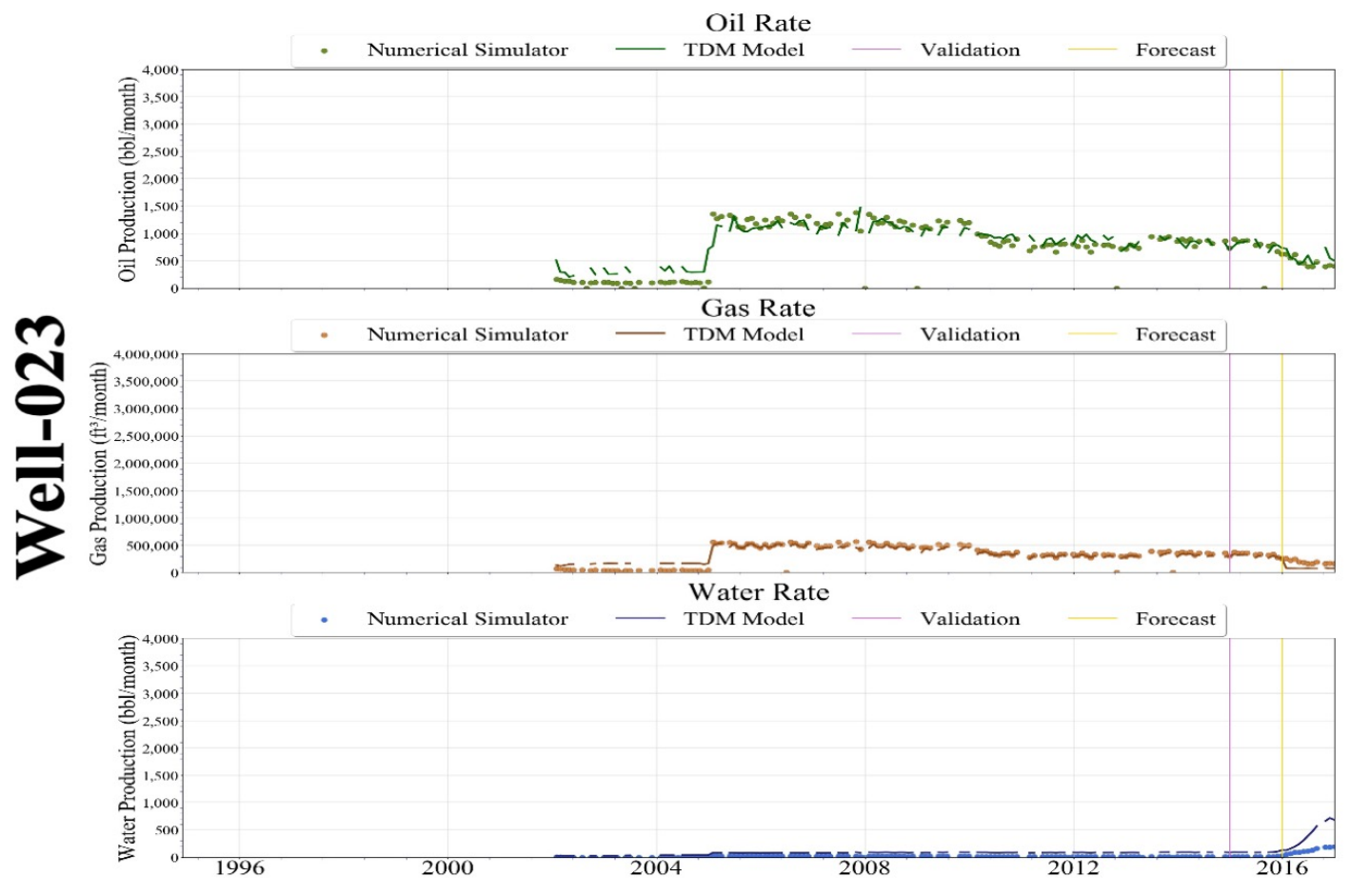

Figure 12-68: Scenario 4 - Well-023 Forecast Production 


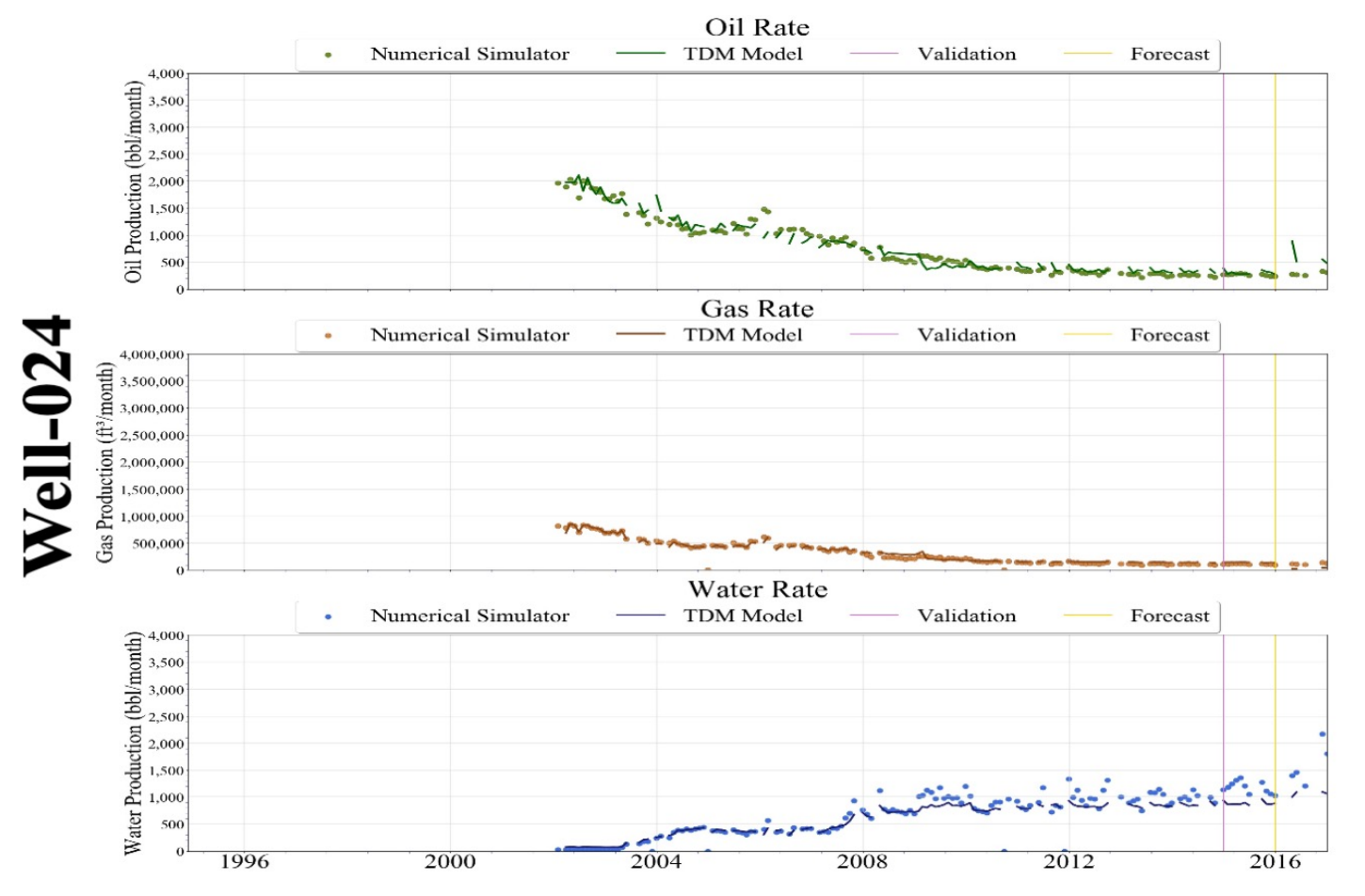

Figure 12-69: Scenario 4 - Well-024 Forecast Production

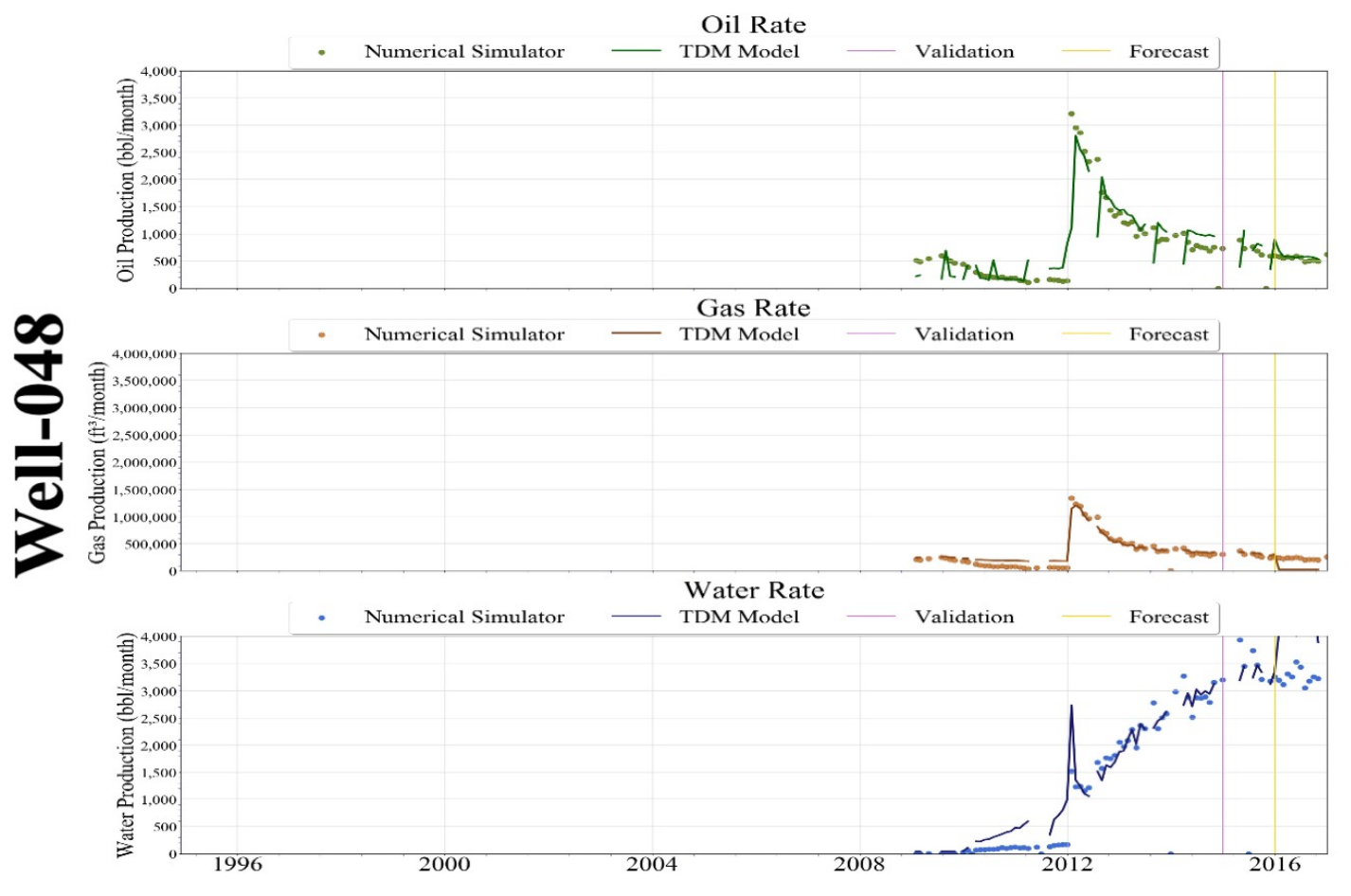

Figure 12-70: Scenario 4 - Well-048 Forecast Production 


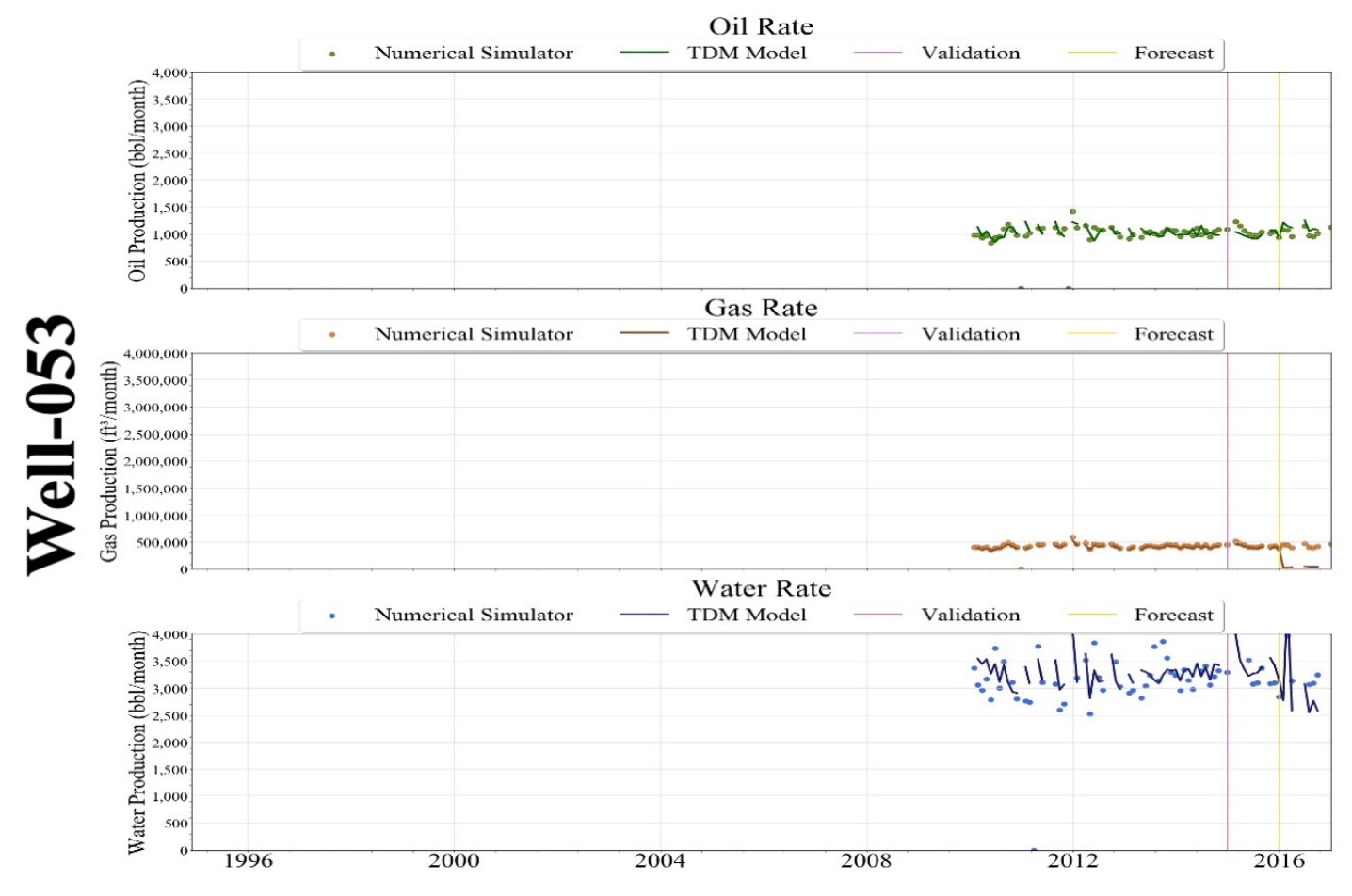

Figure 12-71: Scenario 4 - Well-053 Forecast Production

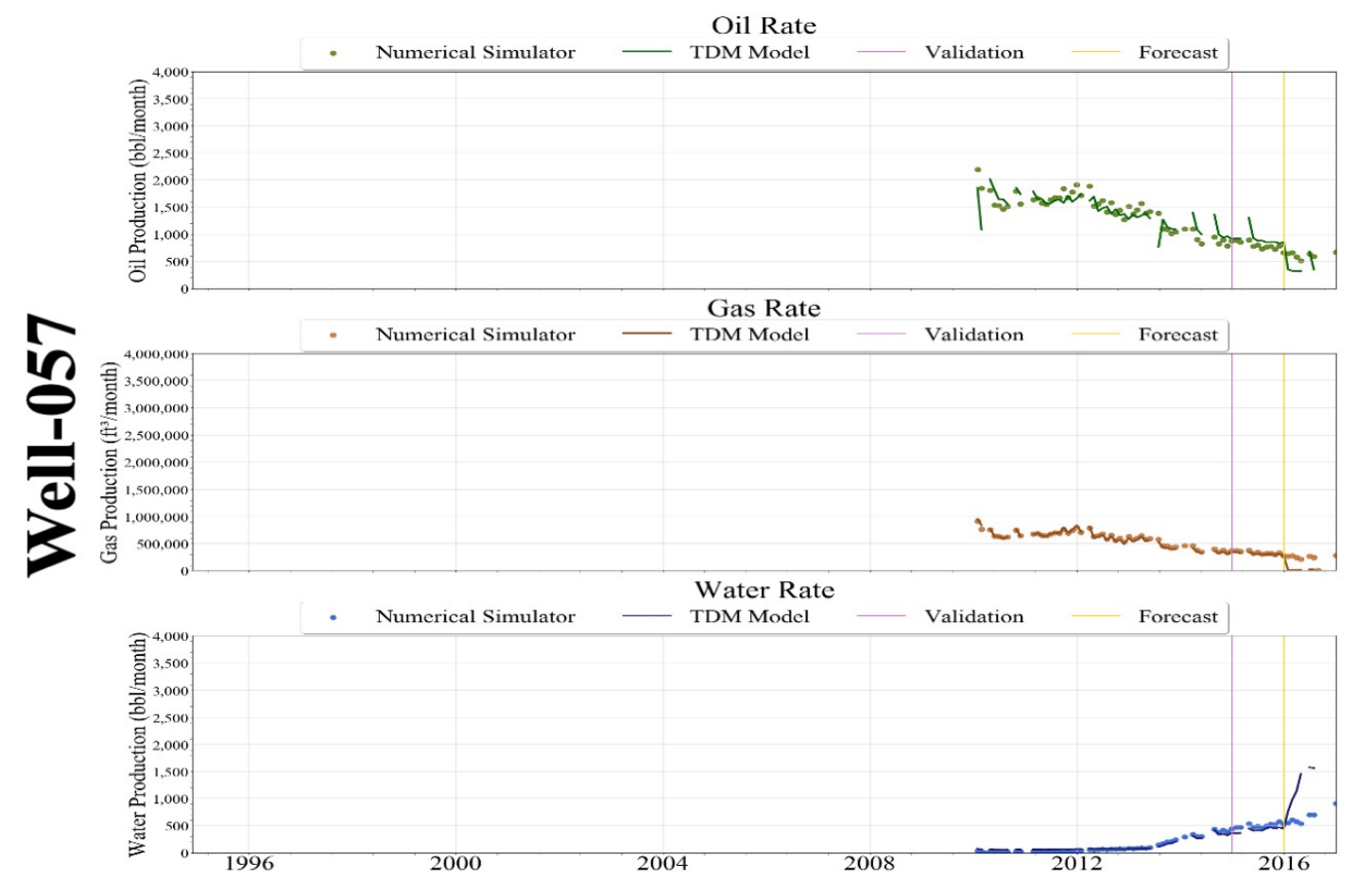

Figure 12-72: Scenario 4 - Well-057 Forecast Production 


\subsubsection{Average Forecast Production}

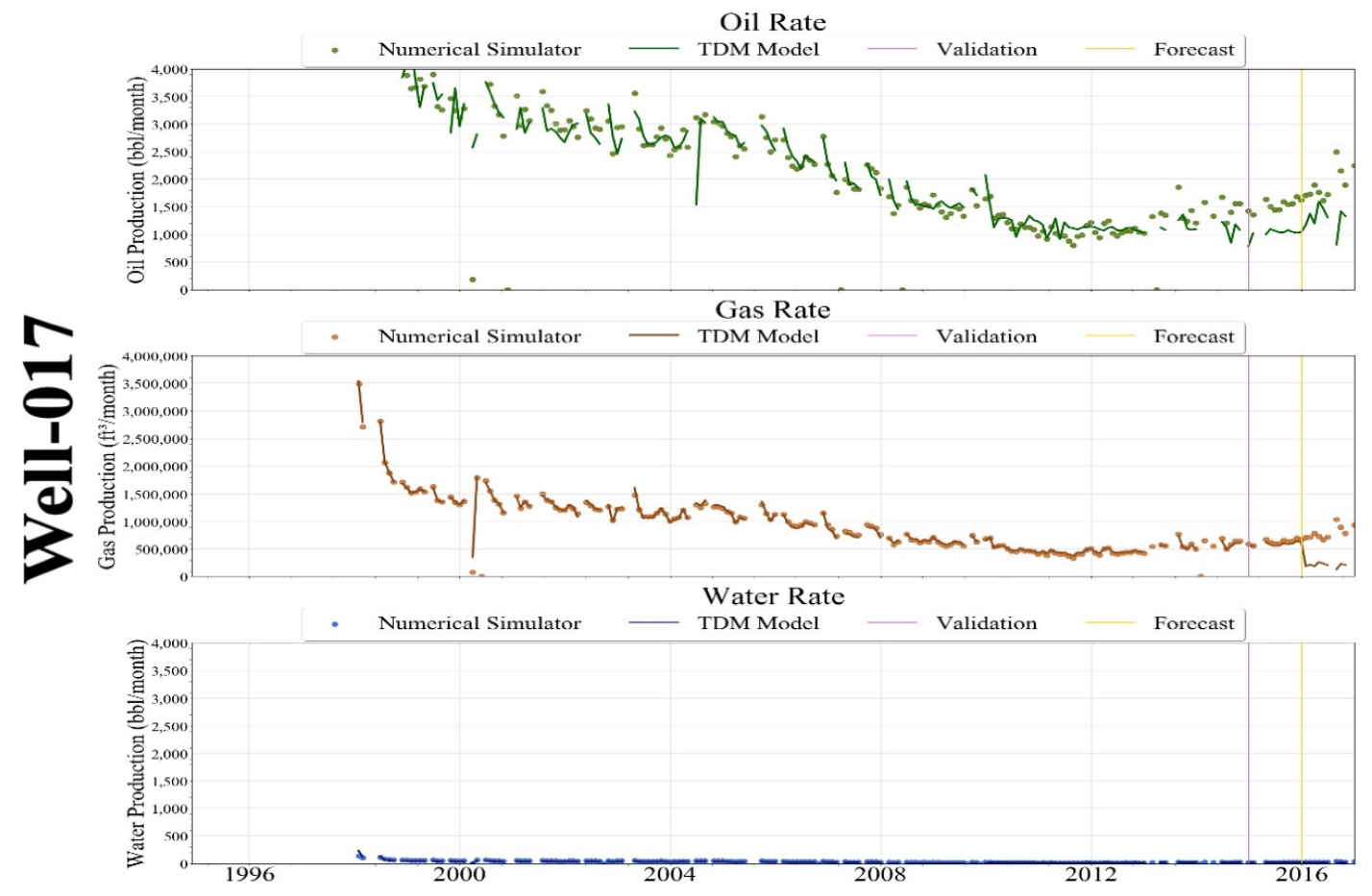

Figure 12-73: Scenario 4 - Well-017 Forecast Production

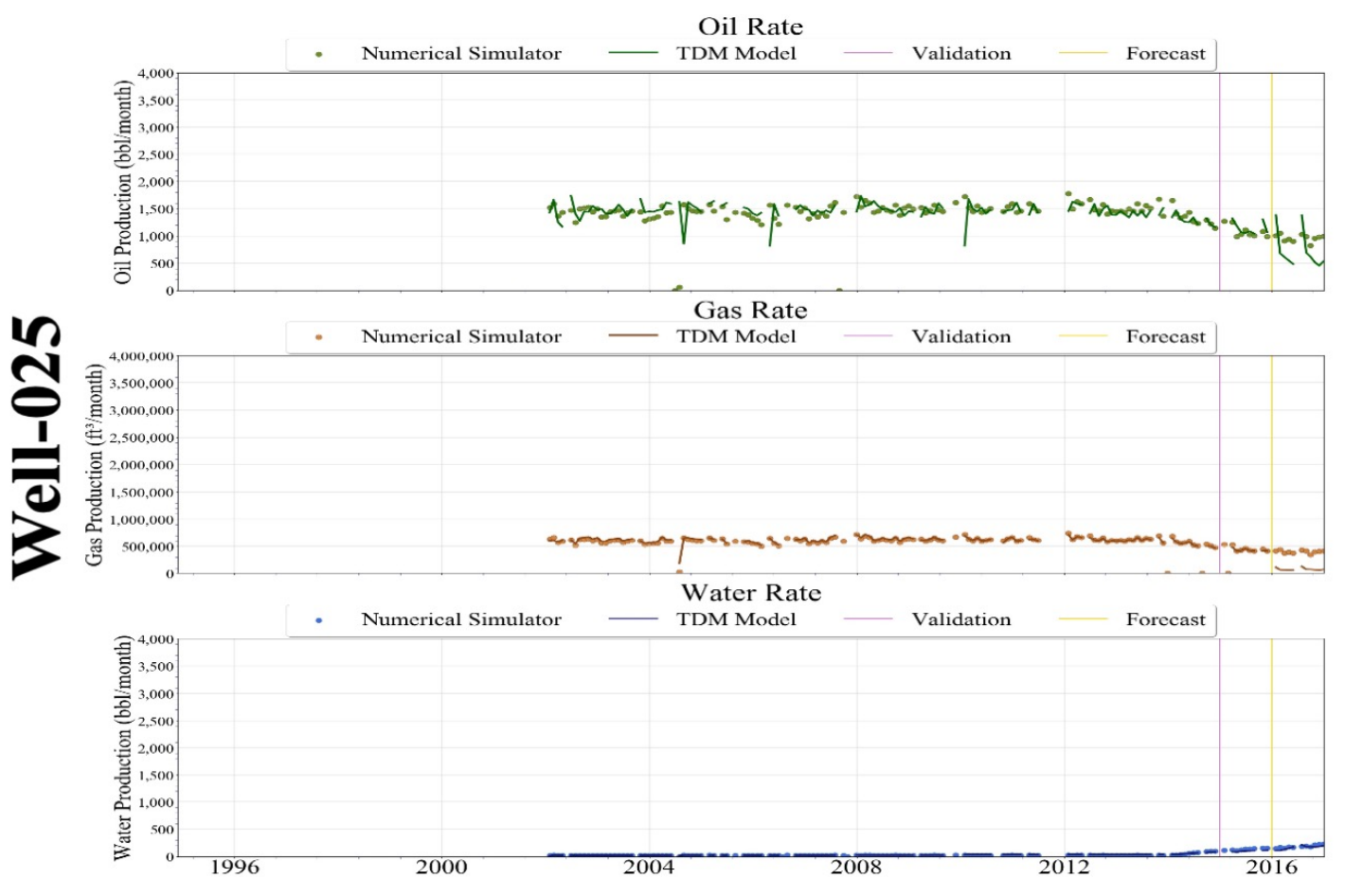

Figure 12-74: Scenario 4 - Well-025 Forecast Production 


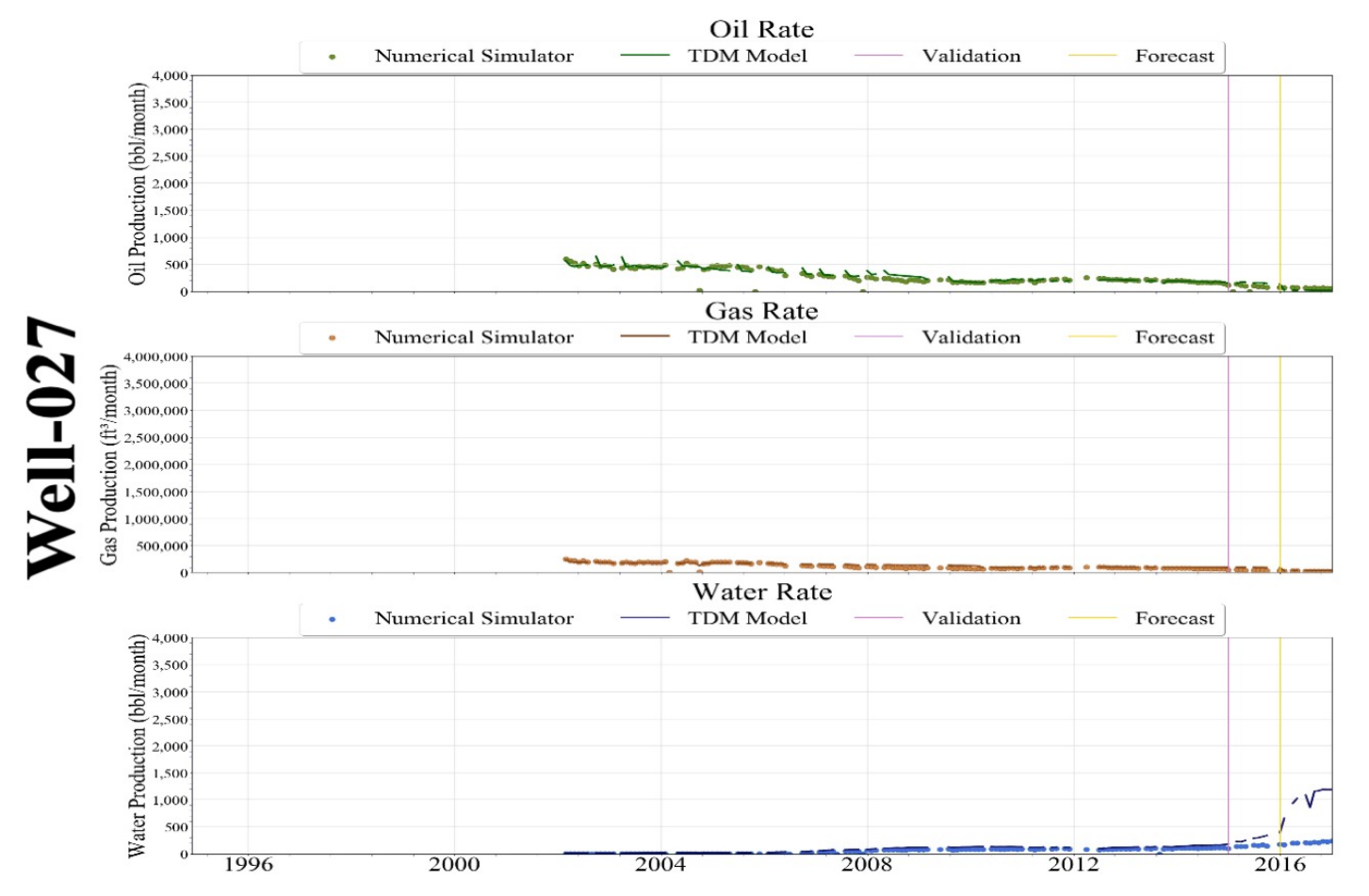

Figure 12-75: Scenario 4 - Well-027 Forecast Production

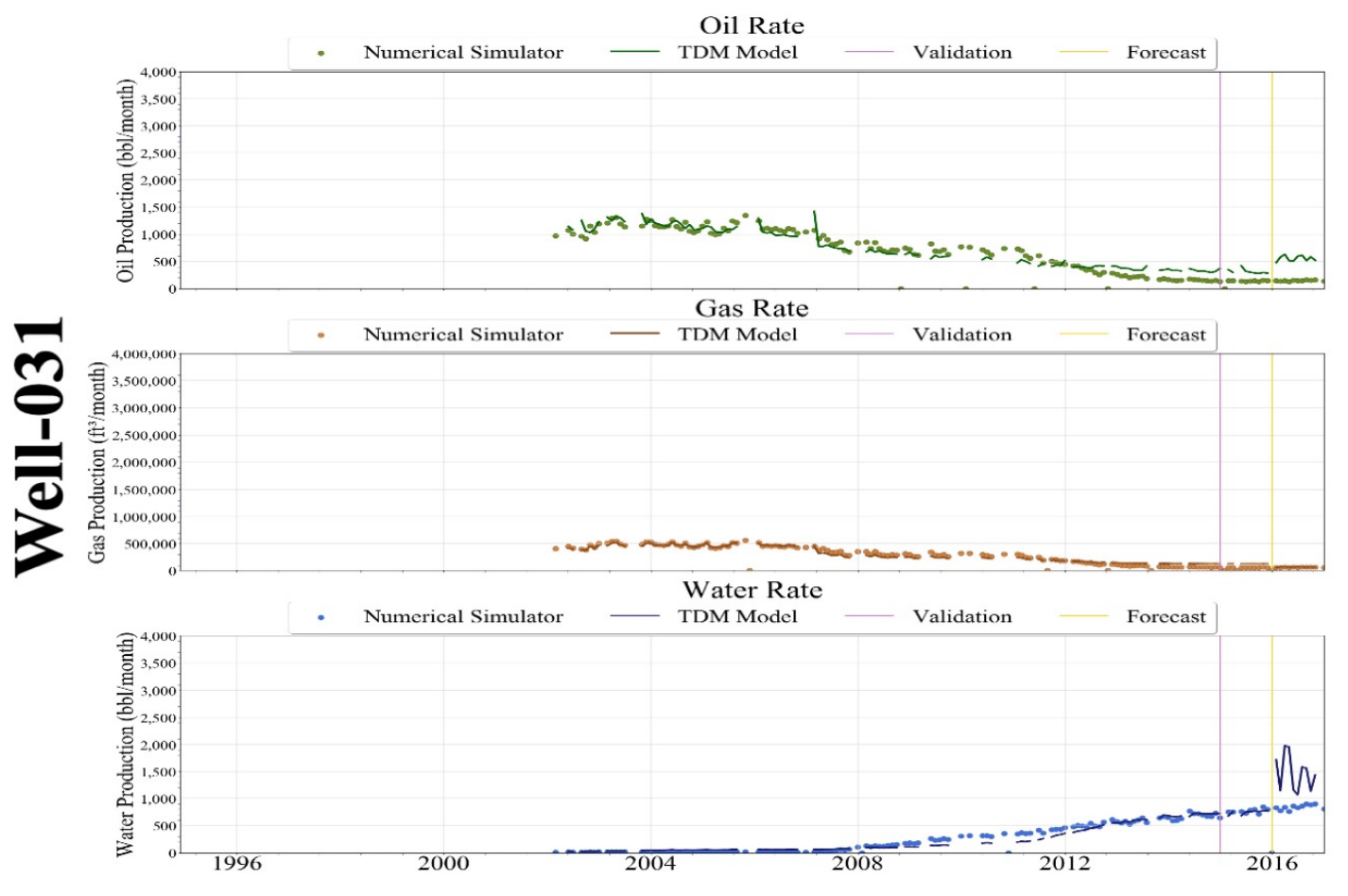

Figure 12-76: Scenario 4 - Well-031 Forecast Production 


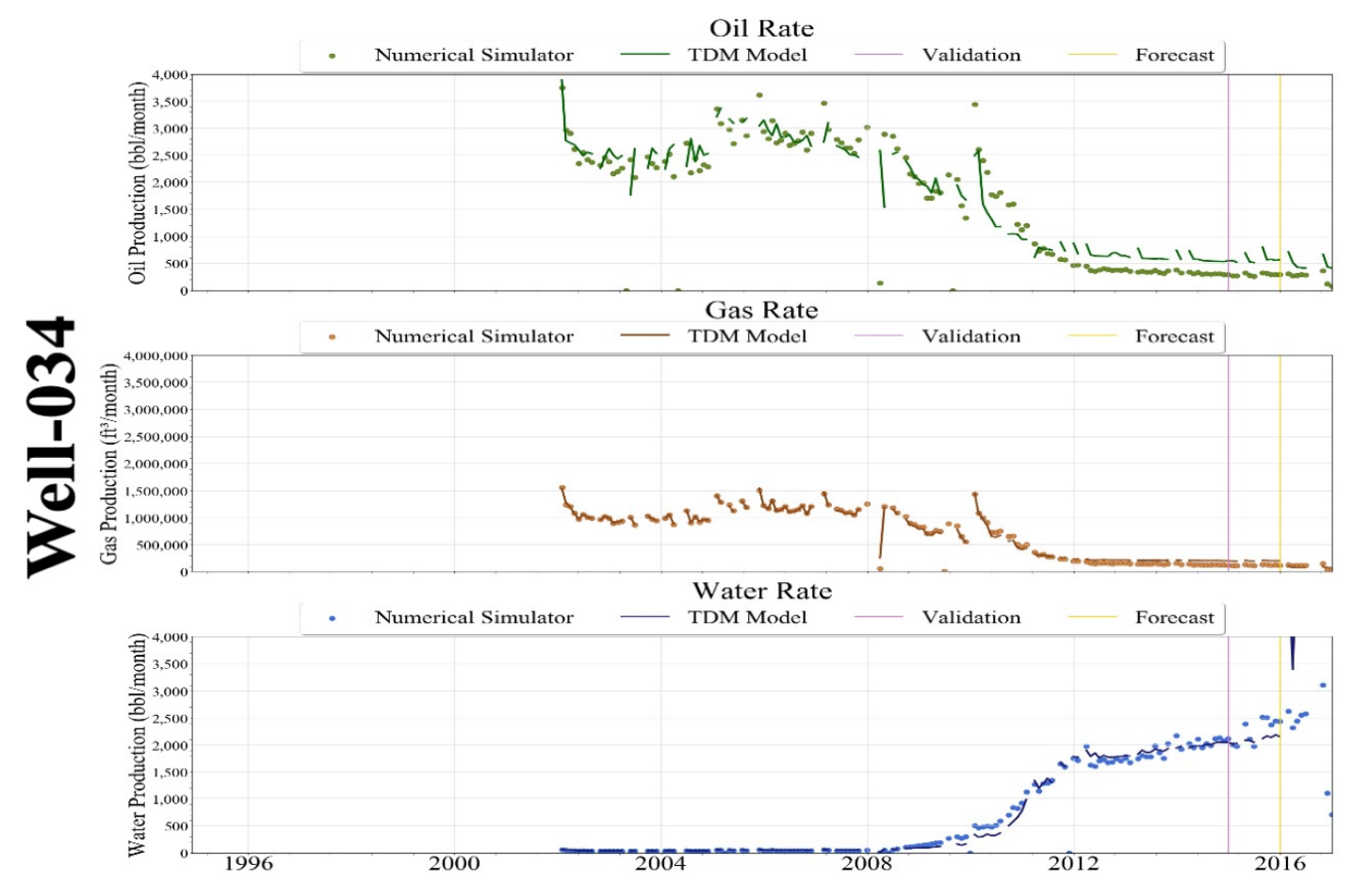

Figure 12-77: Scenario 4 - Well-034 Forecast Production

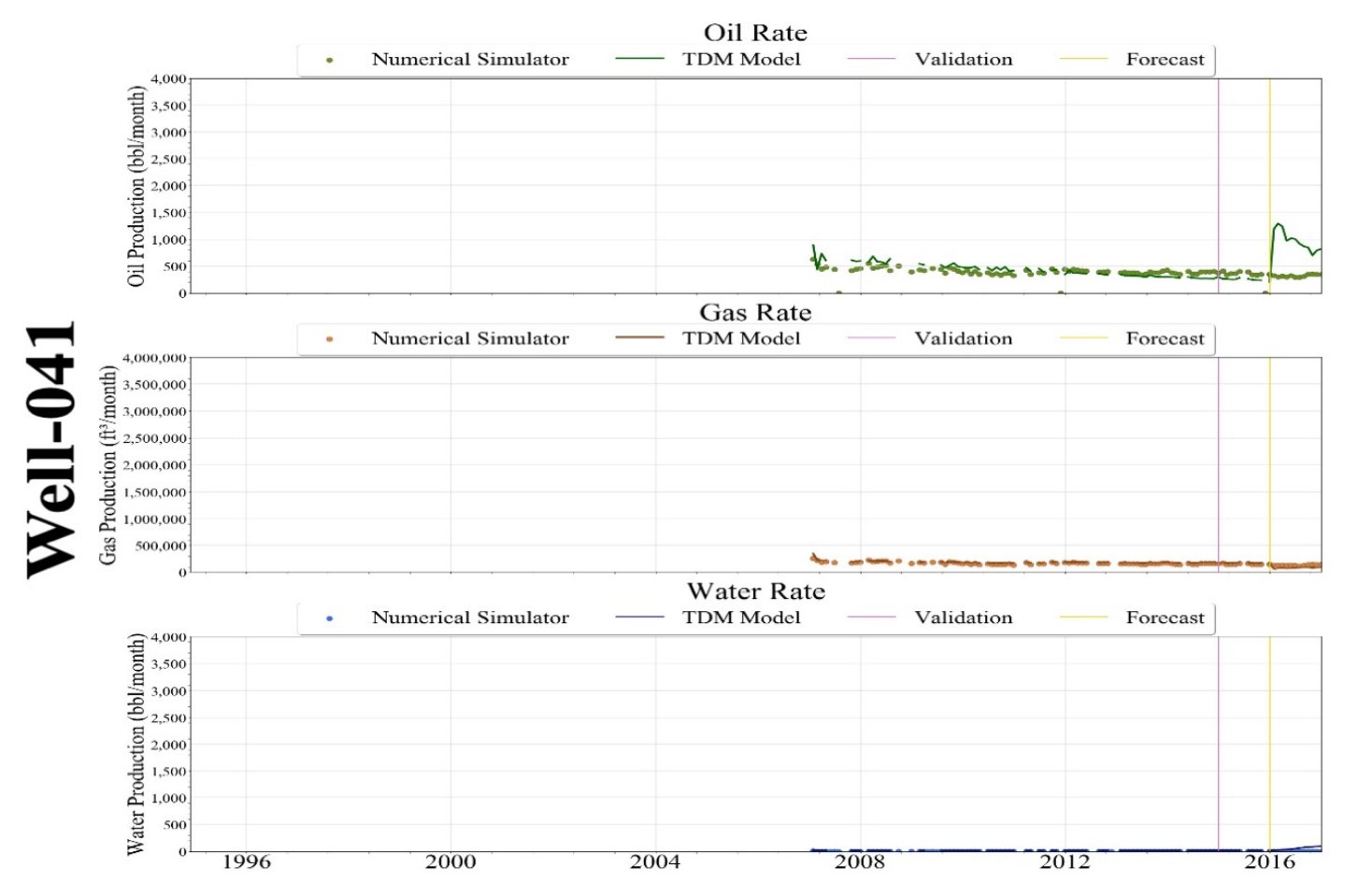

Figure 12-78: Scenario 4 - Well-041 Forecast Production 


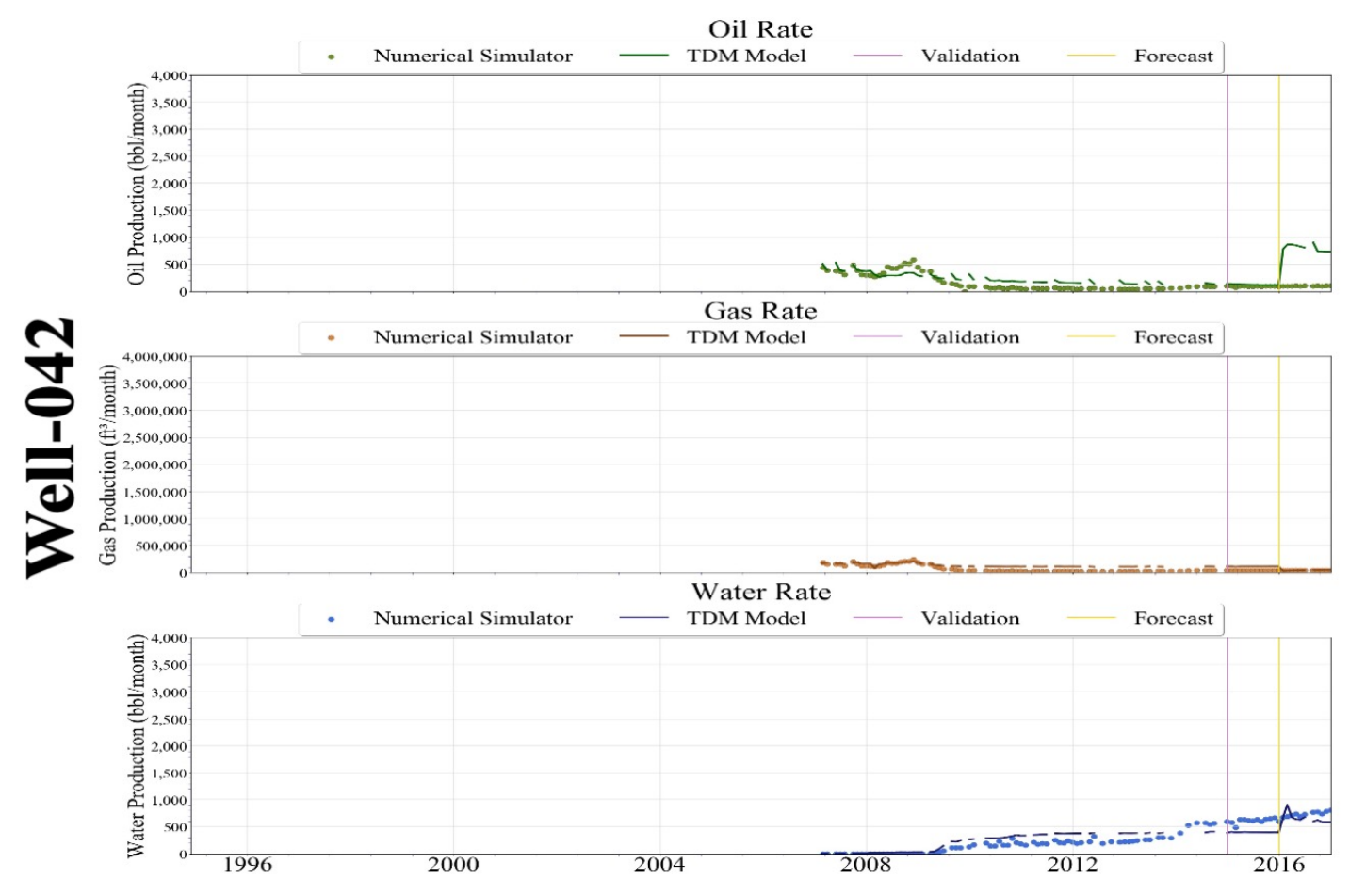

Figure 12-79: Scenario 4 - Well-042 Forecast Production

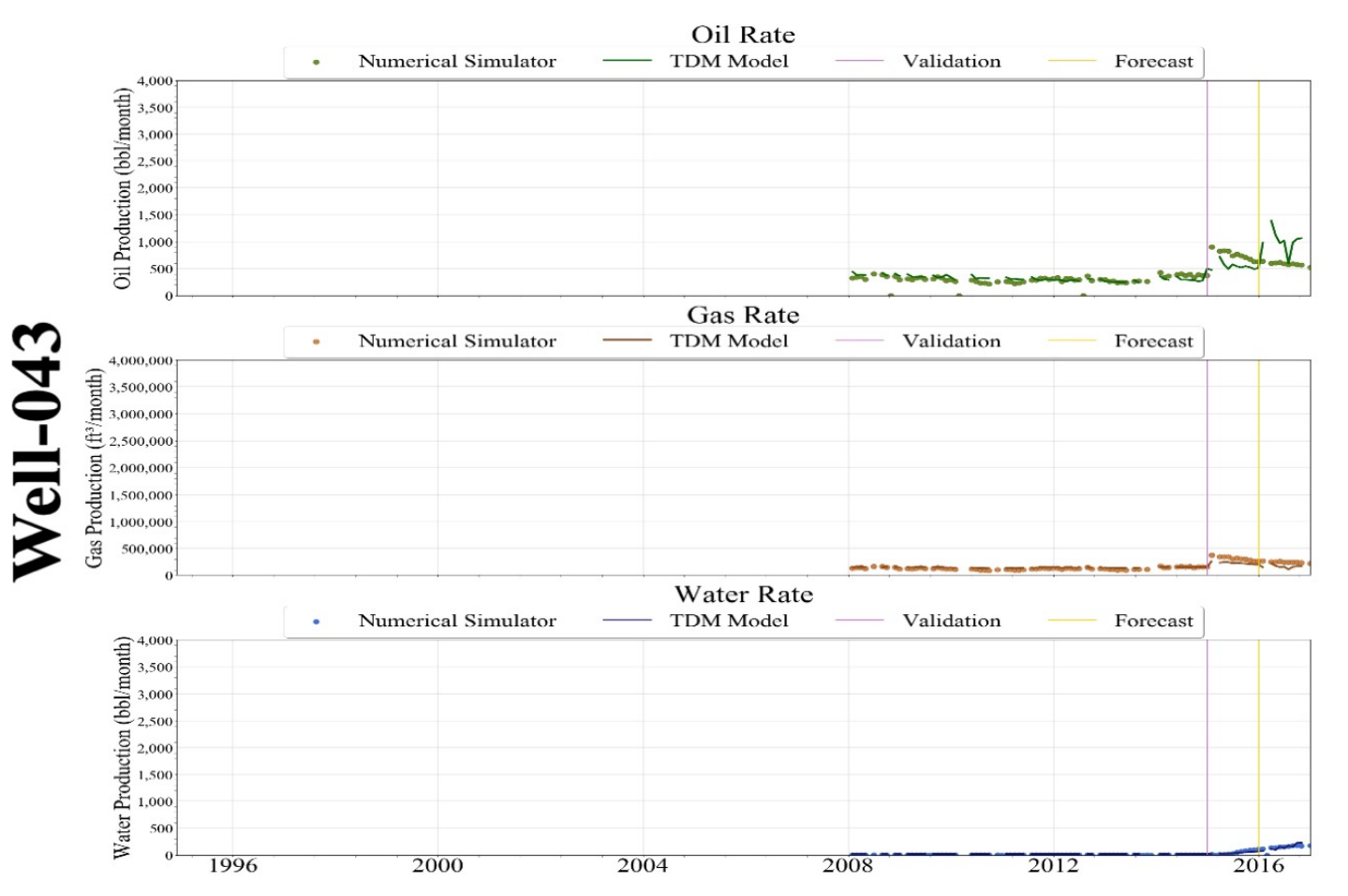

Figure 12-80: Scenario 4 - Well-043 Forecast Production 


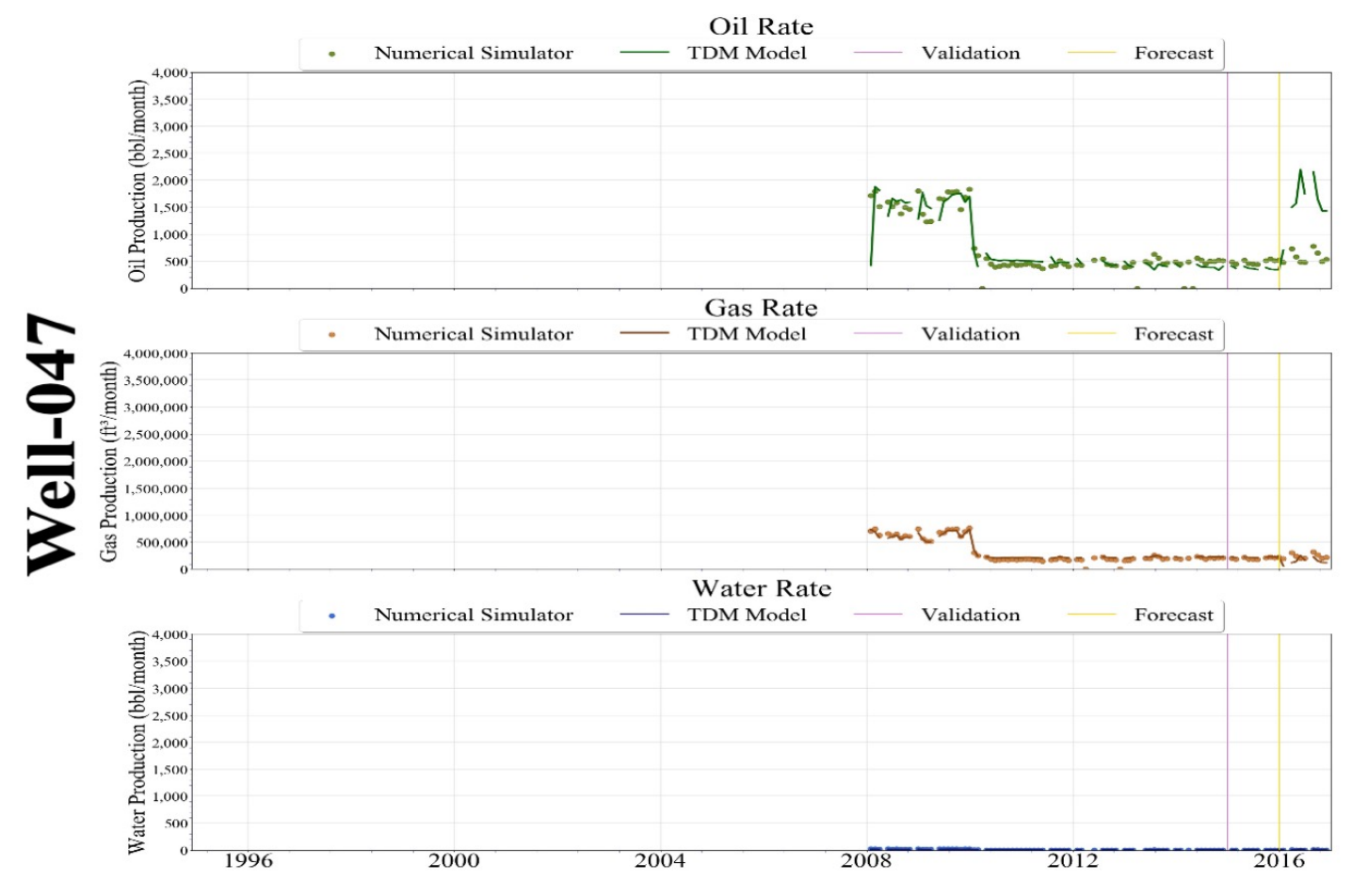

Figure 12-81: Scenario 4 - Well-047 Forecast Production

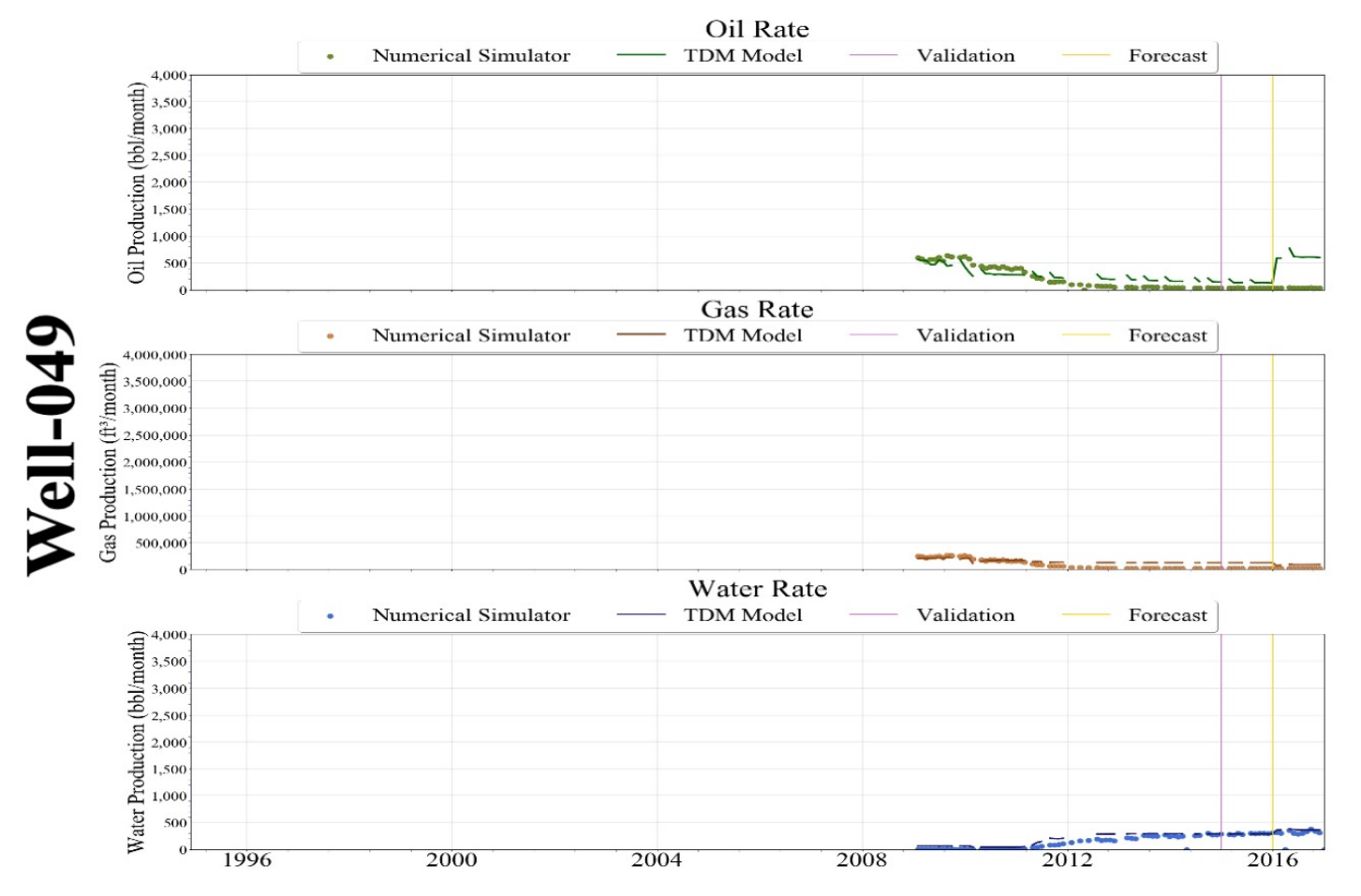

Figure 12-82: Scenario 4 - Well-049 Forecast Production 


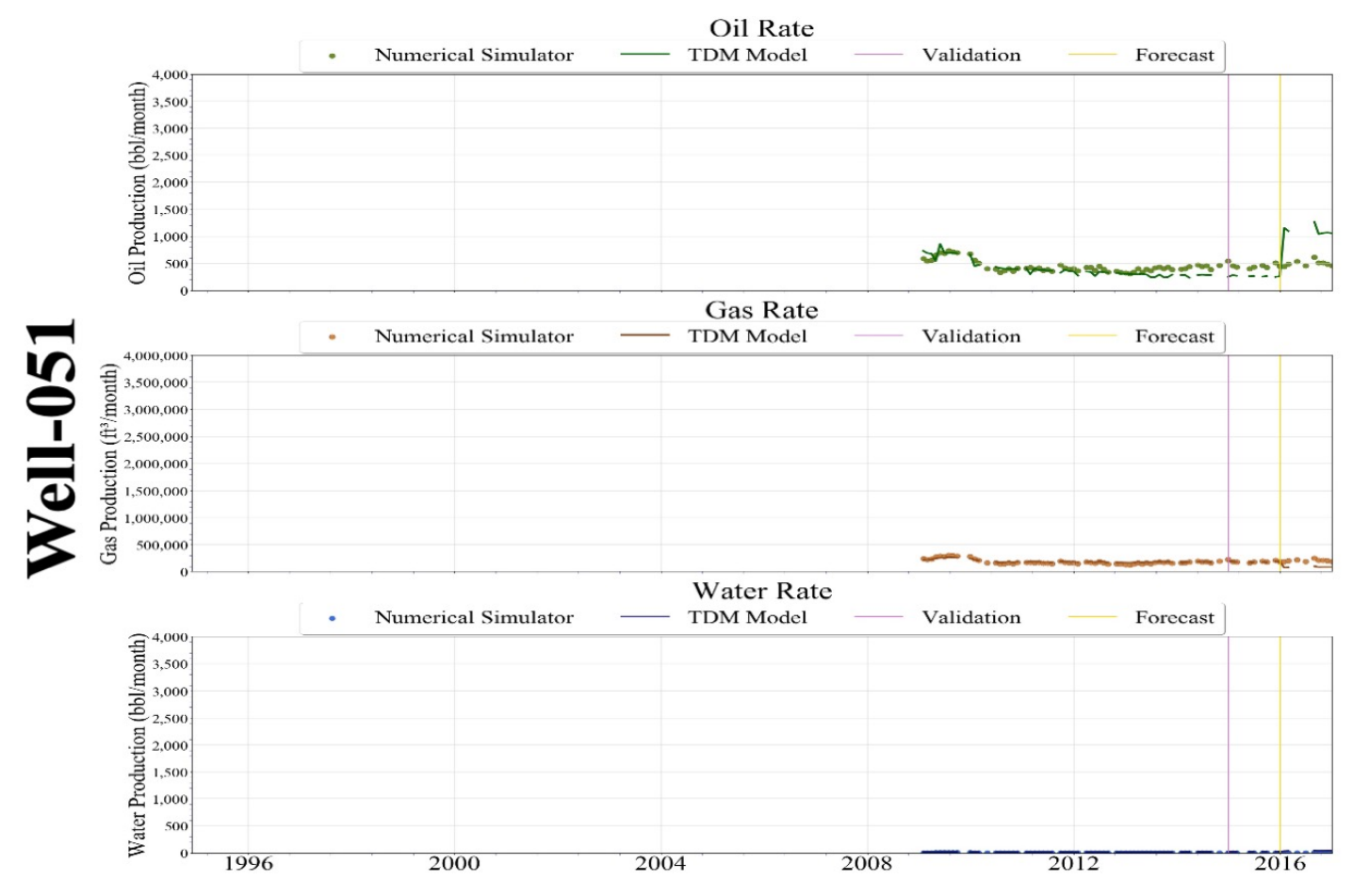

Figure 12-83: Scenario 4 - Well-051 Forecast Production 


\subsubsection{Poor Forecast Production}

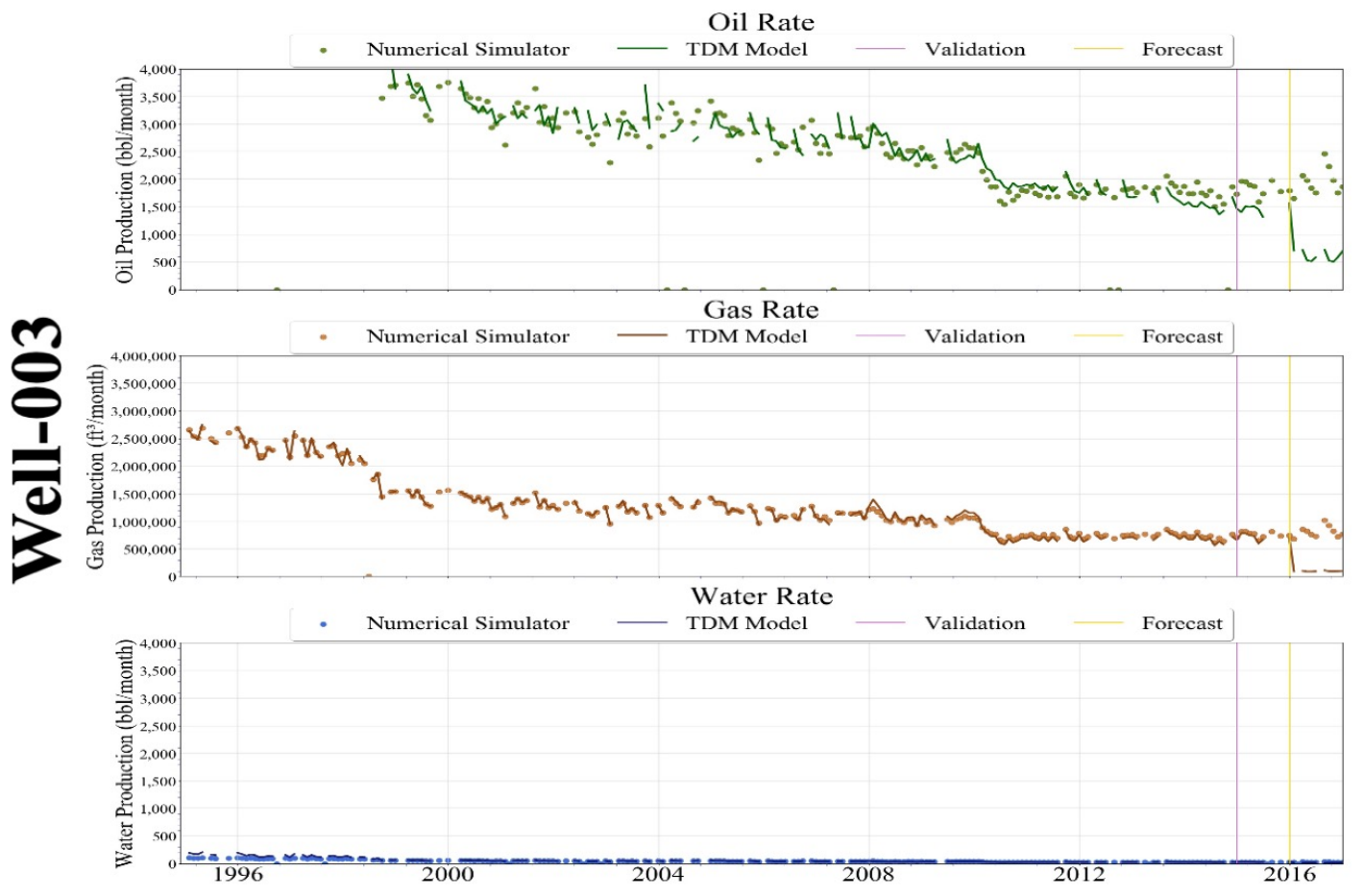

Figure 12-84: Scenario 4 - Well-003 Forecast Production

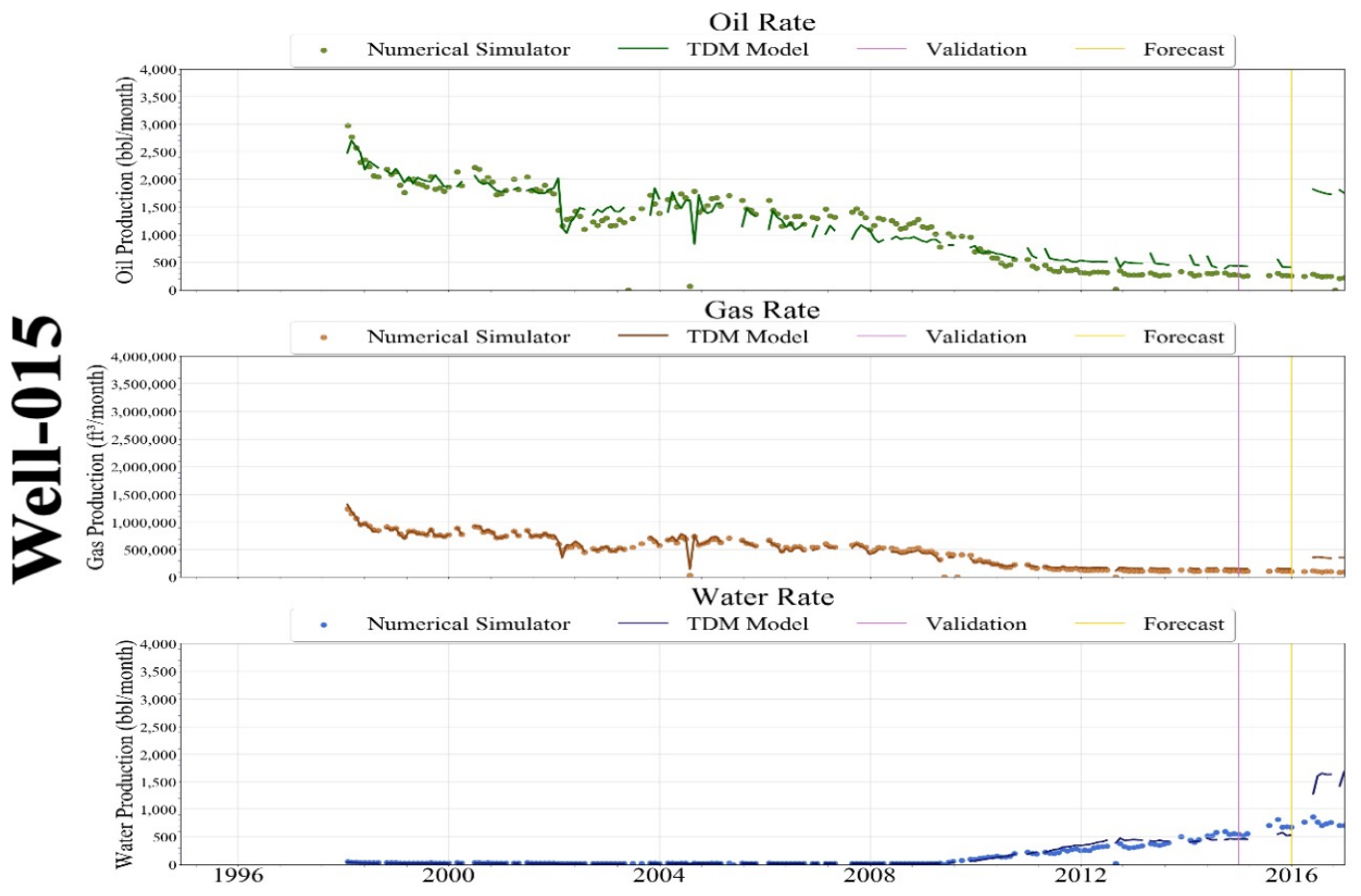

Figure 12-85: Scenario 4 - Well-015 Forecast Production 


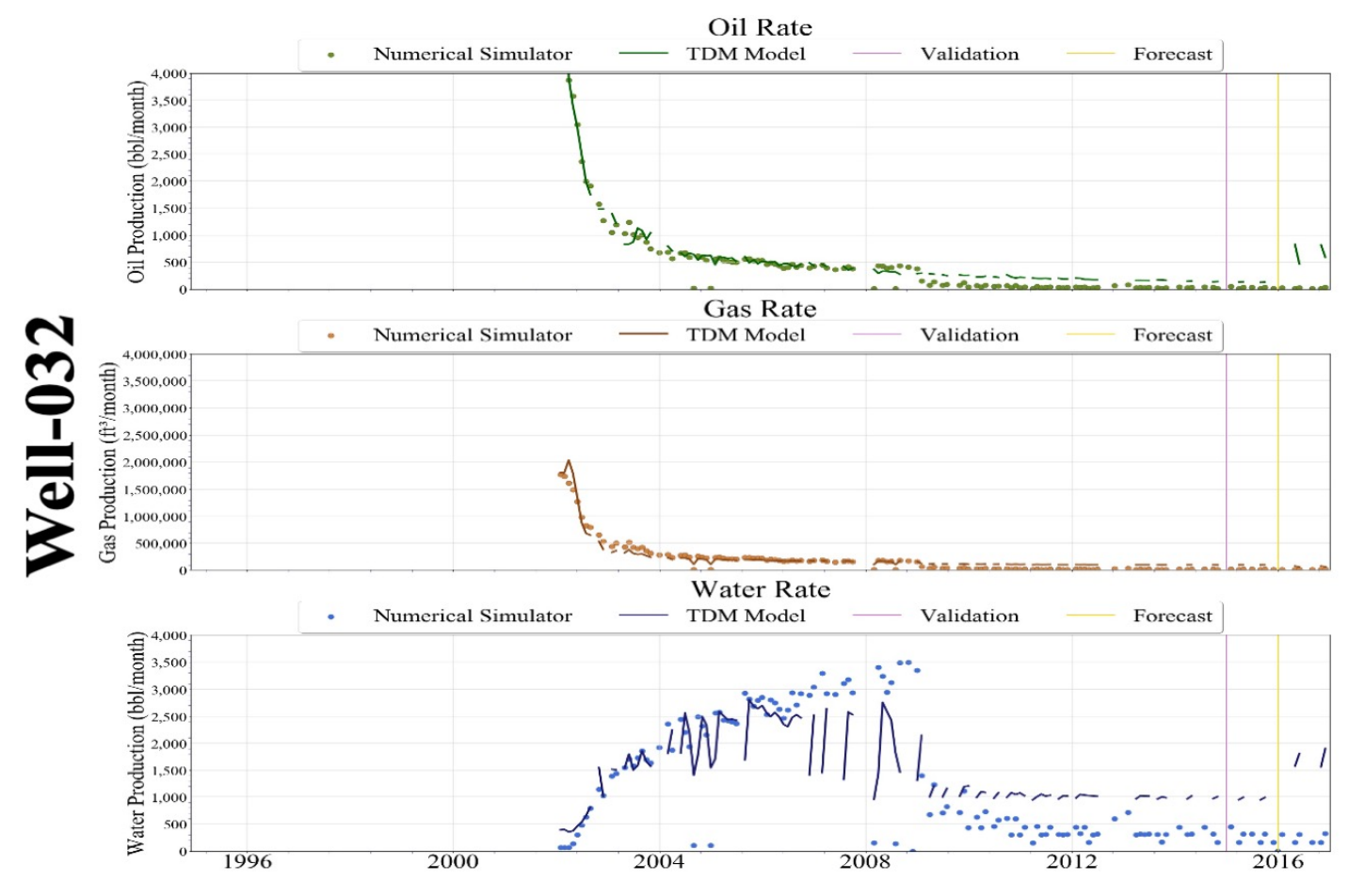

Figure 12-86: Scenario 4 - Well-032 Forecast Production

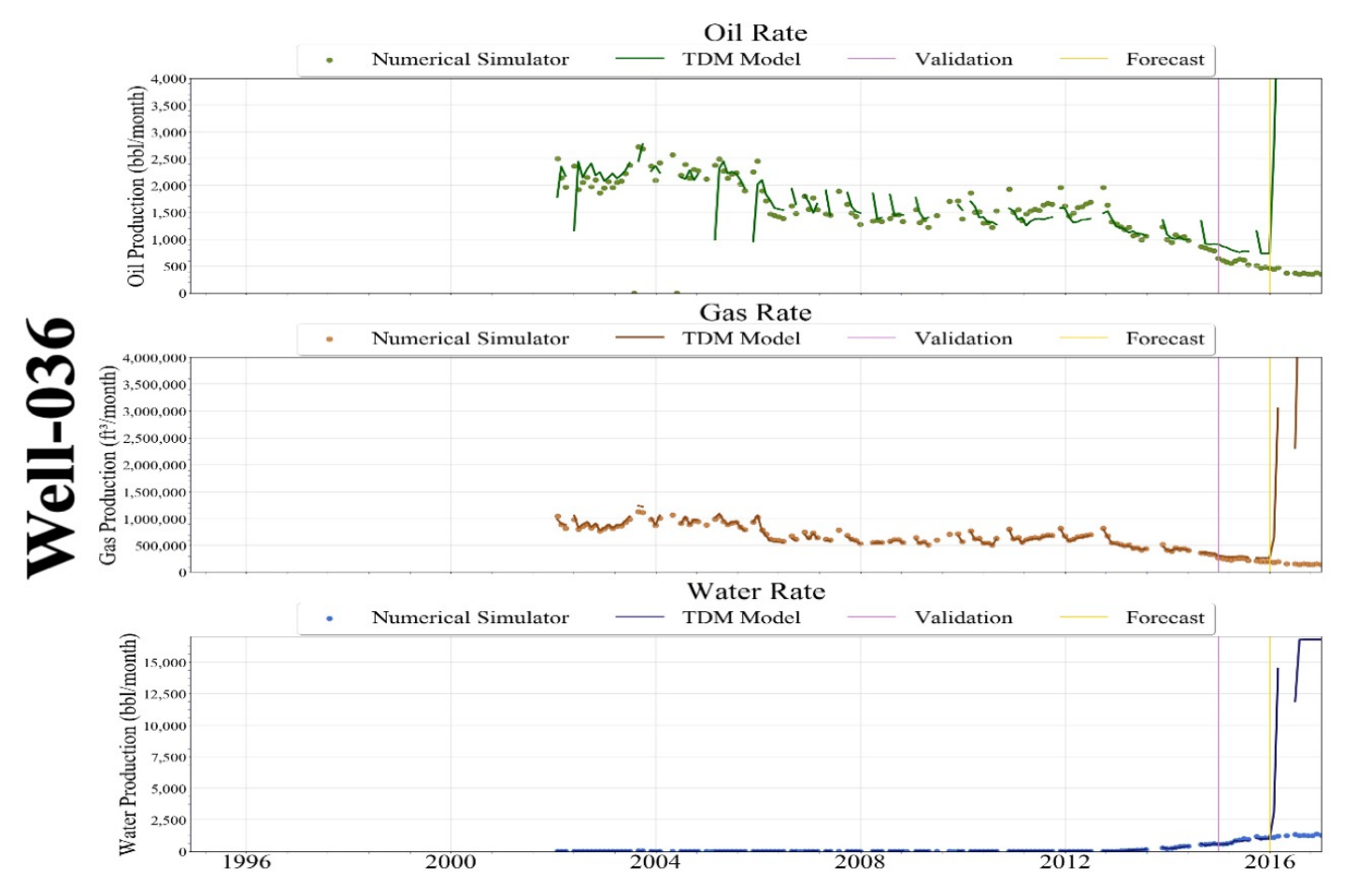

Figure 12-87: Scenario 4 - Well-036 Forecast Production 


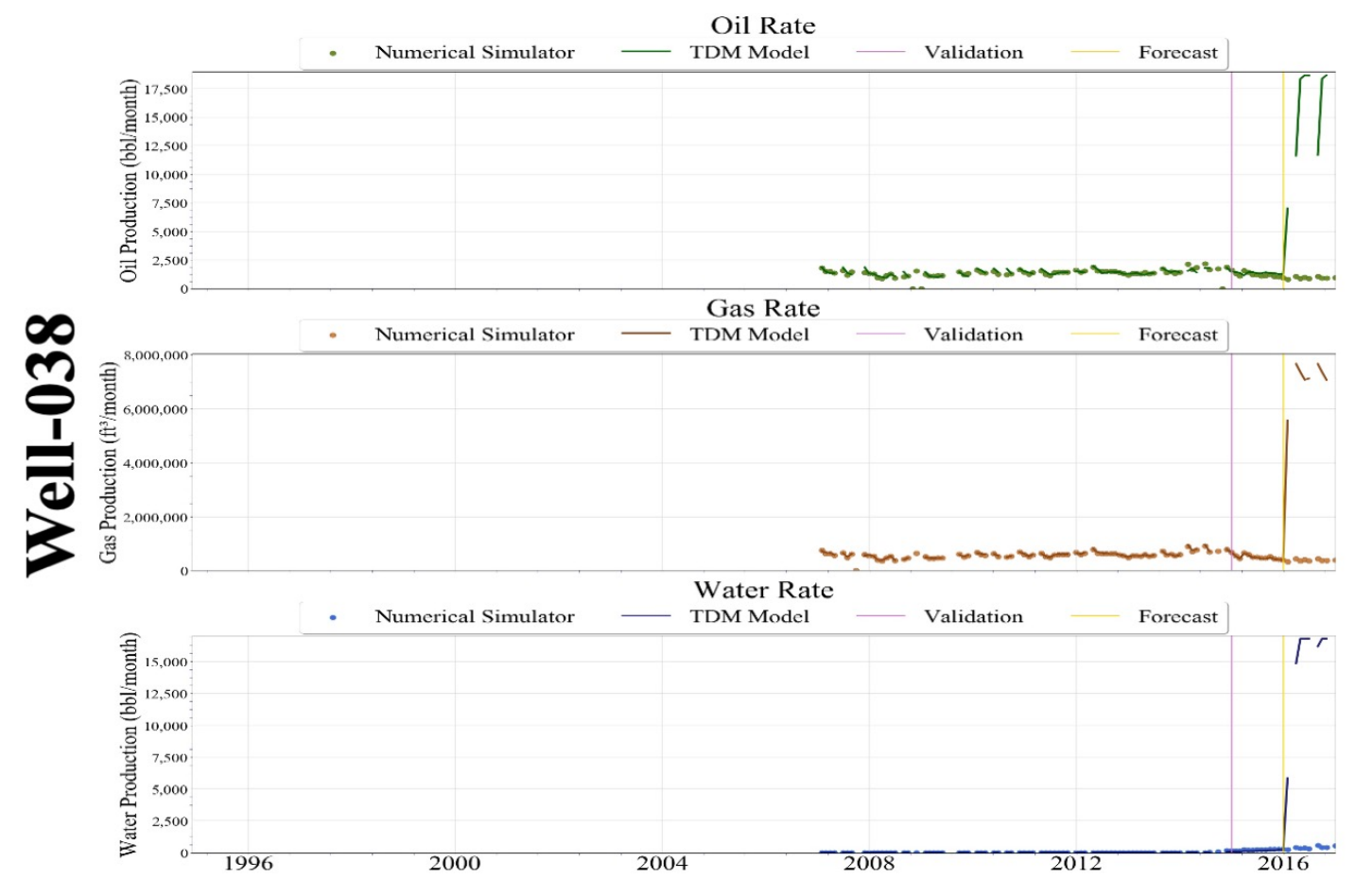

Figure 12-88: Scenario 4 - Well-038 Forecast Production

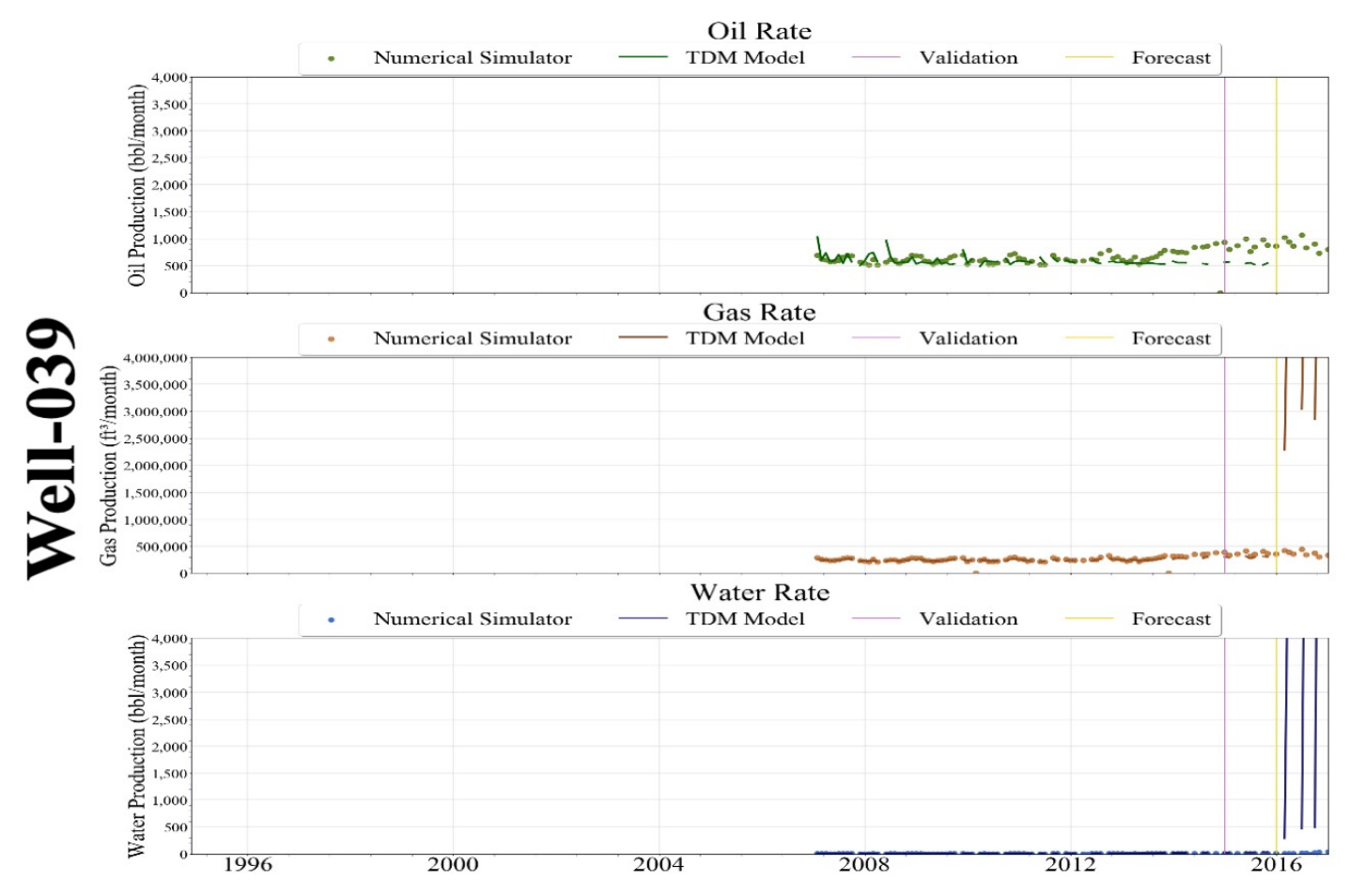

Figure 12-89: Scenario 4 - Well-039 Forecast Production 


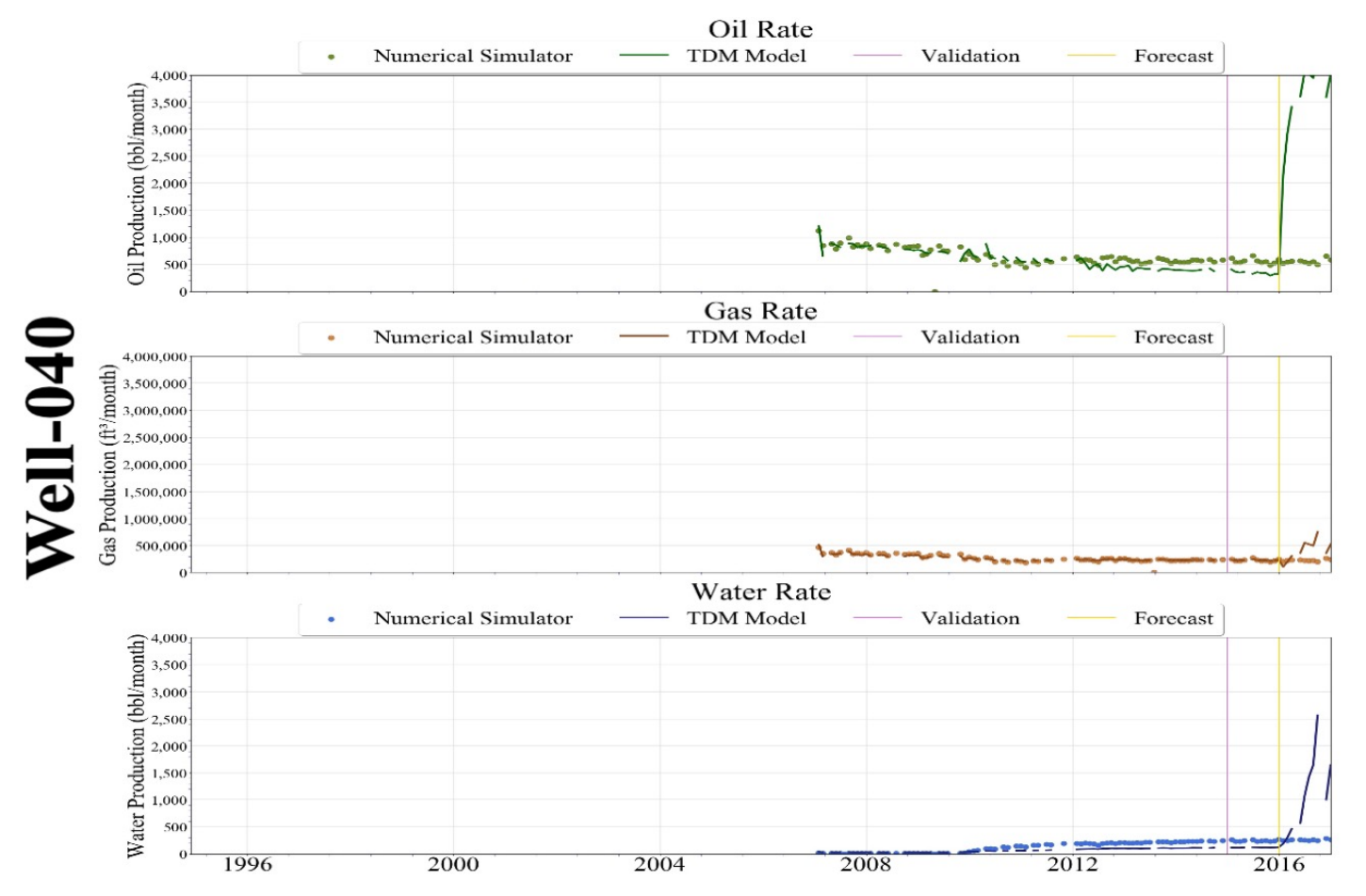

Figure 12-90: Scenario 4 - Well-040 Forecast Production

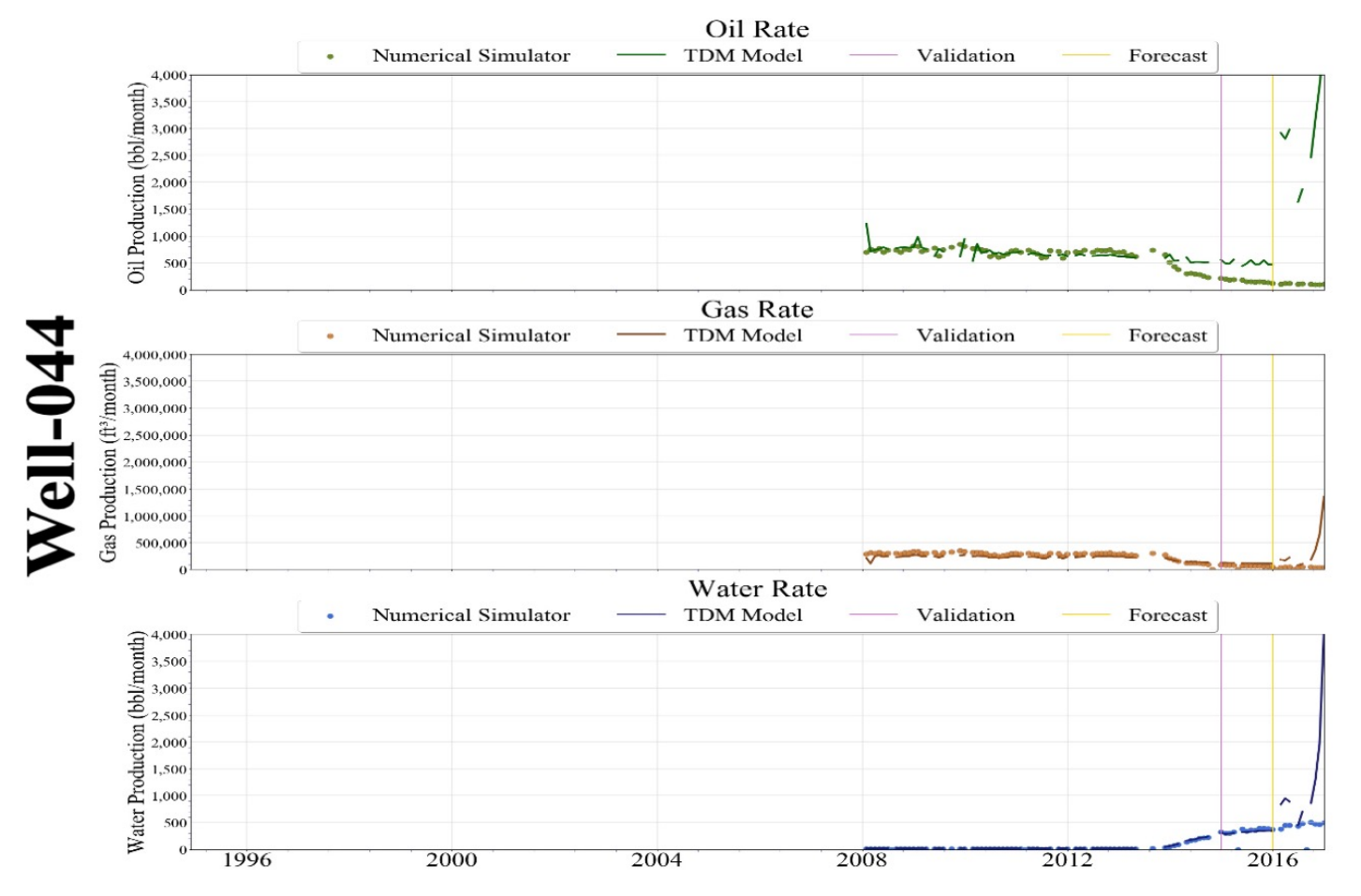

Figure 12-91: Scenario 4 - Well-044 Forecast Production 


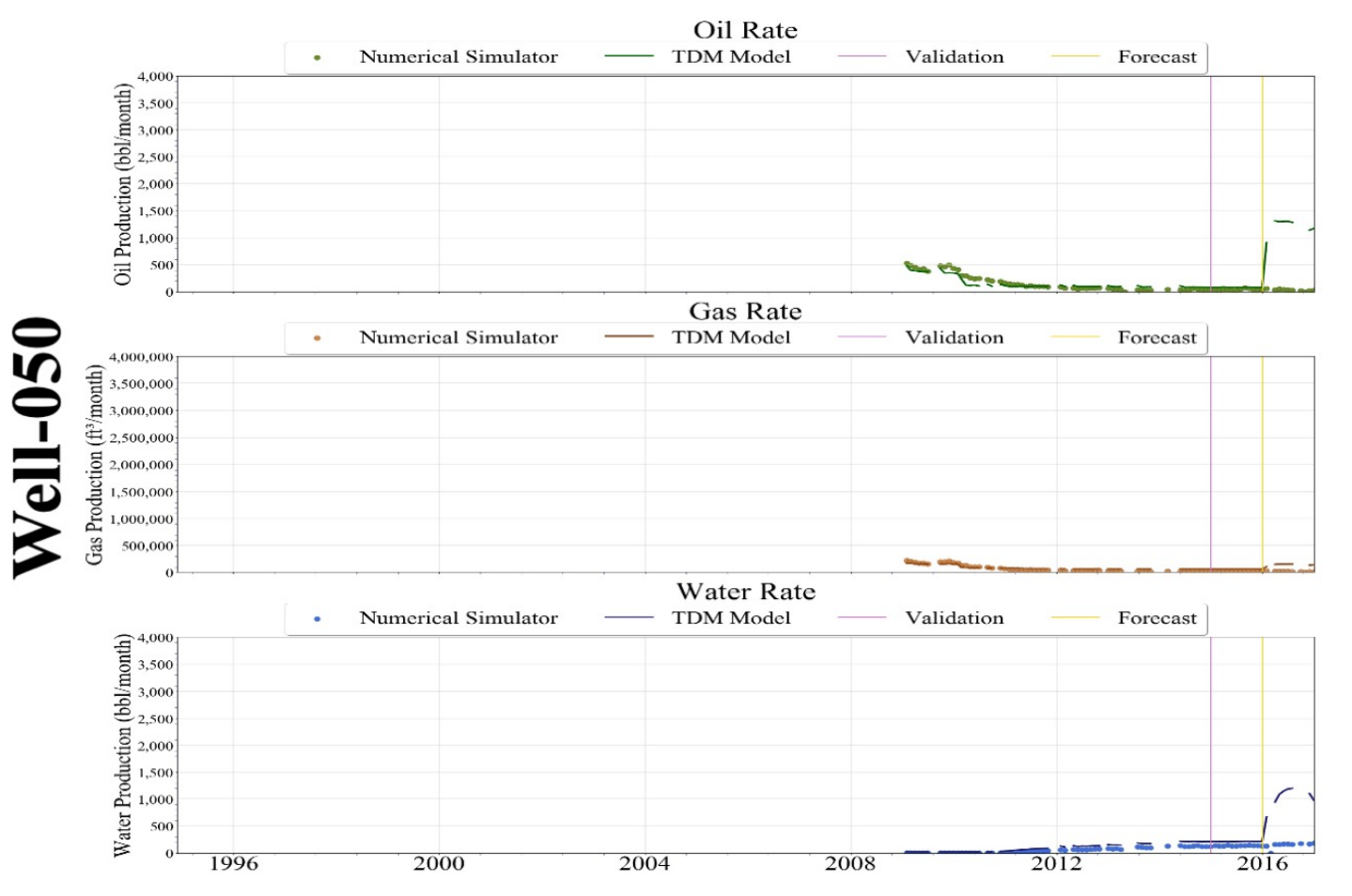

Figure 12-92: Scenario 4 - Well-050 Forecast Production

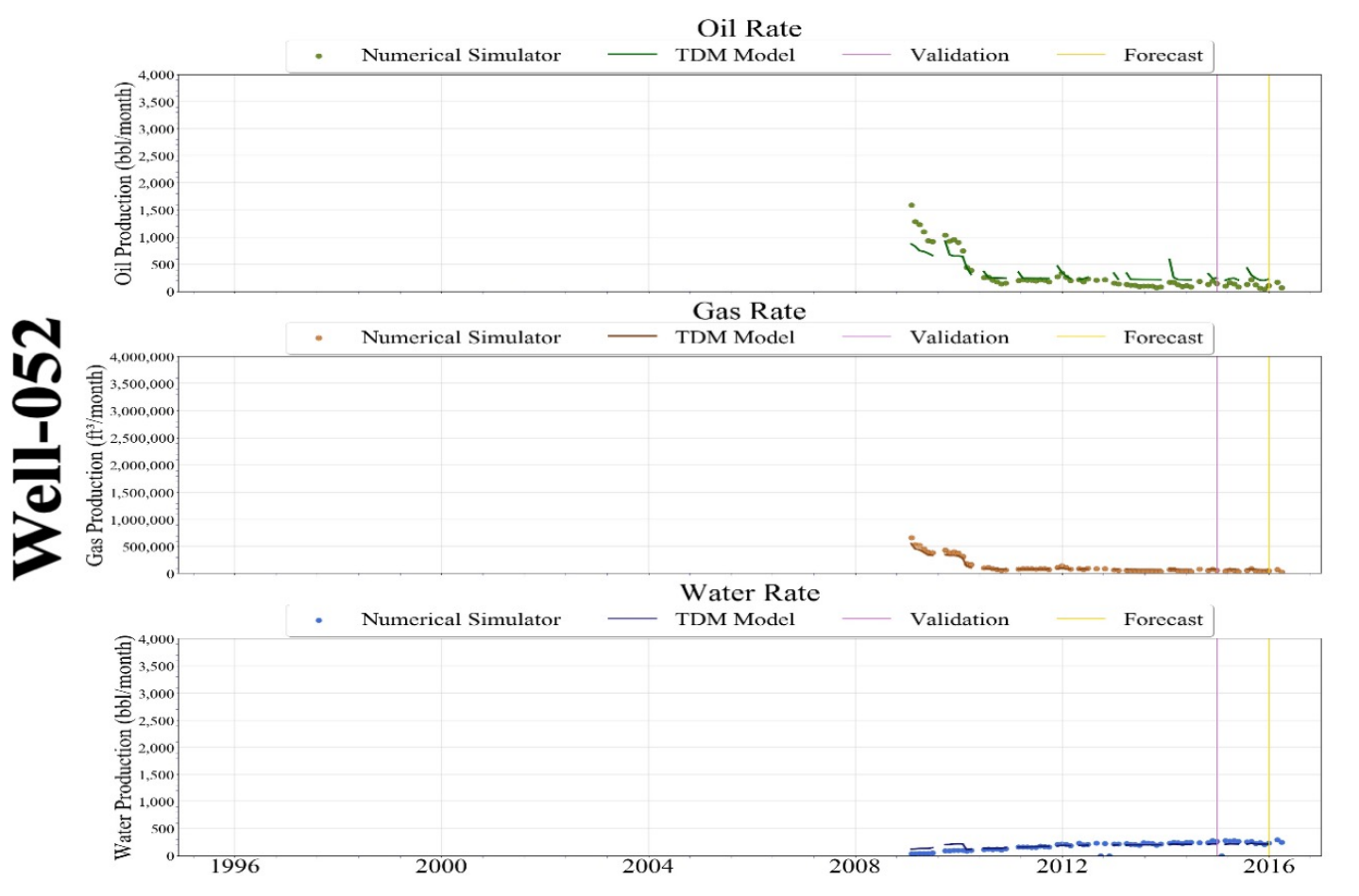

Figure 12-93: Scenario 4 - Well-052 Forecast Production 


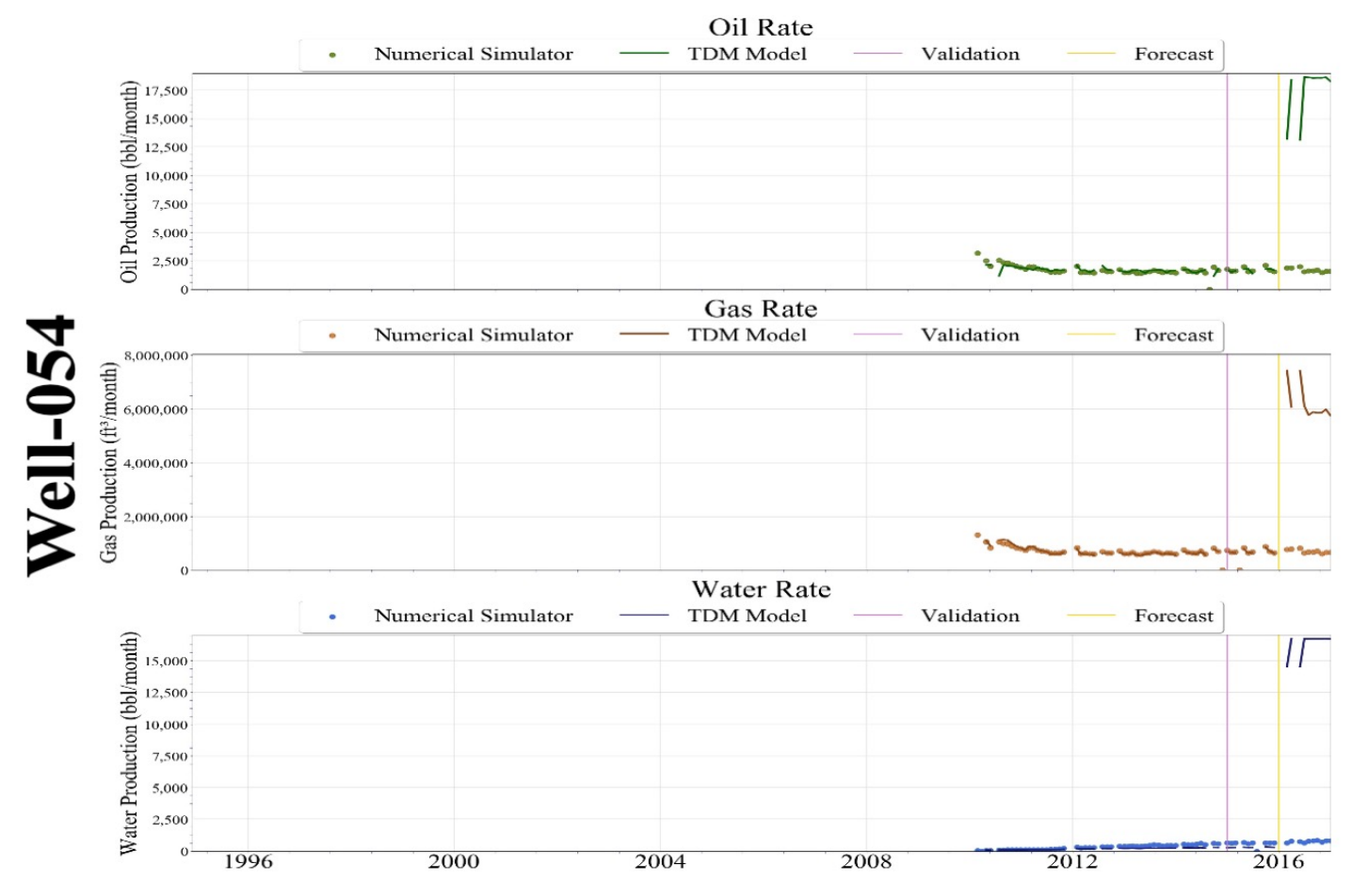

Figure 12-94: Scenario 4 - Well-054 Forecast Production

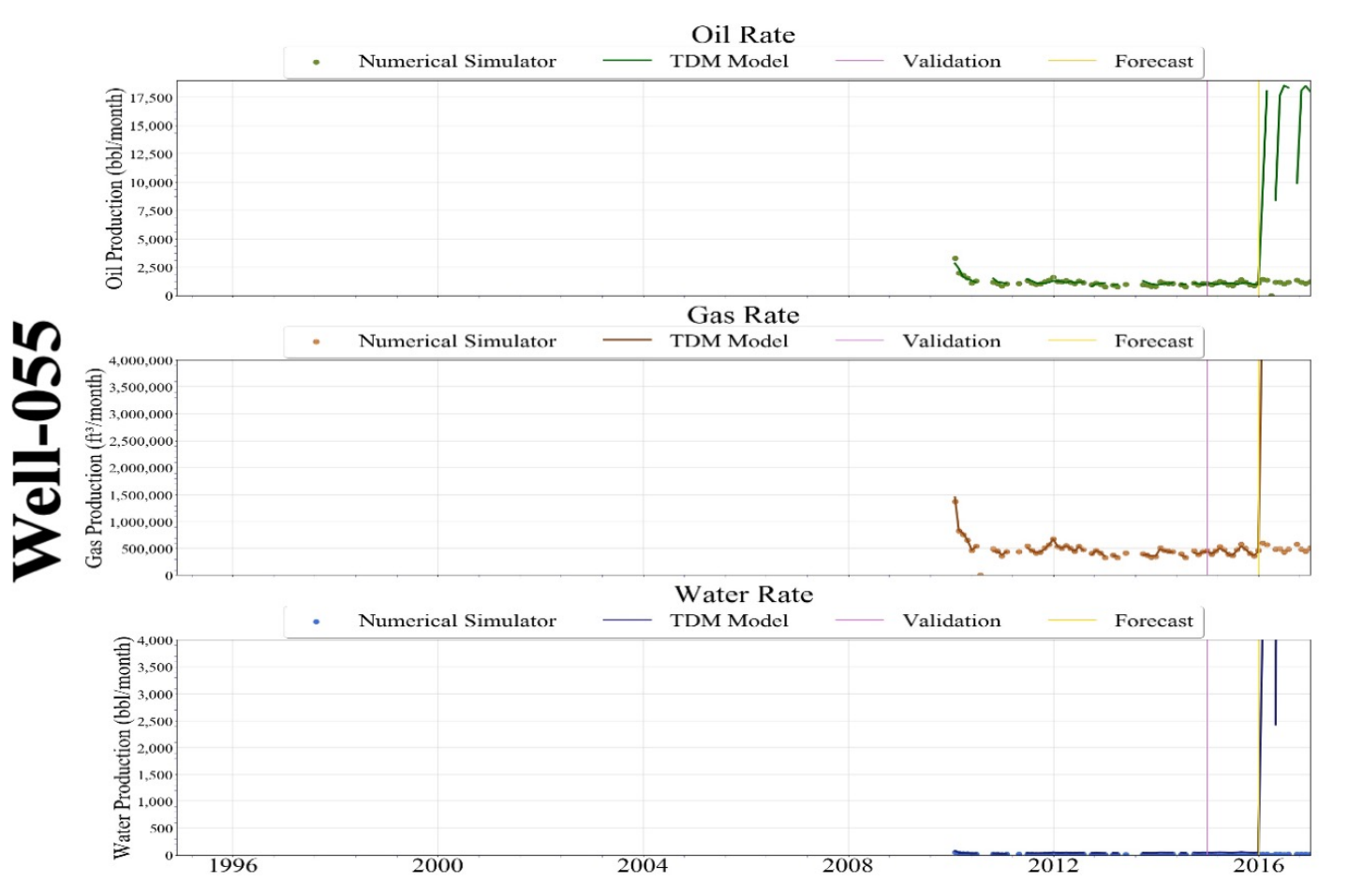

Figure 12-95: Scenario 4 - Well-055 Forecast Production 


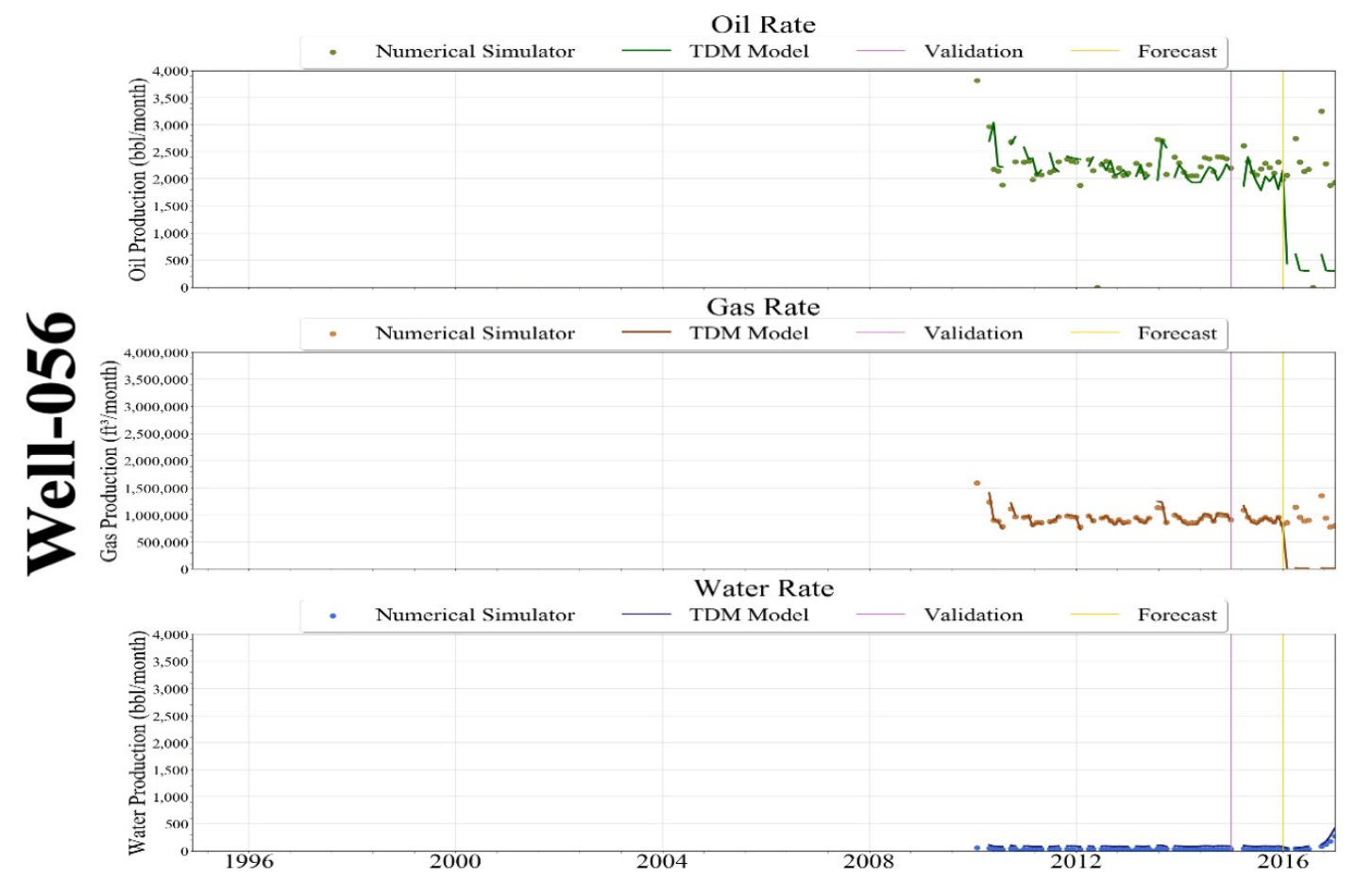

Figure 12-96: Scenario 4 - Well-056 Forecast Production 


\subsection{Distributions Maps}

Distribution maps are presented at different timesteps, including the beginning, middle, and end of the year.

Reservoir Pressure (psi) at 2014-01-31
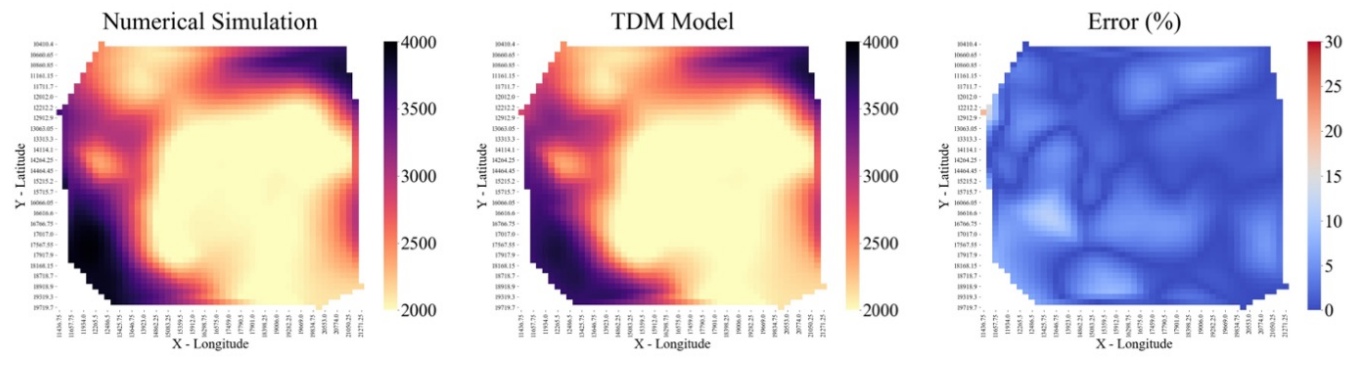

Water Saturation (\%) at 2014-01-31
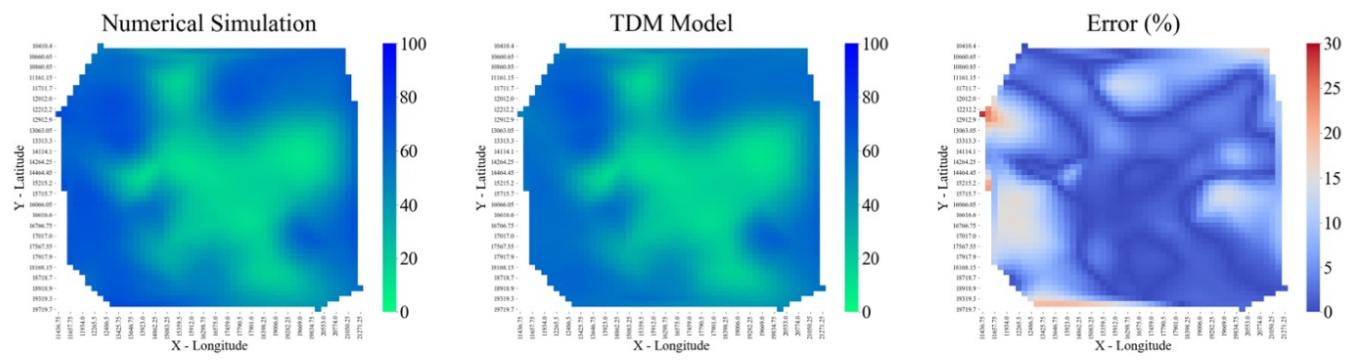

Reservoir Pressure (psi) at 2014-06-30
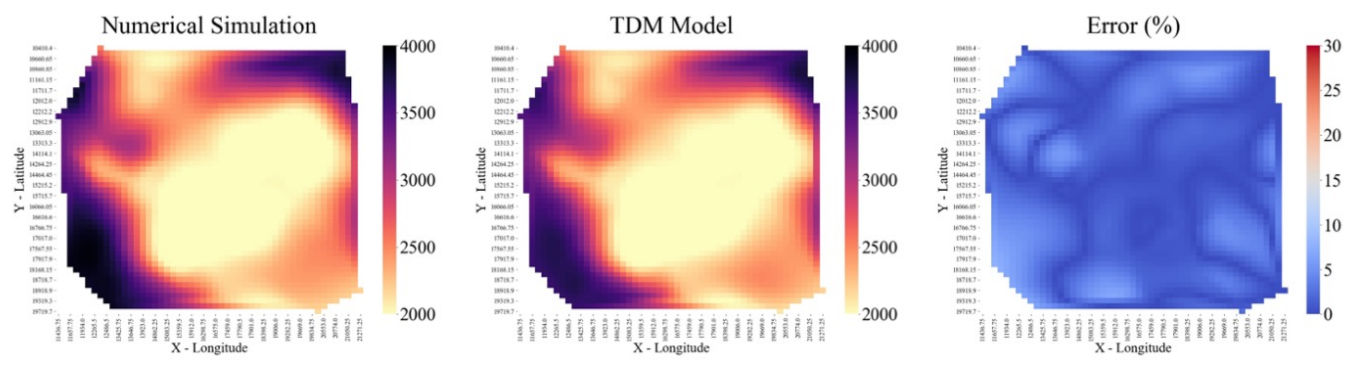

Water Saturation (\%) at 2014-06-30
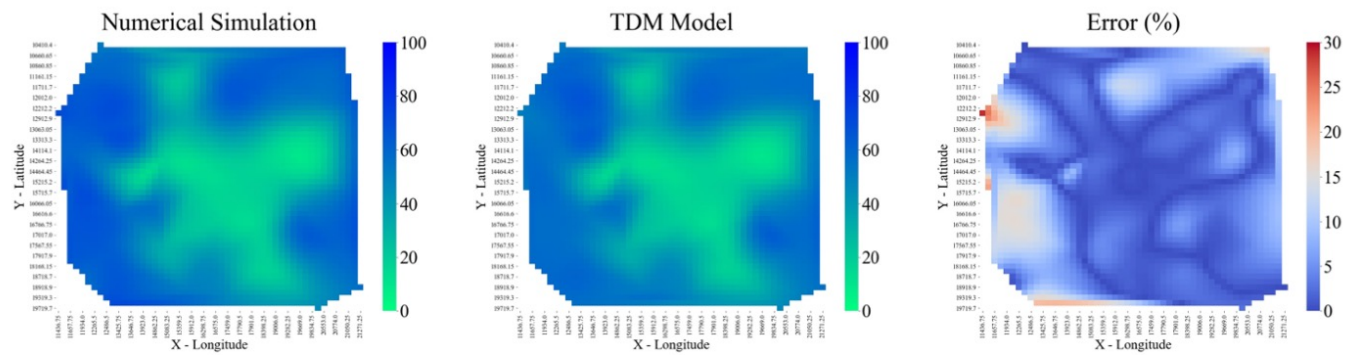
Reservoir Pressure (psi) at 2014-12-31
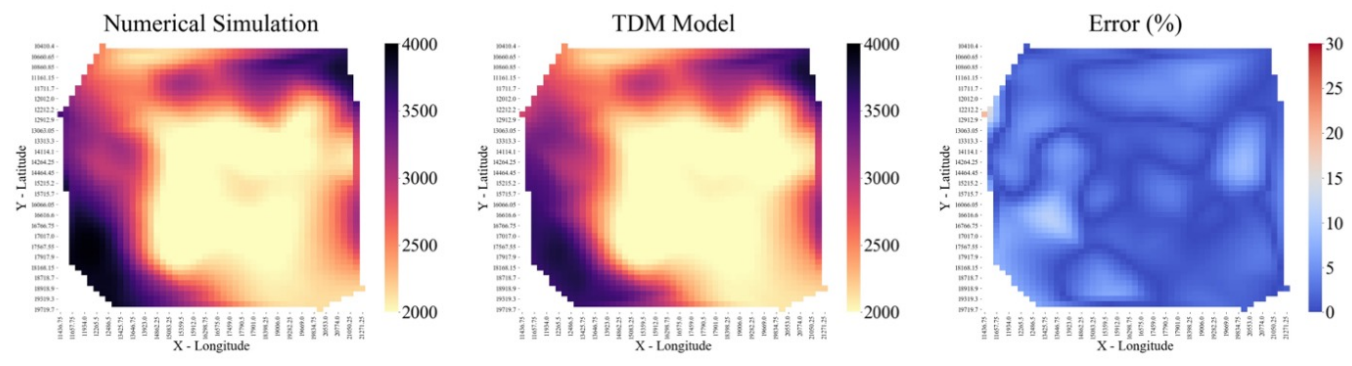

Water Saturation (\%) at 2014-12-31
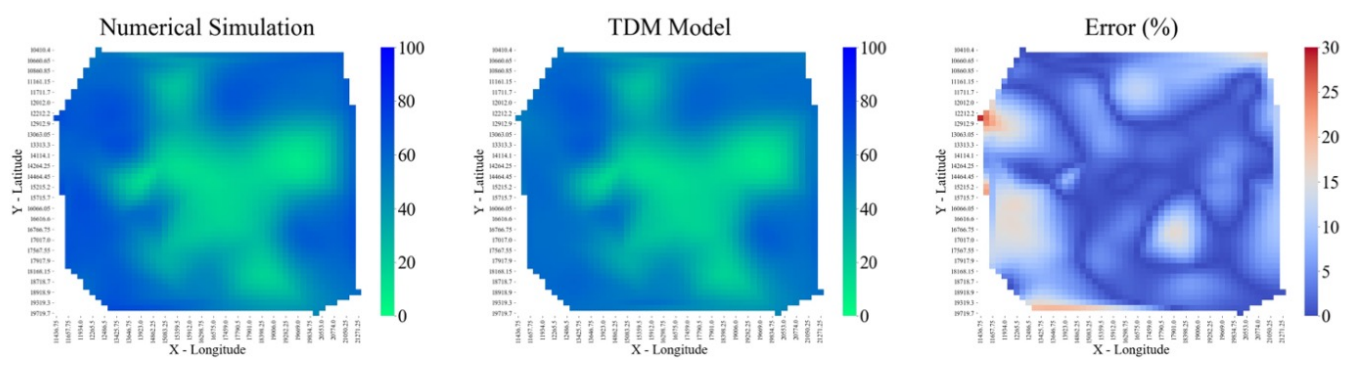

Reservoir Pressure (psi) at 2015-06-30
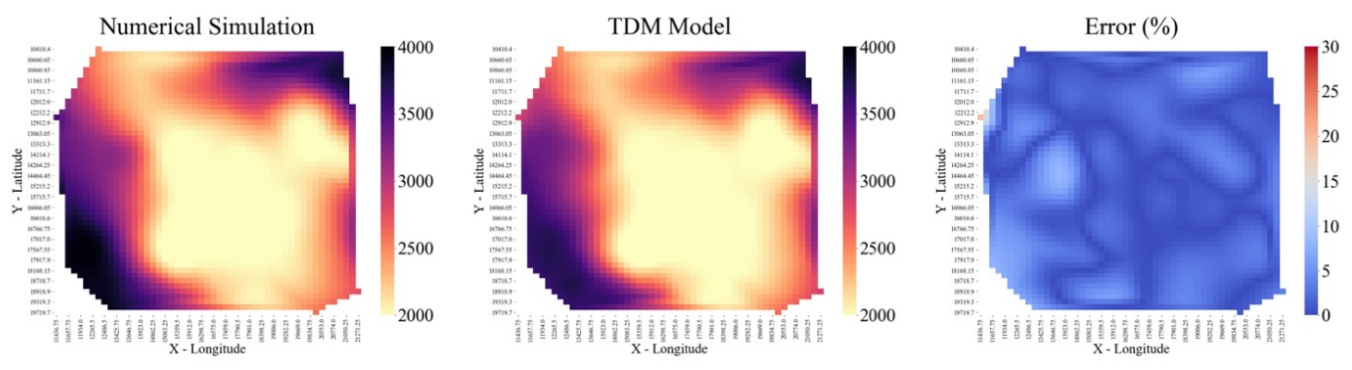

Water Saturation (\%) at 2015-06-30
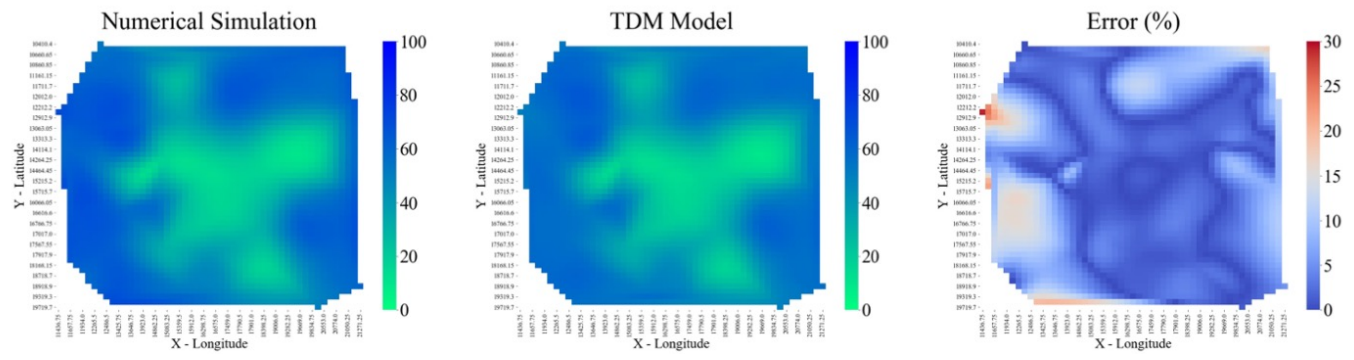
Reservoir Pressure (psi) at 2015-12-31
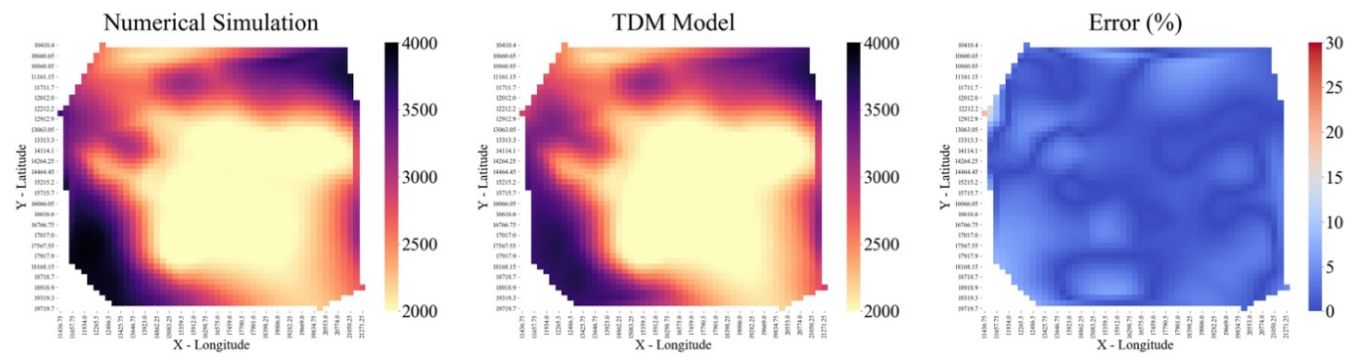

Water Saturation (\%) at 2015-12-31
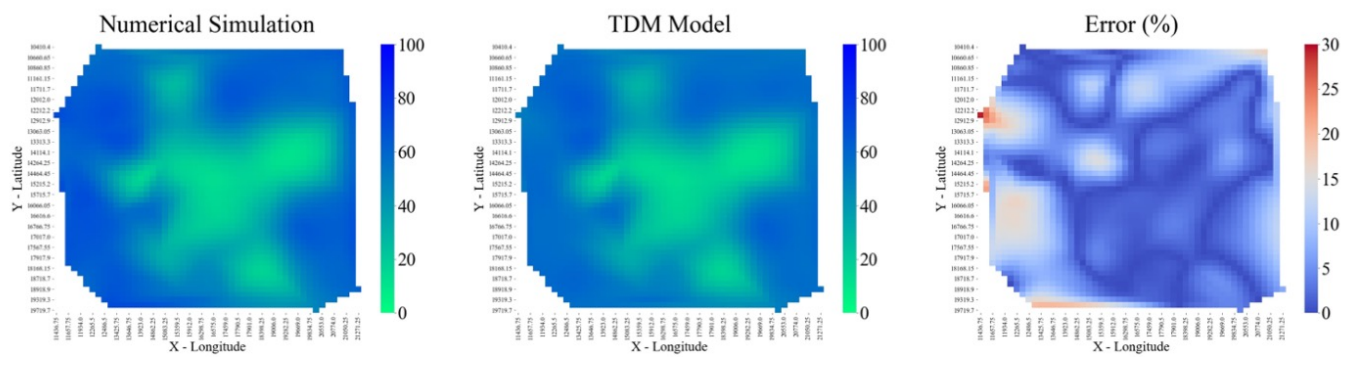

Reservoir Pressure (psi) at 2016-06-30
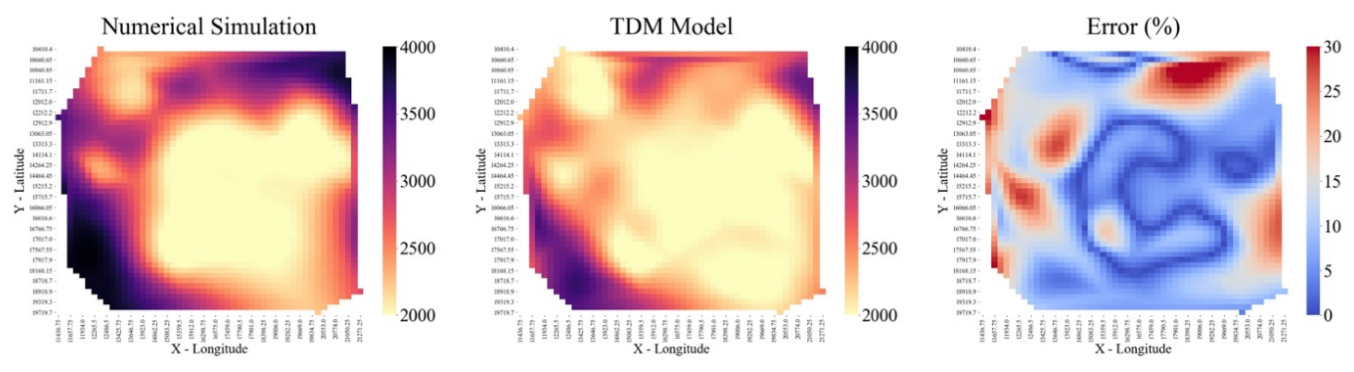

Water Saturation (\%) at 2016-06-30
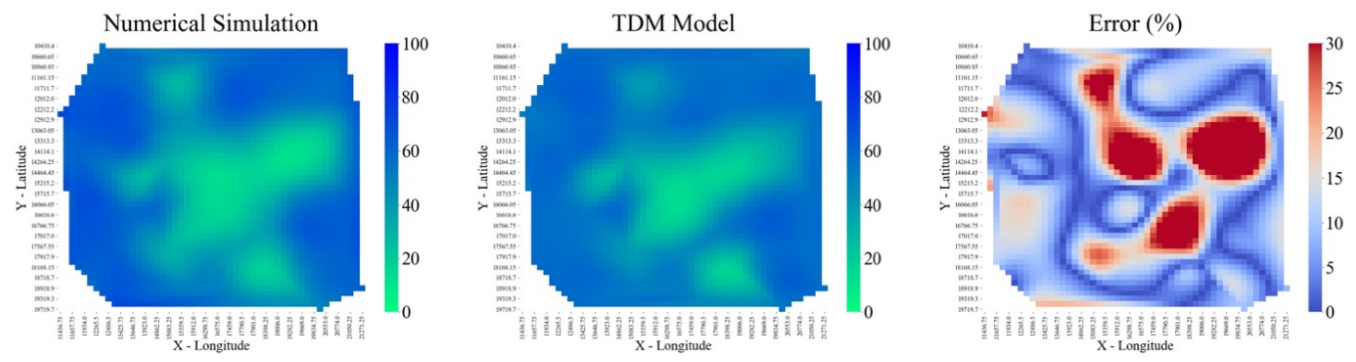
Reservoir Pressure (psi) at 2016-12-31
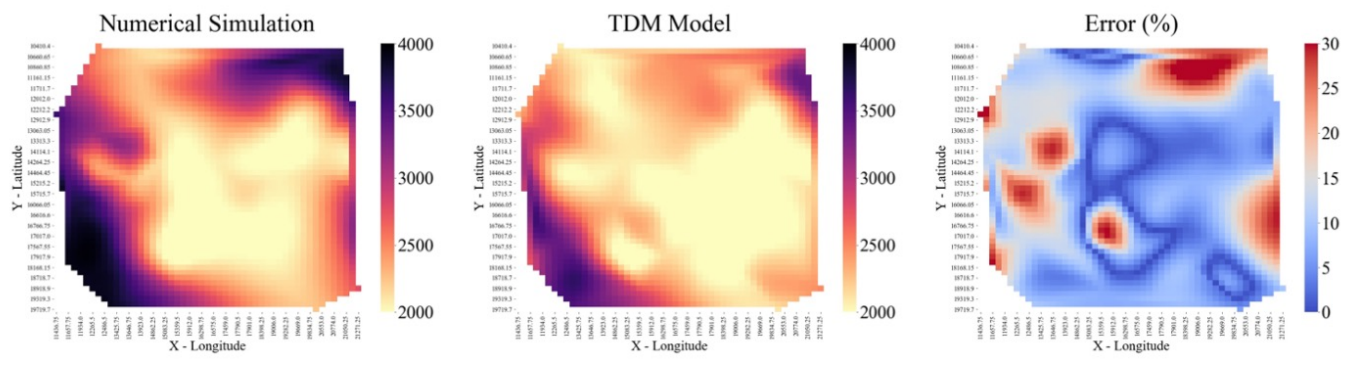

Water Saturation (\%) at 2016-12-31
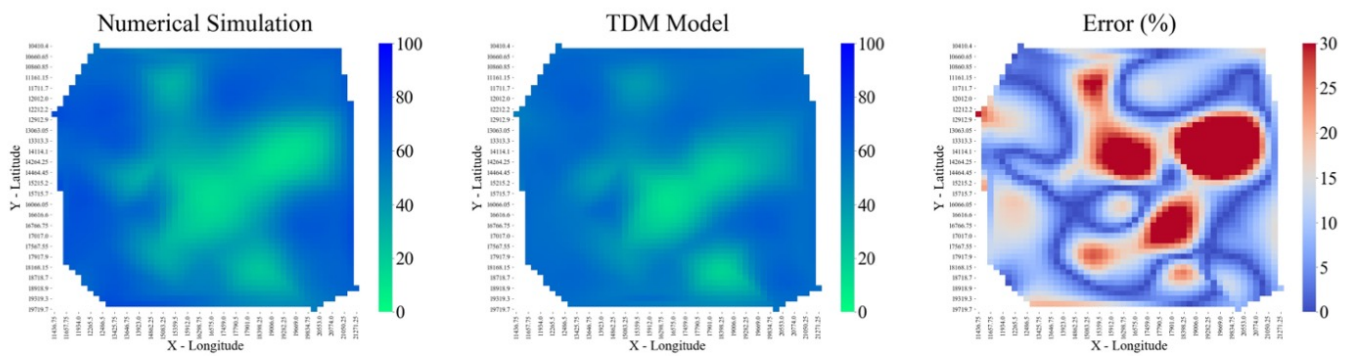

Figure 12-97: Scenario 4 - Distribution Maps at Different Timesteps 


\section{Appendix G: Scenario 5 - Mixed Partitioning (2 Year Forecast)}

\subsection{Input Attributes}

The number of input attributes used in the development of each data-driven model was based on KPI analysis and domain expertise. The following tables provide a list of static and dynamic attributes for both the focal and offset wells. Each table is composed of three columns that indicate the ranking, name of the input attribute, and its degree of influence (DOI) with respect to the output model.

\subsubsection{Oil Predictive Model}

Oil Model - Input Attributes

\begin{tabular}{|c|c|c|c|c|c|}
\hline \multicolumn{3}{|c|}{ FOCAL WELL } & \multicolumn{3}{|c|}{ OFFSET WELLS } \\
\hline \multicolumn{3}{|c|}{ Static Attributes } & \multicolumn{3}{|c|}{ Static Attributes } \\
\hline Rank & \begin{tabular}{|l|} 
Attribute \\
\end{tabular} & DOI & Rank & Attribute & DOI \\
\hline & Porh(1-sw) & 100 & 2 & Porh(1-sw)(1I) & 91 \\
\hline 2 & Porosity $(\%)$ & 90 & 3 & Top (ft)(1I) & 90 \\
\hline & TVD(ft) & 73 & 5 & TVD $(\mathrm{ft})(1 \mathrm{I})$ & 73 \\
\hline \multicolumn{3}{|c|}{3} & 6 & Top (ft)(2P) & 65 \\
\hline & & & 9 & $\operatorname{TVD}(\mathrm{ft})(1 \mathrm{P})$ & 55 \\
\hline \multicolumn{3}{|c|}{ Dynamic Attributes } & 10 & $\mathrm{X} /$ Longitude(1P) & 52 \\
\hline & Oil Rate (t-1) & 100 & 11 & Pay thickness $(\mathrm{ft})(1 \mathrm{P})$ & 50 \\
\hline & Gas Rate $(\mathrm{t}-1)$ & 100 & \multicolumn{3}{|c|}{7} \\
\hline & Permeability I(t-1) & 49 & & & \\
\hline 4 & Time & 48 & \multicolumn{3}{|c|}{ Dynamic Attributes } \\
\hline 9 & Completion $(\mathrm{ft})(\mathrm{t})$ & 12 & 1 & FBH Pressure $(\mathrm{psi})(\mathrm{t})(1 \mathrm{I})$ & 100 \\
\hline \multicolumn{3}{|c|}{5} & 2 & Distance $(\mathrm{t}-1)(2 \mathrm{P})$ & 97 \\
\hline & & & 3 & FBH Pressure (psi)(t-1)(1I) & 96 \\
\hline \multirow[t]{8}{*}{ TOTA } & AL ATTRIBUTES & 25 & 4 & Reservoir Pressure $(\mathrm{psi})(\mathrm{t}-1)(1 \mathrm{I})$ & 96 \\
\hline & & & 5 & Distance $(\mathrm{t})(2 \mathrm{P})$ & 96 \\
\hline & & & 6 & FBH Pressure $(\mathrm{psi})(\mathrm{t})(2 \mathrm{I})$ & 93 \\
\hline & & & 7 & FBH Pressure $(\mathrm{psi})(\mathrm{t}-1)(2 \mathrm{I})$ & 92 \\
\hline & & & 8 & Reservoir Pressure $(\mathrm{psi})(\mathrm{t}-1)(2 \mathrm{I})$ & 92 \\
\hline & & & 9 & Water Saturation $(\%)(\mathrm{t}-1)(2 \mathrm{I})$ & 87 \\
\hline & & & 10 & Oil Saturation $(\%)(\mathrm{t}-1)(2 \mathrm{I})$ & 87 \\
\hline & & & \multicolumn{3}{|c|}{10} \\
\hline
\end{tabular}

Figure 13-1: Scenario 5 - Oil Model Input Attributes 


\subsubsection{Gas Predictive Model}

\section{Gas Model - Input Attributes}

\begin{tabular}{|c|c|c|c|c|c|}
\hline \multicolumn{3}{|c|}{ FOCAL WELL } & \multicolumn{3}{|c|}{ OFFSET WELLS } \\
\hline \multicolumn{3}{|c|}{ Static Attributes } & \multicolumn{3}{|c|}{ Static Attributes } \\
\hline Rank & Attribute & DOI & Rank & Attribute & DOI \\
\hline 11 & Porh(1-sw) & 100 & 1 & Completion (ft)(1P) & 100 \\
\hline 21 & Porosity $(\%)$ & 90 & 2 & Porh $(1-\mathrm{sw})(1 \mathrm{I})$ & 91 \\
\hline \multicolumn{3}{|c|}{2} & 3 & Top $(\mathrm{ft})(1 \mathrm{I})$ & 90 \\
\hline & & & 4 & $\mathrm{X} /$ Longitude(1I) & 84 \\
\hline \multicolumn{3}{|c|}{ Dynamic Attributes } & 5 & $\operatorname{TVD}(\mathrm{ft})(1 \mathrm{I})$ & 73 \\
\hline 1 & Oil Rate $(\mathrm{t})$ & 100 & 8 & Y/Latitude(1I) & 56 \\
\hline 2 & Oil Rate (t-1) & 60 & \multicolumn{3}{|c|}{6} \\
\hline 3 & Gas Rate $(\mathrm{t}-1)$ & 60 & & & \\
\hline 41 & Permeability I(t-1) & 29 & \multicolumn{3}{|c|}{ Dynamic Attributes } \\
\hline \multicolumn{3}{|c|}{4} & 1 & FBH Pressure $(\mathrm{psi})(\mathrm{t})(1 \mathrm{I})$ & 100 \\
\hline & & & 2 & Distance $(\mathrm{t}-1)(2 \mathrm{P})$ & 97 \\
\hline \multirow[t]{9}{*}{ TOT } & AL ATTRIBUTES & 22 & 3 & FBH Pressure $(\mathrm{psi})(\mathrm{t}-1)(1 \mathrm{I})$ & 96 \\
\hline & & & 4 & Reservoir Pressure $(\mathrm{psi})(\mathrm{t}-1)(1 \mathrm{I})$ & 96 \\
\hline & & & 5 & Distance $(\mathrm{t})(2 \mathrm{P})$ & 96 \\
\hline & & & 6 & FBH Pressure $(\mathrm{psi})(\mathrm{t})(2 \mathrm{I})$ & 93 \\
\hline & & & 7 & FBH Pressure $(\mathrm{psi})(\mathrm{t}-1)(2 \mathrm{I})$ & 92 \\
\hline & & & 8 & Reservoir Pressure $(\mathrm{psi})(\mathrm{t}-1)(2 \mathrm{I})$ & 92 \\
\hline & & & 9 & Water Saturation $(\%)(\mathrm{t}-1)(2 \mathrm{I})$ & 87 \\
\hline & & & 10 & Oil Saturation $(\%)(\mathrm{t}-1)(2 \mathrm{I})$ & 87 \\
\hline & & & \multicolumn{3}{|c|}{10} \\
\hline
\end{tabular}

Figure 13-2: Scenario 5 - Gas Model Input Attributes 


\subsubsection{Water Predictive Model}

\section{Water Model - Input Attributes}

\begin{tabular}{|c|c|c|}
\hline \multicolumn{3}{|c|}{ FOCAL WELL } \\
\hline \multicolumn{3}{|c|}{ Static Attributes } \\
\hline Rank & Attribute & DOI \\
\hline 1 & Permeability (md) & 100 \\
\hline 2 & $\mathrm{X} /$ Longitude & 89 \\
\hline & Top (ft) & 84 \\
\hline \multicolumn{3}{|c|}{3} \\
\hline \multicolumn{3}{|c|}{ Dynamic Attributes } \\
\hline 1 & $\mathrm{q}(\mathrm{t}-1)$-Water & 100 \\
\hline 2 & Oil Saturation $(\%)(\mathrm{t}-1)$ & 78 \\
\hline 3 & Water Saturation $(\%)(\mathrm{t}-1)$ & 78 \\
\hline 4 & Permeability I(t-1) & 72 \\
\hline 15 & Oil Rate $(\mathrm{t}-1)$ & 1 \\
\hline 16 & Gas Rate (t-1) & 1 \\
\hline & 6 & \\
\hline
\end{tabular}

\begin{tabular}{|l|r|}
\hline TOTAL ATTRIBUTES & 20 \\
\hline
\end{tabular}

\begin{tabular}{|c|c|c|}
\hline \multicolumn{3}{|c|}{ OFFSET WELLS } \\
\hline \multicolumn{3}{|c|}{ Static Attributes } \\
\hline Rank & Attribute & DOI \\
\hline 1 & $\mathrm{X} /$ Longitude(2P) & 100 \\
\hline 2 & Top $(\mathrm{ft})(2 \mathrm{P})$ & 90 \\
\hline 3 & TVD $(\mathrm{ft})(2 \mathrm{P})$ & 86 \\
\hline 4 & Top $(\mathrm{ft})(2 \mathrm{I})$ & 79 \\
\hline 5 & $\mathrm{X} /$ Longitude(2I) & 75 \\
\hline 7 & $\operatorname{TVD}(\mathrm{ft})(2 \mathrm{I})$ & 65 \\
\hline \multicolumn{3}{|c|}{6} \\
\hline \multicolumn{3}{|c|}{ Dynamic Attributes } \\
\hline 1 & Water Saturation $(\%)(\mathrm{t}-1)(1 \mathrm{P})$ & 100 \\
\hline 2 & Oil Saturation $(\%)(\mathrm{t}-1)(1 \mathrm{P})$ & 100 \\
\hline 3 & Distance $(\mathrm{t})(1 \mathrm{I})$ & 92 \\
\hline 12 & Permeability I(t-1)(2P) & 42 \\
\hline 15 & Permeability I(t-1)(2I) & 39 \\
\hline
\end{tabular}

Figure 13-3: Scenario 5 - Water Model Input Attributes 


\subsubsection{Reservoir Pressure Predictive Model}

\section{Reservoir Pressure Model - Input Attributes}

\begin{tabular}{|r|l|r|}
\hline \multicolumn{3}{|c|}{ FOCAL WELL } \\
\hline \multicolumn{3}{|c|}{ Static Attributes } \\
\hline \multicolumn{2}{|c|}{ Attribute } & DOI \\
\hline Rank & \multicolumn{1}{|c|}{81} \\
\hline 1 & X/Longitude & 100 \\
\hline 2 & Top (ft) \\
\hline \multicolumn{2}{|c|}{2} \\
\hline
\end{tabular}

\begin{tabular}{|r|l|r|}
\hline \multicolumn{3}{|c|}{ Dynamic Attributes } \\
\hline 1 & Reservoir Pressure (psi)(t-1) & 100 \\
\hline 2 & FBH Pressure (psi)(t) & 78 \\
\hline 3 & FBH Pressure (psi)(t-1) & 52 \\
\hline 12 & Water Rate (t) & 5 \\
\hline 13 & Oil Rate $(\mathrm{t})$ & 4 \\
\hline 14 & Gas Rate $(\mathrm{t})$ & 4 \\
\hline \multicolumn{2}{|c|}{6} \\
\hline
\end{tabular}

\begin{tabular}{|l|l|} 
TOTAL ATTRIBUTES & 17 \\
\hline
\end{tabular}

\begin{tabular}{|c|c|c|}
\hline \multicolumn{3}{|c|}{ OFFSET WELLS } \\
\hline \multicolumn{3}{|c|}{ Static Attributes } \\
\hline Rank & Attribute & DOI \\
\hline 1 & $\mathrm{X} /$ Longitude(1P) & 100 \\
\hline 2 & $\mathrm{X} /$ Longitude(1I) & 88 \\
\hline 3 & $\mathrm{X} /$ Longitude(2P) & 88 \\
\hline 4 & Top $(\mathrm{ft})(1 \mathrm{I})$ & 85 \\
\hline 5 & Top (ft)(2P) & 79 \\
\hline 6 & Pay thickness (ft)(1I) & 79 \\
\hline \multicolumn{3}{|c|}{6} \\
\hline \multicolumn{3}{|c|}{ Dynamic Attributes } \\
\hline 1 & Reservoir Pressure (psi)(t-1)(1P) & 100 \\
\hline 2 & FBH Pressure $(\mathrm{psi})(\mathrm{t}-1)(1 \mathrm{P})$ & 91 \\
\hline 3 & FBH Pressure $(\mathrm{psi})(\mathrm{t})(1 \mathrm{P})$ & 90 \\
\hline \multicolumn{3}{|c|}{3} \\
\hline
\end{tabular}

Figure 13-4: Scenario 5 - Reservoir Pressure Model Input Attributes 


\subsubsection{Water Saturation Predictive Model}

\section{Reservoir Pressure Model - Input Attributes}

\begin{tabular}{|c|c|c|}
\hline \multicolumn{3}{|c|}{ FOCAL WELL } \\
\hline \multicolumn{3}{|c|}{ Static Attributes } \\
\hline Rank & Attribute & DOI \\
\hline 1 & Top (ft) & 100 \\
\hline 2 & $\mathrm{X} /$ Longitude & 87 \\
\hline 3 & Y/Latitude & 65 \\
\hline \multicolumn{3}{|c|}{3} \\
\hline
\end{tabular}

\begin{tabular}{|c|c|c|}
\hline \multicolumn{3}{|c|}{ OFFSET WELLS } \\
\hline \multicolumn{3}{|c|}{ Static Attributes } \\
\hline Rank & Attribute & DOI \\
\hline 1 & $\mathrm{X} /$ Longitude $(2 \mathrm{P})$ & 100 \\
\hline 2 & Top (ft)(2P) & 97 \\
\hline 3 & Y/Latitude(1P) & 79 \\
\hline 4 & $\mathrm{X} /$ Longitude $(1 \mathrm{P})$ & 74 \\
\hline & 4 & \\
\hline
\end{tabular}

\begin{tabular}{|r|l|r|}
\hline \multicolumn{3}{|c|}{ Dynamic Attributes } \\
\hline 1 & Oil Saturation (\%)(t-1) & 100 \\
\hline 2 & Water Saturation (\%)(t-1) & 100 \\
\hline 4 & Reservoir Pressure (psi)(t) & 23 \\
\hline 5 & Water Rate $(\mathrm{t})$ & 18 \\
\hline 10 & Oil Rate $(\mathrm{t})$ & 8 \\
\hline 11 & Gas Rate $(\mathrm{t})$ & 8 \\
\hline \multicolumn{2}{|c|}{6} \\
\hline
\end{tabular}

\begin{tabular}{|l|l|} 
TOTAL ATTRIBUTES & 15 \\
\hline
\end{tabular}

\begin{tabular}{|r|l|r|}
\hline \multicolumn{3}{|c|}{ Dynamic Attributes } \\
\hline 1 & Water Saturation (\%)(t-1)(1P) & 100 \\
\hline 2 & Oil Saturation (\%)(t-1)(1P) & 100 \\
\hline \multicolumn{3}{|c|}{2} \\
\hline
\end{tabular}

Figure 13-5: Scenario 5 - Water Saturation Model Input Attributes 


\subsection{Production Profile Plots}

\subsubsection{Entire Reservoir}

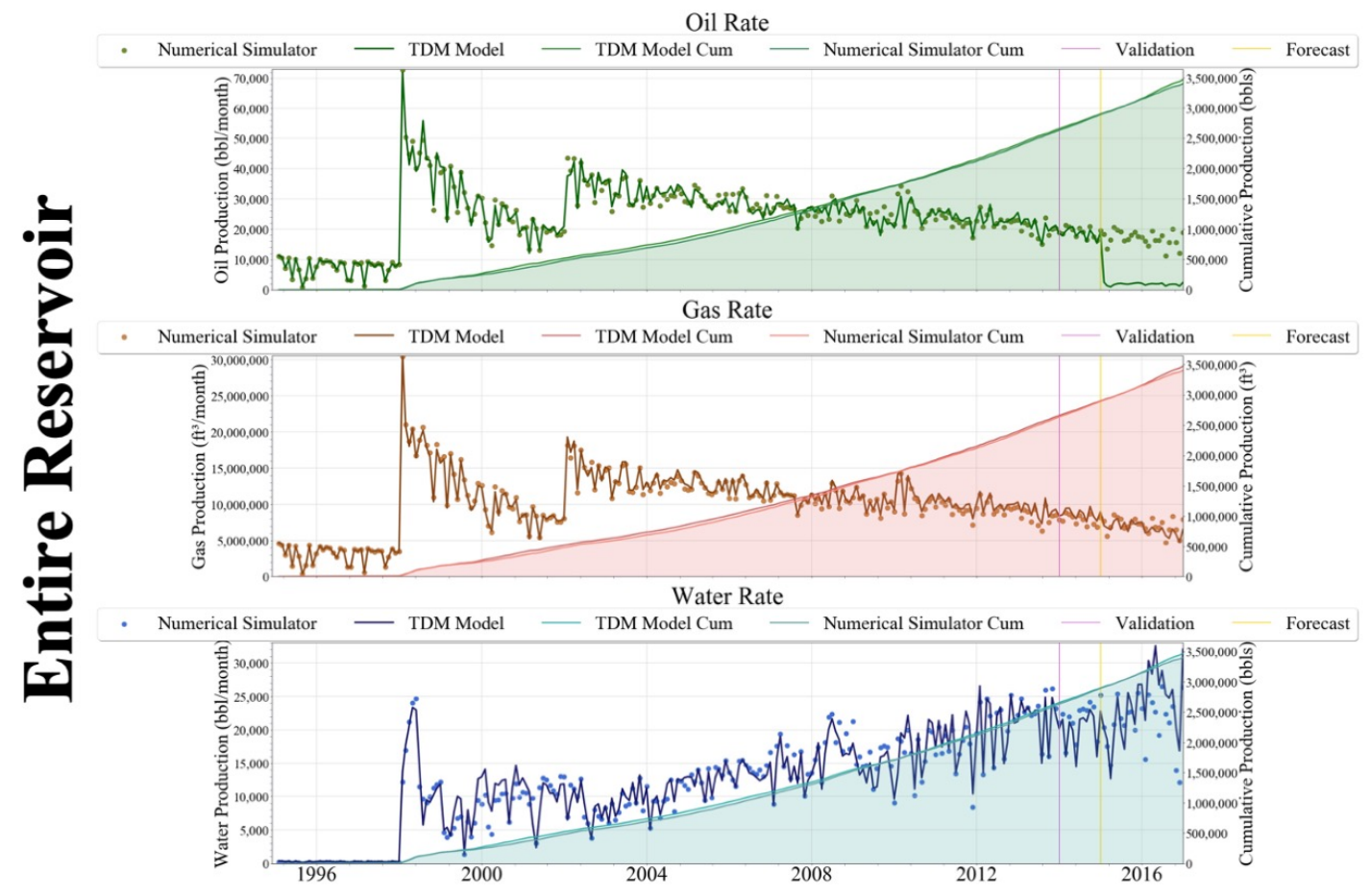

Figure 13-6: Scenario 5 - Entire Field Production 


\subsubsection{Good History Match Production}

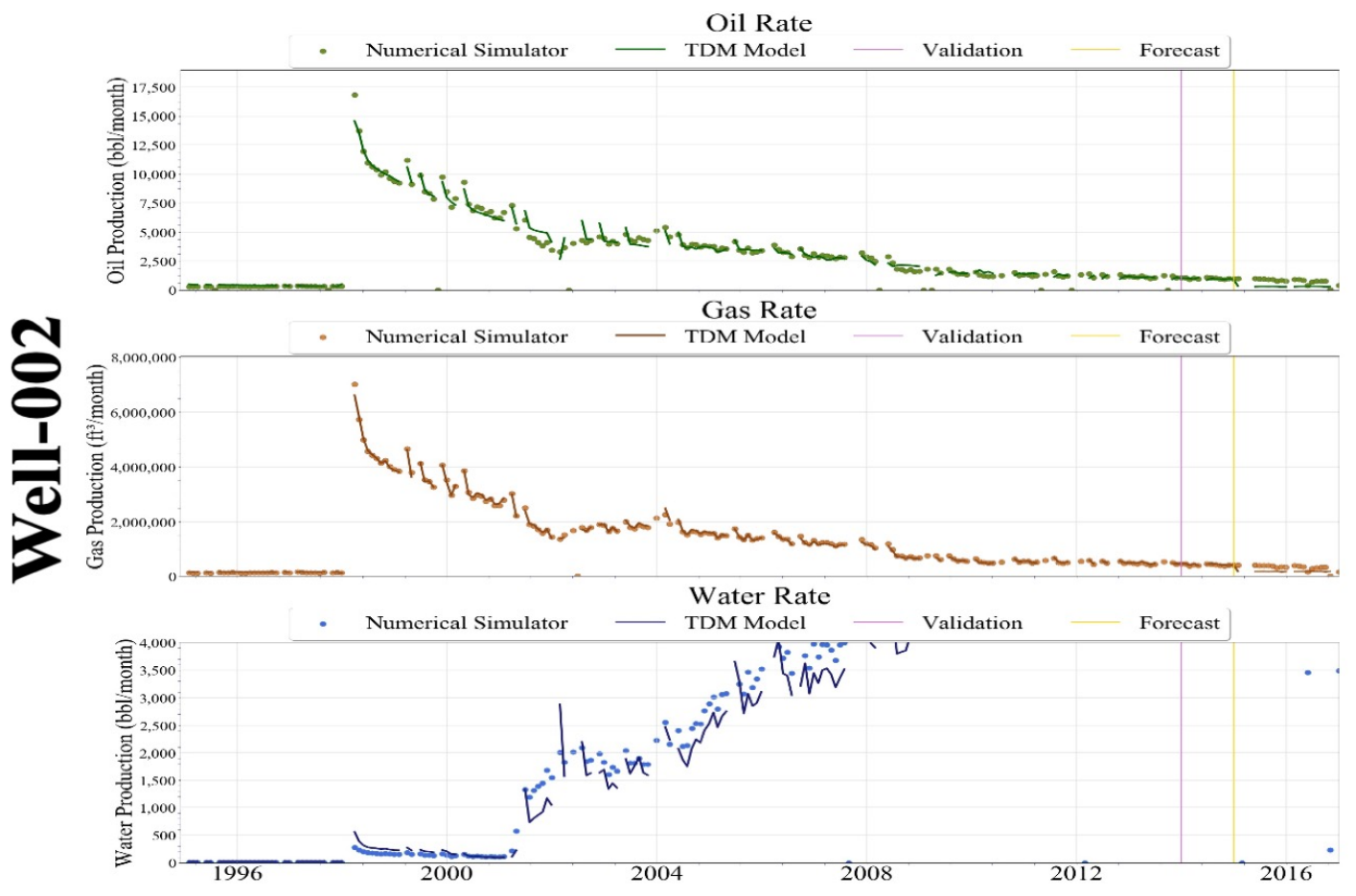

Figure 13-7: Scenario 5 - Well-002 Production History Match

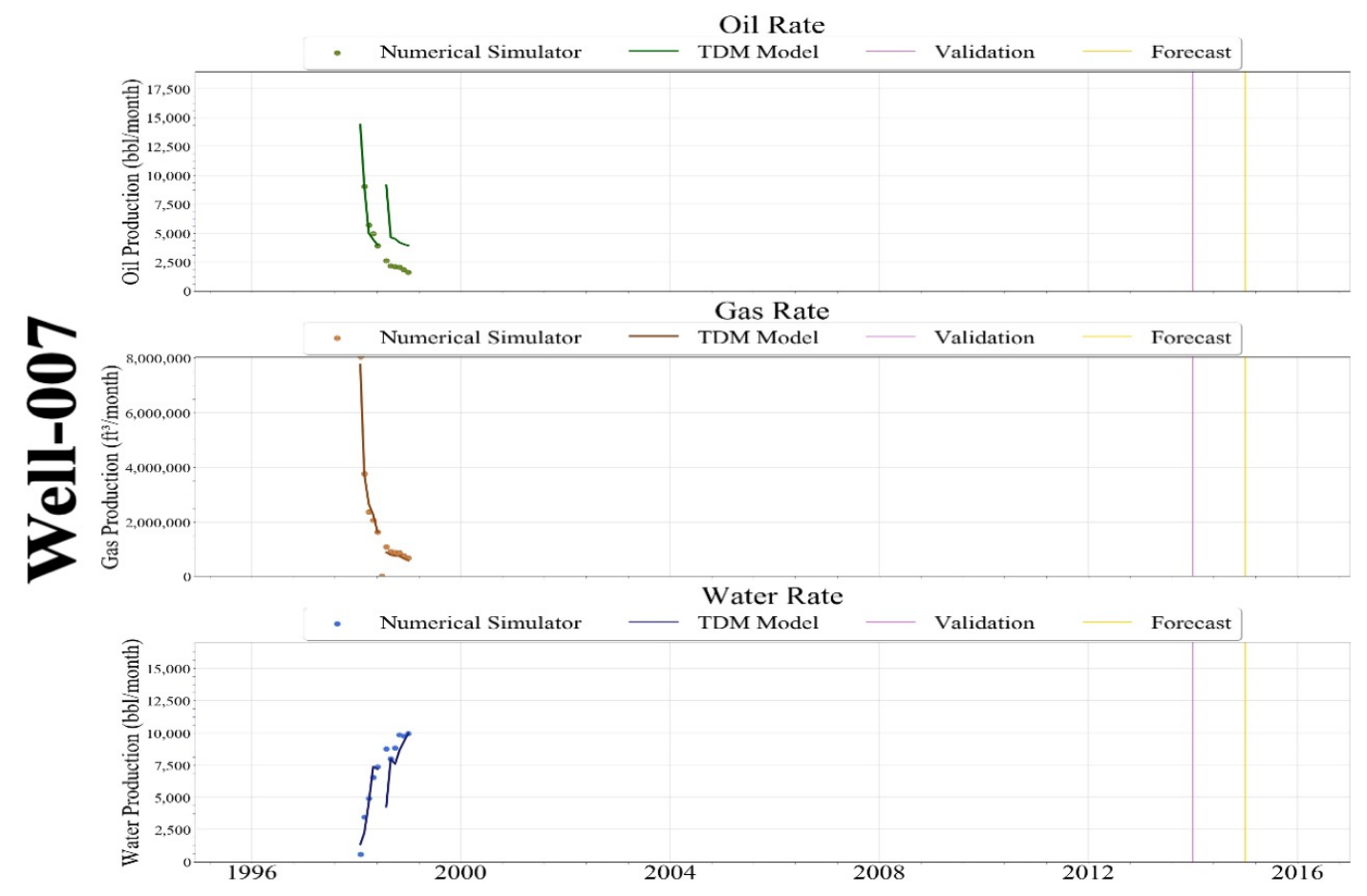

Figure 13-8: Scenario 5-Well-007 Production History Match 


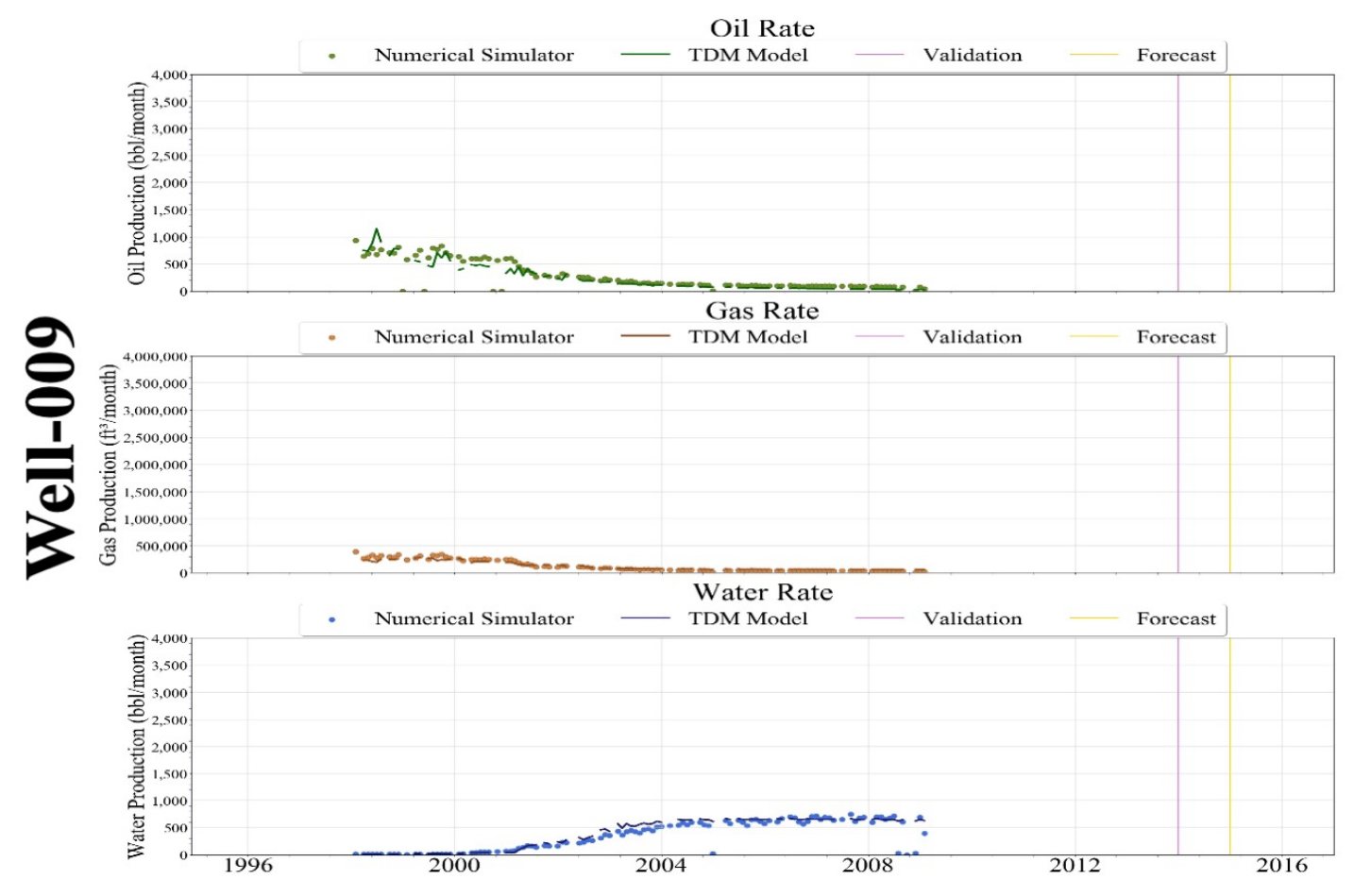

Figure 13-9: Scenario 5 - Well-009 Production History Match

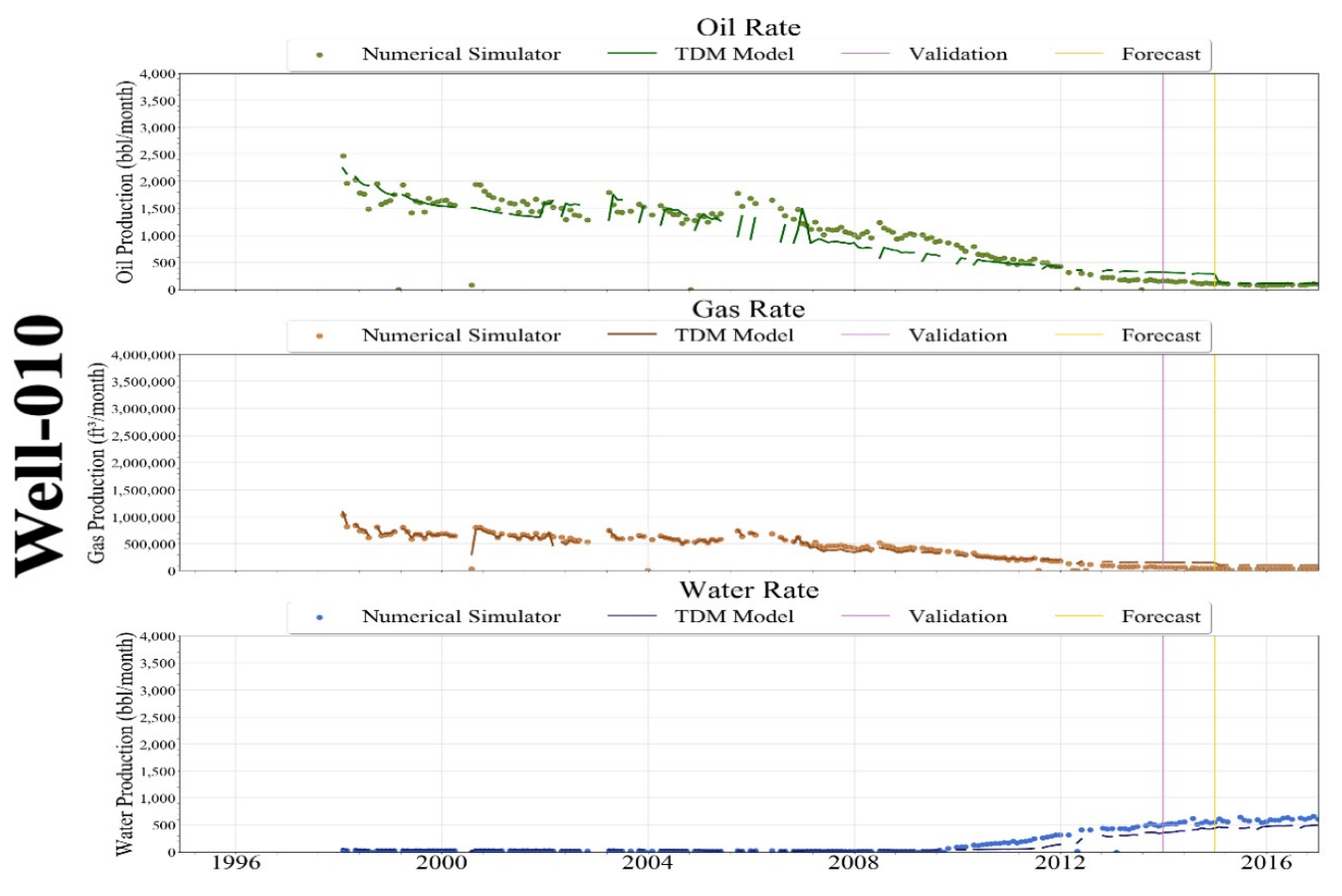

Figure 13-10: Scenario 5 - Well-010 Production History Match 


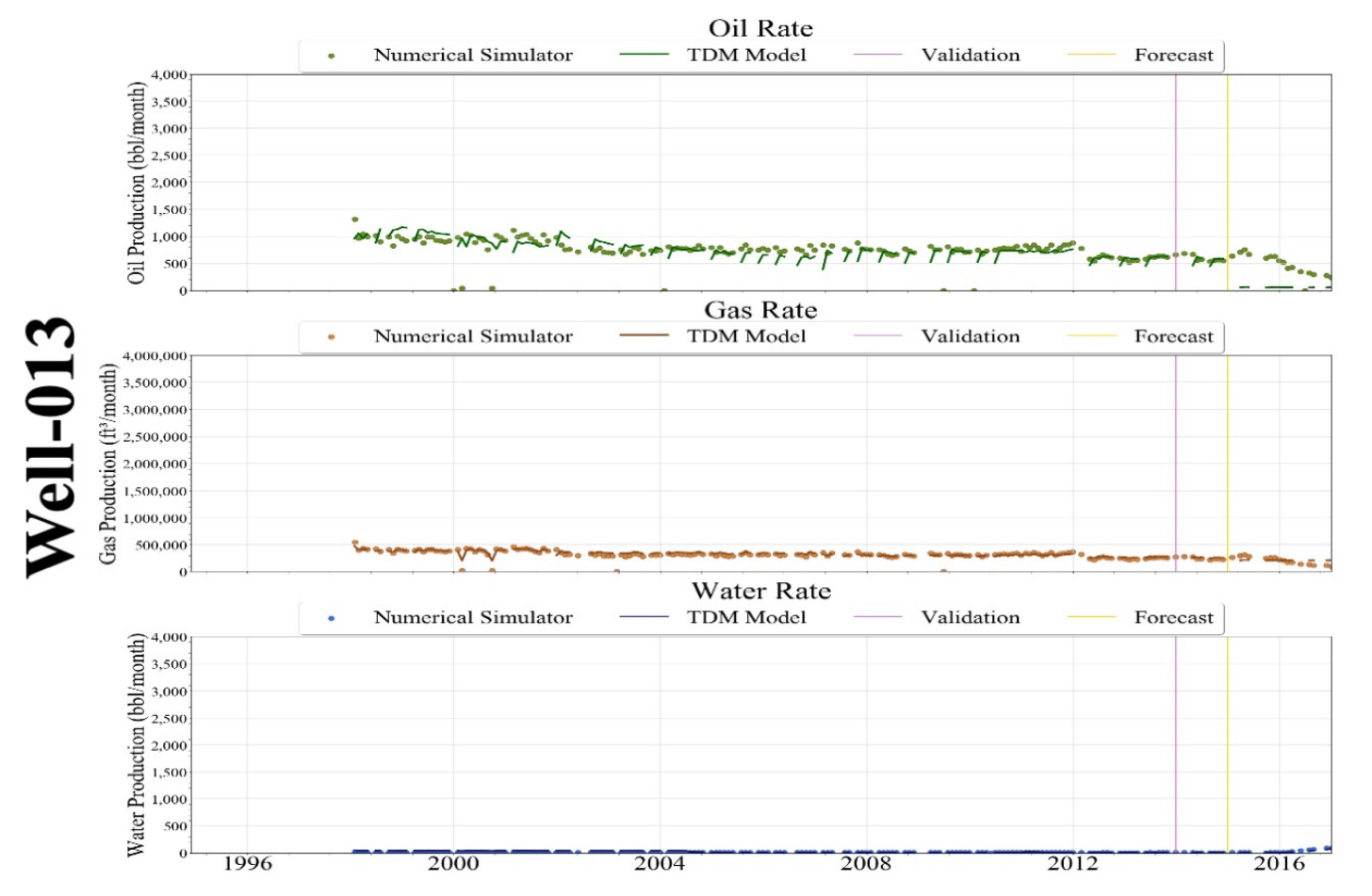

Figure 13-11: Scenario 5 - Well-013 Production History Match

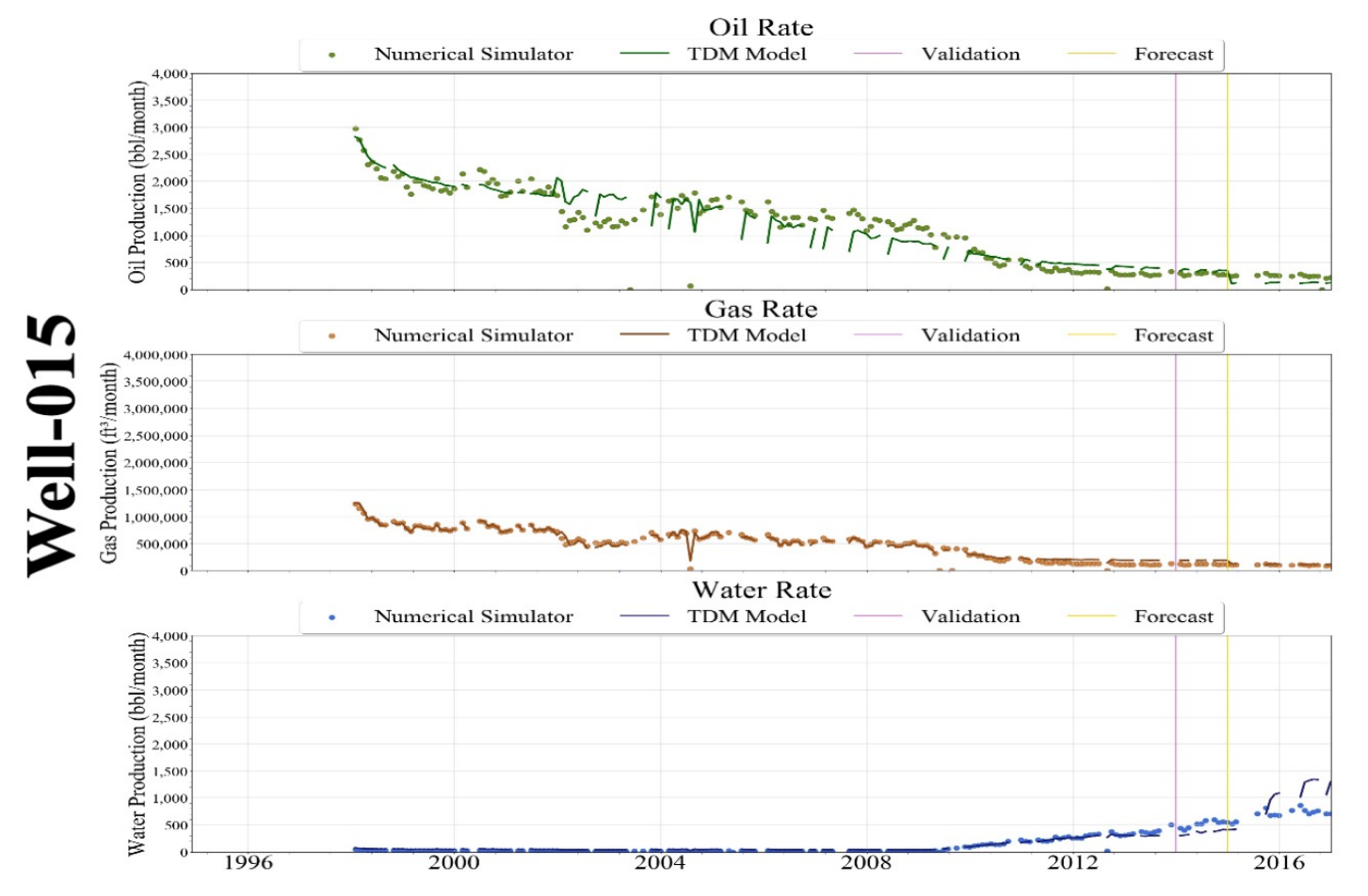

Figure 13-12: Scenario 5 - Well-015 Production History Match 


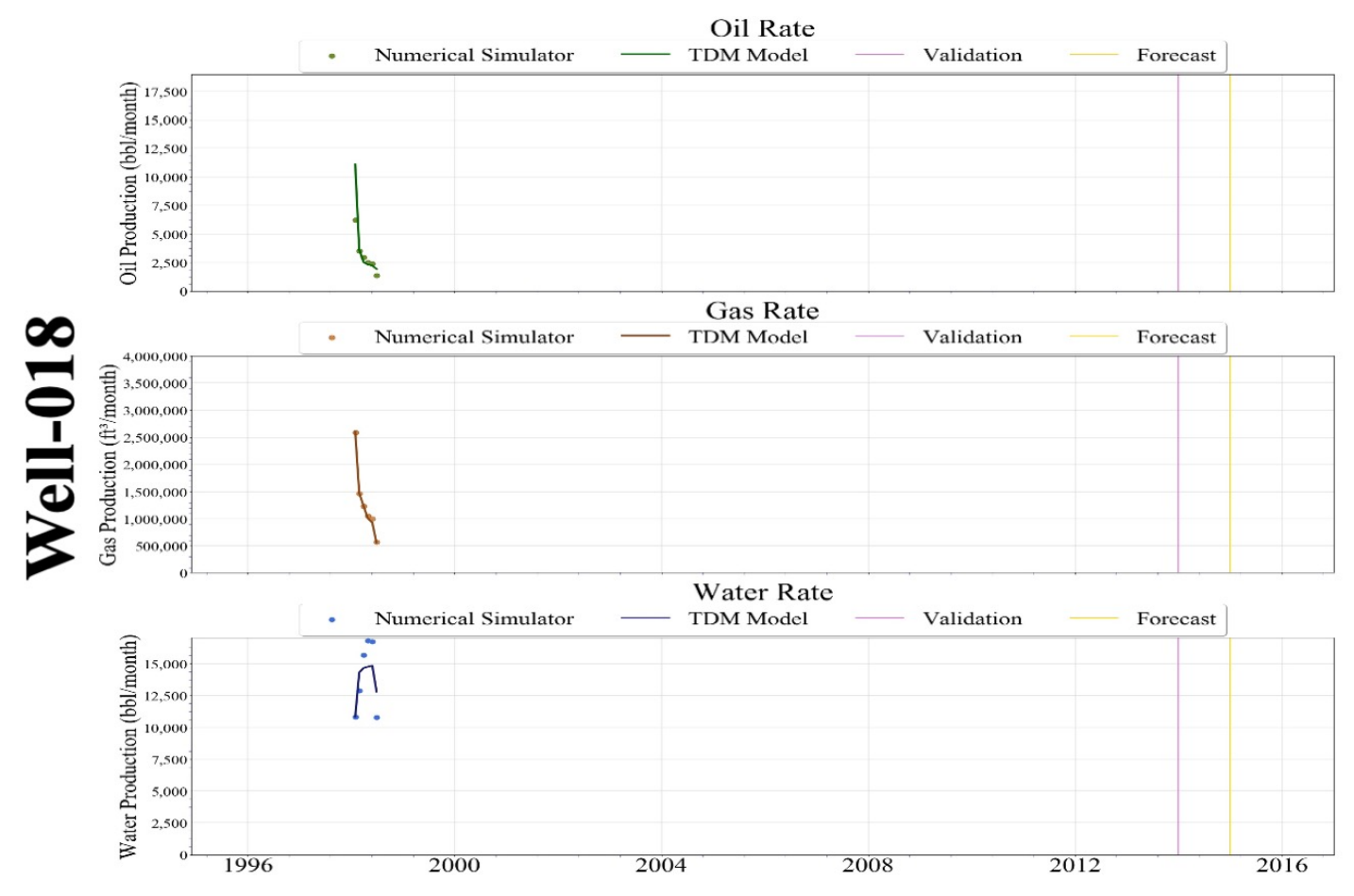

Figure 13-13: Scenario 5 - Well-018 Production History Match

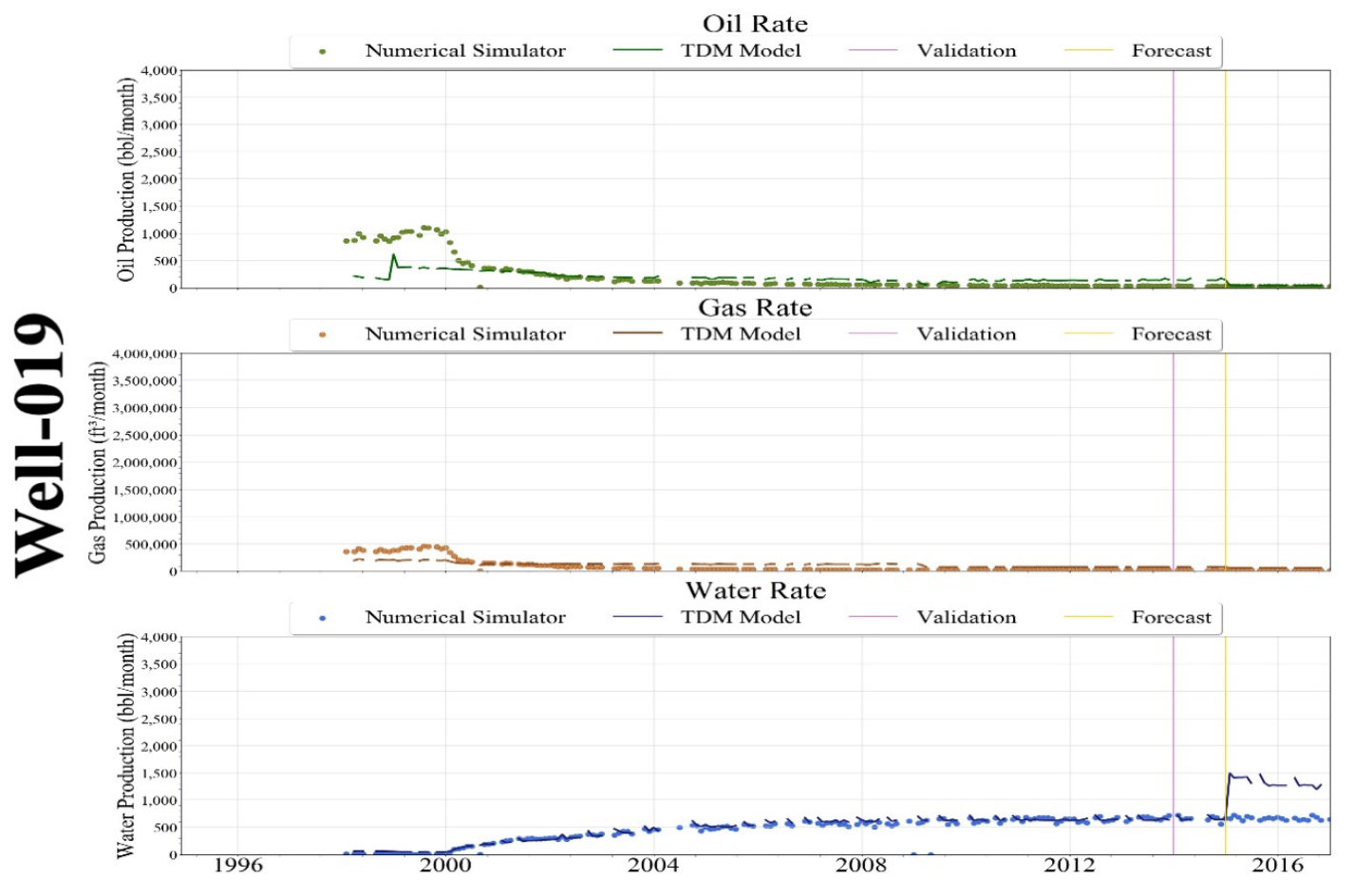

Figure 13-14: Scenario 5 - Well-019 Production History Match 


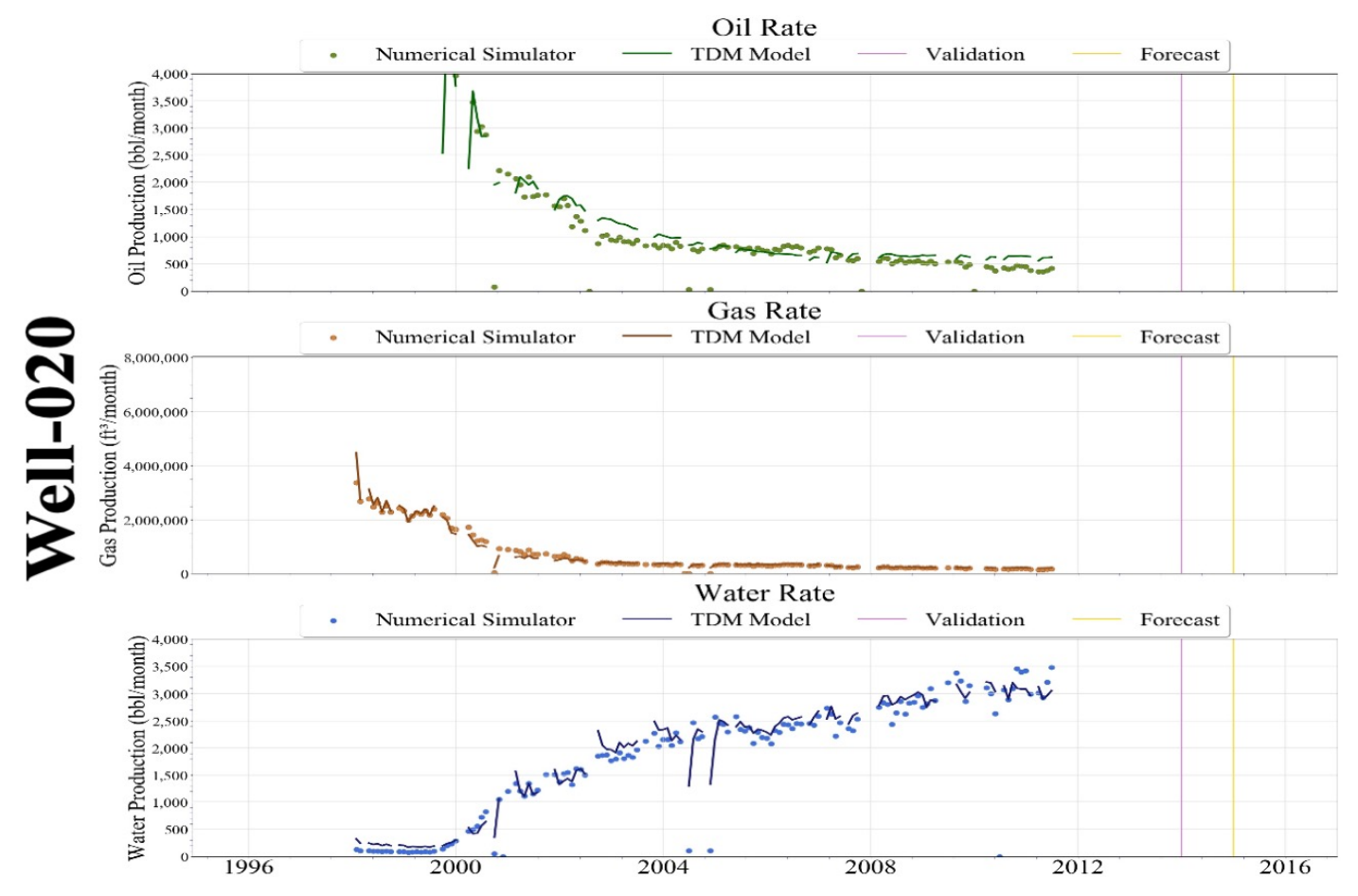

Figure 13-15: Scenario 5 - Well-020 Production History Match

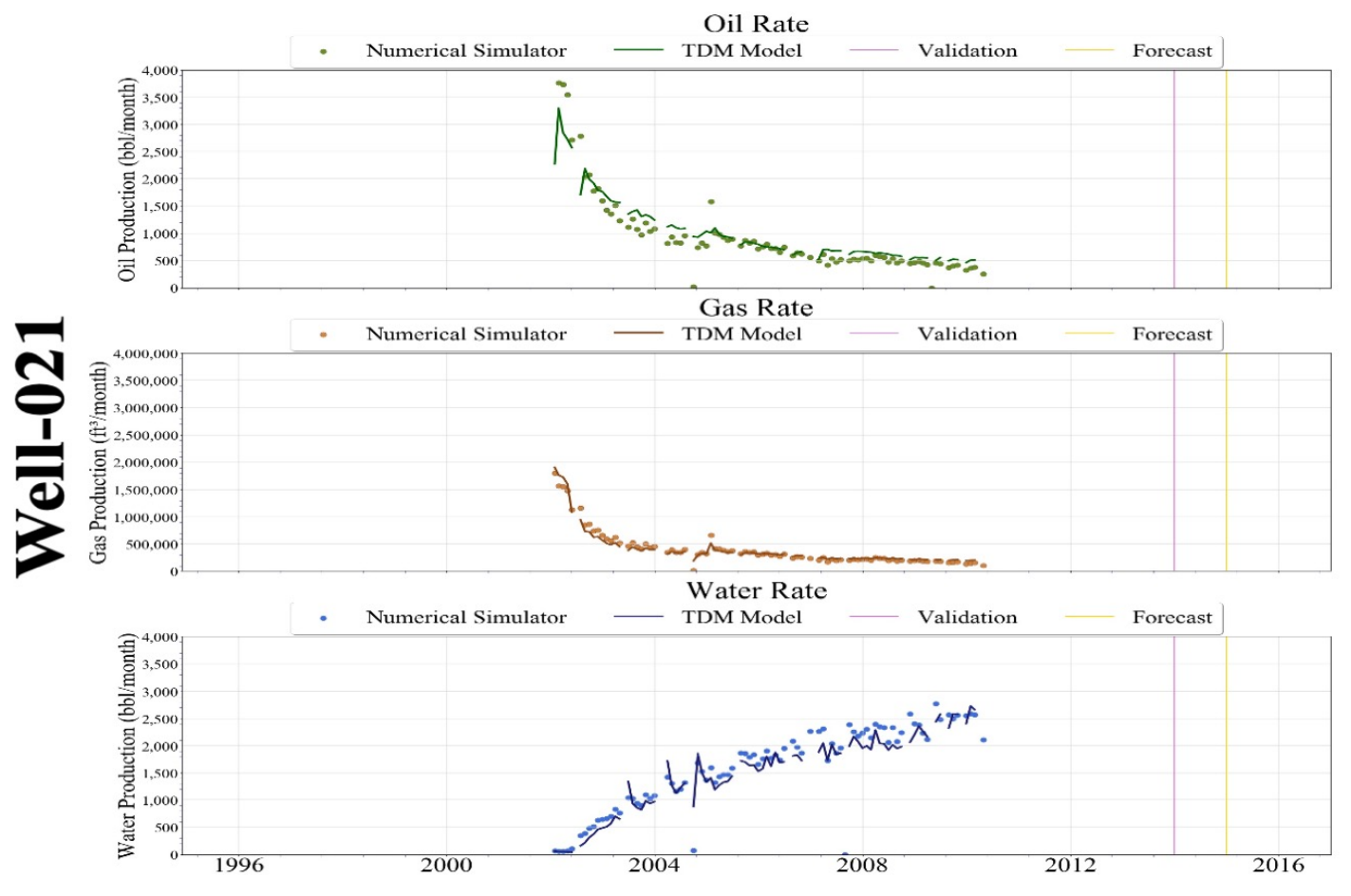

Figure 13-16: Scenario 5 - Well-021 Production History Match 


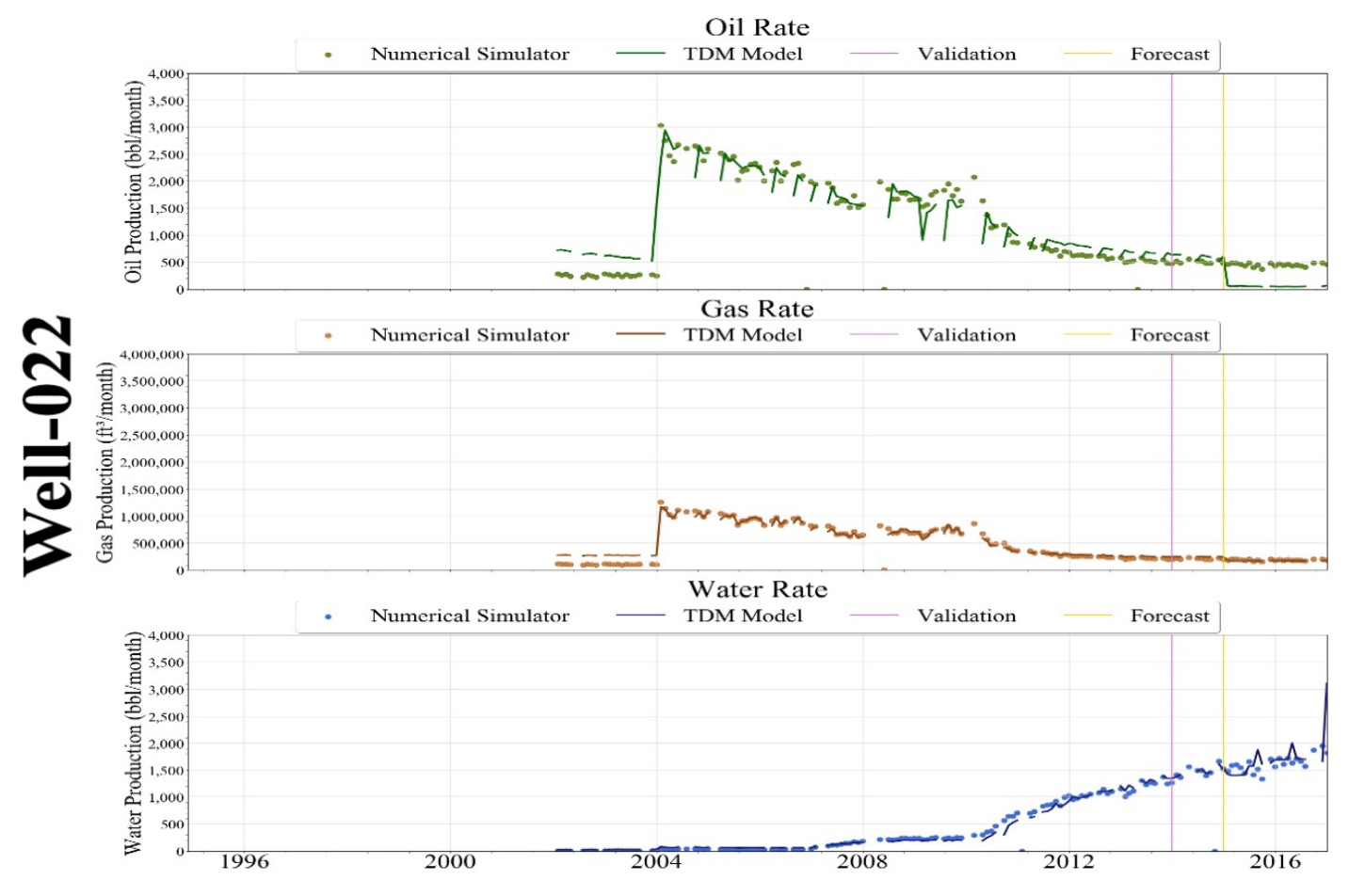

Figure 13-17: Scenario 5 - Well-022 Production History Match

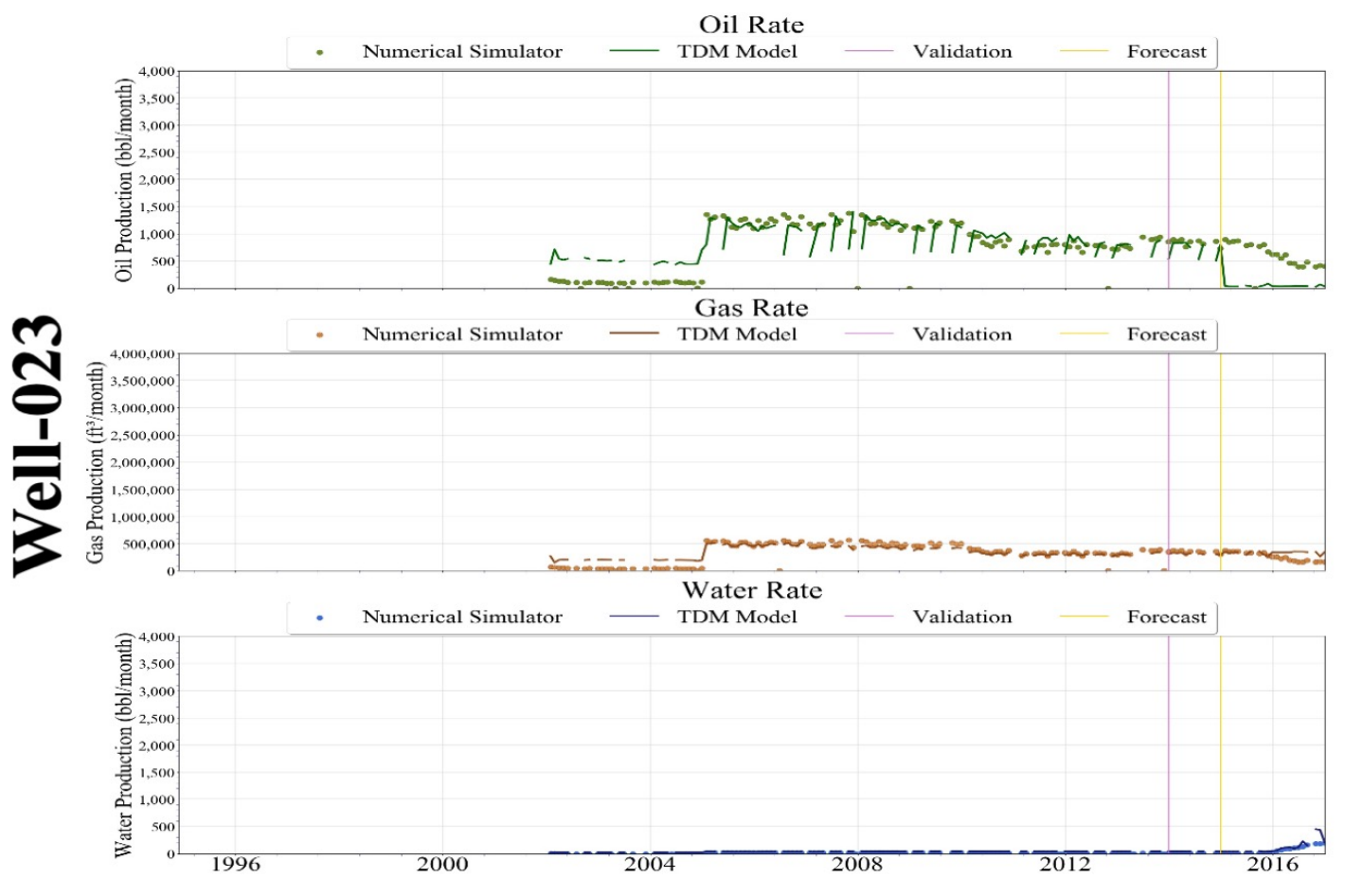

Figure 13-18: Scenario 5 - Well-023 Production History Match 


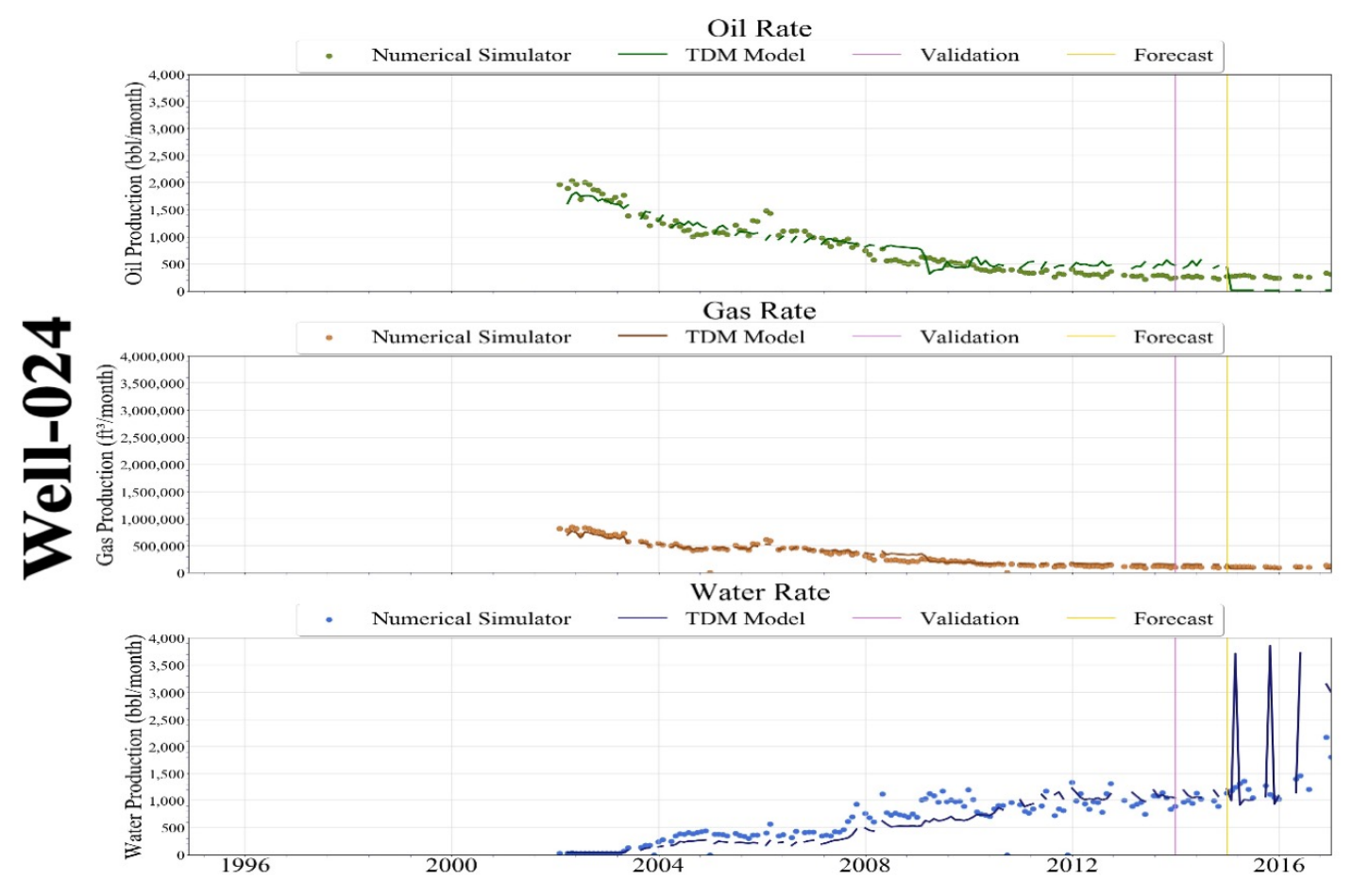

Figure 13-19: Scenario 5 - Well-024 Production History Match

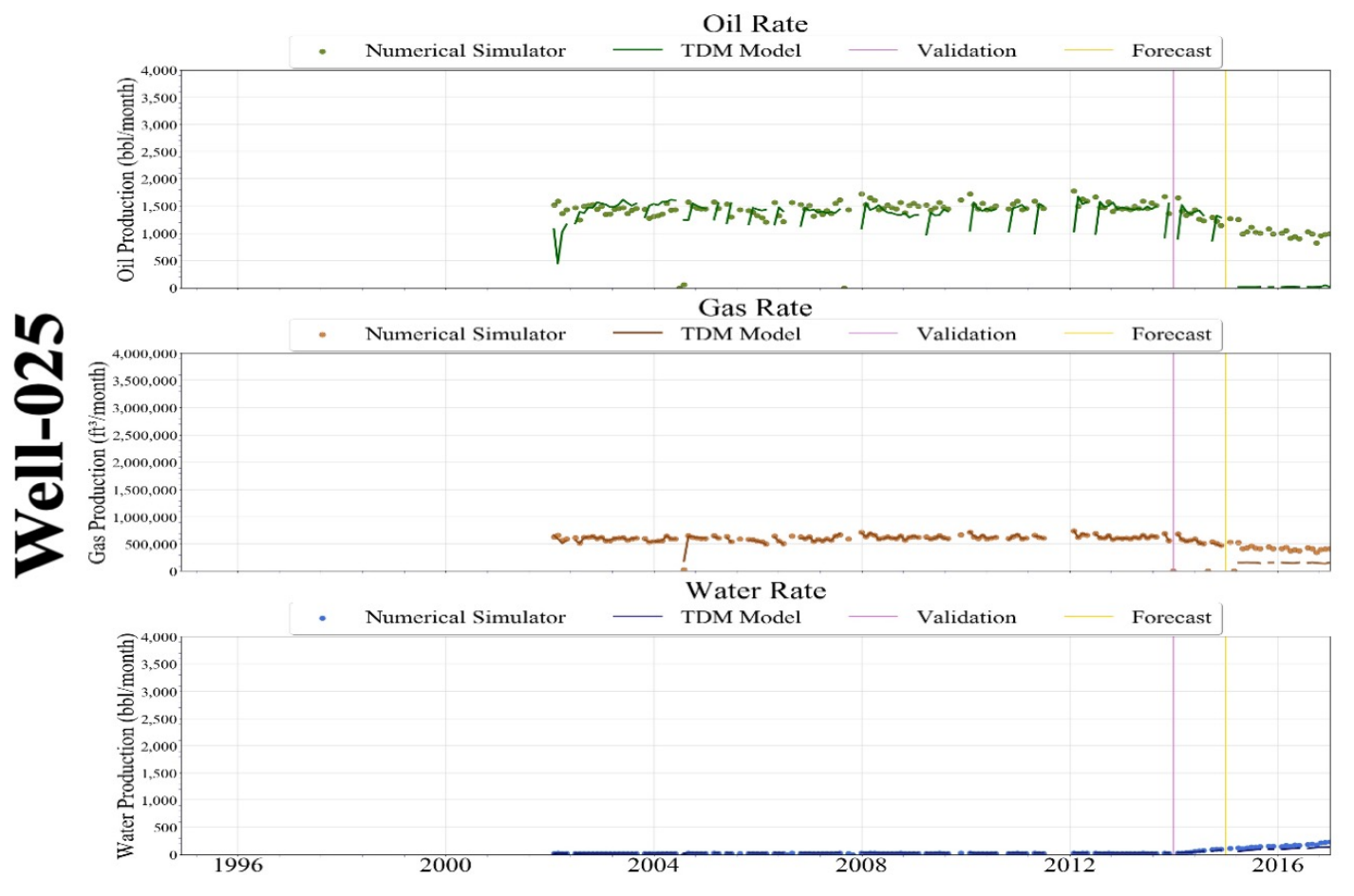

Figure 13-20: Scenario 5 - Well-025 Production History Match 


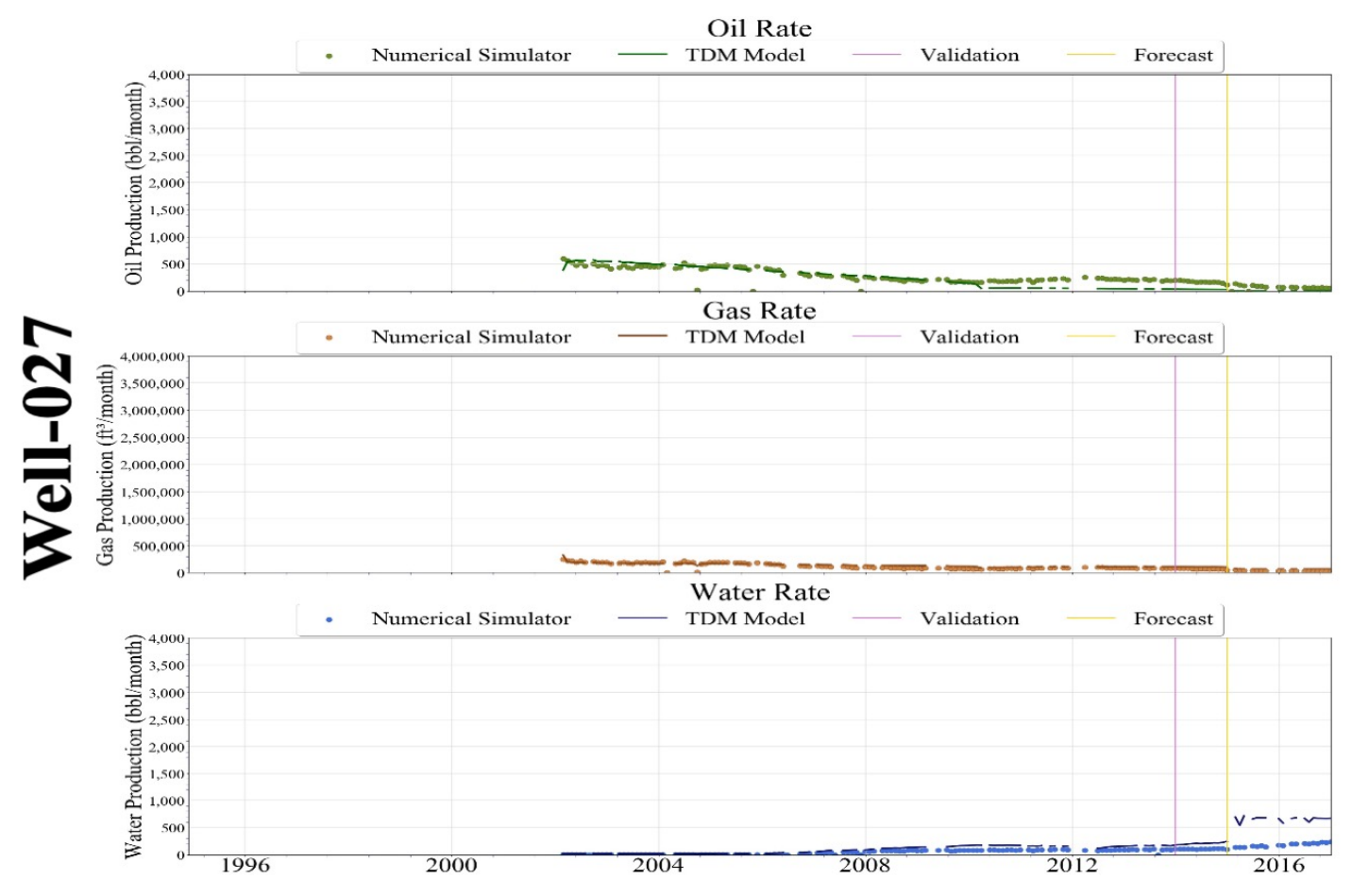

Figure 13-21: Scenario 5 - Well-027 Production History Match

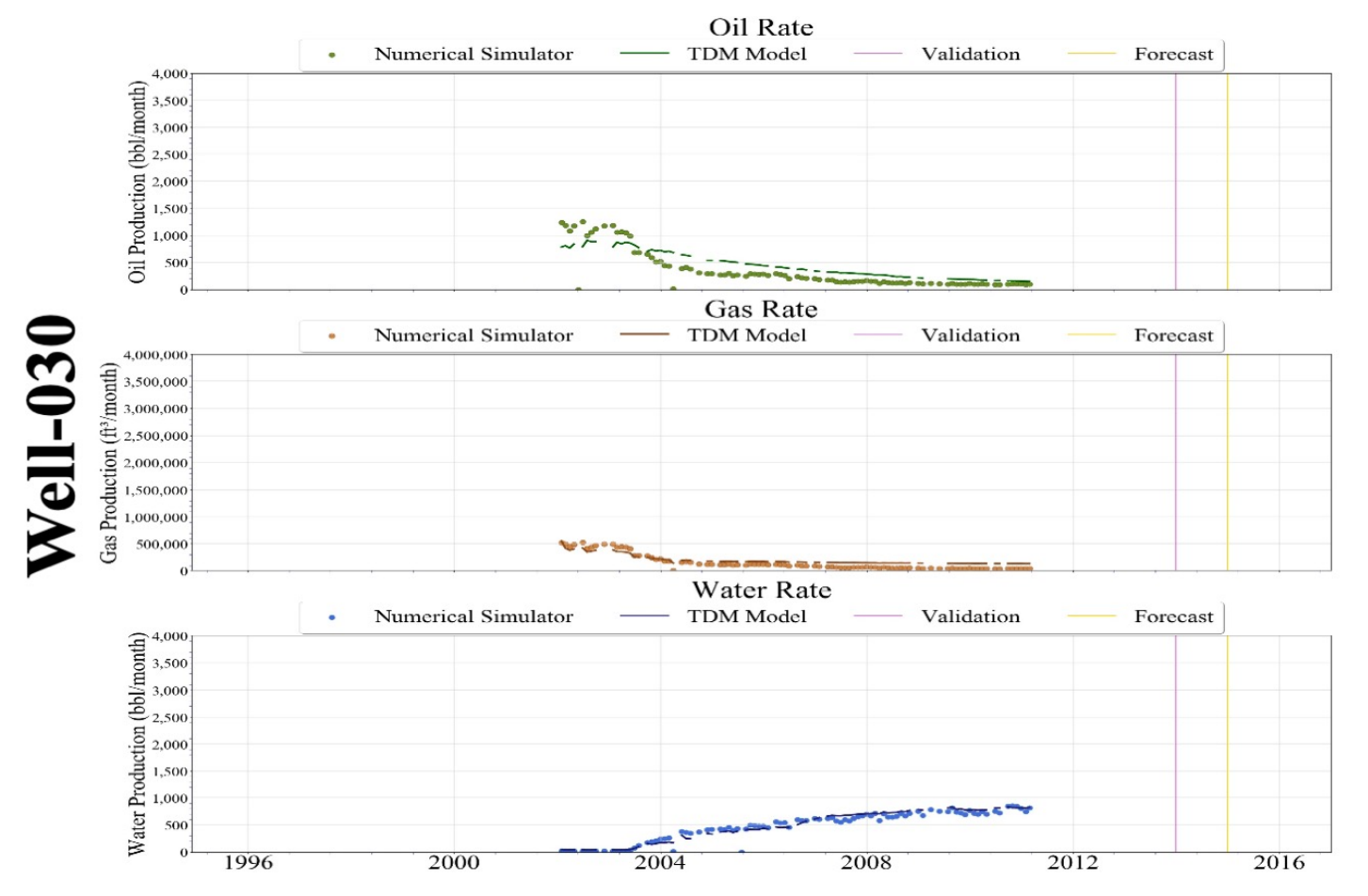

Figure 13-22: Scenario 5 - Well-030 Production History Match 


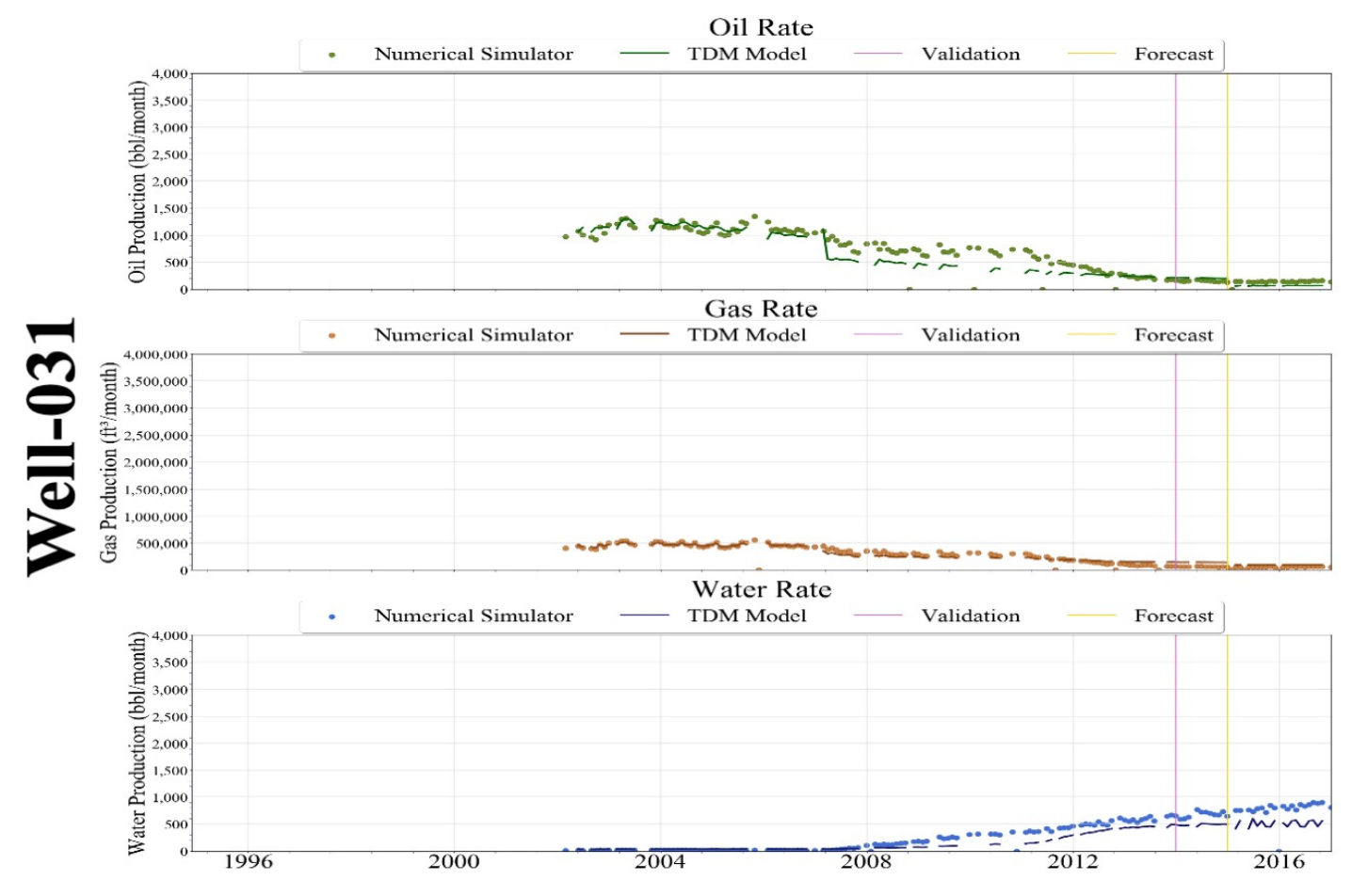

Figure 13-23: Scenario 5 - Well-031 Production History Match

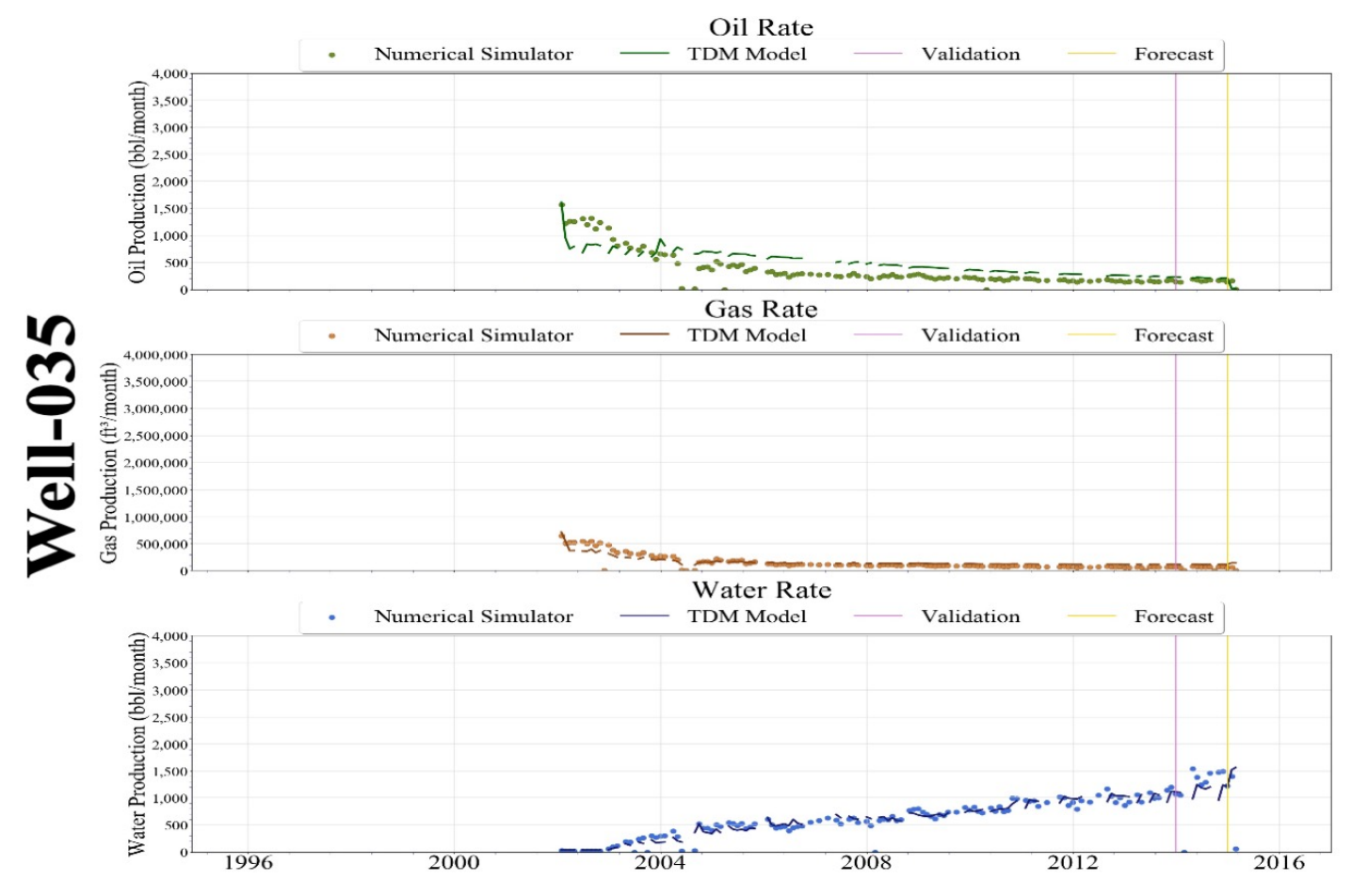

Figure 13-24: Scenario 5 - Well-035 Production History Match 


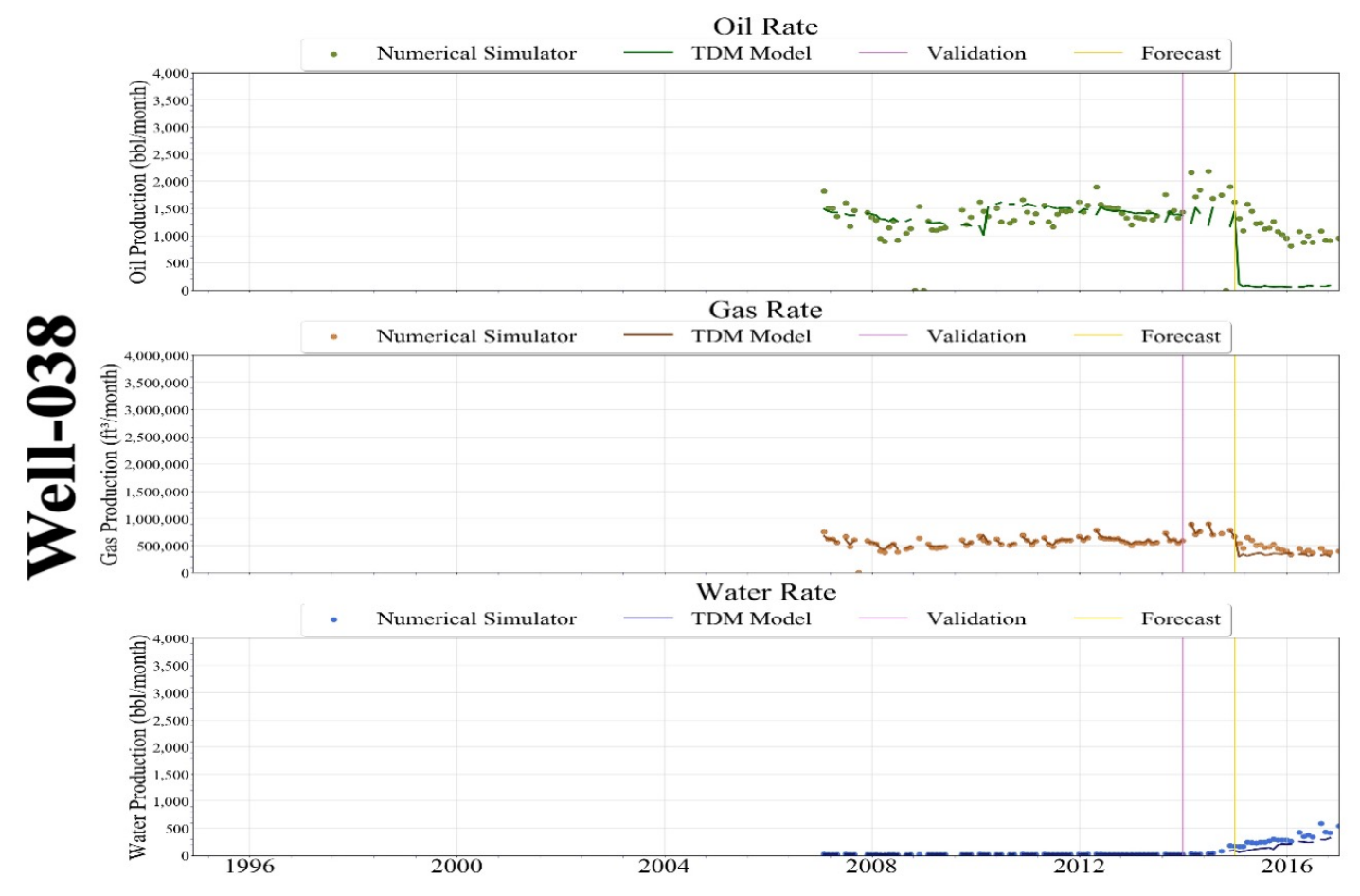

Figure 13-25: Scenario 5 - Well-038 Production History Match

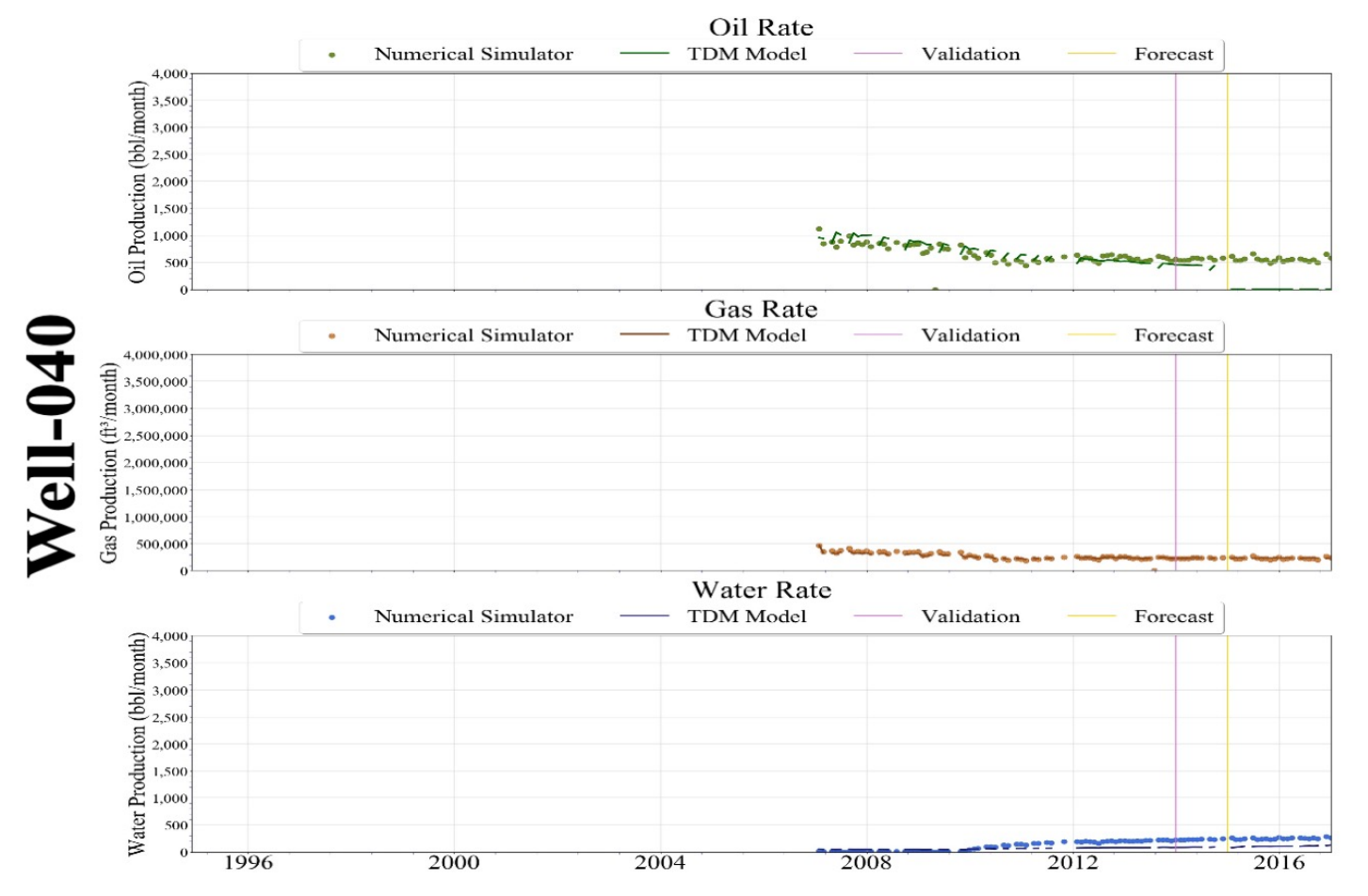

Figure 13-26: Scenario 5 - Well-040 Production History Match 


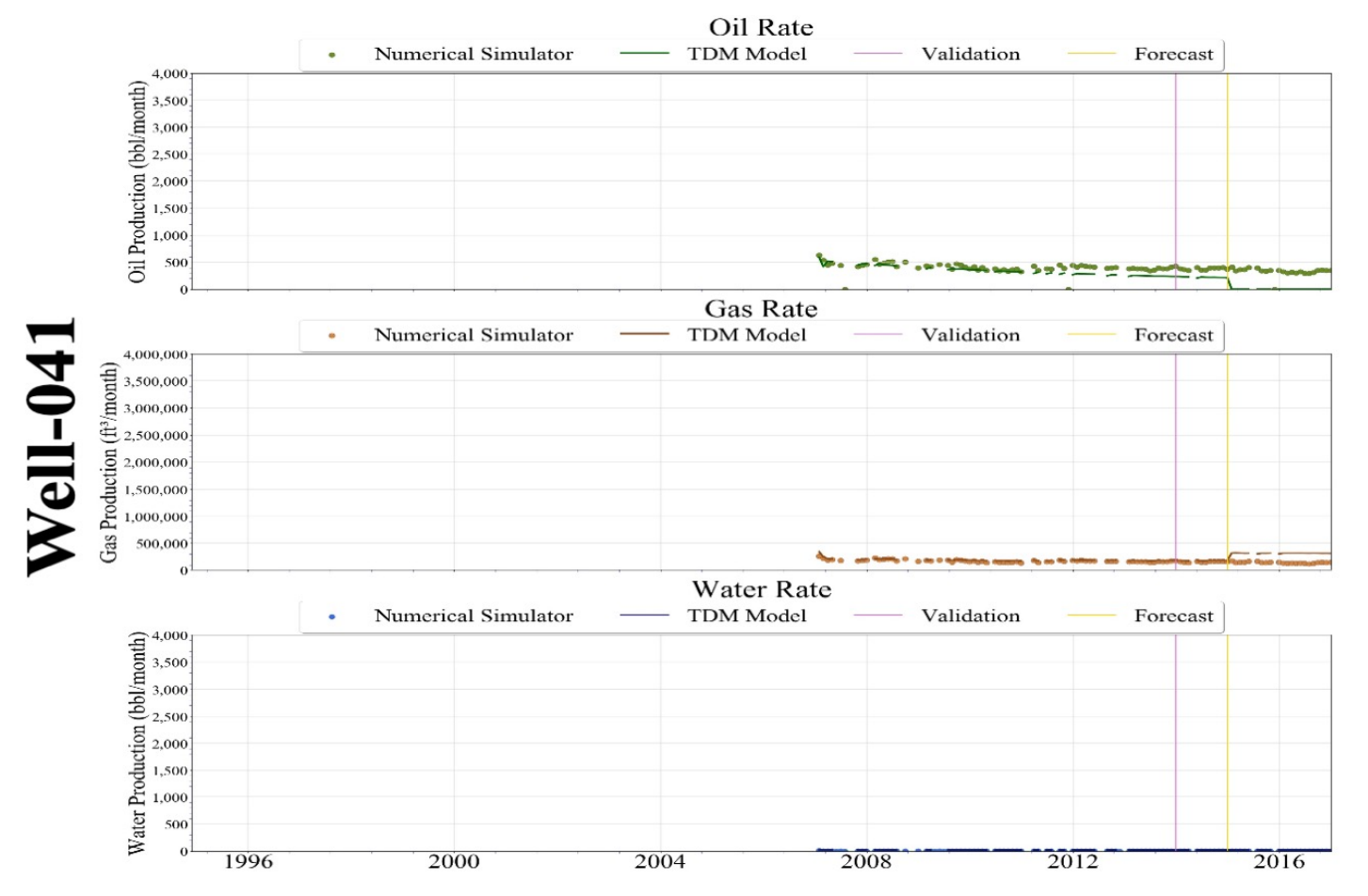

Figure 13-27: Scenario 5 - Well-041 Production History Match

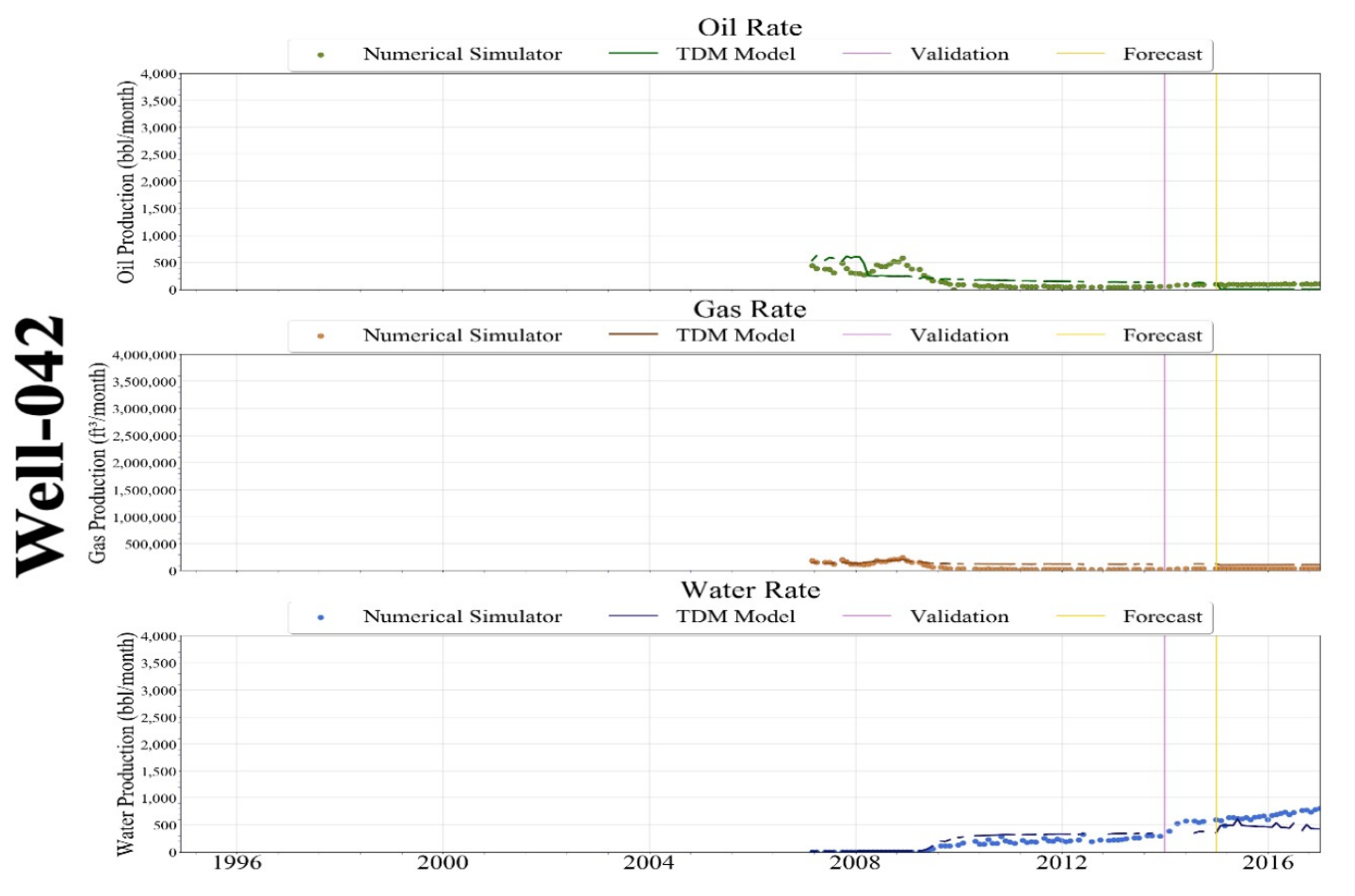

Figure 13-28: Scenario 5 - Well-042 Production History Match 


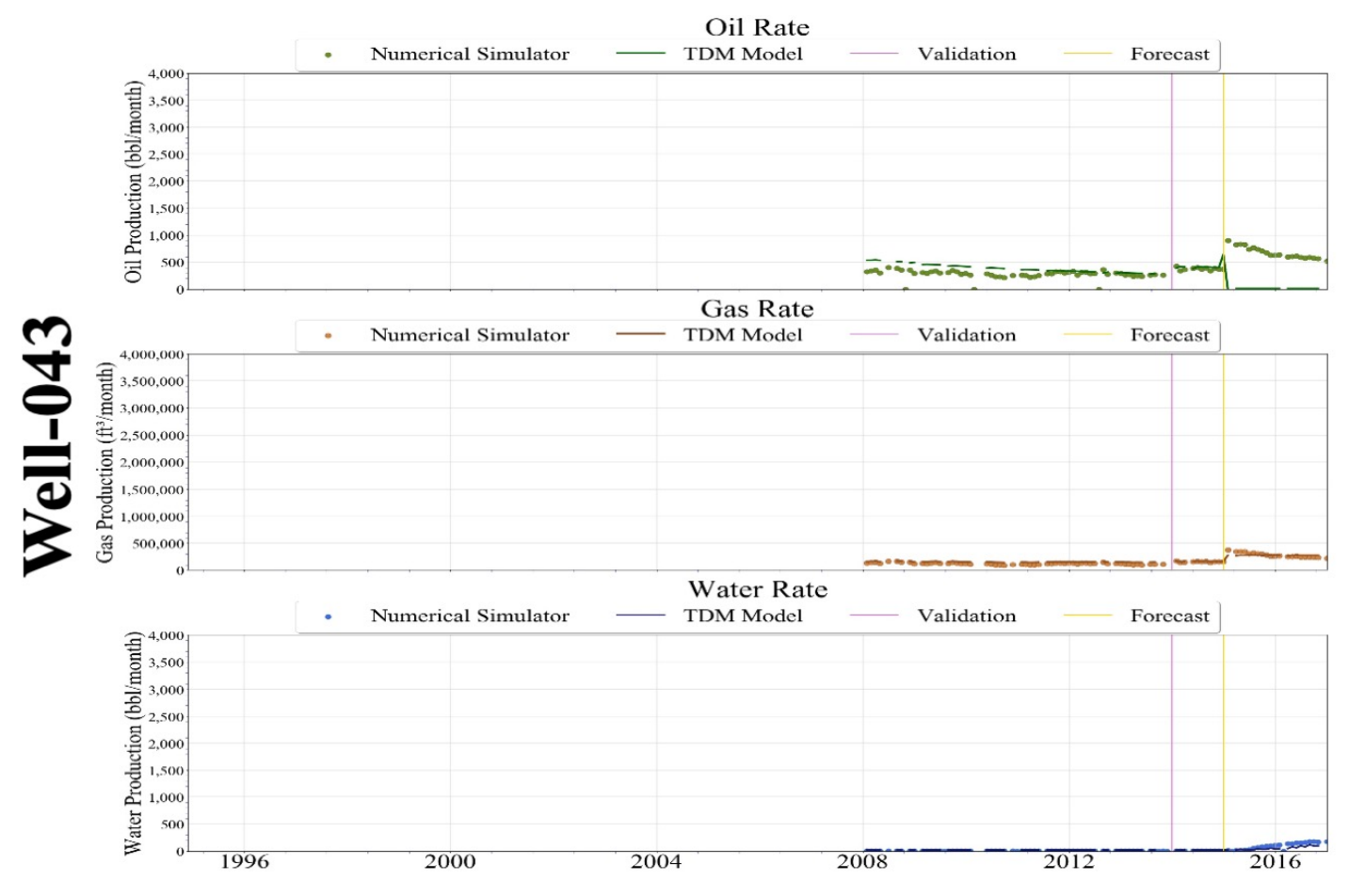

Figure 13-29: Scenario 5 - Well-043 Production History Match

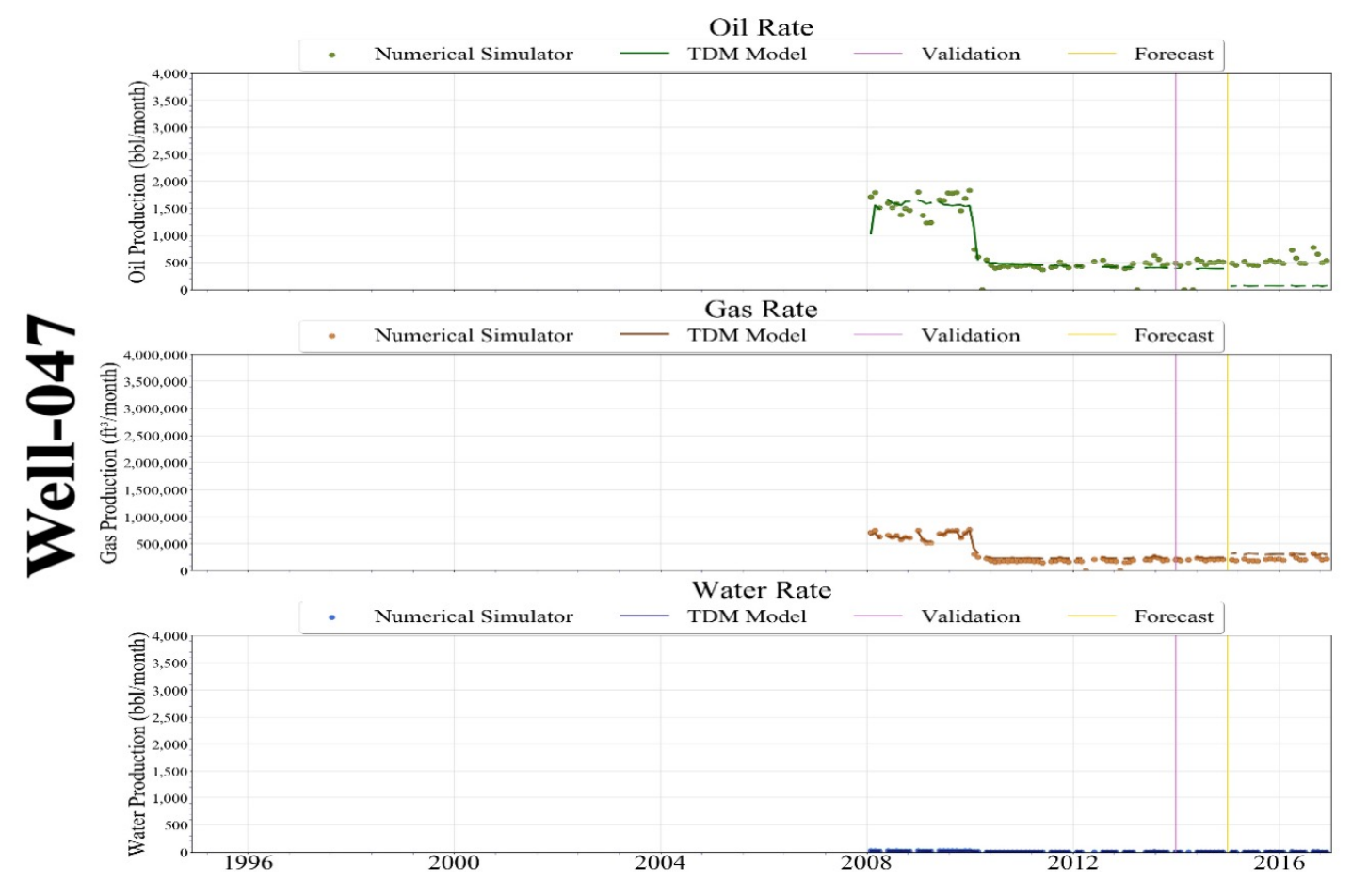

Figure 13-30: Scenario 5 - Well-047 Production History Match 


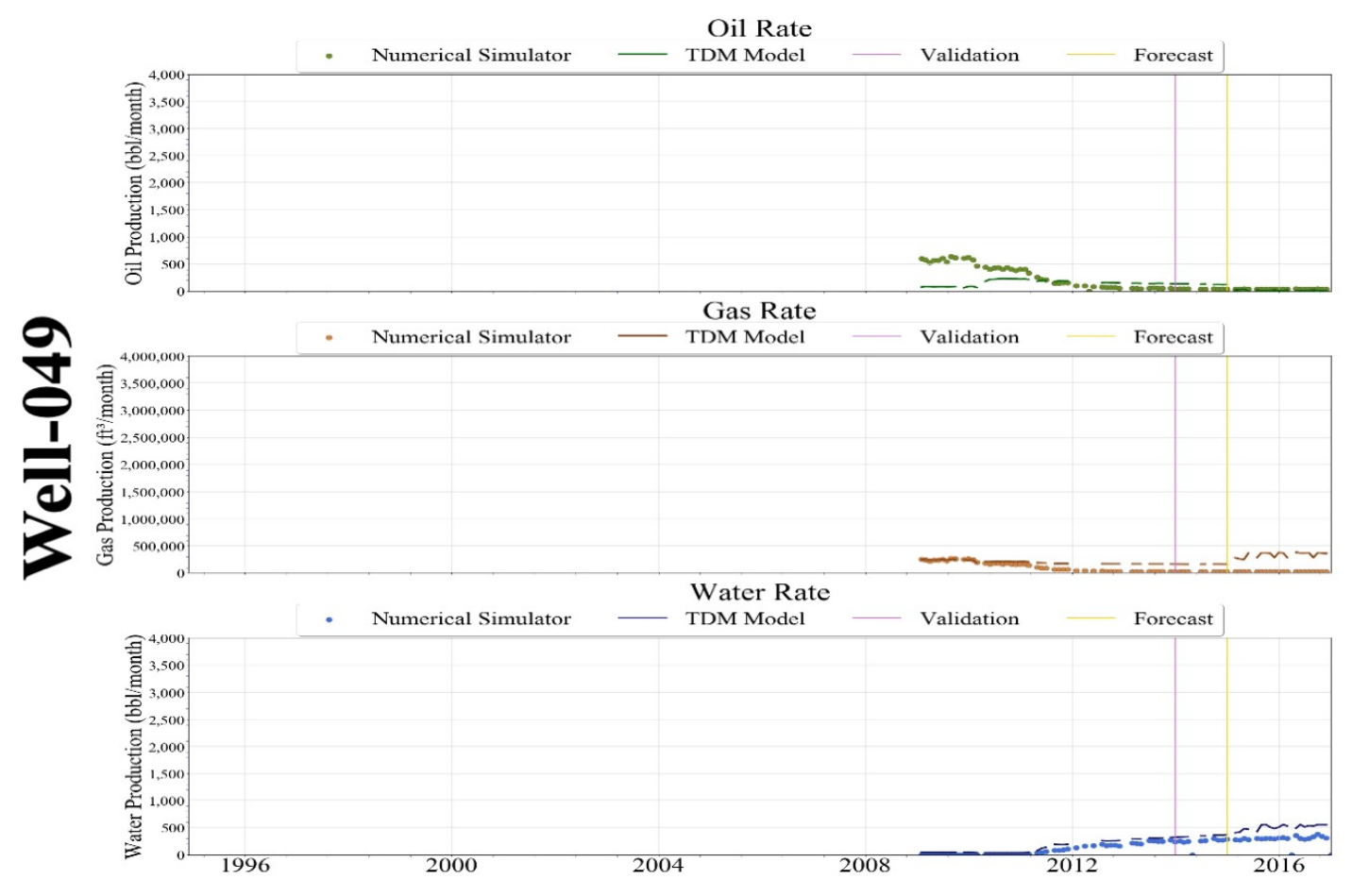

Figure 13-31: Scenario 5 - Well-049 Production History Match

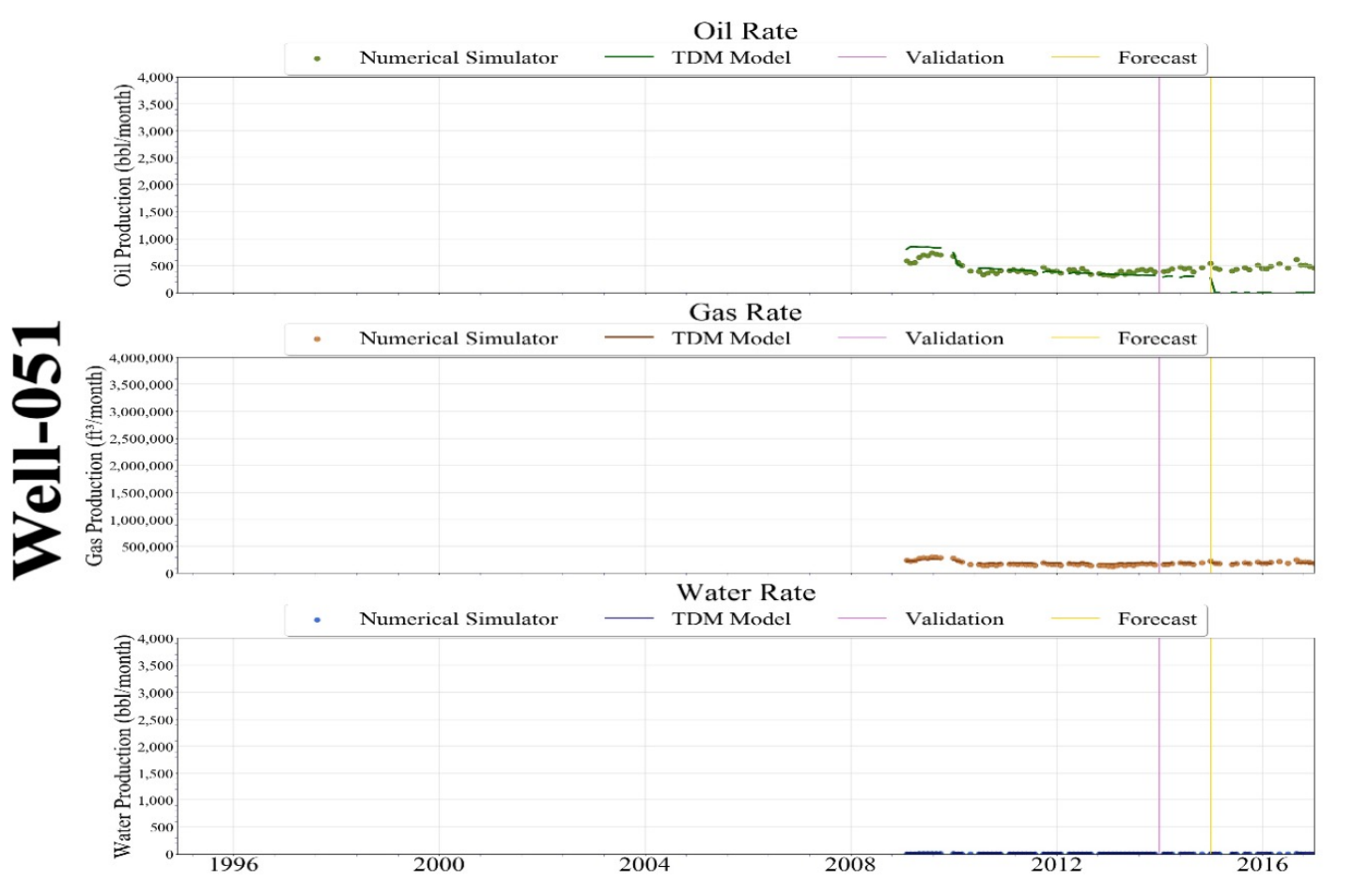

Figure 13-32: Scenario 5 - Well-051 Production History Match 


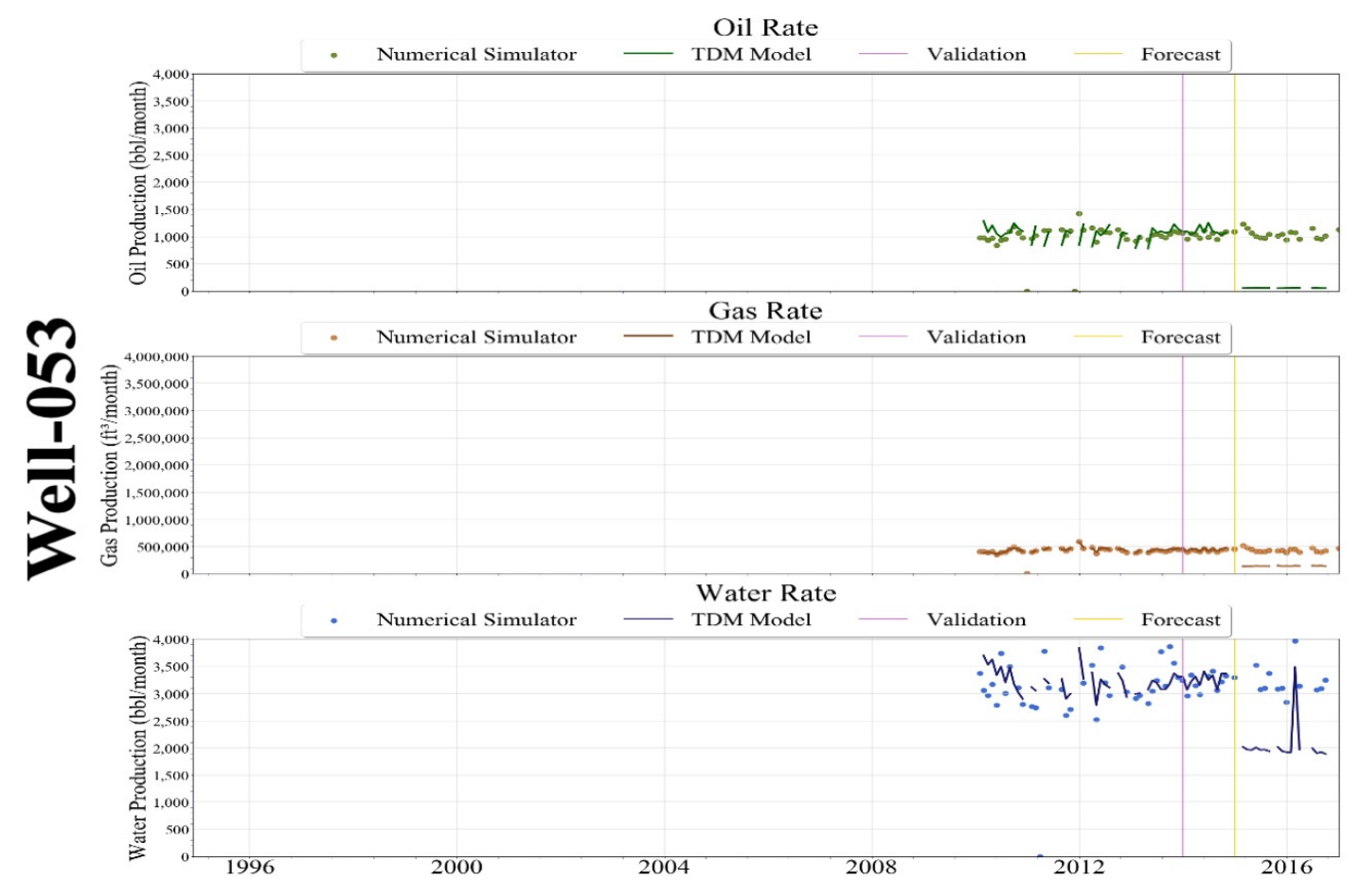

Figure 13-33: Scenario 5 - Well-053 Production History Match

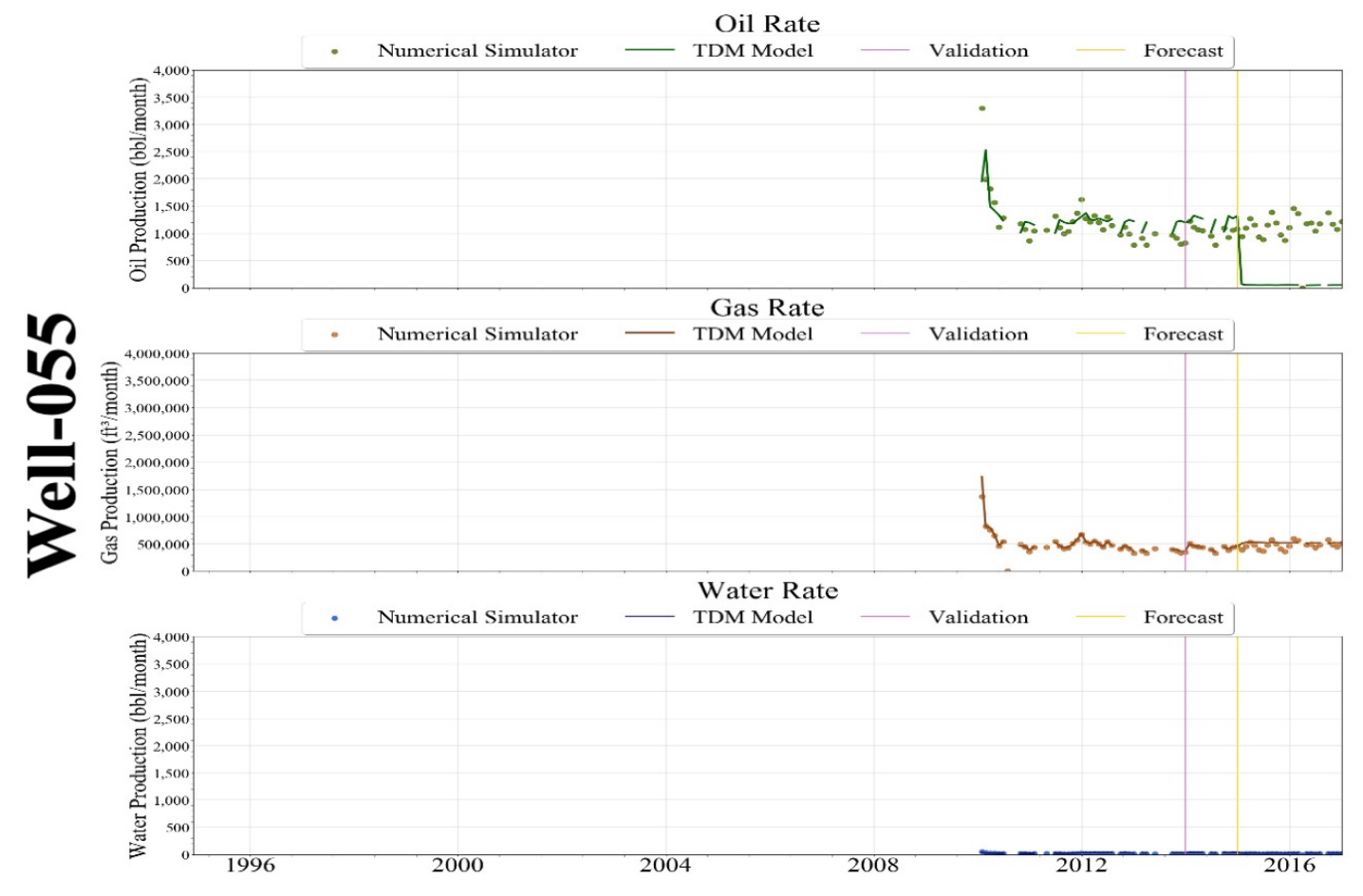

Figure 13-34: Scenario 5 - Well-055 Production History Match 


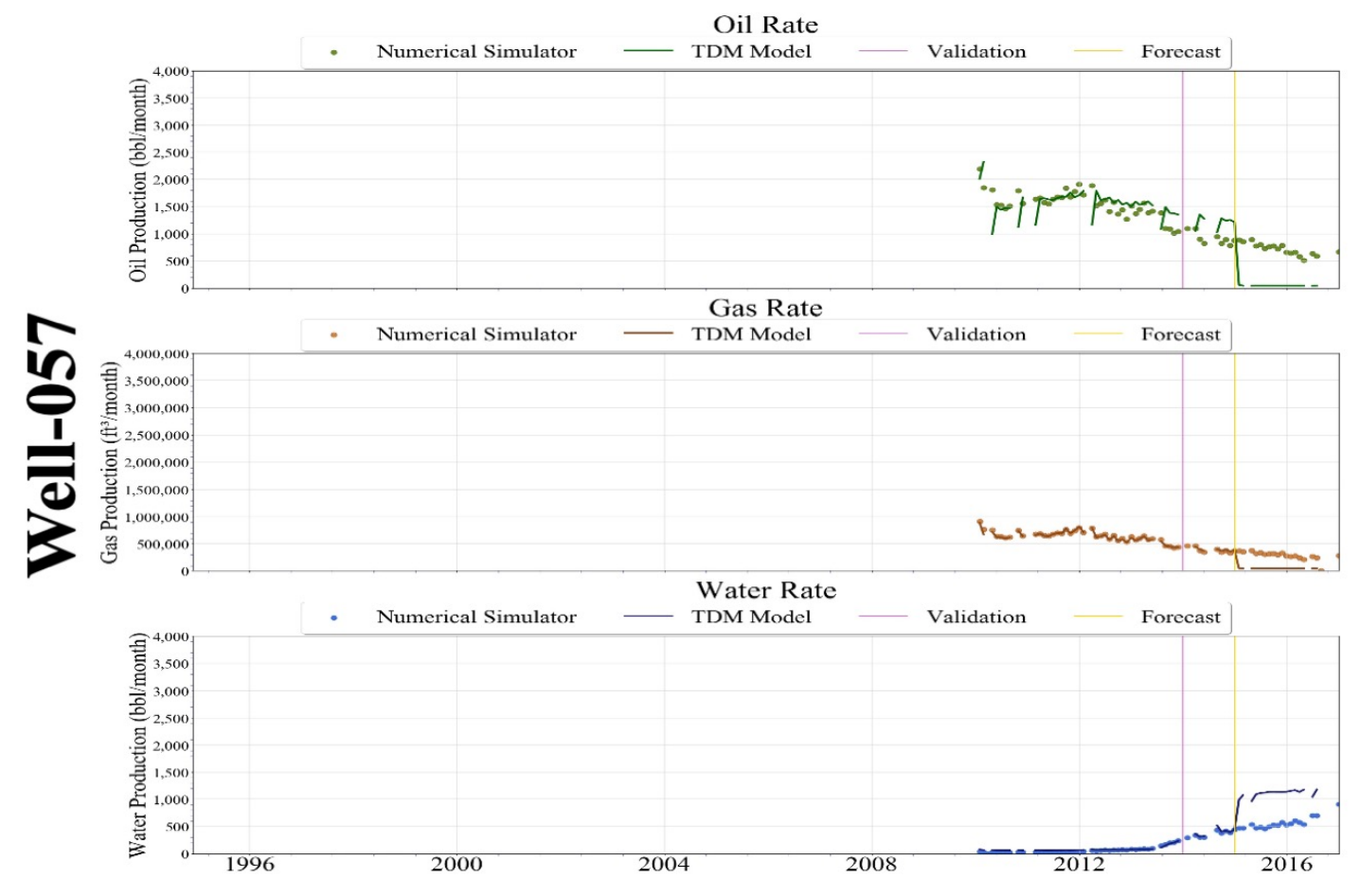

Figure 13-35: Scenario 5 - Well-057 Production History Match 


\subsubsection{Average History Match of Production}

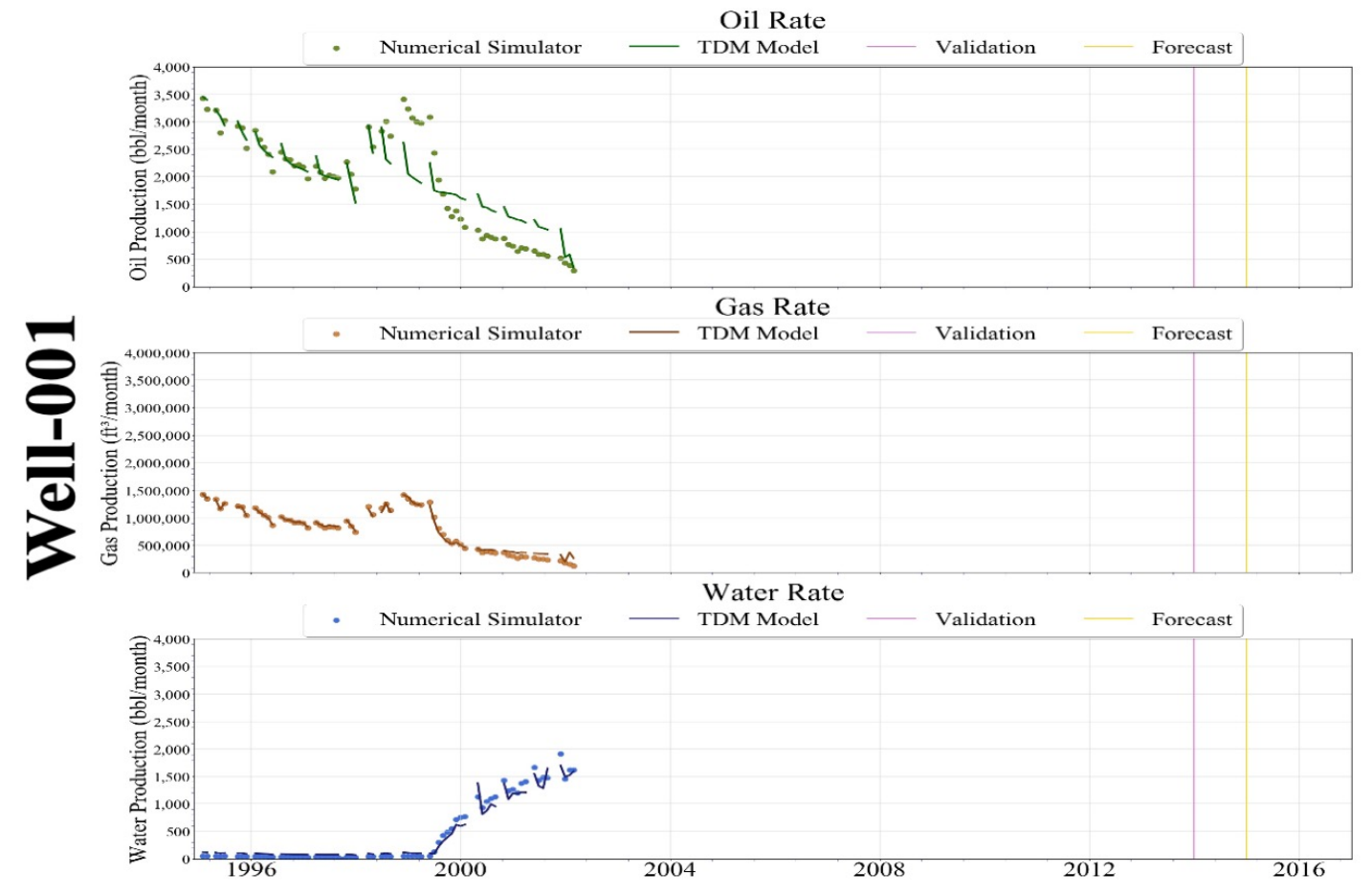

Figure 13-36: Scenario 5 - Well-001 Production History Match

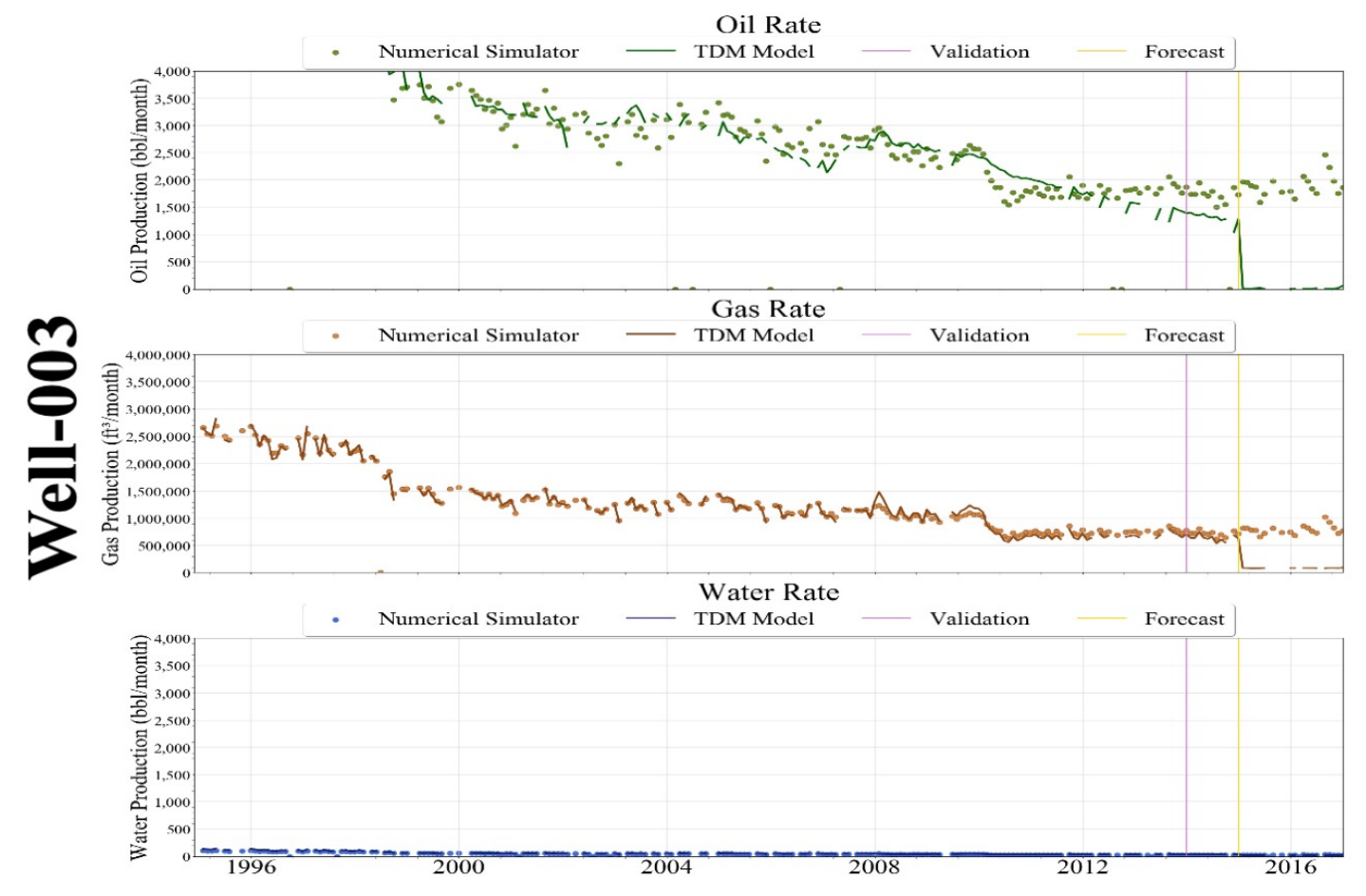

Figure 13-37: Scenario 5 - Well-003 Production History Match 


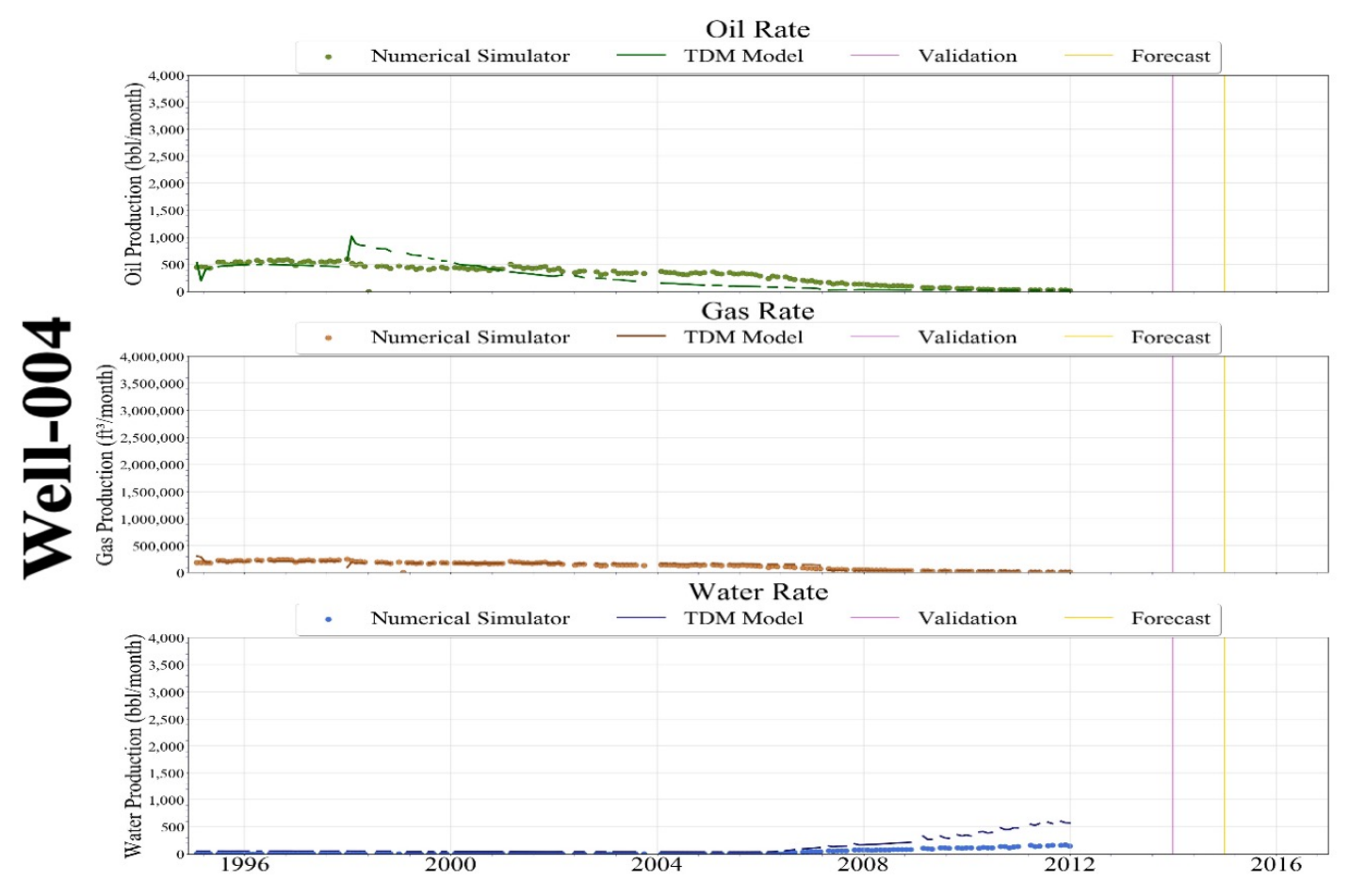

Figure 13-38: Scenario 5 - Well-004 Production History Match

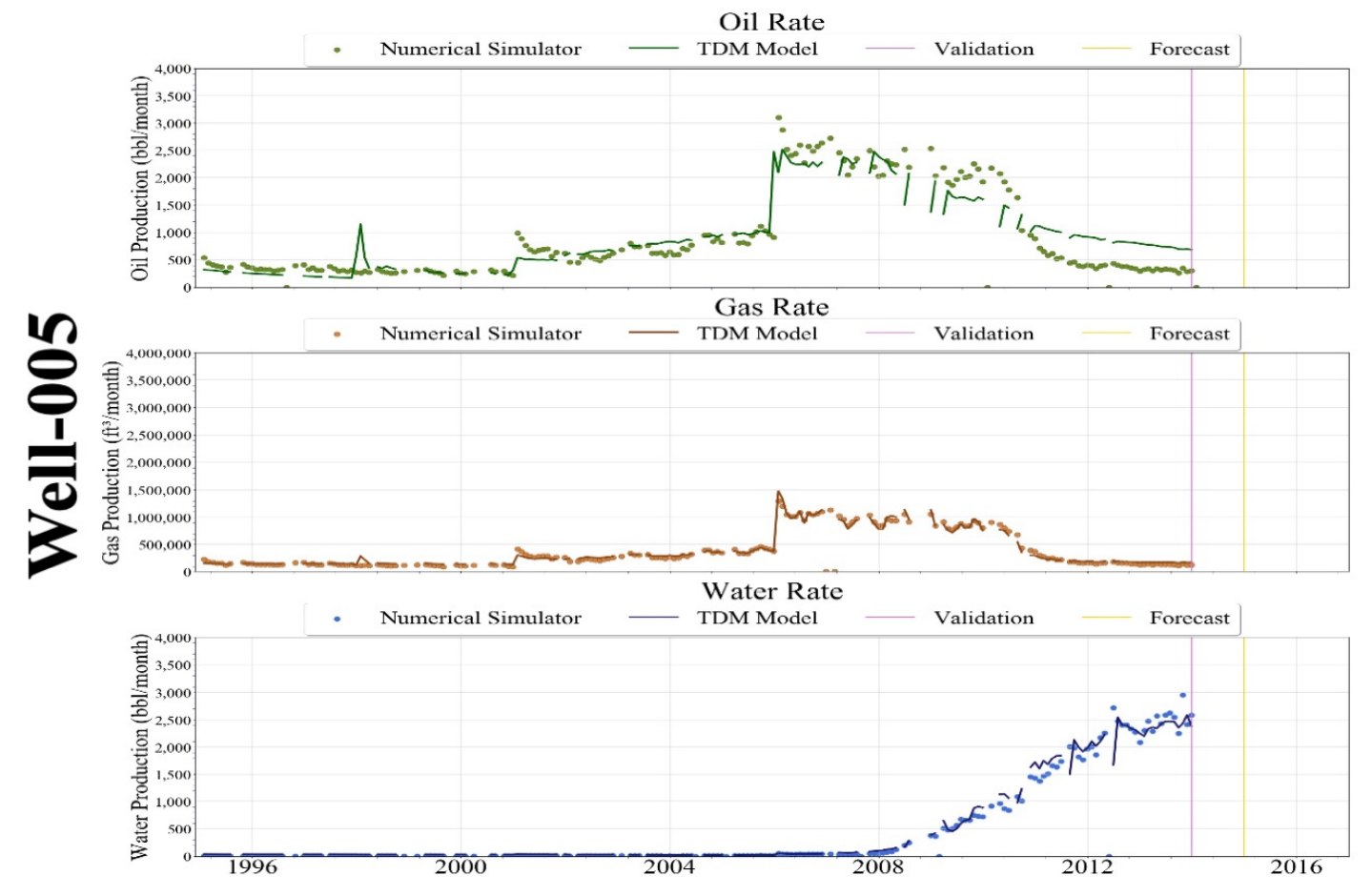

Figure 13-39: Scenario 5 - Well-005 Production History Match 


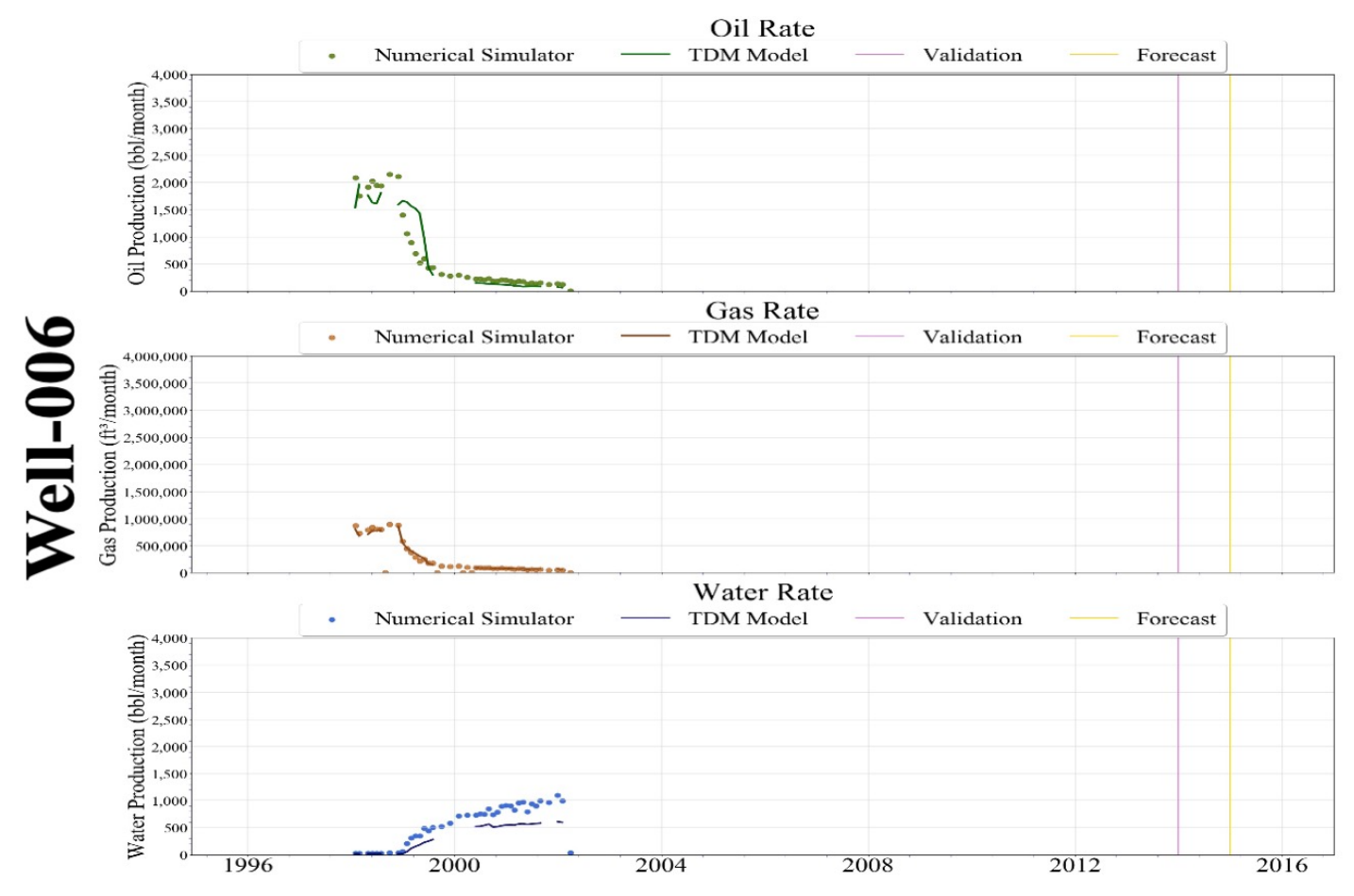

Figure 13-40: Scenario 5 - Well-006 Production History Match

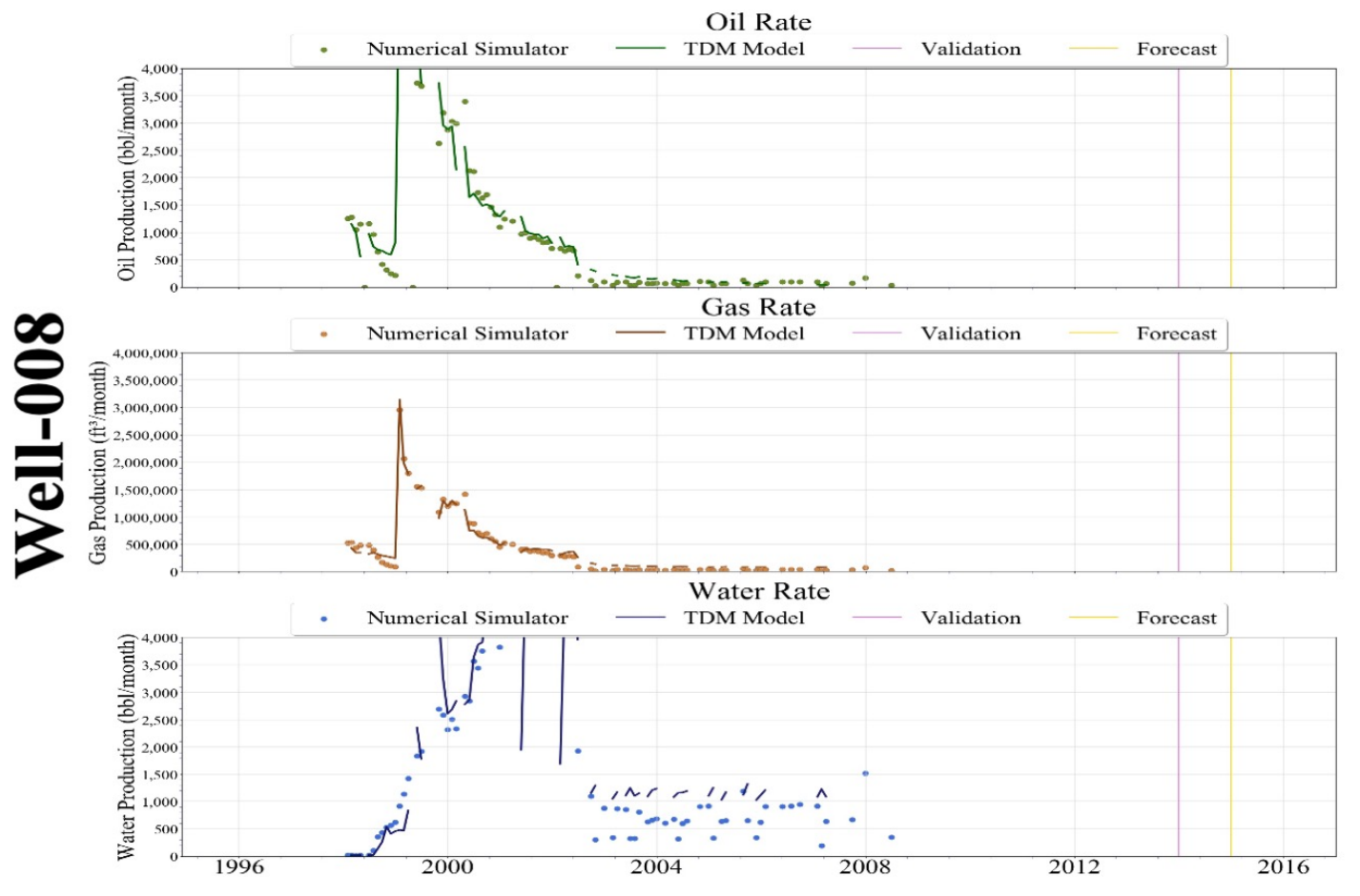

Figure 13-41: Scenario 5 - Well-008 Production History Match 


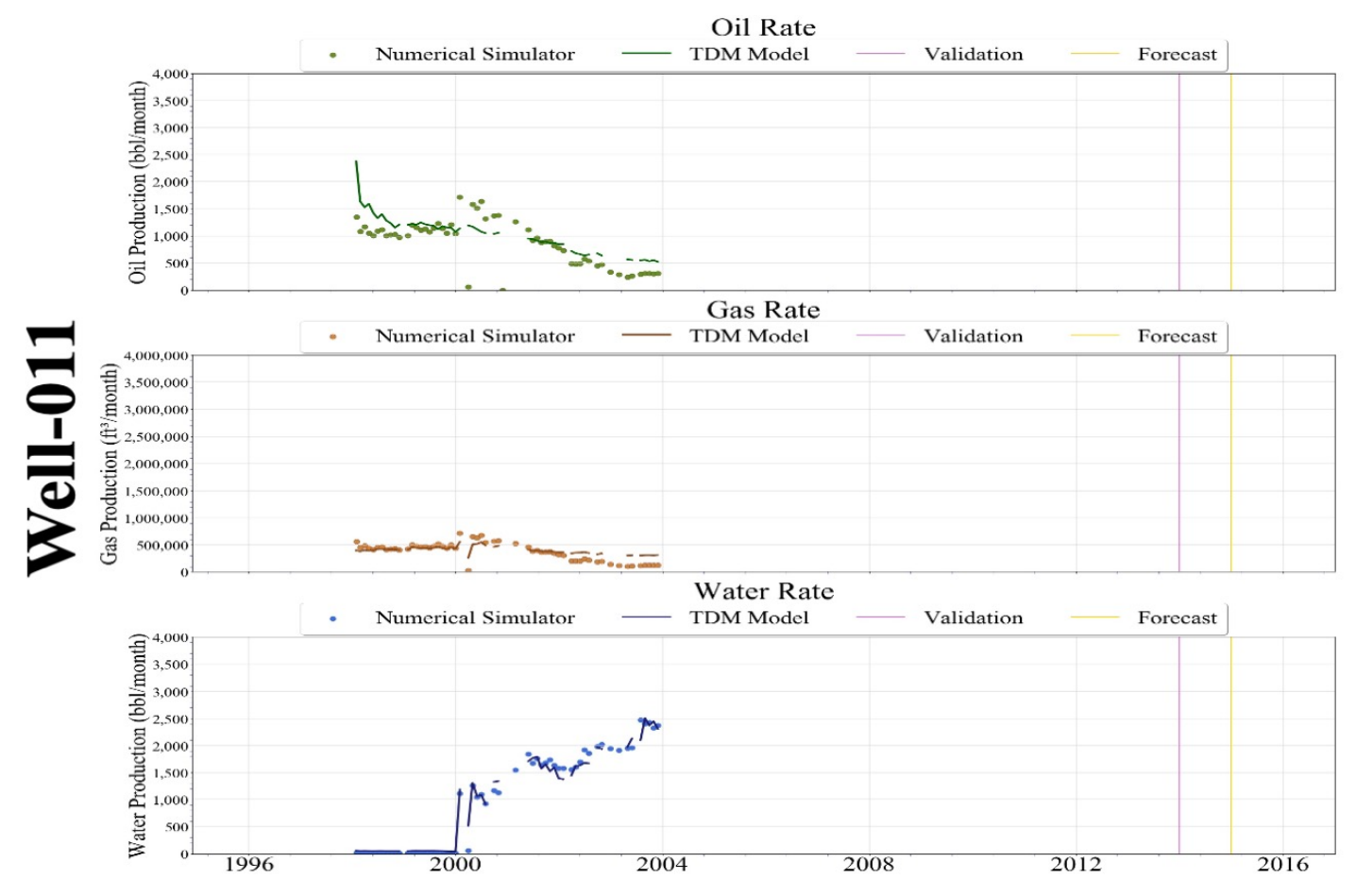

Figure 13-42: Scenario 5 - Well-011 Production History Match

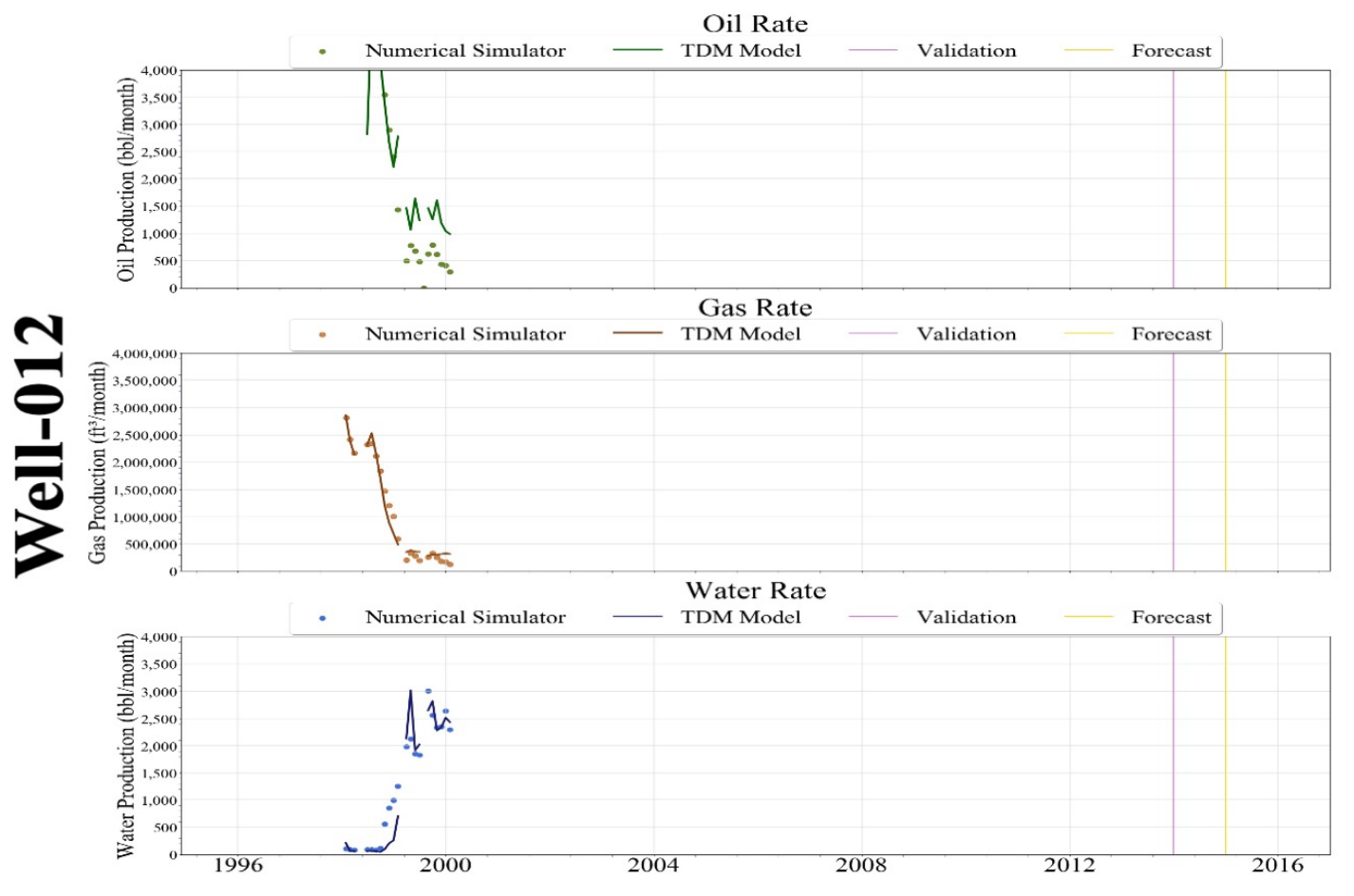

Figure 13-43: Scenario 5 - Well-012 Production History Match 


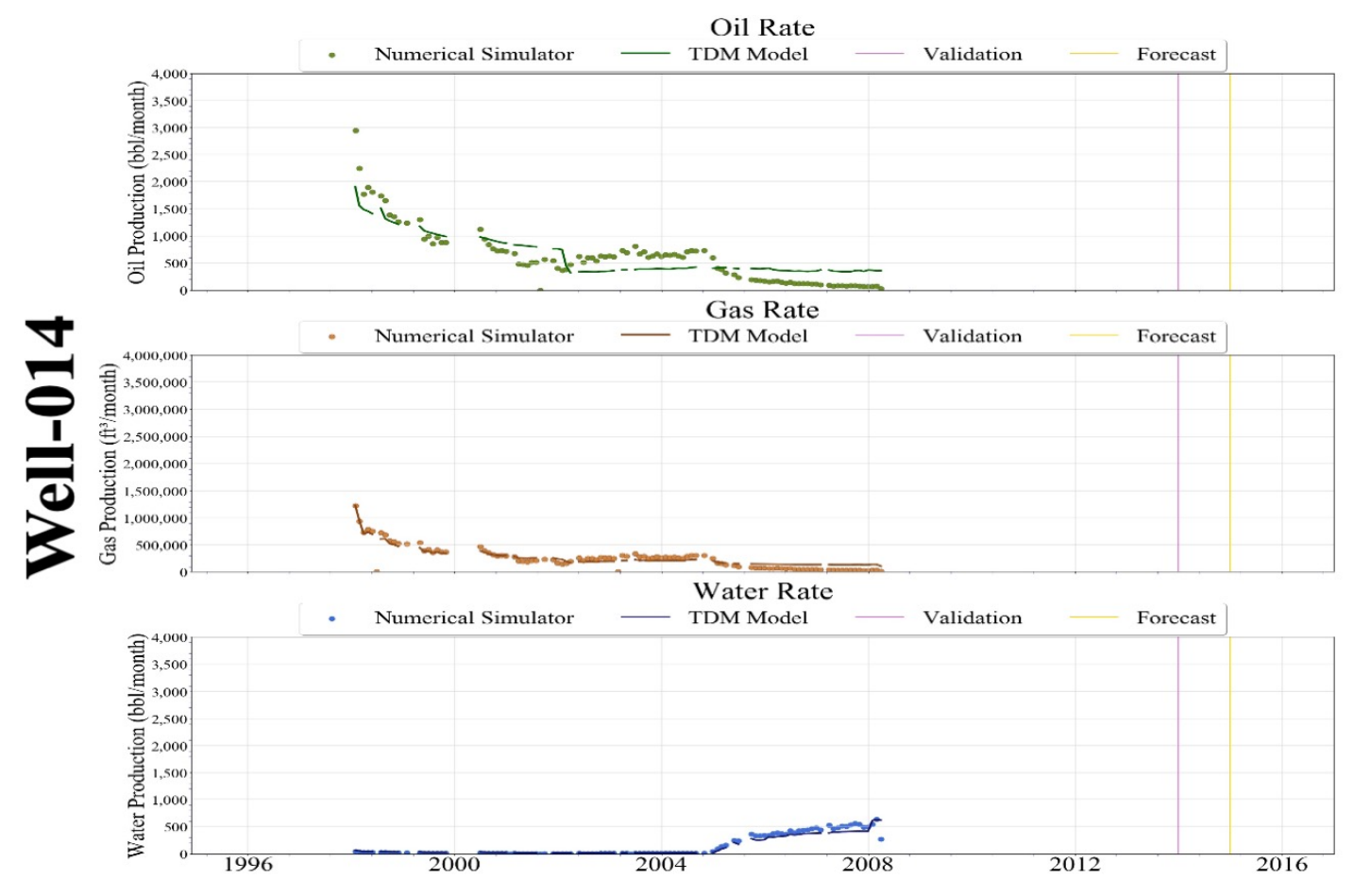

Figure 13-44: Scenario 5 - Well-014 Production History Match

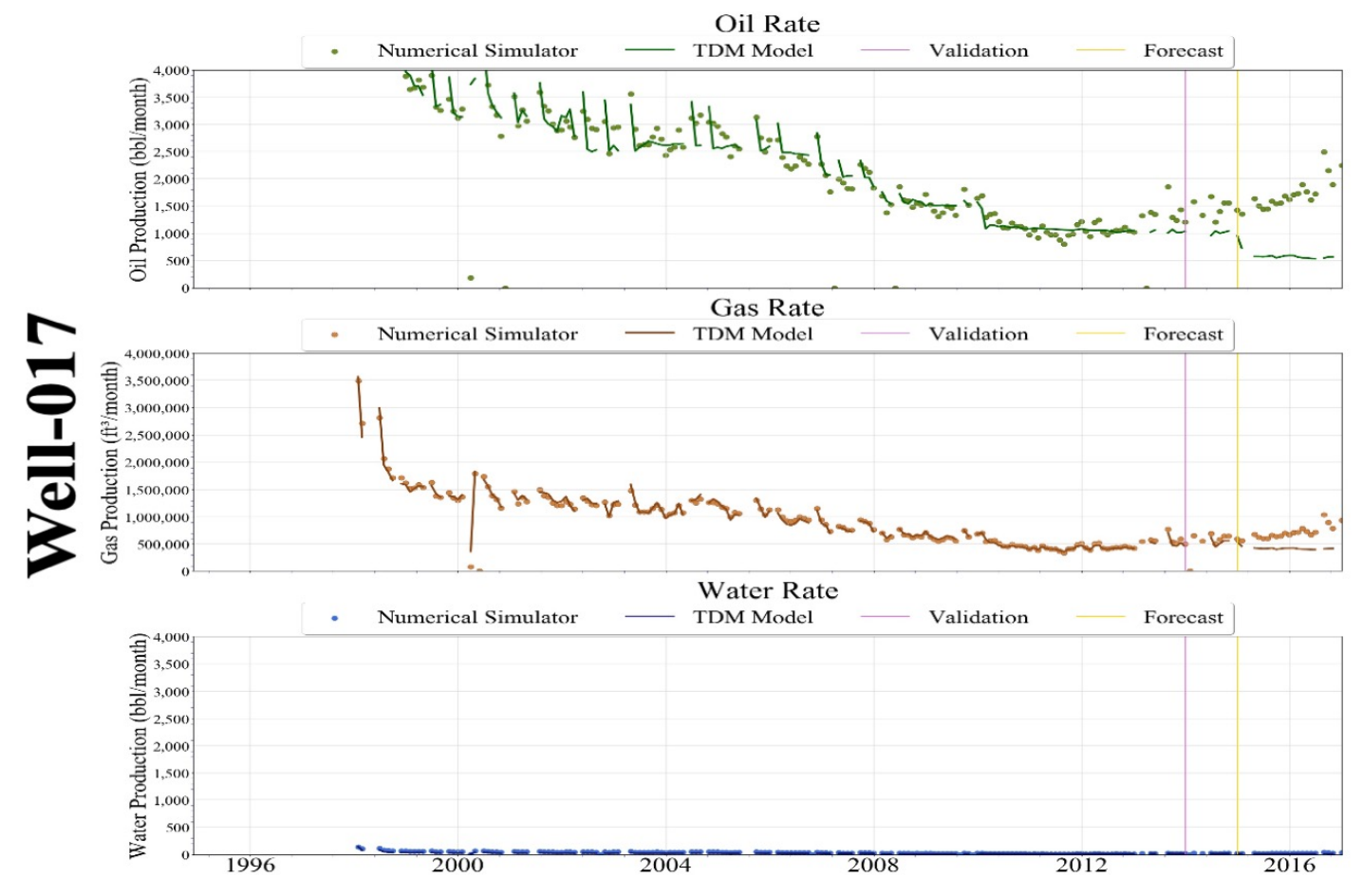

Figure 13-45: Scenario 5 - Well-017 Production History Match 


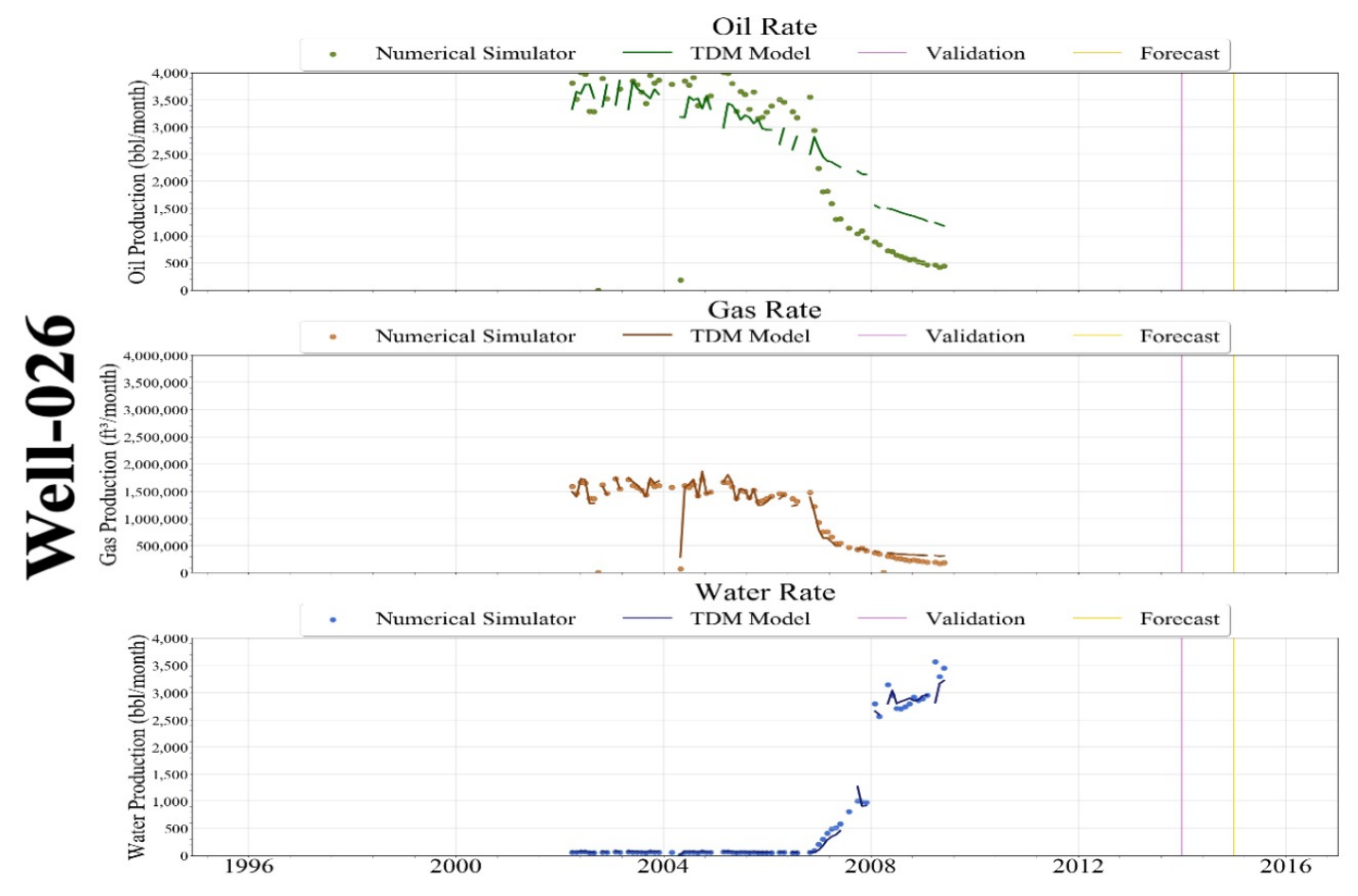

Figure 13-46: Scenario 5 - Well-026 Production History Match

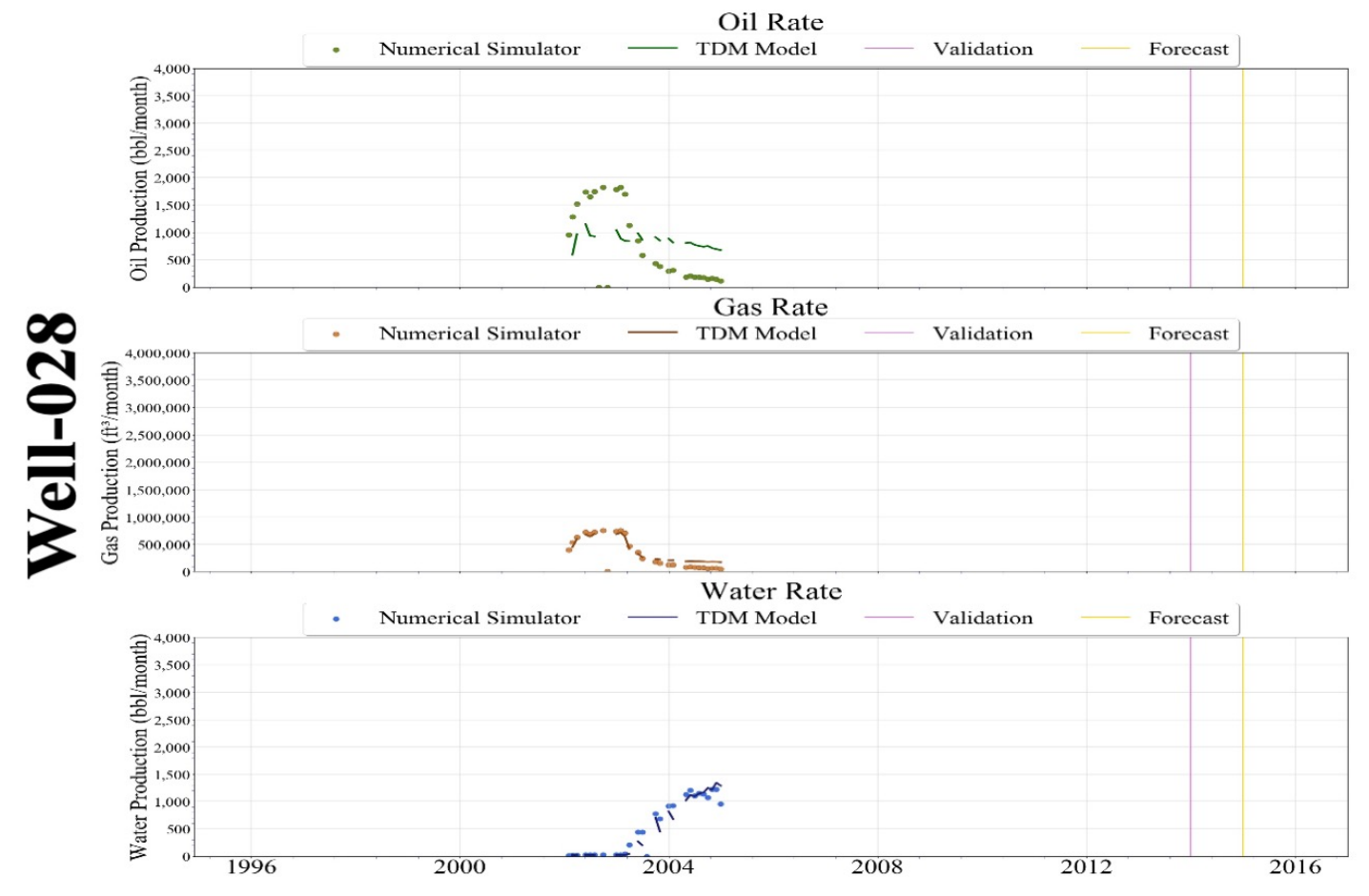

Figure 13-47: Scenario 5 - Well-028 Production History Match 


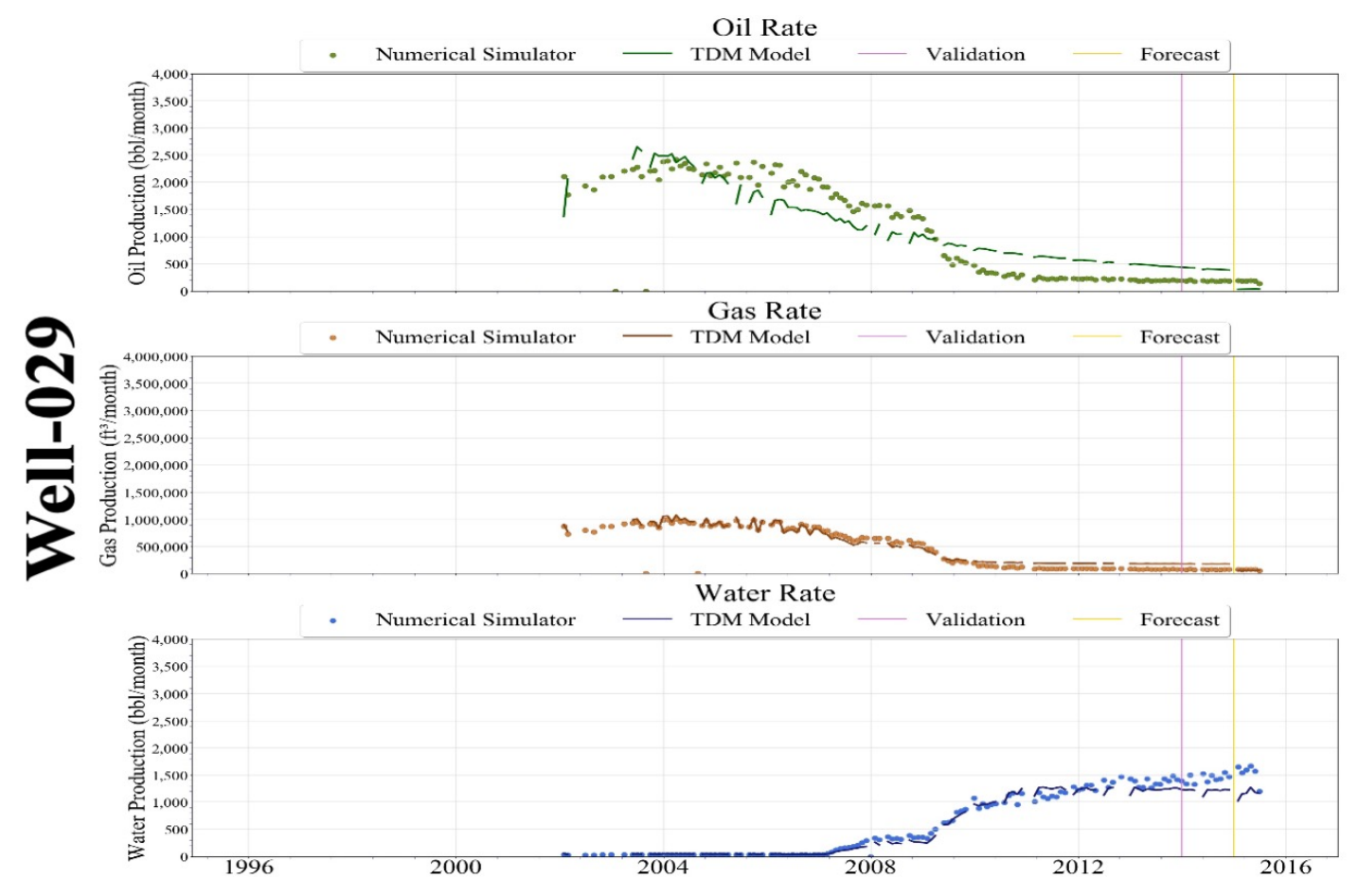

Figure 13-48: Scenario 5 - Well-029 Production History Match

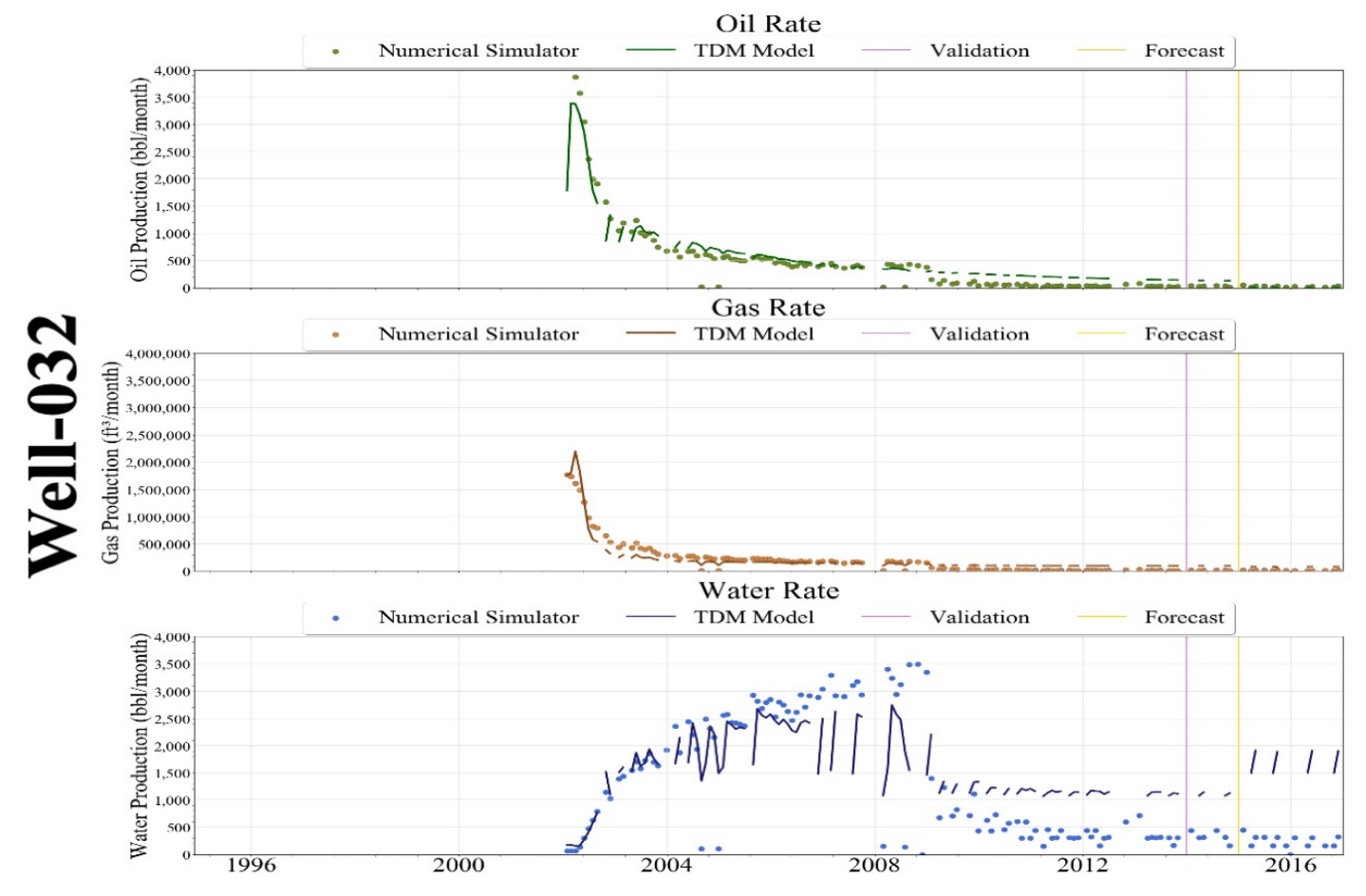

Figure 13-49: Scenario 5 - Well-032 Production History Match 


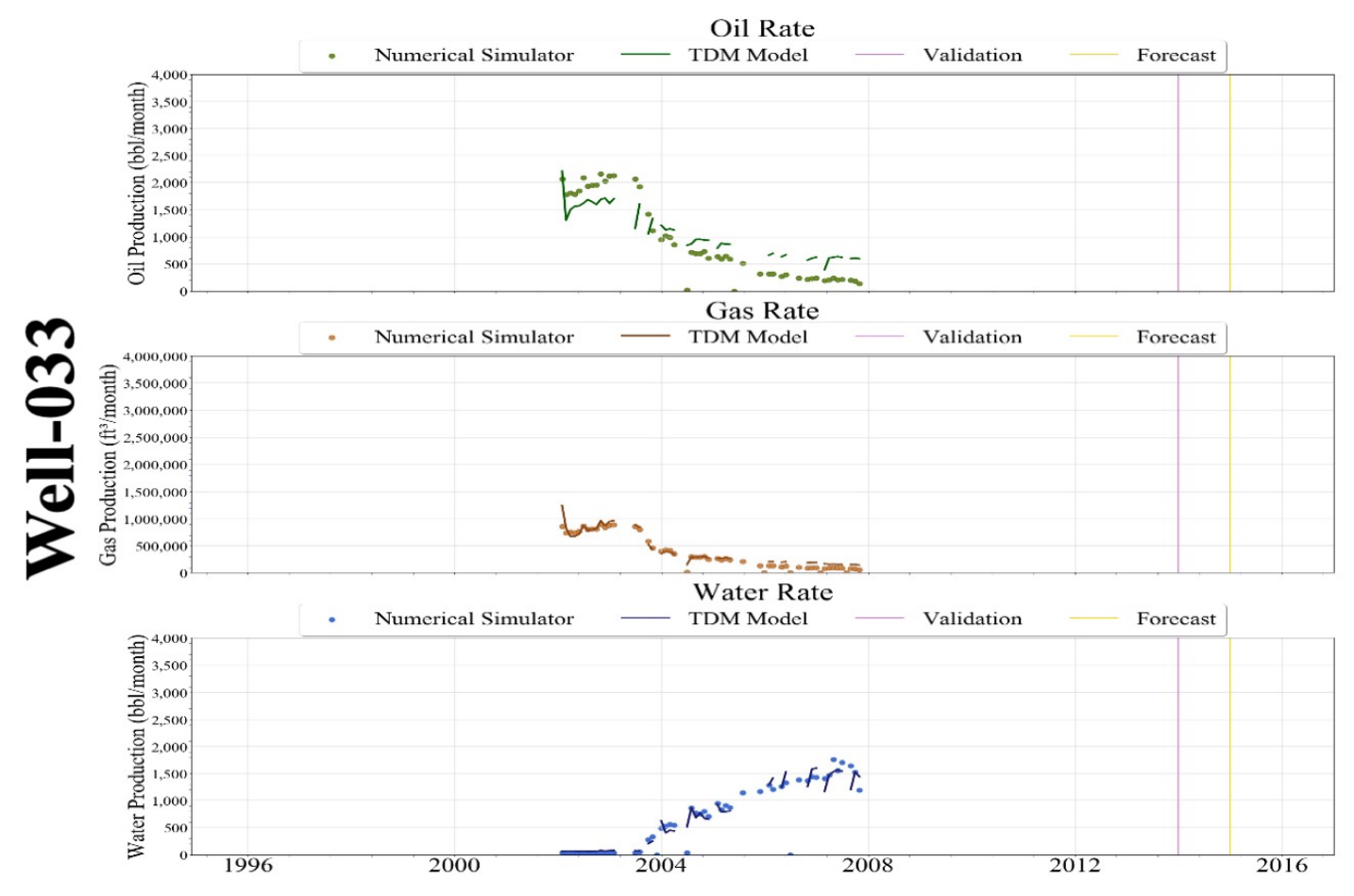

Figure 13-50: Scenario 5 - Well-033 Production History Match

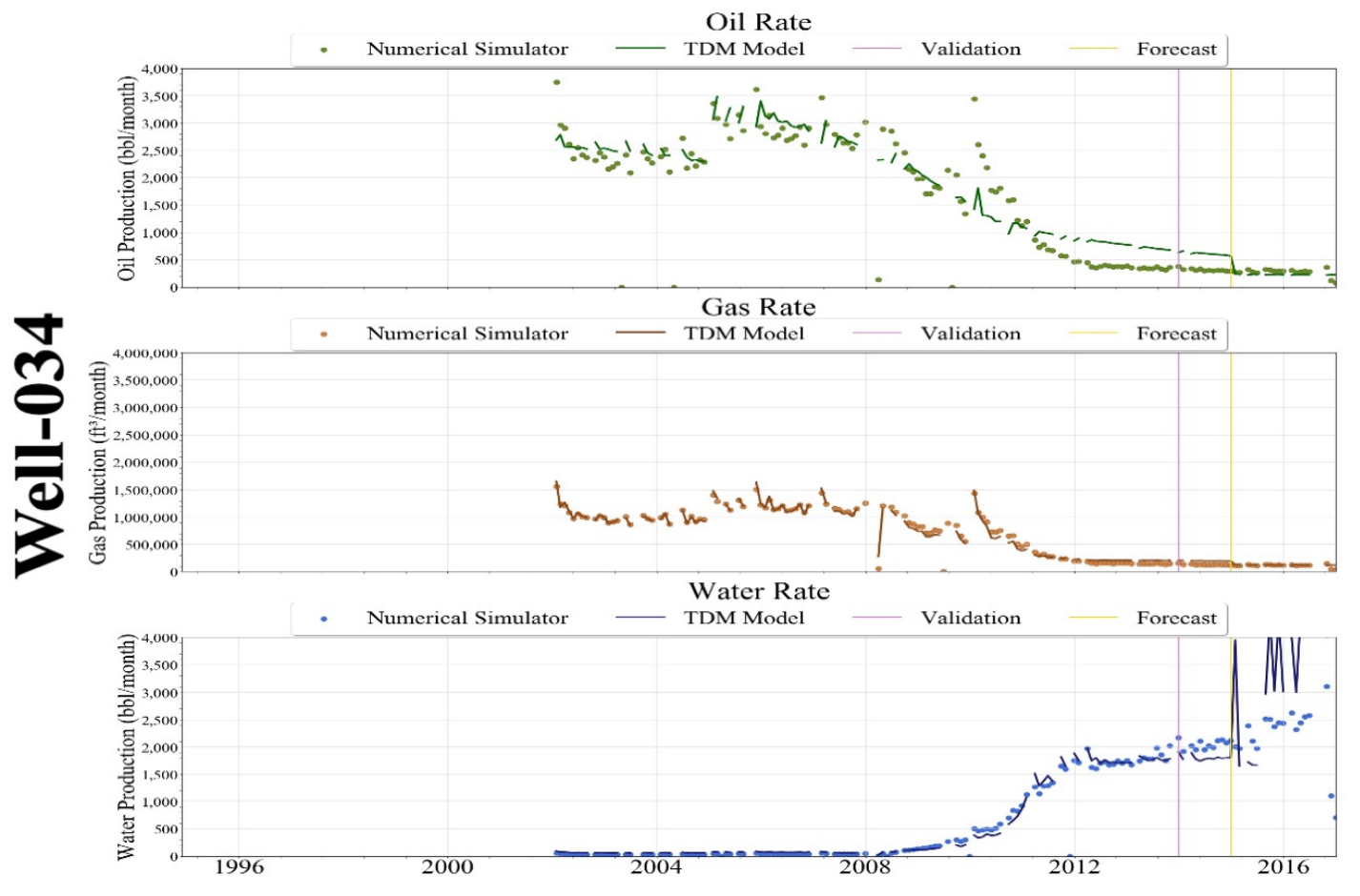

Figure 13-51: Scenario 5 - Well-034 Production History Match 


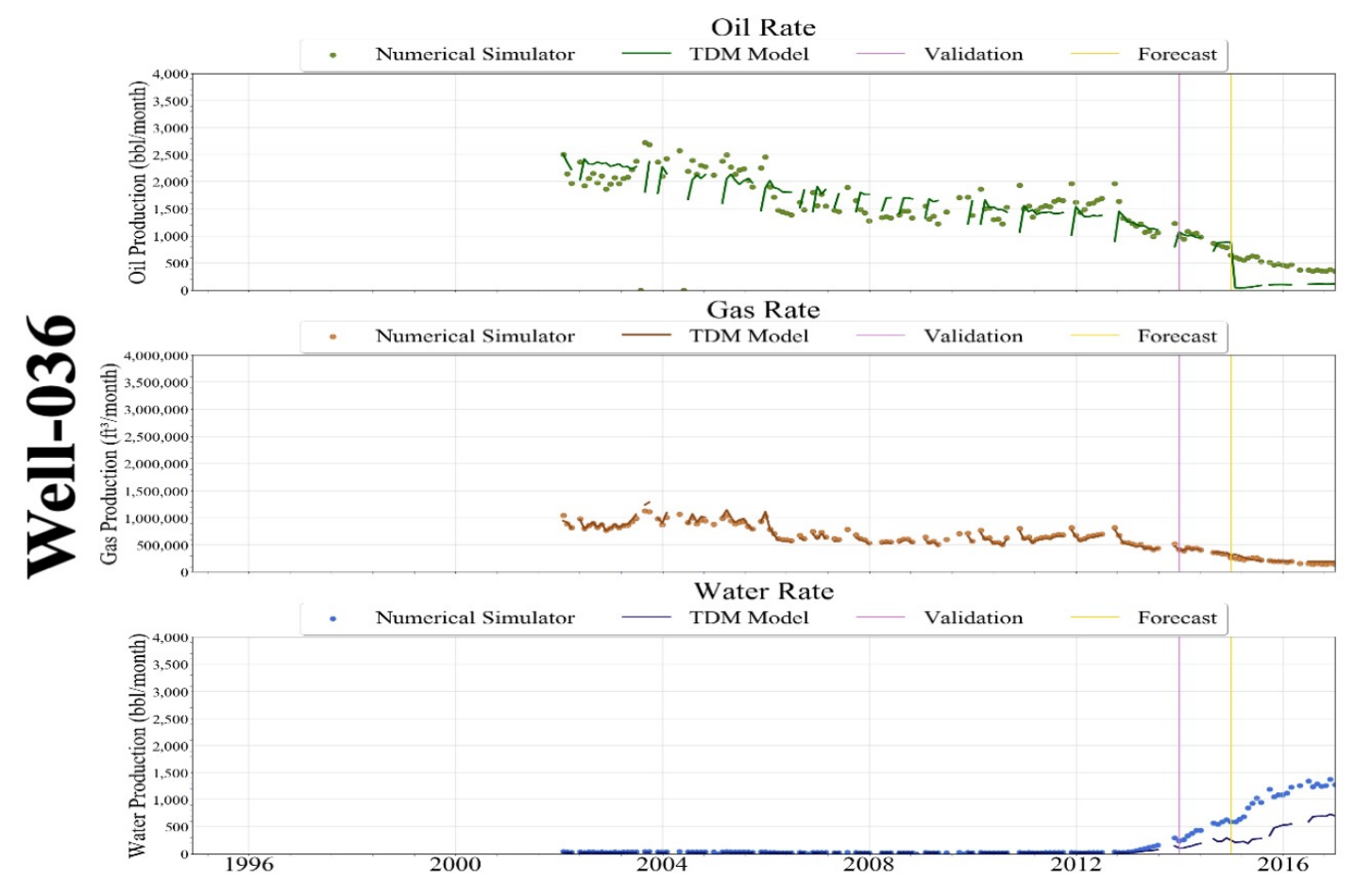

Figure 13-52: Scenario 5 - Well-036 Production History Match

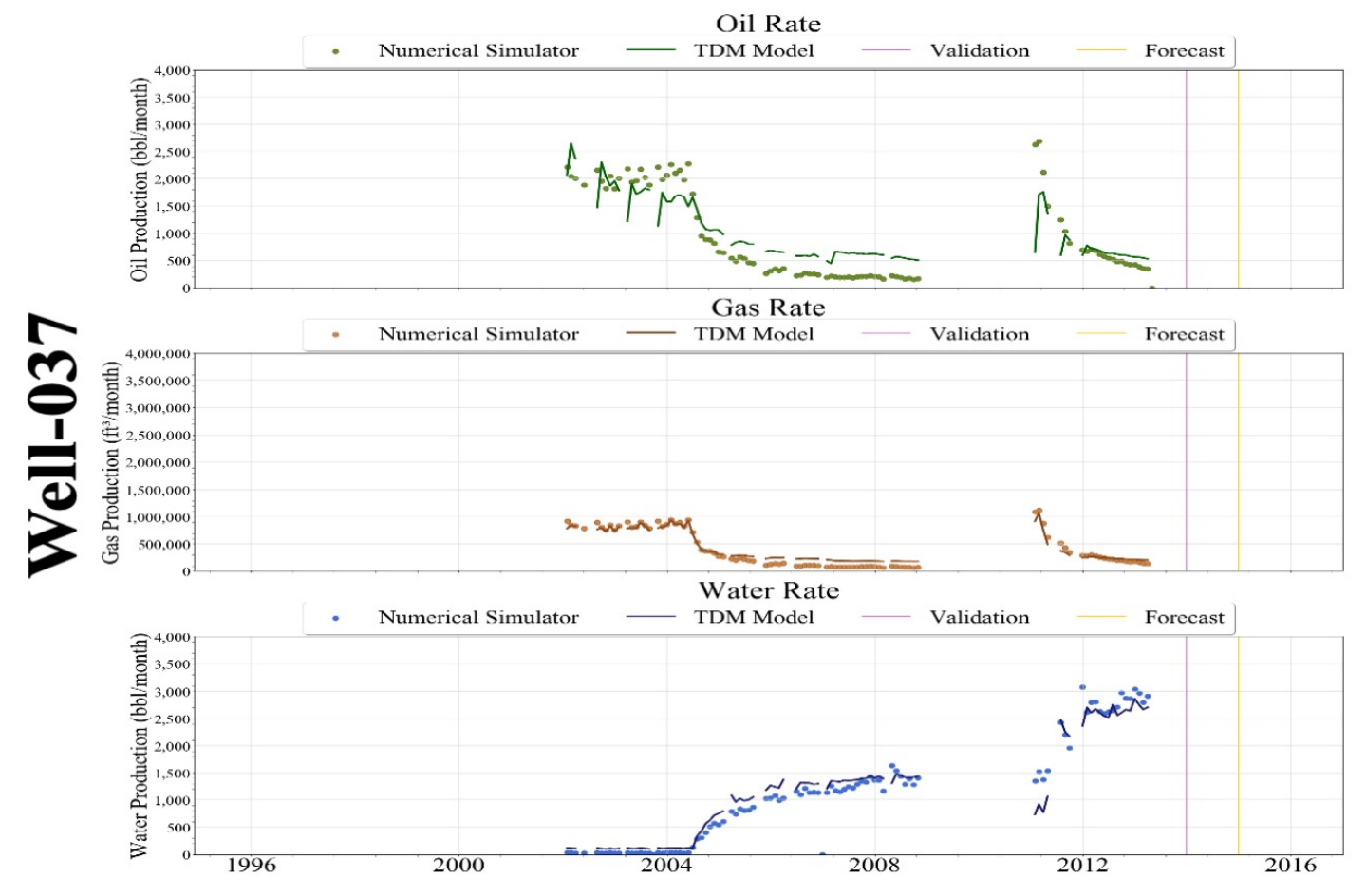

Figure 13-53: Scenario 5 - Well-037 Production History Match 


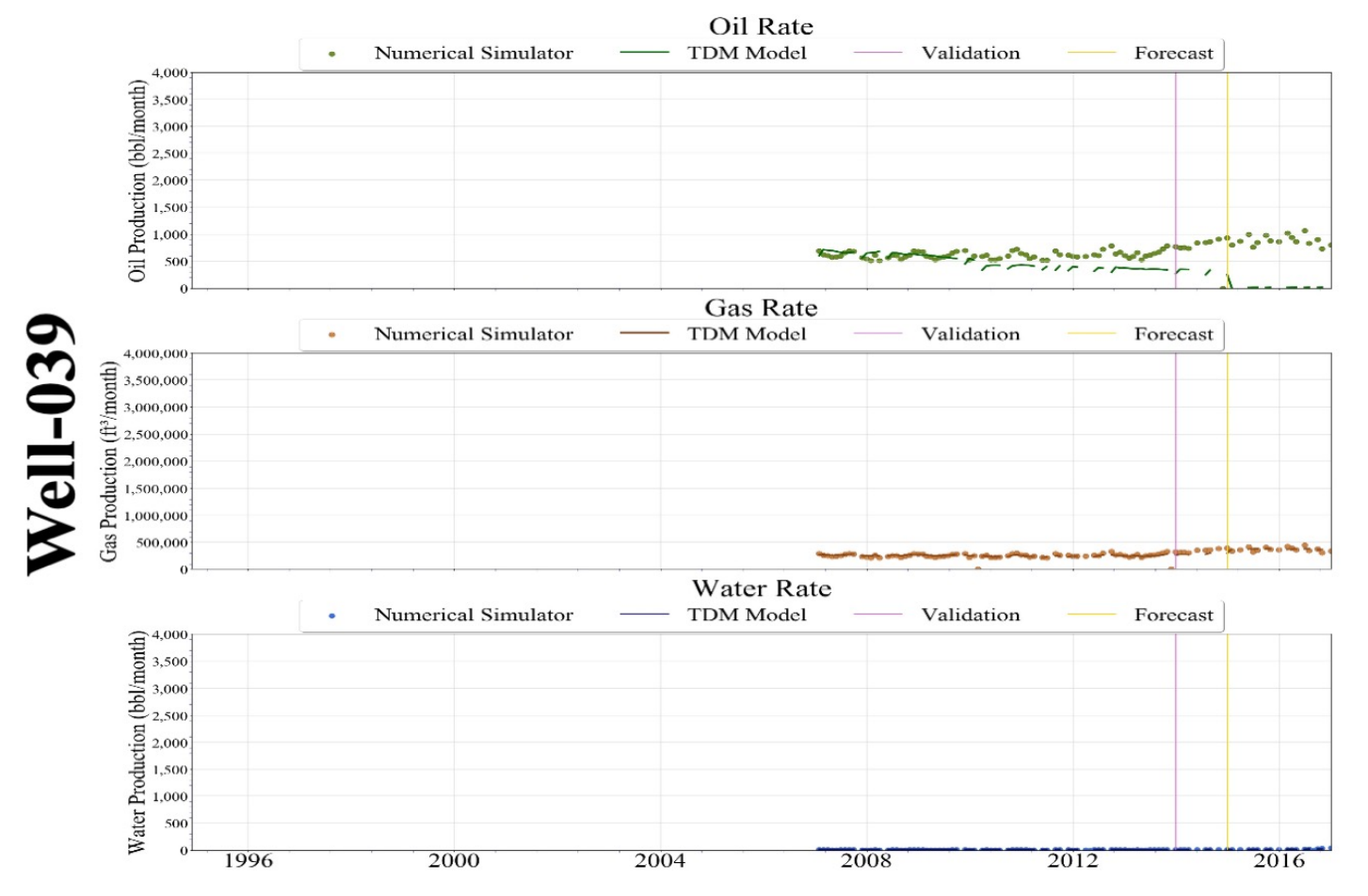

Figure 13-54: Scenario 5 - Well-039 Production History Match

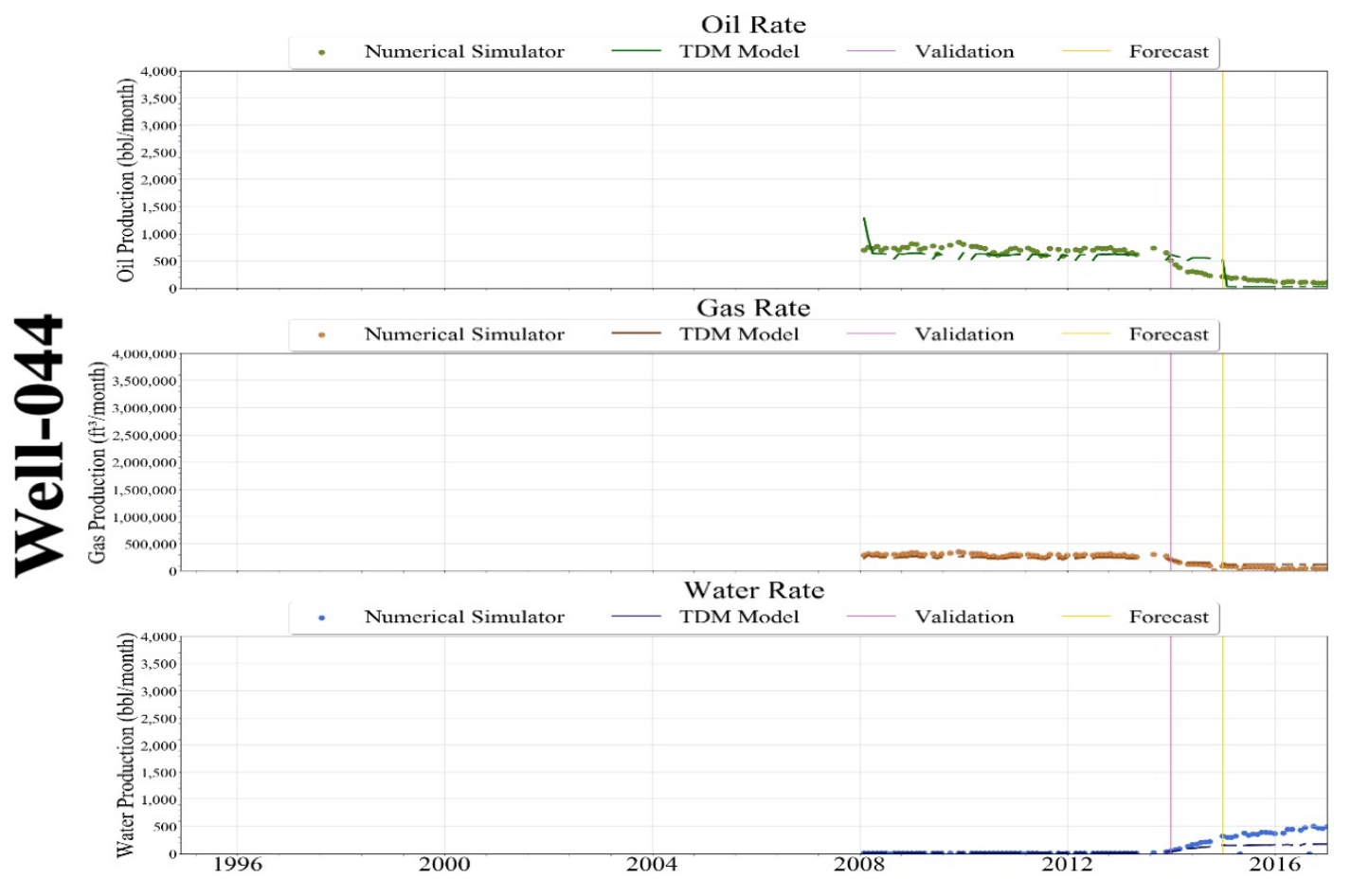

Figure 13-55: Scenario 5 - Well-044 Production History Match 


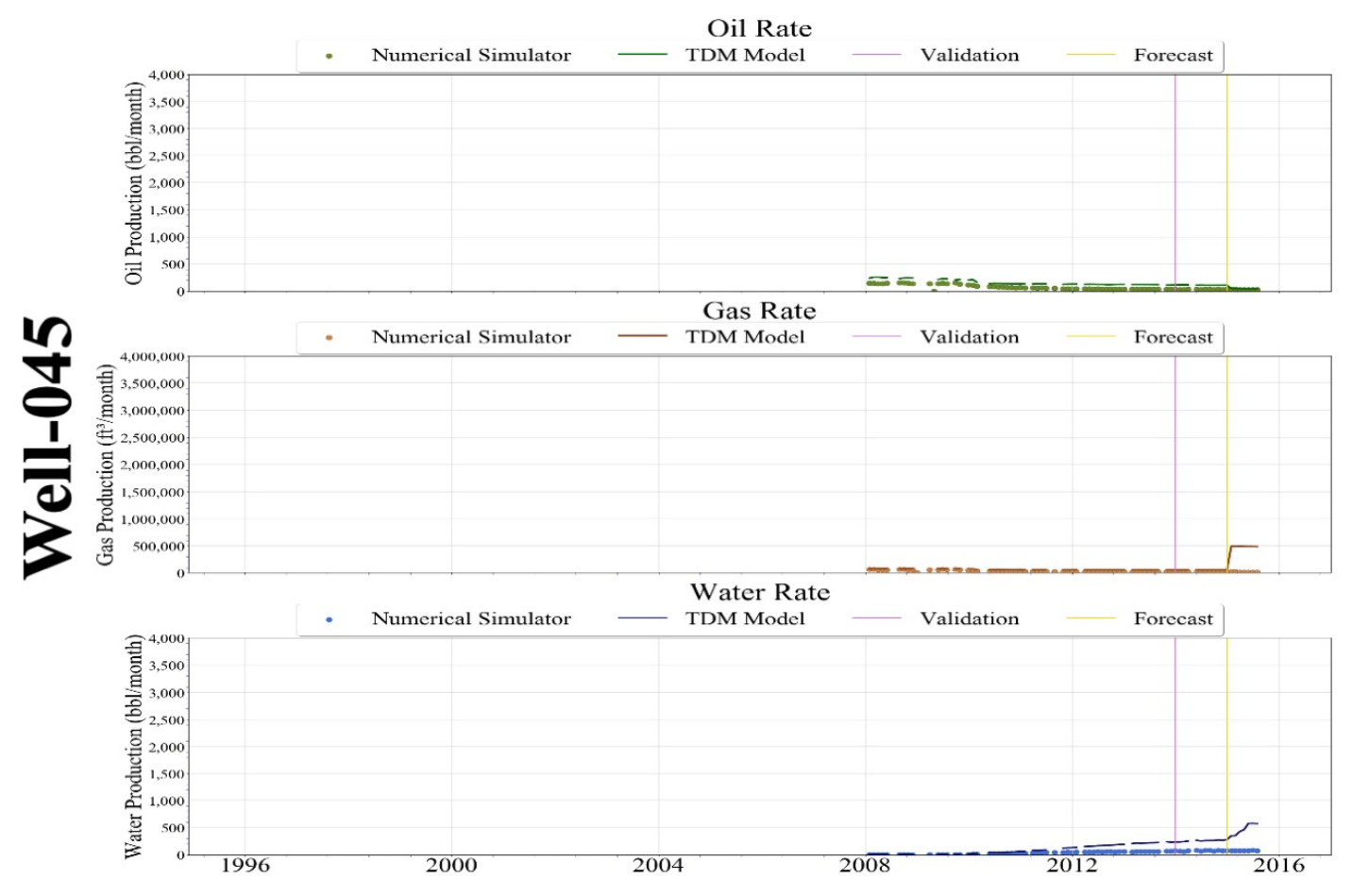

Figure 13-56: Scenario 5 - Well-045 Production History Match

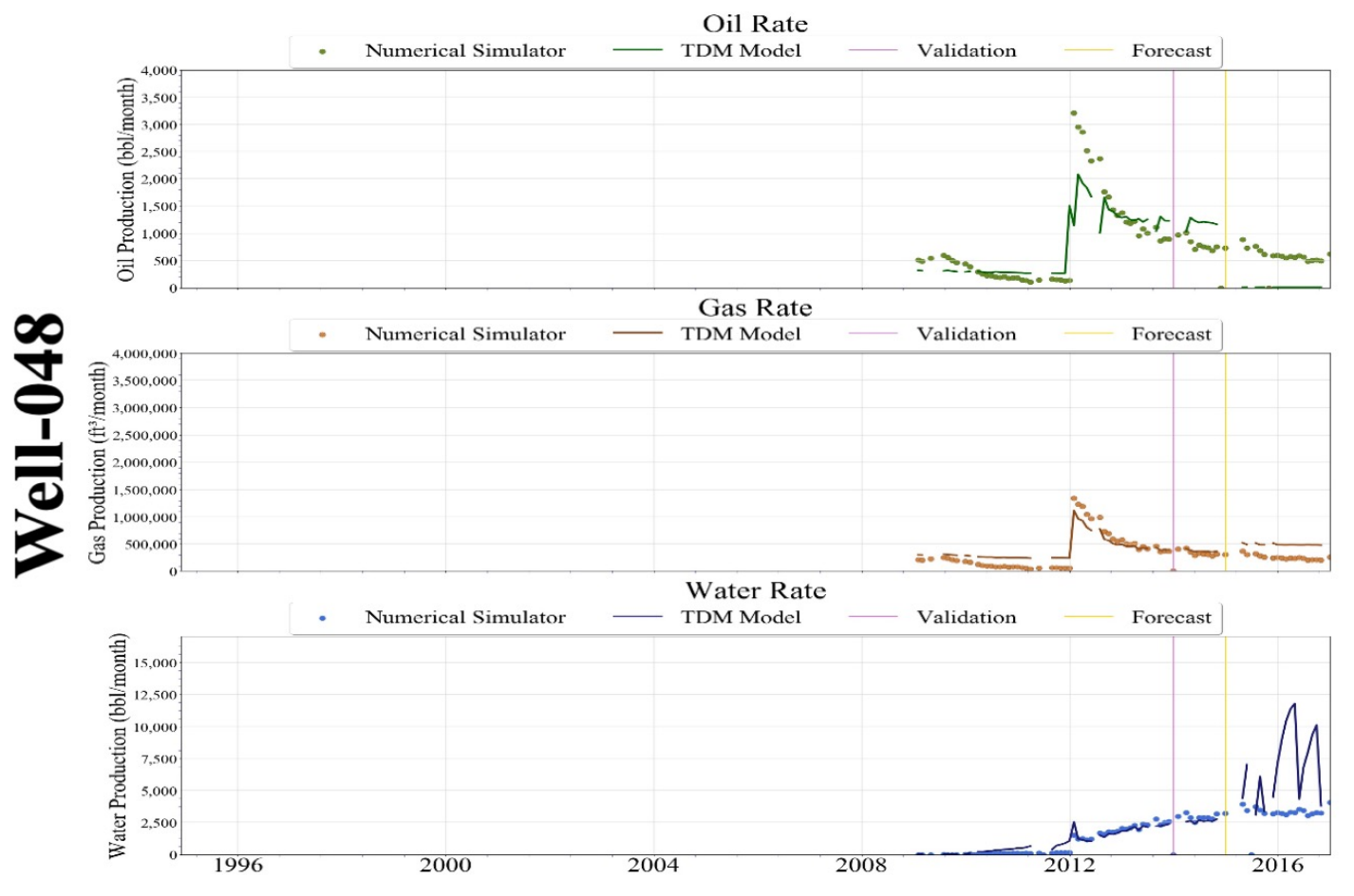

Figure 13-57: Scenario 5 - Well-048 Production History Match 


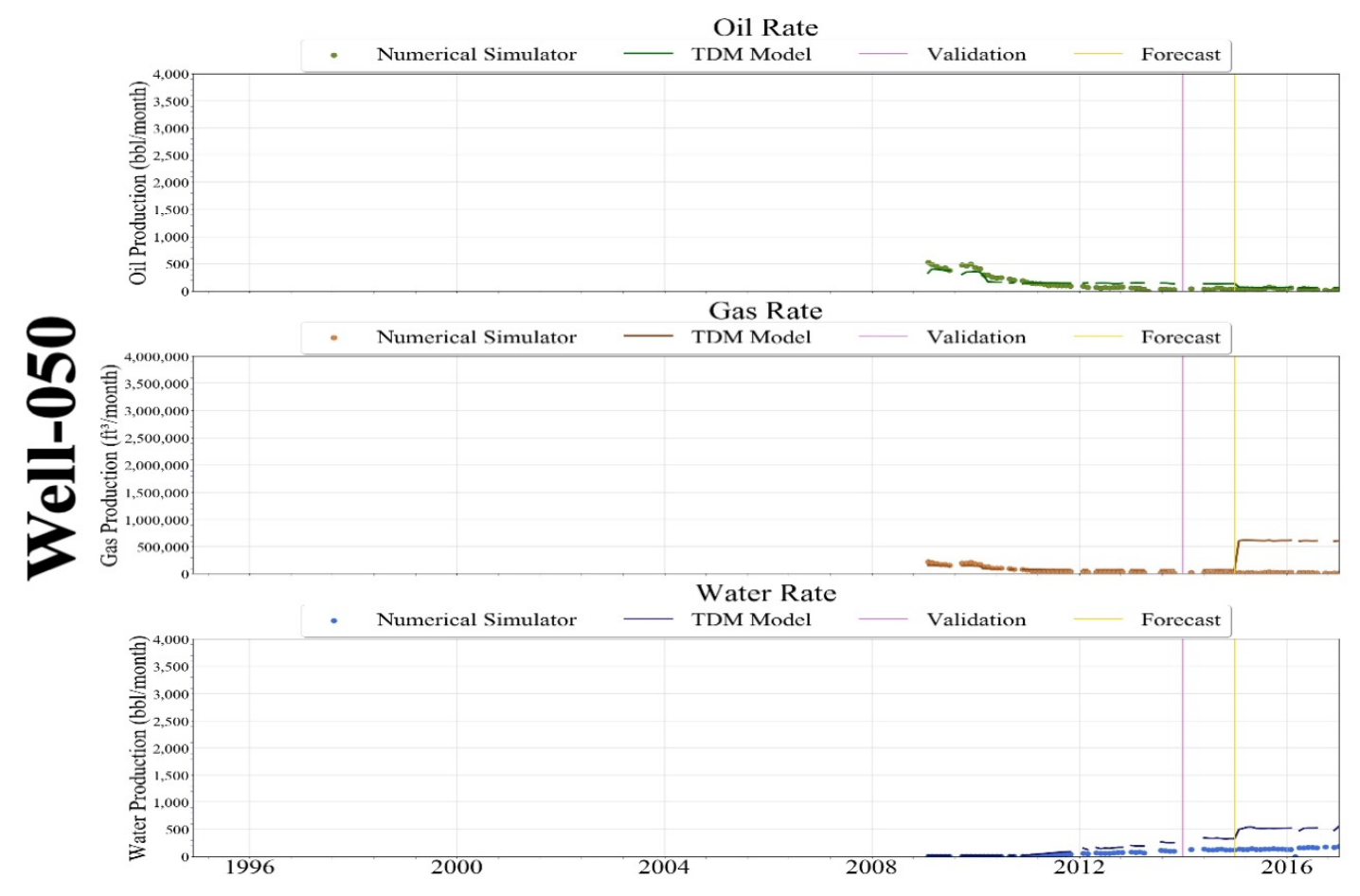

Figure 13-58: Scenario 5 - Well-050 Production History Match

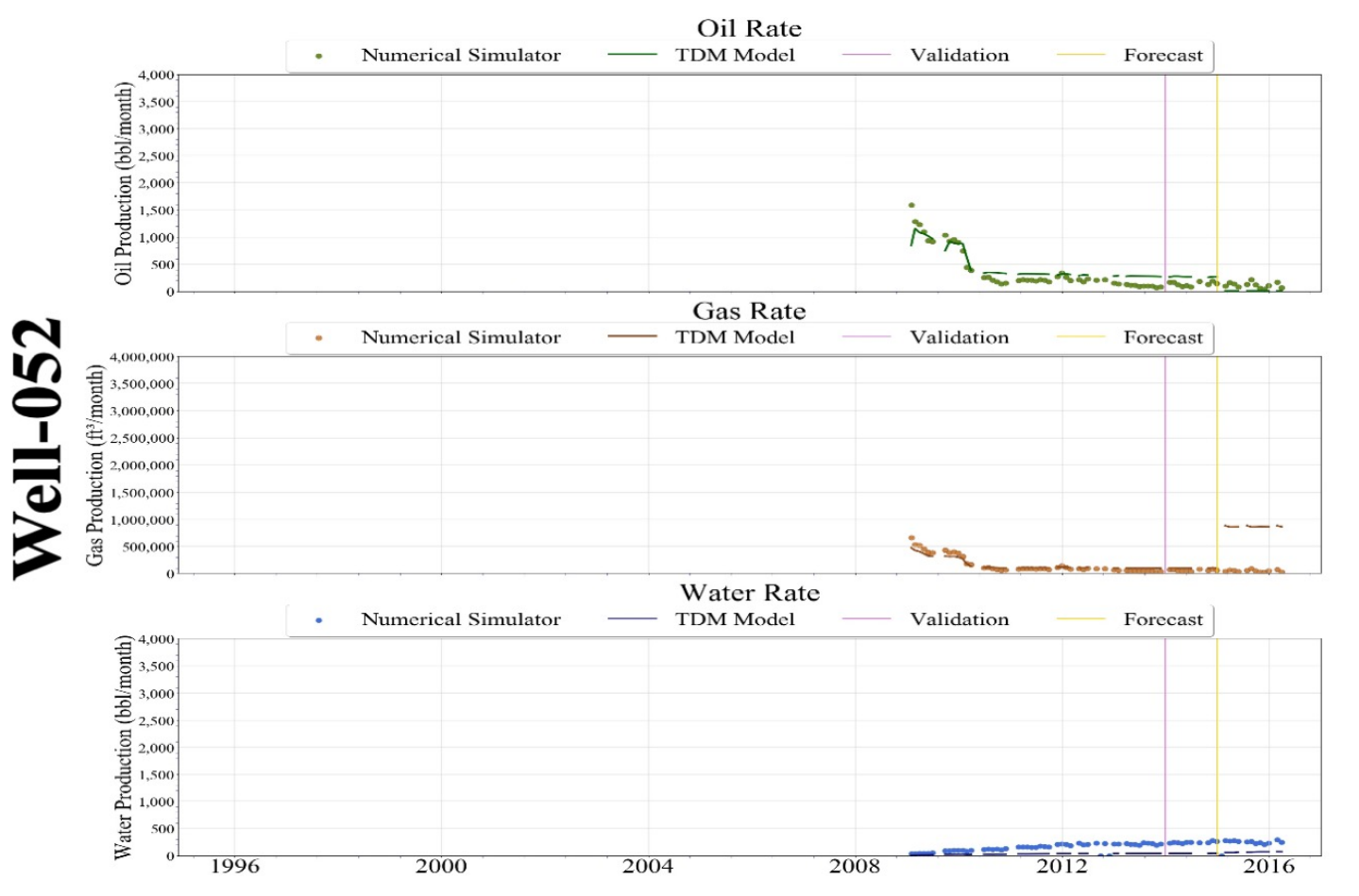

Figure 13-59: Scenario 5 - Well-052 Production History Match 


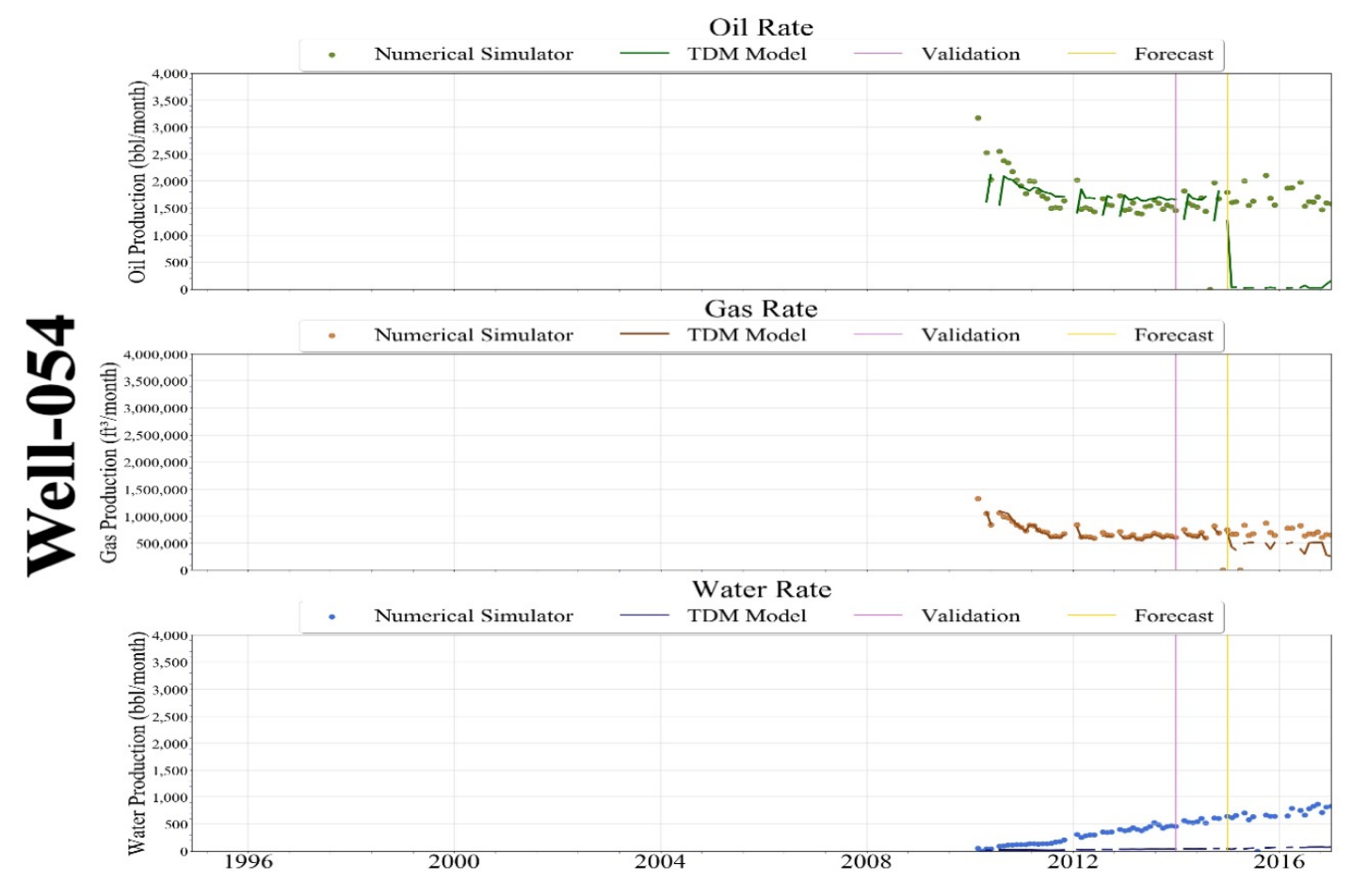

Figure 13-60: Scenario 5 - Well-054 Production History Match

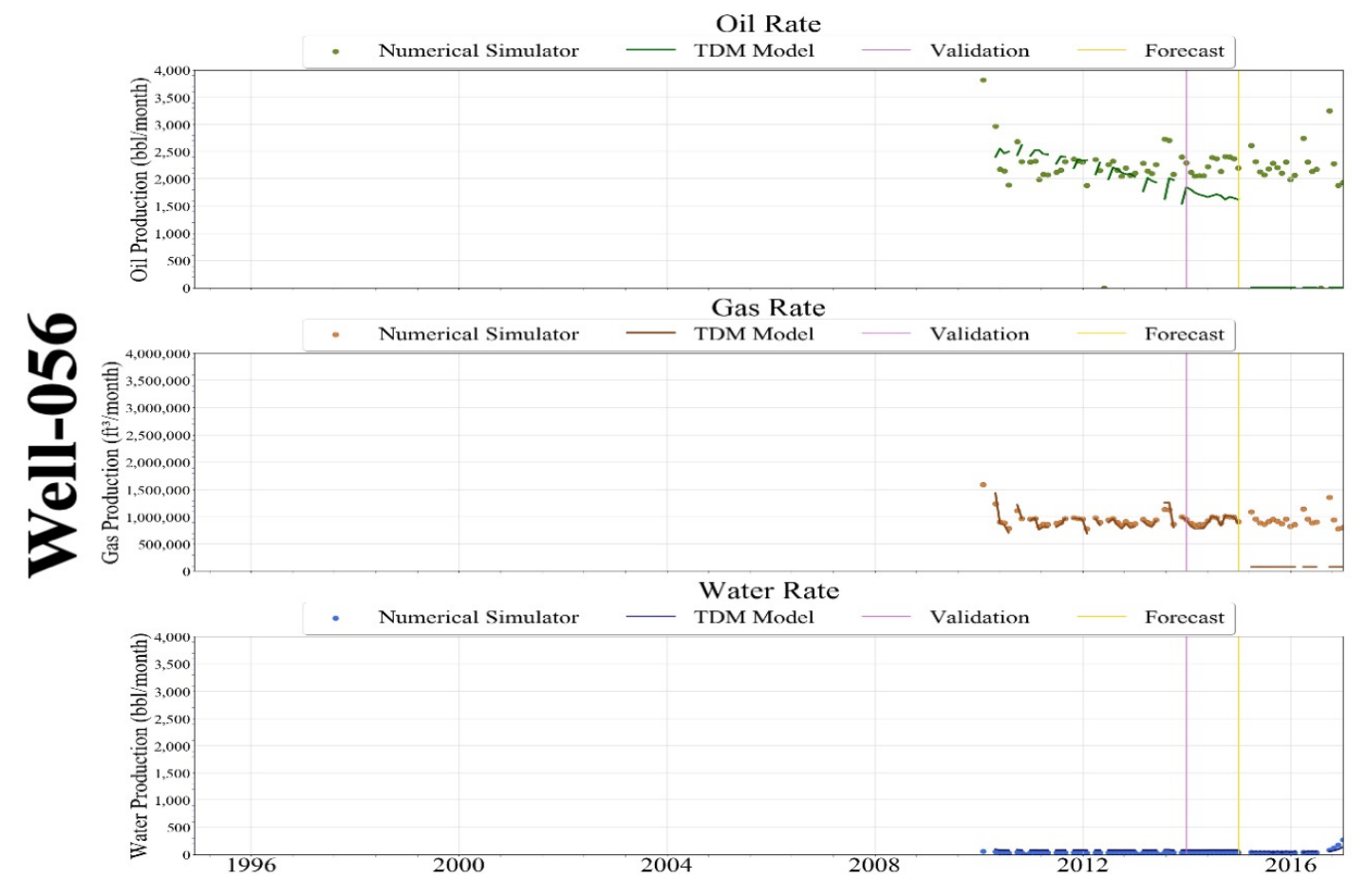

Figure 13-61: Scenario 5 - Well-056 Production History Match 


\subsubsection{Poor History Match of Production}

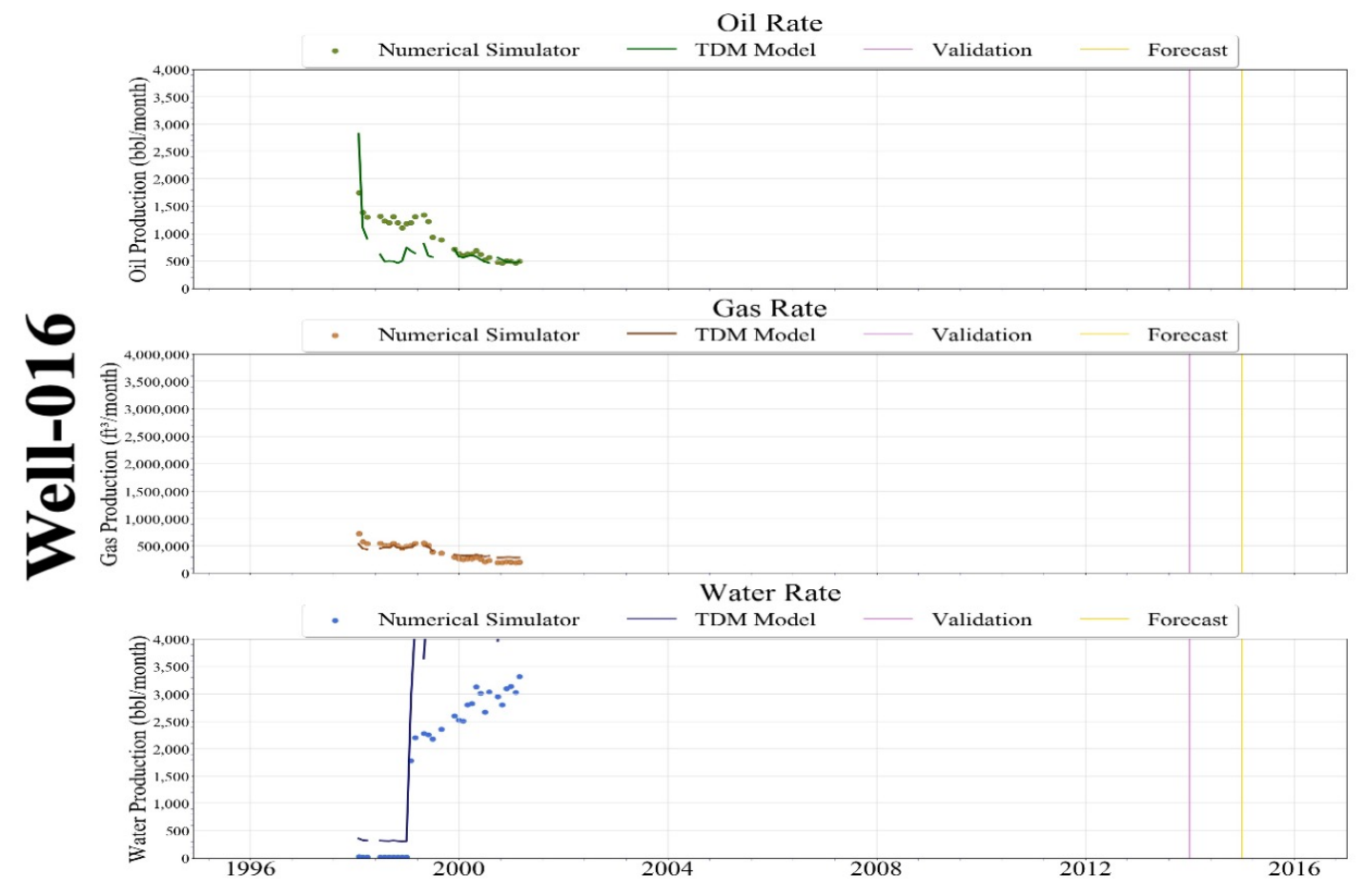

Figure 13-62: Scenario 5 - Well-016 Production History Match 


\subsubsection{Good Forecast Production}

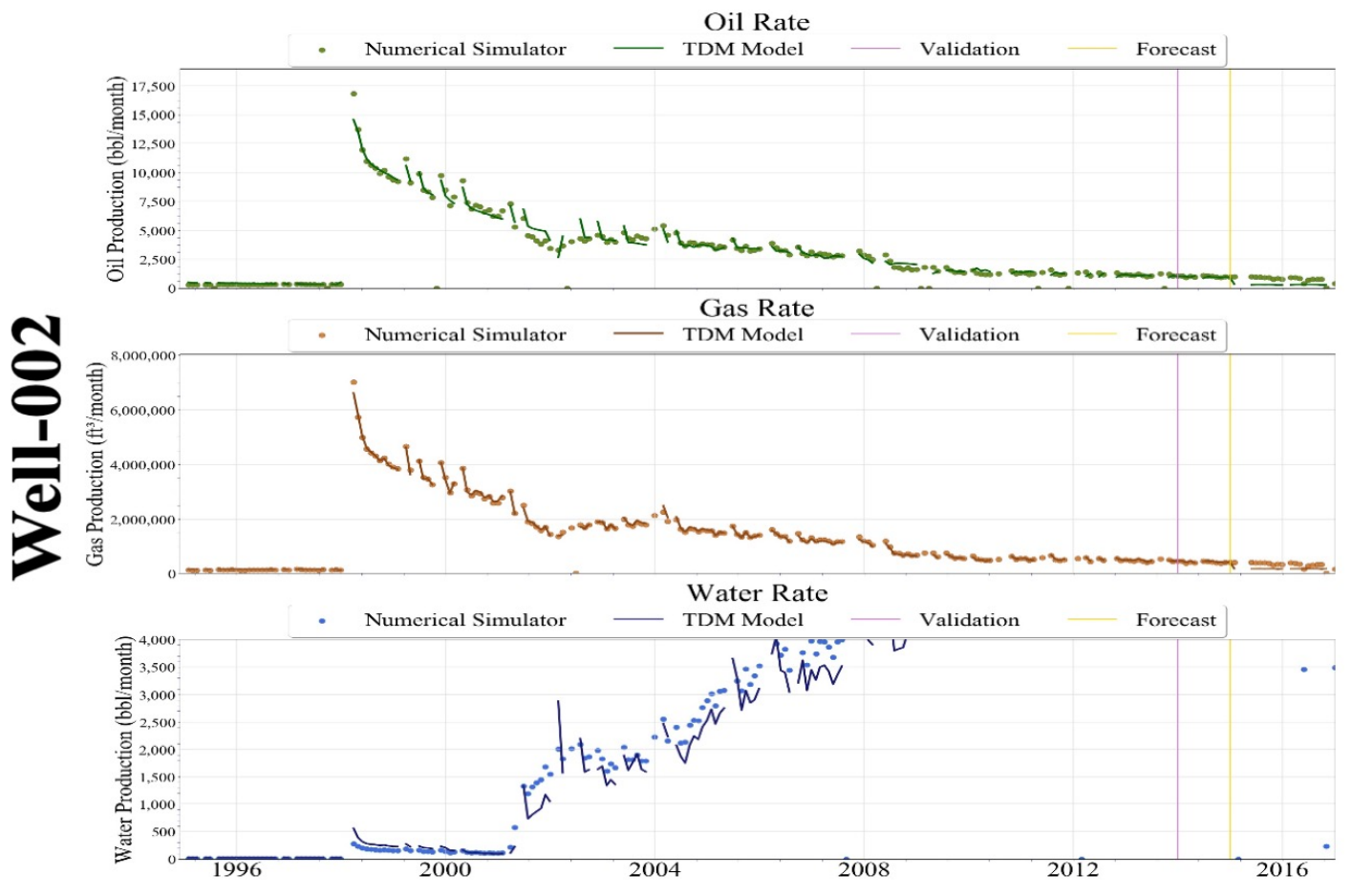

Figure 13-63: Scenario 5 - Well-002 Forecast Production

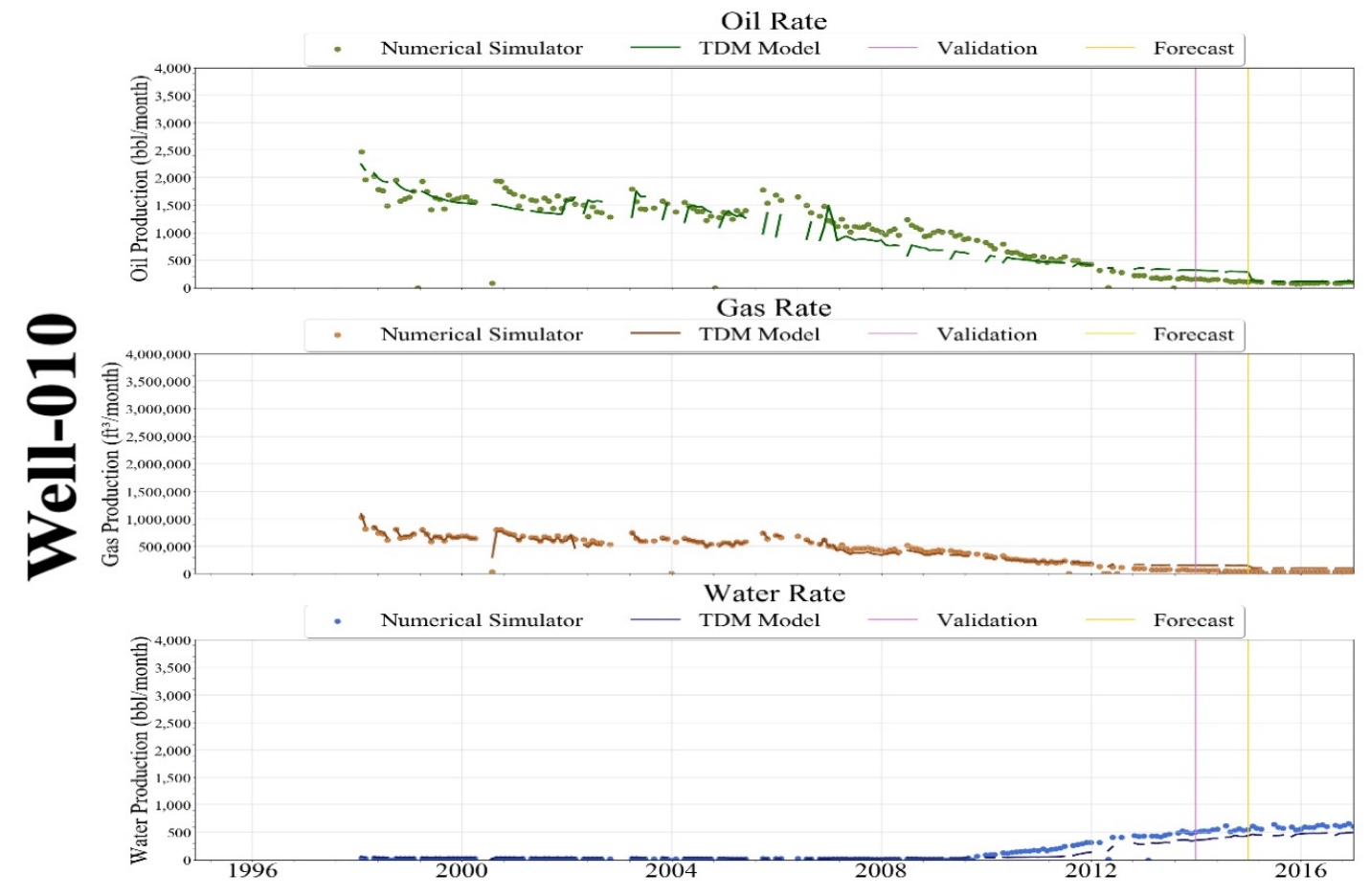

Figure 13-64: Scenario 5 - Well-010 Forecast Production 


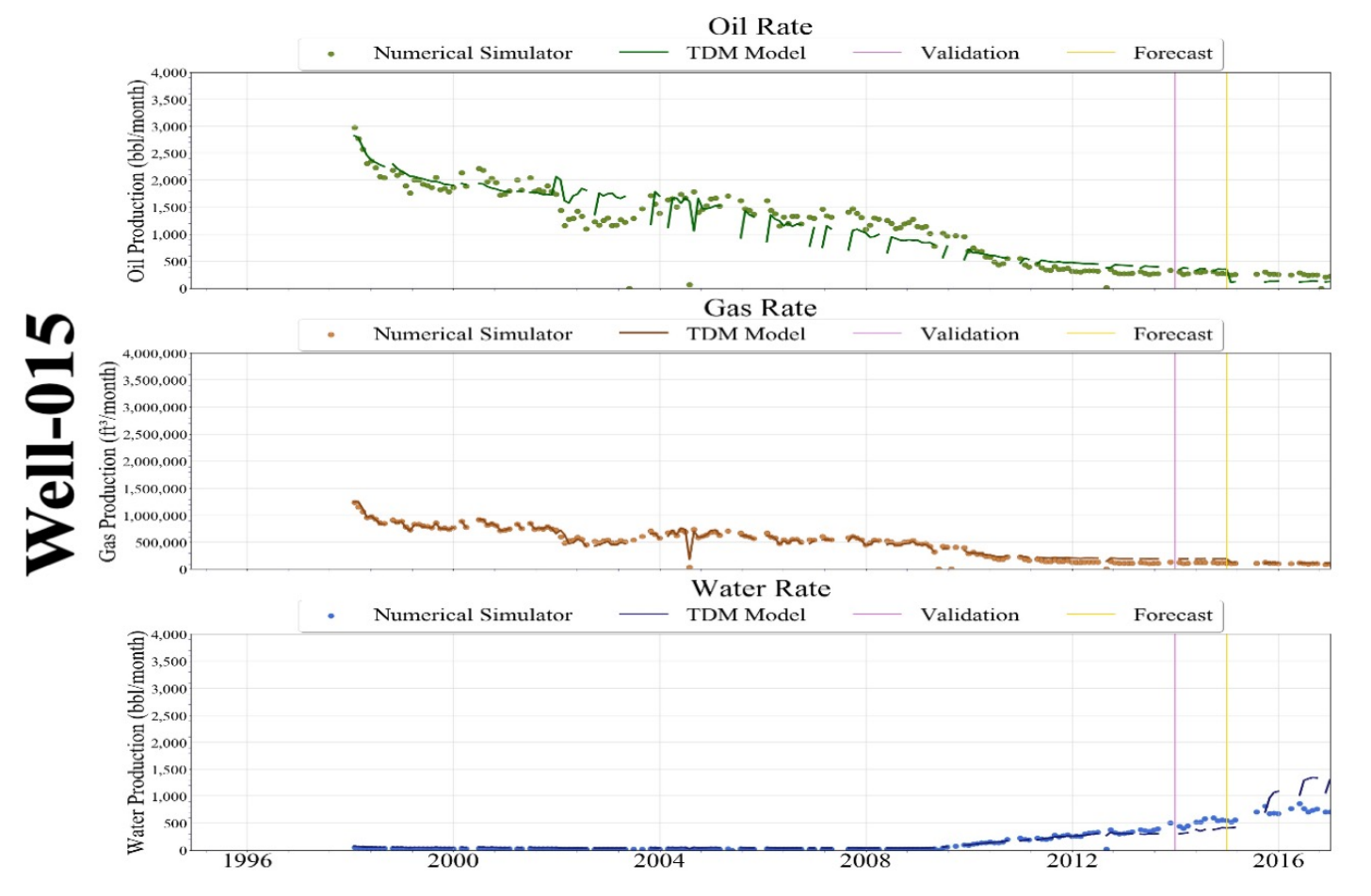

Figure 13-65: Scenario 5 - Well-015 Forecast Production

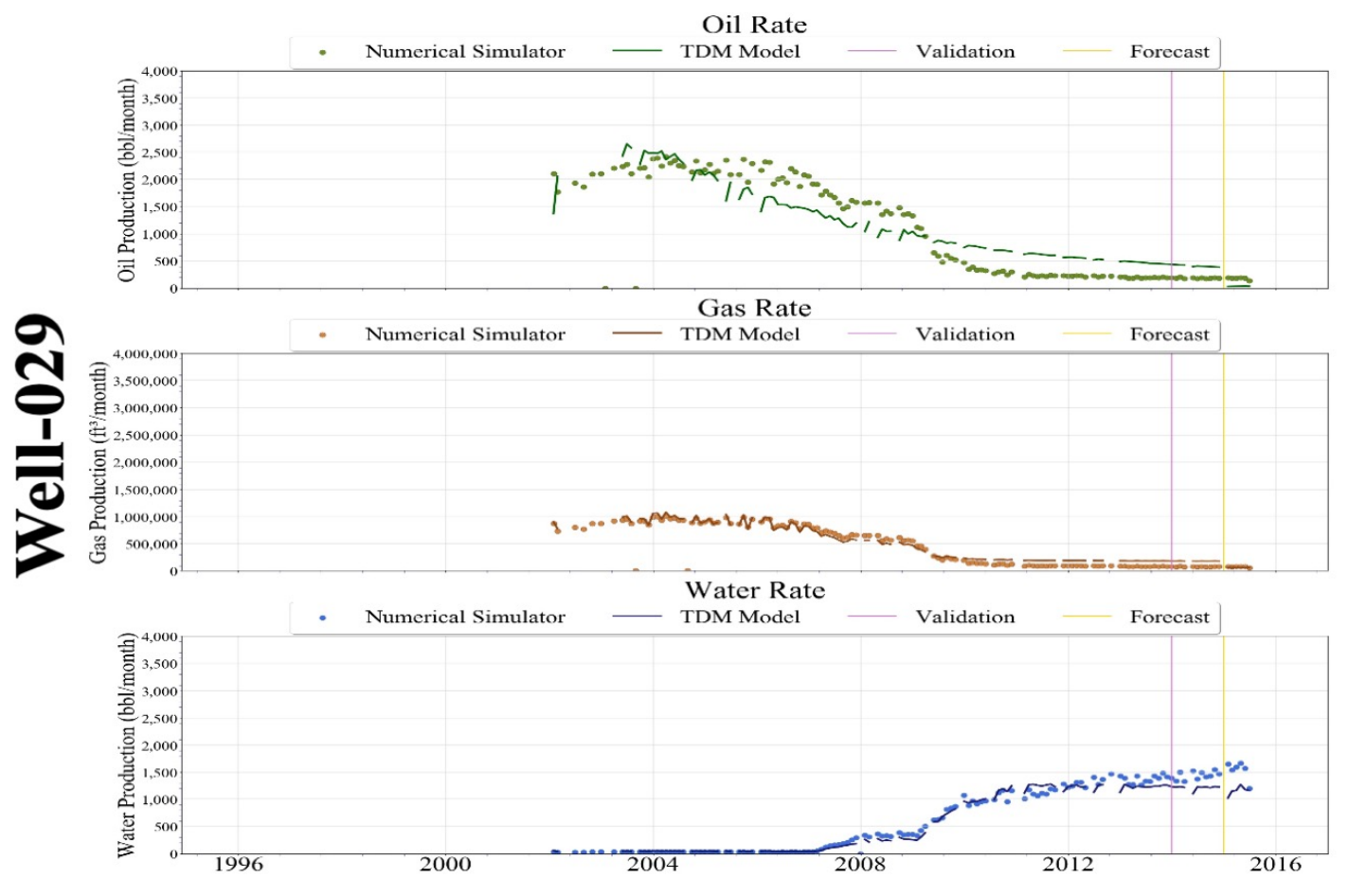

Figure 13-66: Scenario 5 - Well-029 Forecast Production 


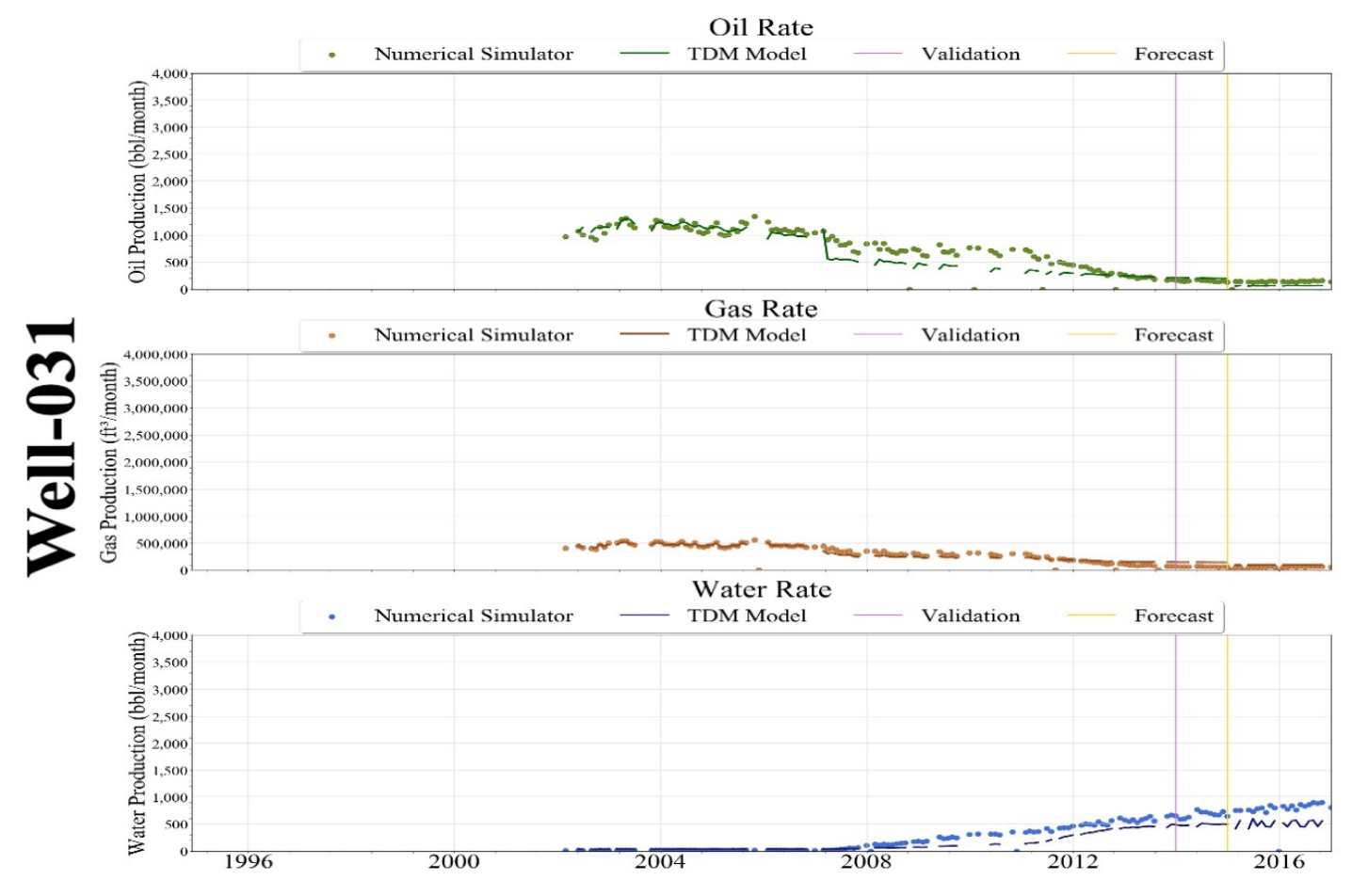

Figure 13-67: Scenario 5 - Well-031 Forecast Production

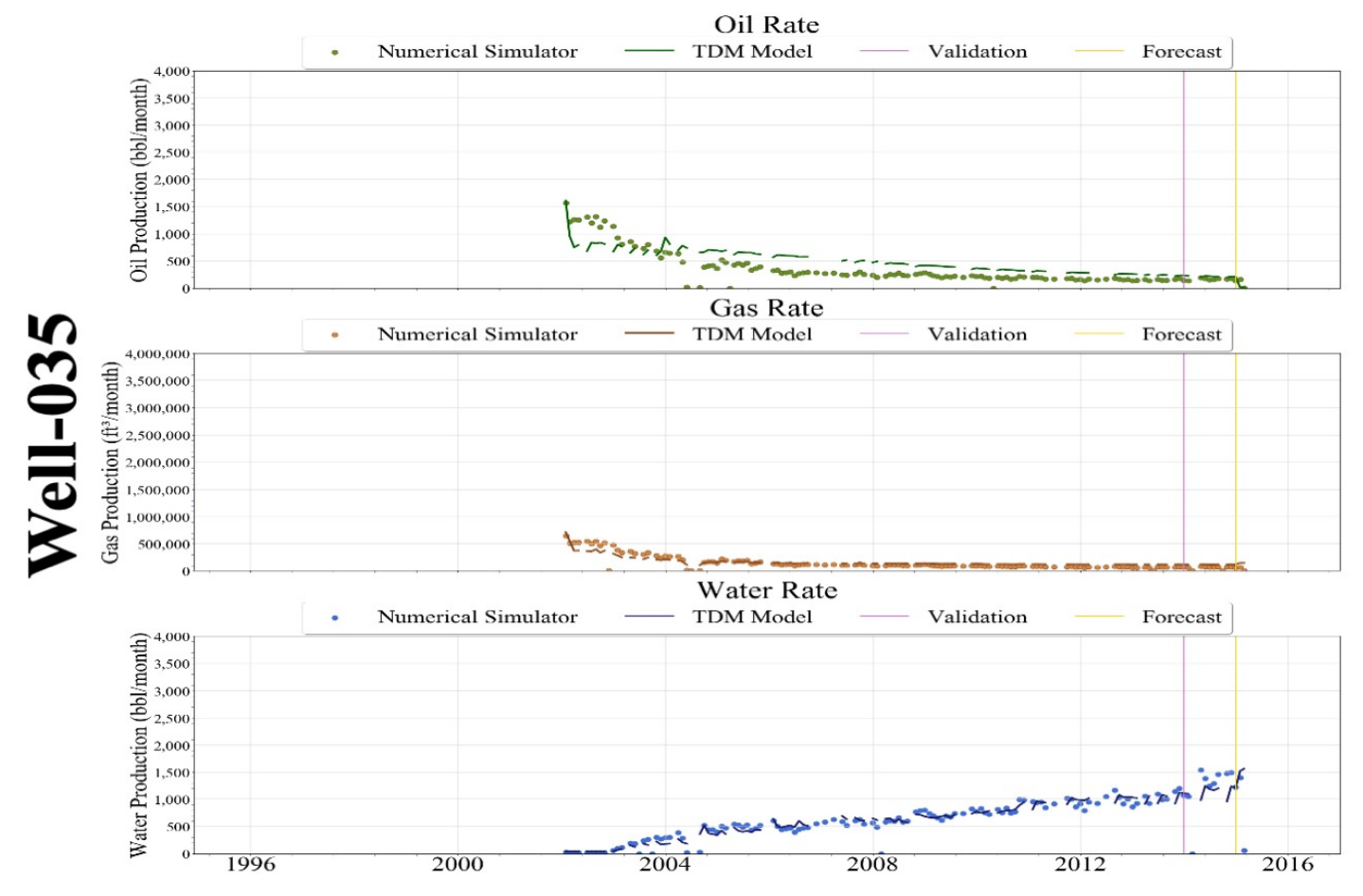

Figure 13-68: Scenario 5 - Well-035 Forecast Production 


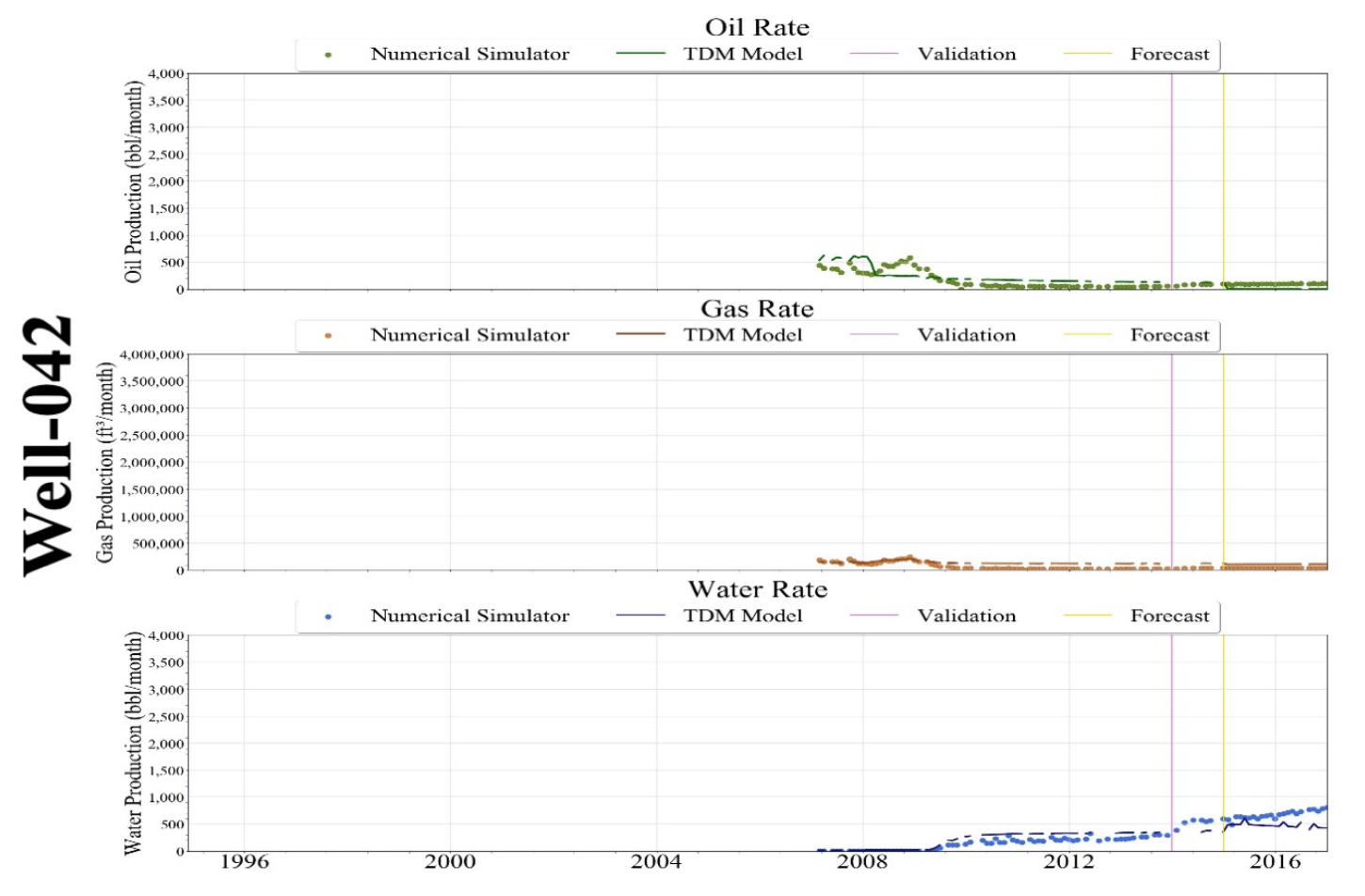

Figure 13-69: Scenario 5 - Well-042 Forecast Production

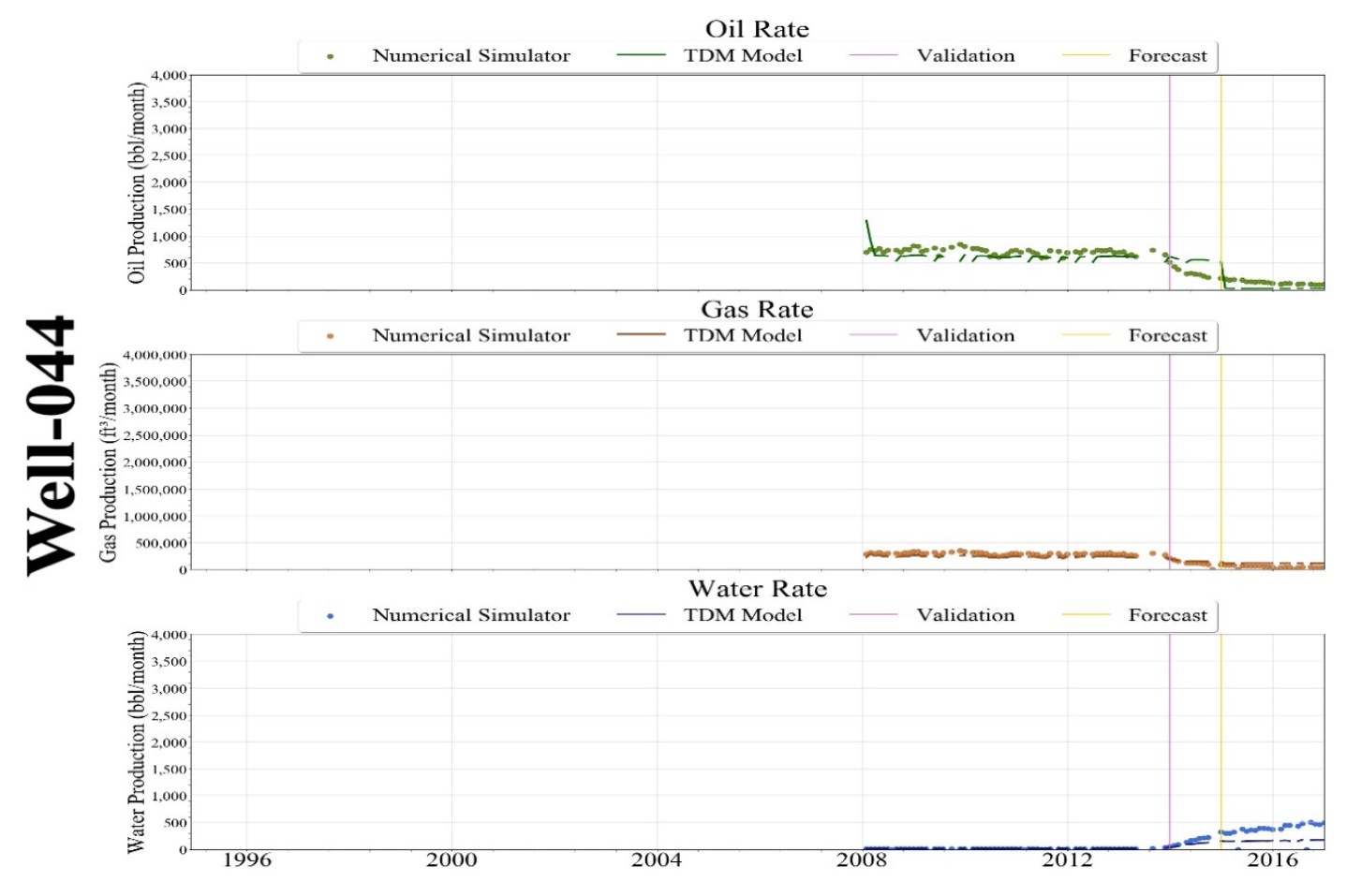

Figure 13-70: Scenario 5 - Well-044 Forecast Production 


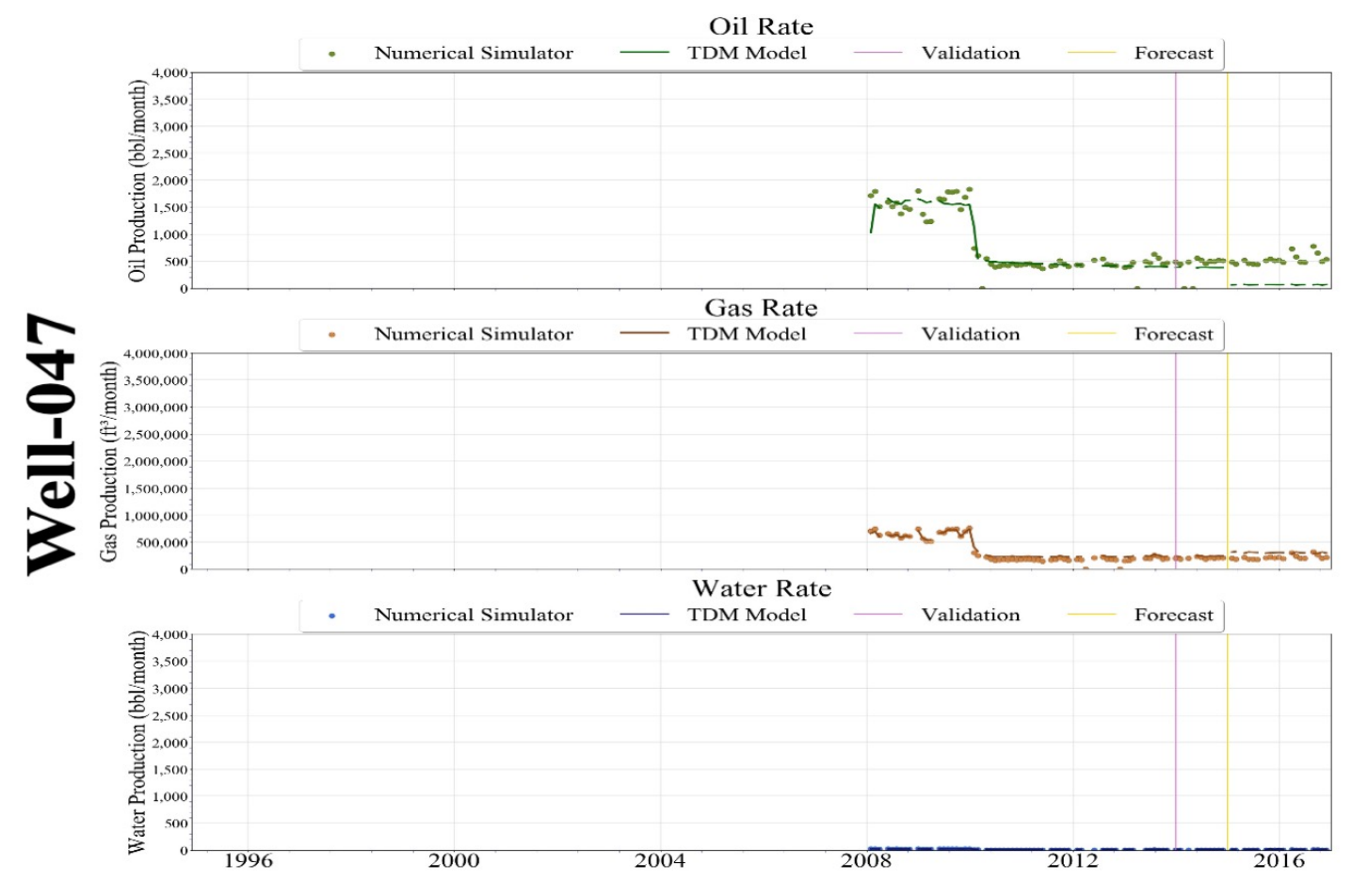

Figure 13-71: Scenario 5 - Well-047 Forecast Production

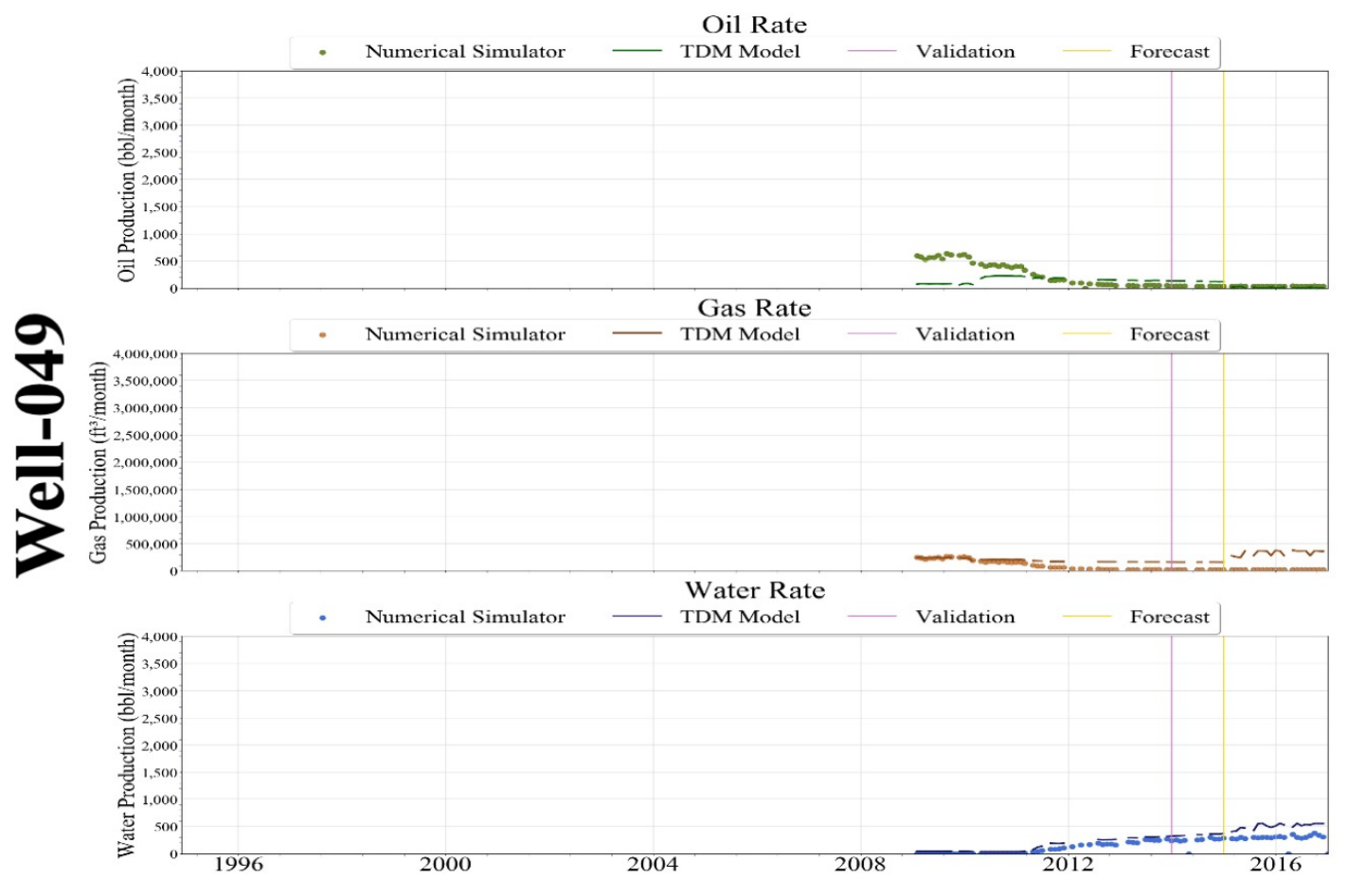

Figure 13-72: Scenario 5 - Well-049 Forecast Production 


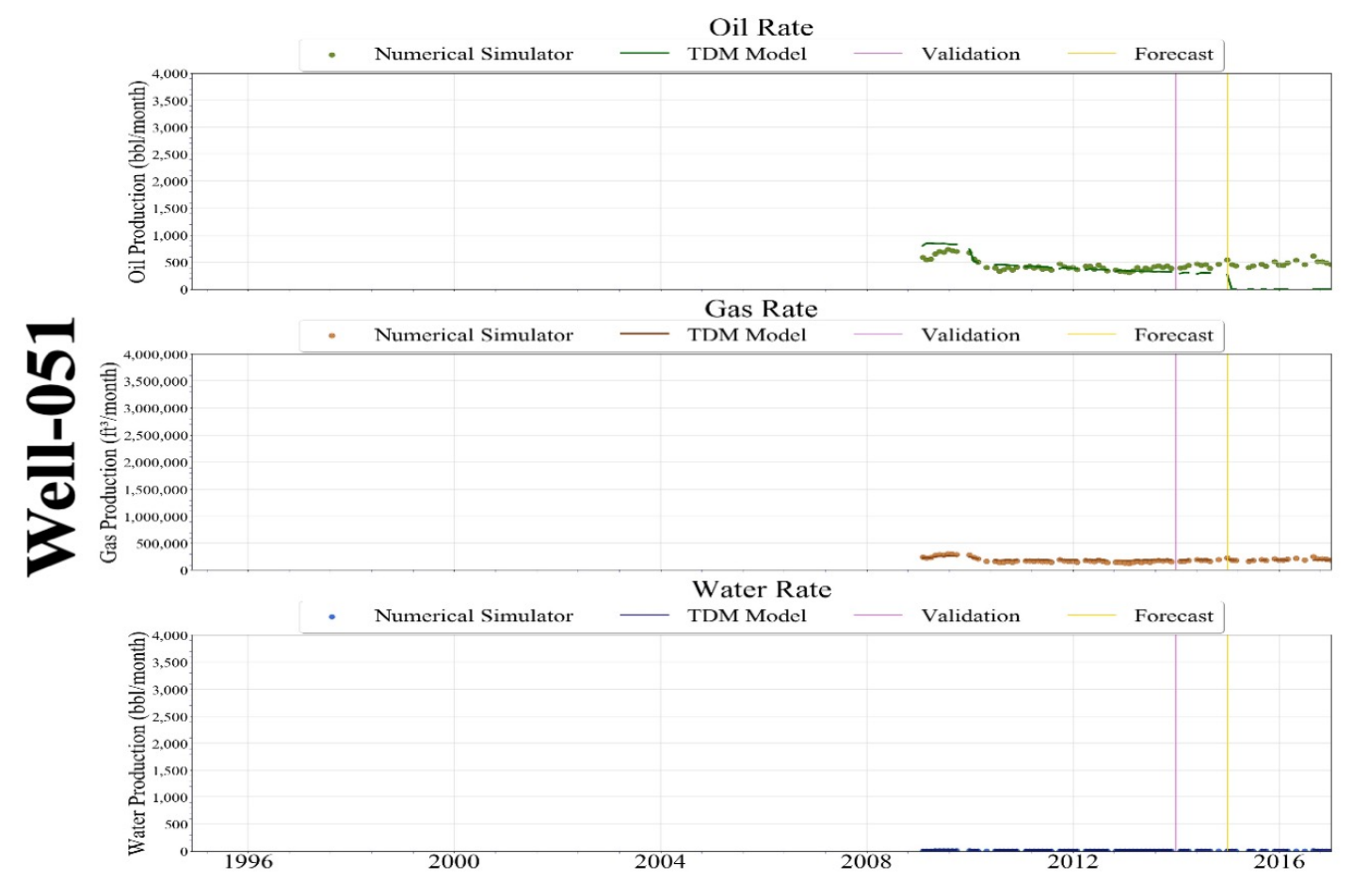

Figure 13-73: Scenario 5-Well-051 Forecast Production 


\subsubsection{Average Forecast Production}

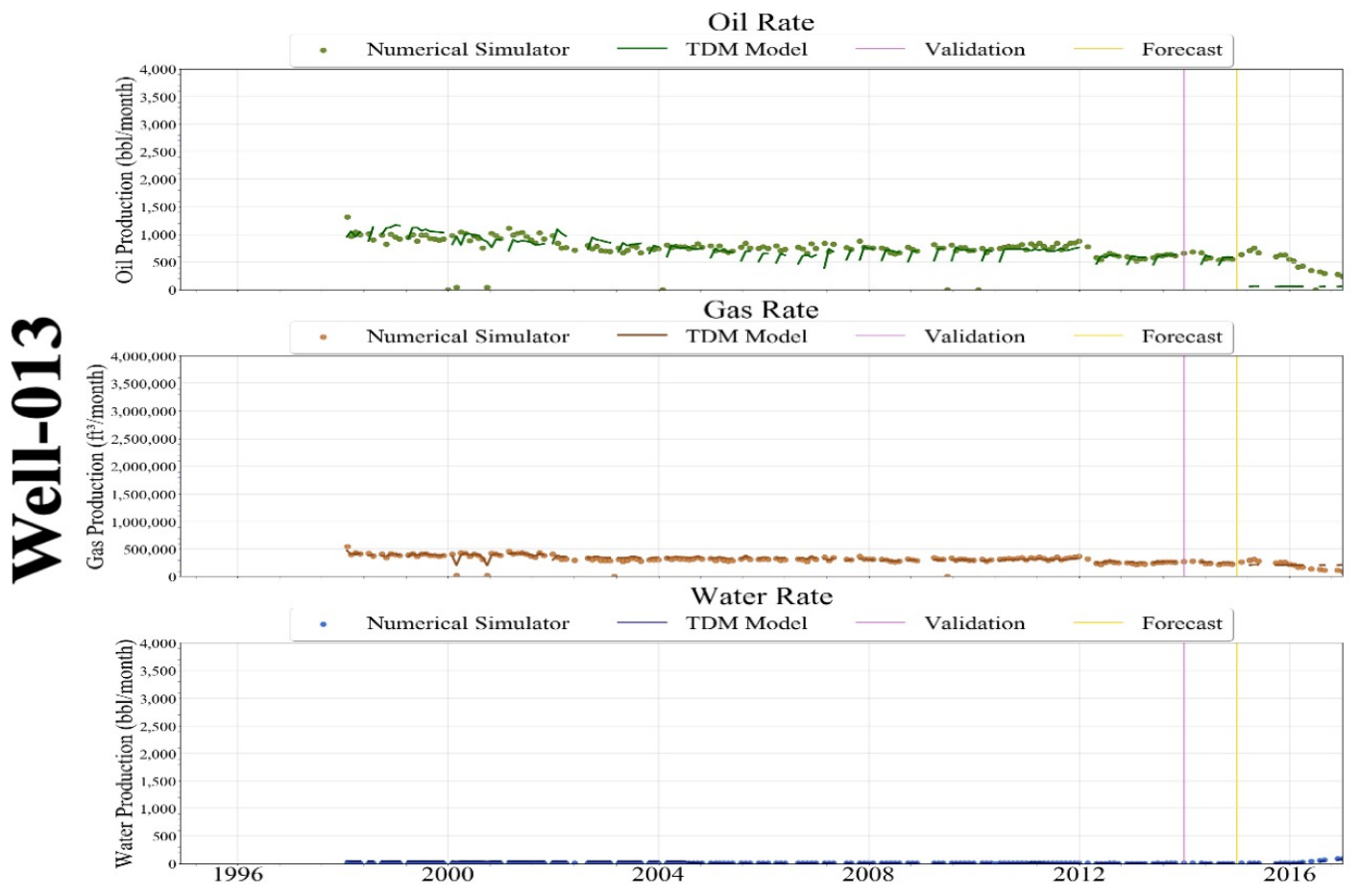

Figure 13-74: Scenario 5 - Well-013 Forecast Production

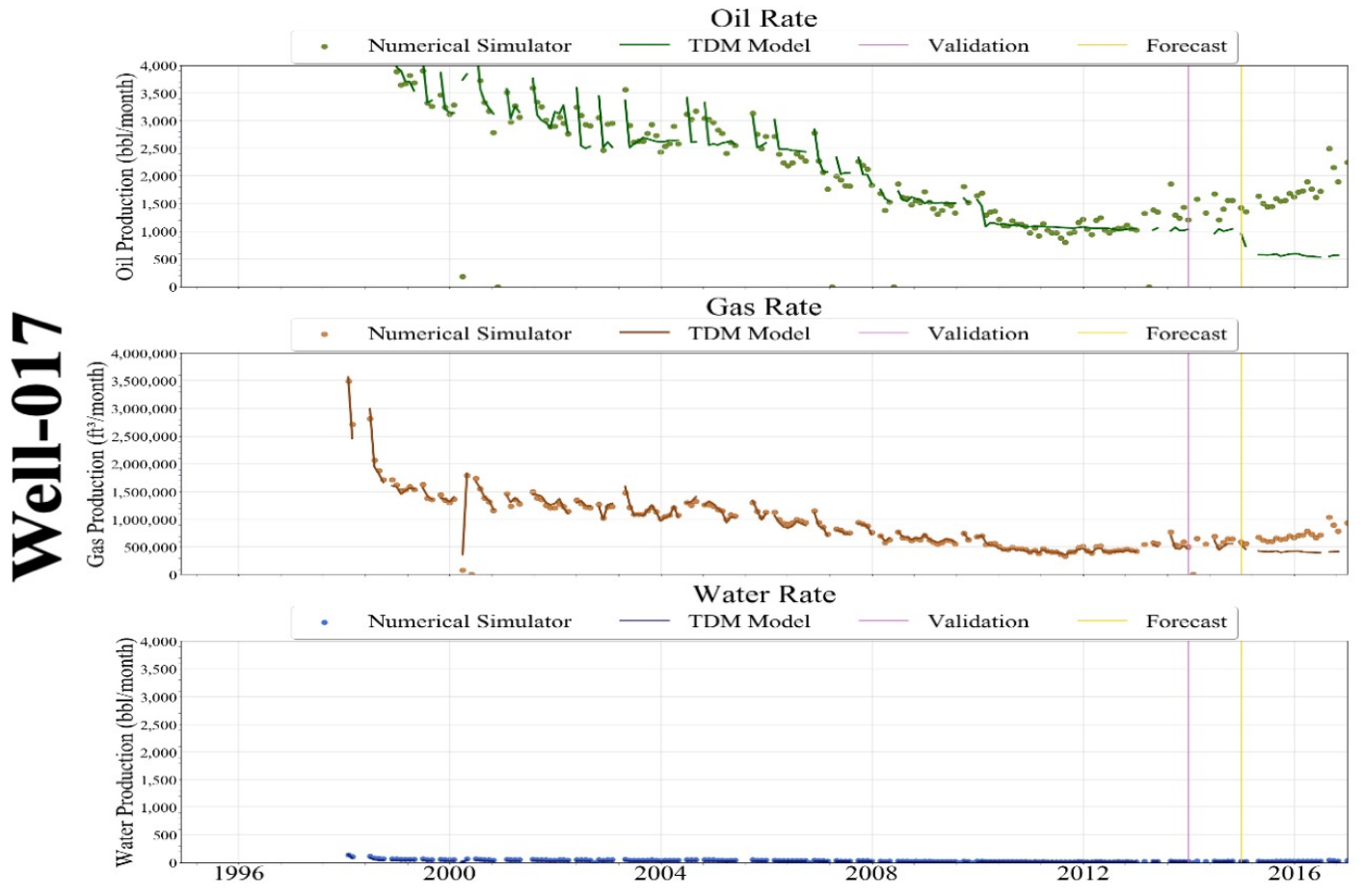

Figure 13-75: Scenario 5 - Well-017 Forecast Production 


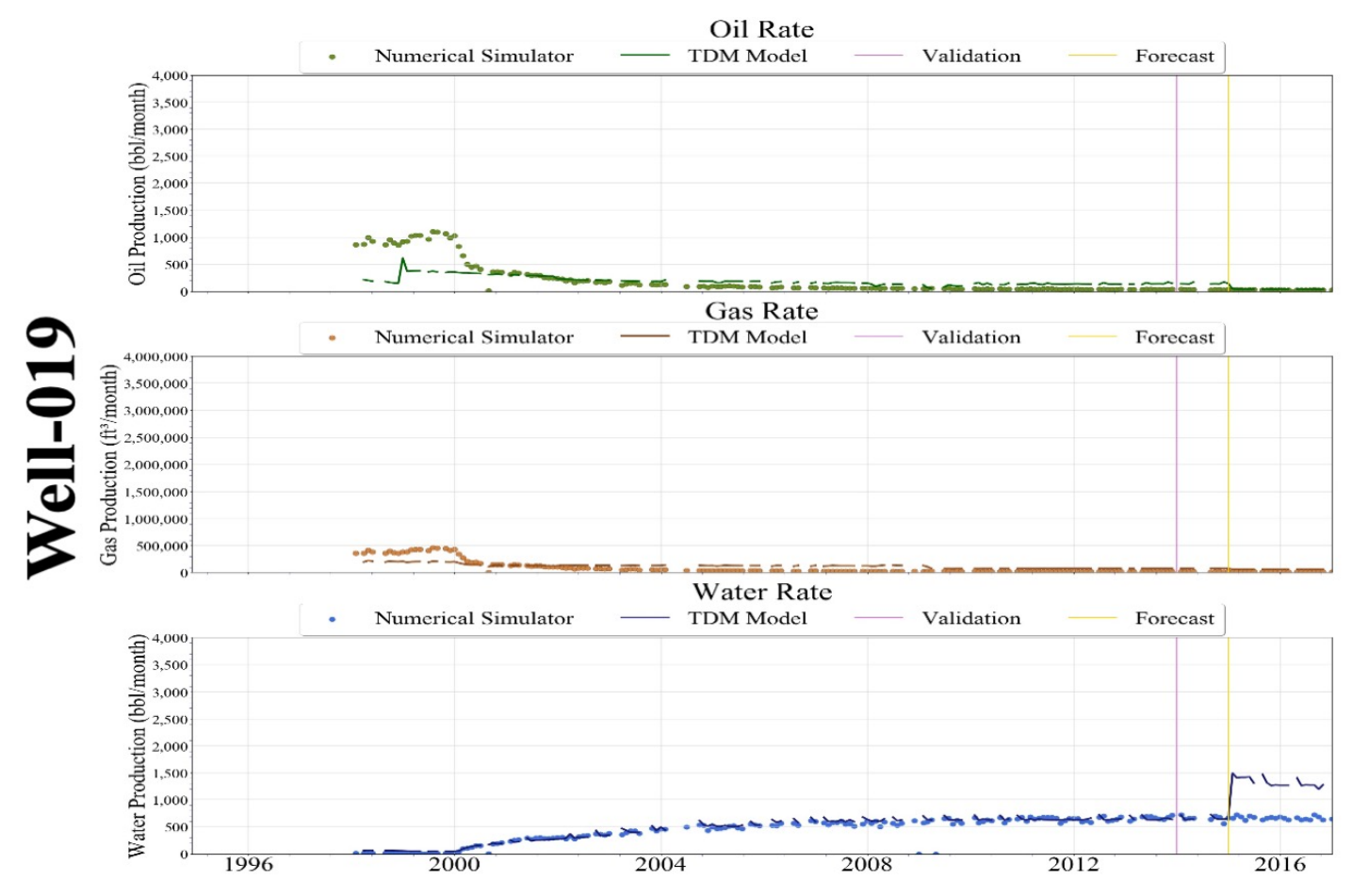

Figure 13-76: Scenario 5 - Well-019 Forecast Production

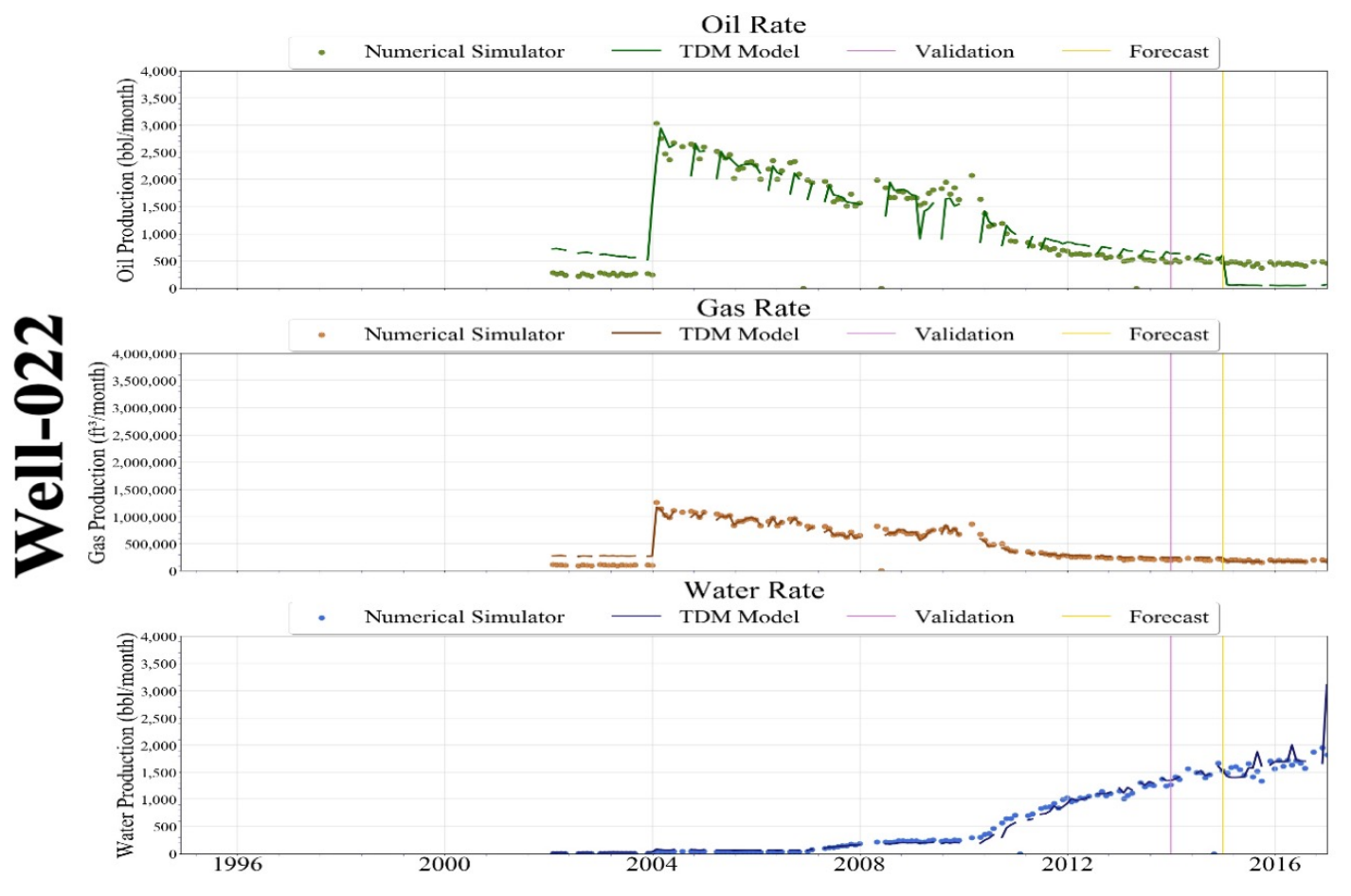

Figure 13-77: Scenario 5 - Well-022 Forecast Production 


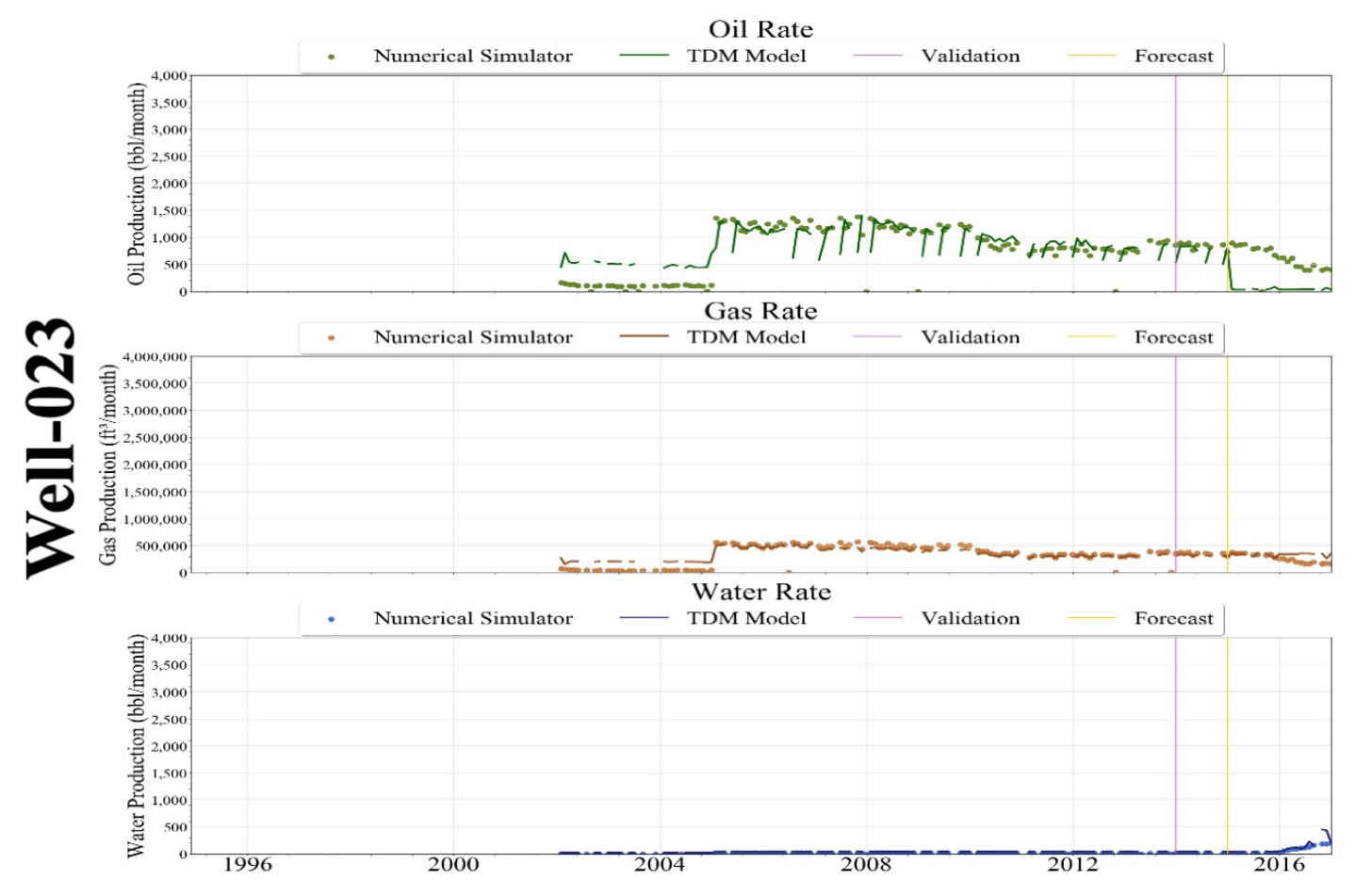

Figure 13-78: Scenario 5 - Well-023 Forecast Production

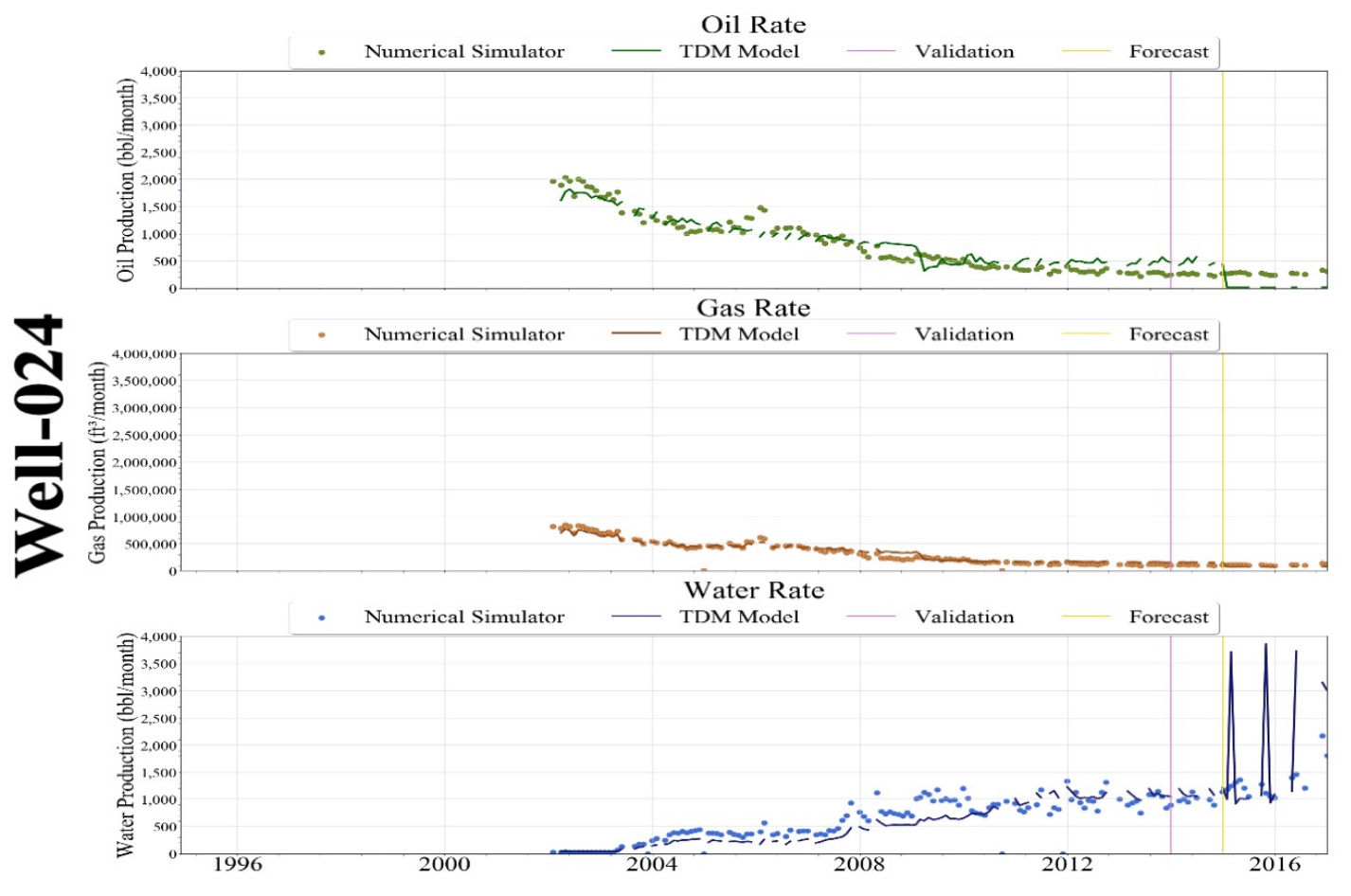

Figure 13-79: Scenario 5 - Well-024 Forecast Production 


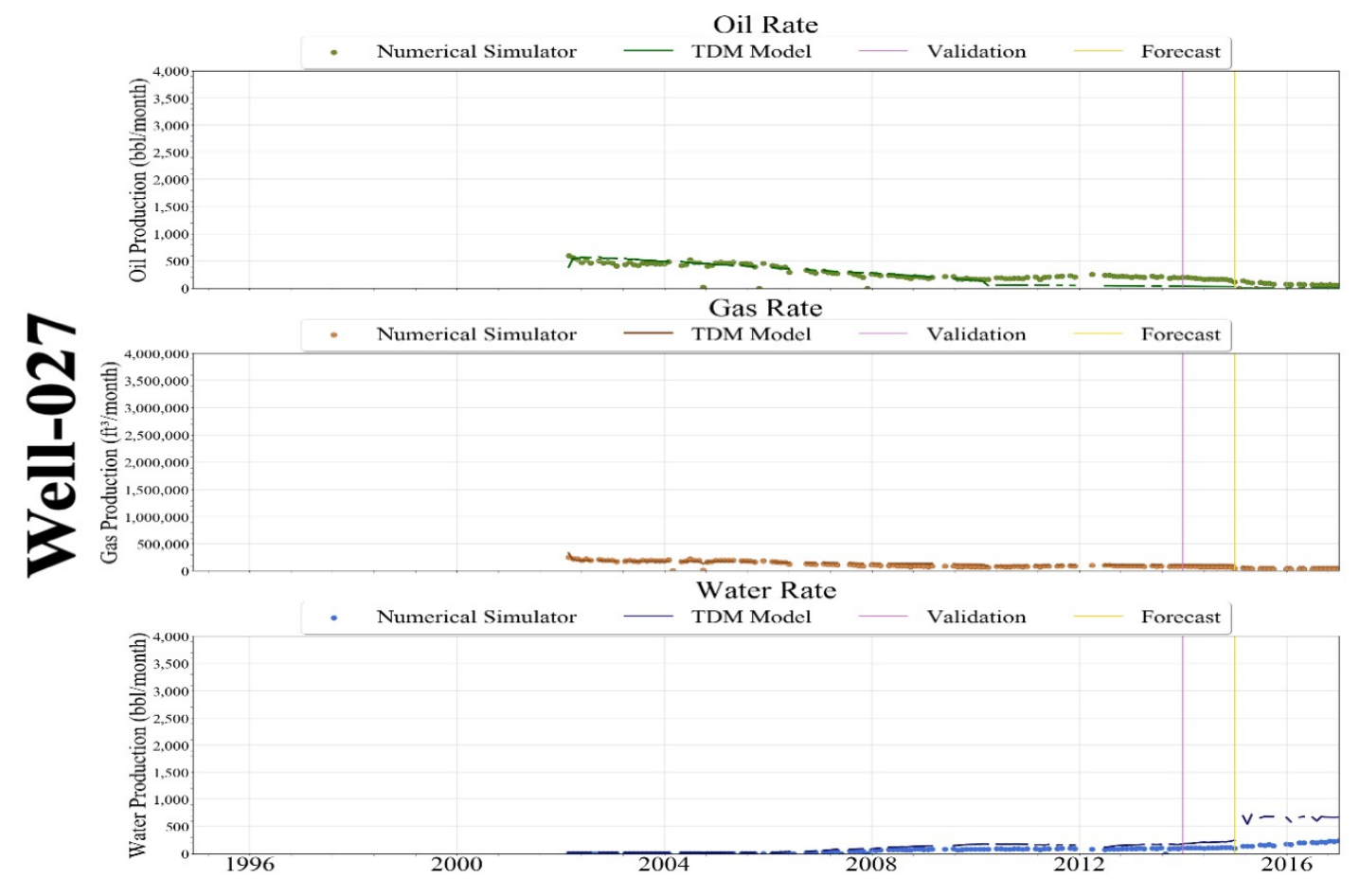

Figure 13-80: Scenario 5 - Well-027 Forecast Production

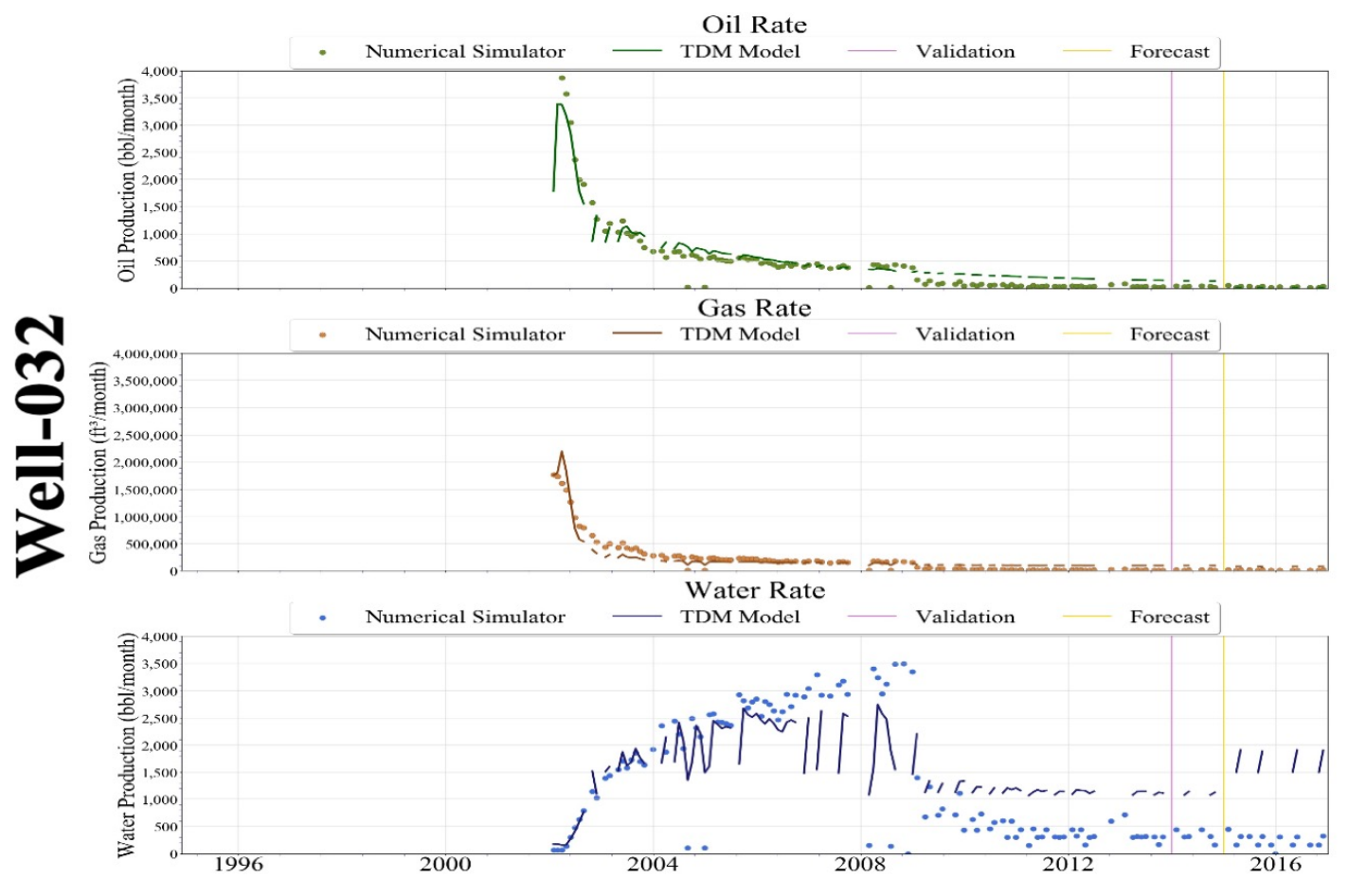

Figure 13-81: Scenario 5 - Well-032 Forecast Production 


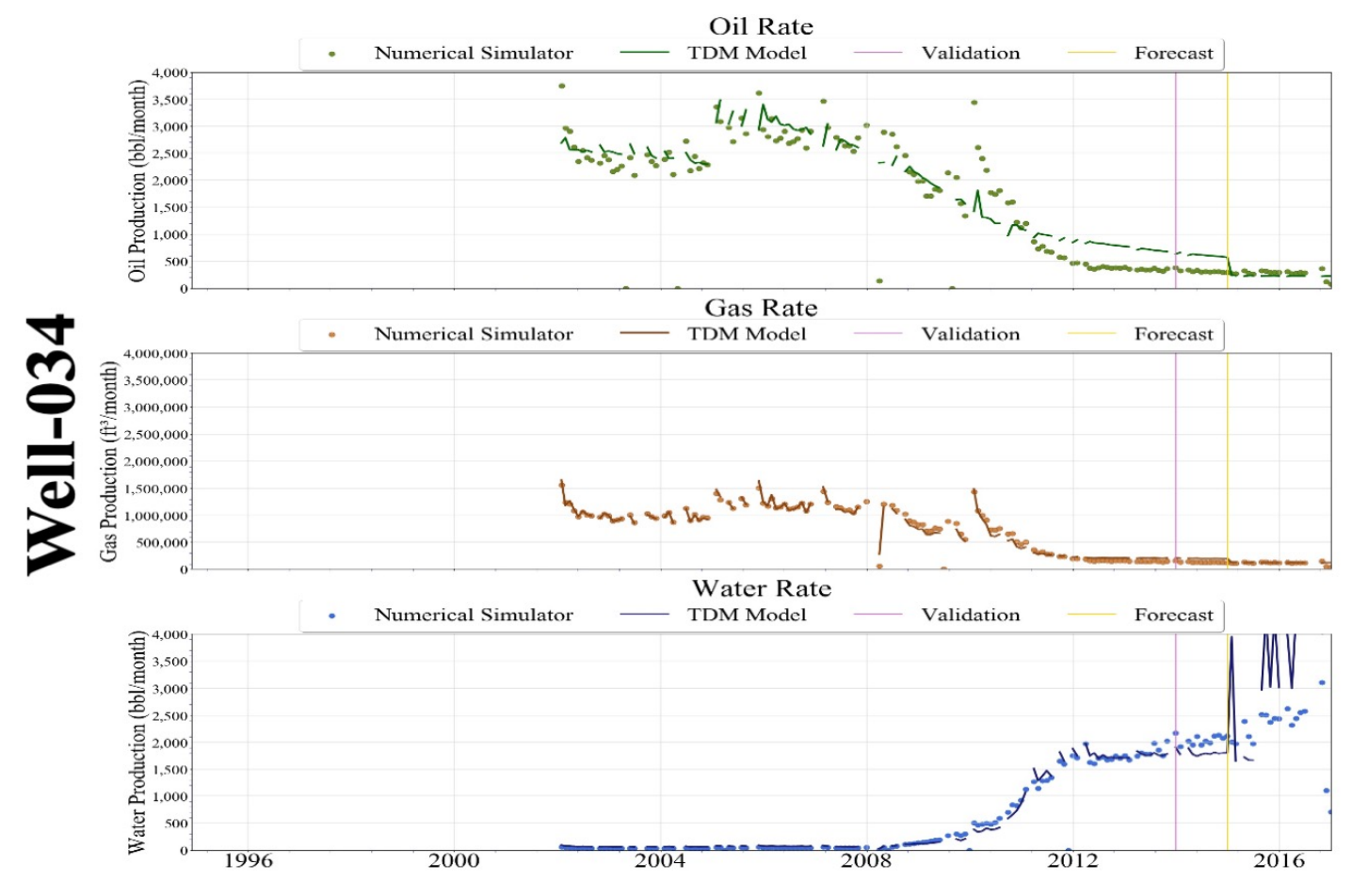

Figure 13-82: Scenario 5 - Well-034 Forecast Production

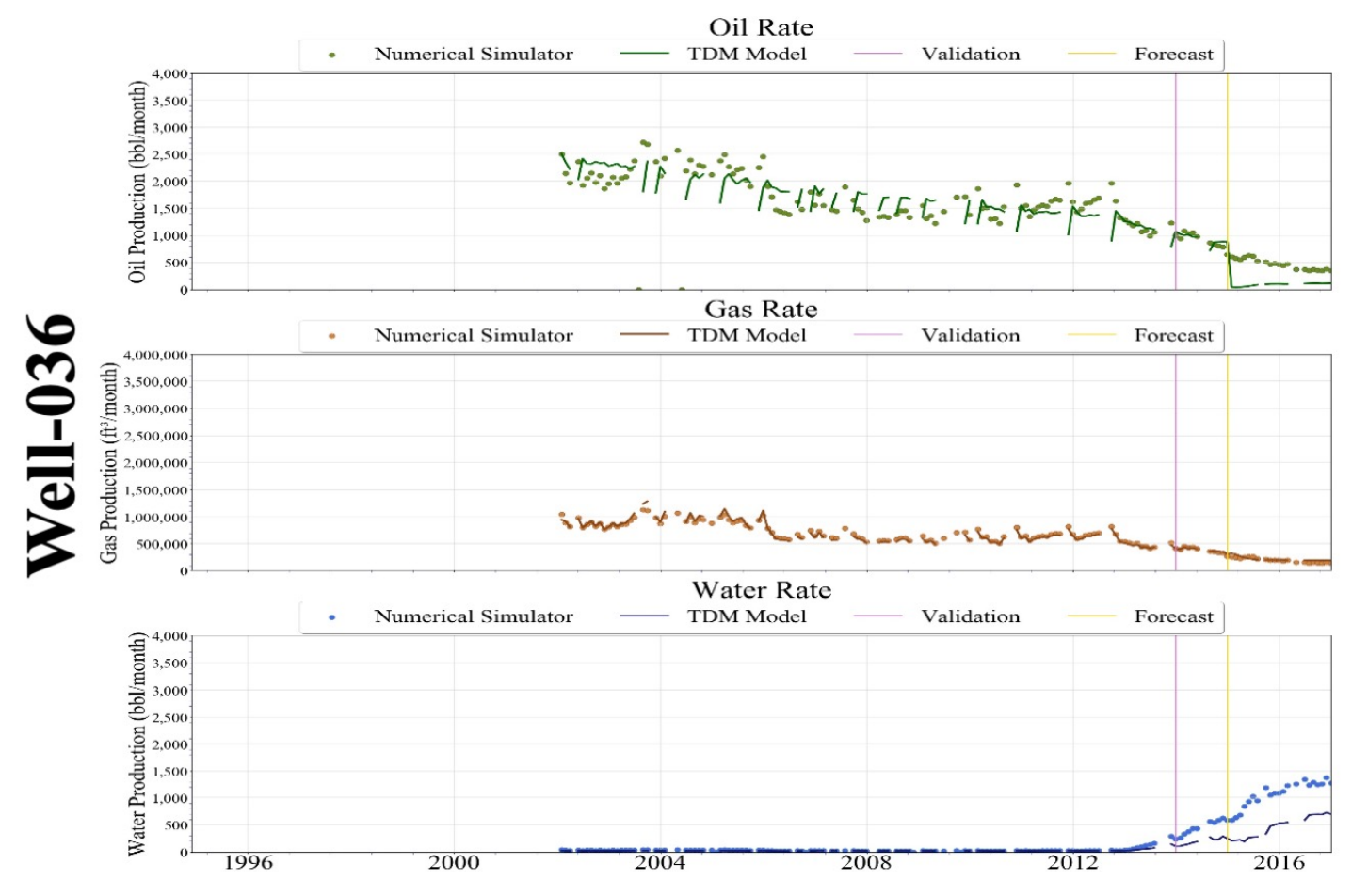

Figure 13-83: Scenario 5 - Well-036 Forecast Production 


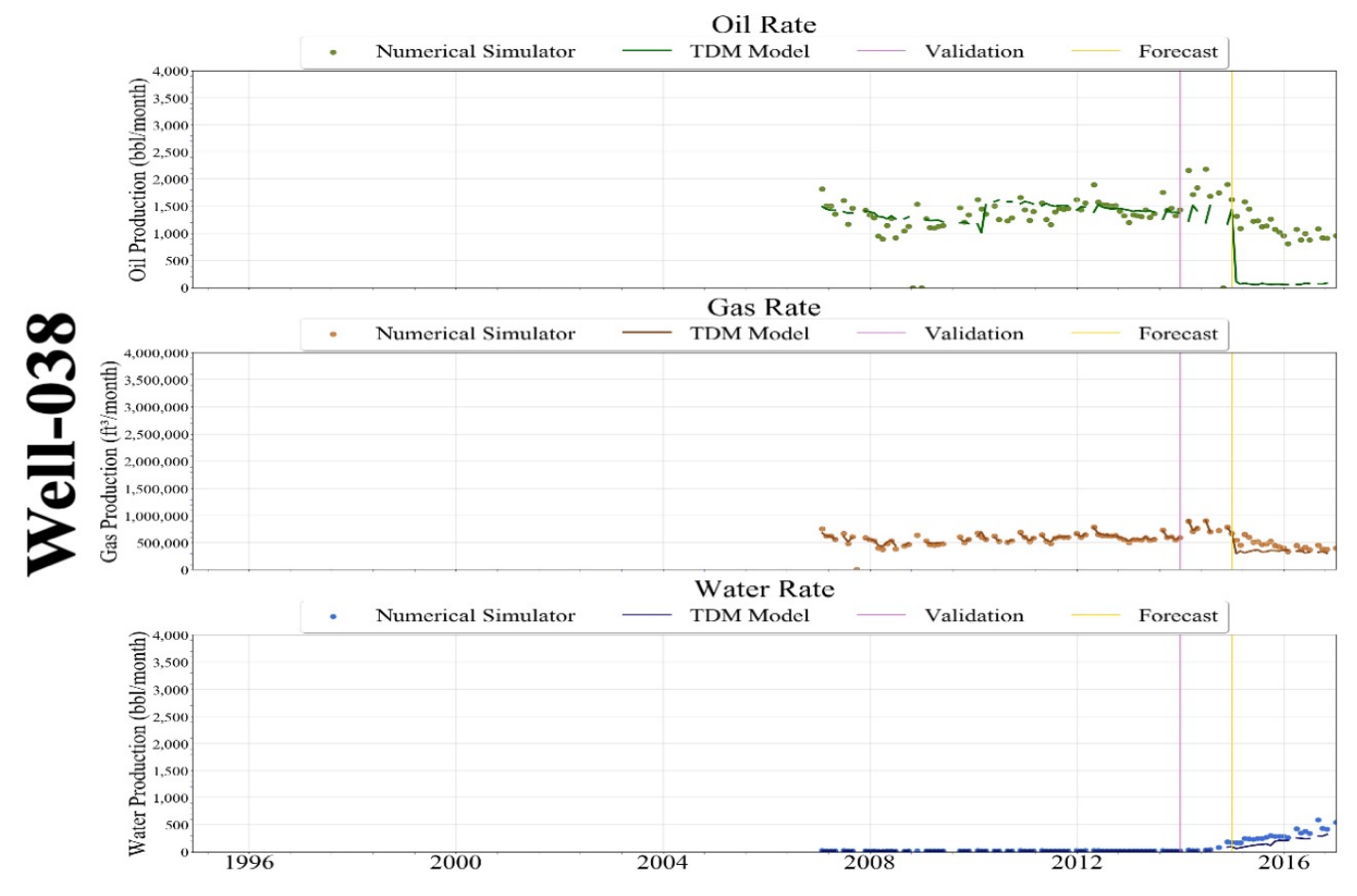

Figure 13-84: Scenario 5 - Well-038 Forecast Production

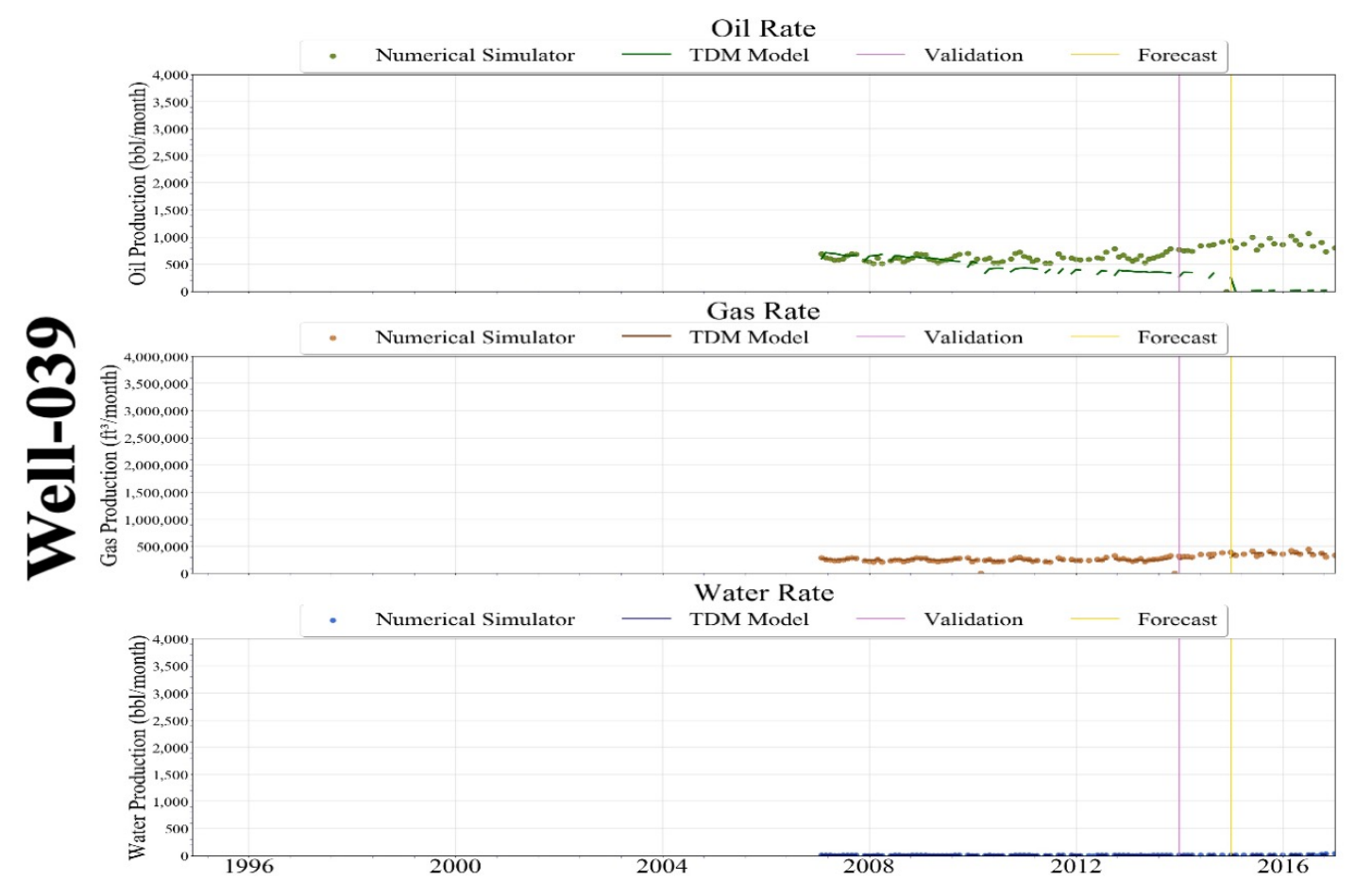

Figure 13-85: Scenario 5 - Well-039 Forecast Production 


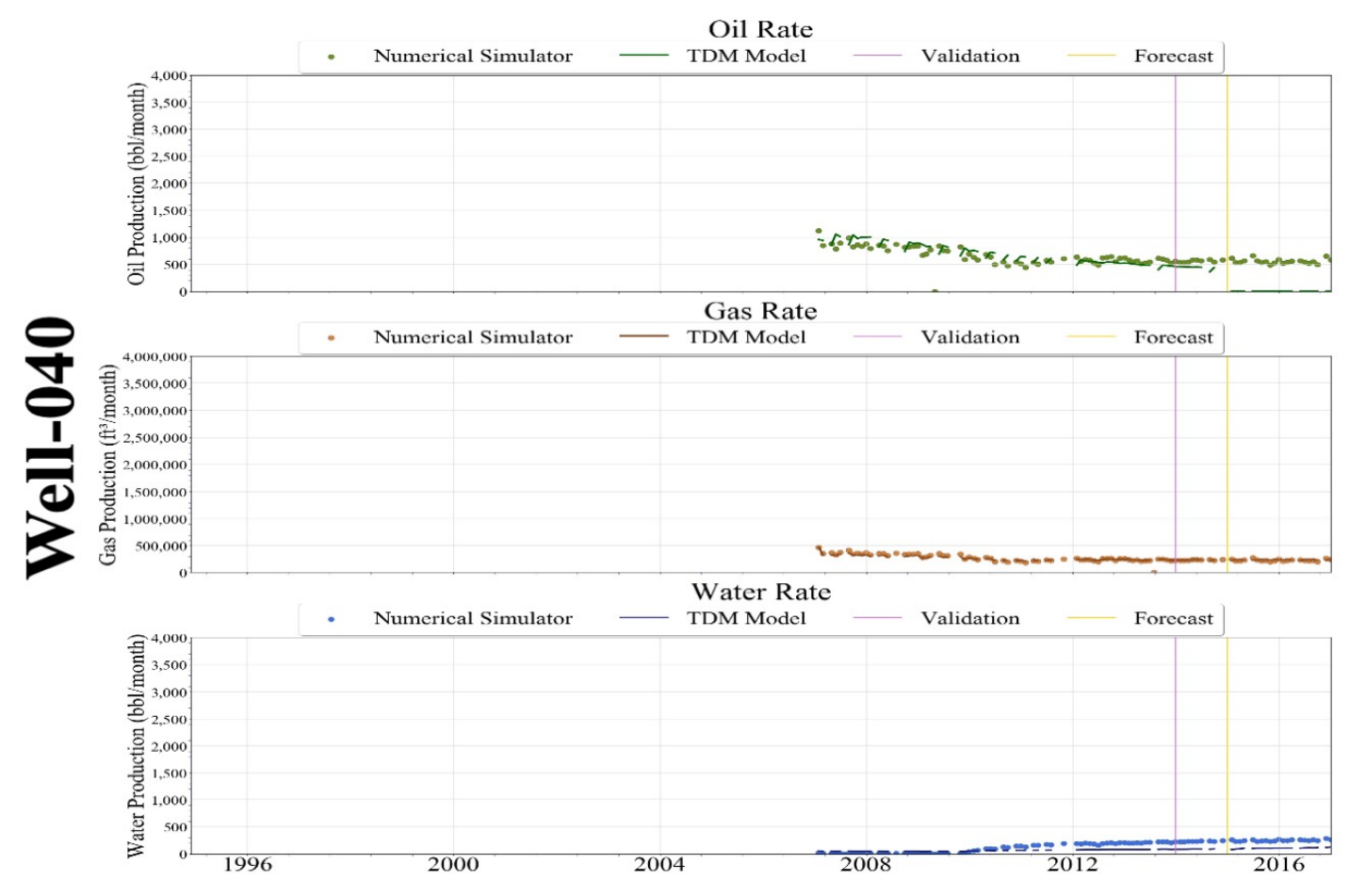

Figure 13-86: Scenario 5 - Well-040 Forecast Production

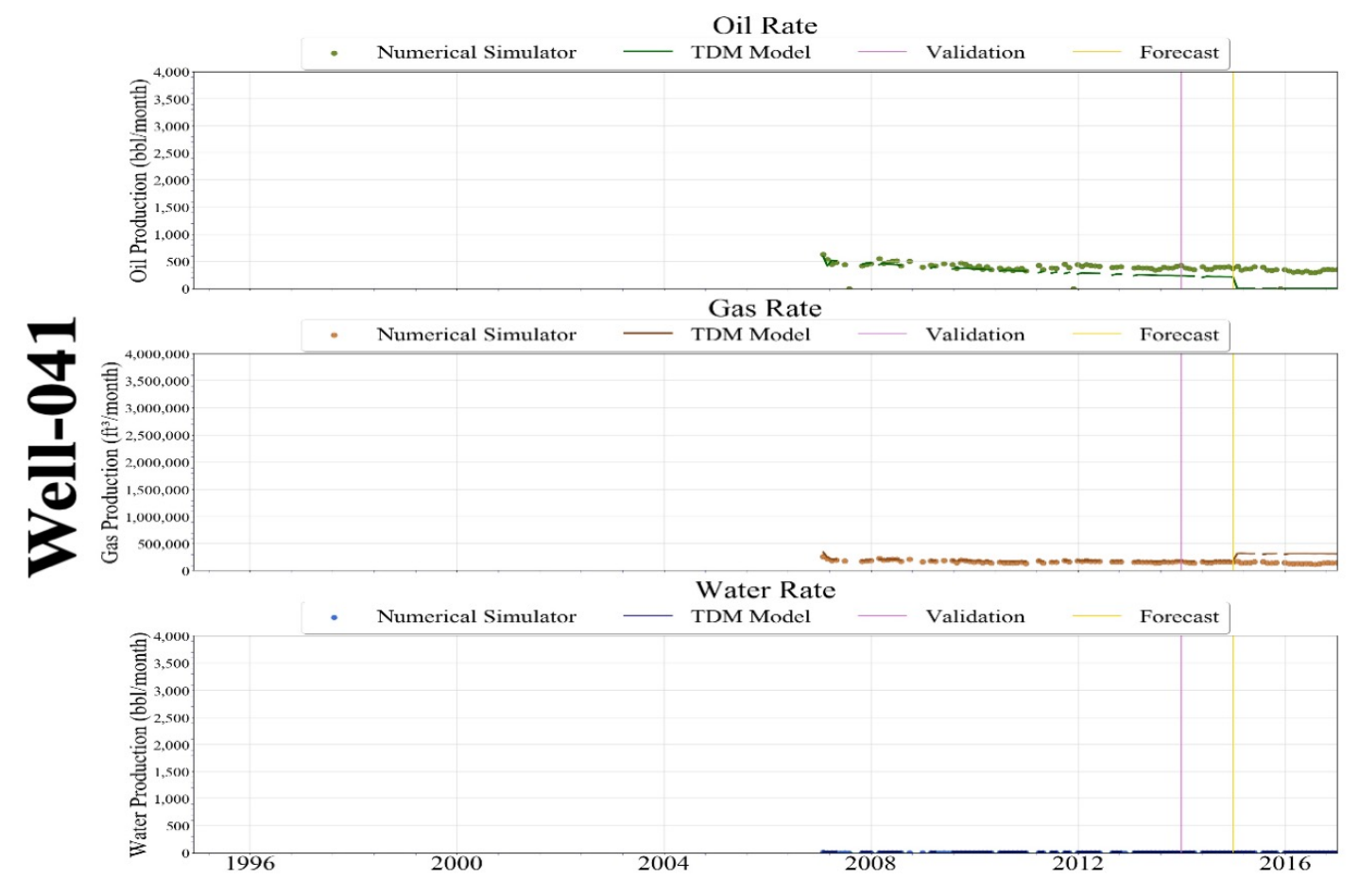

Figure 13-87: Scenario 5 - Well-041 Forecast Production 


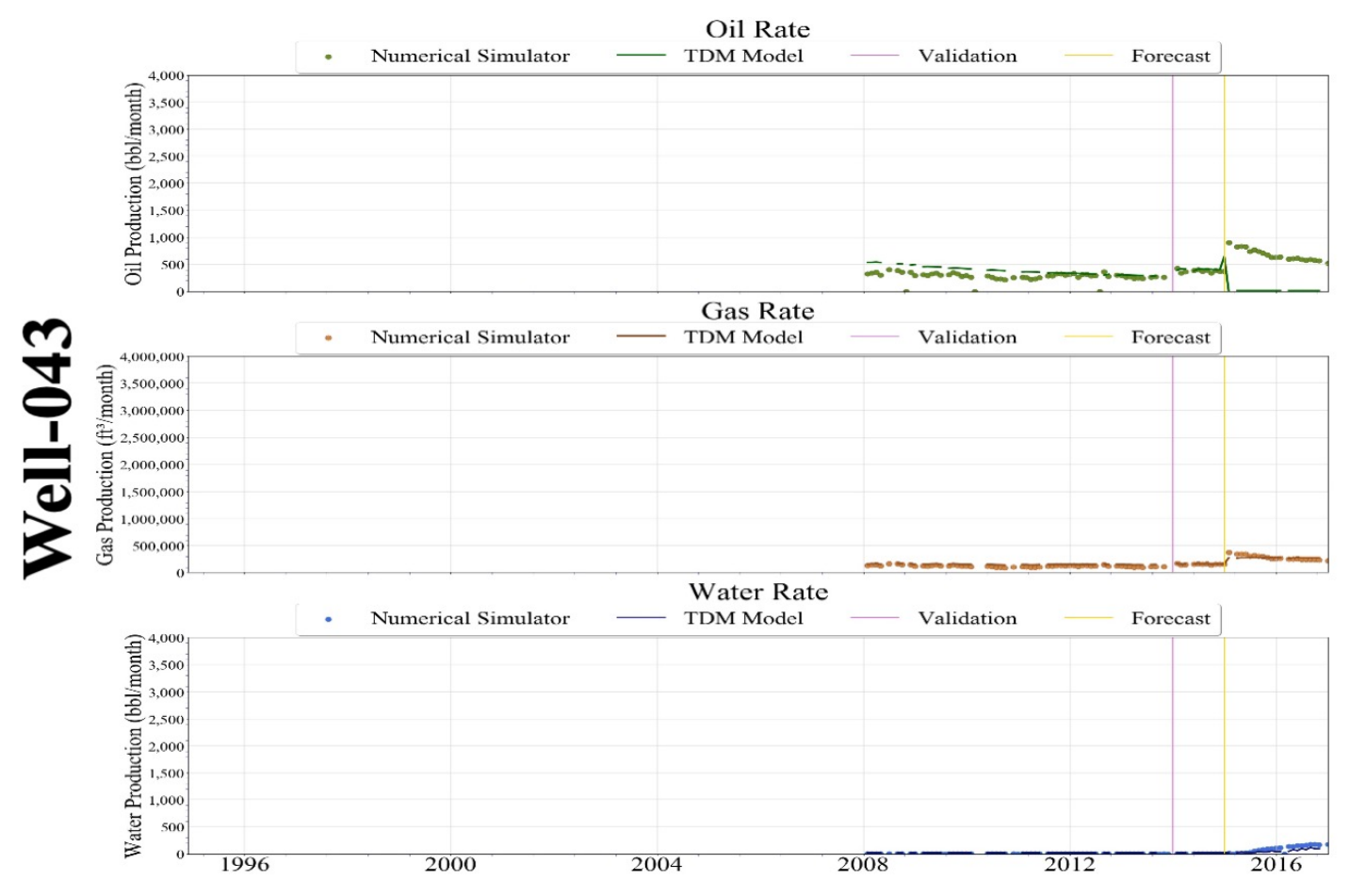

Figure 13-88: Scenario 5 - Well-043 Forecast Production

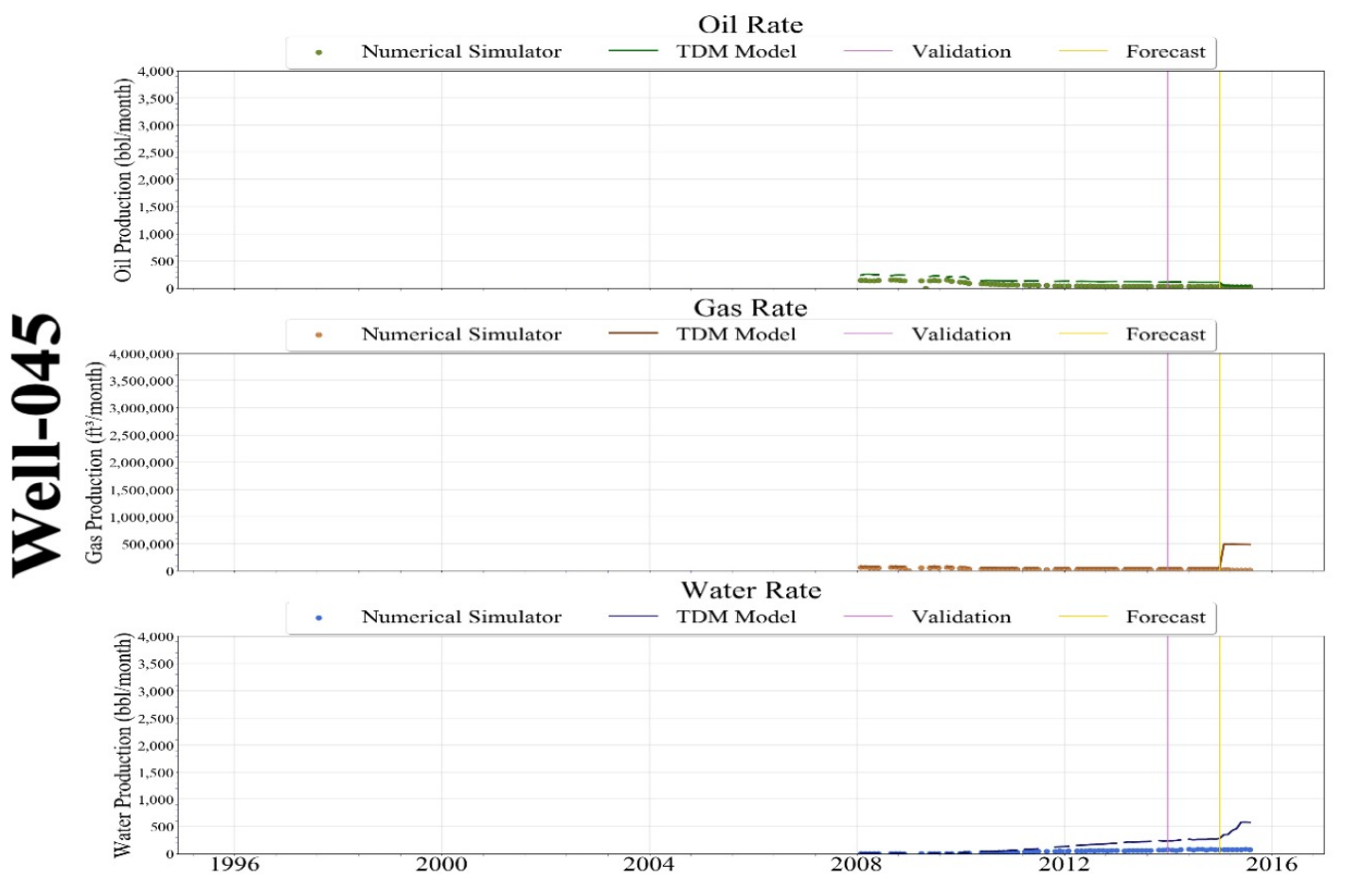

Figure 13-89: Scenario 5 - Well-045 Forecast Production 


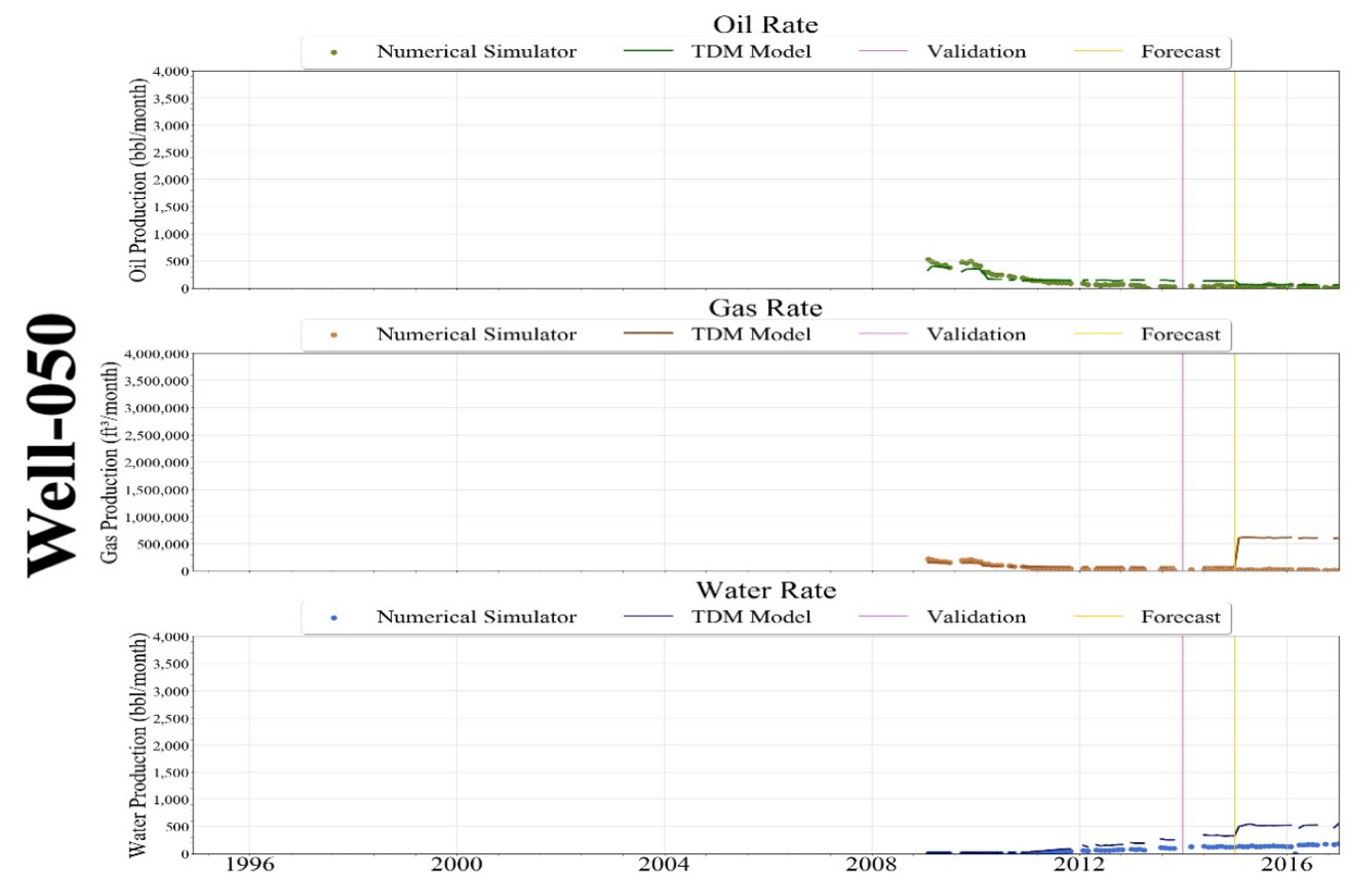

Figure 13-90: Scenario 5 - Well-050 Forecast Production

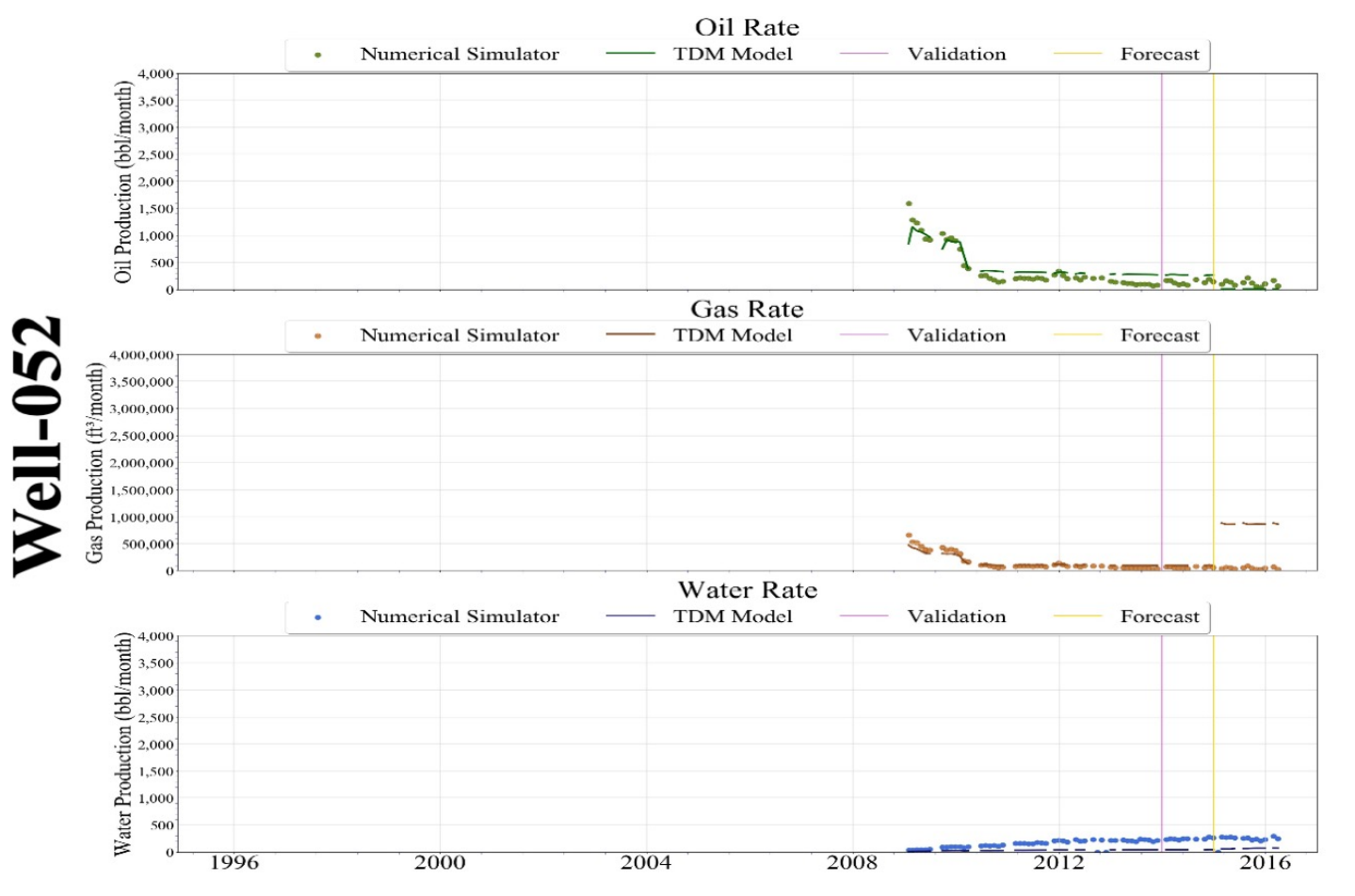

Figure 13-91: Scenario 5 - Well-052 Forecast Production 


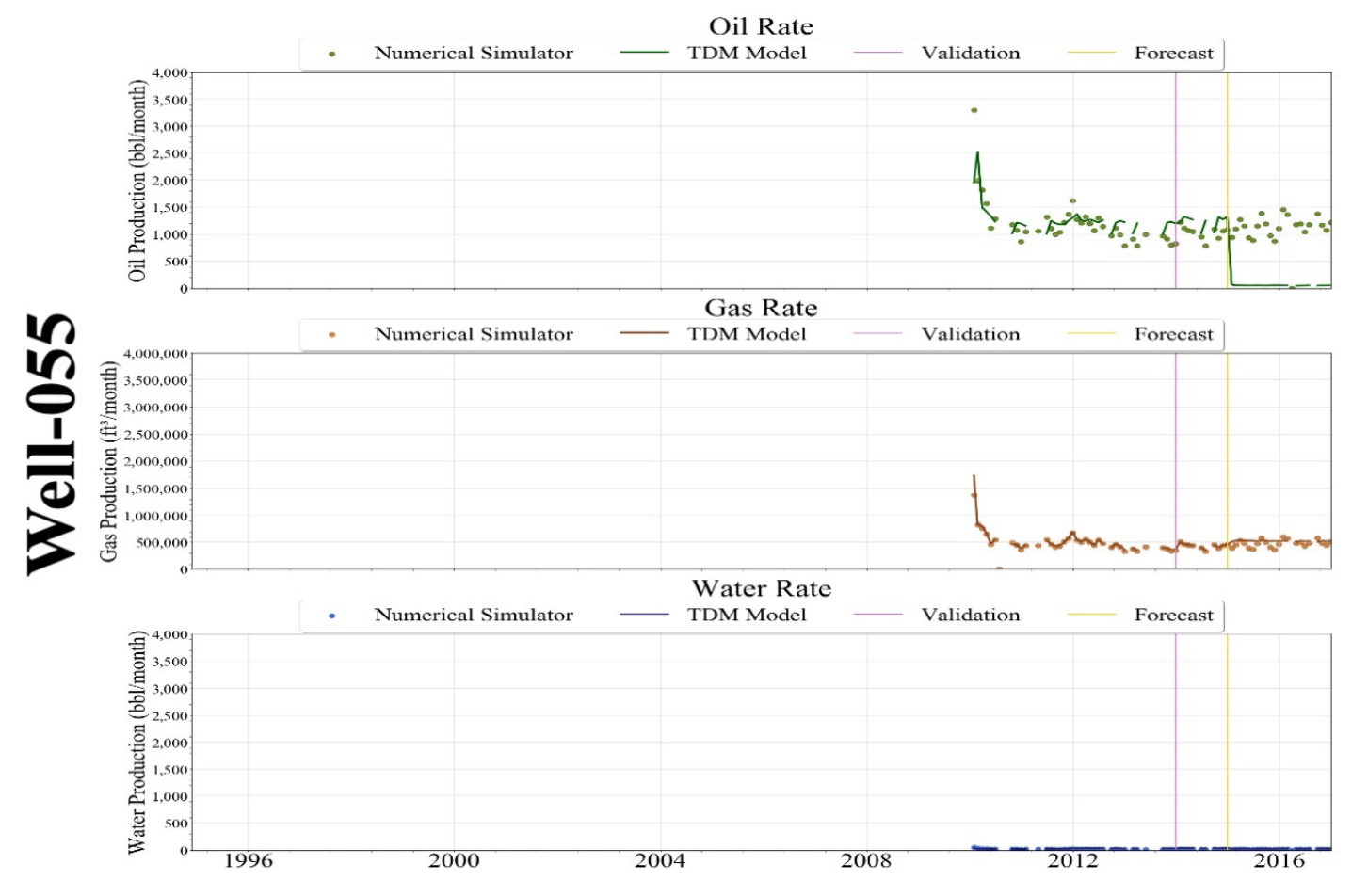

Figure 13-92: Scenario 5 - Well-055 Forecast Production 


\subsubsection{Poor Forecast Production}

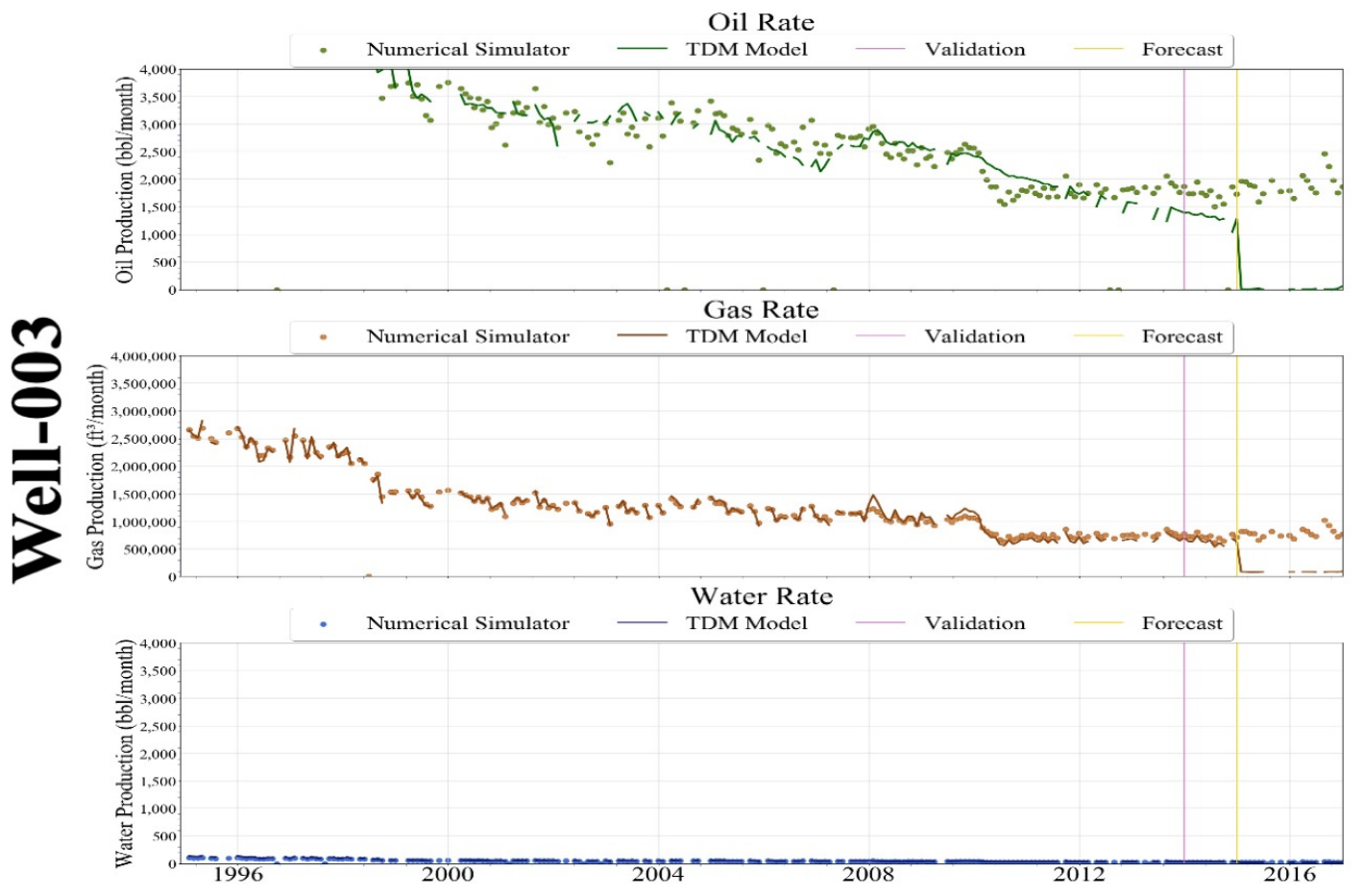

Figure 13-93: Scenario 5 - Well-003 Forecast Production

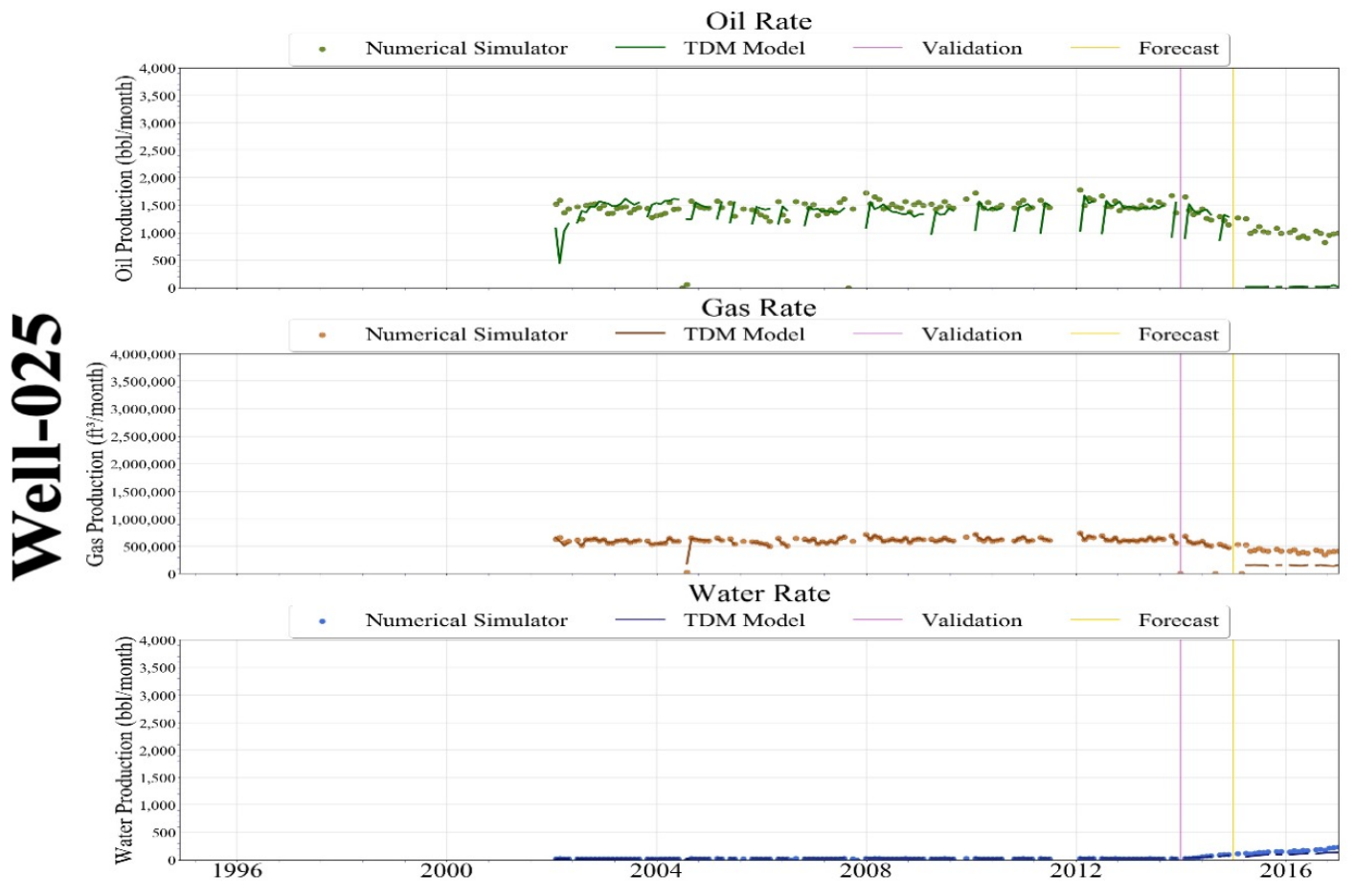

Figure 13-94: Scenario 5 - Well-025 Forecast Production 


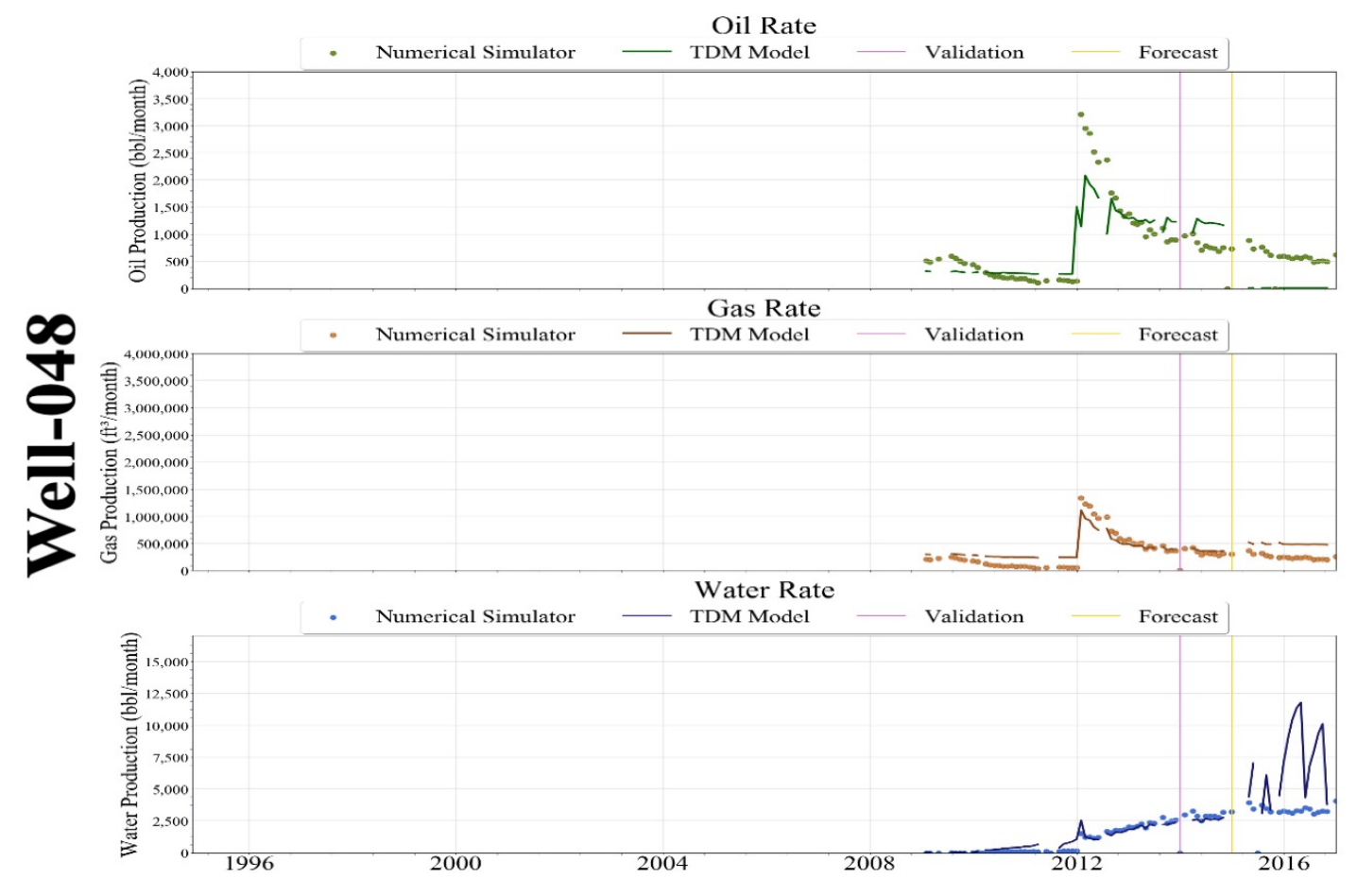

Figure 13-95: Scenario 5 - Well-048 Forecast Production

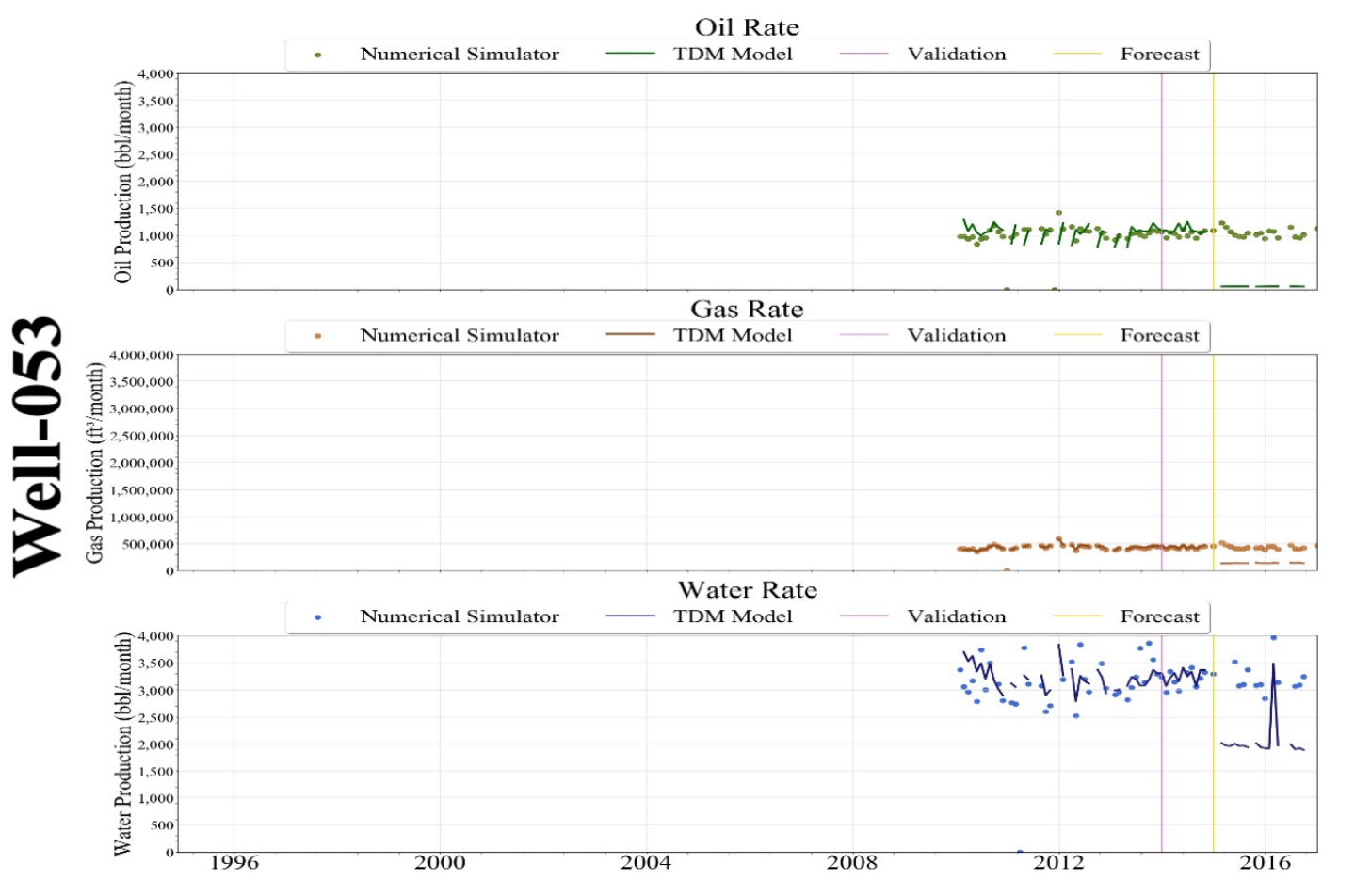

Figure 13-96: Scenario 5 - Well-053 Forecast Production 


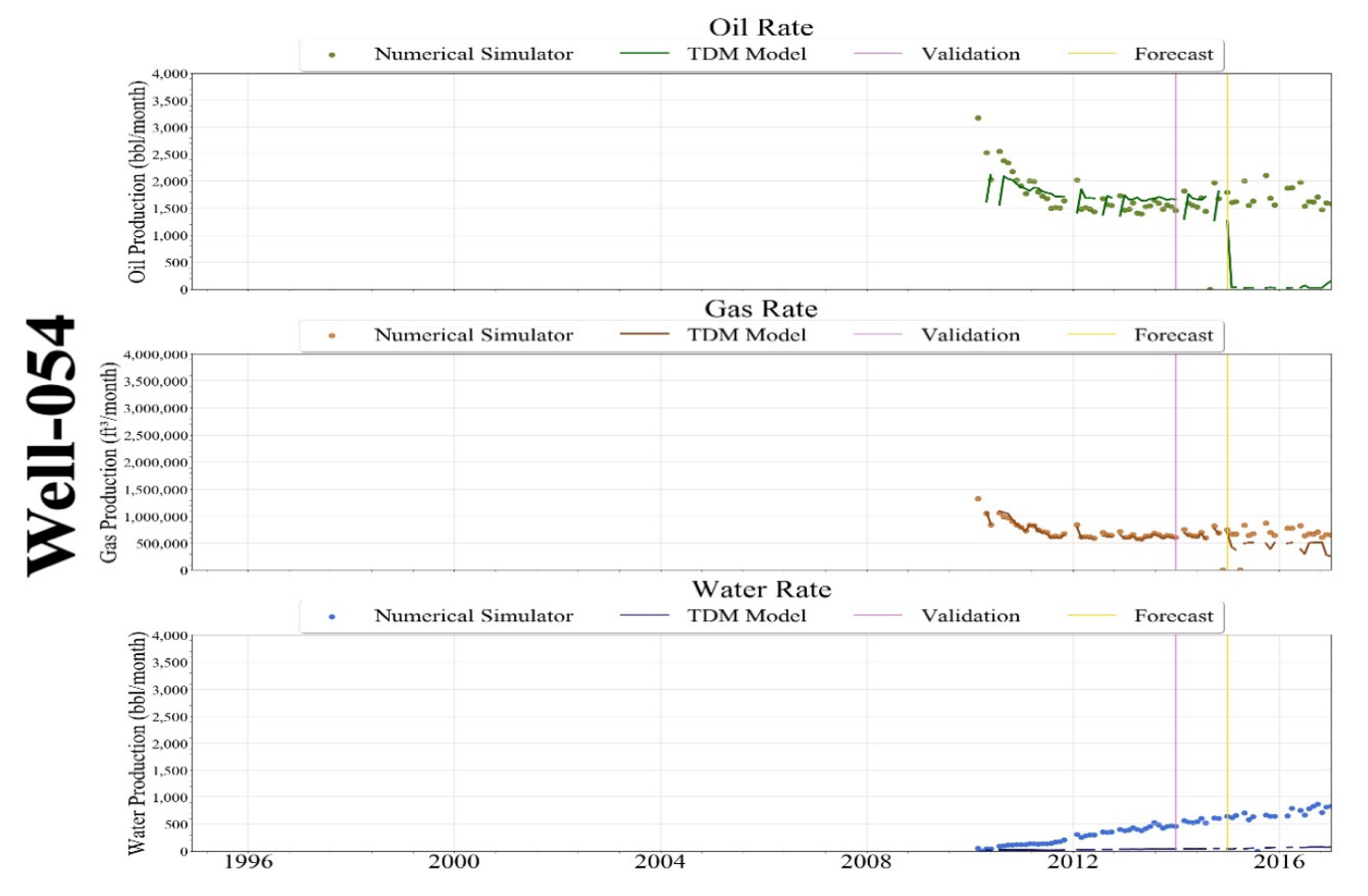

Figure 13-97: Scenario 5 - Well-054 Forecast Production

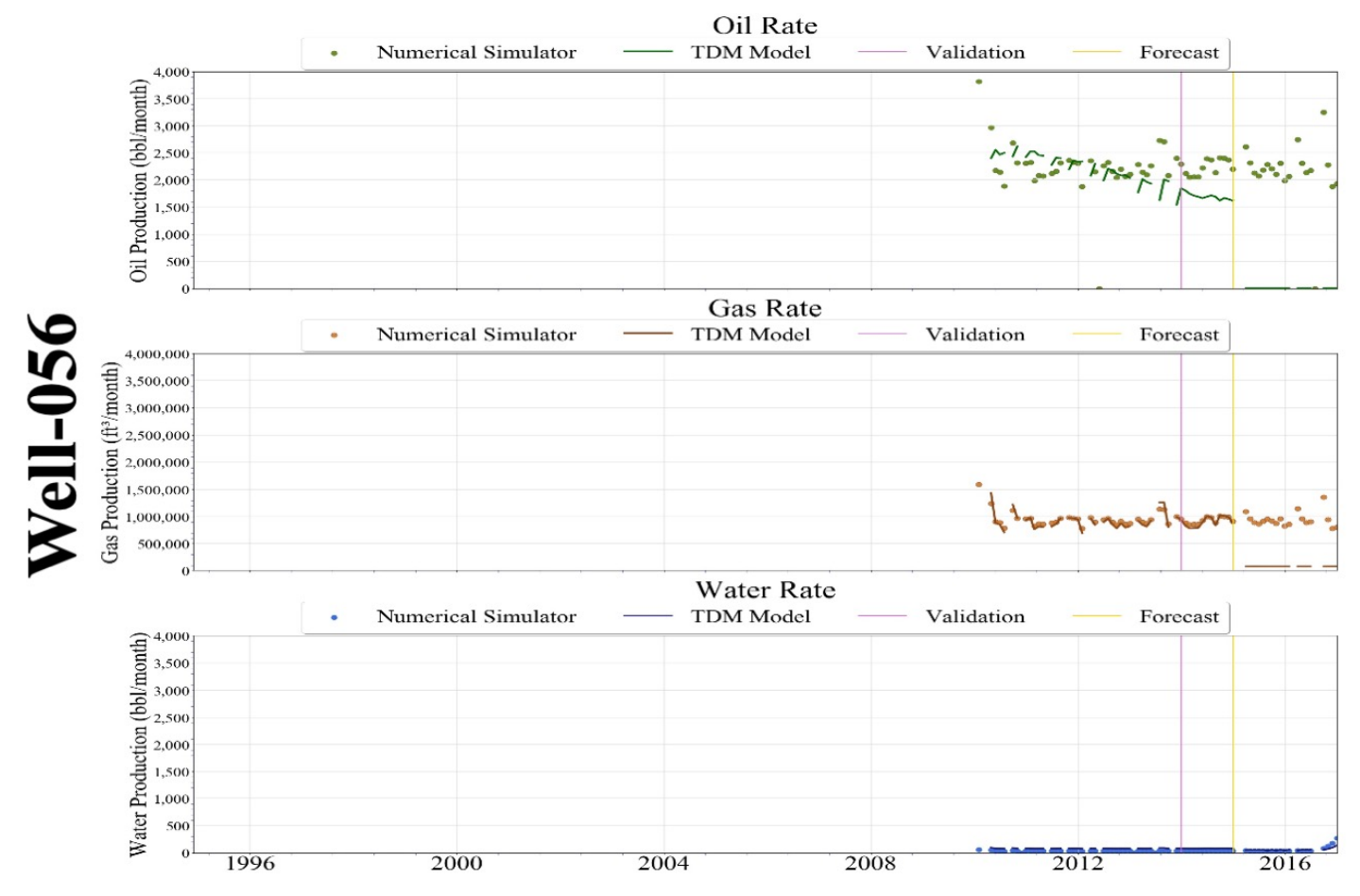

Figure 13-98: Scenario 5 - Well-056 Forecast Production 


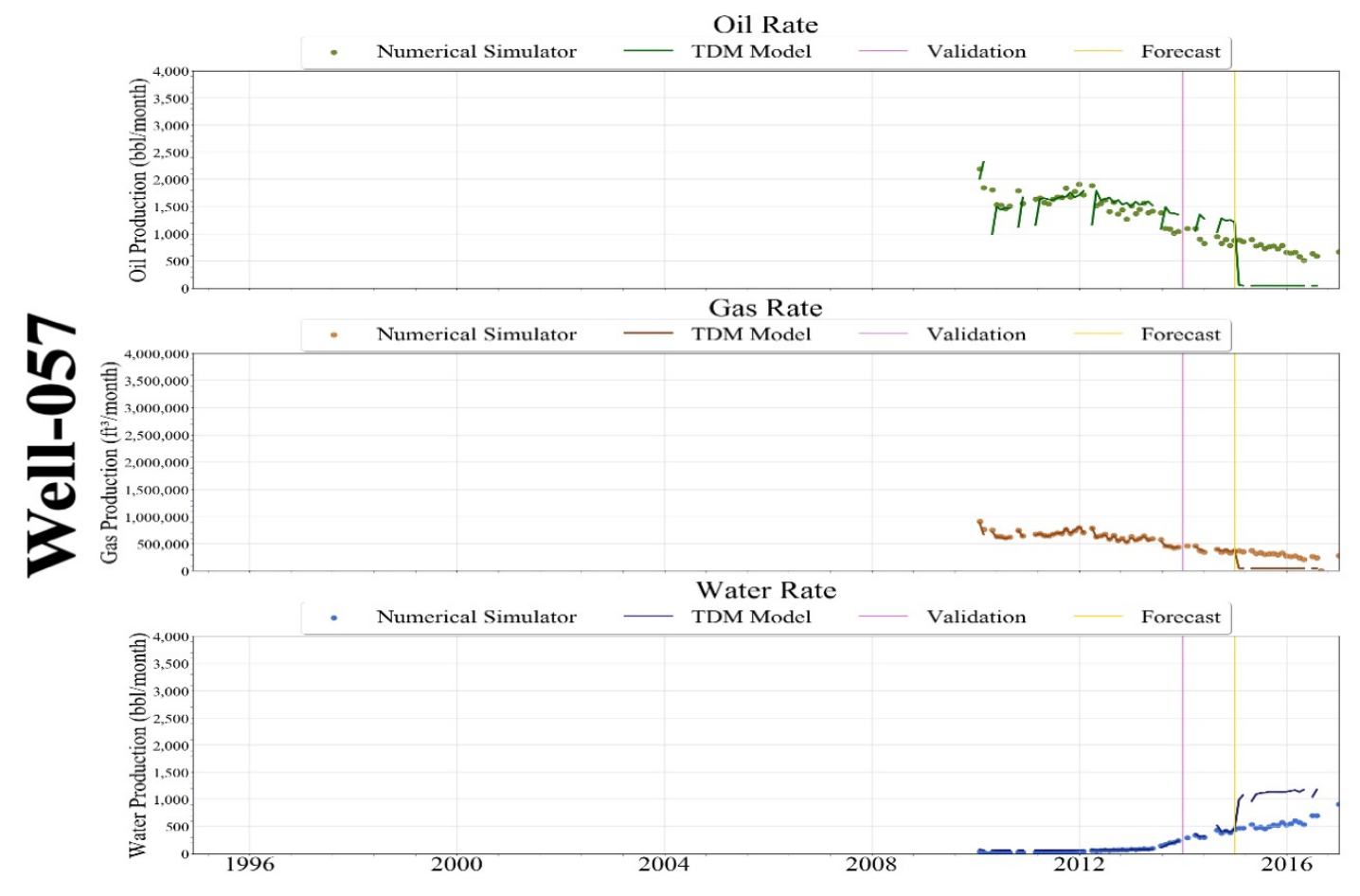

Figure 13-99: Scenario 5 - Well-057 Production History Match 


\subsection{Distribution Maps}

Distribution maps are presented at different timesteps, including the beginning, middle, and end of the year.

Reservoir Pressure (psi) at 2014-01-31
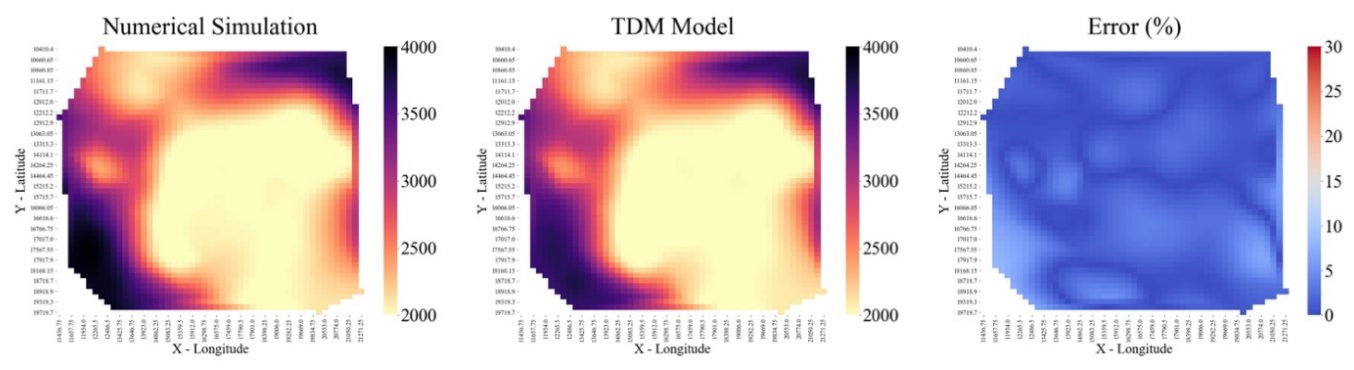

Water Saturation (\%) at 2014-01-31
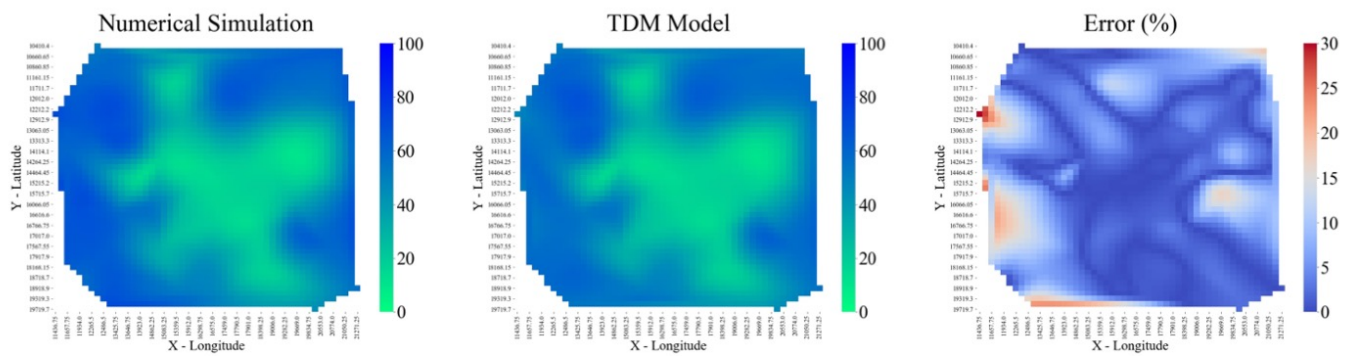

Reservoir Pressure (psi) at 2014-06-30
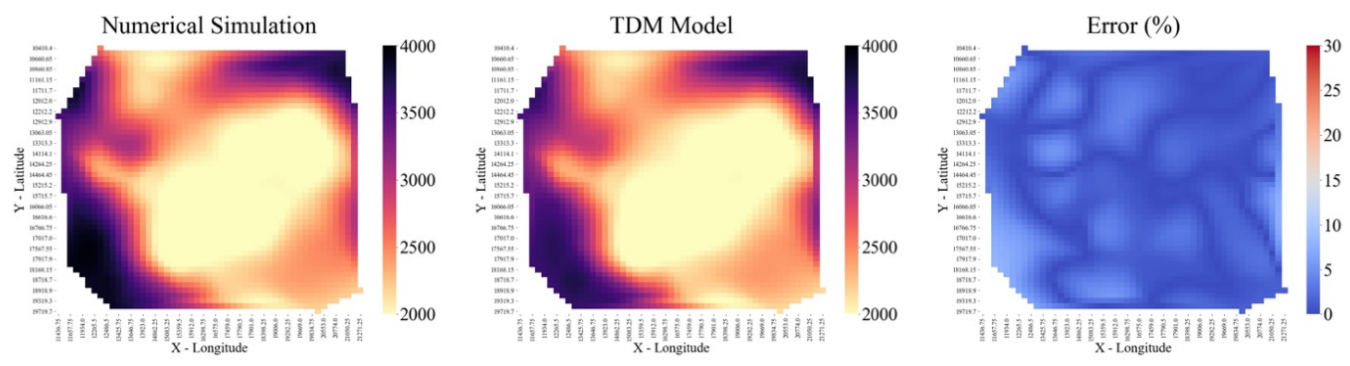

Water Saturation (\%) at 2014-06-30
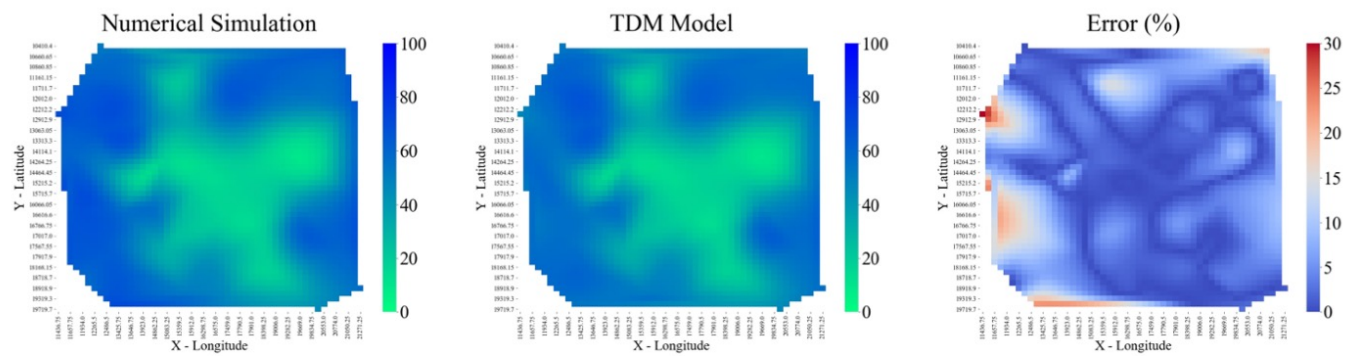
Reservoir Pressure (psi) at 2014-12-31
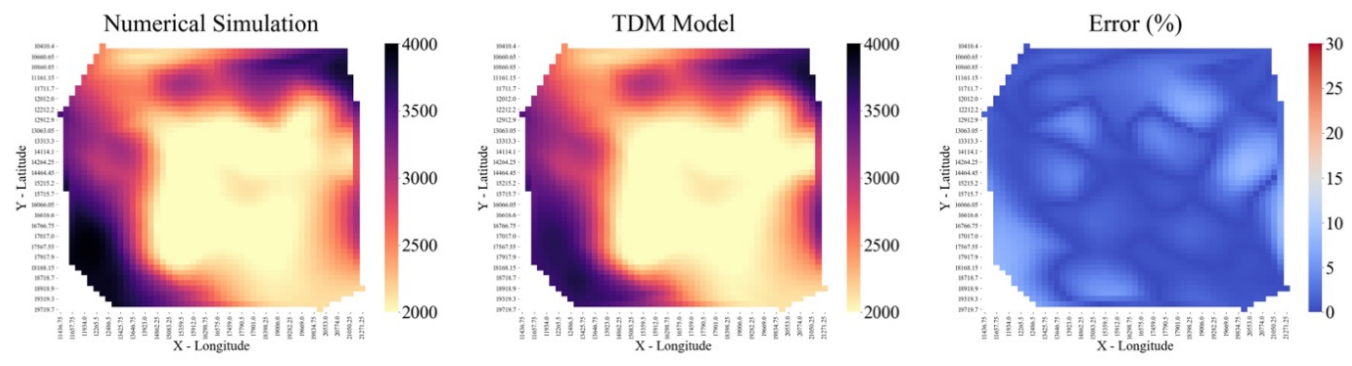

Water Saturation (\%) at 2014-12-31
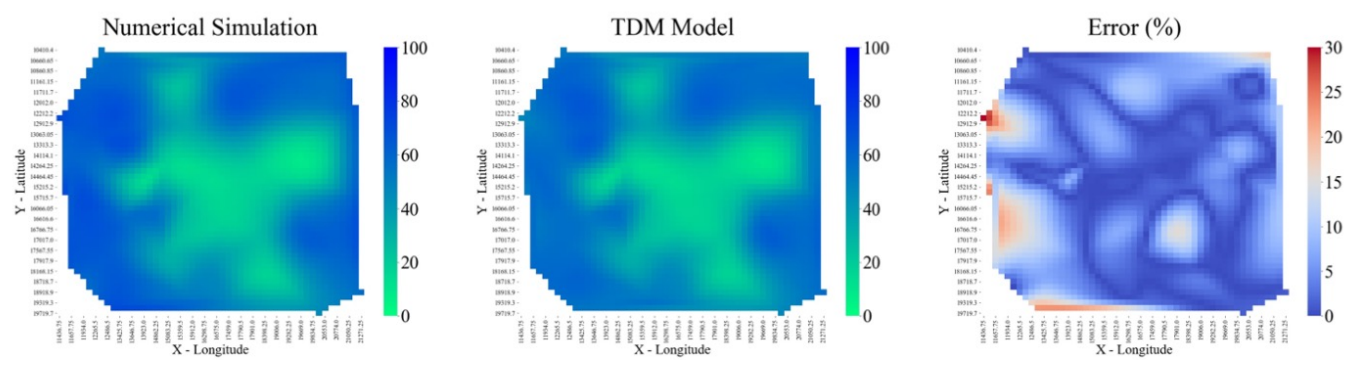

Reservoir Pressure (psi) at 2015-06-30
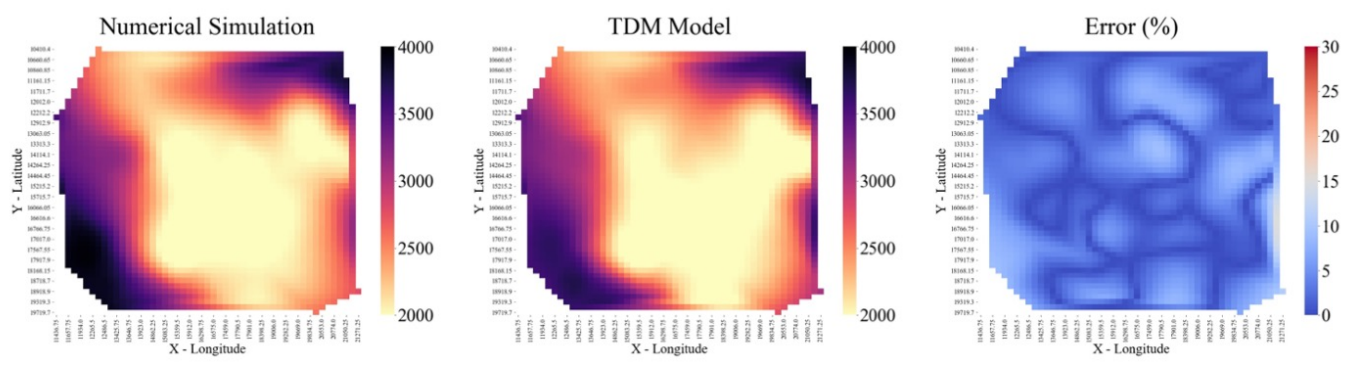

Water Saturation (\%) at 2015-06-30
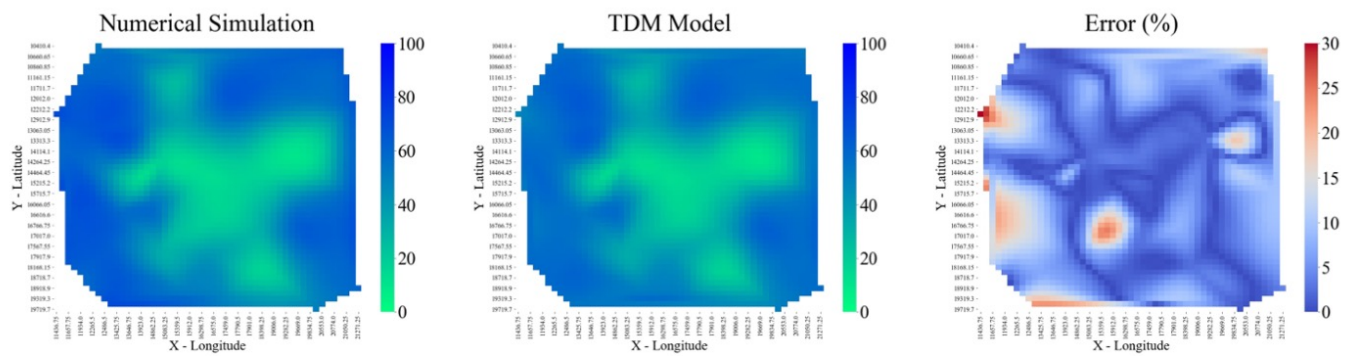
Reservoir Pressure (psi) at 2015-12-31
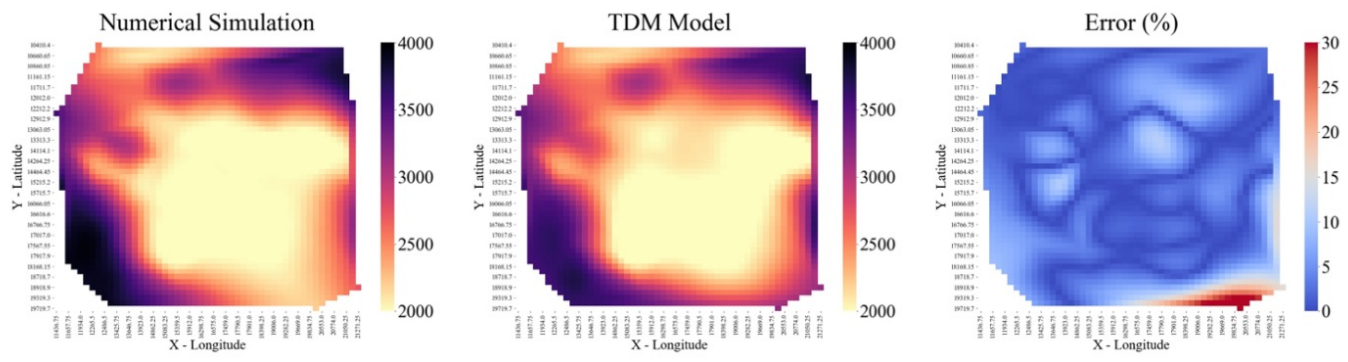

Water Saturation (\%) at 2015-12-31
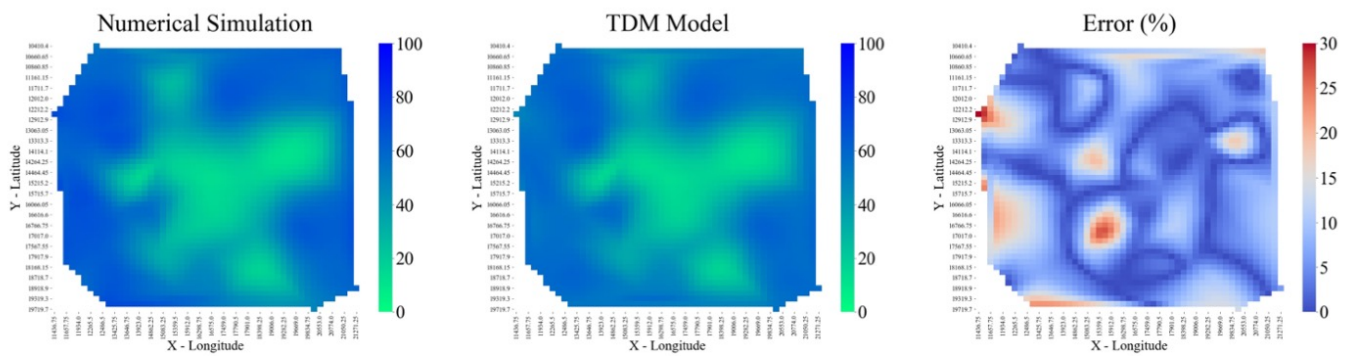

Reservoir Pressure (psi) at 2016-06-30
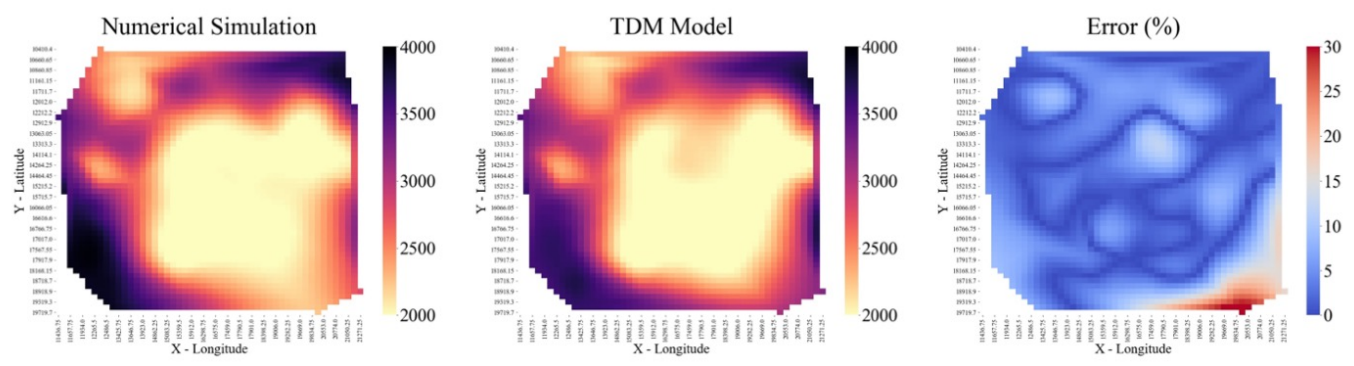

Water Saturation (\%) at 2016-06-30
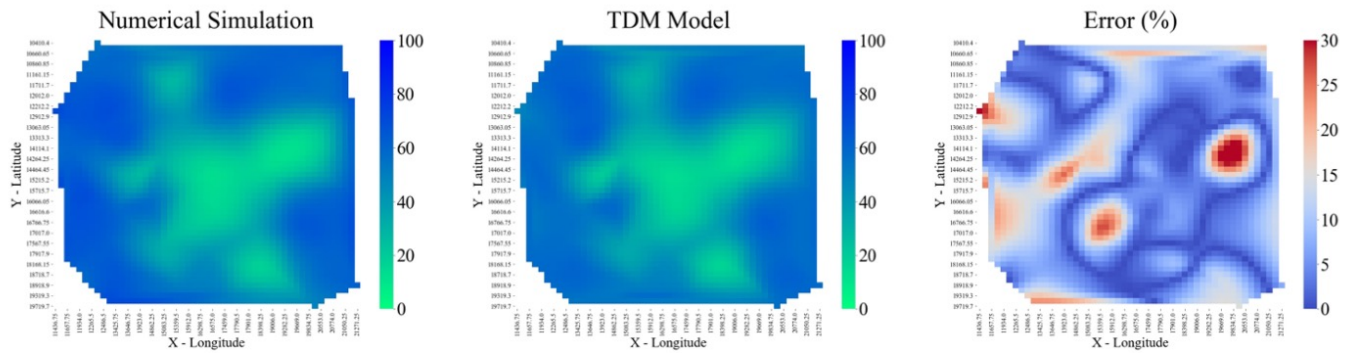
Reservoir Pressure (psi) at 2016-12-31
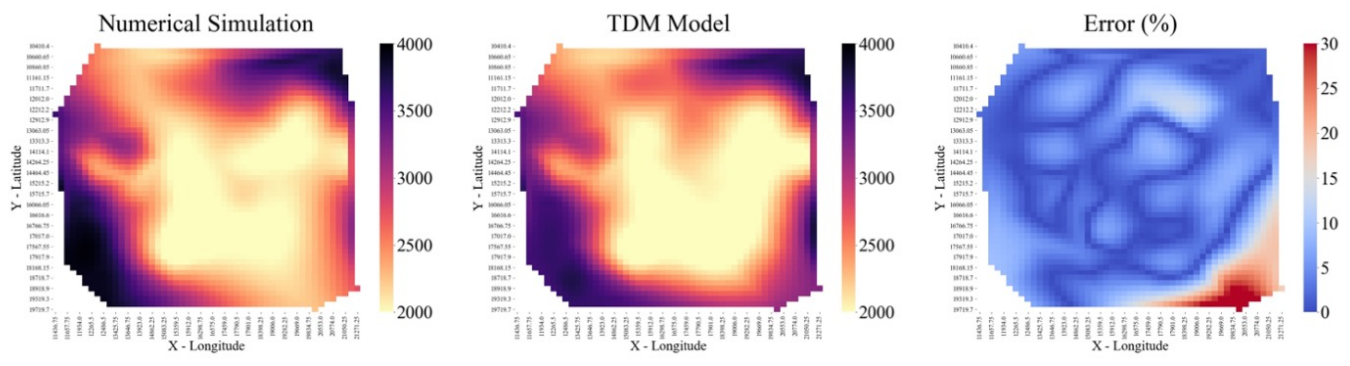

Water Saturation (\%) at 2016-12-31
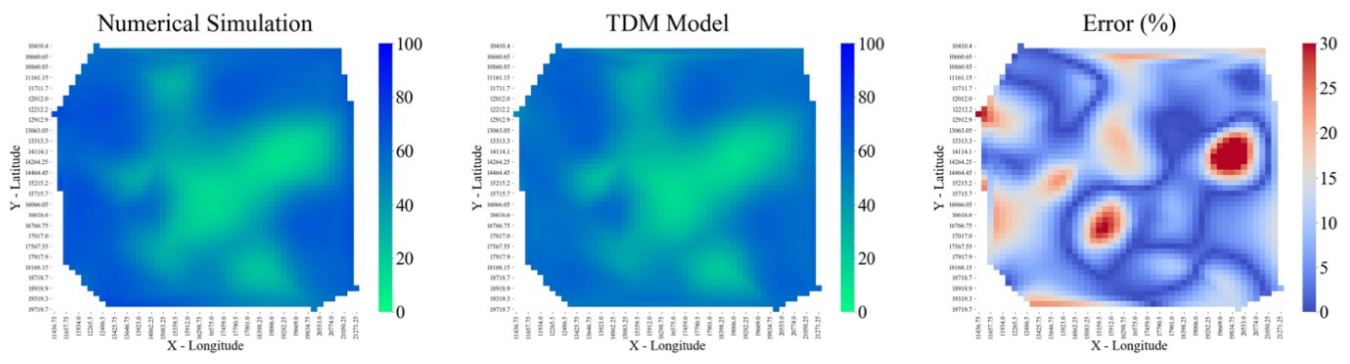

Figure 13-100: Scenario 5 - Distribution Maps at Different Timesteps 